DOE/ER-0313/18

Distribution

Categories

UC- $-423,-424$

\title{
FUSION MATERIALS \\ SEMIANNUAL PROGRESS REPORT \\ FOR THE PERIOD ENDING \\ MARCH 31, 1995
}

Prepared for

DOE Office of Fusion Energy

(AT 1505010 )

DATE PUBLISHED: JULY 1995

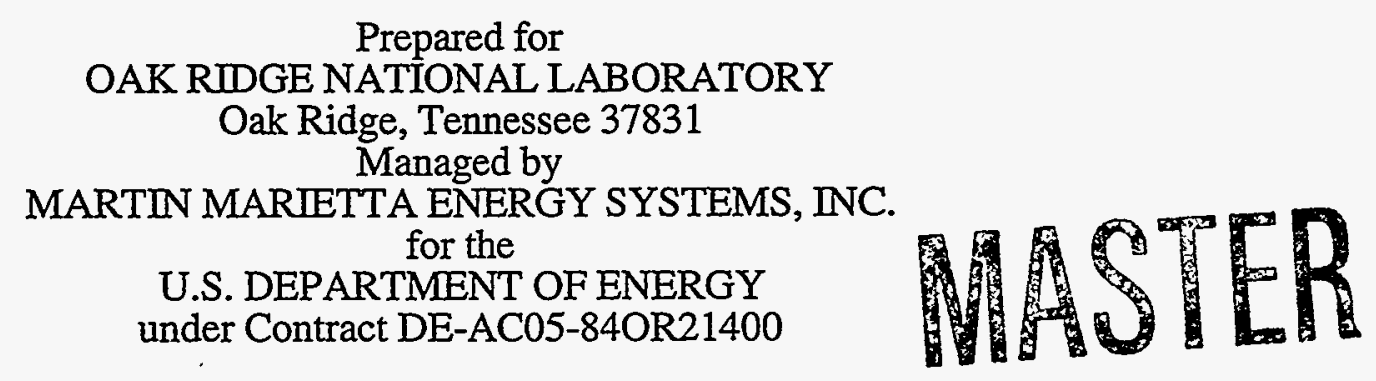

ESTRIBUTION OF THIS DOCUMENT IS UNLIMITER 


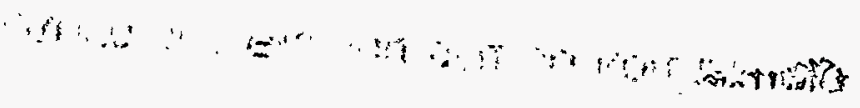




\section{DISCLAMMER}

Portions of this document may be illegible in electronic image products. Images are produced from the best available original document. 


\section{FOREWORD}

This is the eighteenth in a series of semiannual technical progress reports on fusion materials. This report combines research and development activities which were previously reported separately in the following progress reports:

- $\quad$ Alloy Development for Irradiation Performance

- Damage Analysis and Fundamental Studies

- Special Purpose Materials

These activities are concerned principally with the effects of the neutronic and chemical environment on the properties and performance of reactor materials; together they form one element of the overall materials programs being conducted in support of the Magnetic Fusion Energy Program of the U.S. Department of Energy. The other major element of the program is concerned with the interactions between reactor materials and the plasma and is reported separately.

The Fusion Materials Program is a national effort involving several national laboratories, universities, and industries. The purpose of this series of reports is to provide a working technical record for the use of the program participants, and to provide a means of communicating the efforts of materials scientists to the rest of the fusion community, both nationally and worldwide.

This report has been compiled and edited under the guidance of A. F. Rowcliffe by Gabrielle Burn, Oak Ridge National Laboratory. Their efforts, and the efforts of the many persons who made technical contributions, are gratefully acknowledged.

F. W. Wiffen

Division of Advanced Physics and Technology 
Reports previously listed in this series are as follows:

DOE/ER-0313/1

DOE/ER-0313/2

DOE/ER-0313/3

DOE/ER-0313/4

DOE/ER-0313/5

DOE/ER-0313/6

DOE/ER-0313/7

DOE/ER-0313/8

DOE/ER-0313/9

DOE/ER-0313/10

DOE/ER-0313/11

DOE/ER-0313/12

DOE/ER-0313/13

DOE/ER-0313/14

DOE/ER-0313/15

DOE/ER-0313/16

DOE/ER-0313/17

DOE/ER-0313/100
Period ending September 30, 1986

Period ending March 31, 1987

Period ending September 30, 1987

Period ending March 31, 1988

Period ending September 30, 1988

Period ending March 31, 1989

Period ending September 30, 1989

Period ending March 31, 1990

Period ending September 30, 1990

Period ending March 31, 1991

Period ending September 30, 1991

Period ending March 31, 1992

Period ending September 30, 1992

Period ending March 31, 1993

Period ending September 30, 1993

Period ending March 31, 1994

Period ending September 30, 1994

Technical Evaluation of the Technology of Vanadium Alloys for Use as Blanket Structural Materials in Fusion Power Systems 


\section{CONTENTS}

1.0 IRRADIATION FACILITIES, TEST MATRICES, AND EXPERIMENTAL METHODS .

1.1 STATUS OF U.S./JAPAN COLLABORATIVE PROGRAM PHASE II HFIR TARGET AND RB CAPSULES - J. E. Pawel and K. E. Lenox (Oak Ridge National Laboratory), and I. Ioka (Japan Atomic Energy Research Institute). . . . . . . . . . . . . .

Capsules HFIR-MFE-JP9 through JP16 operated in the HFIR target region and accumulated doses of 18,34 , and 57 dpa at temperatures of $300,400,500$, and $600^{\circ} \mathrm{C}$; all eight capsules in this series have been irradiated and disassembled. Capsules JP20, 21 and 22 were designed to accumulate 8,18 , and $34 \mathrm{dpa}$, respectively, with specimen temperatures of $300-600^{\circ} \mathrm{C}$. JP20 and JP21 have been removed from the reactor; JP22 has accumulated $18.6 \mathrm{dpa}$ as of the end of this reporting period. HFIR-MFE-200J-1 and 400J-1 capsules achieved the goal of 20 HFIR irradiation cycles, or approximately $9 \mathrm{dpa}$, and were removed from the reactor to the cooling pool. Disassembly is scheduled for the next reporting period.

1.2 CONTINUING IRRADIATION OF FERRITIC STEELS: EXPERIMENTS HFIR CTR-62 AND -63 - K. E. Lenox, R. L. Klueh, and R. L. Senn (Oak Ridge National Laboratory). . . . . . . . . . . . . . . . . . . . . . . .

The design and structure of the HFIR-CTR-62 and - 63 capsules is described, including detailed descriptions of the specimen materials. The two capsules contain ferritic steel specimens, along with a few austenitic stainless steel TEMs, intended for irradiation at either 300 or $400^{\circ} \mathrm{C}$ until a peak of thirteen dpa is achieved at the center of the capsule. The two capsules, containing eighty-eight one-third size Charpy specimens, 208 TEMs, and thirty-two tensile specimens, have been assembled and are currently scheduled to begin irradiation in the HFIR in April of 1995.

1.3 SCHEDULE AND STATUS OF IRRADIATION EXPERIMENTS - M. L. Grossbeck and A. F. Rowcliffe (Oak Ridge National Laboratory) . . . . . . . . . . . . . .

The current status of reactor irradiation experiments is presented in tables summarizing the experimental objectives, conditions, and schedule.

1.4 IRRADIATION PARAMETERS FOR THE FFTF MATERIALS OPEN TEST ASSEMBLIES FROM 1983 THROUGH 1992 - A. M. Ermi (Westinghouse Hanford Company), L. R. Greenwood and H. L. Heinisch (Pacific Northwest Laboratory). . . . . . .

Results from final analyses of MOTA dosimetry were used to generate listings of irradiation damage parameters for all test locations in all nine MOTAs. Temperature information for all MOTAs is also summarized, and issues regarding temperature transients and gradients are discussed. This report serves as an official reference on the temperatures and damage parameters for all MOTAs and is the basis for more detailed listings of irradiation histories for all MOTA specimens.

1.5 PRELIMINARY REPORT ON THE IRRADIATION PARAMETERS FOR THE EBR-II COBRA-1A2 TEST-A. M. Ermi (Westinghouse Hanford Company) and

M. L. Hamilton (Pacific Northwest Laboratory). . . . . . . . . . . . . . . .

The COBRA-1A2 test specimens were irradiated in the Experimental Breeder Reactor-II (EBRII) during Runs 162 and 163 (as part of the COBRA-1A1 test), and during Runs 164 through 170. The four capsules in the COBRA-1A2 subassembly were irradiated for a total of 337.3 Effective Full Power Days (EFPD) at a nominal reactor power level of $62.5 \mathrm{MWt}$. 
The estimated mid-core total peak fast fluence was $6.85 \times 10^{22} \mathrm{n} / \mathrm{cm}^{2}(\mathrm{E}>0.111 \mathrm{MeV})$, and the estimated total peak displacements per atom was $32.6 \mathrm{dpa}$ (in stainless steel). During reactor operation, the inlet coolant remained at $371^{\circ} \mathrm{C}$ while the calculated coolant outlet temperature was $4.41^{\circ} \mathrm{C}$.

\subsection{NEUTRONICS ASPECTS OF THE DESIGN OF THE A1 DROP-IN EXPERIMENT} AT ATR - I. C. Gomes and D. L. Smith (Argonne National Laboratory). . . . . . . . .

The transmutation rate of vanadium to chromium was controlled with the use of thermal neutron absorber (gadolinium) which was incorporated, by design, within the drop-in experimental capsule. Gadolinium was selected as the filtering material due to several reasons, among those one can mention, high cross section for thermal neutrons, required thickness to survive 5 dpa's irradiation of less than $2 \mathrm{~mm}$, good neutronics data base, easy handling, and overall cost.

The nuclear heat deposition, accounting for gamma-ray and neutron heating from the surroundings (core and reflector region) and gamma-ray heating produced by the capture of thermal neutrons at the thermal neutron filter, was estimated at each region of the capsule. The temperature distribution inside the capsule was analyzed as a function of the gas gap between the sub-capsule and the holder (maintained at the coolant temperature $60^{\circ}$ ). The results presented here are considered preliminary, and a more precise estimation of the values is underway.

1.7 VANADIUM ALLOY IRRADIATION EXPERIMENT ATR-A1 IN THE ADVANCED

TEST REACTOR - H. Tsai, R. V. Strain, I. Gomes, A. G. Hins, and D. L. Smith (Argonne National Laboratory). . . . . . . . . . . . . . . . . . .

A collaborative DOE/Monbusho irradiation experiment is being implemented to generate low-temperature mechanical properties data on vanadium alloys and low-activation ferritic steels. Monbusho is supplying the latter specimens. The experiment will be conducted in the Advanced Test Reactor at the Idaho National Engineering Laboratory and is designated ATR-A1. The core position selected, Channel A10, has relatively high fast neutron flux and fast-to-thermal flux ratio. These qualities are important for achieving a reasonable damage rate in the specimens and reducing the thickness requirements of thermal neutron filters. Filtering out the thermal neutron flux is necessary in the water-cooled ATR in order to avoid excessive $\mathrm{V}(\mathrm{n}, \gamma) \mathrm{Cr}$ transmutation.

The test vehicle will consist of four capsule segments containing a total of 15 subcapsules: 13 for vanadium alloy specimens and two for low-activation ferritic steel specimens. In all subcapsules the specimens will be lithium bonded to provide uniform specimen temperature, maximum heat transfer, and, in the case of vanadium alloy specimens, impurity control. Two test temperatures are planned: 200 and $300^{\circ} \mathrm{C}$. They will be achieved by filling the gasgap between the subcapsules and capsule with different blends of He and Ar. The vanadium alloy test specimens will be biaxial creep (pressurized tubes), Charpy impact, compact tension, tensile, and transmission electron microscope (TEM) disks. For the ferritic steels, the specimens will be Charpy impact, tensile, and TEM disks. The goal fluences for the experiment is $5 \mathrm{dpa}$ (in vanadium), which will be attained in $\approx 135$ effective full power days (EFPDs) in the A10 position.

Most of the test vehicle design has been completed and fabrication of some of the components is underway. The irradiation is scheduled to begin in August 1995 and be completed in January 1996. 
To obtain early irradiation performance data on the new $500-\mathrm{kg}$ production heat of the $\mathrm{V}-4 \mathrm{Cr}$ 4Ti material before the scheduled EBR-II shutdown, an experiment, X530, was expeditiously designed and assembled. Charpy, compact tension, tensile and TEM specimens with different thermal mechanical treatments (TMT) were enclosed in twelve subcapsules and irradiated in the last run of EBR-II, Run 170A. The accrued exposure was 35 effective full power days, yielding a peak damage of $\approx 4 \mathrm{dpa}$ in the specimens. In this reporting period, the irradiation vehicle was disassembled at the Hot Fuel Examination Facility (HFEF) at ANL-West and the subcapsules shipped to ANL-East for disassembly. Subcapsule disassembly is scheduled to be completed at ANL-East in the next reporting period.

\subsection{DOSIMETRY, DAMAGE PARAMETERS, TRANSMUTATION, AND}

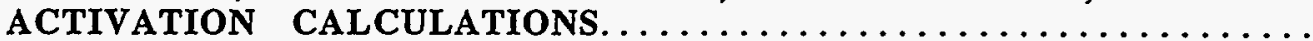

2.1 ACTIVATION OF SILICON CARBIDE IN FUSION REACTORS - H. L. Heinisch (Pacific Northwest Laboratory). . . . . . . . . . . . . . . . . . . .

Because of production of ${ }^{26} \mathrm{Al}$ from $\mathrm{Si}$, $\mathrm{SiC}$ irradiated in a fusion energy system first wall exceeds the limits for shallow land burial, based on $10 \mathrm{CR} 61$, Class $\mathrm{C}$, for irradiation doses typical of a first wall component service lifetime in DEMO, $12.5 \mathrm{MW} \mathrm{y} / \mathrm{m}^{2}$. However, if first wall activities can be averaged over entire components that include portions within the fusion machine where fluxes of high energy neutrons are smaller than at the first wall, production of ${ }^{26} \mathrm{Al}$ may stay under the shallow land burial limit for practical component service lifetimes. Realistic information on energy system design, waste disposal criteria, and decommissioning procedures is necessary to determine with certainty the role $\mathrm{SiC}$ can play as a low activation fusion energy system material. Sequential charged particle reactions have no significant effect on the residual radioactivity of SiC irradiated in a fusion energy system first wall.

2.2 CLEAN STEELS FOR FUSION - D. S. Gelles (Pacific Northwest Laboratory). . . . . . .

A summary of the workshop Clean Steels - Super Clean Steels is provided and a paper given at the Workshop entitled Clean Steels for Fusion is reproduced. The workshop demonstrated, based on ten years of steel making practice, that control of minor impurities, $\mathrm{P}, \mathrm{Sb}, \mathrm{Sn}$, and As, along with $\mathrm{Mn}$ and $\mathrm{Si}$, could effectively eliminate temper embrittlement in $3.5 \mathrm{NiCrMoV}$ rotor steels.

\subsection{THE EFFECTS OF IMPURITIES ON THE ACTIVATION OF SIC, VANADIUM AND}

FERRITIC ALLOYS - H. Attaya and D. Smith (Argonne National Laboratory). . . . . . . .

Consistent transport and activation calculations have been performed to compare the activation responses of the leading reduced-activation materials in a fusion power reactor. Another set of calculations has been made to evaluate the effects of the trace elements on these responses. The materials considered in this work are the $\mathrm{V} 4 \mathrm{Cr} 4 \mathrm{Ti}$ vanadium alloy, the $9 \mathrm{Cr} 2 \mathrm{WVT}$ a ferritic alloy, and the silicon carbide (SiC). In addition, calculations have also been made for the conventional 316SS and HT-9 alloys. The TPSS conceptual design has been utilized in this work. The results show that the V4Cr4Ti alloy has the minimum operational and the minimum long-term radioactivity and decay heat. The $\mathrm{SiC}$ has the minimum intermediate-term radioactivity. The effects of impurities are noticed with respect to the V4Cr4Ti and $\mathrm{SiC}$. With respect to the $9 \mathrm{Cr} 2 \mathrm{WVTa}$, the impurities have small effects. 
NO CONTRIBUTIONS

4.0 FUNDAMENTAL MECHANICAL BEHAVIOR...............

NO CONTRIBUTIONS

5.0 RADIATION EFFECTS, MECHANISTIC STUDIES, THEORY, AND

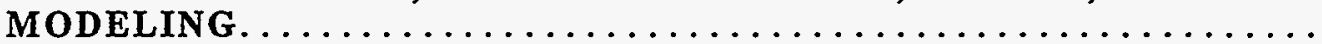

5.1 SIMULATING THE PRODUCTION OF FREE DEFECTS.IN IRRADIATED METALS -

H. L. Heinisch (Pacific Northwest Laboratory) . . . . . . . . . . . . . .

Under cascade-producing irradiation by high energy neutrons or charged particles, only a small fraction of the initially displaced atoms contribute to the population of free defects, i.e. those that are available to migrate throughout the metal and cause microstructural changes. Although, in principle, computer simulations of free defect production could best be done using molecular dynamics, in practice, the wide ranges of time and distance scales involved can be done only by a combination of atomistic models that employ various levels of approximation. An atomic-scale, multimodel approach has been developed that combines molecular dynamics, binary collision models and stochastic annealing simulation. The annealing simulation is utilized in calibrating binary collision simulations to the results of molecular dynamics calculations, as well as to model the subsequent migration of the defects on more macroscopic time and size scales. The annealing simulation and the method of calibrating the multimodel approach are discussed, and the results of simulations of cascades in copper are presented. The temperature dependence of free defect production following simulated annealing of isolated cascades in copper shows a differential in the fractions of free vacancies and interstitial defects escaping from the cascade above Stage V. This differential, a consequence of the direct formation of interstitial clusters in cascades and the relative thermal stability of vacancy and interstitial clusters during subsequent annealing, is the basis for the production bias mechanism of void swelling.

6.0 DEVELOPMENT OF STRUCTURAL ALLOYS...............

6.1 FERRITIC MARTENSITIC AND BAINITIC STEELS............

6.1.1 MICROSTRUCTURAL ANALYSIS OF IRRADIATED MARTENSITIC STEELS J. J. Kai (National Tsing Hua University, Hsinchu, Taiwan), and R. L. Klueh (Oak Ridge

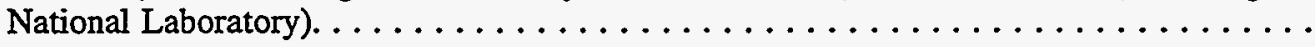

Four martensitic steels were examined by transmission electron microscopy after irradiation in the Fast Flux Test Facility (FFTF). Irradiation in FFTF was at $420^{\circ} \mathrm{C}$ to about $7.8 \mathrm{x}$ $10^{26} \mathrm{n} / \mathrm{m}^{2}$ (E>0.1 MeV), which gave a displacement damage of about $35 \mathrm{dpa}$. The steels were those of interest for fusion applications and included two commercial steels, $9 \mathrm{Cr}$ $1 \mathrm{MoVNb}$ (modified 9Cr-1Mo) and 12Cr-1MoVW (Sandvik HT9), and two experimental reduced-activation steels, $9 \mathrm{Cr}-2 \mathrm{WV}$ and $9 \mathrm{Cr}-2 \mathrm{WVTa}$. Before irradiation, the tempered martensite microstructures of the four steels contained a high dislocation density, and the major precipitate was $\mathrm{M}_{23} \mathrm{C}_{6}$ carbide, with lesser amounts of $\mathrm{MC}$ carbide. Irradiation caused only small changes in these precipitates. Voids were found in all irradiated specimens, but swelling remained below $1 \%$, with the $9 \mathrm{Cr}-1 \mathrm{MoVNb}$ having the highest void density. Although the $12 \mathrm{Cr}-1 \mathrm{MoVW}$ steel showed the best swelling resistance, it also contained the highest density of radiation-induced new phases, which were identified as chi-phase and possibly $\alpha^{\prime}$. Radiation-induced chi phase was also observed in the $9 \mathrm{Cr}-1 \mathrm{MoVNb}$ steel. The two reduced-activation steels showed very stable behavior under irradiation: a high density of 
dislocation loops (average diameter of $50 \mathrm{~nm}$ ) replaced the original high dislocation density; moderate void swelling occurred, but no new phases formed. The differences in microstructural evolution of the steels can explain some of the mechanical properties observations made in these steels.

6.1.2 ON THE ROLE OF STRAIN RATE, SIZE, AND NOTCH ACUITY ON TOUGHNESS: A COMPARISON OF TWO MARTENSITIC STAINLESS STEELS - G. E. Lucas, G. R. Odette, J. W. Sheckherd, K. Edsinger, and B. Wirth (University of California

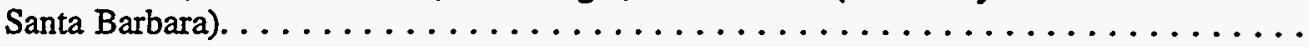

The fracture resistance and micromechanisms of two tempered martensitic steels were characterized over a range of temperatures by both mechanical testing and quantitative fractography. Both HT-9 and F82H undergo a fracture mode transition from quasi-cleavage at low temperature to microvoid coalescence at high temperature. The transition in HT9 is rather gradual, and the transition in $\mathrm{F} 82 \mathrm{H}$ is extremely abrupt. While the toughness of $\mathrm{F} 82 \mathrm{H}$ was higher in all cases, differences between the two steels depended on test type, strain rate and temperature. In general, $\mathrm{F} 82 \mathrm{H}$ had only slightly better properties in the quasi-cleavage regime. For example, the transition temperatures indexed at fracture toughness levels of 100 $\mathrm{MPa} / \mathrm{m}$ were only 25 and $14^{\circ} \mathrm{C}$ lower in F82H than HT-9 under static and dynamic conditions, respectively, and they were identical at the $10 \mathrm{~J}$ level for Charpy impact tests. However, the fracture resistance of F82H was higher than HT9 in the ductile fracture regime. The Charpy V-notch upper shelf energies reflect complex and extrinsically mediated crack tearing processes that have, at best, very limited fundamental or structural significance. Thus, using an energy of $41 \mathrm{~J}$, widely perceived to be appropriate indexing a ductile-to brittle transition temperature (DBTT) for Charpy data, results in a much lower (by $81^{\circ} \mathrm{C}$ ) putative DBTT for F82H compared to HT-9. These results not only demonstrate the inherent nonuniqueness of the so called DBTT, but also call into question the use of Charpy data for ranking the relative performance of various alloys. The similarities in quasi-cleavage fracture and differences in ductile fracture are manifested in the fracture surfaces and are interpreted in terms of the underlying mechanisms and microstructures.

\subsubsection{IRRADIATION CREEP AND SWELLING OF TWO LMR HEATS OF HT9 -} F. A. Garner (Pacific Northwest Laboratory) and M. B. Toloczko (University of California at Santa Barbara). . . . . . . . . . . . . . . . . . . .

The irradiation creep and void swelling of two LMR heats of HT9 are analyzed after irradiation at $-400,495,550$, and $600^{\circ} \mathrm{C}$ to damage levels ranging from 60 to $174 \mathrm{dpa}$. Void swelling ceases somewhere between 400 and $495^{\circ} \mathrm{C}$. Swelling appears to be somewhat stress-sensitive, however, increasing with stress level. When compared with earlier results on another fusion heat of HT-9, both the swelling and creep appear to be somewhat variable from heat-to-heat. The variability of creep appears to arise from the swelling-enhanced creep component.

At higher temperatures there appears to arise a stress-activated component of strain that increases with temperature. This strain component eventually dominates the strain behavior at the highest temperatures and is probably caused by a combination of stress-activated phase changes and radiation-enhanced primary creep.

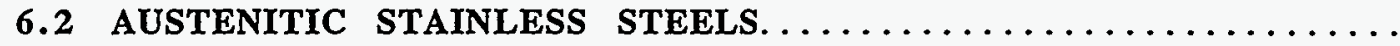

NO CONTRIBUTIONS.

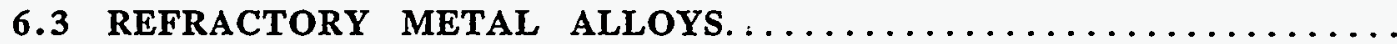


6.3.1 CHARACTERIZATION OF V-4Cr-4Ti HEAT 832665 - M. L. Grossbeck, D. J. Alexander, J. J. Henry, Jr., W. S. Eatherly, and L. T. Gibson (Oak Ridge National Laboratory). . . . .

A new $500 \mathrm{Kg}$ heat of $\mathrm{V}-4 \mathrm{Cr}-4 \mathrm{Ti}$ (Heat 832665 ) is now being characterized by various national laboratories. The Oak Ridge National Laboratory (ORNL) has received sheet of several thicknesses from Argonne National Laboratory (ANL); characterization by chemical analysis, Charpy impact testing, and metallography is in progress. The Charpy tests have shown that the material does not experience a ductile to brittle transition temperature (DBTT) even at temperatures as low as $-196^{\circ} \mathrm{C}$.

\subsubsection{RECOVERY AND RECRYSTALLIZATION STUDY ON VANADIUM ALLOYS -}

A. N. Gubbi, A. F. Rowcliffe, and W. S. Eatherly (Oak Ridge National Laboratory). . . . .

A series of vacuum-anneals at temperatures from $900^{\circ}$ to $1100^{\circ} \mathrm{C}$ for 1 to $4 \mathrm{~h}$ was carried out on vanadium alloys with $\mathrm{Cr}$ and $\mathrm{Ti}$ contents ranging from 3 to $6 \mathrm{wt} . \%$. Compositional variants of vanadium alloys $(\sim 15-\mathrm{kg}$ melt $)$ and a large heat $(-500-\mathrm{kg}$ melt $)$ of $\mathrm{V}-4 \mathrm{Cr}-4 \mathrm{Ti}$ alloy were studied in this work. Optical microscopy, TEM, and microhardness testing were carried out. The alloys tested followed the metallurgically well-established axiom that longer times at low temperatures and shorter times at high temperatures were needed for complete recrystallization. The recrystallization kinetics was faster in the alloys with higher amount of cold work compared to that exhibited by alloys with lower cold work. The large heat of V$4 \mathrm{Cr}-4 \mathrm{Ti}$ alloy with $40 \% \mathrm{CW}$ showed recovery for anneals at $900^{\circ} \mathrm{C}$, and began recrystallizing -at $950^{\circ} \mathrm{C}$. Complete recrystallization in this alloy occurred at $1000^{\circ} \mathrm{C}$, with grain growth for temperatures of $1050^{\circ} \mathrm{C}$ and above. Recovery and recrystallization kinetics were faster for the small heats because of the higher level of cold work (49\%) in the starting material. However, variations in $\mathrm{Cr}$ and $\mathrm{Ti}$ over the range 3 to $6 \mathrm{wt} \%$ had no discernible effect on recovery/recrystallization behavior. The hardness of both recovered and recrystallized structures increased with total $(\mathrm{Cr}+\mathrm{Ti})$ content.

\subsubsection{IMPACT TESTING AND FRACTURE BEHAVIOR OF VANADIUM ALLOYS -}

A. N. Gubbi, A. F. Rowcliffe, D. J. Alexander, M. L. Grossbeck, and W. S. Eatherly

(Oak Ridge National Laboratory). . . . . . . . . . . . . . . . . .

Charpy impact testing was completed on vanadium alloys with $\mathrm{Cr}$ and $\mathrm{Ti}$ contents ranging from 3 to $6 \mathrm{wt} . \%$. A large heat $(-500-\mathrm{kg}$ melt) of $\mathrm{V}-4 \mathrm{Cr}-4 \mathrm{Ti}$ (heat 832665$)$ and small heats $(-15-\mathrm{kg}$ melt each) of compositional variants, V-3Cr-3Ti, V-4Cr-4Ti-Si, V-5Cr-5Ti, V-6Cr$3 \mathrm{Ti}$, and $\mathrm{V}-6 \mathrm{Cr}-6 \mathrm{Ti}$, were examined in this work. One-third-size Charpy impact specimens, machined from 3.81-mm-thick plates of these vanadium alloys, were used for impact testing. In a fully recrystallized condition with a grain size of $\sim 16 \mu \mathrm{m}$, the large heat of $\mathrm{V}-4 \mathrm{Cr}-4 \mathrm{Ti}$ exhibited a high level of resistance to cleavage failure with a DBTT at $\sim-190^{\circ} \mathrm{C}$. The small $(15 \mathrm{~kg})$ heat of $\mathrm{V}-4 \mathrm{Cr}-4 \mathrm{Ti}$ heat treated to produce the same microstructural condition exhibited similar Charpy impact properties. The small heats containing higher concentrations of $\mathrm{Cr}_{\mathbf{r}}$ and $\mathrm{T} i$, in a fully recrystallized condition exhibited a DBTT at around $-100^{\circ} \mathrm{C}$, whereas the V$3 \mathrm{Cr}-3 \mathrm{Ti}$ alloy failed by pure ductile shear at liquid nitrogen temperatures.

\subsubsection{EFFECT OF HEAT TREATMENT AND TEST METHOD ON DBTT OF A V-5Cr-5Ti} ALLOY - Hauxin Li (Associated Western Universities-Northwest Division), M. L. Hamilton and $\mathrm{R}$. H. Jones (Pacific Northwest Laboratory). . . . . . . . . . . . . .

Specimens annealed at $1125^{\circ} \mathrm{C}$ for $1 \mathrm{~h}$ and furnace cooled were brittle at room temperature (RT) and experienced a mixture of intergranular and cleavage fracture. Fracture toughness (JIO) at RT was $52 \mathrm{~kJ} / \mathrm{m}^{2}$ and the Charpy-V impact fracture energy (IFE) on one-third scaled specimens was $0.2 \mathrm{~J}$. While material exhibited high fracture toughness at $100^{\circ} \mathrm{C}\left(\mathrm{J}_{\mathrm{IQ}}\right.$ was $485 \mathrm{~kJ} / \mathrm{m}^{2}$ ) and did not fracture during an impact test, the fracture surface contained a mixture of dimple and intergranular fracture, with intergranular fracture making up to $40 \%$ of the total 
fracture surface. The ductile to brittle transition temperature (DBTT) was estimated to be above RT from the IFE vs. temperature curve. When material was given an additional annealing at $890^{\circ} \mathrm{C}$ for $24 \mathrm{~h}$, it became ductile at $\mathrm{RT}$ and fractured by microvoid coalescence. The J IQ value increased from $52 \mathrm{~kJ} / \mathrm{m}^{2}$ to $\approx 1100 \mathrm{~kJ} / \mathrm{m}^{2}$. During impact tests, the specimens did not fracture at $-100^{\circ} \mathrm{C}$ and warmer due to a large amount of plastic deformation. The DBTT was $-100^{\circ} \mathrm{C}$. However, when evaluated by J-integral testing, the material became brittle at $-50^{\circ} \mathrm{C}$ and fractured by cleavage, yielding a $\mathrm{J}_{\mathrm{IQ}}$ value of $50 \mathrm{~kJ} / \mathrm{m}^{2}$. The DBTTJ estimated from $\mathrm{J}_{\mathrm{IQ}}$ vs. temperature was above $-50^{\circ} \mathrm{C}, 50^{\circ} \mathrm{C}$ higher than that from the IFE vs. temperature curve. The result indicated that the $\mathrm{V}-5 \mathrm{Cr}-5 \mathrm{Ti}$ alloy was sensitive to crack boundaries in the specimens annealed only at $1125^{\circ} \mathrm{C}$, but only 0.9 at\% on grain boundaries if the additional annealing at $890^{\circ} \mathrm{C}$ was given. Moreover, more second phase particles were found in the specimens annealed at $1125^{\circ} \mathrm{C}$ plus $890^{\circ} \mathrm{C}$. Energy dispersive $\mathrm{x}$-ray spectroscopy analysis of the particles indicated that they contained higher Ti concentration. The results indicated that the improved toughness of the specimens annealed at $1125^{\circ} \mathrm{C}$ plus $890^{\circ} \mathrm{C}$ probably resulted from the reduced $S$ concentration on the grain boundaries and precipitation of the second phases. It was found that the embrittlement was thermodynamically reversible because the embrittlement could be restored by giving the ductile material additional annealing at $1125^{\circ} \mathrm{C}$ for $1 \mathrm{~h}$.

\subsubsection{EFFECT OF PREIRRADIATION HEAT TREATMENT ON SWELLING OF NEUTRON-IRRADIATED VANADIUM-BASE ALLOYS - B. Loomis, L. J. Nowicki,} and D. L. Smith (Argonne National Laboratory). . . . . . . . . . . . . .

The dependence of swelling of neutron-irradiated V-14Cr-5Ti, V-7Cr-15Ti, V-3Ti-0.3Si, and $\mathrm{V}$-18Ti alloys on preirradiation heat treatment (which consisted of a 1-h annealing at either $850,950,1100,1125$, or $1200^{\circ} \mathrm{C}$ ) was determined from density measurements of the alloys after irradiation at either 420,520 , or $600^{\circ} \mathrm{C}$ to $21-88 \mathrm{dpa}$. Swelling of the V-14Cr-5Ti alloy was minimal after $1-\mathrm{h}$ annealing at $1125^{\circ} \mathrm{C}$, whereas swelling of the $\mathrm{V}-7 \mathrm{Cr}-15 \mathrm{Ti}$ alloy was minimal after 1-h annealing at 1125 and $1200^{\circ} \mathrm{C}$. Swelling of the V-3Ti-0.3Si alloy increased when the annealing temperature was increased from $850^{\circ} \mathrm{C}$ to $1200^{\circ} \mathrm{C}$, and swelling of the V-18Ti alloy was minimal after preirradiation annealing at $1125^{\circ} \mathrm{C}$.

\subsubsection{MICROSTRUCTURAL EVOLUTION OF V-4Cr-4Ti DURING DUAL-ION} IRRADIATION AT $350^{\circ} \mathrm{C}-\mathrm{J}$. Gazda and M. Meshii (Northwestern University), and B. A. Loomis and H. M. Chung (Argonne National Laboratory). . . . . . . . . . .

The preliminary results of TEM investigation of microstructural evolution of $\mathrm{V}-4 \mathrm{Cr}-4 \mathrm{Ti}$ (Heat \#832665) alloy irradiated with $4.5 \mathrm{MeV} 58 \mathrm{Ni}^{++}$ions at $350^{\circ} \mathrm{C}$, with and without simultaneous $3 \mathrm{He}^{+}$injection, are presented. This work is the basis of an extensive study designed to evaluate ion irradiation experiments as a tool for simulating and understanding fusion neutron damage and helium generation in V-Cr-Ti alloys. The effects of ionirradiation damage (at moderate temperatures of $\left\langle 400^{\circ} \mathrm{C}\right.$ ) on mechanical properties of these alloys will be also evaluated in this study. This initial report includes descriptions of specimen preparation techniques, procedures performed during ion irradiation, postirradiation analysis, and results of preliminary transmission electron microscopy (TEM) investigation. Specimens irradiated to $\approx 10 \mathrm{dpa}$ by $58 \mathrm{Ni}^{++}$ions showed a high density of "black-dot" defects and dislocations. Cavity formation in the specimens irradiated simultaneously with ${ }^{3} \mathrm{He}^{+}$ ions to a rate of $\approx 5 \mathrm{appm} / \mathrm{dpa}$ He was not observed.

\subsubsection{EFFECT OF OXIDATION ON TENSILE BEHAVIOR OF V-5Cr-5Ti ALLOY -}

K. Natesan and W. K. Soppet (Argonne National Laboratory). . . . . . . . . . . . .

Oxidation studies were conducted on V-5Cr-5Ti alloy specimens at $500^{\circ} \mathrm{C}$ in air to evaluate oxygen uptake of the alloy as a function of temperature and exposure time. The oxidation rates derived from thermogravimetric testing are 5, 17, and $27 \mu \mathrm{m}$ after one year of exposure 
at 300,400 , and $500^{\circ} \mathrm{C}$, respectively. Uniaxial tensile tests were conducted on preoxidized specimens of the alloy to examine the effects of oxidation and oxygen migration on tensile strength and ductility. Microstructural characteristics of several of the tested specimens were characterized by electron optic techniques. Correlations have been developed between tensile strength and ductility. Microstructural characteristics of several of the tested specimens were characterized by electron optic techniques. Correlations have been developed between tensile strength and ductility of the oxidized alloy and microstructural characteristics such as oxide thickness, depths of hardened layers, depths of intergranular fracture zones, and lengths of transverse cracks.

\subsubsection{IMPACT PROPERTIES OF PRECRACKED V-4CT-4Ti.CHARPY SPECIMENS -}

H. M. Chung, L. Nowicki, and D. L. Smith (Argonne National Laboratory) . . . . . . . .

Laboratory- and production-scale ( 20 and $500 \mathrm{~kg}$, respectively) heats of $\mathrm{V}-4 \mathrm{Cr}-4 \mathrm{Ti}$, which is the reference vanadium alloy for application in fusion reactor structural components, have recently been produced successfully. Charpy tests conducted previousiy at -196 to $200^{\circ} \mathrm{C}$ on $1 / 3$ size blunt-notch specimens, showed that both heats have excellent impact properties, i.e., ductile-brittle transition temperature (DBTT) lower than $-200^{\circ} \mathrm{C}$ and upper-shelf energy of 10$16 \mathrm{~J}$. Effects of precracking on the impact behavior of the Charpy specimens were investigated in this study. Precracked specimens were tested after annealing of the optimal conditions of $1000^{\circ} \mathrm{C}$ for $1 \mathrm{~h}$. Precracked specimens from both the laboratory-and productionscale heats exhibited normalized energies of 6.7 to $10.9 \mathrm{~J}$ at test temperatures of -196 to $200^{\circ} \mathrm{C}$; no brittle fracture was observed. This demonstrates the excellent dynamic toughness of $\mathrm{V}-4 \mathrm{Cr}-4 \mathrm{Ti}$.

\subsubsection{FABRICATION AND IMPACT PROPERTIES OF LABORATORY-SCALE HEAT OF} V-5Cr-5Ti - H. M. Chung, L. Nowicki, D. Busch, and D. L. Smith (Argonne National Laboratory). . . . . . . . . . . . . . . . . . . . . . .

Impact properties were determined on a new $15-\mathrm{kg}$ laboratory heat of $\mathrm{V}-5 \mathrm{Cr}-5 \mathrm{Ti}$, fabricated by the same procedures as those used to produce a $500-\mathrm{kg}$ production-scale heat of $\mathrm{V}-4 \mathrm{Cr}-4 \mathrm{Ti}$, to identify an optimal annealing procedure for the alloy. Charpy-impact tests were conducted on one-third-size specimens because low-temperature $\left(<0^{\circ} \mathrm{C}\right)$ impact properties have been known to be most sensitive to the structure and toughness of the $\mathrm{V}-(4-5) \mathrm{Cr}-(4-5) \mathrm{Ti}$ alloy class. After final annealing at $\approx 1000^{\circ} \mathrm{C}$ for $1 \mathrm{~h}$ in a high-quality vacuum, the laboratory heat of $\mathrm{V}$ $5 \mathrm{Cr}-5 \mathrm{Ti}$ exhibited impact properties as excellent as those of the production- and laboratoryscale heats of $\mathrm{V}-4 \mathrm{Cr}-4 \mathrm{Ti}$; i.e., ductile-brittle-transition temperatures less than $-200^{\circ} \mathrm{C}$ and absorbed energies of 10-16 J. This finding demonstrates that, when fabricated by the procedure specified in this study and annealed at the common optimal condition of $1000^{\circ} \mathrm{C}$ for $1 \mathrm{~h}$, the V-(4-5)Cr-(4-5)Ti alloy class exhibits excellent impact toughness and a sufficient tolerance to minor variations in alloying-element composition.

6.3.10 TENSILE PROPERTIES OF UNIRRADIATED V-Cr--Ti ALLOYS, AND ALTERNATIVE APPROACHES FOR STRENGTHENING THE V-4Cr-4Ti ALLOY - B. A. Loomis, L. J. Nowicki, and D. L. Smith (Argonne National Laboratory). . . . . . . . . . .

The temperature dependence of tensile properties of unirradiated V-Cr-Ti alloys are presented in the form of tables and figures in this report. These tensile-property data, together with other physical and mechanical property data for unirradiated and neutron-irradiated $\mathrm{V}-\mathrm{Cr}$ - $\mathrm{Ti}$ alloys, are examined for alternative approaches to strengthen the $\mathrm{V} 4 \mathrm{Cr}-4 \mathrm{Ti}$ alloy, which is the current prime-candidate vanadium-base alloy for use as structural material in a fusion reactor. Consideration of three alternative approaches for strengthening (i.e., increased $\mathrm{Cr}$ and/or Ti concentration; heat treatment; or increased $\mathrm{Si}$ and/or $\mathrm{Si}, \mathrm{Al}$, and $\mathrm{Y}$ concentration) lead us to recommend $\mathrm{Si}$ and/or $\mathrm{Si}, \mathrm{Al}$, and $\mathrm{Y}$ additions as most promising for strengthening of the $\mathrm{V} 4 \mathrm{Cr}-4 \mathrm{Ti}$ alloy without major impact on the physical and mechanical properties of $\mathrm{V}-4 \mathrm{Cr}-4 \mathrm{Ti}$. 
6.3:11 EFFECT OF ANNEALING ON IMPACT PROPERTIES OF PRODUCTION-SCALE EAT OF V-4Cr-4Ti - H. M. Chung, L. Nowicki, and D. L. Smith (Argonne National

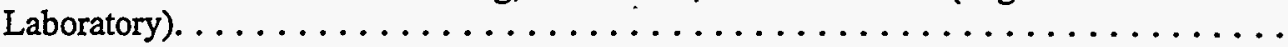

A 500-kg heat of $\mathrm{V}-4 \mathrm{Cr}-4 \mathrm{Ti}$, an alloy identified previously as the primary vanadium-based candidate alloy for application in fusion reactor structural components, has been successfully produced. Impact tests were conducted at -196 to $150^{\circ} \mathrm{C}$ on one-third-size blunt-notch Charpy specimens of the scaleup heat in as-rolled condition and after annealing for $1 \mathrm{~h}$ at 950,1000 , and $1050^{\circ} \mathrm{C}$ in a high-quality vacuum. The annealed material remained ductile at all test temperatures; the ductile-brittle transition temperature was lower than $-200^{\circ} \mathrm{C}$. The upper-shelf energy of the production-scale heat was similar to that of the laboratory-scale $(\approx 30-\mathrm{kg})$ heat of $\mathrm{V}-4 \mathrm{Cr}-4 \mathrm{Ti}$ investigated previously. The effect of annealing temperature between 950 and $1050^{\circ} \mathrm{C}$ was not significant; however, annealing at $1000^{\circ} \mathrm{C}$ for $1 \mathrm{~h}$ not only produced the best impact properties but also ensured a sufficient tolerance to the effect of temperature inhomogeneity that is expected when large components are annealed. The effect of the notch geometry of the Charpy-impact specimens was also investigated. When annealed properly (e.g., at $1000^{\circ} \mathrm{C}$ for $1 \mathrm{~h}$ ), impact properties were not sensitive to notch geometry ( $45^{\circ}$-notch, root radius $0.25 \mathrm{~mm}$; and $30^{\circ}$ notch, root radius $0.08 \mathrm{~mm}$ ).

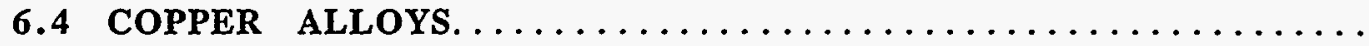

\subsubsection{HIGH TEMPERATURE STABILITY OF DISPERSION STRENGTHENED COPPER} ALLOYS IRRADIATED WITH FAST NEUTRONS - D. J. Edward (Associated Western Universities, F. A. Garner and M. L. Hamilton (Pacific Northwest National Laboratory), and J. D. Troxell (SCM Metal Products, Inc.). . . . . . . . . . . . . . .

Two dispersion strengthened copper alloys, GlidCop CuAl25 and GlidCop-Nb, were irradiated under three different conditions to study their response to high temperature neutron irradiation. Previous studies demonstrated that GlidCop CuAl25 experienced a decrease in yield and ultimate strength by $50 \mathrm{dpa}$, but no further changes in strength occurred at doses up to $150 \mathrm{dpa}$. The implications of this are that cold worked (CW) $\mathrm{CuAl} 25$ alloys will experience most of the changes in mechanical properties at dose levels that are well within the Basic Physics Phase of ITER's operation. Alloying CuAl25 with $10 \mathrm{wt} \% \mathrm{Nb}$ produced a DS copper alloy that was completely resistant to any changes in strength during irradiation. These results, when combined with earlier studies, strongly suggest that high temperature neutron irradiation relaxes the dislocation structure within a few dpa (5.8 dpa or less). Alloying with niobium is thought to effectively prevent this relaxation, thereby maintaining the strength of the material.

\subsubsection{BRAZED DISPERSION STRENGTHENED COPPER: THE EFFECT OF NEUTRON IRRADIATION AND TRANSMUTATION ON BOND INTEGRITY - D. J. Edwards} (Associated Western Universities), F. A. Garner and M. L. Hamilton (Pacific Northwest Laboratory), and J. D. Troxell (SCM Metal Products, Inc.). . . . . . . . . . . .

Four types of brazes were used to join sheets of GlidCop CuAl25. Miniature tensile specimens and TEM disks were fabricated from the joints, and irradiated under various conditions to study their response to high temperature neutron irradiation. Two of the brazes, TiCuAg and TiCuNi, were eliminated from consideration because of the poor quality of the brazed joints. Brazed joints produced using a gold-containing braze were satisfactory for the unirradiated state. However, transmutation of $\mathrm{Au}$ to $\mathrm{Hg}$ affected the integrity of some of the joints in the specimens irradiated in a below-core position where the neutron spectrum was much softer. A CuAG braze yielded satisfactory joints in the unirradiated state, and held up very well when the irradiated specimens were tested. However, transmutation of $\mathrm{Ag}$ to $\mathrm{Cd}$ leads to a high residual radioactivity that limits the usefulness of this braze after exposure to neutron irradiation. Further work is necessary to 
identify brazes that are "transmutation-resistant" and also that minimize the potential for activation by a suitable choice of elemental constituents.

\subsubsection{ROOM TEMPERATURE FATIGUE BEHAVIOR OF CuCrZr OF TWO SIZES - K. Leedy} and J. F. Stubbins (University of Illinois), F. A. Garner and D. J. Edwards (Pacific Northwest Laboratory), and B. N. Singh (Ris $\varnothing$ National Laboratory).................

The room temperature fatigue behavior of unirradiated $\mathrm{CuCrZr}$ in two specimen sizes has been measured. The fatigue performance was found to be intermediate to those of OFHC copper and CuAl25, which were reported earlier. The size effects correlation is complicated somewhat by the sensitivity of this alloy to details of the heat treatment. Declining interest in this alloy for ITER applications and the shut-down of EBR-II will probably preclude irradiation of this alloy.

6.5 ENVIRONMENTAL EFFECTS IN STRUCTURAL MATERIALS.......

\subsubsection{FABRICATION OF ALUMINUM NITRIDES AND ITS STABILITY IN LIQUID ALKALI} METALS - K. Nateson and D. L. Rink (Argonne National Laboratory). ..........

Aluminum nitride (AIN) has been selected as a prime candidate to electrically insulate the V-alloy first wall in the self-cooled concept for ITER application. Detailed investigations were conducted on the fabrication, metallurgical microstructure, compatibility in liquid $\mathrm{Li}$, and electrical characteristics of AlN material obtained from several sources. Coating fabrication methods included physical vapor deposition, reaction sputtering, ion-beamassisted deposition, chemical vapor deposition, and a chemical route. Microstructural characterization of the coated samples was conducted by scanning electron microscopy, energy-dispersive $\mathrm{X}$-ray analysis, and X-ray diffraction. Lithium compatibility studies were conducted in static systems by exposure of AlN-coated specimens to $\mathrm{Li}$ for several time periods. Electrical resistance measurements were made at room temperature on the specimens before and after exposure to liquid $\mathrm{Li}$. The results obtained in this study indicate that AIN is a viable coating from the standpoint of chemical compatibility in $\mathrm{Li}$, electrical insulation characteristics, and ease of fabrication, and that the coating should be examined further for fusion reactor application.

6.5.2 ELECTRICAL INSULATOR COATINGS ON V ALLOYS - J.-H. Park, G. Dragel, and W. D. Cho (Argonne National Laboratory) . . . . . . . . . . . . . . . .

Several intermetallic films were applied to $\mathrm{V}$ alloys to provide electrical insulation and corrosion resistance. Grain-growth behavior for the V-5Cr-5Ti alloy at $1000^{\circ} \mathrm{C}$ was investigated to determine the stability of the alloy substrate during coating formation by chemical vapor deposition or metallic vapor processes at $800-850^{\circ} \mathrm{C}$. Film layers were examined by optical and scanning electron microscopy and by electron-energy-dispersive and $\mathrm{X}$-ray diffraction analysis; they were also tested for electrical resistivity and corrosion resistance. The results elucidated the nature of the coatings, which provided both electrical insulation and high-temperature corrosion protection.

\subsubsection{FORMATION AND SELF-HEALING BEHAVIOR OF CaO INSULATOR COATINGS} ON A VANADIUM-BASE ALLOY IN LIQUID LITHIUM - J.-H. Park, and T. F. Kassner (Argonne National Laboratory). . . . . . . . . . . . . . . . . .

The electrical resistance of $\mathrm{CaO}$ coatings produced on $\mathrm{V}-5 \% \mathrm{Cr}-5 \% \mathrm{Ti}$ by exposure of the alloy to liquid $\mathrm{Li}$ that contained $0.5-85 \mathrm{wt}$.\% dissolved $\mathrm{Ca}$ was measured as a function of time at temperatures between 250 and $600^{\circ} \mathrm{C}$. The solute element, $\mathrm{Ca}$ in liquid $\mathrm{Li}$, reacted with the alloy substrate at $400-420^{\circ} \mathrm{C}$ to produce a $\mathrm{CaO}$ coating. Resistance of the coating layer measured in situ in liquid $\mathrm{Li}$ was $\approx 10^{6} \Omega$ at $400^{\circ} \mathrm{C}$. Thermal cycling between 300 
and $700^{\circ} \mathrm{C}$ changed the resistance of the coating layer, which followed insulator behavior. Examination of the specimens after cooling to room temperature revealed no spallation, but homogeneous crazing cracks were present in the $\mathrm{CaO}$ coating. In-situ self-healing of the cracks occurred at temperatures $\geq 360^{\circ} \mathrm{C}$. These results suggest that thin coatings can be produced on variously shaped surfaces by controlling the exposure time, temperature, and composition of the liquid metal.

\subsubsection{SELECTION OF A LIQUID CALCIUM-LITHIUM ALLOY FOR FABRICATING CaO INSULATOR COATINGS ON V-5\%Cr-5\%Ti - J.-H. Park and T. F. Kassner (Argonne National Laboratory). . . . . . . . . . . . . . . . . . . . .}

An electrically insulating coating at the liquid-metal/structural-material interface of a magnetic fusion reactor is required to prevent adverse.currents generated by the magnetohydrodynamic (MHD) force from passing through the structural walls. Thin, homogeneous, electrically insulating $\mathrm{CaO}$ coatings can be produced on variously shaped surfaces of $\mathrm{V}-5 \% \mathrm{Cr}-5 \% \mathrm{Ti}$ by exposing the alloy at controlled times and temperatures to liquid $\mathrm{Li}$ containing $\mathrm{Ca}$. Formation of $\mathrm{Ca}-\mathrm{Li}$ alloys by dissolution of solid $\mathrm{Ca}$ in liquid $\mathrm{Li}$ in an $\mathrm{Ar}$ environment was investigated, and the exothermic heat of solution was found to be low, as indicated by minimal increases in temperature. The recommended composition of a liquid alloy for fabrication of this coating on reactor components is $\mathrm{Li}-82 \mathrm{wt} . \% \mathrm{Ca}$ (44 at. $\% \mathrm{Ca}$ ), which has a liquidus temperature of $\approx 230^{\circ} \mathrm{C}$. As the solute $\mathrm{Ca}$ in the liquid alloy is consumed during the coating process, the liquidus temperature of the alloy decreases. This coating technique can be applied to various shapes (e.g., inside/outside of tubes, complex geometrical shapes) because the coating is formed by liquid-phase reaction at $=400^{\circ} \mathrm{C}$. Cracks that form in the $\mathrm{CaO}$ coating during thermal cycling exhibit in-situ self-healing behavior at temperatures $\geq 360^{\circ} \mathrm{C}$.

7.0 SOLID BREEDING MATERIALS AND BERYLLIUM............

7.1 INVESTIGATION OF TRITIUM RELEASE FROM TITANATE - J. P. Kopasz and

C. E. Johnson (Argonne National Laboratory) . . . . . . . . . . . . . . . . .

Tritium release from lithium titanate has been investigated using isothermal anneal experiments. These experiments suggest that the rate-controlling step for tritium desorption is desorption of HTO from a titanium site on the Li2TiO3 surface. The experiments also indicate that the presence of hydrogen in the purge gas helps the tritium release by increasing the fraction of tritium released at a given temperature.

7.2 A $b$ initio CALCULATIONS FOR DISSOCIATIVE HYDROGEN ADSORPTION ON LITHIUM OXIDE SURFACES - A. Sutjianto, S. W. Tam, L. Curtiss, and C. E. Johnson (Argonne National Laboratory) and R. Pandey (Michigan Technological University).......

Dissociative hydrogen chemisorption on the $\mathrm{Li}_{2} \mathrm{O}$ surfaces of the (100), (110), and (111) planes has been investigated with $a b$ initio Hartree-Fock calculations. Calculations for unrelaxed crystal $\mathrm{Li}_{2} \mathrm{O}$ structures indicated that except for the (100) surface, the (110) and (111) surfaces are stable. Results on the heterolytic sites of n-layer (110) slabs (where $n \geq$ 2) and three-layer (111) slabs suggest that dissociative hydrogen chemisorption is endothermic. For a one-layer (110) slab at $100 \%$ surface coverage, the dissociative hydrogen chemisorption is exothermic, forming $\mathrm{OH}^{-}$and $\mathrm{Li}^{+} \mathrm{H}^{-} \mathrm{Li}^{+}$. The results also indicate that the low coordination environment in surface step structure, such as kinks and ledges, may play an important role in the hydrogen chemisorption process. On the homolytic sites of the (110) and (111) surfaces, there is no hydrogen chemisorption. 


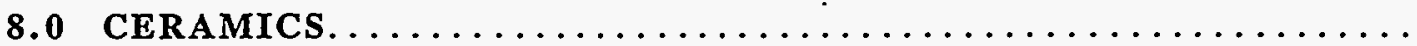

8.1 FATIGUE BEHAVIOR OF NICALON/SiC COMPOSITES - N. Miriyala, P. K. Liaw, and C. J. McHargue (University of Tennessee), X. Mao and W. Mao (University of Calgary), L. L. Snead (Oak Ridge National Laboratory), and D. K. Hsu (Iowa State University). . . . .

A periodic model using a finite element method (FEM) was developed to predict the effect of porosity on the in-plane and through-thickness elastic stiffness constants of Nicalon/SiC composites. The FEM results indicated that the in-plane moduli values will be higher than the through-thickness moduli values. Also, the predicted values were in close agreement with the ultrasonically measured elastic stiffness constants for the composite materials under study.

8.2 MICROSTRUCTURE OF $\mathrm{AL}_{2} \mathrm{O}_{3}$ IRRADIATED WITH AN APPLIED ELECTRIC FIELD S. J. Zinkle, J. D. Hunn, and R. E. Stoller (Oak Ridge National Laboratory). . . . . . . . . .

A thin amorphous film of alumina was irradiated with $2-\mathrm{MeV} \mathrm{He} e^{+}$ions at $\sim 400^{\circ} \mathrm{C}$ up to a damage level of about 0.01 displacements per atom (dpa). The alumina films were sufficiently thin $(\sim 1.8 \mu \mathrm{m})$ to allow the ion beam to be completely transmitted through the specimen. An electric field of $\sim 280 \mathrm{~V} / \mathrm{mm}$ (dc) was applied continuously during the irradiation. Radiation induced electrical degradation (RIED), i.e. a permanent increase in the conductance of the film, was observed in specimens irradiated at temperatures near 400 to $450^{\circ} \mathrm{C}$, but did not occur in a specimen irradiated above $500^{\circ} \mathrm{C}$. An investigation by transmission electron microscopy found no evidence for colloid formation. The observed increase in the conductance of the alumina film may be due to radiation--induced microcracking.

8.3 INVESTIGATION OF RADIATION INDUCED ELECTRICAL DEGRADATION IN ALUMINA UNDER ITER-RELEVANT CONDITIONS - L. L. Snead, D. P. White, and S. J. Zinkle (Oak Ridge National Laboratory) . . . . . . . . . . . . . . . .

An in-situ experiment investigating the radiation induced electrical degradation (RIED) effect in polycrystalline alumina is described. A Wesgo AL-995 polycrystalline alumina sample has been irradiated with fission neutrons to 1.4 displacements per atom (dpa) at $340-365^{\circ} \mathrm{C}$ with no evidence of RIED. The implication of these and previous results are discussed in terms of their impact on the International Thermonuclear Experimental Reactor (ITER), with the conclusion that RIED will be of no consequence during the basic phase of the machines operation.

8.4 X-RAY-INDUCED LUMINESCENCE FROM HYDROXYL-DOPED SILICA FIBERS -D. W. Cooke, E. H. Farnum, F. W. Clinard, Jr., B. L. Bennett (Los Alamos National Laboratory) and A. M. Portis (UC-Berkeley) . . . . . . . . . . . . . . .

Fiber optics is expected to play a very important role in ITER diagnostics. The present consensus is that silica fibers comprised of low-OH silica cores and F-doped cladding are the best candidates for use in optical diagnostic systems in a high-fluence radiation environment. One concern regarding their use, however, is radiation-induced visible luminescence. Accordingly, we have examined the luminescence of low- (fiber $A$ ) and high-OH (fiber $S$ ) content silica fibers subjected to continuous $x$ irradiation as a function of temperature and time. In the interval $7-300 \mathrm{~K}$, fiber $A$ exhibits two well-defined peaks at 520 and $670 \mathrm{~nm}$ with the exact position being dependent upon temperature. Fiber $S$ is characterized by one broad peak near $590 \mathrm{~nm}$ with evidence of a second weak peak near $620 \mathrm{~nm}$. Generally we find that luminescence peak intensities decay with increasing temperature. The time dependence of each peak was measured at various fixed temperatures and was found to exhibit exponential decay. Rate equations were written to explain the time dependent intensities in terms of 
excitation and luminescence center creation and annihilation. Results suggest that Cherenkov radiation may be more important than luminescence in diagnostic fibers.

8.5 OXYGEN EFFECTS ON SiC/SiC COMPOSITES FOR FUSION STRUCTURAL APPLICATIONS - G. D. Springer, C. F. Windisch, Jr., C. H. Henager, Jr., and R. H. Jones (Pacific Northwest Laboratory). . . . . . . . . . . . . . .

Linear-parabolic kinetics governed the oxidation reaction with 100 to $1500 \mathrm{ppm}$ oxygen at $1100^{\circ} \mathrm{C}$. This behavior concurs with the previous research of Windisch et al., which observed a deviation from linearity beginning below $2500 \mathrm{ppm}$. By focusing on the linear region, a simple model estimated the linear rate dependency on oxygen partial pressure to be on the order of 0.911 . Future tests will be performed with 100 and $1000 \mathrm{ppm}$ in the temperature range of 800 to $1000^{\circ} \mathrm{C}$ in order to refine the understanding of temperature and partial pressure effects. The relationship between interfacial oxidation and experimental parameters, such as temperature, pressure, and interfacial thickness, will be described in an upcoming comprehensive model.

8.6 HYDROGEN EFFECTS ON SiC/SiC COMPOSITES FOR FUSION STRUCTURAL APPLICATIONS - G. D. Springer and R. H. Jones (Pacific Northwest Laboratory). . . . . .

Two exploratory experiments at $1100^{\circ} \mathrm{C}$ and $1200^{\circ} \mathrm{C}$ in an argon $+1 \%$ hydrogen environment have demonstrated a relatively slow reaction rate. This slow reaction rate concurs with literature, yet a better understanding of kinetics is still needed. Further experimentation will test the reproducibility of these early results and better determine the influence of experimental conditions by varying temperature and the partial pressure of hydrogen.

8.7 DIMENSIONAL STABILITY OF SiC-TYPE FIBERS NEUTRON IRRADIATED TO HIGH DOSES - G. E. Youngblood, D. J. Senor, and G. W. Hollenberg (Pacific Northwest Laboratory). . . . . . . . . . . . . . . . . . . . . . . .

Silicon carbide based fibers with a range of stoichiometries and microstructures (Nicalon CG, Nicalon HVR, HPZ, Tyranno, and Dow/NASA Xstalline) were selected for evaluation of their dimensional stability after neutron irradiation to high doses. For comparison, carbon fibers with a range of graphitization also were evaluated.

The fibers were irradiated in the MOTA 2B cycle of the FFTF reactor. Two sets of the selected $\mathrm{C}$ and $\mathrm{SiC}$ fiber types were exposed at $430^{\circ} \mathrm{C}$ to a fluence of $5.5 \times 10^{21} \mathrm{n} / \mathrm{cm}^{2}$ or $2.5 \times 10^{22} \mathrm{n} / \mathrm{cm}^{2}(\mathrm{E} \geq 0.1 \mathrm{MeV})$, equivalent to relatively high doses of 5.3 and $25 \mathrm{dpa}-\mathrm{SiC}$. Dimensional stability was determined by measuring the length and density changes of the fibers after the irradiations.

For the $\mathrm{SiC}$-based fibers above $5 \mathrm{dpa}-\mathrm{SiC}$, little dose dependence was observed except for the Tyranno fiber. The HPZ, Tyranno, and Nicalon HVR fibers, whose pre-irradiated densities were quite low, exhibited substantially more axial shrinkage than the Nicalon CG fiber. Even though the shrinkage of the Nicalon CG fiber was moderate (about $2 \%$ at $430^{\circ} \mathrm{C}$ ), fiber shrinkage and debonding from the matrix previously had been observed to result in decreased strengths in Nicalon fiber $\mathrm{SiC} / \mathrm{SiC}$ composites irradiated to the same fluence and ad similar and at higher temperatures. The developmental fiber, Dow/NASA Xstalline, actually exhibited slight swelling rather than shrinkage. The composition of the Dow/NASA fiber was near stoichiometric $\mathrm{SiC}$, the density was $90 \%$ of theoretical for $\mathrm{SiC}$, and the microstructure was reported to be more.crystalline than for the other SiC-based fibers.

For the $C$ fibers, the amount of axial shrinkage was much greater than observed for the irradiated SiC-based fibers and generally was greater the lower the degree of initial graphitization. Also, in contrast to the irradiated $\mathrm{SiC}$ behavior, the radiation damage did not 
appear to saturate, but continuously increased with increasing dose. The axial shrinkage exceeded about $20 \%$ for the most graphitic $C$ fiber and exceeded $60^{\wedge}$ for the less graphitic fiber at the higher dose. Independent of the initial degree of graphitization, the densities of all the $\mathrm{C}$ fibers increased and appeared to saturate at a common value by the $3 \mathrm{dpa}-\mathrm{C}$ dose. With increasing dose above $3 \mathrm{dpa}-\mathrm{C}$, the densities increased and returned almost to their unirradiated values by $15 \mathrm{dpa}-\mathrm{C}$. The density change data indicated that $C$ fibers will continuously shrink in the axial direction (i.e., the preferred alignment of the graphitic a-axis in $\mathrm{C}$ fibers) under irradiation. However, in the diametral direction, graphitic c-axis growth will be accommodated by porosity and/or amorphicity initially, but with continued irradiation diametral swelling will commence once the accommodation is over.

Silicon carbide based fibers that are close to stoichiometric and crystalline appear to have the radiation damage tolerance necessary to make $\mathrm{SiC} / \mathrm{SiC}$ composites suitable for further testing and development for fusion power system applications. Due to the fundamental nature of radiation damage in graphite, dimensional instability (extreme axial shrinkage and diametral swelling) of $\mathrm{C}$ fiber irradiated to high doses will prevent their use in $\mathrm{C} / \mathrm{C}$ composites for long-term operations in a fusion power system. 
1.0 IRRADIATION FACILITIES, TEST MATRICES, AND EXPERIMENTAL METHODS 

STATUS OF U.S./JAPAN COLLABORATIVE PROGRAM PHASE II HFIR TARGET AND RB CAPSULES - J. E. Pawel, K. E. Lenox (Oak Ridge National Laboratory) and I. Ioka (Japan Atomic Energy Research Institute)

\section{OBJECTIVE}

The objective of the High Flux Isotope Reactor (HFIR) irradiations is to determine the response of various U.S. and Japanese austenitic and ferritic steels with different pretreatments and alloy compositions to the combined effects of displacement damage and helium generation. Specimen temperatures during irradiation range from 60 to $600^{\circ} \mathrm{C}$ and fluences range up to $60 \mathrm{dpa}$. The $\mathrm{RB}$ experiments are a continuation of the ORR spectrally tailored experiments in which the spectrum is modified with a hafnium shield to simulate the expected fusion helium to damage (He/dpa) ratio. In the HFIR target capsules, many specimens have been isotopically tailored in order to achieve fusion helium generation rates.

\section{SUMMARY}

Capsules HFIR-MFE-JP9 through JP16 operated in the HFIR target region and accumulated doses of 18, 34 , and $57 \mathrm{dpa}$ at temperatures of $300,400,500$, and $600^{\circ} \mathrm{C}$; all eight capsules in this series have been irradiated and disassembled. Capsules JP20, 21 and 22 were designed to accumulate 8, 18, and $34 \mathrm{dpa}$, respectively, with specimen temperatures of $300-600^{\circ} \mathrm{C}$. JP20 and JP21 have been removed from the reactor; JP22 has accumulated $18.6 \mathrm{dpa}$ as of the end of this reporting period. HFIR-MFE-200J-1 and 400J-1 capsules achieved the goal of $20 \mathrm{HFIR}$ irradiation cycles, or approximately $9 \mathrm{dpa}$, and were removed from the reactor to the cooling pool. Disassembly is scheduled for the next reporting period.

\section{PROGRESS AND STATUS}

\section{Target Capsules JP9 through JP16}

Capsules HFIR-MFE-JP9 through JP16 operated in the HFIR target region and accumulated doses of 18 , 34 , and $57 \mathrm{dpa}$ at temperatures of $300,400,500$, and $600^{\circ} \mathrm{C}$. All eight capsules in this series have been irradiated and disassembled. Specimen testing, including densitometry and tensile testing, is complete on the specimens from JP10,11,13,14, and 16. Transmission electron microscopy examination is in progress. Specimen testing from JP9, 12, and 15 will be conducted over the next 18 months. Complete descriptions of the design, construction, installation, operation, and specimen matrix can be found in previous reports [1-4].

\section{Target Capsules JP20 through 22}

Capsules JP20, 21 and 22 were designed to accumulate 8, 18, and $34 \mathrm{dpa}$, respectively, with specimen temperatures of $300-600^{\circ} \mathrm{C}$. JP2 20 has been removed from the reactor and disassembled. JP21 completed the scheduled 11-cycle irradiation during this reporting period (end of cycle 334) and was removed from the reactor to the cooling pool. It achieved an approximate peak dose of $18.6 \mathrm{dpa}$. JP22 is scheduled to be irradiated for 21 cycles, to an approximate peak dose of $34 \mathrm{dpa}$. As of the end of cycle 334 (April 9, 1995 ) this capsule had accumulated $21337 \mathrm{MWd}$, or approximately $18.6 \mathrm{dpa}$. Details of the operation of these capsules are shown in Table 1 and described elsewhere [5-6].

RB Capsules HFIR-MFE-60J-1, 200J-1, 330J-1 and 400J-1

The design and operation of the four RB capsules have been previously described [7-12]. During this reporting period, the $200 \mathrm{~J}-1$ and $400 \mathrm{~J}-1$ capsules achieved the goal of $20 \mathrm{HFIR}$ irradiation cycles, or approximately $9 \mathrm{dpa}$, and were removed from the reactor. This is in addition to the $7 \mathrm{dpa}$ accumulated during the Oak Ridge Research Reactor (ORR) irradiation, bringing the total for the two-stage irradiation 
to $16 \mathrm{dpa}$. Dosimetry and helium measurements from specimens from the $60 \mathrm{~J}-1$ and $330 \mathrm{~J}-1$ capsules indicate that this experiment was successful in producing fusion relevant helium/dpa levels (approximately 11 appm He/dpa) [13]. Details of the operation of these capsules are shown in Table 2. These capsules are scheduled to be disassembled during the next reporting period.

Table 1. Irradiation History of HFIR Target Capsules JP20, 21, and 22.

\begin{tabular}{|c|c|c|c|c|r|}
\multicolumn{9}{|c|}{ HFIR Operation } & \multicolumn{2}{|c|}{ JP20 ${ }^{\dagger}, 21^{\ddagger}, 22$} \\
Cycle No. & Start Date & End Date & MWd/Cycle & MWd & dpa $^{*}$ \\
\hline 322 & $12 / 16 / 93$ & $1 / 7 / 94$ & 1854 & 1854 & 1.62 \\
323 & $1 / 23 / 94$ & $2 / 14 / 94$ & 1874 & 3728 & 3.25 \\
324 & $3 / 5 / 94$ & $4 / 1 / 94$ & 1907 & 5635 & 4.92 \\
325 & $4 / 10 / 94$ & $5 / 3 / 94$ & 1907 & 7542 & 6.58 \\
\hline 326 & $5 / 8 / 94$ & $6 / 3 / 94$ & 1825 & 9367 & 8.18 \\
327 & $6 / 26 / 94$ & $7 / 18 / 94$ & 1903 & REMOVED FOR \\
328 & $7 / 31 / 94$ & $8 / 21 / 94$ & 1922 & 2 CYCLES \\
329 & $8 / 27 / 94$ & $9 / 16 / 94$ & $1513 * *$ & 10880 & 9.50 \\
330 & $10 / 11 / 94$ & $11 / 3 / 94$ & 1950 & 12830 & 11.21 \\
331 & $11 / 12 / 94$ & $12 / 7 / 94$ & 1994 & 14824 & 12.94 \\
332 & $12 / 18 / 94$ & $1 / 11 / 95$ & 2008 & 16832 & 14.69 \\
333 & $1 / 31 / 95$ & $2 / 27 / 95$ & 2317 & 19149 & 16.72 \\
334 & $3 / 14 / 95$ & $4 / 9 / 95$ & 2188 & 21337 & 18.63 \\
\hline
\end{tabular}

†JP-20 removed at End of Cycle 326

†े21 removed at End of Cycle 334

*dpa levels based on $0.000873 \mathrm{dpa} / \mathrm{MWd}$ in the target capsules

** Due to power variations over this cycle, this number is not exact

\section{REFERENCES}

1. R. L. Senn, "Status of U.S./Japan Collaborative Program Phase II HFIR Target Capsules," Fusion Reactor Materials Semiannual Progress Report for the Period Ending September 30, 1987, DOE/ER-0313/3, U.S. DOE Office of Fusion Energy, 1988, p. 8.

2. R. L. Senn, "Status of U.S./Japan Collaborative Program Phase II HFIR Target Capsules," Fusion Reactor Materials Semiannual Progress Report for the Period Ending March 31, 1988, DOE/ER0313/4, U.S. DOE Office of Fusion Energy, 1988, p. 7.

3. R. L. Senn, "Status of U.S./Japan Collaborative Program Phase II HFIR Target Capsules," Fusion Reactor Materials Semiannual Progress Report for the Period Ending September 30, 1988, DOE/ER-0313/5, U.S. DOE Office of Fusion Energy, 1989, p. 6.

4. J. E. Pawel, K. E. Lenox, A. W. Longest, R. L. Senn and K. Shiba, "Status of U.S./Japan Collaborative Program Phase II HFIR Target Capsules," Fusion Reactor Materials Semiannual Progress Report for the Period Ending September 30, 1994, DOE/ER-0313/17, U.S. DOE Office of Fusion Energy, 1995, p. 3.

5. J. E. Pawel and R. L. Senn, "Status of U.S./Japan Collaborative Program Phase II HFIR Target Capsules," Fusion Reactor Materials Semiannual Progress Report for the Period Ending March 31, 1992, DOE/ER-0313/12, U.S. DOE Office of Fusion Energy, 1992, p. 15. 
Table 2. Irradiation History of HFIR-MFE-200J-1 and 400J-1.

\begin{tabular}{|c|c|c|c|r|r|}
\multicolumn{9}{|c|}{ HFIR Operation } & \multicolumn{2}{|c|}{ 200J-1 and 400J-1 } \\
Cycle No. & Start Date & End Date & MWd/Cycle & MWd & \multicolumn{1}{c|}{ dpa $^{*}$} \\
\hline 313 & $11 / 21 / 92$ & $12 / 15 / 92$ & 1858 & 1858 & 0.46 \\
314 & $12 / 20 / 92$ & $1 / 12 / 93$ & 1867 & 3725 & 0.91 \\
315 & $1 / 19 / 93$ & $2 / 11 / 93$ & 1861 & 5586 & 1.37 \\
\hline 316 & $2 / 17 / 93$ & $4 / 3 / 93$ & 1807 & 7393 & 1.81 \\
317 & $4 / 23 / 93$ & $5 / 14 / 93$ & 1841 & 9234 & 2.26 \\
318 & $5 / 20 / 93$ & $6 / 13 / 93$ & 1878 & 11112 & 2.72 \\
319 & $6 / 18 / 93$ & $7 / 10 / 93$ & 1863 & 12975 & 3.18 \\
320 & $7 / 15 / 93$ & $8 / 7 / 93$ & 1934 & 14909 & 3.65 \\
\hline 321 & $8 / 12 / 93$ & $9 / 4 / 93$ & 1884 & 16793 & 4.11 \\
322 & $12 / 16 / 93$ & $1 / 7 / 94$ & 1854 & 18647 & 4.57 \\
323 & $1 / 23 / 94$ & $2 / 14 / 94$ & 1874 & 20521 & 5.03 \\
324 & $3 / 5 / 94$ & $4 / 1 / 94$ & 1907 & 22428 & 5.49 \\
325 & $4 / 10 / 94$ & $5 / 3 / 94$ & 1907 & 24335 & 5.96 \\
\hline 326 & $5 / 8 / 94$ & $6 / 3 / 94$ & 1825 & 26160 & 6.41 \\
327 & $6 / 26 / 94$ & $7 / 18 / 94$ & 1903 & 28063 & 6.88 \\
328 & $7 / 31 / 94$ & $8 / 21 / 94$ & 1922 & 29985 & 7.35 \\
329 & $8 / 27 / 94$ & $9 / 16 / 94$ & $1513 * *$ & 31498 & 7.72 \\
330 & $10 / 11 / 94$ & $11 / 3 / 94$ & 1950 & 33448 & 8.19 \\
331 & $11 / 12 / 94$ & $12 / 7 / 94$ & 1994 & 35442 & 8.68 \\
332 & $12 / 18 / 94$ & $1 / 11 / 95$ & 2008 & 37450 & 9.18 \\
\hline
\end{tabular}

*dpa levels based on $0.000245 \mathrm{dpa} / \mathrm{MWd}$

${ }^{* *}$ Due to power variations over this cycle, this number is not exact

6. J. E. Pawel, A. W. Longest, R. L. Senn, K. Shiba, D. W. Heatherly and R. G. Sitterson, "Status of U.S./Japan Collaborative Program Phase II HFIR Target and RB* Capsules," Fusion Reactor Materials Semiannual Progress Report for the Period Ending September 30, 1993, DOE/ER0313/15, U.S. DOE Office of Fusion Energy, 1994, p. 3.

7. A. W. Longest, J. E. Corum, D. W. Heatherly and K. R. Thoms, "Design and Fabrication of HFIR-MFE RB* Spectrally Tailored Irradiation Capsules," Fusion Reactor Materials Semiannual Progress Report for the Period Ending September 30, 1987, DOE/ER-0313/3, U.S. DOE Office of Fusion Energy, 1988, p. 2.

8. A. W. Longest, J. E. Corum and D. W. Heatherly, "Design and Fabrication of HFIR-MFE RB" Spectrally Tailored Irradiation Capsules," Fusion Reactor Materials Semiannual Progress Report for the Period Ending March 31, 1988, DOE/ER-0313/4, U.S. DOE Office of Fusion Energy, 1988, p. 2.

9. A. W. Longest, J. E. Corum and D. W. Heatherly, "Design and Fabrication of HFIR-MFE RB" Spectrally Tailored Irradiation Capsules," Fusion Reactor Materials Semiannual Progress Report for the Period Ending September 30, 1988, DOE/ER-0313/5, U.S. DOE Office of Fusion Energy, 1989 , p. 2. 
10. A. W. Longest, J.E. Pawel, D. W. Heatherly, R. G. Sitterson and R. L. Wallace, "Fabrication and Operation of HFIR-MFE RB* Spectrally Tailored Irradiation Capsules," Fusion Reactor Materials Semiannual Progress Report for the Period Ending March 30, 1993, DOE/ER-0313/14, U.S. DOE Office of Fusion Energy, 1993, p. 14.

11. A. W. Longest, D. W. Heatherly, E. D. Clemmer and J. E. Corum, "Fabrication and Operation of HFIR-MFE RB* Spectrally Tailored Irradiation Capsules," Fusion Reactor Materials Semiannual Progress Report for the Period Ending September 30, 1991, DOE/ER-0313/11, U.S. DOE Office of Fusion Energy, 1992, p. 17.

12. A. W. Longest, J. E. Pawel, D. W. Heatherly, R. G. Sitterson and R. L. Wallace, "Fabrication and Operation of HFIR-MFE RB* Spectrally Tailored Irradiation Capsules," Fusion Reactor Materials Semiannual Progress Report for the Period Ending September 30, 1993, DOE/ER-0313/15, U.S. DOE Office of Fusion Energy, 1994, p. 23.

13. L. R. Greenwood, C. A. Baldwin and B. M. Oliver, "Neutron Dosimetry, Damage Calculations, and Helium Measurements for the HFIR-MFE-60J-1 and MFE-330J-1 Spectral Tailoring Experiments," Fusion Reactor Materials Semiannual Progress Report for the Period Ending September 30, 1994, DOE/ER-0313/17, U.S. DOE Office of Fusion Energy, 1995, p. 28. 
CONTINUING IRRADIATION OF FERRITIC STEELS: EX'PERIMENTS HFIR-CTR-62 AND -63 -- K. E. Lenox, R. L. Klueh, and R. L. Senn (Oak Ridge National Laboratory)

\section{OBJECTIVE}

The objective of this experiment is to evaluate the microstructure, tensile properties, and Charpy impact properties of irradiated ferritic steels. These two capsules are follow-up experiments to the ferritic steel irradiations performed in HFIR-CTR-47, $-48,-49,-50,-53,-54,-55$ and -56.

\section{SUMMARY}

The design and structure of the HFIR-CTR-62 and -63 capsules is described, including detailed descriptions of the specimen materials. The two capsules contain ferritic steel specimens, along with a few austenitic stainless steel TEMs, intended for irradiation at either $300^{\circ} \mathrm{C}$ or $400^{\circ} \mathrm{C}$ until a peak of thirteen dpa is achieved at the center of the capsule. The two capsules, containing eighty-eight one-third size Charpy specimens, 208 TEMs, and thirty-two tensile specimens, have been assembled and are currently scheduled to begin irradiation in the HFIR in April of 1995.

\section{PROGRESS AND STATUS}

\section{Introduction}

HFIR-CTR-62 and -63 have been designed and fabricated and are scheduled to start irradiation in the HFIR in April of 1995. The capsules will be irradiated until a peak of thirteen dpa is achieved in specimens at the reactor midplane. These two capsules are follow-up experiments to HFIR-CTR-47 and -48 , which contained Charpy specimens, and HFIR-CTR-49, $-50,-53,-54,-55$ and -56 , which contained tensile specimens. HFIR-CTR-62 contains only Charpy specimens and HFIR-CTR-63 contains Charpy, tensile, and TEM specimens. The differences from previous ferritic steel irradiations are described, as well as the specimen matrix and specimen holders used in the current experiment, along with the thermal analysis required to design the specimen holders.

\section{Differences from Related Previous Experiments}

These two experiments contain some important elements not found in the previous irradiations of ferritic steels (HFIR-CTR-47, -48, -49, -50, -53, -54, -55 and -56). These elements include new specimen materials and types and new analysis techniques. In addition to the conventional Cr-Mo steels (with and without nickel) contained in the previous capsules, CTR-62 and -63 contain new reduced-activation ferritic steels and nickel-doped alloys. In the prior irradiations, one-half size Charpy specimens were irradiated, and one-third size specimens are being irradiated in this experiment. Also, sheet SS-3 tensile specimens are being irradiated in these two capsules, whereas rod tensile specimens were irradiated in CTR-49, $-50,-55$, and -56 . CTR-62 and -63 also contain TEM specimens which were not included in the previous experiments. The majority of the TEMs are ferritic steels, but a few of them are made of austenitic stainless steel; all of the austenitic specimens 
are TEMs. Density measurements and transmission electron microscopy analysis of the TEM specimens will be made after irradiation. In addition, the fracture surfaces of the Charpy specimens from these two experiments will be examined using scanning election microscopy (SEM) after initial testing.

\section{Specimen Matrix}

CTR-62 contains only Charpy specimens, while CTR-63 contains Charpy, tensile, and TEM specimens. The layout of the specimens in each capsule and the desired temperatures are shown in Figs. 1 and 2. Both capsules contain flux monitors at the locations shown in Figs. 1 and 2. The loading lists for the capsules and the alloy compositions of the specimen materials are shown in Tables 1-3.

\section{Specimen Holders}

The three types of specimen holders required for the experiment are shown in Figs. 3, 4, and 5. Fig. 5 , the Charpy holder, is a.configuration and design that has not been used in previous experiments. The other two holders are nearly identical to those used in a previous series of experiments, JP-9 through $-16^{1}$, but with slight modifications. Each holder type is discussed in more detail below.

\section{Tensile Specimen Holder (Fig. 3)}

Four tensile specimens and eight filler pieces (made of the specimen material) are held against an HT9 alloy central core by a two piece aluminum alloy holder. The entire assembly is slid into an HT-9 sleeve. Small spacer tabs on the top and bottom of the aluminum holder are used to maintain the gas gap required for temperature control. The two notches along the length of the aluminum holder have been added to allow for gas flow in the case of a blocked control gap and for easier disassembly after irradiation. Additional gas gap spacer tabs were added on each side of the notch on the top and bottom of the aluminum holder.

TEM Specimen Holder (Fig. 4)

The TEM specimens are stacked into a stainless steel tube that is held within an aluminum alloy holder. The tube and the TEMs are kept within the holder by stainless steel end caps. Unlike previous TEM specimen holders, the length of the holder above and below the stainless steel tube is symmetric.

\section{Charpy Specimen Holder (Fig. 5)}

The Charpy holder is similar to the holder used for the tensile specimens. Four one-third size Charpy specimens are stacked together into an aluminum alloy holder that is slid into an HT-9 sleeve. In this case the aluminum holder is in one piece, but it does have the same notches and gas gap spacer tabs found on the tensile specimen aluminum holder.

\section{Thermal Analysis}

All of the external components of CTR-62 and -63 are identical to the previous JP-9 through -16 series of capsules, and the specimens holders are similar. Due to the similarities of CTR-62 and -63 to the previous JP series, and since the JP series of capsules underwent extensive one- and threedimensional analyses, no additional calculations were performed on the capsule components of the 
CTR-62 and -63 capsules. See Ref. 1 for a description of the analysis of the JP-9 through -16 series of capsules.

Due to the configuration of the specimen holders used in CTR-62 and -63 (Figs. 3-5), onedimensional, cylindrical geometry heat transfer calculations were sufficient to characterize the temperature distribution in the holders and the specimens. (This was also demonstrated in the calculations for JP-9 through -16. ${ }^{1}$ ) The BASIC code, GENGTC ${ }^{3}$, was used to perform onedimensional analysis of the specimen holders and to determine the size of the control gap required to maintain the desired temperatures.

The density, thermal conductivity, and linear expansion properties of each material region is needed for GENGTC calculations. The properties for material regions that contained more than one alloy, (e.g., a specimen holder with two different alloys), were determined by calculating the actual density and determining an average thermal conductivity and linear expansion based on the volume fraction of each material in the specimen holder. All of the material properties were treated as constants for the GENGTC calculations.

The heat generation rate (HGR) in the CTR-62 and -63 capsules was assumed to follow the profile determined in the TTT capsule experiment ${ }^{3}$ :

$$
\text { normalized HGR profile }=0.99768-0.00619595 z-0.00687997 z^{2}
$$

where $\mathrm{z}$ is the distance of the specimen from the reactor horizontal midplane, in inches. The peak HGR values given in the TTT experiment were modified to allow for the current reactor operating level of $85 \mathrm{MW}$, as opposed to the $100 \mathrm{MW}$ operation during the TTT experiment. For the aluminum alloy components of the capsule, the peak HGR was $(34.4 \mathrm{~W} / \mathrm{g})(85 / 100)=29.2 \mathrm{~W} / \mathrm{g}$. For the steel components, mainly specimens, the peak HGR was $(54.6 \mathrm{~W} / \mathrm{g})(85 / 100)=46.4 \mathrm{~W} / \mathrm{g}$.

The material properties, HGRs, design temperatures, calculated temperatures and gas gap sizes from the heat transfer calculations are shown in Table 4 for CTR-62 and in Table 5 for CTR-63. The average and peak temperatures shown are for the specimens, not for the holders.

CTR-63 contains eight temperature monitors, two in the center core of each tensile specimen holder (see Fig. 3). The melt capsules will be inspected with radiography after irradiation to confirm that the desired temperatures were obtained.

\section{FUTURE WORK}

Once irradiation is complete, the capsules will be disassembled and the specimens, flux monitors, and temperature monitors will be recovered for testing. The tensile, Charpy, and TEM specimens, and temperature monitors will be tested at Oak Ridge National Laboratory. The flux monitors will be sent to Battelle Pacific Northwest Laboratories for examination by L. F. Greenwood. 


\section{REFERENCES}

1. R. L. Senn, "Status of U.S./Japan Collaborative Program Phase II HFIR Target Capsules," pp. 8-20 in Fusion Reactor Materials Semiannual Progress Report for the Period Ending September 30, 1987, DOE/ER-0313/3, U.S. DOE, Office of Fusion Energy, 1988.

2. H. C. Roland, GENGTC, A One-Dimensional CEIR Computer Program for Capsule Temperature Calculations in Cylindrical Geometry, ORNL-TM-1942, Oak Ridge National Laboratory, Oak Ridge, Tennessee, December, 1967.

3. I. I. Siman-Tov, “The HFIR Instrumented (JP Type) Target Temperature Test (TTT) Capsule," pp. 10-17 in Fusion Reactor Materials Semiannual Progress Report for the Period Ending March 31, 1987, DOE/ER-0313/2, U.S. DOE, Office of Fusion Energy, 1988. 


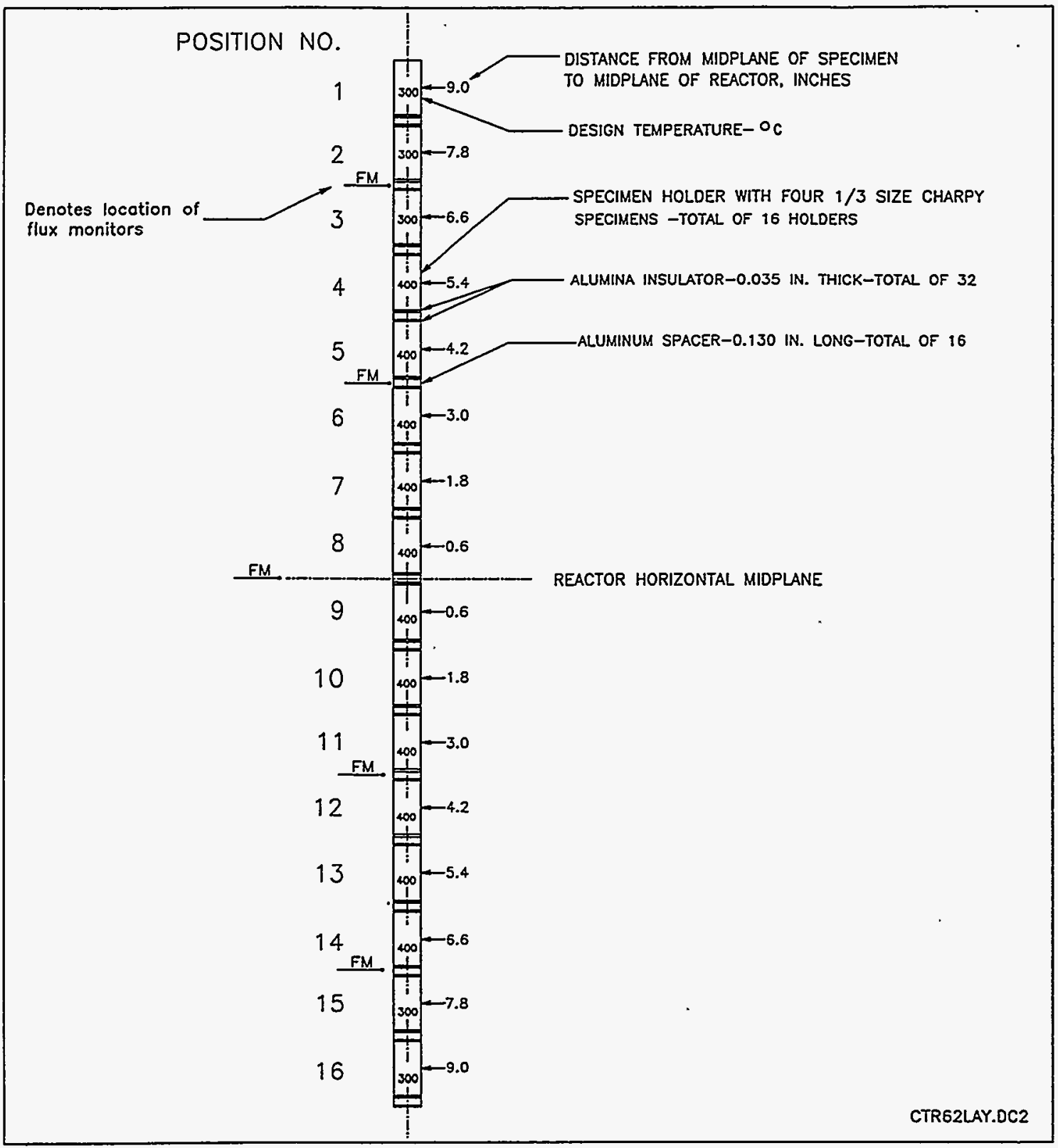

Fig. 1. Specimen layout and desired irradiation temperatures for HFIR-CTR-62. 


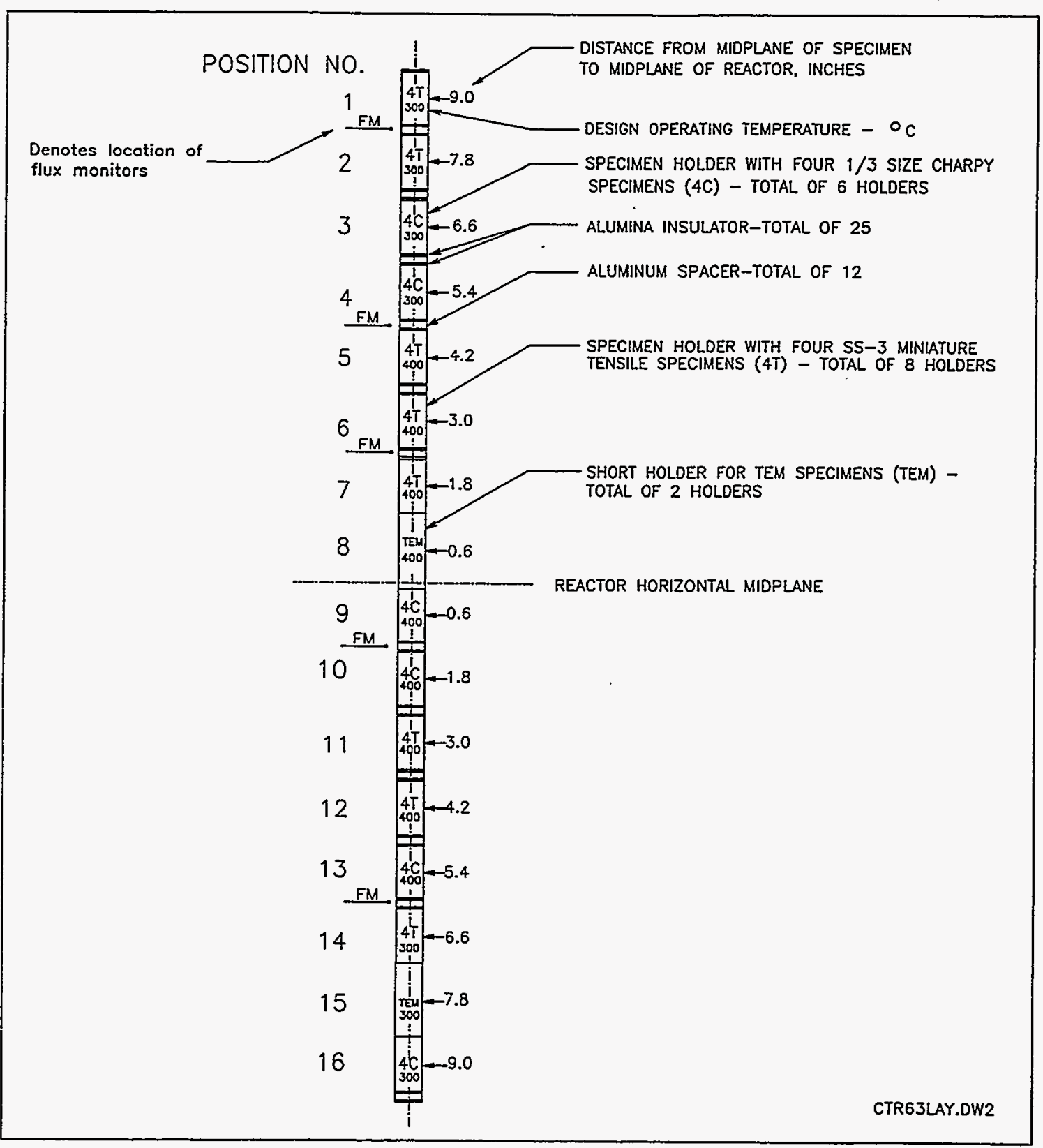

Fig. 2. Specimen layout and desired irradiation temperatures for HFIR-CTR-63. 
Table 1. Loading list for HFIR-CTR-62

\begin{tabular}{cccc}
\hline Position & Specimen & Alloy & Temperature \\
\cline { 3 - 4 } 2 & Charpy & $12 \mathrm{Cr}-1 \mathrm{MoVW}-2 \mathrm{Ni}$ & $300^{\circ} \mathrm{C}$ \\
3 & Charpy & Mix $(1,3,15,16)$ & $300^{\circ} \mathrm{C}$ \\
4 & Charpy & $9 \mathrm{Cr}-1 \mathrm{MoVNb}$ & $300^{\circ} \mathrm{C}$ \\
5 & Charpy & $10 \mathrm{Cr}-0.5 \mathrm{MoVNb}$ & $400^{\circ} \mathrm{C}$ \\
6 & Charpy & Mix $(4,6,12,13)$ & $400^{\circ} \mathrm{C}$ \\
7 & Charpy & $9 \mathrm{Cr}-2 \mathrm{WVTa}-2 \mathrm{Ni}$ & $400^{\circ} \mathrm{C}$ \\
8 & Charpy & $12 \mathrm{Cr}-1 \mathrm{MoVW}-2 \mathrm{Ni}$ & $400^{\circ} \mathrm{C}$ \\
9 & Charpy & $12 \mathrm{Cr}-1 \mathrm{MoVw}$ & $400^{\circ} \mathrm{C}$ \\
10 & Charpy & $9 \mathrm{Cr}-1 \mathrm{MoVNb}$ & $400^{\circ} \mathrm{C}$ \\
11 & Charpy & $\mathrm{Mix}(7,8,9,11)$ & $400^{\circ} \mathrm{C}$ \\
12 & Charpy & $9 \mathrm{Cr}-1 \mathrm{MoVNb}-2 \mathrm{Ni}$ & $400^{\circ} \mathrm{C}$ \\
13 & Charpy & $9 \mathrm{Cr}-2 \mathrm{WVTa}$ & $400^{\circ} \mathrm{C}$ \\
14 & Charpy & $8 \mathrm{Cr}-2 \mathrm{WVTa}$ & $400^{\circ} \mathrm{C}$ \\
15 & Charpy & $\mathrm{Mix}(4,6,12,13)$ & $400^{\circ} \mathrm{C}$ \\
16 & Charpy & $12 \mathrm{Cr}-1 \mathrm{MoVW}$ & $300^{\circ} \mathrm{C}$ \\
\hline & Charpy & $9 \mathrm{Cr}-1 \mathrm{MoVNb}-2 \mathrm{Ni}$ & $300^{\circ} \mathrm{C}$ \\
\hline
\end{tabular}

Notes: Each position will contain four Charpy specimens. The positions identified as "Mix" contain the same type of specimens as those of the postion number shown in parentheses, the actual alloys in these mixed positions are summarized as follows:

$\begin{array}{rcc}\text { Pos } & \text { Temp }\left({ }^{\circ} \mathrm{C}\right) & \text { Alloy Mix } \\ 2 & 300 & 12 \mathrm{Cr}-1 \mathrm{MoVW}-2 \mathrm{Ni}, 9 \mathrm{Cr}-1 \mathrm{MoVNb}, 12 \mathrm{Cr}-1 \mathrm{MoVW}, 9 \mathrm{Cr}-1 \mathrm{MoVNb}-2 \mathrm{Ni} \\ 5 & 400 & 8 \mathrm{Cr}-2 \mathrm{WVTa}, 9 \mathrm{Cr}-2 \mathrm{WVTa}-2 \mathrm{Ni}, 9 \mathrm{Cr}-2 \mathrm{WVTa}, 10 \mathrm{Cr}-0.5 \mathrm{MoVNb}, \\ 10 & 400 & 12 \mathrm{Cr}-1 \mathrm{MoVW}-2 \mathrm{Ni}, 12 \mathrm{Cr}-1 \mathrm{MoVW}, 9 \mathrm{Cr}-1 \mathrm{MoVNb}, 9 \mathrm{Cr}-1 \mathrm{MoVNb}-2 \mathrm{Ni} \\ 14 & 400 & 8 \mathrm{Cr}-2 \mathrm{WVTa}, 9 \mathrm{Cr}-2 \mathrm{WVTa}-2 \mathrm{Ni}, 9 \mathrm{Cr}-2 \mathrm{WVTa}, 10 \mathrm{Cr}-0.5 \mathrm{MoVNb},\end{array}$


Table 2. Loading list for HFIR-CTR-63

\begin{tabular}{cccc}
\hline Position & Specimen & Alloy & Temperature \\
1 & Tensile & $12 \mathrm{Cr}-1 \mathrm{MoVW}, 12 \mathrm{Cr}-1 \mathrm{MoVW}-2 \mathrm{Ni}$ & $300^{\circ} \mathrm{C}$ \\
2 & Tensile & $9 \mathrm{Cr}-1 \mathrm{MoVNb}, 9 \mathrm{Cr}-1 \mathrm{MoVNb}-2 \mathrm{Ni}$ & $300^{\circ} \mathrm{C}$ \\
3 & Charpy & $8 \mathrm{Cr}-2 \mathrm{WVTa}$ & $300^{\circ} \mathrm{C}$ \\
4 & Charpy & $8 \mathrm{Cr}-2 \mathrm{WVTaB}$ & $300^{\circ} \mathrm{C}$ \\
5 & Tensile & $10 \mathrm{Cr}-0.5 \mathrm{MoVNb}, 8 \mathrm{Cr}-2 \mathrm{WVTa}$ & $400^{\circ} \mathrm{C}$ \\
6 & Tensile & $8 \mathrm{Cr}-2 \mathrm{WVTaB}, 12 \mathrm{Cr}-1 \mathrm{MoVW}-1 \mathrm{Ni}$ & $400^{\circ} \mathrm{C}$ \\
7 & Tensile & $12 \mathrm{Cr}-1 \mathrm{MoVW}, 12 \mathrm{Cr}-1 \mathrm{MoVW}-2 \mathrm{Ni}$ & $400^{\circ} \mathrm{C}$ \\
8 & TEM & All Steels & $400^{\circ} \mathrm{C}$ \\
9 & Charpy & $8 \mathrm{Cr}-2 \mathrm{WVTaB}$ & $400^{\circ} \mathrm{C}$ \\
10 & Charpy & $\mathrm{Mix}(9,9,913 \mathrm{C})$ & $400^{\circ} \mathrm{C}$ \\
11 & Tensile & $9 \mathrm{Cr}-1 \mathrm{MoVNb}, 9 \mathrm{Cr}-1 \mathrm{MoVNb}-2 \mathrm{Ni}$ & $400^{\circ} \mathrm{C}$ \\
12 & Tensile & $9 \mathrm{Cr}-2 \mathrm{WVTa}, 9 \mathrm{Cr}-2 \mathrm{WVTa}-2 \mathrm{Ni}$ & $400^{\circ} \mathrm{C}$ \\
13 & Charpy & $\mathrm{Mix}(7 \mathrm{C}, 8 \mathrm{C}, 9 \mathrm{C}, 11 \mathrm{C})$ & $400^{\circ} \mathrm{C}$ \\
14 & Tensile & $8 \mathrm{Cr}-2 \mathrm{WVTaB}, 8 \mathrm{Cr}-2 \mathrm{WVTa}$ & $300^{\circ} \mathrm{C}$ \\
15 & TEM & $\mathrm{All} \mathrm{Steels}$ & $300^{\circ} \mathrm{C}$ \\
16 & Charpy & $\mathrm{Mix}(1 \mathrm{C}, 3 \mathrm{C}, 15 \mathrm{C}, 16 \mathrm{C})$ & $300^{\circ} \mathrm{C}$ \\
\hline
\end{tabular}

Notes: Each position will contain either four tensile or four Charpy specimens or one TEM packet. The positions identified as "Mix" contain the same type of Charpy specimens as those of the position number shown in parentheses. The " $C^{n}$ refers to the positions in HFIR-CTR-62. The actual alloys in these mixed positions are summarized as follows:

$\begin{array}{rrc}\underline{\text { Pos }} & \text { Temp }{ }^{\circ} \mathrm{C} & \text { Alloy Mix } \\ 10 & 400 & \text { 8Cr-2WVTaB, 8Cr-2WVTaB, 8Cr-2WVTaB, 8Cr-2WVTa } \\ 13 & 400 & 12 \mathrm{Cr}-1 \mathrm{MoVW}-2 \mathrm{Ni}, 12 \mathrm{Cr}-1 \mathrm{MoVW}, 9 \mathrm{Cr}-1 \mathrm{MoVNb}, 9 \mathrm{Cr}-1 \mathrm{MoVNb}-2 \mathrm{Ni} \\ 16 & 300 & 12 \mathrm{Cr}-1 \mathrm{MoVW}-2 \mathrm{Ni}, 9 \mathrm{Cr}-1 \mathrm{MoVNb}, 12 \mathrm{Cr}-1 \mathrm{MoVW}, 9 \mathrm{Cr}-1 \mathrm{MoVNV}-2 \mathrm{Ni}\end{array}$


Table 3. Chemical compositions of $\mathrm{Cr}$-Mo steels with and without nickel additions and reduced-activation ferritic steels

\begin{tabular}{|c|c|c|c|c|c|c|c|c|c|c|c|}
\hline \multicolumn{12}{|c|}{ Composition, wt. \% } \\
\hline \multirow[b]{3}{*}{ C } & \multicolumn{2}{|c|}{$9 \mathrm{Cr}-1 \mathrm{MoVNb}$} & \multicolumn{3}{|c|}{$12 \mathrm{Cr}-1 \mathrm{MoVW}$} & \multirow{2}{*}{$10 \mathrm{Cr}-0.5 \mathrm{MoVNa}$} & \multirow[t]{2}{*}{ 9Cr-2WVTa } & \multirow[t]{2}{*}{ 9Cr-2WVTa-2Ni } & \multirow[t]{2}{*}{ 8Cr-2WVTaB } & \multirow[t]{2}{*}{ 8Cr-2WVTa } & \multirow[t]{2}{*}{$\underline{316 S^{1}}$} \\
\hline & Standard 2 & $\underline{2 \% \mathrm{Ni}}$ & Standard $^{2}$ & $1 \% \mathrm{Ni}$ & $2 \% \mathrm{Ni}$ & & & & & & \\
\hline & 0.091 & 0.070 & 0.21 & 0.20 & 0.21 & 0.10 & 0.098 & 0.098 & 0.093 & 0.10 & 0.018 \\
\hline $\mathrm{Mn}$ & 0.35 & 0.35 & 0.51 & 0.47 & 0.48 & 0.76 & 0.39 & 0.38 & 0.23 & 0.10 & 1.57 \\
\hline $\mathbf{P}$ & 0.008 & 0.008 & 0.011 & 0.01 & 0.011 & 0.004 & 0.014 & 0.014 & 0.001 & 0.005 & 0.004 \\
\hline $\mathbf{s}$ & 0.004 & 0.004 & 0.004 & 0.004 & 0.004 & 0.005 & 0.003 & 0.003 & 0.001 & 0.002 & 0.005 \\
\hline $\mathrm{Si}$ & 0.07 & 0.08 & 0.18 & 0.13 & 0.14 & 0.18 & 0.19 & 0.19 & 0.09 & 0.10 & 0.52 \\
\hline $\mathrm{Ni}$ & 0.10 & 2.18 & 0.43 & 1.14 & 2.27 & 0.65 & 0.02 & 2.01 & 0.05 & 0.03 & 13.64 \\
\hline $\mathrm{Cr}$ & 8.64 & 8.54 & 11.97 & 11.97 & 11.73 & 10.37 & 8.71 & 8.55 & 7.65 & 8.0 & 17.18 \\
\hline Mo & 0.97 & 0.97 & 0.94 & 1.04 & 1.00 & 0.58 & $<0.01$ & $<0.01$ & & $<0.10$ & 2.22 \\
\hline V & 0.21 & 0.22 & 0.27 & 0.31 & 0.31 & 0.21 & 0.23 & 0.23 & 0.18 & 0.20 & 0.003 \\
\hline $\mathrm{Nb}$ & 0.064 & 0.068 & 0.018 & $0.015^{\circ}$ & 0.015 & 0.16 & $<0.01$ & $<0.01$ & & $<0.0002$ & 0.02 \\
\hline $\mathrm{Ta}$ & & & & & & & 0.06 & 0.06 & 0.038 & 0.04 & $<0.01$ \\
\hline $\mathrm{Cu}$ & 0.03 & 0.04 & 0.05 & 0.05 & 0.05 & 0.01 & $<0.001$ & $<0.001$ & & $<0.05$ & 0.01 \\
\hline Co & 0.013 & 0.015 & 0.017 & 0.015 & 0.015 & 0.005 & , & & & & \\
\hline Al & 0.013 & 0.015 & 0.030 & 0.017 & 0.017 & 0.007 & 0.021 & 0.021 & 0.01 & $<0.02$ & 0.005 \\
\hline B & $<0.001$ & $<0.001$ & $<0.001$ & $<0.001$ & $<0.001$ & 0.0075 & $<0.001$ & $<0.001$ & 0.034 & $<0.003$ & $<0.001$ \\
\hline w & 0.01 & $<0.01$ & 0.54 & 0.53 & 0.54 & & 2.17 & 2.15 & 1.98 & 2.0 & \\
\hline $\mathrm{Ti}$ & 0.002 & 0.002 & 0.003 & 0.003 & 0.003 & & $<0.01$ & $<0.01$ & & 0.005 & $<0.01$ \\
\hline $\mathbf{N}$ & 0.050 & 0.054 & 0.020 & 0.016 & 0.017 & 0.032 & 0.016 & 0.016 & 0.0018 & 0.005 & 0.005 \\
\hline $\mathrm{Fe}$ & BAL & $\mathrm{BAL}$ & BAL & BAL & BAL & BAL & BAL & $\mathrm{BAL}$ & BAL & BAL & BAL \\
\hline
\end{tabular}

1. TEM disks from five heats of $316 \mathrm{SS}$ will be irradiated. The compositon shown is typical of all five; the other heats show only minor variation from the compositon shown. 2. The standard compositon is that of the conventional $9 \mathrm{Cr}-1 \mathrm{MoVNb}$ and $12 \mathrm{Cr}-1 \mathrm{MoVW}$ steels. 


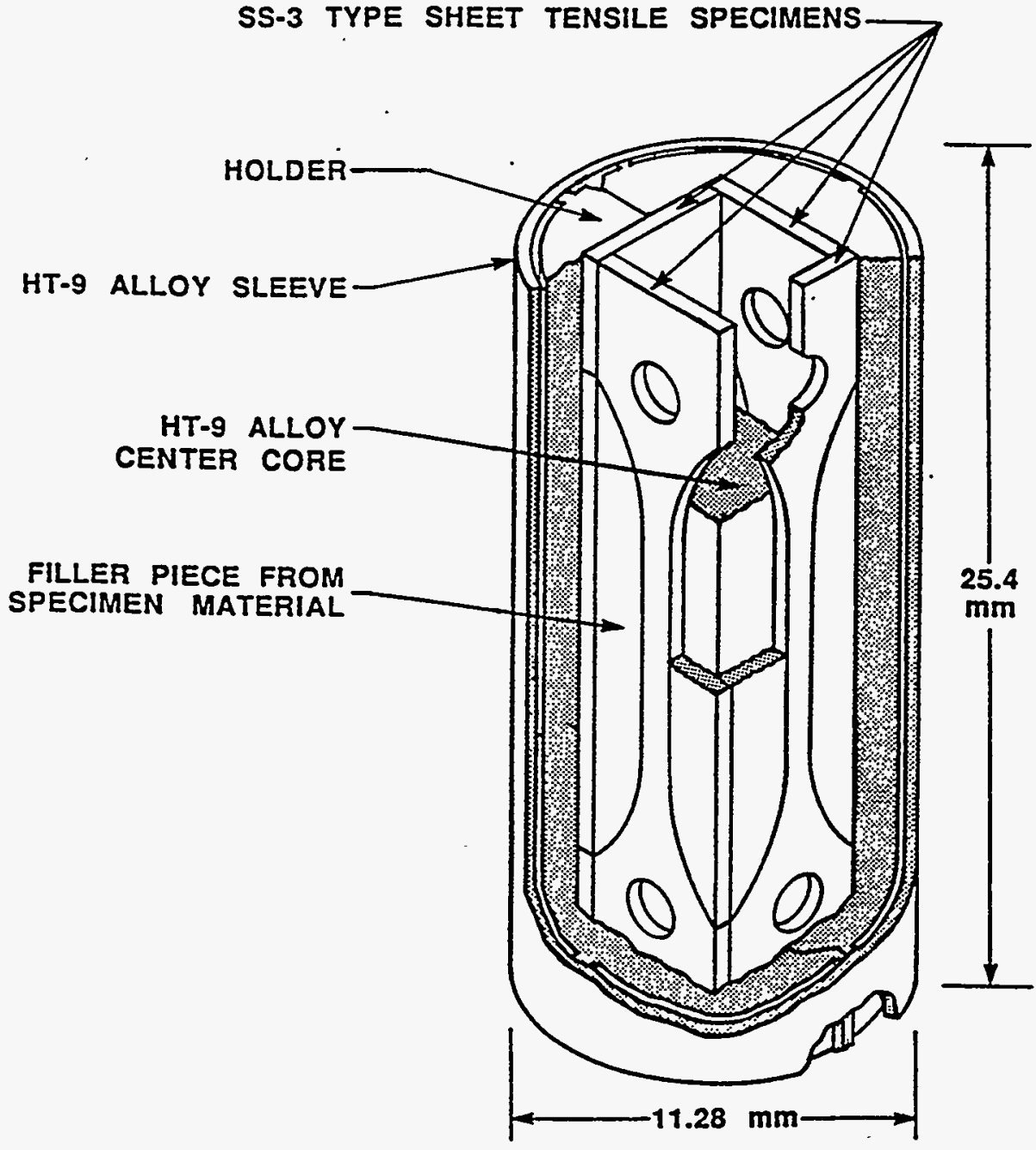

Fig. 3. Tensile specimen holder used in HFIR-CTR-63. 


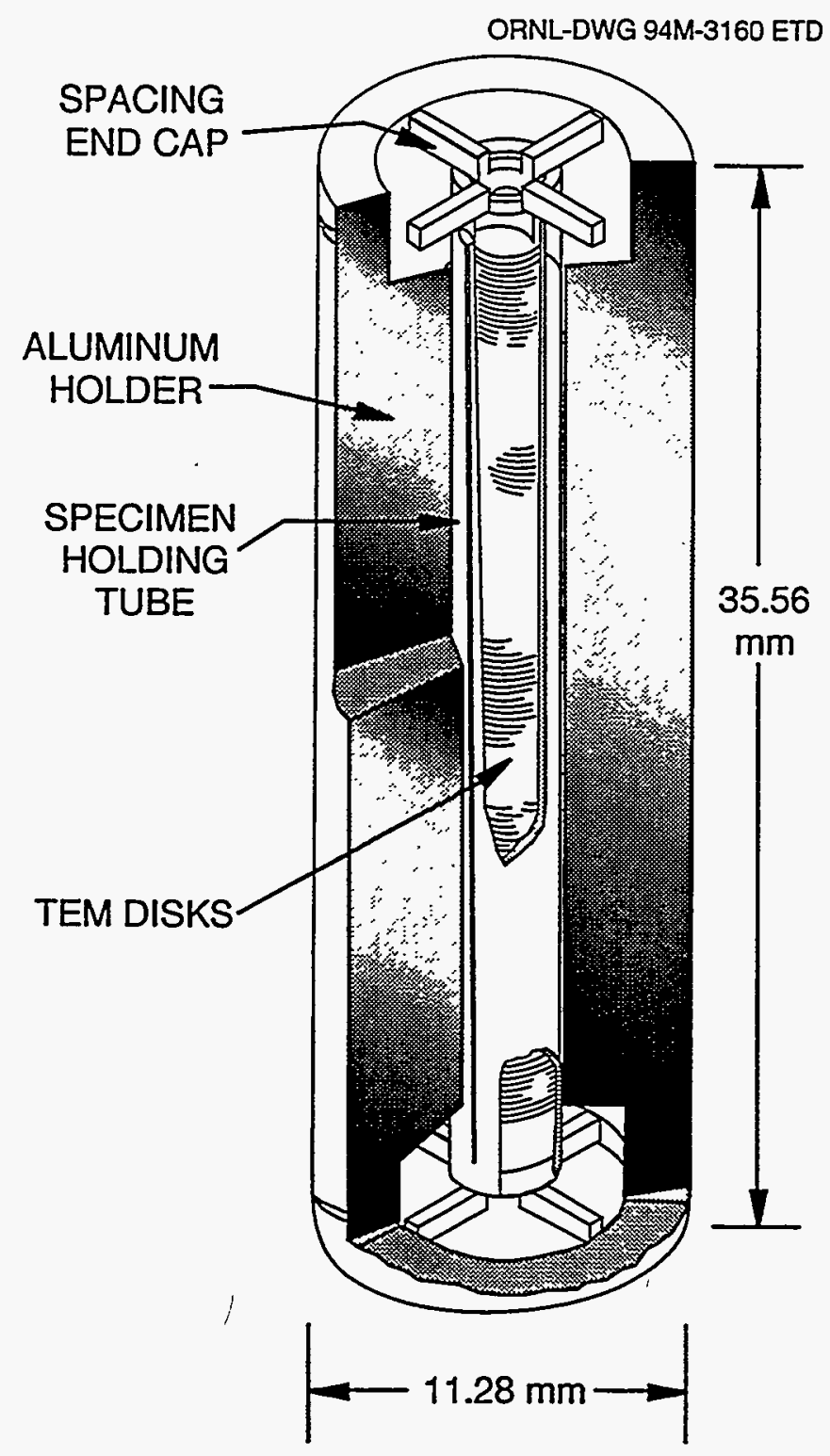

Fig. 4. TEM specimen holder used in HFIR-CTR-63. 


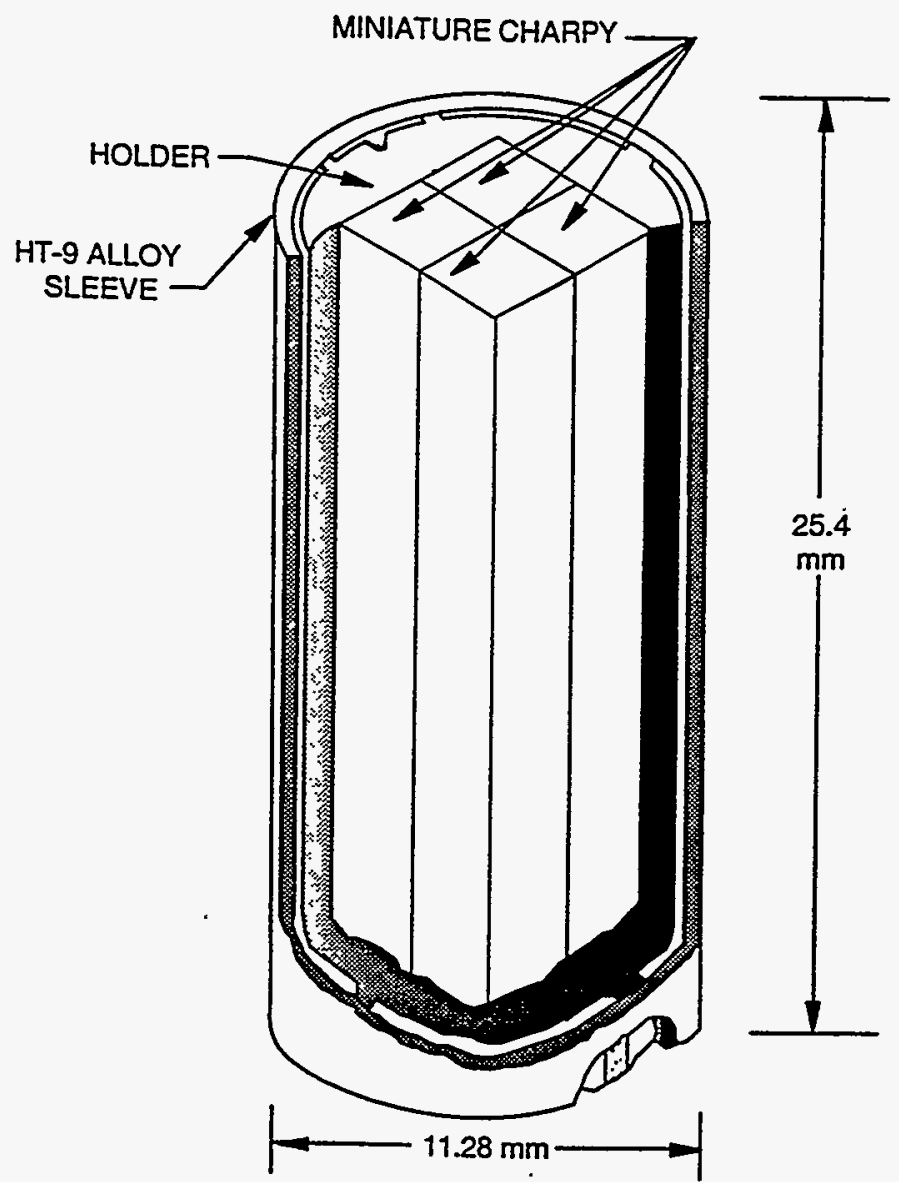

Fig. 5. Charpy specimen holder used in HFIRCTR-62 and -63 . 
Table 4. Specimen layout and thermal characteristics for HFIR-CTR-62.

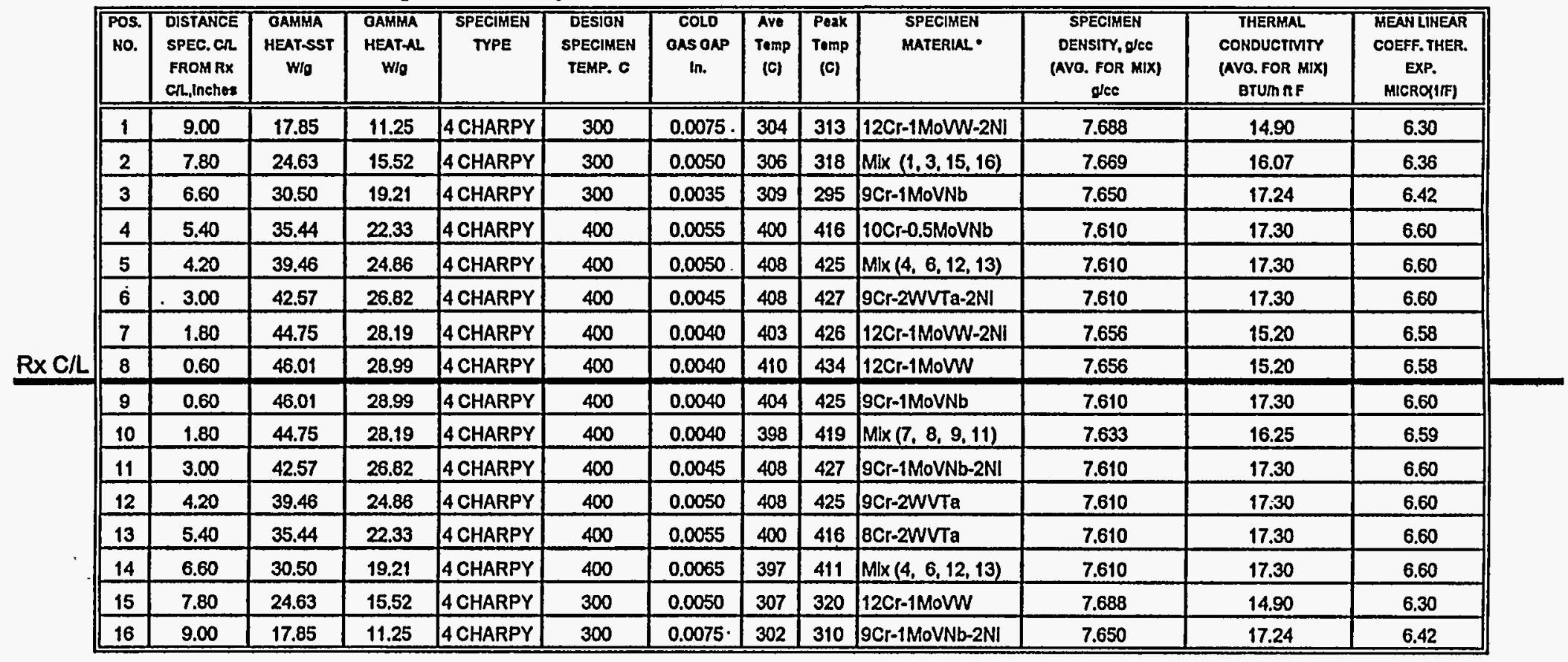

\begin{tabular}{|c|c|c|}
\hline * Pos. & Temp. (C) & Alloy Mix \\
\hline $\begin{array}{c}2 \\
5 \\
10 \\
14\end{array}$ & \begin{tabular}{l|}
300 \\
400 \\
400 \\
400
\end{tabular} & $\begin{array}{l}\text { 12Cr-1MoWW-2Ni, } 9 \mathrm{Cr} r-1 \mathrm{MoVNb}, 12 \mathrm{Cr}-1 \mathrm{MoVW}, 9 \mathrm{Cr}-1 \mathrm{MoVNb}-2 \mathrm{Ni} \\
10 \mathrm{Cr}-0.5 \mathrm{MoVNb}, 9 \mathrm{Cr}-2 \mathrm{WVTa}-2 \mathrm{Ni}, 9 \mathrm{Cr}-2 \mathrm{WVTa}, 8 \mathrm{Cr}-2 \mathrm{WVTa} \\
12 \mathrm{Cr}-1 \mathrm{MoWW}-2 \mathrm{Ni}, 9 \mathrm{Cr}-1 \mathrm{MoVNb}, 12 \mathrm{Cr}-1 \mathrm{MoVW}, 9 \mathrm{Cr}-1 \mathrm{MoVNb}-2 \mathrm{Ni} \\
10 \mathrm{Cr}-0.5 \mathrm{MoVNb}, 9 \mathrm{Cr}-2 \mathrm{WVTa}-2 \mathrm{Ni}, 9 \mathrm{Cr}-2 \mathrm{WVTa}, 8 \mathrm{Cr}-2 \mathrm{WVTa}\end{array}$ \\
\hline
\end{tabular}


Table 5. Specimen layout and thermal characteristics of HFIR-CTR-63.

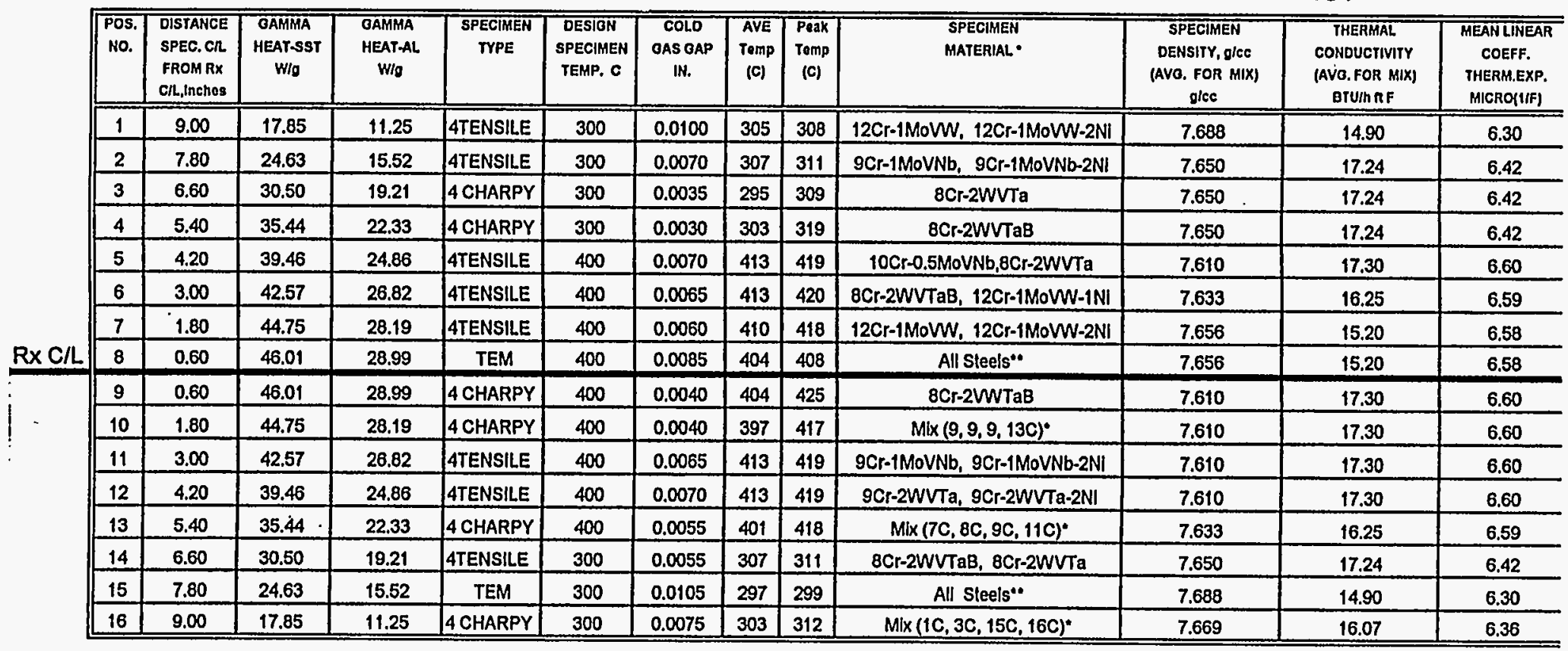

\begin{tabular}{|c|c|c|}
\hline$\cdot$ Pos. & Temp. (C) & \\
\hline 10 & 400 & 8Cr-2WVTaB, 8Cr-2WVTaB, 8Cr-2WVTaB, 8Cr-2WVTa \\
13 & 400 & 12Cr-1MoWW-2Ni, 9Cr-1MoVNb, 12Cr-1MoWW, 9Cr-1MoVNb-2NI \\
16 & 300 & 12Cr-1MoWW-2Ni, 9Cr-1MoVNb, 12Cr-1MoWW, 9Cr-1MoVNb-2NI \\
\hline
\end{tabular}

**The all steels TEM materials were treated as HT-9 and the material properties were allowed to vary with temperature. 
SCHEDULE AND STATUS OF IRRADIATION EXPERIMENTS - M. L. Grossbeck and A. F. Rowcliffe (Oak Ridge National Laboratory)

\section{OBJECTIVE}

To provide an updated summary of the status of irradiation experiments for the neutron-interactive materials program.

\section{SUMMARY}

The current status of reactor irradiation experiments is presented in tables summarizing the experimental objectives, conditions, and schedule.

\section{PROGRESS AND STATUS}

A similar set of tables and graphs was included in the ADIP Progress Reports through the Report for the Period Ending March 31, 1986. On November 14, 1986, the HFIR was shut down until July 17, 1990. During this time, re-evaluation of program priorities resulted in the cancellation of HFIR-CTR-51 and HFIR-CTR-57 through 59. Other HFIR irradiation experiments in progress were terminated at the neutron exposure levels achieved. These changes are reflected in the schedule, which goes back as far as 1984 in order to link with the previous report of 1986.

For convenience, the status of each experiment is shown in the last column with the following legend:

Irradiation complete

Irradiation in progress

Irradiation planned
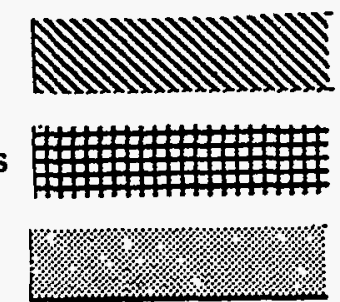

Currently, the program has six irradiation experiments in reactor, a further 18 experiments are in the planning or design stages.

\section{FUTURE WORK}

The schedule will be updated and modified with subsequent reports. The report will be shortened by the elimination of earlier experiments, thus emphasizing the current and future experiments. The extended version was used for this report only in order to provide a complete status report when coupled with the 1986 report. 
Reactor Irradiallon Experiments

Summary and Schedule

\begin{tabular}{|c|c|c|c|c|c|c|c|c|c|c|}
\hline Experiment & Lead Lab & Collaborators & $\begin{array}{c}\text { Responsible } \\
\text { Person }\end{array}$ & Major Oblecilves & Materials & Temperature ${ }^{\circ} \mathrm{C}$ & $\begin{array}{l}\text { Dose (dpa) } \\
\text { or fluence }\end{array}$ & Irrad. Start & Irrad. Finish & Status \\
\hline \multicolumn{10}{|c|}{ Fast Flux Test Facillty, Richland, WA } & \\
\hline MOTA 1A & HEDL & & A.M. Ermi & $\begin{array}{l}\text { Fast neutron irradiation } \\
\text { elfects on microstructure and } \\
\text { mechanical propertios }\end{array}$ & $\begin{array}{l}\text { Ceramics, } \\
\text { graphite, Cu, Be }\end{array}$ & 500 & 28 & Dec-82 & Oct-83 & \\
\hline MOTA 1B & HEDL & . & A.M. Erml & $\begin{array}{l}\text { Fast neutron effects on } \\
\text { tensile prop., Irradiation } \\
\text { creep, fatigue, } \\
\text { microstructure, Impact } \\
\text { properties, and thermal } \\
\text { conductivity. }\end{array}$ & $\begin{array}{l}\text { Austenitlc and } \\
\text { ferritlc steels, } \mathrm{V} \text {, } \\
\text { low act: } \\
\text { materials, } \\
\text { ceramics, Cu, } \\
\text { Be, C-C } \\
\text { composites }\end{array}$ & $370-600$ & 15 & Dec-83 & Apr-84 & \\
\hline MOTA 1C & HEDL & & A.M. Ermi & Similar to MOTA 1B & $\begin{array}{l}\text { Similar to MOTA } \\
1 \mathrm{~B} \text { with the } \\
\text { addition of } \mathrm{Ni} \\
\text { alloys }\end{array}$ & $370-600$ & 36 & May-84 & Jun-85 & \\
\hline MOTA 1D & HEDL & & A.M. Ermi & Similar to MOTA 1B & $\begin{array}{l}\text { Similar to MOTA } \\
1 \mathrm{~B} \text { with the } \\
\text { addltion of Al } \\
\text { alloys and Ni59- } \\
\text { doped steels }\end{array}$ & $370-600$ & 26 & Jul-85 & Jun-86 & \\
\hline MOTA 1E & HEDL & & A.M. Ermi & $\begin{array}{l}\text { Tensile prop., Charpy, } \\
\text { fracture loughness, Irrad. } \\
\text { creep, TEM, fatlgue, and } \\
\text { thermal conductlvity }\end{array}$ & $\begin{array}{l}\text { Austenitic and } \\
\text { ferritic steols, V, } \\
\text { Cu, C, Al alloys, } \\
\text { low act. alloys, } \\
\text { Ni59-doped } \\
\text { steols. }\end{array}$ & 370.600 & 38 & Jul-86 & Sep-87 & \\
\hline MOTA 1F & HEDL & & A.M. Ermi & Similar to MOTA 1E. & $\begin{array}{l}\text { Similar to MOTA } \\
1 \mathrm{E} \text { but no Al } \\
\text { alloys }\end{array}$ & $370-600$ & 37 & Nov- 87 & Dec-88 & \\
\hline MOTA 1G & HEDL & - & A.M. Ermi & $\begin{array}{l}\text { Tensile and Charpy impact } \\
\text { prop., irrad. creep, TEM, crack } \\
\text { growth, and fallgue }\end{array}$ & $\begin{array}{l}\text { Austenilic and } \\
\text { ferrilic steels, } \mathrm{V}_{1} \\
\mathrm{Be}, \mathrm{Cu}, \mathrm{Ni59}- \\
\text { doped steels, } \\
\text { low act. alloys }\end{array}$ & 370.600 & 44 & Jan-90 & Mar-91 & \\
\hline MOTA 2A & PNL & MONBUSHO & M.L. Hamilton & $\begin{array}{l}\text { Tensile and Charpy Impact } \\
\text { prop., Irrad. creep, TEM, } \\
\text { thermal conductivity }\end{array}$ & $\begin{array}{l}\text { Austenitlc and } \\
\text { ferrilic steels, V, } \\
\mathrm{Be}, \mathrm{Cu}, \mathrm{C}, \mathrm{Mo}, \\
\mathrm{W}, \mathrm{W} \cdot \mathrm{Pe}, \mathrm{Cu} / \mathrm{C}, \\
\text { low acl. } \\
\text { malerials, } \\
\text { ceramics }\end{array}$ & $370-800$ & 44 & Jan-90 & Mar-91 & \\
\hline
\end{tabular}




\begin{tabular}{|c|c|c|c|c|c|c|c|c|c|c|}
\hline Experiment & Lead Lab & Collaborators & $\begin{array}{c}\text { Responsible } \\
\text { Person }\end{array}$ & Major Objectives & Materlals & Temperature ${ }^{\circ} \mathrm{C}$ & $\begin{array}{c}\text { Dose (dpa) } \\
\text { or fluence }\end{array}$ & Irrad. Start & Irrad. Finish & Status \\
\hline & PNL & $\begin{array}{l}\text { MONBUSHO, } \\
\text { ORNL, ANL }\end{array}$ & M.L. Hamilton & $\begin{array}{l}\text { Tensile and Charpy impact } \\
\text { prop., fracture toughness, } \\
\text { irrad, creep, TEM, crack } \\
\text { growth, fatigue, and thermal } \\
\text { conductlvity }\end{array}$ & \begin{tabular}{|l|} 
Austeniltic and \\
ferritic sleels, V, \\
$\mathrm{Be}, \mathrm{Cu}, \mathrm{C}, \mathrm{Mo}, \mathrm{C}-$ \\
$\mathrm{C}$ composites, \\
$\mathrm{SiC}, \mathrm{SiC}-\mathrm{SiC}, \mathrm{C}-$ \\
$\mathrm{Cu}, \mathrm{C}-\mathrm{TZM}$ \\
\end{tabular} & $370-800$ & 26 & May-91 & Mar-92 & \\
\hline MOTA 2B & 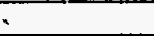 & & & & & & & & & \\
\hline \multicolumn{10}{|c|}{ EBR-II, Reactor, ANL, Idaho Falls, ID } & \\
\hline COBRA 1A1 & PNL & $\begin{array}{l}\text { ORNL, ANL, } \\
\text { MONBUSHO }\end{array}$ & M.L. Hamillon & $\begin{array}{l}\text { Tensile and fallgue prop., } \\
\text { Charpy impact, fracture } \\
\text { loughness, TEM }\end{array}$ & \begin{tabular}{|l|} 
Austenitic and \\
ferritic steels, \\
Fe-alloys, V, Be, \\
low act. \\
materials, Cu \\
alloys, Ti-Al, Sic, \\
C-C comp. \\
\end{tabular} & $370,500,600$ & 9 & Nov-92 & Apr-93 & \\
\hline COBRA $1 A 2$ & PNL & $\begin{array}{l}\text { ORNL, ANL, } \\
\text { MONBUSHO }\end{array}$ & M.L. Hamilton & $\begin{array}{l}\text { Tensile and fallgue prop., } \\
\text { Charpy Impact, fracture } \\
\text { toughness. TEM }\end{array}$ & $\begin{array}{l}\text { Aust. and ferritic } \\
\text { steels, Fe-alloys, } \\
\mathrm{V}, \mathrm{Be}, \text { low act. } \\
\text { materials, Cu } \\
\text { alloys, Ti-Al, SiC. } \\
\text { C.C comp. }\end{array}$ & $370,400,800$ & 33 & Nov-92 & Sep-94 & \\
\hline$\times 530$ & ANL & & $\begin{array}{l}\text { H. Tsal, H.M. } \\
\text { Chung }\end{array}$ & $\begin{array}{l}\text { He-effects, swelling, Charpy } \\
\text { impact, fracture toughness, } \\
\text { tensile prop. }\end{array}$ & $V$ alloys & 370. & 5 & Aug -94 & Sep-94. & \\
\hline \multicolumn{10}{|c|}{ High Flux Isotope Reactor, ORNL, Oak Rldge, TN } & \\
\hline HFIR-CTR-49. & ORNL & & R.L. Klueh. & Tensile Prop.: TEM. & Ferrilic steols. & $300-500$ & $\underline{5} \underline{2}$ & Jul -84 . & Jan-86. & \\
\hline HFIR.CTR.50 & ORNL & & R.L. Klueh & Tensile Propl, TEM & Ferritic steels & 400,600 & 고 & Mar-84 & Nov-86 & \\
\hline HFIR-CTR-51, 52 & ORNL & & & Cancelled & & & & & & \\
\hline HFIR-CTR-53, 54 . & OPNL. & & R.L.‥ Klueh. & Chargy Impact. & Ferrilic steels. & $200=300$ & 2. & Oct -86 & Nov: 86 . & \\
\hline HFIR.CTR-55, 56 & ORNL & & A.L. Klueh & Tensile Prop.. TEM & $\begin{array}{l}\text { Ferritic steels, } \\
\text { low act. ferritics }\end{array}$ & 400,600 & 53 & Nov-84 & Nov-86 & \\
\hline HFIRJP-TTT & ORNL & LAERI & 1.1. Siman Tov & Nuclear Healling Measurement & & & & Jul-86 & Nov-86 & \\
\hline HFIR-CTR-57, 58,59 & ORML & & & Cancelled & & & & & & \\
\hline
\end{tabular}


Reactor Irradiation Experiments

Summary and Schedule

\begin{tabular}{|c|c|c|c|c|c|c|c|c|c|c|}
\hline Experiment & Lead Lab & Collaborators & $\begin{array}{c}\text { Responsible } \\
\text { Person }\end{array}$ & Major Objectives & Materials & Temperature ${ }^{\circ} \mathrm{C}$ & $\begin{array}{l}\text { Dose (dpa) } \\
\text { or fluence }\end{array}$ & Irrad. Start & Irrad. Finish & Status \\
\hline HFIR-CTR. 60 & OPNL & & S.J. Zinkle & $\begin{array}{l}\text { Flexure bars, TEM, indentalion } \\
\text { disks }\end{array}$ & $\begin{array}{l}\text { Isolopically } \\
\text { tailored ceramics }\end{array}$ & $100-600$ & $2.4 E+26 \mathrm{n} / \mathrm{m} 2$ & Dec-94 & Nov-95 & 册 \\
\hline HFIR-CTA-61 & OFNL & & S.J. Zinkle & Similar to HFIR-CTR-60 & & & $7.20 E+26$ & Dec-94 & Aug-98 & 册 \\
\hline HFIR.CTR-62 & OANL & & A.L. Klueh & $\begin{array}{l}\text { Charpy impact prop. and } \mathrm{He} \\
\text { elfects }\end{array}$ & $\begin{array}{l}\text { Reduced act. } \\
\text { and conventional } \\
\text { ferrilic steels }\end{array}$ & 300,400 & 10 & Feb-95 & Aug-95 & 册 \\
\hline HFIR.CTR.63. & OANL & & R.L. Klueh & $\begin{array}{l}\text { Charpy impact and tensilo } \\
\text { prop., TEM, He olfects }\end{array}$ & $\begin{array}{l}\text { Reduced act. } \\
\text { and conventional } \\
\text { ferritlc steels }\end{array}$ & 300,400 & 10 & Feb-95 & Aug-95 & 册册 \\
\hline HFIRJP-9 & ORNL & MAEFI & $\begin{array}{l}\text { P.J. Mazlasz' } \\
\text { J.E. Pawel }\end{array}$ & $\begin{array}{l}\text { He effects by isolopic } \\
\text { tailoring, tensile prop., TEM }\end{array}$ & $\begin{array}{l}\text { Austenilic and } \\
\text { ferritic steels }\end{array}$ & $300-600$ & 57 & Jul-90 & Apr-94 & \\
\hline HFIRJP-10 & ORNL & JAERI & $\begin{array}{l}\text { P.J. Maziaszl } \\
\text { J.E. Pawel }\end{array}$ & $\begin{array}{l}\text { He effects by isotopic } \\
\text { talloring, tensile prop., TEM }\end{array}$ & $\begin{array}{l}\text { Austenilic and } \\
\text { ferritic steels }\end{array}$ & $300-600$ & 18 & Jul-90 & Sep-91 & \\
\hline HFIPJP-11 & ORNL & JAERI & $\begin{array}{l}\text { P.J. Maziaszl } \\
\text { J.E. Pawel }\end{array}$ & Similar to HFIR-JP-10 & & & 18 & Jul-90 & Sep-91 & \\
\hline HFIRUP-12. & ORNL & LAERI & $\begin{array}{l}\text { P.J. Maziaszl } \\
\text { J.E. Pawel }\end{array}$ & Similar to HFIR-JP-9 & & & 57 & Jul-90 & Apr-94 & \\
\hline HFIRUP-13 & ORNL & JAERI & $\begin{array}{l}\text { P.J. Maziasz/ } \\
\text { J.E. Pawel } \\
\end{array}$ & Similar to HFIR-JP-10 & & & 18 & Jul-90 & Sep-91 & \\
\hline HFIR-JP-14 & OANL & JAERI & $\begin{array}{l}\text { P.J. Maziaszl } \\
\text { J.E. Pawel } \\
\end{array}$ & $\begin{array}{l}\text { He effects by isolopic } \\
\text { talloring, lensile prop. TEM }\end{array}$ & $\begin{array}{l}\text { Auslenilic and } \\
\text { ferritic steels }\end{array}$ & $300-600$ & 34 & Jul-90 & Sep-92 & \\
\hline HFIR JP-15. & OANL & JAERI & $\begin{array}{l}\text { P.J. Maziasz/ } \\
\text { J.E. Pawel } \\
\end{array}$ & Similar to HFIR-JP-9 & & & $\underline{57}$ & Jul-90 & Apr-94 & \\
\hline HFIR JP-16 & ORNL & JAERI & $\begin{array}{l}\text { P.J. Maziasz } \\
\text { J.E. Pawel }\end{array}$ & Similar to HFIR-JP-10 & & & 18 & Jul-90. & Sep-91 & \\
\hline HFIRIP-17 & ORNL & JAEPI & $\begin{array}{l}\text { M.L. GrossbeckJ } \\
\text { J.E. Pawel } \\
\end{array}$ & $\begin{array}{l}\text { Fracture toughness, tensile } \\
\text { prop. TEM }\end{array}$ & $\begin{array}{l}\text { Austenilic and } \\
\text { ferritic steels }\end{array}$ & $250-300$ & 3 & Dec:-91 & Feb-92 & \\
\hline HFIR-JP-18 & ORNL & JAERI & $\begin{array}{l}\text { M.L. GrossbeckJ } \\
\text { J.E. Pawel }\end{array}$ & $\begin{array}{l}\text { Fracture toughness, tensile } \\
\text { prop. TEM }\end{array}$ & $\begin{array}{l}\text { Austenitic and } \\
\text { ferritic steels }\end{array}$ & $60-125$ & 3 & Aug $=91$ & Oct-91 & \\
\hline HFIRJP-19 & ORNL & LAERI & $\begin{array}{l}\text { M.L. Grossbeck/ } \\
\text { J.E. Pawel }\end{array}$ & Similar to HFIR-JP-18 & & $60-125$ & 3 & Aug-91 & Oct-91 & \\
\hline HFIPJP-20 & ORML & LAEPU & J.E. Pawel & $\begin{array}{l}\text { Tensile Prop., TEM, He effecis } \\
\text { by Isotoplc tailoring }\end{array}$ & $\begin{array}{l}\text { Austenitle and } \\
\text { ferritlc steels }\end{array}$ & $300-600$ & 8 & Dec-93 & Jun-94 & \\
\hline HFIRJP-21 & ORML & JAERU & J.E. Pawel & Similar to HFIR-JP-20 & & & 18 & Dec.93 & Apr-95 & \\
\hline
\end{tabular}




\begin{tabular}{|c|c|c|c|c|c|c|c|c|c|c|}
\hline Experiment & Lead Lab & Collaborators & $\begin{array}{c}\text { Responsible } \\
\text { Person }\end{array}$ & Major Objeclives & Materials & Temperalure ${ }^{\circ} \mathrm{C}$ & $\begin{array}{l}\text { Dose (dpa) } \\
\text { or fluence }\end{array}$ & Irrad. Slart & Irrad. Finish & Status \\
\hline HFIRJP-22 & OPNR & JAERS & J.E. Pawel & Similar to HFIR -JP-20 & & & 34 & Doc-93 & Dec-95 & \\
\hline HFIRJP-23 & PNL & MONBUSHO & D.S. Gelles & IEM & $\begin{array}{l}\text { Austenitic and } \\
\text { ferritic steels, } \\
\mathrm{Cu}, \mathrm{Mo}, \mathrm{V} \text { alloys, } \\
\mathrm{IIAl}\end{array}$ & $300-600$ & 8 & Dec-93 & Jun-94 & \\
\hline HFIR-MFE-60U & ORN & NAERI & $\begin{array}{l}\text { J.L. Scoll/M.L. } \\
\text { Grossbeck }\end{array}$ & $\begin{array}{l}\text { Spectrally tailored for lusion } \\
\text { Ho prod. Began in ORR as } \\
\text { ORR-MFE-6J (6.9 dpa). TEM, } \\
\text { Charpy, irrad. creep, tensile } \\
\text { and crack growth prop. }\end{array}$ & $\begin{array}{l}\text { Austenitic and } \\
\text { ferritic steels, } \\
\text { and Ni alloys }\end{array}$ & 60 & 18 (tolal) & Jul-90 & Nov-92 & \\
\hline HFIR-MFE-330 & OANL & JAERI & $\begin{array}{l}\text { J.L. Scott/M.L. } \\
\text { Grossbeck }\end{array}$ & $\begin{array}{l}\text { Similar to HFIR-MFE-60J. } \\
\text { Began in ORR as ORR-MFE-7J } \\
(7.4 \mathrm{dpa})\end{array}$ & & 330 & 18 (total) & Jul-90 & Nov-92 & \\
\hline HFIR-MFE-200N & ORNL & JAERI & $\begin{array}{l}\text { M.L. } \\
\text { Grossbeck/J.E. } \\
\text { Pawel } \\
\end{array}$ & $\begin{array}{l}\text { Similar to HFIR-MFE-60J. } \\
\text { Began in ORR as ORR-MFE-6J } \\
(6.9 \text { dpa) }\end{array}$ & & 200 & 18 (total) & Nov-92 & Jan-95 & \\
\hline HFIR-MFE-400 & ORNL & JAERI & $\begin{array}{l}\text { M.L. } \\
\text { Grossbeck/J.E. } \\
\text { Pawel }\end{array}$ & $\begin{array}{l}\text { Similar to HFIR-MFE-60J, } \\
\text { Began as ORR-MFE-7J (7.4 } \\
\text { dpa) }\end{array}$ & & 400 & 18 (total) & Nov-92 & Jan-95 & \\
\hline HFIR-TRIST-ER1 & ORNL. & MONBUSHO & S.J. Zinkle & In-silu electrical conductivily & At2O3 & 450 & $3 E+25 \mathrm{n} / \mathrm{m} 2$ & Aug-95 & Nov-95 & \\
\hline HFIR-TRIST-ER2 & ORNL & LAEPI & S.J. Zinkle & $\begin{array}{l}\text { Electrical properties of } \\
\text { Insulating ceramics }\end{array}$ & $\begin{array}{l}\mathrm{MgAl} 2 \mathrm{OA}, \overline{\mathrm{AIN}} \\
\text { Si3N4} \\
\end{array}$ & 300 & $1 \mathrm{E}+25 \mathrm{n} / \mathrm{m} 2$ & May-96 & Jun-96 & \\
\hline HFIR-MFE-AB-10 & ORNL & JAEFI & J.E. Pawel & Tensile; fraclure & $316 \mathrm{LN}-1 \mathrm{G}, \mathrm{J} 316$ & 200,300 & 4 & Jan-96 & Sepp-96 & \\
\hline HFIR JP24 & OANL & LAEFI & J.E. Pawel & $\begin{array}{l}\text { Tensile, fatlgue, fraclure } \\
\text { toughness }\end{array}$ & $316 \mathrm{LN}-1 \mathrm{G}, \mathrm{J} 316$ & 300 & 4 & Apr-96. & Jul-96 & \\
\hline HFIR-MFE-RB-11J & OANL & $\begin{array}{l}\text { JAERII } \\
\text { MONBUSHO }\end{array}$ & A.L. Klueh & Tensile, fracture, TEM & $\begin{array}{l}\text { Low activation } \\
\text { territtics }\end{array}$ & 300 & 5 & Mar-96 & Fob-97 & \\
\hline HFIA-MFE-RB-12J & ORNL & $\begin{array}{c}\text { JAERV } \\
\text { MONBUSHO }\end{array}$ & R.L. Klueh & Tensile, fracture, TEM & $\begin{array}{l}\text { Low activation } \\
\text { forritics }\end{array}$ & 500 & 5 & Nov-96 & Dec-97 & \\
\hline HFIRJP25 & ORNL & LAEFI & R.L. Klueh & Tenslle, fracture, TEM & $\begin{array}{l}\text { Low aclivalion } \\
\text { ferrltics }\end{array}$ & $300,400,500$ & 20 & Jun-97 & Sep-98 & \\
\hline HFIRJP26 & ORNL & JAEFI & R.L. Klueh & Tensile, fracture. TEM & $\begin{array}{l}\text { Low activalion } \\
\text { ferritics }\end{array}$ & 300,500 & 5 & May-96 & Sep.96 & \\
\hline
\end{tabular}


Reactor Irradialion Experiments

Summary and Schedule

\begin{tabular}{|c|c|c|c|c|c|c|c|c|c|c|}
\hline Experiment & Lead Lab & Collaborators & $\begin{array}{c}\text { Responsible } \\
\text { Person }\end{array}$ & Major Objeclives & Materials & Temperalure ${ }^{\circ} \mathrm{C}$ & $\begin{array}{l}\text { Dose (dpa) } \\
\text { or fluence }\end{array}$ & Irrad. Start & Irrad. Finish & Status \\
\hline HFIRJP27 & ORNL & JAERI & L.L. Snead & Fraclure, TEM & $\begin{array}{l}\text { Intermetallics, } \\
\text { Sic }\end{array}$ & $500-800$ & 10 & FY.97 & FY-97 & \\
\hline HFIRJP28 & ORNL & LAERI & L.L. Snead & Fracture, TEM & sic & $500-800$ & 10 & FY.99 & FY-99 & \\
\hline HFIR-HT-C1, -C2 & ORNL & & L.L. Snead & Thermal conductivity & $\begin{array}{l}\text { Various } \\
\text { insulators }\end{array}$ & $80-350$ & $0.01-1.0$ & Jun-95 & Aug-95 & \\
\hline HFIR-HT-VV1 & ORNL. & & L.L. Snead & Tensile TEM & $\begin{array}{l}316 L N-I G, \quad \text { In } \\
625\end{array}$ & 150 & $0.1-1.0$ & Jul-95 & Sep-95 & \\
\hline \multicolumn{10}{|c|}{ High Flux Beam Reactor, Brookhaven National Laboratory } & \\
\hline HFBR.ISEC-3 & ORNL & & L.L. Snead & In-situ electrical & WESGO A2O3 & 450 & 1.5 & Jun-95 & Jul-95 & \\
\hline HFBR-V1 & OANL & & L.L. Snead & Tensile, tracture & $V-4 C r-4 T$ & $75,150,225$ & 0.5 & May-95 & Jun-95 & \\
\hline HFBR-V2 & ORNL & & L.L. Snead & Tenslle, fracture & $\mathrm{V}-4 \mathrm{Cr}-4 \mathrm{TI}$ & $\begin{array}{c}75,225,300 \\
375 \\
\end{array}$ & 0.5 & Jul-95 & Aug-95 & \\
\hline \multicolumn{10}{|c|}{ Advanced Test Reactor, Idaho Falls } & \\
\hline ATR-A1 & ANL & MONBUSHO & D.L. Smith & $\begin{array}{l}\text { Tensile, fracture toughness, } \\
\text { TEM, creep }\end{array}$ & Vanadium alloys & 200,300 & 5 & Jul-95 & Jan-95 & \\
\hline \multicolumn{10}{|c|}{ BOR-60 Reactor, RIAR, DImltrovgrad, Russla } & \\
\hline BOR-60-Fusion-1 & ORNL, ANL & RDIPE, RIAR & $\begin{array}{l}\text { A.F. Rowclilie, } \\
\text { D.L. Smlth }\end{array}$ & $\begin{array}{l}\text { Mechanical and } \\
\text { mlcrostructural properties }\end{array}$ & V alloys & $350-380$ & 10 & Jul-95 & Feb-96 & \\
\hline \multicolumn{10}{|c|}{-2 Reactor, RIAR, Dimitrovgrad, Russia } & \\
\hline SM2-Phase 1 & ORNL, PNL & RIAP & S.J. Zinkle & $\begin{array}{l}\text { mlcrostructural, and creep } \\
\text { properties }\end{array}$ & Cu alloys & $100,200,330$ & 1,5 & Dec-93 & Feb-94 & \\
\hline \multicolumn{10}{|c|}{$\begin{array}{l}\text { RBT-10 Heactor, RIAR, Dimitrovgrad, Russia } \\
\text { Mechanical behavior of }\end{array}$} & \multirow{3}{*}{$\cdots$} \\
\hline RBT-10/1,2 & PNL & SPIAR & D.J. Edwards & $\begin{array}{l}\text { Mechanlcal behavlor of } \\
\text { bonded materials }\end{array}$ & $\begin{array}{l}\text { Cu alloys/SS, } \\
\text { Cu/Be }\end{array}$ & 120,300 & 0.2 & Sep-95. & Dec-95 & \\
\hline RBT $-10 / 3,4,5$ & PNL & SRLAP & D.J. Edwards & $\begin{array}{l}\text { Mechanical behavlor of } \\
\text { bonded materials }\end{array}$ & $\begin{array}{l}\text { Cu alloys/SS, } \\
\text { Cu/Be }\end{array}$ & 100,250 & 0.2 & Jun $\cdot 96$ & Oct-96 & \\
\hline
\end{tabular}


IRRADIATION PARAMETERS FOR THE FFTF MATERIALS OPEN TEST ASSEMBLIES FROM 1983 THROUGH 1992 - A. M. Ermi (Westinghouse Hanford Company), L. R. Greenwood and H. L. Heinisch (Pacific Northwest Laboratory)

\section{OBJECTIVE}

The objective of this effort was to report on the final irradiation parameters for all Materials Open Test Assemblies (MOTAs) irradiated in the Fast Flux Test Facility (FFTF). The report covers all nine MOTAs irradiated from 1983 through 1992.

\section{SUMMARY}

Results from final analyses of MOTA dosimetry were used to generate listings of irradiation damage parameters for all test locations in all nine MOTAs. Temperature information for all MOTAs is also summarized, and issues regarding temperature transients and gradients are discussed. This report serves as an official reference on the temperatures and damage parameters for all MOTAs and is the basis for more detailed listings of irradiation histories for all MOTA specimens.

\section{PROGRESS AND STATUS}

\section{Introduction}

From 1983 through 1992, nine MOTAs were irradiated in the FFTF at Hanford, Washington: MOTAs $1 \mathrm{~A}$ through $1 \mathrm{G}$, and MOTAs $2 \mathrm{~A}$ and $2 \mathrm{~B}$. Each test vehicle was irradiated for approximately one year, except MOTA-1B which was irradiated for only four months to obtain low fluence data. The complete MOTA operating history is detailed in Table 1.

At the conclusion of each FFTF cycle or MOTA irradiation, reports were issued which detailed (a) operation of the test and support hardware in the FFTF, (b) the performance of the MOTA vehicle, and (c) the temperature histories. The complete listing of these reports is included as references 1 through 15. References $1,2,3,5$, and 7 are summary reports for MOTAs $1 \mathrm{~A}, 1 \mathrm{~B}, 1 \mathrm{C}$, and the first half of MOTA-1D; references 4,6 , and 8 through 15 are comprehensive reports for MOTAs 1C through 2B, and contain complete sets of temperature plots. Deficiencies in the original data acquisition system prevented generation of comprehensive temperature plots for MOTAs 1A and $1 B$.

Although the MOTA temperatures have been well documented, no official reports have documented key irradiation damage.parameters, specifically fast fluence and dpa, for all of the MOTA test positions and specimens. This report uses the final results of the MOTA dosimetry analyses to specify these damage parameters for the MOTA test positions. All of the details regarding the MOTA configurations and parameters have been specified elsewhere.[16] It is beyond the scope of this report to list the detailed irradiation histories of all MOTA specimens; that information is available through the Pacific Northwest Laboratory (PNL) program coordinators. Copies of these specimen listings, customized for specific experimenters, have also been transmitted to each experimenter.

"Operated for the U.S. Department of Energy by Battelle Memorial Institute under Contract DE-AC0676RLO 1830. 
Table 1. MOTA Operating History

\begin{tabular}{|c|c|c|c|c|c|}
\hline MOTA & $\begin{array}{c}\text { FFTF Cycle } \\
\text { Number }\end{array}$ & $\begin{array}{l}\text { Cycle } \\
\text { Startup }\end{array}$ & $\begin{array}{c}\text { Cycle } \\
\text { Shutdown }\end{array}$ & $\begin{array}{l}\text { Cycle } \\
\text { EFPD }\end{array}$ & $\begin{array}{c}\text { MOTA } \\
\text { EFPD }\end{array}$ \\
\hline $1 \mathrm{~A}$ & $\begin{array}{l}2 \\
3\end{array}$ & $\begin{array}{l}\text { Jan. } 18,1983 \\
\text { July } 01,1983\end{array}$ & $\begin{array}{c}\text { May } 22,1983 \\
\text { Oct. 23, } 1983\end{array}$ & $\begin{array}{l}100.5 \\
101.5\end{array}$ & 202.0 \\
\hline $1 B$ & 4 & Jan. 01, 1984 & Apr. 23, 1984 & 109.5 & 109.5 \\
\hline $1 C$ & $\begin{array}{l}5 \\
6\end{array}$ & $\begin{array}{l}\text { June } 16,1984 \\
\text { Dec. } 26,1984\end{array}$ & $\begin{array}{l}\text { Nov. 03, } 1984 \\
\text { June } 24,1985\end{array}$ & $\begin{array}{l}122.7 \\
134.0\end{array}$ & 256.7 \\
\hline ID & $\begin{array}{l}7 \\
8\end{array}$ & $\begin{array}{l}\text { Aug. 17, } 1985 \\
\text { Feb. 05, } 1986\end{array}$ & $\begin{array}{l}\text { Jan. 03, } 1986 \\
\text { July } 19,1986\end{array}$ & $\begin{array}{r}122.8 \\
63.0\end{array}$ & 185.8 \\
\hline $1 E$ & $\begin{array}{l}9 A \\
9 B \\
9 C\end{array}$ & $\begin{array}{l}\text { Sep. 10, } 1986 \\
\text { Mar. 04, } 1987 \\
\text { July 01, } 1987\end{array}$ & $\begin{array}{l}\text { Feb. } 05,1987 \\
\text { June } 20,1987 \\
\text { Oct. } 10,1987\end{array}$ & $\begin{array}{r}137.7 \\
106.4 \\
97.7\end{array}$ & 341.8 \\
\hline IF & $\begin{array}{l}10 \mathrm{~A} \\
10 \mathrm{~B} \\
10 \mathrm{C} .1\end{array}$ & $\begin{array}{l}\text { Nov. } 18,1987 \\
\text { June } 11,1988 \\
\text { Nov. } 09,1988\end{array}$ & $\begin{array}{c}\text { May } 08,1988 \\
\text { Oct. } 17,1988 \\
\text { Jan. } 08,1989\end{array}$ & $\begin{array}{r}151.8 \\
126.7 \\
56.9 \\
\end{array}$ & 335.4 \\
\hline $\begin{array}{c}1 G \\
\& \\
2 A\end{array}$ & $\begin{array}{l}11 \mathrm{~B} .1 \\
11 \mathrm{~B} .2 \\
11 \mathrm{C}\end{array}$ & $\begin{array}{c}\text { Jan. 04, } 1990 \\
\text { May 29, } 1990 \\
\text { Dec. 20, } 1990\end{array}$ & $\begin{array}{c}\text { Apr. 09, } 1990 \\
\text { Oct. 28, } 1990 \\
\text { Mar. } 19,1991\end{array}$ & $\begin{array}{r}85.5 \\
132.7 \\
81.5\end{array}$ & 299.7 \\
\hline 2B & $\begin{array}{l}12 \mathrm{~A}-1 \\
12 \mathrm{~A}-2 \\
12 \mathrm{~B}-1 \\
12 \mathrm{~B}-2\end{array}$ & $\begin{array}{c}\text { May } 27,1991 \\
\text { July } 30,1991 \\
\text { Nov. } 21,1991 \\
\text { Jan. } 26,1992\end{array}$ & $\begin{array}{l}\text { July } 20,1991 \\
\text { Sep. } 21,1991 \\
\text { Jan. } 15,1992 \\
\text { Mar. 19, } 1992\end{array}$ & $\begin{array}{l}52.8 \\
48.6 \\
50.3 \\
51.6\end{array}$ & 203.3 \\
\hline
\end{tabular}

Note: FFTF reactor power was $400 \mathrm{MWth}$ through Cycle 8, and $291 \mathrm{MWth}$ thereafter.

\section{MOTA Configuration}

Each MOTA vehicle consisted of nine levels: a below-core (BC) level, in-core levels 1 through 5 , and above-core levels 6 through 8 . Each level was approximately $21.5 \mathrm{~cm}(8.5$ inches) in axial length, although there were exceptions (below-core levels and special tests in level 5). Each level could accommodate up to six instrumented MOTA canisters or special capsules, except the MOTA-1 series below-core level which could accommodate 7 uninstrumented canisters. The specimen regions in the canisters (or capsules in some cases) were typically 12.7 to $16.2 \mathrm{~cm}$. (5 to 6.4 inches) long by approximately $2.8 \mathrm{~cm}$ (1.1 inches) in diameter. Canisters typically contained stacks of baskets of various lengths that contained the test specimens. Some of the canisters were instrumented with temperature control gas lines, thermocouples, or other gas and electrical lines.

Information used to describe each MOTA canister location is as follows:

(a) The canister number (e.g., $\mathrm{BCA}, 1 \mathrm{~F}, 8 \mathrm{E}$ );

(b) The operating temperature (from the temperature analysis reports);

(c) The program sponsor (e.g., Fusion, Monbusho, Surveillance, High Heat Flux);

(d) Type of canister (e.g., Weeper or Gas-gapped);

(e) Thermocouple type (e.g., Type $\mathrm{K}$, Type $\mathrm{C}$, Offset Type $\mathrm{K}$, none); 
(g) The axial location (z-value) of the top of the top basket with respect to the core horizontal midplane; and

(h) Canister footnote (information pertaining to the entire canister, such as any over-temperatures or temperature change tests).

The information described above was reproduced in various formats with a MOTA canister matrix layout which shows the canister levels vertically (from bottom to top: $B C, 1,2, \ldots 7,8$, similar to their positions in reactor), and the individual canister positions for each level ( $A, B, \ldots E, F$ and $O$, where O represents the MOTA-1 below-core central position). The program sponsor matrices, thermocouple matrices, basket (or capsule) length matrices, and the axial position z-values matrices are provided in reference 16.

\section{Temperature Results}

As stated, reports were generated after each MOTA irradiation tabulating detailed temperature information for each canister containing a thermocouple (and plotted for MOTA-1C and beyond). The temperatures listed in these reports reflected averages at the thermocouple locations. However, the single temperature value assigned to a particular MOTA canister may not always give the complete picture. Experimenters using this temperature information to describe their irradiation conditions should consider transients, radial gradients, and axial gradients.

\section{A. Transients}

The temperatures recorded from the thermocouples were time-averaged over the duration of the irradiation. Values below $300^{\circ} \mathrm{C}$ were not used in the calculations since they normally represented a zero reactor power condition (the zero power, standby heatup temperature was $325^{\circ} \mathrm{C}$; the coolant temperature during shutdowns was approximately $210^{\circ} \mathrm{C}$ ). The reported temperatures were nearly always equal to the average temperatures at the thermocouples at full reactor power, because the times spent at lower temperatures and lower power levels during startups and shutdowns were much shorter than the duration of the irradiation. The exception was during FFTF Cycle 8 (see below).

However, as pointed out in the performance reports, the experimenters should always review the temperature plots to become aware of the temperature fluctuations and transients that cannot easily be quantified in tabular form. This is especially true for specimens that were irradiated in MOTA-1D during FFTF Cycles 7 and 8 . During Cycle 7, all 25 temperature-controlled gas-gapped canisters experienced over-temperatures of $63^{\circ}$ to $280^{\circ} \mathrm{C}$ for 50 to 70 minutes due to an inadvertent purge of the gas gaps with argon instead of helium (Table 2).[8] Specimens in the 18 weeper canisters were unaffected. During Cycle 8, a series of reactor transient tests resulted in temperature profiles for all canisters (gas-gapped and weeper) that mirrored these tests.[9]

In addition to these off-normal circumstances, the manner in which the reactor and/or the MOTA control system were routinely shut down at the end of cycles has affected specimen substructures and materials behavior.[17] Again, the experimenters should review the shutdown histories for each MOTA when interpreting their data. 
Table 2. Canister Footnotes for all MOTAs

\begin{tabular}{|c|c|}
\hline No. & FOOTHOTE DESCRIPTION \\
\hline 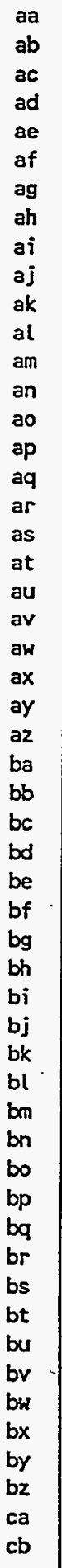 & 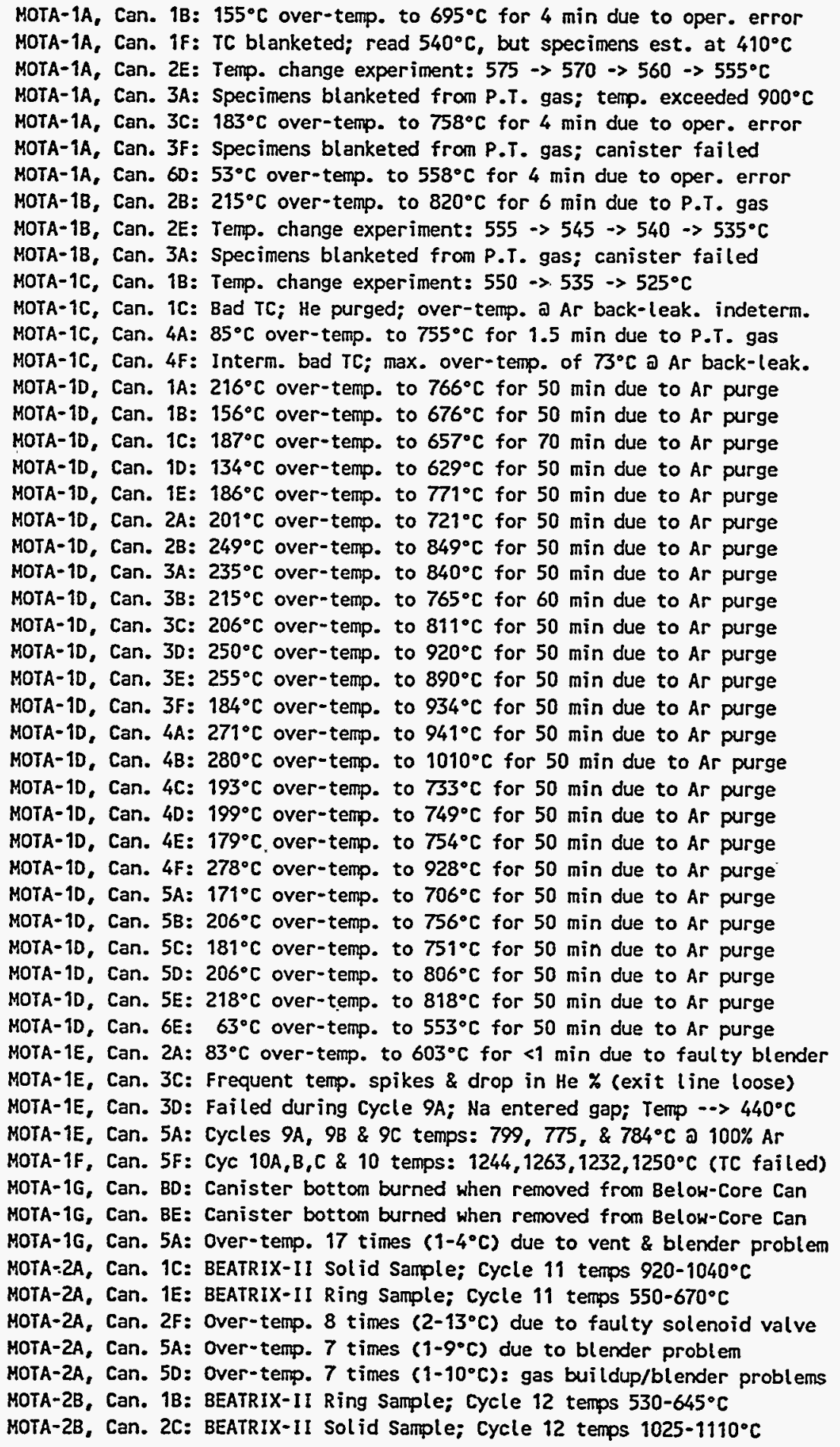 \\
\hline
\end{tabular}




\section{B. Radial Gradients}

Radial gradients across MOTA gas-gapped canisters are inherent to the design and are nearly impossible to avoid. The magnitude of the gradient from the center of a canister to the inner wall varies with the axial location in reactor, the design temperature, the specimen compositions, and the specimen mass distribution. For most of the typical MOTA canisters, the gradients were $5^{\circ}$ to $20^{\circ} \mathrm{C}$, with most in the $10^{\circ}$ to $15^{\circ} \mathrm{C}$ range. Since these values were across the radius of the canister $(1.3 \mathrm{~cm}$ or $0.5 \mathrm{inch})$, the actual temperature gradients across typical, smaller specimens were proportionally smaller.

As stated, reported temperatures were at the thermocouple locations. Therefore, for most MOTA canisters that contained a centerline thermocouple, the temperatures represented a maximum at that axial location and some specimens were slightly cooler. Conversely, for the few offset thermocouple canisters, the temperatures represented a minimum and some specimens were slightly warmer.

The radial temperature gradients are for gas-gapped canisters and weeper canisters, in which the specimens are in contact with reactor sodium. The arguments would also apply to specimens in lithiumfilled subcapsules. However, temperatures of specimens in helium-filled subcapsules could be expected to be even higher due to the gradients caused by the presence of the additional helium-filled gaps. The exact magnitude of the temperatures would depend on several factors and would require separate, complex calculations.

\section{Axial Gradients}

Weeper canisters exhibit unavoidable axial temperature gradients of about $5^{\circ}$ to $10^{\circ} \mathrm{C}$ from the bottoms to the tops of the canisters because the sodium coolant heats up as it travels through the MOTA.

For gas-gapped canisters, the coolant temperature profile is factored into the design, and in theory, centerline axial temperatures should be fairly uniform. However, pressurized-tube diameter measurement data from MOTAs $1 \mathrm{~A}$ through $1 \mathrm{E}$ suggest axial temperature gradients on the order of $30^{\circ} \mathrm{C}$; both ends of the canisters were apparently running hotter than the readings of the central thermocouples. The axial gradient at the top of canisters was confirmed during a multi-thermocouple test in MOTA-1E. No conclusion could be made regarding the bottom of canisters because the thermocouple braze failed and the bottom of the test canister filled with sodium.[10]

As a result of this knowledge, much effort went into reviewing the original MOTA canister design, and performing new, detailed two-dimensional design calculations. The canister design was changed to flatten the axial temperature profiles by shortening the large insulating gap at the tops of canisters, and by adding shims at the sodium inlet ends of canisters.[18] The changes preceded the design of the MOTA-1F canisters. Axial gradients for canisters irradiated in MOTA-1F and beyond should be on the order of $\pm 10^{\circ} \mathrm{C}$.

In conclusion, if test specimen data are sensitive to temperature variations and the types of temperature uncertainties described, experimenters should (a) make an effort to "correct" their temperature values, if possible, and (b) factor pertinent temperature transient information into the interpretation of their results.

\section{Dosimetry Results}

Each MOTA vehicle contained a variety of dosimeters at several radial and axial positions along the specimen regions.[16] The dosimeters were to be analyzed shortly after each irradiation to characterize the irradiation environment for each MOTA. However, for various reasons (related to manpower and budgetary considerations), the analyses were incomplete and results were sometimes inconsistent. 
These inconsistencies and the resulting lack of comprehensive, final MOTA dosimetry reports delayed this report. Unofficial listings for MOTA test locations and.MOTA specimens, based on available dosimetry results or physics calculations, have been available to the experimenters on request, but the authors were reluctant to publish and distribute a detailed report until the dosimetry analysis issues had been resolved.

On completion of the MOTA $1 F, 1 G, 2 A$ and $2 B$ dosimetry analyses, all past dosimetry (except for that from MOTA-ID) was re-analyzed with a consistent code and correction factors. The temperature excursion that resulted in suspect data from most specimens in temperature controlled canisters and a lack of resources during that period of time led to the failure to analyze the MOTA-1D data. In this case, the fluence and dpa profiles were based on the flux and dpa-rate curves generated for MOTAs 1A, IB and 1C. [Note that the FFTF operated at $400 \mathrm{MW}$ thermal (MWth) through Cycle 8 (MOTAs 1A through 1D), and at $291 \mathrm{MWth}$ for the Core Demonstration Experiment during Cycle 9 and beyond (MOTAs IE through 2B).]

The details of the radiometric counting, raw data, and numerical analysis of the MOTA dosimetry are described elsewhere.[19-27] The fast fluence and dpa data that resulted from the analyses were used to generate smooth curves depicting axial flux, fluence, dpa rate and dpa profiles for each MOTA. The axial region of interest was typically -78 to $+129 \mathrm{~cm}(-31$ to +51 inches) from the FFTF core horizontal midplane (HMP). The FFTF core extends $\pm 46.1 \mathrm{~cm}( \pm 18.1$ inches) from the HMP.

From the smooth curves, flux and dpa-rate values were assigned to axial position " $z$-values" approximately every 5 to $10 \mathrm{~cm}$ ( 2 to 4 inches). These flux and dpa-rate values were used for calculating all damage parameters of MOTA test positions. Note that the fast flux and fast fluence values are for energies greater than $0.1 \mathrm{MeV}$, and the dpa rates and dpa values are for an $\mathrm{Fe}-18 \mathrm{Cr}-8 \mathrm{Ni}$ stainless steel.

Plots of the fast flux versus distance from the horizontal midplane were generated for all MOTAs except MOTA-1D.[16] Data from MOTAs IA, IB and 1C were combined to generate a single fast flux profile for MOTAs 1A through 1D. The points shown with the curves in reference 16 represent the results from the analysis of the dosimetry spectral sets. All six of the fast flux profiles are replotted in Figure 1 for comparison.

Similar to the fast flux plots, plots of the dpa rate versus distance from the horizontal midplane for all MOTAs (except MOTA-1D) were also generated.[16] Again, data from MOTAs IA, 1B and 1C were combined to generate a single profile that was used for MOTAs 1A through 1D. All six of the dpa rate profiles are replotted in Figure 2 for comparison.

Close examination of the curves in Figures 1 and 2 reveals that the MOTA 1A (1B, 1C) curve is, in general, higher than the curves for MOTAs $1 E$ through 2B particularly from below-core to near the top of the core. This is to be expected because the FFTF operated at $400 \mathrm{MW}$ th during irradiation of MOTAs 1A through $1 D$ and at $291 \mathrm{MW}$ th during irradiation of MOTAs $1 E$ through $2 \mathrm{~B}$. When the data are normalized for power by comparing the fast fluence per MWD or dpa/MWD for all of the MOTAs (Table 3), the differences diminish.

The variations in neutron flux for the different MOTAs are greater than the uncertainties in the measured neutron fluxes from the dosimetry analyses. These differences in the fluxes (normalized by the reactor power, as shown in Table 3) are greatest in the regions below and above the FFTF core. Major environmental effects on these fluxes in the out-of-core regions include the specimen test matrices in each MOTA, the local power distribution in the core, and the characteristics of the nearest neighbor assemblies. For example, MOTA-1E contained significant quantities of europium oxide in level 6 (just above the 


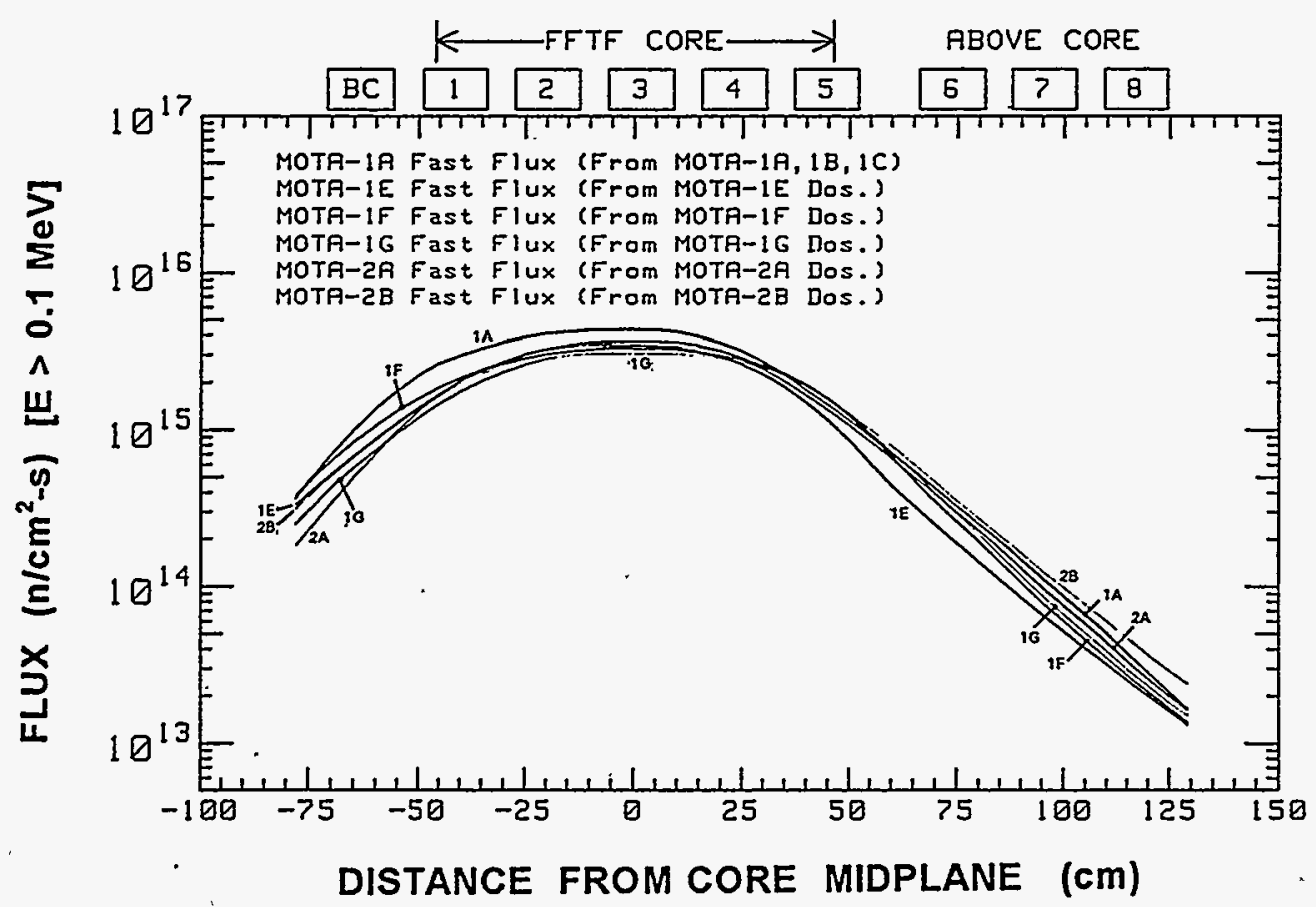

Figure 1. Fast Flux vs. Distance from Core Midplane for MOTAs 1A-1C, 1E-1G, 2A and 2B.

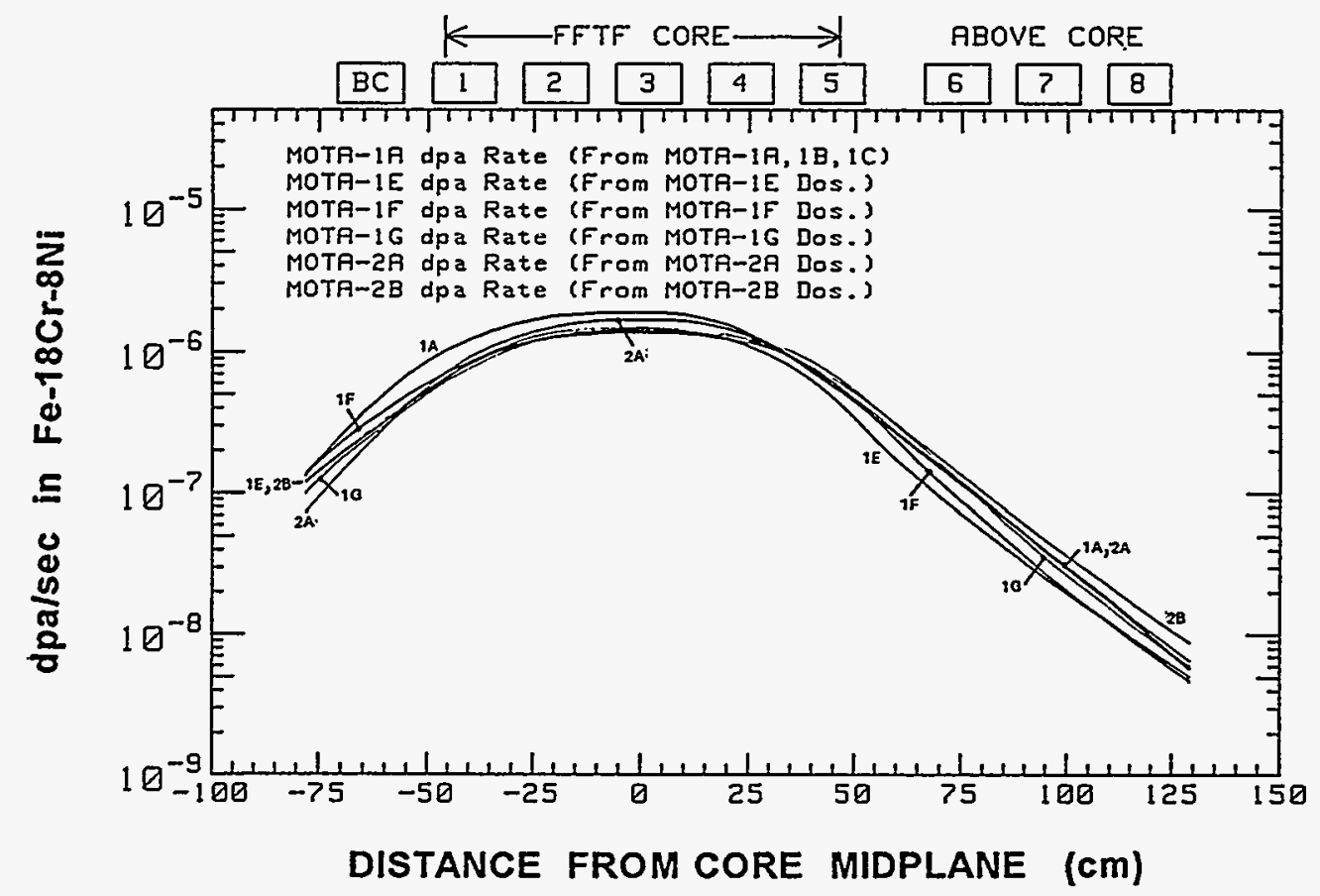

Figure 2. Dpa Rate vs. Distance from Core Midplane for MOTAs $1 A-1 C, 1 E-1 G, 2 A$ and $2 B$. 
core). Europium oxide has a large neutron-capture cross-section; therefore, one would expect the neutron flux in the above core region for this MOTA to be depressed relative to other MOTA fluxes at this level. Indeed, this flux suppression is clearly obvious in the flux and dpa plots shown in Figures 1 and 2, respectively. Similarly, MOTA-2A contained significantly more enriched lithium- 6 ceramics at and near the bottom of the core than the other MOTAs (including MOTA-2B). Again the neutron flux for MOTA-2A would likely be suppressed in the below-core region, and indeed flux suppression is obvious in the flux and dpa plots of Figures 1 and 2, respectively.

Table 3. Comparison of MOTA Fluence/MWD and dpa/MWD Values

\begin{tabular}{|c|c|c|c|c|c|c|}
\hline \multirow{2}{*}{ MOTA } & \multicolumn{3}{|c|}{$\begin{array}{l}\text { Fast Fluence/MWD } \\
\left(10^{17} \mathrm{n} / \mathrm{cm}^{2} \text { per } \mathrm{MWD}\right)\end{array}$} & \multicolumn{3}{|c|}{$\begin{array}{c}\text { Dpa/MWD } \\
\left(10^{-4} \text { dpa per MWD) }\right.\end{array}$} \\
\hline & $\begin{array}{c}\text { BELOW } \\
\text { CORE } \\
z=-65 \mathrm{~cm}\end{array}$ & $\begin{array}{l}\text { CORE } \\
\text { CENTER } \\
z=0 \mathrm{~cm}\end{array}$ & $\begin{array}{c}\text { ABOVE } \\
\text { CORE } \\
z=+122 \mathrm{~cm}\end{array}$ & $\begin{array}{c}\text { BELOW } \\
\text { CORE } \\
z=-65 \mathrm{~cm}\end{array}$ & $\begin{array}{c}\text { CORE } \\
\text { CENTER } \\
z=0 \mathrm{~cm}\end{array}$ & $\begin{array}{c}\text { ABOVE } \\
\text { CORE } \\
z=+122 \mathrm{~cm}\end{array}$ \\
\hline $1 \mathrm{~A}, 1 \mathrm{~B}, 1 \mathrm{C}$ & 2.16 & 9.40 & 0.0538 & 0.808 & 4.13 & 0.0187 \\
\hline $1 E$ & 2.01 & 10.2 & 0.0531 & 0.733 . & 4.39 & 0.0205 \\
\hline $1 F$ & 2.51 & 9.80 & 0.0564 & 0.909 & 4.13 & 0.0195 \\
\hline $1 G$ & 1.72 & 9.17 & 0.0621 & 0.698 & 4.28 & 0.0251 \\
\hline $2 \mathrm{~A}$ & 1.50 & 10.8 & 0.0680 & 0.621 & 5.05 & 0.0278 \\
\hline \multirow[t]{2}{*}{$2 B$} & 2.00 & 10.2 & 0.0977 & 0.763 & 4.39 & 0.0360 \\
\hline & $\downarrow$ & $\downarrow$ & $\downarrow$ & $\downarrow$ & $\downarrow$ & $\downarrow$ \\
\hline $\begin{array}{l}\text { Max. Difference } \\
\text { Between } \\
\text { MOTAs }\end{array}$ & $67 \%$ & $18 \%$ & $84 \%$ & $46 \%$ & $22 \%$ & $92 \%$ \\
\hline
\end{tabular}

The locations of the MOTAs in the reactor and the nearest neighbor assemblies influence the neutron environment for each MOTA. The core positions for all MOTAs and the neighboring assemblies for each MOTA irradiation cycle are shown in Figures 3 and 4, respectively. A quick glance at Figure 4 reveals numerous changes from cycle-to-cycle in the core assemblies surrounding the MOTAs. Even when the general configuration appears unchanged, rotation and movement of fuel assemblies routinely occurred.

Power distribution in the FFTF core was changed to accommodate different reactor missions and specific experimenter needs, or to optimize fuel utilization. This impacted the axial and radial flux distributions at the MOTA positions. For example the axial power distribution for the FFTF core when operated at $400 \mathrm{MWth}$ peaked more toward the lower end of the core than when the FFTF was operated at 291 MWth. Comparison of the flux distribution for MOTA-1A (B and $C$ ) to the axial flux profiles for the other MOTA irradiations provides evidence of the shift in power distribution.

The effect of the nearest neighbor fuel assemblies on the MOTA fluxes is more complex. A typical driver assembly has axial reflectors at the top and bottom of the fuel region. Several test fuel assemblies located next to the MOTA positions, however, had different geometries. For example, the Core Demonstration Experiment (CDE) test assemblies included axial blankets above and below the fuel region. These blankets absorbed neutrons early during the irradiation and then became a source of neutrons as 


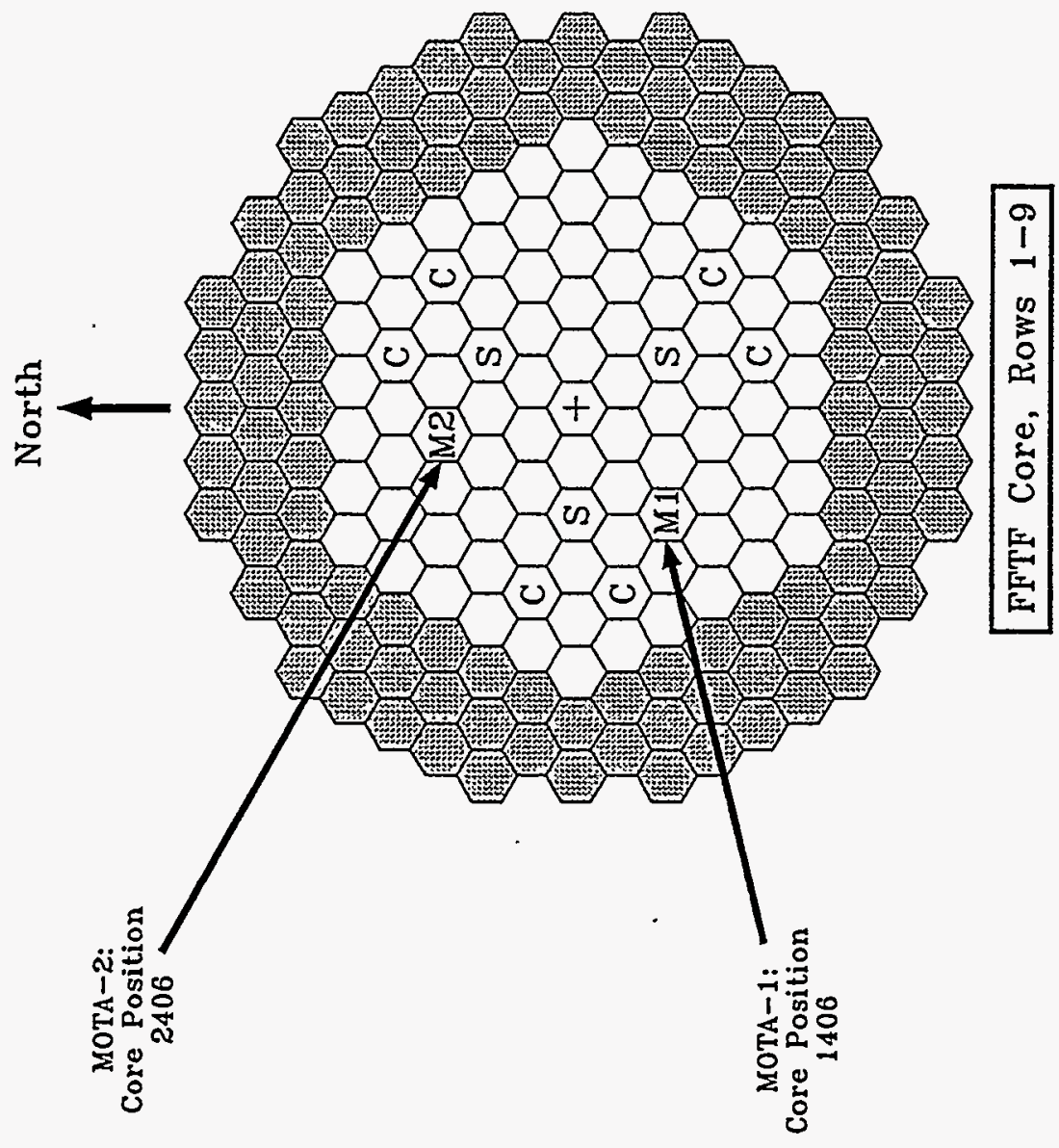

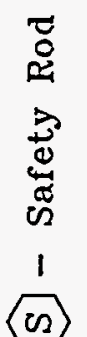

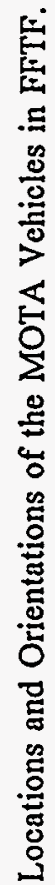

(1) (1)

(a)

范

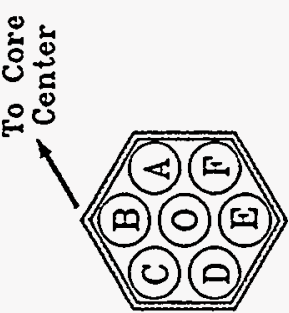

禹

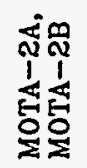

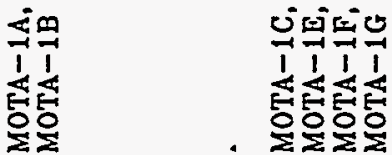

$\frac{1}{2}$ 

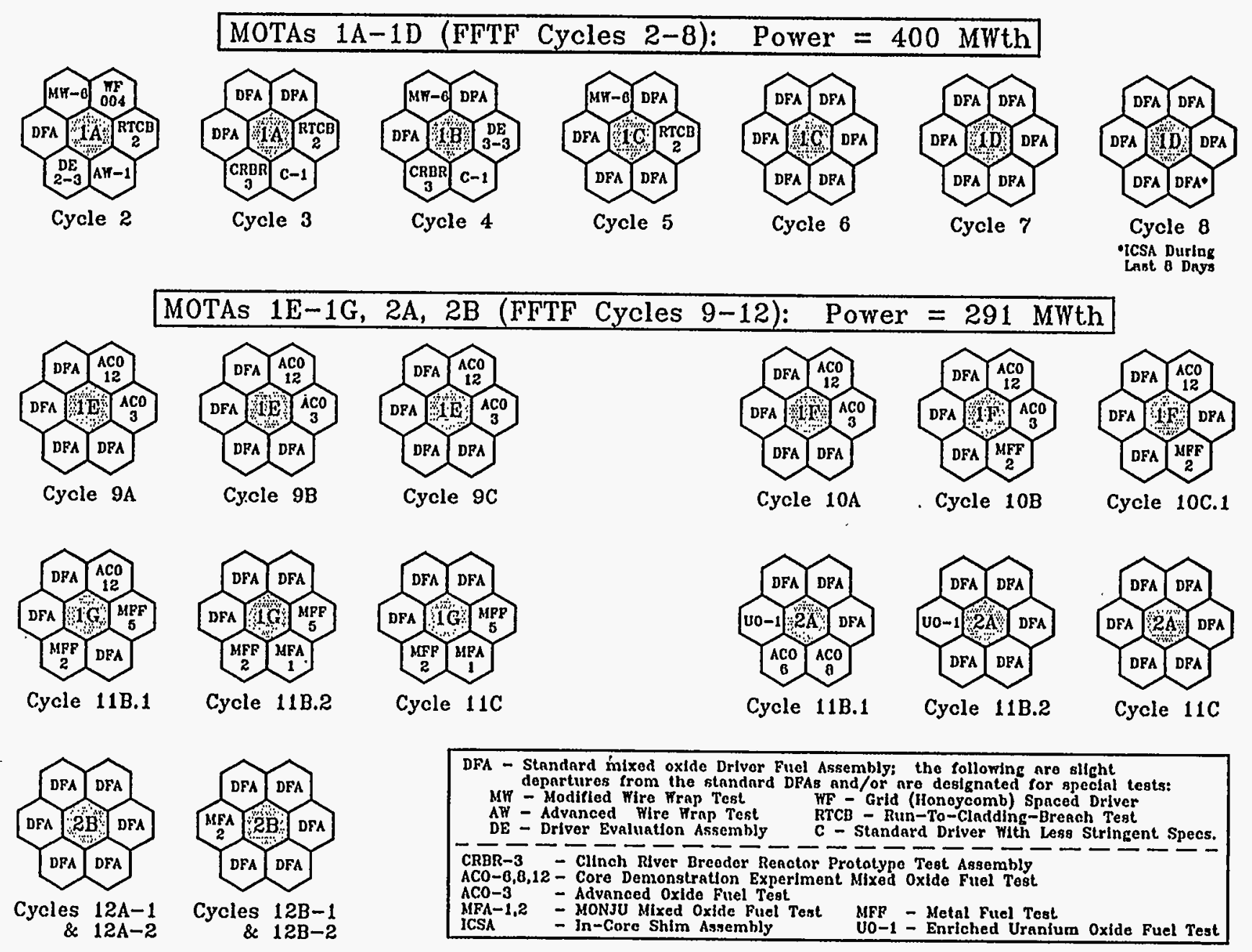

Figure 4. Assemblies Surrounding the MOTA Vehicles During FFTF Cycles 2-12. 
plutonium was "bred" into the blanket. The Metal Fuel test assemblies contained a fuel that produced a higher mean energy for the neutrons and did not have axial reflectors above the fuel region. These differences would influence the neutron fluxes and would have a measurable impact in the flux regions outside the core.

As seen in Figure 3, each MOTA consists of specimen canisters in radial positions designated by A through $G$ (and $O$ for MOTA-1). Since the dosimeters were in various canisters, radial effects became a concern. Radial effects as high as $10 \%$ were observed at some axial locations where multiple-gradientset dosimeters were located.[21] However, due to a lack of a comprehensive radial mapping of the MOTAs, radial effects were not factored into the final "smooth data" flux and dpa rate curves for the MOTA axial locations. The flux and dpa rate values depicted by the curves are therefore considered to be average values for each axial location.

In summary, there are uncertainties associated with the flux and dpa rate data; but there are also valid explanations for the differences illustrated in Figures 1 and 2 and tabulated in Table 3 . Therefore, these curves were accepted on their own merit and were used to determine fast fluence and dpa values for all MOTA axial locations. Plots of the fast fluence versus distance from the horizontal midplane for all MOTAs are shown in Figures 5,6 and 7; plots of the dpa (in an Fe-18Cr-8Ni stainless steel) versus distance from the horizontal midplane for all MOTAs are shown in Figures 8, 9 and 10.

Finally, one parameter of interest to experimenters is the ratio of the dpa to fluence, a value that is frequently used to quickly estimate dpa given the fluence, or vice versa. Smoothed curves of $\mathrm{dpa} /\left(10^{22} \mathrm{n} / \mathrm{cm}^{2}\right)[\mathrm{E}>0.1 \mathrm{MeV}]$, based on the described dpa and fluence curves, are shown in Figure 11. Since these curves were generated from the ratio of two curves, they are highly sensitive to small deviations in either curve. Consequently, one should not be concerned by the differences exhibited among the MOTAs. For most of the in-core region, the value for an $\mathrm{Fe}-18 \mathrm{Cr}-8 \mathrm{Ni}$ stainless steel was 4.2 to 4.6 , or an average of about $4.4 \mathrm{dpa} /\left(10^{22} \mathrm{n} / \mathrm{cm}^{2}\right)$. The average out-of-core value was about $3.8 \mathrm{dpa} /\left(10^{22} \mathrm{n} / \mathrm{cm}^{2}\right)$.

The "smooth curve" dosimetry information for all MOTAs is listed in reference 16.

\section{MOTA Damage Parameters}

Matrices showing the fast fluence and dpa values for each basket (or capsule) were generated from the dosimetry information, the basket length information, and the basket z-values. Values were calculated for the tops of the top baskets, the bottoms of the bottom baskets, and the centers of all baskets. The values were determined by linear interpolation (on a semi-log scale) of the dosimetry curves.

Tables 4 through 12 list canister matrices of the fast fluence information. Again note that the values are for energies greater than $0.1 \mathrm{MeV}$. Tables 13 through 21 list the dpa information for an $\mathrm{Fe}-18 \mathrm{Cr}-8 \mathrm{Ni}$ stainless steel; experimenters will need to apply an appropriate dpa correction factor for other materials.[28]

Finally, the values in Tables 4 through 21 may not exactly match those values in the detailed specimen listings that are available to the MOTA experimenters. The values in Tables 4 through 21 are for the centers of the baskets or capsules. Values assigned to the specimens were calculated for the center of each specimen (or subcapsule). Therefore, short specimens and longer specimens located side-by-side in the same basket may have slightly different fluence and dpa values. Similarly, specimens that were stacked vertically in a basket or capsule may also have slightly different fluence and dpa values. 


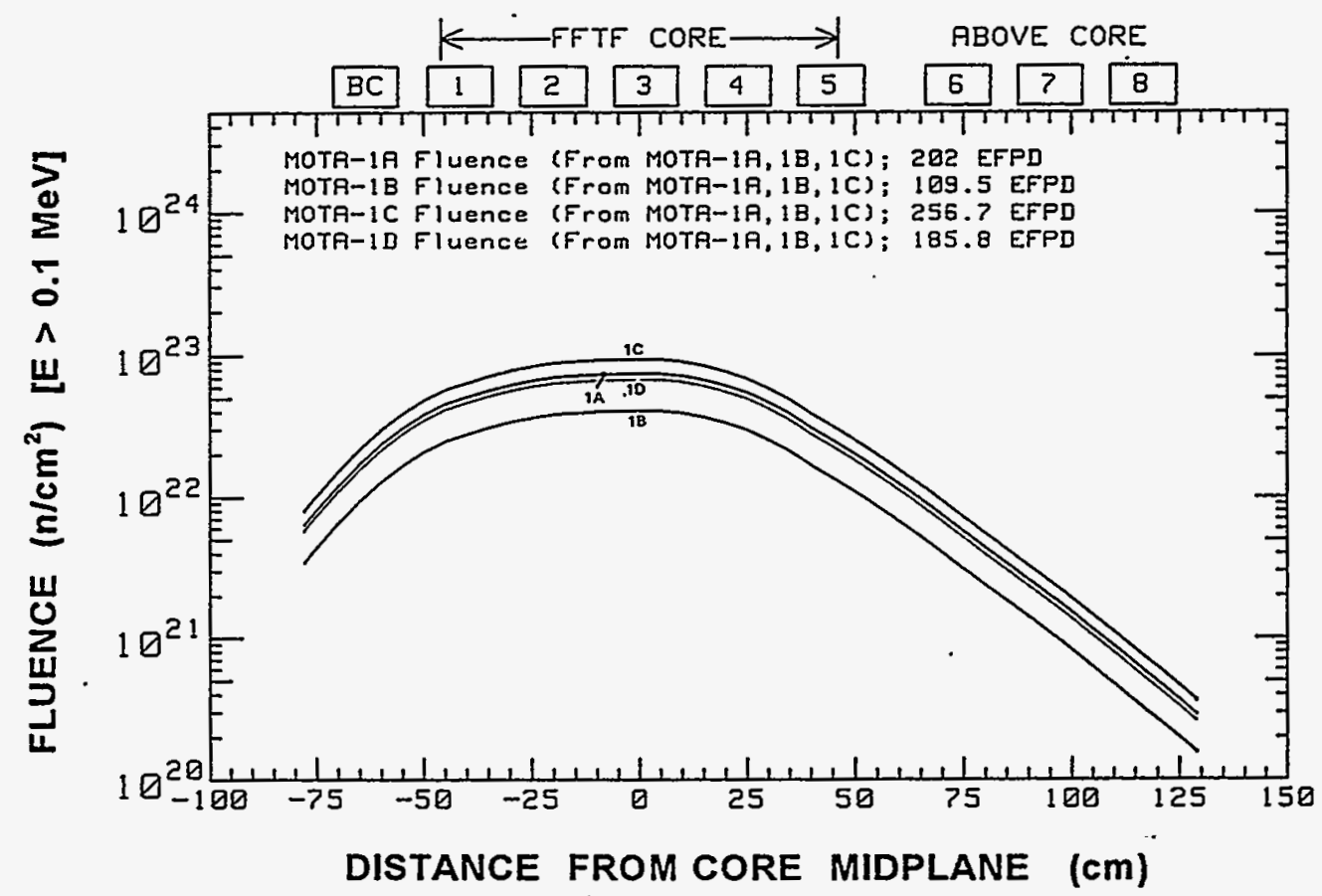

Figure 5. Fast Fluence vs: Distance from Core Midplane for MOTAs 1A, 1B, 1C and 1D.

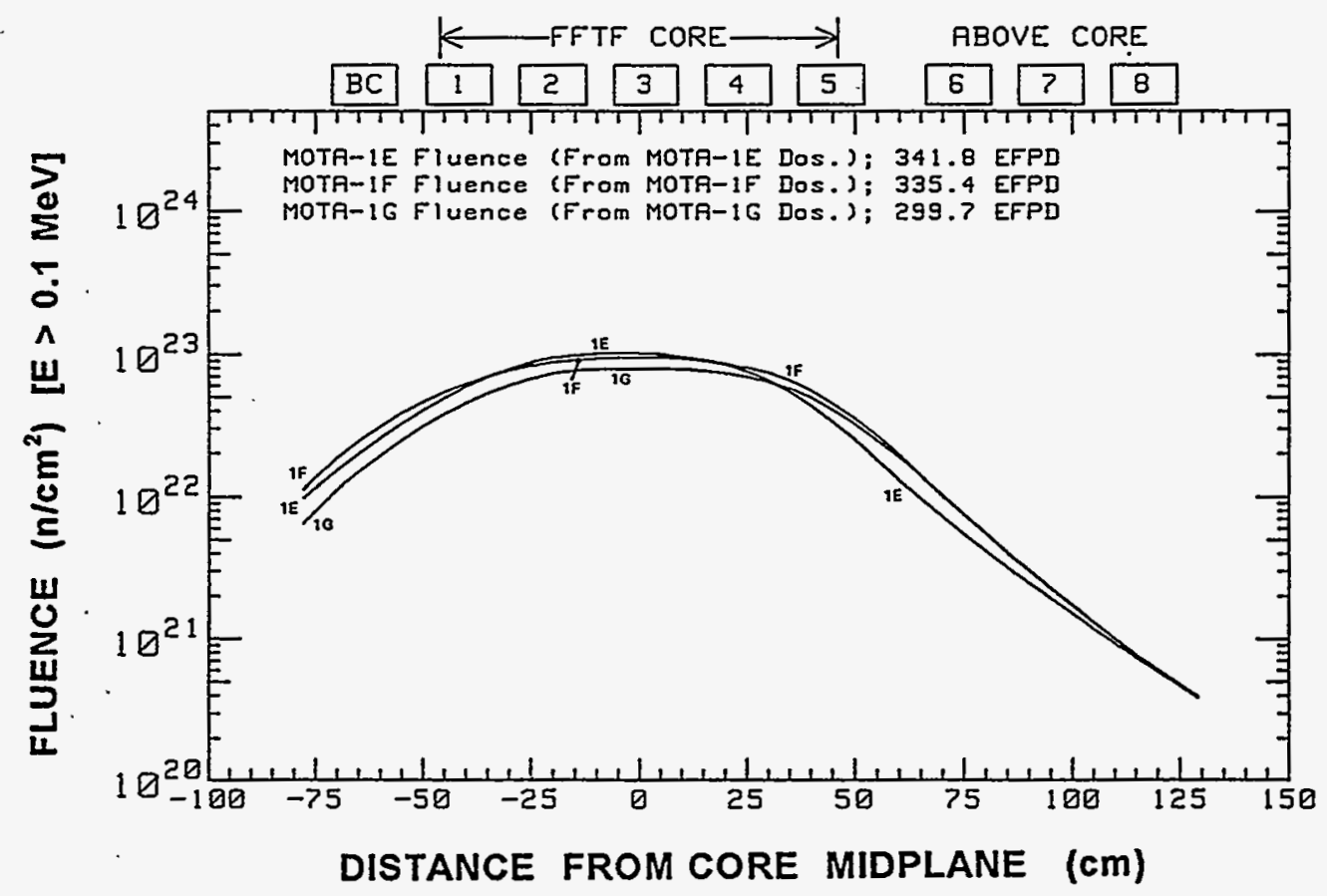

Figure 6. Fast Fluence vs. Distance from Core Midplane for MOTAs IE, IF, and IG. 


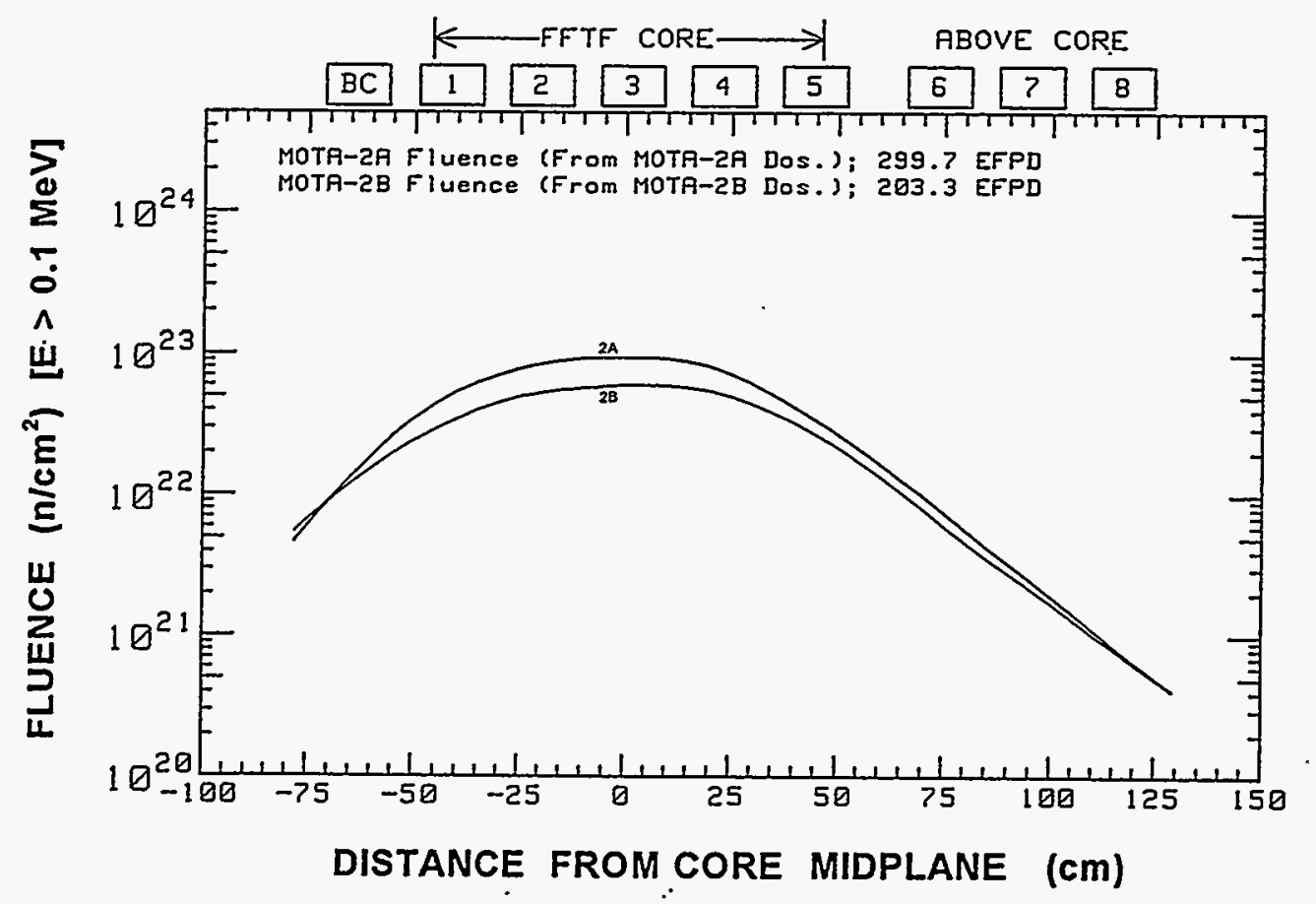

Figure 7. Fast Fluence vs. Distance from Core Midplane for MOTAs $2 \mathrm{~A}$ and 2B.

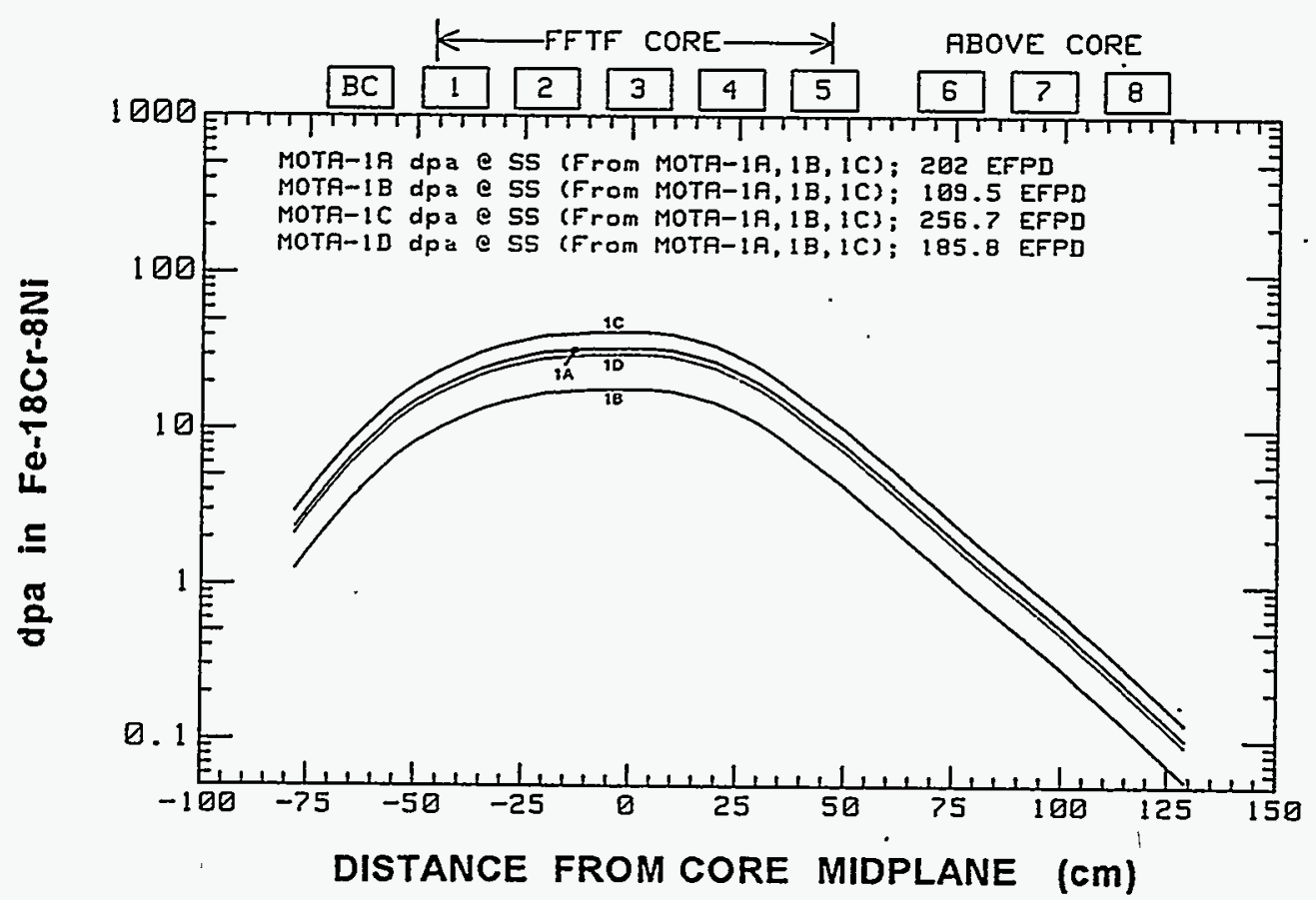

Figure 8. $\mathrm{Dpa}$ (in Stainless Steel) vs. Distance from Core Midplane for MOTAs 1A, 1B, 1C and 1D. 


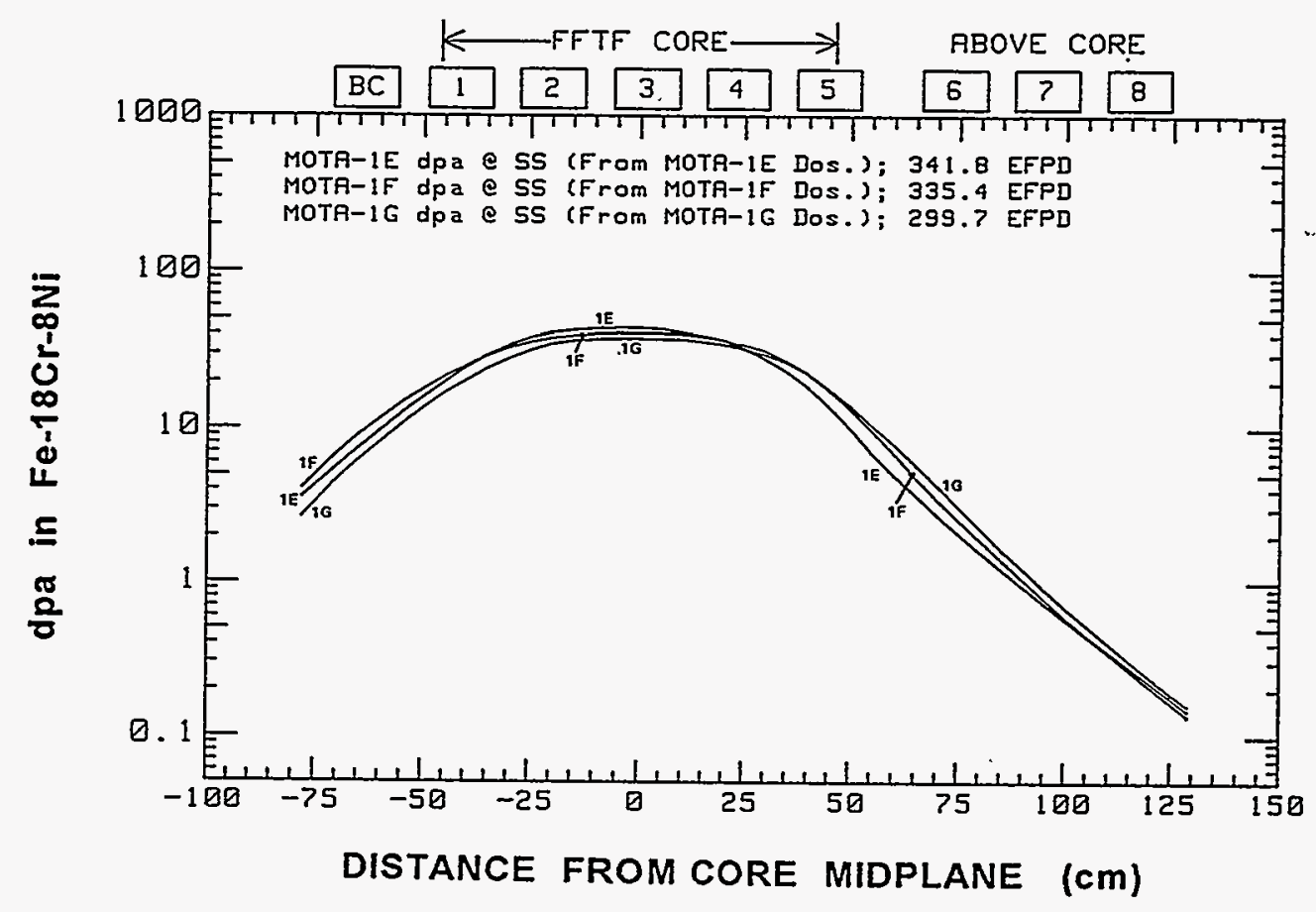

Figure 9. Dpa (in Stainless Steel) vs. Distance from Core Midplane for MOTAs 1E, 1F, and 1G.

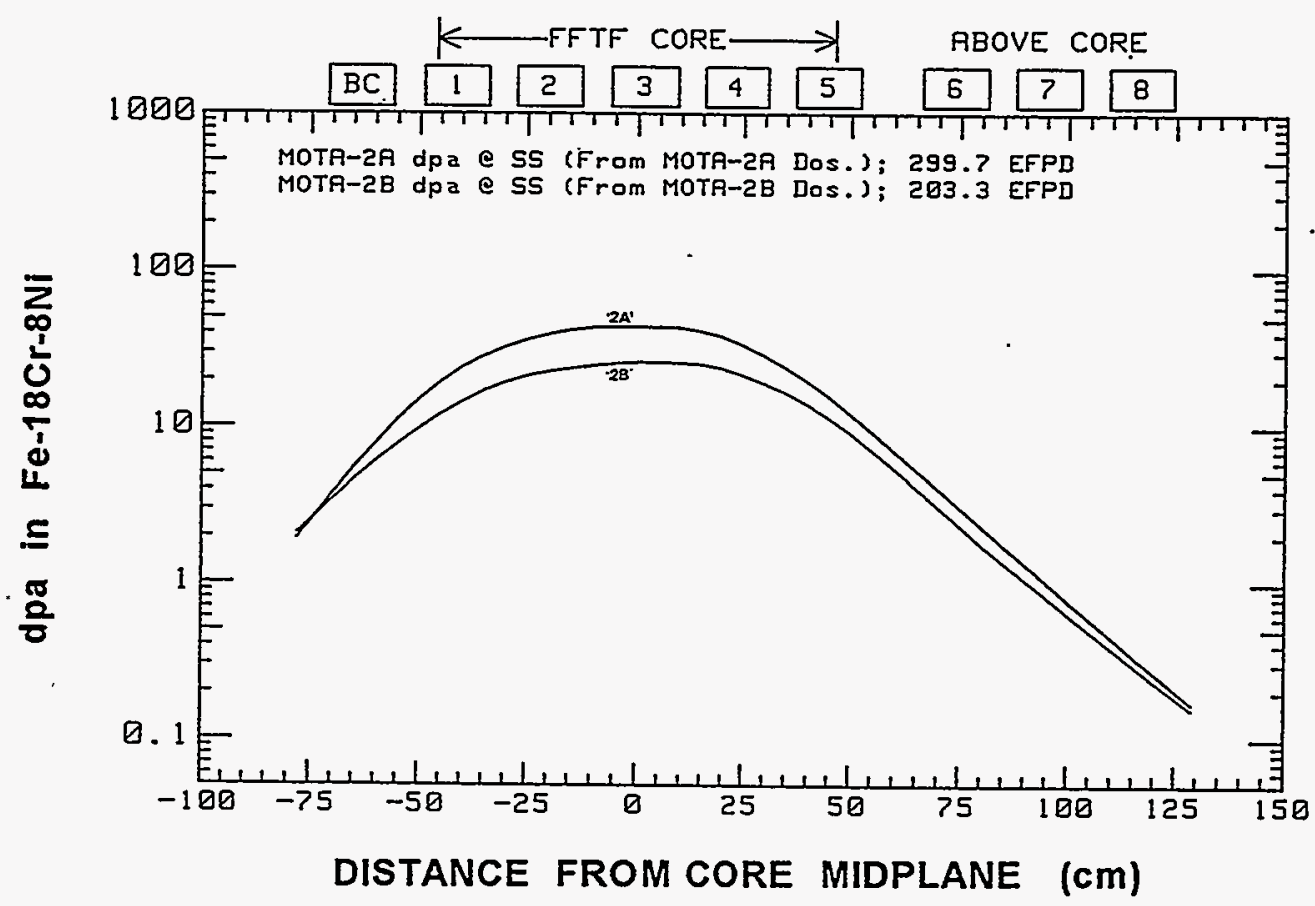

Figure 10. Dpa (in Stainless Steel) vs. Distance from Core Midplane for MOTAs 2A and 2B. 


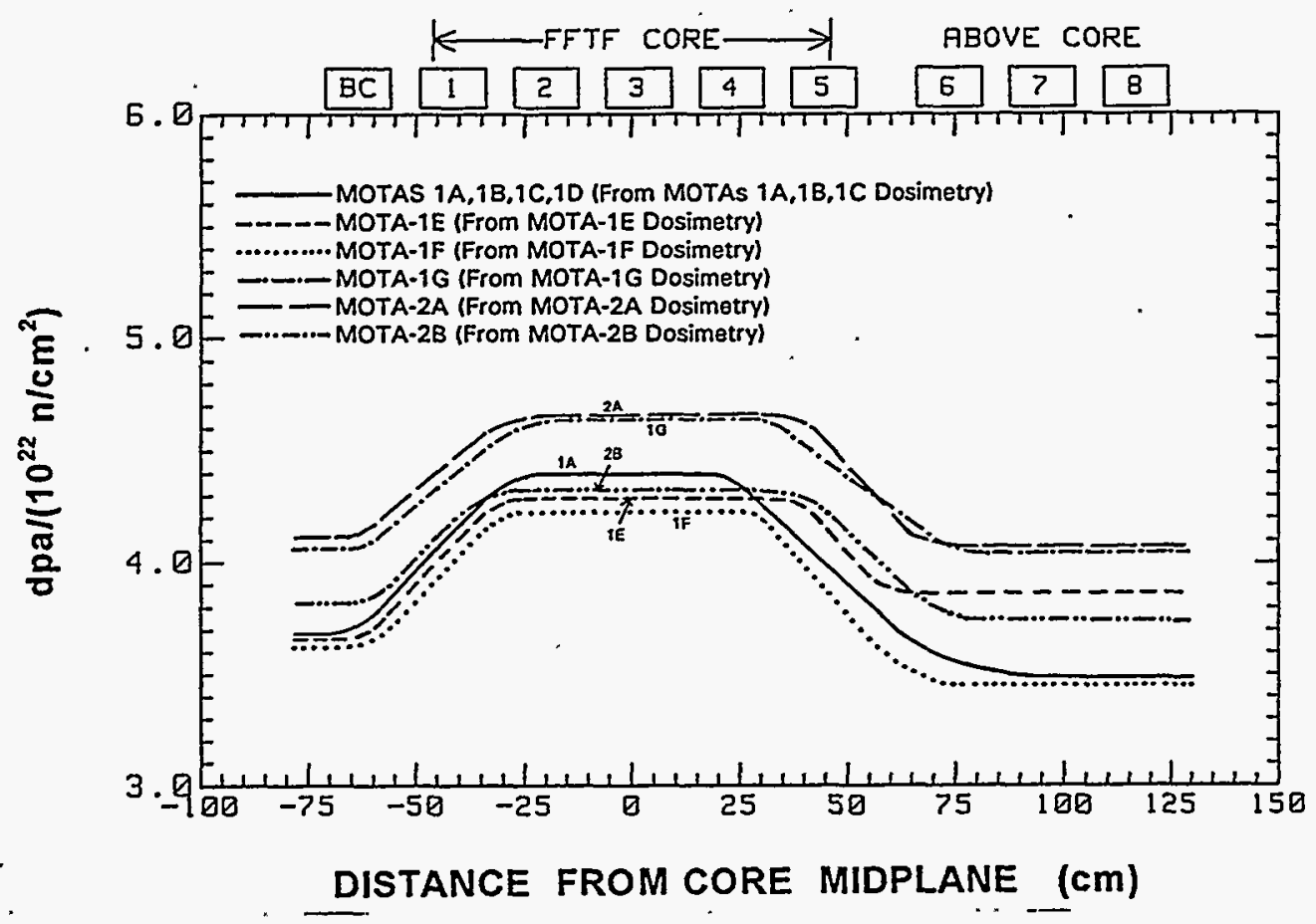

Figure 11. Dpa per $10^{22} \mathrm{n} / \mathrm{cm}^{2}$ vs. Distance from Midplane for MOTAs 1A-1C, 1E-1G, 2A, and $2 B$.

\section{CONCLUSIONS}

Irradiation parameters (temperatures, fluences and dpa values) for all test locations in all nine MOTAs were reported and discussed. Additional details regarding the irradiation conditions for each MOTA have been published.[16] Details regarding individual specimens are on file at PNL.

\section{FUTURE WORK}

Issuance of this report concludes the last major activity associated with the operation of the MOTA in the FFTF.

\section{REFERENCES}

1. R. E. Bauer and R. W. Truitt, "MOTA Instrumentation and Control System Performance During FFTF Cycle 2," National Cladding/Duct Materials Development Program Quarterly Technical Progress Letter, HEDL-TC-160-37, April-May-June 1983, pp. 99-113.

2. R. E, Bauer and S. C. Cantrell, "MOTA Instrumentation and Control (I\&C) System Performance For FFTF Cycles 3 and 4," National Cladding/Duct Materials Development Program Quarterly Technical Progress Letter, HEDL-TC-160-41, April-May-June 1984, pp. 2-7. 
3. A. M. Ermi, "MOTA-1C Performance During FFTF Cycle 5," National Cladding/Duct Materials Development Program Quarterly Technical Progress Letter, HEDL-TC-160-43, October-NovemberDecember 1984, pp. 58-79.

4. A. M. Ermi, "MOTA-1C Performance - FFTF Cycle 5," HEDL-TC-2653-1, November 1984.

5. A. M. Ermi, "MOTA-1C Performance During FFTF Cycle 6," National Cladding/Duct Materials Development Program Quarterly Technical Progress Letter, HEDL-TC-160-45, April-May-June 1985, pp. 1-25.

6. A. M. Ermi, "MOTA-1C Performance - FFTF Cycle 6," HEDL-TC-2653-2, July 1985.

7. A. M. Ermi, "MOTA-1D Performance During FFTF Cycle 7," National Cladding/Duct Materials Development Program Quarterly Technical Progress Letter, HEDL-TC-160-47, October-NovemberDecember 1985, pp. 1-20.

8. A. M. Ermi, "MOTA-1D Performance - FFTF Cycle 7," HEDL-TC-2653-3, January 1986.

9. A. M. Ermi, "MOTA-ID Performance - FFTF Cycle 8," HEDL-TC-2653-4, September 1986.

10. A. M. Ermi, "MOTA-1E Performance - FFTF Cycle 9A," HEDL-TC-2653-5, March 1987.

11. A. M. Ermi, "MOTA-1E Performance - FFTF Cycles 9B and 9C," WHC-SP-0220, January 1988.

12. A. M. Ermi, "MOTA-IF Performance - FFTF Cycle 10," WHC-SP-0477, May 1989.

13. A. M. Ermi, "MOTA-1G Performance - FFTF Cycle 11," WHC-SD-FF-TD-007, August 1991.

14. A. M. Ermi, "MOTA-2A Performance - FFTF Cycle 11," WHC-SD-FF-TD-008, August 1991.

15. A. M. Ermi, "MOTA-2B Performance - FFTF Cycle 12," WHC-SD-FF-TD-009, May 1992.

16. A. M. Ermi, L. R. Greenwood and H. I. Heinisch, "Irradiation Parameters for the FFTF Materials Open Test Assemblies from 1983 to 1992," WHC-SD-FF-TD-010, August 1994.

17. F. A. Garner, N. Sekimura, M. L. Grossbeck, A. M. Ermi, J. W. Newkirk, H. Watanabe and M. Kiritani, "Influence of Details of Reactor History on Microstructural Development During Neutron Irradiation," Journal of Nuclear Materials 205 (1993) pp. 206-218.

18. L. S. Williams, "Test Design Deseription for the Materials Open Test Assembly (MOTA-1G): Design Description and Safety Analysis, Volume 1A," WHC-SP-0215 Rev. 1, December 1988.

19. R. L. Simons, "Analysis of Damage Exposure Rates in the MOTA of the FFTF," Damage Analysis and Fundamental Studies Quarterly Progress Report, DOE/ER-0046/21 (May 1985) pp. 10-16.

20. L. R. Greenwood and L. S. Kellogg, "Neutron Dosimetry for the MOTA-1F Experiment in FFTF," Fusion Reactor Materials Semiannual Progress Report for the Period Ending September 30, 1990, DOE/ER-0313/9 (April 1990) pp. 31-36. 
21. L. R. Greenwood and L. S. Kellogg, "Neutron Dosimetry for the MOTA-2A Experiment in FFTF," Fusion Reactor Materials Semiannual Progress Report for the Period Ending_March 31, 1992, DOE/ER-0313/12 (July 1992) pp. 49-53.

22. L. R. Greenwood and L. S. Kellogg, "Neutron Dosimetry for the MOTA-1G Experiment in FFTF," Fusion Reactor Materials Semiannual Progress Report for the Period Ending March 31, 1993, DOE/ER-0313/14 (July 1993) pp. 51-54.

23. L. R. Greenwood, "Reanalysis of Neutron Dosimetry for the MOTA-1E Experiment in FFTF," Fusion Reactor Materials Semiannual Progress Report for the Period Ending September 30, 1993, DOE/ER-0313/15 (February 1994) pp. 53-59.

24. L. R. Greenwood and L. S. Kellogg, "Neutron Dosimetry for the MOTA-2B Experiment in FFTF," Fusion Reactor Materials Semiannual Progress Report for the Period Ending March 31, 1994, DOE/ER-03 13/16 (1994).

25. L. R. Greenwood, "Reanalysis of Neutron Dosimetry for the MOTA-1A/1B Experiments in FFTF," Fusion Reactor Materials Semiannual Progress Report for the Period Ending March 31, 1994, DOE/ER-0313/16 (1994).

26. I. R. Greenwood, "Neutron Dosimetry for the MOTA-1C Experiment in FFTF," Fusion Reactor Materials Semiannual Progress Report for the Period Ending March 31. 1994, DOE/ER-0313/16 (1994).

27. L. R. Greenwood, "Revised Neutron Dosimetry for the MOTA-2A Experiment in FFTF," Fusion Reactor Materials Semiannual Progress Report for the Period Ending March 31, 1994, DOE/ER0313/16 (1994).

28. F. A. Gamer, L. R. Greenwood and A. M. Ermi, "Calculation of Displacement Levels for Pure Elements and Most Multicomponent Alloys Irradiated in MOTA-1F," Fusion Reactor Materials Semiannual Progress Report for the Period Ending March 31, 1992, DOE/ER-0313/12 (July 1992), pp. 54-58. 
Table 4. MOTA-1A Canister Matrix Showing Fast Fluence Information HOTA LEVELS 8 TO BC a 202 EFPO Units: n/Cri 2 [E>0.1 HeV]

\begin{tabular}{|c|c|c|c|c|c|c|}
\hline 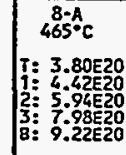 & 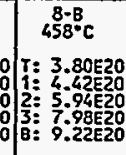 & 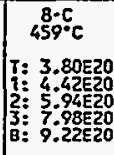 & 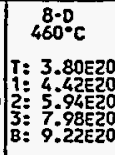 & $\left\{\begin{array}{c}8 \cdot \overline{8} \\
460^{\circ} \mathrm{c} \\
\text { HO CAHIST. }\end{array}\right.$ & $\begin{array}{c}8-F \\
460^{\circ} \mathrm{C} \\
\text { HO CAHIST. }\end{array}$ & \\
\hline $455^{\circ} \mathrm{C}$ & $455^{\circ} \mathrm{C}$ & 45 & $45^{\circ} 5^{\circ} \mathrm{C}$ & $\begin{array}{l}7-E \\
455^{\circ} \mathrm{C}\end{array}$ & $4755^{\circ} \mathrm{c}$ & \\
\hline HO CAMIST. & - HO CANIST. & HO CANIST. & Ho Canist. & HO CANIST. & HO CANIST. & \\
\hline & & $\begin{array}{l}6-c \\
504^{\circ} \mathrm{c}\end{array}$ & $503^{6-c} \mathrm{C}$ & $481^{\circ} \mathrm{c}$ & $483^{\circ} \cdot \mathrm{C}$ & \\
\hline 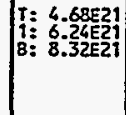 & 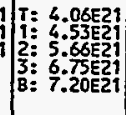 & 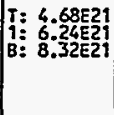 & 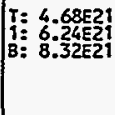 & $\begin{array}{l}\text { I: } 4.68 \mathrm{6E} 1 \\
1: 5.36 \mathrm{E} 21 \\
2: 6.87 \mathrm{E} 21 \\
3: 8.99 \mathrm{EL21} \\
\mathrm{B}: 8.73 \mathrm{E} 21\end{array}$ & 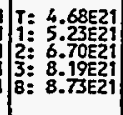 & \\
\hline $536^{5} \mathrm{~A}$ & $\begin{array}{c}5-8 \\
597^{\circ} \mathrm{C}\end{array}$ & $\begin{array}{c}5 . \mathrm{C} \\
567^{\circ} \mathrm{C}\end{array}$ & $\begin{array}{c}5 \cdot 0 \\
597^{\circ} \mathrm{c}\end{array}$ & \begin{tabular}{|c|}
$59-E^{\circ} \mathrm{C}$ \\
596.
\end{tabular} & $\begin{array}{c}5-5 \\
445 \cdot c\end{array}$ & \\
\hline 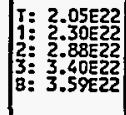 & 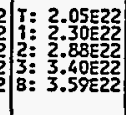 & 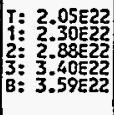 & 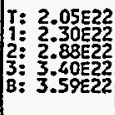 & 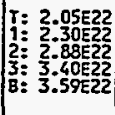 & 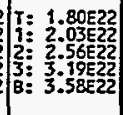 & \\
\hline $\begin{array}{c}4-A \\
665\end{array}$ & $\begin{array}{c}4-8 \\
547^{\circ} \mathrm{C}\end{array}$ & $\begin{array}{c}4-c \\
549^{-c} \mathrm{c}\end{array}$ & $583^{\circ} \mathrm{C}$ & $646^{\circ} \mathrm{C}$ & $\frac{4-F}{722 \cdot c}$ & \\
\hline 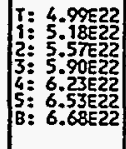 & 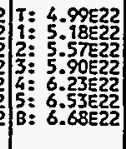 & 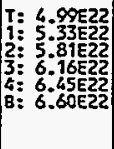 & $\begin{array}{l}\text { T: } 4.99 \mathrm{E} 22 \\
1: 5.33 \mathrm{E22} \\
2: 5.81 \mathrm{E22} \\
3:-6.16 \mathrm{E22} \\
6: 6.45 \mathrm{E2} \\
\text { B: } 6.60 \mathrm{E22}\end{array}$ & $\begin{array}{l}T=4.99 \mathrm{E}^{22} \\
1=5.33 \mathrm{E} 22 \\
2: 5.81 \mathrm{E2} \\
3: 6.16 \mathrm{E22} \\
4: 6.45 \mathrm{E22} \\
\mathrm{B}=6.60 \mathrm{E22}\end{array}$ & 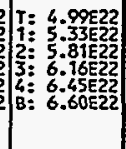 & \\
\hline$\frac{3-A}{730^{\circ} \mathrm{C}}$ & \begin{tabular}{c|c|}
$3 \cdot 8$ \\
$547^{\circ} \mathrm{C}$
\end{tabular} & $572^{3-c} \mathrm{c}$ & $\begin{array}{c}3-0 \\
601 \cdot c\end{array}$ & $\begin{array}{c}3 . E_{1} \\
6655^{\circ} \mathrm{c}\end{array}$ & ${ }_{745}^{3-F}$ & \\
\hline $\begin{array}{l}\text { T: } 7.44 \mathrm{E2} \\
1: 751522 \\
2: 7.56222 \\
3: 77.58222 \\
4: 7.56522 \\
B: 7.55 \mathrm{E} 22\end{array}$ & 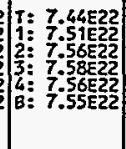 & 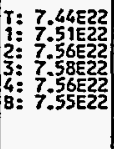 & 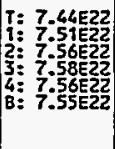 & 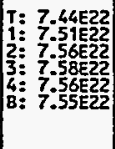 & 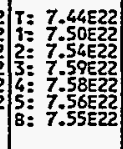 & \\
\hline $603^{2} \mathrm{~A}$ & 5 & $\begin{array}{c}2-c \\
494 \cdot c\end{array}$ & $\begin{array}{c}2-0 \\
569-\mathrm{c} \\
\end{array}$ & $\begin{array}{l}2-E \\
575->555-c \\
x\end{array}$ & $\begin{array}{c}2-F \\
427^{\circ} \mathrm{c}\end{array}$ & \\
\hline 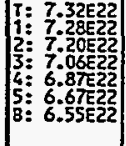 & 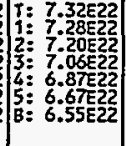 & 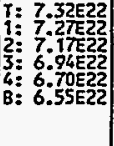 & 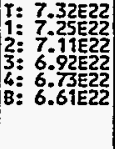 & $\begin{array}{l}Y=7.32 E 22 \\
1: 7.27 E 22 \\
2: 7.17 E 22 \\
3: 6.94 E 22 \\
4: 6.70 E 22 \\
B=6.55 E 22\end{array}$ & 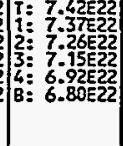 & \\
\hline $\begin{array}{c}1-1 \\
480^{\circ} \mathrm{C}\end{array}$ & $537^{\circ} \mathrm{c}$ & $\begin{array}{c}1-c \\
469 \cdot c \\
-c\end{array}$ & $\begin{array}{l}1-D \\
405^{\circ} \mathrm{C}\end{array}$ & $\begin{array}{c}1+E \\
403^{\circ} \mathrm{c}\end{array}$ & $410^{9-5}$ & \\
\hline 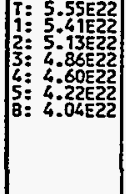 & 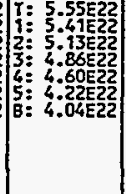 & 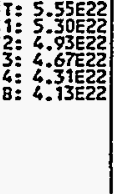 & 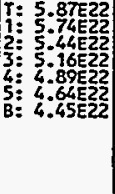 & 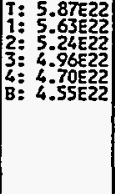 & 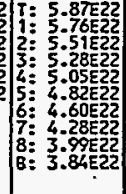 & \\
\hline $\begin{array}{c}\mathrm{BC}-1 \\
370 \cdot \mathrm{C} \\
\text { Ко CANIST. }\end{array}$ & $\begin{array}{c}\mathrm{BC}-2 \\
3700 \mathrm{C} \\
\text { HO CANIST. }\end{array}$ & $\begin{array}{c}\mathrm{BC}-3 \\
370^{\circ} \mathrm{C}\end{array}$ & $\begin{array}{c}8 \mathrm{BC}-6 \\
370 \cdot \mathrm{c}\end{array}$ & $\begin{array}{c}\mathrm{BC}-5 \\
370^{\circ \mathrm{C}} \\
\end{array}$ & $\begin{array}{c}\mathrm{BC} \cdot-6 \\
370^{\circ} \mathrm{c}\end{array}$ & $\begin{array}{c}\mathrm{BC}-0 \mathrm{O} \\
370^{\circ} \mathrm{C}\end{array}$ \\
\hline SO CANIST. & HO CANIST. & HO CAMIST & HO CAMIST. & HO CARIST. & . HO CAHIST. & NO CANIST. \\
\hline
\end{tabular}


Table 5. MOTA-1B Canister Matrix Showing Fast Fluence Information

\begin{tabular}{|c|c|c|c|c|c|c|}
\hline MOTA LEVELS & 58 ro BC & 109.5 EFPD & Units & $\operatorname{ven}{ }^{-2}$ & {$[\mathrm{HaV}]$} & \\
\hline 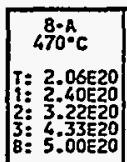 & 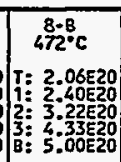 & 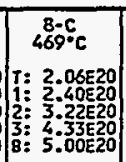 & 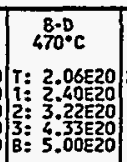 & $\begin{array}{c}8-E^{\circ} \mathrm{C} \\
470^{\circ} \mathrm{C} \\
\text { NO CANIST. }\end{array}$ & $\begin{array}{c}88-\mathrm{f} \\
470^{\circ} \mathrm{C} \\
\text { Ho curist. }\end{array}$ & \\
\hline \begin{tabular}{c|}
$7-\mathrm{A}$ \\
$460^{\circ} \mathrm{C}$ \\
Ho CAN1ST.
\end{tabular} & $\begin{array}{c}7.88 \\
460^{\circ} \mathrm{C} \\
\text { HO CANIST. }\end{array}$ & $\begin{array}{c}6-\mathrm{c} \\
460^{\circ} \mathrm{C} \\
\text { NO CANIST. }\end{array}$ & $\begin{array}{c}7-0 \\
480^{\circ} \mathrm{c} \\
\text { NO CAHIST. }\end{array}$ & $\begin{array}{c}7-\mathrm{E} \\
460^{\circ} \mathrm{C} \\
\text { HO CAN1ST. }\end{array}$ & $\begin{array}{c}7-8 \\
460^{\circ} \mathrm{C} \\
\text { HO CANIST. }\end{array}$ & \\
\hline $68^{6.1} \mathrm{C}$ & $50^{6 \cdot 1} \cdot \mathrm{C}$ & $50^{6-c} \mathrm{c}$ & \begin{tabular}{c|}
$60-0$ \\
$50^{\circ} c$
\end{tabular} & $487^{\circ} \mathrm{c}$ & $4966^{\circ} \mathrm{C}$ & \\
\hline 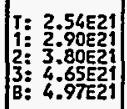 & 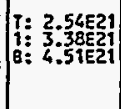 & 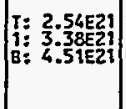 & 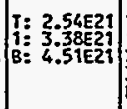 & 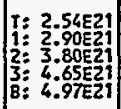 & 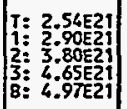 & \\
\hline \begin{tabular}{c|c|}
$5-A$ & $A$ \\
$535^{\circ} \mathrm{C}$
\end{tabular} & \begin{tabular}{|c|}
$5-6$ \\
$596^{\circ} \mathrm{C}$
\end{tabular} & \begin{tabular}{|c|}
$5-\mathrm{C}$ \\
$568^{\circ} \mathrm{C}$
\end{tabular} & \begin{tabular}{c|}
$5 \cdot 0$ \\
$585 \circ \mathrm{c}$
\end{tabular} & \begin{tabular}{|c|}
$5-E$ \\
$5877^{\circ} \mathrm{C}$
\end{tabular} & $\begin{array}{c}5-F \\
445^{\circ} \mathrm{c}\end{array}$ & \\
\hline 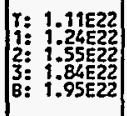 & 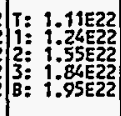 & 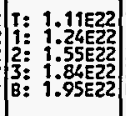 & 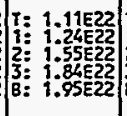 & 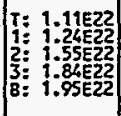 & 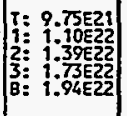 & \\
\hline \begin{tabular}{l|}
$4-A$ \\
$063^{\circ} \mathrm{C}$
\end{tabular} & \begin{tabular}{c|}
448 \\
$548^{\circ} \mathrm{C}$
\end{tabular} & 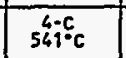 & \begin{tabular}{l|l}
$4=0$ \\
$569 \cdot c$
\end{tabular} & $\begin{array}{l}4: E^{\circ} \\
645^{\circ} \mathrm{c}\end{array}$ & $722^{4-5} \cdot \mathrm{c}$ & \\
\hline 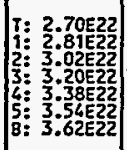 & 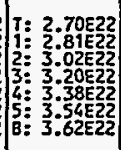 & 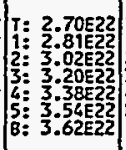 & 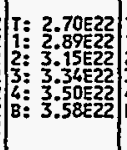 & $\begin{array}{l}\text { I: }: 2.70 E 22 \\
1: 2.89 \mathrm{E} 22 \\
2: 3.15 E 22 \\
3: 3.34 E 22 \\
4: 30522 \\
B: 3.58 E 22\end{array}$ & 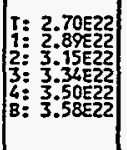 & \\
\hline$\frac{3-\mathrm{A}}{750^{\circ} \mathrm{C}}$ & \begin{tabular}{|c|}
$3-\mathrm{B}$ \\
$547^{\circ} \mathrm{C}$ \\
\end{tabular} & \begin{tabular}{l|}
$3-c$ \\
$571 \% c$
\end{tabular} & $\begin{array}{ll}3 \cdot 0 \\
603 \cdot \mathrm{C}\end{array}$ & \begin{tabular}{|c|}
$3-E$ \\
$666 \% \mathrm{c}$
\end{tabular} & $\begin{array}{c}3-\mathrm{F} \\
743^{\circ} \mathrm{c}\end{array}$ & \\
\hline 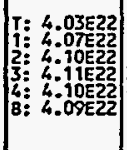 & $\begin{array}{l}\text { T: } 4.03 E 22 \\
1: 4.07 t 22 \\
2: 4.10 E 22 \\
3: 4.11 E 22 \\
4: 4.10 E 22 \\
B: 4.09 E 22\end{array}$ & 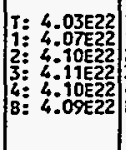 & 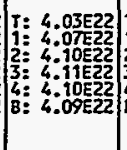 & 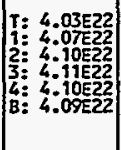 & 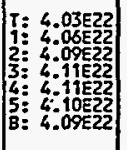 & \\
\hline $600^{2-A} \mathrm{c}$ & \begin{tabular}{|c|}
$2-8$ \\
$595^{\circ} \mathrm{c}$
\end{tabular} & \begin{tabular}{c|}
$2-c$ \\
518
\end{tabular} & \begin{tabular}{|c|}
$2 \cdot 0$ \\
$580^{\circ} \mathrm{C}$
\end{tabular} & $555-2535 \cdot c$ & $4 \frac{2-F}{431^{*} c}$ & \\
\hline 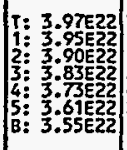 & 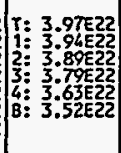 & 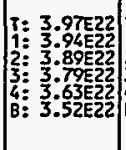 & 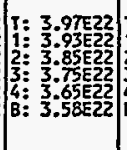 & 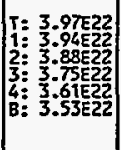 & 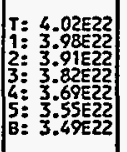 & \\
\hline $\begin{array}{c}1-\mathrm{A} \\
490^{\circ} \mathrm{C}\end{array}$ & \begin{tabular}{c|}
$118 \mathrm{~B}$ \\
$493^{\circ} \mathrm{C}$
\end{tabular} & \begin{tabular}{|l|}
$1-\mathrm{c}$ \\
$471^{\circ} \mathrm{c}$
\end{tabular} & $401^{10} \mathrm{C}$ & \begin{tabular}{l|}
$1-E$ \\
$407^{\circ} \mathrm{C}$
\end{tabular} & $\begin{array}{c}1-F \\
409^{\circ} \mathrm{C}\end{array}$ & \\
\hline 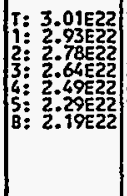 & 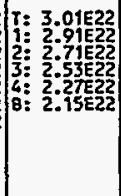 & 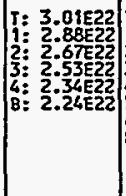 & 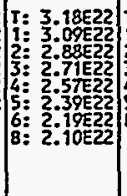 & 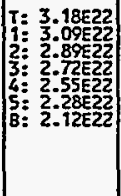 & 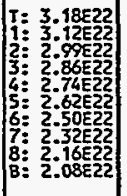 & \\
\hline \begin{tabular}{|c|}
$\mathrm{BC}-1$ \\
$370^{\circ} \mathrm{C}$ \\
\end{tabular} & $\begin{array}{c}\mathrm{BC}-2 \\
370^{\circ} \mathrm{C}\end{array}$ & \begin{tabular}{|c|}
$\mathrm{BC}-3$ \\
$370^{\circ} \mathrm{C}$
\end{tabular} & $\begin{array}{c}8 c-4 \\
370^{\circ} 6\end{array}$ & $\begin{array}{l}8 \mathrm{8c}-5 \\
370^{\circ} \mathrm{C}\end{array}$ & $\begin{array}{c}3^{8 c-6}-6 \\
370^{\circ} \mathrm{C}\end{array}$ & $\begin{array}{l}\mathrm{BC}-0 \\
370^{\circ} \mathrm{C}\end{array}$ \\
\hline 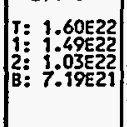 & 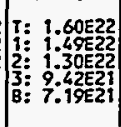 & 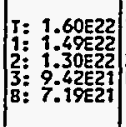 & 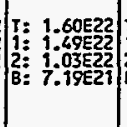 & 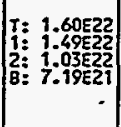 & $\begin{array}{l}T=1.60 E 22 \\
1=1.32 E^{2} \\
2=8.74 E 21 \\
8=7.19 E 21\end{array}$ & NO CAMIST. \\
\hline
\end{tabular}


Table 6. MOTA-1C Canister Matrix Showing Fast Fluence Information

\begin{tabular}{|c|c|c|c|c|c|c|}
\hline \multicolumn{3}{|c|}{ HOTA LEVELS 8 TO BC a 256.7 EFPD } & \multicolumn{3}{|c|}{ Units: $n / \mathrm{Cm}^{-2}$ [E>0.1 $\left.\mathrm{MaV}\right]$} & \\
\hline $\begin{array}{c}8-A \\
455 \circ c\end{array}$ & \begin{tabular}{|l|}
$8-8$ \\
$455^{\circ} \mathrm{c}$
\end{tabular} & $\begin{array}{ll}885 \\
455 \cdot c\end{array}$ & $455^{\circ} \mathrm{c}$ & \begin{tabular}{|c|}
$85-5$ \\
$455^{\circ} \mathrm{c}$
\end{tabular} & $\begin{array}{l}885 \\
455 \% c\end{array}$ & \\
\hline Ho Baskets & No Baskets & No Baskets & Ho Baskets & KO CARIST. & HO CANIST. & \\
\hline $\begin{array}{c}7 \cdot A \\
450^{\circ} \mathrm{C}\end{array}$ & \begin{tabular}{|l|}
$7-8$ \\
$450^{\circ} \mathrm{C}$
\end{tabular} & $47 \cdot c$ & $\begin{array}{l}7-0 \\
450^{\circ} \mathrm{c}\end{array}$ & $450^{\circ} \mathrm{C}$ & $\begin{array}{l}75 \cdot \mathrm{F} \\
450^{\circ} \mathrm{c}\end{array}$ & \\
\hline HO CAMIST. & HO CAMIST. & HO СAHIST. & HO CAMIST. & HO CAHIST. & HO CAMIST. & \\
\hline $470^{\circ} \mathrm{C}$ & $\begin{array}{l}6-8 \\
570^{\circ} \mathrm{C}\end{array}$ & $4 \pi^{6} c c$ & $464^{\circ} \mathrm{C}$ & $490^{\circ} \mathrm{E}$ & $\begin{array}{l}6-9 \\
487^{\circ} \mathrm{c}\end{array}$ & \\
\hline $\begin{array}{l}\text { T: } 5.95 \mathrm{SE} 2 \\
1: 6.81 \mathrm{E} 1 \\
2 \vdots 8.94 \mathrm{E} 1 \\
3: 1.09 \mathrm{E} 2 \\
\mathrm{~B}: 1.16 \mathrm{EZ2}\end{array}$ & 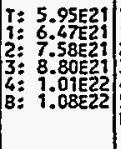 & 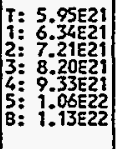 & 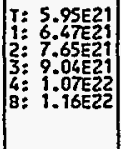 & 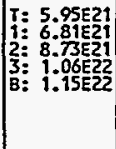 & 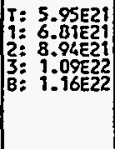 & \\
\hline $5355^{\circ} \mathrm{C}$ & \begin{tabular}{|c|}
$5-8$ \\
$550^{\circ} \mathrm{C}$
\end{tabular} & $\begin{array}{c}5-c \\
570^{\circ} \mathrm{c}\end{array}$ & $\begin{array}{c}5-0 \\
600^{\circ} \mathrm{C}\end{array}$ & $\begin{array}{c}5-E^{\circ} \\
599^{\circ} \mathrm{C}\end{array}$ & $\frac{5-5}{438^{\circ} \mathrm{C}}$ & \\
\hline $\begin{array}{l}\mathrm{T}: 2.60 \mathrm{gz2} 2 \\
: 2.92 \mathrm{z} 2 \\
2: 3.65 \mathrm{EL22} \\
3: 4.32 \mathrm{EL2} \\
\mathrm{B}: 4.56 \mathrm{E22}\end{array}$ & 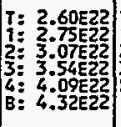 & 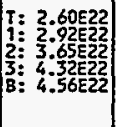 & 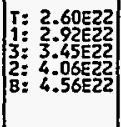 & 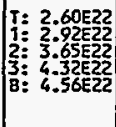 & 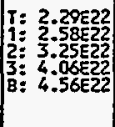 & \\
\hline $670^{\circ} \mathrm{A}$ & \begin{tabular}{l|}
$4 \cdot 8$ \\
$730^{\circ} \mathrm{c}$
\end{tabular} & $\begin{array}{c}4-\tau \\
540^{\circ} c\end{array}$ & $\begin{array}{c}4-D \\
550^{\circ} \mathrm{c}\end{array}$ & $\begin{array}{c}44 E^{2} \\
575^{\circ} \mathrm{c}\end{array}$ & $\begin{array}{c}4-5 \\
65^{\circ} \mathrm{c}\end{array}$ & \\
\hline 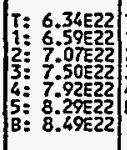 & 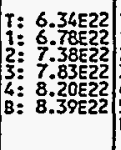 & 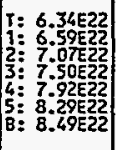 & 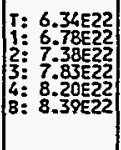 & 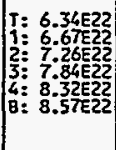 & 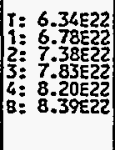 & \\
\hline $\begin{array}{c}3-A \\
550^{\circ} \mathrm{c}\end{array}$ & $\begin{array}{c}3-B \\
550^{\circ} \mathrm{C}\end{array}$ & \begin{tabular}{c|}
$3-c$ \\
$605^{\circ} c$
\end{tabular} & \begin{tabular}{|c|}
$3-D$ \\
$670^{\circ} \mathrm{c}$ \\
\end{tabular} & $\begin{array}{c}3-E \\
635^{\circ} \mathrm{c}\end{array}$ & $\frac{3-F}{750^{\circ} \mathrm{C}}$ & \\
\hline 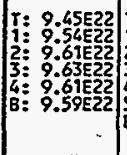 & 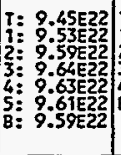 & 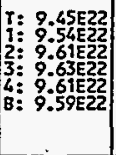 & 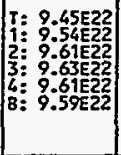 & 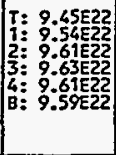 & $\begin{array}{l}\text { I: } 9.45 \mathrm{E} 22 \\
1: 9.54 \mathrm{EZ2} \\
2: 9.61 \mathrm{EL2} \\
3: 9.63 \mathrm{E} 22 \\
6: 9.61 \mathrm{E} 22 \\
\mathrm{~B}: 9.59 \mathrm{EZ2}\end{array}$ & \\
\hline $55^{2-A} 0^{-A} C$ & \begin{tabular}{c|}
$22-B$ \\
$600^{\circ} c$ \\
\end{tabular} & $\begin{array}{c}2-c \\
425 \circ c\end{array}$ & \begin{tabular}{|c|}
$2-0$ \\
$439^{\circ} \mathrm{C}$
\end{tabular} & $605^{2-\varepsilon} c$ & $\frac{2-F}{420^{\circ} \mathrm{C}}$ & \\
\hline 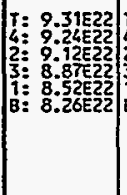 & 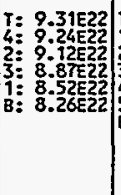 & 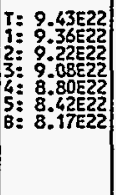 & 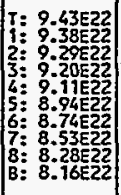 & 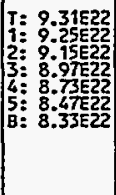 & 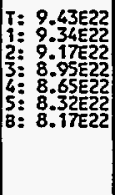 & \\
\hline $490^{\circ-1} \mathrm{C}$ & $550=>525 \cdot c$ & $270^{\circ} \mathrm{c}$ & \begin{tabular}{|l|}
$9-0$ \\
$495^{\circ} \mathrm{c}$
\end{tabular} & 585.5 & $396^{19-\mathrm{C}}$ & \\
\hline 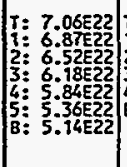 & 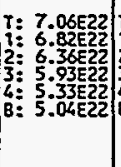 & 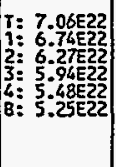 & 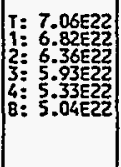 & 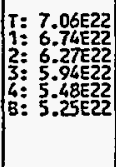 & 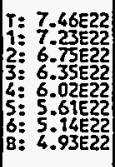 & \\
\hline $\begin{array}{l}\mathrm{BC}-\mathrm{A} \\
370^{\circ} \mathrm{C}\end{array}$ & $\begin{array}{l}8 c-8 \\
370^{\circ} \mathrm{C}\end{array}$ & $\begin{array}{l}8 c-c \\
370^{\circ} c\end{array}$ & $\begin{array}{l}B \mathrm{BC}=0 \\
370^{\circ} \mathrm{C}\end{array}$ & $\begin{array}{l}3 \mathrm{BC}-\mathrm{E} \\
370 \% \mathrm{C}\end{array}$ & $\begin{array}{l}\mathrm{BC}-\mathrm{F} \\
370^{\circ} \mathrm{C}\end{array}$ & $\begin{array}{l}8 \mathrm{Bc}-0 \\
370^{\circ} \mathrm{c}\end{array}$ \\
\hline 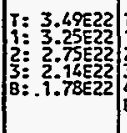 & $\begin{array}{l}T=3.73 E 22 \\
1: 3.4622 \\
2: 2.96622 \\
3: 2.44 E 22 \\
4: 1.99922 \\
B: 1.78 E 22\end{array}$ & \begin{tabular}{|l|l}
$7:$ & $3.71 E 22$ \\
$1: 3.12 E 22$ \\
$2: 2.31 \in 22$ \\
$3: 1.93 E 22$ \\
$8: 1.78 E 22$
\end{tabular} & 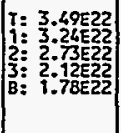 & 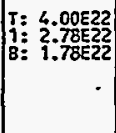 & 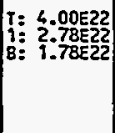 & 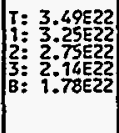 \\
\hline
\end{tabular}


Table 7. MOTA-1D Canister Matrix Showing Fast Fluence Information

MOTA LEVELS 8 TO BC a 185.8 EFPD Units: $N / \mathrm{CDO}^{-2} 2$ [E>0.1 HeV]

\begin{tabular}{|c|c|c|c|c|c|}
\hline $\begin{array}{l}8^{8-A} \mathrm{~A} \\
480^{\circ} \mathrm{c} \\
\text { KO CAHIST. }\end{array}$ & $\begin{array}{c}8 \cdot 8 \\
460^{\circ} \mathrm{C} \\
\text { NO CANIST. }\end{array}$ & $\begin{array}{c}8-\mathrm{C} \\
460^{\circ} \mathrm{C} \\
\text { MO CANIST. }\end{array}$ & $\mid \begin{array}{c}8-0 \\
462 \cdot c \\
T=3.50 E 20 \\
1: 55520 \\
8: 8.73 E 20\end{array}$ & $\left\{\begin{array}{c}8-E \\
462 \cdot c \\
T=3.50 E 20 \\
15.55520 \\
B=8.73 E 20\end{array}\right.$ & 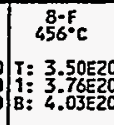 \\
\hline $\begin{array}{c}7 \bar{A}^{\mathrm{A}} \\
455^{\circ} \mathrm{C} \\
\text { NO CANIST. }\end{array}$ & $\begin{array}{c}75^{B} \\
455^{\circ} \mathrm{C} \\
\text { Ho CANIST. }\end{array}$ & $\begin{array}{c}7-c \\
455^{\circ} \mathrm{C} \\
\text { no CAAIST. }\end{array}$ & $\begin{array}{c}75^{\circ 0} \\
45^{\circ} \mathrm{C} \\
\text { No CANIST. }\end{array}$ & $\begin{array}{c}7-E \\
455^{\circ} \mathrm{C} \\
\text { HO CAMIST. }\end{array}$ & $\begin{array}{c}7-5 \\
455^{\circ} \mathrm{C} \\
\text { No CAHIST. }\end{array}$ \\
\hline $\begin{array}{c}60^{6-A} \mathrm{~A} \\
45^{\circ} \mathrm{C} \\
\text { Ho CANIST. }\end{array}$ & $\begin{array}{c}6-\mathrm{B} \\
445^{\circ} \mathrm{C} \\
\text { HO CAMIST. }\end{array}$ & $\begin{array}{c}65^{6-c} \mathrm{C} \\
\text { NO CARIST. }\end{array}$ & $\begin{array}{c}66^{\circ-0} \\
44^{\circ} \mathrm{C} \\
\text { No Boskets }\end{array}$ & 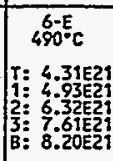 & 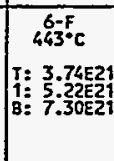 \\
\hline 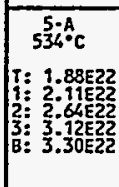 & 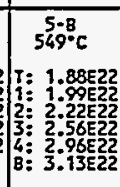 & 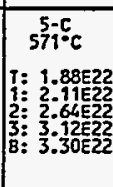 & 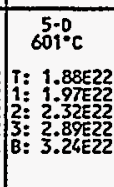 & 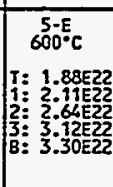 & 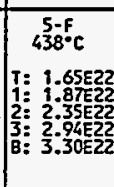 \\
\hline 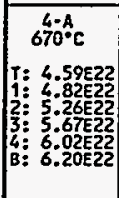 & 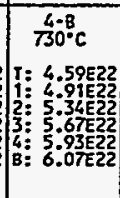 & 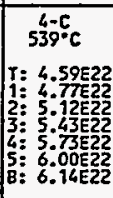 & 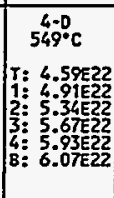 & 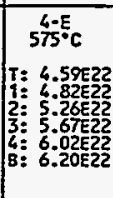 & 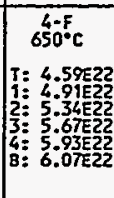 \\
\hline 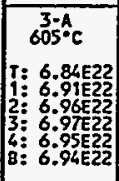 & 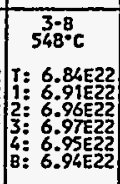 & 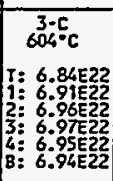 & 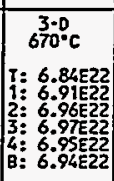 & 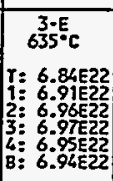 & 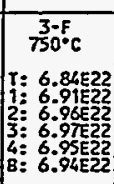 \\
\hline 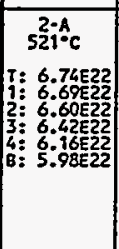 & 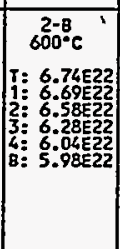 & 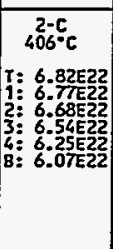 & 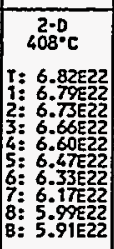 & 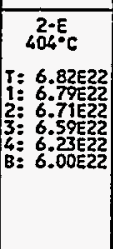 & 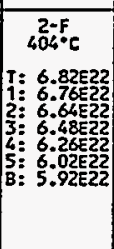 \\
\hline 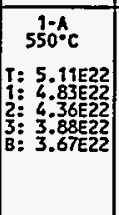 & 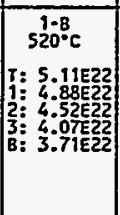 & 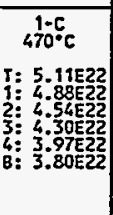 & 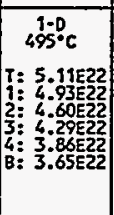 & 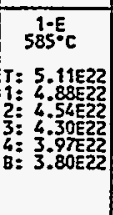 & 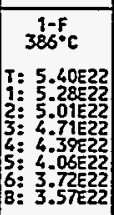 \\
\hline $\begin{array}{c}\mathrm{BC}-\hat{-A} \\
370^{\circ} \mathrm{C}\end{array}$ & $\begin{array}{r}8 C-8 \\
370^{\circ}=\end{array}$ & $\begin{array}{c}8 c-c \\
370^{\circ} \mathrm{C}\end{array}$ & \begin{tabular}{|c|}
$\mathrm{BC}-\mathrm{D}$ \\
$370^{\circ} \mathrm{C}$
\end{tabular} & \begin{tabular}{|c|}
$\mathrm{BC}-\mathrm{E}$ \\
$370^{\circ} \mathrm{C}$
\end{tabular} & $\begin{array}{c}\text { BC-F } \\
370^{\circ} \mathrm{C}\end{array}$ \\
\hline 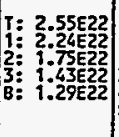 & 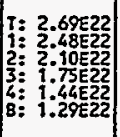 & 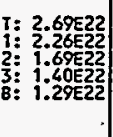 & 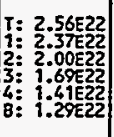 & 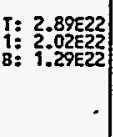 & 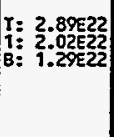 \\
\hline
\end{tabular}

Values Based on Results from MOTAs IA, IB and IC. 
Table 8. MOTA-IE Canister Matrix Showing Fast Fluence Information HOTA LEVELS 8 to $8 C$ a 341.8 EFPO Units: N/CE"2 [E>O.1 MeV]

\begin{tabular}{|c|c|c|c|c|c|}
\hline $\begin{array}{c}80^{-A} \\
40^{\circ} \mathrm{C} \\
\text { TO CAMIST. }\end{array}$ & $\begin{array}{c}8-8 \\
440^{\circ} \mathrm{C} \\
\text { NO CANIST. }\end{array}$ & $\begin{array}{c}8-\mathrm{C} \\
440^{\circ} \mathrm{C} \\
\text { NO CANIST. }\end{array}$ & $\begin{array}{c}8-0 \\
440^{\circ} \mathrm{C} \\
\text { No Boskets }\end{array}$ & 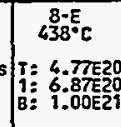 & 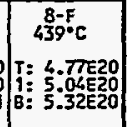 \\
\hline $\begin{array}{c}75^{\circ} \mathrm{C} \\
\text { \%о санIST. }\end{array}$ & $\begin{array}{c}75^{78} \\
435^{\circ} \mathrm{C} \\
\text { HO CAHIST. }\end{array}$ & $\begin{array}{c}435 \cdot \mathrm{C} \\
\text { No CANIST. }\end{array}$ & $\begin{array}{c}4-0 \mathrm{c} \\
435^{\circ} \mathrm{C} \\
\text { No CAHIST. }\end{array}$ & $\begin{array}{c}7 \cdot E \mathrm{E} \\
435^{\circ} \mathrm{C} \\
\text { NO CANIST. }\end{array}$ & $\begin{array}{c}7-F^{\circ} \\
435^{\circ} \mathrm{C} \\
\text { Yo CANIST. }\end{array}$ \\
\hline 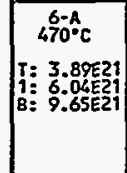 & 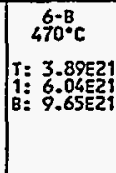 & $\begin{array}{c}6 . \mathrm{C} \\
470^{\circ} \mathrm{c} \\
\mathrm{T}=3.89 \mathrm{E} 21 \\
1=6.04 \mathrm{EL2} \\
\mathrm{B}: 9.65 \mathrm{EL} 21\end{array}$ & $\begin{array}{c}6-0 \\
460^{\circ} \mathrm{C} \\
\mathrm{T}: 3.89 \mathrm{E} 21 \\
1: 6.04 \mathrm{E} 21 \\
\mathrm{~B}: 9.65 \mathrm{E} 21 \\
\end{array}$ & 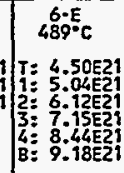 & $\begin{array}{c}6 . \mathrm{F} \\
460^{\circ} \mathrm{C} \\
\mathrm{T}: 3.89 \mathrm{E21} \\
1: 6.04 \mathrm{E21} \\
\mathrm{B}: 9.65 \mathrm{E21} \\
\end{array}$ \\
\hline 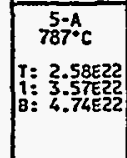 & 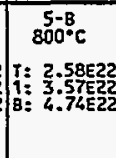 & $\begin{array}{c}5-\mathrm{C} \\
800^{\circ} \mathrm{C} \\
\mathrm{T}: 2.58 \mathrm{E} 22 \\
1: 3.57 \mathrm{EZ2} \\
\mathrm{B}: 4.74 \mathrm{EZ2}\end{array}$ & 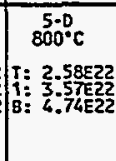 & 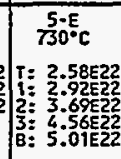 & 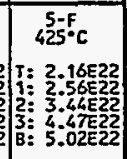 \\
\hline 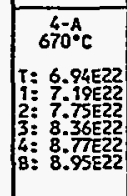 & $\begin{array}{c}4.8 \\
800^{\circ} \mathrm{C} \\
\mathrm{T}=6.94 \mathrm{EZ2} \\
1: 8.07 \mathrm{EL2} \\
\mathrm{B}: 8.89 \mathrm{EZ2} \\
\end{array}$ & 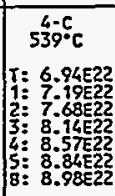 & 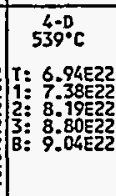 & 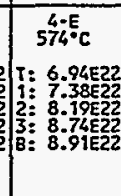 & 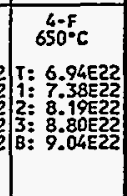 \\
\hline 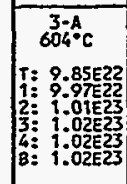 & 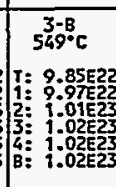 & 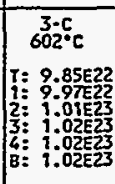 & 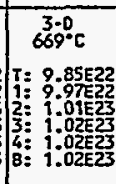 & 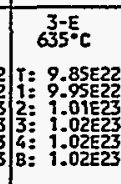 & 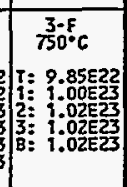 \\
\hline 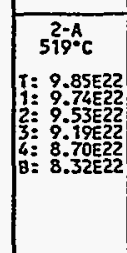 & 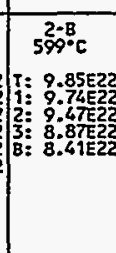 & 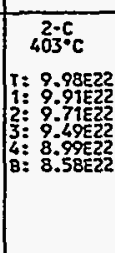 & 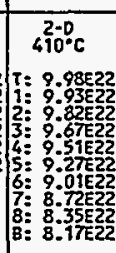 & 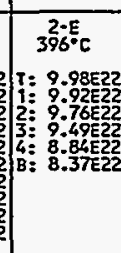 & 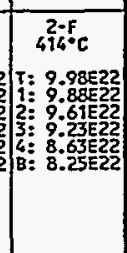 \\
\hline 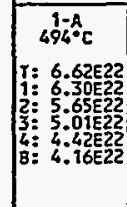 & 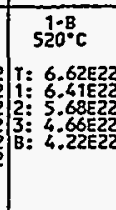 & 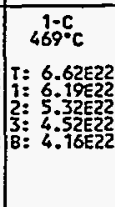 & 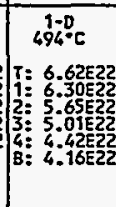 & 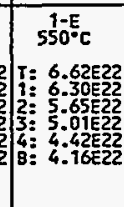 & 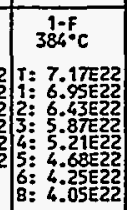 \\
\hline 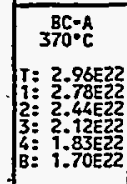 & 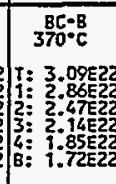 & 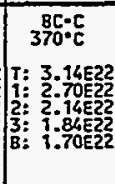 & 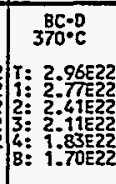 & 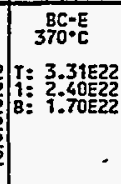 & 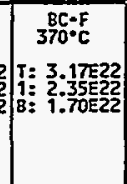 \\
\hline
\end{tabular}


Table 9. MOTA-1F Canister Matrix Showing Fast Fluence Information

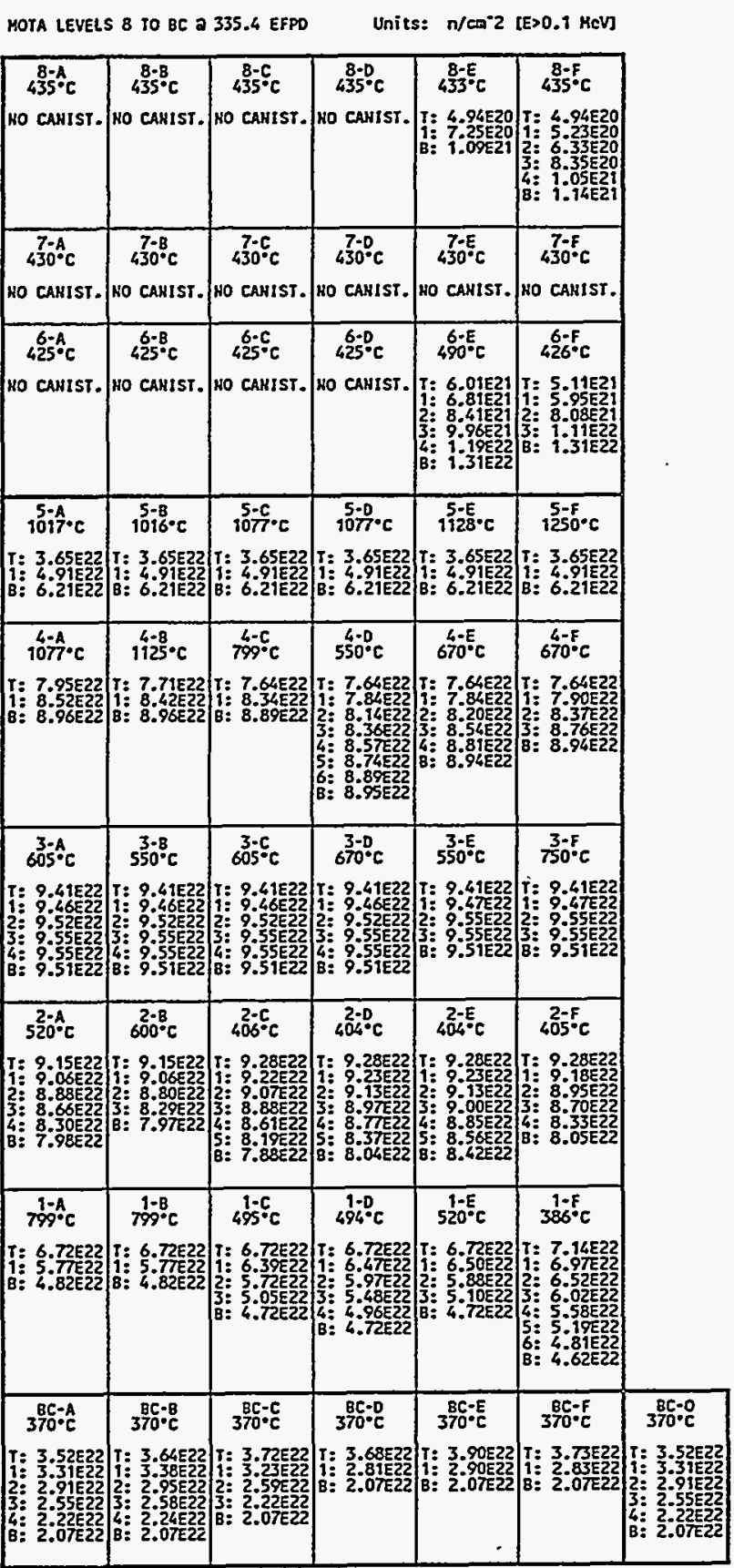


Table 10. MOTA-1G Canister Matrix Showing Fast Fluence Information MOTA LEVELS 8 TO BC a 299.7 EFPO Units: $n / \mathrm{cm}^{-2}$ [E>0.1 MeV]

\begin{tabular}{|c|c|c|c|c|c|c|}
\hline $\begin{array}{l}880^{A A} \mathrm{C} \\
\text { HO CAMIST. }\end{array}$ & $\mid \begin{array}{c}848 \\
40^{\circ} \mathrm{C} \\
\text { мо CANIST }\end{array}$ & $\begin{array}{c}8-c \\
44^{\circ} \mathrm{C} \\
\text { No CaMIST. }\end{array}$ & $\begin{array}{c}880 \\
44^{\circ} \mathrm{C} \\
\text { Ho CANIST. }\end{array}$ & 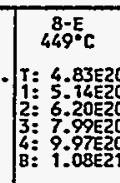 & 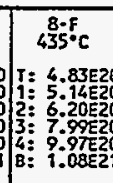 & \\
\hline $\begin{array}{l}475^{\circ}{ }^{\circ} \mathrm{C} \\
\text { MO CANIST. }\end{array}$ & $\begin{array}{c}475^{\circ} \mathrm{C} \\
\text { No caNIST. }\end{array}$ & $\begin{array}{c}7 \bar{c}^{\circ} \mathrm{C} \\
\text { Mo CANIST. }\end{array}$ & $\begin{array}{c}475^{\circ} \mathrm{C} \\
\text { Mo CAMIST. }\end{array}$ & $\begin{array}{c}475^{\circ} \mathrm{C} \\
\text { Ho CAMIST. }\end{array}$ & $\begin{array}{c}7-5 \\
45^{\circ} \mathrm{C} \\
\text { No CANIST. }\end{array}$ & \\
\hline $\begin{array}{l}630^{6 A} \mathrm{C} \\
\text { NO CAMIST. }\end{array}$ & 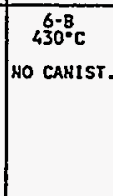 & 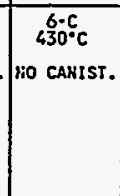 & No canisr. & 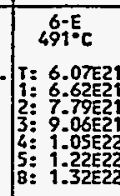 & 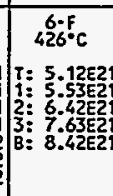 & \\
\hline 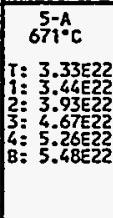 & 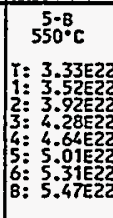 & 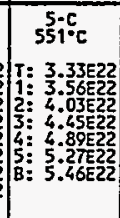 & 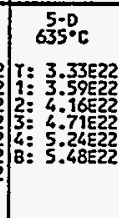 & 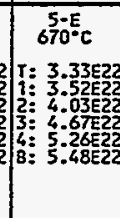 & 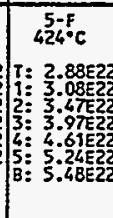 & \\
\hline 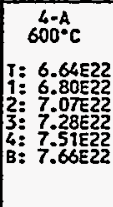 & 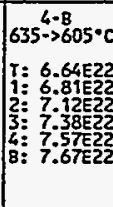 & 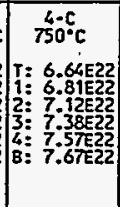 & 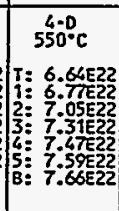 & 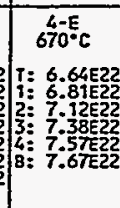 & 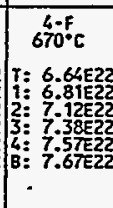 & \\
\hline 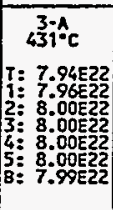 & 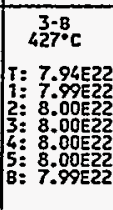 & 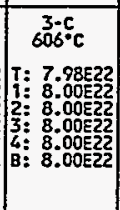 & 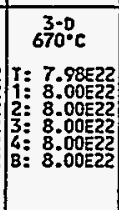 & 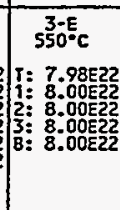 & 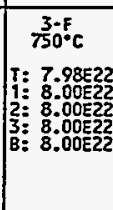 & \\
\hline 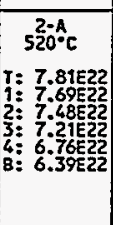 & 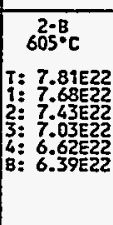 & 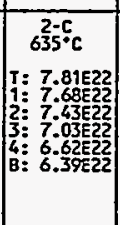 & 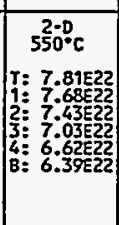 & 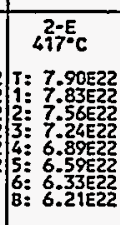 & 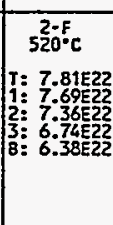 & \\
\hline 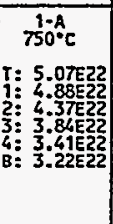 & 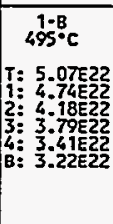 & 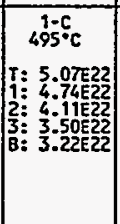 & 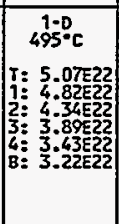 & 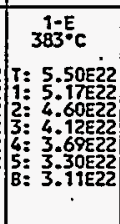 & 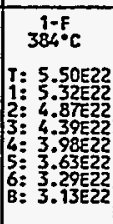 & \\
\hline 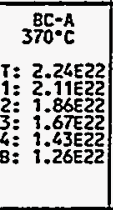 & 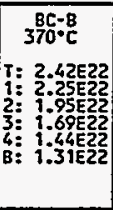 & 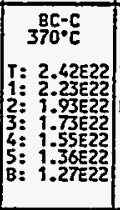 & 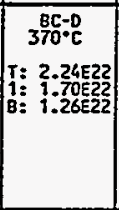 & 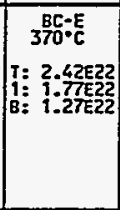 & 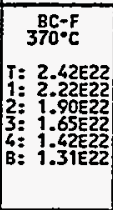 & 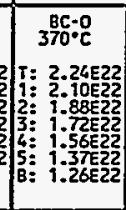 \\
\hline
\end{tabular}


Table 11. MOTA-2A Canister Matrix Showing Fast Fluence Information MOTA LEVELS 8 TO 8C a 299.7 EFPO Units: n/CA"2 IE>0.1 MEV

\begin{tabular}{|c|c|c|c|c|c|c|}
\hline 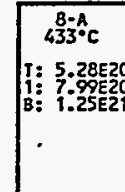 & 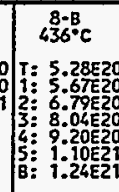 & $\begin{array}{c}8-c \\
440^{\circ C} \\
\text { HO CARIST. }\end{array}$ & $\begin{array}{c}800 \\
440^{\circ} \mathrm{C} \\
\text { HO CANIST. }\end{array}$ & $\begin{array}{c}8-E \\
440^{\circ} \mathrm{C} \\
\text { HO CAMIST }\end{array}$ & $\begin{array}{c}8-F \\
440^{\circ} \mathrm{C} \\
\text { NO CANIST. }\end{array}$ & \\
\hline 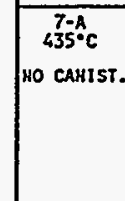 & 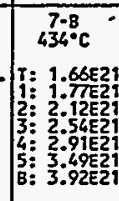 & $\begin{array}{c}7-c \mathrm{c} \\
435^{\circ} \mathrm{C} \\
\text { Ho CANIST. }\end{array}$ & $\begin{array}{c}7-D \\
435^{\circ} \mathrm{C} \\
\text { HO CANIST. }\end{array}$ & $\begin{array}{c}7-E \\
435^{\circ} \mathrm{C} \\
\text { No canIst }\end{array}$ & $\begin{array}{c}7-\mathrm{F} \\
435^{\circ} \mathrm{C} \\
\text { No CANIST. }\end{array}$ & \\
\hline 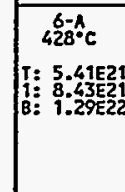 & 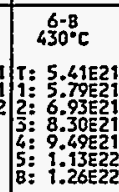 & $\begin{array}{c}6-\mathrm{C} \\
430^{\circ} \mathrm{C} \\
\mathrm{T}: 5.41 \mathrm{E21} \\
1: 8.43521 \\
\mathrm{~B}: 1.29 \mathrm{z22} \\
\\
\end{array}$ & $\begin{array}{c}430^{\circ} \mathrm{c} \\
\text { HO carist }\end{array}$ & $\begin{array}{c}6.3^{\circ} \mathrm{C} \\
\text { No CANIST. }\end{array}$ & $\begin{array}{c}63^{6 \%} \mathrm{C} \\
\text { MO CANIST. }\end{array}$ & \\
\hline 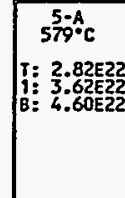 & $\begin{array}{c}5 \cdot 8 \\
42{ }^{\circ} \mathrm{C} \\
T: 2.48 \mathrm{E} 22 \\
13.57 \mathrm{Ez22} \\
8: 5.00 \mathrm{E} 22\end{array}$ & 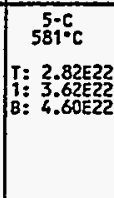 & 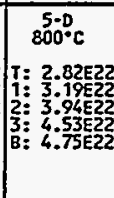 & 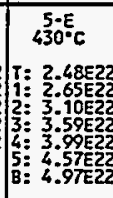 & 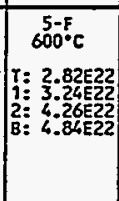 & \\
\hline 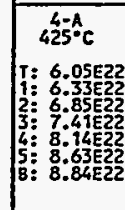 & 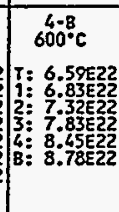 & 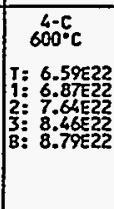 & 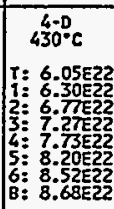 & 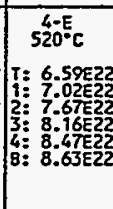 & 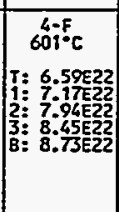 & \\
\hline 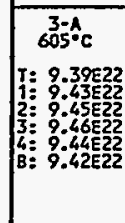 & 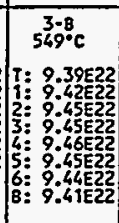 & 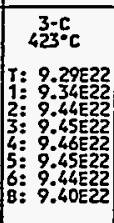 & 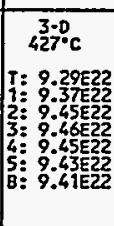 & 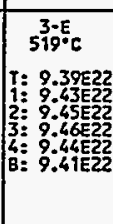 & 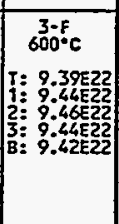 & \\
\hline 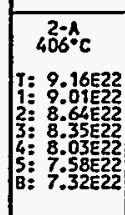 & 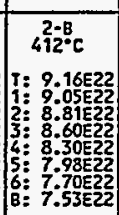 & 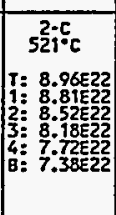 & 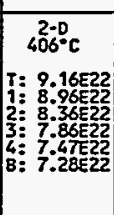 & 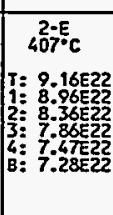 & 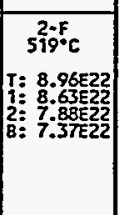 & \\
\hline 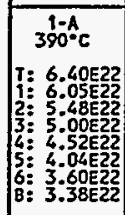 & 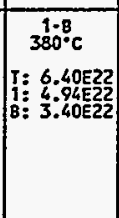 & $\begin{array}{c}1+c \\
385 \rightarrow 1000 C \\
T=6.15 E 22 \\
1: 4.81 E 22 \\
B=3.44 E 22\end{array}$ & 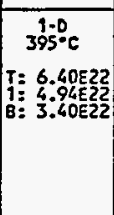 & 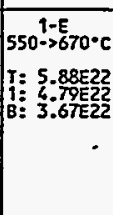 & 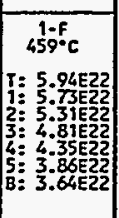 & \\
\hline 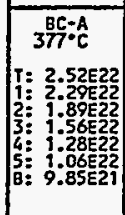 & 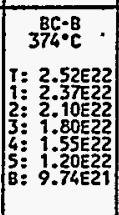 & 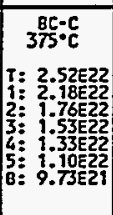 & 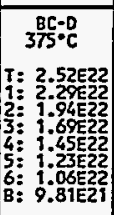 & 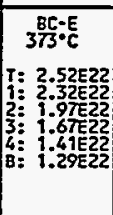 & 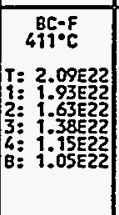 & $\begin{array}{c}\mathrm{BC}-0 \\
370^{\circ} \mathrm{C} \\
\text { No CAMtst. }\end{array}$ \\
\hline
\end{tabular}


Table 12. MOTA-2B Canister Matrix Showing Fast Fluence Information MOTA LEVELS 8 TO BC a 203.3 EFPO Units: $\mathrm{n} / \mathrm{CH}-2$ [E>0.1 HeV]

\begin{tabular}{|c|c|c|c|c|c|}
\hline $\begin{array}{c}8-4 . \\
40^{\circ} \cdot \mathrm{C} \\
\text { NO CARIST. }\end{array}$ & 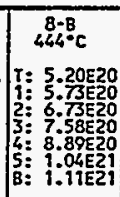 & 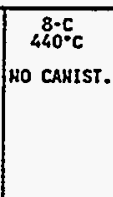 & $\begin{array}{c}8-0 \mathrm{D} \\
400^{\circ} \mathrm{C} \\
\text { No cantst. }\end{array}$ & 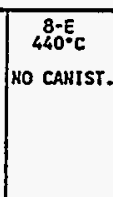 & wo casist \\
\hline HO canst. & 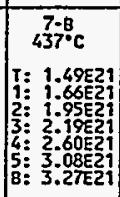 & 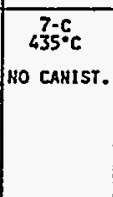 & 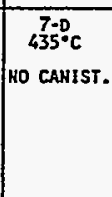 & 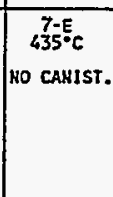 & $\begin{array}{c}7-F^{\circ} \\
435^{\circ} \mathrm{C} \\
\text { HO CANIST. }\end{array}$ \\
\hline 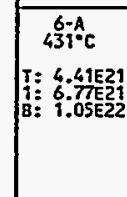 & 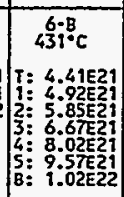 & 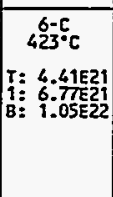 & 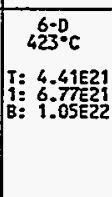 & 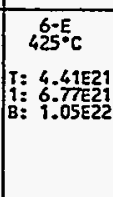 & 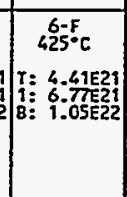 \\
\hline 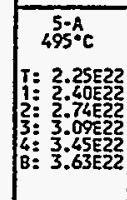 & 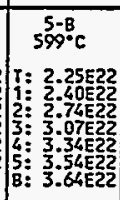 & 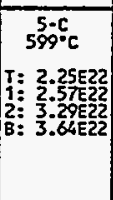 & 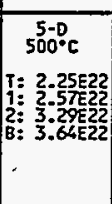 & 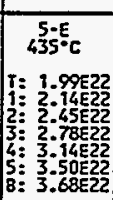 & 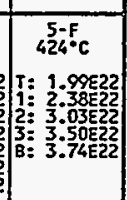 \\
\hline 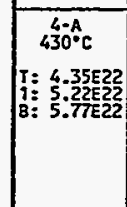 & 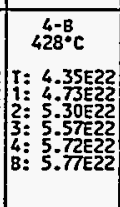 & 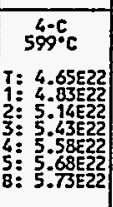 & 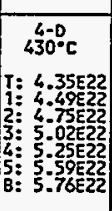 & 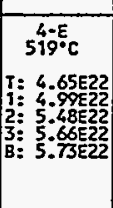 & 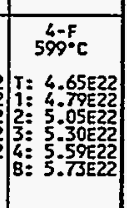 \\
\hline 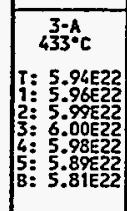 & 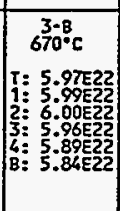 & 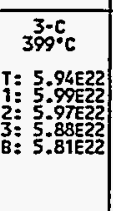 & 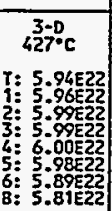 & 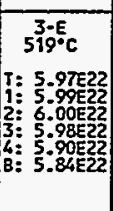 & 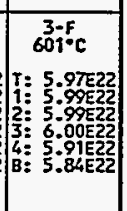 \\
\hline 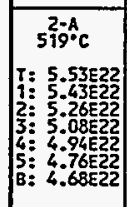 & 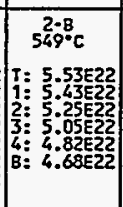 & 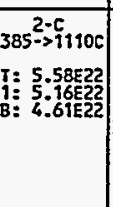 & 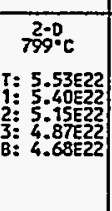 & 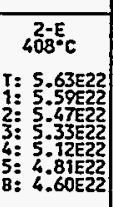 & 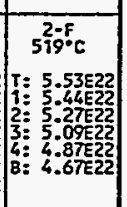 \\
\hline 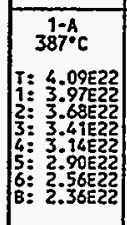 & 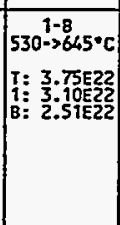 & 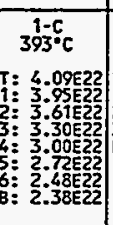 & 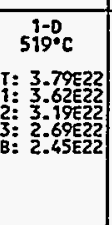 & 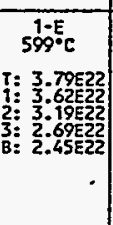 & 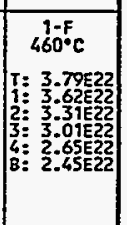 \\
\hline 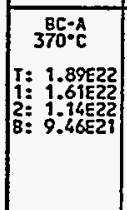 & 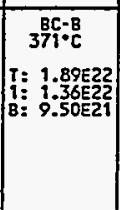 & 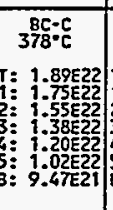 & 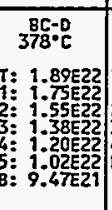 & 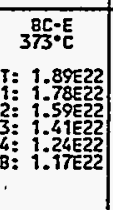 & 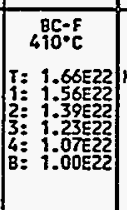 \\
\hline
\end{tabular}


Table 13. MOTA-1A Canister Matrix Showing displacements per atom Information

\begin{tabular}{|c|c|c|c|c|c|c|}
\hline \multicolumn{4}{|c|}{ KOTA LEVELS 8 TO BC a 202 EFPO } & \multicolumn{2}{|c|}{ Units: dpa } & \\
\hline $465^{8 * A} \mathrm{~A}$ & $\begin{array}{l}88-8 \\
458^{\circ} \mathrm{c}\end{array}$ & 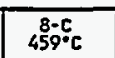 & $\frac{8-0}{460^{\circ} \mathrm{C}}$ & ${ }_{460^{\circ} \mathrm{C}} \mathrm{C}$ & $\begin{array}{c}8-F \\
460^{\circ} \cdot \mathrm{C}\end{array}$ & \\
\hline $\begin{array}{ll}r: & 0.13 \\
1 & 0.15 \\
2: & 0.20 \\
3: & 0.27 \\
8: & 0.32\end{array}$ & $\begin{array}{ll}\text { T: } & 0.13 \\
1: & 0.15 \\
2: & 0.20 \\
3: & 0.27 \\
\text { B: } & 0.32\end{array}$ & $\begin{array}{ll}\text { T: } & 0.13 \\
1: & 0.15 \\
2: & 0.20 \\
3: & 0.27 \\
8: & 0.32\end{array}$ & $\begin{array}{ll}\tau: & 0.13 \\
: & 0.15 \\
2: & 0.20 \\
3: & 0.27 \\
B: & 0.32\end{array}$ & NO CAMIST. & HO CAMIST. & \\
\hline 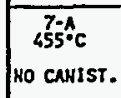 & $\begin{array}{c}75^{\circ} \mathrm{C} \\
\text { HO CANIST. }\end{array}$ & $\begin{array}{c}7-\mathrm{C} \\
455^{\circ} \mathrm{C} \\
\text { NO САMIST. }\end{array}$ & $\begin{array}{c}75^{\circ} \\
45^{\circ} \mathrm{C} \\
\text { HO CANIST. }\end{array}$ & $\begin{array}{c}7-E \\
455 \% \mathrm{C} \\
\text { NO CANIST. }\end{array}$ & $\begin{array}{c}7-\mathrm{F} \\
455^{\circ} \mathrm{C} \\
\text { KO CANIST. }\end{array}$ & \\
\hline $506^{6} \cdot \mathrm{A}$ & $\begin{array}{l}6-8 \\
440^{\circ} \mathrm{c}\end{array}$ & 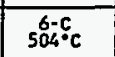 & $\begin{array}{l}6=0 \\
503^{\circ} \mathrm{C}\end{array}$ & ${ }_{481 \cdot C}^{6-E_{5}}$ & $\frac{6-F}{483^{\circ} \cdot c}$ & \\
\hline $\begin{array}{ll}\text { I: } & 1.66 \\
1 \vdots & 2.25 \\
1: & 3.01\end{array}$ & $\begin{array}{ll}T: & 1.44 \\
1: & 1.61 \\
2: & 2.02 \\
3: & 2.63 \\
8: & 2.60\end{array}$ & $\begin{array}{ll}1: & 1.65 \\
1: & 2.25 \\
8: & 3.01\end{array}$ & 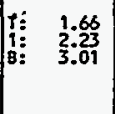 & $\begin{array}{ll}T: & 1.66 \\
\vdots & 1.91 \\
2: & 2.47 \\
3: & 2.96 \\
8: & 3.16\end{array}$ & $\begin{array}{ll}\text { T: } & 1.68 \\
1: & 1.86 \\
2: & 2.41 \\
3: & 2.96 \\
\text { B: } & 3.16\end{array}$ & . \\
\hline $534^{5-A} \mathrm{C}$ & $\begin{array}{l}55-8 \\
597^{\circ} \mathrm{C}\end{array}$ & $\begin{array}{c}5 . c \\
567 . \mathrm{C}\end{array}$ & $\begin{array}{l}550 \\
597 \cdot c\end{array}$ & $\begin{array}{c}5 . E \\
596^{\circ} \mathrm{C}\end{array}$ & $\begin{array}{l}5-F \\
445^{\circ} c\end{array}$ & \\
\hline $\begin{array}{ll}\text { T: } & 8.02 \\
: & 9.08 \\
2: & 91.6 \\
3: & 14.0 \\
\text { B: } & 14.9\end{array}$ & $\begin{array}{ll}T: & 8.02 \\
1: & 9.08 \\
2: & 7 j .6 \\
3: & 74.00 \\
8: & 14.9\end{array}$ & $\begin{array}{ll}\text { T: } & 8.02 \\
1: & 9.08 \\
2: & 11.6 \\
3: & 14.0 \\
8: & 14.9\end{array}$ & $\begin{array}{ll}\text { I: } & 8.02 \\
1: & 9.03 \\
2: & 19.6 \\
3: & 14.0 \\
B: & 14.9\end{array}$ & $\begin{array}{ll}\text { T: } & 8.02 \\
\vdots & 9.08 \\
2: & 19.6 \\
3: & 14.0 \\
\text { B: } & 14.9\end{array}$ & $\begin{array}{ll}r: & 6.94 \\
1: & 7.96 \\
2: & 10.2 \\
3: & 13.1 \\
8: & 16.8\end{array}$ & \\
\hline $\cos ^{4-A} \mathrm{~s}$ & \begin{tabular}{|c|}
4488 \\
$547^{\circ} c$
\end{tabular} & $\begin{array}{c}44-c \\
549^{\circ} \mathrm{c}\end{array}$ & $\begin{array}{c}4-D \\
583^{\circ} \mathrm{C}\end{array}$ & $\begin{array}{l}4-E \\
646^{\circ} \mathrm{C}\end{array}$ & $722^{4 \cdot C} \cdot \mathrm{C}$ & \\
\hline \begin{tabular}{ll|} 
r: & 21.3 \\
$1:$ & 22.2 \\
$2:$ & 23.9 \\
$3:$ & 25.7 \\
$4:$ & 27.4 \\
$5:$ & 28.6 \\
$B:$ & 29.3
\end{tabular} & 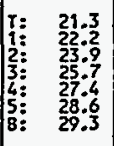 & $\begin{array}{ll}r: & 21.3 \\
1: & 22.8 \\
2: & 25.2 \\
3: & 27.0 \\
4: & 28.3 \\
8: & 28.9\end{array}$ & $\begin{array}{ll}1: & 21.3 \\
1: & 22.8 \\
2: & 25.2 \\
3: & 27.0 \\
4: & 28.3 \\
\text { B: } & 28.9\end{array}$ & $\begin{array}{ll}\text { T: } & 21.3 \\
1: & 22.8 \\
2: & 25.2 \\
3: & 27.0 \\
4: & 28.3 \\
8: & 28.9\end{array}$ & $\begin{array}{ll}T: & 21.3 \\
\vdots & 22.8 \\
2 & 25.2 \\
3: & 27.0 \\
4: & 28.3 \\
\text { B: } & 28.9\end{array}$ & \\
\hline$\frac{3-A}{730^{\circ} \mathrm{C}}$ & $\begin{array}{c}3.8 \\
547^{\circ} \mathrm{C}\end{array}$ & $572 \cdot c$ & $\begin{array}{c}3-0 \\
601 \% \mathrm{C}\end{array}$ & $\begin{array}{c}3 \cdot \mathrm{E}^{\circ} \\
685^{\circ} \mathrm{C}\end{array}$ & $345 \% c$ & \\
\hline $\begin{array}{ll}1: & 32.7 \\
1 & 3350 \\
2: & 35.2 \\
3: & 33.3 \\
6: & 35.2 \\
B: & 33.1\end{array}$ & $\begin{array}{ll}1: & 32.7 \\
1: & 33.0 \\
2: & 33.2 \\
3: & 33.3 \\
4: & 33.2 \\
8: & 33.1\end{array}$ & $\begin{array}{ll}T: & 32.7 \\
1: & 33.0 \\
2: & 33.2 \\
3: & 33.3 \\
4: & 33.2 \\
B: & 33.1\end{array}$ & $\begin{array}{ll}1: & 32.7 \\
1 & 33.0 \\
2: & 33.2 \\
3: & 33.3 \\
4: & 33.2 \\
8: & 33.1\end{array}$ & $\begin{array}{ll}T: & 32.7 \\
1: & 33.0 \\
2: & 33.2 \\
3: & 33.3 \\
4: & 33.2 \\
8: & 33.1\end{array}$ & $\begin{array}{ll}T: & 32.7 \\
1: & 335.0 \\
2:= & 333.1 \\
3:= & 33.3 \\
4: & 35.3 \\
5: & 33.2 \\
8: & 33.1\end{array}$ & \\
\hline $\begin{array}{c}2 \cdot A \\
603^{\circ} C\end{array}$ & $\frac{2 \cdot-8}{5 R^{\circ} c}$ & $\begin{array}{c}2-c c \\
494^{\circ} c\end{array}$ & $\begin{array}{l}2-D \\
569 \cdot c\end{array}$ & $57 s^{2-E^{-5}}$ & $427 \cdot 5$ & \\
\hline $\begin{array}{ll}1: & 32.1 \\
1: & 31: 9 \\
2: & 31.6 \\
3: & 30.9 \\
4: & 29.9 \\
5: & 28.9 \\
8: & 28.3\end{array}$ & $\begin{array}{ll}1: & 32.1 \\
1 & 31.9 \\
2: & 31.6 \\
3: & 30.9 \\
4 \vdots & 29.9 \\
5: & 28.9 \\
8: & 28.3\end{array}$ & $\mid \begin{array}{ll}1: & 32.1 \\
1: & 31.9 \\
2: & 31.5 \\
3: & 30.2 \\
4: & 28.0 \\
8: & 28.3\end{array}$ & $\begin{array}{ll}1: & 32.1 \\
1: & 31.8 \\
2: & 31.2 \\
3: & 30.1 \\
4: & 29.1 \\
8: & 28.6\end{array}$ & $\begin{array}{ll}\mathrm{T}: & 32.1 \\
1: & 31.9 \\
2: & 31.5 \\
3: & 30.2 \\
4: & 29.0 \\
8: & 28.3\end{array}$ & $\begin{array}{ll}r: & 32.6 \\
1: & 32.3 \\
2: & 31.8 \\
3: & 31.4 \\
4: & 30.1 \\
B: & 29.5\end{array}$ & \\
\hline $489^{\circ} \mathrm{A}$ & $\frac{198 \mathrm{~B}}{537^{\circ} \mathrm{C}}$ & $\frac{1-c}{469 \cdot c}$ & $\begin{array}{l}1-0 \\
405^{\circ} \mathrm{c}\end{array}$ & $\begin{array}{c}4-E \\
403^{\circ} \mathrm{c}\end{array}$ & 49 & \\
\hline $\begin{array}{ll}7: & 23.5 \\
1: & 22.7 \\
2: & 21.2 \\
3: & 19.6 \\
4: & 18.2 \\
5: & 16.6 \\
8: & 15.9\end{array}$ & $\begin{array}{ll}7: & 23.5 \\
1: & 22.7 \\
2: & 21.2 \\
3: & 19.6 \\
4: & 18.2 \\
5: & 16.6 \\
8: & 15.9\end{array}$ & $\begin{array}{ll}T: & 23.5 \\
\vdots & 22.5 \\
\vdots & 20.0 \\
3: & 18.0 \\
3: & 17.0 \\
4: & 16.3 \\
B: & \end{array}$ & $\begin{array}{ll}1: & 25.1 \\
1: & 24.5 \\
2: & 22.9 \\
3: & 21.4 \\
6: & 19.8 \\
5: & 18.4 \\
B: & 17.6\end{array}$ & $\begin{array}{ll}1 & 25.1 \\
1: & 23.9 \\
2: & 21.8 \\
3 \vdots & 20.2 \\
4: & 18.8 \\
B: & 18.0\end{array}$ & $\begin{array}{ll}1: & 25.1 \\
1 \vdots & 24.6 \\
2: & 23.3 \\
3: & 22.0 \\
3: & 20.7 \\
5: & 19.4 \\
6: & 18.2 \\
7: & 16.9 \\
8: & 15.7 \\
8: & 15: 0\end{array}$ & \\
\hline \begin{tabular}{|c|}
$\mathrm{BC}-1$ \\
$370^{\circ} \mathrm{c}$
\end{tabular} & \begin{tabular}{c|}
$\mathrm{BC}-2$ \\
$370^{\circ} \mathrm{C}$
\end{tabular} & \begin{tabular}{|c|}
$8 C-3$ \\
$370^{\circ} \mathrm{C}$
\end{tabular} & \begin{tabular}{|c|}
$\mathrm{BC}-4$ \\
$370^{\circ} \mathrm{C}$ \\
\end{tabular} & \begin{tabular}{|c|}
$8 c-5$ \\
$370 \cdot c$
\end{tabular} & \begin{tabular}{|c|}
$\mathrm{BC}:-6$ \\
$370^{\circ} \mathrm{C}$
\end{tabular} & $\begin{array}{l}\mathrm{BC}-0 \\
370^{\circ} \mathrm{C}\end{array}$ \\
\hline HO CANIST. & No canist. & HO CANIST. & HO CAKIST. & HO CANIST. & HO CANIST. & CANIST. \\
\hline
\end{tabular}


Table 14. MOTA-1B Canister Matrix Showing displacements per atom Information

\begin{tabular}{|c|c|c|c|c|c|c|}
\hline \multicolumn{4}{|c|}{ MOTA LEVELS 8 TO BC a 109.5 EFPD } & \multicolumn{3}{|c|}{ Units: dpa } \\
\hline $470^{\circ \cdot C} \mathrm{C}$ & $482^{8} \cdot c$ & $\begin{array}{l}8-c \\
469 \cdot 6\end{array}$ & $670^{\circ \circ} \mathrm{c}$ & $480^{\circ} \mathrm{c}$ & $\frac{8-F}{470^{\circ} \mathrm{c}}$ & \\
\hline $\begin{array}{ll}1: & 0.071 \\
1 & 0.083 \\
20 & 0.11 \\
3: & 0.15 \\
B: & 0.17\end{array}$ & 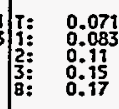 & $\mid \begin{array}{ll}\mid: & 0.071 \\
1 & 0.083 \\
2: & 0.011 \\
3: & 0.15 \\
3: & 0.17\end{array}$ & 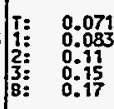 & HO CANIST. & HO CARIST. & \\
\hline $460^{\circ} \mathrm{C}$ & $\begin{array}{c}7-8 \\
460^{\circ} \mathrm{c}\end{array}$ & $\begin{array}{l}7-c \\
460 \cdot c\end{array}$ & $460^{\circ} \mathrm{D}$ & $46^{7-E^{\circ} \mathrm{c}}$ & $\begin{array}{c}7-5 \\
460^{\circ} \mathrm{c}\end{array}$ & \\
\hline HO CAMIST. & HO CARIST. & MO CAMIST. & No CAMIST. & No CANIST. & NO CANIST. & \\
\hline $48-A$ & $\begin{array}{c}6-\mathrm{B} \\
504^{\circ} \mathrm{C}\end{array}$ & $503^{6-c} \mathrm{c}$ & $505 \% \mathrm{C}$ & $487^{\circ} \mathrm{E}$ & $40^{6-\mathrm{F}}$ & \\
\hline $\begin{array}{ll}1: & 0.90 \\
1: & 1.03 \\
2: & 1.37 \\
3: & 1.68 \\
B: & 1.80\end{array}$ & $\mid \begin{array}{ll}: & 0.90 \\
1 & 1.21 \\
8: & 1.63\end{array}$ & $\begin{array}{ll}1: & 0.90 \\
1 & 1 \\
1: 21 & 1.63\end{array}$ & 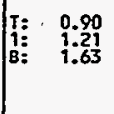 & $\begin{array}{ll}T: & 0.90 \\
1: & 1.03 \\
2: & 1.37 \\
3: & 1.68 \\
B: & .1 .80\end{array}$ & $\begin{array}{ll}T: & 0.90 \\
1: & 1.03 \\
2: & 1.37 \\
3: & 1.08 \\
B: & 1.80\end{array}$ & \\
\hline $\begin{array}{c}5-A-A \\
535^{\circ} \mathrm{C}\end{array}$ & 5 & $\begin{array}{c}5-c \\
588^{\circ} \mathrm{c}\end{array}$ & $\begin{array}{c}5.0 \\
595^{\circ} \mathrm{C}\end{array}$ & $\begin{array}{c}59 \mathrm{E}^{\circ} \\
597^{\circ} \mathrm{c}\end{array}$ & $\begin{array}{c}5-8 \\
45^{\circ} \mathrm{C}\end{array}$ & \\
\hline $\begin{array}{ll}\text { T: } & 4.35 \\
1: & 4.92 \\
2: & 6.28 \\
3: & 7.56 \\
B: & 8.06\end{array}$ & $\begin{array}{ll}\text { T: } & 4.35 \\
1: & 4.92 \\
2: & 6.28 \\
3: & 7.56 \\
8: & 8.06\end{array}$ & $\begin{array}{ll}\text { T: } & 4.35 \\
1: & 4.92 \\
2: & 6.28 \\
3: & 7.56 \\
8: & 8.06\end{array}$ & $\begin{array}{ll}\text { T: } & 4.35 \\
1: & 4.92 \\
2: & 6.28 \\
3: & 7.56 \\
B: & 8.06\end{array}$ & $\begin{array}{ll}\text { T: } & 4.35 \\
1: & 4.92 \\
2: & 6.28 \\
3: & 7.56 \\
8: & 8.06\end{array}$ & $\begin{array}{ll}T: & 3.76 \\
1 & 4.31 \\
2: & 5.53 \\
3: & 7.08 \\
8: & 8.04\end{array}$ & \\
\hline $663^{\circ} \mathrm{C}$ & $\begin{array}{c}4-8 \\
548^{\circ} \mathrm{C}\end{array}$ & $541^{4-6} \mathrm{c}$ & $\begin{array}{c}4-0 \\
569^{\circ} \mathrm{C}\end{array}$ & $\begin{array}{l}44-E \\
845 \cdot c\end{array}$ & $\frac{4-F}{722^{\circ}}$ & \\
\hline \begin{tabular}{ll|}
$1:$ & 11.6 \\
$1:$ & 12.0 \\
$2:$ & 13.0 \\
$3:$ & 13.9 \\
$4:$ & 4.8 \\
$5:$ & 15.5 \\
$8:$ & 15.9
\end{tabular} & 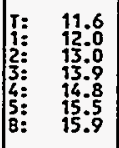 & 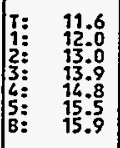 & $\begin{array}{ll}Y: & 11.6 \\
1: & 12.4 \\
2: & 13.7 \\
3: & 14.7 \\
4: & 15.3 \\
B: & 15.7\end{array}$ & $\begin{array}{ll}1: & 11.6 \\
1: & 12.4 \\
2: & 13.7 \\
3: & 14.7 \\
4: & 15.3 \\
8: & 15.7\end{array}$ & $\begin{array}{ll}\mathrm{T}: & 11.6 \\
1: & 12.4 \\
2: & 13.7 \\
3: & 14.7 \\
4: & 15.3 \\
\mathrm{~B}: & 15.7\end{array}$ & \\
\hline$\frac{3-A}{750^{\circ} \mathrm{C}}$ & $\begin{array}{ll}33-8 \\
547^{\circ} \mathrm{c}\end{array}$ & $577^{3-c}$ & $\begin{array}{c}3-0 \\
603 * 6\end{array}$ & $\frac{3-5}{664: c}$ & $\frac{3-5}{743 * c}$ & \\
\hline $\begin{array}{ll}T: & 17.7 \\
1: & 18.9 \\
3: & 18.0 \\
4: & 18.0 \\
8: & 18.0\end{array}$ & $\begin{array}{ll}\text { I: } & 17.7 \\
1: & 17.9 \\
2: & 18.0 \\
3: & 18.0 \\
4: & 18.0 \\
8: & 18.0\end{array}$ & $\begin{array}{ll}1: & 17.7 \\
1: & 17.9 \\
2: & 18.0 \\
3 \vdots & 18.0 \\
6: & 18.0 \\
8: & 18.0\end{array}$ & $\begin{array}{ll}T: & 17.7 \\
1 & 77.9 \\
2: & 78.0 \\
3: & 18.0 \\
4: & 18.0 \\
8: & 18.0\end{array}$ & $\begin{array}{ll}T: & 17.7 \\
1: & 17.9 \\
2: & 18.0 \\
3: & 18.0 \\
4: & 18.0 \\
8: & 18.0\end{array}$ & 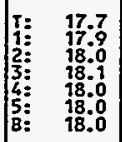 & \\
\hline $600^{\circ} \mathrm{C}$ & $595 \cdot c$ & $5 i^{2-c} c$ & $580^{2.0} \mathrm{C}$ & $\begin{array}{c}2-E^{\prime} \\
555^{\circ}>535{ }^{\circ} \mathrm{C}\end{array}$ & $42-F^{2}$ & \\
\hline $\begin{array}{ll}17.4 \\
17 & 17.3 \\
2 & 17.1 \\
3 & 16.7 \\
4: & 16.2 \\
5: & 15.6 \\
8: & 15.4\end{array}$ & $\mid$\begin{tabular}{ll|}
$7:$ & 17.4 \\
$1:$ & 17.3 \\
$2:$ & 17.1 \\
$3:$ & 16.5 \\
$4:$ & 15.7 \\
$8:$ & 15.2
\end{tabular} & $\begin{array}{ll}\text { T: } & 17.4 \\
1: & 17.3 \\
2: & 17.1 \\
3: & 16.5 \\
4: & 15.7 \\
8: & 15.2\end{array}$ & $\begin{array}{ll}1: & 17.4 \\
1 \vdots & 77.2 \\
2: & 16.9 \\
3: & 16.3 \\
4: & 15.8 \\
B: & 15.5\end{array}$ & $\begin{array}{ll}1: & 17.4 \\
1: & 17.3 \\
2: & 17.0 \\
3: & 16.3 \\
4: & 15.6 \\
8: & 15.2\end{array}$ & $\begin{array}{ll}1: & 17.6 \\
1 & 17.5 \\
20 & 17.2 \\
3: & 16: 7 \\
6= & 16.0 \\
5: & 15: 4 \\
8: & 15.4\end{array}$ & \\
\hline $490^{9} \mathrm{C}$ & $\frac{1-8}{493^{\circ} \mathrm{c}}$ & $471-c$ & $4010^{\circ} \mathrm{c}$ & $\frac{1-E}{407^{-c} c}$ & $\begin{array}{r}1-\mathrm{F} \\
409^{\circ} \mathrm{C}\end{array}$ & \\
\hline $\begin{array}{ll}1: & 12.7 \\
1: & 12.3 \\
2: & 19.5 \\
3: & 10.6 \\
5: & 9.87 \\
5: & 9.01 \\
8: & 8.61\end{array}$ & $\mid \begin{array}{ll}\mathrm{T}: & 12.7 \\
1: & 12.2 \\
2: & 11.1 \\
3: & 10.1 \\
4: & 8.96 \\
\text { B: } & 8.44\end{array}$ & $\begin{array}{ll}\mathrm{T}: & 12.7 \\
1 \vdots & 12.0 \\
2: & 10.9 \\
3: & 10.1 \\
4: & 9.23 \\
B: & 8.82\end{array}$ & $\begin{array}{ll}I: & 13.6 \\
13 & 13: 1 \\
2: & 12.0 \\
3: & 11.1 \\
5: & 10.3 \\
5: & 9.45 \\
6: & 8.62 \\
6: & 8.24\end{array}$ & 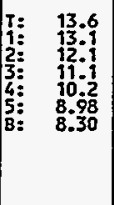 & $\begin{array}{ll}1: & 13.6 \\
1 & 13.3 \\
2 & 12.6 \\
3: & 11: 9 \\
4: & 11.2 \\
5: & 10.5 \\
6: & 9.89 \\
7: & 9.16 \\
8: & 8.49 \\
8: & 8.15\end{array}$ & \\
\hline $\begin{array}{r}8 c-9 \\
370^{\circ} c\end{array}$ & $\begin{array}{l}\mathrm{BC-2} \\
370^{\circ} \mathrm{C}\end{array}$ & $\begin{array}{c}\mathrm{BC}-3 \\
370^{\circ} \mathrm{C}\end{array}$ & $\begin{array}{c}\mathrm{BC}-4 \\
370^{\circ} \mathrm{C}\end{array}$ & $\begin{array}{l}8 \mathrm{BC}-5 \\
370 \cdot C\end{array}$ & $\begin{array}{l}8 C-6 \\
370^{\circ} \mathrm{C}\end{array}$ & $\begin{array}{l}\mathrm{BCC}: 0 \\
370^{\circ} \mathrm{C}\end{array}$ \\
\hline $\begin{array}{ll}: & 6.16 \\
\vdots & 5 \\
2 & 5.69 \\
3 & 2.85 \\
8: & 2.65\end{array}$ & $\begin{array}{ll}T: & 6.16 \\
1: & 5.69 \\
2: & 4.85 \\
3: & 3.52 \\
B= & 2.65\end{array}$ & $\begin{array}{ll}T= & 6.16 \\
1 & 5.69 \\
2: & 4.85 \\
3: & 3.52 \\
B: & 2.65\end{array}$ & $\begin{array}{ll}7: & 6.16 \\
1: & 5.69 \\
2: & 3.83 \\
B: & 2.65\end{array}$ & $\begin{array}{ll}x: & 6.16 \\
: & 5.69 \\
2:= & 3.83 \\
B: & 2.65\end{array}$ & $\begin{array}{ll}1: & 6.16 \\
1: & 4.93 \\
2: & 3.26 \\
8: & 2.65\end{array}$ & HO CAMIST. \\
\hline
\end{tabular}


Table 15. MOTA-1C Canister Matrix Showing displacements per atom Information

\begin{tabular}{|c|c|c|c|c|c|c|}
\hline \multicolumn{4}{|c|}{ HOTA LEVELS 8 TO BC a 256.7 EFPD } & \multicolumn{2}{|c|}{ Units: dpa } & \multirow{2}{*}{ 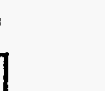 } \\
\hline & \multirow{2}{*}{ 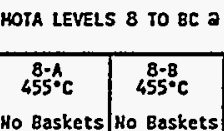 } & 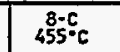 & $\begin{array}{c}8=0 \\
455^{\circ} \mathrm{c}\end{array}$ & $\begin{array}{c}8-E_{2} \\
455^{\circ} \mathrm{c}\end{array}$ & \multirow{2}{*}{$\begin{array}{c}8-5 \\
45^{\circ}{ }^{\circ} \mathrm{C} \\
\text { No CANIST. }\end{array}$} & \\
\hline & & Ho Baskets & Ho Baskets & NO CANIST. & & \\
\hline $\begin{array}{c}7-A \\
450^{\circ} \mathrm{C}\end{array}$ & $\begin{array}{c}7-8 \\
450^{\circ} \mathrm{c}\end{array}$ & $45^{7-c} c$ & $470^{7-0} \mathrm{c}$ & 75 & $\begin{array}{c}7-F \\
450^{\circ} \mathrm{C}\end{array}$ & \\
\hline HO CAMIST. & HO CAHIST. & MO CAMIST. & HO CANIST. & HO CAHIST. & HO CAMIST. & \\
\hline $470^{6 \cdot 4} \mathrm{C}$ & $570^{6.8} \mathrm{c}$ & $473^{6 * c} \mathrm{c}$ & $474^{6 \circ} \mathrm{C}$ & $690^{\circ} \mathrm{C}$ & $487^{6 \cdot} \cdot \mathrm{c}$ & \\
\hline 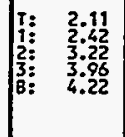 & $\mid \begin{array}{ll}T: & 2.11 \\
1: & 2.30 \\
2: & 2.71 \\
3: & 3.17 \\
6 \vdots & 3.66 \\
B: & 3.90\end{array}$ & $\begin{array}{ll}\text { I: } & 2.11 \\
1 & 2.25 \\
2: & 2.57 \\
3: & 2.94 \\
4: & 3.37 \\
5: & 3.84 \\
B: & 4.10\end{array}$ & $\begin{array}{ll}\text { T: } & 2.11 \\
1 & 2.30 \\
2: & 2.73 \\
3: & 3.26 \\
4: & 3.87 \\
8: & 4.21\end{array}$ & $\begin{array}{ll}7: & 2.11 \\
1: & 2.42 \\
2: & 3.14 \\
3: & 3.84 \\
B: & 4.18\end{array}$ & 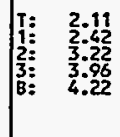 & \\
\hline $\begin{array}{l}53{ }^{\circ} \mathrm{c} \\
535^{\circ} \mathrm{c}\end{array}$ & $\begin{array}{l}55-8 \\
550^{\circ} \mathrm{c}\end{array}$ & $\begin{array}{c}5-c \\
570 \cdot c\end{array}$ & $60^{5-0} \mathrm{C}$ & $\begin{array}{c}5-\mathrm{E} \\
599^{\circ} \mathrm{C}\end{array}$ & $\begin{array}{c}5-F \\
438^{\circ} \mathrm{c}\end{array}$ & \\
\hline $\begin{array}{ll}r: & 10.2 \\
: & 19.5 \\
: & 14.8 \\
3: & 17.8 \\
8: & 18.9\end{array}$ & $\begin{array}{ll}\mathrm{T}: & 10.2 \\
1: & 10.8 \\
2: & 12.2 \\
3: & 14.3 \\
4: & 16.7 \\
\mathrm{~B}: & 17.8\end{array}$ & $\begin{array}{ll}7: & 10.2 \\
1: & 11.5 \\
2: & 14.8 \\
3: & 17.8 \\
8: & 18.9\end{array}$ & $\begin{array}{ll}T: & 10.2 \\
1 \vdots & 11.5 \\
3: & 13.8 \\
2: & 16.6 \\
8: & 18.9\end{array}$ & $\begin{array}{ll}\text { T: } & 10.2 \\
1: & 11.5 \\
2: & 16.8 \\
3 \vdots & 17.8 \\
B: & 18.9\end{array}$ & $\begin{array}{ll}1: & 8.82 \\
1: & 10.1 \\
2: & 13.0 \\
3: & 16.6 \\
B: & 18.9\end{array}$ & \\
\hline $670^{\circ} \mathrm{C}$ & $\frac{4-B}{730^{\circ} \mathrm{C}}$ & $540^{4-c} \mathrm{c}$ & $\begin{array}{c}4-0 \\
550^{\circ} \mathrm{C}\end{array}$ & $575^{\circ} \mathrm{C}$ & $\begin{array}{r}4-F \\
652^{\circ} \mathrm{C}\end{array}$ & \\
\hline 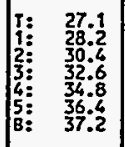 & $\left|\begin{array}{ll}T: & 27.9 \\
1 & 29: 0 \\
2: & 32.0 \\
3: & 34: 4 \\
4 \vdots & 35: 9 \\
8: & 36.8\end{array}\right|$ & $\begin{array}{ll}T: & 27.1 \\
1 \vdots & 28.2 \\
2: & 30.4 \\
3: & 32.6 \\
4: & 34.8 \\
5: & 36.4 \\
8: & 37.2\end{array}$ & $\begin{array}{ll}r: & 27.9 \\
\vdots & 20.0 \\
2: & 32.0 \\
3: & 34.4 \\
4: & 35.4 \\
8: & 36.8\end{array}$ & $\begin{array}{ll}\mathrm{T}: & 27.1 \\
1: & 28.5 \\
2: & 31.4 \\
3: & 34.4 \\
4: & 36.5 \\
8: & 37.6\end{array}$ & $\begin{array}{ll}1: & 27.1 \\
1: & 20.0 \\
2: & 32.0 \\
3: & 34: 4 \\
4: & 35: 9 \\
B: & 36.8\end{array}$ & \\
\hline $\begin{array}{c}3-1 \\
550^{\circ} \mathrm{C}\end{array}$ & $\begin{array}{c}3.8 \\
550^{\circ} \mathrm{C}\end{array}$ & $\begin{array}{l}3-c \\
605 \cdot c\end{array}$ & $\begin{array}{c}3-0 \\
670 \cdot \mathrm{c}\end{array}$ & $\begin{array}{c}3-E \\
635 \cdot c\end{array}$ & $\frac{3-F}{750^{\circ} \mathrm{C}}$ & \\
\hline $\begin{array}{ll}7: & 41.6 \\
2 & 41: 8 \\
20: & 42.2 \\
3: & 42.3 \\
4: & 42: 1 \\
8: & 42.1\end{array}$ & $\mid \begin{array}{ll}T: & 49.6 \\
1 & 41.8 \\
2: & 42.1 \\
3: & 42.3 \\
4: & 42.3 \\
5: & 42.2 \\
B: & 42.1\end{array}$ & $\mid \begin{array}{ll}T: & 41.6 \\
1 & 41.9 \\
2: & 42.2 \\
3: & 42.3 \\
4: & 42.2 \\
8: & 42.1\end{array}$ & $\begin{array}{ll}7: & 41.6 \\
1: & 41.9 \\
2: & 42.2 \\
3: & 42.3 \\
4: & 42.2 \\
8: & 42.1\end{array}$ & $\begin{array}{ll}\text { T: } & 41.6 \\
2: & 41.9 \\
3: & 42.2 \\
4: & 42.2 \\
8: & 42.1\end{array}$ & $\mid \begin{array}{ll}\mathrm{T}: & 41.6 \\
1: & 41.9 \\
2: & 42.2 \\
3: & 42.3 \\
4: & 42.2 \\
B: & 42.1\end{array}$ & \\
\hline $520^{2-A} \mathrm{C}$ & $\begin{array}{c}2-8 \\
600^{\circ} \mathrm{c}\end{array}$ & $\begin{array}{c}2-c-c \\
425 \div c\end{array}$ & $239 \cdot c$ & 60 & $420^{\circ} \mathrm{c}$ & \\
\hline $\begin{array}{ll}T: & 40.8 \\
\vdots & 40.5 \\
2 & 40.0 \\
3: & 38.7 \\
1 \vdots & 36.9 \\
B: & 35.7\end{array}$ & $\begin{array}{ll}\text { T: } & 40.8 \\
4: & 40.5 \\
2 & 40.0 \\
3: & 38.7 \\
1 & 36.9 \\
\text { B: } & 35.7\end{array}$ & $\begin{array}{ll}7: & 41.4 \\
1: & 41.0 \\
2: & 40.4 \\
3: & 30.8 \\
4: & 38.3 \\
5: & 36.4 \\
8: & 35.3\end{array}$ & 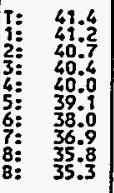 & 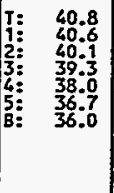 & $\begin{array}{ll}\text { I: } & 41.4 \\
1 & 40.9 \\
2: & 40.2 \\
3: & 39.2 \\
4: & 37.5 \\
5: & 36.0 \\
B: & 35.3\end{array}$ & \\
\hline $\begin{array}{l}1+\mathrm{A} \\
490^{\circ} \mathrm{C}\end{array}$ & $\begin{array}{c}1-8 \\
550^{\circ}>525 \circ\end{array}$ & $470^{\circ} \mathrm{c}$ & $495^{\circ} \mathrm{C}$ & $585 \%$ & $\frac{1-5}{396^{\circ} \mathrm{C}}$ & \\
\hline $\begin{array}{ll}7: & 29.8 \\
1: & 28: 8 \\
2: & 26.9 \\
3: & 25: 0 \\
4: & 23: 1 \\
5: & 21: 1 \\
8: & 20: 2\end{array}$ & $\mid \begin{array}{ll}1 & 29.8 \\
1 & 28.5 \\
2 & 26.0 \\
3 & 23.6 \\
4 & 21.0 \\
B: & 19.8\end{array}$ & \begin{tabular}{|ll}
$T:$ & 29.8 \\
1 & 28.1 \\
20 & 25.5 \\
$3:$ & 23.6 \\
$4:$ & 21.6 \\
$8:$ & 20.7
\end{tabular} & $\begin{array}{ll}1: & 29.8 \\
: & 28.5 \\
2: & 26.0 \\
3: & 23.6 \\
3: & 21.0 \\
B: & 19.8\end{array}$ & $\begin{array}{ll}1 \vdots & 29.8 \\
2 & 28.1 \\
20 & 25.5 \\
3: & 23.6 \\
4: & 21.6 \\
B: & 20.7\end{array}$ & $\begin{array}{ll}1: & 31.9 \\
1: & 30.8 \\
2: & 28.2 \\
3: & 26.0 \\
3: & 24.0 \\
5: & 22.1 \\
5: & 20.1 \\
6: & 20.2 \\
8: & 19.3\end{array}$ & \\
\hline $\begin{array}{l}8 \mathrm{BC}-\hat{A} \\
370^{\circ} \mathrm{C}\end{array}$ & $\begin{array}{l}8 \mathrm{BC}-\mathrm{B} \\
37^{\circ} \mathrm{C}\end{array}$ & 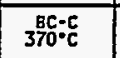 & $\begin{array}{l}3^{8 C-D} \\
370^{\circ} \mathrm{C}\end{array}$ & $\begin{array}{l}8 \mathrm{BC} \cdot \mathrm{E} \\
370^{\circ} \mathrm{C}\end{array}$ & $\begin{array}{l}\text { BC-F } \\
370^{\circ} \mathrm{C}\end{array}$ & $\begin{array}{l}8 C-0 \\
370^{\circ} \mathrm{C}\end{array}$ \\
\hline $\begin{array}{cc}T: & 13.3 \\
\vdots & 12.2 \\
20.3 \\
\vdots: \\
3: & 7.98 \\
8: & 6.58\end{array}$ & $\mid \begin{array}{ll}T: & 16.3 \\
1 \vdots & 13.2 \\
2: & 11.00 \\
3: & 9.12 \\
4: & 7.39 \\
B: & 6.58\end{array}$ & $\begin{array}{ll}T: & 14.2 \\
\vdots & 19.7 \\
2 & 8.64 \\
3: & 6.58\end{array}$ & $\begin{array}{ll}13.3 \\
\vdots & 12.3 \\
2: & 10.2 \\
3: & 7.90 \\
8: & 6.58\end{array}$ & $\begin{array}{l}15.5 \\
10.4 \\
8: \\
8.58\end{array}$ & $\begin{array}{ll}I: & 15.5 \\
1 & 10.5 \\
B: & 6.58\end{array}$ & $\begin{array}{ll}T: & 13.3 \\
1: & 12.2 \\
2: & 10.3 \\
3: & 7.98 \\
B: & 6.58\end{array}$ \\
\hline
\end{tabular}


Table 16. MOTA-1D Canister Matrix Showing displacements per atom Information

\begin{tabular}{|c|c|c|c|c|c|c|}
\hline \multicolumn{3}{|c|}{ HOTA LEVELS 8 TO BC a 185.8 EFP } & \multicolumn{3}{|r|}{ Units: dpo } & \\
\hline $\begin{array}{c}88 \mathrm{~A} \\
460 \mathrm{C} \\
\text { HO CANIST. }\end{array}$ & $\begin{array}{c}8-8 \\
460^{\circ} \mathrm{C} \\
\text { HO CANIST. }\end{array}$ & . $460^{8-C}$ CAHIST. & $\cdot \begin{array}{cc}8 \cdot 0 \\
462^{\circ} \mathrm{C} \\
\mathrm{T}: & 0.12 \\
\mathrm{i}: & 0.19 \\
\mathrm{~B}: & 0.30\end{array}$ & $\begin{array}{cc}8-E \\
462^{\circ} \mathrm{C} \\
\mathrm{T}: & 0.12 \\
8: & 0.19 \\
8: & 0.30\end{array}$ & 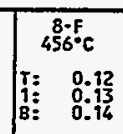 & \\
\hline 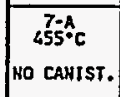 & $\begin{array}{c}75^{7-B} \\
\text { Ho CANIST. }\end{array}$ & $\begin{array}{c}7-\mathrm{c} \\
45^{\circ} \mathrm{C} \\
\text { HO CAMIST. }\end{array}$ & $\begin{array}{c}\frac{7 \cdot D}{455^{\circ} \mathrm{C}} \\
\text { Ho CANIST. }\end{array}$ & - $\begin{array}{c}7-E \\
455^{\circ} \mathrm{C} \\
\text { Ho CANIST. }\end{array}$ & $\begin{array}{c}7-F \\
455^{\circ} \mathrm{C} \\
\text { HO CANIST. }\end{array}$ & \\
\hline $\begin{array}{c}6-\mathrm{A} \\
445^{\circ} \mathrm{C} \\
\text { NO CANIST. }\end{array}$ & $\begin{array}{c}640 \\
445^{\circ} \mathrm{C} \\
\text { No CANIST. } \\
\end{array}$ & $\begin{array}{c}64-\mathrm{C} \\
445 \mathrm{C} \\
\text { NO CANIST. }\end{array}$ & $\begin{array}{c}6-0 \\
446^{\circ} \mathrm{C} \\
\text { Ho Boskets }\end{array}$ & 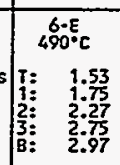 & 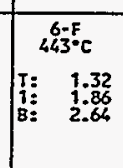 & \\
\hline $\begin{array}{c}5-\mathrm{A} \\
534^{\circ} \mathrm{C}\end{array}$ & $\begin{array}{c}5-8 \\
549^{\circ} \mathrm{C}\end{array}$ & $571 \div c$ & $\begin{array}{c}5 \cdot 0 \\
601^{\circ} \mathrm{C}\end{array}$ & $\begin{array}{c}5-E_{5} \\
600^{\circ} \mathrm{C}\end{array}$ & $\begin{array}{ll}5-F \\
438.6\end{array}$ & \\
\hline $\begin{array}{ll}7: & 7.38 \\
1: & 8.35 \\
2: & 10.7 \\
3: & 12.9 \\
B: & 13.7\end{array}$ & $\begin{array}{ll}1: & 7.38 \\
1: & 7.82 \\
2: & 8.80 \\
3: & 10.3 \\
4: & 12.1 \\
B: & 12.9\end{array}$ & $\begin{array}{ll}7: & 7.38 \\
1: & 8.35 \\
2: & 10.7 \\
3: & 12: 9 \\
8: & 13.7\end{array}$ & $\begin{array}{ll}\tau: & 7.38 \\
1: & 7.75 \\
2: & 9.71 \\
3: & 11.8 \\
8: & 13.4\end{array}$ & $\begin{array}{ll}7: & 7.38 \\
1: & 8.35 \\
2: & 10.7 \\
3: & 12.9 \\
8: & 13.7\end{array}$ & $\begin{array}{ll}T= & 6.38 \\
1= & 7.32 \\
2: & 9.38 \\
3= & 12.0 \\
B= & 13.6\end{array}$ & \\
\hline $670^{4-A}$ & \begin{tabular}{l|}
$430^{\circ} \mathrm{C}$ \\
\end{tabular} & 5 & $\begin{array}{c}4-\mathrm{D} \\
549^{\circ} \mathrm{C}\end{array}$ & $5 \frac{4-E}{\pi 5} \cdot c$ & $650^{\circ} \mathrm{F}$ & \\
\hline $\begin{array}{ll}1: & 19.6 \\
1: & 20.6 \\
3: & 22.7 \\
3: & 24.9 \\
8: & 26.4 \\
8: & 27.2\end{array}$ & $\mid \begin{array}{ll}T: & 19.6 \\
1 & 21.0 \\
2: & 23.2 \\
3: & 24.9 \\
6: & 26.0 \\
B: & 26.6\end{array}$ & $\begin{array}{ll}1: & 19.6 \\
1: & 20.4 \\
2: & 22.0 \\
3: & 23.6 \\
4: & 25.0 \\
5: & 26.3 \\
B: & 26.9\end{array}$ & $\begin{array}{ll}1: & 19.6 \\
1 & 21.0 \\
2: & 23.2 \\
3: & 24.9 \\
4: & 26.0 \\
8: & 26.6\end{array}$ & $\begin{array}{ll}\text { T: } & 19.6 \\
1: & 20.6 \\
20 & 22.7 \\
3: & 24.9 \\
4: & 26.4 \\
B: & 27.2\end{array}$ & $\begin{array}{ll}T: & 19.6 \\
\vdots & 21.0 \\
2 & 23.2 \\
3: & 26.9 \\
8: & 26.0 \\
B: & 26.6\end{array}$ & \\
\hline $\begin{array}{l}3-A \\
605 \% C\end{array}$ & $\begin{array}{c}3-\mathrm{B} \\
548^{\circ} \mathrm{C}\end{array}$ & $\begin{array}{c}3-\mathrm{c} \\
604^{\circ} \mathrm{c}\end{array}$ & $\frac{3-0}{670 . \mathrm{C}}$ & $635 \% \mathrm{c}$ & $\begin{array}{l}3-\mathrm{F} \\
750^{\circ} \mathrm{C}\end{array}$ & \\
\hline $\begin{array}{ll}\mathrm{T}: & 30.1 \\
1: & 30 . / 4 \\
20 & 30.6 \\
3: & 30.6 \\
30 & 30.5 \\
\text { B: } & 30.5\end{array}$ & $\begin{array}{ll}T: & 30.1 \\
\vdots & 30.4 \\
2: & 30.6 \\
3: & 30.6 \\
4: & 30.5 \\
B= & 30.5\end{array}$ & $\begin{array}{ll}1: & 30.1 \\
\vdots & 30.4 \\
2: & 30.6 \\
30.6 & 30.5 \\
4: & 30.5 \\
8: & 30.5\end{array}$ & $\begin{array}{ll}\mathrm{Z}: & 30.9 \\
\vdots & 30.4 \\
2: & 30.6 \\
3: & 30.6 \\
4: & 30.5 \\
8: & 30.5\end{array}$ & $\begin{array}{ll}\text { T: } & 30.1 \\
\vdots: & 30.4 \\
2: & 30.6 \\
30 & 30.6 \\
4: & 30.5 \\
B: & 30.5\end{array}$ & $\begin{array}{ll}T: & 30.9 \\
1 & 30.4 \\
20 & 30.6 \\
30 & 30.6 \\
4 \vdots & 30.5 \\
B: & 30.5\end{array}$ & \\
\hline $\sin ^{2} i^{A} \cdot \mathrm{C}$ & $\begin{array}{ll}2-B \\
600 \cdot c\end{array}$ & $\begin{array}{ll}2-c \\
400^{\circ} c\end{array}$ & $\begin{array}{c}2 \cdot 0 \\
408^{\circ} \mathrm{C}\end{array}$ & $\begin{array}{c}2 \cdot E^{\prime} \\
404 \cdot \mathrm{c}\end{array}$ & $\begin{aligned} 2-F \\
4040\end{aligned}$ & \\
\hline $\begin{array}{ll}T: & 29.5 \\
1 \vdots & 29.3 \\
2: & 29.0 \\
3: & 28.0 \\
4: & 26.7 \\
8: & 25.9\end{array}$ & $\begin{array}{ll}\text { : } & 29.5 \\
1: & 29.5 \\
2: & 28.9 \\
3: & 27.2 \\
4: & 26.7 \\
\text { B: } & 25.9\end{array}$ & $\begin{array}{ll}\text { T: } & 29.9 \\
1: & 29.7 \\
2: & 29.3 \\
3 \vdots & 28.7 \\
4: & 27.1 \\
\text { B: } & 26.2\end{array}$ & $\begin{array}{ll}T: & 29.9 \\
1 & 29.8 \\
2 & 29.5 \\
3: & 29.2 \\
4 \vdots & 29.0 \\
5: & 28.3 \\
6 \vdots & 27.5 \\
7 \vdots & 26.7 \\
8 \vdots & 25.9 \\
8: & 25.5\end{array}$ & $\begin{array}{ll}r: & 29.9 \\
1: & 29.8 \\
2: & 29.4 \\
3: & 28.9 \\
4: & 27.0 \\
B: & 26.0\end{array}$ & $\begin{array}{ll}1: & 29.9 \\
1 & 29.6 \\
2: & 20.6 \\
3 \vdots & 28: 3 \\
4: & 27.1 \\
5: & 26.0 \\
8: & 25.6\end{array}$ & \\
\hline $\begin{array}{l}1-A \\
550 \cdot c\end{array}$ & $\begin{array}{l}1-8 \\
520^{\circ} \mathrm{c}\end{array}$ & $47-c$ & $\begin{array}{l}11-0 \\
495^{\circ} \mathrm{c}\end{array}$ & $\begin{array}{ll}9-E_{1} \\
585 \circ \mathrm{C}\end{array}$ & $\begin{array}{c}1-F \\
386 \cdot c\end{array}$ & \\
\hline \begin{tabular}{ll|}
$1:$ & 21.6 \\
$1:$ & 20.1 \\
$2:$ & 17.4 \\
$3:=$ & 15.3 \\
$8:$ & 14.4
\end{tabular} & $\left|\begin{array}{cc}1: & 21.6 \\
1 & 200 \\
20 & 18.3 \\
30 & 16.3 \\
3: & 14.6 \\
8: & 14.6\end{array}\right|$ & $\begin{array}{ll}T: & 21.6 \\
1 \vdots & 20.3 \\
2: & 18.4 \\
3 \vdots & 17.1 \\
4: & 15.7 \\
B: & 15.0\end{array}$ & $\begin{array}{ll}T: & 21.6 \\
1: & 20.7 \\
2: & 18.8 \\
3: & 17.1 \\
4: & 15.2 \\
B: & 14.3\end{array}$ & $\begin{array}{ll}1: & 21.6 \\
1: & 20.3 \\
2: & 18.4 \\
3 \vdots & 17.9 \\
4: & 15.7 \\
\text { B: } & 15.0\end{array}$ & 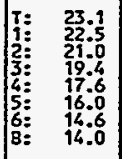 & \\
\hline $\begin{array}{l}\mathrm{BC}=\mathrm{A} \\
370^{\circ} \mathrm{C}\end{array}$ & $\begin{array}{l}\text { BC:B } \\
370^{\circ}=\mathrm{C}\end{array}$ & $\begin{array}{l}\mathrm{BC}-\mathrm{c} \\
370^{\circ} \mathrm{c}\end{array}$ & $\begin{array}{l}8 \mathrm{Bc}-\mathrm{D} \\
370^{\circ} \mathrm{c}\end{array}$ & $\begin{array}{l}\mathrm{BC}-\mathrm{E} \\
370^{\circ} \mathrm{C}\end{array}$ & $\begin{array}{ll}B C-F \\
370 \% C\end{array}$ & $\begin{array}{l}\mathrm{BC}-0 \\
370^{\circ} \mathrm{C}\end{array}$ \\
\hline $\begin{array}{ll}\mathrm{T}: & 9.74 \\
2: & 8.37 \\
2: & 6.52 \\
3: & 5.32 \\
8: & 4.76\end{array}$ & $\left|\begin{array}{ll}T: & 10.3 \\
1: & 9.42 \\
2: & 7.83 \\
3 \vdots & 6.53 \\
4: & 5.34 \\
B: & 4.77\end{array}\right|$ & $\begin{array}{ll}T: & 10.3 \\
1: & 8.48 \\
2: & 6.31 \\
3 \vdots & 5.21 \\
8: & 4.76\end{array}$ & $\begin{array}{ll}7: & 9.76 \\
1 & 8.94 \\
2: & 7.48 \\
3: & 6.30 \\
4: & 5.25 \\
8: & 4.77\end{array}$ & $\left|\begin{array}{ll}7 \\
1 & 11.2 \\
1 & 7.52 \\
8: & 4.76\end{array}\right|$ & $\begin{array}{ll}T: & 11.22 \\
1 & 7.52 \\
8: & 4.76\end{array}$ & 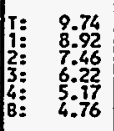 \\
\hline
\end{tabular}

Values Based on Results from MOTAs $1 \mathrm{~A}, \mathrm{IB}$ and $1 \mathrm{C}$. 
Table 17. MOTA-1E Canister Matrix Showing displacements per atom Information

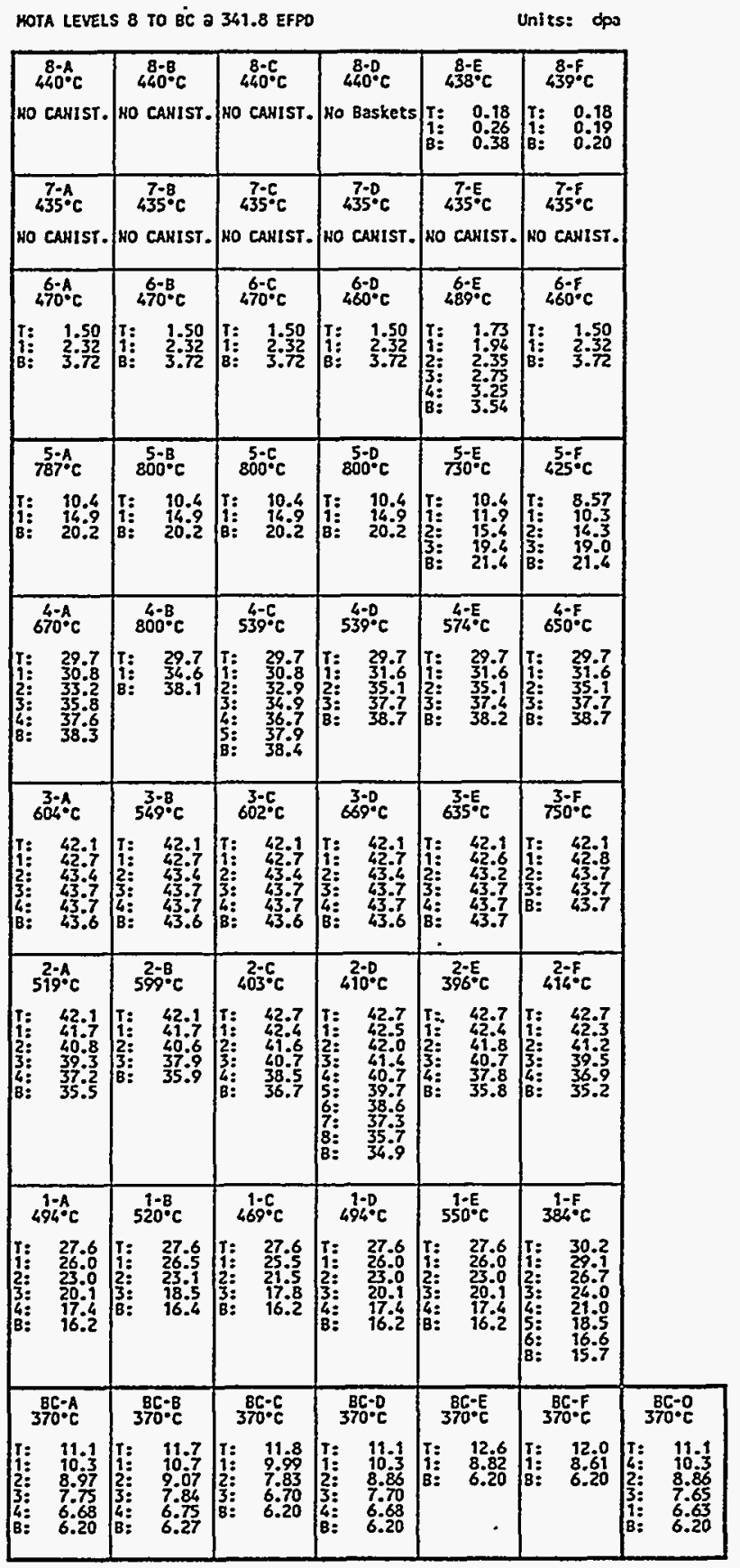


Table 18. MOTA-1F Canister Matrix Showing displacements per atom Information

\begin{tabular}{|c|c|c|c|c|c|c|}
\hline \multicolumn{4}{|c|}{ MOTA LEVELS 8 TO BC a 335.4 EFPD } & \multicolumn{2}{|r|}{ Units: dpa } & \\
\hline $\begin{array}{c}8-4 . A \\
435^{\circ} \mathrm{C} \\
\text { NO CANIST. }\end{array}$ & $\begin{array}{c}88^{8} \\
45^{\circ} \mathrm{C} \\
\text { No CANIST. }\end{array}$ & $\begin{array}{c}8-\mathrm{C} \\
435^{\circ} \mathrm{C} \\
\text { NO CANIST. }\end{array}$ & $\begin{array}{c}4^{8-D} 5^{\circ} \mathrm{C} \\
\text { NO CAMIST. }\end{array}$ & $\begin{array}{cc} & 8-E \\
433^{\circ} \mathrm{C} \\
\mathrm{Y}: & 0.17 \\
1: & 0.25 \\
\mathrm{~B}: & 0.37\end{array}$ & $\begin{array}{cc} & 8-F \\
435^{\circ} \mathrm{C} \\
\mathrm{T} & 0.17 \\
1: & 0.18 \\
2: & 0.21 \\
3: & 0.28 \\
4: & 0.36 \\
B: & 0.39\end{array}$ & \\
\hline $\begin{array}{c}7-A A \\
40^{\circ} \mathrm{C} \\
\text { NO CAMIST. }\end{array}$ & $\begin{array}{c}7-\mathrm{B} \\
430^{\circ} \mathrm{C} \\
\text { No CANIST. }\end{array}$ & \begin{tabular}{|c|}
$7-\mathrm{C}$ \\
$430^{\circ} \mathrm{c}$ \\
ко санIST.
\end{tabular} & $\begin{array}{c}7-D \\
430^{\circ} \mathrm{C} \\
\text { HO CANIST. }\end{array}$ & $\begin{array}{c}73-\mathrm{E} \\
430^{\circ} \mathrm{C} \\
\text { NO CANIST. }\end{array}$ & $\begin{array}{c}73-\mathrm{F} \\
430^{\circ} \mathrm{C} \\
\text { Ho CANIST. }\end{array}$ & \\
\hline $\begin{array}{l}{ }^{6-\mathrm{A}^{\circ} \mathrm{C}} \\
5^{\circ} \mathrm{C} \\
\text { NO CANIST. }\end{array}$ & $\begin{array}{c}60^{6} 8 \\
425^{\circ} \mathrm{C} \\
\text { HO CANIST. }\end{array}$ & $\begin{array}{c}4255^{\circ} \mathrm{C} \\
\text { NO CANIST. }\end{array}$ & $\begin{array}{c}65^{6-0} \mathrm{C} \\
\text { No CANIST. }\end{array}$ & 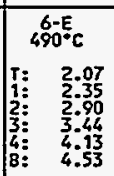 & $\begin{array}{cc} & 6-F \\
& 426^{\circ} \mathrm{C} \\
\mathrm{T}: & 1.76 \\
1 & 2.05 \\
2: & 2.79 \\
3: & 3.83 \\
\mathrm{~B}: & 4.53\end{array}$ & \\
\hline$\sqrt{10-A \cdot C}$ & $\begin{array}{l}5-8 \\
1016^{\circ} \cdot \mathrm{C}\end{array}$ & $\begin{array}{l}5-c \\
107 \cdot c\end{array}$ & $\begin{array}{l}5 \cdot 0 \\
1077 \cdot c\end{array}$ & $\begin{array}{c}5 \cdot E \cdot C \\
1128 \cdot c\end{array}$ & $\begin{array}{ll}5.5 \\
1250^{\circ} \mathrm{C}\end{array}$ & \\
\hline 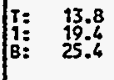 & $\mid \begin{array}{ll}T & 13.8 \\
1 & 13.8 \\
B: & 10.4 \\
B= & 25.4\end{array}$ & $\left|\begin{array}{ll}1: & 13.8 \\
1: & 10.4 \\
B: & 25.4\end{array}\right|$ & $\mid \begin{array}{ll}1 & 13.8 \\
\vdots & 19.8 \\
8: & 25.4\end{array}$ & $\begin{array}{ll}\text { I: } & 13.8 \\
1: & 19.4 \\
8: & 25.4\end{array}$ & 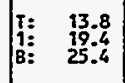 & \\
\hline $\begin{array}{ll}4 \cdot A \cdot C \\
10 \pi 7 \cdot C\end{array}$ & $1125 \cdot c$ & $7 \begin{array}{c}4-c \\
799^{\circ} \mathrm{c}\end{array}$ & $\begin{array}{ll}4400 \\
550 \cdot c\end{array}$ & $670 \cdot \mathrm{C}$ & $670^{\circ} \cdot \mathrm{C}$ & \\
\hline $\mid \begin{array}{ll}T: & 33.6 \\
1: & 35.0 \\
B: & 37.9\end{array}$ & $\begin{array}{ll}1: & 32.5 \\
1 & 35.5 \\
8: & 37.9\end{array}$ & 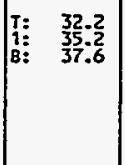 & 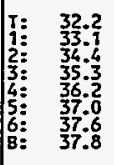 & 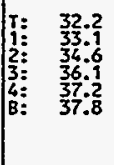 & $\begin{array}{ll}T: & 32.2 \\
1: & 33.4 \\
2: & 35.4 \\
3: & 37.1 \\
B: & 37.8\end{array}$ & \\
\hline${ }_{605}^{30} \hat{\circ}^{\circ} \mathrm{c}$ & $\begin{array}{ll}3-8 \\
550^{\circ} \mathrm{C}\end{array}$ & $\begin{array}{c}3-c \\
605 \cdot c\end{array}$ & $\begin{array}{c}3-0 \\
670^{\circ} \mathrm{C}\end{array}$ & $\begin{array}{l}3-E \\
550^{\circ} \mathrm{C}\end{array}$ & $\frac{3-F}{750 \cdot C}$ & \\
\hline $\begin{array}{ll}\text { T: } & 39.8 \\
2: & 40.0 \\
2: & 40.3 \\
3: & 40.4 \\
4: & 40.4 \\
8: & 40.2\end{array}$ & $\begin{array}{ll}T: & 39.8 \\
1: & 40.0 \\
2: & 40.3 \\
3: & 60.4 \\
4: & 40.4 \\
B: & 40.2\end{array}$ & $\begin{array}{ll}\text { T: } & 39.8 \\
3: & 40.0 \\
2: & 40.3 \\
3: & 40.4 \\
4: & 40.4 \\
\text { B: } & 40.2\end{array}$ & $\begin{array}{ll}1: & 39.8 \\
1: & 40.0 \\
2: & 40.3 \\
3: & 40.4 \\
4: & 40.4 \\
8: & 40.2\end{array}$ & $\begin{array}{ll}7: & 39.8 \\
1: & 40.1 \\
2: & 40.4 \\
3: & 40.4 \\
B: & 40.2\end{array}$ & $\begin{array}{ll}\text { T: } & 39.8 \\
1: & 40.1 \\
2: & 40.4 \\
3: & 40.4 \\
8: & 40.2\end{array}$ & \\
\hline $520^{2-A} \mathrm{C}$ & $\begin{array}{c}2 \cdot 8 \\
600^{\circ} \mathrm{C}\end{array}$ & $\frac{2-c}{405^{\circ} c}$ & $\begin{array}{l}220 \\
404 \cdot c\end{array}$ & $404^{\circ} \mathrm{C}$ & $40-F$ & \\
\hline $\begin{array}{ll}\text { I: } & 38.6 \\
1: & 38.3 \\
2: & 37.6 \\
3: & 36.6 \\
4: & 35.0 \\
B: & 33.6\end{array}$ & $\begin{array}{ll}\mathrm{T}: & 38.6 \\
1: & 38.3 \\
2: & 37.2 \\
3: & 35.0 \\
B: & 33.6\end{array}$ & $\begin{array}{ll}r: & 39.2 \\
1 & 39.0 \\
2: & 38.3 \\
3: & 37.6 \\
4: & 35.4 \\
5: & 34.6 \\
8: & 33.2\end{array}$ & $\begin{array}{ll}1: & 39.2 \\
\vdots & 39.0 \\
2 & 38.6 \\
3 & 37.9 \\
4 & 37.1 \\
5: & 35.3 \\
8: & 35.9\end{array}$ & $\begin{array}{ll}1: & 39.2 \\
1 \vdots & 39.0 \\
2: & 38.6 \\
3: & 38.0 \\
4 \vdots & 37.4 \\
5 \vdots & 36.2 \\
B: & 35.6\end{array}$ & $\mid \begin{array}{ll}1: & 38.2 \\
1: & 38.8 \\
2: & 37.9 \\
3: & 36.8 \\
4: & 35.2 \\
8: & 34.0\end{array}$ & \\
\hline$\frac{1-A}{790^{\circ} \mathrm{C}}$ & $\begin{array}{c}1-\mathrm{B} \\
799^{\circ} \mathrm{C}\end{array}$ & $\begin{array}{c}1-c \\
495^{\circ} \mathrm{C}\end{array}$ & $494 \cdot c$ & $520^{1-E} \mathrm{C}$ & $\begin{array}{c}1-F \\
3866^{\circ} \mathrm{C}\end{array}$ & \\
\hline $\mid \begin{array}{ll}7 & 27.5 \\
1 & 27.5 \\
B: & 22.8 \\
B= & 18.5\end{array}$ & $\mid \begin{array}{ll}7: & 27.5 \\
1 & 22.5 \\
3: & 18.5 \\
8: & 18.5\end{array}$ & $\begin{array}{ll}\text { T: } & 27.5 \\
1: & 25.8 \\
2 \vdots & 22.6 \\
3: & 19.5 \\
8: & 18.0\end{array}$ & $\begin{array}{ll}\text { T: } & 27.5 \\
1: & 26.2 \\
2: & 23.8 \\
3 \vdots & 21.5 \\
4: & 19.1 \\
B: & 18.0\end{array}$ & $\begin{array}{ll}T: & 27.5 \\
1 & 26.4 \\
2 & 23.4 \\
2: & 19.8 \\
3 & 18.0 \\
B= & 18.0\end{array}$ & $\mid \begin{array}{ll}1 & 29.6 \\
1 & 28: 6 \\
2: & 26: 5 \\
2: & 24: 0 \\
3: & 22: 0 \\
5: & 20: 0 \\
5: & 18: 2 \\
6: & 17: 6 \\
B: & 18.6\end{array}$ & \\
\hline $370^{\circ} \mathrm{C}$ & $370^{\circ} \mathrm{C}$ & $\begin{array}{l}\mathrm{BC}-\mathrm{C} \\
370^{\circ} \mathrm{C}\end{array}$ & $\begin{array}{l}8 \mathrm{BC}-0 \\
370^{\circ} \mathrm{C}\end{array}$ & $370^{\circ} \mathrm{C}$ & $37^{\circ C-F}$ & $\begin{array}{l}8 \mathrm{BC}-0 \\
370^{\circ} \mathrm{C}\end{array}$ \\
\hline $\begin{array}{ll}T= & 13.0 \\
12 & 12.1 \\
2: & 10.6 \\
3: & 9.27 \\
6: & 8.06 \\
8: & 7.50\end{array}$ & $\begin{array}{ll}1: & 13.5 \\
1: & 12.4 \\
2: & 10.7 \\
3: & 9.38 \\
4: & 8.10 \\
8: & 7.50\end{array}$ & $\begin{array}{ll}r: & 13.8 \\
1 & 11.8 \\
2: & 9.38 \\
3 \vdots & 8.04 \\
8: & 7.50\end{array}$ & $\mid \begin{array}{ll}\mid \begin{array}{l}1 \\
1\end{array} & 13.6 \\
10.2 & 10.2 \\
8: & 7.50\end{array}$ & $\mid \begin{array}{ll}r: & 14.6 \\
1 & 10.6 \\
B: & 7.50\end{array}$ & $\begin{array}{ll}1: & 13.9 \\
10 & 10.3 \\
8: & 7.50\end{array}$ & $\begin{array}{ll}T: & 13.0 \\
1 & 12.1 \\
2: & 10.5 \\
3: & 9.27 \\
4: & 8.04 \\
8: & 7.50\end{array}$ \\
\hline
\end{tabular}


Table 19. MOTA-1G Canister Matrix Showing displacements per atom Information

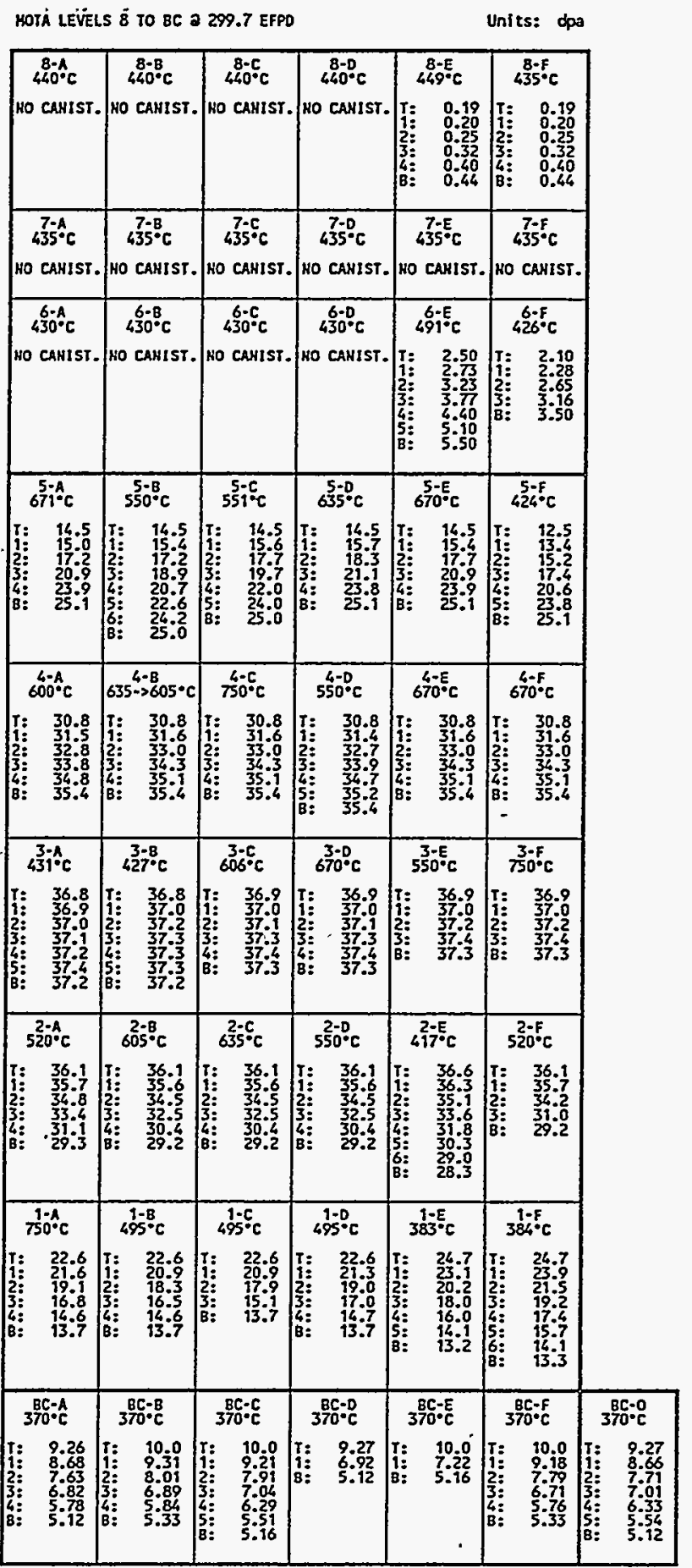


Table 20. MOTA-2A Canister Matrix Showing displacements per atom Information

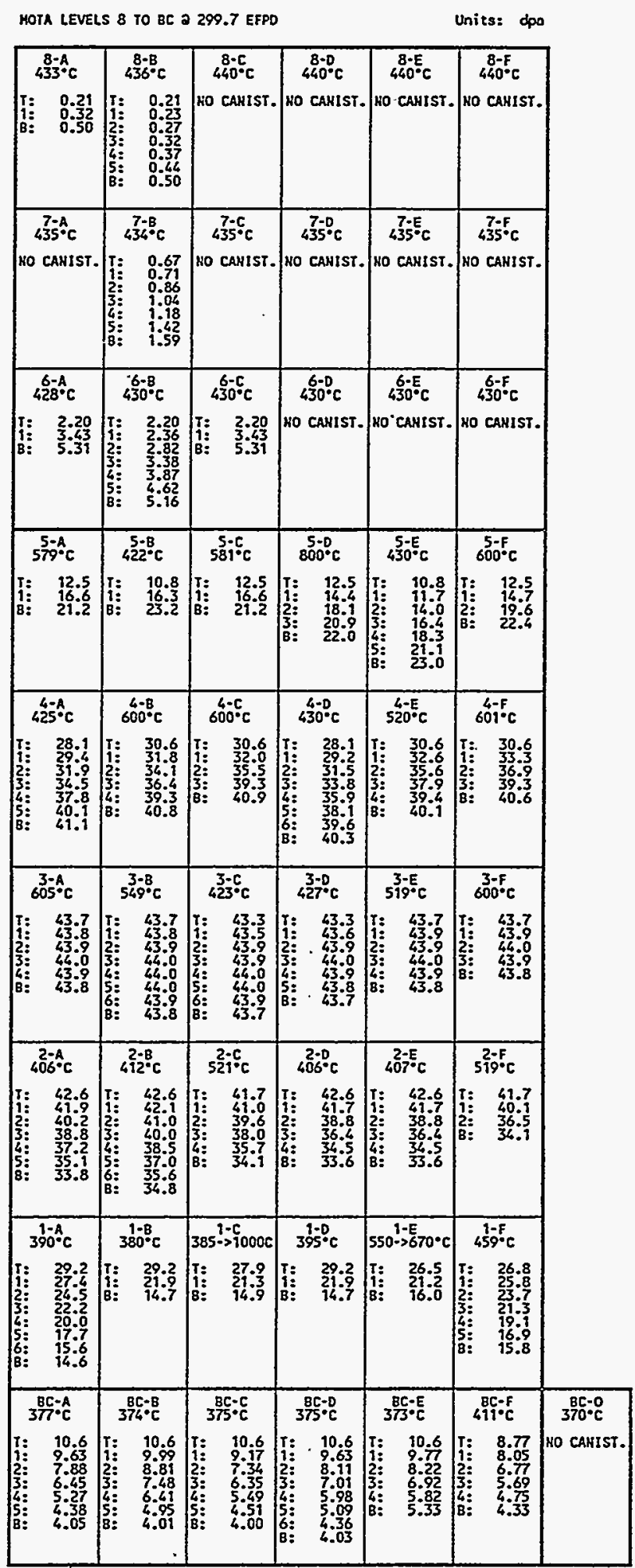


Table 21. MOTA-2B Canister Matrix Showing displacements per atom Information

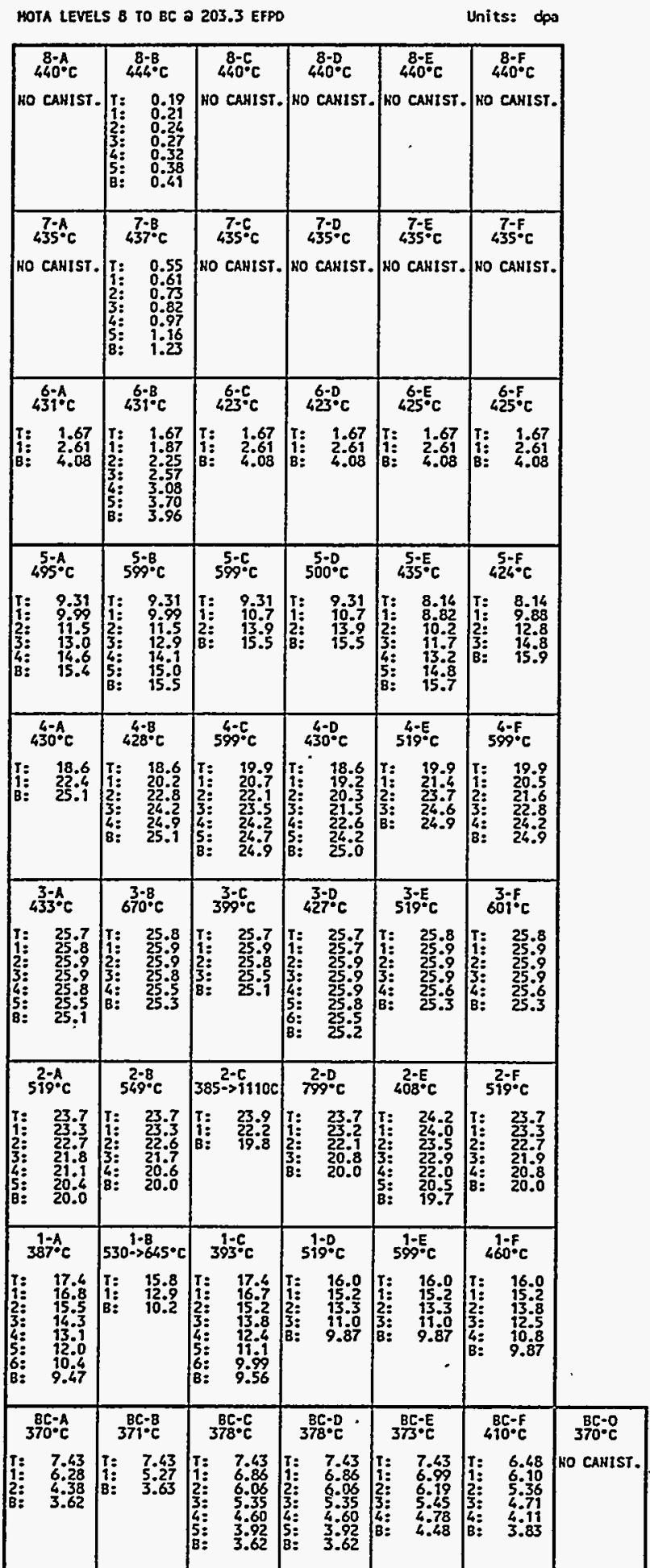


PRELIMINARY REPORT ON THE IRRADIATION PARAMETERS FOR THE EBR-II COBRA-1A2 TEST - A. M. Ermi (Westinghouse Hanford Company) and M. L. Hamilton (Pacific Northwest Laboratory)

\section{OBJECTIVE}

The objective of this effort was to report on the preliminary irradiation parameters (temperatures, fluences and dpa values) for the COBRA-1A2 test irradiated in the EBR-II. The report covers specimens irradiated in four B7A capsules from November 1992 to September 1994.

\section{SUMMMARY}

The COBRA-1A2 test specimens were irradiated in the Experimental Breeder Reactor - II (EBR-II) during Runs 162 and 163 (as part of the COBRA-1A1 test), and during Runs 164 through 170 . The four capsules in the COBRA-1A2 subassembly were irradiated for a total of 337.3 Effective Full Power Days (EFPD) at a nominal reactor power level of $62.5 \mathrm{MWt}$. The estimated mid-core total peak fast fluence was $6.85 \times 10^{22} \mathrm{n} / \mathrm{cm}^{2}(\mathrm{E}>0.111 \mathrm{MeV})$, and the estimated total peak displacements per atom was 32.6 dpa (in stainless steel). During reactor operation, the inlet coolant remained at $371^{\circ} \mathrm{C}$ while the calculated coolant outlet temperature was $441^{\circ} \mathrm{C}$.

\section{PROGRESS AND STATUS}

\section{Introduction}

The COBRA-1A experiment was sponsored by the U.S. Neutron Interactive Materials Program (NIMS) and the Japanese Ministry of Education, Science and Culture (Monbusho). This test was part of an ongoing U.S./Japan collaborative program to study the effects of neutron irradiation on fusion reactor candidate materials.

The COBRA-1A subassembly, designated as X516, consisted of seven B7A capsules, and was irradiated in EBR-II core position $2 \mathrm{~B} 1$. The seven capsules were divided into four high fluence capsules (B-388 through B-391) and three low fluence capsules (B-392 through B-394). The three low fluence capsules were discharged after Run 163 (the COBRA-1Al irradiation), while the four high fluence capsules continued to be irradiated during Runs 164 through 170 (the COBRA-1A2 irradiation).

The COBRA-1A2 subassembly, designated as X516A, consisted of the four B7A capsules from COBRA-1A1, and three dummy capsules. This subassembly was also irradiated in core position $2 B 1$. The location of position 2B1 in the EBR-II reactor grid is shown in Figure 1. The positions of the B7A specimen capsules and dummy capsules in subassembly X516A and their relative position to the core center are shown in Figure 2.

The four specimen capsules in the COBRA-1A2 subassembly consisted of three weeper capsules (B-388, B-389 and B-390) and one gas-gapped capsule (B-391). The weeper capsules were designed to expose the test specimens and specimen subcapsules to the reactor coolant. The gas-gapped capsule was

"Operated for the U.S. Department of Energy by Battelle Memorial Institute under Contract DE-AC0676RLO 1830. 


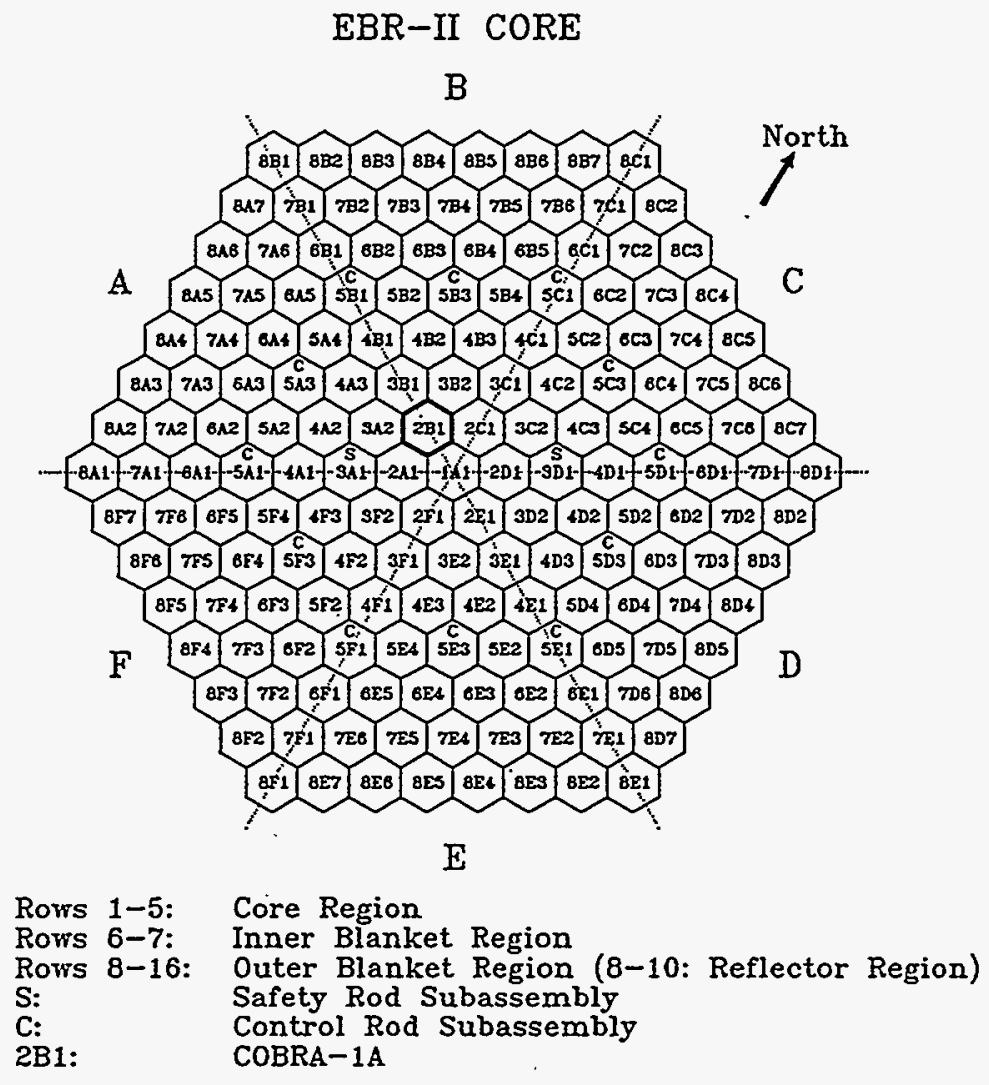

Figure 1. Location of Position 2B1 in the EBR-II Reactor Grid.

\section{COBRA-1A2 SUBASSEMBLY LAYOUT \\ - EBR-II CORE POSITION 2B1 -}

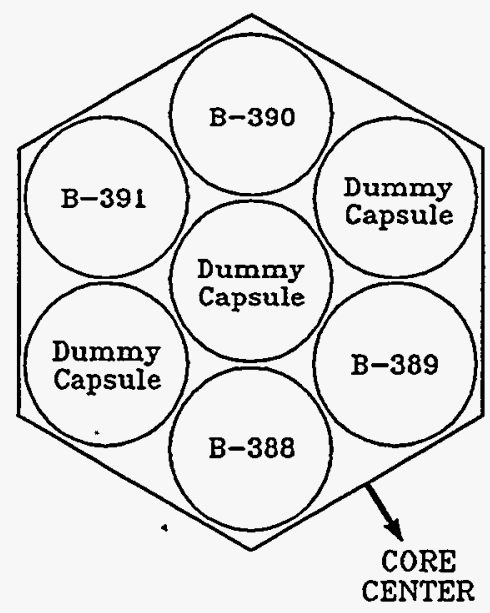

Figure 2. Position of COBRA-1A2 B7A Capsules in Subassembly X516A. 
designed to irradiate one subcapsule (D05) at a goal temperature of $800^{\circ} \mathrm{C}$. The remaining specimens in this capsule were designed to operate at temperatures close to the ambient coolant temperature. Baskets and subcapsules were used in all capsules to maintain the specimens at pre-determined positions. References 1 through 6 give more details on the test matrix, baskets, subcapsules, capsules, specimen loading and the overall experiment.

\section{Summary of Reactor Conditions for EBR-II Runs 162 through 170}

EBR-II Run 162 commenced on November 26, 1992, marking the beginning of the COBRA-1A irradiation. The seven COBRA-1A1 capsules remained in the reactor through Run 163 which ended on April 1, 1993. Following the long spring maintenance and refueling outage, the four COBRA-1A2 capsules continued the irradiation with Run 164, which commenced on June 4, 1993. The capsules remained in the reactor through Run 170, which ended on September 26, 1994.

There were five unscheduled reactor shutdown periods during the twenty-two month irradiation period. One was caused by severe winter storms that prevented required reactor crew changes. The other four were caused by various minor problems with operating systems or equipment. The power levels for EBR-II Runs 162 through 170 are shown in Figures 3 through 6, while reactor operations details for the nine runs are given in References 7 through 15. The reactor operation during the COBRA-1A irradiation is summarized in Table 1 . The cumulative EFPD for the COBRA-1A2 specimens during Runs 162 through 170 was 337.3 EFPD (at a nominal full power level of $62.5 \mathrm{MWt}$ ).

Table 1. Summary of EBR-II Operation During the COBRA-1A Irradiation.

\begin{tabular}{|c|c|c|c|c|c|}
\hline Run \# & Start Date & End Date & Shutdown Remarks & $\underset{\text { EFPD }}{\operatorname{Run}}$ & $\begin{array}{l}\text { Total } \\
\text { EFPD* }\end{array}$ \\
\hline \multirow{2}{*}{162} & Nov. 26, 1992 & Jan. 20, 1993 & Severe Winter Storms & \multirow{2}{*}{55.44} & \multirow{2}{*}{55.44} \\
\hline & Jan. 30, 1993 & Feb. 1, 1993 & Scheduled End of Run & & \\
\hline 163 & Feb. 26, 1993 & April 1, 1993 & Scheduled End of Run & 33.17 & 88.61 \\
\hline 164 & June 4, 1993 & July 6,1993 & Scheduled End of Run & 30.26 & 118.87 \\
\hline 165 & July 31, 1993 & Oct. 7,1993 & Scheduled End of Run & 66.00 & 184.87 \\
\hline \multirow{2}{*}{166} & Oct. 30,1993 & Nov. 6,1993 & Loss of Instrument Air & \multirow{2}{*}{26.34} & \multirow{2}{*}{211.21} \\
\hline & Nov. 8,1993 & Dec. 1,1993 & Scheduled End of Run & & \\
\hline \multirow{3}{*}{167} & Dec. 23, 1993 & Dec. 28,1993 & Loss of Control Rod Movement & \multirow{3}{*}{30.67} & \multirow{3}{*}{241.88} \\
\hline & Jan. 8,1994 & Jan. 17, 1994 & Loss of Coolant Flow & & \\
\hline & Jan. 19, 1994 & Feb. 7, 1994 & Scheduled End of Run & & \\
\hline \multirow{2}{*}{168} & Feb. 25, 1994 & Mar. 5, 1994 & Scheduled End of 1st Run & \multirow{2}{*}{13.84} & \multirow{2}{*}{255.72} \\
\hline & Mar. 22, 1994 & Mar. 30, 1994 & Scheduled End of 2nd Run & & \\
\hline 169 & June 23, 1994 & Aug. 9, 1994 & Scheduled End of Run & 46.54 & 302.26 \\
\hline \multirow{2}{*}{170} & Aug. 20, 1994 & Aug. 31, 1994 & Loss of Steam Pressure Control & \multirow{2}{*}{35.00} & \multirow{2}{*}{337.26} \\
\hline & Sep. 2, 1994 & Sep. 26, 1994 & Scheduled End of Run & & \\
\hline
\end{tabular}

*Note: Full Power was nominally $62.5 \mathrm{MWt}$ 


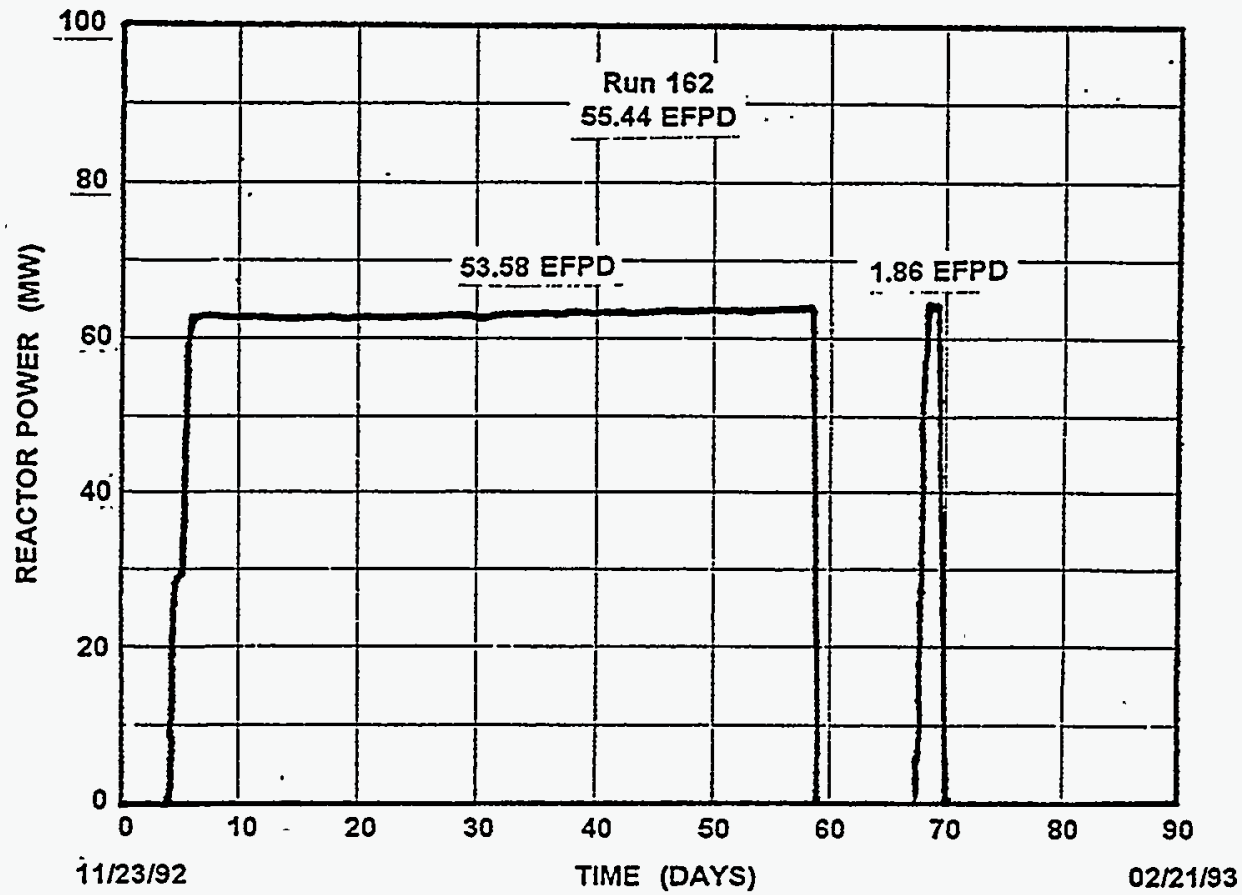

Figure 3. EBR-II Reactor Power During Run 162.

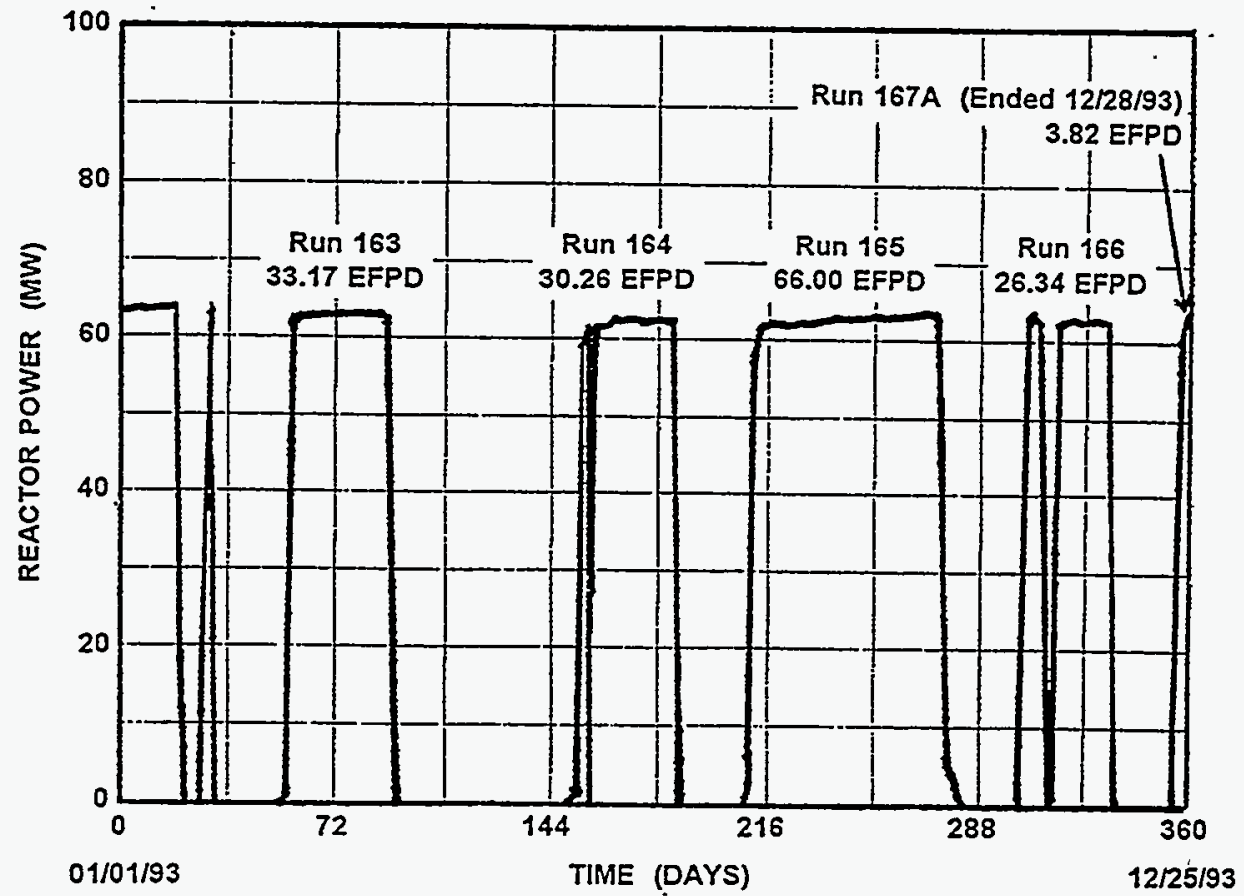

Figure 4. EBR-II Reactor Power During Runs 163 through 167A. 


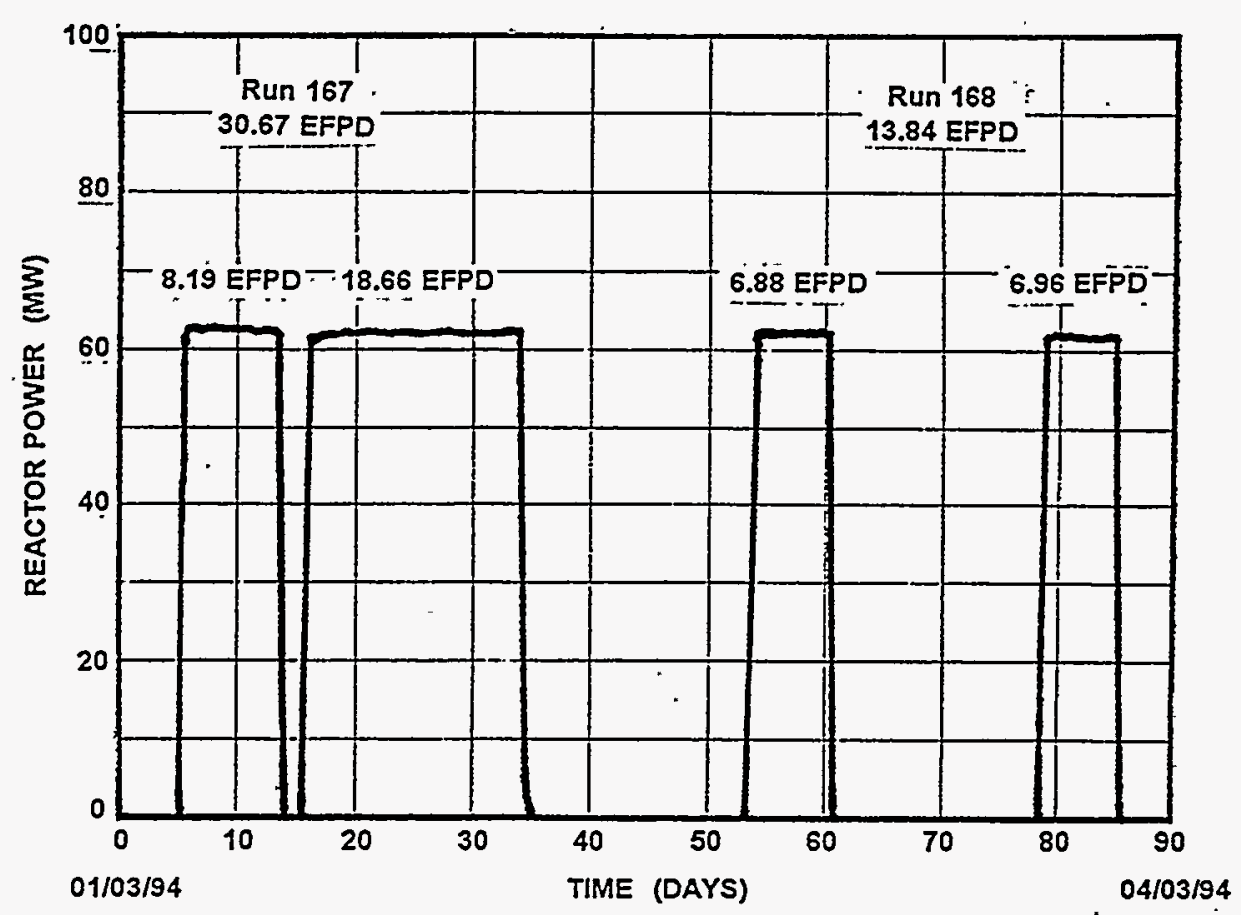

Figure 5. EBR-II Reactor Power During Runs 167B through 168.

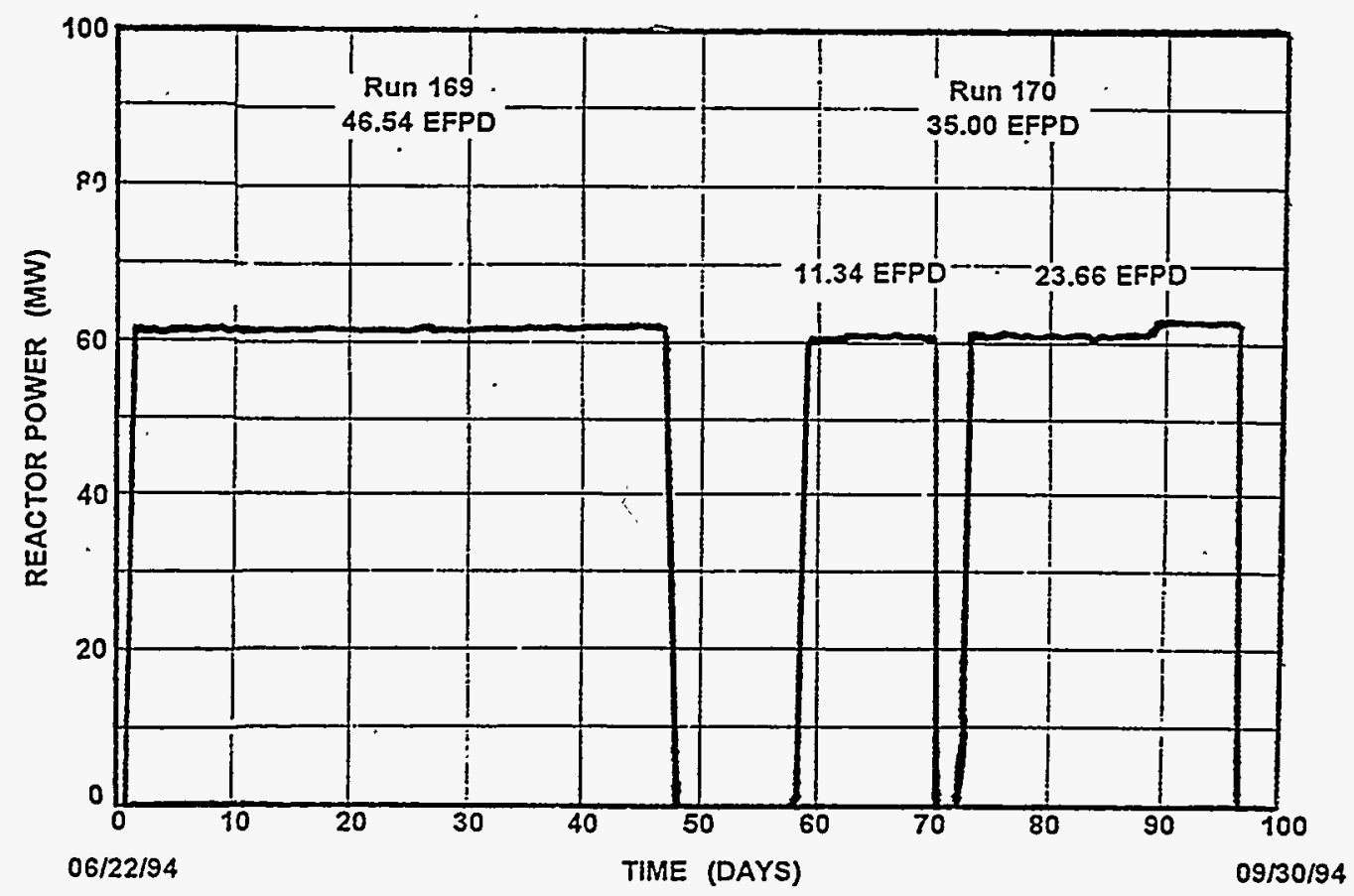

Figure 6. EBR-II Reactor Power During Runs 169 and 170. 


\section{Temperature Results}

The B7A subassembly tests in EBR-II are uninstrumented, and therefore do not contain any active temperature monitoring devices. Thermal expansion difference monitors (TEDs) and silicon carbide ( $\mathrm{SiC}$ ) monitors were placed throughout the test to monitor peak temperatures in some baskets and subcapsules. However, it will be several months before the information from these temperature monitors are available. In the meantime, estimates of the temperatures, based on prior COBRA-1Al experience, were used.

The capsules were designed to operate at specific irradiation temperatures based on various reactor and capsule parameters: nuclear heating, sodium coolant temperature, material compositions and mass distribution; for gas-gapped subcapsules, additional parameters are the gas-gap and conductivity of the gas.

The inlet coolant temperature remained constant during the irradiation of COBRA-1A. The inlet temperature was kept at $371^{\circ} \mathrm{C}$ during full power operation and during the short outages between runs. However, during the long maintenance and refueling outages in the springs of 1993 and 1994 (between Runs 163 and 164, and between Runs 168 and 169), the coolant temperature was lowered to approximately $177^{\circ} \mathrm{C}$. It should also be noted that the COBRA-1A capsules were removed from the core between Runs 163 and 164 for the reconstitution of four COBRA-1Al (X516) capsules into COBRA-1A2 (X516A).

The sodium outlet temperature for the COBRA-1A subassemblies depended on the reactor power and the heat generated from the adjacent subassemblies. The calculated outlet sodium temperature of $441^{\circ} \mathrm{C}$ was used for both COBRA-1A1 and COBRA-1A2.

The approximate mixed mean coolant temperature in the test assembly is given in Table 2. These temperatures were used to assign temperature values to the specimens in baskets in the weeper capsules B-388, B-389 and B-390 (baskets A03-A13, B03-B08, B10-B12, and C04-C10). For specimens in subcapsules in the weeper capsules (A01, A02, A14-A16, B01, B02, B09, and C01-C03), the assigned temperatures were $5-10^{\circ} \mathrm{C}$ higher. This was based on engineering judgement which took into account the core locations of the subcapsules in conjunction with encapsulation considerations (lower thermal conductivities of the gaseous bonding media).

Although capsule B-391 was gas-gapped, only subcapsule D05 was designed to operate at an elevated temperature. The remaining subcapsules (D01-D03) and basket (D04) were designed to operate close to the ambient sodium temperature, and were assigned values $5-20^{\circ} \mathrm{C}$ above the coolant temperature profile (for the same reasons as cited above). Subcapsule D 05 was designed to operate at $800^{\circ} \mathrm{C}$. However, based on a recent worst case analysis (Reference 16 ), the operating temperature of this subcapsule may have decreased by the end of the irradiation from $800^{\circ} \mathrm{C}$ to as low as $736^{\circ} \mathrm{C}$. Since there is no way to assign a verifiable temperature to this subcapsule at present, the design temperature of $800^{\circ} \mathrm{C}$ was used in this preliminary report.

\section{Dosimetry Results}

Calculated mid-plane peak fast fluxes $(E>0.111 \mathrm{MeV})$ for core position $2 B 1$ were obtained from References 17-25, and are listed in Table 3 . The peak fluences were then calculated based on the EFPD for each run.

Since the COBRA-1A2 dosimeter data have not been analyzed, flux profile information from Run 75D (Reference 26) and dosimetry results from a recent EBR-II test (Reference 27) were used to construct an estimated flux profile for a row 2 reactor position. Figure 7 shows the normalized flux curve. 
Table 2. Calculated Mixed Mean Coolant Temperature for COBRA-1A.

\begin{tabular}{|c|c|c|}
\hline \multicolumn{2}{|c|}{ Distance from Bottom of EBR-II Core } & \multirow{2}{*}{$\begin{array}{c}\text { Mixed Mean } \\
\text { Coolant } \\
\text { Temperature }\left({ }^{\circ} \mathrm{C}\right)\end{array}$} \\
\hline inches & $\mathbf{m m}$ & \\
\hline 0 & 0.0 & 375 \\
\hline 1 & 25.4 & 377 \\
\hline 2 & 50.8 & 379 \\
\hline 3 & 76.2 & 381 \\
\hline 4 & 101.6 & 384 \\
\hline 5 & 127.0 & 387 \\
\hline 6 & 152.4 & 390 \\
\hline 7 & 177.8 & 393 \\
\hline 8 & 203.2 & 396 \\
\hline 9 & 228.6 & 399 \\
\hline 10 & 254.0 & 401 \\
\hline 11 & 279.4 & 403 \\
\hline 12 & 304.8 & 405 \\
\hline 13 & 330.2 & 407 \\
\hline 14 & 355.6 & 409 \\
\hline 15 & 381.0 & 411 \\
\hline 16 & 406.4 & 413 \\
\hline 17 & 431.8 & 415 \\
\hline 18 & 457.2 & 417 \\
\hline 19 & 482.6 & 418 \\
\hline 20 & 508.0 & 421 \\
\hline 21 & 533.4 & 423 \\
\hline 22 & 558.8 & 425 \\
\hline 23 & 584.2 & 427 \\
\hline 24 & 609.6 & 429 \\
\hline 25 & 635.0 & 431 \\
\hline 26 & 660.4 & 432 \\
\hline 27 & 685.8 & 433 \\
\hline 28. & 711.2 & 434 \\
\hline 29 & 736.6 & 435 \\
\hline 30 & 762.0 & 436 \\
\hline 31 & 787.4 & 437 \\
\hline 32 & 812.8 & 438 \\
\hline 33 & 838.2 & 439 \\
\hline 34 & 863.6 & 440 \\
\hline
\end{tabular}


Table 3. Estimated Mid-Core Peak Fast Fluxes and Fluences for COBRA-1A2.

\begin{tabular}{|c||c||c||c|}
\hline $\begin{array}{c}\text { EBR-II } \\
\text { Run number }\end{array}$ & $\begin{array}{c}\text { Calculated } \\
\text { Mid-Core } \\
\text { Fast Flux } \\
{[\mathrm{E}>0.111 \mathrm{MeV}]} \\
\left(\mathrm{n} / \mathrm{cm}^{2} / \mathrm{sec}\right)\end{array}$ & $\begin{array}{c}\text { Effective Full } \\
\text { Power Days, } \\
\text { EFPD } \\
\text { (Days) }\end{array}$ & $\begin{array}{c}\text { Estimated } \\
\text { Mid-Core } \\
\text { Fast Fluence } \\
\text { [E>0.111 MeV }] \\
\left(\mathrm{n} / \mathrm{cm}^{2}\right)\end{array}$ \\
\hline 162 & $2.357 \times 10^{15}$ & 55.44 & $1.13 \times 10^{22}$ \\
\hline 163 & $2.321 \times 10^{15}$ & 33.17 & $0.67 \times 10^{22}$ \\
\hline 164 & $2.327 \times 10^{15}$ & 30.26 & $0.61 \times 10^{22}$ \\
\hline 165 & $2.341 \times 10^{15}$ & 66.00 & $1.33 \times 10^{22}$ \\
\hline 166 & $2.320 \times 10^{15}$ & 26.34 & $0.53 \times 10^{22}$ \\
\hline 167 & $2.355 \times 10^{25}$ & 30.67 & $0.62 \times 10^{22}$ \\
\hline 168 & $2.379 \times 10^{15}$ & 13.84 & $0.28 \times 10^{22}$ \\
\hline 169 & $2.376 \times 10^{15}$ & 46.54 & $0.96 \times 10^{22}$ \\
\hline 170 & $2.384 \times 10^{15}$ & 35.00 & $0.72 \times 10^{22}$ \\
\hline Totals & $2.351 \times 10^{15 *}$ & 337.26 & $6.85 \times 10^{22}$ \\
\hline
\end{tabular}

*Time-Averaged Value

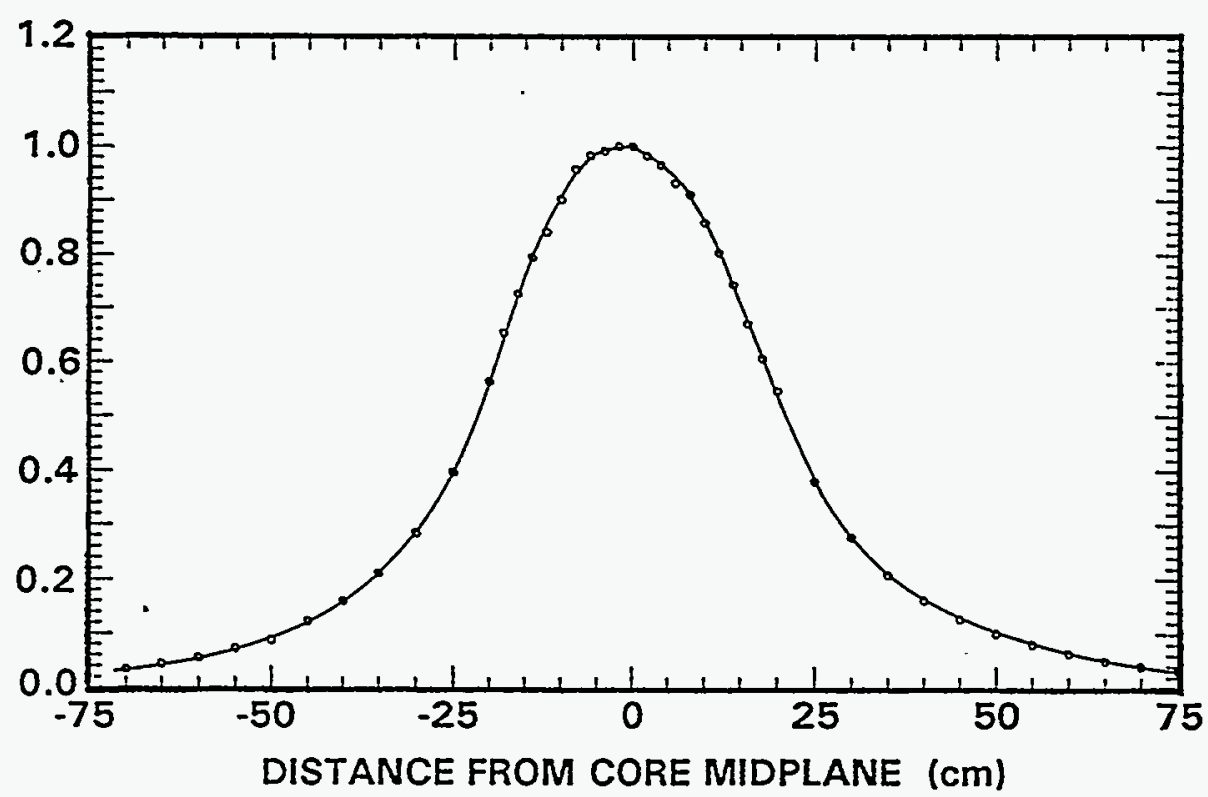

Figure 7. Estimated Normalized Flux Curve for an EBR-II Row 2 Position. 
The estimated fast flux and fast fluence data along the vertical axis are given in Table 4. The values are based on the average mid-plane fast flux value from Table 3 and the normalized flux curve in Figure 7. Table 4 also gives the irradiation exposure in dpa (for stainless steel). The dpa values are based on dosimetry results (Reference 27), and a dpa per $10^{22} \mathrm{n} / \mathrm{cm}^{2}$ profile for an EBR-II row 2 position.

Table 4. Estimated COBRA-1A2 Flux and Fluence Data.

Based on 337.3 EFPD for EBR-11 Runs 162-170

\begin{tabular}{|c|c|c|c|c|c|}
\hline $\begin{array}{l}\text { VERTICAL } \\
\text { DISTANCE FROM } \\
\text { HORIZONTAL } \\
\text { MIDPLANE [cm] }\end{array}$ & $\begin{array}{c}\text { FAST } \\
\text { FLUX, } \\
\text { E>0.1 MeV } \\
{\left[n /\left(\mathrm{cm}^{-2-s)]}\right.\right.}\end{array}$ & $\begin{array}{c}\text { FAST } \\
\text { FLUENCE, } \\
\text { E>0.1 MeV } \\
{\left[n / \mathrm{cm}^{-2} \text { ] }\right.}\end{array}$ & $\begin{array}{c}\text { dpa } \\
\text { per } \\
\text { second }\end{array}$ & $\begin{array}{l}\text { TOTAL } \\
\text { dpa }\end{array}$ & $\begin{array}{c}\text { dpa per } \\
\left(10^{-22} \mathrm{n} / \mathrm{cm}^{-2} 2\right)\end{array}$ \\
\hline+75.00 & $7.35 E+13$ & $2.14 \mathrm{E}+21$ & $2.47 E-08$ & 0.720 & 3.36 \\
\hline+70.00 & $9.27 E+13$ & $2.70 E+21$ & $3.12 E-08$ & 0.909 & 3.37 \\
\hline+65.00 & $1.16 E+14$ & $3.38 E+21$ & $3.94 E-08$ & 1.148 & 3.40 \\
\hline+60.00 & $1.49 E+14$ & 4.34E+21 & 5.07E-08 & 1.478 & 3.40 \\
\hline+55.00 & $1.88 E+14$ & $5.48 E+21$ & $6.48 E-08$ & 1.888 & 3.45 \\
\hline+50.00 & $2.36 E+14$ & $6.88 E+21$ & 8.27E-08 & 2.410 & 3.50 \\
\hline+45.00 & $2.99 E+14$ & $8.71 E+21$ & 1.06E-07 & 3.089 & 3.55 \\
\hline+40.00 & $3.81 E+14$ & $1.11 E+22$ & 1.39E-07 & 4.051 & 3.65 \\
\hline+35.00 & $4.90 E+14$ & $1.43 E+22$ & $1.86 E-07$ & 5.421 & 3.80 \\
\hline+30.00 & $6.50 E+14$ & $1.89 E+22$ & $2.54 E-07$ & 7.402 & 3.91 \\
\hline+25.00 & $8.93 E+14$ & $2.60 E+22$ & $3.66 E-07$ & 10.666 & 4.10 \\
\hline+20.00 & $1.29 E+15$ & $3.76 E+22$ & $5.54 E-07$ & 16.145 & 4.29 \\
\hline+18.00 & $1.43 E+15$ & 4.17E+22 & $6.33 E-07$ & 18.447 & 4.43 \\
\hline+16.00 & $1.58 E+15$ & $4.60 E+22$ & $7.18 E-07$ & 20.924 & 4.54 \\
\hline+14.00 & $1.75 E+15$ & $5.10 E+22$ & $8.97 E-07$ & 23.810 & 4.67 \\
\hline+12.00 & $1.89 E+15$ & $5.51 E+22$ & $8.99 E-07$ & 26.199 & 4.76 \\
\hline+10.00 & $2.02 E+15$ & $5.89 E+22$ & $9.67 E-07$ & 28.181 & 4.79 \\
\hline+8.00 & $2.14 E+15$ & $6.24 E+22$ & $1.02 E-06$ & 29.726 & 4.77 \\
\hline+6.00 & $2.20 E+15$ & $6.41 E+22$ & $1.05 E-06$ & 30.600 & 4.77 \\
\hline+4.00 & $2.27 E+15$ & $6.62 E+22$ & $1.08 E-06$ & 31.474 & 4.76 \\
\hline+2.00 & $2.31 E+15$ & $6.73 E+22$ & $1.10 E-06$ & 32.057 & 4.76 \\
\hline+0.00 & $2.35 E+15$ & $6.85 E+22$ & $1.12 E-06$ & 32.640 & 4.77 \\
\hline-2.00 & $2.35 E+15$ & $6.85 E+22$ & $1.12 E-06$ & 32.640 & 4.77 \\
\hline-4.00 & $2.33 E+15$ & $6.79 E+22$ & $1.11 E-06$ & 32.348 & 4.76 \\
\hline-6.00 & $2.31 E+15$ & $6.73 E+22$ & $1.10 E-06$ & 32.057 & 4.76 \\
\hline-8.00 & $2.25 E+15$ & $6.56 E+22$ & 1.07E-06 & 31.183 & 4.76 \\
\hline-10.00 & 2. $12 E+15$ & $6.18 E+22$ & 1.01E-06 & 29.434 & 4.76 \\
\hline-12.00 & $1.98 E+15$ & $5.77 E+22$ & $9.39 E-07$ & 27.365 & 4.74 \\
\hline-14.00 & $1.87 E+15$ & $5.45 \mathrm{E}+22$ & 8.74E-07 & 25.471 & 4.67 \\
\hline-16.00 & $1.71 E+15$ & $4.98 E+22$ & $7.78 E-07$ & 22.673 & 4.55 \\
\hline-18.00 & $1.54 E+15$ & $4.49 E+22$ & $6.82 E-07$ & 19.875 & 4.43 \\
\hline-20.00 & $1.33 E+15$ & $3.88 E+22$ & $5.74 E-07$ & 16.728 & 4.32 \\
\hline-25.00 & $9.33 E+94$ & $2.72 E+22$ & $3.83 E-07$ & 11.162 & 4.11 \\
\hline-30.00 & $6.67 E+94$ & $1.94 E+22$ & $2.61 E-07$ & 7.606 & 3.91 \\
\hline-35.00 & $4.95 E+14$ & $1.44 E+22$ & $1.88 E-07$ & 5.479 & 3.80 \\
\hline-40.00 & $3.75 E+14$ & $1.09 E+22$ & $1.37 E-07$ & 3.993 & 3.65 \\
\hline-45.00 & $2.87 E+14$ & $8.36 E+21$ & $9.02 E-07$ & 2.973 & 3.55 \\
\hline-50.00 & $2.06 E+14$ & $6.00 E+21$ & $7.21 E-08$ & 2.101 & 3.50 \\
\hline-55.00 & $1.70 E+14$ & $4.95 E+21$ & $5.84 E-08$ & 1.702 & 3.44 \\
\hline-60.00 & $1.29 E+14$ & $3.76 E+21$ & 4.39E-08 & 1.279 & $3.40^{\circ}$ \\
\hline-65.00 & $1.01 E+14$ & $2.94 E+21$ & $3.42 E-08$ & 0.997 & 3.39 \\
\hline-70.00 & $7.88 E+13$ & $2.30 E+21$ & $2.65 E-08$ & 0.772 & 3.36 \\
\hline
\end{tabular}

Flux and dpa profiles based on calculations and previous dosimetry. dpa values are estimates for an $\mathrm{Fe}-18 \mathrm{Cr}-8 \mathrm{Ni}$ stainless steel. 


\section{COBRA-1A2 Damage Parameters}

Combining the information from Table 3, Figure 7 and Reference 27 with the basket and subcapsule length information and the basket $z$-values, the fast fluence and dpa values for each basket and subcapsule were generated. Values were calculated for the tops, bottoms and middles of all baskets and subcapsules. The values were determined by linearly interpolation (on a semi-log scale) of flux and dpa rate curves. Tables $5,6,7$, and 8 give the fluences and dpa values for each basket and subcapsule in capsules B-388, B-389, B-390 and B-391, respectively. Again note that the fluence values are for energies greater than $0.111 \mathrm{MeV}$, and the dpa values are for an $\mathrm{Fe}-18 \mathrm{Cr}-8-\mathrm{Ni}$ stainless steel. Experimenters will need to apply an appropriate dpa correction factor for other materials.

The entire database listing for the COBRA-1A2 specimens has been generated and is available at PNL.[28] Also included are the COBRA-1A2 capsule loading diagrams showing all baskets and subcapsules, their relative stacking within each capsule, and various capsule, basket, subcapsule and specimen related information.

\section{CONCLUSIONS}

Preliminary irradiation parameters (temperatures, fluences and dpa values) for all test locations and specimens in COBRA-1A2 were reported. Additional details regarding the estimated irradiation conditions for individual specimens are available through PNL.

\section{FUTURE WORK}

A final report for the COBRA-1A2 test will be issued once the TED and $\mathrm{SiC}$ temperature monitors, and dosimetry from the four COBRA-1A2 capsules have been analyzed.

\section{REFERENCES}

1. L. M. McWethy and C. R. Eiholzer, "As-Built Data Package for X516 COBRA-1A Experiment (Capsules B-388 through B-394)," WHC-SD-GN-DP-30001, October 1992.

2. C. R. Eiholzer and L. M. McWethy, "Data Package-Part One, Experiment Description of the COBRA-1A Experiment," WHC-SD-GN-DR-30002, September 1992.

3. L. M. MoWethy, "Data Package - Part Two, Safety Analyses for the COBRA-1A Experiment," WHC-SD-GN-SAR-30001, September 1992.

4. L. M. Mowethy and C. R. Eiholzer, "Fabrication Travelers for X516 COBRA-1A Experiment (Capsules B388-B394)," WHC-SD-GN-DP-30002, October 1992.

5. M. L. Hamilton, R. M. Ermi and C. R. Eiholzer, "Preparation of COBRA-1A for Insertion into EBR-II, ${ }^{n}$ Fusion Reactor Materials Semiannual Progress Report for the Period Ending March 31, 1993, DOE/ER-0313/14 , pp. 3-13.

6. L. M. McWethy and C. R. Eiholzer, "Data Package Addendum for COBRA-1A Reconstitution (X516A)," WHC-SD-GN-SAR-30003, March 1993. 
7. Argonne National Laboratory IFR Division Run Report. EBR-II Run 162 , November 20 - February 1, 1993.

8. Argonne National Laboratory IFR Division Run Report. EBR-II Run 163, February 26 - April I, 1993.

9. Argonne National Laboratory IFR Division Run Report. EBR-II Run 164, June 4 - July 6, 1993.

10. Argonne National Laboratory IFR Division Run Report. EBR-II Run 165, July 29 - October 7, 1993.

11. Argonne National Laboratory IFR Division Run Report. EBR-II Run 166, October 30 - December $1,1993$.

12. Argonne National Laboratory IFR Division Run Report. EBR-II Run 167, December 23, 1993 February 6, 1994.

13. Argonne National Laboratory IFR Division Run Report. EBR-II Run 168, February 25 - March 30, 1994.

14. Argonne National Laboratory IFR Division Run Report. EBR-II Run 169, June 22 - August 9 , 1994.

15. Argonne National Laboratory IFR Division Run Report. EBR-II Run 170, August 19 - September 30, 1994.

16. S. L. Hecht and A. M. Ermi, "Data Package Addendum for COBRA-1A2 Life Extension to 400 EFPD," WHC-SD-GN-DP-20002, August 1994.

17. Letter, E. K. Fujita (ANL-W) to EBR-II Irradiation Experimenters, "Information for Run 162A," December 10, 1992.

18. Letter, E. K. Fujita (ANL-W) to EBR-II Irradiation Experimenters, "Information for Run 163A," March 19, 1993.

19. Letter, E. K. Fujita (ANL-W) to EBR-II Irradiation Experimenters, "Information for Run 164A," June 14, 1993.

20. Letter, E. K. Fujita (ANL-W) to EBR-II Iradiation Experimenters, "Information for Run 165A," August 12, 1993.

21. Letter, E. K. Fujita (ANL-W) to EBR-II Irradiation Experimenters, "Information for Run 166A," November 10, 1993.

22. Letter, E. K. Fujita (ANL-W) to EBR-II Iradiation Experimenters, "Information for Run 167B," January 18, 1994.

23. Letter, E. K. Fujita (ANL-W) to EBR-II Irradiation Experimenters, "Information for Run 168A," March 14, 1994. 
24. Letter, E. K. Fujita (ANL-W) to EBR-II Irradiation Experimenters, "Information for Run 169A," July $25,1994$.

25. Letter, E. K. Fujita (ANL-W) to EBR-II Irradiation Experimenters, "Information for Proposed Run 170A," August 2, 1994.

26. C.L. Long, J.A. Ulseth, E.P. Lippincott, N.J. Graves, " EBR-II Spectral Parameters Run 75D," HEDL-TME-78-84, March 1979.

27. Letter, L.R. Greenwood (PNL) to D.J. Trimble (WHC), "Dosimetry Results for the KIST I Experiment in EBR-II," October 3, 1990.

28. Letter, A. M. Ermi (WHC) to R. H. Jones (PNL), "Preliminary Report on the Irradiation Conditions of the EBR-II COBRA-1A2 Test," WHC Correspondence No. 9457838, November 17, 1994. 
Table 5. Estimated Irradiation Parameters for COBRA-1A2, Capsule B-388.

Based on 337.3 EFPD for EBR-1I Runs $162-170$

\begin{tabular}{|c|c|c|c|c|c|c|c|c|}
\hline I.D. & ${ }^{T e m p .}$ & $\begin{array}{l}\text { Temp. } \\
\text { Monitor }\end{array}$ & Program & $\begin{array}{l}\text { Capsule } \\
\text { Insert }\end{array}$ & $\begin{array}{l}\text { Length } \\
\text { (in)** }\end{array}$ & $\begin{array}{l}\text { Z-Horizontal } \\
\text { Midplane (in)\# }\end{array}$ & $\begin{array}{c}\text { Fast } \\
\text { Fluence }\end{array}$ & $\begin{array}{l}\text { dpa } \\
\text { in SS }\end{array}$ \\
\hline A16 & 440 & none & Fusion & Subcapsule & 4.164 & $\begin{array}{l}\text { Top: }+27.308 \\
\text { Mid: }+25.398 \\
\text { Bot: }+23.488\end{array}$ & $\begin{array}{l}2.78 E 21 \\
3.46 E 21 \\
4.41 E 21\end{array}$ & $\begin{array}{l}0.93 \\
1.18 \\
1.50\end{array}$ \\
\hline A15 & 432 & none & Fusion & subcapsule & 4.164 & $\begin{array}{l}\text { Top: }+19.067 \\
\text { Mid: }+17.157 \\
\text { Bot: }+15.247\end{array}$ & $\begin{array}{l}7.41 E 21 \\
9.34 E 21 \\
1.18 E 22\end{array}$ & $\begin{array}{l}2.61 \\
3.34 \\
4.36\end{array}$ \\
\hline A94 & 420 & none & Fusion & Subcapsule & 4.164 & $\begin{array}{l}\text { Top: }+10.722 \\
\text { Mid: }+8.812 \\
\text { Bot: } \quad+6.902\end{array}$ & $\begin{array}{l}2.26 E 22 \\
3.16 E 22 \\
4.27 E 22\end{array}$ & $\begin{array}{l}9.06 \\
13.3 \\
19.0\end{array}$ \\
\hline$A 13$ & 406 & none & fusion & Basket & 1.220 & $\begin{array}{l}\text { Top: }+6.710 \\
\text { Mid: }+6.110 \\
\text { Bot: }+5.510\end{array}$ & $\begin{array}{l}4.37 E 22 \\
4.72 E 22 \\
5.10 E 22 \\
\end{array}$ & $\begin{array}{l}19.6 \\
21.6 \\
23.8\end{array}$ \\
\hline $\mathrm{A} 12$ & 404 & none & Fusion & Basket & 1.220 & $\begin{array}{ll}\text { Top: } & +5.490 \\
\text { Mid: } & +4.890 \\
\text { Bot: } & +4.290\end{array}$ & $\begin{array}{l}5.11 E 22 \\
5.42 E 22 \\
5.71 E 22\end{array}$ & $\begin{array}{l}23.9 \\
25.7 \\
27.3\end{array}$ \\
\hline A11 & 401 & none & Fusion & Basket & 1.220 & $\begin{array}{ll}\text { Top: } & +4.270 \\
\text { Mid: } & +3.670 \\
\text { Bot: } & +3.070\end{array}$ & $\begin{array}{l}5.72 E 22 \\
6.00 E 22 \\
6.25 E 22\end{array}$ & $\begin{array}{l}27.3 \\
28.7 \\
29.8\end{array}$ \\
\hline A10 & 399 & none & Fusion & Basket & 1.220 & $\begin{array}{l}\text { Top: }+3.050 \\
\text { Mid: }+2.450 \\
\text { Bot: }+9.850\end{array}$ & $\begin{array}{l}6.26 E 22 \\
6.39 E 22 \\
6.54 E 22\end{array}$ & $\begin{array}{l}29.8 \\
30.5 \\
31.2\end{array}$ \\
\hline$A 09$ & 395 & none & Fusion & Basket & 1.220 & $\begin{array}{ll}\text { Top: } & +1.830 \\
\text { Mid: } & +1.230 \\
\text { Bot: } & +0.630\end{array}$ & $\begin{array}{l}6.55 E 22 \\
6.67 E 22 \\
6.76 E 22\end{array}$ & $\begin{array}{l}31.2 \\
31.7 \\
32.2\end{array}$ \\
\hline A08 & 392 & none & Fusion & Basket & 1.220 & $\begin{array}{ll}\text { Top: } & +0.610 \\
\text { Mid: } & +0.010 \\
\text { Bot: } & -0.590\end{array}$ & $\begin{array}{l}6.76 E 22 \\
6.85 E 22 \\
6.85 E 22\end{array}$ & $\begin{array}{l}32.2 \\
32.6 \\
32.6\end{array}$ \\
\hline$A 07$ & 388 & none & Fusion & Basket & 1.220 & $\begin{array}{ll}\text { Top: } & -0.610 \\
\text { Mid: } & -1.210 \\
\text { Bot: } & -1.810\end{array}$ & $\begin{array}{l}6.85 E 22 \\
6.82 E 22 \\
6.7 \pi E 22\end{array}$ & $\begin{array}{l}32.6 \\
32.5 \\
32.3\end{array}$ \\
\hline A06 & 384 & none & Fusion & Basket & 1.220 & $\begin{array}{ll}\text { Top: } & -1.830 \\
\text { Mid: } & -2.430 \\
\text { Bot: } & -3.030\end{array}$ & $\begin{array}{l}6.77 \mathrm{E} 22 \\
6.72 \mathrm{E} 22 \\
6.58 \mathrm{E} 22 \\
\end{array}$ & $\begin{array}{l}32.3 \\
32.0 \\
31.3\end{array}$ \\
\hline A05 & 381 & none & Fusion & Basket & 1.220 & $\begin{array}{ll}\text { Top: } & -3.050 \\
\text { Mid: } & -3.650 \\
\text { Bot: } & -4.250\end{array}$ & $\begin{array}{l}6.58 E 22 \\
6.31 E 22 \\
6.01 E 22\end{array}$ & $\begin{array}{l}31.3 \\
30.1 \\
28.6\end{array}$ \\
\hline $\mathrm{AO4}$ & 378 & none & Fusion & Basket & 1.220 & $\begin{array}{ll}\text { Top: } & -4.270 \\
\text { Mid: } & -4.870 \\
\text { Bot: } & -5.470\end{array}$ & $\begin{array}{l}\text { 6.00E22 } \\
5.71 \mathrm{E22} \\
5.47 \mathrm{E} 22\end{array}$ & $\begin{array}{l}28.5 \\
27.0 \\
25.6\end{array}$ \\
\hline $\mathrm{A} 03$ & 376 & TED(Ine) & Fusion & Basket & 1.220 & $\begin{array}{ll}\text { Top: } & -5.490 \\
\text { Mid: } & -6.090 \\
\text { Bot: } & -6.690\end{array}$ & $\begin{array}{l}5.46 \mathrm{E} 22 \\
5.10 \mathrm{E} 22 \\
4.73 \mathrm{E} 22\end{array}$ & $\begin{array}{l}25.5 \\
23.4 \\
21.2\end{array}$ \\
\hline $\mathrm{AOZ}$ & $3 \pi$ & none & Fusion & Subcapsule & 2.464 & $\begin{array}{l}\text { Top: }-11.882 \\
\text { Mid: }-12.942 \\
\text { Bot: }-14.002\end{array}$ & $\begin{array}{l}1.92 \mathrm{E} 22 \\
1.64 \mathrm{E22} \\
1.40 \mathrm{E} 22\end{array}$ & $\begin{array}{l}7.52 \\
6.30 \\
5.29\end{array}$ \\
\hline A01 & 375 & none & Fusion & Subcapsule & $2.464^{\circ}$ & $\begin{array}{l}\text { Top: }-14.346 \\
\text { Mid: }-15.406 \\
\text { Bot: }-16.466\end{array}$ & $\begin{array}{l}1.33 E 22 \\
1.15 E 22 \\
9.91 \mathrm{E} 21\end{array}$ & $\begin{array}{l}5.00 \\
4.22 \\
3.59\end{array}$ \\
\hline
\end{tabular}

* Average Temperatures Based on Calculations and Coolant Profile

** Total Length Ineluding Basket/Subeapsule Tops and Bottoms

\# Includes Only Specimen Region, Not Basket/Subcapsule Tops and Bottoms

\# Fluence Units: $\mathrm{n} / \mathrm{cm}^{* 2}$ [E>0.1 MeV] 
Table 6. Estimated Irradiation Parameters for COBRA-1A2, Capsule B-389.

\begin{tabular}{|c|c|c|c|c|c|c|c|c|}
\hline I.D. & ${ }^{T} \mathrm{C}^{\star}$ & $\begin{array}{l}\text { Temp. } \\
\text { Monitor }\end{array}$ & Program & $\begin{array}{c}\text { Capsule } \\
\text { Insert }\end{array}$ & $\begin{array}{l}\text { Length } \\
\text { (in)** }\end{array}$ & $\begin{array}{l}\text { 2-Horizontal } \\
\text { Kidplane (in)\# }\end{array}$ & $\begin{array}{c}\text { Fast } \\
\text { Fluence\# }\end{array}$ & $\begin{array}{l}\text { dpa } \\
\text { in Ss }\end{array}$ \\
\hline$B 12$ & 431 & none & Dos. & Basket & 1.300 & $\begin{array}{l}\text { Top: }+19.214 \\
\text { Mid: }+18.574 \\
\text { Bot: }+17.934\end{array}$ & $\begin{array}{l}7.28 E 21 \\
7.86 E 21 \\
8.49 E 21\end{array}$ & $\begin{array}{l}2.56 \\
2.77 \\
3.01\end{array}$ \\
\hline B11 & 415 & TED (InC) & Temp/Dos & Basket & 1.300 & $\begin{array}{l}\text { Top: }+10.912 \\
\text { Mid: }+10.272 \\
\text { Bot: }+9.632 \\
\end{array}$ & $\begin{array}{l}2.19 E 22 \\
2.43 E 22 \\
2.71 E 22 \\
\end{array}$ & $\begin{array}{r}8.75 \\
9.85 \\
11.1 \\
\end{array}$ \\
\hline B10 & 407 & none & Dos. & Basket & 1.000 & $\begin{array}{ll}\text { Top: } & +6.803 \\
\text { Mid: } & +6.313 \\
\text { Bot: } & +5.823\end{array}$ & $\begin{array}{l}4.32 E 22 \\
4.60 E 22 \\
4.90 E 22\end{array}$ & $\begin{array}{l}19.3 \\
20.9 \\
22.6\end{array}$ \\
\hline 809 & 410 & sic & Fusion & Subcapsule & 3.664 & $\begin{array}{ll}\text { Top: } & +5.631 \\
\text { Mid: } & +3.971 \\
\text { Bot: } & +2.311 \\
\end{array}$ & $\begin{array}{l}5.02 E 22 \\
5.87 E 22 \\
6.42 E 22 \\
\end{array}$ & $\begin{array}{l}23.3 \\
28.1 \\
30.7\end{array}$ \\
\hline 808 & 395 & TED (Inc) & Fusion & Basket & 1.940 & $\begin{array}{ll}\text { Top: } & +2.119 \\
\text { Mid: } & +1.159 \\
\text { Bot: } & +0.199\end{array}$ & $\begin{array}{l}6.47 \mathrm{E} 22 \\
6.68 \mathrm{E} 22 \\
6.82 \mathrm{E} 22\end{array}$ & $\begin{array}{l}30.9 \\
31.8 \\
32.5\end{array}$ \\
\hline BO7 & 389 & none & Fusion & Basket & 1.940 & $\begin{array}{ll}\text { Top: } & +0.179 \\
\text { Mid: } & -0.781 \\
\text { Bot: } & -1.741 \\
\end{array}$ & $\begin{array}{l}6.82 \mathrm{E} 22 \\
6.85 \mathrm{E} 22 \\
6.78 \mathrm{E} 22 \\
\end{array}$ & $\begin{array}{l}32.5 \\
32.6 \\
32.3 \\
\end{array}$ \\
\hline BO6 & 383 & none & Fusion & Basket & 1.940 & $\begin{array}{ll}\text { Top: } & -1.761 \\
\text { Mid: } & -2.721 \\
\text { Bot: } & -3.681 \\
\end{array}$ & $\begin{array}{l}6.78 E 22 \\
6.65 E 22 \\
6.30 \mathrm{E} 22\end{array}$ & $\begin{array}{l}32.3 \\
31.7 \\
30.0\end{array}$ \\
\hline 805 & 379 & none & Fusion & Basket & 1.940 & $\begin{array}{ll}\text { Top: } & -3.701 \\
\text { Mid: } & -4.661 \\
\text { Bot: } & -5.621 \\
\end{array}$ & $\begin{array}{l}6.29 E 22 \\
5.80 E 22 \\
5.38 E 22 \\
\end{array}$ & $\begin{array}{l}29.9 \\
27.5 \\
25.1 \\
\end{array}$ \\
\hline$B 04$ & $376^{\prime}$ & none & Fusion & Basket & 1.100 & $\begin{array}{ll}\text { Top: } & -5.641 \\
\text { Mid: } & -6.181 \\
\text { Bot: } & -6.721\end{array}$ & $\begin{array}{l}5.37 E 22 \\
5.05 E 22 \\
4.71 E 22 \\
\end{array}$ & $\begin{array}{l}25.0 \\
23.1 \\
21.1\end{array}$ \\
\hline $\mathrm{BO3}$ & 373 & TED (Inc) & Fusion & Basket & 1.300 & $\begin{array}{l}\text { Top: }-10.410 \\
\text { Mid: }-11.050 \\
\text { Bot: }-11.690\end{array}$ & $\begin{array}{l}2.47 \mathrm{E} 22 \\
2.21 \mathrm{E} 22 \\
1.98 \mathrm{E} 22 \\
\end{array}$ & $\begin{array}{l}9.99 \\
8.82 \\
7.79\end{array}$ \\
\hline $\mathrm{BO2}$ & 377 & none & Fusion & Subcapsule & 2.464 & $\begin{array}{l}\text { Top: }-11.882 \\
\text { Mid: }-12.942 \\
\text { Bot: }-14.002\end{array}$ & $\begin{array}{l}1.92 E 22 \\
1.64 \mathrm{E22} \\
1.40 \mathrm{E} 22\end{array}$ & $\begin{array}{l}7.52 \\
6.30 \\
5.29\end{array}$ \\
\hline B01 & 375 & none & Fusion & Subcapsule & 2.464 & $\begin{array}{l}\text { Top: }-14.346 \\
\text { Mid: }-15.406 \\
\text { Bot: }-16.466\end{array}$ & $\begin{array}{l}1.33 \mathrm{E22} \\
1.15 \mathrm{E22} \\
9.91 \mathrm{E21}\end{array}$ & $\begin{array}{l}5.00 \\
4.22 \\
3.59\end{array}$ \\
\hline
\end{tabular}

* Average Temperatures Based on Calculations and Coolant Profile

** Total Length Including Basket/Subcapsule Tops and Bottoms

\# Includes Only Specimen Region, Not Basket/Subcapsule Tops and Bottoms

\# Fluence Units: $n / \mathrm{cm}^{-2}$ [E>0.1 $\left.\mathrm{HeV}\right]$ 
Table 7. Estimated Irradiation Parameters for COBRA-1A2, Capsule B-390.

Based on 337.3 EFPD for EBR-11 Runs $162-170$

\begin{tabular}{|c|c|c|c|c|c|c|c|c|c|}
\hline I.D. & $\begin{array}{l}\text { Temp. } \\
\text { " }^{\star}\end{array}$ & $\begin{array}{l}\text { Temp. } \\
\text { Monitor }\end{array}$ & Program & $\begin{array}{l}\text { Capsule } \\
\text { Insert }\end{array}$ & $\begin{array}{l}\text { Length } \\
\text { (in) }\end{array}$ & \multicolumn{2}{|c|}{$\begin{array}{l}\text { Z-Horizontal } \\
\text { Midplane (in) \# }\end{array}$} & $\begin{array}{c}\text { Fast } \\
\text { Fluencew= }\end{array}$ & $\begin{array}{l}\text { dpa } \\
\text { in SS }\end{array}$ \\
\hline C10 & 405 & $T E D($ ine) & Fusion & Basket & 1.220 & $\begin{array}{l}\text { Top: } \\
\text { Mid: } \\
\text { Bot: }\end{array}$ & $\begin{array}{r}+6.254 \\
+5.654 \\
+5.054\end{array}$ & $\begin{array}{l}4.63 E 22 \\
5.01 E 22 \\
5.33 E 22\end{array}$ & $\begin{array}{l}21.1 \\
23.3 \\
25.2\end{array}$ \\
\hline $\cos$ & 403 & none & Fusion & Basket & 1.220 & $\begin{array}{l}\text { Top: } \\
\text { Mid: } \\
\text { Bot: }\end{array}$ & $\begin{array}{r}+5.034 \\
+4.434 \\
+3.834\end{array}$ & $\begin{array}{l}5.34 \mathrm{E} 22 \\
5.64 \mathrm{E} 22 \\
5.93 \mathrm{E} 22\end{array}$ & $\begin{array}{l}25.2 \\
26.9 \\
28.4\end{array}$ \\
\hline c08 & 401 & none & Fusion & Basket & 1.220 & $\begin{array}{l}\text { Top: } \\
\text { Mid: } \\
\text { Bot: }\end{array}$ & $\begin{array}{r}+3.814 \\
+3.214 \\
+2.614\end{array}$ & $\begin{array}{l}5.94 \mathrm{E} 22 \\
6.21 \mathrm{E} 22 \\
6.35 \mathrm{E} 22\end{array}$ & $\begin{array}{l}28.4 \\
29.6 \\
30.3\end{array}$ \\
\hline $\mathrm{CO}$ & 397 & none & Fusion & Basket & 1.220 & $\begin{array}{l}\text { Top: } \\
\text { Mid: } \\
\text { Bot: }\end{array}$ & $\begin{array}{r}+2.594 \\
+1.994 \\
+1.394\end{array}$ & $\begin{array}{l}6.36 E 22 \\
6.51 E 22 \\
6.64 E 22\end{array}$ & $\begin{array}{l}30.3 \\
31.0 \\
31.6\end{array}$ \\
\hline $\cos$ & 394 & none & Fusion & Basket & 1.220 & $\begin{array}{l}\text { Top: } \\
\text { Mid: } \\
\text { Bot: }\end{array}$ & $\begin{array}{l}+1.374 \\
+0.774 \\
+0.174\end{array}$ & $\begin{array}{l}6.64 E 22 \\
6.73 E 22 \\
6.82 E 22\end{array}$ & $\begin{array}{l}31.6 \\
32.1 \\
32.5\end{array}$ \\
\hline $\cos$ & 390 & none & Fusion & Basket & 1.220 & $\begin{array}{l}\text { Top: } \\
\text { Mid: } \\
\text { Bot: }\end{array}$ & $\begin{array}{l}+0.154 \\
-0.446 \\
-1.046\end{array}$ & $\begin{array}{l}6.83 E 22 \\
6.85 E 22 \\
6.83 E 22\end{array}$ & $\begin{array}{l}32.5 \\
32.6 \\
32.5\end{array}$ \\
\hline $\mathrm{CO}$ & 386 & none & Fusion & Basket & 1.220 & $\begin{array}{l}\text { Top: } \\
\text { Mid: } \\
\text { Bot: }\end{array}$ & $\begin{array}{l}-1.066 \\
-1.666 \\
-2.266\end{array}$ & $\begin{array}{l}6.83 E 22 \\
6.78 E 22 \\
6.74 E 22\end{array}$ & $\begin{array}{l}32.5 \\
32.3 \\
32.1\end{array}$ \\
\hline $\cos$ & 388 & none & Fusion & Subcapsule & 9.424 & $\begin{array}{l}\text { Top: } \\
\text { Mid: } \\
\text { Bot: }\end{array}$ & $\begin{array}{r}-2.458 \\
-6.998 \\
-11.538\end{array}$ & $\begin{array}{l}6.71 E 22 \\
4.54 E 22 \\
2.04 E 22\end{array}$ & $\begin{array}{c}31.9 \\
20.2 \\
8.02\end{array}$ \\
\hline $\mathrm{CO} 2$ & 378 & none & Fusion & Subcapsule & 2.464 & $\begin{array}{l}\text { Top: } \\
\text { Mid: } \\
\text { Bot: }\end{array}$ & $\begin{array}{l}-11.882 \\
-12.942 \\
-14.002\end{array}$ & $\begin{array}{l}1.92 E 22 \\
1.64 E 22 \\
1.40 E 22\end{array}$ & $\begin{array}{l}7.52 \\
6.30 \\
5.29\end{array}$ \\
\hline $\mathrm{COI}$ & 375 & none & Fusion & Subcapsule & 2.464 & $\begin{array}{l}\text { Top: } \\
\text { Mid: } \\
\text { Bot: }\end{array}$ & $\begin{array}{l}-14.346 \\
-15.406 \\
-16.466\end{array}$ & $\begin{array}{l}1.33 \mathrm{E} 22 \\
1.15 \mathrm{EE22} \\
9.91 \mathrm{E} 21\end{array}$ & $\begin{array}{l}5.00 \\
4.22 \\
3.59\end{array}$ \\
\hline
\end{tabular}

- Average Temperatures Based on Calculations and coolant Profile

** Total Length Including Basket/Subcapsule Tops and Bottons

\# Includes Only Specimen Region, Not Basket/Subcapsule Tops and Bottons

\#\# Fluence Units: $\mathrm{n} / \mathrm{cm}^{-2}$ [E>0.1 MeV] 
Table 8. Estimated Irradiation Parameters for COBRA-1A2, Capsule B-391.

Based on 337.3 EFPD for EBR-II Runs 162-170

\begin{tabular}{|c|c|c|c|c|c|c|c|c|}
\hline I.D. & $\operatorname{Temp.}^{-c^{\star}}$ & $\begin{array}{l}\text { Temp. } \\
\text { Monitor }\end{array}$ & Program & $\begin{array}{l}\text { Capsule } \\
\text { Insert }\end{array}$ & $\begin{array}{l}\text { Length } \\
\text { (in)** }\end{array}$ & $\begin{array}{l}\text { Z-Horizontal } \\
\text { Midplane (in)\# }\end{array}$ & $\begin{array}{c}\text { Fast } \\
\text { Fluencem }\end{array}$ & $\begin{array}{l}\text { dpa } \\
\text { in Ss }\end{array}$ \\
\hline D05 & 800 & sic & Fusion & Subcapsule & 5.170 & $\begin{array}{ll}\text { Top: } & +4.108 \\
\text { Mid: } & +1.695 \\
\text { Bot: } & -0.718\end{array}$ & $\begin{array}{l}5.80 E 22 \\
6.58 \mathrm{E} 22 \\
6.85 \mathrm{E} 22\end{array}$ & $\begin{array}{l}27.7 \\
31.3 \\
32.6\end{array}$ \\
\hline D04 & 405 & none & Dos. & Basket & 1.000 & $\begin{array}{ll}\text { Top: } & -1.460 \\
\text { Mid: } & -1.950 \\
\text { Bot: } & -2.440 \\
\end{array}$ & $\begin{array}{l}6.80 E 22 \\
6.76 E 22 \\
6.71 E 22 \\
\end{array}$ & $\begin{array}{l}32.4 \\
32.2 \\
32.0\end{array}$ \\
\hline $\mathrm{D} 03$ & 395 & none & Fusion & Subcapsule & 9.250 & $\begin{array}{lr}\text { Top: } & -2.800 \\
\text { Mid: } & -7.086 \\
\text { Bot: } & -11.372 \\
\end{array}$ & $\begin{array}{l}6.63 E 22 \\
4.49 E 22 \\
2.09 E 22\end{array}$ & $\begin{array}{c}31.6 \\
19.9 \\
8.29\end{array}$ \\
\hline D02 & 378 & none & Fusion & Subcapsule & 2.464 & $\begin{array}{l}\text { Top: }-11.882 \\
\text { Mid: }-12.942 \\
\text { Bot: }-14.002 \\
\end{array}$ & $\begin{array}{l}1.92 E 22 \\
1.64 \mathrm{E} 22 \\
1.40 \mathrm{E} 22 \\
\end{array}$ & $\begin{array}{l}7.52 \\
6.30 \\
5.29 \\
\end{array}$ \\
\hline DOI & 375 & none & Fusion & Subcapsule & 2.464 & $\begin{array}{l}\text { Top: }-14.346 \\
\text { Mid: }-15.406 \\
\text { Bot: }-16.466\end{array}$ & $\begin{array}{l}1.33 \mathrm{E} 22 \\
1.15 \mathrm{E} 22 \\
9.91 \mathrm{E21}\end{array}$ & $\begin{array}{l}5.00 \\
4.22 \\
3.59\end{array}$ \\
\hline
\end{tabular}

* Average Temperatures Based on Calculations and Coolant Profile

** Total Length Including Basket/Subcapsule Tops and Bottoms

\# Includes Only Specimen Region, Not Basket/Subcapsule Tops and Bortoms

\#\# Fluence Units: $\mathrm{n} / \mathrm{cm}^{-2}$ [E>0.1 MeV] 
NEUTRONICS ASPECTS OF THE DESIGN OF THE A1 DROP-IN EXPERIMENT AT ATR Itacil C. Gomes and Dale L. Smith

\section{OBJECTIVE}

The objective of this task is to reduce the vanadium to chromium transmutation rate to acceptable levels during irradiation at the A-10 position of the ATR fission reactor and to estimate the nuclear heating deposition on the specimens and structure of the capsule within the narrowest possible band of uncertainty.

\section{SUMMARY}

The transmutation rate of vanadium to chromium was controlled with the use of thermal neutron absorber (gadolinium) which was incorporated, by design, within the drop-in experimental capsule. Gadolinium was selected as the filtering material due to several reasons, among those one can mention, high cross section for thermal neutrons, required thickness to survive 5 dpa's irradiation of less than $2 \mathrm{~mm}$, good neutronics data base, easy handling, and overall cost.

The nuclear heat deposition, accounting for gamma-ray and neutron heating from the surroundings (core and reflector region) and gamma-ray heating produced by the capture of thermal neutrons at the thermal neutron filter, was estimated at each region of the capsule. The temperature distribution inside the capsule was analyzed as a function of the gas gap between the sub-capsule and the holder (maintained at the coolant temperature 600). The results presented here are considered preliminary, and a more precise estimation of the values is underway.

\section{PROGRESS AND STATUS}

\section{Introduction}

The ATR (Advanced Test Reactor) is an irradiation testing reactor with several positions for irradiation. The outer A positions of ATR are the most suitable, among the drop-in positions, to perform irradiation testing of fusion materials because of the characteristics of the neutron energy spectrum. The Al experiment is to be performed at the A-10 position of ATR. The test matrix for the A1 experiment is composed primarily of vanadium with a few specimens of ferritic steel. It is well known that vanadium irradiation in fission reactors has to be carefully designed to avoid excessive transmutation of vanadium to chromium. The Al experiment is a drop-in experiment in which the temperature of the specimens is controlled by the design of the capsule. The use of the thermal neutron filter to reduce the transmutation rates of vanadium to acceptable levels further complicates the control of the temperature due to the additional gamma-ray source produce by the filter itself due the neutron capture.

This paper describes the neutronics calculations and the design approach to accommodate the requirement of the experiment within the narrowest possible band of uncertainty concerning temperature and transmutation rate during the experiment.

\section{Procedure}

The transmutation and the expected lifetime of the filtering material were estimated based on an experimental neutron flux spectrum for the A-10 channel of ATR measured by JW Rogers [1]. The transmutation rate of vanadium to chromium was calculated based on the spectrum obtained from the transport of the above mentioned neutron flux spectrum through the absorber's wall. The REAC3 [2] code was used to quantify the transmutation rate and the ONEDANT [3] and MCNP [4] codes to transport the neutrons though the filtering region. 
The nuclear heating deposition estimation was based on the nominal gamma-ray heating deposition provided by ATR for the A-10 position [5] (calculations are underway to provide gammaray and neutron heating deposition for the actual configuration of the capsule design for each region) and the estimated gamma-ray flux generated by the capture of neutrons. This part of the calculation is still underway and only preliminary estimations are available at the time of this writing.

$\underline{\text { Results and Discussion }}$

The thickness of gadolinium required to survive up to $5 \mathrm{dpa}$ 's was estimated to be $1.7 \mathrm{~mm}$ based on the spectrum at the midplane of the reactor. This thickness could be reduced if alternative materials such as dysprosium or europium were used. The option of not using these materials is due mainly to the lack of information about the gamma-ray generation for the dysprosium and cost, handling, and fabrication for the europium. The required thickness for the filtering material, despite being considerably large ( $3.4 \mathrm{~mm}$ on the diameter, compared with the $15.8 \mathrm{~mm}$ OD of the holder), could be accommodated within the sub-capsule and still provide enough room for irradiating a significant number of samples.

The preliminary estimate of the nuclear heating deposition is 11 to $15 \mathrm{~W} / \mathrm{g}$ (SS-316) for the different positions within the capsule. Preliminary estimation of the temperature profile [5] within the capsule indicated that it is possible to perform the irradiation at two different temperatures, $200^{\circ} \mathrm{C}$ and $300^{\circ} \mathrm{C}$, for different sub-capsules by controlling the gas mixture into the gas gap.

\section{CONCLUSION}

It was shown that the use of the outer A positions of the ATR reactor are suitable for fusion materials irradiation testing, and that an acceptable volume of samples can be irradiated up to 5 dpa's using gadolinium as thermal filtering material. The gadolinium filter will reduce the vanadium to chromium transmutation rate to acceptable levels.

\section{FUTURE WORK}

The final values for the expected nuclear heating deposition and temperature distribution inside the capsule are to be determined.

\section{REFERENCES}

1. JW Rogers, R.A. Anderl, and M. H. Putnam, "Neutron Spectrum Studies in the ATR," Proceedings of the Seventh ASTM-EURATOM Symposium on Reactor Dosimetry, Strasbourg, France, August, 1990.

2. F. Mann, "REAC3, Activation and Transmutation Computer Code System," HEDL-TME, Westinghouse Hanford Company, Richland, WA, 1994.

3. R. Douglas O'Dell, at al., "ONEDANT: A Code Package for One-Dimensional, DiffusionAccelerated, Neutral-Particle Transport," LA-9184, Los Alamos National Laboratory, 1989.

4. J. F. Briesmeister, Editor, "MCNP - A General Monte Carlo N-Particle Transport Code - version 4A," LA-12625, Los Alamos National Laboratory, 1993.

5. B. Schinitzler, Idaho National Engineering Laboratory, private communication.

6. R. Strain, Argonne National Laboratory, private communication. 
VANADIUM ALLOY IRRADIATION EXPERIMENT ATR-A1 IN THE ADVANCED TEST

REACTOR $^{*}$ H. Tsai, R. V. Strain, I. Gomes, A. G. Hins, and D. L. Smith

(Argonne National Laboratory)

\section{OBJECTIVE}

The objective of the ATR-A1.irradiation experiment is to obtain mechanical properties data, including fracture properties and irradiation creep, on vanadium alloys at low temperatures. Such data are presently lacking.

\section{SUMMARY}

A collaborative DOE/Monbusho irradiation experiment is being implemented to generate low-temperature mechanical properties data on vanadium alloys and low-activation ferritic steels. Monbusho is supplying the latter specimens. The experiment will be conducted in the Advanced Test Reactor at the Idaho National Engineering Laboratory and is designated ATR-A1. The core position selected, Channel A10, has relatively high fast neutron flux and fast-to-thermal flux ratio. These qualities are important for achieving a reasonable damage rate in the specimens and reducing the thickness requirements of thermal neutron filters. Filtering out the thermal neutron flux is necessary in the water-cooled ATR in order to avoid excessive $\mathrm{V}(\mathrm{n}, \gamma) \mathrm{Cr}$ transmutation.

The test vehicle will consist of four capsule segments containing a total of 15 subcapsules: 13 for vanadium alloy specimens and two for low-activation ferritic steel specimens. In all subcapsules the specimens will be lithium bonded to provide uniform specimen temperature, maximum heat transfer and, in the case of vanadium alloys specimens, impurity control. Two test temperatures are planned: 200 and $300^{\circ} \mathrm{C}$. They will be achieved by filling the gas-gap between the subcapsules and capsule with different blends of He and Ar. The vanadium alloy test specimens will be biaxial creep (pressurized tubes), Charpy impact, compact tension, tensile, and transmission electron microscope (TEM) disks. For the ferritic steels, the specimens will be Charpy impact, tensile, and TEM disks. The goal fluence for the experiment is $5 \mathrm{dpa}$ (in vanadium), which will be attained in $\approx 135$ effective full power days (EFPDs) in the A10 position.

Most of the test vehicle design has been completed and fabrication of some of the components is underway. The irradiation is scheduled to begin in August 1995 and be completed in January 1996.

\section{DESCRIPTION OF EXPERIMENT}

\section{ATR}

The ATR is a light-water-moderated and -cooled reactor with highly enriched uranium in plate-type fuel. The core height is $1.22 \mathrm{~m}(4 \mathrm{ft})$. Forty fuel elements are arranged in a serpentine pattern that forms four corner lobes and one central lobe. The nominal operating power of the reactor is $\approx 120 \mathrm{MW}$ and the lobes can be operated at significantly different power levels. A combination of hafnium control drums and shim rods is used to adjust power and minimize flux distortion. Cooling water enters the ATR core from the top at a nominal inlet temperature of $\approx 52^{\circ} \mathrm{C}$. Typical ATR cycles are 5,6 or 7 weeks at power followed by a 1 or 2 week refueling/maintenance outage.

\footnotetext{
* Work supported by U.S. Department of Energy, Office of Fusion Energy Research, under Contract W-31-109Eng-38.
} 
Compared to other available irradiation positions, the A-10 channel selected for the Al experiment is among the highest fast neutron flux and lowest thermal flux locations in ATR. These are important attributes that led to this position being selected. These requirements stem from the need to filter out the thermal flux to minimize the $\mathrm{V}(\mathrm{n}, \gamma) \mathrm{Cr}$ transmutation. The low thermal flux in $\mathrm{A}-10$ leads to a relatively thin filter being sufficient.

The axial profile for the fast flux in the A-10 channel is relatively flat over the middle $\approx 0.9 \mathrm{~m}$ of the core region. Based on data obtained in an earlier run, only the top and bottom $\approx 0.15 \mathrm{~m}$ of the channel will have a fast flux that dips below $\approx 70 \%$ of the peak at the midplane. At the projected lobe power of $27 \mathrm{MW}$, preliminary analysis showed that $13.5 \mathrm{dpa}$ can be attained in vanadium in one effective full power year.

With double encapsulation and other precautions, lithium can be used as the thermal bond for the specimens in the subcapsules. This is an important feature for the irradiation of vanadium alloy specimens in the ATR-A1 experiment.

\section{Test Vehicle}

The test vehicle will be a capsule made up of four segments joined by thread connections and spot welds. The 1.22-m core height will be fully utilized. One of the segments will contain three subcapsules and the other three will contain four subcapsules each. The space between the subcapsules and capsule wall will have different gas blends in each segment to attain the two target temperatures of 200 or $300^{\circ} \mathrm{C}$. The capsule and subcapsules will be constructed of Type 304 stainless steel tubing, $0.381 \mathrm{~mm}$ thick. The diameter of the A-10 channel and the outside diameters for the capsule and subcapsules are 15.88, 13.46 and $12.40 \mathrm{~mm}$, respectively.

The goal fluence for the ATR-A1 experiment is $5 \mathrm{dpa}$ in the vanadium alloys. Extensive effort went into the selection of the thermal neutron filter material for the experiment. The principal criteria for the selection were maximizing the available test volume and good compatibility between the filter and the lithium bond. Among the candidates evaluated -- $\mathrm{Hf}, \mathrm{B}_{4} \mathrm{C}, \mathrm{Dy}, \mathrm{Cd}, \mathrm{Eu}$ and $\mathrm{Gd}--\mathrm{Eu}$ and $\mathrm{Gd}$ were found to have the best overall attributes. Gd was finally selected over Eu because $\mathrm{Gd}$ can be more easily handled and machined, an important consideration in light of the tight fabrication schedule. (Eu is pyrophoric at $\approx 150^{\circ} \mathrm{C}$ and oxidizes rapidly in air, although it has the best neutronic characteristics.) Preliminary calculations indicated that for the $5 \mathrm{dpa}$ exposure, a thickness of $1.7 \mathrm{~mm}$ of $\mathrm{Gd}$ would be required for the peak flux position.

With the current vehicle design, each subcapsule is $76.20 \mathrm{~mm}$ long, including the end caps. The gadolinium filter, in the form of a 1.70-mm-thick cylindrical shell with end disks, is located in the inner periphery of the subcapsule. Because of the reduced thermal flux towards the ends of the core, a thinner filter $(1.30 \mathrm{~mm}$ ) will be used in the top and bottom subcapsules. These two end capsules will be used exclusively for the 9.6-mm-dia. compact tension specimens, which will not fit inside a 1.7-mm-thick filter body. Thermodynamic data suggest that $\mathrm{Gd}$ in the lithium bond will act as a getter for oxygen and hydrogen impurities during the irradiation. A plenum in the subcapsule above the lithium level provides room to accommodate the gas released from the pressurized creep capsule in case of a specimen rupture.

The relatively small diameter of the A-10 channel and the lack of an instrument lead in the reactor preclude the incorporation of a thermocouple in the test vehicle. In order to obtain postmortem indications of the peak temperatures attained, metals and alloys with melting temperatures in the range of $\approx 200-400^{\circ} \mathrm{C}$ will be included in selected subcapsules. These indicator materials will be in the forms of shavings and contained in separately sealed holders. Radiography before and after the irradiation will be conducted to determine whether the shavings have melted into a solid mass. A tentative selection of the indicator materials includes: $\mathrm{Sn} / \mathrm{Pb}$ eutectic $\left(183^{\circ} \mathrm{C}\right)$, Se $\left(221^{\circ} \mathrm{C}\right)$, $\mathrm{Sn}\left(232^{\circ} \mathrm{C}\right), \mathrm{Bi}\left(271^{\circ} \mathrm{C}\right), \mathrm{Pb}\left(327^{\circ} \mathrm{C}\right)$, and $\mathrm{Zn}\left(420^{\circ} \mathrm{C}\right)$. 
Flux monitor wires will be included in selected subcapsules to provide data on the neutron spectrum and the axial distribution of the neutron flux. For the spectral data, wires of $\mathrm{Fe}, 0.1 \% \mathrm{Co}-\mathrm{Al}, \mathrm{Ti}, \mathrm{Nb}, \mathrm{Cu}$ and $80 \% \mathrm{Mn}$-Cu will be used. The wire sets will be incorporated at the midplane and bottom-of-core locations. Iron and $0.1 \% \mathrm{Co}-\mathrm{Al}$ wires will be used for the flux gradient determination and will be placed at five nearly evenly spaced locations along the length of the vehicle.

\section{Test Specimens}

The collaborative agreement with Monbusho stipulates approximately 1/3 of the ATR-A1 test volume be used for Monbusho specimens and the remaining $2 / 3$ for DOE specimens. Vanadium alloy test specimens for both Monbusho and DOE will consist of miniature biaxial creep (pressurized tubes), Charpy impact, compact tension, tensile, and TEM disks. Table 1 shows the dimensions of the Monbusho and DOE specimens and the number of specimens that can be accommodated in the vehicle based on a mixed loading of Monbusho and DOE specimens. (Because of differences in sizes in US and Monbusho Charpy and tensile specimens, a mixed loading can significantly improve the overall loading efficiency.)

Table 1. Specimen Types and Loading Capacities for the ATR-A1 Experiment

\begin{tabular}{|c|c|c|}
\hline & Specimen Type & Quantity \\
\hline \multirow{5}{*}{ US } & Creep capsules ( $4.6 \mathrm{~mm}$ dia. $\times 22.9 \mathrm{~mm}$ ) & 8 \\
\hline & Compact tension ( $9.6 \mathrm{~mm}$ dia. $\times 3.6 \mathrm{~mm}$ ) & 18 \\
\hline & Charpy $(3.3 \mathrm{~mm} \times 3.3 \mathrm{~mm} \times 25.4 \mathrm{~mm})$ & 33 \\
\hline & Tensile $(0.8 \mathrm{~mm} \times 5.0 \mathrm{~mm} \times 25.4 \mathrm{~mm})$ & 31 \\
\hline & TEM disks & $\approx 160$ \\
\hline \multirow{5}{*}{ JP } & Creep capsules ( $4.6 \mathrm{~mm}$ dia. $\times 22.9 \mathrm{~mm}$ ) & 2 \\
\hline & Compact tension $(9.6 \mathrm{~mm}$ dia. $\times 3.6 \mathrm{~mm})$ & 10 \\
\hline & Charpy $(1.5 \mathrm{~mm} \times 1.5 \mathrm{~mm} \times 20.0 \mathrm{~mm})$ & 60 \\
\hline & Tensile $(0.25 \mathrm{~mm} \times 4.0 \mathrm{~mm} \times 16.0 \mathrm{~mm})$ & 70 \\
\hline & TEM disks & $\approx 128$ \\
\hline
\end{tabular}

The principal vanadium material to be tested by the US will be the reference $500-\mathrm{kg}$ heat of $\mathrm{V}-4 \% \mathrm{Cr}-4 \% \mathrm{Ti}$ alloy and its weldment. Limited specimens from several laboratory-size alloy heats will be included to study the effects of compositional variations. For Monbusho, several different heats of $\mathrm{V}-\mathrm{Cr}(\mathrm{Fe})-\mathrm{Ti}$ alloys with and without Si-Al-Y additions will be studied.

Biaxial creep capsules will be irradiated for the first time in the US vanadium alloy development program. Thin-wall tubing, $4.57 \mathrm{~mm} \mathrm{OD}, 0.25 \mathrm{~mm}$ wall, for making the pressurized creep capsules is being produced by drawing and sinking of a bored bar stock from the $500-\mathrm{kg}$ V-4\% $\mathrm{Cr}-4 \% \mathrm{Ti}$ heat. Thus far, the process has progressed well. More details on tubing fabrication and creep specimen production will be presented in the next report.

The ferritic steel specimens will be submitted by Monbusho and will include F82H and several other lowactivation heats. The specimens will consist of miniature tensile, Charpy and TEM disks. These specimens will be in two dedicated subcapsules containing no vanadium alloy specimens. 


\section{FUTURE ACTIVTTIES}

The final design and fabrication of the ATR-Al experiment are expected to be completed in the next reporting period. Irradiation is expect to begin in ATR cycle 107A, starting in August 1995. The irradiation is scheduled to last three cycles, 107A, 107B and 108A, ending in January 1996. In the three cycles, the experiment is expected to accrue 133 EFPDs, which is consistent with the target exposure of 135 EFPDs. Following the irradiation, the capsule will be opened in the ATR canal tray. The subcapsules will be returned to ANL for disassembly, lithium removal and specimen retrieval. The cleaned specimens will be disseminated to DOE and Monbusho laboratories for postirradiation examination and testing. 
STATUS OF VANADIUM ALLOY IRRADIATION EXPERIMENT X530 IN EBR-I*

H. Tsai, R. V. Strain, A. G. Hins, H. M. Chung, L. J. Nowicki and D. L. Smith

(Argonne National Laboratory)

\section{OBJECTIVE}

The objective of the X530 experiment in EBR-II was to obtain early irradiation performance data, particularly the fracture properties, on the new $500-\mathrm{kg}$ production heat of $\mathrm{V}-4 \mathrm{Cr}-4 \mathrm{Ti}$ material. Irradiation was completed in EBR-II and postirradiation disassembly is underway.

\section{SUMMARY}

To obtain early irradiation performance data on the new $500-\mathrm{kg}$ production heat of the $\mathrm{V}-4 \mathrm{Cr}-4 \mathrm{Ti}$ material before the scheduled EBR-II shutdown, an experiment, X530, was expeditiously designed and assembled. Charpy, compact tension, tensile and TEM specimens with different thermal mechanical treatments (TMT) were enclosed in twelve subcapsules and irradiated in the last run of EBR-II, Run 170A. The accrued exposure was 35 effective full power days, yielding a peak damage of $\approx 4 \mathrm{dpa}$ in the specimens. In this reporting period, the irradiation vehicle was disassembled at the Hot Fuel Examination Facility (HFEF) at ANL-West and the subcapsules shipped to ANL-East for disassembly. Subcapsule disassembly is scheduled to be completed at ANL-East in the next reporting period.

\section{PROGRESS AND STATUS}

\section{Introduction}

The X530 experiment was conducted to provide an early confirmation on the irradiation performance of the new 500-kg production heat of $\mathrm{V}-4 \mathrm{wt} . \% \mathrm{Cr}-4 \mathrm{wt}$.\%Ti alloy. For comparison, several previous laboratory heats of ternary and binary vanadium alloys with known properties and a Russian heat of $\mathrm{V}-4 \mathrm{Cr}-4 \mathrm{Ti}$ were included in the experiment. TMT of the material before irradiation was a key test parameter for this experiment. A ${ }^{10} \mathrm{~B}$-doped $\mathrm{V}-4 \mathrm{Cr}-4 \mathrm{Ti}$ material was included to study the effect of helium generation on materials properties.

The specimens were enclosed in 12 lithium-bonded subcapsules, which were contained in two flow-through (weeper) capsule tubes for the irradiation. The list of specimens included in the X530 experiment is shown in Table 1 and specimen loadings in the 12 subcapsules are summarized in Table 2.

The irradiation was conducted in Run 170A from August 9 through September 27, 1994. The core position was $2 \mathrm{~F} 1$ with a fast flux of $2.4 \times 10^{15} \mathrm{n} / \mathrm{cm}^{2} / \mathrm{s}, \mathrm{E}>0.1 \mathrm{MeV}$. The accrued exposure was 35 effective full power days, yielding a peak damage of $\approx 4 \mathrm{dpa}$ in the specimens. To accommodate the needs of this experiment, the reactor inlet temperature for Run $170 \mathrm{~A}$ was lowered from the nominal 371 to $366^{\circ} \mathrm{C}$. The reduced inlet temperature and the flow-through capsule design yielded in the test specimens the desired low temperature of $\approx 375-400^{\circ} \mathrm{C}$.

\section{Status of Vehicle Disassembly}

In this reporting period, the X530 irradiation vehicle was dischargèd from EBR-II and transferred to the adjacent HFEF for disassembly. Neutron radiographs of the subcapsules in the two flow-through capsule tubes were taken at HFEF. The data, shown in Fig. 1, indicate the condition of the subcapsules to be normal and that the locations of specimens in the subcapsules to be as expected.

\footnotetext{
* Work supported by U.S. Department of Energy, Office of Fusion Energy Research, under Contract W-31-109Eng-38.
} 
Table 1. Types and Numbers of Specimens Irradiated in the X530 Experiment

\begin{tabular}{|c|c|c|c|c|c|c|}
\hline $\begin{array}{l}\text { Composition, } \\
\text { wt.\% }\end{array}$ & $\begin{array}{l}\text { ANL ID } \\
\text { Number }\end{array}$ & $\begin{array}{l}\text { DCT-A, } \\
0.140 \text { in. }\end{array}$ & $\begin{array}{l}\text { DCT-B, } \\
0.230 \text { in. }\end{array}$ & $\begin{array}{l}\text { 1/3-size } \\
\text { Charpy }\end{array}$ & $\begin{array}{c}\text { SS-3 } \\
\text { Tensile } \\
\end{array}$ & TEM \\
\hline V-3Ti-1Si & $\mathrm{BL}-45$ & - & - & 5 & 2 & - \\
\hline V-STi & $\mathrm{BL}-46$ & 3 & - & 5 & 2 & 5 \\
\hline $\mathrm{V}-4 \mathrm{Cr}-4 \mathrm{Ti}$ & BL-74 & - & 4 & 6 & - & - \\
\hline $\mathrm{V}-7 \mathrm{Cr}-5 \mathrm{Ti}$ & BL-49 & 3 & - & 5 & 2 & 5 \\
\hline $\mathrm{V}-5 \mathrm{Cr}-3 \mathrm{Ti}$ & BL-54 & - & - & 5 & - & - \\
\hline $\mathrm{V}-3 \mathrm{Ti}$ & BL-62 & 3 & - & 5 & 2 & 4 \\
\hline $\mathrm{V}-5 \mathrm{Cr}-5 \mathrm{Ti}$ & BL-63 & - & 2 & 5 & 2 & - \\
\hline $\mathrm{V}-5 \mathrm{C} \mathrm{T}-5 \mathrm{Ti}$ & BL-63-CR950 & 1 & - & 5 & 2 & 3 \\
\hline $\mathrm{V}-5 \mathrm{C} r-5 \mathrm{Ti}$ & BL-63-CR1050 & 1 & - & 5 & 2 & 3 \\
\hline $\mathrm{V}-5 \mathrm{Cr}-5 \mathrm{Ti}$ & BL-63-WR950 & 1 & - & 5 & 2 & 3 \\
\hline $\mathrm{V}-5 \mathrm{Cr}-5 \mathrm{Ti}$ & BL-63-WR1050 & 1 & - & 5 & 2 & 3 \\
\hline $\mathrm{V}-4 \mathrm{Cr}-4 \mathrm{Ti}-\mathrm{RF}$ & BL-69 & - & - & - & 5 & 5 \\
\hline $\mathrm{V}-4 \mathrm{Cr}-4 \mathrm{Ti}-\mathrm{B}$ & BL-70 & 4 & 4 & 6 & 5 & 5 \\
\hline$V-4 C r-4 T i$ & BL-71-WR950 & 4 & - & 6 & 5 & 5 \\
\hline $\mathrm{V}-4 \mathrm{Cr}-4 \mathrm{Ti}$ & BL-71-WR1050 & 4 & - & 6 & 5 & 5 \\
\hline $\mathrm{V}-4 \mathrm{Cr}-4 \mathrm{Ti}$ & BL-71-WR1125 & 3 & - & 6 & 5 & 5 \\
\hline SUBTOTAL & & 28 & 10 & 80 & 43 & 51 \\
\hline \multicolumn{7}{|c|}{$\mathrm{B}=$ Boron doped $\left(250 \mathrm{appm}{ }^{10} \mathrm{~B}\right)$} \\
\hline \multicolumn{7}{|l|}{$R F=$ Russian Federation } \\
\hline \multicolumn{7}{|c|}{$\mathrm{CR} 950=$ Cold roll and final anneal at $950^{\circ} \mathrm{C}$} \\
\hline \multicolumn{7}{|c|}{$\mathrm{CR} 1050=$ Cold roll and final anneal at $1050^{\circ} \mathrm{C}$} \\
\hline \multicolumn{7}{|c|}{ WR950 = Warm roll and final anneal at $950^{\circ} \mathrm{C}$} \\
\hline \multirow{2}{*}{\multicolumn{7}{|c|}{ WRIO50 $=$ Warm roll and final anneal at $1050^{\circ} \mathrm{C}$}} \\
\hline WR1125 = Warm roll as & final anneal at $1125^{\circ} \mathrm{C}$ & & & & & \\
\hline
\end{tabular}

The routine water rinses of the flow-through capsules during the transfer from EBR-II to HFEF did not sufficiently remove the residual sodium in the capsules. To remedy this situation for subsequent handling at ANL-E, the capsules were cut open at HFEF and the subcapsules removed and cleaned individually with alcohol. The 12 sodium-free subcapsules were then placed in a shipping tube and shipped to ANL-East for disassembly and specimen retrieval.

Because of the high induced radioactivity of the subcapsules (made of stainless steel), the procedure previously established at ANL-East for processing lithium-bonded TZM subcapsules had to be modified. This procedural modification has been accomplished and an appropriate hot cell area has been identified for the work. Preparations are underway in this hot cell area to conduct the work. 
Table 2. Subcapsule Specimen Loading for X530

\begin{tabular}{|c|c|c|c|c|c|c|c|}
\hline Capsule & $\begin{array}{l}\text { Specimen } \\
\text { Type }\end{array}$ & $\begin{array}{c}\text { Material } \\
\text { Composition }\end{array}$ & Quantity & Capsule & $\begin{array}{l}\text { Specimen } \\
\text { Type }\end{array}$ & $\begin{array}{c}\text { Material } \\
\text { Composition }\end{array}$ & Quantity \\
\hline \multirow[t]{5}{*}{ S1 } & DCT-B & $\mathrm{V}-4 \mathrm{Cr}-4 \mathrm{Ti}(\mathrm{BL}-74)$ & 2 & S8 & Tensile & V-3Ti (BL-62) & 2 \\
\hline & Charpy & V-3Ti-1Si (BL-45) & 5 & & Tensile & V-5Ti (BL-46) & 2 \\
\hline & Charpy & V-5Ti (BL-46) & 5 & & Tensile & V-7Cr-5Ti (BL-49) & 2 \\
\hline & Charpy & $\mathrm{V}-7 \mathrm{Cr}-5 \mathrm{Ti}(\mathrm{BL}-49)$ & 2 & & Tensile & V-3Ti (BL-62) & 2 \\
\hline & & & & & Tensile & V-5Cr-5Ti (BL-63 & 2 \\
\hline \multirow[t]{5}{*}{ S2 } & DCT-B & $\mathrm{V}-4 \mathrm{Cr}-4 \mathrm{Ti}(\mathrm{BL}-74)$ & 2 & & Tensile & V-5Cr-5Ti (BL-63) & 2 \\
\hline & Charpy & $\mathrm{V}-4 \mathrm{Cr}-4 \mathrm{Ti}(\mathrm{BL}-74)$ & 6 & & Tensile & V-5Cr-5Ti (BL-63) & 2 \\
\hline & Charpy & $\mathrm{V}-7 \mathrm{Cr}-5 \mathrm{Ti}(\mathrm{BL}-49)$ & 1 & & Tensile & V-5Cr-5Ti (BL-63) & 2 \\
\hline & Charpy & V-5Cr-3Ti (BL-54) & 5 & & Tensile & V-5Cr-5Ti (BL-63) & 2 \\
\hline & & & & & Tensile & $\mathrm{V}-4 \mathrm{Cr}-4 \mathrm{Ti}(\mathrm{RF})$ & 3 \\
\hline \multirow[t]{5}{*}{ S3 } & DCT-B & V-5Cr-5Ti (BL-63) & 2 & & TE & V-5Ti (BL-46) & 5 \\
\hline & Charpy & $\mathrm{V}-7 \mathrm{Cr}-5 \mathrm{Ti}(\mathrm{BL}-49)$ & 2 & & $\mathrm{TE}$ & $\mathrm{V}-7 \mathrm{Cr}-5 \mathrm{Ti}(\mathrm{BL}-49)$ & 5 \\
\hline & Charpy & V-3Ti (BL-62) & 5 & & $\mathrm{TE}$ & V-3Ti (BL-62) & 4 \\
\hline & Charpy & V-5Cr-5Ti (BL-63) & 5 & & TE & V-5Cr-5Ti (BL-63) & 3 \\
\hline & & & & & TE & V-5Cr-5Ti (BL-63) & 3 \\
\hline \multirow[t]{4}{*}{ S14 } & DCT-B & $V-4 C r-4 T i-B(B L-70)$ & 2 & & $\mathrm{TE}$ & V-5Cr-5Ti (BL-63) & 3 \\
\hline & Charpy & V-5Cr-5Ti (BL-63) & 5 & & $\mathrm{TE}$ & V-5Cr-5Ti (BL-63) & 3 \\
\hline & Charpy & $\mathrm{V}-4 \mathrm{Cr}-4 \mathrm{Ti}-\mathrm{B}(\mathrm{BL}-70)$ & 6 & & & . & \\
\hline & & & & S9 & Tensile & V-4Cr-4Ti (RF) & 2 \\
\hline \multirow[t]{4}{*}{ S5 } & DCT-B & $\mathrm{V}-4 \mathrm{Cr}-4 \mathrm{Ti}-\mathrm{B}(\mathrm{BL}-70)$ & 2 & & Tensile & V-4Cr-4Ti-B (BL-70) & 5 \\
\hline & Charpy & V-5Cr-5Ti (BL-63) & 5 & & Tensile & $\mathrm{V}-4 \mathrm{Cr}-4 \mathrm{Ti}(\mathrm{BL}-71)$ & 5 \\
\hline & Charpy & $\mathrm{V}-4 \mathrm{Cr}-4 \mathrm{Ti}(\mathrm{BL}-71)$ & 6 & & Tensile & $\mathrm{V}-4 \mathrm{Cr}-4 \mathrm{Ti}(\mathrm{BL}-71)$ & 5 \\
\hline & & & & & Tensile & $\mathrm{V}-4 \mathrm{Cr}-4 \mathrm{Ti}(\mathrm{BL}-7 \mathrm{I})$ & 5 \\
\hline \multirow[t]{4}{*}{ S6 } & DCT-A & V-5Ti (BL-46) & 2 & & $\mathrm{TE}$ & $\mathrm{V}-4 \mathrm{Cr}-4 \mathrm{Ti}(\mathrm{RF})$ & 5 \\
\hline & Charpy & V-5Cr-5Ti (BL-63) & 5 & & TE & $\mathrm{V}-4 \mathrm{Cr}-4 \mathrm{Ti}-\mathrm{B}(\mathrm{BL}-70)$ & 5 \\
\hline & Charpy & $\mathrm{V}-4 \mathrm{Cr}-4 \mathrm{Ti}(\mathrm{BL}-71)$ & 6 & & $\mathrm{TE}$ & $\mathrm{V}-4 \mathrm{Cr}-4 \mathrm{Ti}(\mathrm{BL}-71)$ & 5 \\
\hline & & & & & TE & $\mathrm{V}-4 \mathrm{Cr}-4 \mathrm{Ti}(\mathrm{BL}-71)$ & 5 \\
\hline \multirow[t]{12}{*}{ S7 } & DCT-A & V-5Ti (BL-46) & 1 & & $\mathrm{TE}$ & $\mathrm{V}-4 \mathrm{Cr}-4 \mathrm{Ti}(\mathrm{BL}-71)$ & 5 \\
\hline & DCT-A & V-7Cr-5Ti (BL-49) & 1 & & & & \\
\hline & Charpy & V-5Cr-5Ti (BL-63) & 5 & S10 & DCT-A & V-7Cr-5Ti (BL-49) & 2 \\
\hline & Charpy & $\mathrm{V}-4 \mathrm{Cr}-4 \mathrm{Ti}(\mathrm{BL}-71)$ & 6 & & DCT-A & V-3Ti (BL-62) & 3 \\
\hline & & & & & DCT-A & $\mathrm{V}-4 \mathrm{Cr}-4 \mathrm{Ti}(\mathrm{BL}-71)$ & 3 \\
\hline & & & & S11 & DCT-A & V-5Cr-5Ti (BL-63) & 1 \\
\hline & & & & & DCT-A & V-5Cr-5Ti (BL-63) & 1 \\
\hline & & & & & DCT-A & V-5Cr-5Ti (BL-63) & 1 \\
\hline & & & & & DCT-A & V-5Cr-5Ti (BL-63) & 1 \\
\hline & & & & & DCT-A & $\mathrm{V}-4 \mathrm{Cr}-4 \mathrm{Ti}-\mathrm{B}(\mathrm{BL}-70)$ & 4 \\
\hline & & & & $\mathrm{S} 12$ & DCT-A & $\mathrm{V}-4 \mathrm{Cr}-4 \mathrm{Ti}(\mathrm{BL}-71)$ & 4 \\
\hline & & & & & DCT-A & $\mathrm{V}-4 \mathrm{Cr}-4 \mathrm{Ti}(\mathrm{BL}-71)$ & 4 \\
\hline
\end{tabular}

\section{FUTURE ACTIVITIES}

In the next reporting period, all 12 subcapsules in X530 are scheduled to be disassembled. Bond lithium will be removed by dissolution with liquid ammonia and alcohol. The cleaned specimens will be available for examination and testing. 


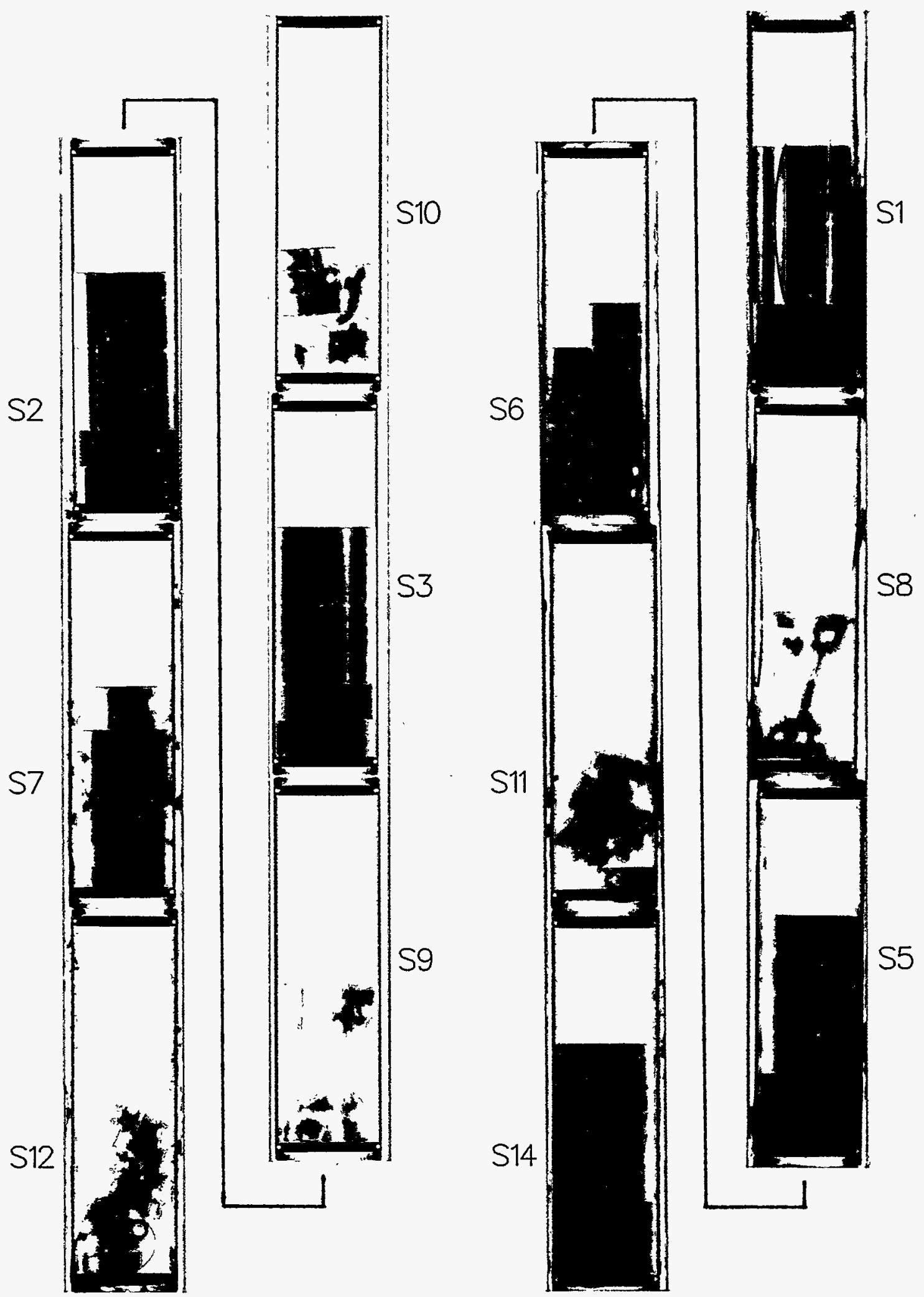

Fig. 1. Radiograph of X530 subcapsule in two flow-through capsule tubes after irradiation. All features of subcapsules and specimens appear normal. 
2.0 DOSIMETRY, DAMAGE PARAMETERS, AND ACTIVATION CALCULATIONS 
ACTIVATION OF SILICON CARBIDE IN FUSION ENERGY SYSTEMS - H. L. Heinisch, Pacific Northwest Laboratory*

\section{OBJECTIVE}

The objective of this work is to review the information on activation of silicon carbide with respect to use as a low activation material in fusion energy systems.

\section{SUMMARY}

Because of production of ${ }^{26} \mathrm{Al}$ from $\mathrm{Si}, \mathrm{SiC}$ irradiated in a fusion energy system first wall exceeds the limits for shallow land burial, based on 10 CFR 61 , Class C, for irradiation doses typical of a first wall component service lifetime in DEMO, $12.5 \mathrm{MWy} / \mathrm{m}^{2}$. However, if first wall activities can be averaged over entire components that include portions within the fusion machine where fluxes of high energy neutrons are smaller than at the first wall, production of ${ }^{26} \mathrm{Al}$ may stay under the shallow land burial limit for practical component service lifetimes. Realistic information on energy system design, waste disposal criteria, and decommissioning procedures is necessary to determine with certainty the role $\mathrm{SiC}$ can play as a low activation fusion energy system material. Sequential charged particle reactions have no significant effect on the residual radioactivity of SiC irradiated in a fusion energy system first wall.

\section{PROGRESS AND STATUS}

SiC as a Low Activation Material. Silicon carbide has enjoyed a reputation as a potential low activation structural material for fusion energy systems for about the past 15 years. $^{3}$. Although there was uncertainty about the usefulness of monolithic SiC associated primarily with its being a brittle ceramic, lately, silicon carbide fiber-reinforced silicon carbide composites $(\mathrm{SiC} / \mathrm{SiC})$ with improved fracture toughness offer the promise of acceptable mechanical performance. In 1983, the report of a DOE panel on low activation materials for fusion applications ${ }^{2}$ considered $\mathrm{SiC}$ to be a "very low activation" material (indeed, the panel's reference "low activation" Tokamak design consisted almost entirely of $\mathrm{Al}$ alloy and $\mathrm{SiC}$ ). However, since at least 1988, the long term environmental limitations of neutron activated SiC, due to the production of the radioisotope ${ }^{26} \mathrm{Al}$, have been well documented ${ }^{3-7}$.

Environmental Limits on ${ }^{26} \mathrm{Al}$. It is likely that ${ }^{25} \mathrm{Al}$ (from irradiation of either $\mathrm{Al}$ or $\mathrm{Si}$ ) was not recognized as a limited radionuclide earlier because it was not included in the original list of the dozen or so radionuclides in the 10 CFR 61 limits for Class C shallow land burial. In 1985, Maninger ${ }^{3}$ calculated an estimated Class $\mathrm{C}$ limit of $0.1 \mathrm{Ci} / \mathrm{m}^{3}$ for ${ }^{26} \mathrm{Al}$ using modified versions of the $\mathrm{NRC}$ computer codes. In 1988 , Fetter, Cheng and $\mathrm{Mann}^{4}$, using the same methodology as the NRC, but somewhat different criteria, determined a limit of $0.09 \mathrm{Ci} / \mathrm{m}^{3}$. Thus, although $10 \mathrm{CFR} 61$ does not explicitly place limits on ${ }^{26} \mathrm{Al}$, regulations similar to 10 CFR 61, applying to activated materials in fusion energy systems, will likely have such limits. It is also possible that regulations applying to shallow burial of fusion energy system wastes will be more conservative than $10 \mathrm{CFR} 61$, which was not originally developed for waste streams containing large amounts of activated structural materials.

Production of ${ }^{26} \mathrm{Al}$. In neutron irradiated $\mathrm{Al},{ }^{26} \mathrm{Al}$ is made directly in the reaction ${ }^{27} \mathrm{Al}(\mathrm{n}, 2 \mathrm{n}){ }^{26} \mathrm{Al}$, which has a significant cross section only for neutrons above about $13.5 \mathrm{MeV}$. In neutron irradiated $\mathrm{Si},{ }^{26} \mathrm{Al}$ is

"Pacific Northwest Laboratory is operated for the U. S. Department of Energy by Battelle Memorial Institute under Contract DE-AC06-76RLO 1830. 
produced by either the two-step process ${ }^{28} \mathrm{Si}(\mathrm{n}, \mathrm{d})^{27} \mathrm{Al}(\mathrm{n}, 2 \mathrm{n})^{26} \mathrm{Al}$ or the alternate two-step process ${ }^{28} \mathrm{Si}(\mathrm{n}, \mathrm{np})^{27} \mathrm{Al}(\mathrm{n}, 2 \mathrm{n})^{26} \mathrm{Al}$. Because two reactions with neutrons are required, the production of ${ }^{26} \mathrm{Al}$ increases during irradiation approximately as the square of the fluence. Both reactions require high energy neutrons $(>10 \mathrm{MeV})$. Thus, the amounts of ${ }^{26} \mathrm{Al}$ produced from $\mathrm{Si}$, relative to production of other radionuclides, will in general depend on both the neutron energy spectrum and the neutron fluence.

The production of ${ }^{26} \mathrm{Al}$ from $\mathrm{Si}$ (or its importance) may have gone unnoticed earlier on for several reasons. Earlier activation calculation codes did not often contain provisions for multiple reactions, so one would have to anticipate this two-reaction process and calculate it specifically. Furthermore, analyses with activation calculations that compared only the activities (not doses, biological hazard potential, etc.) would have shown that the major contributor to the activity of $\mathrm{SiC}$ is ${ }^{14} \mathrm{C}$ (which is not a gamma emitter and is allowed in relatively high concentration under $10 \mathrm{CFR} 61$ ). Also, ${ }^{26} \mathrm{Al}$ is not included in $10 \mathrm{CFR} 61$. Today multireaction processes are routinely addressed in the major activation codes, and the production of significant amounts of ${ }^{26} \mathrm{Al}$ from $\mathrm{Si}$ is widely known.

All activation calculations contain uncertainties due to incomplete knowledge of nuclear data and uncertainties in neutron spectra. The neutron cross sections for ${ }^{27} \mathrm{Al}$ production from ${ }^{28} \mathrm{Si}$ that are in present nuclear data bases are calculated from theoretical models. Some experimental measurements for the ${ }^{28} \mathrm{Si}(\mathrm{n}, \mathrm{d})^{27} \mathrm{Al}$ cross section exist, but they have not been evaluated nor incorporated into present data bases. Evaluation of Si cross sections over the entire energy spectrum of interest are in progress $s^{8}$. It is expected that the (n,d) data will be reviewed, and, if acceptable, used to scale the cross sections for the high threshold interactions. We speculate that any corrections to these cross sections will be within an order of magnitude of present calculated values, and conclusions drawn from present calculations might not be significantly changed. However, until the evaluations are done, we will not know for sure. It is important to include the best available information because of the potential technological importance of SiC.

Sequential Charged Particle Reactions. When a proton or alpha particle is a product of the interaction of an energetic neutron with a nucleus, the charged particle has usually been assumed to end up as a gas atom in the material. However, some of these charged particles are emitted with enough energy to enter into a nuclear reaction with another atom (with greater than negligible probability). These reactions are known as sequential charged particle reactions (SCPR), and they should not be confused with the process involving two separate neutron reactions that leads to ${ }^{26} \mathrm{Al}$ from $\mathrm{Si}$, as discussed in the previous section. Because $(\mathrm{n}, \mathrm{p})$ and $(n, a)$ reactions generally have high thresholds, SCPR are expected to be significant only for high energy neutrons. Until recent calculations were performed, it was not known whether they might make important contributions to activation or transmutation in fusion energy systems (or in other facilities having neutron energies $>10-15 \mathrm{MeV}$ ). Cierjacks ${ }^{9,10}$ developed the methodology and nuclear data libraries for including SCPR in activation calculations for fusion energy system materials. In 1994, Ehrlich, Cierjacks et al. ${ }^{11}$ reported on the results of the investigation of all stable elements $(Z=1-83)$ for the effects of SCPR. Table 1 of that paper lists all elements for which activity, dose rate or decay heat are increased by SCPR in a DEMO first wall spectrum at $12.5 \mathrm{MWy} / \mathrm{m}^{2}$. Neither Si nor C have significant enough SCPR contributions to be included in the table. The only effect of SCPR for potential fusion materials is an increase in total activity of $\mathrm{V}$ after 1000 years, due to production of ${ }^{53} \mathrm{Mn}$ (which has no gamma, is not in $10 \mathrm{CFR} 61$, and is not limited for Class $\mathrm{C}$ disposal according to Fetter et $\mathrm{al}^{4}$ ). Thus, even for vanadium alloys, the effects of SCPR are probably much less than effects of impurities.

The Cierjacks calculations were done for a DEMO first wall spectrum. The magnitude of the SCPR contribution at neutron energies higher than $14 \mathrm{MeV}$ is not known. The chance that significant new SCPR interactions occur at energies in the $14-20 \mathrm{MeV}$ range is probably small, but should be examined for the sake of completeness. 


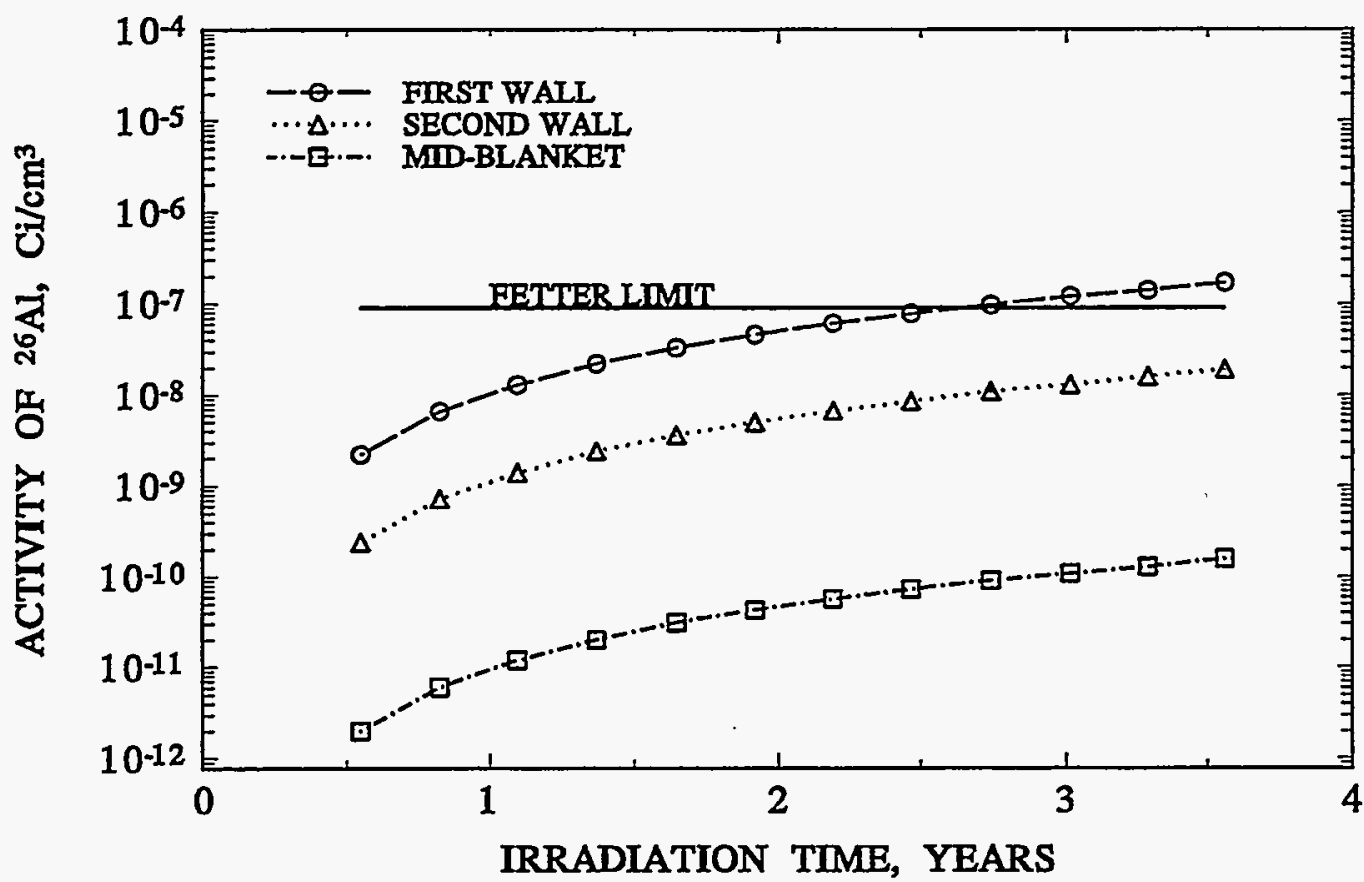

Figure 1. The buildup of ${ }^{26} \mathrm{Al}$ in SiC irradiated in STARFIRE for 3.5 years $(12.5$ $M W y\left(m^{2}\right)$ in the first wall, second wall and mid-blanket positions. The limit for ${ }^{26} \mathrm{Al}$ activity calculated by Fetter et al. ${ }^{4}$ using 10 CFR 61 methodology is indicated.

Implications for Use of $\mathrm{SiC}$ in Fusion Energy Systems. With respect to waste disposal by shallow land burial, based on the present (Fetter) limits for ${ }^{26} \mathrm{Al}, \mathrm{SiC}$ is at best marginal for use in the first wall region, at least based on recent activation calculations using DEMO and STARFIRE fusion machine designs. Levels of ${ }^{25} \mathrm{Al}$ obtained in exposures on the order of DEMO component lifetimes just exceed the best present guess for disposal limits. Figure 1 shows the results of calculations of the quantity of ${ }^{26} \mathrm{Al}$ produced in SiC irradiated in STARFIRE as a function of irradiation time. The calculations were done using the REAC*2 code over 12 time steps, for a total radiation time of 3.5 years, corresponding to $12.5 \mathrm{MWy} / \mathrm{m}^{2}$ (the anticipated service life of DEMO first wall components). The results are compared to the Fetter et al. ${ }^{4}$ limit for ${ }^{25} \mathrm{Al}$ that was calculated using $10 \mathrm{CFR} 61$ methodology. In the STARFIRE first wall spectrum, the Fetter limit is exceeded after only 2.5 years of irradiation $\left(9 \mathrm{MWy} / \mathrm{m}^{2}\right)$. The lower activities achieved in the STARFIRE second wall ( $6 \mathrm{~cm}$ behind the first wall) and mid-blanket $(0.5 \mathrm{~m}$ behind the first wall) regions are primarily because of reduced total neutron fluxes there rather than the spectral differences. According to htese results, at the second wall the Fetter limit will not be reached for about 25 years, while in the mid-blanket region the concentration of ${ }^{26} \mathrm{Al}$ will be two orders of magnitude under the Fetter limit for any fusion system lifetime. The activation of $\mathrm{SiC}$ in these STARFIRE locations should be seen as only qualitatively similar to a machine constructed of SiC (the STARFIRE first wall design uses PCA stainless steel backed by a Be neutron multiplier, with a $\mathrm{LiAlO}_{2}$ breeder in the PCA supported blanket). 
Figure 2 shows the residual radioactivity of $\mathrm{SiC}$ as a function of time after irradiation for the present STARFIRE calculations using REAC*2. The activity of ${ }^{3} \mathrm{H}$ is omitted from the plot, and the separate contributions of $\mathrm{Si}$ and $\mathrm{C}$ are shown. The contribution from $\mathrm{C}$ is exclusively from ${ }^{14} \mathrm{C}$, while the major contribution from Si after 50 years is from ${ }^{26} \mathrm{Al}$.

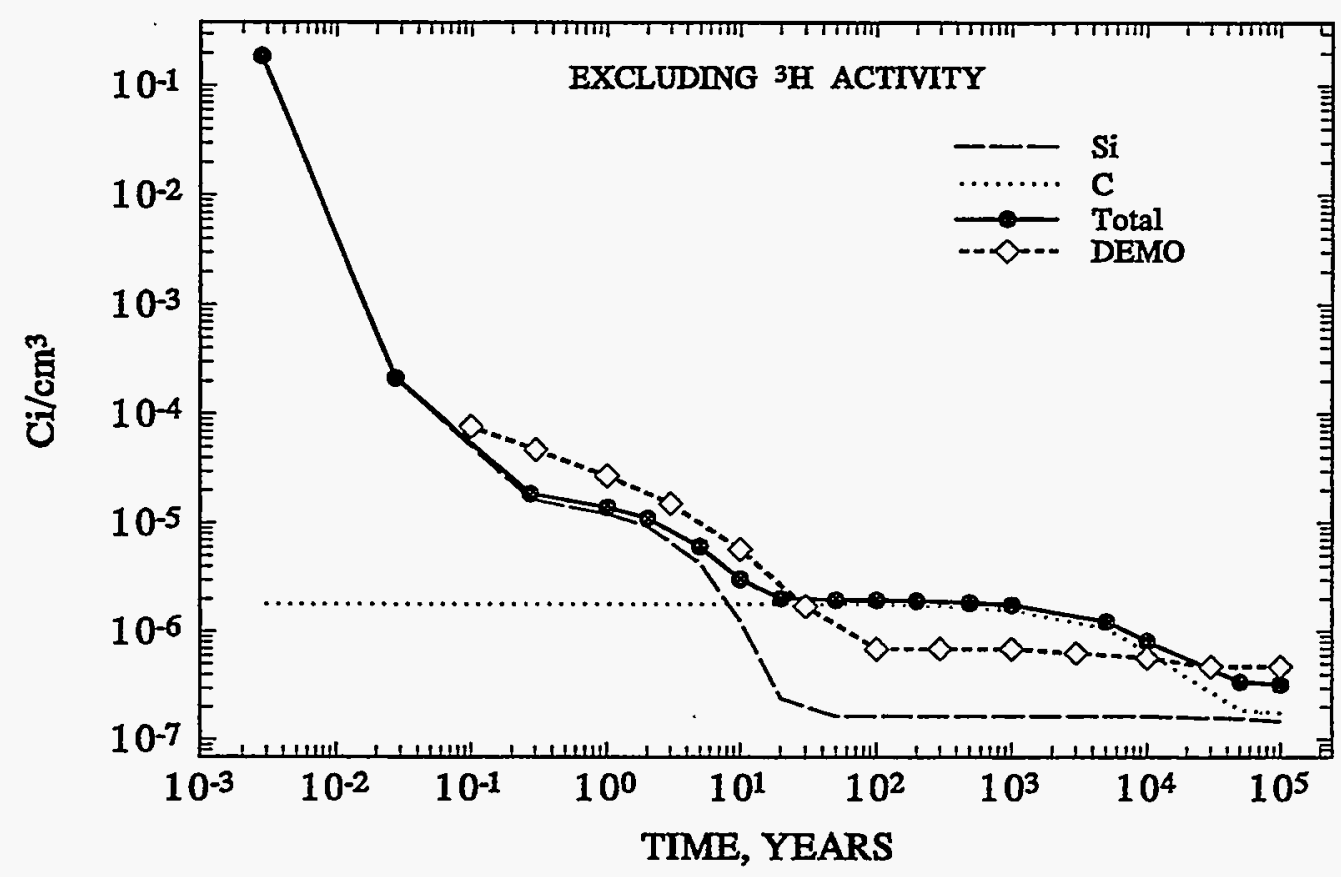

Figure 2. The residual radioactivity in $\mathrm{Ci} / \mathrm{cm}^{3}$ of SiC after irradiation in STARFIRE to a dose of $12.5 \mathrm{MWy} / \mathrm{m}^{2}$ as a function of time after irradiation. The large dashed and dotted lines are the separate contributions of Si and $C$, respectively. The solid line with data points is the total for SiC. The curve with open diamonds is the result of a calculation by Butterworth for SiC in DEMO to the same dose, $12.5 \mathrm{MWy} / \mathrm{m}^{2}$.

The STARFIRE results are compared in Fig. 2 with calculations for DEMO (to $12.5 \mathrm{MWy} / \mathrm{m}^{2}$ ) by Butterworth ${ }^{5}$ (who apparently omitted activities of both ${ }^{3} \mathrm{H}$ and ${ }^{14} \mathrm{C}$ from his plot). The DEMO calculation shows residual activity of ${ }^{26} \mathrm{Al}$ four times greater than that from the present STARFIRE calculation. This difference could be due to differences in neutron spectra, differences in nuclear data bases or even computational methods.

By present computational methods of evaluation, SiC activation is essentially at the Class $\mathrm{C}$ limit in these "generic" fusion energy system spectra. For a more precise evaluation of whether or not SiC can meet Class $\mathrm{C}$ burial limits as a fusion material, it is important to have the most realistic energy system design and neutron spectrum information available. If it is safe and practical to average activities over large components for disposal purposes, then perhaps the higher concentrations of ${ }^{26} \mathrm{Al}$ in the first wall areas will not prohibit shallow land burial of $\mathrm{SiC}$ components containing the first wall. Fusion energy system waste 
disposal criteria, waste stream characteristics and decommissioning procedures will be extremely important factors in determining if $\mathrm{SiC}$ can be considered a low activation fusion material.

\section{REFERENCES}

1. G. Hopkins, G.C. Trantina and J. Corelli, "Ceramic Materials for Fusion Reactors," EPRI Report AP-1702 (1981).

2. R.W. Conn et al., "Report of the DOE Panel on Low Activation Materials for Fusion Applications," UCLA-PPG-72B (1983).

3. R.C. Maninger, "Qualitative Comparison of Fusion Reactor Materials for Waste Handling and Disposal," Fusion Tech. 8 (1985) 1367.

4. $\quad$ S. Fetter, E.T. Cheng and F.M. Mann, "Long Term Radioactivity in Fusion Reactors," Fusion Eng. Des. 6 (1988) 123.

5. G.J. Butterworth, "Low Activation Structural Materials for Fusion," Fusion Eng. Des. 11 (1989) 231.

6. H. Bolt, "Nonmetalic Materials for Plasma Facing and Structural Applications in Fusion Reactors," Fusion Eng. and Des. 22 (1993) 85.

7. A.P. Kinzig, J.P. Holdren and P.J. Hibbard, "Safety and Environmental Comparisons of Stainless Steel with Alternative Structural Materials for Fusion Reactors," Fusion Tech. 26 (1994) 79.

8. D. Larson, Oak Ridge National Laboratory, private communication, April 5, 1995.

9. S. Cierjacks and Y. Hino, "The Importance of Sequential Reactions on Element Activation of Fusion Reactor Materials," J. Nucl. Mat. 170 (1990) 134.

10. S. Cierjacks, P. Oblozinsky, S. Kelzenberg and B. Rzehorz, "Development of a Novel Algorithm and Production of New Nuclear Data Libraries for the Treatment of Sequential $(x, n)$ Reactions in Fusion Materials Activation Calculations," Fusion Tech. 24 (1993) 277.

11. K. Ehrlich, S.W. Cierjacks, S. Kelzenberg and Anton Moeslang, "The Development of Structural Materials for Reduced Long-term Activation," 17th International Symposium on Effects of Radiation on Materials, ASTM, June 20-23, 1994, Sun Valley, Idaho, to be published in J. Nucl. Mater. 
CLEAN STEELS FOR FUSION - D. S. Gelles, (Pacific Northwest Laboratory)*

\section{OBJECTIVE}

The objective of this work is to incorporate clean steel technological development into reduced activation ferritic alloy development efforts.

\section{SUMMARY}

A summary of the workshop Clean Steels - Super Clean Steels is provided and a paper given at the Workshop entitled Clean Steels for Fusion is reproduced. The workshop demonstrated, based on ten years of steelmaking practise, that control of minor impurities $\mathrm{P}, \mathrm{Sb}, \mathrm{Sn}$ and $\mathrm{As}$ along with $\mathrm{Mn}$ and $\mathrm{Si}$ could effectively elliminate temper embrittlement in $3.5 \mathrm{NiCrMoV}$ rotor steels.

\section{PROGRESS AND STATUS}

\section{Introduction}

This report is in two sections: a summary of the workshop Clean Steels - Super Clean Steels and reproduction of the paper Clean Steels for Fusion, presented at the workshop.

\section{CLEAN STEELS SUPERCLEAN STEELS Workshop}

The workshop CLEAN STEELS SUPERCLEAN STEELS organized by the Institute of Materials on behalf of the Electric Power Research Institute (EPRI) is the fifth in a series. The previous workshops were held in July 1986, July 1987, June 1988 and August 1989 in Kapfenberg, Dusseldorf, Dusseldorf, and Sapporo, respectively. The concern is temper embrittlement arising from in-service temperature conditions for large rotor shafts used in the Power Generation Industry. The adverse effects of impurity elements phosphorus (P), antimony (Sb), tin (Sn), arsenic (As), sulfur (S), oxygen $(\mathrm{O})$, and deoxidants aluminum (Al) and silicon ( $\mathrm{Si}$ ) on the mechanical properties of steels have been known for many decades. $\mathrm{P}, \mathrm{Sb}, \mathrm{Sn}$, and As, interacting with $\mathrm{Si}$ and $\mathrm{Mn}$, cause temper embrittlement and lead to reduction in the fracture toughness $\left(\mathrm{K}^{\mathrm{IC}}\right)$ and increase in the ductile-brittle transition temperature as measured by fracture appearance (FATT). The presence of sulfide inclusions, and nonmetallic inclusions containing $\mathrm{Al}$ and $\mathrm{Si}$ can facilitate cavity nucleation at the grain boundaries and in the grains, thus facilitating creep fracture at high temperatures and ductile fractures in the upper shelf region. These changes result in reduced creep ductility at high temperatures and reduced fracture toughness at lower temperatures.

Following the identification of the elements responsible for temper embrittlement, various semiempirical relationships have been developed and reported in the literature, enabling the steel maker and the steel user to have a "figure of merit" in relation to temper embrittlement. These relationships are of the form:

$$
" \mathrm{~J} "=(\mathrm{Mn}+\mathrm{Si})(\mathrm{P}+\mathrm{Sn})
$$

\footnotetext{
*Operated for the U.S. Department of Energy by Battelle Memorial Institute under Contract DEAC06-76RLO 1830.
} 


$$
\begin{aligned}
& \text { "K" }=(M n+S i)(10 P+5 S b+4 S n+A s) \\
& " X "(\text { Broscato })=(10 P+5 S b+4 S n+A s) / 10
\end{aligned}
$$

Such values are now frequently quoted by the steel maker together with the chemical analysis. The lower the value for the figure of merit, the more resistant the steel is to temper embrittlement. In fact, an expression similar to (1) for J was used to define allowable residual element levels in early heats of low activation ferritic steels melted at Carpenter Technology for the Fusion program. $\left[(\mathrm{Mn}+\mathrm{Si})(\mathrm{P}+\mathrm{Sn}+\mathrm{Sb}) \times 10^{4} \leq 70\right.$, with impurity levels in wt\% $]$

Advancements in the steel making technology during the last two decades have enabled reduction of these impurities and deoxidants to levels as low as $20 \mathrm{ppm}$ leading to what might be called "clean steels". Further realization that in view of the low sulfur levels achievable, $\mathrm{Mn}$ is no longer necessary to 'fix' the sulfur and can, therefore, be reduced to levels as low as 0.01 to $0.02 \%$, has resulted in "superclean steels".

The development that has made "clean" and "superclean" steels possible was secondary steel refining via ladle furnaces in conjunction with vacuum degassing in the ladle and during casting. Ladle treatment of molten steel for the purpose of desulfurization and vacuum carbon deoxidation was developed only in 1975. This provided a production means of manufacturing high purity steels that previously could only be made in the laboratory as a control for temper embrittlement research studies. The practical solution to the problem in alloy steels was to refine $\mathrm{Mn}, \mathrm{Si}, \mathrm{P}, \mathrm{Sn}, \mathrm{As}$, and $\mathrm{Sb}$ from the steels during steel making operations. Manganese, silicon, and phosphorus are easily removed during the oxidizing stage of steel making, because they oxidize preferentially to iron, and enter the oxidizing slag. This generally is done in the electric arc furnace. Tin, arsenic, and antimony are controlled by scrap selection, with basic oxygen furnace steel scrap used as the starting material for electric arc furnace melting if possible. After separation of the oxidized steel from the oxidizing slag, it is transferred to a reducing slag in a ladle refining furnace, which removes the sulfur. Vacuum treatment of the desulfurized steel in the ladle furnace accompanied by argon bubbling provides a means for deoxidation. This leaves no oxide particles dispersed in the steel, as would be done if deoxidation were done with $\mathrm{Si}$. The result is a superclean steel free of oxides and sulfides.

Several presentations were noteworthy. In his presentation at the conference, Tanaka verified the advantage of superclean steel compositions against temper embrittlement. His figure plotting values of $\triangle$ FATT following aging at $454^{\circ} \mathrm{C}$ for $100,000 \mathrm{~h}$ as a function of the parameter $\mathrm{J}$ for very clean steels is shown in Figure 1. From Figure 1, it is apparent that superclean steels are insensitive to embrittlement and that the parameter $\mathrm{J}$ can predict low levels of embrittlement.

Nougaret showed that oxide and sulfide reduction in superclean steels also provide the benefits of improved pitting resistance and resistance to stress corrosion cracking. Tsuchiyama described complex heat treatment procedures so that a single rotor shaft forging could be used to operate both the high pressure (HP) and low pressure (LP) sections of a turbine as one unit. This required different austenitizing and tempering treatments for the shaft segments $\left(940^{\circ} \mathrm{C} / 658^{\circ} \mathrm{C}\right.$ for the HP section to provide higher creep rupture strength and $910^{\circ} \mathrm{C} / 650^{\circ} \mathrm{C}$ for the LP section to get higher toughness). The shaft was approximately $7 \mathrm{~m}$ long and up to $1.4 \mathrm{~m}$ in diameter, and a vertical electric furnace was used for heat treatment.

Also of note was a request for a show of interest in a subsequent workshop on clean steels in the 9 to 12 chrome range that would be held in 12 to 18 month, again in London. The show of interest was high. 


\section{Clean Steels for Fusion}

Abstract

Fusion energy production has an inherent advantage over fission: a fuel supply with reduced long term radioactivity. One of the leading candidate materials for structural applications in a fusion reactor is a tungsten stabilized 9\% chromium Martensitic steel. This alloy class is being considered because it offers the opportunity to maintain that advantage in the reactor structure as well as provide good high temperature strength and radiation induced swelling and embrittlement resistance. However, calculations indicate that to obtain acceptable radioactivity levels within 500 years after service, clean steel will be required because the niobium impurity levels must be kept below about 2 appm and nickel, molybdenum, nitrogen, copper, and aluminum must be intentionally restricted. International efforts are addressing the problems of clean steel production. Recently, a $5000 \mathrm{~kg}$ heat was vacuum induction melted in Japan using high purity commercial raw materials giving niobium levels less than 0.7 appm. This paper reviews the need for reduced long term radioactivity, defines the advantageous properties of the tungsten stabilized Martensitic steel class, and describes the international efforts to produce acceptable clean steels.

\section{Introduction}

Ever since mankind has learned to duplicate the nuclear reaction controlling our sun, it has been a goal of society to harness that nuclear fusion process to create limitless quantities of energy. This goal is not yet achievable, and it is now apparent that immense finances will be needed because the machines required must be very large, and the technical problems to be overcome are very complicated. In an international effort to demonstrate the practicality of fusion energy power production, a device called the International Thermonuclear Experimental Reactor (ITER) is being designed. A recent partial assembly sketch of the ITER design is shown in Figure 2.

In the quest to procure funds for the ITER and earlier machines, it was apparent that fusion power needed to demonstrate advantages over other sources of energy. One of the inherent advantages for fusion over fission energy production is a fuel supply with reduced long term radioactivity. This was first emphasized in 1983 with the publication of the Report of the DOE Panel on Low Activation Materials for Fusion Applications. 1 The panel recommended that one of the goals of the fusion program should be a reference reactor that meets the requirements for near surface disposal of radioactive waste. The recommendation was tied to a United States regulation, $10 \mathrm{CFR} 61^{2}$, requiring that for shallow land burial of class $\mathrm{C}$ waste, radioactivity levels in waste must decay to safe levels 


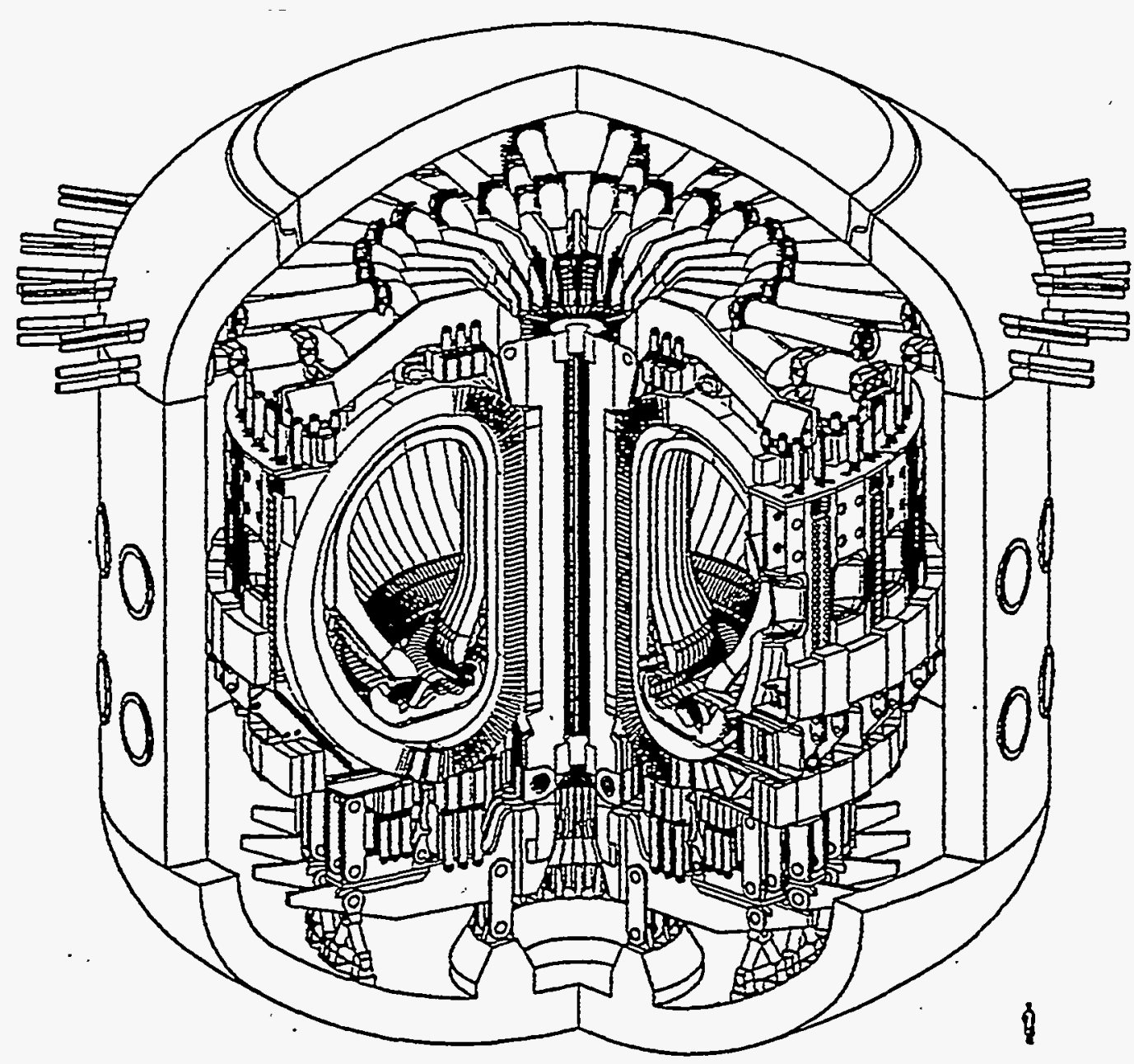

Figure 2. ITER partial assembly sketch as of July 18, 1994.

after 500 years.

To meet the requirement of safe radioactivity levels within 500 years, the panel noted that reactor components that become radioactive must not contain certain deleterious elements that produce radioactive isotopes with very long half lives. The list included nickel, nitrogen, copper, molybdenum, and niobium, but the restriction on niobium was by far the most severe: 1 atom part per million in the first wall structure. An early example of the activation level and rate of decay for an austenitic stainless steel exposed for $9 \mathrm{MW}-\mathrm{y} / \mathrm{m}^{2}$ in the neutron flux at a first wall of a fusion reactor is shown in Figure $3 .^{3}$ Activity levels vary with time as a function of the half lives for the activated isotopes and daughter products of each element shown. High levels of radioactivity are maintained in the stainless steel first wall component for very long times due to nitrogen, niobium, and molybdenum. Therefore, impurities in reactor materials had to be strictly controlled to meet such a goal.

The materials development community took this suggestion to heart in subsequent years, and efforts are now proceeding to develop reduced activation structural material versions of the following alloy classes: silicon carbide/silicon carbide composites, vanadium alloys containing chromium and titanium, and tungsten stabilized Martensitic steels. The purpose of this paper is to provide further details 
concerning the development of reduced activation tungsten stabilized Martensitic steels.

\section{Low activation Guidelines}

Since 1983, the list of elements contributing to unacceptable long term radioactivity has come under further scrutiny. ${ }^{4-7}$ The criterion has been expanded to consider not only shallow land burial, but also direct handling (or "hands on" applications), and recycling of materials. The list of elements that can make an irradiated material unacceptable for shallow land burial is now considerably longer, as provided in Table 1. (Differences in the composition limits given in Table 1 are partly a measure of the assumed irradiation conditions used and partly calculational procedures.) Table 1 also includes two estimates of required composition limits for hands on applications. However, for the purposes of steel production, niobium levels on the order of $1 \mathrm{wppm}$ for disposal, or 0.01 to $0.2 \mathrm{wppm}$ for hands on applications, are expected to provide the greatest restriction.

\section{Development of Steels for Fusion}

Super 12 chrome steels are found to be viable for fusion structural applications. Interest in this alloy class first evolved from materials development for liquid metal fast fission breeder reactors, where it was shown that ferritic steels had inherent resistance to irradiation induced swelling, a process whereby materials expand in volume due to the accumulation of vacancies in internal cavities. ${ }^{8,9}$ The combination of high temperature strength, good thermal conductivity, and good resistance to irradiation induced swelling and creep in these Martensitic steels has been demonstrated to provide an engineering window for fusion reactor design..$^{10-14}$ The high temperature limit may be restricted to temperatures as low as $450^{\circ} \mathrm{C}$ as a result of design specific details such as liquid lithium compatibility, but the swelling resistance of this class of materials appears to provide a stable structural material to very high irradiation doses, avoiding the need for component replacement. Precipitation of chromium rich $\alpha^{\prime}$ results in irradiation induced hardening and embrittlement, ${ }^{15}$ which can be avoided by lower chromium levels in the range 7 to $9 \%$.

Composition specifications were possible for super 12 chrome low activation steel by restricting the additions of niobium, molybdenum, nitrogen, and nickel. A large number of alloys have been designed, manufactured, and tested at laboratories around the world, ${ }^{16}$ and it has been shown that tungsten can be directly substituted for molybdenum on an atom for atom basis and that tantalum can be used for niobium, providing alloys with high temperature strength on a par with $9 \mathrm{Cr}-1 \mathrm{Mo}$ and $12 \mathrm{Cr}-1 \mathrm{Mo}$ steels. Lower chromium levels avoided the need for a nickel substitute or for higher 
Table 1. Low Activation Guidelines Based on Waste Disposal Criteria.

\begin{tabular}{|c|c|c|c|c|c|c|c|c|c|c|c|c|c|c|c|}
\hline \multicolumn{2}{|c|}{ Element } & $\mathrm{Nb}$ & Mo & $\mathrm{Cu}$ & $\mathrm{N}$ & $\mathrm{Ni}$ & $\mathrm{Pb}$ & $\mathrm{Al}$ & Ho & $\mathrm{Tb}$ & Ir & $\mathrm{Gd}$ & $\mathrm{Bi}$ & $\operatorname{Re}$ & Hf \\
\hline \multirow{3}{*}{$\begin{array}{l}\text { Wastc } \\
\text { disposal } \\
\text { criterion }\end{array}$} & $\begin{array}{c}1983^{1} \\
(\text { appm) }\end{array}$ & 1 & 3650 & 2400 & 3650 & 20000 & & & & & & & & & \\
\hline & $\begin{array}{c}1984^{4} \\
\text { (wppm) }\end{array}$ & 2.9 & 30 & 1200 & 3300 & 9100 & 31000 & 36000 & & & & & & & \\
\hline & $\begin{array}{c}1988^{5} \\
\text { (wppm) }\end{array}$ & 10 & 500 & 5000 & 1000 & 20000 & 500000 & 5000 & 1 & 2 & 10 & 20 & 100 & 1000 & 1000 \\
\hline \multirow[t]{2}{*}{$\begin{array}{l}\text { Hands on } \\
\text { criterion }\end{array}$} & $\begin{array}{r}1992^{6} \\
(\mathrm{ppm}) \\
\end{array}$ & .18 & 31 & 651 & & 355 & 900 & 184 & .057 & .021 & .32 & .39 & .13 & 72 & .30 \\
\hline & $\begin{array}{c}1995^{7} \\
\text { (wppm) }\end{array}$ & .0141 & 1.67 & & & 14800 & & 5.24 & .00608 & 0.0134 & 1.56 & 0.118 & 0.119 & 4.75 & \\
\hline \multicolumn{2}{|c|}{ Element } & Se & $\mathrm{Cd}$ & $\mathrm{K}$ & $\mathrm{Sm}$ & $\mathrm{Tm}$ & $\mathrm{Pd}$ & $\mathrm{Ag}$ & $\mathrm{Eu}$ & $\mathrm{Lu}$ & Dy & $\mathrm{Yb}$ & Os & Co & Er \\
\hline $\begin{array}{c}\text { Waste } \\
\text { disposal } \\
\text { criterion }\end{array}$ & $\begin{array}{c}1988^{5} \\
\text { (wppm) }\end{array}$ & 1000 & 2000 & 2000 & 2000 & 3000 & 5000 & 20000 & 1000 & 100000 & 3000 & & & & 100 \\
\hline \multirow[t]{2}{*}{$\begin{array}{l}\text { Hands on } \\
\text { criterion }\end{array}$} & $\begin{array}{r}1992^{6} \\
(\mathrm{ppm}) \\
\end{array}$ & & 4.9 & 137 & .33 & & .72 & .011 & .074 & .22 & .54 & .63 & 1.2 & 1.7 & 3.1 \\
\hline & $\begin{array}{c}1995^{7} \\
\text { (wppm) }\end{array}$ & & 2.3 & 1652 & & & 0.212 & .00494 & .585 & & .0048 & & .517 & 119 & 0.196 \\
\hline
\end{tabular}


carbon levels to maintain a fully Martensitic structure, as well as preventing $\alpha^{\prime}$ precipitation hardening. In fact, the tungsten stabilized Martensitic steel class is found to have excellent impact resistance, with ductile to brittle transition temperatures (DBTT) below $-60^{\circ} \mathrm{C}$, and excellent resistance to irradiation embrittlement. ${ }^{16}$

\section{Studies on Clean Steel}

Two papers have addressed the question of the practicality of producing clean low activation tungsten stabilized steels. ${ }^{6,17}$ Butterworth and Keown ${ }^{6}$ concluded in 1991 that state of the art residual levels are generally in the range 10 to $100 \mathrm{ppm}$ for high-integrity steels used for aerospace, military, and other demanding applications and therefore did not meet the more exacting requirements for hands on limits. They proposed that the route used for producing nickel-based superalloys for aerospace components where specifications were possible for some impurities to the sub-ppm level might be more successful. Careful selection of starting materials was required to exclude specific high activation elements from the feedstock.

Feasibility has in fact been demonstrated in Japan. The Nippon Kokan Corporation (NKK) has been actively developing an alloy designated F-82H for fusion reactor applications. ${ }^{17-20}$ This alloy's approximate composition is $\mathrm{Fe}-8 \mathrm{Cr}-2 \mathrm{~W}-0.2 \mathrm{~V}-0.04 \mathrm{Ta}$ (in wt\%) with carbon levels of about $0.1 \%$. As part of that effort, an attempt was made to reduce the content of activating elements below the guidelines of reduced activation. ${ }^{17}$ A $5000 \mathrm{~kg}$ ingot was vacuum induction melted from high purity commercial raw materials using commercial practices. The chemical analysis for the starting materials is given in Table 2, and the composition of the mill product is given in Table 3. Given the tight requirement needed to satisfy activation requirements, only niobium was analyzed in the raw materials. From Table 2, it can be shown that the major source of niobium is from iron and chromium, with lesser amounts from tungsten, tantalum, and vanadium. Mill product chemical analysis shows that the niobium content is quite uniform, varying from $0.5 \mathrm{wppm}$ in the center to 0.07 wppm at both ends, and that silver and cobalt levels are $50 \mathrm{wppm}$. It can therefore be concluded from comparison with Table 1 that the NKK $5000 \mathrm{~kg}$ heat would satisfy the waste disposal criterion, but would not meet hands on criteria based on silver and niobium impurities, and cobalt levels may be too high, depending on the irradiation conditions and calculation procedures used to define the hands on low activation limit.

\section{Discussion}

The ITER development and testing program is expected to continue well into the next century and is presently not being designed within low activation guidelines. The first commercial fusion reactor is not expected to be constructed before 2025. A commercial reactor would be expected to follow low activation guidelines, but it is not yet clear that a Martensitic steel will be selected as the structural material. Therefore, commercial production of a clean steel for fusion will not be needed in the immediate future; we have 30 years in which to develop the technology.

\section{Conclusions}

Fusion power systems will be required to use low activation structural materials to allow shallow land burial of waste and possibly hands on or recycling options. This will mean that certain elements will be restricted from structural materials specifications. In particular, niobium must be kept below about 2 appm for shallow land burial and 0.01 to $0.1 \mathrm{wppm}$ for hands on and recyling options. A tungsten stabilized Martensitic steel appears to be a good choice for fusion structural materials applications, and therefore clean steels may be selected. However, commercial production of such steels will not be needed for another thirty years, giving ample time to advance steel making to the levels needed. 
Table 2. Chemical analysis of raw materials ${ }^{\mathrm{a}}$

\begin{tabular}{|c|l|c|c|c|c||}
\hline Element & Raw materials & $\begin{array}{c}\mathrm{Nb} \\
{[\mathrm{ppm}]}\end{array}$ & $\begin{array}{c}\text { Mass of melting } \\
{[\mathrm{kg}]}\end{array}$ & $\begin{array}{c}\text { Nominal content } \\
{[\mathrm{wt} \%]}\end{array}$ & $\begin{array}{c}\text { Calculated Nb } \\
\text { content in F-82H } \\
\text { [ppm] }\end{array}$ \\
\hline \hline $\mathrm{C}$ & carbonet & - & 5 & 0.1 & - \\
\hline $\mathrm{Si}$ & metallic silicon & $<1.0$ & 5 & 0.1 & $<0.001$ \\
\hline $\mathrm{Mn}$ & metallic manganese & $<1.0$ & 5 & 0.1 & $<0.001$ \\
\hline $\mathrm{Cr}$ & high purity metallic & 10 & 385 & 7.7 & 0.15 \\
\hline $\mathrm{W}$ & metallic tungsten & 2.0 & 100 & 2.0 & 0.04 \\
\hline $\mathrm{V}$ & metallic vanadium & 10.0 & 10 & 0.2 & 0.02 \\
\hline $\mathrm{Ta}$ & metallic tantalum & 85.0 & 1 & 0.04 & 0.034 \\
\hline $\mathrm{Ti}$ & sponge titanium & 1.1 & 1 & 0.02 & $<0.0004$ \\
\hline $\mathrm{Fe}$ & converter steel & $<0.5$ & 4487 & 60. & $<0.45$ \\
\hline
\end{tabular}

a The dash means not analyzed.

Table 3. Chemical Composition of Mill Product F-82H (wt.\%). ${ }^{\mathrm{a}}$

\begin{tabular}{|c|c|c|c|c|c|c|c|c|c|}
\hline \multirow[t]{2}{*}{ Impurity } & \multirow[t]{2}{*}{ Ladle } & \multicolumn{3}{|c|}{ Plates } & \multirow[t]{2}{*}{ Impurity } & \multirow[t]{2}{*}{ Ladle } & \multicolumn{3}{|c|}{ Plates } \\
\hline & & top & middle & bottom & & & top & middle & bottom \\
\hline C & 0.096 & 0.097 & 0.110 & 0.094 & $T i$ & 0.008 & 0.007 & 0.007 & 0.007 \\
\hline $\mathrm{Si}$ & 0.10 & 0.09 & 0.09 & 0.09 & $\mathrm{Nb}$ & $<0.0005$ & 0.00007 & 0.00005 & 0.00007 \\
\hline $\mathrm{Mn}$ & 0.15 & 0.07 & 0.07 & 0.07 & Sol.Al & 0.005 & 0.007 & 0.007 & 0.008 \\
\hline $\mathbf{P}$ & 0.003 & 0.002 & 0.003 & 0.003 & W & 2.1 & 2.1 & 2.1 & 2.1 \\
\hline$s$ & 0.003 & 0.0032 & 0.0029 & 0.0027 & $\mathrm{Ta}$ & 0.04 & 0.03 & 0.03 & 0.03 \\
\hline $\mathrm{Cu}$ & 0.01 & $<0.01$ & $<0.01$ & $<0.01$ & B & - & 0.0004 & 0.0003 & 0.0004 \\
\hline $\mathrm{Ni}$ & $<0.1$ & 0.03 & 0.03 & 0.03 & T.N & 0.0043 & 0.0043 & 0.0044 & 0.0047 \\
\hline $\mathrm{Cr}$ & 7.71 & 7.46 & 7.46 & 7.46 & T.O & 0.0028 & 0.0033 & 0.0049 & 0.0037 \\
\hline Mo & $<0.01$ & $<0.001$ & $<0.001$ & $<0.001$ & $\mathrm{Ag}$ & - & - & $<0.005$ & - \\
\hline $\mathrm{V}$ & 0.18 & 0.18 & 0.18 & 0.18 & Co & - & - & 0.005 & - \\
\hline
\end{tabular}

${ }^{a}$ The dash means not analyzed. 


\section{FUTURE WORK}

This effort will be continued only when appropriate.

\section{REFERENCES}

1. Report of the DOE Panel on Low Activation Materials for Fusion Applications, UCLA/PPF-728, June 1983.

2. Federal Register, Vol. 47, No 248, Monday, December 27, 1982, pp 57446-57482.

3. F. W. Wiffen and R. T. Santoro, in Proceedings of Topical Conference on Ferritic Alloys for Use in Nuclear Energy Technologies, J. W. Davis and D. J. Michel, Eds. (AIME, Warrendale, PA 1984) 195.

4. F. M. Mann, Fusion Tech., 6 (1984) 273; or J. Nucl. Mater., 122 \& 123 (1984) 1053.

5. C. Ponti, Fusion Tech., 13 (1988) 157

6. G. J. Butterworth and S. R. Keown, J. Nucl. Mater., 186 (1992) 283.

7. K. Ehrlich, S. W. Cierjacks, S. Kelzenberg and A Möslang, "The Development of Structural Materials for Reduce Long-Term Activation" submitted for publication in Effects of Radiation on Materials: 17th International Symposium, ASTM STP 1270 (ASTM, Philadelphia, PA 1996) to be published.

8. S. D. Harkness, B. J. Kestel and P. Okamoto, in Radiation-Induced Voids in Metals, J. W. Corbett and L. C. Ianniello, Eds., CONF-710601 (USAEC, Oak Ridge, TN 1972) 334.

9. D. S. Gelles, in Ferritic Steels for High Temperature Applications, A. K. Khare, Ed. (ASM, Metals Park, OH 1982) 197.

10. Starfire, A Commercial Tokamak Fusion Power Plant Study, ANL/FPP-80-1, V1, Sept. 1980, p. 10232.

11. A Demonstration Tokamak Power Plant Study, ANL/Fpp/82-1, Sept. 1982, p. 2-3.

12. MARS Mirror Advanced Reactor Study, Final Report, Volume 1-B, UCRL-53480, July 1984, pp. 129 to $12-24$.

13. Blanket Comparison and Selection Study, Final Report, ANL/FPP-84-1, Sept. 1984, pp. 7.3-4.

14. Modeling, Analysis \& Experiments for Fusion Nuclear Technology, FNT Progress Report: Modeling and FINESSE, Jan. 1987, p. 1021.

15. D. S. Gelles and L. E. Thomas, in Proceedings of Topical Conference on Ferritic Alloys for Use in Nuclear Energy Technologies, J. W. Davis and D. J. Michel, Eds. (AIME, Warrendale, PA 1984) 559.

16. D. S. Gelles, Plasma Devices and Operations, 3 (1994) 31. 
17. N. Yamanouchi, M. Tamura, H. Hayakawa, A. Hishinuma and T. Kondo, J. Nucl. Mater., 191-194 (1992) 822.

18. M. Tamura, H. Hayakawa, M. Tanimura, A. Hishinuma and T. Kondo, J. Nucl. Mater., 141-143 (1986) 1067.

19. M. Tamura, H. Hayakawa, A. Yoshitake, A. Hishinuma and T. Kondo, J. Nucl. Mater., 155-157 (1988) 620.

20. H. Hayakawa, A. Yoshitake, M. Tamura, S. Natsume, A. Gotoh and A. Hishinuma, J. Nucl. Mater., 179-181 (1991) 693. 
THE EFFECTS OF IMPURITIES ON THE ACTIVATION OF SIC, VANADIUM AND FERRITIC ALLOYS. H. Attaya and D. Smith (Argonne National Laboratory)

\section{OBJECTIVE}

The objective of this work is to assess the impact of the trace elements on the activation of the leading reduced activation candidate materials for fusion reactors. The materials considered in this work are the $\mathrm{V} 4 \mathrm{Cr} 4 \mathrm{Ti}$ vanadium alloy, the $9 \mathrm{Cr} 2 \mathrm{WVTa}$ ferritic alloy, and the silicon carbide ( $\mathrm{SiC}$ ).

\section{SUMMARY}

Consistent transport and activation calculations have been performed to compare the activation responses of the leading reduced-activation materials in a fusion power reactor. Another set of calculations has been made to evaluate the effects of the trace elements on these responses. The materials considered in this work are the V4Cr4Ti vanadium alloy, the $9 \mathrm{Cr} 2 \mathrm{WVT}$ a ferritic alloy, and the silicon carbide ( $\mathrm{SiC})$. In addition, calculations have also been made for the conventional 316SS and HT-9 alloys. The TPSS conceptual design has been utilized in this work. The results show that the V4Cr4Ti alloy has the minimum operational and the minimum long-term radioactivity and decay heat. The $\mathrm{SiC}$ has the minimum intermediate-term radioactivity. The effects of impurities are noticed with respect to the V4Cr4Ti and $\mathrm{SiC}$. With respect to the $9 \mathrm{Cr} 2 \mathrm{WVTa}$, the impurities have small effects.

\section{INTRODUCTION}

The selection of structural materials for fusion reactors is influenced by the activation responses of these materials. The activation response of any material, in turn, is affected by the composition of this material and equally important by the neutron spectrum seen by the material. The neutron spectrum itself depends strongly on the materials 'compositions in and around any particular region in a reactor. Thus there is a direct and strong dependency of the activation responses of a material on the design of the reactor in which it is used. This fact is often overlooked and most of the time a single spectrum is used to evaluate the activation responses of different materials.

In this work, we have utilized the tokamak power system study (TPSS) reactor design ${ }^{1}$ to evaluate the activation responses of the V4Cr4Ti vanadium alloy, the $9 \mathrm{Cr} 2 \mathrm{WVTa}$ ferritic alloy, the silicon carbide (SiC), and the conventional 316SS and HT-9 alloys. This design is based on the self-cooled lithiumvanadium concept and uses natural lithium in the first wall (FW), the breeder, and the reflector. The structural material (SM), the V15Cr5Ti alloy, is used only in these regions. The FW is $1 \mathrm{~cm}$ thick and has equal volume fractions of $\mathrm{Li}$ and SM. In these calculations, we assume $5 \mathrm{MW} / \mathrm{m}^{2}$ neutron wall loading and 5 years of operation i.e., $25 \mathrm{MWa} / \mathrm{m}^{2}$ neutron fluence.

It should be emphasized that changing the structural material of a design would require optimizing the design for that material and may result in a completely different design. This optimization is beyond the scope of the present work. Nevertheless, the consistent transport and activation provides a reasonable comparison of the different structural materials.

\section{ALLOYS' COMPOSITIONS AND NEUTRON FLUX}

Table 1 shows the weight and the atomic compositions of the alloys used in this work. The weight fractions and the atomic fractions of the elements are given in percentage or in ppm. The fractions given in ppm are preceded by *. The $\mathrm{V} 4 \mathrm{Cr} 4 \mathrm{Ti}$ impurity content is based on chemical analyses of different heats of similar alloys. The SiC composition is assumed stiochiometric and its impurities are partially taken from Ref. 2. The impurities of the ORNL 9Cr2WVTa ferritic steel are assumed as that of the modified HT- $9^{3}$. 
The neutron fluxes in the TPSS FW, for each SM, have been calculated by the transport code $\mathrm{ONEDANT}^{4}$ and are shown in Fig. 1. In this figure, the neutron flux of the V4Cr4Ti case is shown in absolute values (right scale) and the other SMs' fluxes are shown relative to V4Cr4Ti's flux (left scale). It is clear that there are large differences in the neutron fluxes among the different SMs. For example, the SiC's thermal flux is more than two orders of magnitude higher than the V4Cr4Ti's thermal flux. This also indicates the necessity of consistent transport and activation calculations.

\section{ACTIVATION OF PURE ALLOYS}

The activation code $\operatorname{RACC}^{5,6}$ has been used in the activation calculations together with the neutron cross-section library EAF37. Consider first the reduced activation materials $\mathrm{V} 4 \mathrm{Cr} 4 \mathrm{Ti}, \mathrm{SiC}$, and $9 \mathrm{Cr} 2 \mathrm{WVT}$, without impurities. Figure 2 shows the radioactive inventories of these materials and for the conventional materials HT9 and 316SS after $25 \mathrm{MWa} / \mathrm{m}^{2}$ neutron fluence. The decay heat generation rates and the point-source contact doses of these materials are shown in Figs. 3 and 4, respectively. During operation and at shutdown, the $\mathrm{V} 4 \mathrm{Cr} 4 \mathrm{Ti}$ alloy has the least radioactive inventory, the least decay heat, and the least contact dose. After less than an hour after shutdown, these activation responses of the $\mathrm{SiC}$ became the least compared to those of the other SMs, and with large difference, and remain as such for about ten years. Afterward, the V4Cr4Ti's responses became the lowest. It can be also noticed that there are small differences between the activation responses of the $9 \mathrm{Cr} 2 \mathrm{WVTa}$ alloy and those of the conventional HT9 alloy for about ten years after shutdown.

\section{EFFECTS OF IMPURITIES}

The V4Cr4Ti alloy cnotains $0.05 \mathrm{wt} \% \mathrm{Si}$ which generates the long-lived isotope ${ }^{26} \mathrm{Al}$. Other impurities in this alloy are capable of producing long-lived isotopes such as ${ }^{14} \mathrm{C}$ (from $\mathrm{N}$ and $\mathrm{O}$ ), ${ }^{59} \mathrm{Ni}$ (from $\mathrm{Ni}$ ), ${ }^{99} \mathrm{Tc}$ and ${ }^{94} \mathrm{Nb}$ ( from Mo and. $\mathrm{Nb}$ ). Figure 5 shows the radioactive inventories of the pure alloy with and without $\mathrm{Si}$ and with the full composition listed in Table. 1.

Figure 6 shows the effects of the impurities in the case of SiC. In this case also, more ${ }^{14} \mathrm{C}$ is produced by $\mathrm{N}$ and $\mathrm{O}$ and this isotope dominates the $\mathrm{SiC}$ radioactivity after 10 years and for about 10000 years. The isotope ${ }^{55} \mathrm{Fe}$ (from $\mathrm{Fe}$ ) dominates the radioactivity from one week after shutdown and for few years afterword. The very long-term radioactivity is due to $C\left({ }^{10} \mathrm{Be}\right)$ and $\mathrm{Si}\left({ }^{26} \mathrm{Al}\right)$.

Figure 7 shows the effects of the impurities on the $9 \mathrm{Cr} 2 \mathrm{WVTa}$ alloy and shows also the radioactivity of the conventional HT9 alloy. The impurities in this case do not make make a substantial difference since most of the radioactivity comes from $\mathrm{Fe}, \mathrm{Mn}$, and $\mathrm{W}$. Adding $\mathrm{Ni}$ and $\mathrm{Cu}$ to this alloy results in the increase of the radioactivity at about 100 years.

\section{CONCLUSIONS}

Consistent transport and activation calculations have been performed to compare the activation responses of the leading reduced-activation materials in a fusion power reactor. Another set of calculations has been made to evaluate the effects of the trace elements on these responses. The materials considered in this work are the V4Cr4Ti vanadium alloy, the $9 \mathrm{Cr} 2 \mathrm{WVTa}$ ferritic alloy, and the silicon carbide ( $\mathrm{SiC}$ ). In addition, calculations have also been made for the conventional 316 SS and HT-9 alloys. The TPSS conceptual design has been utilized in this work. The results show that the V4Cr4Ti alloy has the minimum operational and the minimum long-term radioactivity and decay heat. The $\mathrm{SiC}$ has the minimum intermediate-term radioactivity . The effects of impurities are noticed with respect to the V4Cr4Ti and SiC. With respect to the $9 \mathrm{Cr} 2 \mathrm{WVTa}$, the impurities have small effects 
Table 1. The weight and atomic compositions of the different alloys in percentage or in wppm/appm (marked by *).

\begin{tabular}{|c|c|c|c|c|c|c|c|c|c|c|}
\hline & \multicolumn{2}{|c|}{ V4CR4Ti } & \multicolumn{2}{|c|}{ SiC } & \multicolumn{2}{|c|}{ 9Cr2WVTa } & \multicolumn{2}{|c|}{ HT9 } & \multicolumn{2}{|c|}{ 316SS } \\
\hline & $\mathrm{gm} / \mathrm{cc}$ & $\mathrm{a}-\mathrm{b} / \mathrm{cc} \mathrm{c}^{2}$ & $\mathrm{gm} / \mathrm{cc}$ & $a-b / c c$ & $\mathrm{gm} / \mathrm{cc}$ & $a-b / c c$ & $\mathrm{gm} / \mathrm{cc}$ & $a-b / c c$ & $\mathrm{gm} / \mathrm{cc}$ & $a-b / c c$ \\
\hline den. & 6.1 & $7.234-2^{b}$ & 3.217 & $9.762-2$ & 7.8 & $8.401-2$ & 7.8 & $8.531-2$ & 7.855 & $8.503-2$ \\
\hline & $\begin{array}{c}\% \text { or } \\
\text { wppm }(*) \\
\end{array}$ & $\begin{array}{c}\% \text { or } \\
\operatorname{appm}(*)\end{array}$ & $\begin{array}{c}\text { \% or } \\
\text { wppm(*) } \\
\end{array}$ & $\begin{array}{c}\% \text { or } \\
\text { appm(*) }\end{array}$ & $\begin{array}{c}\% \text { or } \\
\text { mppm(*) }\end{array}$ & $\begin{array}{c}\% \text { or } \\
\text { appm (*) }\end{array}$ & $\begin{array}{c}\% \text { or } \\
\left.\text { wppm( }{ }^{*}\right)\end{array}$ & \begin{tabular}{|c|}
$\%$ or \\
appm $(*)$ \\
\end{tabular} & $\begin{array}{c}\text { \% or } \\
\text { Fppm (*) }\end{array}$ & $\begin{array}{c}\% \text { or } \\
\text { appm }\left({ }^{*}\right)\end{array}$ \\
\hline B & & & & & $* 10.00$ & $* 51.72$ & 0.01 & \begin{tabular}{|l|} 
\\
\end{tabular} & & \\
\hline C & $* 50.00$ & 0.02 & 28.74 & $47: 48$ & $\because 0.1:$ & 0.47 & 0.2 & 0.92 & & \\
\hline $\mathrm{N}$ & 0.01 & 0.04 & $* 620.00$ & 0.09 & $* 10.00$ & $* 39.92$ & 0.05 & 0.2 & & \\
\hline 0 & 0.02 & 0.06 & 3.98 & 4.94 & $* 70.00$ & 0.02 & 0.01 & 0.03 & & \\
\hline $\mathrm{Na}$ & & & $* 12.00$ & $* 10.36$ & & & & & & \\
\hline $\mathrm{Al}$ & 0.01 & 0.02 & $* 25.00$ & $* 18.39$ & $* 80.00$ & 0.02 & 0.01 & 0.02 & 0.3 & 0.62 \\
\hline $\mathrm{Si}$ & 0.05 & 0.09 & 67.2 & 47.48 & 02 & 0.4 & 0.35 & 0.69 & 0.46 & 0.91 \\
\hline$P$ & $* 30.00$ & $* 49.19$ & & & 0.01 & 0.02 & 0.02 & 0.04 & & \\
\hline$S$ & $* 10.00$ & $* 15.84$ & & & $* 40.00$ & $* 69.75$ & 0.02 & 0.03 & & \\
\hline $\mathrm{Cl}$ & $* 0.20$ & $* 0.29$ & & & & & & & & \\
\hline$\underline{K}$ & $* 0.10$ & $* 0.13$ & $* 8.00$ & $* 4.06$ & $* 3.00$ & $* 4.29$ & $* 3.00$ & $* 4.22$ & & \\
\hline $\mathrm{Ti}$ & 4 & 4.24 & $* 8.00$ & $* 3.32$ & 0.1 & 0.12 & 0.09 & 0.1 & 0.04 & 0.05 \\
\hline $\mathrm{V}$ & 91.9 & $91: 61$ & & & 0,25 & 0.27 & 0.3 & 0.32 & & \\
\hline $\mathrm{Cr}$ & 4 & 3.91 & $* 30.00$ & $* 11.45$ & 99 & 9.68 & 12 & 12.71 & 17.1 & 18.3 \\
\hline $\mathrm{Mn}$ & & & & & 0,45 & 0.46 & 0.55 & 0.55 & 1.7 & 1.72 \\
\hline $\mathrm{Fe}$ & $* 40.00$ & *36.37 & $* 130.00$ & $* 46.20$ & 84.78 & 87.88 & 84.16 & 82.98 & 64.57 & 64.33 \\
\hline Co & & & & & $* 50.00$ & $* 47.44$ & 0.02 & 0.02 & 0.03 & 0.03 \\
\hline $\mathrm{Ni}$ & $* 4.00$ & $* 3.46$ & $* 18.00$ & $* 6.09$ & $* 60.00$ & $* 57.16$ & 0.5 & 0.47 & 13.2 & 12.51 \\
\hline $\mathrm{Cu}$ & $* 1.00$ & $* 0.80$ & & & $* 30.00$ & $* 26.40$ & 0.09 & 0.08 & 0.1 & 0.09 \\
\hline As & $* 0.10$ & $*^{*} 0.07$ & & & & & & & & \\
\hline $\mathrm{Zr}$ & & & & & $* 10.00$ & $* 6.13$ & $* 10.00$ & $* 6.04$ & & \\
\hline $\mathrm{Nb}$ & $* 1.00$ & $* 0.55$ & & & $* 1.10$ & $* 0.66$ & 0.11 & 0.07 & & \\
\hline Mo & $* 4.00$ & $* 2.12$ & & & $* 2.70$ & $* 1.57$ & 1 & 0.57 & 2.5 & 1.45 \\
\hline $\mathrm{Ag}$ & & & & & $* 0.90$ & $* 0.47$ & $* 1.00$ & $* 0.51$ & & \\
\hline $\mathrm{Cd}$ & & & & & $* 1.00$ & $* 0.50$ & $* 1.00$ & $* 0.49$ & & \\
\hline Sn & & & & & $* 30.00$ & $* 14.13$ & $* 30.00$ & $* 13.91$ & & \\
\hline $\mathrm{Sb}$ & & & & & $* 5.00$ & $* 2.30$ & $* 10.00$ & $* 4.52$ & & \\
\hline $\mathrm{Ba}$ & & & & & $* 2.00$ & $* 0.81$ & $* 10.00$ & $* 4.01$ & & \\
\hline $\mathrm{Tb}$ & & & & & $* 2.00$ & $* 0.70$ & $* 5.00$ & $* 1.73$ & & \\
\hline $\mathrm{Ta}$ & $* 2.00$ & $* 0.56$ & & & 0.07 & 0.02 & $* 10.00$ & $* 3.04$ & & \\
\hline $\mathrm{W}$ & $* 2.00$ & $* 0.55$ & & & 2 & 0.61 & 0.5 & 0.15 & & \\
\hline Ir & & & & & $* 2.00$ & $* 0.58$ & $* 5.00$ & $* 1.43$ & & \\
\hline $\mathrm{Pb}$ & & & & & $* 5.00$ & $* 1.35$ & $* 10.00$ & $* 2.66$ & & \\
\hline $\mathrm{Bi}$ & & & & & $* 2.00$ & $* 0.54$ & $* 10.00$ & $* 2.63$ & & \\
\hline
\end{tabular}

* = wppm or appm, shaded numbers are the major constituents.

(a) atomic density in atoms-barn/cc, barn $=10^{-24}$

(b) reads as $7.234 \times 10^{-2}$. 
苛

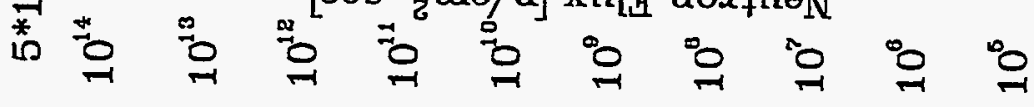

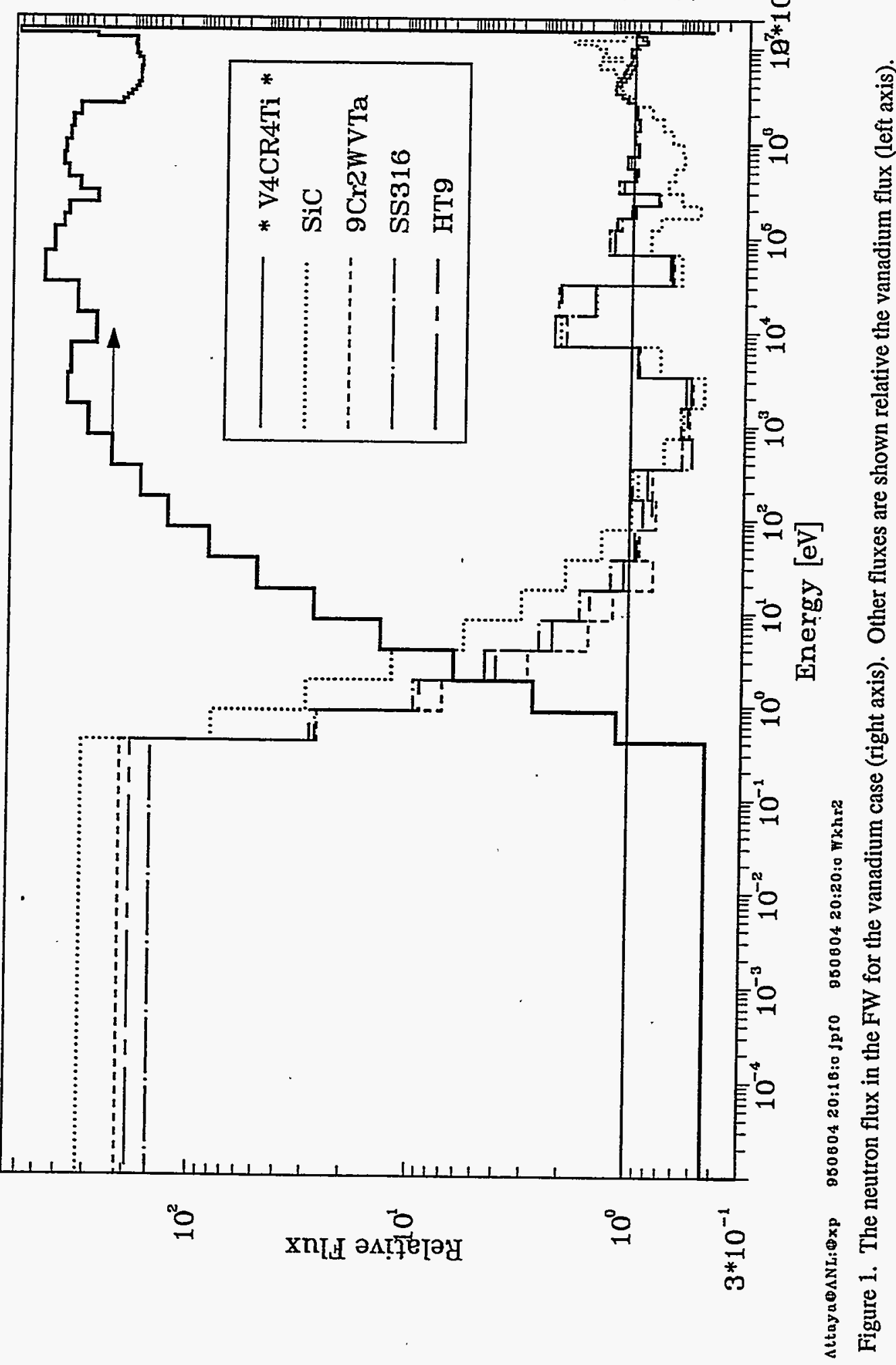




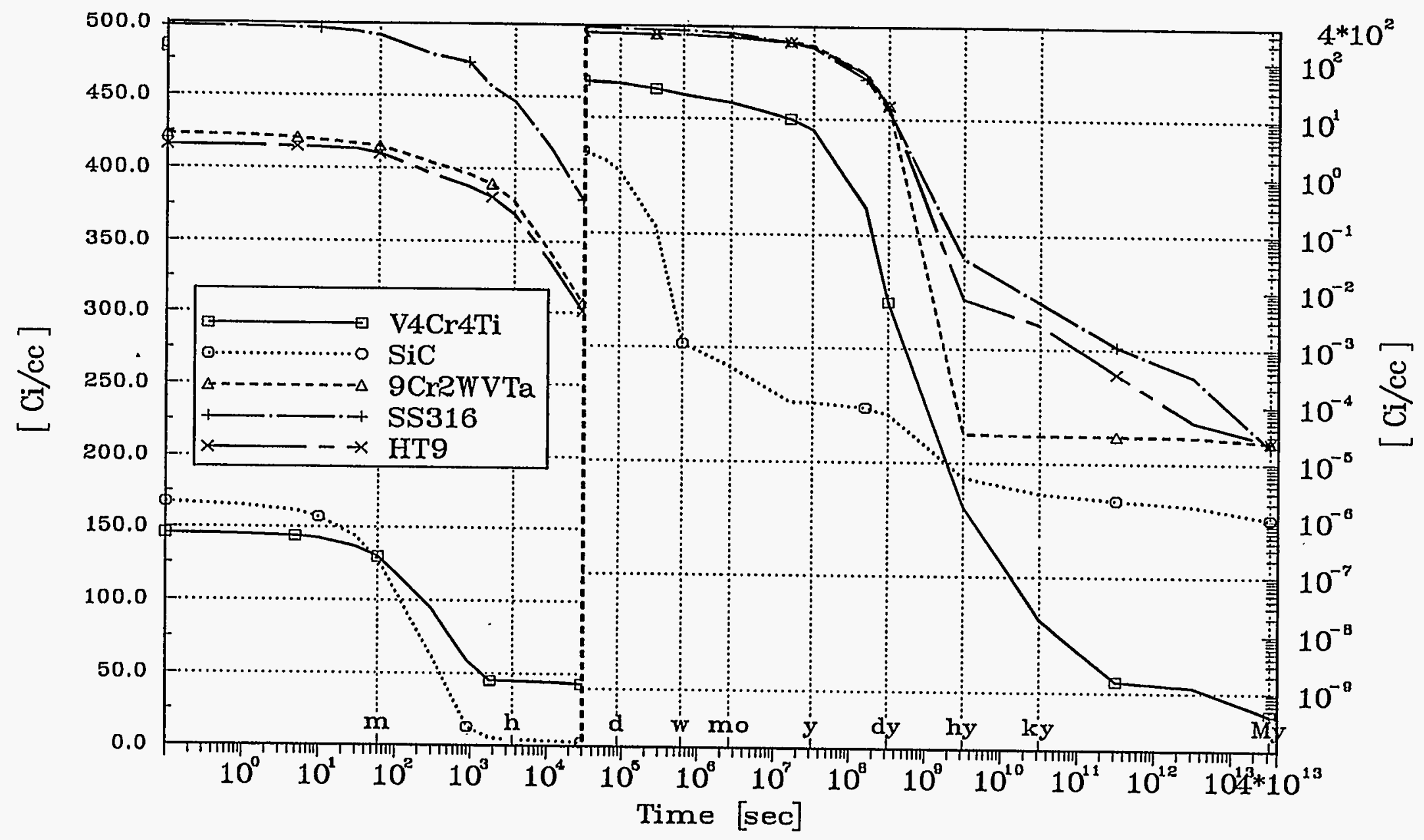

Figure 2. The radioactive inventories of the different SMs after shutdown. The short-term radioactive inventories are shown in linear scale (left) and the long-term radioactive inventories are shown in logarithmic scale (right). 


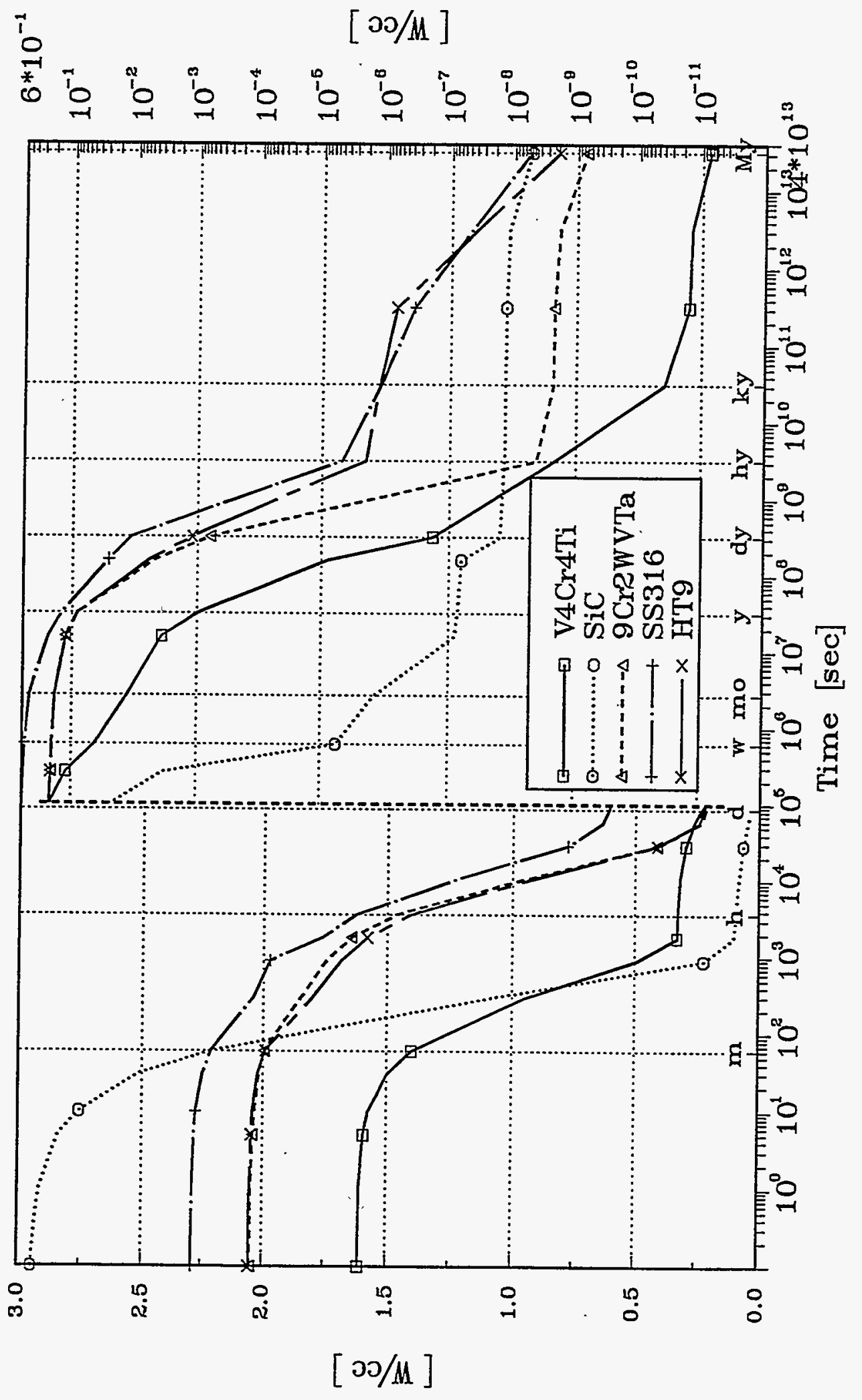

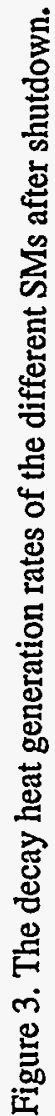




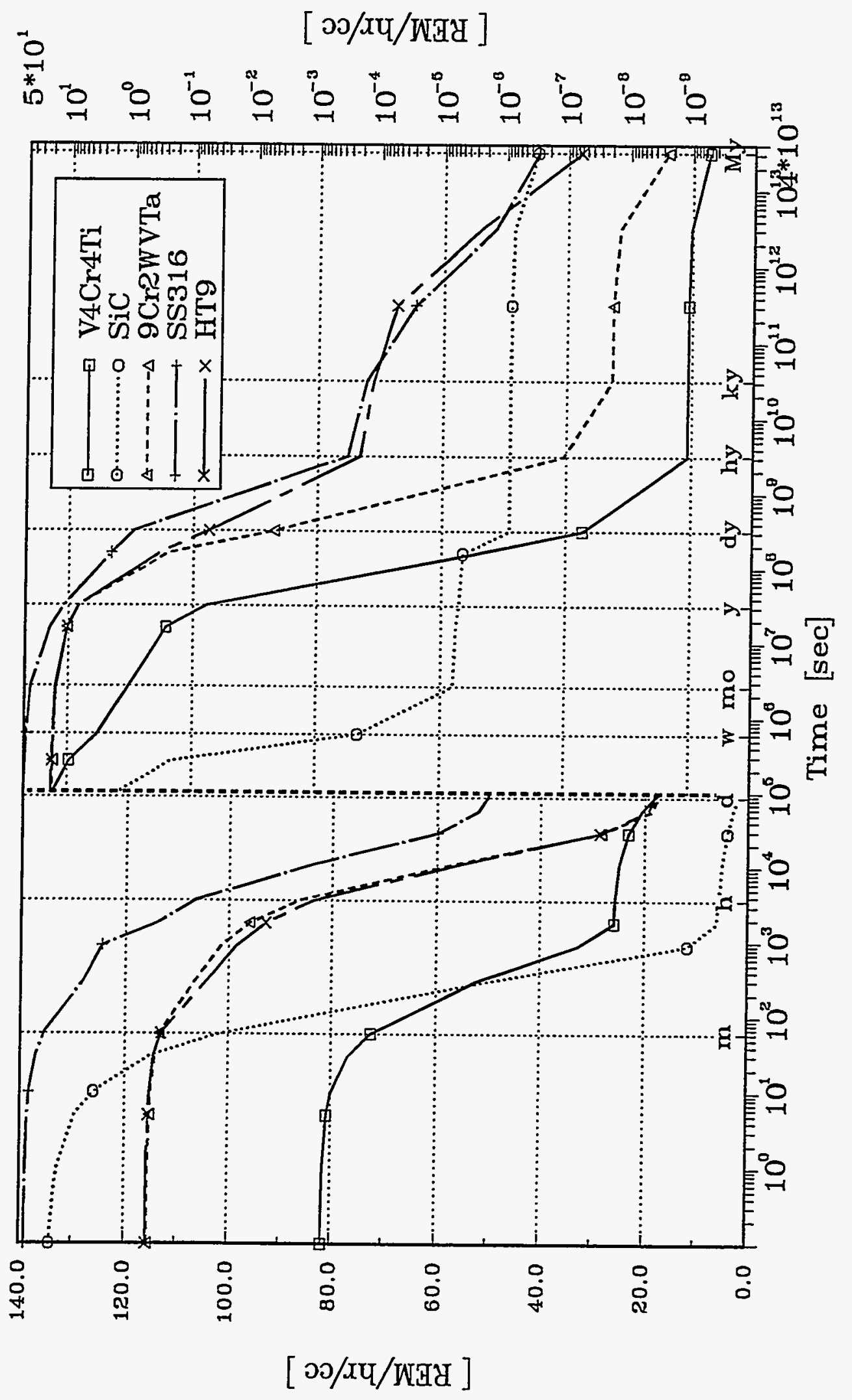

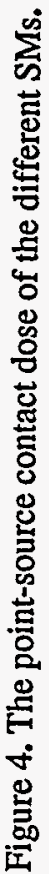




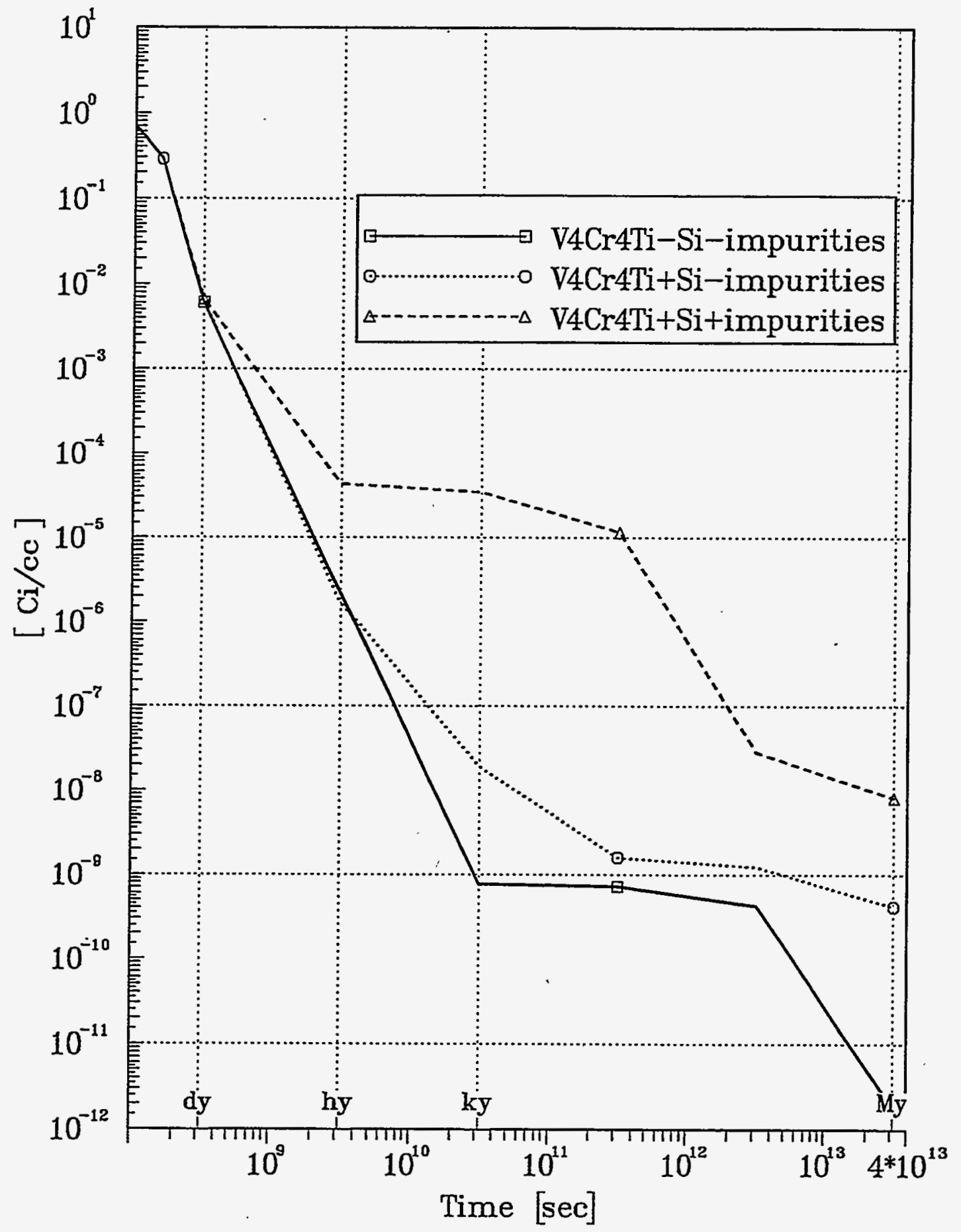

Figure 5. The radioactivity of the $\mathrm{V} 4 \mathrm{Cr} 4 \mathrm{Ti}$ alloy, with only $\mathrm{V}, \mathrm{Cr}, \mathrm{Ti}$, with $\mathrm{Si}$ included, and with the full composition in Table 1 


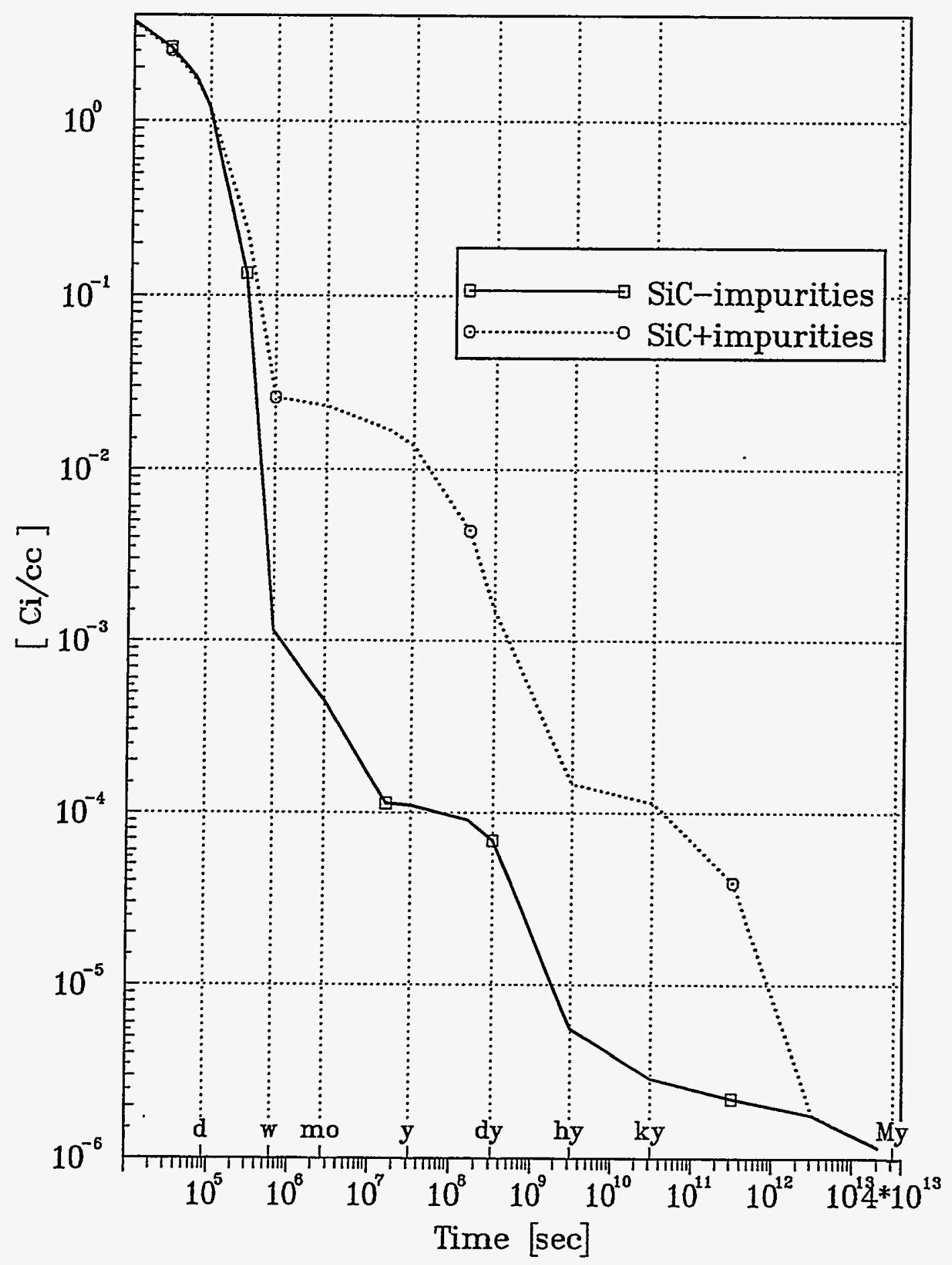

.Figure 6 . The radioactivity of $\mathrm{SiC}$ with and without impurities. 


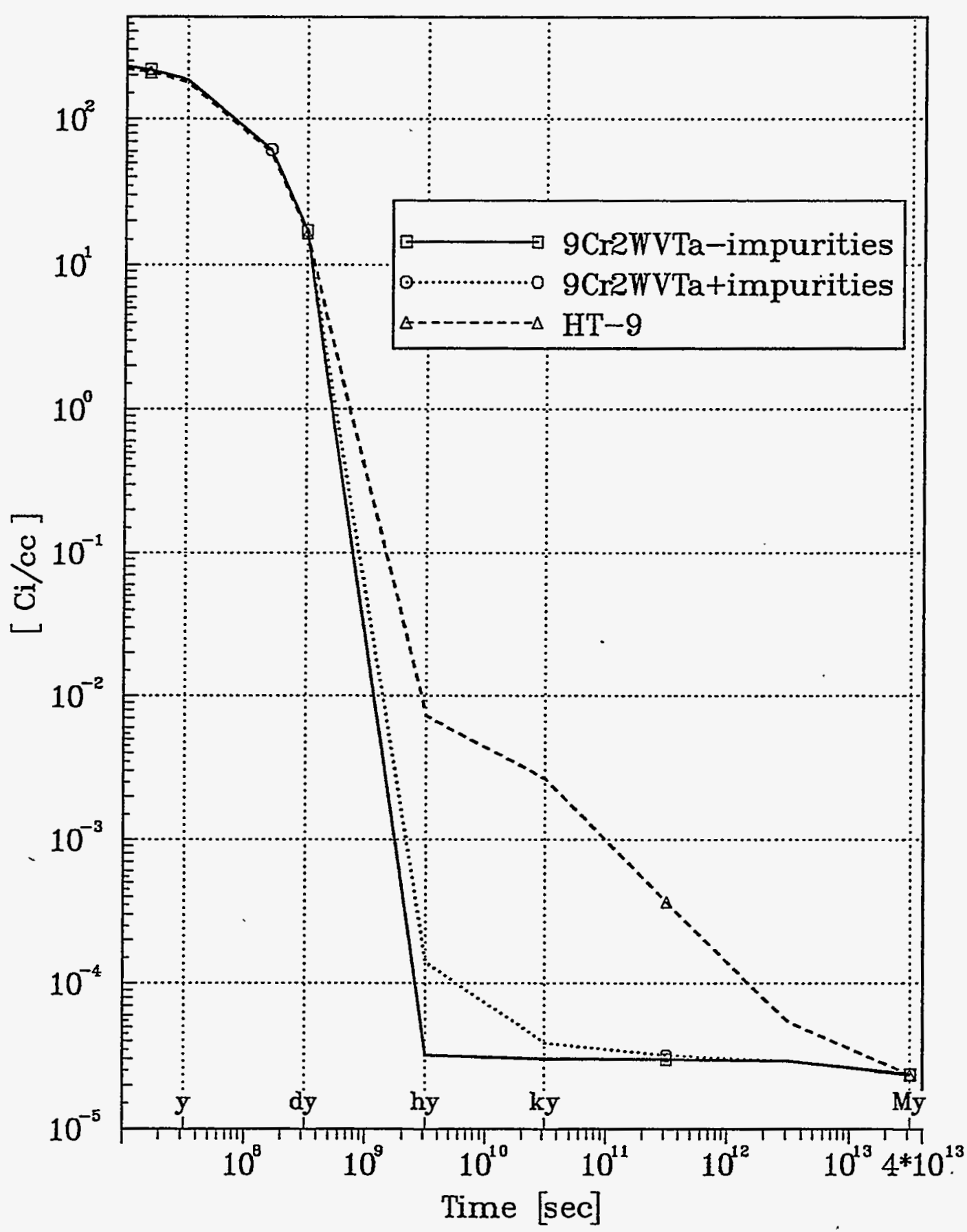

Figure 7. The radioactivity of $\mathrm{HT} 9$ and $9 \mathrm{Cr} 2 \mathrm{WVTa}$ with and without impurities. 


\section{REFERENCES}

[1] D. Ehst et al., Argonne National Laboratory, ANL/FPP/86-1 (1987).

[2] H.W. Scholz et al.,"Purity and radioactive decay behavior of industrial 2D-reinforced $\mathrm{SiC}_{\mathrm{f}} / \mathrm{SiC}$ composites," J. Nucl. Mater. 212-215 (1994) 655-661.

[3] H. Attaya and D. Smith, "Activation analyses for different fusion structural alloys," J. Nucl. Mater. 191-194 (1992) 1469-1473.

[4] R. O’Dell et al., Los Alamos National Laboratory Report, LA-9184-N (1982).

[5] J. Jung, Argonne National Laboratory, ANL/FPP/TM-122(1979).

[6] H. Attaya, Argonne National Laboratory, ANL/FPP/TM-270(1994).

[7] J. Kopecky and D. Nierop, ECN Report ECN-I-92-023 (1992). 


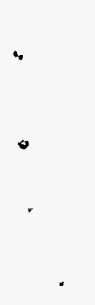




\subsection{MATERIALS ENGINEERING AND DESIGN REQUIREMENTS} No contributions. 


$$
\text { . }
$$




\subsection{FUNDAMENTAL MECHANICAL BEHAVIOR}

No contributions. 

5.0 RADIATION EFFECTS, MECHANISTIC STUDIES, THEORY AND MODELING 

SIMULATING THE PRODUCTION OF FREE DEFECTS IN IRRADIATED METALS - H. L. Heinisch (Pacific Northwest Laboratory')

\section{OBJECTTVE}

The objective of this work is to determine the energy and temperature dependence of defect production and microstructure evolution for the development of fission-fusion correlations.

\section{SUMMARY}

Under cascade-producing irradiation by high energy neutrons or charged particles, only a small fraction of the initially displaced atoms contribute to the population of free defects, i.e. those that are available to migrate throughout the metal and cause microstructural changes. Although, in principle, computer simulations of free defect production could best be done using molecular dynamics, in practice, the wide ranges of time and distance scales involved can be done only by a combination of atomistic models that employ various levels of approximation. An atomic-scale, multimodel approach has been developed that combines molecular dynamics, binary collision models and stochastic annealing simulation. The annealing simulation is utilized in calibrating binary collision simulations to the results of molecular dynamics calculations, as well as to model the subsequent migration of the defects on more macroscopic time and size scales. The annealing simulation and the method of calibrating the multimodel approach are discussed, and the results of simulations of cascades in copper are presented. The temperature dependence of free defect production following simulated annealing of isolated cascades in copper shows a differential in the fractions of free vacancies and interstitial defects escaping from the cascade above Stage V. This differential, a consequence of the direct formation of interstitial clusters in cascades and the relative thermal stability of vacancy and interstitial clusters during subsequent annealing, is the basis for the production bias mechanism of void swelling.

\section{PROGRESS AND STATUS}

\section{Introduction}

When cascade-producing radiation damage occurs in a solid, a distribution of single point defects and clustered point defects is produced in the local region where displacement damage is deposited. This defect distribution evolves in time. Some of the mobile defects interact within the cascade

region, while others escape the cascade and interact globally as part of the "free" or "available" defects that are responsible for many radiation-induced microstructural changes. Only a small fraction of all the atoms initially displaced in a single cascade survive in the form of point defects, and, depending on the temperature, only a fraction of the survivors interact outside the cascade region.

There are four stages in the process of defect production in a cascade: 1.) the initial displacing collisions, 2.) formation of a thermal spike, 3.) quenching of the thermal spike, and 4.) annealing within the cascade. In the collisional phase, which lasts a few tenths of a picosecond, a primary recoil atom initiates a cascade

\footnotetext{
'Pacific Northwest Laboratory is operated for the U.S. Department of Energy by Battelle Memorial Institute under Contract DE-AC06-76RLO 1830.
} 
of displacive collisions that continues until no atom contains enough energy to create further displacements. During the thermal spike stage, a molten zone is created as the collisional energy is shared among the atoms in a localized region having a high density of deposited energy. The identity of defects within the molten zone is largely lost, but the defects outside the molten zone (displaced atoms at the ends of replacement collision sequences, those ejected ballistically, and some vacancies) retain their identity. The displaced atoms become self-interstitial atoms (SIA). Molecular dynamics (MD) simulations indicate that elastic interactions lead to clustering of SIAs outside the molten zone'. During the quenching stage, which lasts for about $10 \mathrm{ps}$, the molten zone returns to a condensed state containing a distribution of vacancies within it. During the annealing stage, which may last for seconds, further rearrangement and interaction of the remaining defects takes place by normal, thermally-activated diffusion of mobile defects. It is in this stage that some of the mobile defects escape the cascade region to become the "free defects."

The four stages of cascade development occur over time scales differing by 15 orders of magnitude and can involve volumes of material containing millions of atoms. Hence, $\mathrm{MD}$ cannot be used to describe the entire cascade evolution. In this paper a methodology is discussed for simulating defect production through the annealing stage, well beyond the capabilities of $\mathrm{MD}$, that incorporates information about the spatial distribution of individual defects. This methodology utilizes a discrete, defect-scale, stochastic annealing simulation code, ALSOME. Two examples of using ALSOME to extend our knowledge of the cascade damage state beyond the spatial and time constraints of MD calculations are presented here. First, ALSOME is used to describe the subsequent annealing stage of cascades in copper that have been simulated through the quenching stage by $\mathrm{MD}$. The results illustrate for isolated cascades the key concept of the "production bias".considered in theories of void swelling". In the second example, the role of annealing simulations in the calibration procedure for dealing with high energy cascades (those intractable by $\mathrm{MD}$ ) by the multimodel approach (MMA) ${ }^{3}$ is discussed and illustrated for cascades in copper.

\section{The ALSOME Model}

In the stochastic annealing code ALSOME defects are the interacting entities. Each defect or defect cluster is associated with a lattice site. Mobile defects move by single, uncorrelated, random jumps to adjacent lattice sites. The next defect to jump is selected randomly from a distribution of the existing mobile defects that is weighted by the relative jump probabilities. Two defects coming within a defect-specific critical reaction distance are assumed to coalesce (cluster or annihilate), with the product defect (if any) residing at the target defect's lattice site. Thermally unstable defect clusters can dissociate one point defect at a time according to the relative probability of defect emission from the cluster.

The relative jump probabilities are calculated from the equation

$$
P(k, n, T)=P_{0} \exp \left(-E_{a}(k, n) / k T\right),
$$

where $k$ is the defect type (vacancy or SIA), $n$ is the cluster size, $T$ is the absolute temperature, and $E_{2}$ is the activation energy for the event. The pre-exponential factor $P_{0}$ is assumed constant (i.e., it has small variations relative to the differences in the exponential term). In the present calculations all probabilities are calculated relative to the jump probability of a single SIA at $300 \mathrm{~K}$. For conversion to real time, the jump frequency of a single interstitial is taken as $10^{13} \mathrm{~s}^{-1}$.

In earlier work, summarized in Ref. 4, ALSOME was applied to the annealing of cascades through Stage III, to about room temperature in copper. Simulations were carried out to the point where no mobile defects remained in the cascade region. Therefore, the specific values used for the relative jump probabilities were not very important. It was found that, as long as the relative jump probabilities of the mobile species were ranked in the proper order (i.e., SIAs move well before vacancies), their actual values did not significantly affect the final results. 
In the present work, where both dissociation and migration must be considered, and the actual annealing times and temperature dependence are important, it is necessary to use the best values for the relative probabilities of occurrence of all phenomena. Few of the activation energies have been determined experimentally, so for the present work we used calculated values determined by static MD calculations found in the literature, many of which were obtained with reliable long-range potentials derived from first principles. The static defect calculations indicate that vacancy clusters up to size $n=4$ and SIA clusters up to size $\mathrm{n}=3$ have significant mobilities relative to single vacancies and SIAs, respectively. In addition, there is evidence from $\mathrm{MD}$ simulations ${ }^{5}$ that small glissile interstitial loops readily form in cascades in copper, and these will glide in one dimension along $<111\rangle$ directions. The migration energy of these loops is estimated to be about equal to that of single SIAs ${ }^{6}$.

The activation energies were tested in ALSOME by simulating the isochronal annealing of copper after electron irradiation at $4.2 \mathrm{~K}$ and comparing with resistivity recovery experiments. Some adjustments and judgements regarding different calculated values were made as a result of these tests. A thorough review of calculations and experiments on defect migration and stability, with recommended values for activation energies, is necessary.

\section{Annealing Simulations of MD Cascades}

Two $25 \mathrm{keV}$ cascades generated with MD were annealed using ALSOME. The cascades were produced by Diaz de la Rubia and Guinan ${ }^{7}$ using the MOLDYCASK MD code, and they are the highest energy cascades generated by $\mathrm{MD}$ computer simulation to date. Their simulations followed the cascades for about the first $10 \mathrm{ps}$ of their development, by which time the temperatures of the cascade regions returned to near the original crystal temperature of $10 \mathrm{~K}$, and no further defect motion was detectable on the time scale of $\mathrm{MD}$ simulations. The MD output for each cascade was analyzed to identify vacancies and SIAs, and then each cascade was read into ALSOME as a list of point defect locations. ALSOME immediately assigns each defect to a lattice site and performs defect interactions according to the critical reaction distances. Thus, the starting configuration consists of a distribution of defect clusters (of from $n=1, n_{\max }$ defects), each associated with a lattice site.

The two cascades were each annealed 100 times for simulated annealing times of $1000 \mathrm{~s}$, and the numbers of each type of defect remaining were averaged. This was done for 17 temperatures between $0 \mathrm{~K}$ and 600 $\mathrm{K}$. The cascade region was assumed to rise instantaneously from $10 \mathrm{~K}$ to the annealing temperature at the beginning of each anneal.

A rectangular annealing volume was defined for each cascade that extends 25 lattice parameters beyond the maximum and minimum rectangular coordinates of the defect distribution. Any defect that goes outside this volume is assumed to have escaped from the cascade and is no longer followed. The annealing volume and time are consistent with cascade production in a typical fast reactor irradiation, i.e., on average another cascade will not occur in this volume during this time. These results are for isolated cascades only, and they do not reflect interactions of the defects with defects from prior or subsequent cascades in the material.

Figure 1 shows the total number of surviving defect pairs as a function of annealing temperature. These values include all defects that survive annihilation, including the escaping defects. Recovery Stages I, III and $V$ are evident at temperatures of approximately $0.03 \mathrm{~T}_{\mathrm{m}}, 0.15 \mathrm{~T}_{\mathrm{m}}$, and $0.32 \mathrm{~T}_{\mathrm{m}}$, respectively, as indicated by the decreases in the value of the total surviving defects. Escaping vacancies and escaping SIAs are also plotted separately in Fig. 1. At Stage I small SIA clusters and glissile loops become significantly mobile. The fraction of SIAs that escape the cascade is independent of temperature above that temperature. The SIAs lie at the periphery of the cascade region, and they will migrate more readily than vacancies at any temperature. The surviving SIAs remaining in the cascade region are in a few large clusters. 


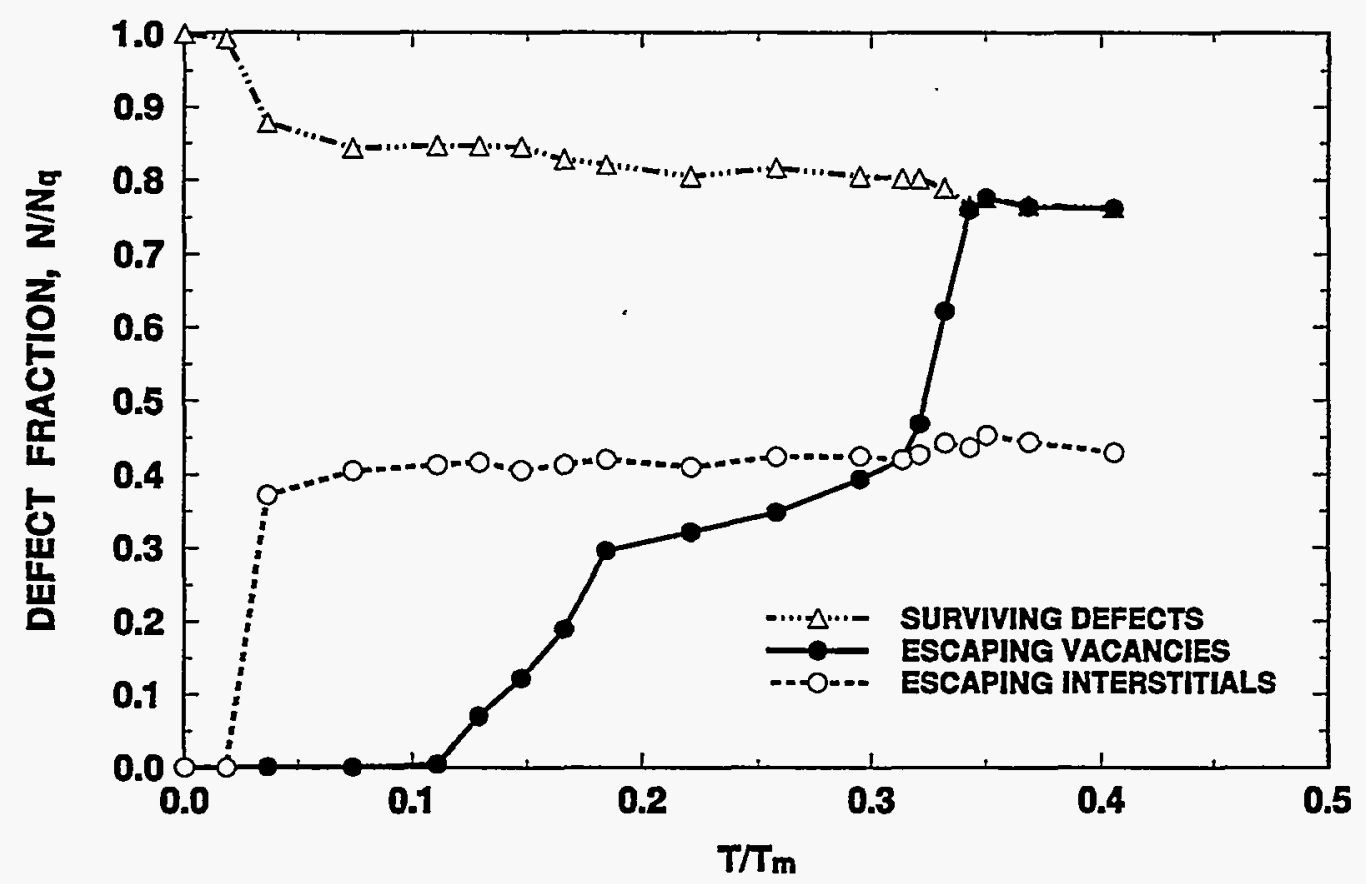

FIGURE 1. Annealing of Isolated $25 \mathrm{keV}$ Cascades in Copper. The defect fractions for the total number of defects surviving recombination and the vacancies and SIAs that escape from the cascade are plotted as a function of annealing temperature. Each data point is the average of 100 anneals of each of the two $25 \mathrm{keV}$ cascades generated in MD simulations [8]. The defect fractions are relative to the number of point defects existing after the quenching stage. The temperatures are relative to the experimental melting temperature of copper.

At temperatures in the somewhat broad Stage $I$, between $0.12-0.18 \mathrm{~T}_{\mathrm{m}}$, small vacancy clusters become mobile, and nearly all escape the cascade region during the anneal, except for a few that annihilate at the stable, stationary large SIA clusters. Above Stage $\mathrm{V}$, at $0.3 \mathrm{~T}_{\mathrm{m}}$, the vacancy clusters in the cascade core begin to dissociate, and nearly all of them also escape the cascade region. Thus, at temperatures of Stage $\mathrm{V}$ and above, nearly twice as many vacancies as SIAs escape the cascades to become free defects. In this simulation, where SIA loops up to size $n=9$ were considered mobile, about half the escaping SIAs are in the form of glissile loops that move randomly in one dimension. The SIAs in glissile loops will move rapidly to sinks, compared to those in small SIA clusters, which make three-dimensional random walks. This differential in production of free vacancies relative to free SIAs for defects produced in cascades is the "production bias" that may be responsible for void swelling", which begins at temperatures above Stage $\mathrm{V}$. 
ALSOME in the Multimodel Approach for High Energies

The MMA defines a procedure for simulating defect production through the annealing stage for high energy cascades beyond the capabilities of MD. Cascades are generated through the collisional stage using the binary collision approximation (BCA), then a modified version of ALSOME is used to simulate the defect arrangement arrived at during quenching. The regular version of ALSOME is used for annealing the quenched cascades in the same way as was done for the $\mathrm{MD}$ cascades described in the previous example. The crucial step of the MMA is to devise a version of ALSOME that, after operating on the collisional phase "defect" distribution, yields a reasonable description of the actual defect distribution remaining after quenching. The term "defect" is applied loosely here because at the end of the collisional phase, no stable defects exist; there is only a collection of displaced atoms and vacant lattice sites. Results of MD simulations are used to calibrate the MMA quenching procedure, which is described in detail in Ref. 3 .

In the initial attempts to devise a modified ALSOME for simulating the quenching operation for the BCA cascades, extensive use has been made of the two MD simulations of $25 \mathrm{keV}$ cascades in copper described in the annealing simulation example above. To calibrate the quenching operation, collisional phase information was extracted from the two $25 \mathrm{keV} \mathrm{MD}$ cascades in the same form as if it had been produced with the BCA code MARLOWE ${ }^{8}$. The ALSOME quenching scheme was then applied to the MARLOWElike collisional stage configurations, and the ALSOME parameter values used during quenching were varied until the best agreement was obtained between the fully $\mathrm{MD}$ and MMA versions, as shown in Table 1 . Of course, it is not possible to duplicate the actions

\section{TABLE 1}

Defect Production in $25 \mathrm{keV}$ Cascades in Cu at $300 \mathrm{~K}$. MD cascades at the "quenching stage" (the end of the MD simulation) were only annealed with ALSOME. Those starting from the "collisional stage" (extracted from the MD simulations) were quenched using the ALSOME quenching calibration, then annealed with ALSOME.

\begin{tabular}{|l|l|l|c|c||}
\hline \hline \multirow{2}{*}{$\begin{array}{c}\text { STARTING } \\
\text { CONFIGURATION }\end{array}$} & \multicolumn{2}{c|}{ TOTAL DEFECT PAIRS } & \multicolumn{2}{c|}{ FREELY MGRATING } \\
QUENCHED & ANNEAIED & VACANCIES & SIAS \\
\hline \hline QUENCHING STAGE & 60 & $49 \pm 4$ & $8 \pm 4$ & $9 \pm 3$ \\
\hline COLLISIONAL STAGE & $61 \pm 10$ & $48 \pm 7$ & $8 \pm 3$ & $9 \pm 4$ \\
\hline \hline
\end{tabular}

of atoms or defects during the development and quenching of the thermal spike using a model in which defects simply move and interact. The criterion for agreement of the MMA and the fully MD versions of the cascades was taken to be similarity of the defect configurations following the annealing stage for annealing at $300 \mathrm{~K}$. In particular, the total number of defect pairs remaining after the quench and the total number of pairs and the numbers of free defects remaining after annealing could be made to agree for the MMA and the fully MD versions of the cascades, as shown in Table 1.

While the numbers of defects agree well, the spatial distributions of the defects after quenching were significantly different for the MMA and MD versions. The distribution of SIAs had the same size (the root mean square average radius of the defects from the centroid) in both the MMA and MD versions, but the vacancy distribution after quenching in the MMA version was much broader than in the MD version. The 
vacancy distributions of the fully $\mathrm{MD}$ cascades after the quenching stage diminished to an average radius about half that of the initial collisional stage, whereas in the MMA case the average radius remained unchanged after quenching. Apparently, these differences in the spatial distributions do not affect the ability of this simple model to correctly partition the defects with respect to annihilation, clustering and free defects, at least at room temperature. Further attempts at this BCA-MD calibration using ALSOME will demand the temperature dependence of defect production after annealing to be consistent between the MMA and $M D$ versions. This may require that an ALSOME quenching scheme be devised to produce the correct spatial distribution of defects in the quench, if possible.

\section{Conclusions}

Two examples of ALSOME simulations are described here: the temperature dependence of differential defect production in cascades and the investigation of ALSOME as an approach to simulating quenching in high energy cascades. These examples illustrate the use of defect-scale Monte Carlo annealing simulations as the critical modeling link between the atomistic description of defect production and continuum theories of microstructure evolution under irradiation. Thus, in principal, the radiation damage process can be modeled at a level of physical reality relevant to the time and size scale at each stage from the initial atomic collisions to the development of microstructural features.

\section{REFERENCES}

1. T. Diaz de la Rubia and M.W. Guinan, J. Nucl. Mater. 174 (1990) 151.

2. C.H. Woo and B.N. Singh, Phil Mag. A65 (1992) 889.

3. H.L. Heinisch, B.N. Singh and T. Diaz de la Rubia; J. Nucl. Mater. 212-215 (1994) 127.

4. H.L. Heinisch, Rad. Eff. Def. Solids 113 (1990) 53.

5. A.J.E. Foreman, W.J. Phythian and C.A. English, Phil. Mag. A 66 (1992) 671.

6. H. Trinkaus, B.N. Singh and A.J.E. Foreman, J. Nucl. Mater. 206 (1993) 200.

7. T. Diaz de la Rubia and M.W. Guinan, Mater. Res. Forum 97-99 (1992) 23.

8. M.T. Robinson and I.M. Torrens, Phys. Rev. B 9 (1974) 5008. 


\subsection{DEVELOPMENT OF STRUCTURAL ALLOYS}

6.1 Ferritic Martensitic and Bainitic Steels 
MICROSTRUCTURAL ANALYSIS OF IRRADIATED MARTENSITIC STEELS -- J.J. Kai (National Tsing Hua University, Hsinchu, Taiwan) and R.L. Klueh (Oak Ridge National Laboratory)

\section{OBJECTIVE}

The goal of this study is the development of reduced-activation ferritic steels.

\section{SUMMARY}

Four martensitic steels were examined by transmission electron microscopy after irradiation in the Fast Flux Test Facility (FFTF). Irradiation in FFTF was at $420^{\circ} \mathrm{C}$ to about $7.8 \times 10^{26} \mathrm{n} / \mathrm{m}^{2}$ (E>0.1MeV), which gave a displacement damage of about $35 \mathrm{dpa}$. The steels were those of interest for fusion applications and included two commercial steels, $9 \mathrm{Cr}-1 \mathrm{MoVNb}$ (modified $9 \mathrm{Cr}-1 \mathrm{Mo}$ ) and $12 \mathrm{Cr}-1 \mathrm{MoVW}$ (Sandvik HT9), and two experimental reduced-activation steels, $9 \mathrm{Cr}-2 \mathrm{WV}$ and $9 \mathrm{Cr}-2 \mathrm{WVTa}$. Before irradiation, the tempered martensite microstructures of the four steels contained a high dislocation density, and the major precipitate was $\mathrm{M}_{23} \mathrm{C}_{6}$ carbide, with lesser amounts of $\mathrm{MC}$ carbide. Irradiation caused only small changes in these precipitates. Voids were found in all irradiated specimens, but swelling remained below $1 \%$, with the $9 \mathrm{Cr}-1 \mathrm{MoVNb}$ hating the highest void density. Although the $12 \mathrm{Cr}-1 \mathrm{MoVW}$ steel showed the best swelling resistance, it also contained the highest density of radiation-induced new phases, which were identified as chi-phase and possibly $\alpha^{\prime}$. Radiation-induced chi phase was also observed in the $9 \mathrm{Cr}-$ $1 \mathrm{MoVNb}$ steel. The two reduced-activation steels showed very stable behavior under irradiation: a high density of dislocation loops (average diameter of $50 \mathrm{~nm}$ ) replaced the original high dislocation density; moderate void swelling occurred, but no new phases formed. The differences in microstructural evolution of the steels can explain some of the mechanical properties observations made in these steels.

\section{PROGRESS AND STATUS}

\section{Introduction}

Reduced-activation or fast-induced radioactivity decay (FIRD) martensitic steels are one of the major candidate materials for the first wall and blanket structures for future fusion reactors. A FIRD alloy cannot contain molybdenum and niobium, important constituents in conventional $\mathrm{Cr}-\mathrm{Mo}$ steels of interest for fusion. Previous publications on the FIRD steels developed at Oak Ridge National Laboratory [1-3] reported on microstructure, tempering and tensile behavior [2], and Charpy impact behavior [3] in the unirradiated condition. Results were also reported on the tensile and Charpy properties of neutron-irradiated specimens [4-6].

Ferritic/martensitic steels containing 7-9 wt\% $\mathrm{Cr}$ are favored for fusion. FIRD 9Cr alloys were patterned after the composition of conventional $9 \mathrm{Cr}-1 \mathrm{MoVNb}$ (modified $9 \mathrm{Cr}-1 \mathrm{Mo}$ ) steel, with molybdenum replaced by tungsten and niobium replaced by tantalum. $\mathrm{A} 9 \mathrm{Cr}$ $2 \mathrm{~W}-0.25 \mathrm{~V}(9 \mathrm{Cr}-2 \mathrm{WV})$ and this nominal composition with $0.07 \% \mathrm{Ta}(9 \mathrm{Cr}-2 \mathrm{WVTa})$ were irradiated. In order to compare these steels with the conventional $\mathrm{Cr}-\mathrm{Mo}$ steels of interest for fusion, both $12 \mathrm{Cr}-1 \mathrm{MoVW}$ (Sandvik HT9) and $9 \mathrm{Cr}-1 \mathrm{MoVNb}$ steels were also included in this study. In this paper, the effect of neutron irradiation on the microstructural evolution of the four martensitic steels irradiated to $35 \mathrm{dpa}$ at $420^{\circ} \mathrm{C}$ in the FFTF is presented. The microstructural evolution affects the mechanical property 

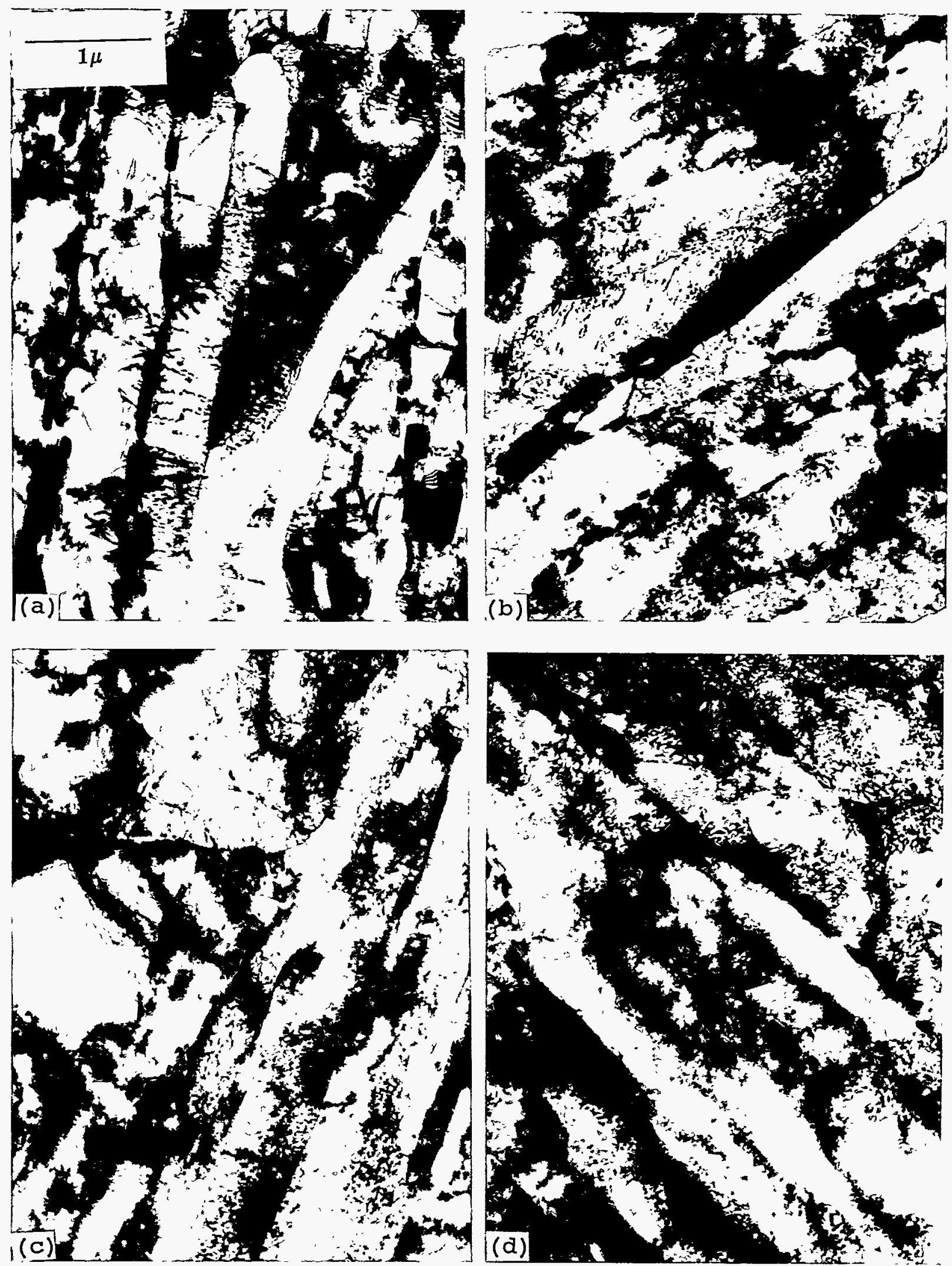

Fig. 1. Microstructures of (a) normalized-and-tempered $12 \mathrm{Cr}-1 \mathrm{MoVW}$, (b) irradiated $12 \mathrm{Cr}-1 \mathrm{MoVW}$, (c) normalized-and-tempered $9 \mathrm{Cr}-1 \mathrm{MoVNb}$, and (c) irradiated $9 \mathrm{Cr}-1 \mathrm{MoVNb}$. 
changes, which under a fusion environment will determine the applicability of these steels for future fusion power plants.

\section{Experimental Procedure}

Four martensitic steels were used in this study: the commercial steels $12 \mathrm{Cr}-1 \mathrm{MoVW}$ and $9 \mathrm{Cr}-1 \mathrm{MoVNb}$ and the experimental steels $9 \mathrm{Cr}-2 \mathrm{WV}$ and $9 \mathrm{Cr}-2 \mathrm{WVTa}$. In addition to nominal compositions of $\mathrm{Cr}, \mathrm{V}, \mathrm{W}, \mathrm{C}$, and $\mathrm{Ta}$ in the experimental steels, concentrations of elements normally found in commercial steels, such as $\mathrm{Mn}, \mathrm{P}, \mathrm{Si}$, etc., were added in the levels typical of commercial practice. Chemical compositions are given in Table 1.

Table 1. Chemical Composition of Four Steels Tested

\begin{tabular}{|c|c|c|c|c|c|c|c|c|c|c|c|c|c|}
\hline Steel & Fe & $\mathrm{Cr}$ & $\mathrm{Mo}$ & $\mathrm{C}$ & $\mathrm{V}$ & $\mathrm{W}$ & $\mathrm{Nb}$ & $\mathrm{Ta}$ & $\mathrm{Si}$ & $\mathrm{Mn}$ & $\mathrm{P}$ & $\mathrm{S}$ & $\mathrm{N}$ \\
\hline \hline $12 \mathrm{Cr}-1 \mathrm{MoVW}$ & bal. & 12.1 & 1.04 & 0.2 & 0.29 & 0.61 & - & - & 0.17 & 0.57 & 0.016 & 0.003 & 0.027 \\
\hline 9Cr-1MoVNb & bal. & 8.32 & 0.86 & 0.092 & 0.2 & - & 0.06 & - & 0.15 & 0.48 & 0.012 & 0.004 & 0.054 \\
\hline $9 \mathrm{Cr}-2 \mathrm{WV}$ & bal. & 8.73 & - & 0.12 & 0.25 & 2.09 & - & - & 0.25 & 0.51 & 0.014 & 0.005 & - \\
\hline $9 \mathrm{Cr}-2 W V T a$ & bal. & 8.72 & - & 0.1 & 0.23 & 2.09 & - & 0.07 & 0.23 & 0.43 & 0.015 & 0.005 & - \\
\hline
\end{tabular}

Specimens from each steel were irradiated in the Materials Open Test Assembly (MOTA) of the Fast Flux Test Facility (FFTF) at $420^{\circ} \mathrm{C}$. Irradiation was to about $7.8 \times 10^{26} \mathrm{n} / \mathrm{m}^{2}$ $(E>0.1 \mathrm{MeV})$, which produced a damage dose of about 35 dpa.

Microstructural examinations were performed on a Philips CM-30 scanning transmission electron microscope operating at $300 \mathrm{keV}$ and equipped with an EDAX $9900 \mathrm{X}$-ray energy dispersive spectroscopy system.

\section{$\underline{\text { Results }}$}

Microstructural examination indicated that irradiation caused basically three types of microstructural changes, which involved voids, dislocations and dislocation loops, and precipitates. Figures 1 and 2 show the unirradiated and irradiated microstructures of the two $\mathrm{Cr}-\mathrm{Mo}$ and two $\mathrm{Cr}-\mathrm{W}$ steels, respectively. Before irradiation, all specimens were $100 \%$ tempered martensite with a lath width of about 0.5 micron. Neutron irradiation produced micro features in the matrix and caused some coarsening of lath width.

\section{Void swelling}

Figure 3 shows the void morphology in the four irradiated steels. The $9 \mathrm{Cr}-1 \mathrm{MoVNb}$ steel showed the highest void density with a relatively larger average void diameter. Table 2 contains the estimated void density, average void diameter, and total swelling of the four different materials. Swelling values for all four steels are less than $1 \%$.

The $9 \mathrm{Cr}-1 \mathrm{MoVNb}$ developed the largest amount of swelling $(0.85 \%)$, with the $12 \mathrm{Cr}-1 \mathrm{MoVW}$ showing the best swelling resistance $(<0.01 \%)$. The two tungsten-containing alloys also showed good swelling resistance, with the swelling about 3 to 4 times better than $9 \mathrm{Cr}$ $1 \mathrm{MoVNb}$. The $9 \mathrm{Cr}-2 \mathrm{WV}$ performed slightly better than the $9 \mathrm{Cr}-2 \mathrm{WVTa}$. Therefore, the FIRD steels are highly swelling resistant and better than conventional $9 \mathrm{Cr}-1 \mathrm{MoVNb}$ steel. 

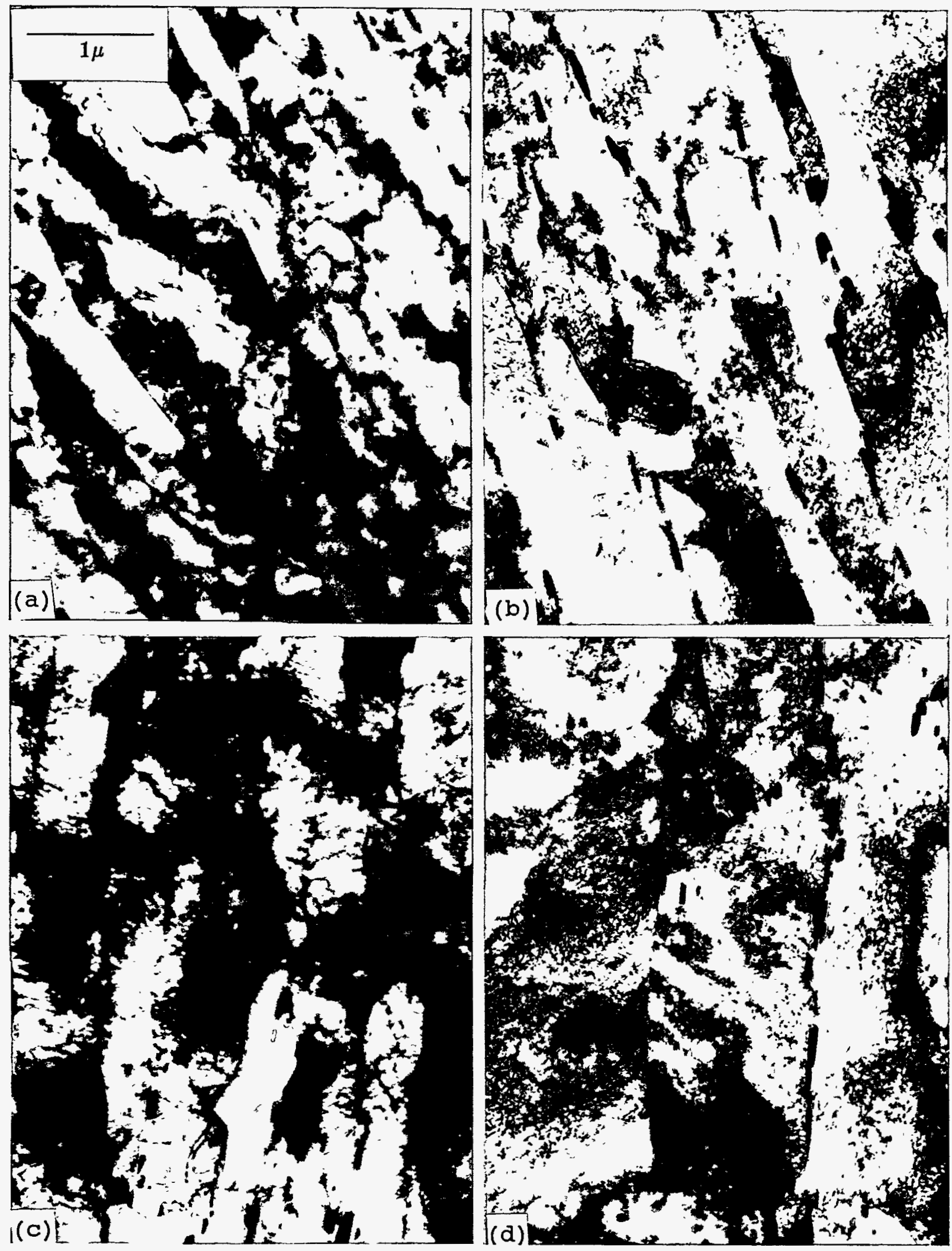

Fig. 2. Microstructures of (a) normalized-and-tempered $9 \mathrm{Cr}-2 \mathrm{WV}$, (b) irradiated $9 \mathrm{Cr}$ $2 \mathrm{WV}$, (c) normalized-and-tempered $9 \mathrm{Cr}-2 \mathrm{WVTa}$, and (c) irradiated $9 \mathrm{Cr}-2 \mathrm{WVTa}$. 


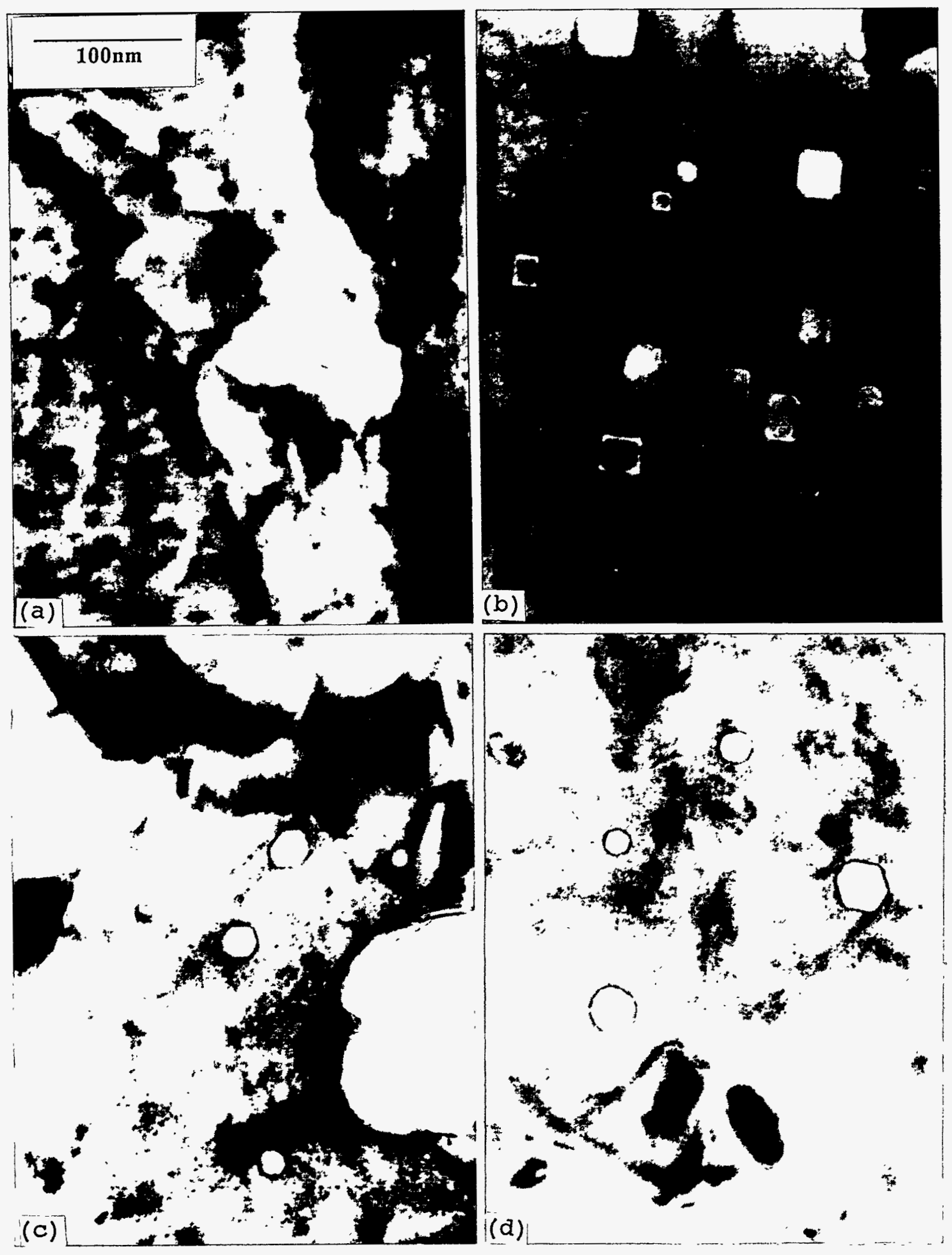

Fig. 3. Voids in (a) $12 \mathrm{Cr}-1 \mathrm{MoVW},($ b) $9 \mathrm{Cr}-1 \mathrm{MoVNb}$, (c) $9 \mathrm{Cr}-2 \mathrm{WV}$, and (d) $9 \mathrm{Cr}-2 \mathrm{WVTa}$. 
Dislocations and dislocation loops

Before irradiation, all four steels had a very high density of dislocations (about $10^{15} \mathrm{~m}^{-2}$ ). Figure 4 shows the dislocation segments and loops of specimens after neutron irradiation. A quantitative summary of the dislocation loop density and total dislocation density is given in Table 2. It was observed that the $12 \mathrm{Cr}-1 \mathrm{MoVW}$ and $9 \mathrm{Cr}-1 \mathrm{MoVNb}$ steels contained a lower density of loops but with larger average diameter (about $100 \mathrm{~nm}$ ) than the two tungsten-containing steels. The $12 \mathrm{Cr}-1 \mathrm{MoVW}$ and $9 \mathrm{Cr}-1 \mathrm{MoVNb}$ also contained some dislocation segments. On the other hand, the $9 \mathrm{Cr}-2 \mathrm{WV}$ and $9 \mathrm{Cr}-2 \mathrm{WVTa}$ alloys contained only loops and at a much higher density (around $3 \times 10^{21} \mathrm{~m}^{-3}$ ) and relatively smaller diameter (about $50 \mathrm{~nm}$ ).

Table 2. Dislocation and Void Statistics For Four Steels Tested

\begin{tabular}{|l|c|c|c||c|c|c|}
\hline \multicolumn{1}{|c|}{ Steel } & Void & $\begin{array}{c}\text { Void mean } \\
\text { diameter } \\
(\mathrm{nm})\end{array}$ & $\begin{array}{c}\text { void } \\
\text { swelling } \\
(\%)\end{array}$ & $\begin{array}{c}\text { dislocation } \\
\text { loop } \\
\text { diameter } \\
(\mathrm{nm})\end{array}$ & $\begin{array}{c}\text { loop } \\
\text { density } \\
\left(\mathrm{m}^{-3}\right)\end{array}$ & $\begin{array}{c}\text { total } \\
\text { dislocation } \\
\text { density } \\
\left(\mathrm{m}^{-2}\right)\end{array}$ \\
\hline $12 \mathrm{Cr}-1 \mathrm{MoVW}$ & $5 \times 10^{18}$ & 30 & 0.007 & 100 & $5 \times 10^{20}$ & ${ }^{*} 5 \times 10^{14}$ \\
\hline $9 \mathrm{Cr}-1 \mathrm{MoVNb}$ & $6 \times 10^{20}$ & 30 & 0.85 & 100 & $5 \times 10^{19}$ & ${ }^{*} 2 \times 10^{14}$ \\
\hline $9 \mathrm{Cr}-2 \mathrm{WV}$ & $2.5 \times 10^{19}$ & 25 & 0.2 & 50 & $3 \times 10^{21}$ & $5 \times 10^{14}$ \\
\hline $9 \mathrm{Cr}-2 \mathrm{WVTa}$ & $4 \times 10^{19}$ & 25 & 0.33 & 50 & $3 \times 10^{21}$ & $5 \times 10^{14}$ \\
\hline
\end{tabular}

${ }^{*} 9 \mathrm{Cr}-1 \mathrm{MoVNb}$ and $12 \mathrm{Cr}-1 \mathrm{MoVW}$ had fewer loops but some dislocation lines

After irradiation, all of the specimens still contained a high density of dislocations (if the loop density is converted into dislocations). In $12 \mathrm{Cr}-1 \mathrm{MoVW}$, the dislocation density was about $5 \times 10^{14} \mathrm{~m}^{-2}$. The loops in $9 \mathrm{Cr}-1 \mathrm{MoVNb}$ grew to a much larger size and looked like dislocation segments; the dislocation density of this steel was the lowest of the four steels at about $2 \times 10^{14} \mathrm{~m}^{-2}$. Both tungsten-containing alloys were similar and contained medium-sized loops and a dislocation density of about $5 \times 10^{14} \mathrm{~m}^{-2}$.

\section{Precipitate evolution}

It is well known that the majority of precipitates in these steels in the normalized-andtempered condition are $\mathrm{M}_{23} \mathrm{C}_{6}$ carbides. It was observed that there was little difference in the $\mathrm{M}_{23} \mathrm{C}_{6}$ of the four steels in terms of size and distribution before and after irradiation. Nevertheless, the internal microstructure of the $\mathrm{M}_{23} \mathrm{C}_{6}$ particles did show some change after neutron irradiation. Figure 5 shows the microstructural features of $\mathrm{M}_{23} \mathrm{C}_{6}$ carbides after irradiation. The nature of this internal microstructural change was not identified.

Quantitative observations on the size and distribution of the precipitates are given in Table 3. The data indicate that the amount of $\mathrm{M}_{23} \mathrm{C}_{6}$ carbide in $12 \mathrm{Cr}-1 \mathrm{MoVW}$ is about twice as much as in the other three steels, which is understandable because there is twice as much carbon in the $12 \mathrm{Cr}-1 \mathrm{MoVW}(0.2 \mathrm{wt} \%)$ than in the other three steels $(0.1 \mathrm{wt} \%)$. 


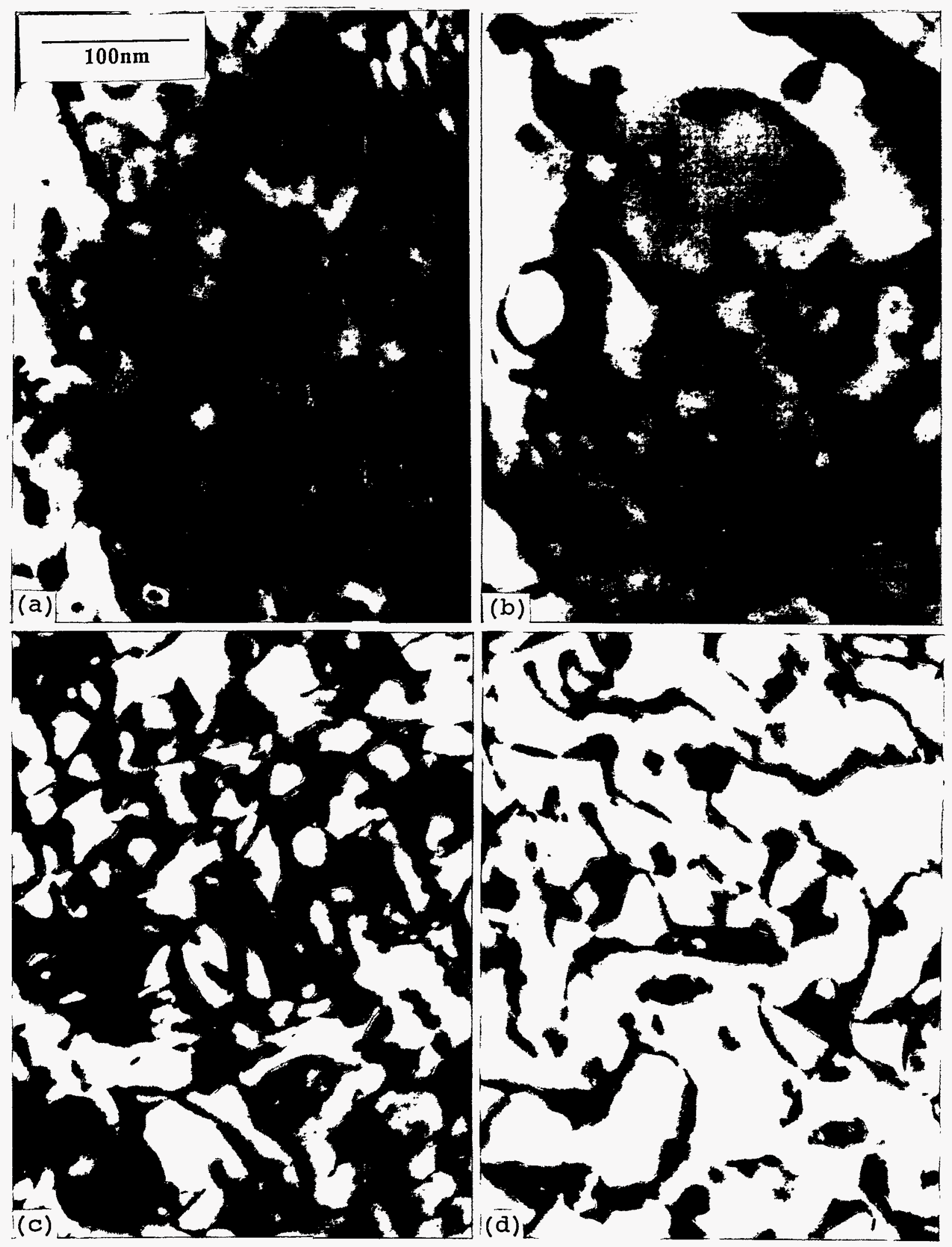

Fig. 4. Dislocation and dislocation loop structures in irradiated specimens of (a) $12 \mathrm{Cr}-$ $1 \mathrm{MoVW}$, (b) $9 \mathrm{Cr}-1 \mathrm{MoVNb}$ (c) $9 \mathrm{Cr}-2 \mathrm{WV}$, and (d) $9 \mathrm{Cr}-2 \mathrm{WVTa}$. 


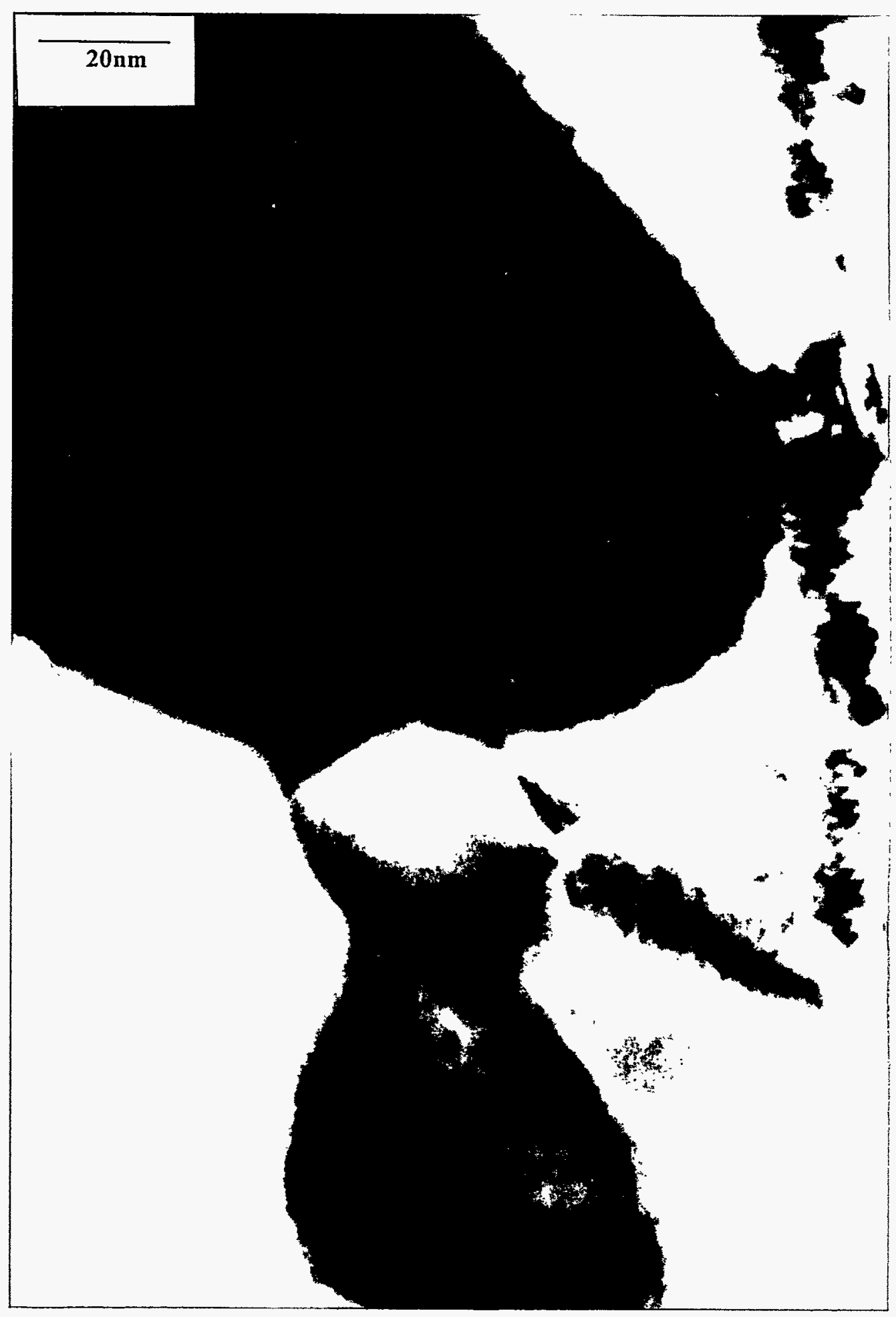

Fig. 5. Microstructure of $\mathrm{M}_{23} \mathrm{C}_{6}$ carbide in $9 \mathrm{Cr}-1 \mathrm{MoVNb}$ after neutron irradiation. 
Table 3. Precipitate Statistics for Four Steels Tested

\begin{tabular}{|c|c|c|c|c|c|c|}
\hline \multirow[b]{2}{*}{ steel } & \multicolumn{3}{|c|}{ before irradiation } & \multicolumn{3}{|c|}{ after irradiation } \\
\hline & ppt. & $\begin{array}{c}\text { density } \\
\left(\mathrm{m}^{-3}\right)\end{array}$ & $\begin{array}{l}\text { average } \\
\text { diameter } \\
(\mathrm{nm})\end{array}$ & ppt. & $\begin{array}{l}\text { density } \\
\left(\mathrm{m}^{-3}\right)\end{array}$ & $\begin{array}{c}\text { average } \\
\text { diameter } \\
(\mathrm{nm})\end{array}$ \\
\hline \multirow[t]{4}{*}{$12 \mathrm{Cr}-1 \mathrm{MoVW}$} & $\mathrm{M}_{23} \mathrm{C}_{6}$ & $7.1 \times 10^{19}$ & 155 & $\mathrm{M}_{23} \mathrm{C}_{6}$ & $5.6 \times 10^{19}$ & 164 \\
\hline & $\mathrm{MC}$ & $1.6 \times 10^{18}$ & 50 & $\mathrm{MC}$ & $1.0 \times 10^{18}$ & 55 \\
\hline & & & & $\alpha^{\prime}$ & $1.5 \times 10^{22}$ & 5 \\
\hline & & & & $\chi$ & $6.1 \times 10^{20}$ & 13 \\
\hline \multirow[t]{3}{*}{$9 \mathrm{Cr}-1 \mathrm{MoVNb}$} & $\mathrm{M}_{23} \mathrm{C}_{6}$ & $2.8 \times 10^{19}$ & 151 & $\mathrm{M}_{23} \mathrm{C}_{6}$ & $2.6 \times 10^{19}$ & 155 \\
\hline & $\mathrm{MC}$ & $7.9 \times 10^{18}$ & 32 & $\mathrm{MC}$ & $6.8 \times 10^{18}$ & 40 \\
\hline & & & & $\chi$ & $8.6 \times 10^{20}$ & 10 \\
\hline \multirow[t]{2}{*}{$9 \mathrm{Cr}-2 \mathrm{WV}$} & $\mathrm{M}_{23} \mathrm{C}_{6}$ & $5.9 \times 10^{19}$ & 125 & $\mathrm{M}_{23} \mathrm{C}_{6}$ & $3.2 \times 10^{19}$ & 160 \\
\hline & $\mathrm{MC}$ & $1.2 \times 10^{18}$ & 54 & $\mathrm{MC}$ & $1.1 \times 10^{18}$ & 160 \\
\hline \multirow[t]{2}{*}{$9 \mathrm{Cr}-2 \mathrm{WVTa}$} & $\mathrm{M}_{23} \mathrm{C}_{6}$ & $4.5 \times 10^{19}$ & 136 & $\mathrm{M}_{23} \mathrm{C}_{6}$ & $4.1 \times 10^{19}$ & 143 \\
\hline & $\mathrm{MC}$ & $7.5 \times 10^{18}$ & 29 & $\mathrm{MC}$ & $5.6 \times 10^{18}$ & 36 \\
\hline
\end{tabular}

MC carbides are the other type of precipitate commonly found in these steels (Fig. 6). In $12 \mathrm{Cr}-1 \mathrm{MoVW}$, the $\mathrm{MC}$ carbides are usually vanadium rich with some exceptions, which were chromium rich. The number density of $\mathrm{MC}$ carbides in $12 \mathrm{Cr}-1 \mathrm{MoVW}$ was small compared to $\mathrm{M}_{23} \mathrm{C}_{6}$. The $\mathrm{MC}$ carbides in $9 \mathrm{Cr}-1 \mathrm{MoVNb}$ are usually enriched in niobium and/or vanadium rich, with a number density $\approx 7 \times 10^{18} \mathrm{~m}^{-3}$ and an average diameter of $40 \mathrm{~nm}$. In the tungsten-containing steels, the number density and diameter are $1 \times 10^{18} \mathrm{~m}^{-3}$ and $60 \mathrm{~nm}$ for the $9 \mathrm{Cr}-2 \mathrm{WV}$ steel and are $6 \times 10^{18} \mathrm{~m}^{-3}$ and $36 \mathrm{~nm}$ for $9 \mathrm{Cr}-2 \mathrm{WVTa}$ steel. These MC carbides are either vanadium rich (in $9 \mathrm{Cr}-2 \mathrm{WV}$ ) and/or tantalum rich (in $9 \mathrm{Cr}-2 \mathrm{WVTa}$ ). Table 3 also summarizes the quantitative data of these carbides.

A high density of small precipitates in the matrix of the neutron-irradiated $12 \mathrm{Cr}-1 \mathrm{MoVW}$ steel specimen was tentatively identified as $\alpha^{\prime}$ phase [see Fig. 7(a)]. The number density is about $1.5 \times 10^{22} \mathrm{~m}^{-3}$ and the size varied from 4 to $6 \mathrm{~nm}$ in diameter. No similar precipitates were observed in the other three steels irradiated to similar conditions.

Another type of small precipitate was observed in neutron-irradiated $12 \mathrm{Cr}$-1MoVW. These precipitates have a number density of $\approx 6.1 \times 10^{20} \mathrm{~m}^{-3}$ and an average diameter of $13 \mathrm{~nm}$. It was identified with the lattice fringe image as chi phase (Fig. 7). This phase was also found in neutron-irradiated $9 \mathrm{Cr}-1 \mathrm{MoVNb}$ steel, where the number density was $8.6 \times 10^{20} \mathrm{~m}^{-3}$ and the size about $10 \mathrm{~nm}$ in diameter. No such precipitate was found in the two tungsten-containing steels. 


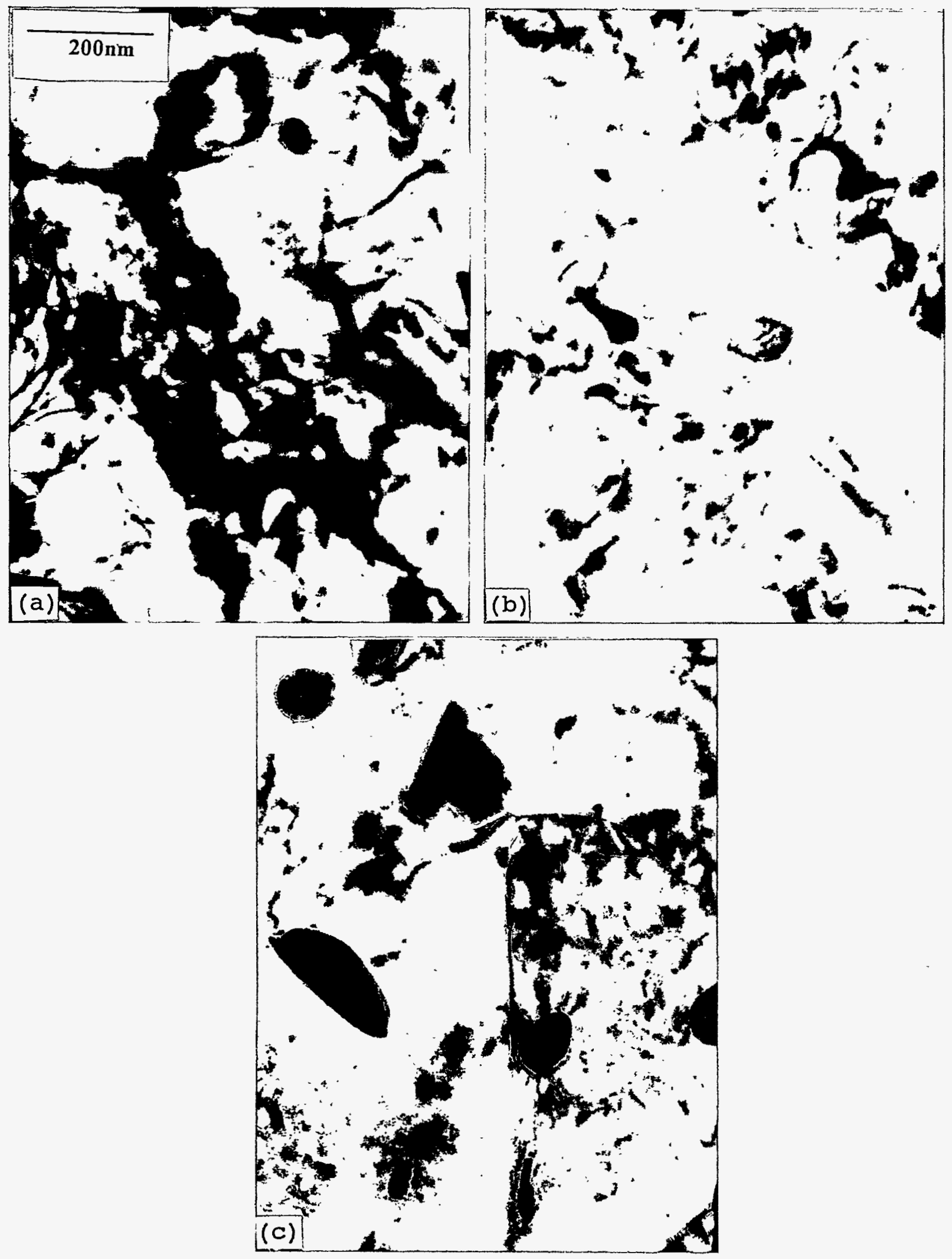

Fig. 6. Microstructures showing the MC carbides in (a) $9 \mathrm{Cr}-1 \mathrm{MoVNb}$, (b) $9 \mathrm{Cr}-2 \mathrm{WV}$, and (c) $9 \mathrm{Cr}-2 \mathrm{WVTa}$. 

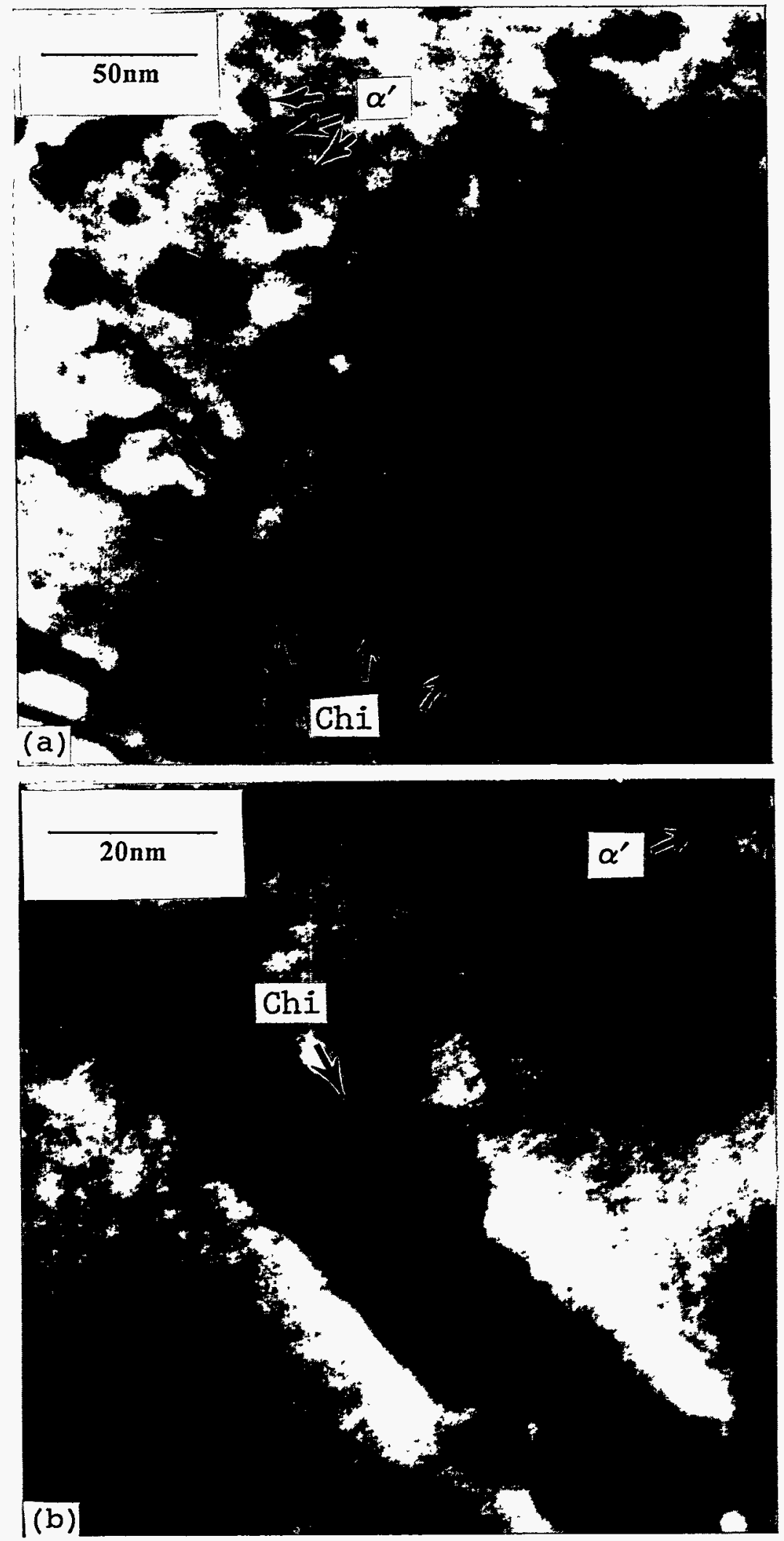

Fig. 7. The $\alpha^{\prime}$ and chi phases in $12 \mathrm{Cr}-1 \mathrm{MoVW}$ specimen after neutron irradiation. 


\section{$\underline{\text { Discussion }}$}

The difference in microstructure among the four unirradiated steels was minimal. In the normalized-and-tempered condition, all four steels contained $100 \%$ tempered martensite. The only significant difference was that the $12 \mathrm{Cr}-1 \mathrm{MoVW}$ steel contained twice the amount of carbides as were in the $9 \mathrm{Cr}$ steels, which was attributed to twice as much carbon in the $12 \mathrm{Cr}-1 \mathrm{MoVW}$ steel. The $9 \mathrm{Cr}$ steels with $\mathrm{Nb}$ or $\mathrm{Ta}$ contained small amounts of $\mathrm{MC}$ carbides enriched in either $\mathrm{Nb}$ or $\mathrm{Ta}$, respectively. Despite these small differences before irradiation, the microstructural evolution during neutron irradiation caused significant differences among the four steels. In the following discussion, void swelling resistance, dislocation loop formation, and precipitate modification will be compared for the four steels.

It is well known that ferritic steels have excellent swelling resistance among the alloys considered for fusion structural applications. For the four steels, the $12 \mathrm{Cr}-1 \mathrm{MoVW}$ steel showed the best swelling resistance during neutron irradiation to $35 \mathrm{dpa}$, the total swelling being around $0.01 \%$. Although the $9 \mathrm{Cr}-1 \mathrm{MoVNb}$ steel showed the most swelling among the four steels, swelling was still less than $1 \%$ at $35 \mathrm{dpa}$. Previous studies of several research groups showed similar results [8-12]. The void swelling behavior of the two tungsten-containing steels was similar that of the molybdenum-containing steels with the measured values falling between that of the two molybdenum-containing steels, around $0.2 \%$ to $0.3 \%$ at $35 \mathrm{dpa}$. The difference in void swelling among the four steels may be explained by the observations on the microstructural evolution. During irradiation of the $12 \mathrm{Cr}-1 \mathrm{MoVW}$ specimen, a very high density of small precipitates, both $\alpha^{\prime}$ and chi phase, formed in the matrix, which served as sinks for vacancies and interstitials to recombine (it is known that coherent precipitates are sinks for recombination only), therefore suppressing the void nucleation and growth. A similar observation was found in protonirradiated Inconel 600 alloy [13]. Although there were no such precipitates in the tungsten-containing steels, the high density of dislocation loops formed during irradiation served the same purpose with less effectiveness. In the irradiated $9 \mathrm{Cr}-1 \mathrm{MoVNb}$ specimen, there were fewer irradiation-induced precipitate particles compared to the $12 \mathrm{Cr}-1 \mathrm{MoVW}$ steel, and this steel also contained a lower dislocation density compared to that of the tungsten-containing steels. Therefore, it showed the highest void swelling during neutron irradiation.

Neutron-irradiation-induced precipitates were found in $12 \mathrm{Cr}-1 \mathrm{MoVW}$ steel. Chi phase particles were positively identified through the lattice image technique in both molybdenum-containing steels. The formation of this phase is believed to be due to the molybdenum content in the matrix or from decomposed $\mathrm{M}_{23} \mathrm{C}_{6}$ carbides which segregated during irradiation. However, no such phase formed in the two tungsten-containing steels. This observation agrees with other experimental evidence and thermodynamic calculations on the $\mathrm{Fe}-\mathrm{Cr}-\mathrm{Mo}[20]$ and on the $\mathrm{Fe}-\mathrm{Cr}-\mathrm{W}$ [21] ternary systems, which indicated that a higher concentration of chromium is required to form chi phase in the $\mathrm{Fe}-\mathrm{Cr}-\mathrm{W}$ system than in the $\mathrm{Fe}-\mathrm{Cr}-\mathrm{Mo}$ system.

Another type of very small precipitates was found in the $12 \mathrm{Cr}-1 \mathrm{MoVW}$ steel but not in the other three steels, and it was tentatively identified as $\alpha^{\prime}$. From Fig. 7(b), it is seen that these smaller particles are not chi phase, because although they were in the same matrix, they displayed a different orientation. It is generally believed that in high-chromium ferritic steels $(>15 \%$ wt.), there is a possibility of aging embrittlement due to the formation of $\alpha^{\prime}$ phase through either spinodal decomposition or nucleation and growth, depending on the aging temperature [15]. Under irradiation, however, the critical chromium content necessary to form $\alpha^{\prime}$ phase may be lower than that during thermal aging. Previous studies of irradiated $12 \mathrm{Cr}$ steel [16-18] also reported the similar particles and identified them as 
chromium-enriched $\alpha^{\prime}$ phase. Mechanical property studies of the four steels indicated that of the four steels, the $12 \mathrm{Cr}-1 \mathrm{MoVW}$ steel showed the highest shift in ductile-brittle transition temperature (DBTT) and the most hardening after neutron irradiation. As discussed in a companion paper [19], it is believed that both new phases formed in $12 \mathrm{Cr}-$ $1 \mathrm{MoVW}$ may contribute to the increase in strength and decrease in toughness.

It was observed that in $9 \mathrm{Cr}-2 \mathrm{WV}$ and $9 \mathrm{Cr}-2 \mathrm{WVTa}$ steels, a relatively high density of dislocation loops formed during irradiation at $420^{\circ} \mathrm{C}$, which was not found in the molybdenum-containing steels ( $12 \mathrm{Cr}-1 \mathrm{MoVW}$ and $9 \mathrm{Cr}-1 \mathrm{MoVNb})$. This observation has not been reported in the literature. It is believed that during neutron irradiation, the preexisting dislocations gradually recovered and were replaced by dislocation loops (average size around $50 \mathrm{~nm}$ ). These loops could then serve as the point defect sinks that suppressed the void swelling below that observed in $9 \mathrm{Cr}-1 \mathrm{MoVNb}$, where no such loops formed.

\section{Conclusions}

An examination of the microstructural evolution of four martensitic steels before and after neutron-irradiation at $420^{\circ} \mathrm{C}$ to about $7.8 \times 10^{26} \mathrm{n} / \mathrm{m}^{2}$ leads to the following conclusions:

(a) Before irradiation, the microstructures of the four steels were tempered martensite containing $\mathrm{M}_{23} \mathrm{C}_{6}$ and a few $\mathrm{MC}$ carbides. Due to the higher carbon concentration, the $12 \mathrm{Cr}-1 \mathrm{MoVW}$ steel contained twice as much $\mathrm{M}_{23} \mathrm{C}_{6}$ carbides than the other three $9 \mathrm{Cr}$ steels.

(b) During irradiation of the $12 \mathrm{Cr}-1 \mathrm{MoVW}$ steel, a very high density of small precipitates formed, which were identified as chi phase (13 $\mathrm{nm}$ in diameter and $6.1 \times 10^{20} \mathrm{~m}^{-3}$ ) and $\alpha^{\prime}$ phase $\left(5 \mathrm{~nm}\right.$ in diameter and $\left.1.5 \times 10^{22} \mathrm{~m}^{-3}\right)$. These radiationinduced precipitates may be the reason for the large increase in DBTT of this steel after irradiation. The $\alpha^{\prime}$ phase forms because of the higher chromium content in this steel.

(c) In irradiated $9 \mathrm{Cr}-1 \mathrm{MoVNb}$ steel, the only radiation-induced phase observed was chi phase. The formation of chi phase in both $9 \mathrm{Cr}-1 \mathrm{MoVNb}$ and $12 \mathrm{Cr}-1 \mathrm{MoVW}$ steels and not in the $9 \mathrm{Cr}-2 \mathrm{WV}$ and $9 \mathrm{Cr}-2 \mathrm{WVTa}$ steels is believed to be due to the molybdenum in these steels.

(d) Irradiation caused no new phases to form in the $9 \mathrm{Cr}-2 \mathrm{WV}$ and $9 \mathrm{Cr}-2 \mathrm{WVT}$ a steels; however, a relatively high density of dislocation loops formed (the dislocation density is around $5 \times 10^{14} \mathrm{~m}^{-2}$ ).

(e) The $12 \mathrm{Cr}-1 \mathrm{MoVW}$ showed the best swelling resistance among the four steels irradiated, and the $9 \mathrm{Cr}-1 \mathrm{MoVNb}$ had the highest void swelling. The difference in void swelling behavior was attributed to the microstructural variations, including the radiation-induced precipitates and dislocation loops.

\section{Acknowledgement}

The following people are acknowledged for their assistance in completing the work: L.T. Gibson and W.S. Eatherley prepared the irradiated TEM specimens; J.W. Jones prepared the unirradiated TEM specimens. One of the authors (JJK) was partially supported by the National Science Council of the Republic of China-TAIWAN. 


\section{REFERENCES}

1. R.L. Klueh and P.J. Maziasz, Met. Trans. 20A (1989) 373.

2. R.L. Klueh, Met. Trans. 20A (1989) 463.

3. R.L. Klueh and W.R. Corwin, J. Eng. Mater., 11 (1989) 169.

4. R.L. Klueh, D.J. Alexander, and P.J. Maziasz, J. Nucl. Mater., 186 (1992) 185.

5. R.L. Klueh and D.J. Alexander, J Nucl. Mater., 212-215 (1994) 736.

6. R.L. Klueh and D.J. Alexander, Effects of Radiation on Materials: 16th International Symposium, ASTM STP 1175, eds. A.S. Kumar, D.S. Gelles, and R.K. Nanstad, (American Society for Testing and Materials, Philadelphia, 1994) p.591.

7. R.L. Klueh, J. Nucl. Mater., 179-181 (1991) 728.

8. P.J. Maziasz and R.L. Klueh, Effects of Radiation on Materials: 14th International Symposium (volume I), ASTM STP 1046, eds. N.H. Packan, R.E. Stoller, and A.S. Kumar (American Society for Testing and Materials, Philadelphia, 1990) p.35.

9. D.S. Gelles and L.E. Thomas, Proceeding of Topical Conference on Ferritic Alloys for use in Nuclear Energy Technologies, eds. J.W. Davis and D.J. Michel (Metallurgical Society of AIME, Warrendale, PA 1984) p. 559.

10. J. M. Vitek and R.L. Klueh, ibid, p. 551.

11. P.J. Maziasz, R.L. Klueh, and J.M. Vitek, J. Nucl. Mater., 141-143 (1986) 929.

12. D.S. Gelles, J. Nucl. Mater., 212-215, (1994) 714.

13. J.J. Kai and R.D. Lee, J. Nucl. Mater., 207 (1993) 286.

14. R.W.K. Honeycombe, Structure and Strength of Alloy Steels, Climax Molybdenum Co. Ltd., London, 1974.

15. Metals Handbooks, tenth edition, volume 1, American Society for Metals,

16. J.J. Kai and G.L. Kulcinski, J. Nucl. Mater., 175 (1990) 227.

17. P. Dubuisson, D. Gilbon, and J.L. Seran, J. Nucl. Mater., 205 (1993) 178.

18. D.S. Gelles, Effects of Radiation on Materials: 14th International Symposium, volume I, ASTM STP 1046, eds. N.H. Packan, R.E. Stoller, and A.S. Kumar (American Society for Testing and Materials, Philadelphia, 1990) p.73.

19. R.L. Klueh, J.J. Kai, and D.J. Alexander, J. Nucl. Mater., to be published.

20. J.O. Andersson and N. Lange, Met. Trans., 19A (1988) 1385.

21. P. Gustafson, Met. Trans., 19A (1988) 2531. 
ON THE ROLE OF STRAIN RATE, SLZE AND NOTCH ACUITY ON TOUGHNESS: A COMPARISON OF TWO MARTENSITIC STAINLESS STEELS - G. E. Lucas, G. R. Odette, J. W. Sheckherd, K. Edsinger, B. Wirth (Department of Chemical \& Nuclear Engineering and Mechanical Engineering, University of California, Santa Barbara)

\section{OBJECTTVE}

Ongoing work is being conducted to characterize the mechanical properties of tempered martensitic (TM) stainless steels. The objective of the present report is to relate observations for two of these steels, HT9 and F82H.

\section{SUMMARY}

The fracture resistance and micromechanisms of two tempered martensitic steels were characterized over a range of temperatures by both mechanical testing and quantitative fractography. Both HT-9 and F82H undergo a fracture mode transition from quasi-cleavage at low temperature to microvoid coalescence at high temperature. The transition in HT9 is rather gradual, and the transition in F82H is extremely abrupt. While the toughness of F82H was higher in all cases, differences between the two steels depended on test type, strain rate and temperature. In general F82H had only slightly better properties in the quasi-cleavage regime. For example, the transition temperatures indexed at fracture toughness levels of $100 \mathrm{MPa} / \mathrm{m}$ were only 25 and $14^{\circ} \mathrm{C}$ lower in F82H than HT9 under static and dynamic conditions, respectively, and they were identical at the $10 \mathrm{~J}$ level for Charpy impact tests. However, the fracture resistance of F82H was higher than HT9 in the ductile fracture regime. The Charpy V-notch upper shelf initiation energies in F82H were roughly twice those of HT-9, and total upper shelf energies were three times larger. Differences appeared to be smaller for both static and dynamic upper shelf toughness. Charpy upper shelf energies reflect complex and extrinsically mediated crack tearing processes that have, at best, very limited fundamental or structural significance. Thus, using an energy of $41 \mathrm{~J}$, widely perceived to be appropriate indexing a ductile-to-brittle transition temperature (DBTT) for Charpy data, results in a much lower (by $81^{\circ} \mathrm{C}$ ) putative DBTT for F82H compared to HT-9. These results not only demonstrate the inherent non-uniqueness of the so called DBTT, but also call into question the use of Charpy data for ranking the relative performance of various alloys. The similarities in quasi-cleavage fracture and differences in ductile fracture are manifested in the fracture surfaces and are interpreted in terms of the underlying mechanisms and microstructures.

\section{PROGRESS AND STATUS}

Introduction

The demonstrated swelling resistance and high heat flux capacity make tempered martensitic (TM) steels a leading candidate alloy class for application to fusion first wall and blanket structures. However, TM alloys undergo 
a change from nominally ductile to nominally brittle fracture below a so called ductile-to-brittle transition temperature (DBTI) that may be substantially increased by irradiation. Hence, radiation embrittlement is widely believed to be the major disadvantage of TM steels.

As we have shown elsewhere, however, there is no unique DBTT, and the defect tolerant capabilities of a material must be judged by more structurally relevant measures of strength and strain limits in the presence of cracks.[1,2] Developing and applying appropriate measures requires a more fundamental approach, based on an understanding of underlying fracture processes. To this end we have carried out a comprehensive series of mechanical property tests coupled with detailed fractographic analyses on two leading candidate TM steels which have been, or are being, characterized in a number of irradiation programs. The objective is to compare and contrast various macroscopic and microscopic measures of fracture resistance and to interpret the results both in terms of fundamental mechanisms and structural implications.

\section{Experiment}

The two steels examined were HT-9 and F82H. HT9 is a $12 \mathrm{Cr}-1 \mathrm{Mo}-\mathrm{W}-\mathrm{V}$ steel originally developed for fossil energy plants that has been investigated broadly for both fast reactor and fusion reactor applications.[3] The F82H is an optimized reduced activation $8 \mathrm{Cr}-2 \mathrm{~W}-\mathrm{V}$ steel specifically targeted for fusion applications.[4] It is the immediate precursor to a large International Energy Agency (IEA) heat that will be the focus of research on TM alloys in the next several years. [5]

The composition of the electroslag refined (ESR) heat of HT-9 is given in Table 1. After hot rolling at 1050 to $1090^{\circ} \mathrm{C}$ the $\sim 25 \mathrm{~mm}$ thick plate was stress relieved at $850^{\circ} \mathrm{C}$ for $2 \mathrm{~h}$ cooled at $5^{\circ} \mathrm{C} / \mathrm{h}$ to $700^{\circ} \mathrm{C}$, held for $6 \mathrm{~h}$ and air cooled.[6] Previous analysis has shown that this steel has a tempered martensitic structure with prior austenite grains (PAG) of about $55 \mu \mathrm{m}$ diameter containing martensite laths in packets of about 7-8 $\mu \mathrm{m}$ in diameter.[7] The carbon content of HT- 9 is relatively high at $0.23 \%$. The matrix contains a fine scale distribution of $\mathrm{MO}_{2} \mathrm{C}$ and $\mathrm{MC}$ precipitates and coarser $\mathrm{M}_{23} \mathrm{C}_{6}$ and $\mathrm{M}_{6} \mathrm{C}$ carbides. The lath, the lath packet and PAG boundaries are heavily decorated with (mostly $\mathrm{M}_{23} \mathrm{C}_{6}$ ) carbides typically less than $0.2 \mu \mathrm{m}$ in size; there is also a smaller population of relatively large $(1 \mu \mathrm{m})$ carbides along PAG boundaries; the boundary carbides are rich in $\mathrm{Cr}$ and contain significant amounts of iron and molybdenum.[6,7]

The composition of the F82H steel, obtained courtesy of A. Hishinuma of Japan Atomic Energy Research Institute, is also shown in Table 1. Nickel, molybdenum and niobium contents have been minimized to achieve reduced neutron activation and tungsten, vanadium and tantalum have been added as replacements - viz., as strong carbide formers and for other metallurgical purposes such as grain size control. The carbon content of 


\begin{tabular}{|c|c|c|c|c|c|c|c|c|c|c|c|}
\hline \multicolumn{12}{|c|}{ Composition (Wt \%) } \\
\hline Steel & $C$ & $M n$ & $S i$ & $\mathrm{Ni}$ & $\mathrm{Cr}$ & Mo & $V$ & $W$ & $\mathrm{Ta}$ & $S$ & $P$ \\
\hline HT-9 & .23 & .39 & .17 & .51 & 12.1 & 1.04 & .28 & .45 & - & .003 & .016 \\
\hline $\mathrm{F} 82 \mathrm{H}$ & .10 & .5 & .1 & - & 8.0 & - & .2 & 2.0 & .04 & .003 & .003 \\
\hline
\end{tabular}

Table 1. Compositions of HT-9 and F82H

F82H, at $0.10 \%$, is significantly lower than in HT9. The material was received as $25 \mathrm{~mm}$ thick plate which had been normalized at $1040^{\circ} \mathrm{C}$ for $0.5 \mathrm{~h}$ and tempered at $740^{\circ} \mathrm{C}$ for $1 \mathrm{~h}$. The reported microstructure consists of tempered martensite with a prior austenite grain size of about $120 \mu \mathrm{m}$. Boundary and matrix precipitation consists primarily of $\mathrm{Cr}$-rich $\mathrm{M}_{2}{ }_{3} \mathrm{C}_{6}$. Consistent with the lower carbon content, the boundary carbides tend to be finer (on average $\leq 0.15 \mu \mathrm{m}$ ) and less numerous than those observed in the HT-9.[8,9] Although not reported specifically for F82H, microstructures of steels with similar compositions and heat treatments have been observed to contain significant populations of matrix and boundary carbides, which include, depending on steel composition, $\mathrm{M}_{6} \mathrm{C}$ (Ta and W-rich) and $\mathrm{MC}(\mathrm{V}$ and Ta-rich).[10,11]

Round bar tensile specimens $3.2 \mathrm{~mm}$ in diameter by $25.4 \mathrm{~mm}$ in gage length were cut from the HT-9 plate in the transverse orientation. Flat miniature tensile specimens with gage sections $9 \mathrm{~mm} \times 2 \mathrm{~mm} \times 0.5 \mathrm{~mm}$ were punched from coupons cut from the F82H and lapped to $0.5 \mathrm{~mm}$ thickness. These miniature tensile specimens have provided data in good agreement with larger specimens.[12] Fracture specimens included standard ASTM E23 blunt-notched Charpy specimens (CVN), subsized Charpy (MCVN) specimens scaled by a factor of one-third in all dimensions, and precracked three-point bend specimens. The three-point bend specimens (3PB) were fatigue pre-cracked at a final $\Delta \mathrm{K} \leq 20 \mathrm{MPa} / \mathrm{m}$ to a depth (a) to width $(\mathrm{W}$ ) ratio of a/W $\approx 0.5$. They included full thickness (T) Charpy specimens (PCCV) and $0.2 \mathrm{~T}, 0.4 \mathrm{~T}$ and $0.6 \mathrm{~T}$ bend bars. In the case of HT-9, 0.15 to $1 \mathrm{~T}$ compact tension (CT) and disc compact tension (DCT) test specimens were also included in the test matrix.

Tensile tests on HT-9 were conducted at temperatures ranging from $-101^{\circ} \mathrm{C}$ to $66^{\circ} \mathrm{C}$ at strain rates in the range $10^{-3}$ to $3 \mathrm{~s}^{-1}$ on a servo-hydraulic load frame. Tensile tests on F82H were performed at strain rates of $10^{-3} \mathrm{~s}^{-1}$ over a temperature range of $-196^{\circ} \mathrm{C}$ to $25^{\circ} \mathrm{C}$ and at $10^{-1}$ and $10 \mathrm{~s}^{-1}$ at $25^{\circ} \mathrm{C}$. Fracture tests were also carried out over a wide range of loading rates and temperatures from -196 to $350^{\circ} \mathrm{C}$. Temperature control was achieved by a number of techniques ranging from a variety of baths to pre-cooling specimen/fixture assemblies. Impact tests were performed on both the CVN and PCCV specimens on an instrumented pendulum impact machine. The MCVN specimens were tested on a drop tower at somewhat lower ( -5 times) impact velocities. In all cases loadtime data were used to determine both the total and partitioned (e.g., initiation) energies; and for the PCCV specimens, dynamic elastic ( $\left.\mathrm{K}_{\mathrm{Id}}\right)$ and elastic-plastic toughness $\left(\mathrm{K}_{\mathrm{Jd}}\right.$, assuming crack initiation at maximum 
loads).[13] The static, pre-cracked 3PB, CT, and DCT specimens were tested at relatively low displacement rates $(\sim 0.008 \mathrm{~mm} / \mathrm{s})$ on a servo-hydraulic load frame. Standard ASTM practices were used to determine valid linear elastic toughness, $\mathrm{K}_{\mathrm{Ic}}$ (ASTME 399), or critical elastic-plastic energy release rates, $\mathrm{J}_{\mathcal{C}}$ (E 813); in the latter case crack growth $(\Delta \mathrm{a})$, if any, was measured by unloading compliance (PCCV and 3PB) or electric potential drop (CT, DCT) methods.[14]

Scanning electron microscopy (SEM) and confocal microscopy (CM) were performed on selected specimens to characterize details of the fracture process. The CM was used to generate quantitative, three dimensional topographic maps of the fracture surfaces. Maps of conjugate fracture surfaces were input to a fracture reconstruction (FR) technique to evaluate the damage evolution/fracture sequence-of-events ahead of the crack tip as a function of crack tip opening displacement (d). Details of the CM/FR method are described elsewhere.[15,16]

\section{Results - Mechanical Properties}

Tensile and Charpy Tests- - Uniaxial yield stress $\sigma_{\mathrm{y}}$ and ultimate tensile strength (UTS) are plotted in Figure 1 against a strain rate $(\dot{\varepsilon})$ compensated temperature parameter, $\mathrm{P}_{\mathrm{T}}=\mathrm{T}(\mathrm{K}) \log \left(10^{8} / \dot{\varepsilon}\right)$. Although not a unique way of correlating tensile properties to temperature and strain rate, $\mathrm{P}_{\mathrm{T}}$ has been found useful for other steels [17] and reasonably collapses the dynamic to static data for both $\mathrm{HT} 9$ and F82H. In spite of differences in composition and heat treatments, the strengths of these two steels are quite similar (note, on average the UTS for the HT9 is about $50 \mathrm{MPa}$ higher than for the $\mathrm{F} 82 \mathrm{H}$ ). The uniform elongations (not shown) ranged from about $12 \%$ at room temperature to $15 \%$ at $-100^{\circ} \mathrm{C}$ in the $\mathrm{HT}$, and from about $7 \%$ at room temperature to $10 \%$ at $-100^{\circ} \mathrm{C}$ in the $\mathrm{F} 82 \mathrm{H}$. The strain hardening behavior was also similar, with strain hardening exponents of about 0.1 to 0.15 .

Total absorbed energy (E)-temperature ( $T$ ) data for the Charpy impact tests are shown in Figure 2a. The HT9 shows a very broad transition from lower shelf (ending at about $-100^{\circ} \mathrm{C}$ ) to an upper (beginning at about $120^{\circ} \mathrm{C}$ ) shelf energy of about $125 \mathrm{~J}$. In contrast, the $\mathrm{F} 82 \mathrm{H}$ shows an extremely abrupt transition at about $-50 \pm 10^{\circ} \mathrm{C}$ to an upper shelf energy of over $300 \mathrm{~J}$, consistent with data reported elsewhere.[9] The DBTT indexed at $41 \mathrm{~J}$, $\mathrm{T}_{41}$, is about $81^{\circ} \mathrm{C}$ higher in the HT9 $\left(25^{\circ} \mathrm{C}\right.$ versus $-56^{\circ} \mathrm{C}$ for the $\left.\mathrm{F} 82 \mathrm{H}\right)$. However, the choice of $41 \mathrm{~J}$, where the fracture mode involves a mixture of cleavage and microvoid coalescence, as an index for a DBTT is arbitrary. Other DBTT values are obtained using alternate measures, such as: 1) $50 \%$ shear fracture appearance $\left(34 \pm 5^{\circ} \mathrm{C}\right.$ for the HT9 versus $-55 \pm 5^{\circ} \mathrm{C}$ for the $\left.\mathrm{F} 82 \mathrm{H}\right)$; 2) 35 mils $\left(0.89 \mathrm{~mm}\right.$ ) lateral expansion $\left(119 \pm 5^{\circ} \mathrm{C}\right.$ versus $\left.-56 \pm 5^{\circ} \mathrm{C}\right)$; and 3 ) $50 \%$ of the upper shelf energy ( $50 \pm 5$ versus $-50 \pm 5^{\circ} \mathrm{C}$ ). A more physically meaningful index is at an absorbed energy level of $10 \mathrm{~J}, \mathrm{~T}_{10}$, which has been found to approximately correspond to the onset of linear elastic fracture.[18] Remarkably, the $\mathrm{T}_{10}$ for $\mathrm{F} 82 \mathrm{H}$ and $\mathrm{HT} 9$ are virtually the same, about $-60 \pm 5^{\circ} \mathrm{C}$. 
A better physical measure of fracture resistance is the energy expended up to the initiation of crack extension. Since it is generally difficult to define the exact initiation point, the initiation energy $\left(E_{i}\right)$ is usually defined as the energy absorbed at maximum load.[13] Figure $2 b$ shows that the $E_{i}$ for F82H also has an extremely abrupt transition compared to HT9. The DBTT based on the highest temperature for cleavage initiation (evident as a sharp drop in load in the load-time curve) in blunt notched Charpy impact tests is about $60 \pm 6$ and $-43 \pm 3^{\circ} \mathrm{C}$, respectively, for $\mathrm{HT} 9$ and $\mathrm{F} 82 \mathrm{H}$, a difference of about $103^{\circ} \mathrm{C}$.

Figure $2 c$ shows the E-T curve for the MCVN tests. Here we have multiplied the actual $\mathrm{E}$ by a factor of 27 which
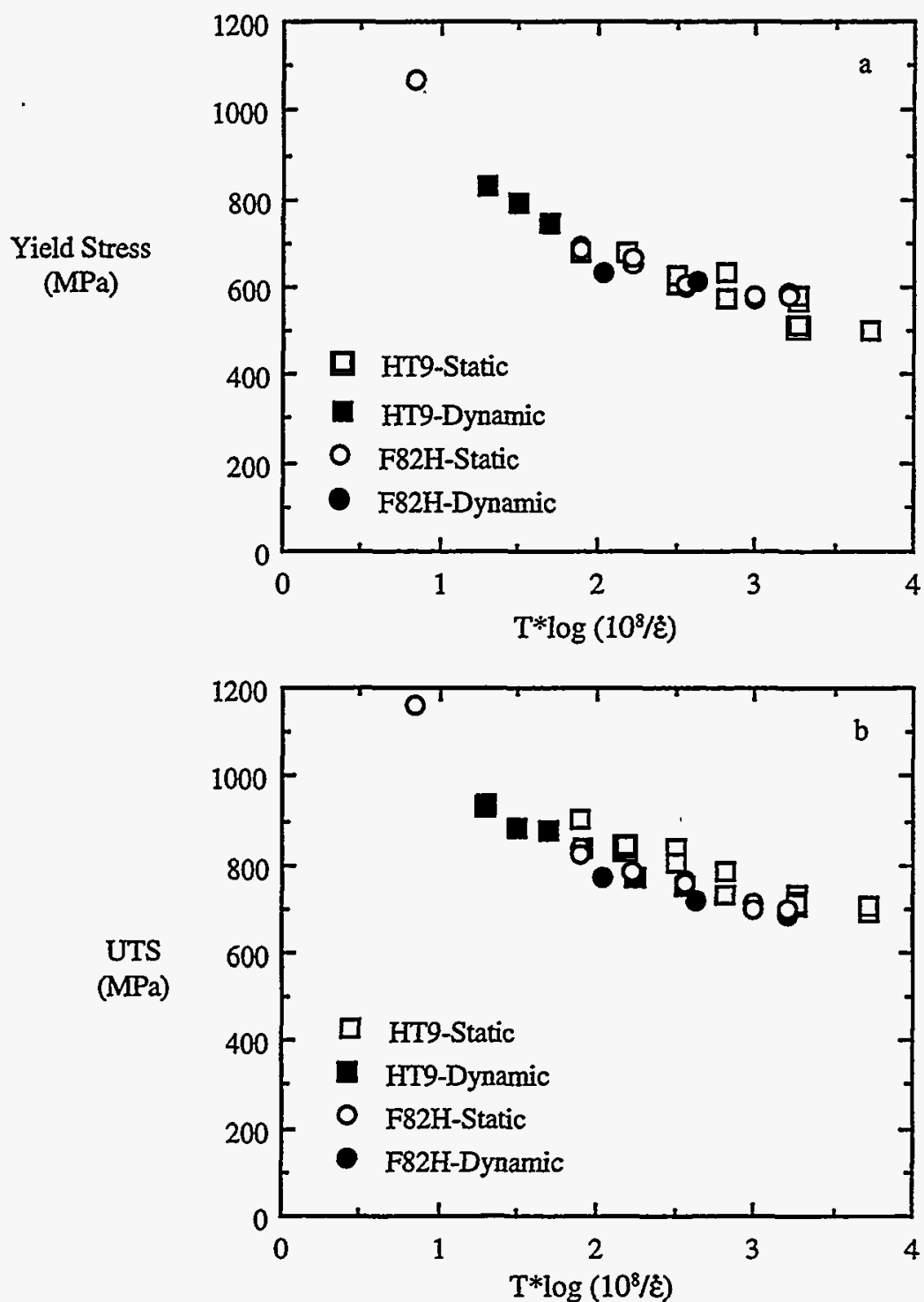

Figure. 1 Comparison of a) yield stresses and b) ultimate tensile strengths of HT9 and F82H as a function of strain rate compensated temperature. 

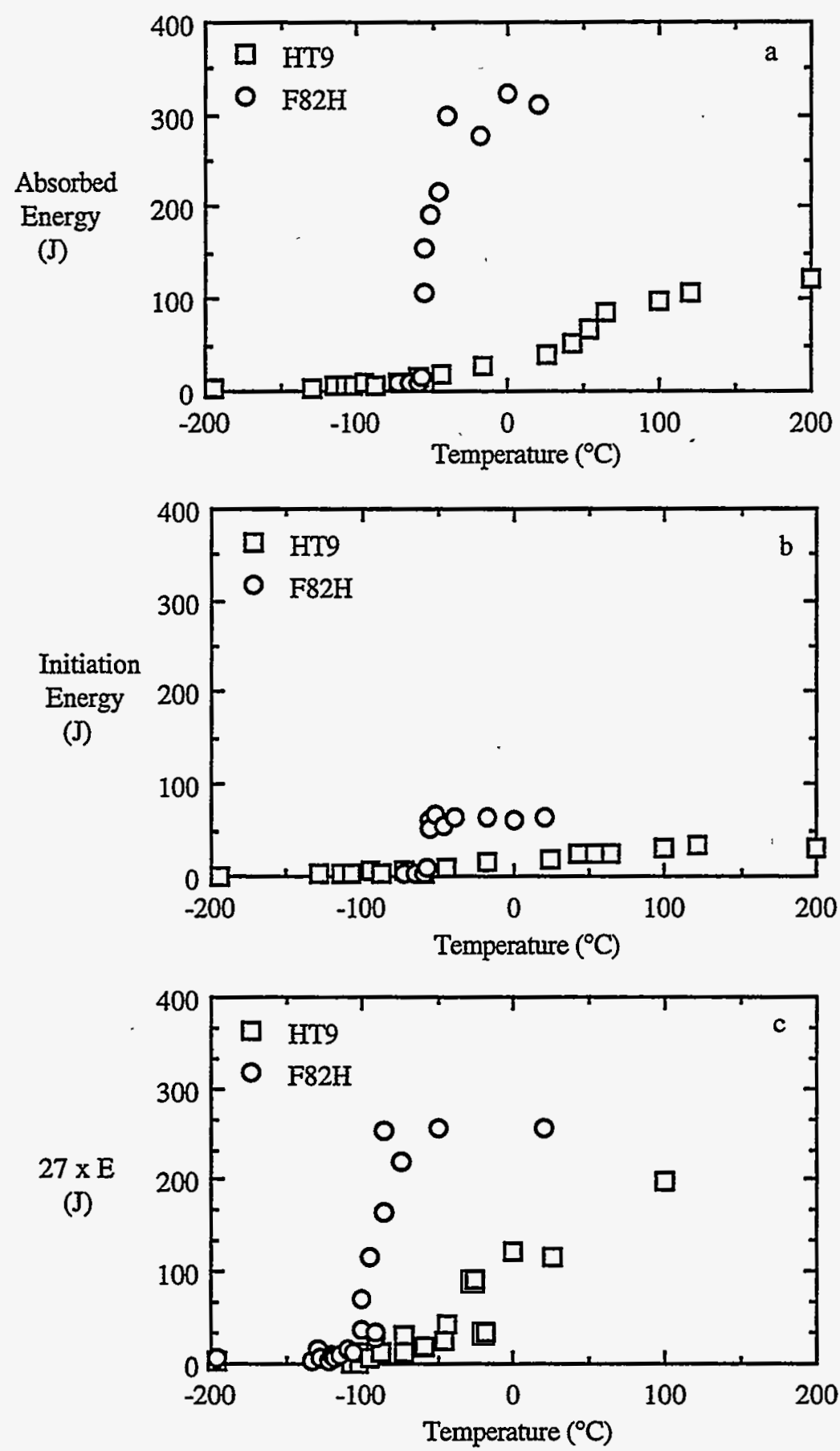

Figure 2 a) Charpy impact energy curves, b) initiation energies as a function of temperature for F82H and HT9 and c) Charpy impact energy curves for MCVN specimens.

is the appropriate continuum mechanics, self-similarity scaling factor for a $1 / 3$-sized specimen. Based on the normalized $41 \mathrm{~J}(\approx 1.5$ actual $)$ index, the DBTT's for HT9 and F82H are $-35 \pm 5$ and $-100 \pm 5^{\circ} \mathrm{C}$, respectively. Thus, in addition to giving different absolute values of DBTT, the MCVN and CVN tests also yield somewhat different measures of the relative advantage of $\mathrm{F} 82 \mathrm{H}$ based on the same normalized energy index, but for different geom- 
etries -i.e., $65^{\circ} \mathrm{C}$ for the $\mathrm{MCVN}$ versus $81^{\circ} \mathrm{C}$ for the CVN. More elaborate interpretations of the MCVN data are available but will not be pursued here.

At this point it is important to reiterate that there is no unique DBTT, and to note that any measure of DBTT from the Charpy test is to some extent arbitrary and extrinsically mediated - that is, dependent on the details of this particular test as well as the basic properties of the material. However, among the least meaningful indices is $41 \mathrm{~J}$ of total absorbed energy. In general $41 \mathrm{~J}$ represents a non-unique combination of two different and, in themselves, not fully defined fracture processes.

The difference between $E$ and $E_{i}$ represents the energy dissipated during crack propagation. In the upper shelf regime, $\mathrm{E}$ is dominated ( $>70 \%$ ) by this propagation energy. However, ductile tearing in Charpy specimens occurs under enormously complex conditions of massive deformation, loss of crack tip and lateral constraint and out-of-plane deflection in the vicinity of the compressed region under the striker. Hence, it is not surprising that efforts to relate the upper shelf energy to more meaningful measures of fracture resistance, such as upper shelf initiation toughness and tearing modulus, have met with limited success.[19] A potentially better relationship might be obtained between upper shelf toughness and the initiation energy for ductile tearing; since this parameter avoids many of the complications noted above.

Fracture Toughness - While also beset with a number of questions concerning both measurement and application, fracture toughness clearly provides a far more meaningful and direct measure of the stress and strain capacity of cracked structures. The variation of static fracture toughness with test temperature for the two steels in this study is shown in Figure 3. We have included some recently published estimates of the upper shelf toughness data for F82H from Ref. 20. It is important to emphasize that the data in Figure 3 represent different measures of toughness ( $\mathrm{K}_{\mathrm{Ic}}$ and $\mathrm{K}_{\mathrm{Ic}}$ and $\left.\mathrm{K}_{\mathrm{JN}}\right)^{1}$ based on, in a number of cases, small specimen tests that may not be strictly valid. However, our discussion will focus on a comparison of the overall $\mathrm{K}(\mathrm{T})$ curves rather than details of each data point. The HT-9 reaches an upper shelf toughness of about $200 \mathrm{MPa} / \mathrm{m}$ at about $20^{\circ} \mathrm{C}$. The upper shelf static toughness of F82H is estimated to be about $250 \mathrm{MPa} / \mathrm{m}$. Notably, the upper shelf, ductile initiation toughness advantage of roughly $25 \%$ for F82H versus HT9 compares to a factor of 3 in Charpy upper shelf energy. A fairer comparison would be based on the square root of the Charpy energy; on this basis the total energy and initiation energies would predict an F82H upper shelf toughness advantage of $70 \%$ and $40 \%$, respectively.

It is also useful to characterize the transition temperatures indexed by toughness. While various indices could be chosen, fracture toughness is typically indexed at an elastic-plastic, cleavage-initiation level of $100 \mathrm{MPa} / \mathrm{m}$. Unfortunately, there are only limited data in the transition regime, particularly for $\mathrm{F} 82 \mathrm{H}$. At $-40^{\circ} \mathrm{C}$ the latter

1 Here $J$-values have been converted based on the elastic equivalent $\mathrm{K}=\sqrt{\sqrt{\mathrm{E}^{\prime}}}$ where $\mathrm{E}^{\prime}$ is the plane strain modulus. 


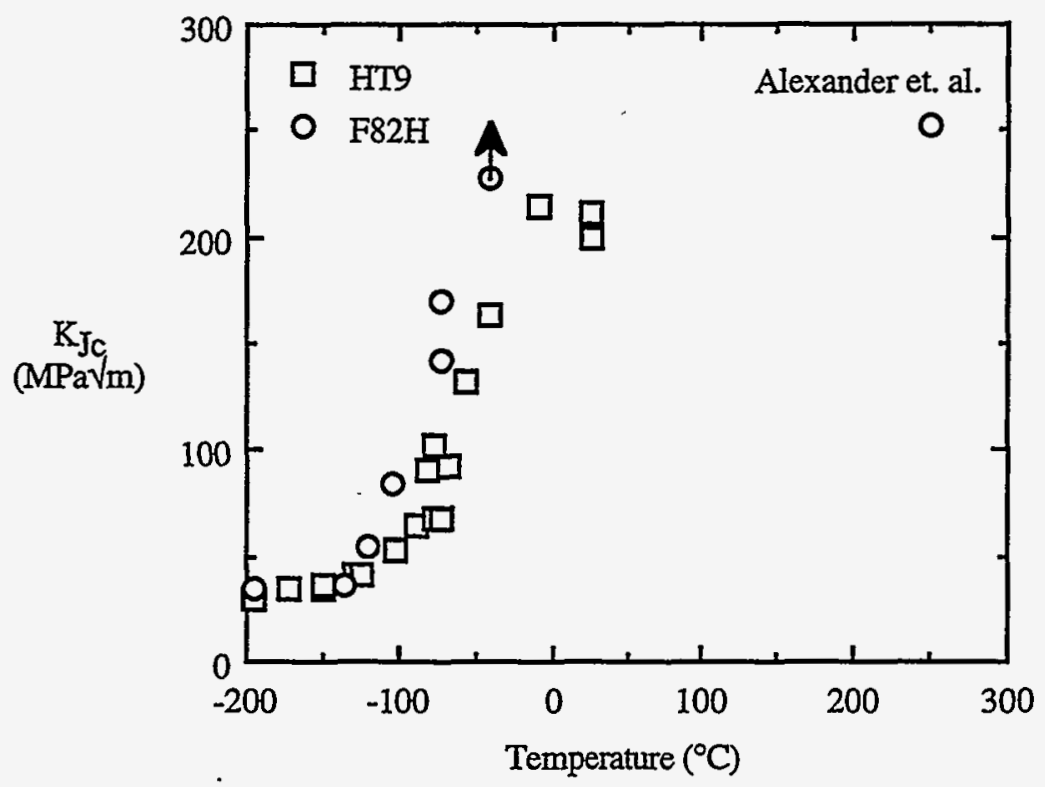

Figure 3 Comparison of static fracture toughness as a function of test temperature.

merely blunted up to the maximum available displacement. Hence, as indicated by the arrow, this represents a lower bound on the toughness in Charpy-sized specimens at this temperature; the value may be as high as the upper shelf toughness of about $250 \mathrm{MPa} \sqrt{\mathrm{m}}$. Using these limited values as a guide, we estimate the $100 \mathrm{MPa} / \mathrm{m}$ transition temperature for $\mathrm{F} 82 \mathrm{H}$ to be about $-100^{\circ} \mathrm{C} \pm 5^{\circ} \mathrm{C}$, compared to $-75^{\circ} \mathrm{C} \pm 10^{\circ} \mathrm{C}$ for $\mathrm{HT}$.

The variation of dynamic fracture toughness with test temperature as determined from instrumented PCCV tests is shown in Figure 4. As expected the dynamic loading rates have shifted the curves up in temperature. The F82H once again undergoes a very steep transition to an upper shelf toughness of about $310 \mathrm{MPa} / \mathrm{m}$. There are insufficient data to establish an upper shelf for the HT9; however, the maximum toughness of $276 \mathrm{MPa} / \mathrm{m}$ suggests the relative advantage of F82H may be even smaller for dynamic toughness. A greater similarity of the behavior of the two materials is also reflected in the $100 \mathrm{MPa} \sqrt{m}_{\mathrm{m}}$ transition temperature which is about $0^{\circ} \mathrm{C}$ for $\mathrm{F} 82 \mathrm{H} \mathrm{com}$ pared to about $14^{\circ} \mathrm{C}$ for the HT9. The corresponding differences between dynamic and static transition temperatures at $100 \mathrm{MPa} V_{\mathrm{m}}$ are about $89^{\circ} \mathrm{C}$ and $100^{\circ} \mathrm{C}$ for the HT9 and $\mathrm{F} 82 \mathrm{H}$, respectively. The shift in the dynamic versus static toughness curves at $100 \mathrm{MPa} / \mathrm{m}$ roughly coincides with the difference in temperatures at which the same value of $\sigma_{\mathrm{y}}$ is obtained in dynamic versus static tests.

Results - Quantitative Fractography

The SEM and confocal microscopy/fracture reconstruction (CM/FR) results are described below for various fracture mechanism regimes. In the fracture reconstructions, the fracture sequences as a function of crack tip 


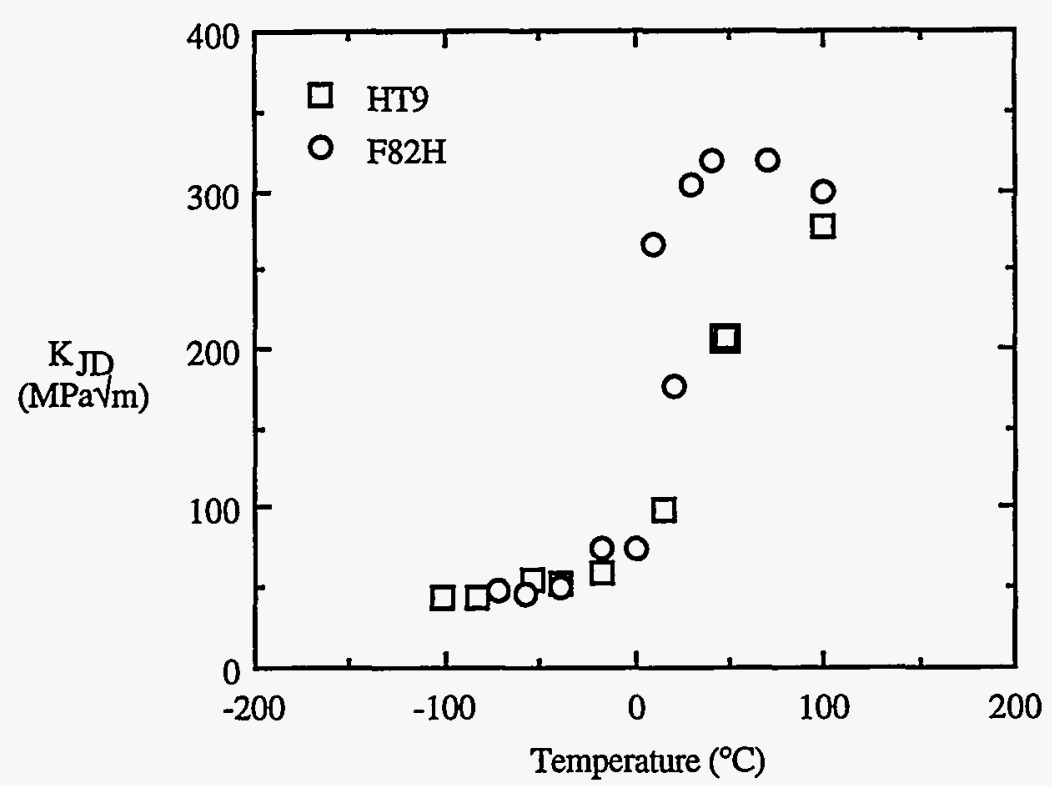

Figure 4 Comparison of dynamic fracture toughness as a function of test temperature

opening displacement $(\delta)$ are presented as views down onto the crack plane, often at the specimen center. Regions corresponding to material separation are shown in black and the regions corresponding to intact material are shown in white.

Lower Shelf /Lower Knee - Although not shown, the fracture processes for both HT9 and F82H are very similar on the lower shelf below about $45 \mathrm{MPa} \sqrt{\mathrm{m}}$, with fracture in both alloys occurring by quasi-cleavage. Quasicleavage also dominates the lower knee regime in both steels.

Figure 5a shows a typical SEM fractograph corresponding to a static test of $\mathrm{HT} 9$ at $-73^{\circ} \mathrm{C}$ in the lower knee region. Packets of cleavage facets are separated by thin regions of ductile tearing. The crack plane is characterized by an uneven surface, where out of plane areas of cleavage resulted in large multi- grain/packet "plugs" pulled out of "holes" in the conjugate surface. A corresponding CM/FR reconstruction of a 3PB specimen containing a crack with an $\mathrm{a} / \mathrm{W} \approx 0.4$ is shown in Figure 6 for a toughness corresponding to a $\mathrm{K}_{\mathrm{Jc}}$ of about 68 $\mathrm{MPa} \sqrt{\mathrm{m}}$. As the pre-crack blunts, stable multiple microcracking (black areas) initiates at a $\delta$ of about 16-17 $\mu \mathrm{m}$ and becomes completely unstable by about $20 \mu \mathrm{m}$. The region along the bottom is actually the specimen edge, which exhibits increased ductility, as would be expected. The critical condition appears to be controlled by a rapid coalescence of neighboring microcrack/tear ridge regions into a single or few large process zone cracks (PZC) extending over many PAG's. Assuming that $\mathrm{KJ}_{\mathrm{J} \delta} \approx \sqrt{2 \sigma_{\mathrm{y}} \delta^{*} \mathrm{E}^{\prime}}$, critical crack opening of $19 \mu \mathrm{m}$ corresponds to a $\mathrm{K}_{\mathrm{J} \delta}$ of about $81 \mathrm{MPa} \mathrm{V}_{\mathrm{m}}$, in reasonable agreement with the mechanical test measurements of $\mathrm{KJc}$ at this temperature. 


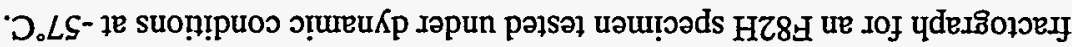

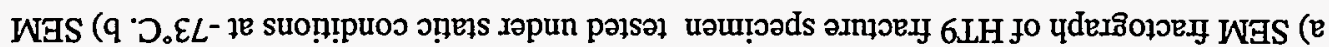

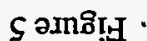
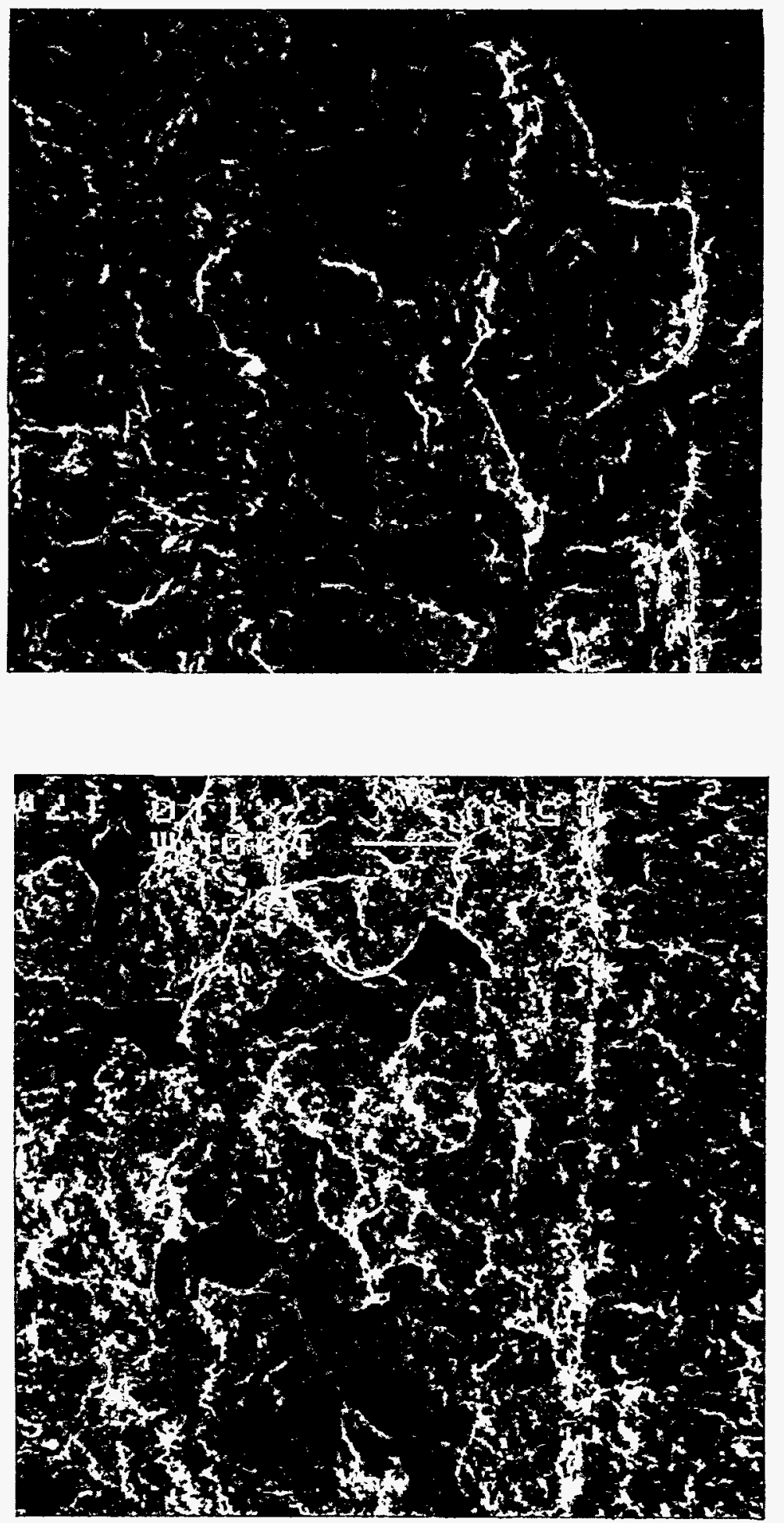

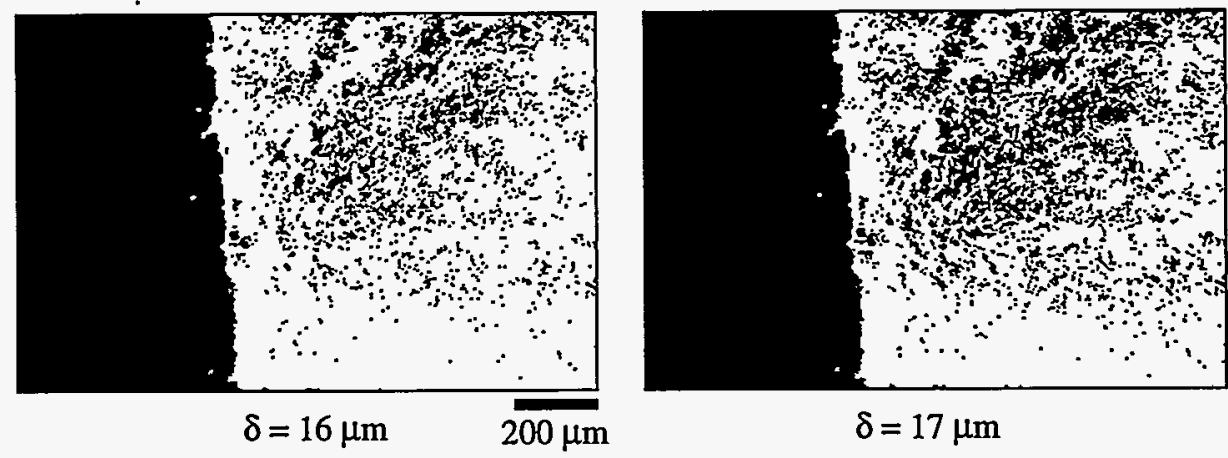

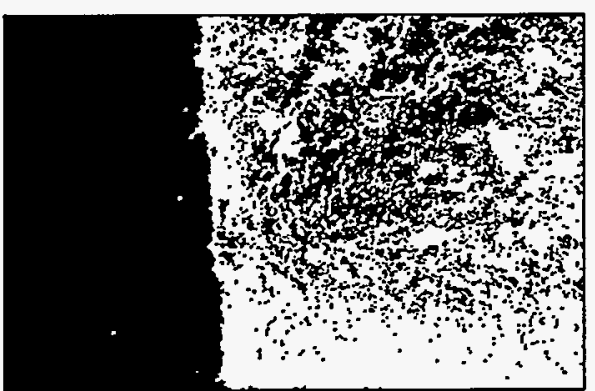

$\delta=18 \mu \mathrm{m}$

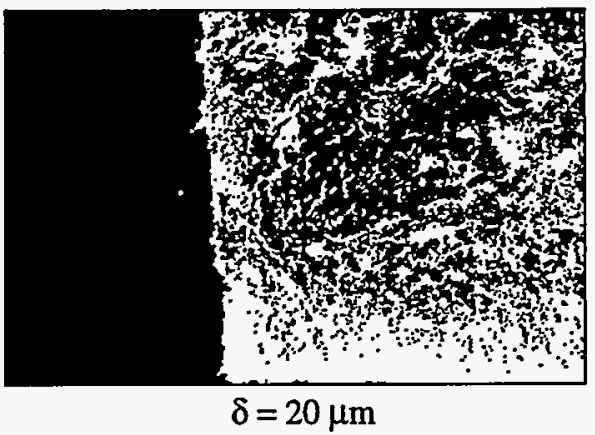

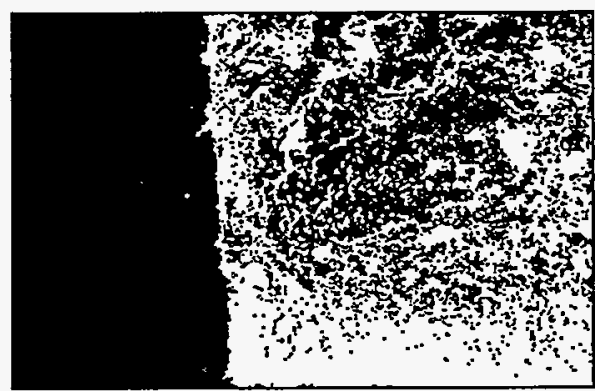

$\delta=19 \mu \mathrm{m}$

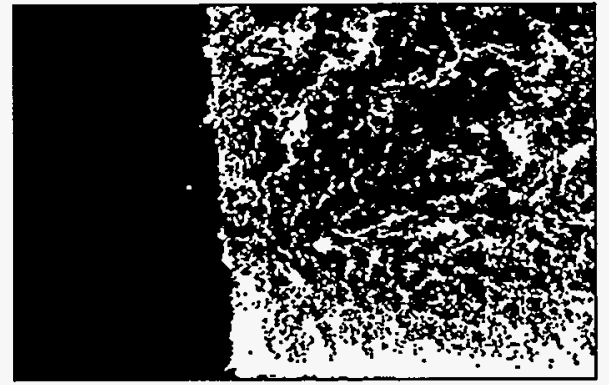

$\delta=22 \mu \mathrm{m}$

Figure 6 Fracture surface reconstruction of an HT9 $3 \mathrm{pB}$ specimen containing a crack with $\mathrm{a} / \mathrm{w}=0.4$ tested under static conditions at $-73^{\circ} \mathrm{C}$

Figure 5b shows a typical SEM fractograph corresponding to a dynamic test of $\mathrm{F} 82 \mathrm{H}$ at $-57^{\circ} \mathrm{C}$, and Figure 7 shows a fracture reconstruction for a 3PB static test of F82H at $-120^{\circ} \mathrm{C}$. These tests represent KJc's of about 47 and $60 \mathrm{MPa} \sqrt{\mathrm{m}}$, respectively, closer to the lower shelf than the corresponding test on HT9. However, as evident in Figure $5 b$, the fracture surface is similar; i.e., again cleavage facets separated by tear ridges and a tortuous crack path. Moreover, as seen in Figure 7, a similar sequence of events leading to unstable fracture is observed: the crack blunts up to about $2-3 \mu \mathrm{m}$ prior to initiation of a small amount of microcracking, followed by unstable crack propagation between about 4-6 $\mu \mathrm{m}$. A critical $\delta^{*}$ of $5 \mu \mathrm{m}$ corresponds to a $\mathrm{KJ} \delta$ of about $68 \mathrm{MPa} \sqrt{\mathrm{m}}$ in reasonable agreement with the standard measures of $\mathrm{KJc}_{\mathrm{J}}$ at this temperature (note that this specimen has an 

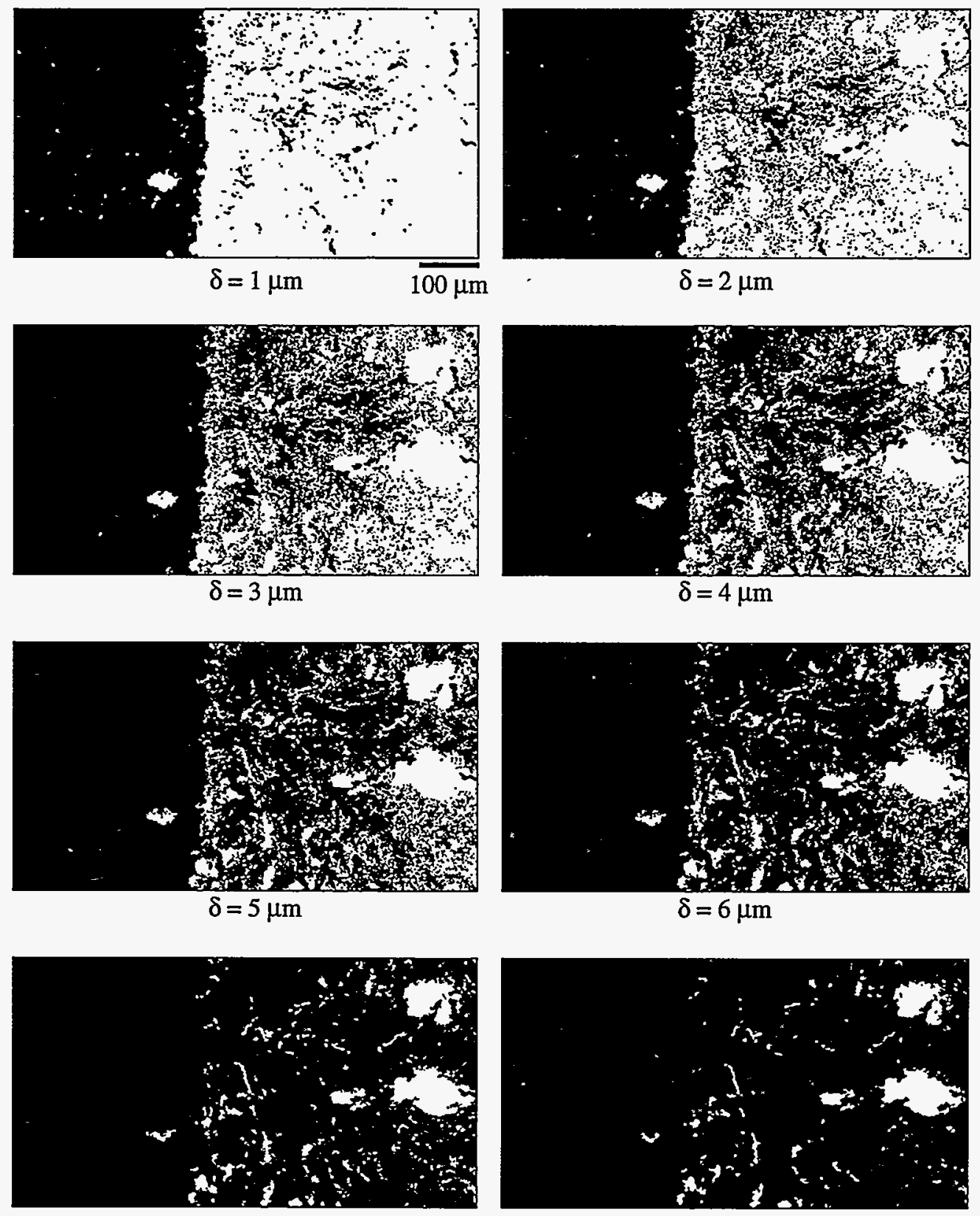

$\delta=8 \mu \mathrm{m}$

$\delta=10 \mu \mathrm{m}$

Figure 7 Fracture reconstruction for an $\mathrm{F} 82 \mathrm{H} 3 \mathrm{pB}$ specimen tested statically at $-120^{\circ} \mathrm{C}$

elastic component to $\mathrm{KJc}_{\mathrm{Jc}}$ of $54 \mathrm{MPa} \sqrt{\mathrm{m}}$ ). Note also that several intact ligaments remain in the crack wake (white regions at large $\delta$ in Figure 7). These correspond to "plugs" that have been geometrically interlocked in their "holes," resulting in formation of "hinge" like features propped up out of the fracture plane.

Transition region - As test temperature increases above the lower knee the same multiple microcrack coalescence instability process is observed. This is demonstrated by the CM/FR of a test on $\mathrm{HT} 9$ at $-57^{\circ} \mathrm{C}$ shown in Figure 8 . 

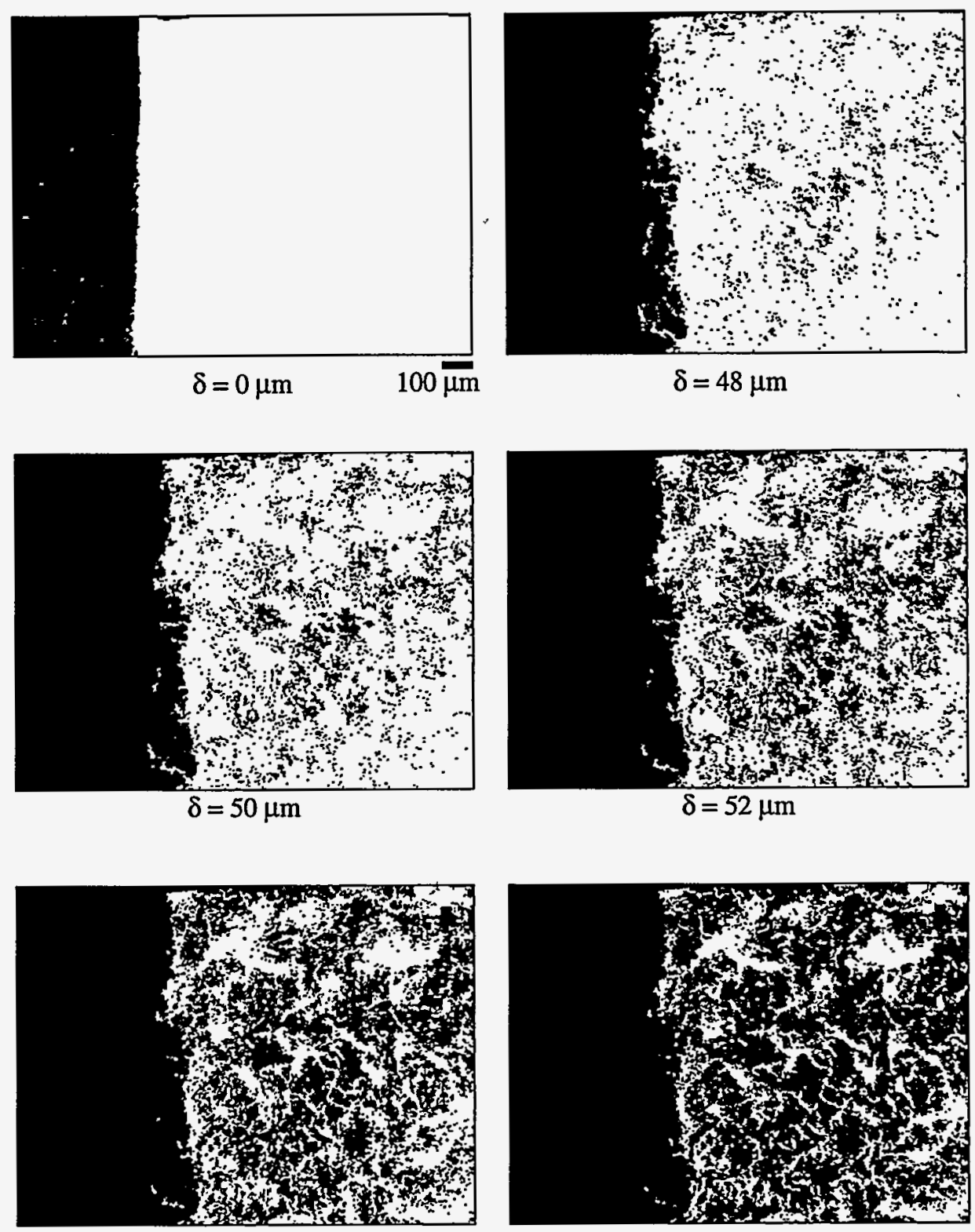

$\delta=54 \mu \mathrm{m}$

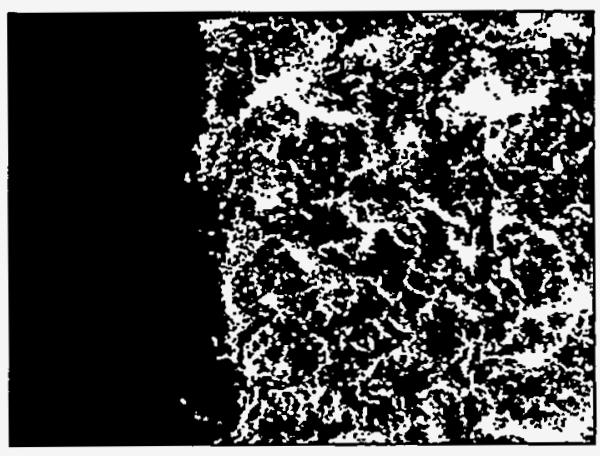

$$
\delta=56 \mu \mathrm{m}
$$

Figure 8 Fracture surface reconstruction for $\mathrm{HT} 9$ tested at $-57^{\circ} \mathrm{C}$.

However, the tear ridges become thicker as shown in the corresponding SEM micrographs in Figure 9, and more crack blunting is required to induce PZC instability conditions as seen in Figure 8. The critical crack opening of about $54 \mu \mathrm{m}$ corresponds to a $\mathrm{K}_{\mathrm{J} \delta}$ of about $132 \mathrm{MPa} \sqrt{\mathrm{m}}$, the same value measured during mechanical testing. A qualitatively identical sequence of events is observed for a static test on $\mathrm{F} 82 \mathrm{H}$ at $-73^{\circ} \mathrm{C}$ (not shown); in this case, the critical $\delta^{*}$ is about $65 \mu \mathrm{m}$ corresponding to a $\mathrm{K}_{\mathrm{J} \delta}$ of about $141 \mathrm{MPa} \sqrt{\mathrm{m}}_{\mathrm{m}}$ compared to a $\mathrm{K}_{\mathrm{Jc}}$ of $142 \mathrm{MPa} \sqrt{\mathrm{m}}$.

As shown in the SEM micrograph in Figure 10 , by $-40^{\circ} \mathrm{C}$ the fracture process in $\mathrm{HT} 9$ transforms to a mixture of 


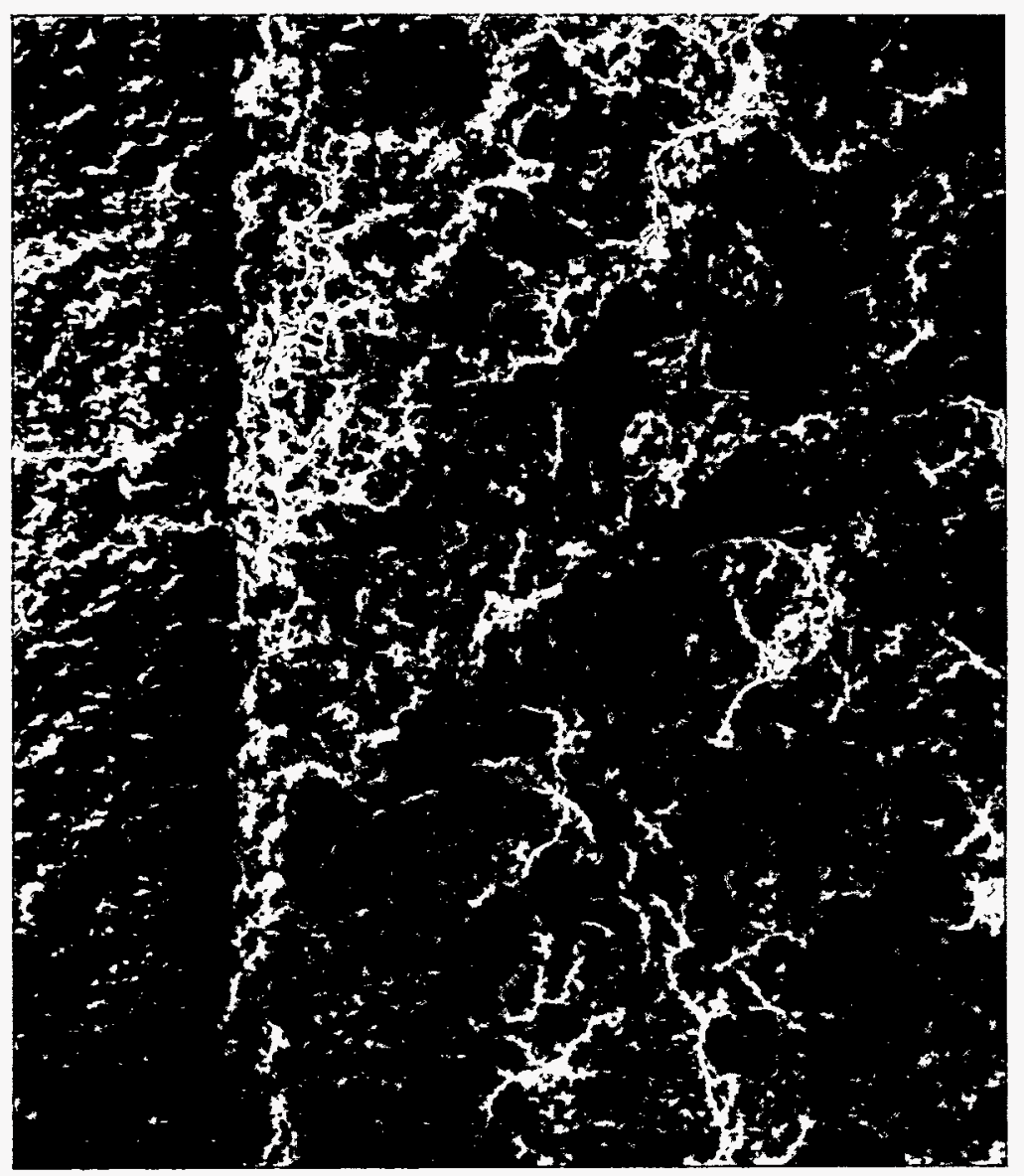

Figure 9 SEM micrograph of a region at the root of the pre-crack in $\mathrm{HT} 9$ tested at $-57^{\circ} \mathrm{C}$.

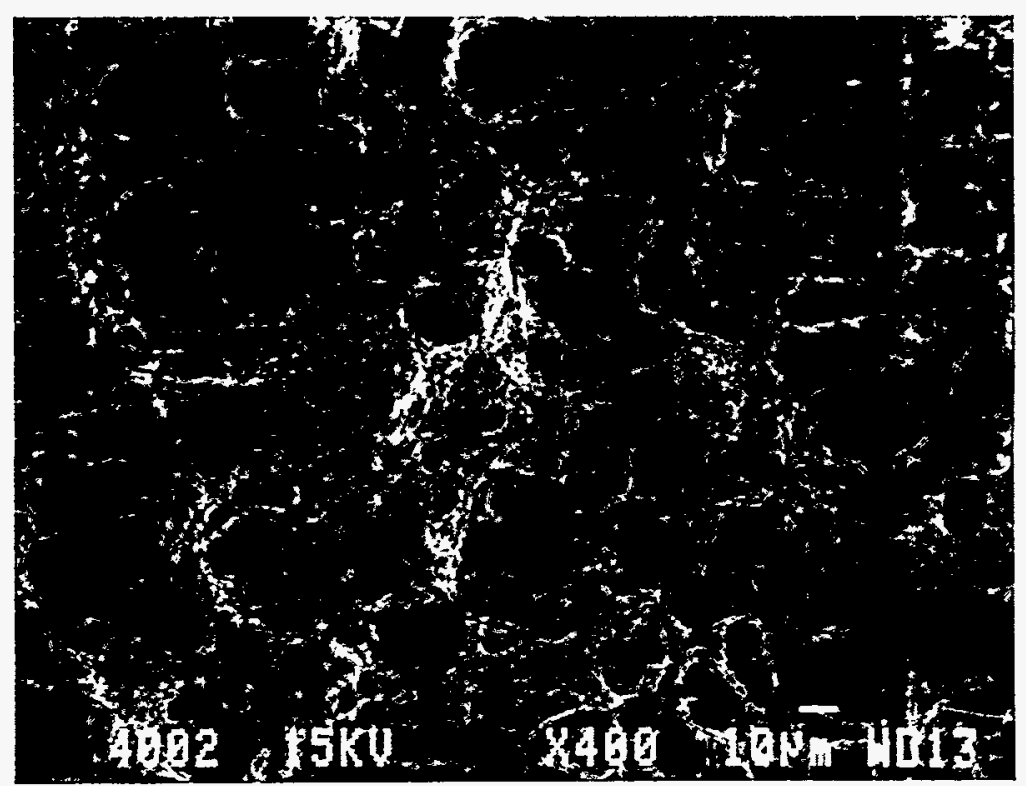

Figure 10 SEM fractograph of HT9 fracture specimen tested under static conditions at $-40^{\circ} \mathrm{C}$. 
predominantly quasi-cleavage with smaller regions of microvoid growth and coalescence in the fracture plane, in contrast to ductile shear fracture in the tear ridges. The CM/FR shown in Figure 11 demonstrates that the bridging ligaments provided by limited regions of microvoid coalescence also corresponds to the onset of stable crack propagation at an initiation $\delta^{*}$ of about $56 \mu \mathrm{m}$. The associated $\mathrm{K}_{\mathrm{J} \delta}$ is about $130 \mathrm{MPa} / \mathrm{m}$ compared to a $\mathrm{K}_{\mathrm{Jc}}$ of $140 \mathrm{MPa} \sqrt{\mathrm{m}}$. The F82H does not show such a gradual transition to the upper shelf.

Upper shelfknee region - The fraction of microvoid coalescence in HT9 increases with increasing temperature and becomes dominant on the upper shelf. The CM/FR in Figure 12 for static test at $20^{\circ} \mathrm{C}$ shows that crack growth in HT9 takes place by a repeated sequence of microvoid nucleation and growth terminated by coalescence with the blunting crack tip. Initiation is difficult to define in terms of $\delta^{*}$, due to the subtle onset of crack advance. A slight increase in the rate of crack growth was detected at a $\delta^{*}$ of about $180 \mu \mathrm{m}$ corresponding to a $\mathrm{KJ} \delta$ of about
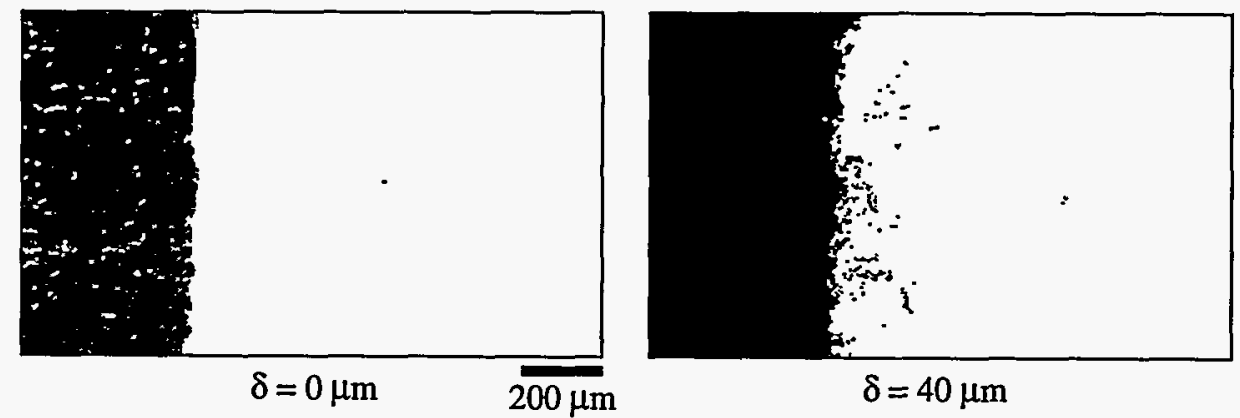

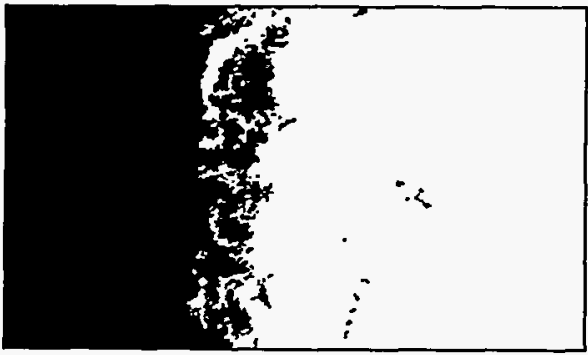

$\delta=60 \mu \mathrm{m}$

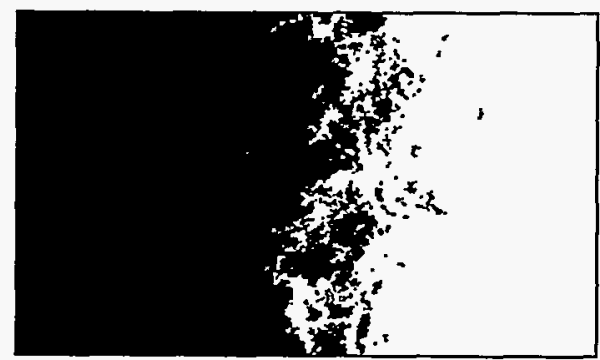

$\delta=100 \mu \mathrm{m}$

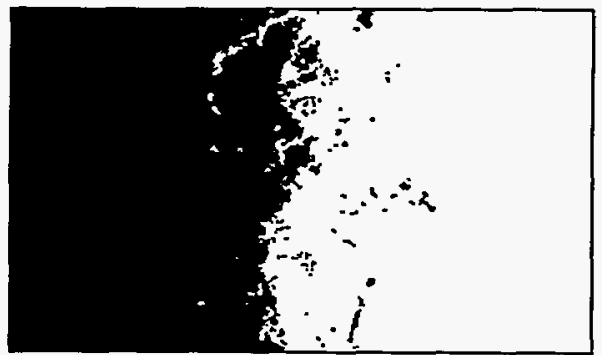

$\delta=80 \mu \mathrm{m}$

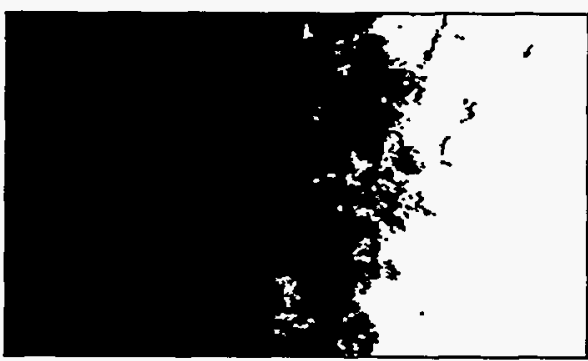

$\delta=120 \mu \mathrm{m}$

Figure 11 Fracture surface reconstruction for $\mathrm{HT} 9$ tested under static conditions at $-40^{\circ} \mathrm{C}$ 

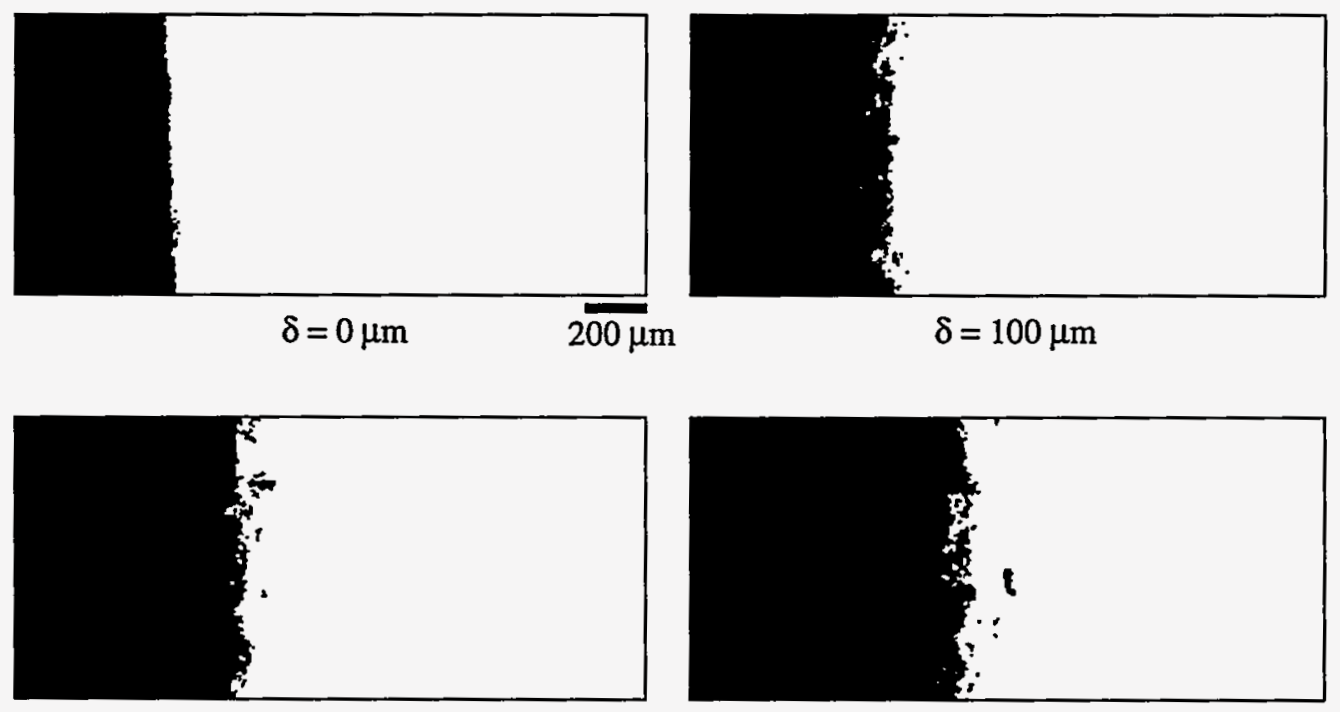

$\delta=150 \mu \mathrm{m}$

$\delta=200 \mu \mathrm{m}$

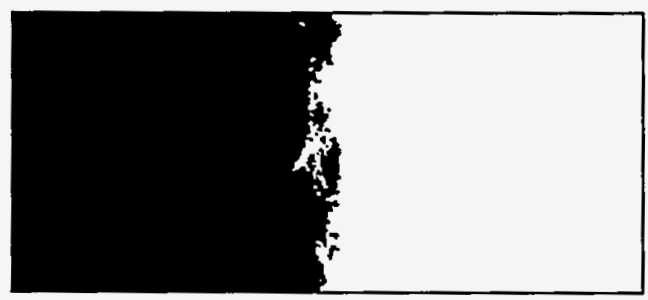

$\delta=250 \mu \mathrm{m}$

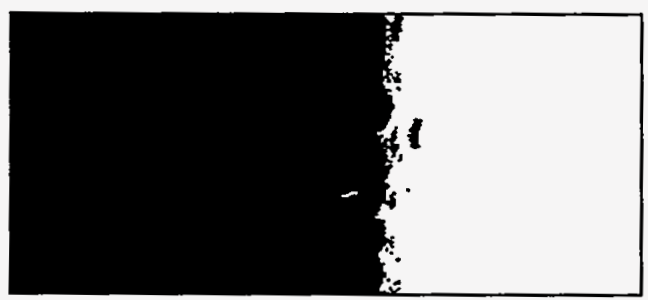

$\delta=350 \mu \mathrm{m}$

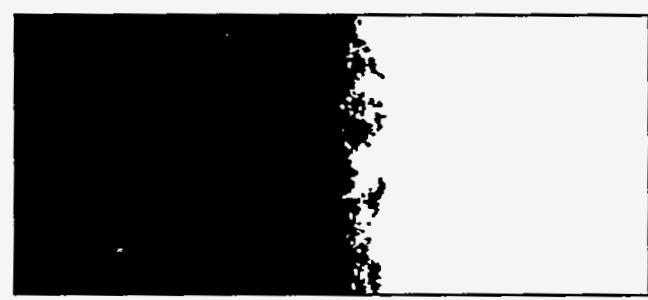

$\delta=300 \mu \mathrm{m}$

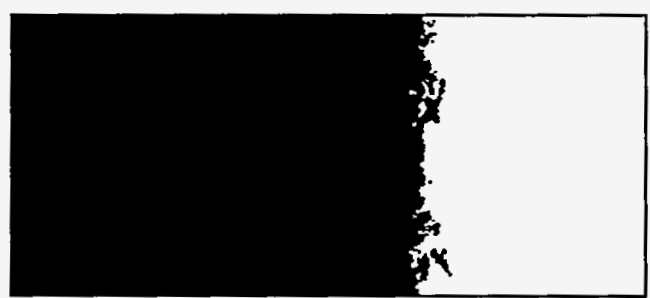

$\delta=400 \mu \mathrm{m}$

Figure 12 Fracture surface reconstruction for $\mathrm{HT} 9$ tested under static conditions at $20^{\circ} \mathrm{C}$

$216 \mathrm{MPa} \sqrt{m}_{\mathrm{m}}$ compared to $\mathrm{K} \mathrm{Kc}$ of about $214 \mathrm{MPa} \sqrt{m}_{\mathrm{m}}$. However, only three points in the J-da plot lie to the right of the exclusion line, so that, while this value is reasonable, it is not technically valid. As shown in the SEM micrographs in Figure 13, even on the upper shelf, clusters of cleavage facets appear frequently at the center of the large microvoids, suggesting cleavage nucleation of these large microvoids. The growth of the cleavagenucleated microvoids and linkage by regions with generally finer scale populations of microvoids formed on particles leads to coalescence. Upper shelf processes in F82H are qualitatively similar, as illustrated in the SEM micrograph in Figure 14 of the stretch zone region; this shows large voids associated with particles and cleavage facet clusters linked by regions of very fine microvoids leading to coalescence. 


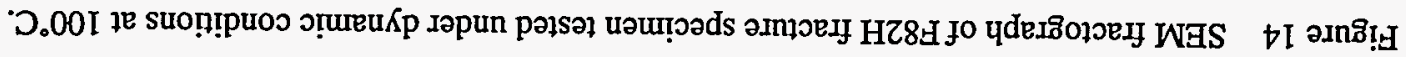
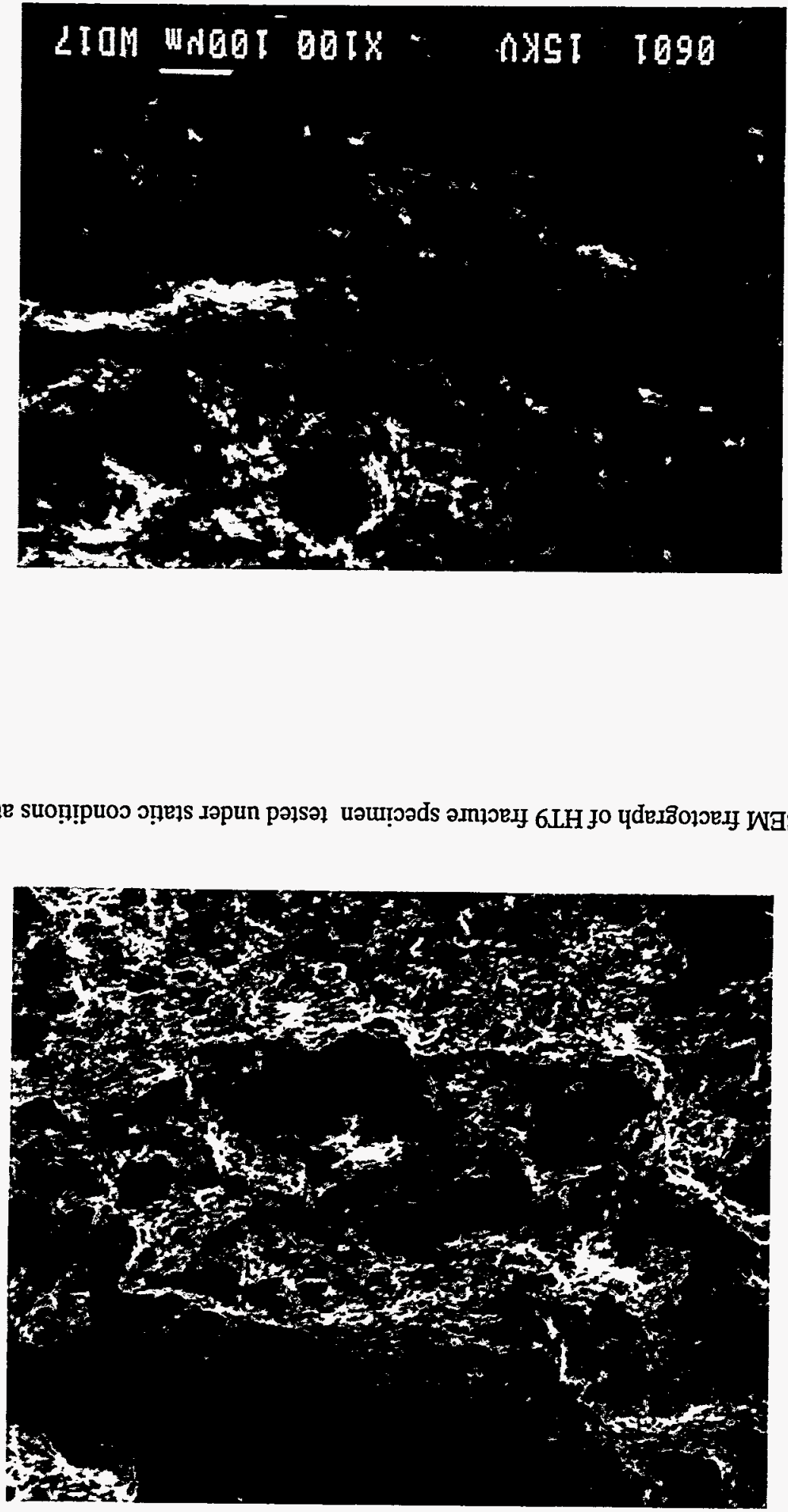


\section{DISCUSSION}

The results of the previous section can be summarized as follows:

- The behavior of HT9 and F82H is similar in the quasi-cleavage regime. As measured by transition temperatures, $\mathrm{F} 82 \mathrm{H}$ has only slight advantages - i.e., transition temperatures ranging from about 0 to $25^{\circ} \mathrm{C}$ less than HT9 depending on the reference index.

- F82H can have higher fracture resistance in the upper shelf microvoid coalescence regime, ranging from factors of less than of 1.15 (dynamic toughness) to about 3 (Charpy upper shelf energy).

- The transition from quasi-cleavage to microvoid coalescence fracture is very gradual in HT9 and very abrupt in $\mathrm{F} 82 \mathrm{H}$.

- Primarily as a reflection of the width of the transition regime, mixed mode DBTT indexes show appreciably larger advantages for $\mathrm{F} 82 \mathrm{H}$, ranging from 65 to $175^{\circ} \mathrm{C}$. However, the structural significance of these measures is not clear.

- Both steels manifest qualitatively similar fracture mechanisms in both quasi-cleavage and microvoid coalescence regions. The major differences appear to be: a) an intermediate mechanism regime unique to HT9, involving a mixture of the limiting micro-mechanisms; and b) slightly and significantly lower fracture resistance of the HT9 relative to $\mathrm{F} 82 \mathrm{H}$ in the quasi-cleavage and microvoid coalescence regimes, respectively.

The basic micromechanics of the quasi-cleavage and microvoid coalescence regimes has been described elsewhere. $[1,15]$ The more pertinent question in comparing these steels is - what gives rise to the large differences in the width of the transition regime? At lower temperatures in the mixed mode regime of HT9, small regions which ultimately fail by microvoid coalescence contribute to toughness by acting as bridging ligaments that can also sustain stable crack growth. The contribution of the microvoid coalescence regions gradually increases with increasing temperature to the point where the microvoid-associated ligaments give way to cleavage-facet-nucleated microvoids. The absence of the transition regime in $\mathrm{F} 82 \mathrm{H}$ is not understood but might be rationalized on the basis of a synergistic interaction between microcrack formation and linking of microcrack-nucleated microvoids. Both processes appear to be more difficult in F82H compared to HT9. Thus the higher strains needed to form microcracks in $\mathrm{F} 82 \mathrm{H}$ also promote the formation of more uniform dilational damage, lowering the peak stresses and preventing the nucleation of more microcracks. By definition, isolated microcracks transform to microvoids, 

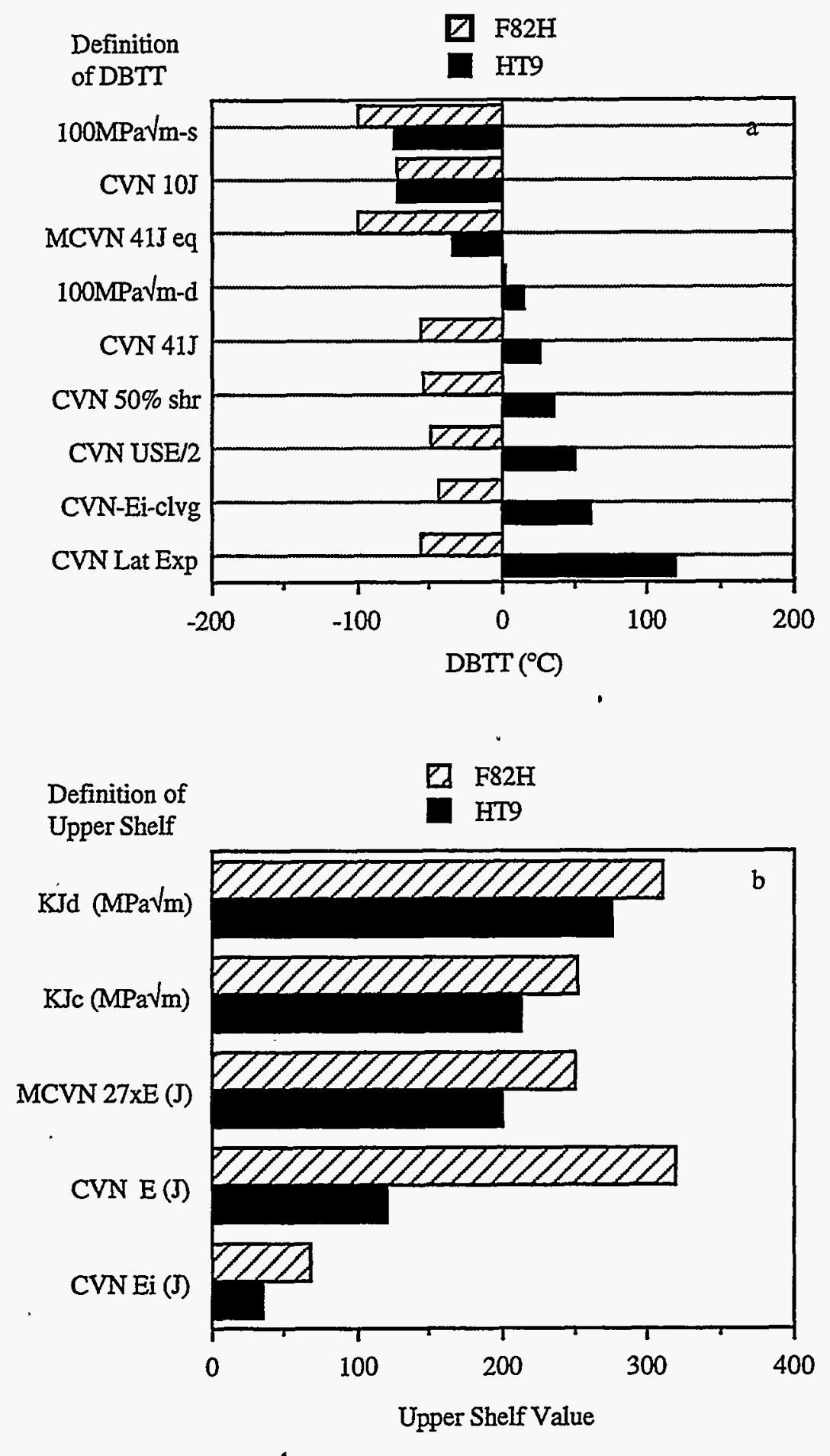

Figure 15 Comparison of a) transition temperatures and b) upper shelf values in F82H and HT9 for a variety of test types and indices. 
rather than unstable or quasi-stable process zone cracks. More isolated microvoids also require larger strains to reach coalescence conditions, which may also be more inherently difficult in F82H. The larger strains lead to local (dilational) and global (large scale yielding) loss of constraint, further reducing microvoid growth rates and delaying coalescence. Thus, subtle difference in the underlying processes can lead to large differences in regions where they have the potential to interact.

An even more fundamental question is - what is the microstructural basis for these differences? While more detailed microstructural characterization will be needed, we believe the major difference is probably due to the relative compositions and heat treatments of the two alloys and the corresponding differences in carbide populations. The ratio of fine scale carbide formers - molybdenum + tungsten + vanadium - to carbon is about 8 for HT-9 compared to 22 for F82H. The corresponding ratio of chromium, which is associated with coarser carbides, to carbon is roughly similar: that is 53 for $\mathrm{HT} 9$ versus 80 for F82H. These compositional factors lead to a greater proportion of finer matrix and boundary carbides in $\mathrm{F} 82 \mathrm{H}$, and the lower $\mathrm{C}$ content results in an overall lower volume fraction of carbides. In addition, the HT9 heat treatment led to coarser boundary carbide distributions. The greater quantity of coarse carbides promote both quasi-cleavage microcrack nucleation and the nucleation of the finer scale secondary microvoịds leading to coalescence of the large microvoids.

Details of the mechanisms aside, the results of this study clearly demonstrate the non-uniqueness of both absolute and relative values of the so-called DBTT. This is illustrated in Figure 15a, which compares the numerous measures of DBTT for the various indices described in the Results section for HT9 versus F82H. Variations of almost $200^{\circ} \mathrm{C}$ (e.g., tracking the solid bars from top to bottom) were found for HT9 depending on the specimen size and choice of reference index, while the variations for F82H were substantially less. Corresponding differences in material ranking by DBTT (solid versus hatched bars) ranged from relatively small (top of the bar chart) to more than $150^{\circ} \mathrm{C}$ (bottom of the bar chart) depending only on the reference index. Similar differences in the measures of upper shelf fracture resistance are shown in Figure 15b; again differences between HT9 and F82H (solid versus hatched bars) varied by factors of only slightly more than 1 to about 3 . Clearly, a more quantitative and structurally relevant approach is needed.

\section{CLOSING REMARKS}

While simple standard test methods yield widely divergent measures of fracture resistance, even greater differences can be expected for actual structures characterized by complicated configurations and loading conditions. We believe that a much more rigorous and reliable approach to structural integrity assessment can be based on a combination of macromechanics and micromechanics; neither alone is sufficient.[1] The basic concept is to combine finite element simulations of the evolution of multiaxial crack tip stress and strain fields with local 
measures of the conditions leading to crack extension (initiation or stable growth). The effects of variations in stress states can be directly modeled, even in complex geometries which deviate from small scale yielding conditions. This approach also opens the way to far more rigorous use of small specimens. Local measures of fracture resistance may involve simple stress-volume (distance) or strain-volume criteria or more complex statistical cleavage or microvoid growth models. Calibration of the fields and local fracture parameters to one, or ideally more than one, specimen geometry can be used to interpolate or extrapolate to other structurally relevant geometries. This approach can also be used to specify qualitative/ quantitative criteria for failure: elastic-plastic cleavage initiation at a specified toughness level corresponding to a specified stress and strain margin; the occurrence of some stable crack growth prior to cleavage instability; and ductile tearing. Not only would such criteria give physical relevance to specified safety margins, but they would also be readily incorporated into statistical/ probabilistic-based safety assessment. We believe that the local approach is critical to the intelligent and effective use of not only TM steels but also for essentially all other candidate structural materials for fusion applications.

\section{FUTURE WORK}

The work on $\mathrm{F} 82 \mathrm{H}$ is continuing with an emphasis on further developing micromechanical models of quasicleavage and ductile fracture for this class of steels, and applying these models to failure prediction.

\section{ACKNOWLEDGEMENTS}

This work has been supported by the Office of Fusion Energy, Department of Energy, under grant number DEFG03-87ER-52143. The authors would like to acknowledge the assistance of A. Hishinuma of JAERI in acquiring the F82H steel.

\section{REFERENCES}

1. G. R. Odette, J. Nucl. Mater., Proceedings of ICFRM-6.

2. G. R. Odette, B. L. Chao, G. E., Lucas, J. Nucl. Mater., Proceedings of ICFRM-6.

3. G. R.Odette, G. E. Lucas, B. L. Chao, submitted to J. Nucl. Mater.

4. M. Tamura, H. Hayakawa, M. Tanimura, A. Hishnuma, T. Kondo, J. Nucl. Mater. 141-143 (1986) 1067.

5. Proceedings IEA Working Group Meeting on Ferritic/Martensitic Steels, ORNL, May 20-21, 1993.

6. C. K. Elliott, G. E. Lucas, R.. Maiti, G. R.Odette, J. Nucl. Mater. 141/143 (1986) 439.

7. G. R. Odette, G. E.Lucas, R.Maiti, J. W. Sheckherd, J Nucl. Mater, 122/123 (1984) 442. 
8. Y. Kohno, D.Gelles, A. Kohyama, M. Tamura, A. Hishinuma, J. Nucl. Mater. $191 / 194$ (1992) 868.

9. M. Tamura, H. Hayakawa, A. Yoshitake, A. Hishinuma, T. Kondo, J. Nucl. Mater. 155/157 (1988) 620.

10. R. L. Klueh, J.-J. Kai, D. J.Alexander, submitted to ASTM conference proceedings, Sun Valley, ID, 1994.

11. A. Kimura and H. Matsui, J. Nucl. Mater., Proceedings of ICFRM-6.

12. G. E. Lucas, G. R Odette, R. Maiti, J. W. Sheckherd, ASTM-STP-956, American Society for Testing and Materials, Philadelphia, PA (1987) 379.

13. W. L. Server, J. Test. and Eval., 6, 1 (1978) 29.

14. C. Elliott, M. Enmark, G. E. Lucas, G. R. Odette, A. Rowcliffe, J. Nucl. Mater. 179/181 (1991) 434.

15. K. Edsinger, G. R. Odette, G. E. Lucas, J. Nucl. Mater., Proceedings of the IEA International Symposium on Miniaturized Specimens for Testing of Irradiated Materials, Julich, Germany, 1994.

16. K. Edsinger, B. Wirth, G. R. Odette and G. E. Lucas, submitted to ASTM conference proceedings, Sun Valley, ID, 1994.

17. J. M. Steichen and J. A. Williams, J. Nucl. Mater. 57 (1975) 303.

18. G. R. Odette, P. M. Lombrozo, R. A. Wullaert, Effects of Radiation on Materials: 12 th International Symposium, ASTM STP 870, F. A. Garner and J. S. Perrin, Eds., ASTM, Philadelphia, PA (1985) 840

19. S. T. Rolfe and J. M. Barsom, Fracture and Fatigue Control in Structures, Prentice Hall, New Jersey (1977) 174.

20. D. Alexander, J. E. Pawel, M. L. Grossbeck, A. F. Rowcliffe, submitted to ASTM conference proceedings, Sun Valley, ID, 1994. 


\title{
IRRADIATION CREEP AND SWELLING OF TWO LMR HEATS OF HT9
}

\author{
F. A. Garner ${ }^{1}$ and M. B.Toloczko² \\ ${ }^{1}$ Pacific Northwest Laboratory, Richland, WA \\ ${ }^{2}$ University of California at Santa Barbara
}

\section{OBJECTIVE}

The objective of this effort is to determine the creep characteristics of ferritic steels during neutron irradiation at elevated temperatures.

\section{SUMMARY}

The irradiation creep and void swelling of two LMR heats of HT9 are analyzed after irradiation at $-400,495,550$ and $600^{\circ} \mathrm{C}$ to damage levels ranging from 60 to 174 dpa. Void swelling ceases somewhere between 400 and $495^{\circ} \mathrm{C}$. Swelling appears to be somewhat stress-sensitive, however, increasing with stress level. When compared with earlier results on another fusion heat of HT-9, both the swelling and creep appear to be somewhat variable from heat-to-heat. The variability of creep appears to arise from the swelling-enhanced creep component.

At higher temperatures there appears to arise a stress-activated component of strain that increases with temperature. This strain component eventually dominates the strain behavior at the highest temperatures and is probably caused by a combination of stress-activated phase changes and radiation-enhanced primary creep.

\section{PROGRESS AND STATUS}

\section{Introduction}

Ferritic-martensitic steels are being considered for structural applications in fusion reactors. In order to provide data on the response of such steels to radiation, a series of experiments were conducted in FFTF. One of these experiments involved the simultaneous measurement of irradiation creep and void swelling using gas pressurized tubes.

In an earlier report, the response of the fusion heats of HT9 and 9Cr-iMo (heats 9607R2 and 30176, respectively) was presented after irradiation at $-400^{\circ} \mathrm{C}$ to $\sim 208 \mathrm{dpa}$ in FFTF-MOTA ${ }^{1}$. These fusion heats were included as part of a larger LMR (Liquid Metal Reactor) program on irradiation creep.. In an effort to better define the behavior of HT9 over a wider range of temperature and heat-to-heat variations, analysis of the data on the LMR heats 84425 (designated HT9-1) and 91353 (HT9-2) is now in progress. The results attained to date are presented in this report. 


\section{EXPERIMENTAL DETAILS}

These tubes ( $2.24 \mathrm{~cm}$ long by $0.46 \mathrm{~cm}$ diameter) were nominally irradiated at constant temperature. Periodically, they were discharged from the reactor, and prior to reinsertion into the reactor, diameter measurements were made using laser profilometry ${ }^{2}$. The tubes were originally scheduled for insertion into every MOTA vehicle from MOTA-1A through MOTA-1G, but tubes at temperatures higher than $400^{\circ} \mathrm{C}$ were discarded after MOTA-1D experienced a large temperature excursion that destroyed many tubes. Thus the data presented in this report involve seven measurements vs. dpa level at $-400^{\circ} \mathrm{C}$, but only three measurements at 495,550 and $600^{\circ} \mathrm{C}$.

The dpa levels reached at each nominal irradiation temperature are shown in Table 1. Note that there was sometimes a variation in irradiation temperature from one MOTA to the next. The maximum stress levels chosen for this experiment also decrease with temperature. This is a common practice in irradiation creep experiments that avoids testing at unrealistic stresses leading to guaranteed failure.

Table 1. Nominal temperature in ${ }^{\circ} \mathrm{C}$ and dpa level

$\begin{array}{lllll}\text { MOTA } & \frac{\left(-400^{\circ} \mathrm{C}\right)}{427,26.4} & \frac{\left(-495^{\circ} \mathrm{C}\right)}{494,25.8} & \frac{\left(-550^{\circ} \mathrm{C}\right)}{547,28.4} & \frac{\left(-600^{\circ} \mathrm{C}\right)}{603,25.7} \\ \text { IA } & 401,38.6 & 490,36.1 & 548,40.7 & 600,39.6 \\ \text { IB } & 396,67.2 & 490,60.1 & 550,76.4 & 605,74.1 \\ \text { IC } & 386,88.0 & & & \\ \text { ID } & 384,114.1 & & & \\ \text { IE } & 386,145.9 & & & \\ \text { IF } & 390,174.3 & & & \\ \text { IG } & & & & \end{array}$

\section{RESULTS}

The diametral strains at $-400^{\circ} \mathrm{C}$ for both HT9-1 and HT9-2 are shown in Figure 1. Note that tubes having hoop stresses of zero develop small but measurable strains that most likely represent one-third of the volumetric swelling rate. HT9-1 swells somewhat less than HT9-2, and both appear to be swelling at relatively constant rates. There may be some small contribution to the strain arising from elemental segregation or phase changes, but these cannot be separated from the void contribution without extensive microscopy measurements.

Figure 2 shows the calculated midwall creep strains at $400^{\circ} \mathrm{C}$ divided by the hoop stress. The creep strain is calculated by subtracting the stress-free swelling strain from the total strain. This procedure assumes that swelling is not enhanced by stress, an assumption that is known not to be completely correct. Destructive analysis of the tubes from the HT9 fusion heat after irradiation to $\sim 210 \mathrm{dpa}$ at $-400^{\circ} \mathrm{C}$ showed that stress indeed enhanced the swelling somewhat ${ }^{1}$.

It can also be seen in Figure 2, however, that the creep strain per unit stress curves shown in Figure 2 tend to converge toward each other, with the least scatter observed in HT9-2. If one ignores the 200 Mpa hoop stress curve for HT9-1, however, the scatter is least for HT9-1. This convergence indicates that the creep rate is essentially linear with stress (stress-exponent $=1.0$ ), a finding which is especially significant for such large stress levels. Also noteworthy is that, when compared on a basis of the same stress levels, the creep strains are a little larger in HT9-2, consistent with its larger swelling rate at zero stress. There also appears to be some stress-enhancement of swelling-induced creep. This trend can be 
seen more clearly in Figure 3, where the strain rate for HT9-1 increases considerably at the higher stress levels.

At $-495^{\circ} \mathrm{C}$ the total strain rates at the lower stress levels tend to decrease with increasing dpa, as shown in Figure 4. This is usually an indication that some other non-creep component of strain has occurred. Although such behavior is normally ascribed solely to the transition from primary to secondary creep, it is quite likely also due to phase changes which occur relatively early in the irradiation. Note, however, that there are no creep strains in the absence of stress, indicating that the non-creep component is probably stress-activated. There is also a large increase in the creep strain rates between $\sim 100$ and $\sim 200$ $\mathrm{MPa}$, as shown in Figure 4, a behavior that probably arises from recrystallization assisted by the combined effects of stress, high temperature and irradiation.

Figure 5 shows the irradiation creep rates at $495^{\circ} \mathrm{C}$ initially are independent of stress (to $65 \mathrm{MPa}$ and $100 \mathrm{MPa}$ in HT9-1 and HT9-2, respectively) and tertiary creep appears to develop at higher stress levels.

As shown in Figure 6, only HT9-2 was irradiated at $550^{\circ} \mathrm{C}$, but this figure also shows that the strain rates tend to decrease with increasing dpa and the dependence of creep rate on stress level is to a power greater than 1.0. Note that again there are no strains in the absence of stress.

As shown in Figure 7, the tendency toward saturation of creep strain rate and onset of tertiary creep in HT9-1 at $600^{\circ} \mathrm{C}$ occurs at even lower stress levels. Once again, there is no strain observed at zero stress.

\section{CONCLUSIONS}

Swelling of HT9 occurs in the absence of stress at $-400^{\circ} \mathrm{C}$ and appears to be small, relatively linear with dpa and somewhat variable from heat-to-heat. Stress-enhancement of swelling also seems to be present. The concurrent irradiation creep at $400^{\circ} \mathrm{C}$ is relatively linear with both stress and dpa level, with the expected swelling-enhancement of creep rate evident when comparing the relative creep rates of the two heats.

As the temperature increases, swelling decreases to zero somewhere between 400 and $495^{\circ} \mathrm{C}$ and some stress-activated non-swelling, non-creep component of strain arises. The tendency for this component to dominate the overall strain behavior increases with increasing temperature.

\section{FUTURE WORK}

Additional data on these two heats will be collected and analyzed, and then compared with results from the fusion heat of HT9.

\section{REFERENCES}

1. M. B. Toloczko, F. A. Garner and C. R. Eiholzer, J. Nucl. Mater. 212-215 (1994) 604-607.

2. E. R. Gilbert and B. A. Chin, Proc. Symp. on Effects of Radiation on Materials, 10th Conference, ASTM STP 725 (1981) p. 665. 

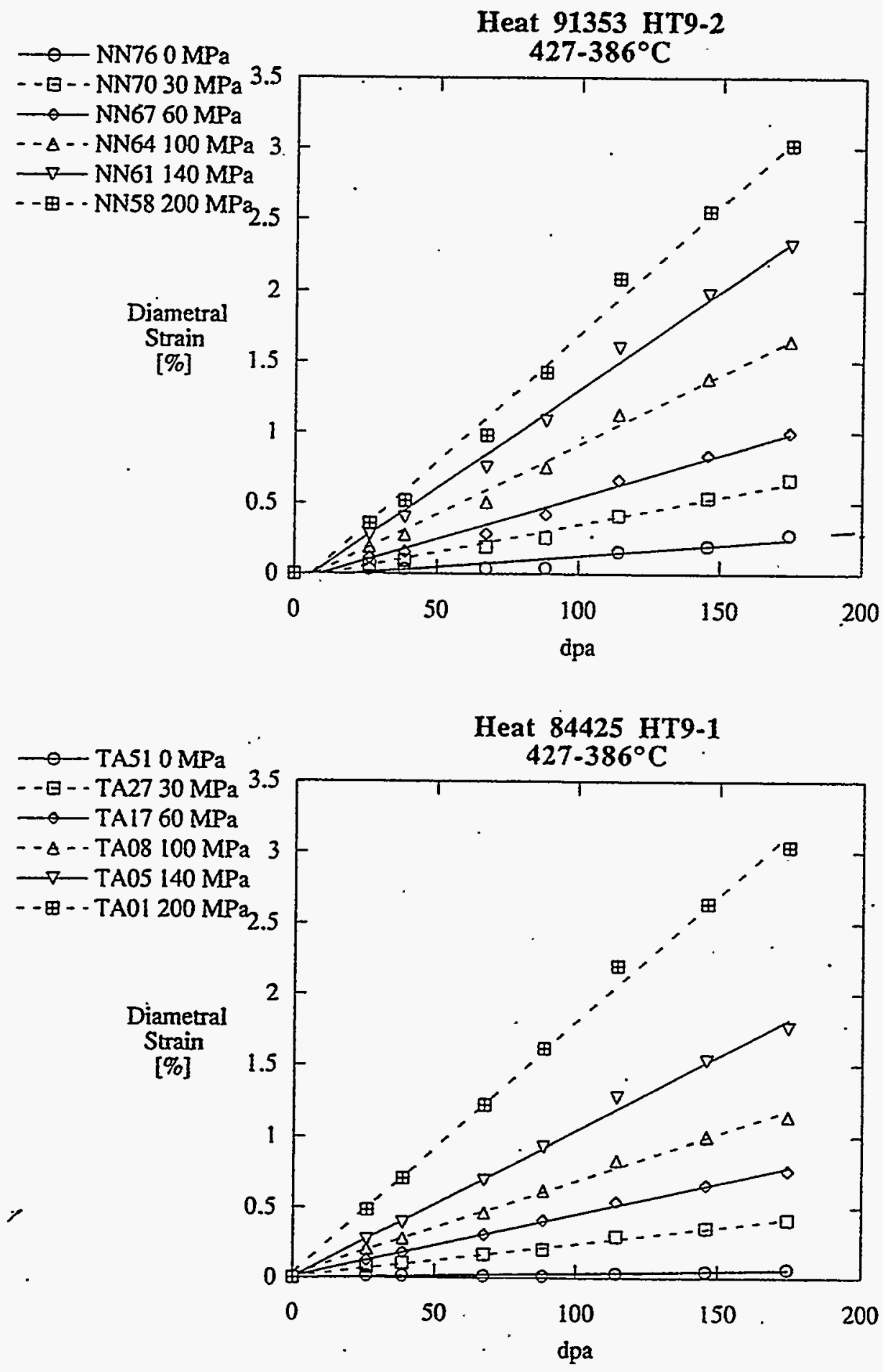

Figure 1. Total diametral strains observed in HT9-1 and HT9-2 at $-400^{\circ} \mathrm{C}$. Hoop stresses are used to denote the stress levels. 

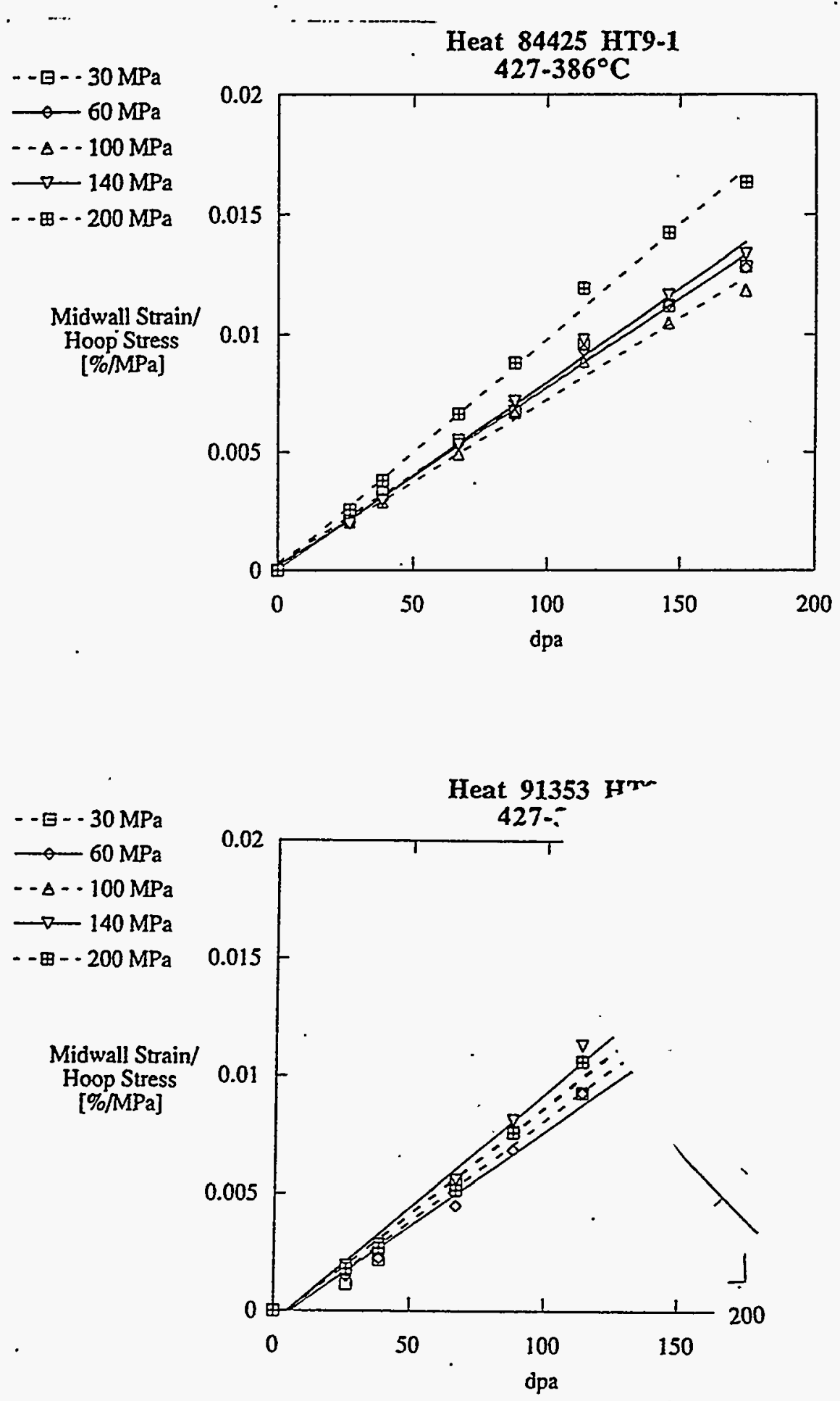

Figure 2. Midwall creep strains per unit hoop stress for HT9-1 and HT9-2 at $\sim 400^{\circ} \mathrm{C}$ 


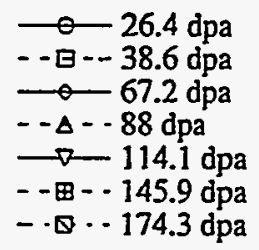

Heat 84425 HT9-1

$400^{\circ} \mathrm{C}$

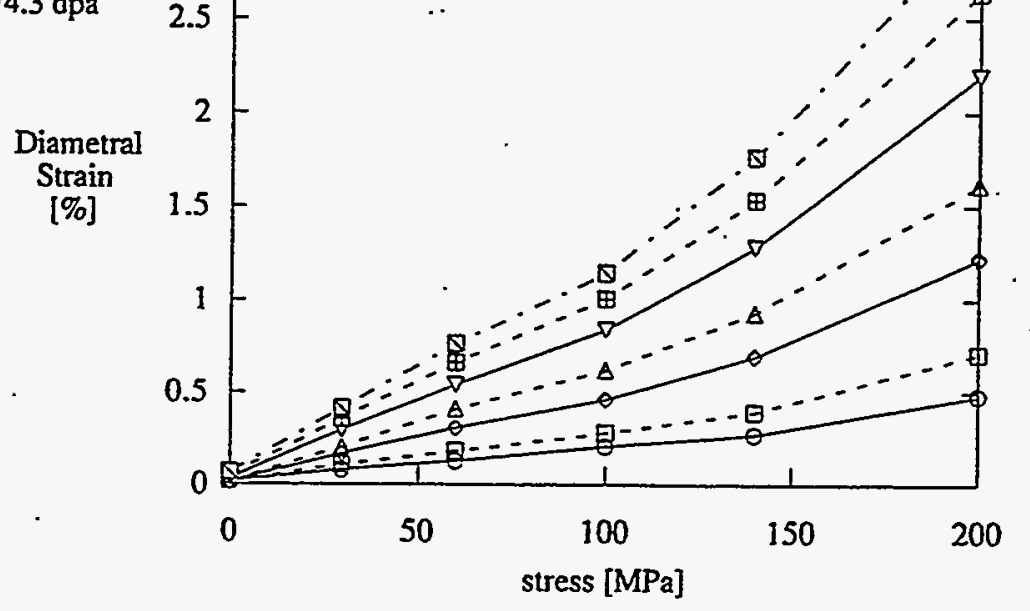

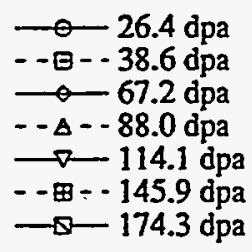

Heat 91353 HT9-2

$427-386^{\circ} \mathrm{C}$

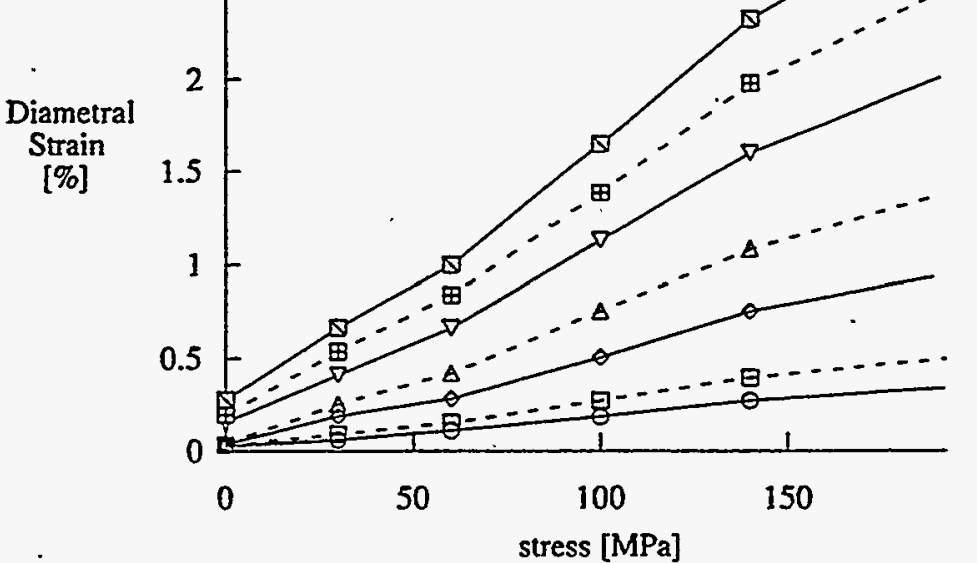

Figure 3. Diametral strains vs. hoop stress level, showing greater tendency toward stress-enhancement of total strain in $\mathrm{HT} 9-1$ at $-400^{\circ} \mathrm{C}$. 

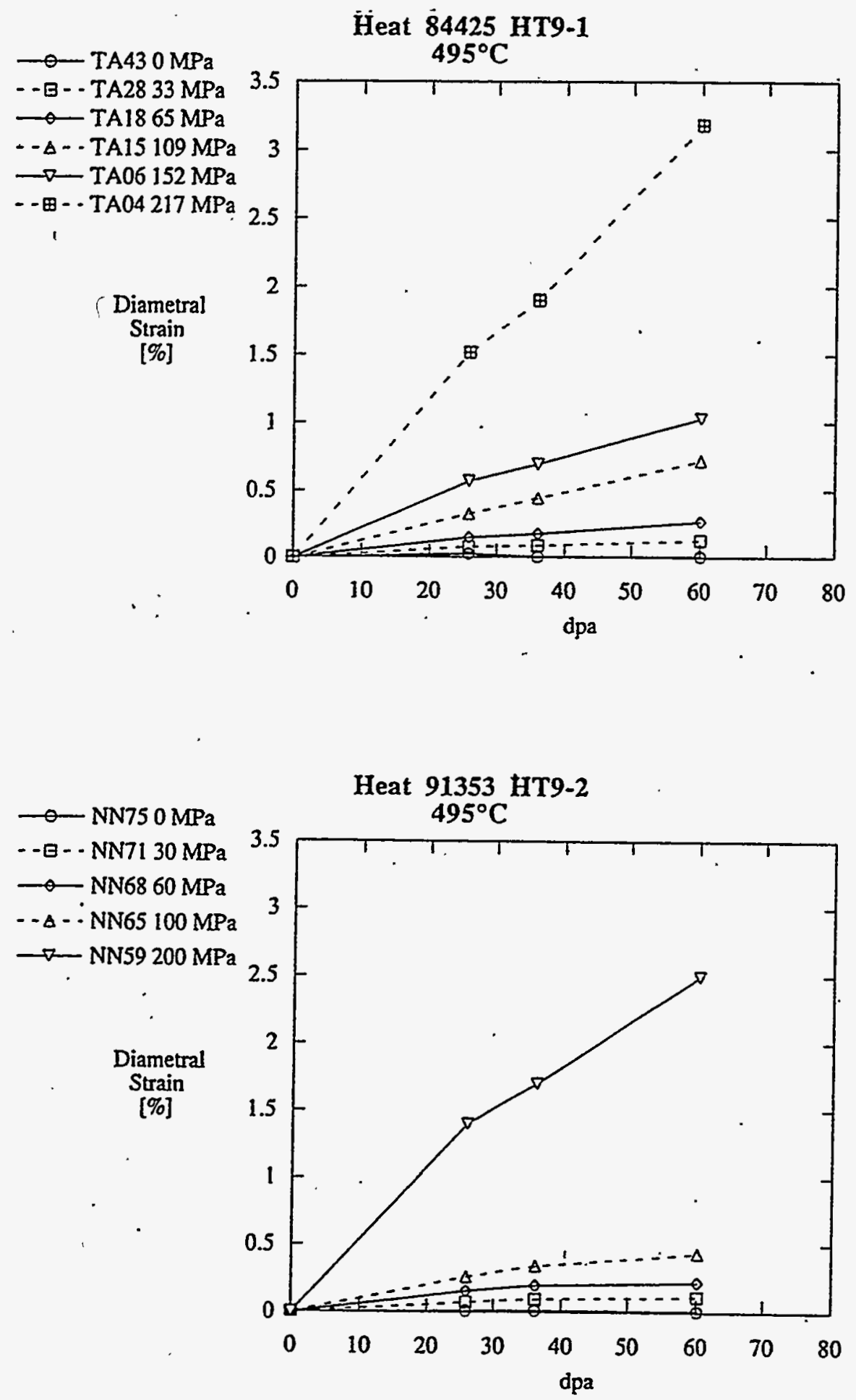

Figure 4. Total diametral strains observed at $\sim 495^{\circ} \mathrm{C}$. 

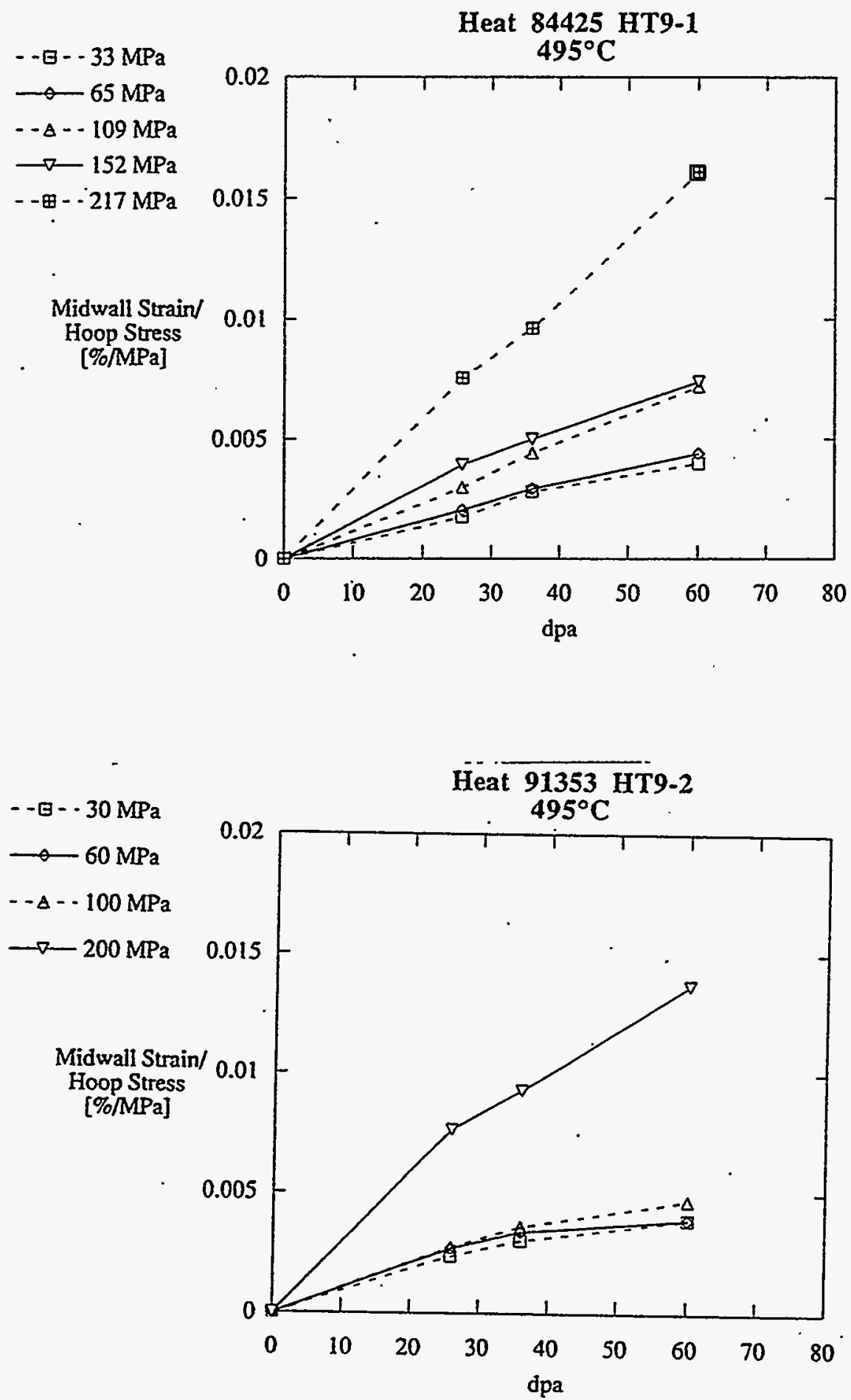

Figure 5. Midwall creep strains per unit hoop stress at $\sim 495^{\circ} \mathrm{C}$. 

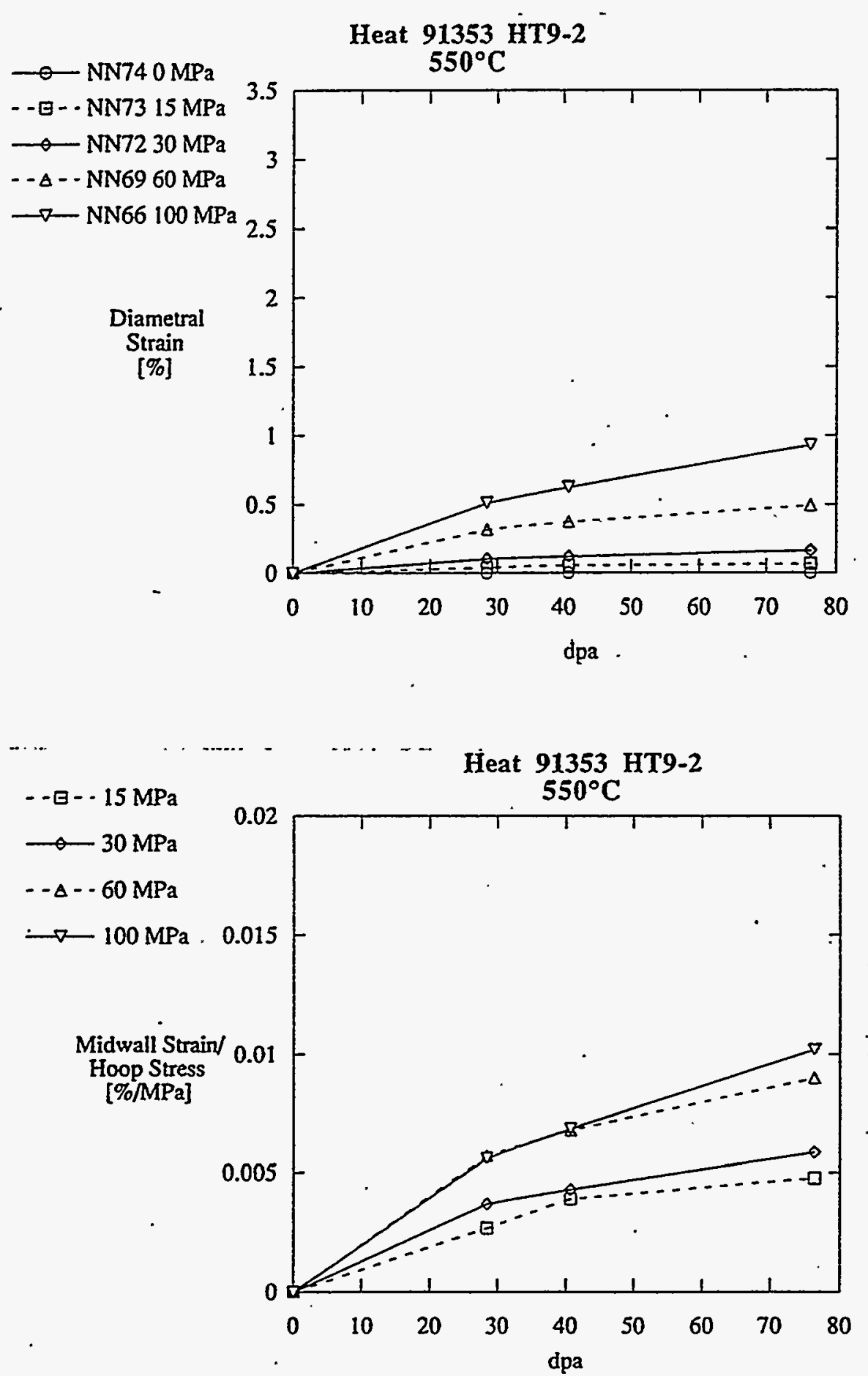

Figure 6. Total strains and midwall creep strain rates observed in $\mathrm{HT} 9-2$ at $\sim 550^{\circ} \mathrm{C}$. 

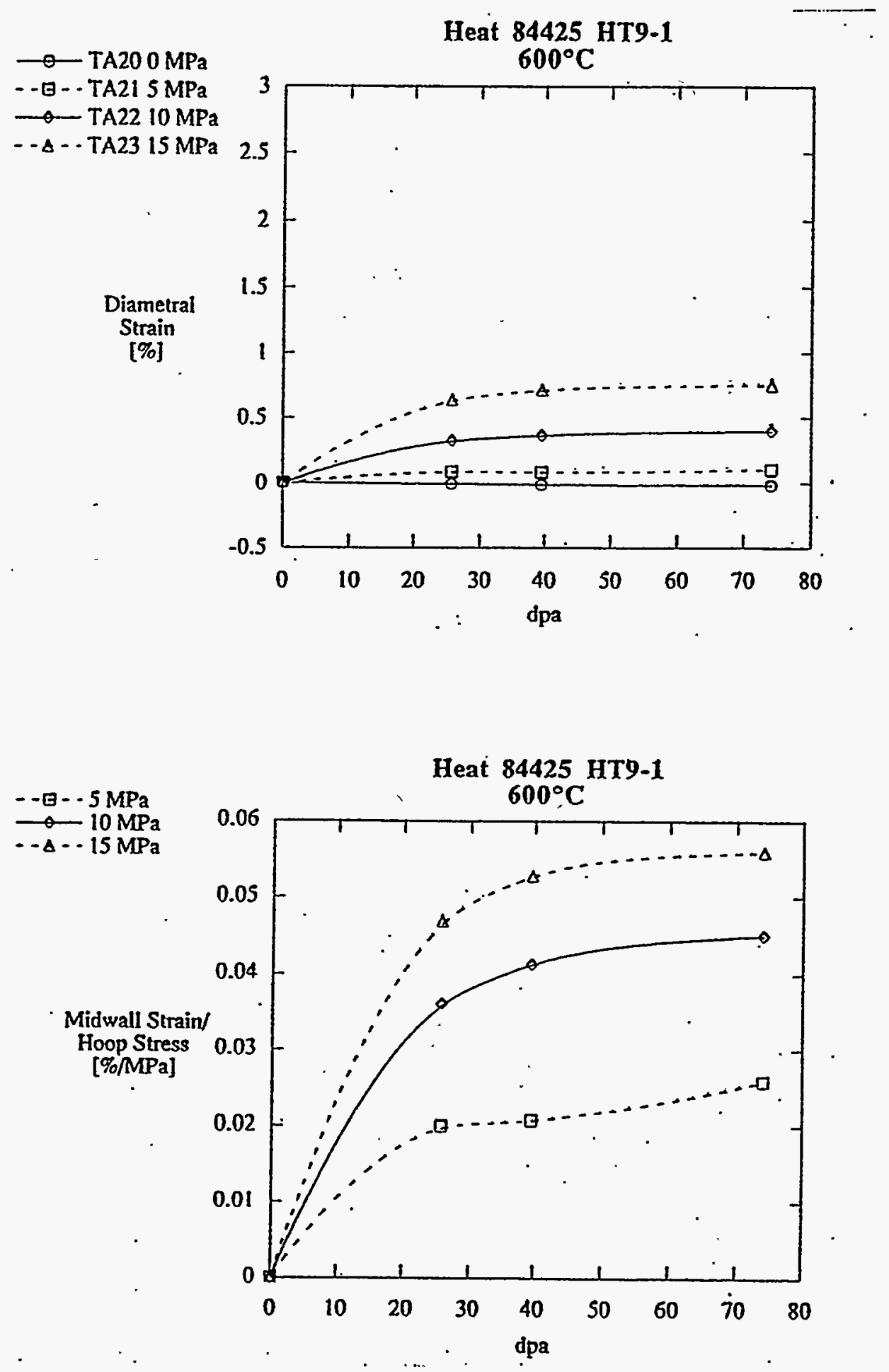

Figure 7. Total strains and midwall creep strains observed in $\mathrm{HT} 9-1$ at $\sim 600^{\circ} \mathrm{C}$. 
6.2 Austenitic Stainless Steels

No contributions. 
6.3 Refractory Metal Alloys 
:

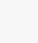


Characterization of $\mathrm{V}-4 \mathrm{Cr}-4 \mathrm{Ti}$ Heat 832665 - M. L. Grossbeck, D. J. Alexander, J.J . Henry, Jr., W. S. Eatherly, and L. T. Gibson (Oak Ridge National Laboratory)

\section{OBJECTIVE}

A liquid lithium-cooled vanadium structure is a favored concept for an advanced breeding blanket. The objective of this task is to define the processing parameters for optimal alloy performance in the $\mathrm{V}-\mathrm{Cr}-\mathrm{Ti}$ alloy system.

\section{SUMMARY}

A new $500 \mathrm{Kg}$ heat of $\mathrm{V}-4 \mathrm{Cr}-4 \mathrm{Ti}$, Heat 832665 , is now being characterized by various national laboratories. The Oak Ridge National Laboratory has received sheet of several thicknesses from Argonne National Laboratory (ANL); characterization by chemical analysis, Charpy impact testing, and metallography is in progress. The Charpy tests have shown that the material does not experience a ductile to brittle transition temperature even at temperatures as low as $-196^{\circ} \mathrm{C}$.

\section{PROGRESS AND STATUS}

\section{Introduction}

A $500 \mathrm{Kg}$ heat of $\mathrm{V}-4 \mathrm{Cr}-4 \mathrm{Ti}$ has been procured by Argonne National Laboratory from Teledyne Wah Chang Albany Corporation. This alloy is considered to be the most promising candidate vanadium alloy in the U.S. program for future fusion devices. This alloy will be used to evaluate optimization of processing, welding and fabrication, irradiation properties, and liquid metal compatibility of the low-Cr, low-Ti vanadium alloys. The present contribution is a status report of the recent work at Oak Ridge National Laboratory (ORNL) to characterize plate material $0.150 \mathrm{in}$. thick which had been annealed by the vendor at $1050^{\circ} \mathrm{C}$ for 2 hours.

\section{Chemical Analysis .}

Chemical analysis was done by three methods to supplement the ingot analysis provided by the vendor. Table 1 shows the results reported by the vendor and subsequent analyses. The inert gas fusion analysis was performed by Leco Corp., St. Joseph, MI. The glow discharge mass analysis and the inductively coupled plasma emission (ICP) were performed at ORNL. The inert gas fusion method has been found to be reliable for interstitials. The ICP method dissolves the metal allowing an accurate solution standard to be used. This method is believed to be the most reliable for the major elements. The methods used by the vendor are not known, so no evaluation will be made of their results.

The inert gas fusion analysis provided higher concentrations of the interstitials $\mathrm{O}, \mathrm{N}$, and $\mathrm{C}$. This is not inconsistent with the ingot analyses since the inert gas fusion analyses were made on a $3.8 \mathrm{~mm}$ warmrolled and annealed plate. It is possible, and in fact expected, that the interstitial concentrations, especially of oxygen, would increase in processing. The glow discharge analysis is not considered reliable for the interstitial elements. Glow discharge mass analysis identified about $11 \mathrm{ppm}$ Hf which was not reported by the vendor. If this later proves to be a concern for neutron economy in a future breeding fusion device, more careful analysis will have to be done. There is also a discrepancy in the $\mathrm{Cr}$ concentration. Since $\mathrm{Cr}$ is a major element, more analysis must be done to obtain more accurate values for this element. With these exceptions, the values are reasonably consistent. 
Table 1. Chemical Analyses of V-4Cx-4Ti (Ht. 832665)

\begin{tabular}{|c|c|c|c|c|c|c|}
\hline \multirow{2}{*}{ Element } & \multicolumn{3}{|c|}{$\begin{array}{c}\text { Teledyne Analysis } \\
3 \text { Ingot Positions } \\
\text { (wt. ppm) }\end{array}$} & \multirow{2}{*}{$\begin{array}{c}\text { Glow Discharge Mass } \\
\text { Analysis (wt ppm) } \\
( \pm 10-30 \%) \\
<200\end{array}$} & \multirow[t]{2}{*}{$\begin{array}{c}\text { Inductively coupled } \\
\text { plasma-emission } \\
( \pm 5-10 \%)\end{array}$} & \multirow[t]{2}{*}{$\begin{array}{c}\text { Inert gas } \\
\text { fusion analysis } \\
\text { (wt. ppm) }\end{array}$} \\
\hline & 180 & 190 & 105 & & & \\
\hline As & & & & $<3$ & & \\
\hline $\mathrm{B}$ & 7 & $<5$ & $<5$ & $<6^{*}$ & & \\
\hline $\mathrm{C}$ & 64 & 80 & 94 & $<310$ & & 139 \\
\hline $\mathrm{Ca}$ & $<10$ & $<10$ & $<10$ & & & \\
\hline $\mathrm{Cl}$ & $<2$ & $<2$ & $<2$ & & & \\
\hline $\mathrm{Cr}$ & $3.76 \%$ & $3.72 \%$ & $3.83 \%$ & $3.0 \%$ & $3.1 \%$ & \\
\hline $\mathrm{Fe}$ & 180 & 220 & 270 & 256 & & \\
\hline Hf & & & & 10.8 & & \\
\hline Mo & 330 & 350 & 280 & 244 & & \\
\hline $\mathrm{N}$ & 82 & 80 & 93 & $<4$ & & 102 \\
\hline $\mathrm{Nb}$ & $<60$ & 60 & $<60$ & $<80$ & & \\
\hline $\mathrm{Ni}$ & & & & $<12$ & & \\
\hline 0 & 280 & 360 & 290 & $<190$ & & 383 \\
\hline$P$ & $<30$ & $<30$ & $<30$ & $<61$ & & \\
\hline $\mathrm{Ru}$ & & & & $<7$ & & \\
\hline$S$ & $<10$ & $<10$ & $<10$ & 40 & & 8 \\
\hline $\mathrm{Si}$ & 790 & 840 & 720 & 1000 & & \\
\hline $\mathrm{Sr}$ & & & & $<60$ & & , \\
\hline $\mathrm{Ta}$ & & & & $<3 *$ & & \\
\hline $\mathrm{Ti}$ & $4.16 \%$ & $3.78 \%$ & $3.80 \%$ & $5.3 \%$ & $4.1 \%$ & \\
\hline $\mathrm{V}$ & & & & 91.6 & & \\
\hline W & & & & 22.8 & & \\
\hline $\mathrm{Zx}$ & & & & $<65$ & & \\
\hline
\end{tabular}

*known contaminant

Metallography

The annealed plate was prepared using standard polishing procedures and etched with $30 \% \mathrm{HNO}_{3}-10 \% \mathrm{HF}-$ $60 \% \mathrm{H}_{2} \mathrm{O}$. The microstructure is shown in Fig. 1. The bonded appearance derives from the presence of stringers of particles of titanium oxycarbonitrides, which presumably became aligned during the hot extrusion process. In the vicinity of stringers, grain growth during the final anneal is impeded; in the regions between stringers grain growth is more rapid and the final grain size is much larger. The overall average grain size is around $25 \mu \mathrm{m}$.

\section{Charpy Testing}

Charpy impact specimens $3.33 \mathrm{~mm}$ square and $25.4 \mathrm{~mm}$ long were used for the tests. They had a $30^{\circ}$ notch $0.51 \mathrm{~mm}$ deep with a root radius of $0.08 \mathrm{~mm}$. The specimens were oriented such that the crack propagated perpendicular to the direction of the stringers ( $\mathrm{L}-\mathrm{T}$ direction). Following machining and etching, the specimens were divided into two groups: One was annealed at $950^{\circ} \mathrm{C}$ for 2 hours, and the other was outgassed at $400^{\circ} \mathrm{C}$ for one hour to remove hydrogen.

The specimens were tested in a semiautomated pendulum type Charpy impact testing system modified for testing subsize specimens. ${ }^{1}$ The testing temperature was achieved by cold gas from liquid nitrogen for 


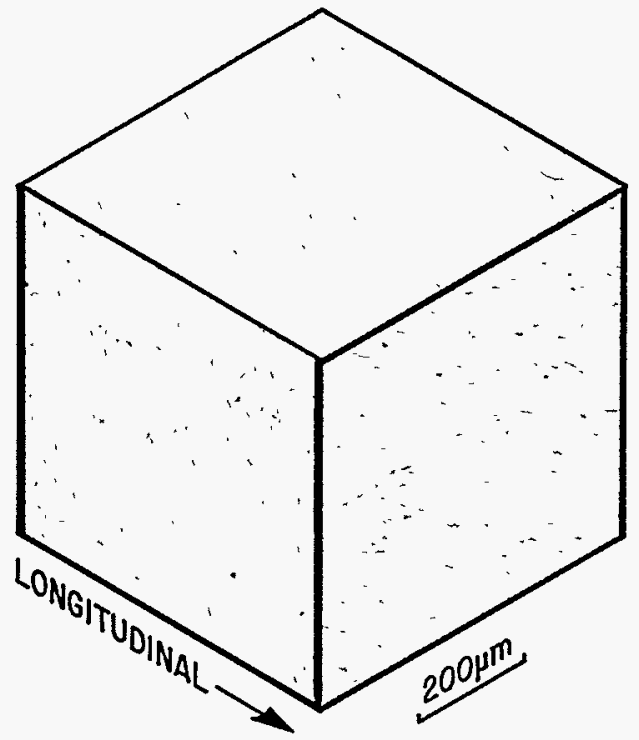

Fig. 1. Three orthogonal views of the grain structure of $\mathrm{V}-4 \mathrm{Cr}-4 \mathrm{Ti}(\mathrm{Ht} .832665)$ in the as-received annealed condition.

cooling or hot air for heating. The results of absorbed energy were fitted with a hyperbolic tangent function to allow the DBTT and the upper shelf energy to be determined at an energy level midway between the upper and lower shelf energy levels.

The results are plotted in Fig. 2 for both heat treatments. As can be seen from the figure, no ductile-tobrittle transition was observed to temperatures as low as $-196^{\circ} \mathrm{C}$.

\section{DISCUSSION}

The excellent Charpy impact properties shown if Fig. 2 are largely in agreement with previous results on an earlier Teledyne heat of $\mathrm{V}-4 \mathrm{Cr}-4 \mathrm{Ti}$ (designated BL -47 by ANL). It is also evident from the Charpy impact curves that the absorbed energy increases with decreasing temperature. This phenomenon has also been observed by Loomis et $\mathrm{al}^{2}$ in Charpy tests of $\mathrm{V}-\mathrm{Cr}-\mathrm{Ti}$ alloys. A similar phenomenon has also been observed in tensile tests by Loomis and Carlson. ${ }^{3}$ Such results are very similar to behavior observed by Hardie and McIntyre ${ }^{4}$ in vanadium and niobium and by Gahr et al. in niobium. ${ }^{5}$

A suggested mechanism is that hydrogen is diffusing to points of stress concentration in the material initiating hydrogen embrittlement where hydrogen diffuses to the crack tip and forms

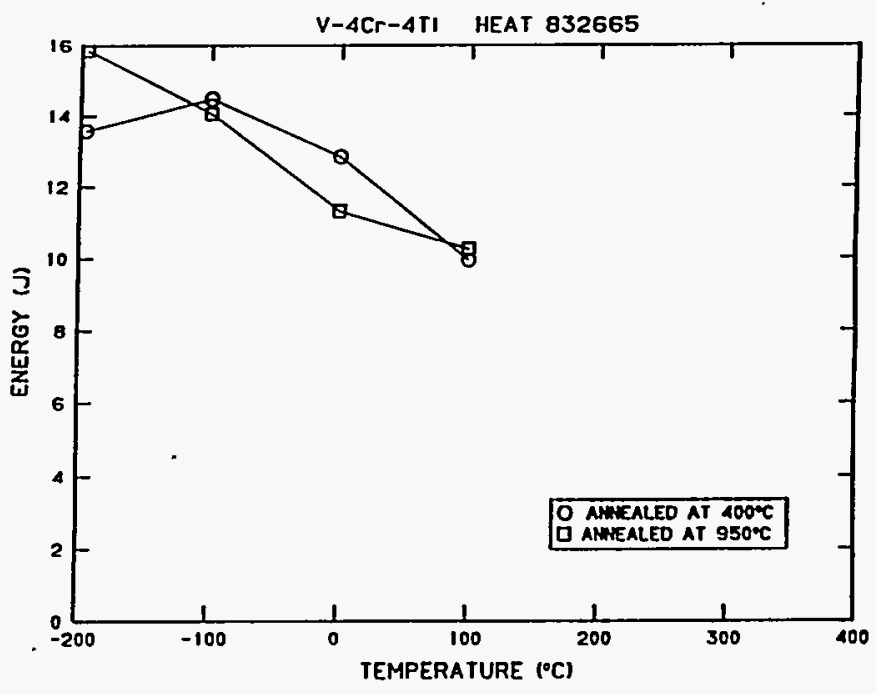

Fig. 2. Absorbed energy as a function of test temperature from Charpy impact tests of $\mathrm{V}-4 \mathrm{Cr}-$ 4Ti (Ht. 832665) in an annealed $\left(950^{\circ} \mathrm{C} / 2 \mathrm{hrs}\right.$.) condition and following an outgassing treatment $\left(400^{\circ} \mathrm{C} / 1 \mathrm{hr}\right)$. 
brittle hydride. Another mechanism is the diffusion of hydrogen to dislocations causing a strain-aging effect. Since only hydrogen is mobile at the temperatures of minimum ductility, both of these mechanisms appear to be viable. At still lower temperatures, even hydrogen does not diffuse sufficiently fast to cause either strengthening or hydride formation, and ductility returns. In the case of the Charpy tests, the result is higher absorbed energy.

To investigate the effect of hydrogen, or to remove effects of hydrogen, one set of Charpy specimens was heat treated at $400^{\circ} \mathrm{C}$ for 1 hour to reduce hydrogen to very low levels. Previous experience has shown the hydrogen concentration following such heat treatment to be about one ppm or less. The results also appear in Fig. 2 where it can be seen that the process had no apparent effect. It is therefore likely that either the phenomenon is not related to hydrogen or that only fractions of ppm are sufficient to produce an effect. If either of the previously suggested mechanisms are active, lower strain rate testing should exacerbate the effect of hydrogen. This hypothesis will be tested with tensile testing in future experiments.

\section{FUTURE WORK}

Mechanical testing will continue on this particular heat of $\mathrm{V}-4 \mathrm{Cr}-4 \mathrm{Ti}$ with tensile and fracture toughness testing. Welding research as well as interstitial impurity studies will also be shifted to this heat.

\section{REFERENCES}

1. D.J. Alexander, R.K. Nanstad, W.R. Corwin, and J.T. Hutton, "A Semiautomated ComputerInteractive Dynamic Impact Testing System," in Applications of Automation Technology to Fatigue and Fracture Testing, ASTM STP 1092, A.A. Braun, N.E. Ashbaugh, and F.M. Smith, eds., American Society for Testing and Materials, Philadelphia (1990) 83.

2. .B.A. Loomis, H.M. Chung, L.J. Nowicki, and D.L. Smith, "Effects of Neutron Irradiation and Hydrogen on Ductile-Brittle Transition Temperatures of V-Cr-Ti Alloys," Sixth International Conference on Fusion Reactor Materials, September 27 - October 1, 1993, Stresa, Italy.

3. B.A. Loomis and O.N. Carlson, "Investigation of the Brittle-Ductile Transition in Vanadium," in Reactive Metals, Interscience, New York, 1959, p. 227.

4. D. Hardie and P. McIntyre, Met Trans. 4 (1973) 1247.

5. S. Gahr, M.L. Grossbeck, and H.K. Birnbaum, "Hydrogen Embrittlement of Nb: I-Macroscopic Behavior at Low Temperatures," Acta Met. 25 (1977) 125. 
RECOVERY AND RECRYSTALLIZATION STUDY ON VANADIUM ALLOYS A. N. Gubbi, A. F. Rowcliffe, and W. S. Eatherly (Oak Ridge National Laboratory)

\section{OBJECTIVE}

The aim of this work is to determine the kinetics of recovery and recrystallization, and to develop a suitable model to explain mechanistics of recrystallization of vanadium alloys with $\mathrm{Cr}$ and $\mathrm{Ti}$ contents ranging from 3 to 6 wt \%.

\section{SUMMARY}

A series of vacuum-anneals at temperatures from $900^{\circ}$ to $1100^{\circ} \mathrm{C}$ for 1 to $4 \mathrm{~h}$ was carried out on vanadium alloys with $\mathrm{Cr}$ and $\mathrm{Ti}$ contents ranging from 3 to $6 \mathrm{wt}$.\%. Compositional variants of vanadium alloys $(\sim 15-\mathrm{kg}$ melt $)$ and a large heat $(-500-\mathrm{kg}$ melt $)$ of $\mathrm{V}-4 \mathrm{Cr}-4 \mathrm{Ti}$ alloy were studied in this work. Optical microscopy, TEM, and microhardness testing were carried out. The alloys tested followed the metallurgically well-established axiom that longer times at low temperatures and shorter times at high temperatures were needed for complete recrystallization. The recrystallization kinetics was faster in the alloys with higher amount of cold work compared to that exhibited by alloys with lower cold work. The large heat of $\mathrm{V}-4 \mathrm{Cr}-4 \mathrm{Ti}$ alloy with $40 \% \mathrm{CW}$ showed recovery for anneals at $900^{\circ} \mathrm{C}$, and began recrystallizing at $950^{\circ} \mathrm{C}$. Complete recrystallization in this alloy occurred at $1000^{\circ} \mathrm{C}$, with grain growth for temperatures of $1050^{\circ} \mathrm{C}$ and above. Recovery and recrystallization kinetics were faster for the small heats because of the higher level of cold work (49\%) in the starting material. However, variations in $\mathrm{Cr}$ and $\mathrm{Ti}$ over the range 3 to $6 \mathrm{wt} \%$ had no discernible effect on recovery/recrystallization behavior. The hardness of both recovered and recrystallized structures increased with total $(\mathrm{Cr}+\mathrm{Ti})$ content.

\section{INTRODUCTION}

Vanadium alloys with $\mathrm{Cr}$ and $\mathrm{Ti}$ contents ranging from 3 to $6 \mathrm{wt}$.\% were proposed earlier as possible candidate materials for first wall/blanket structure in fusion reactors. ${ }^{1-4}$ More recently, 5 it was suggested that a V-4Cr-4Ti alloy could be a suitable candidate for the first wall and blanket structure for ITER. This was based on its thermal creep properties, low DBTT determined by Charpy (CVN) testing, resistance to helium- and irradiation-induced embrittlement, and swelling resistance. All these tests were conducted on a laboratory-scale heat of $\mathrm{V}-4 \mathrm{Cr}-4 \mathrm{Ti}$ alloy. Recently, a large heat $(-500-\mathrm{kg}$ melt $)$ of $\mathrm{V}-4 \mathrm{Cr}-4 \mathrm{Ti}$ alloy (heat 832665 ) was fabricated by Teledyne Wah Chang (Albany, Oregon). No serious efforts have been made till now to determine the kinetics and mechanistics of recovery and recrystallization of vanadium alloys in general, and $\mathrm{V}-4 \mathrm{Cr}-4 \mathrm{Ti}$ alloy in particular. The present study has been undertaken to accomplish the fundamental understanding of the recrystallization phenomenon in vanadium alloys. Also included in this study were small heats $(-15-\mathrm{kg}$ melt) of compositional variants of vanadium alloys with $\mathrm{Cr}$ and $\mathrm{Ti}$ contents ranging from 3 to $6 \mathrm{wt} . \%$. The objective of including the compositional variants is to obtain a window on the tolerable limits of $\mathrm{Cr}$ and $\mathrm{Ti}$ contents without significant change in the physical and mechanical properties.

\section{EXPERIMENTAL PROCEDURE}

A large heat $(\sim 500-\mathrm{kg}$ melt) of $\mathrm{V}-4 \mathrm{Cr}-4 \mathrm{Ti}$ alloy (heat 832665$)$ and a small heat of $(\sim 15-\mathrm{kg}$ melt $) \mathrm{V}-5 \mathrm{Cr}-5 \mathrm{Ti}$ (T87) were produced by Teledyne Wah Change as per the specifications supplied by Argonne National Laboratory. Four small heats (each $\sim 15-\mathrm{kg}$ melt), V-3Cr-3Ti (heat T91), V-4Cr-4Ti-Si (heat T89), V-6Cr$3 \mathrm{Ti}$ (heat T92), and $\mathrm{V}-6 \mathrm{Cr}-6 \mathrm{Ti}$ (heat $\mathrm{T} 90$ ) were fabricated according to the specifications set by Oak Ridge National Laboratory. The heat T89 was intended to have a higher Si content than that in heat 832665 , but ended up being almost the same composition as heat 832665 . Therefore, this heat can be considered as a small heat of $\mathrm{V}-4 \mathrm{Cr}-4 \mathrm{Ti}$ with a different processing history. The samples for the present study were obtained from the rolled plates $(-1.02-\mathrm{mm}$ thick) of both the large and small heats. The V-4Cr-4Ti alloy (heat 832665) and the small heat of compositional variant V-5Cr-5Ti had a cold work level of approximately $40 \%^{6}$ whereas the other small heats had a cold work of approximately $49 \%$. The chemical 
composition of the large heat is given in Table 1; that of the small heats is given in Table 2. Heat treatments were carried out on samples (for both optical metallography and TEM analysis) from $900^{\circ}$ to $1100^{\circ} \mathrm{C}$ for 1 to $4 \mathrm{~h}$ in a vacuum better than $1 \times 10^{-6}$ torr $\left(<10^{-4} \mathrm{~Pa}\right)$. Optical metallography, microhardness testing, and TEM analysis were carried out to understand the effect of temperature-time on the recovery and recrystallization of vanadium alloys.

Table1. Chemical Composition of the large heat of $\mathrm{V}-4 \mathrm{Cr}-4 \mathrm{Ti}$

\begin{tabular}{|c|c|c|c|c|c|c|}
\hline \multirow{2}{*}{$\begin{array}{c}\text { Element } \\
\mathrm{Al}\end{array}$} & \multicolumn{3}{|c|}{$\begin{array}{l}\text { Teledyne Analyses } \\
3 \text { Ingot Positions } \\
\text { (wt ppm) }\end{array}$} & \multirow{2}{*}{$\begin{array}{c}\text { Glow } \\
\text { Discharge } \\
\text { Mass } \\
\text { Analysis } \\
\text { (wt. ppm) } \\
( \pm 10-30 \%) \\
<200\end{array}$} & \multirow{2}{*}{$\begin{array}{c}\text { Inductively } \\
\text { coupled } \\
\text { Plasma- } \\
\text { emission } \\
( \pm 5-10 \%) \\
\end{array}$} & \multirow[t]{2}{*}{$\begin{array}{l}\text { Inert Fusion } \\
\text { Analysis } \\
\text { (wt. ppm) }\end{array}$} \\
\hline & 180 & 190 & 105 & & & \\
\hline As & & & & $<3$ & & \\
\hline B & 7 & $<5$ & $<5$ & $<6^{*}$ & & \\
\hline $\mathrm{C}$ & 64 & 80 & 94 & $<310$ & & 139 \\
\hline $\mathrm{Ca}$ & $<10$ & $<10$ & $<10$ & & & \\
\hline $\mathrm{Cl}$ & $<2$ & $<2$ & $<2$ & & & \\
\hline $\mathrm{Cr}$ & $3.76 \%$ & $3.72 \%$ & $3.83 \%$ & $3.0 \%$ & $3.1 \%$ & \\
\hline $\mathrm{Fe}$ & 180 & 220 & 270 & 256 & & \\
\hline $\mathrm{Hf}$ & & & & 10.8 & & \\
\hline Mo & 330 & 350 & 280 & 244 & & \\
\hline $\mathrm{N}$ & 82 & 80 & 93 & $<4$ & & 102 \\
\hline $\mathrm{Nb}$ & $<60$ & 60 & $<60$ & $<80$ & & \\
\hline $\mathrm{Ni}$ & & & & $<12$ & & \\
\hline 0 & 280 & 360 & 290 & $<190$ & & 383 \\
\hline $\mathrm{P}$ & $<30$ & $<30$ & $<30$ & $<61$ & & \\
\hline $\mathrm{Ru}$ & & & & $<7$ & & \\
\hline$S$ & $<10$ & $<10$ & $<10$ & 40 & & 8 \\
\hline $\mathrm{Si}$ & 790 & 840 & 720 & 1000 & & \\
\hline $\mathrm{Sr}$ & & & & $<60$ & & \\
\hline $\mathrm{Ta}$ & & & & $<3^{*}$ & & \\
\hline $\mathrm{Ti}$ & $4.16 \%$ & $3.78 \%$ & $3.80 \%$ & $5.3 \%$ & $4.1 \%$ & \\
\hline $\mathrm{V}$ & & & & $91.6 \%$ & & \\
\hline $\mathrm{W}$ & & & & 22.8 & & \\
\hline $\mathrm{Zr}$ & & & & $<65$ & & \\
\hline
\end{tabular}

*Known contaminant

\section{RESULTS AND DISCUSSION}

\section{LARGE HEAT OF V-4Cr-4Ti (Heat 832665)}

The starting material was $1.02 \mathrm{~mm}$ thick sheet, which had been annealed by the manufacturer at $1050^{\circ} \mathrm{C}$ for 2 hours after cold rolling $-40 \%$ reduction in thickness. The microstructure contained an elongated grain structure and precipitate particles which had been aligned into stringers during the initial hot working operations. The initial hardness was $200 \pm 5 \mathrm{DPH}$. Annealing at $900^{\circ} \mathrm{C}$ for 1 to 4 hours reduced the hardness to 165-168 DPH (Fig. 1); corresponding microstructures are shown in Fig. 2. After 1 hour at $950^{\circ} \mathrm{C}$, sub-grains approximately $1 \mu \mathrm{m}$ dia developed within the original elongated grain structure. With increasing annealing time the residual dislocation density within the sub-grains continued to decrease and 
Table 2. Chemical Compositions of small heats of Compositional Variants

\begin{tabular}{|c|c|c|c|c|c|c|c|c|c|c|}
\hline & \multicolumn{2}{|c|}{$\begin{array}{l}\text { V-3Cr-3Ti } \\
\text { (T91) } \\
\text { Wt.ppm }\end{array}$} & \multicolumn{2}{|c|}{$\begin{array}{c}\text { V-4Cr-4Ti-Si } \\
\text { (T89) } \\
\text { Wt.ppm }\end{array}$} & \multicolumn{2}{|c|}{$\begin{array}{c}\text { V-5Cr-5Ti } \\
\text { (T87) } \\
\text { Wt.ppm }\end{array}$} & \multicolumn{2}{|c|}{$\begin{array}{c}\text { V-6Cr-3Ti } \\
\text { (T92) } \\
\text { Wt.ppm }\end{array}$} & \multicolumn{2}{|c|}{$\begin{array}{c}\text { V-6Cr-6Ti } \\
\text { (T90) } \\
\text { Wt.ppm }\end{array}$} \\
\hline Element & $\mathrm{Lab}^{* *}$ & TWCA $^{*}$ & $\mathrm{Lab}^{* *}$ & TWCA* & $\mathrm{Lab}^{* * *}$ & TWCA ${ }^{*}$ & $\mathrm{Lab}^{* *}$ & TWCA ${ }^{*}$ & $\mathrm{Lab}^{* *}$ & TWCA* \\
\hline $\mathrm{B}$ & 3.8 & & 3.5 & & 2.7 & $<6$ & 3.4 & & 3.9 & \\
\hline C & $<140$ & 120 & $<120$ & 112 & $<110$ & 111 & $<92$ & 105 & $<120$ & 104 \\
\hline $\bar{N}$ & $<5.5$ & 62 & $<1.8$ & 79 & $<5.5$ & 89 & $<1.8$ & 95 & $<4.5$ & 85 \\
\hline 0 & $<270$ & 230 & $<270$ & 270 & $<370$ & 380 & $<200$ & 280 & $<260$ & 250 \\
\hline$\overline{\mathrm{Al}}$ & 240 & 200 & 270 & 200 & 260 & 160 & 300 & 255 & 270 & 235 \\
\hline$\overline{\mathrm{Si}}$ & 1200 & 940 & 1100 & 1050 & 830 & 545 & 1000 & 950 & 1400 & 960 \\
\hline $\mathbf{P}$ & 26 & $<50$ & 24 & $<50$ & 32 & $<30$ & 22 & $<50$ & 24 & $<50$ \\
\hline $\mathrm{S}$ & 27 & 12 & 23 & 10 & 20 & $<20$ & 21 & 12 & 20 & 10 \\
\hline$\overline{\mathrm{Ti}}$ & $3.1 \%$ & $3.02 \%$ & $5.3 \%$ & $4.14 \%$ & $4.8 \%$ & $5.07 \%$ & $3.0 \%$ & $2.94 \%$ & $4.6 \%$ & $5.98 \%$ \\
\hline $\mathrm{V}$ & $94 \%$ & bal. & $90 \%$ & bal. & $90 \%$ & bal. & $91 \%$ & bal. & $91 \%$ & bal. \\
\hline $\mathrm{Cr}$ & $3.0 \%$ & $2.85 \%$ & $4.9 \%$ & $3.7 \%$ & $4.7 \%$ & $4.94 \%$ & $6.2 \%$ & $5.91 \%$ & $4.3 \%$ & $5.74 \%$ \\
\hline $\mathbf{M n}$ & 1.1 & & 1.9 & & 3.2 & & 1.7 & & 1.7 & \\
\hline $\mathrm{Fe}$ & 110 & 130 & 140 & 170 & 210 & 160 & 140 & 165 & 120 & 195 \\
\hline $\mathrm{Ni}$ & 7.6 & & 12 & & 4.8 & 77 & 8.3 & 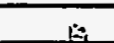 & 10 & \\
\hline $\mathrm{Cu}$ & 79 & 83 & 50 & 83 & 62 & & 130 & 140 & 48 & 55 \\
\hline $\mathrm{Zn}$ & 5.3 & & 4.7 & & 5.8 & & 4.5 & & 4.0 & \\
\hline $\mathbf{G a}$ & 3.9 & & 5.9 & & 5.4 & & 7.6 & & 5.0 & \\
\hline As & 1.7 & & 2.4 & & 0.31 & & 1.4 & & 2.0 & \\
\hline $\mathbf{S r}$ & $<76$ & & $<120$ & & $<150$ & & $<70$ & & $<110$ & \\
\hline $\mathrm{Y}$ & $<5.9$ & & $<9.3$ & & $<11$ & & $<6.1$ & & $<8.6$ & \\
\hline$\overline{Z r}$ & $<48$ & & $<63$ & & $<73$ & & $<56$ & & $<66$ & \\
\hline $\mathrm{Nb}$ & $\leq 55$ & $<50$ & $\leq 56$ & $<50$ & $\leq 75$ & $<100$ & $\leq 50$ & $<50$ & $\leq 54$ & $<50$ \\
\hline Mo & 380 & & 360 & & 340 & 515 & 380 & & 340 & \\
\hline $\mathrm{Rh}$ & 0.024 & & 0.016 & & $<0.008$ & & 0.02 & & 0.0083 & \\
\hline $\mathrm{Ru}$ & 0.22 & & 0.18 & & 0.35 & & 0.25 & & 0.252 & \\
\hline $\mathrm{Hf}$ & 0.45 & & 01.2 & & 0.35 & & 0.45 & & 0.82 & \\
\hline $\mathrm{Ta}$ & $<9.7$ & & $<5.2$ & & $<430$ & & $<9.0$ & & $<98$ & \\
\hline $\bar{W}$ & 32 & & 32 & & 35 & & 32 & & 28 & \\
\hline
\end{tabular}

*Teledyne Wah Chang analysis

**Analysis obtained by ORNL from a private lab

after 4 hours a few recrystallized grain nuclei could be detected. No additional precipitation at grain boundaries or within the sub-grains could be detected.

At $950^{\circ} \mathrm{C}$ the hardness dropped rapidly to $\sim 155 \mathrm{DPH}$ after only 1 hour at temperature (Fig. 1). From the metallography, it was estimated that the material was approximately $10 \%$ recrystallized at this point. After 4 hours, the hardness dropped to its minimum value of $\sim 145 \mathrm{DPH}$, with recrystallization about $30-40 \%$ complete. The remaining un-recrystallized regions consisted of well developed sub-grains with a low dislocation density, see Fig. 3 . There was some evidence that pre-existing grain boundaries were favored sites for the nucleation of new grains.

Recrystallization occurred rapidly at $1000^{\circ} \mathrm{C}$ and was complete after 2 hours (Fig. 4); all sub-grains were consumed, leaving a low density of individual dislocations. Particles of an unidentified phase formed on many of the new grain boundaries during cooling from $1000^{\circ} \mathrm{C}$. 


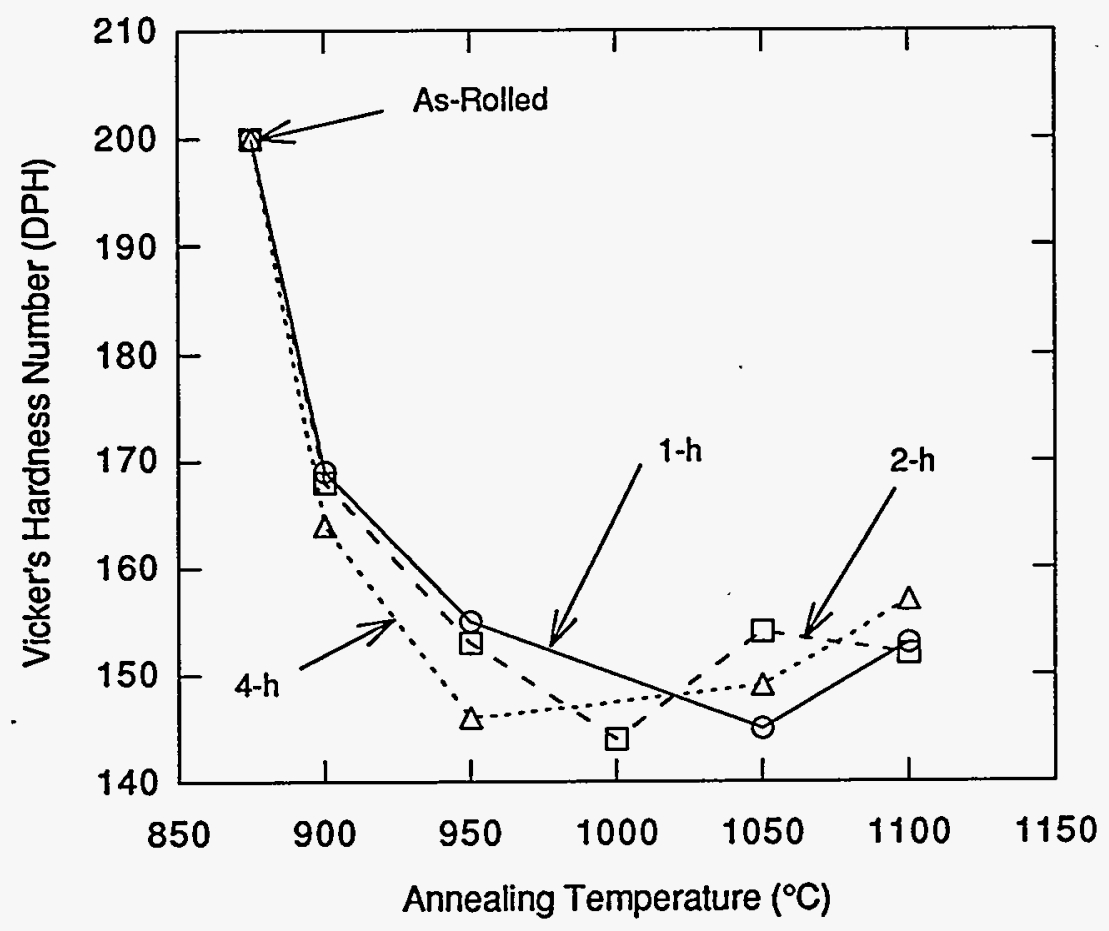

Figure 1. Microhardness as a function of Annealing Temperature for Heat $832665 \mathrm{~V}-4 \mathrm{Cr}-4 \mathrm{Ti}$ alloy
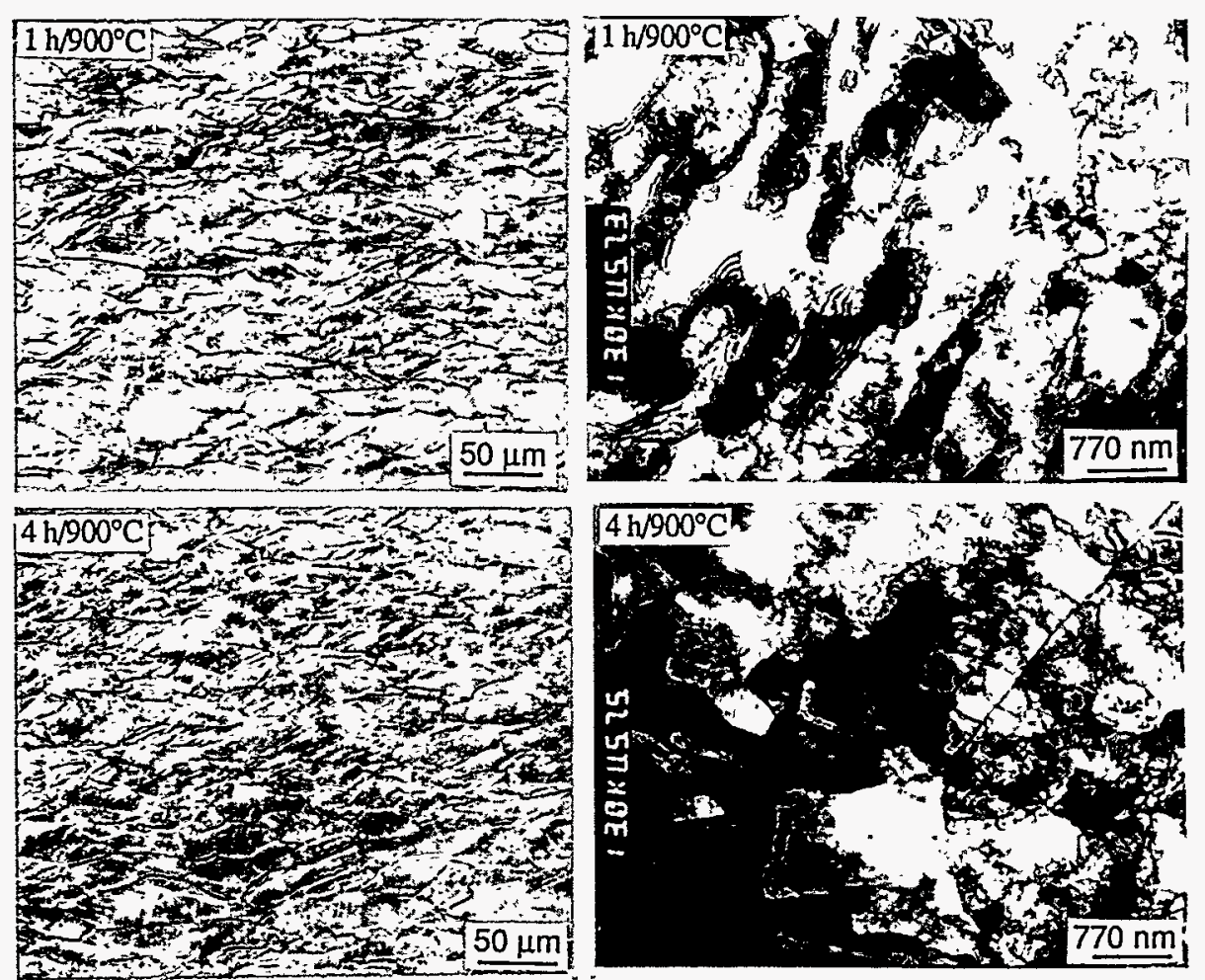

Figure 2. Optical and TEM microstructures at $900^{\circ} \mathrm{C}$ for the large heat of $\mathrm{V}-4 \mathrm{Cr}-4 \mathrm{Ti}$ 

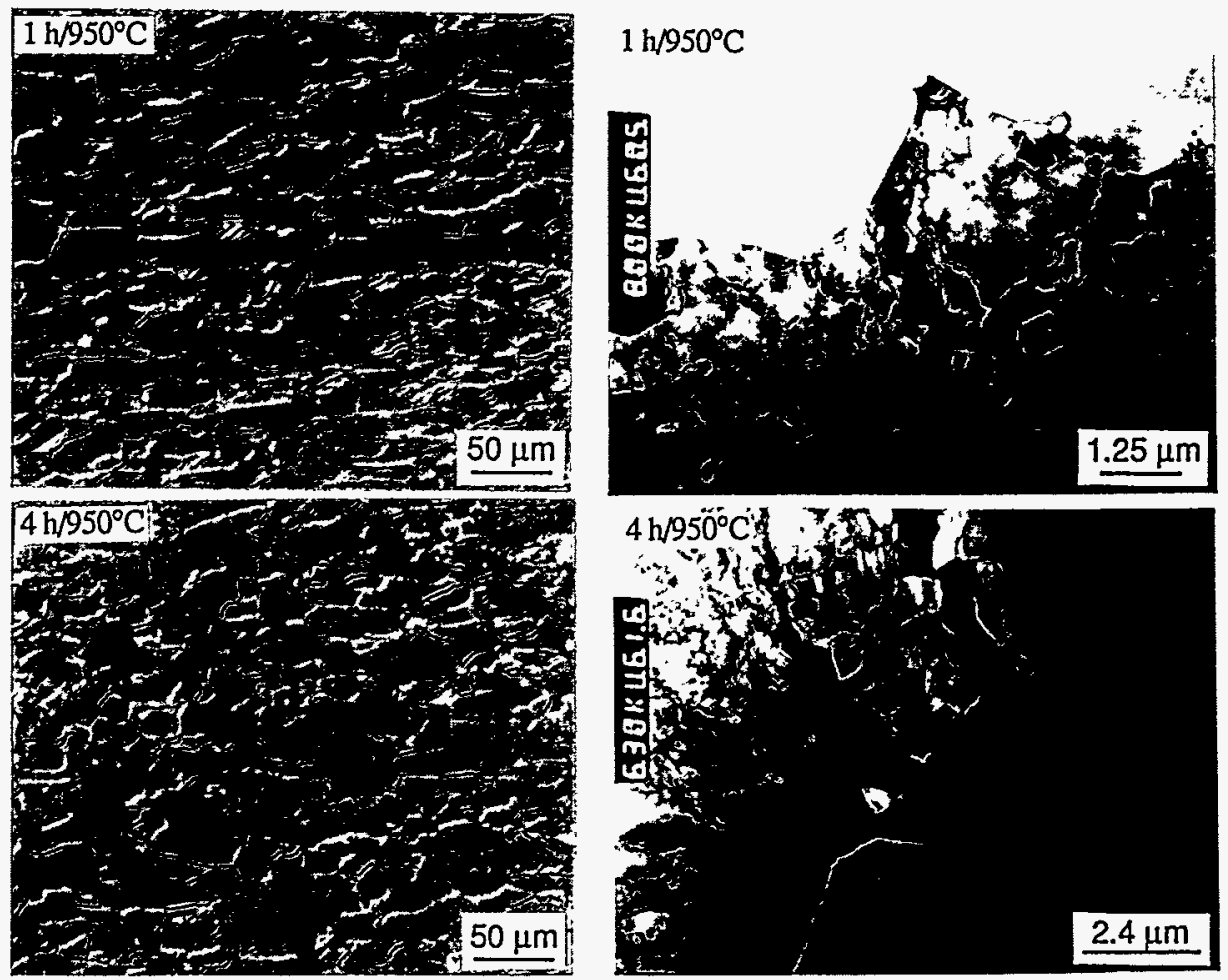

Figure 3. Optical and TEM microstructures at $950^{\circ} \mathrm{C}$ for the large heat of $\mathrm{V}-4 \mathrm{Cr}-4 \mathrm{Ti}$
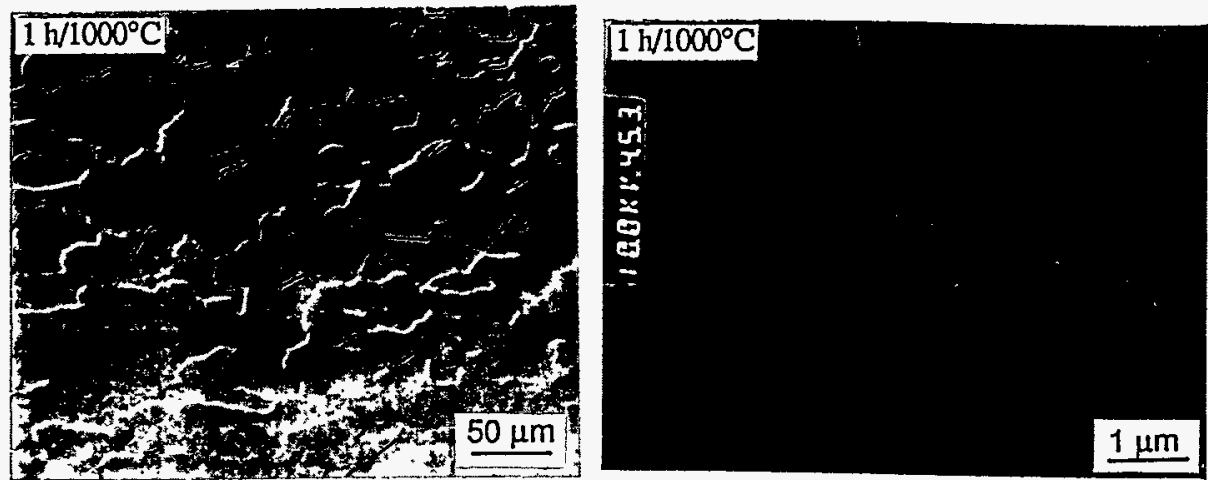

Figure 4. Optical and TEM microstructures at $1000^{\circ} \mathrm{C}$ for the large heat of $\mathrm{V}-4 \mathrm{Cr}-4 \mathrm{Ti}$ 
At $1050^{\circ} \mathrm{C}$ after 1-h anneal, the microstructure (Fig. 5) exhibited a mixture of new fine-grains and some grains retaining the original texture (elongated in the rolling direction which is horizontal and parallel to the plane of the micrograph). The hardness decreased to around $145 \mathrm{DPH}$, see Fig. 1. With further increase in annealing time to 2 and $4 \mathrm{~h}$, the hardness value increased, see Fig. 1. Grain growth occurred at this temperature and some grain boundaries were decorated with fine particles. The increase in hardness was possibly due to either precipitation of new phase or due to dissolution of existing precipitates which results in solution-hardening.
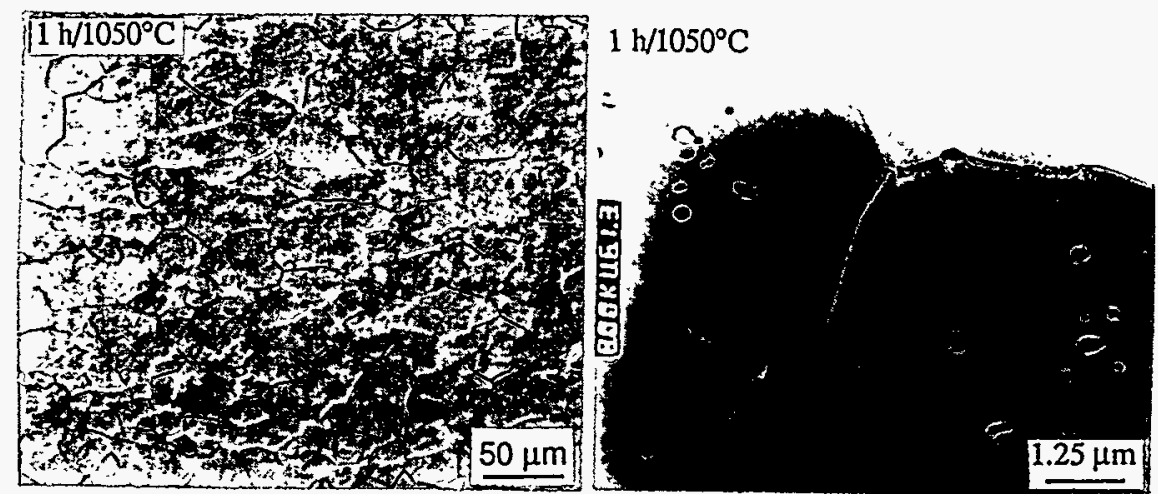

Figure 5. Optical and TEM microstructures at $1050^{\circ} \mathrm{C}$ for the large heat of $\mathrm{V}-4 \mathrm{Cr}-4 \mathrm{Ti}$

At $1100^{\circ} \mathrm{C}$ there was an appreciable amount of grain growth and a bimodal grain distribution developed (see Fig. 6). This can be related to the non-uniform distribution of precipitates which are present in the form of stringers. The grain growth is significant where stringers are absent due to the lack of pinning of grain boundaries. On the other hand, the grains in the vicinity of stringers show little grain growth due strong pinning effect of precipitates on the grain boundaries. Hardness is higher than the minimum ( $145 \mathrm{DPH})$, in the range of $150-155 \mathrm{DPH}$ at $1100^{\circ} \mathrm{C}$ (see Fig. 1).
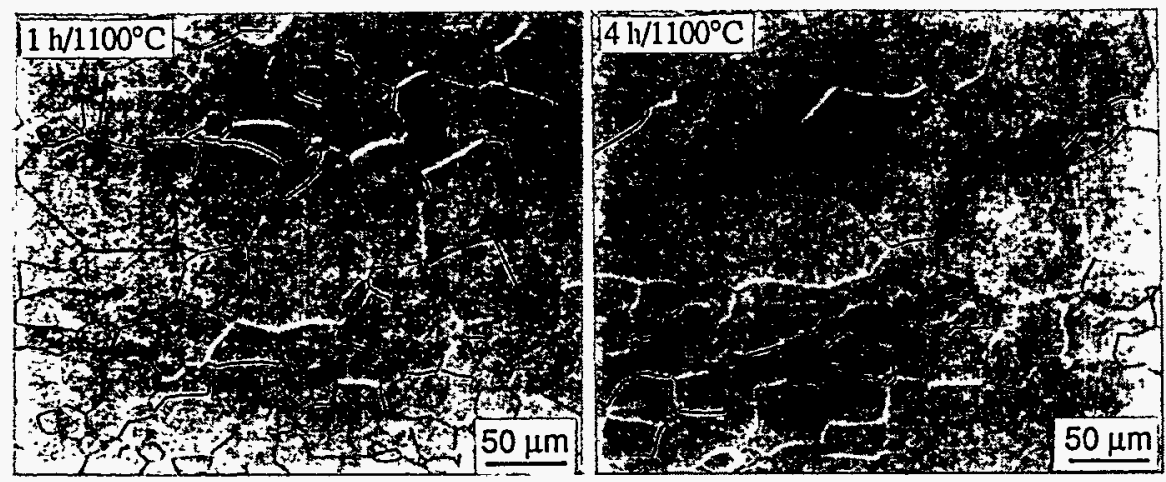

Figure 6. Optical microstructures at $1100^{\circ} \mathrm{C}$ for the large heat of $\mathrm{V}-4 \mathrm{Cr}-4 \mathrm{Ti}$ 
Figure 7 shows the microhardness as a function of annealing time at various temperatures. The data fall into two groups. At $900^{\circ} \mathrm{C}$, softening is primarily due to recovery with little recrystallization; the microhardness value drops from $200 \mathrm{DPH}$ in the cold-rolled state to a range of $165-168 \mathrm{DPH}$. The other group is for temperatures from $950^{\circ}$ to $1100^{\circ} \mathrm{C}$ where recrystallization takes place partially at $950^{\circ} \mathrm{C}$ and completely at $1000^{\circ} \mathrm{C}$. Grain-coarsening and precipitation at the grain boundaries occurs with further increase in temperature $\left(1050-1100^{\circ} \mathrm{C}\right)$. After the 4 hour anneals there is a tendency for final hardness to increase with temperature, possibly related to impurity pick-up from the furnace atmosphere.

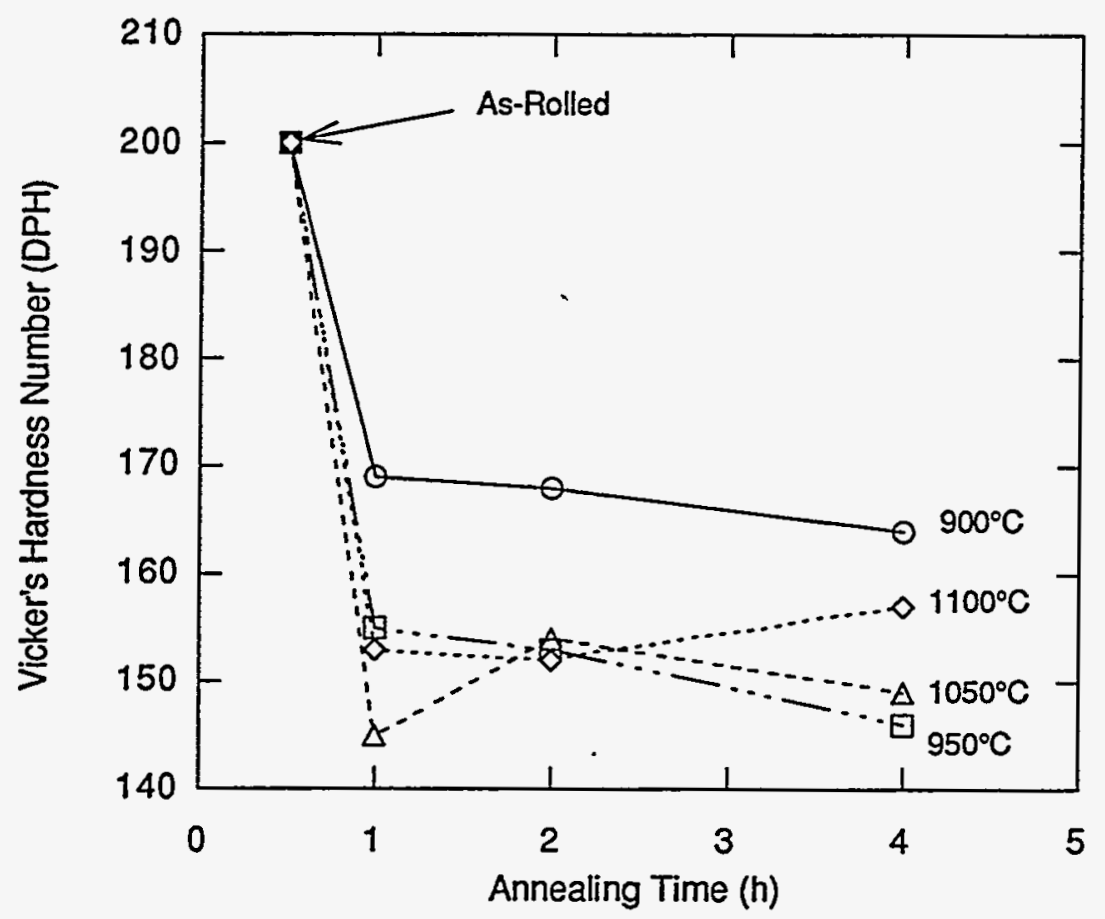

Figure 7. Hardness as a function of Annealing Time for different temperatures for the large heat of $\mathrm{V}-4 \mathrm{Cr}-4 \mathrm{Ti}$

Figure 8 shows the comparison of variation in microhardness with annealing temperature for the large and small heats of $\mathrm{V}-4 \mathrm{Cr}-4 \mathrm{Ti}$. The difference in the kinetics of recrystallization is clearly evident in the two heats. The small heat (T89) which has a higher cold work of $\sim 49 \%$ recrystallizes faster than the large heat (heat 832665 ) with $40 \%$ cold work. Due to the similar compositions, both heats had almost the same maximum and minimum hardness values of 200 and $140 \mathrm{DPH}$, respectively. Microstructural examination revealed that the small heat is $80-90 \%$ recrystallized at $950^{\circ} \mathrm{C}$ after $2 \mathrm{~h}$ as compared to $20-30 \%$ recrystallization in the large heat for the same anneal. The large heat is fully recrystallized at $1000^{\circ} \mathrm{C}$. It was reported by Chung, et al. that the 0.250 in. thick plate of the large heat of $\mathrm{V}-4 \mathrm{Cr}-4 \mathrm{Ti}$ was not fully recrystallized after $1 \mathrm{~h}$ at $1000^{\circ} \mathrm{C} .^{8}$ This thicker sheet was warm-rolled at $400^{\circ} \mathrm{C}$ from the extruded bar in contrast to the thin sheet which was cold-rolled at room temperature. Even though the thicker sheet had a warm work of around $-40 \%$, because of the higher temperature of rolling the dislocation density is probably lower than that of the $.040 \mathrm{in}$. sheet, leading to the slower recrystallization kinetics of the thicker sheet. ${ }^{9}$ 


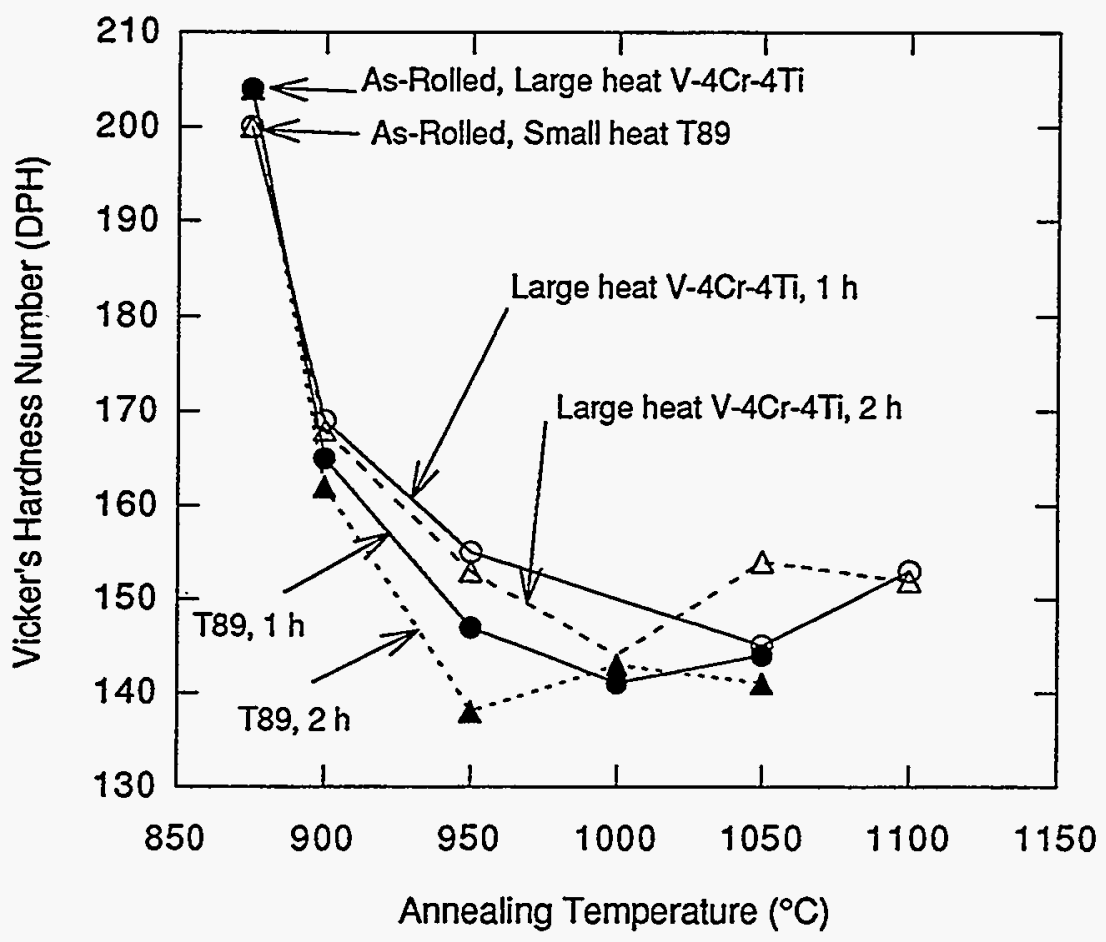

Figure 8. Comparison of variation in Hardness with Annealing Temperature for Large and Small heats of V-4Cr-4Ti

\section{SMALL HEATS OF COMPOSITIONAL VARIANTS}

There are five alloys with varying amounts of $\mathrm{Cr}$ and Ti; Fig. 9 (a) to (e) shows the variation of hardness with temperature for each alloy and these data will be discussed individually as follows.

\section{V-3Cr-3Ti (Heat T91)}

Figure 10 shows the microstructures corresponding to the data in Fig. 9 (a). New grains start nucleating at $900^{\circ} \mathrm{C}$ after $1 \mathrm{~h}$. The hardness drops from $\sim 190$ to $\sim 158 \mathrm{DPH}$, see Fig. 9 (a). After $2 \mathrm{~h}$ at $900^{\circ} \mathrm{C}$, the hardness drops further to $148 \mathrm{DPH}$ with more or less the same amount of nucleated grains. At $950^{\circ} \mathrm{C}$ after $1 \mathrm{~h}$, more new grains nucleate with 20-30\% recrystallization, and the hardness is reduced to $\sim 145 \mathrm{DPH}$. After $2 \mathrm{~h}$ at $950^{\circ} \mathrm{C}$, recrystallization is 70 to $80 \%$ complete, and the hardness is at its minimum of $\sim 125 \mathrm{DPH}$, see Fig. 9 (a). At $1000^{\circ} \mathrm{C}$ for 1 to $2 \mathrm{~h}$, a fully equi-axed grain structure develops, and at $1050^{\circ} \mathrm{C}$, the material is clearly in the grain growth regime.

\section{V-4Cr-4Ti-Si (Heat T89)}

The microstructures resulting from annealing for 1 to $2 \mathrm{~h}$ from $900^{\circ}$ to $1050^{\circ} \mathrm{C}$ are shown in Fig. 11. The nucleation and recrystallization phenomenon is similar to that observed for V-3Cr-3Ti with $\sim 80 \%$ recrystallization occurring after $2 \mathrm{~h}$ at $950^{\circ} \mathrm{C}$. The grain structure becomes more equi-axed at $1000^{\circ} \mathrm{C}$ and grain growth occurs at $1050^{\circ} \mathrm{C}$. The only difference between $\mathrm{V}-3 \mathrm{Cr}-3 \mathrm{Ti}$ and $\mathrm{V}-4 \mathrm{Cr}-4 \mathrm{Ti}-\mathrm{Si}$ is in the hardness values with the latter having consistently higher hardness from the as-rolled condition to the fully recrystallized state. The minimum hardness for $\mathrm{V}-4 \mathrm{Cr}-4 \mathrm{Ti}-\mathrm{Si}$ is $\sim 138 \mathrm{DPH}$, see Fig. 9 (b). 

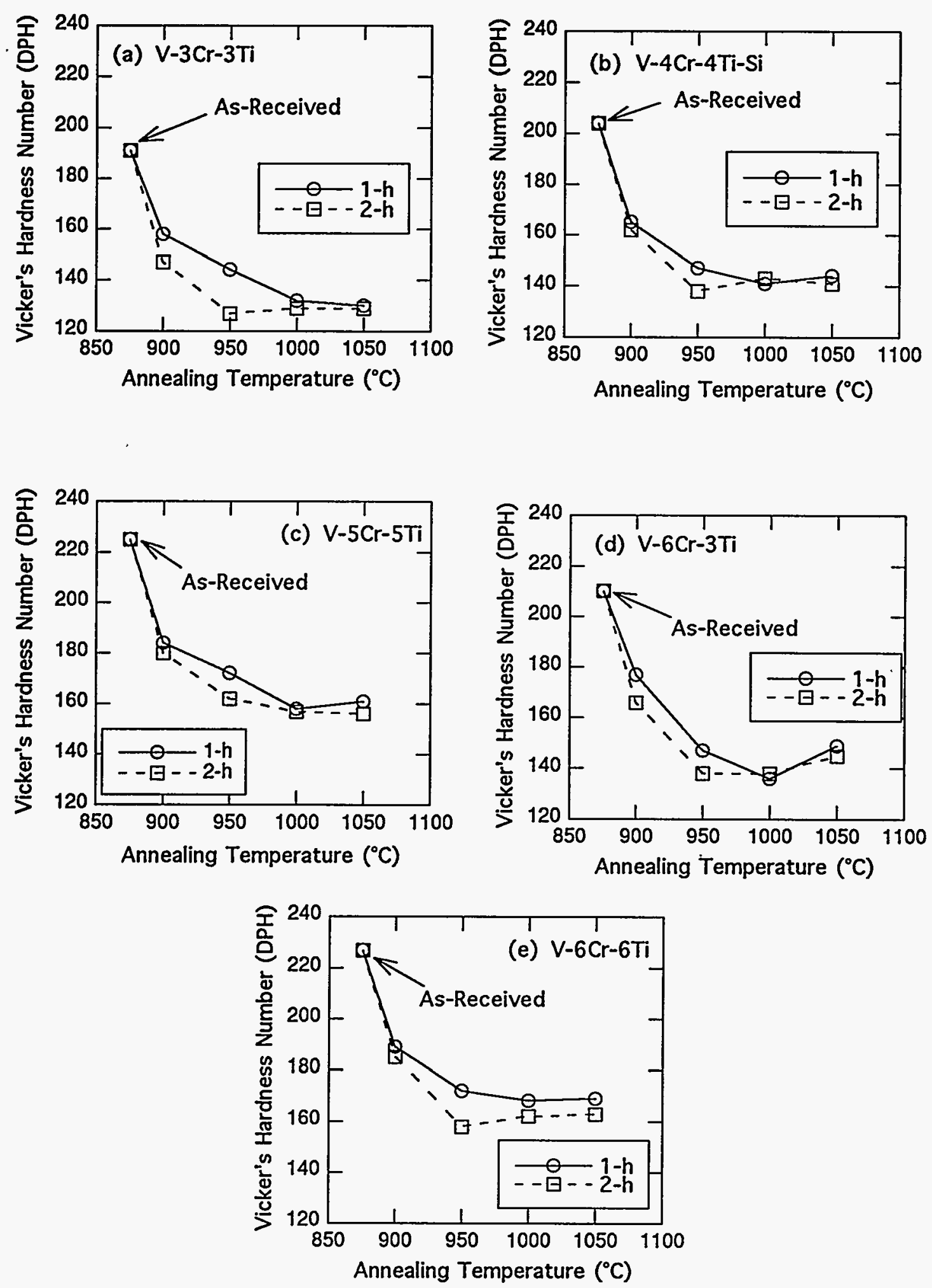

Figure 9. Microhardness as a function of annealing temperature for small heats of compositional variants 

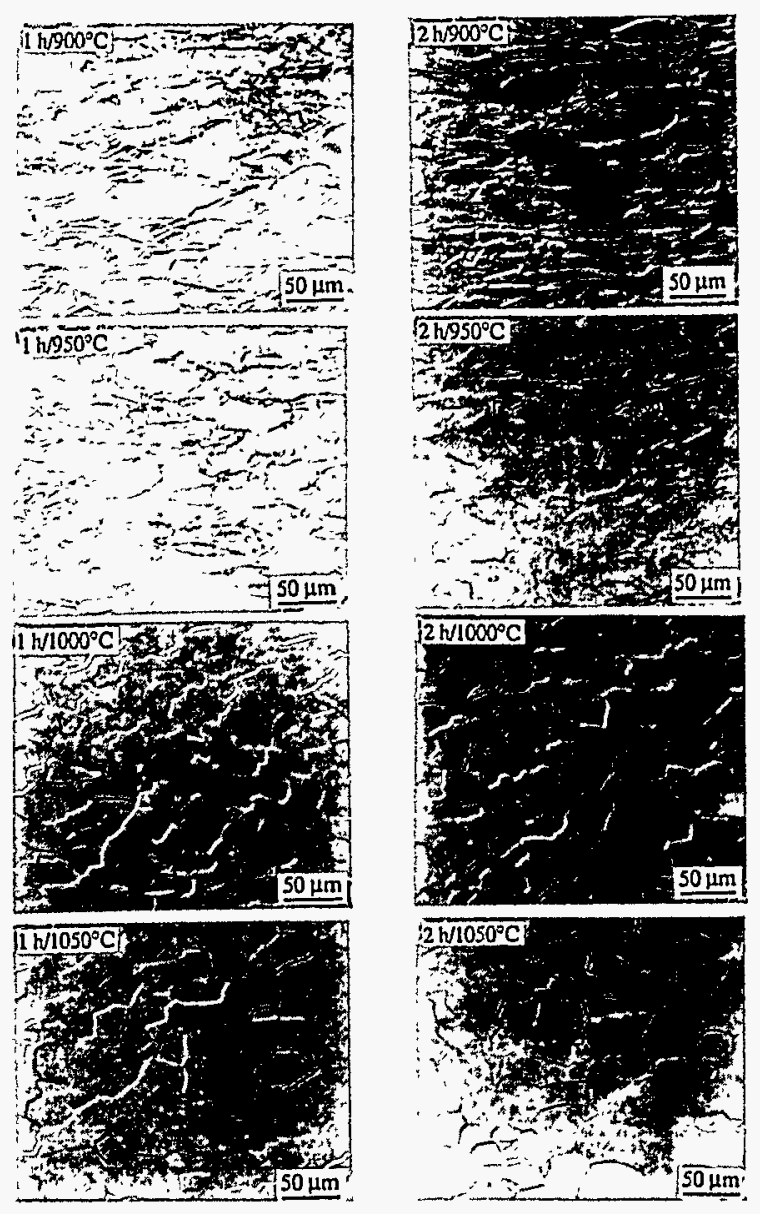

Figure 10. Microstructures of $\mathrm{V}-3 \mathrm{Cr}-3 \mathrm{Ti}$ as a function of annealing temperature and time
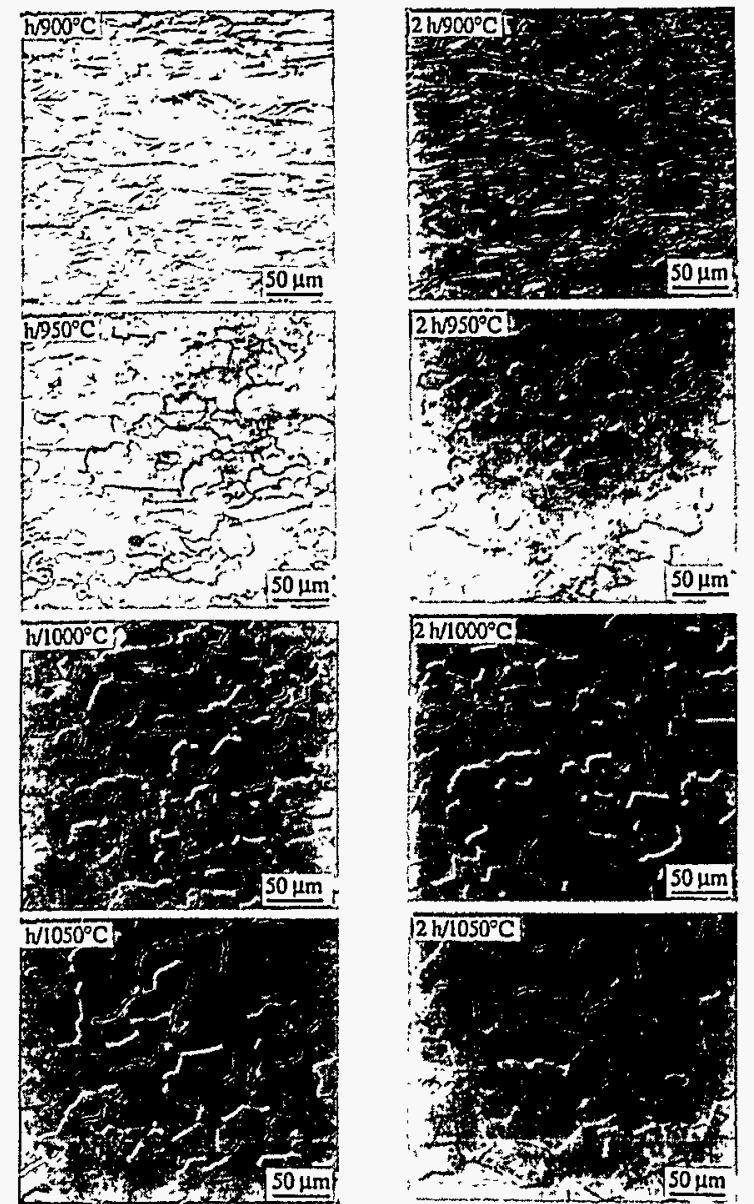

Figure 11. Microstructures of V-4Cr-4Ti-Si as a function of annealing temperature and time 


\section{V-6Cr-3Ti (Heat T92)}

This alloy exhibits microstructural changes (Figure 12) as a function annealing temperature in an identical manner to that shown by the preceding 2 alloys. In this alloy also, the recrystallization is practically complete after $2 \mathrm{~h}$ at $950^{\circ} \mathrm{C}$, with grains becoming more equi-axed after $2 \mathrm{~h}$ at $1000^{\circ} \mathrm{C}$ and at $1050^{\circ} \mathrm{C}$ grain growth occurs. The hardness also changes in a similar fashion with a minimum hardness of around 140 DPH, see Fig. 9 (d).
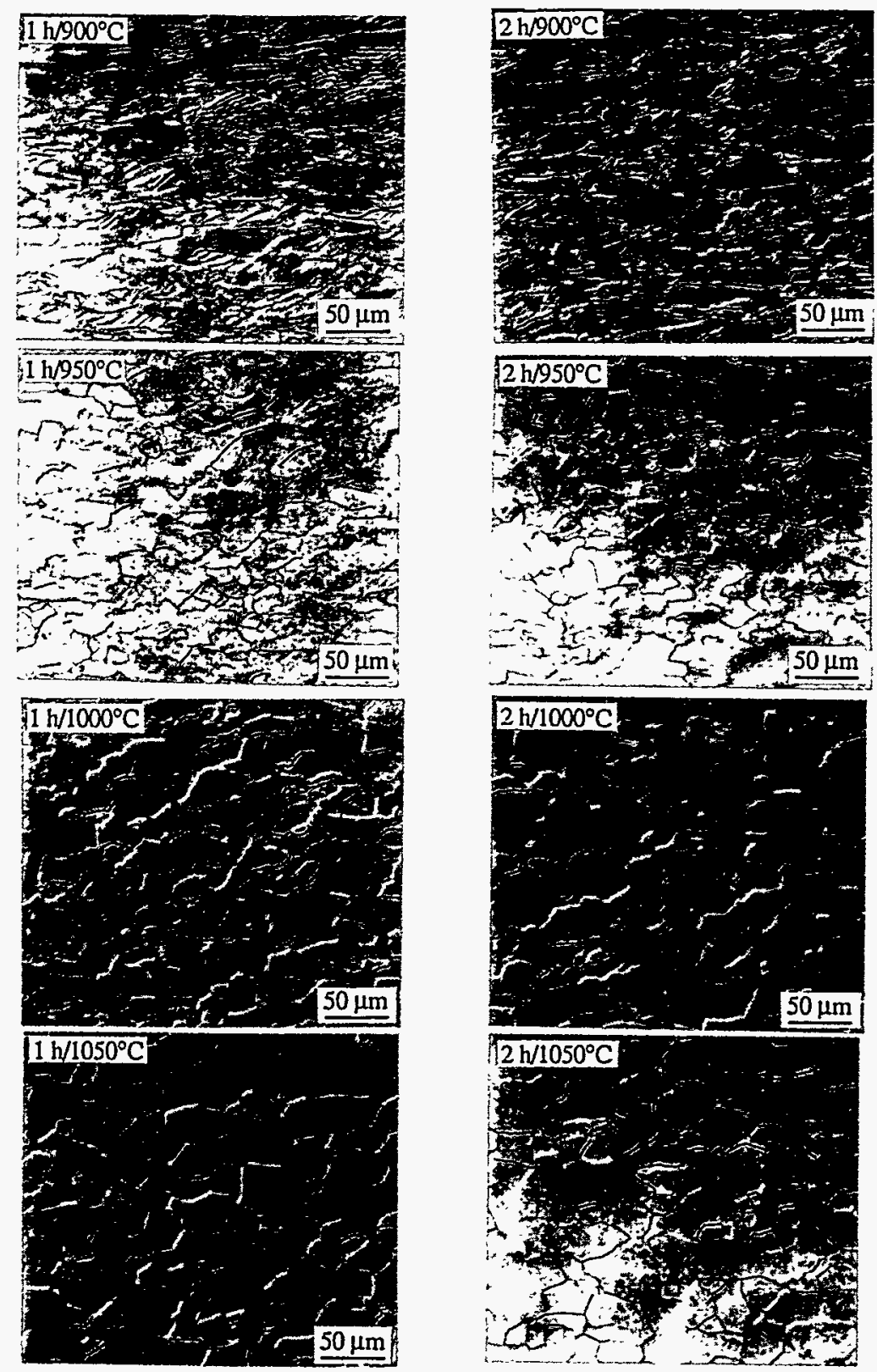

Figure 12. Microstructures of $\mathrm{V}-6 \mathrm{Cr}-3 \mathrm{Ti}$ as a function of annealing temperature and time 


\section{V-6Cr-6Ti (Heat T90)}

The hardness and microstructural changes are again similar to the other alloys. The microstructure shows some new grains nucleating at $900^{\circ} \mathrm{C}$, see Fig. 13. After $1 \mathrm{~h}$ at $950^{\circ} \mathrm{C}$, recrystallization is 20 to $30 \%$ complete, and after $2 \mathrm{~h}$ recrystallization is near completion, with the hardness reaching a minimum of around $160 \mathrm{DPH}$. For temperatures of $1000^{\circ} \mathrm{C}$ and above, grain growth occurs.
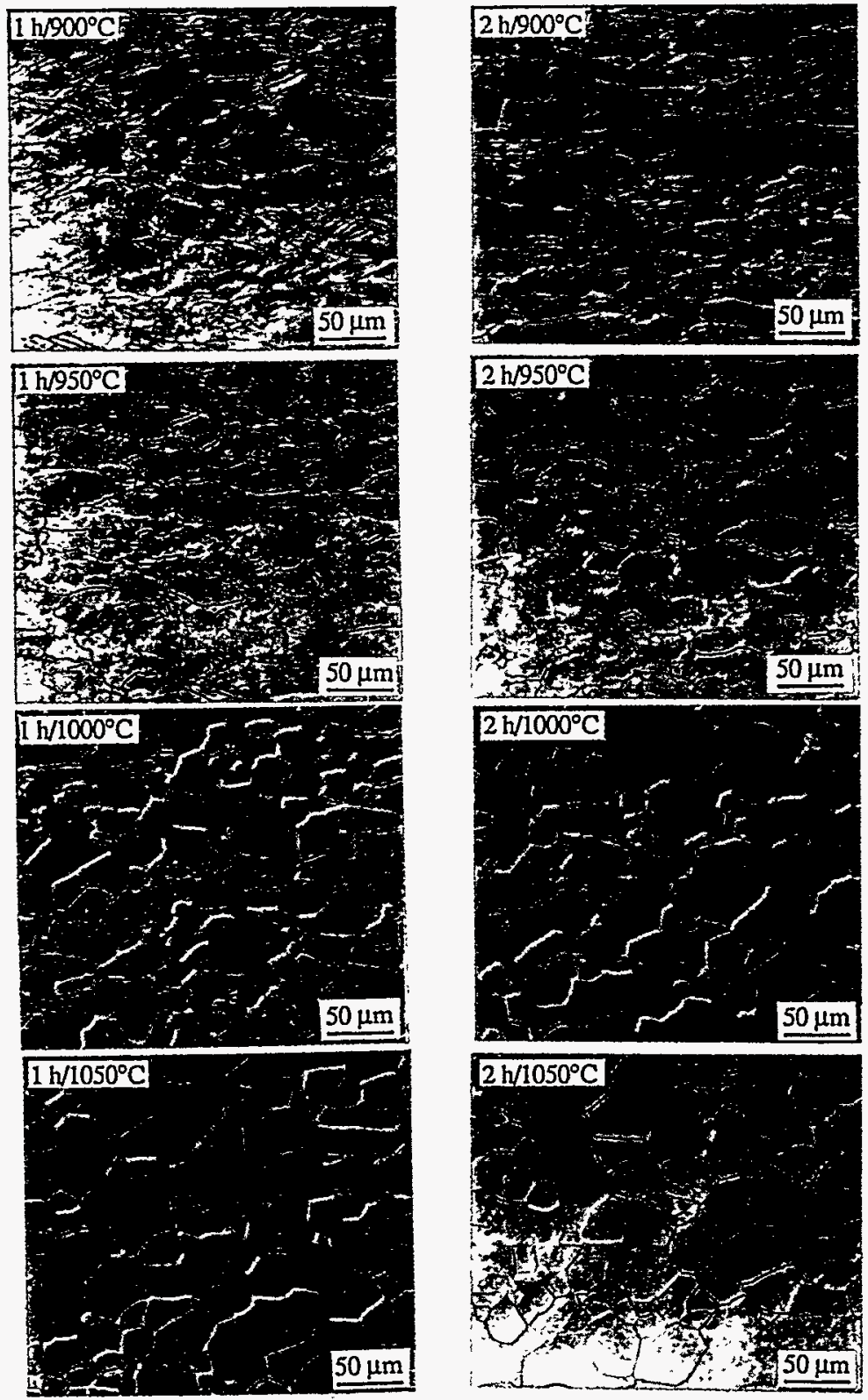

Figure 13. Microstructures of $\mathrm{V}-6 \mathrm{Cr}-6 \mathrm{Ti}$ as a function of annealing temperature and time 


\section{V-5Cr-5Ti (Heat T87)}

Figure 14 shows the microstructural evolution of $\mathrm{V}-5 \mathrm{Cr}-5 \mathrm{Ti}$ with change in annealing temperature and time. The microhardness drops initially from $\sim 225 \mathrm{DPH}$ (as-rolled) to $\sim 180 \mathrm{DPH}$ for $900^{\circ} \mathrm{C}$ anneals for 1 and $2 \mathrm{~h}$, see Fig. 9 (c). In contrast to the other alloys, this is just a recovery process with very little or no recrystallization. New grains start appearing at $950^{\circ} \mathrm{C}$ after $1 \mathrm{~h}$ indicating the onset of recrystallization. After $2 \mathrm{~h}$ at $950^{\circ} \mathrm{C}$, the recrystallization is 30 to $40 \%$ complete. At $1000^{\circ} \mathrm{C}$, the recrystallization is complete and the hardness drops to a minimum of around 158 DPH, see Fig. 9 (c). There is a slight grain growth at $1050^{\circ} \mathrm{C}$. The observed difference in the recrystallization temperature (of $1000^{\circ} \mathrm{C}$ ) of this alloy and that of the other four compositional variants $\left(\right.$ of $\left.950^{\circ} \mathrm{C}\right)$ can be attributed to the difference in the amount of cold work between them. It can be recalled that V-5Cr-5Ti had less cold work $(-40 \%)$ compared to that of the other four compositional variants (V-3Cr-3Ti, V-4Cr-4Ti-Si, V-6Cr-3Ti, and V-6Cr-6Ti have $-49 \%$ cold work). Due to the higher amount of cold work in latter group of alloys, they exhibit faster kinetics of recrystallization as compared to that shown by V-5Cr-5Ti, in accordance with the wellestablished law of recrystallization. 9
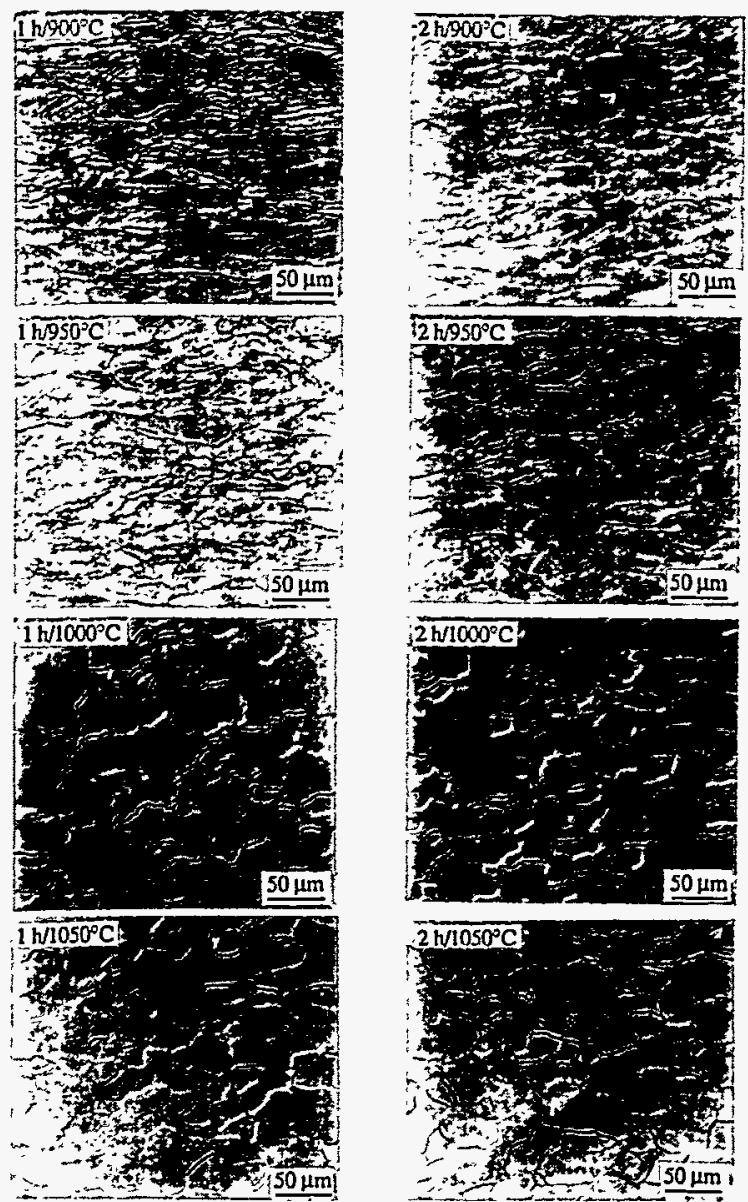

Figure 14. Microstructures of V-5Cr-5Ti as a function of annealing temperature and time

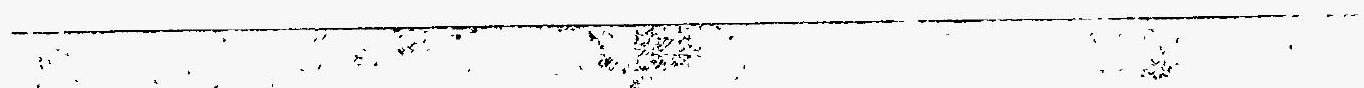




\section{EFFECT OF Cr AND Ti ADDITIONS ON HARDNESS}

Figure 15 shows a plot of microhardness as a function of $(\mathrm{Cr}+\mathrm{Ti})$ content for alloys in a recovered $\left(900^{\circ} \mathrm{C}\right)$ condition and in a fully recrystallized $\left(1050^{\circ} \mathrm{C}\right)$ condition. The increasing dependence of hardness of $\mathrm{V}$ alloys on $\mathrm{Cr}$ and $\mathrm{Ti}$ concentration has been reported by Loomis et al. ${ }^{10}$ and the data reported here follow the same trend. In the present work, however, there does seem to be a significant incremental step in hardness values when the combined $\mathrm{Cr}+\mathrm{Ti}$ concentration exceeds $\sim 9 \mathrm{wt} \%$. This can also be seen in Fig. 9; the 3Cr-3Ti, 4Cr-4Ti, and 6Cr-3Ti alloys have a minimum hardness in the range 130 to $142 \mathrm{DPH}$, whereas minimum hardness for the $5 \mathrm{Cr}-5 \mathrm{Ti}$ and $6 \mathrm{Cr}-6 \mathrm{Ti}$ alloys fall in the range 160 to $165 \mathrm{DPH}$.

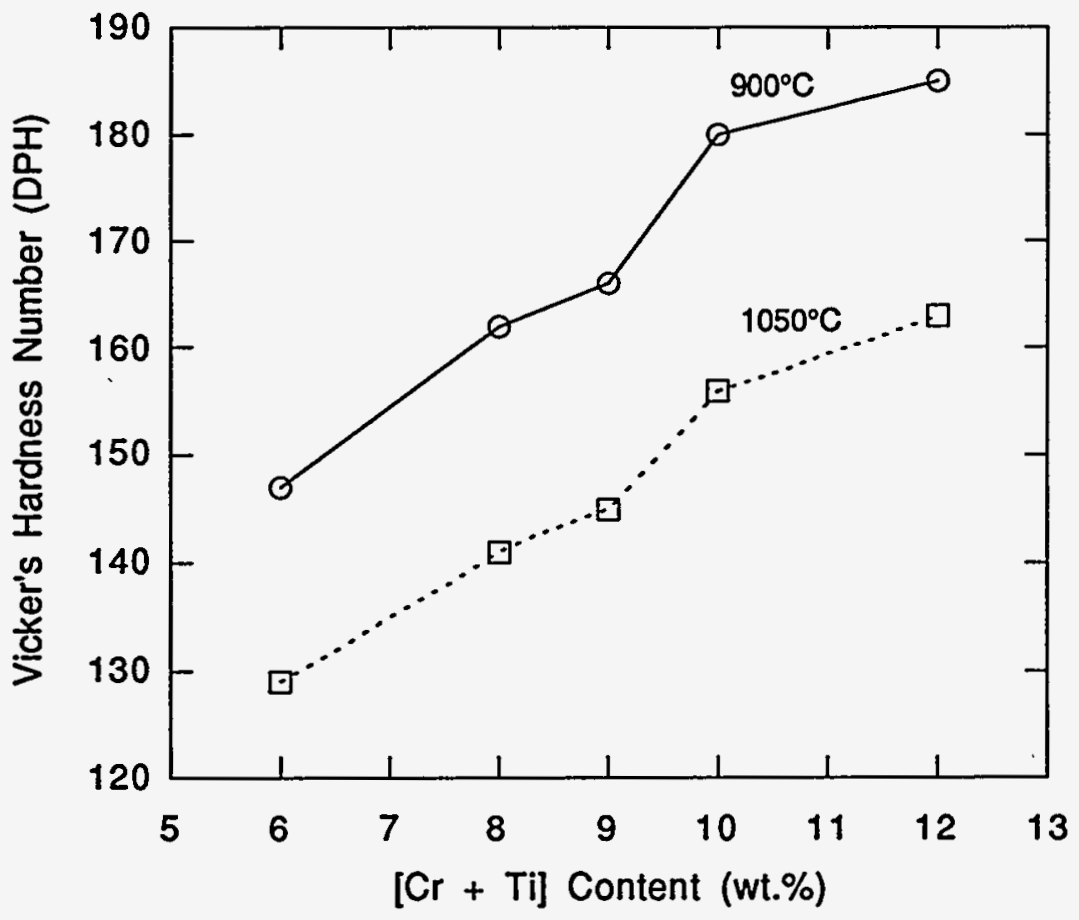

Figure 15. Variation of Hardness with $(\mathrm{Cr}+\mathrm{Ti})$ content (All 2-h anneals)

\section{CONCLUSIONS}

The recovery and recrystallization behavior of the $500 \mathrm{~kg}$ heat of $\mathrm{V}-4 \mathrm{Cr}-4 \mathrm{Ti}$ in the $40 \% \mathrm{CW}$ condition has been studied using hardness and TEM. For 1 hour vacuum heat treatments, recovery and subgrain formation occurs at $900^{\circ} \mathrm{C}$, partial recrystallization at $950^{\circ} \mathrm{C}$, nearly complete recrystallization at $1000^{\circ} \mathrm{C}$, full recrystallization at $1050^{\circ} \mathrm{C}$, and significant grain growth at $1100^{\circ} \mathrm{C}$.

The $15 \mathrm{~kg}$ heat of $\mathrm{V}-4 \mathrm{Cr}-4 \mathrm{Ti}$ exhibits faster recovery and recrystallization kinetics than the large heat because of the higher cold work level of the initial sheet material. 
Variations in $\mathrm{Cr}$ and Ti over the range 3 to $6 \mathrm{wt} \%$ have no discemible effects on recovery and recrystallization kinetics; the hardness of both recovered and recrystallized structures increases with total $(\mathrm{Cr}+\mathrm{Ti})$ content.

\section{WORK IN PROGRESS}

Differential Scanning Calorimetry analysis has been initiated for quantitative determination of activation energy for recrystallization in the large heat of $\mathrm{V}-4 \mathrm{Cr}-4 \mathrm{Ti}$ (heat 832665 ) alloy. TEM analysis is underway for completing microstructural characterization of small heats. Modeling work is being thought of to depict the mechanistics of recrystallization phenomenon.

\section{ACKNOWLEDGMENT}

This research is sponsored by the Office of Fusion Energy, U. S. Department of Energy, under contract DE-AC05-84OR21400 with Martin Marietta Energy Systems, Inc. We are grateful to

Dr. M. L. Grossbeck for providing the chemical compositions of the alloys studied in this work.

\section{REFERENCES}

(1) B. A. Loomis and D. L. Smith, J. Nucl. Matls., 179-181 (1991), pp 783-786.

(2) B. A. Loomis, D. L. Smith, and F. A Gamer, J. Nucl. Matls., 179-181 (1991), pp 771-776.

(3) H. M. Chung and D. L. Smith, J. Nucl. Matls., 191-194 (1992), pp 942-947.

(4) B. A. Loomis, L. J. Nowicki, J. Gazda, and D. L. Smith, Fusion Reactor Materials Semiannual Progress Report, DOE/ER-0313/14, March 31, 1993, pp 318-325.

(5) B. A. Loomis, H. M. Chung, L. J. Nowicki, and D. L. Smith, J. Nucl. Matls., 212-215 (1994), pp 799-803.

(6) H. M. Chung, H.-C. Tsai, D. L. Smith, R. Peterson, C. Curtis, C. Wojcik, and R. Kinney, Fusion Reactor Materials Semiannual Progress Report, DOE/ER-0313/17, September 30, 1994.

(7) J. Gazda, B. A. Loomis, L. J. Nowicki, D. L. Smith, and S. Danyluk, Fusion Reactor Materials Semiannual Progress Report, DOE/ER-0313/15, September 30, 1993, pp 232-239.

(8) H. M. Chung, L. J. Nowicki, J. Gazda, and D. L. Smith, Fusion Reactor Materials Semiannual Progress Report, DOE/ER-0313/17, September 30, 1994.

(9) R. W. Cahn, Physical Metallurgy, Elsevier Science Publishers, 1983, pp 1595-1671.

(10) B. A. Loomis, J. Gazda, L. J. Nowicki, and D. L. Smith, Fusion Reactor Materials Semiannual Progress Report, DOE/ER-0313/13, September 30, 1992, pp 217-221. 


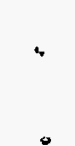


IMPACT TESTING AND FRACTURE BEHAVIOR OF VANADIUM ALLOYS A. N. Gubbi, A. F. Rowcliffe, D. J. Alexander, M. L. Grossbeck, and W. S. Eatherly (Oak Ridge National Laboratory)

\section{OBJECTIVE}

The purpose of this research is to evaluate the impact properties and fracture behavior of the large heat of V-4Cr-4Ti (heat 832665) and small heats of compositional variants with $\mathrm{Cr}$ and Ti contents ranging from 3 to $6 \mathrm{wt} . \%$.

\section{SUMMARY}

Charpy impact testing was completed on vanadium alloys with $\mathrm{Cr}$ and Ti contents ranging from 3 to 6 wt.\%. A large heat ( $\sim 500-\mathrm{kg}$ melt) of $\mathrm{V}-4 \mathrm{Cr}-4 \mathrm{Ti}$ (heat 832665$)$ and small heats $(\sim 15-\mathrm{kg}$ melt each) of compositional variants, V-3Cr-3Ti, V-4Cr-4Ti-Si, V-5Cr-5Ti, V-6Cr-3Ti, and V-6Cr-6Ti, were examined in this work. One-third-size Charpy impact specimens, machined from 3.81-mm-thick plates of these vanadium alloys, were used for impact testing. In a fully recrystallized condition with a grain size of $\sim 16 \mu \mathrm{m}$, the large heat of $\mathrm{V}-4 \mathrm{Cr}-4 \mathrm{Ti}$ exhibited a high level of resistance to cleavage failure with a DBTT at $\sim-190^{\circ} \mathrm{C}$. The small $(15 \mathrm{~kg})$ heat of $\mathrm{V}-4 \mathrm{Cr}-4 \mathrm{Ti}$ heat treated to produce the same microstructural condition exhibited similar Charpy impact properties. The small heats containing higher concentrations of $\mathrm{Cr}$ and $\mathrm{Ti}$, in a fully recrystallized condition exhibited a DBTT at around $-100^{\circ} \mathrm{C}$, whereas the V-3Cr-3Ti alloy failed by pure ductile shear at liquid nitrogen temperatures.

\section{INTRODUCTION}

In the early stages of the program on the development of alloys for fusion reactor applications, vanadium alloys with 3 to $6 \mathrm{wt} . \% \mathrm{Cr}$ and Ti were investigated. ${ }^{1-4}$ This composition range was subsequently narrowed down to vanadium alloys with $4 \mathrm{wt}$.\% each of $\mathrm{Cr}$ and Ti based on the thermal creep properties, low DBTT under Charpy impact testing, resistance to swelling, and also resistance to helium-and irradiation-induced embrittlement exhibited by a laboratory-scale heat of this alloy. 5 A production-scale heat $(-500-\mathrm{kg}$, heat 832665$)$ of $\mathrm{V}-4 \mathrm{Cr}-4 \mathrm{Ti}$ alloy has been fabricated by Teledyne Wah Chang, Albany, Oregon (TWCA) recently. Initial impact data have been reported from the testing conducted on the samples machined from a warm-worked plate. ${ }^{6}$ The present work reports the Charpy impact testing on the samples machined from $3.81 \mathrm{~mm}$ thick plate supplied by TWCA in an annealed condition. Impact behavior of the small heats of compositional variants has also been evaluated and presented here. These alloys will give the window for permissible ranges of $\mathrm{Cr}$ and $\mathrm{Ti}$ concentrations for consistent properties.

\section{EXPERIMENTAL PROCEDURE}

The chemical compositions of the large heat of $\mathrm{V}-4 \mathrm{Cr}-4 \mathrm{Ti}$ and the small heats of compositional variants have been presented in the companion article in this document. ${ }^{7}$ One-third-size blunt-notch Charpy specimens ( $3.33 \times 3.33 \times 25.4 \mathrm{~mm}$ ), with a notch that was $0.51 \mathrm{~mm}$ deep, with a root radius of $0.08 \mathrm{~mm}$ and an included angle of $30^{\circ}$, were obtained by electrodischarge machining from 3.81-mm-thick plates. All the specimens were oriented such that the crack could propagate parallel to the rolling direction. The 3.81mm-thick plate of $\mathrm{V}-4 \mathrm{Cr}-4 \mathrm{Ti}$ (heat 832665) was annealed by the manufacturer at $1050^{\circ} \mathrm{C}$ for 2 hours. Following machining, the Charpy specimens were annealed for 2 hours at either $950^{\circ} \mathrm{C}, 1000^{\circ} \mathrm{C}$, or $1050 . \mathrm{C}$ in a vacuum better than $1 \times 10^{-6}$ torr. These annealing treatments removed any residual deformation induced by cutting and machining operations. In addition, during the recovery/recrystallization studies reported in a companion article, ${ }^{7}$ it was observed that as the final annealing temperature is increased over this range, there is an increasing tendency for a fine precipitate dispersion to develop at grain boundaries.

The compositional variants were supplied in the form of 3.81 -mm-thick plate in a $40 \%$ warm-rolled $\left(400^{\circ} \mathrm{C}\right)$ condition. The machined Charpy samples were annealed at temperatures from $950^{\circ}$ to $1050^{\circ} \mathrm{C}$ for $2 \mathrm{~h}$ in a vacuum better than $1 \times 10^{-6}$ torr $\left(<10^{-4} \mathrm{~Pa}\right)$. Impact testing was carried out in a semiautomated 
pendulum-type impact testing system modified for subsize specimens. ${ }^{8}$ Test temperatures employed were from $-196^{\circ}$ to $100^{\circ} \mathrm{C}$ with low temperatures being achieved by using liquid nitrogen. The results from the testing were fitted with a hyperbolic tangent function for determining the DBTT and upper-shelf energy. The lower-shelf energy was fixed at $0.2 \mathrm{~J}$. The midpoint between the upper- and lower-shelf energy levels was considered as the DBTT.

Fractography was done using a scanning electron microscope on the fracture surfaces obtained after the impact testing. Metallography and TEM analysis for microstructural characterization were carried out on the samples cut from the undeformed sections of the impact specimens. The grain size was measured in a plane parallel to the rolling direction using the method of lineal intercepts.

\section{RESULTS AND DISCUSSIONS}

\section{LARGE HEAT OF V-4Cr-4Ti (Heat 832665)}

Figure 1 shows the typical optical microstructures of as received (annealed at $1050^{\circ} \mathrm{C}$ for $2 \mathrm{~h}$ at TWCA), and after 2-h anneals at $950^{\circ}, 1000^{\circ}$, and $1050^{\circ} \mathrm{C}$. Since the Charpy specimens were obtained from the preannealed (at TWCA) sheet, they were already recrystallized in the as-machined state. The fully recrystallized structure from the pre-anneal was quite stable for temperatures from $950^{\circ}$ to $1050^{\circ} \mathrm{C}$ with no appreciable grain growth. The measured grain size for the three annealing conditions was identical at $\sim 16 \pm 4 \mu \mathrm{m}$.
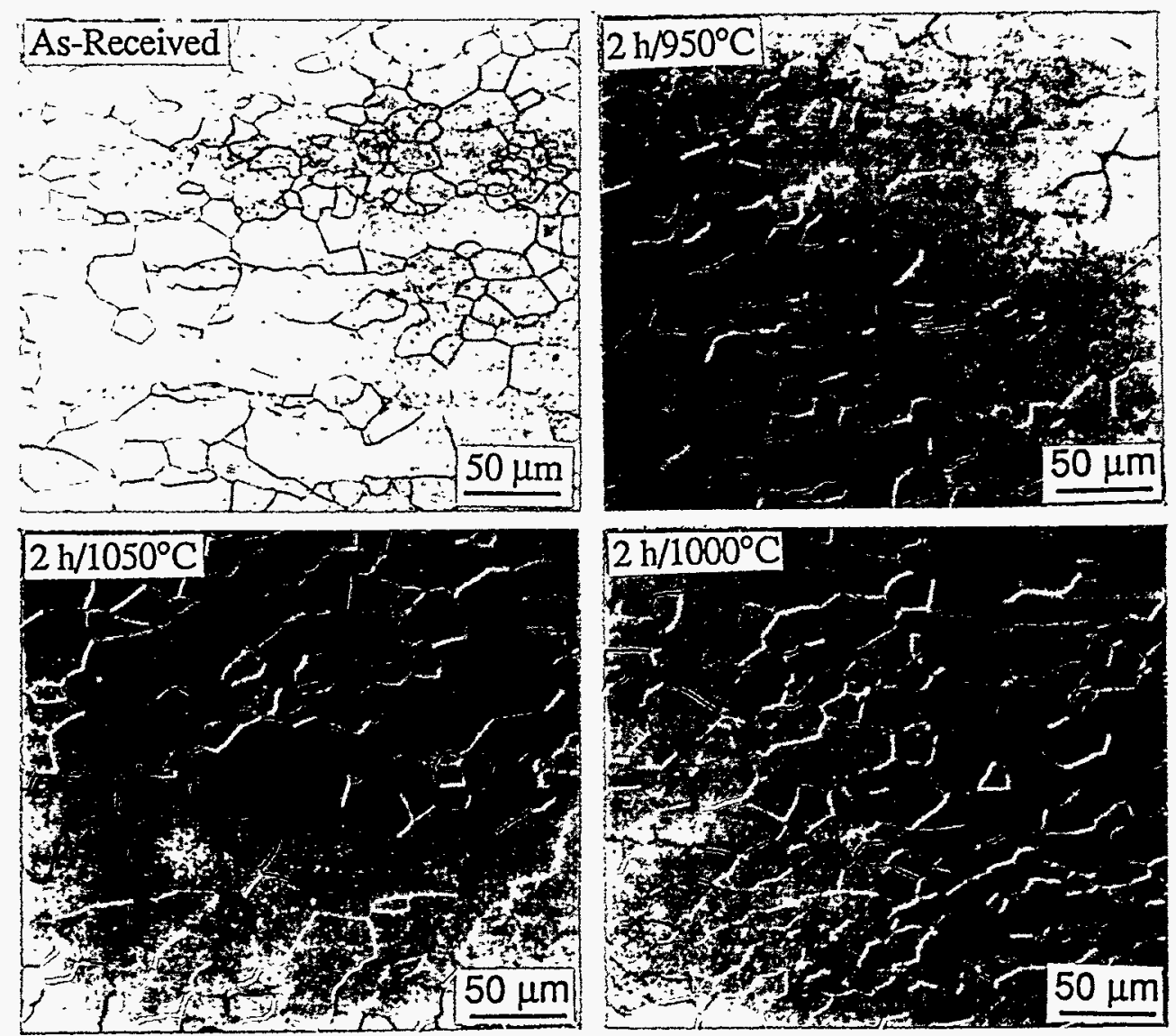

Figure 1. Typical microstructures of the large heat $\mathrm{V}-4 \mathrm{Cr}-4 \mathrm{Ti}$ as received, and after 2-h anneal from $950^{\circ}$ to $1050^{\circ} \mathrm{C}$. 
The data obtained from Charpy impact testing are shown in Fig. 2 with absorbed impact energy plotted as a function of test temperature. There was no significant difference between the impact behavior of the three heat treated conditions indicating that the presence of varying amounts of the finely dispersed grain boundary phase has no effect on impact behavior. In Fig. 2 , the data from the three anneals are fitted to a single curve. Thus, in a fully recrystallized condition a DBTT occurs at around $-190^{\circ} \mathrm{C}$.

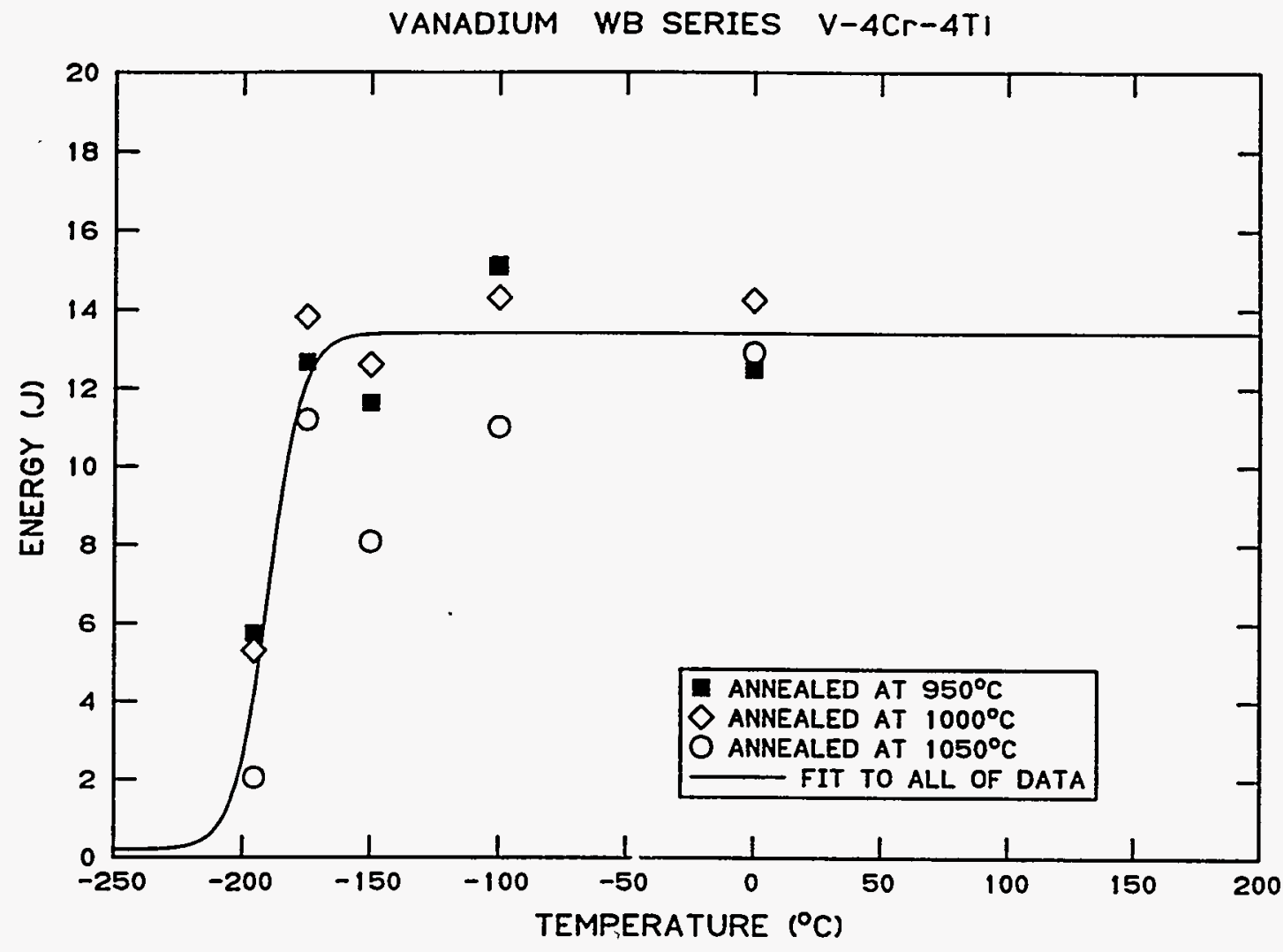

Figure 2. Third-size Charpy impact data for the large heat V-4Cr-4Ti (Heat 832665).

Figure 3 shows the typical fracture surfaces of the large heat of $\mathrm{V}-4 \mathrm{Cr}-4 \mathrm{Ti}$ at various test temperatures. As there was not much difference in the absorbed energy or grain size among the samples after 2-h anneals at $950^{\circ}, 1000^{\circ}$, and $1050^{\circ} \mathrm{C}$, only one set of fracture surfaces of samples annealed at $1050^{\circ} \mathrm{C}$ has been presented as representative of the three anneals. At a test temperature of $0^{\circ} \mathrm{C}$, the fracture mode is purely ductile shear and the sample did not open up much but was bent under impact which resulted in a higher absorbed energy. With a decrease in temperature to $-100^{\circ} \mathrm{C}$, the fracture mode still remains as pure ductile shear. With further decrease in temperature $\left(t 0-150^{\circ} \mathrm{C}\right)$, the fracture mode changes to mixed transgranular (TG) cleavage and microvoid coalescence with a drop in absorbed energy (from around $11 \mathrm{~J}$ to $8 \mathrm{~J}$ ). At liquid nitrogen temperature $\left(-196^{\circ} \mathrm{C}\right)$, the sample fails in a predominantly brittle TG cleavage mode with some secondary intergranular (IG) cracks which results in a dramatic drop in the absorbed energy to $\sim 2 \mathrm{~J}$. It is important to note here that there is no noticeable amount of IG failure in the transition or in the lowershelf energy regions. This is in contrast to the results from impact testing of $\mathrm{V}-5 \mathrm{Cr}-5 \mathrm{Ti}$ (heat BL 63) which exhibited a predominant IG fracture in the transition region with TG fracture dominating the lower shelf energy region. 8 

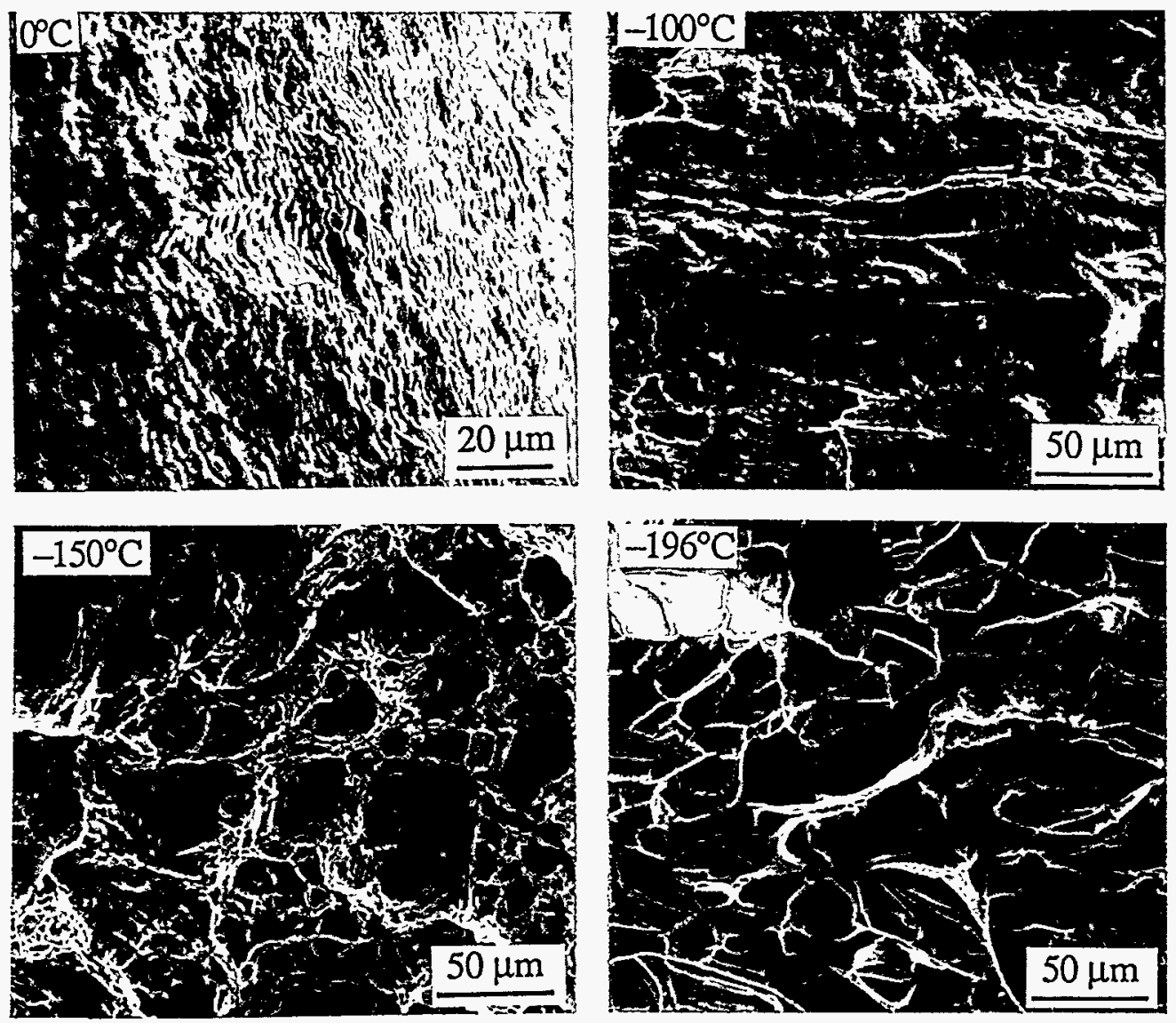

Figure 3. Typical fracture surfaces of the large heat $\mathrm{V}-4 \mathrm{Cr}-4 \mathrm{Ti}$ at different test temperatures. All samples are annealed at $1050^{\circ} \mathrm{C}$ for $2 \mathrm{~h}$.

\section{SMALL HEATS OF COMPOSITIONAL VARIANTS}

Of the five compositional variants with various $\mathrm{Cr}$ and Ti contents, only Charpy specimens of $\mathrm{V}-6 \mathrm{Cr}-3 \mathrm{Ti}$ (heat T92) were annealed from $950^{\circ}$ to $1050^{\circ} \mathrm{C}$ for $2 \mathrm{~h}$ to obtain different microstructures. The other four alloys, V-3Cr-3Ti (heat T91), V-4Cr-4Ti-Si (heat T89), V-5Cr-5Ti (heat T87), and V-6Cr-6Ti (heat T90), were annealed at $1000^{\circ} \mathrm{C}$ for $2 \mathrm{~h}$ to obtain a recrystallized structure in order to study their impact behavior.

Figure 4 shows the optical and TEM microstructures of V-6Cr-3Ti after annealing from $950^{\circ}$ to $1050^{\circ} \mathrm{C}$ for $2 \mathrm{~h}$. At $950^{\circ} \mathrm{C}$, the microstructure consists of well-developed subgrains together with a small volume fraction $(<10 \%)$ of new recrystallized grains. At $1000^{\circ} \mathrm{C}$, recrystallization is $70-80 \%$ complete with isolated regions containing subgrains. Annealing at $1050^{\circ} \mathrm{C}$ produced complete recrystallization.

The results from the impact testing of Charpy specimens of $\mathrm{V}-6 \mathrm{Cr}-3 \mathrm{Ti}$ which were annealed from $950^{\circ}$ to $1050^{\circ} \mathrm{C}$ for $2 \mathrm{~h}$ is depicted in Fig. 5 . All the three microstructures produced by these anneals showed a typical ductile-to-brittle transition behavior with decrease in impact test temperature. The DBTT ranged from around $-175^{\circ} \mathrm{C}$ for the $950^{\circ} \mathrm{C}$ microstructure to around $-75^{\circ} \mathrm{C}$ for the fully recrystallized structure produced by the $2 \mathrm{~h}$ anneal at $1050^{\circ} \mathrm{C}$. The DBTT of the microstructure with $70-80 \%$ recrystallization (after 2-h anneal at $1000^{\circ} \mathrm{C}$ ) falls in-between at $-125^{\circ} \mathrm{C}$. This indicates that the final microstructure has a significant influence on the impact behavior which was also shown in an earlier study by Grossbeck et $\mathrm{al}^{8}$ on the V-5Cr-5Ti alloy (heat BL 63). 

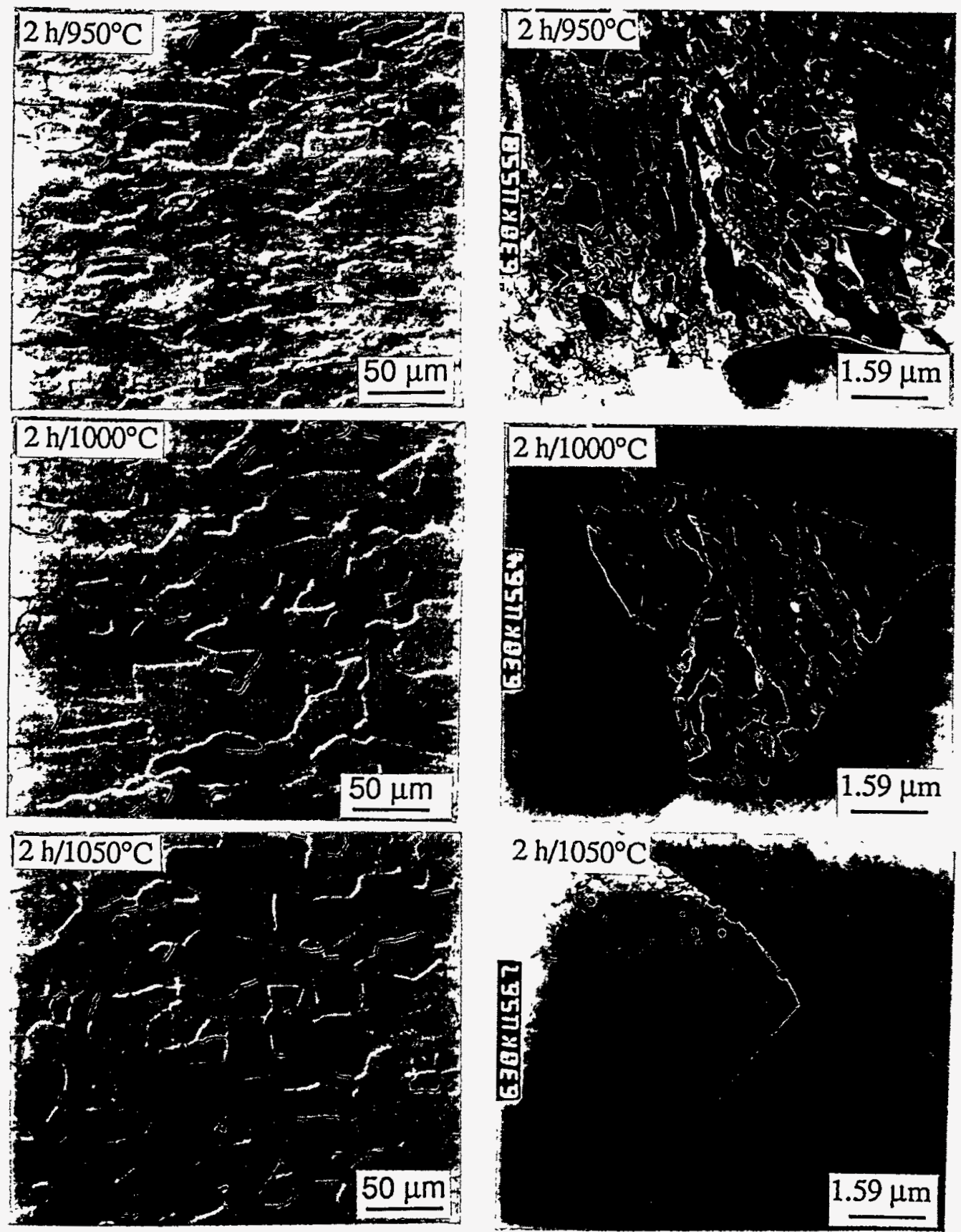

Figure 4. Typical optical and TEM microstructures of $\mathrm{V}-6 \mathrm{Cr}-3 \mathrm{Ti}$ after anneals from $950^{\circ}$ to $1050^{\circ} \mathrm{C}$ for $2 \mathrm{~h}$. 


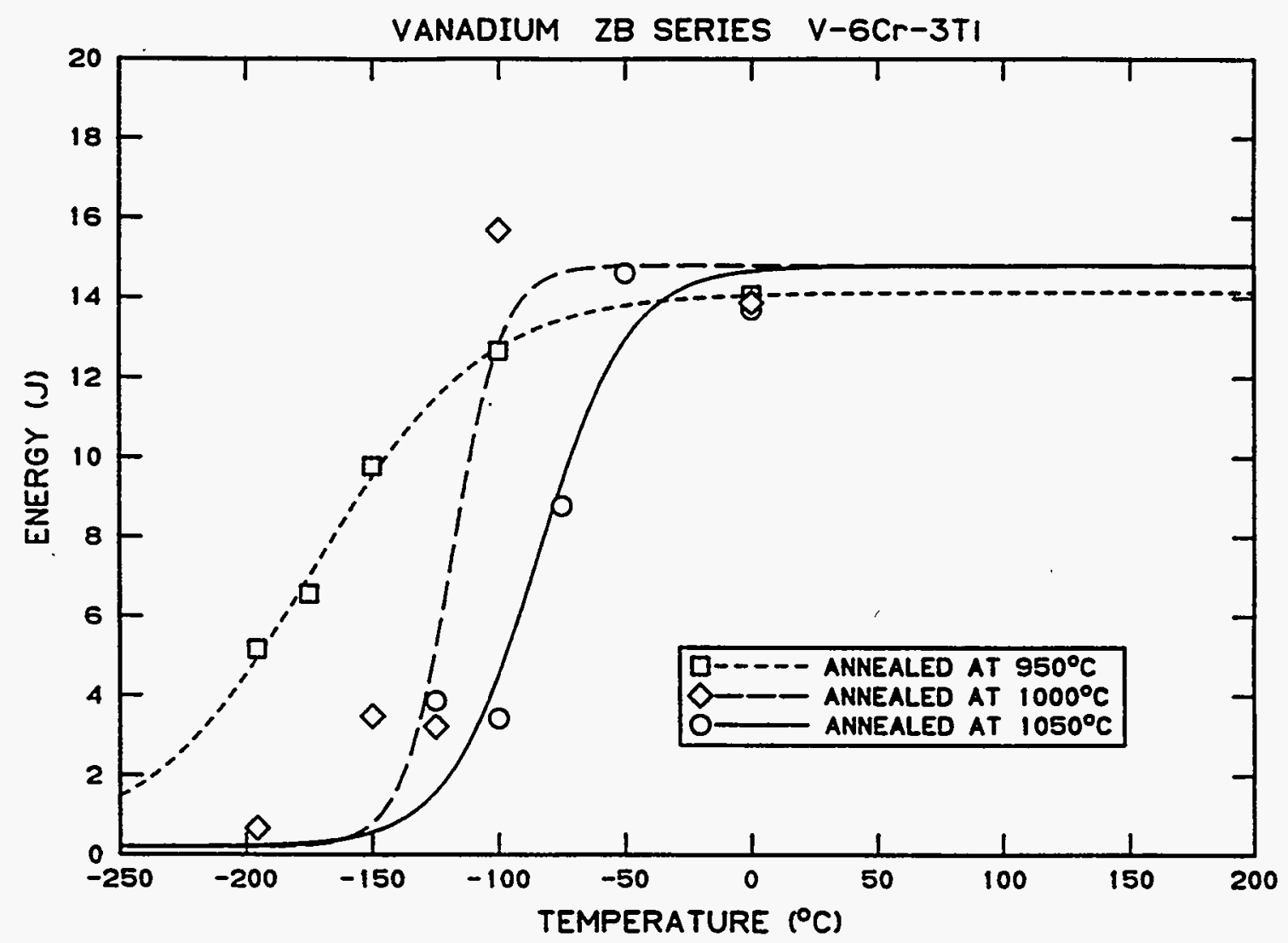

Figure 5. Third-size Charpy impact data for the small heat of V-6Cr-3Ti.

The typical fracture surfaces of the specimens after impact testing are shown in Fig. 6. At higher test temperatures where the absorbed impact energy is high, the fracture mode is a pure ductile shear irrespective of the annealing treatment. The samples which were annealed at $950^{\circ} \mathrm{C}$ (with high dislocation density and minor recrystallization) showed a mixture of ductile rupture and microvoid coalescence with some TG cleavage at lower temperatures $\left(\leq-175^{\circ} \mathrm{C}\right)$, and in the transition range the fracture mode was a mixture of TG cleavage and microvoid coalescence. The samples which were annealed at $1000^{\circ} \mathrm{C}$ (resulting in a mostly recrystallized microstructure) and $1050^{\circ} \mathrm{C}$ (resulting in a fully recrystallized microstructure) exhibited almost identical modes of failure at high and low test temperatures. At high temperatures, these samples failed in a pure ductile shear whereas at low temperatures, they fractured in a predominantly TG cleavage. In the transition region, the samples annealed at $1050^{\circ} \mathrm{C}$ showed some shear and microvoid coalescence with mostly TG cleavage.

Figure 7 shows the optical microstructures of the four compositional variants, $\mathrm{V}-3 \mathrm{Cr}-3 \mathrm{Ti}, \mathrm{V}-4 \mathrm{Cr}-4 \mathrm{Ti}-\mathrm{Si}$, $\mathrm{V}-5 \mathrm{Cr}-5 \mathrm{Ti}$, and $\mathrm{V}-6 \mathrm{Cr}-6 \mathrm{Ti}$, after $2-\mathrm{h}$ anneal at $1000^{\circ} \mathrm{C}$. All the four alloys are almost fully recrystallized at this temperature. The third-size Charpy samples from these alloys, after annealing at $1000^{\circ} \mathrm{C}$ for $2 \mathrm{~h}$, were tested under impact conditions. The results from the Charpy impact testing are plotted in Fig. 8 with absorbed energy as a function of test temperature. Also included in Fig. 8 are the data for V-6Cr-3Ti, the samples of which were annealed similarly $\left(2 \mathrm{~h}\right.$ at $\left.1000^{\circ} \mathrm{C}\right)$ for comparison. The impact results shown in Fig. 8 can be placed into two groups: one group containing alloys with lower $(\mathrm{Cr}+\mathrm{Ti})$ contents, i.e. $\mathrm{V}$ $3 \mathrm{Cr}-3 \mathrm{Ti}$ and $\mathrm{V}-4 \mathrm{Cr}-4 \mathrm{Ti}-\mathrm{Si}$, and the other group having alloys with higher $(\mathrm{Cr}+\mathrm{Ti})$ contents, i.e. $\mathrm{V}-5 \mathrm{Cr}$ $5 \mathrm{Ti}, \mathrm{V}-6 \mathrm{Cr}-3 \mathrm{Ti}$, and $\mathrm{V}-6 \mathrm{Cr}-6 \mathrm{Ti}$. The lower $(\mathrm{Cr}+\mathrm{Ti})$-containing alloys exhibit excellent impact behavior with V-4Cr-4Ti-Si showing DBTT of around $-175^{\circ} \mathrm{C}$. The V-3Cr-3Ti alloy did not show any ductile-tobrittle transition and remained quite ductile even at $-196^{\circ} \mathrm{C}$ with shelf energy around $12 \mathrm{~J}$. The higher 

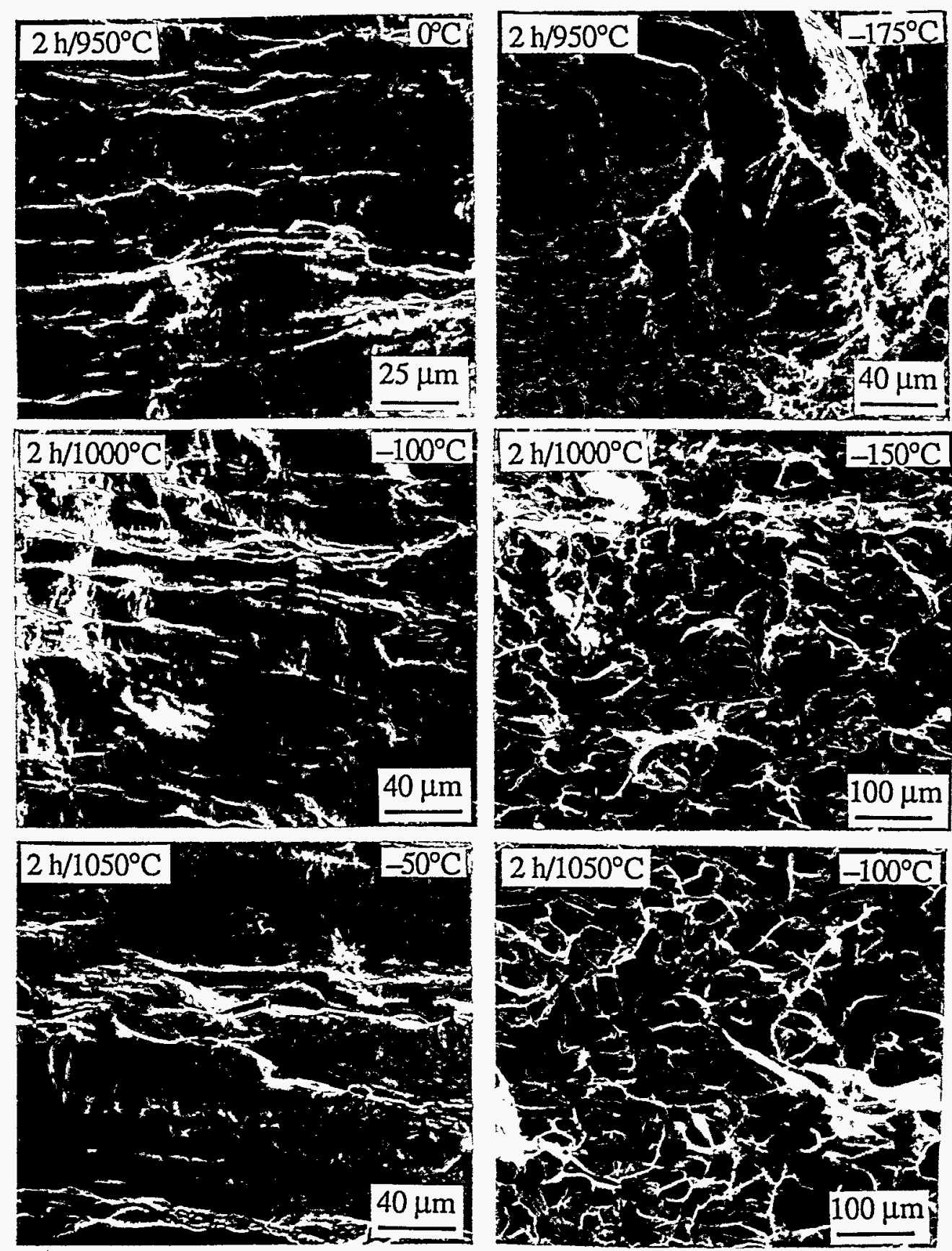

Figure 6. Typical fracture surfaces of the small heat of V-6Cr-3Ti at different test temperatures and anneals. 

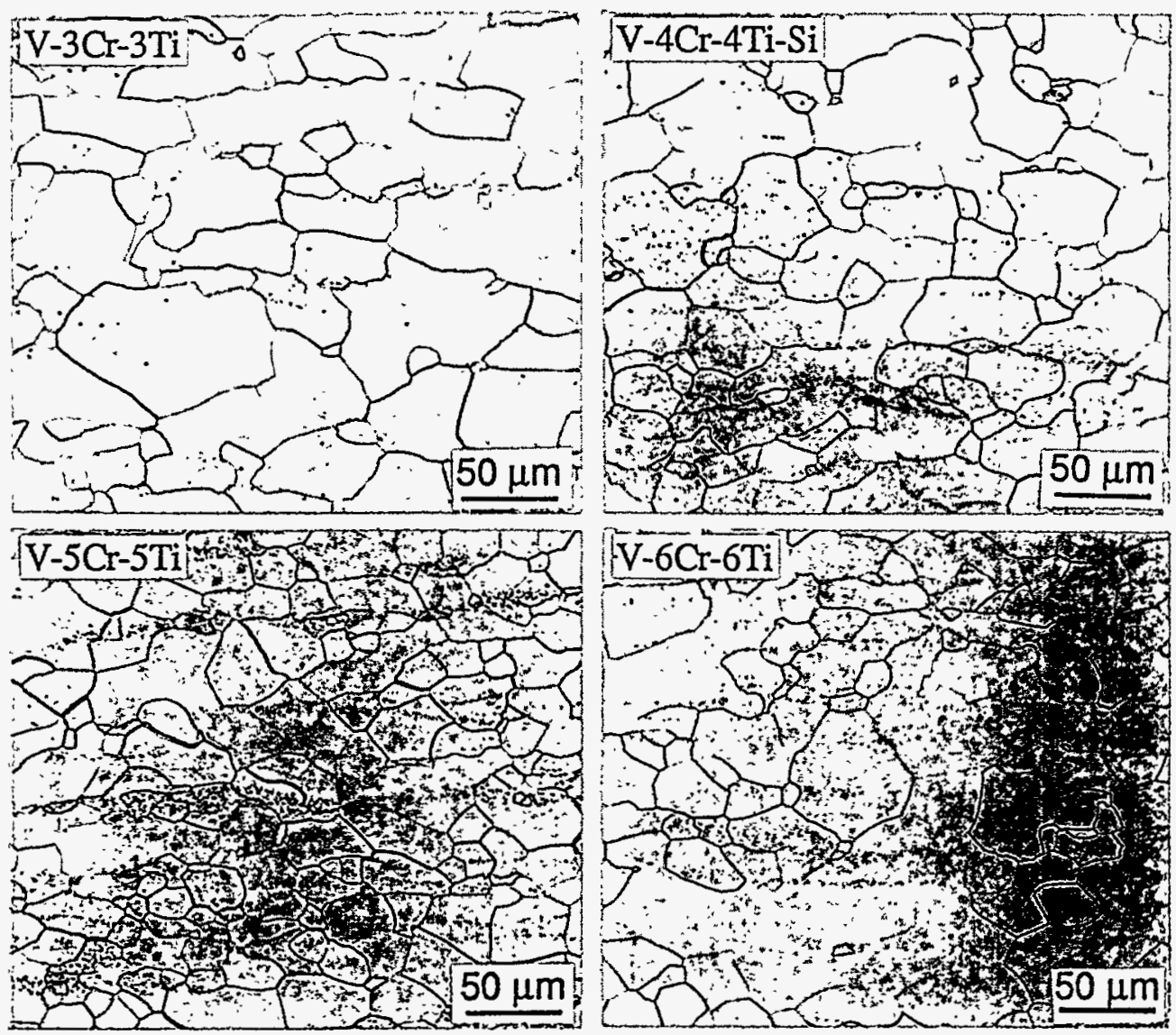

Figure 7. Typical optical microstructures of small heats of Compositional Variants after annealing at $1000^{\circ} \mathrm{C}$ for $2 \mathrm{~h}$.

$(\mathrm{Cr}+\mathrm{Ti})$-containing alloys, V-5Cr-5Ti, V-6Cr-3Ti, and V-6Cr-6Ti all had a DBTT of $\sim-120^{\circ} \mathrm{C}$. The only difference among these alloys is in the upper shelf energy with that for $\mathrm{V}-6 \mathrm{Cr}-3 \mathrm{Ti}$ being around $15 \mathrm{~J}$ and $\mathrm{V}$ $5 \mathrm{Cr}-5 \mathrm{Ti}$ and $\mathrm{V}-6 \mathrm{Cr}-6 \mathrm{Ti}$ having around $11 \mathrm{~J}$. In a companion article in this document, ${ }^{7}$ it was reported that the microhardness of the same alloys studied in the present work was grouped in a similar fashion. In the fully recrystallized conditions, the lower $(\mathrm{Cr}+\mathrm{Ti})$-containing alloys had lower microhardness values $(130$ $140 \mathrm{DPH})$ compared to the higher $(\mathrm{Cr}+\mathrm{Ti})$-containing alloys which possessed higher hardness values (155-160 DPH). Thus, the results of the present study, in conjunction with those of the companion article, ${ }^{7}$ indicate that there is an incremental change in the physical and mechanical properties when the combined $(\mathrm{Cr}+\mathrm{Ti})$ content exceeds $\sim 8 \mathrm{wt} \%$.

It is interesting to compare the impact behavior of large heat of $\mathrm{V}-4 \mathrm{Cr}-4 \mathrm{Ti}$ (heat 832665) and the small heat of $\mathrm{V}-4 \mathrm{Cr}-4 \mathrm{Ti}-\mathrm{Si}$ (heat T89) both of which have similar chemical compositions. For a similar fully recrystallized microstructure, there is no significant difference in the DBTT or the upper-shelf energy (compare Figs. 2 and 8) of the large and small heats of $\mathrm{V}-4 \mathrm{Cr}-4 \mathrm{Ti}$, with the DBTT of large heat being around $-190^{\circ} \mathrm{C}$ and that for the small heat being around $-175^{\circ} \mathrm{C}$. It was reported earlier by Grossbeck et $a^{8}$ that the large heat of $\mathrm{V}-5 \mathrm{Cr}-5 \mathrm{Ti}$ (heat BL 63) exhibited a DBTT of around $-120^{\circ} \mathrm{C}$ in the fully recrystallized condition. In the present study, the small heat of V-5Cr-5Ti (heat T87) had an identical DBTT of $\sim-120^{\circ} \mathrm{C}$ for a fully recrystallized microstructure. This indicates that the scaling (large or small heat) of an alloy has little effect on the impact behavior provided the chemical compositions and microstructures are similar. 


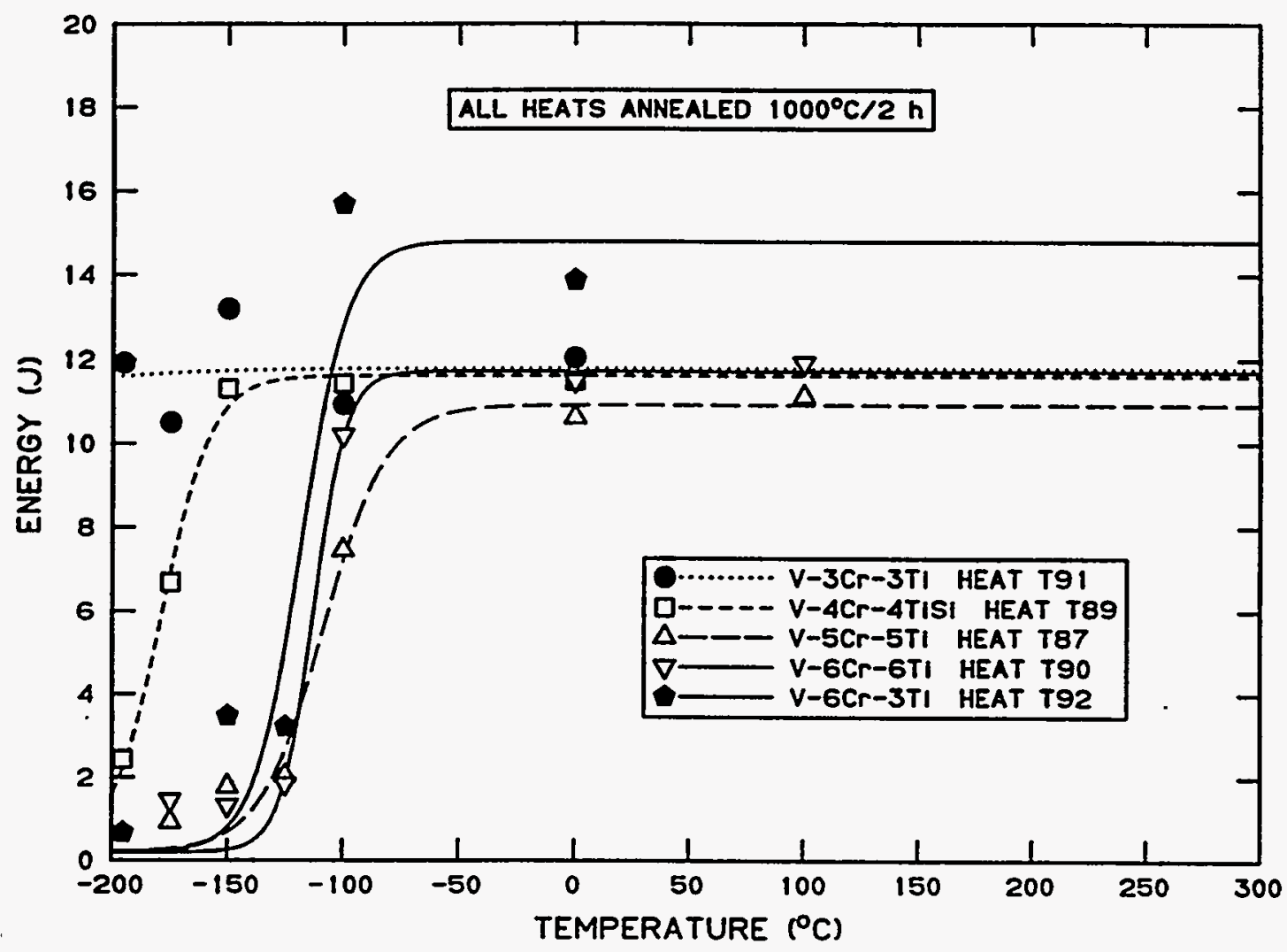

Figure 8. Third-size Charpy impact data for the small heats of Compositional Variants.

The typical fracture surfaces of the four compositional variants, V-3Cr-3Ti, V-4Cr-4Ti-Si, V-5Cr-5Ti, and V-6Cr-6Ti are shown in Fig. 9. The fractographs presented here were taken from samples tested at different impact temperatures. The three alloys, $\mathrm{V}-4 \mathrm{Cr}-4 \mathrm{Ti}-\mathrm{Si}, \mathrm{V}-5 \mathrm{Cr}-5 \mathrm{Ti}$, and $\mathrm{V}-6 \mathrm{Cr}-6 \mathrm{Ti}$, showed pure ductile shear for temperatures from $+100^{\circ}$ to $-100^{\circ} \mathrm{C}$ with the exception of $\mathrm{V}-5 \mathrm{Cr}-5 \mathrm{Ti}$ which had some microvoid coalescence. At lower temperatures of $-175^{\circ}$ to $-196^{\circ} \mathrm{C}$, the fracture mode for these three alloys was predominantly TG cleavage with some secondary IG cracks. In the intermediate temperature range, the fracture mode was a mixture of TG cleavage and microvoid coalescence. In the whole test temperature range from $0^{\circ}$ to $-196^{\circ} \mathrm{C}, \mathrm{V}-3 \mathrm{Cr}-3 \mathrm{Ti}$, which exhibited no ductile-to-brittle transition with high shelf energy, did not fracture completely and the fracture mode was always a pure ductile shear.

\section{CONCLUSIONS}

(1) In the fully recrystallized condition with a grain size of $\sim 16 \mu \mathrm{m}$, the large heat of $\mathrm{V}-4 \mathrm{Cr}-4 \mathrm{Ti}$ has very high fracture resistance at temperatures in the fusion operating regime with a DBTT at $\sim-190^{\circ} \mathrm{C}$. The fracture mode in blunt notch Charpy tests is pure ductile shear at the higher test temperatures and transgranular cleavage in the lower shelf regime.

(2) The $15 \mathrm{~kg}$ heat of $\mathrm{V}-6 \mathrm{Cr}-6 \mathrm{Ti}$ showed a significant variation in impact properties depending on the extent of recrystallization induced by the final anneal. The resistance to transgranular cleavage at low temperatures is greater when the microstructure contains a high proportion of recovered subgrains.

(3) In a fully recrystallized microstructural condition, the Charpy impact properties of the compositional variant heat falls into two groups. Alloys containing a combined $(\mathrm{Cr}+\mathrm{Ti})$ content in excess of 

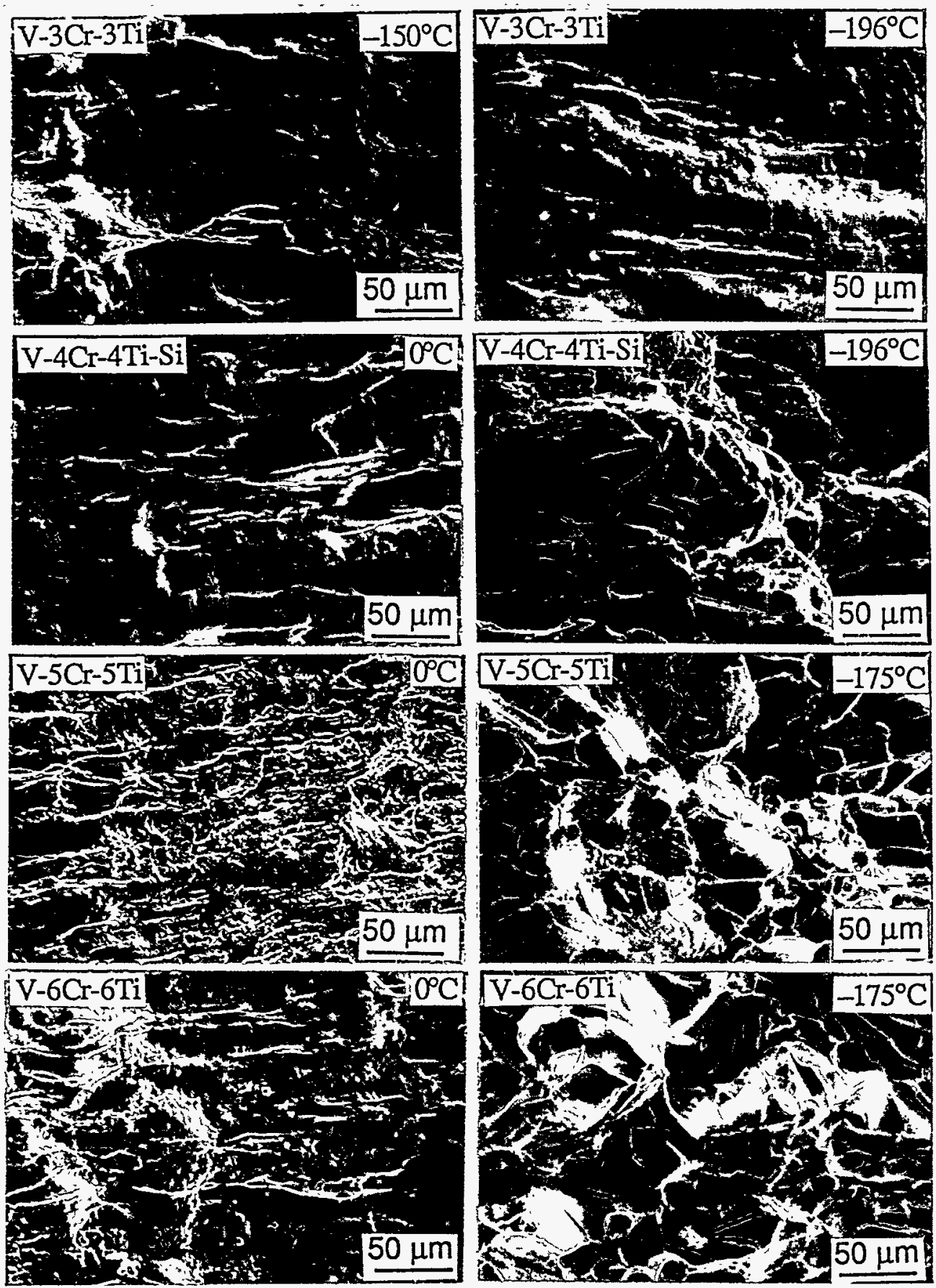

Figure 9. Typical fracture surfaces of the small heats of Compositional Variants at different test temperatures. All are annealed at $1000^{\circ} \mathrm{C}$ for $2 \mathrm{~h}$. 
$\sim 8 \mathrm{wt} \%$ exhibit a DBTT at $\sim-120^{\circ} \mathrm{C}$. Alloys containing $3 \mathrm{Cr} 3 \mathrm{Ti}$ and $4 \mathrm{Cr} 4 \mathrm{Ti}$ showed better resistance to cleavage fracture at low temperatures.

(4) The results from the present study in conjunction with those of earlier works demonstrate that scaling (large or small heat) of an alloy has little effect on the impact behavior provided the chemical compositions and microstructures are similar.

\section{WORK IN PROGRESS}

The effects of varying the degree of recrystallization on the irradiated properties of the large heat will be investigated. The tensile properties of the compositional variants in the range 400 to $650^{\circ} \mathrm{C}$ will be determined.

\section{ACKNOWLEDGMENT}

This research is sponsored by the Office of Fusion Energy, U. S. Department of Energy, under contract DE-AC05-84OR21400 with Martin Marietta Energy Systems, Inc.

\section{REFERENCES}

(1) B. A. Loomis and D. L. Smith, J. Nucl. Matls., 179-181 (1991), pp 783-786.

(2) B. A. Loomis, D. L. Smith, and F. A Gamer, J. Nucl. Matls., 179-181 (1991), pp 771-776.(3) H. M. Chung and D. L. Smith, J. Nucl. Matls., 191-194 (1992), pp 942-947.

(4) B. A. Loomis, L. J. Nowicki, J. Gazda, and D. L. Smith, Fusion Reactor Materials Semiannual Progress Report, DOE/ER-0313/14, March 31, 1993, pp 318-325.

(5) B. A. Loomis, H. M. Chung, L. J. Nowicki, and D. L. Smith, J. Nucl. Matls., 212-215 (1994), pp 799-803.

(ด) H. M. Chung, L. Nowicki, J. Gazda, and D. L. Smith, Fusion Reactor Materials Semiannual Progress Report, DOE/ER-0313/15, September 30, 1994.

(7) A. N. Gubbi, A. F. Rowcliffe, and W. S. Eatherly - Recovery and Recrystallization Study on Vanadium Alloys - in this report.

(8) M. L. Grossbeck, A. F. Rowcliffe, and D. J. Alexander, Fusion Reactor Materials Semiannual Progress Report, DOE/ER-0313/16, March 31, 1994, pp 244-257. 
- 
EFFECT OF HEAT TREATMENT AND TEST METHOD ON DBTT OF A V-5Cr-5Ti ALLOY - Huaxin Li (Associated Western Universities--Northwest Division), M. L. Hamilton and R. H. Jones (Pacific Northwest Laboratory)*

\section{OBJECTIVE}

The purpose of this research is to investigate further the effect of heat treatment (HT) on fracture properties of a V-5Cr-5Ti alloy in the temperature range -190 to $90^{\circ} \mathrm{C}$, and also to investigate how its DBTT depends on $\mathrm{HT}$ and test method.

\section{SUMMARY}

Specimens annealed at $1125^{\circ} \mathrm{C}$ for $1 \mathrm{~h}$ and furnace cooled were brittle at room temperature (RT) and experienced a mixture of intergranular and cleavage fracture. Fracture toughness (JQ) at RT was $52 \mathrm{~kJ} / \mathrm{m}^{2}$ and the Charpy-V impact fracture energy (IFE) on one-third scaled specimens was $0.2 \mathrm{~J}$. While material exhibited high fracture toughness at $100^{\circ} \mathrm{C}\left(\mathrm{J}_{\mathrm{IO}}\right.$ was $\left.485 \mathrm{~kJ} / \mathrm{m}^{2}\right)$ and did not fracture during an impact test, the fracture surface contained a mixture of dimple and intergranular fracture, with intergranular fracture making up $40 \%$ of the total fracture surface. The ductile to brittle transition temperature (DBTT) was estimated to be above RT from the IFE vs. temperature curve. When material was given an additional annealing at $890^{\circ} \mathrm{C}$ for $24 \mathrm{~h}$, it became ductile at $\mathrm{RT}$ and fractured by microvoid coalescence. The $\mathrm{J}_{\mathrm{IO}}$ value increased from $52 \mathrm{~kJ} / \mathrm{m}^{2}$ to $\approx 1100 \mathrm{~kJ} / \mathrm{m}^{2}$. During impact tests, the specimens did not fracture at $-100^{\circ} \mathrm{C}$ and warmer due to a large amount of plastic deformation. The DBTT was $-100^{\circ} \mathrm{C}$. However, when evaluated by J-integral testing, the material became brittle at $-50^{\circ} \mathrm{C}$ and fractured by cleavage, yielding a $\mathrm{J}_{\mathrm{IQ}}$ value of $50 \mathrm{~kJ} / \mathrm{m}^{2}$. The $\mathrm{DBTT}_{\mathrm{J}}$ estimated from $\mathrm{J}_{\mathrm{IQ}}$ vs. temperature curve was above $-50^{\circ} \mathrm{C}, 50^{\circ} \mathrm{C}$ higher than that from the IFE vs. temperature curve. The result indicated that the V-5Cr-5Ti alloy was sensitive to crack acuity. Auger electron microscopy analysis showed significant sulfur enrichment (6 at\%) on grain boundaries in the specimens annealed only at $1125^{\circ} \mathrm{C}$, but only 0.9 at $\%$ on grain boundaries if the additional annealing at $890^{\circ} \mathrm{C}$ was given. Moreover, more second phase particles were found in the specimens annealed at $1125^{\circ} \mathrm{C}$ plus $890^{\circ} \mathrm{C}$. Energy dispersive $\mathrm{x}$-ray spectroscopy analysis of the particles indicated that they contained higher Ti concentration. The results indicated that the improved toughness of the specimens annealed at $1125^{\circ} \mathrm{C}$ plus $890^{\circ} \mathrm{C}$ probably resulted from the reduced $\mathrm{S}$ concentration on the grain boundaries and precipitation of the second phases. It was found that the embrittlement was thermodynamically reversible because the embrittlement could be restored by giving the ductile material additional annealing at $1125^{\circ} \mathrm{C}$ for $1 \mathrm{~h}$.

\section{PROGRESS AND STATUS}

\section{Introduction}

A vanadium (V)-based alloy with $5 \%(w t) \mathrm{Cr}$ and $5 \%(\mathrm{wt}) \mathrm{Ti}(\mathrm{V}-5 \mathrm{Cr}-5 \mathrm{Ti})$ is being considered as a candidate structural material for a fusion energy system. Besides retaining good strength and ductility at both ambient and elevated temperatures, V-based alloys possess some unique neutronic properties as

*Pacific Northwest Laboratory is operated for the U.S. Department of Energy by Battelle Memorial Institute under Contract DE-AC06-76RLO 1830. 
austenitic and Ferritic steels. Low neutron activation in the short-term, and especially in intermediate and long terms, and low biological hazard potential are particularly attractive properties of vanadium alloys. However, the alloy was found to be brittle at room temperature (RT) and experienced mixed intergranular and cleavage fracture when annealed at $1125^{\circ} \mathrm{C}$ for $1 \mathrm{~h}$ and then furnace cooled (HT1)'. While it became ductile at $100^{\circ} \mathrm{C}$, it still failed by intergranular and microvoid coalescence modes ${ }^{2,3}$. However, if an additional heat treatment of $890^{\circ} \mathrm{C}$ for $24 \mathrm{~h}$ (HT2) was given, the material become ductile,5 Auger electron spectroscopy analysis showed a significant enrichment of sulfur (S) on grain boundaries ( $6 \%$ at) in a specimen annealed at $1125^{\circ} \mathrm{C}$ for $1 \mathrm{~h}^{4,5}$, as compared with that $\mathrm{HT} 2$ specimens ( $0.9 \%$ at). Besides, optical microscopic investigation found significantly more second phase in HT2 specimens. In this study, the reversibility of the embrittlement investigated and the DBTTs were evaluated by Charpy-V impact and fracture toughness (J-integral) testing.

\section{Material and Experimental Methods}

A 6.35-mm-thick V-5Cr-5Ti alloy plate (ANL \#BL-63) was produced by Teledyne Wah Chang, Albany, OR. The chemical composition of the plate (as provided by the vendor) is listed in Table 1.

Table 1. Chemical Composition of V-5Cr-5Ti

\begin{tabular}{|lllllllll||}
\hline (in wt\%) & $\mathrm{Cr}$ & $\mathrm{Ti}$ & (in wt ppm) & $\mathrm{O}$ & $\mathrm{C}$ & $\mathrm{N}$ & $\mathrm{Si}$ & $\mathrm{V}$ \\
\hline & 4.6 & 5.1 & & 440 & 73 & 28 & 310 & bal. \\
\hline
\end{tabular}

The following heat treatments were investigated for grain boundary chemistry.

1. Heat treatment 1 ( $\mathrm{HTl}$ ): $1125^{\circ} \mathrm{C} / 1 \mathrm{~h} /$ furnace cooled

2. Heat treatment 2 (HT2): $\mathrm{HT} 1$ plus $890^{\circ} \mathrm{C} / 24 \mathrm{~h} /$ furnace cooled

3. Heat treatment 3 (HT3): HT1 plus HT2 plus $1125^{\circ} \mathrm{C} / 1 \mathrm{~h} /$ furnace cooled

All heat treatments were conducted in a vacuum of $1.33 \times 10^{-5} \mathrm{~Pa}$. Grain boundary chemistry was analyzed by means of a scanning Auger electron spectrometer (AES) (PERKIN-ELMER-660). Specimens were cooled by extracting heat with liquid nitrogen, and were fractured in the AES chamber in a vacuum of 1 $\times 10^{-7} \mathrm{~Pa}$ or better. Auger spectra were taken at an accelerating voltage of $5 \mathrm{kV}$ and an incident electron current of about $250 \mathrm{nA}$. At least 22 intergranular facets and 6 grain interiors were analyzed; sometimes duplicate samples were tested. Microstructure was analyzed using an optical microscope and a scanning electron microscope (SEM). Specimens were etched for the same length of time using a solution composed of $30 \mathrm{ml}$ lactic, $10 \mathrm{ml} \mathrm{HNO}_{3}$, and $10 \mathrm{ml} \mathrm{HF}$ Fracture surfaces were also investigated using SEM. Energy dispersive $\mathrm{x}$-ray spectroscopy (EDS) was used to determine semiquantitatively the composition of second particles in HT2 specimens.

The specimens used for fracture toughness and Charpy-V impact tests were cut in the $T-L$ orientation as specified in ASTM E399-90. The compact tension specimen was $25.4 \mathrm{~mm}$ wide and $6.35 \mathrm{~mm}$ thick. ASTM E813-89 was used to determine critical J-integrals $\left(\mathrm{J}_{\mathrm{IQ}}\right)$, and ASTM E399-90 was used to determine the critical stress intensity factor $\left(\mathrm{K}_{\mathrm{rQ}}\right)$. The subscript " $\mathrm{Q}$ " is used because our specimen size did not satisfy plane strain conditions. Mechanical properties, listed in Table 2, from another heat of V-5Cr-5Ti were used for determination of $\mathrm{J}_{\mathrm{IQ}}$ values. Charpy-V impact specimens of $23.6 \times 3.33 \times 3.33 \mathrm{~mm}$ (one-third scaled) were tested on the HT2 specimens in the range $-190^{\circ} \mathrm{C}$ to RT, and on the HT1 and HT3 specimens at RT and $90^{\circ} \mathrm{C}$ to estimate the DBTTs. Fracture toughness was determined at RT and $100^{\circ} \mathrm{C}$ on the HT1 
specimen, and $-50^{\circ} \mathrm{C}$ and $\mathrm{RT}$ on the HT2 specimens.

Table 2. Mechanical Properties of a V-5Cr-5Ti Alloy

\begin{tabular}{||cccc|}
\hline \hline Temp. $\left({ }^{\circ} \mathrm{C}\right)$ & Yield strength $(\mathrm{MPa})$ & UTS $^{*}(\mathrm{MPa})$ & Elongation (\%) \\
\hline 25 & 387 & 454 & 34 \\
100 & 325 & 420 & 33 \\
\hline
\end{tabular}

* UTS: ultimate tensile strength.

Fracture toughness was determined by the J-integral test method for an $\mathrm{HT} 1$ specimen tested at $100^{\circ} \mathrm{C}$ and an HT2 specimen tested at RT. For an HT1 specimen tested at RT and an HT2 specimen tested at $50^{\circ} \mathrm{C}$, fracture toughness was measured using the $\mathrm{K}$-test method. The $\mathrm{K}_{\mathrm{IQ}}$ values were then converted to $\mathrm{J}_{\mathrm{IQ}}$ values by means of Eq. 1 . Temperatures were controlled within $\pm 5^{\circ} \mathrm{C}$ during testing using either a heating tape or a refrigerator, respectively. The single-specimen technique was used in this study, which allows a J-R curve (J-integral vs. crack extension, $\Delta a$ ) to be generated with one specimen. At least 40 pairs of $J-\Delta$ a data were used to construct a J-R curve.

FO4On! $S($, ,2)), E)

$\left.\left.\left.J_{i} S\right\}_{i} D O 8(I O)=\prod_{i} F(K)_{i} S(2, I Q)\right\}_{i} D\right\}_{i} F O 40\left(I !_{i} D\right\}_{i} F O 40-$

Where $\mathrm{E}$ is Young's modulus and $\mathbf{n}$ is a Poisson ratio.

(1)

\section{$\underline{\text { Results }}$}

Effect of Heat Treatment on Grain Boundary S Concentration and Microstructure

\section{a. On Grain Boundary Chemistry}

The specimens subjected to HTI were brittle at RT and fractured with a mixture of intergranular and cleavage modes, indicating that the grain boundary strength was low. AES analysis of two specimens showed significant enrichment of S (6 at\%) in more than 40 intergranular facets, as compared to 0.3 at\% on the cleavage facets. In order to obtain intergranular facets, HT2 specimens had to be charged with hydrogen before being fractured in the AES chamber. The effect of heat treatment on grain size, grain boundary chemistry, and microstructure is summarized in Table 3. Phosphorus, oxygen, nitrogen, and carbon concentrations were also investigated using AES, but their concentrations did not vary significantly with heat treatments, so only $\mathrm{S}$ was listed in Table 3. From Table 3, it is evident that HT2 gives much lower grain boundary S concentration than HTl does. 
Table 3. Effect of Heat Treatment on Grain Boundary S Concentrations and Number Precipitates

\begin{tabular}{|c|c|c|c|}
\hline Heat treatments & Grain Size $(\mu \mathrm{m})$ & Grain Boundary S (at\%) & $\begin{array}{c}\text { Number of } \\
\text { Precipitates }\end{array}$ \\
\hline $1125^{\circ} \mathrm{C} / 1 \mathrm{~h}$ & 45 & 6.0 & few \\
\hline $1125^{\circ} \mathrm{C} / 890^{\circ} \mathrm{C} / 24 \mathrm{~h}$ & 45 & 0.9 & many \\
\hline As received & 37 & $\mathrm{NM}$ & some \\
\hline
\end{tabular}

NM: not measured

\section{b. On Microstructure}

The HT2 also produced significantly more second-phase precipitates than HT1, as shown in Figs. 1a and lb. SEM photos at higher magnification showed that the HT2 specimen contained pores and second phase particles, as shown in Figs. 2 and 3. EDS analysis showed that the second phase was enriched slightly with $\mathrm{Ti}$, as compared with that of the matrix. The chemical composition from the second phase and the matrix is given in Table 4. It should be noticed that due to the small size of particles and the penetration of SEM electron beam, the composition for the second phase must be a mixture of the second phase and matrix. The actual Ti concentration in the second phase will be higher than that in Table 4. The pores probably resulted from local dissolution during etching. This feature suggested that HT2 may produce two types of precipitates because the HT1 specimen did have as many pores when etched identically. In order to gain more accurate chemical composition and nature of the dissolved particles, TEM examination is under way.

Table 4. Chemical Composition (\%wt) of the Second Phase in HT2 Specimen (by EDS)

\begin{tabular}{|c|c|c|c|}
\hline Location & $\mathrm{V}$ & $\mathrm{Ti}$ & $\mathrm{Cr}$ \\
\hline Matrix & 88.1 & 7.0 & 4.9 \\
\hline Second Phase & 87.2 & 8.0 & 4.8 \\
\hline
\end{tabular}

Mechanical Properties

a. Specimens Subjected to HTl

The dependence of IFE on temperature is presented in Fig. 4. The specimens treated using HT1 were brittle at RT and below. The IFE at RT was $0.2 \mathrm{~J}$. At $90^{\circ} \mathrm{C}$ the specimen did not fracture due to a large amount of plastic deformation at the notch tip. The data in Fig. 4 present only the nominal energy consumed 
amount of plastic deformation at the notch tip. The data in Fig. 4 present only the nominal energy consumed deforming the specimens during testing. The energy does not include the portion for crack initiation and propagation; therefore, the IFE could not be determined. However, based on an upper shelf IFE (about $12 \mathrm{~J}$ ) obtained from another test ${ }^{5}$, the IEF for the sample could be as high as $12 \mathrm{~J}$. An upward arrow is superimposed on some of the data in Fig. 4 to indicate that the IFE should be higher. The DBTT is apparently greater than RT.

Fig. 5 shows the dependence of fracture toughness on testing temperature. $J_{I Q}$ at RT was $52 \mathrm{~kJ} / \mathrm{m}^{2}$. The specimen fractured with a mixture of intergranular and cleavage failure, as shown in Fig. 6 . Fig. $6 \mathrm{~b}$ shows that cleavage facets appear to initiate at the grain boundaries and propagate through the grains. When tested at $100^{\circ} \mathrm{C}$, the material was ductile and exhibited stable crack growth. $\mathrm{J}_{\mathrm{IQ}}$ was about 485 $\mathrm{kJ} / \mathrm{m}^{2}$ and the tearing modulus was $250 \mathrm{~mJ} / \mathrm{m}^{3}$. Despite the high $\mathrm{J}_{\mathrm{TQ}}$ value at $100^{\circ} \mathrm{C}$, the fracture surface consisted of intergranular and microvoid coalescence features [2]. The intergranular portion made up about $40 \%$ of the total fracture surface. However, the grains experienced a large amount of plastic deformation before they fractured along the grain boundaries, yielding high fracture toughness.

\section{b. Specimens Subjected to HT2}

The HT2 specimens were very ductile at RT. As a result, a complete J-R curve could not be constructed with the compact tension specimen. The $\mathrm{J}_{\mathrm{IQ}}$ estimated from the partial J-R curve (Fig. 7) is about 1100 $\mathrm{kJ} / \mathrm{m}^{2}$. The specimen fractured by microvoid coalescence, as shown in Fig. 8a. The fracture toughness was sensitive to temperature: $\mathrm{J}_{\mathrm{IQ}}$ at $-50^{\circ} \mathrm{C}$ was $45 \mathrm{~kJ} / \mathrm{m}^{2}$, only about one-twentieth that at $\mathrm{RT}$. The fracture mode also changed to cleavage fracture, as shown in.Fig. $8 \mathrm{~b}$. The dependence of fracture toughness on testing temperature is shown in Fig. 5.

Charpy testing failed to cause fracture at temperatures of $-100^{\circ} \mathrm{C}$ and higher (Fig. 4) due to a large amount of plastic deformation; therefore, IFEs could not be determined. The dashed line in Fig. 3 represents the estimated dependence of IFE of HT2 specimens on testing temperature. Based on the data from Ref. 5 , $12 \mathrm{~J}$ IFE was chosen as the upper shelf IFE (Fig. 4). The IFEs were $4 \mathrm{~J}$ at $-115^{\circ} \mathrm{C}$ and $0.2 \mathrm{~J}$ at $-190^{\circ} \mathrm{C}$. The DBTT was estimated to be $-110^{\circ} \mathrm{C}$. 
Table 5. Effect of Heat Treatment and Temperature on Fracture Toughness

\begin{tabular}{|c|c|c|c|c|}
\hline Heat treatment & $J_{I Q}\left(\mathrm{~kJ} / \mathrm{m}^{2}\right)$ at $-50^{\circ} \mathrm{C}$ & at $\mathrm{RT}$ & at $100^{\circ} \mathrm{C}$ & Fracture at RT \\
\hline $\mathrm{HT} 1$ & $\mathrm{NM}$ & 52 & 485 & $\mathrm{IG}^{*}$ \& Cleavage \\
\hline $\mathrm{HT} 2$ & 45 & 1100 & $\mathrm{NM}$ & Dimpled \\
\hline
\end{tabular}

* IG: intergranular; NM: not measured.

c. Specimens Subjected to HT3

The dependence of IFE on test temperature for the HT3 specimens is shown in Fig. 4 The HT3 specimens were brittle at RT. The IFE at RT was only $3 \mathrm{~J}$ and fell in the lower shelf energy range although it was higher than that of the HT1 specimen. SEM showed that the specimen fractured by a mixture of intergranular and cleavage modes, as shown in Fig 8 . At $90^{\circ} \mathrm{C}$, the specimen did not fracture due to a large amount of plastic deformation at the notch tip. An upward arrow is superimposed to indicate that the IFE should be higher. The DBTT is apparently greater than RT. This result indicated that the embrittlement was reversible, though not completely. The effects of heat treatment and temperature on fracture properties of the V-5Cr-5Ti alloy are summarized in Figs. 3 and 4, and also in Tables 5 and 6

Table 6. Effect of Heat Treatment and Test Method on DBTT

\begin{tabular}{|c|c|l|}
\hline Heat treatment & $\operatorname{DBTT}\left({ }^{\circ} \mathrm{C}\right)$ & \multicolumn{1}{|c|}{$\operatorname{DBTT}_{\mathrm{J}}\left({ }^{\circ} \mathrm{C}\right)$} \\
\hline $\mathrm{HT} 1$ & $>\mathrm{RT}$ & $>\mathrm{RT}$ \\
\hline $\mathrm{HT} 2$ & $\approx-100$ & $\approx-30$ \\
\hline $\mathrm{HT} 3$ & $>\mathrm{RT}$ & $\mathrm{NM}$ \\
\hline
\end{tabular}

NM: not measured. 


\section{$\underline{\text { Discussion }}$}

The mixture of intergranular and cleavage fracture modes in the HTl specimens appears to result from a low grain boundary fracture strength. It is known that impurity segregation to grain boundaries in a metallic material can reduce grain boundary strength, and that interstitial impurities can enhance cleavage fracture. Optical microscopy and SEM analysis of HT1 and HT2 specimens showed that second-phase formation occurred at about $890^{\circ} \mathrm{C}$ in this V-5Ti-5Cr alloy. Because the grain size in both $\mathrm{HTI}$ and HT2 specimens was almost identical, the increase in fracture toughness of the HT2 specimens probably resulted from two factors: 1) HT2 increases grain boundary strength by reducing grain boundary S concentration, and 2) HT2 improves the ductility of grains by decreasing interstitial impurity concentration via precipitate formation. The reversibility of the brittleness suggested that dissolution of the second phases occurred at $1125^{\circ} \mathrm{C}$, which caused the brittleness in the $\mathrm{V}-5 \mathrm{Ti}-5 \mathrm{Cr}$ alloy. TEM analysis of the precipitates is underway.

\section{Conclusion}

1. Specimens of $\mathrm{V}-5 \mathrm{Cr}-5 \mathrm{Ti}$ annealed at $1125^{\circ} \mathrm{C} / 1 \mathrm{~h}(\mathrm{HTl})$ were brittle at $\mathrm{RT}$ and fractured by intergranular and cleavage modes. The $\mathrm{J}_{10}$ was about $52 \mathrm{~kJ} / \mathrm{m}^{2}$. At $100^{\circ} \mathrm{C}$, specimens were ductile, giving a $\mathrm{J}_{\mathrm{IQ}}$ value of $485 \mathrm{~kJ} / \mathrm{m}^{2}$, but fracture surfaces were composed of both intergranular and dimple fracture. The DBTT as determined from impact tests was higher than RT.

2. Annealing specimens at $1125^{\circ} \mathrm{C} / 1 \mathrm{~h}$ and then at $890^{\circ} \mathrm{C} / 24 \mathrm{~h}(\mathrm{HT} 2)$ improved the RT fracture toughness dramatically, from 52 to about $1100 \mathrm{~kJ} / \mathrm{m}^{2}$, and changed the mode of fracture to microvoid coalescence. Specimens were brittle at $-50^{\circ} \mathrm{C}$, yielding a $\mathrm{J}_{\mathrm{IQ}}$ value of $45 \mathrm{~kJ} / \mathrm{m}^{2}$. The DBTT was $-100^{\circ} \mathrm{C}$.

3. The HT2 reduced grain boundary S concentration (0.9 at\%) greatly as compared to HT1 (6 at\%) and produced more precipitates.

\section{Acknowledgments}

We are grateful to Dr. M. L. Grossbeck of Oak Ridge National Lab. for supplying us with the V-5Cr-5Ti alloy. The assistance of Mr. J. L. Humason at Pacific Northwest Laboratory in developing the test methods is gratefully acknowledged. This research was supported by the Office of Fusion Energy of the U. S. Department of Energy under Contract DE-AC06-76RLO 1830 with Battelle Memorial Institute.

\section{References}

1. Huaxin Li, R. H. Jones, and J. P. Hirth, Fusion Reactor Materials Semiannual Progress Report. DOE/ER-0313/16, Oak Ridge National Lab., Oak Ridge, TN (March 1994), pp. 279-92.

2. Huaxin Li, R. H. Jones, and J. P. Hirth, Scripta Metall. Mater., 32 (1995), pp. 611-16.

3. R. H. Jones, in Mechanical Properties and Phase Transformations in Engineering Materials, S. D. Antolovich, R. O. Ritchie, and W. W. Gerberich, eds. The Metallurgical Society of AIME, 1986, pp. 227-49.

4. B. A. Loomis, J. Gazda, L. J. Nowicki, and D. L. Smith, "Relationship of Microstructure and Mechanical Properties of V-Cr-Ti Alloys," CFRM-6/Ref. No. H016, Sixth International Conference 
5. Huaxin Li, M. L. Hamilton, and R. H. Jones, Fusion Reactor Materials Semiannual Progress Report. DOE/ER-0313/17, Oak Ridge National Lab., Oak Ridge, TN (October 1994), in press.

\section{Fig. Captions}

Fig. 1. The dependence of critical total J-integrals of $\mathrm{V}-5 \mathrm{Cr}-5 \mathrm{Ti}$ on crack inclination angles and temperatures. The results for a reduced activation Ferritic/martensitic steel $(\mathrm{F}-82 \mathrm{H})$ is included for comparison.

Fig. 2. The geometry of the compact tension specimen used in this study.

Fig. 3. Optical micrographs $(50 \mathrm{X})$ showing microstructures resulting from: a.) as-received; b.) $1050^{\circ} \mathrm{C} /$ $1 \mathrm{~h} /$ furnace cooled (FC); c.) $1125^{\circ} \mathrm{C} / \mathrm{lh} / \mathrm{FC}$; and d.) $1125^{\circ} \mathrm{C} / 1 \mathrm{~h} / \mathrm{FC}$ plus $890^{\circ} \mathrm{C} / 24 \mathrm{~h} / \mathrm{FC}$.

Fig. 4. Fracture surfaces of specimens annealed at $1125^{\circ} \mathrm{C}$ for $1 \mathrm{~h}$ and fractured at room temperature during $\mathrm{K}$ testing. a.) a mixture of intergranular, cleavage, and a little dimple failure; $b$.) a cleavage fracture facet showing the cleavage crack initiates at a grain boundary and passes through the whole grain.

Fig. 5. Impact fracture energy vs. testing temperature. PNL and ORNL indicate the tests were performed at Pacific Northwest Laboratory and Oak Ridge National Laboratory, respectively.

Fig. 6. Fracture surfaces of specimens annealed at $1125^{\circ} \mathrm{C}$ for $1 \mathrm{~h}$ and fractured at $100^{\circ} \mathrm{C}$ during J-integral testing. They are a mixture of dimple and intergranular (about $40 \%$ ) failure. The arrows indicate typical intergranular feature.

Fig. 7. The dimpled fracture surface of a specimen annealed at $1125^{\circ} \mathrm{C}$ for $1 \mathrm{~h}$ plus $890^{\circ} \mathrm{C}$ for $24 \mathrm{~h}$ and fractured at RT during J-integral testing.

Fig. 8. The J-integral vs. crack growth curve generated from a specimen annealed at $1125^{\circ} \mathrm{C}$ for $1 \mathrm{~h}$ plus $890^{\circ} \mathrm{C}$ for $24 \mathrm{~h}$ during J-integral testing at RT. $\mathrm{J}_{\mathrm{IQ}}$ is estimated as about $1100 \mathrm{~kJ} / \mathrm{m}^{2}$.

Fig. 9. the cleavage fracture surface of a specimen annealed at $1125^{\circ} \mathrm{C}$ for $1 \mathrm{~h}$ plus $890^{\circ} \mathrm{C}$ for $24 \mathrm{~h}$ and fractured at $-50^{\circ} \mathrm{C}$ during $\mathrm{K}$ testing.

Fig. 10. Fracture toughness vs. testing temperature for specimens annealed either at $1125^{\circ} \mathrm{C}$ for $1 \mathrm{~h}$ or at $1125^{\circ} \mathrm{C}$ for $1 \mathrm{~h}$ plus $890^{\circ} \mathrm{C}$ for $24 \mathrm{~h}$. 


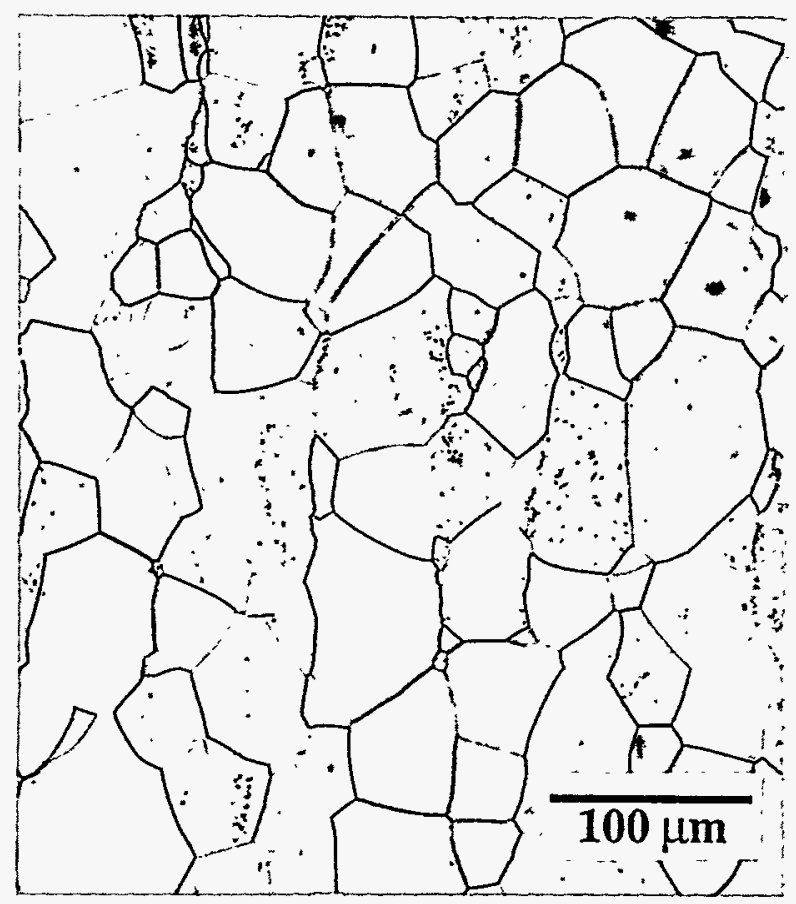

(a)

Fig. 1. Optical micrographs showing microstructure resulting from treatments of a) $1125^{\circ} \mathrm{C} / 1 \mathrm{~h} /$ furnace cooled; 


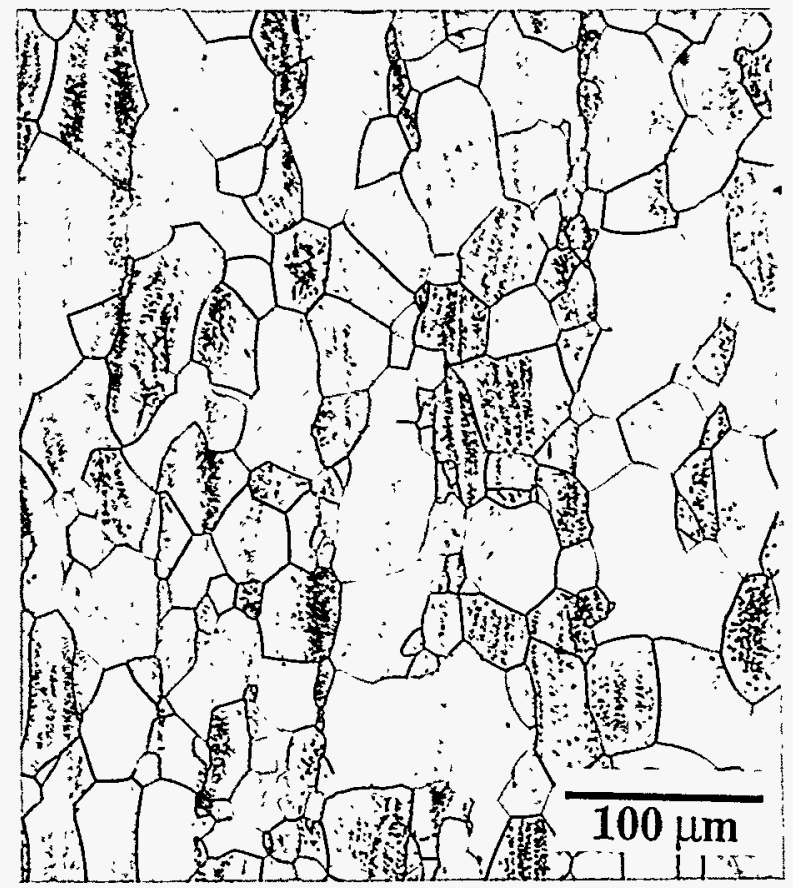

(b)

and b) $1125^{\circ} \mathrm{C} / 1 \mathrm{~h} /$ furnace cooled plus $890^{\circ} \mathrm{C} / 24 \mathrm{~h} /$ furnace cooled. 


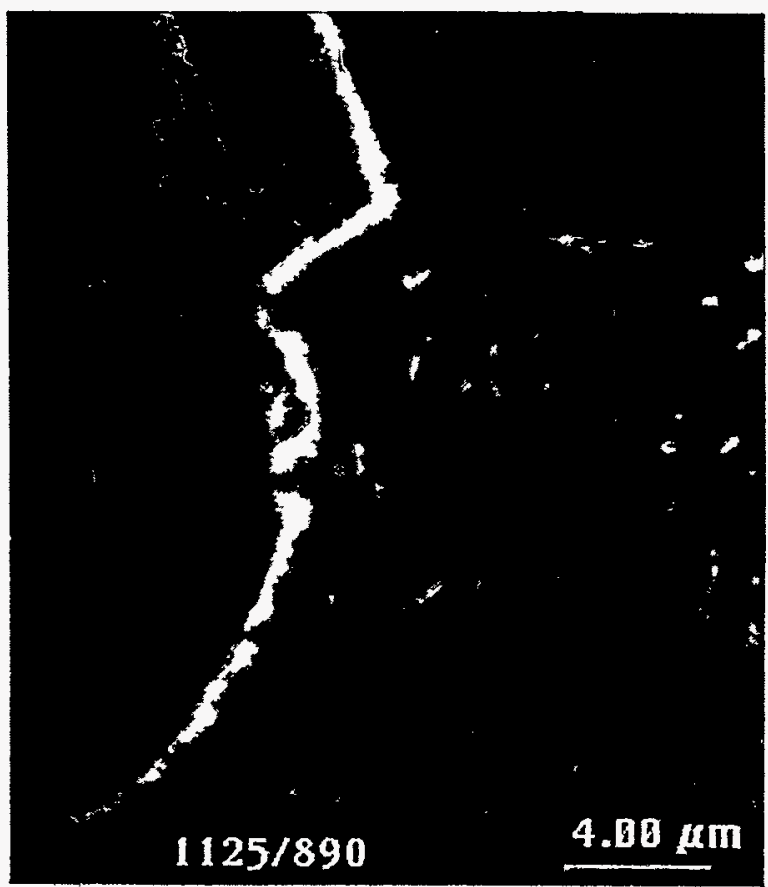

(a)

Fig. 2. SEM micrographs showing the microstructure resulting from treatment of $1125^{\circ} \mathrm{Cl} \mathrm{h} /$ furnace cooled plus $890^{\circ} \mathrm{C} / 24 \mathrm{~h} /$ furnace cooled. a) secondary electron beam; 


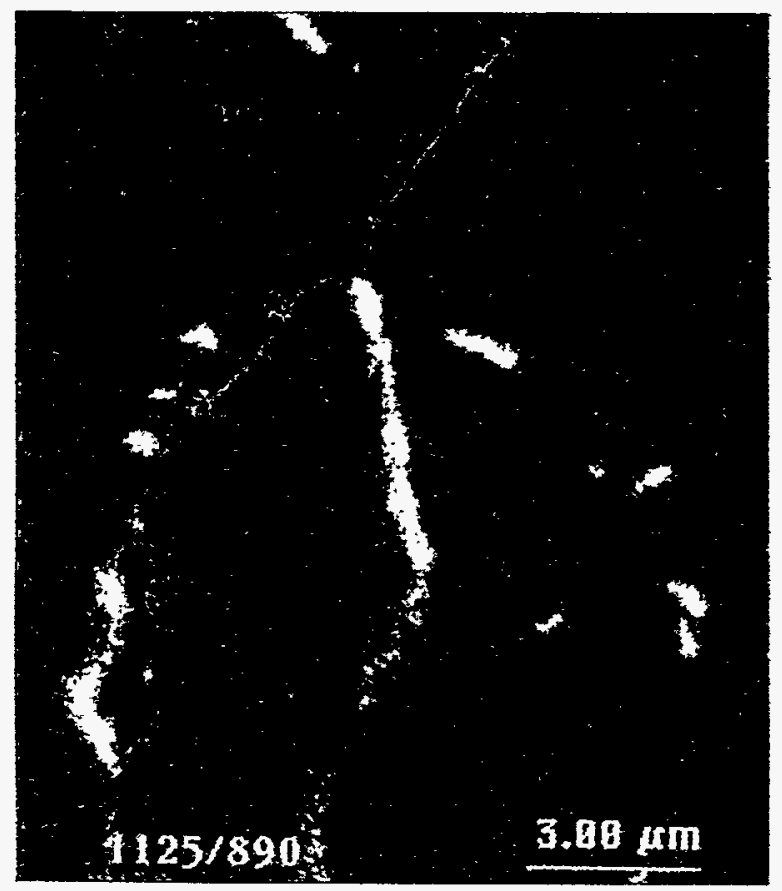

(b)

b) backscattered electron beam. 


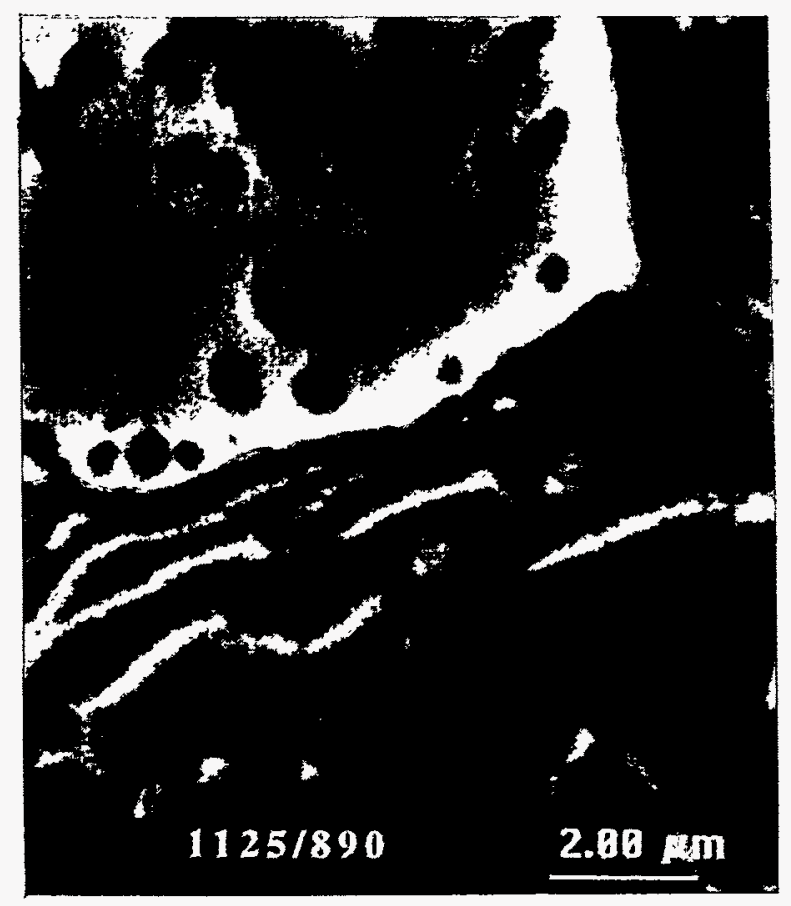

(a)

Fig. 3. SEM micrographs at higher mignification showing the microstructure resulting from treatment of $1125^{\circ} \mathrm{C} / 1 \mathrm{~h} /$ furnace cooled plus $890^{\circ} \mathrm{C} / 24 \mathrm{~h} /$ furnace cooled. a) pores and second phase; 


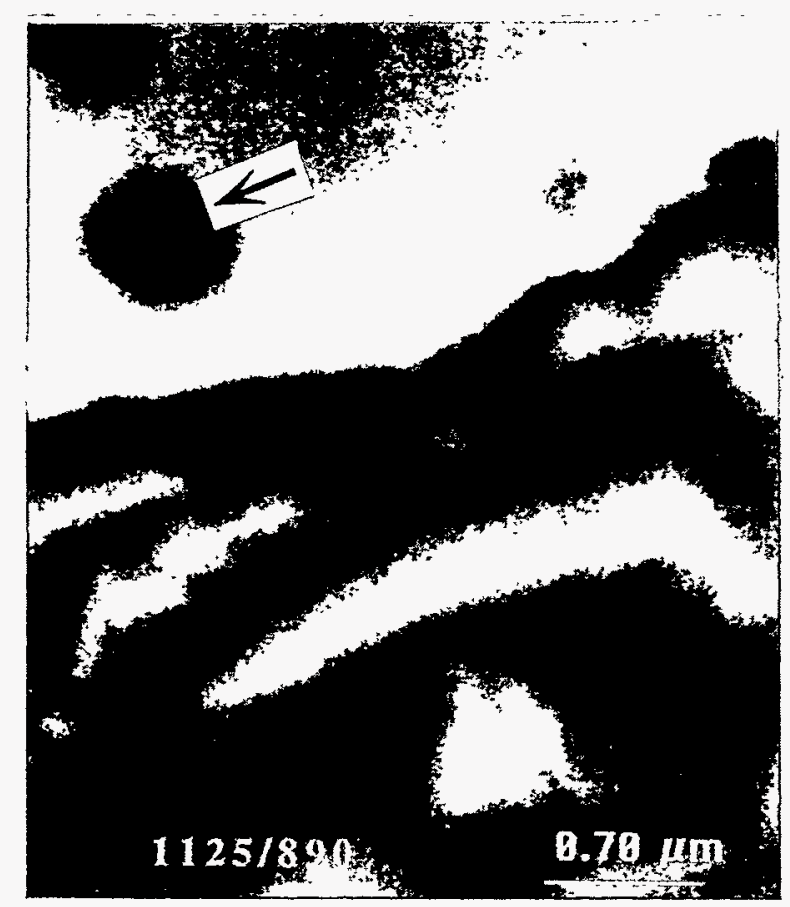

(b)

b) same location as (a) at higher magnification; the arrow indicates a precipitate particle. 


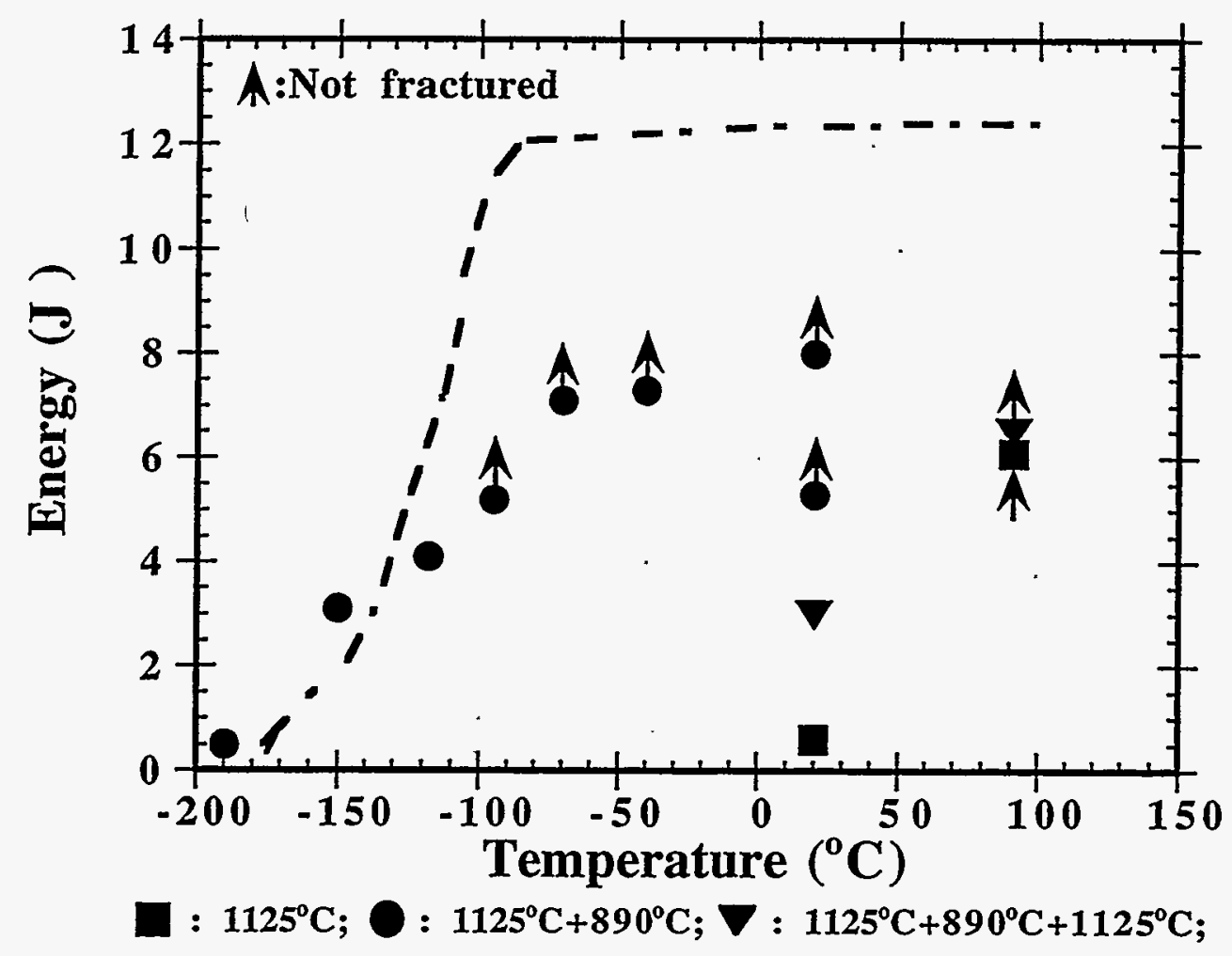

Fig. 4. Charpy V impact fracture energy vs. test temperature. 


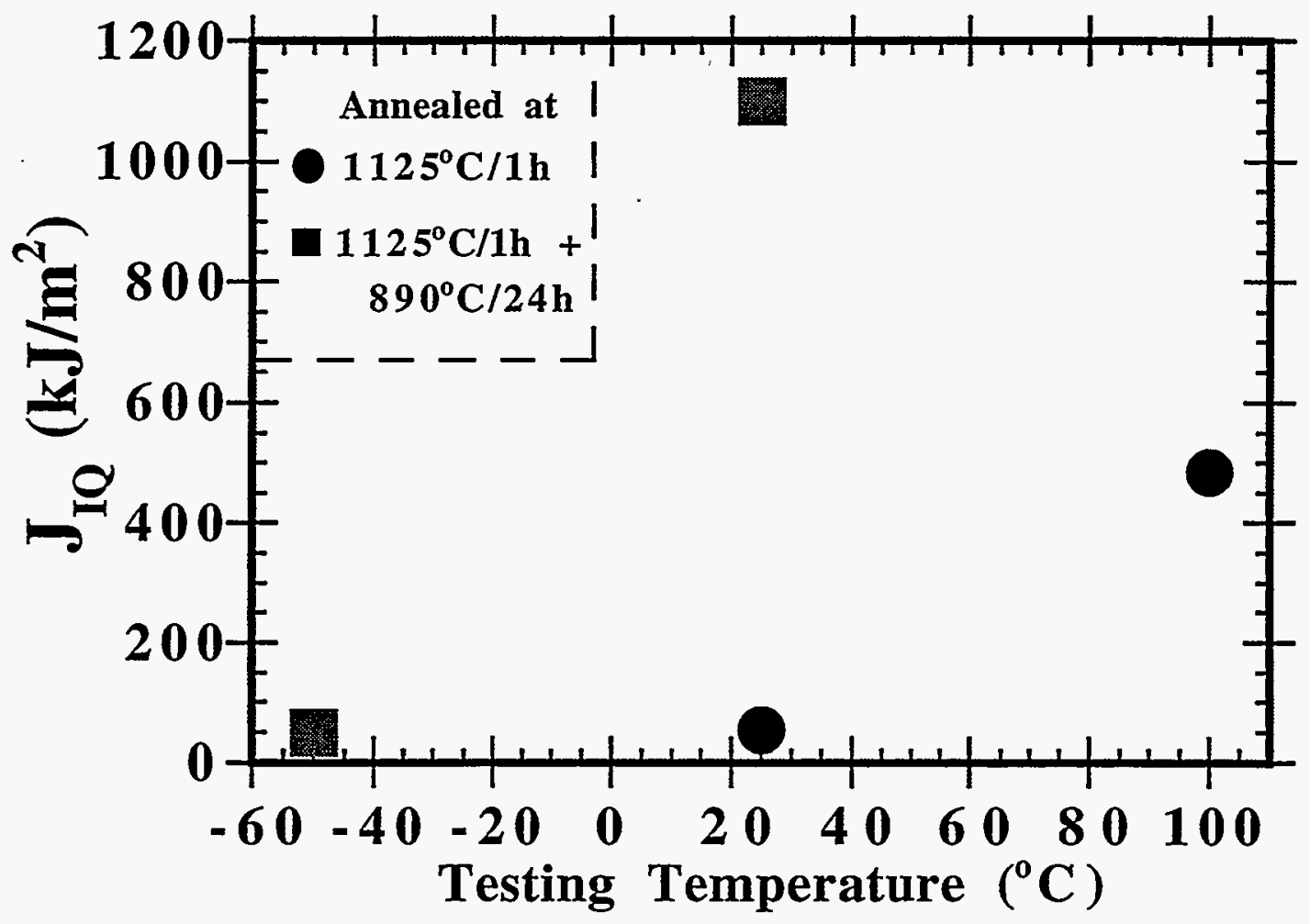

Fig. 5. Fracture toughness vs test temperature for specimens annealed either at $1125^{\circ}$ for $1 \mathrm{~h}$ or at $1125^{\circ} \mathrm{C}$ for $1 \mathrm{~h}$ plus $890^{\circ} \mathrm{C}$ for $24 \mathrm{~h}$. 


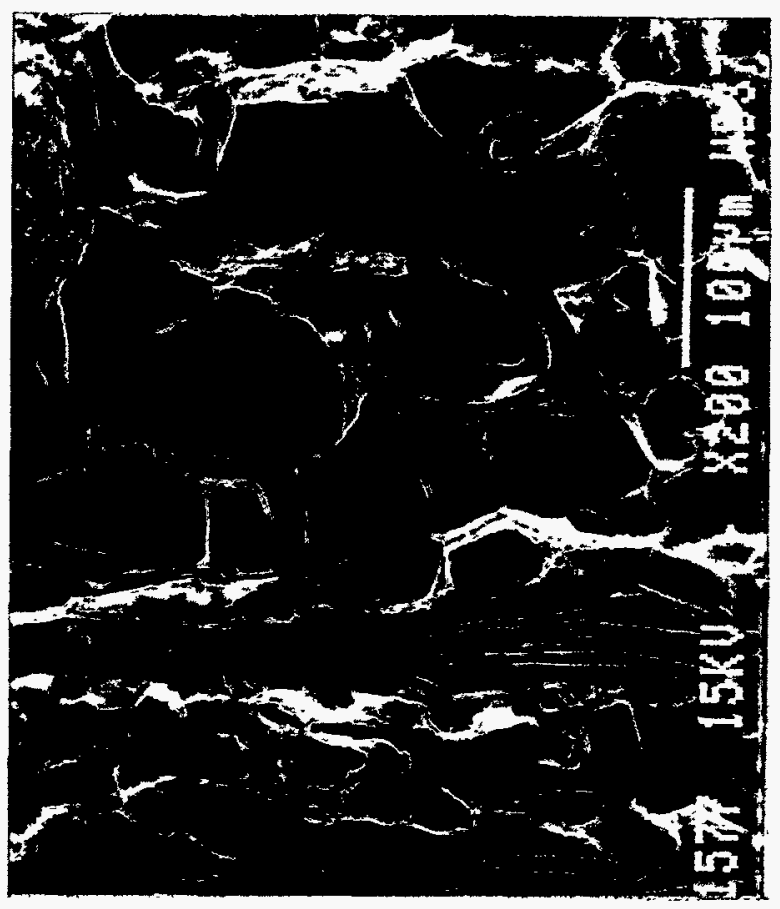

(a)

Fig. 6. Fracture surfaces of specimens annealed at $1125^{\circ} \mathrm{C}$ for $1 \mathrm{~h}$ and fractured at RT during K-testing. a) a mixture of intergranular, cleavage, and a little dimple failure; 


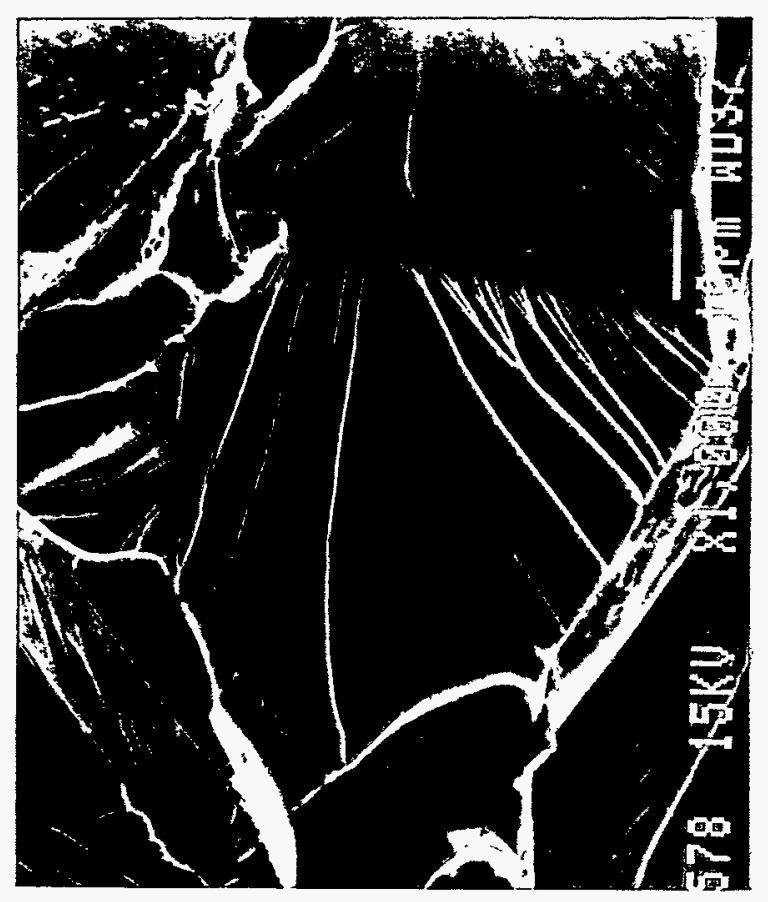

(b)

b) a cleavage fracture facet showing that the cleavage crack initiates at a grain boundary and passes through the whole grain. 


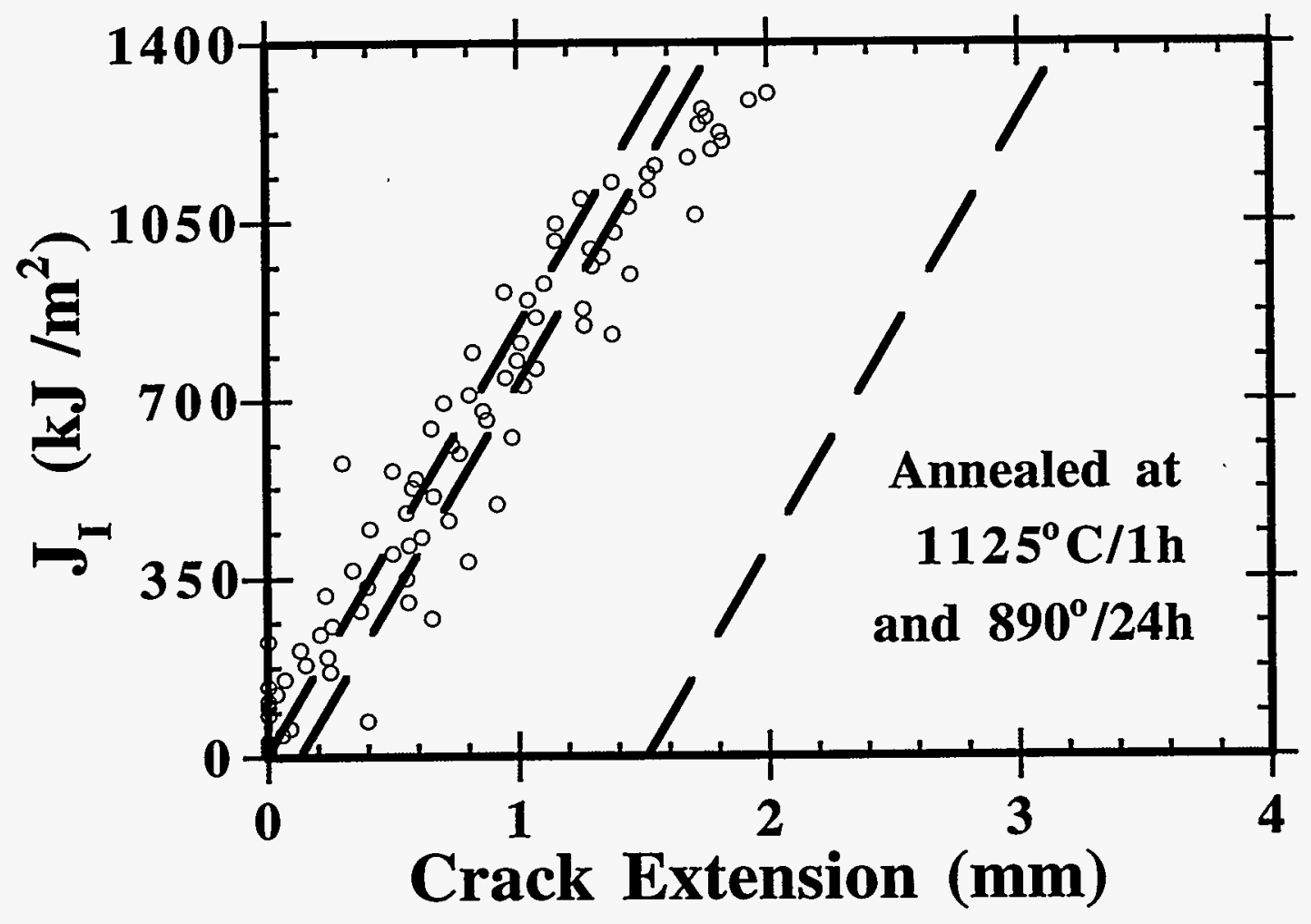

Fig. 7. The J-integral vs. crack growth curve generated from a specimen annealed at $1125^{\circ} \mathrm{C}$ for $1 \mathrm{~h}$ plus $890^{\circ} \mathrm{C}$ for $24 \mathrm{~h}$ during J-integral testing at RT. $\mathrm{J}_{\mathrm{IQ}}$ is estimated at about $1100 \mathrm{~kJ} / \mathrm{m}^{2}$. 


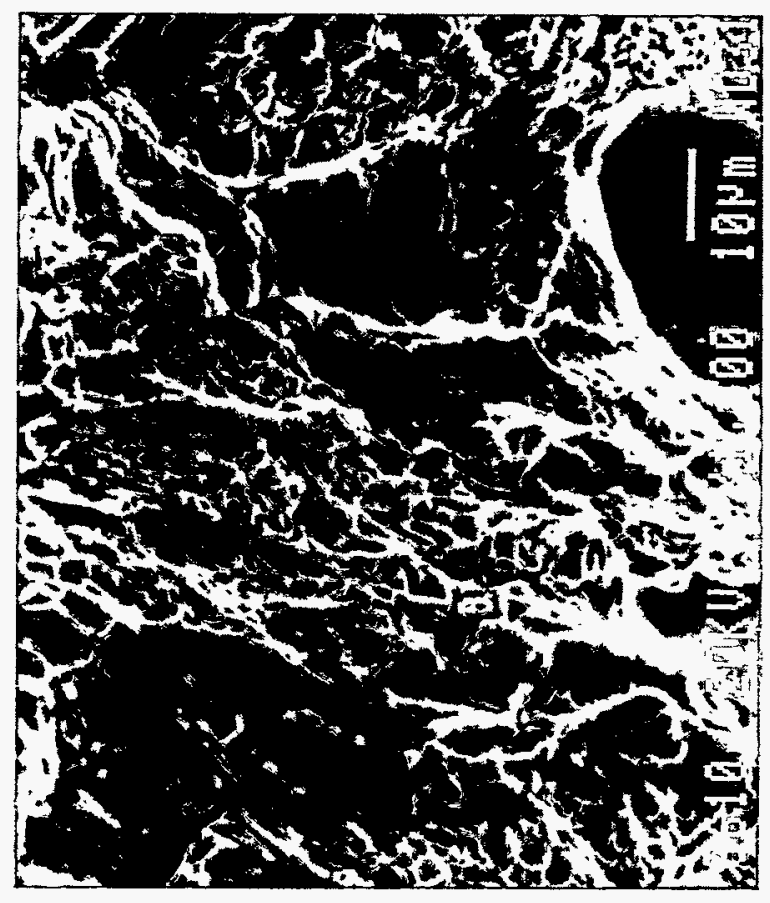

(a)

Fig. 8. The fracture surfaces of specimens annealed at $1125^{\circ} \mathrm{C}$ for $1 \mathrm{~h}$ plus $890^{\circ} \mathrm{C}$ for $24 \mathrm{~h}$. a) dimpled fracture at RT during J-integral testing; 


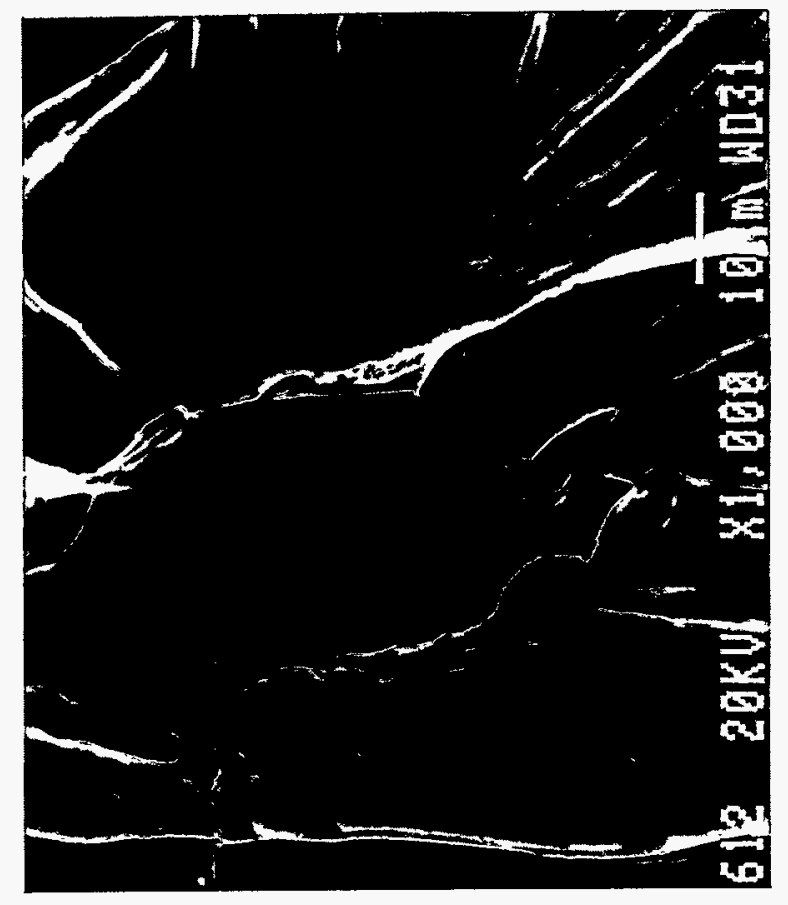

(b)

b) cleavage fracture $-50^{\circ} \mathrm{C}$ during $\mathrm{K}$ testing. 



\section{EFFECT OF PREIRRADIATION HEAT TREATMENT ON SWELLING OF NEUTRON-IRRADIATED VANADIUM-BASE ALLOYS* - B. Loomis, L. J. Nowicki, and D. L. Smith (Argonne National Laboratory)}

\section{OBJECTIVE}

The objective of this research is to determine the effect of preirradiation heat treatment on the physical and mechanical properties of neutron-irradiated vanadium-base alloys. These results are expected to show the importance of selecting appropriate preirradiation heat treatment for prime-candidate vanadium alloys that will result in the optimal combination of physical and mechanical properties of the alloy for use as structural material in a fusion reactor.

\section{SUMMARY}

The dependence of swelling of neutron-irradiated $\mathrm{V}-14 \mathrm{Cr}-5 \mathrm{Ti}, \mathrm{V}-7 \mathrm{Cr}-15 \mathrm{Ti}, \mathrm{V}-3 \mathrm{Ti}-0.3 \mathrm{Si}$, and $\mathrm{V}-18 \mathrm{Ti}$ alloys on preirradiation heat treatment (which consisted of a $1-\mathrm{h}$ annealing at either $850,950,1100,1125$, or $1200^{\circ} \mathrm{C}$ ) was determined from density measurements of the alloys after irradiation at either 420,520 , or $600^{\circ} \mathrm{C}$ to $21-88$ dpa. Swelling of the $\mathrm{V}-14 \mathrm{Cr}-5 \mathrm{Ti}$ alloy was minimal after $\mathrm{l}-\mathrm{h}$ annealing at $1125^{\circ} \mathrm{C}$, whereas swelling of the $\mathrm{V}$ $7 \mathrm{Cr}-15 \mathrm{Ti}$ alloy was minimal after $1-\mathrm{h}$ annealing at 1125 and $1200^{\circ} \mathrm{C}$. Swelling of the V-3Ti-0.3Si alloy increased when the annealing temperature was increased from $850^{\circ} \mathrm{C}$ to $1200^{\circ} \mathrm{C}$, and swelling of the V-18Ti alloy was minimal after preirradiation annealing at $1125^{\circ} \mathrm{C}$.

\section{INTRODUCTION}

Vanadium-base alloys have been identified as leading candidates for application as first-wall/blanket structural material in a fusion reactor [1-5]. The advantages of the physical and mechanical properties of vanadium-base alloys over other structural materials for a fusion reactor, in addition to their excellent safety and environmental features, have been evaluated in several design studies [1-5]. However, the effects of preirradiation heat treatment on the physical and mechanical properties of irradiated vanadium-base alloys have not been determined for selection of the heat treatment that will result in optimal combination of properties in the anticipated, hostile environment of a fusion reactor.

In a previous report [6], it was shown that the recovery of the microhardness of cold-worked (85\%) vanadiumbase alloys significantly depends on annealing temperature. Here, we present experimental data on the dependence of swelling of irradiated $\mathrm{V}-14 \mathrm{Cr}-5 \mathrm{Ti}, \mathrm{V}-7 \mathrm{Cr}-15 \mathrm{Ti}, \mathrm{V}-3 \mathrm{Ti}-0.3 \mathrm{Si}$, and $\mathrm{V}-18 \mathrm{Ti}$ alloys on preirradiation heat treatment. In a future report, we will present experimental data on the dependence of the tensile properties of these irradiated alloys on preirradiation heat treatment.

\section{MATERIALS AND PROCEDURES}

Specimens $\approx 3 \mathrm{~mm}$ in diameter and $0.3 \mathrm{~mm}$ thick were obtained from $50 \%$ cold-worked sheets of $\mathrm{V}-14 \mathrm{Cr}-5 \mathrm{Ti}$, V-7Cr-15Ti, V-3Ti-0.3Si, and V-18Ti alloys with the compositions listed in Table 1 . The cold-worked specimens were annealed at either $850,950,1100,1125$, or $1200^{\circ} \mathrm{C}\left( \pm 10^{\circ} \mathrm{C}\right)$ for $1 \mathrm{~h}$ in an ion-pumped vacuum system with a typical pressure of $1.3 \times 10^{-5} \mathrm{~Pa}$. The annealed specimens, irradiated in the Materials Open Test Assembly (MOTA) in the Fast Flux Test Facility (FFTF) reactor, were contained in sealed, $\mathrm{Li}^{7}$-filled, TZM molybdenum capsules to prevent contamination from oxygen, nitrogen, and carbon impurities in the sodium coolant of the FFTF. The specimens were irradiated at 420,520 , and $600^{\circ} \mathrm{C}$ to neutron fluences $(E>0.1 \mathrm{MeV})$ ranging from $3.9 \times 10^{22} \mathrm{n} / \mathrm{cm}^{2}(21 \mathrm{dpa})$ to $1.6 \times 10^{23} \mathrm{n} / \mathrm{cm}^{2}$ (88 dpa) during Cycles 9,10 , and 11 of the FFTFMOTA facility. The irradiated specimens were removed from the Li-filled, TZM molybdenum capsules by immersion of the opened capsules in liquid $\mathrm{NH}_{3}$ and subsequent immersion of the specimens in a mixture of

*Work supported by the Office of Fusion Energy, U. S. Department of Energy, under Contract W-31-109-Eng38. 
$50 \%$ ethanol and $50 \%$ methanol.

The swelling $(S)$ of an irradiated specimen was obtained by determining the density of an unirradiated $\left(D_{\text {snn }}\right)$

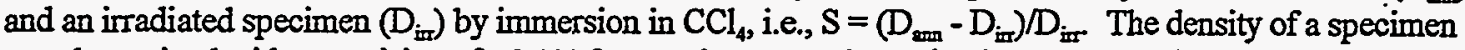
was determined with a precision of $\pm 0.1 \%$ from 3-6 separate determinations on a specimen.

Table 1. Composition of Vanadium-Base Alloys.

\begin{tabular}{cccccccc}
\hline Alloy & $\begin{array}{c}\text { ANL } \\
\text { ID }\end{array}$ & $\begin{array}{c}\text { Cr, } \\
\text { wt. \% }\end{array}$ & $\begin{array}{c}\text { Ti, } \\
\text { wt. \% }\end{array}$ & $\begin{array}{c}\text { O, } \\
\text { wt. ppm }\end{array}$ & $\begin{array}{c}\text { N, } \\
\text { wt.ppm }\end{array}$ & $\begin{array}{c}\text { C, } \\
\text { wt. ppm }\end{array}$ & $\begin{array}{c}\text { Si, } \\
\text { wt. ppm }\end{array}$ \\
\hline V-14Cr-5Ti & BL 24 & 13.5 & 5.2 & 1190 & 360 & 500 & 390 \\
V-7Cr-15Ti & BL 10 & 7.2 & 14.5 & 1110 & 250 & 400 & 400 \\
V-3Ti-0.3Si & BL 27 & - & 3.1 & 210 & 310 & 310 & 2500 \\
V-18Ti & BL 15 & - & 17.7 & 830 & 160 & 380 & 480 \\
\hline
\end{tabular}

\section{EXPERIMENTAL RESULTS}

The dependence of swelling on preirradiation heat treatment temperature of $\mathrm{V}-14 \mathrm{Cr}_{\mathrm{r}}-5 \mathrm{Ti}$ alloy after irradiation at 420,520 , and $600^{\circ} \mathrm{C}$ is shown in Fig. 1 . The data show that the swelling of this alloy was substantially reduced by increasing the preirradiation anneal temperature from 850 to $1100-1125^{\circ} \mathrm{C}$. Increase of the annealing temperature from 1125 to $1200^{\circ} \mathrm{C}$ resulted in significant increase of swelling.

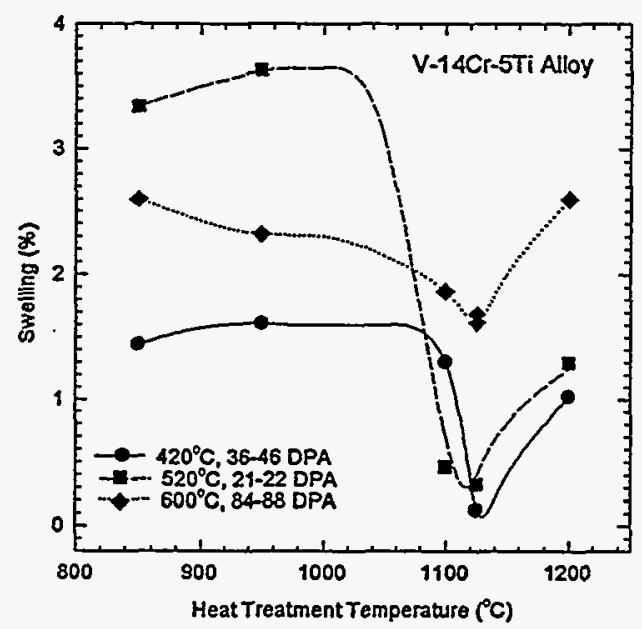

Fig. 1. Dependence of swelling of V-14Cr-5Ti alloy on temperature of preirradiation heat treatment.

Figure 2 shows the dependence of swelling on preirradiation heat treatment temperature of V-7Cr-15Ti alloy after irradiation at 420 and $600^{\circ} \mathrm{C}$. The swelling of this alloy increased when the heat treatment temperature was increased from $850^{\circ} \mathrm{C}$ to $1100^{\circ} \mathrm{C}$; it then decreased to a minimum when the heat treatment temperature was increased from 1125 to $1200^{\circ} \mathrm{C}$. 
The extent to which the swelling of V-3Ti-0.3Si alloy after irradiation at 420,520 , and $600^{\circ} \mathrm{C}$ depended on preirradiation heat treatment temperature is shown in Fig. 3. The swelling of this alloy generally increased with increase of heat treatment temperature from $850^{\circ} \mathrm{C}$ to $1200^{\circ} \mathrm{C}$.

Figure 4 shows the dependence of the swelling on preirradiation heat treatment temperature of the V-18Ti alloy after irradiation at 420,520 , and $600^{\circ} \mathrm{C}$. Although, the swelling of this alloy after irradiation at 420 and $520^{\circ} \mathrm{C}$ decreased significantly when the heat treatment temperature was increased from $850^{\circ} \mathrm{C}$ to $1125^{\circ} \mathrm{C}$, on irradiation at $600^{\circ} \mathrm{C}$, it did not strongly depend on preirradiation heat treatment temperature.

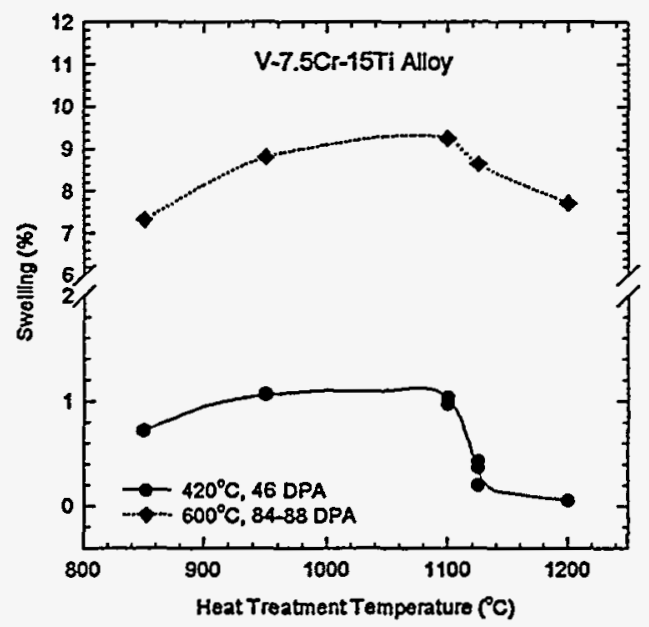

Fig. 2. Dependence of swelling of V-7Cr-15Ti alloy on preirradiation heat treatment temperature.

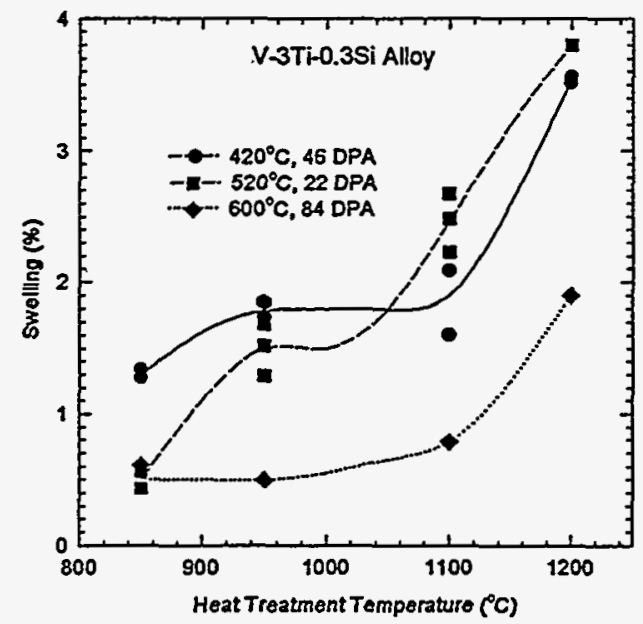

Fig. 3. Dependence of swelling of V-3Ti-0.3Si alloy on preirradiation heat treatment temperature. 


\section{DISCUSSION OF RESULTS}

Experimental data presented in Figs. 1-4 show that the swelling of V-14Cr-5Ti, V-7Cr-15Ti, V-3Ti-0.3Si, and $\mathrm{V}$-18Ti alloys strongly depends on preirradiation heat treatment. Therefore, it may be inferred that the swelling of other vanadium-base alloys, e.g., V-(3-5)Cr-(3-5)Ti alloys, which are the current focus of experimental effort, will exhibit a similar strong dependence of swelling on preirradiation heat treatment [7-10].

The microstructures of $50 \%$ cold-worked V-14Cr-5Ti, V-7Cr-15Ti, V-3Ti-1 Si, and V-18Ti alloys after annealing at 1050 and $1125^{\circ} \mathrm{C}$ for $1 \mathrm{~h}$ have been observed by optical and transmission electron microscopy by Gazda et al. [11]. The annealing conditions resulted in an average recrystallized-grain diameter of 0.02-0.04 $\mathrm{mm}$ and a dislocation density of $\approx 10^{13} \mathrm{~m}^{-2}$. It may be inferred from these results that a recrystallized microstructure contributed, in part, to the minimal swelling of the irradiated V-14Cr-5Ti, V-7Cr-15Ti, and V-18Ti alloys after a preirradiation heat treatment at $1125^{\circ} \mathrm{C}$.

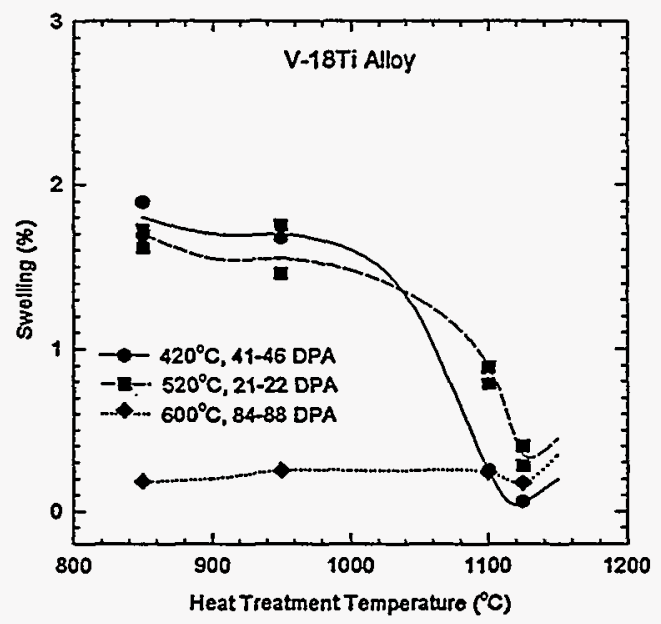

Fig. 4. Dependence of swelling of V-18Ti alloy on preirradiation heat treatment temperature.

However, other factors, e.g., grain growth, precipitate formation and growth, and dislocation structure, also must have contributed to the observed dependence of swelling on preirradiation heat treatment, because swelling of the $\mathrm{V}-14 \mathrm{Cr}-5 \mathrm{Ti}$ alloy increased when the preirradiation heat treatment temperature was increased to $1200^{\circ} \mathrm{C}$, swelling of the $\mathrm{V}-7 \mathrm{Cr}-15 \mathrm{Ti}$ alloy decreased when the heat treatment temperature was increased to $1200^{\circ} \mathrm{C}$, and swelling of the V-3Ti-0.3Si alloys generally increased when the heat treatment temperature was increased from $850^{\circ} \mathrm{C}$ to $1200^{\circ} \mathrm{C}$. Further interpretation of the dependence of swelling of these alloys on preirradiation heat treatment would be suppositious in the absence of a comprehensive series of microstructural observations by optical and transmission electron microscopy.

\section{FUTURE EFFORT}

1. The tensile properties of irradiated V-14Cr-5Ti, V-7Ci-15Ti, V-3Ti-0.3Si, and V-18Ti alloys subjected to different preirradiation heat treatments will be determined.

2. Swelling, tensile properties, and microhardness of the irradiated alloys will be correlated with the microstructures of alloys subjected to different preirradiation heat treatments. 


\section{REFERENCES}

[1]. D. L. Smith, et'al., Fusion Technology, 8, 10 (1985).

[2]. D. Ehst, et al., Tokamak Power System Studies, Argonne National Laboratory, Report ANL/FPP/86-1 (1986).

[3]. The ARIES Team, The ARIES-II Tokamak Reactor Study, University of California at Los Angeles, Report UCLA-PPG-1461.

[4]. J. Holdren, et al., "Report of the Senior Committee on Environmental, Safety, and Economic Aspects of Magnetic Fusion Energy," Lawrence Livermore National Laboratory, Report UCRL-53776 (1989).

[5]. H. K. Birnbaum, et al., "Technical Evaluation of the Technology of Vanadium Alloys for Use as Blanket Structural Materials in Fusion Power Systems, " Report DOE/ER-0313/100, August 4, 1993.

[6]. B. A. Loomis, L. J. Nowicki, and D. L. Smith, "Hardness Recovery of $85 \%$ Cold-Worked V-Ti and V-CrTi Alloys upon Annealing at $180^{\circ} \mathrm{C}$ to $1200^{\circ} \mathrm{C}$, "Fusion Reactor Materials Semiannual Progress Report for Period Ending September 30, 1994, Report DOE/ER-0313/17 (1995).

[7]. B. A. Loomis, L. J. Nowicki, and D. L. Smith, "Effect of Neutron Irradiation on Tensile Properties of VCr-Ti Alloys," J. Nucl. Mater. 212-215 (1994) 790-793.

[8]. B. A. Loomis, H. M. Chung, L. J. Nowicki, and D. L. Smith, "Effects of Neutron Irradiation and Hydrogen on Ductile-Brittle Transition Temperatures of V-Cr-Ti Alloys," J. Nucl. Mater. 212-215 (1994) 799-803.

[9]. H. M. Chung, B. A. Loomis, and D. L. Smith, "Effect of Irradiation Damage and Helium on Swelling and Structure of Vanadium-Base Alloys," J. Nucl. Mater. 212-215 (1994) 804-812.

[10]. H. M. Chung, B. A. Loomis, and D. L. Smith, "Creep Properties of Vanadium-Base Alloys," J. Nucl. Mater. 212-215 (1994) 772-777.

[11]. J. Gazda, B. A. Loomis, L. J. Nowicki, D. L. Smith, and S. Danyluk, "Relationship of Microstructure and Mechanical Properties of V-Cr-Ti Alloys," in: Fusion Reactor Materials Semiannual Progress Report for Period Ending September 30, 1993, pp. 232-239 (1994). 


\section{MICROSTRUCTURAL EVOLUTION OF V-4Cr-4Ti DURING DUAL-ION} IRRADIATION AT $350^{\circ} \mathrm{C}^{*} \mathrm{~J}$. Gazda and M. Meshii (Northwestern University), and B. A. Loomis and H. M. Chung (Argonne National Laboratory)

\section{OBJECTIVE}

The objective of this study is to simulate simultaneous irradiation by fusion-energy neutrons and helium generation in the reference vanadium alloy $\mathrm{V}-4 \mathrm{Cr}-4 \mathrm{Ti}$ at relatively low temperatures $\left(<400^{\circ} \mathrm{C}\right)$ by dual ion irradiation utilizing ${ }^{58} \mathrm{Ni}^{++}$and ${ }^{3} \mathrm{He}^{+}$ions generated in tandem ion accelerator/high voltage electron microscope facility in Argonne National Laboratory and to characterize the concomitant microstructural evaluation in the alloy.

\section{SUMMARY}

The preliminary results of TEM investigation of microstructural evolution of $\mathrm{V}-4 \mathrm{Cr}-4 \mathrm{Ti}$ (Heat \#832665) alloy irradiated with $4.5 \mathrm{MeV}{ }^{58} \mathrm{Ni}^{++}$ions at $350^{\circ} \mathrm{C}$, with and without simultaneous ${ }^{3} \mathrm{He}^{+}$injection, are presented. This work is the basis of an extensive study designed to evaluate ion irradiation experiments as a tool for simulating and understanding fusion neutron damage and helium generation in V-Cr-Ti alloys. The effects of ion-irradiation damage (at moderate temperatures of $\left\langle 400^{\circ} \mathrm{C}\right.$ ) on mechanical properties of these alloys will be also evaluated in this study. This initial report includes descriptions of specimen preparation techniques, procedures performed during ion irradiation, postirradiation analysis, and results of preliminary transmission electron microscopy (TEM) investigation. Specimens irradiated to $\approx 10 \mathrm{dpa}$ by ${ }^{58} \mathrm{Ni}^{++}$ions showed a high density of "black-dot" defects and dislocations. Cavity formation in the specimens irradiated simultaneously with ${ }^{3} \mathrm{He}^{+}$ions to a rate of $\approx 5 \mathrm{appm} / \mathrm{dpa}$ He was not observed.

\section{INTRODUCTION}

Vanadium-base alloys are the most promising candidate materials for application in fusion reactor first wall structures. Recently, the $\mathrm{V}-4 \mathrm{Cr}-4 \mathrm{Ti}$ alloy was identified as having the optimal combination of mechanical and physical properties. ${ }^{1}$ Previous ion and neutron irradiation experiments have demonstrated that several $\mathrm{V}-\mathrm{Cr}-\mathrm{Ti}, \mathrm{V}-\mathrm{Ti}$, and $\mathrm{V}-\mathrm{Ti}-\mathrm{Si}$ alloys retain high ductility, toughness, and strength and undergo minimal irradiation-induced swelling during irradiation in the temperature range of 425 to $600^{\circ} \mathrm{C} .^{2-9}$ However, there is lack of information on the irradiation performance of vanadium-base alloys in the moderate temperature range $\left(200\right.$ to $\left.425^{\circ} \mathrm{C}\right)$ relevant to, e.g., the projected operational conditions of the International Thermonuclear Experimental Reactor (ITER). Of particular importance are the confirmation of minimal swelling and the demonstration of good resistance to embrittlement by displacement damage and helium in this irradiation temperature range.

The customary method for determining the irradiation performance of fusion candidate materials is to conduct fission-reactor tests utilizing fast neutrons (E $>0.1 \mathrm{MeV}$ ), e.g., in FFTF and EBR-II. Unfortunately, because these fast fission reactors are no longer available, alternate means must be sought. One option is simulation of neutron damage by irradiation with ions, and extrapolation of the results to predict property changes due to neutron irradiation effects. This study follows such an approach in evaluating the irradiation performance of vanadium-base alloys at moderate temperatures. Preliminary work consisted of irradiating specimens at $350^{\circ} \mathrm{C}$ to $10 \mathrm{dpa}$. Microstructural changes in the production-scale $(500-\mathrm{kg})$ heat ${ }^{10}$ of $\mathrm{V}-4 \mathrm{Cr}-4 \mathrm{Ti}$ alloy were generated by single $\left({ }^{58} \mathrm{Ni}^{++}\right)$and dual $\left({ }^{58} \mathrm{Ni}^{++}\right.$and $\left.{ }^{3} \mathrm{He}^{+}\right)$ion beam irradiation in the tandem ion accelerator/high voltage electron microscope facility located at Argonne National Laboratory. Conventional TEM observations were performed to identify the type and number density of produced defects, precipitates, and voids.

\footnotetext{
- Work supported by U.S. Department of Energy, Office of Fusion Energy Research, under Contract W-31-109-Eng-38.
} 
In a previous investigation of a laboratory-scale (30-kg) heat of V-4CI-4Ti (ANL ID BL-47) irradiated in the Dynamic Helium Charging Experiment (DHCE), contrasting behaviors of irradiation-induced precipitation of $\mathrm{Ti}_{5} \mathrm{Si} 3$ and helium bubbles were observed upon irradiation at $500-600^{\circ} \mathrm{C}$ and $425^{\circ} \mathrm{C}$. ${ }^{9}$ That is, $\mathrm{Ti}_{5} \mathrm{Si}_{3}$ precipitation was significant and helium bubbles were negligible at the high irradiation temperatures, whereas $\mathrm{Ti}_{5} \mathrm{Si}_{3}$ precipitation was negligible and helium bubble density was relatively higher at the low irradiation temperature. In view of this, special attention was given to characterizing the behavior of $\mathrm{Ti}_{5} \mathrm{Si}_{3}$ precipitation and $\mathrm{He}$ bubble formation at $\angle 400^{\circ} \mathrm{C}$ in the dual-ion-irradiated specimens.

\section{MATERIAL AND PROCEDURES}

Fabrication of the V-4Cr-4Ti (Heat ID 832665) alloy is described in Ref. 10. Chemical composition of the extruded alloy plate is given in Table 1 . Specimens for ion irradiation were prepared from $\approx 250-\mathrm{mm}-$ thick cold-worked sheets obtained by cold rolling of $1.02 \mathrm{~mm}$ plate without intermediate annealing. The 3-mm-diameter TEM disks were punched out, polished to $0.05 \mathrm{~mm}$ surface finish, and annealed in $1 \times 10^{-5} \mathrm{~Pa}$ vacuum in an ion-pumped ultrahigh vacuum-furnace for $1 \mathrm{~h}$ at $1050^{\circ} \mathrm{C}$. The resultant average grain diameter was $\approx 30 \mathrm{~mm}$. Disks were then electropolished to remove thermal etching and ensure the flat surface necessary for ion irradiation. The ion irradiations were performed at the Argonne Tandem Accelerator facility operated by the Materials Science Division. Beams of $4.5 \mathrm{MeV}{ }^{58} \mathrm{Ni}^{++}$were produced by the 2-MV NEC tandem ion accelerator. The $0.35 \mathrm{MeV}^{3} \mathrm{He}^{+}$ion beams were obtained from the $0.65-\mathrm{MV}$ NEC ion implanter. The ion chambers used for the irradiations allow simultaneous irradiation with both types of ions. Irradiation temperature was $350 \pm 2^{\circ} \mathrm{C}$, and vacuum was maintained at $1 \times 10^{-6} \mathrm{~Pa}$ in the chambers during irradiation.

Table 1. Chemical composition (impurities in wppm) of production heat of $\mathrm{V}-4 \mathrm{Cr}-4 \mathrm{Ti}$

\begin{tabular}{llllllllllllllllll}
\hline Heat ID & ANL ID & Heat Type & $\mathrm{Cr}$ & $\mathrm{Ti}$ & $\mathrm{Cu}$ & $\mathrm{Si}$ & $\mathrm{O}$ & $\mathrm{N}$ & $\mathrm{C}$ & $\mathrm{S}$ & $\mathrm{P}$ & $\mathrm{Ca}$ & $\mathrm{Cl}$ & $\mathrm{Na}$ & $\mathrm{K}$ & $\mathrm{B}$ \\
\hline 832665 & BL-71 & $\begin{array}{c}\text { production } \\
500 \mathrm{~kg}\end{array}$ & $\begin{array}{c}3.8 \\
\text { wt.\% }\end{array}$ & $\begin{array}{c}3.9 \\
\text { wt.\% }\end{array}$ & $<50$ & 783 & 310 & 85 & 80 & $<10$ & $<30$ & $<10$ & $<2$ & - & - & $<5$ \\
\hline
\end{tabular}

After irradiation, TEM foils were prepared by removing a 800-nm thick section from the irradiated surface and back thinning the specimen to electron transparency. The depth of $800 \mathrm{~nm}$ was selected based on the basis of computer simulation (TRIM code ${ }^{11}$ ) of ion deposition depths and damage profiles. Thin foils prepared at this depth allow observation of the region with maximum He deposition rate and significant irradiation damage rate. In Fig. 1, examples of damage profiles calculated by the TRIM code are given. An optical photomicrograph of typical grain structure of the material is shown in Fig. 2.

\section{RESULTS}

TEM investigation of the specimens irradiated to $\approx 10 \mathrm{dpa}$ with and without implantation of 50 appm $\mathrm{He}$ showed a rather simple microstructure. The prevailing features consisted of a high density of "black dot" defects and small dislocations present in the matrix. The observed dislocations were both small loops ( $<50 \mathrm{~nm}$ diameter) and small segments with Burgers vector $\mathrm{a}_{0}<100>$. No irradiation-induced or -enhanced precipitation was observed. This seems to be consistent with a previous report in which $\mathrm{Ti}_{5} \mathrm{Si}_{3}$ precipitates, usually present in $\mathrm{V}-4 \mathrm{Cr}-4 \mathrm{Ti}$ after neutron irradiation at $500-600^{\circ} \mathrm{C}$, were absent after neutron irradiation at $425^{\circ} \mathrm{C} .9$ The specimens with injected helium did not show cavity formation in the matrix or near grain boundaries. Figure 3 is a TEM micrograph of nonirradiated $\mathrm{V}-4 \mathrm{Cr}-4 \mathrm{Ti}$ alloy. Figure 4 shows the microstructure after $\approx 10 \mathrm{dpa}$ irradiation with $4.5 \mathrm{MeV} \mathrm{Ni}$ ions, while Fig. 5 shows the microstructure after $\approx 10 \mathrm{dpa}$ irradiation and $5 \mathrm{appm} / \mathrm{dpa}$ He injection. 

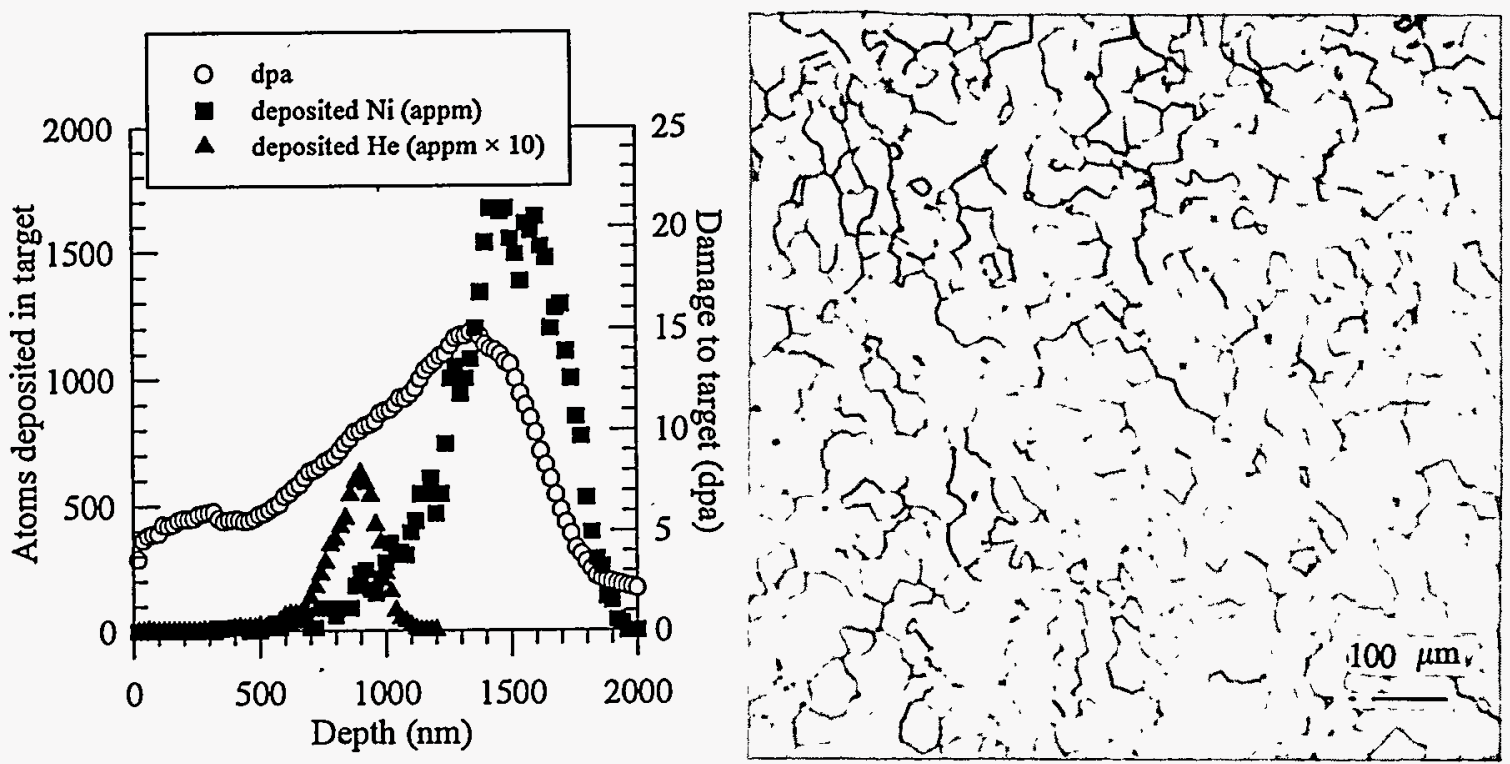

Fig. 1. Damage profile and atom deposition profiles calculated by TRIM Version 92.12 for $4.5 \mathrm{MeV} \mathrm{Ni}{ }^{++}$ions and $0.35 \mathrm{MeV} \mathrm{He}{ }^{+}$ ions irradiating $\mathrm{V}-4 \mathrm{Cr}-4 \mathrm{Ti}$ alloy

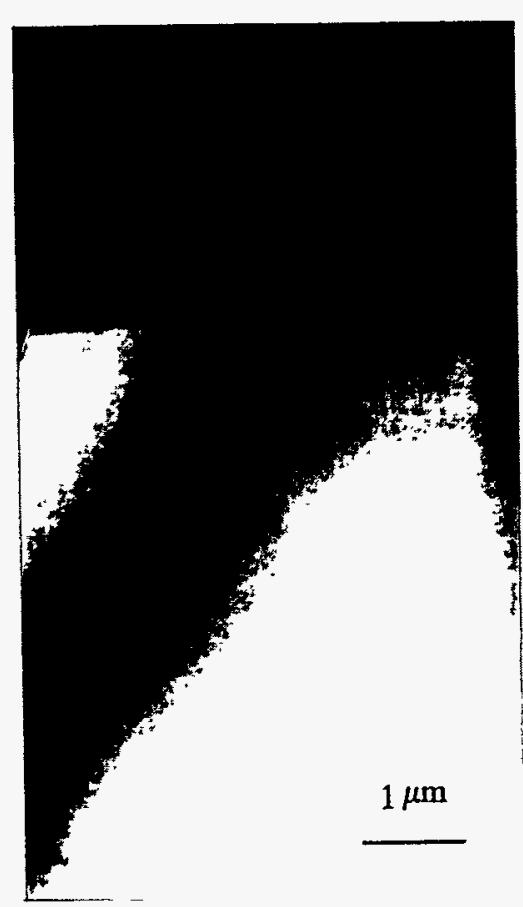

Fig. 3. TEM micrograph of unirradiated $\mathrm{V}-4 \mathrm{Cr}-4 \mathrm{Ti}$

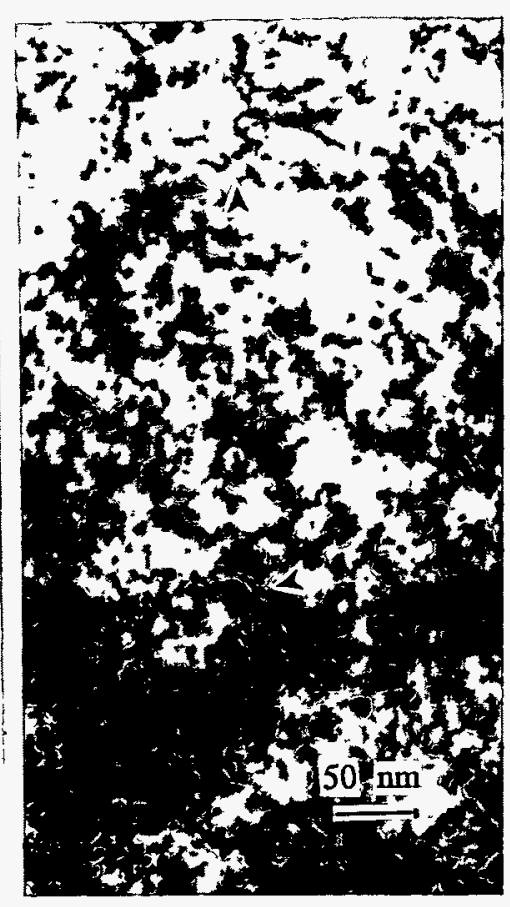

Fig. 4. TEM micrograph of $\mathrm{V}-4 \mathrm{Cr}-4 \mathrm{Ti}$ irradiated at $350^{\circ} \mathrm{C}$ with $4.5 \mathrm{MeV}$ $\mathrm{Ni}^{++}$ions to $\approx 10 \mathrm{dpa}$

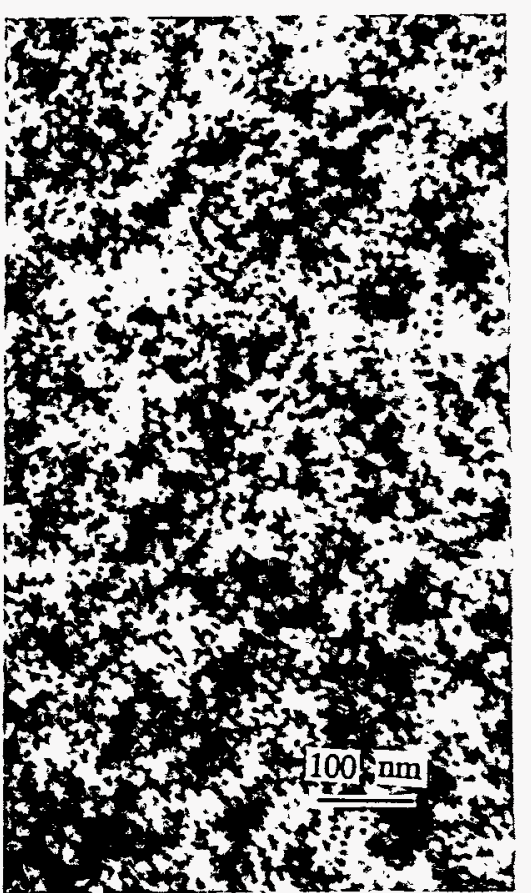

Fig. 5. TEM micrograph of $\mathrm{V}-4 \mathrm{Cr}-4 \mathrm{Ti}$ irradiated at $350^{\circ} \mathrm{C}$ with $4.5 \mathrm{MeV}$ $\mathrm{Ni}^{++}$ions to $\approx 10 \mathrm{dpa}$ with $\approx 50$ appm $\mathrm{He}^{+}$ implanted 


\section{FUTURE WORK}

Future work on this project will include a variety of $\mathrm{Ni}$ ion irradiations with and without He injection. Two series of experiments are planned: (a) exploring alloy performance under various irradiation doses at $200^{\circ} \mathrm{C}$ and (b) investigating temperature effects within the range of 25 to $425^{\circ} \mathrm{C}$ at 5 dpa. Results of these investigations will be compared to results from fast neutron irradiation of the same production-scale heat of $\mathrm{V}-4 \mathrm{Cr}-4 \mathrm{Ti}$ in the EBR-II X-530 experiment $\left(\approx 5 \mathrm{dpa}\right.$ at $\left.375^{\circ} \mathrm{C}\right)$.

\section{REFERENCES}

1. H. M. Chung, B. A. Loomis, and D. L. Smith, "Properties of V-4Cr-4Ti for Application as Fusion Reactor Structural Components," Fusion Eng. Design 29 (1995), pp. 455-464.

2. B. A. Loomis, L. Nowicki, and D. L. Smith, "Effect of Neutron Irradiation on Tensile Properties of V-Cr-Ti Alloys," in Fusion Reactor Materials, Semiannual Prog. Report, DOE/ER-0313/15, Oak Ridge National Laboratory, Oak Ridge, TN (1994), pp. 219-222.

3. B. A. Loomis, H. M. Chung, L. Nowicki, and D. L. Smith, "Effects of Neutron Irradiation and Hydrogen on Ductile-Brittle Transition Temperatures of V-Cr-Ti Alloys," ibid., pp. 253-257.

4. H. M. Chung, B. A. Loomis, L. Nowicki, J. Gazda, and D. L. Smith, "Irradiation-Induced Density Change and Microstructural Evolution of Vanadium-Base Alloys," ibid., pp. 223-231.

5. H. M. Chung, B. A. Loomis, and D. L. Smith, "Thermal Creep Behavior of V-5Cr-5Ti and V-10Cr-5Ti Alloys," in Fusion Reactor Materials, Semiannual Prog. Report, DOE/ER-0313/14, Oak Ridge National Laboratory, Oak Ridge, TN (1993), pp. 309-317.

6. H. M. Chung, B. A. Loomis, and D. L. Smith, in Effects of Radiation on Materials, ASTM-STP 1175, A. S. Kumar, D. S. Gelles, R. K. Nanstad, and T. A. Little, Eds., American Society for Testing and Materials, Philadelphia, 1993, pp. 1185-1200.

7. H. M. Chung, B. A. Loomis, L. Nowicki, and D. L. Smith, "Effect of Dynamically Charged Helium on Tensile Properties of $\mathrm{V}-4 \mathrm{Cr}-4 \mathrm{Ti}$," in Fusion Reactor Materials, Semiannual Prog. Report for Period Ending September 30, 1994, DOE/ER-0313/17, Oak Ridge National Laboratory, Oak Ridge, TN, in press.

8. H. M. Chung, L. J. Nowicki, D. E. Busch, and D. L. Smith, "Ductile-Brittle Transition Behavior of $\mathrm{V}-4 \mathrm{Cr}-4 \mathrm{Ti}$ Irradiated in the Dynamic Helium Charging Experiment," in Fusion Reactor Materials, Semiannual Prog. Report for Period Ending September 30, 1994, DOE/ER-0313/17, Oak Ridge National Laboratory, Oak Ridge, TN, in press.

9. H. M. Chung, L. Nowicki, J. Gazda, and D. L. Smith, "Void Structure and Density Change of Vanadium-Base Alloys Irradiated in the Dynamic Helium Charging Experiment," in Fusion Reactor Materials, Semiannual Prog. Report for Period Ending September 30, 1994, DOE/ER-0313/17, Oak Ridge National Laboratory, Oak Ridge, in press.

10. H. M. Chung, H.-C. Tsai, D. L. Smith, R. Peterson, C. Curtis, C. Wojcik, and R. Kinney, "Fabrication of 500-kg Heat of $\mathrm{V}-4 \mathrm{Cr}-4 \mathrm{Ti}$," in Fusion Reactor Materials, Semiannual Prog. Report for Period Ending Scptember 30, 1994, DOE/ER-0313/17, Oak Ridge National Laboratory, Oak Ridge, $\mathrm{TN}$, in press.

11. "TRIM-The Transport of Ions in Matter," Version 92, J. F. Ziegler, IBM Research Yorktown, NY; see also "The Stopping and Range of Ions in Solids," J. F. Ziegler, J. P. Biersack, and U. Littmach, Pergamon Press, New York, 1985. 


\section{EFFECT OF OXIDATION ON TENSILE BEHAVIOR OF V-5Cr-5Ti ALLOY* \\ K. Natesan and W. K. Soppet (Argonne National Laboratory)}

\section{OBJECTIVE}

The objectives of this task are to (a) evaluate the oxygen uptake of V-5Cr-5Ti alloy as a function of temperature and oxygen partial pressure in the exposure environment, (b) examine the microstructural characteristics of oxide scales and oxygen trapped at the grain boundaries in the substrate alloy, (c) evaluate the influence of oxygen uptake on the tensile properties of the alloy at room and elevated temperatures, (d) evaluate oxidation kinetics of the alloy with aluminum-enriched surface layers, and (e) determine the effect of oxygen uptake on the tensile behavior of the alloy.

\section{SUMMARY}

Oxidation studies were conducted on $\mathrm{V}-5 \mathrm{Cr}-5 \mathrm{Ti}$ alloy specimens at $500^{\circ} \mathrm{C}$ in air to evaluate oxygen uptake of the alloy as a function of temperature and exposure time. The oxidation rates derived from thermogravimetric testing are 5,17 , and $27 \mu \mathrm{m}$ after one year of exposure at 300,400 and $500^{\circ} \mathrm{C}$, respectively. Uniaxial tensile tests were conducted on preoxidized specimens of the alloy to examine the effects of oxidation and oxygen migration on tensile strength and ductility. Microstructural characteristics of several of the tested specimens were characterized by electron optic techniques. Correlations have been developed between tensile strength and ductility of the oxidized alloy and microstructural characteristics such as oxide thickness, depths of hardened layers, depths of intergranular fracture zones, and lengths of transverse cracks.

\section{INTRODUCTION}

Refractory alloys in general and vanadium alloys in particular are susceptible to pickup of interstitials such as oxygen, carbon, and nitrogen, which can affect the short- and long-term mechanical properties of the materials. The vanadium alloy with a composition of $\mathrm{V}-5 \mathrm{Cr}-5 \mathrm{Ti}$ contains $5 \mathrm{wt}$.\% Ti (a much more stable oxide-former than $\mathrm{V}$ and $\mathrm{Cr}$ ), which can have an even stronger effect on mechanical properties, especially on tensile and creep ductility. The degree of influence of interstitials such as oxygen on the alloy's properties will be dictated by alloy grain size (the amount of grain-boundary areas), amount and distribution of oxygen in the alloy, amount and size of second-phase oxide precipitates (such as Ti oxide), service temperature and time of exposure. The purpose of this study is to examine the role of oxygen and oxidation rate on tensile properties of the alloy.

\section{EXPERIMENTAL PROGRAM}

The heat of vanadium alloy selected for the study had a nominal composition of $\mathrm{V}-5 \mathrm{wt} . \% \mathrm{Cr}-5 \mathrm{wt}$.\%Ti and was designated as BL-63. Actual composition of the alloy is given in Table 1. A sheet of the alloy was annealed for $1 \mathrm{~h}$ at $1050^{\circ} \mathrm{C}$ prior to its use in oxidation and tensile testing. Coupon specimens measuring $\approx 15 \times 7.5 \times 1 \mathrm{~mm}$ were used for the oxidation studies. Oxidation experiments were conducted in air in a thermogravimetric test apparatus. The test temperatures ranged from 300 to $650^{\circ} \mathrm{C}$.

Tensile specimens were fabricated according to ASTM specifications with a gauge length of $\approx 19 \mathrm{~mm}$ and a gauge width of $\approx 4.5 \mathrm{~mm}$. Grain size of the specimens was $\approx 32 \mu \mathrm{m}$. The specimens were preoxidized in air at $500^{\circ} \mathrm{C}$ for $24,250,600,1000$, and $2060 \mathrm{~h}$ prior to tensile testing in air at $500^{\circ} \mathrm{C}$. As-annealed specimens were tensile tested on an Instron machine at constant crosshead speeds between 0.0005 and 0.2 $\mathrm{cm} / \mathrm{min}$. These speeds correspond to initial strain rates in the range of $4.3 \times 10^{-6}$ and $1.8 \times 10^{-3} \mathrm{~s}^{-1}$. The preoxidized specimens were tested at a strain rate of $1.75 \times 10^{-4} \mathrm{~s}^{-1}$. All tests were performed in air at $500^{\circ} \mathrm{C}$ and the test temperature was maintained within $\pm 2^{\circ} \mathrm{C}$. The specimens were loaded by means of pins

\footnotetext{
*This work has been supported by the U.S. Department of Energy, Office of Fusion Energy Research, under Contract W-31-109-Eng-38.
} 
that pass through holes in the enlarged end sections, thus minimizing misalignment. Total elongation was measured by vernier caliper on the tested specimens and from load/elongation chart records. The fracture surfaces and longitudinal and axial cross sections of tested specimens were examined by scanning electron microscopy (SEM) and optical metallography. In addition, Vickers hardness measurements were made on several of the tested specimens. Coupon specimens of the alloy that were oxidized along with the tensile specimens were analyzed for their bulk oxygen content by the vacuum-fusion technique.

\section{RESULTS AND DISCUSSION}

Oxidation Behavior. Oxidation of the alloy followed parabolic kinetics with time. Detailed SEM analysis of the oxidized samples showed that the outer layer was predominantly vanadium-rich oxide and the inner layer was $(\mathrm{V}, \mathrm{Ti})$ oxide. A parabolic rate equation was used to calculate oxide scale thicknesses, which were in agreement with the values determined by metallography; the results are discussed in an earlier report (1).

Effect of Oxidation on Tensile Properties. To evaluate the effects of oxidation and oxide penetration into the substrate alloy, several tests were conducted to examine the tensile behavior of the alloy as a function of oxygen ingress and oxide scale formation. Tensile specimens were exposed to air for 24-2060 h in air at $500^{\circ} \mathrm{C}$ and then tensile tested in air at the same temperature. Most of the tests were conducted at a strain rate of $1.8 \times 10^{-4} \mathrm{~s}^{-1}$.

Figure 1 shows the engineering stress/engineering strain curves for specimens after oxidation for several exposure times in a range 0-2060 h. The data indicate that the stress/strain behavior of the alloy is virtually unaffected by $24-\mathrm{h}$ exposure in air at $500^{\circ} \mathrm{C}$. As the exposure time increases to $250 \mathrm{~h}$, alloy strength increases, with some loss in tensile ductility. In the exposure period of $250-1000 \mathrm{~h}$, the alloy has essentially the same ultimate tensile strength, but tensile ductility is reduced from 0.21 at $24 \mathrm{~h}$ exposure to 0.14 at $1000 \mathrm{~h}$. Further exposure of the alloy to air at $500^{\circ} \mathrm{C}$ results in loss of strength and tensile ductility, as evidenced by the stress/strain curve for the specimen preoxidized for $2060 \mathrm{~h}$.

Microstructural Observations. Axial cross sections of several tested specimens were examined SEM. Figure 2 shows sections of specimen tested in as-annealed condition and after oxidation for 24, 250, 1000, and $2060 \mathrm{~h}$ in air at $500^{\circ} \mathrm{C}$. Crack depths in the transverse direction increase as the oxidation time increases. Further, crack spacing in the axial direction increases as oxidation time is increased. As oxidation time increases, the alloy undergoes little necking in the gauge section of the specimen during the tensile test. It is evident, especially from the 1000 and $2060 \mathrm{~h}$ specimens, that fracture occurred by propagation of one of these axial cracks and that because the core of the alloy is somewhat ductile, the crack propagation direction in the core region is $\approx 45^{\circ}$.

Figure 3 shows SEM photomicrographs of fracture surfaces of specimens tested in as-annealed condition and after oxidation for several time periods. The fracture mode was predominantly ductile in the as-annealed specimen. The specimen exposed for $24 \mathrm{~h}$ to air at $500^{\circ} \mathrm{C}$ showed a layer of grain-boundary or cleavage morphology to a depth of $\approx 25 \mu \mathrm{m}$, beyond which a ductile fracture mode was observed. With increases in oxidation time, the zone of intergranular fracture increased, and for the $2060 \mathrm{~h}$ oxidized specimen the depth of this zone was $165 \mu \mathrm{m}$.

Table 1 lists the calculated and measured thicknesses of oxide layers, depths of hardened layers (from Vickers hardness measurements), thicknesses of intergranular fracture zone, and lengths of transverse cracks for asannealed/preoxidized specimens that were tensile tested at $500^{\circ} \mathrm{C}$. The data in Table 1 show that the oxide layer is fairly thin even after $2060 \mathrm{~h}$ exposure to air at $500^{\circ} \mathrm{C}$. However, oxygen diffusion into the substrate alloy and its enrichment in the surface regions of the specimens alter the fracture mode from ductile to cleavage. Further, thicknesses of the zones of intergranular fracture are in agreement with the crack lengths measured in the transverse direction. The difference in intergranular fracture zone thickness and crack length can be attributed to a subsurface oxygen-enriched layer that is not fully brittle. There is also a threshold oxygen concentration in the alloy for embrittlement to ensue, and this aspect is presently being investigated. Figure 4 shows variations in hardened layer thickness, intergranular fracture zone thickness, and transverse crack length as a function of oxidation time. Tensile rupture strain values are also 
shown in the figure. Results to date indicate that the alloy is not subject to catastrophic embrittlement due to oxygen ingress into the material. Additional exposures as a function of oxygen partial pressure in the exposure environment, as well as tensile tests at lower temperatures, are in progress to establish the performance envelope for the alloy in an oxygenated environment.

\section{REFERENCES}

1. K. Natesan and W. K. Soppet, "Effect of Oxidation on Tensile Behavior of V-5Cr-5Ti Alloy," Argonne National Laboratory, Fusion Reactor Materials Semiannual Progress Report for the Period Ending September 30, 1994, Argonne National Laboratory.

Table 1. Oxidation, hardness, and fracture data for $\mathrm{V}-5 \mathrm{Cr}-5 \mathrm{Ti}$ alloy at $500^{\circ} \mathrm{C}$

\begin{tabular}{ccccccc}
\hline $\begin{array}{c}\text { Exposure } \\
\text { time }(\mathrm{h})\end{array}$ & $\begin{array}{c}\text { Calculated } \\
\text { oxide } \\
\text { thickness } \\
(\mu \mathrm{m})\end{array}$ & $\begin{array}{c}\text { Measured } \\
\text { oxide } \\
\text { thickness } \\
(\mu \mathrm{m})\end{array}$ & $\begin{array}{c}\text { Depth of } \\
\text { hardened } \\
\text { layer }(\mu \mathrm{m})\end{array}$ & $\begin{array}{c}\text { Thickness of } \\
\text { intergranular- } \\
\text { fracture zone } \\
(\mu \mathrm{m})\end{array}$ & $\begin{array}{c}\text { Measured } \\
\text { crack length } \\
(\mu \mathrm{m})\end{array}$ & $\begin{array}{c}\text { Rupture } \\
\text { strain }\end{array}$ \\
\hline 0 & 0 & 0 & 0 & 0 & 10 & 0.233 \\
24 & 1.4 & 1.2 & $<25$ & 25 & 22 & 0.215 \\
250 & 4.6 & 5.0 & 45 & 65 & 50 & 0.172 \\
600 & 7.1 & 7.1 & 68 & 100 & 90 & 0.143 \\
1000 & 9.1 & 9.0 & 80 & 120 & 110 & 0.135 \\
2060 & 13.1 & 14.0 & 120 & 165 & 160 & 0.090 \\
\hline
\end{tabular}

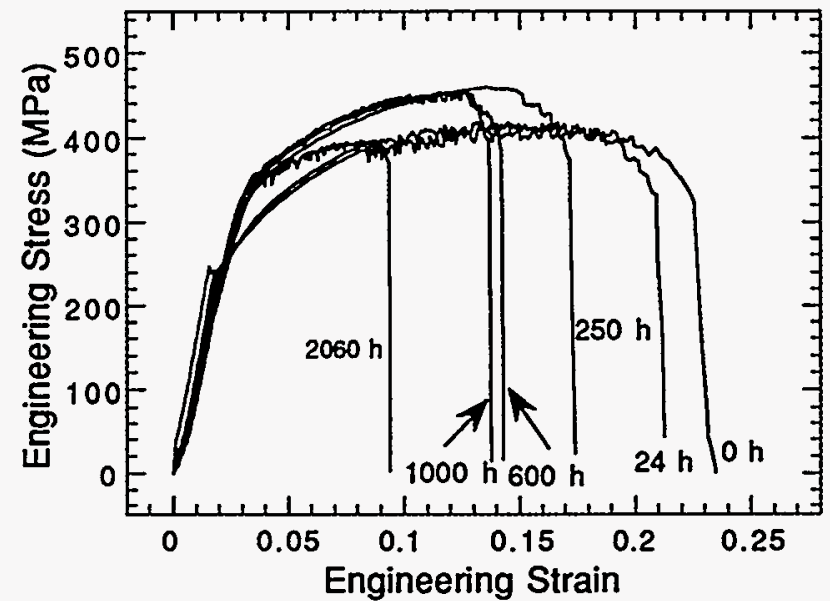

Figure 1. Effect of preoxidation at $500^{\circ} \mathrm{C}$ on stress-strain behavior of V-5Cr-5Ti.alloy tested at $500^{\circ} \mathrm{C}$ in air at a strain rate of $1.75 \times 10^{-4} \mathrm{~s}^{-1}$. 


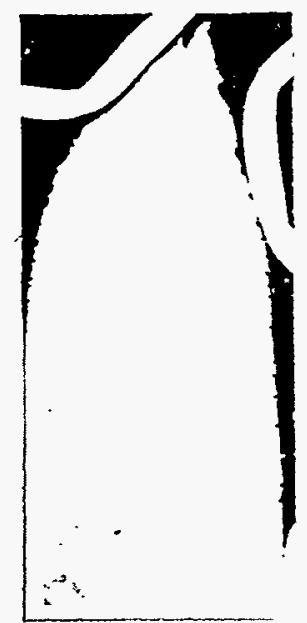

As annealed

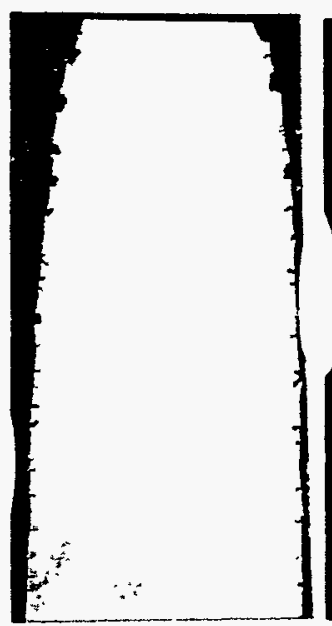

$24 \mathrm{~h}$

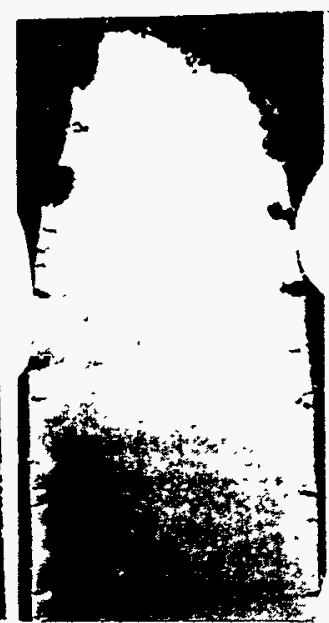

$250 \mathrm{~h}$

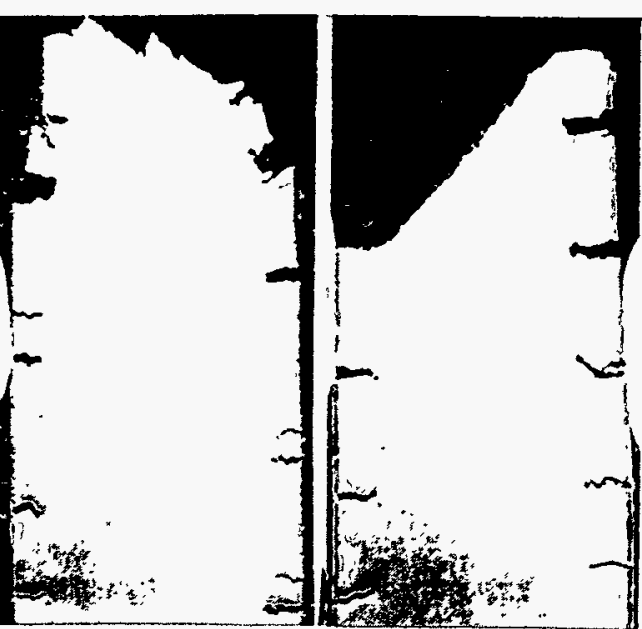

$1000 \mathrm{~h}$
$2060 \mathrm{~h}$

$0.5 \mathrm{~mm}$

Figure 2. SEM photomicrographs of axial sections of $\mathrm{V}-5 \mathrm{Cr}-5 \mathrm{Ti}$ specimens tensile tested in as-annealed condition and after oxidation in air at $500^{\circ} \mathrm{C}$ for several exposure times

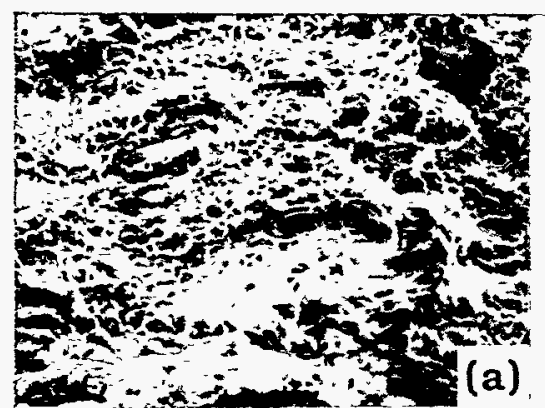

(a)

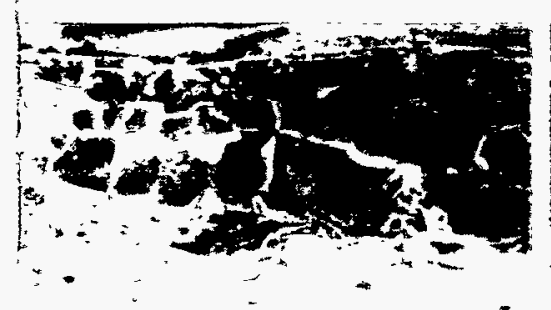

(d)
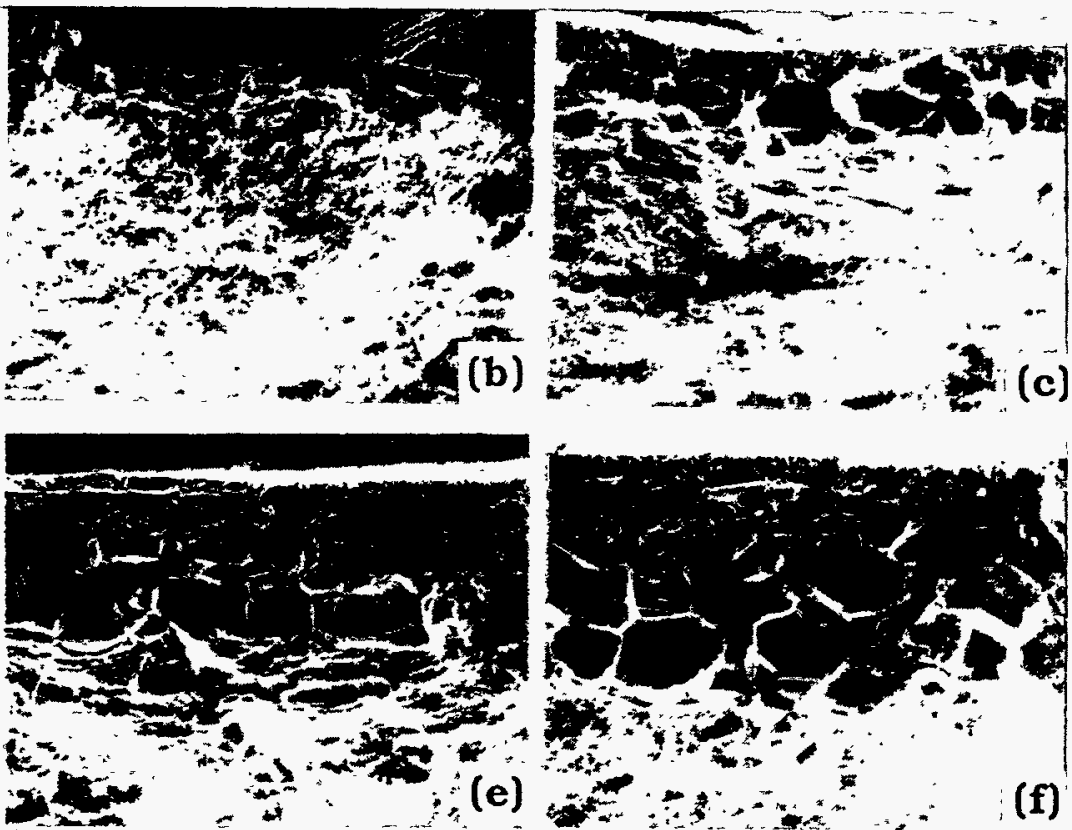

Figure 3. SEM photomicrographs of fracture surfaces of V-5Cr-5Ti specimens tensile tested

(a) in as-annealed condition and after oxidation in air at $500^{\circ} \mathrm{C}$ for (b) $24 \mathrm{~h}$, (c) $250 \mathrm{~h}$, (d) $600 \mathrm{~h}$, (e) $1000 \mathrm{~h}$, and (f) $2060 \mathrm{~h}$. 


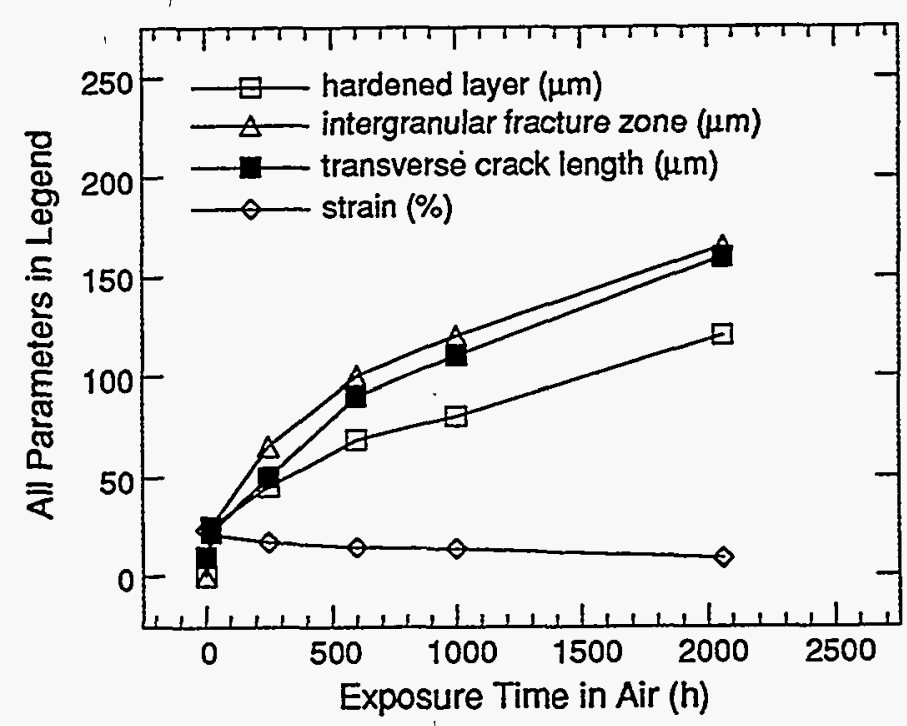

Figure 4. Variation in hardened-layer thickness, intergranular fracture zone depth, transverse crack length, and rupture strain as a function of exposure time at $500^{\circ} \mathrm{C}$ for V-5Cr-5Ti alloy. 


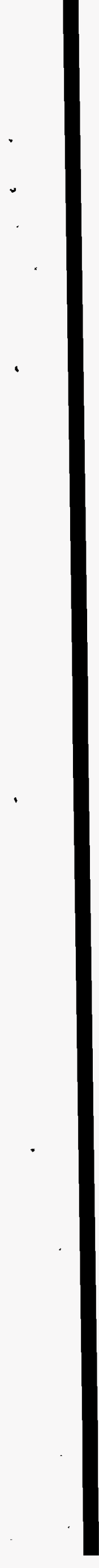


IMPACT PROPERTIES OF PRECRACKED V-4Cr-4Ti CHARPY SPECIMENS* H. M. Chung, L. Nowicki, and D. L. Smith (Argonne National Laboratory)

\section{OBJECTIVE}

The objective of this study is to determine impact properties of production- and laboratory-scale heats of $\mathrm{V}-4 \mathrm{Cr}-4 \mathrm{Ti}$, both fabricated and annealed with the same procedures, from precracked Charpy specimens.

\section{SUMMARY}

Laboratory- and production-scale ( 30 and $500 \mathrm{~kg}$, respectively) heats of $\mathrm{V}-4 \mathrm{Cr}-4 \mathrm{Ti}$, which is the reference vanadium alloy for application in fusion reactor structural components, have recently been produced successfully. Charpy tests conducted previously at -196 to $200^{\circ} \mathrm{C}$ on $1 / 3$-size blunt-notch specimens, showed that both heats have excellent impact properties, i.e., ductile-brittle transition temperature (DBTT) lower than $-200^{\circ} \mathrm{C}$ and upper-shelf energy of $10-16 \mathrm{~J}$. Effects of precracking on the impact behavior of the Charpy specimens were investigated in this study. Precracked specimens were tested after annealing at the optimal condition of $1000^{\circ} \mathrm{C}$ for $1 \mathrm{~h}$. Precracked specimens from both the laboratoryand production-scale heats exhibited normalized energies of 6.7 to $10.9 \mathrm{~J}$ at test temperatures of -196 to $200^{\circ} \mathrm{C}$; no brittle fracture was observed. This demonstrates the excellent dynamic toughness of $\mathrm{V}-4 \mathrm{Cr}-4 \mathrm{Ti}$.

\section{INTRODUCTION}

To develop and identify an optimal vanadium-base alloy for application in fusion reactor first wall/blanket structures, extensive investigations were conducted earlier on the swelling behavior, tensile properties, creep strength, impact toughness, and microstructural stability of $\mathrm{V}-\mathrm{Ti}, \mathrm{V}-\mathrm{Cr}-\mathrm{Ti}$, and V-Ti-Si alloys before and after irradiation by fast neutrons at $420-600^{\circ} \mathrm{C} .{ }^{1-5}$ These investigations revealed that V-Cr-Ti alloys containing $\approx 4$ wt. $\% \mathrm{Cr}, \approx 4$ wt. $\% \mathrm{Ti}, 500-1000$ wt. ppm Si, and $<1000$ wt. ppm $\mathrm{O}+\mathrm{N}+\mathrm{C}$ were most desirable because they exhibit superior physical and mechanical properties. Excellent impact properties were reported previously for laboratory- and production-scale heats, ${ }^{6}$ including a small heat (ANL ID BL-47, 30-kg) that exhibited excellent resistance to thermal creep, ${ }^{4}$ irradiation-induced embrittlement, ${ }^{1,2}$ swelling, ${ }^{3,5}$ and helium embrittlement. ${ }^{7-10}$

However, no impact properties have been reported for precracked Charpy specimens of either heat. Precracked Charpy impact properties are generally considered a better measure of dynamic toughness of a material because without the complication of crack initiation in such a test, absorbed energy represents the resistance to crack propagation more accurately than in a blunt-notch specimen. In this work, impact behavior of fatigue-precracked Charpy specimens of the laboratory- $(30-\mathrm{kg}$, ANL ID BL-47) and production-scale (Heat 832665) ${ }^{11}$ heats of $\mathrm{V}-4 \mathrm{Cr}-4 \mathrm{Ti}$ was investigated according to ASTM Standard E23 (Standard Test Methods for Notched Bar Impact Testing of Metallic Materials, Annex A1, Precracking Charpy V-Notch Impact Specimens).

\section{EXPERIMENTAL PROCEDURE}

Chemical composition of the 30- and 500-kg heats of $\mathrm{V}-4 \mathrm{Cr}-4 \mathrm{Ti}$ is given in Table 1. One-thirdsize Charpy specimens $(3.33 \times 3.33 \times 25.4 \mathrm{~mm})$ were machined from $3.81-\mathrm{mm}$-thick plates of the materials, which had been received in as-rolled condition. The specimens were machined so that the plane of crack propagation was perpendicular to rolling direction (L-S and L-T directions, Fig. 1). However, directions of precracking, and hence the direction of crack propagation during impact testing of the

\footnotetext{
Work supported by U.S. Department of Energy, Office of Fusion Energy Research, under Contract W-31-109-Eng-38.
} 
production- and laboratory-scale heats, were different, i.e., in thickness and width direction of the plate, respectively. By this selection of specimen orientation, we wished to determine any effect of anisotropic crack propagation in the alloy.

Table 1. Chemical composition (impurities in wppm) of production-and laboratory-scale heats of $\mathrm{V}-4 \mathrm{Cr}-4 \mathrm{Ti}$

\begin{tabular}{cccccccccccccccc}
\hline Heat ID & Heat Type & $\mathrm{Cr}$ & $\mathrm{Ti}$ & $\mathrm{Cu}$ & $\mathrm{Si}$ & $\mathrm{O}$ & $\mathrm{N}$ & $\mathrm{C}$ & $\mathrm{S}$ & $\mathrm{P}$ & $\mathrm{Ca}$ & $\mathrm{Cl}$ & $\mathrm{Na}$ & $\mathrm{K}$ & $\mathrm{B}$ \\
\hline $\mathrm{BL}-47$ & laboratory & 4.1 & 4.3 & 6 & 870 & 350 & 220 & 200 & 20 & $<40$ & 1 & 1 & 0.1 & 0.1 & 15 \\
& $30 \mathrm{~kg}$ & wt.\% & wt.\% & & & & & & & & & & & & \\
832665 & $\begin{array}{c}\text { production } \\
500 \mathrm{~kg}\end{array}$ & $\begin{array}{c}3.8 \\
\text { wt.\% }\end{array}$ & $\begin{array}{c}3.9 \\
\text { wt.\% }\end{array}$ & $<50$ & 783 & 310 & 85 & 80 & $<10$ & $<30$ & $<10$ & $<2$ & - & - & $<5$ \\
& & & & & & & & & & & & & & &
\end{tabular}

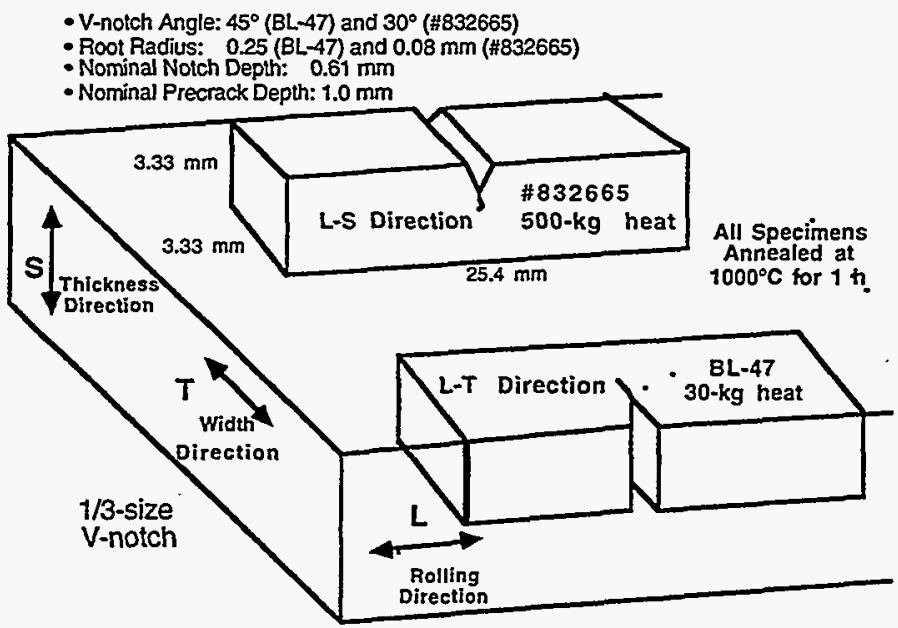

Fig. 1 .

Orientation of precracked Charpy-impact specimens with respect to plate rolling direction of $\mathrm{V}-4 \mathrm{Cr}-4 \mathrm{Ti}$

Notch depth in both types of specimens was kept constant at $0.61 \mathrm{~mm}$. The impact specimens, machined from the as-rolled plates and precracked by cyclic fatigue, were tested after an annealing heat treatment at $1000^{\circ} \mathrm{C}$ for $1 \mathrm{~h}$ in ion-pumped vacuum, the optimal annealing procedure identified in a separate study. ${ }^{7}$ Details of the drop-weight-type impact test are described in Ref. 2.

The machined blunt-notch specimens were precracked by three-point bending with an MTS servohydraulic mechanical test system fitted with a 454-kg (1000-lb) load cell and interfaced with a computer system to operate the system under constant stress intensity. Precracking was induced by cyclic fatigue loading of the specimen between a maximum stress intensity $\mathrm{K}_{\max }=10 \mathrm{MPa} \mathrm{m} \mathrm{m}^{0.5}$ and a minimum stress intensity $\mathrm{K}_{\min }=0.1 \mathrm{~K}_{\max }$. That is, maximum stress intensity and stress ratio were kept constant at $10 \mathrm{MPa} \mathrm{m} \mathrm{m}^{0.5}$ and $0.1(\mathrm{R}=0.1)$, respectively. Crack length was monitored continuously by the direct current potential difference technique, enabling stress intensity to be controlled as a function of crack length. Typical initial and final loading were 365 and $169 \mathrm{~N}$, respectively. To produce a crack depth of $0.9-1.0 \mathrm{~mm}$, the typical numbers of $200,000-240,000$ and $18,000-210,000$ cycles were required for the production- (Heat 832665) and laboratory-scale (BL-47) heats, respectively.

\section{RESULTS AND DISCUSSION}

Typical examples of the precracking morphology, and the fracture appearance (produced during impact testing) of the production-and laboratory-scale heats, are shown in Figs. 2A and 2B, respectively. 

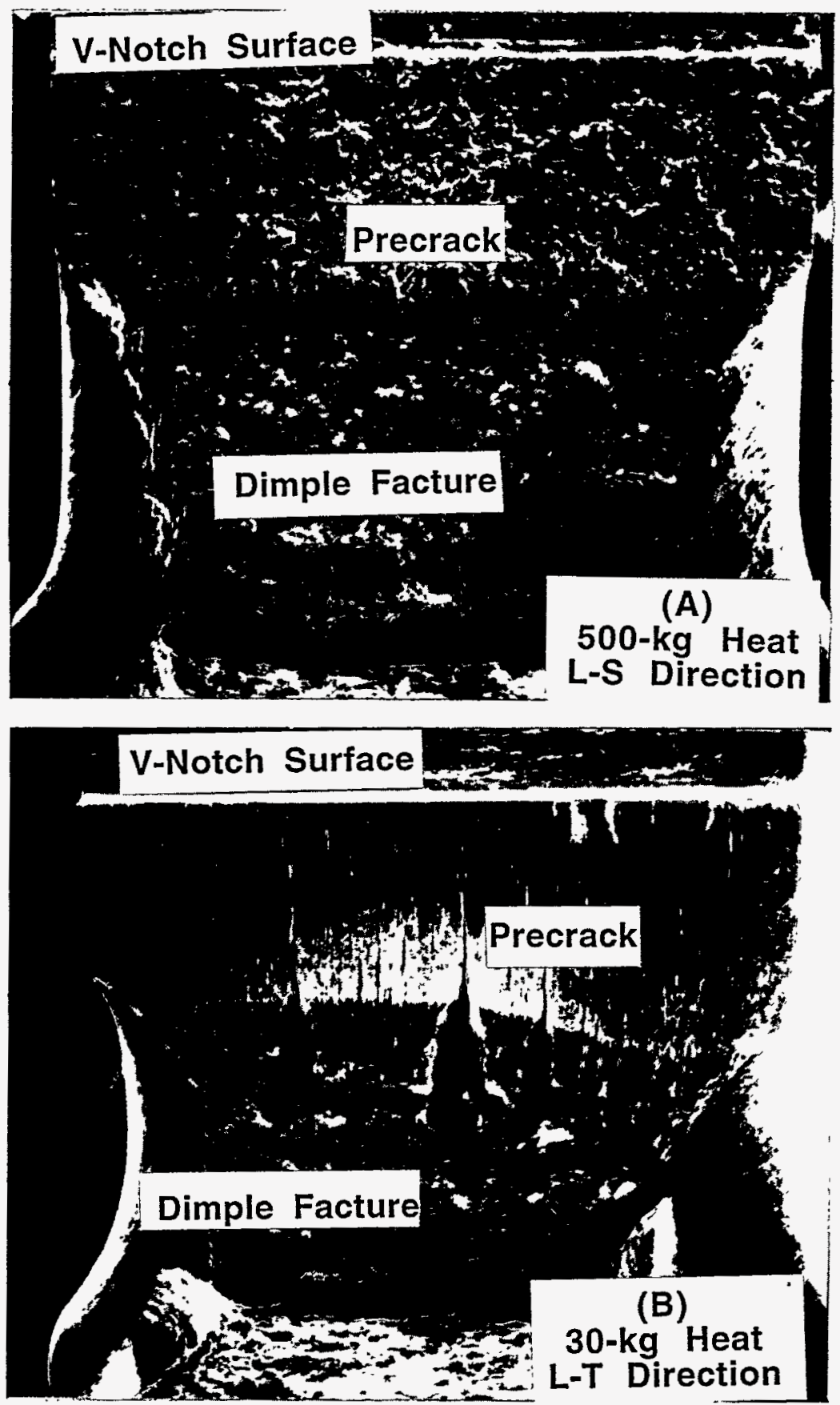

Fig. 2. Appearance of precracking and impact-fracture surfaces in $(A)$ production-scale heat (\#832665) tested at $-150^{\circ} \mathrm{C}$; and $(B)$ laboratory-scale heat $(B L-47)$ tested at $21^{\circ} \mathrm{C}$

In the figures, three distinct types of surfaces, i.e., machined $\mathrm{V}$-notch, precracking, and dimple fracture, are clearly visible. In contrast to the production-scale heat, precracking produced in the laboratory heat was characterized by a relatively nonuniform crack front. This is most likely related to the difference in the orientation of the specimens of the two heats (Fig. 1). Small and shallow secondary cracks are also visible on the precracking surface of the laboratory heat (Fig. 2B). These secondary cracks, perpendicular to. the direction of the primary precracking, are indeed parallel to the rolling plane of the 3.8-mm-thick plate 
from which the Charpy specimens were machined. This observation seems to be consistent with the tendency for unannealed plates of $\mathrm{V}-(4-5) \mathrm{Cr}-(4-5) \mathrm{Ti}$ alloys to develop low-energy laminated cracking in exactly the same direction. 12

From examination of fractured precracked specimens similar to those shown in Fig. 2, combined crack lengths (V-notch plus precrack depth) were measured at three locations on each specimen per ASTM Standard E 23, and absorbed impact energies were normalized relative to the remaining uncracked cross section of each specimen. Results are listed in Table 2. Also reported in Table 2 are fractions of ductile and brittle-cleavage fracture surface morphologies for each specimen. No brittle cleavage was observed in specimens tested after annealing at $1000^{\circ} \mathrm{C}$ for $1 \mathrm{~h}$. In contrast, a few specimens tested after annealing at $1100^{\circ} \mathrm{C}$ for $1 \mathrm{~h}$ exhibited limited brittle cleavage at $<-170^{\circ} \mathrm{C}$. This observation seems to corroborate the selection of the optimal annealing condition at $1000^{\circ} \mathrm{C}$ for $1 \mathrm{~h}$ for both $\mathrm{V}-4 \mathrm{Cr}-4 \mathrm{Ti}^{7}$ and $\mathrm{V}-5 \mathrm{Cr}-5 \mathrm{Ti} .{ }^{12}$

Table 2. Summary of combined notch and precracking depths and normalized absorbed energies measured in precracked Charpy impact specimens of production-scale (500- $\mathrm{kg}$, \#832665) and laboratory (30-kg, BL-47) heats of $\mathrm{V}-4 \mathrm{Cr}-4 \mathrm{Ti}$, measured after impact fracture per ASTM E-23.

\begin{tabular}{|c|c|c|c|c|c|c|c|c|c|c|c|}
\hline $\begin{array}{c}\text { Heat } \\
\text { ID }\end{array}$ & $\begin{array}{l}\text { PCVN } \\
\text { ID }\end{array}$ & $\begin{array}{c}\text { Final } \\
\text { Anneala } \\
\text { Temp. } \\
\left({ }^{\circ} \mathrm{Cl}\right)\end{array}$ & $\begin{array}{l}\text { Impact } \\
\text { Temp. } \\
\left({ }^{\circ} \mathrm{C}\right)\end{array}$ & $\begin{array}{c}\text { Crack } \\
\text { Length } \\
\text { Left } \\
\text { (mm) }\end{array}$ & $\begin{array}{l}\text { Crack } \\
\text { Length } \\
\text { Center } \\
\text { (mm) }\end{array}$ & $\begin{array}{l}\text { Crack } \\
\text { Length } \\
\text { Right } \\
\text { (mm) }\end{array}$ & $\begin{array}{c}\text { Crack } \\
\text { Length } \\
\text { Average } \\
\text { (mm) }\end{array}$ & $\begin{array}{c}\text { Absorbed } \\
\text { Energy } \\
\text { (J) }\end{array}$ & $\begin{array}{c}\text { Normalized } \\
\text { Energy } \\
\text { (J) }\end{array}$ & $\begin{array}{c}\text { Ductile } \\
\text { Dimple } \\
\text { Fracture } \\
\text { (\%) }\end{array}$ & $\begin{array}{l}\text { Brittle } \\
\text { Cleavage } \\
\text { Fracture } \\
\text { (\%) }\end{array}$ \\
\hline BL-47 & $\overline{A 10}$ & 1000 & -196 & 1.28 & 1.49 & 1.76 & 1.52 & 3.66 & 6.73 & 100 & 0 \\
\hline BL -47 & A12 & 1000 & -150 & 1.55 & 1.49 & 1.48 & 1.51 & 4.01 & 7.34 & 100 & 0 \\
\hline$B L-47$ & A9 & 1000 & -100 & 1.50 & 1.50 & 1.67 & 1.56 & 5.22 & 9.82 & 100 & 0 \\
\hline 832665 & W42 & 1000 & -196 & 1.65 & 1.66 & 1.65 & 1.65 & 4.34 & 8.60 & 100 & 0 \\
\hline $\begin{array}{l}832665 \\
832665\end{array}$ & $\begin{array}{l}\text { W46 } \\
\text { W36 }\end{array}$ & $\begin{array}{l}1000 \\
1000\end{array}$ & $\begin{array}{l}-150 \\
-100\end{array}$ & $\begin{array}{l}1.61 \\
1.58\end{array}$ & $\begin{array}{l}1.63 \\
1.60\end{array}$ & $\begin{array}{l}1.62 \\
1.56\end{array}$ & $\begin{array}{l}1.62 \\
1.58\end{array}$ & $\begin{array}{l}5.59 \\
4.86\end{array}$ & $\begin{array}{r}10.89 \\
9.25\end{array}$ & $\begin{array}{l}100 \\
100\end{array}$ & $\begin{array}{l}0 \\
0\end{array}$ \\
\hline 832665 & W52 & 1000 & 21 & 1.67 & 1.69 & 1.70 & 1.69 & 3.68 & 7.47 & 100 & 0 \\
\hline 832665 & W49 & 1000 & 175 & 1.64 & 1.64 & 1.62 & 1.64 & 3.62 & 7.13 & 100 & 0 \\
\hline
\end{tabular}

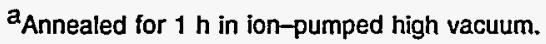

The normalized energies for the production- and laboratory-scale heats listed in Table 2 are plotted as function of impact temperature in Figs. 3 and 4, respectively. For comparison, similar results obtained from blunt-notch specimens are also plotted in the figures. In Fig. 5, all impact data of both heats of $\mathrm{V}-4 \mathrm{Cr}-4 \mathrm{Ti}$ alloy, obtained from blunt-notch and precracked specimens annealed at $950-1050^{\circ} \mathrm{C}$ for $1 \mathrm{~h}$, are shown for a comprehensive comparison.

The results in Figs. 3-5 demonstrate that remarkably excellent dynamic toughness of $\mathrm{V}-4 \mathrm{Cr}-4 \mathrm{Ti}$ will be ensured when a component fabricated from the alloy is given a final annealing treatment at 1000 $\pm 50^{\circ} \mathrm{C}$ for $1 \mathrm{~h}$. When annealed at $1000^{\circ} \mathrm{C}$ for $1 \mathrm{~h}$, precracked specimens of the laboratory and production heats, machined in two different orientations (Fig. 1), displayed essentially the same impact properties (Fig. 5); this indicates the negligible effect of anisotropic crack propagation.

\section{CONCLUSIONS}

(1) After annealing at $1000^{\circ} \mathrm{C}$ for $1 \mathrm{~h}$, impact tests were conducted on precracked 1/3-size Charpy specimens of $30-\mathrm{kg}$ laboratory-scale and $500-\mathrm{kg}$ production-scale heats of $\mathrm{V}-4 \mathrm{Cr}-4 \mathrm{Ti}$. Both heats exhibited excellent impact properties, i.e., normalized energies of 6.7 to $10.9 \mathrm{~J}$ at test temperatures of -196 to $200^{\circ} \mathrm{C}$. No brittle-cleavage fracture morphology was observed in the precracked specimens. This demonstrates the excellent dynamic toughness of $\mathrm{V}-4 \mathrm{Cr}-4 \mathrm{Ti}$. 

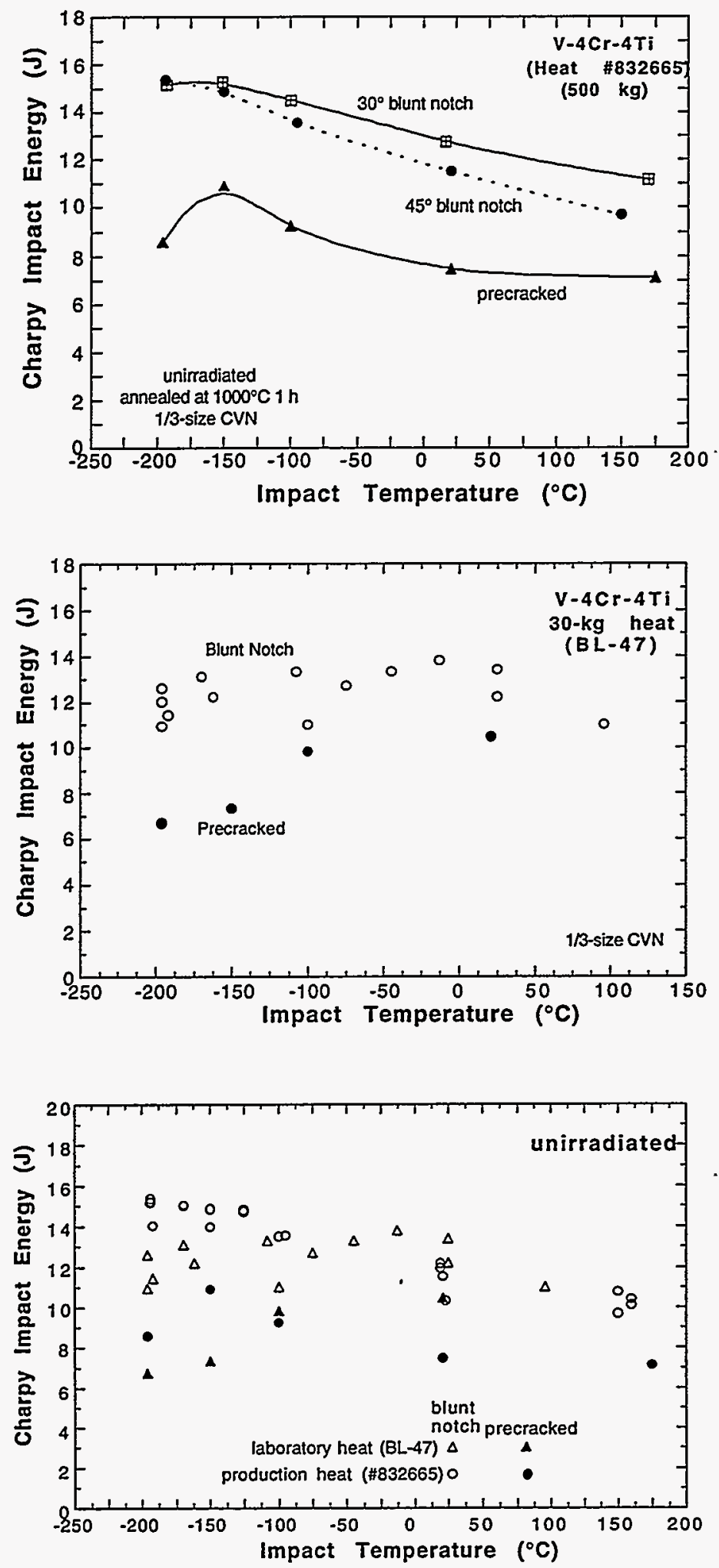

Fig. 3.

Precracked and blunt-notch Charpy energy as a function of impact temperature of production-scale heat of $V-4 C r-4 T i$ after annealing for $I$ h at $1000^{\circ} \mathrm{C}$

Fig. 4.

Precracked and blunt-notch Charpy energy as a function of impact temperature of laboratory-scale heat of $\mathrm{V}-4 \mathrm{Cr}-4 \mathrm{Ti}$. Precracked and blunt-notch specimens were annealed for $1 \mathrm{~h}$ at $1000^{\circ} \mathrm{C}$ and $\approx 1050^{\circ} \mathrm{C}$, respectively

Fig. 5.

Impact properties measured from blunt-notch and precracked Charpy specimens of the production- and laboratorys cale heats of $\mathrm{V}-4 \mathrm{Cr}$ $4 T i$. 
(2) Annealing at $1100^{\circ} \mathrm{C}$ for $1 \mathrm{~h}$ induced limited cleavage fracture in precracked specimens at test temperatures $<-170^{\circ} \mathrm{C}$. This corroborates the selection of the optimal annealing condition of $1000^{\circ} \mathrm{C}$ for $1 \mathrm{~h}$.

(3) When annealed at $1000^{\circ} \mathrm{C}$ for $1 \mathrm{~h}$, impact properties of precracked specimens of two different orientations were similar, indicating the negligible effect of anisotropic crack propagation.

\section{ACKNOWLEDGMENTS}

The authors thank J. K. Donald and D. Busch for precracking the Charpy-impact specimens and SEM fractography, respectively.

\section{REFERENCES}

1. B. A. Loomis, L. Nowicki, and D. L. Smith, "Effect of Neutron Irradiation on Tensile Properties of V-Cr-Ti Alloys," in Fusion Reactor Materials, Semiannual Prog. Report, DOE/ER-0313/15, Oak Ridge National Laboratory, Oak Ridge, TN (1994), pp. 219-222.

2. B. A. Loomis, H. M. Chung, L. Nowicki, and D. L. Smith, "Effects of Neutron Irradiation and Hydrogen on Ductile-Brittle Transition Temperatures of V-Cr-Ti Alloys," ibid., pp. 253-257.

3. H. M. Chung, B. A. Loomis, L. Nowicki, J. Gazda, and D. L. Smith, "Irradiation-Induced Density Change and Microstructural Evolution of Vanadium-Base Alloys," ibid., pp. 223-231.

4. H. M. Chung, B. A. Loomis, and D. L. Smith, "Thermal Creep Behavior of V-5Cr-5Ti and V-10Cr-5Ti Alloys," in Fusion Reactor Materials, Semiannual Prog. Report, DOE/ER-0313/14, Oak Ridge National Laboratory, Oak Ridge, TN (1993), pp. 309-317.

5. H. M. Chung, B. A. Loomis, and D. L. Smith, in Effects of Radiation on Materials, ASTM-STP 1175 , A. S. Kumar, D. S. Gelles, R. K. Nanstad, and T. A. Little, Eds., American Society for Testing and Materials, Philadelphia, 1993, pp. 1185-1200.

6. H. M. Chung, B. A. Loomis, and D. L. Smith, "Properties of V-4Cr-4Ti for Application as Fusion Reactor Structural Components," Proc. 3rd Intl. Symp. on Fusion Nuclear Technology, June 27-July 1, 1994, Los Angeles, CA, in press.

7. H. M. Chung, L. Nowicki, and D. L. Smith, "Impact Properties of Production-Scale Heat of V-4CF4Ti," in this report.

8. H. M. Chung, B. A. Loomis, L. Nowicki, and D. L. Smith, "Effect of Dynamically Charged Helium on Tensile Properties of V-4Cr-4Ti," in Fusion Reactor Materials, Semiannual Prog. Report for Period Ending September 30, 1994, DOE/ER-0313/17, Oak Ridge National Laboratory, Oak Ridge, TN, in press.

9. H. M. Chung, L. J. Nowicki, D. E. Busch, and D. L. Smith, "Ductile-Brittle Transition Behavior of V-4Cr-4Ti Irradiated in the Dynamic Helium Charging Experiment," in Fusion Reactor Materials, Semiannual Prog. Report for Period Ending September 30, 1994, DOE/ER-0313/17, Oak Ridge National Laboratory, Oak Ridge, TN, in press.

10. H. M. Chung, L. Nowicki, J. Gazda, and D. L. Smith, "Void Structure and Density Change of Vanadium-Base Alloys Irradiated in the Dynamic Helium Charging Experiment," in Fusion Reactor Materials. Semiannual Prog. Report for Period Ending September 30, 1994, DOE/ER-0313/17, Oak Ridge National Laboratory, Oak Ridge, TN, in press.

11. H. M. Chung, H.-C. Tsai, D. L. Smith, R. Peterson, C. Curtis, C . Wojcik, and R. Kinney, "Fabrication of 500-kg Heat of V-4Cr-4Ti," in Fusion Reactor Materials, Semiannual. Prog. Report for Period Ending Septemher 30, 1994, DOE/ER-0313/17, Oak Ridge National Laboratory, Oak Ridge, TN, in press.

12. H. M. Chung, L. Nowicki, and D. L. Smith, "Fabrication and Impact Properties of Laboratory-Scale Heat of $\mathrm{V}-5 \mathrm{Cr}-5 \mathrm{Ti}$," in this report. 
FABRICATION AND IMPACT PROPERTIES OF LABORATORY-SCALE HEAT OF V-5Cr-5Ti* H. M. Chung, L. Nowicki, D. Busch, and D. L. Smith (Argonne National Laboratory)

\section{OBJECTIVE}

The immediate objective of this work is to fabricate a new laboratory-scale heat of $\mathrm{V}-5 \mathrm{Cr}-5 \mathrm{Ti}$ and identify an optimal annealing procedure that produces the highest impact toughness in the alloy. By comparing the result with the optimal annealing procedure identified for production- and laboratory-scale heats of $\mathrm{V}-4 \mathrm{Cr}-4 \mathrm{Ti}$, the long-range objective of the study is to demonstrate that excellent and reliable mechanical properties of the $\mathrm{V}-(4-5) \mathrm{Cr}-(4-5) \mathrm{Ti}$ alloy class can be produced by common fabrication and annealing procedures.

\section{SUMMARY}

Impact properties were determined on a new $15-\mathrm{kg}$ laboratory heat of $\mathrm{V}-5 \mathrm{Cr}-5 \mathrm{Ti}$, fabricated by the same procedures as those used to produce a $500-\mathrm{kg}$ production-scale heat of $\mathrm{V}-4 \mathrm{Cr}-4 \mathrm{Ti}$, to identify an optimal annealing procedure for the alloy. Charpy-impact tests were conducted on one-third-size specimens because low-temperature $\left(\angle 0^{\circ} \mathrm{C}\right)$ impact properties have been known to be most sensitive to the structure and toughness of the $\mathrm{V}-(4-5) \mathrm{Cr}-(4-5) \mathrm{Ti}$ alloy class. After final annealing at $\approx 1000^{\circ} \mathrm{C}$ for $1 \mathrm{~h}$ in a high-quality vacuum, the laboratory heat of $\mathrm{V}-5 \mathrm{Cr}-5 \mathrm{Ti}$ exhibited impact properties as excellent as those of the production- and laboratory-scale heats of $\mathrm{V}-4 \mathrm{Cr}-4 \mathrm{Ti}$; i.e., ductile-brittle-transition temperatures less than $-200^{\circ} \mathrm{C}$ and absorbed energies of $10-16 \mathrm{~J}$. This finding demonstrates that, when fabricated by the procedure specified in this study and annealed at the common optimal condition of $1000^{\circ} \mathrm{C}$ for $1 \mathrm{~h}$, the $\mathrm{V}-(4-5) \mathrm{Cr}-(4-5) \mathrm{Ti}$ alloy class exhibits excellent impact toughness and a sufficient tolerance to minor variations in alloying-element composition.

\section{INTRODUCTION}

$\mathrm{V}-(4-5) \mathrm{Cr}-(4-5) \mathrm{Ti}$ has been identified previously as the most promising vanadium-base candidate alloy for application in fusion reactor structural components. 1,2 Subsequently, some laboratory heats of $\mathrm{V}-5 \mathrm{Cr}-3 \mathrm{Ti}$ (ANL ID Heat BL-54) and V-5Cr-5Ti (BL-63), fabricated by procedures different from those that produced the excellent laboratory heat of $\mathrm{V}-4 \mathrm{Cr}-4 \mathrm{Ti}$ (ANL ID Heat BL-47), were found to exhibit impact properties significantly inferior to those of the $\mathrm{V}-4 \mathrm{Cr}-4 \mathrm{Ti}$ heat, in spite of small differences in alloying-element composition. ${ }^{3}$ Because of this, two contrasting but related concerns were raised. One concern was on the tolerance of the most promising alloy $\mathrm{V}-4 \mathrm{Cr}-4 \mathrm{Ti}$ to inevitable minor variations in $\mathrm{Cr}$ and $\mathrm{Ti}$ content. The other was the reliability of fabrication, i.e., the effects of minor impurities, use of low-quality raw materials, and incorrect rolling and annealing procedures that may upset reliable fabrication of the alloy class. ${ }^{3}$ Subsequently, a new $500-\mathrm{kg}$ heat of $\mathrm{V}-4 \mathrm{Cr}-4 \mathrm{Ti}$ was produced successfully by a procedure essentially the same as that used to produce the excellent laboratory heat of $\mathrm{V}-4 \mathrm{Cr}-4 \mathrm{Ti}$ (Heat $\mathrm{BL}-47$ ). ${ }^{4}$ Charpy-impact testing showed that the new production-scale heat of $\mathrm{V}-4 \mathrm{Cr}-4 \mathrm{Ti}$ (Heat \#832665) exhibited properties as excellent as those of the laboratory-scale heat of the alloy (i.e., BL-47). ${ }^{5}$ Parallel to this effort, it was decided to fabricate a new laboratory-scale heat of $\mathrm{V}-5 \mathrm{Cr}-5 \mathrm{Ti}$, hoping to demonstrate that the heat exhibits mechanical properties as good as those of $\mathrm{V}-4 \mathrm{Cr}-4 \mathrm{Ti}$. This paper briefly outlines the fabrication procedure for a new $15-\mathrm{kg}$ heat of $\mathrm{V}-5 \mathrm{Cr}-5 \mathrm{Ti}$ and presents comprehensive results of impact performance of the heat. By comparing the results with the optimal annealing procedure identified for $\mathrm{V}-4 \mathrm{Cr}-4 \mathrm{Ti}$ in a separate investigation, 5 the real objective of the study was to demonstrate that excellent and reliable mechanical properties of $\mathrm{V}-(4-5) \mathrm{Cr}-(4-5) \mathrm{Ti}$ alloy class can be produced by common fabrication and annealing procedures.

\footnotetext{
* Work supported by U.S. Department of Energy, Office of Fusion Energy Research, under Contract W-31-109-Eng-38. 


\section{EXPERIMENTAL PROCEDURES}

The fabrication procedure for the $15-\mathrm{kg}$ heat of $\mathrm{V}-5 \mathrm{Cr}-5 \mathrm{Ti}$ was essentially the same as that used for the $500-\mathrm{kg}$ production-scale heat of $\mathrm{V}-4 \mathrm{Cr}-4 \mathrm{Ti},{ }^{4}$ except that the former was produced in the laboratory, on a small scale; the latter was produced in the production facility of Teledyne Wah Chang in Albany, Oregon. Therefore, for details of specification and fabrication procedure, the reader is referred to Ref. 4. The same raw materials were used to melt the ingots of both heats by multiple vacuum-arc melting. Secondary fabrication procedures, i.e., extruding the ingot at $1150^{\circ} \mathrm{C}$, subsequent cross-rolling (at $400^{\circ} \mathrm{C}$ ), and heat treating between rolling (at $1050^{\circ} \mathrm{C}-1070^{\circ} \mathrm{C}$ ) to manufacture final products in the form of plates and sheets of various thickness, were also similar.

The elemental composition of the alloy ingot and of the raw vanadium that was used to melt the alloy ingot, are given in Table 1 . The raw vanadium feedstock was produced by electron-beam melting. Charpy-impact specimens, machined from the 3.8-mm-thick alloy plates, were cleaned, and annealed at high temperatures before testing. Typical test specimens were annealed at 1000,1050 , or $1100^{\circ} \mathrm{C}$ for $1 \mathrm{~h}$ in a high-quality ion-pumped vacuum system. Orientation of Charpy-impact specimens was such that crack propagation was perpendicular to the rolling and parallel to the thickness direction of the 3.8-mm-thick plates. The one-third-size $(3.33 \times 3.33 \times 25.4 \mathrm{~mm})$ specimens were $30^{\circ}-$ or $45^{\circ}$-notched, with root radii of 0.08 or $0.25 \mathrm{~mm}$, respectively. Notch depth was kept constant at $0.61 \mathrm{~mm}$.

Table 1. Elemental composition (impurities in wppm) of laboratory (15-kg) heat of $\mathrm{V}-5 \mathrm{Cr}-5 \mathrm{Ti}$ and vanadium raw stock used to melt the ingot

\begin{tabular}{cccccccccccccccccccc}
\hline Heat & Material & Spot & $\mathrm{Cr}$ & $\mathrm{Ti}$ & $\mathrm{Al}$ & $\mathrm{Fe}$ & $\mathrm{Mo}$ & $\mathrm{Nb}$ & $\mathrm{Cu}$ & $\mathrm{Si}$ & $\mathrm{O}$ & $\mathrm{N}$ & $\mathrm{C}$ & $\mathrm{H}$ & $\mathrm{S}$ & $\mathrm{P}$ & $\mathrm{Ca}$ & $\mathrm{Cl}$ & $\mathrm{B}$ \\
\hline 820630 & raw & - & $<100$ & $<50$ & 100 & 230 & 410 & $<50$ & $<50$ & 780 & 200 & 62 & 75 & 3 & 10 & $<30$ & - & $<2$ & $<5$ \\
T87 & $\mathrm{V}-5 \mathrm{Cr}-5 \mathrm{Ti}$ & top & $4.96 \mathrm{wt} \%$ & $5.10 \mathrm{wt} \%$ & 160 & 150 & 520 & $<100$ & 71 & 570 & 380 & 86 & 111 & 7 & $<20$ & $<30$ & $<17$ & $<5$ & $<5$ \\
& & & bottom $4.92 \mathrm{wt} \%$ & $5.03 \mathrm{wt} \%$ & 160 & 170 & 510 & $<100$ & 63 & 520 & 380 & 93 & 107 & 27 & $<20$ & $<30$ & $<55$ & $<5$ & $<5$ \\
\hline
\end{tabular}

a Determined from ingot

\section{RESULTS AND DISCUSSION}

Charpy impact energies were measured between -196 and $200^{\circ} \mathrm{C}$ by an instrumented drop-weight machine. The effects of annealing temperature on impact properties of the $45^{\circ}$-and $30^{\circ}$-notched specimens are shown in Figs. 1 and 2, respectively. Some specimens in Fig. 1 were tested in as-rolled condition, i.e., without annealing (at $1000-1100^{\circ} \mathrm{C}$ ) or after the customary degassing treatment $\left(400^{\circ} \mathrm{C}\right.$ for $1 \mathrm{~h}$ ). The effects of annealing at 1000,1050 , and $1100^{\circ} \mathrm{C}$ (for $1 \mathrm{~h}$ in an ion-pumped vacuum) on impact properties of $30^{\circ}$-notched specimens are shown in Fig. 2. Also shown in the figure are data obtained on similar specimens annealed in the factory in an oil-diffusion-pumped vacuum at a nominal temperature of $1050^{\circ} \mathrm{C}$ for $2 \mathrm{~h}$.

For impact temperatures $<25^{\circ} \mathrm{C}$, unannealed specimens were characterized by a tendency to exhibit laminated cracking parallel to the rolling direction and perpendicular to the thickness direction of the 3.8-mm-thick plate (from which the Charpy specimens were machined) (see Fig. 3). That is, the direction of the laminated cracking was perpendicular to the normal crack propagation of annealed specimens (Fig. $3 \mathrm{~A})$. As a result, relatively low absorbed energy was registered. However, the fracture surface of the laminated cracking was ductile in nature when examined by scanning electron microscopy (Fig. 3B). A similar mode of laminated cracking was observed in unannealed specimens from the $500-\mathrm{kg}$ heat of $\mathrm{V}-4 \mathrm{Cr}-$ 4Ti. ${ }^{5}$ Although the mechanism of the peculiar laminated cracking is not well understood, these observations underscore the importance of proper annealing of the $\mathrm{V}-(4-5) \mathrm{Cr}-(4-5) \mathrm{Ti}$ alloy class. 


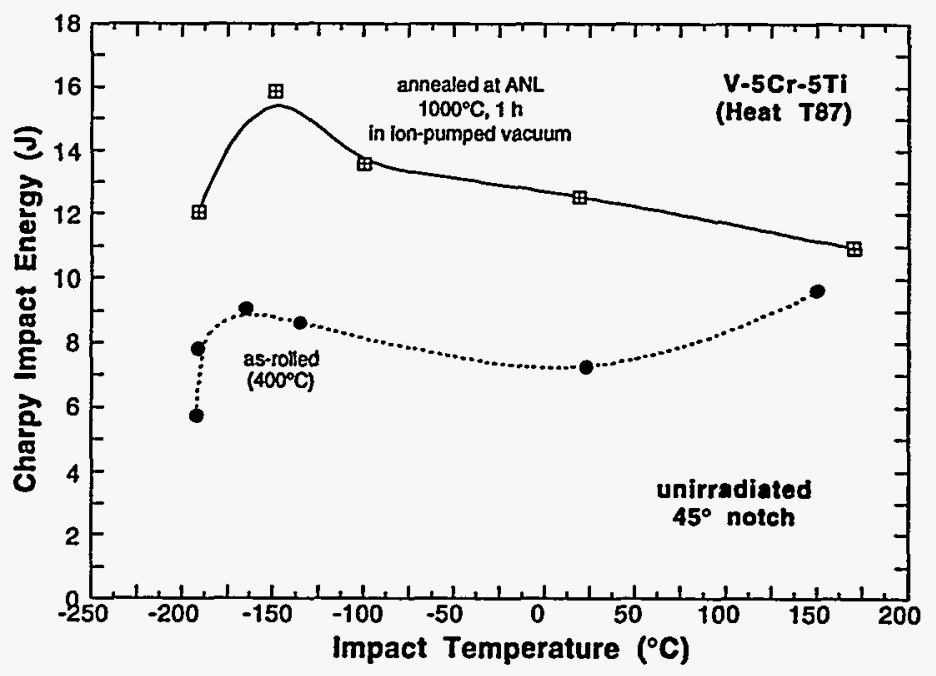

Fig. 1. Impact properties of $45^{\circ}$-notched Charpy specimens in as-rolled condition and after annealing at $1000^{\circ} \mathrm{C}$ for $1 \mathrm{~h}$

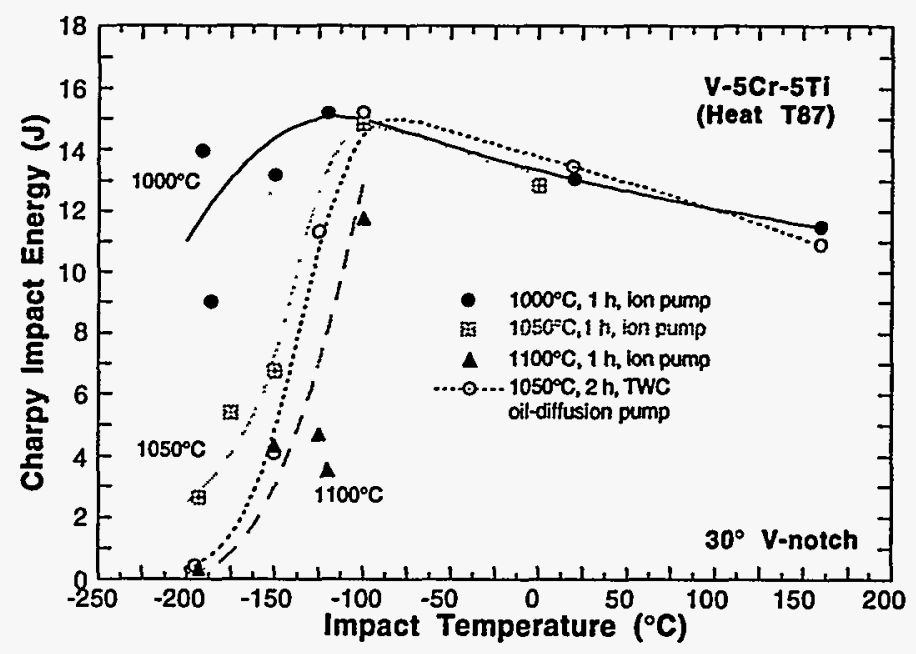

Fig. 2. Effect of annealing on impact properties of $30^{\circ}$-notched Charpy specimens

Absorbed energy measured at $-196^{\circ} \mathrm{C}$ and ductile-brittle transition temperature (DBTT) of the heat were markedly sensitive to annealing temperature. This is shown in Figs. 4 and 5, respectively. Obviously, the results in Figs. 1-5 show that the optimal conditions for annealing are at $1000^{\circ} \mathrm{C}$ for $1 \mathrm{~h}$ in a high-quality (ion-pumped) vacuum system. Evidently, annealing at $>1050^{\circ} \mathrm{C}$ is conducive to somewhat inferior impact properties. In Figs. 4 and 5, similar effects of annealing temperature on absorbed energy (measured at $-196^{\circ} \mathrm{C}$ ) and DBTT of the $500-\mathrm{kg}$ heat of $\mathrm{V}-4 \mathrm{Cr}-4 \mathrm{Ti}$ are also shown for comparison. In the figures, it is important to note that sensitivity to annealing of impact properties of the two alloy heats is quite different. The laboratory heat of $\mathrm{V}-5 \mathrm{Cr}-5 \mathrm{Ti}$ is significantly more sensitive than production-scale heat of $\mathrm{V}-4 \mathrm{Cr}-4 \mathrm{Ti}$. The $30-\mathrm{kg} \mathrm{V}-4 \mathrm{Cr}-4 \mathrm{Ti}$ (ANL ID BL-47) was least sensitive and Heat BL-63 of V-5Cr$5 \mathrm{Ti}$ was most sensitive to annealing conditions. ${ }^{3}$ At present, the root cause of the heat-to-heat variation of sensitivity to annealing conditions is not well understood. Minor impurities, $\mathrm{Cr}$ content, or both could be contributing factors. 

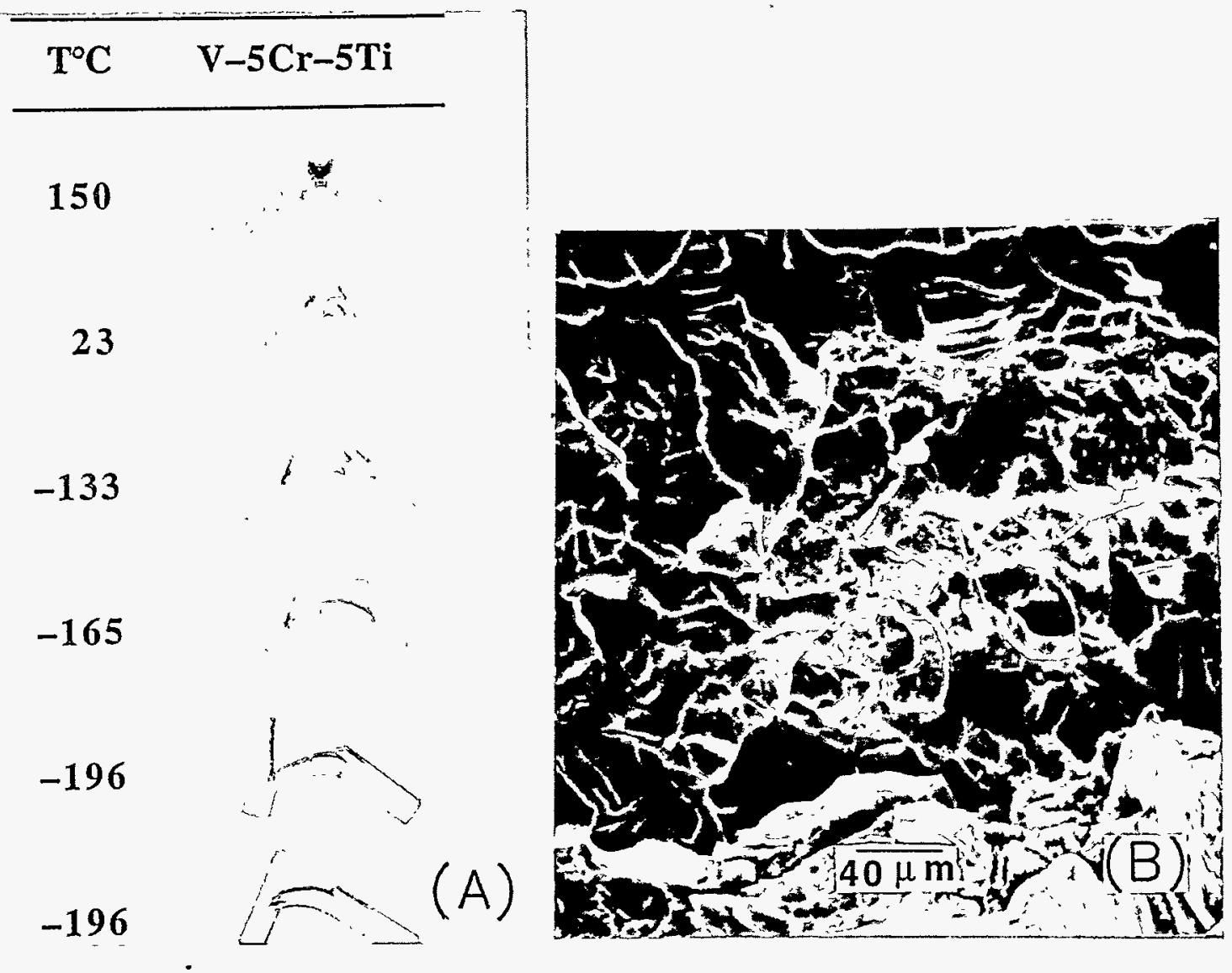

Fig. 3. Appearance of Charpy-impact specimens machined from as-rolled plates of $\mathrm{V}-5 \mathrm{Cr}-5 \mathrm{Ti}$ and tested at -196 to $150^{\circ} \mathrm{C}$, showing $(A)$ tendency for laminated cracking and $(B)$ ductile nature of laminated fracture surface morphology, produced at $23^{\circ} \mathrm{C}$

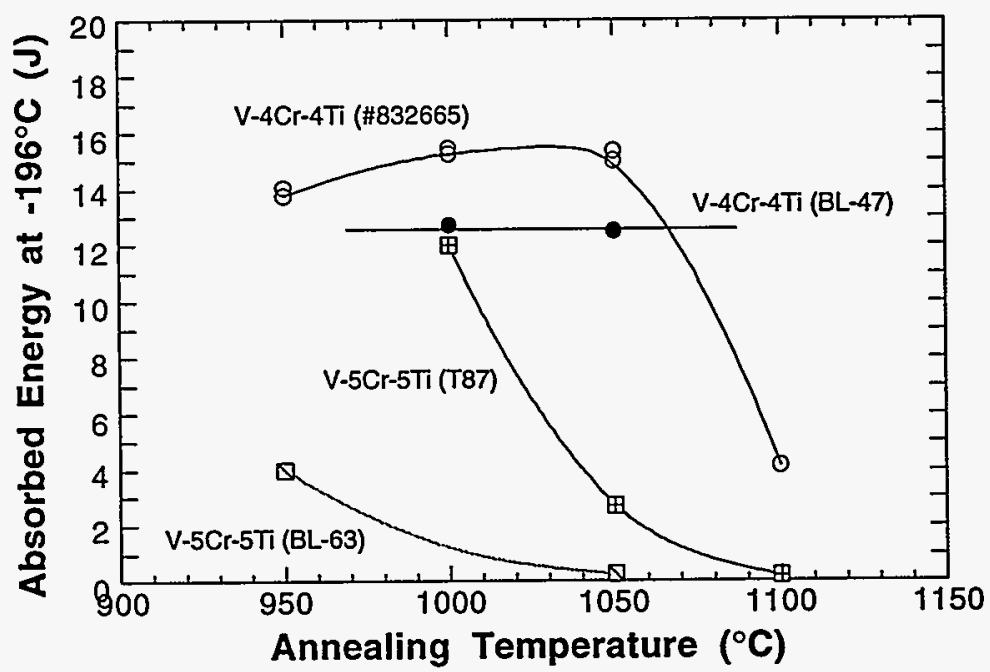

Fig. 4. Effect of annealing on Charpy absorbed energies of $15-\mathrm{kg}$ V-5Cr-5Ti (\#T87) and 500-kg V-4Cr-4Ti (\#832665) measured at $-196^{\circ} \mathrm{C}$ 


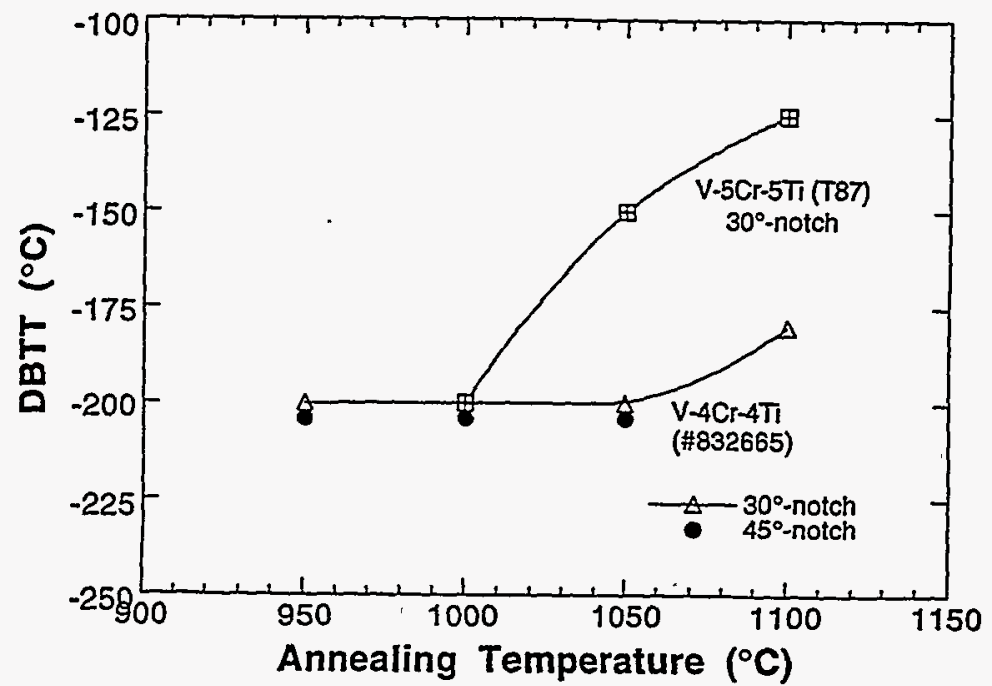

Fig. 5. Effect of annealing on DBTT of $15-\mathrm{kgV}-5 \mathrm{Cr}-5 \mathrm{Ti}$ and $500-k g V-4 C r-4 T i$

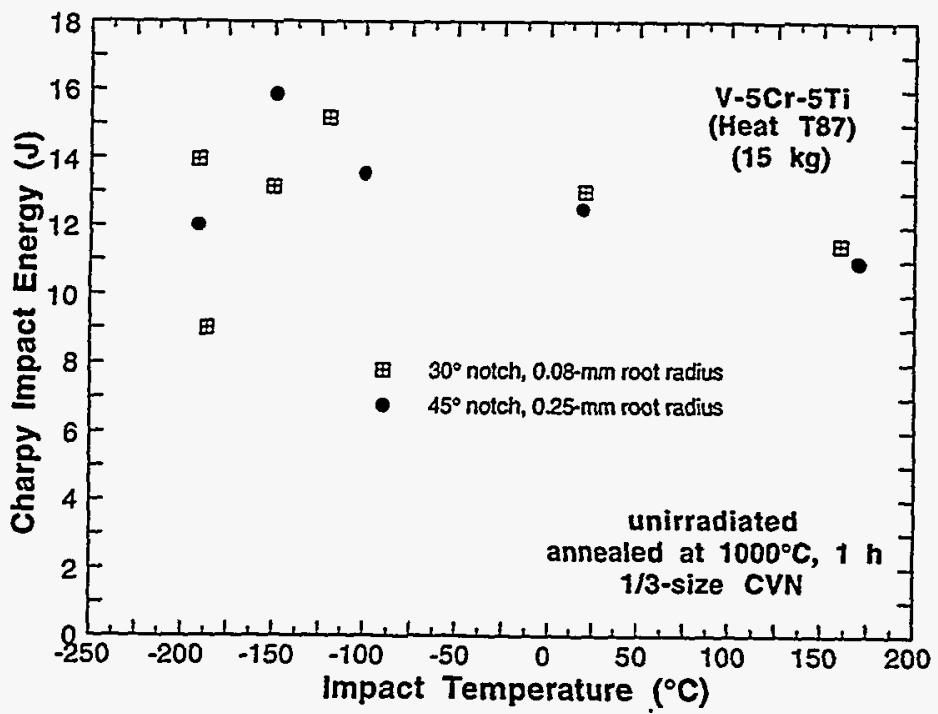

Fig. 6. Effect of notch geometry on Charpy impact properties of $\mathrm{V}-5 \mathrm{Cr}-5 \mathrm{Ti}$ laboratory heat annealed at $1000^{\circ} \mathrm{C}$ for $1 \mathrm{~h}$

The effects of notch geometry on the impact properties of the laboratory heat, annealed under the optimal condition of $1000^{\circ} \mathrm{C}$ for $1 \mathrm{~h}$ are shown in Fig. 5. The results in the figure demonstrate that, when annealed properly, impact properties of $\mathrm{V}-5 \mathrm{Cr}-5 \mathrm{Ti}$ are not sensitive to notch geometry.

When annealed at the optimal condition, the impact properties of the unirradiated 15-kg laboratory heat of $\mathrm{V}-5 \mathrm{Cr}-5 \mathrm{Ti}$ and the $500-\mathrm{kg}$ production-scale heat of $\mathrm{V}-4 \mathrm{Cr}-4 \mathrm{Ti}$ were essentially the same. 5 This means that, as long as a component is annealed properly, a sufficient tolerance of impact toughness to minor variations in alloying composition can be ensured for the $\mathrm{V}-(4-5) \mathrm{Cr}-(4-5) \mathrm{Ti}$ alloy class. 


\section{CONCLUSIONS}

1. Impact properties were determined on a $15-\mathrm{kg}$ laboratory heat of $\mathrm{V}-5 \mathrm{Cr}-5 \mathrm{Ti}$, fabricated by the procedure that was followed to produce a $500-\mathrm{kg}$ production-scale heat of $\mathrm{V}-4 \mathrm{Cr}-4 \mathrm{Ti}$. After final annealing at $1000^{\circ} \mathrm{C}$ for $1 \mathrm{~h}$, the laboratory heat of $\mathrm{V}-5 \mathrm{Cr}-5 \mathrm{Ti}$ exhibited impact properties as excellent as those of the production-scale heat of $\mathrm{V}-4 \mathrm{Cr}-4 \mathrm{Ti}$, i.e., DBTT $<-200^{\circ} \mathrm{C}$ and absorbed energies of $10-16 \mathrm{~J}$. When annealed at 1050 or $1100^{\circ} \mathrm{C}, \mathrm{DBTT}$ of the alloy increased to -175 and $-125^{\circ} \mathrm{C}$, respectively.

2. Unannealed as-rolled plates of $\mathrm{V}-(4-5) \mathrm{Cr}-(4-5) \mathrm{Ti}$ alloys are susceptible to laminated cracking parallel to the rolling plane, a mode of low-energy ductile fracture. Although the mechanism of the laminated cracking is not well understood, this study underscores the importance of proper annealing of this class of alloys.

3. Impact properties of some heats of $\mathrm{V}-(4-5) \mathrm{Cr}-(4-5) \mathrm{Ti}$ alloys are more sensitive to annealing than others. Although this significant heat-to-heat variation is not well understood, minor impurities are believed to play an important role.

4. Final annealing at $1000^{\circ} \mathrm{C}$ for $1 \mathrm{~h}$ in a high-quality vacuum is optimal for components fabricated from $\mathrm{V}-(4-5) \mathrm{Cr}-(4-5) \mathrm{Ti}$ alloys. When annealed at these conditions, excellent impact properties of the alloy class in unirradiated state can be ensured, regardless of minor variations in alloying-element composition.

\section{REFERENCES}

[1] D. L. Smith, B. A. Loomis, and H. M. Chung, Plasma Devices and Operations, Vol. 3, 1994, pp. 167-179.

[2] H. M. Chung, B. A. Loomis, and D. L. Smith, "Properties of V-4Cr-4Ti for Application as Fusion Reactor Structural Components," Fusion Eng. Design, 29 (1995), pp. 455-464.

[3] H. M. Chung, J. Gazda, L. Nowicki, J. E. Sanecki, and D. L. Smith, "Effects of Fabrication Variables on Impact Properties and Microstructure of V-Cr-Ti Alloys," in Fusion Reactor Materials, Semiannual. Prog. Report, DOE/ER-0313/15, Oak Ridge National Laboratory, Oak Ridge, TN (1994), pp. 207-218.

[4]. H. M. Chung, H.-C. Tsai, D. L. Smith, R. Peterson, C. Curtis, C . Wojcik, and R. Kinney, "Fabrication of 500-kg Heat of V-4Cr-4Ti", in Fusion Reactor Materials, Semiannual Prog. Report for Period Ending September 30, 1994, DOE/ER-0313/17, Oak Ridge National Laboratory, Oak Ridge, in press.

[5] H. M. Chung, L. Nowicki, and D. L. Smith, "Effect of Annealing on Impact Properties of Production-Scale Heat of $\mathrm{V}-4 \mathrm{Cr}-4 \mathrm{Ti}$," in this report. 
TENSILE PROPERTIES OF UNIRRADIATED V-Cr-Ti ALLOYS, AND ALTERNATIVE APPROACHES FOR STRENGTHENING THE V-4Cr-4Ti ALLOY* - B. A. Loomis, L. J. Nowicki, and D. L. Smith (Argonne National Laboratory)

\section{OBJECTIVE}

The objective of this research is to determine the temperature dependence of physical and mechanical properties of unirradiated and neutron-irradiated V-Cr-Ti alloys for the purpose of determining the composition of a $\mathrm{V}$-Cr-Ti alloy with the optimal combination of physical and mechanical properties in the environment of a magnetic fusion reactor.

\section{SUMMARY}

The temperature dependence of tensile properties of unirradiated V-Cr-Ti alloys are presented in the form of tables and figures in this report. These tensile-property data together with other physical and mechanical property data for unirradiated and neutron-irradiated V-Cr-Ti alloys, are examined for alternative approaches to strengthen the $\mathrm{V}-4 \mathrm{Cr}-4 \mathrm{Ti}$ alloy, which is the current prime-candidate vanadium-base alloy for use as structural material in a fusion reactor. Consideration of three alternative approaches for strengthening (i.e., increased $\mathrm{Cr}$ and/or Ti concentration; heat treatment; or increased $\mathrm{Si}$ and/or $\mathrm{Si}, \mathrm{Al}$, and $\mathrm{Y}$ concentration) lead us to recommend $\mathrm{Si}$ and/or $\mathrm{Si}, \mathrm{Al}$, and $\mathrm{Y}$ additions as most promising for strengthening of the $\mathrm{V}-4 \mathrm{Cr}-4 \mathrm{Ti}$ alloy without major impact on the physical and mechanical properties of $\mathrm{V}-4 \mathrm{Cr}-4 \mathrm{Ti}$.

\section{MATERIALS AND PROCEDURES}

Unalloyed vanadium and vanadium-base alloys with the compositions listed in Table 1 were obtained in the form of $\approx 50 \%$ cold-worked sheet with a thickness of $\approx 0.9 \mathrm{~mm}$. Tensile specimens with a gauge length of 7.62 $\mathrm{mm}$ and a gauge width of $1.52 \mathrm{~mm}$ were machined from the as-received sheet. Surfaces of the tensile specimens were mechanically ground and polished to a surface finish of $\approx 0.3 \mu \mathrm{m}$. The polished tensile specimens were recrystallized by annealing for $1 \mathrm{~h}$ in a vacuum of $2 \times 10^{-5} \mathrm{~Pa}$. The unalloyed vanadium and $\mathrm{V}-1 \mathrm{Ti}$ alloy were annealed at $1050^{\circ} \mathrm{C}$; the V-3Ti, V-3Ti-0.25Si, V-3Ti-0.5Si, V-3Ti-1Si, V-5Ti, V-10Ti, and V-18Ti alloys were annealed at $1100^{\circ} \mathrm{C}$; and the $\mathrm{V}-5 \mathrm{Cr}-3 \mathrm{Ti}, \mathrm{V}-4 \mathrm{Cr}-4 \mathrm{Ti}, \mathrm{V}-5 \mathrm{Cr}-5 \mathrm{Ti}, \mathrm{V}-8 \mathrm{Cr}-6 \mathrm{Ti}$, V-9Cr-5Ti, V-11 Cr$5 \mathrm{Ti}, \mathrm{V}-13 \mathrm{Cr}-6 \mathrm{Ti}, \mathrm{V}-14 \mathrm{Cr}-5 \mathrm{Ti}, \mathrm{V}-15 \mathrm{Cr}-5 \mathrm{Ti}, \mathrm{V}-10 \mathrm{Cr}-9 \mathrm{Ti}, \mathrm{V}-7 \mathrm{Cr}-15 \mathrm{Ti}$, and Vanstar-7 alloys were annealed at $1125^{\circ} \mathrm{C}$. These annealing temperatures resulted in an average recrystallized grain diameter of 20-30 $\mu \mathrm{m}$.

The tensile specimens were tested at a tensile strain rate of $0.0011 \mathrm{~s}^{-1}$ and a crosshead speed of $0.008 \mathrm{~mm} \cdot \mathrm{s}^{-1}$. The tensile tests were conducted in an environment of flowing argon $\left(3 \times 10^{-5} \mathrm{~m}^{3} \cdot \mathrm{s}^{-1}\right)$ of $99.9999 \%$ purity. Specimen temperature was determined by a chromel-alumel thermocouple that was arc-welded to the edge of the specimen; the temperature of each specimen during the tensile test was controlled to $\pm 1^{\circ} \mathrm{C}$.

The compositions of V-4Cr-5Ti-1Si,Al, Y and V-14Cr-25Ti-1 Si,Al, Y alloys investigated by Satou et al. [1] are also listed in Table 1 . These tensile specimens were annealed for $1 \mathrm{~h}$ at $1100^{\circ} \mathrm{C}$, which resulted in an average grain diameter of $20 \mu \mathrm{m}$.

\section{EXPERIMENTAL RESULTS}

The yield strength (YS), ultimate tensile strength (UTS), uniform elongation $\left(E_{\mathcal{U}}\right)$, and total elongation $\left(E_{T}\right)$ for the unalloyed vanadium and vanadium alloys listed in Table $l$ are presented in Table 2. Yield strength in Table 2 is defined at either the yield point or at $0.2 \% \mathrm{E}_{\mathrm{T}}$ from the elastic portion of the tensile load-elongation curve. The tensile properties data in Table 2 include those (with minor corrections) previously presented in Ref. 2 .

*Work supported by the Office of Fusion Energy, U. S. Department of Energy, under Contract W-31-109-Eng38. 
Table 1. Composition of Unalloyed Vanadium and Vanadium-base Alloys

\begin{tabular}{|c|c|c|c|c|c|c|c|c|}
\hline Material & $\begin{array}{c}\text { ANL } \\
\mathrm{ID}\end{array}$ & $\begin{array}{l}\text { Cr, } \\
\text { wt.\% }\end{array}$ & $\begin{array}{c}\mathrm{Ti}, \\
\text { wt.\% }\end{array}$ & $\begin{array}{c}\text { Al, Fe, } \\
\mathrm{Y}, \mathrm{Zr} \\
\text { wt.\% }\end{array}$ & $\begin{array}{c}\text { O, } \\
\text { wt. ppm }\end{array}$ & $\begin{array}{c}\mathrm{N}, \\
\text { wt. ppm } \\
\end{array}$ & $\begin{array}{r}\text { C, } \\
\text { wt. ppm } \\
\end{array}$ & $\begin{array}{c}\mathrm{Si}, \\
\text { wt. ppm } \\
\end{array}$ \\
\hline $\mathrm{V}$ & BL 51 & - & - & $0.03 \mathrm{~A} 1$ & 297 & 35 & 30 & 287 \\
\hline V-ITi & BL 50 & - & 1.0 & $0.08 \mathrm{Al}$ & 230 & 130 & 235 & 1050 \\
\hline $\mathrm{V}-3 \mathrm{Ti}$ & BL 62 & - & 3.1 & $0.07 \mathrm{Al}$ & 320 & 86 & 109 & 660 \\
\hline $\mathrm{V}-3 \mathrm{Ti}-0.25 \mathrm{Si}$ & BL 27 & - & 3.1 & $0.04 \mathrm{Fe}$ & 210 & 310 & 300 & 2500 \\
\hline V-3Ti-0.5Si & BL 42 & & 3.1 & $0.02 \mathrm{Fe}$ & 580 & 190 & 140 & 5400 \\
\hline V-3Ti-1Si & BL 45 & - & 2.5 & $0.01 \mathrm{Fe}$ & 345 & 125 & 90 & 9900 \\
\hline $\mathrm{V}-5 \mathrm{Ti}$ & BL 46 & - & 4.6 & $0.04 \mathrm{Al}$ & 305 & 53 & 85 & 160 \\
\hline V-10Ti & BL 12 & - & 9.8 & $0.63 \mathrm{Fe}$ & 1670 & 390 & 450 & 245 \\
\hline $\mathrm{V}-18 \mathrm{Ti}$ & BL 15 & - & 17.7 & $0.04 \mathrm{Fe}$ & 830 & 160 & 380 & 480 \\
\hline V $5 \mathrm{Cr}-3 \mathrm{Ti}$ & BL 54 & 5.1 & 3.0 & $0.07 \mathrm{Al}$ & 480 & 82 & 133 & 655 \\
\hline $\mathrm{V}-4 \mathrm{Cr}-4 \mathrm{Ti}$ & BL 47 & 4.1 & 4.3 & $0.03 \mathrm{Al}$ & 350 & 220 & 200 & 870 \\
\hline $\mathrm{V}-5 \mathrm{Cr}-5 \mathrm{Ti}$ & BL 63 & 4.6 & 5.1 & $0.02 \mathrm{Al}$ & 440 & 28 & 73 & 310 \\
\hline $\mathrm{V}-8 \mathrm{Cr}-6 \mathrm{Ti}$ & BL 49 & 7.9 & 5.7 & $0.02 \mathrm{Al}$ & 400 & 150 & 127 & 36 \\
\hline $\mathrm{V}-9 \mathrm{Cr}-5 \mathrm{Ti}$ & BL 43 & 9.2 & 4.9 & $0.02 \mathrm{Fe}$ & 230 & 31 & 100 & 340 \\
\hline $\mathrm{V}-11 \mathrm{Cr}-5 \mathrm{Ti}$ & BL 40 & 10.9 & 5.0 & $0.04 \mathrm{Fe}$ & 470 & 80 & 90 & 270 \\
\hline $\mathrm{V}-13 \mathrm{Cr}-6 \mathrm{Ti}$ & BL 23 & 12.9 & 5.9 & $0.04 \mathrm{Fe}$ & 400 & 490 & 280 & 1230 \\
\hline $\mathrm{V}-14 \mathrm{Cr}-5 \mathrm{Ti}$ & BL 24 & 13.5 & 5.2 & $0.05 \mathrm{Fe}$ & 1190 & 360 & 500 & 390 \\
\hline $\mathrm{V}-15 \mathrm{Cr}-5 \mathrm{Ti}$ & BL 41 & 14.5 & 5.0 & $0.02 \mathrm{Fe}$ & 330 & 96 & 120 & 400 \\
\hline V-10-Cr-9Ti & BL 44 & 9.9 & 9.2 & $0.04 \mathrm{Fe}$ & 300 & 87 & 150 & 270 \\
\hline V-7CI-15Ti & BL 10 & 7.2 & 14.5 & $0.09 \mathrm{Fe}$ & 1110 & 250 & 400 & 400 \\
\hline $\mathrm{V}-4 \mathrm{Cr}-5 \mathrm{Ti}$ & - & 4.0 & 4.8 & $0.95 \mathrm{Al}$ & 126 & 140 & 54 & 8500 \\
\hline ISi,Al,Y & & & & $0.77 \mathrm{Y}$ & & & & \\
\hline $\begin{array}{l}\mathrm{V}-14 \mathrm{Cr}-25 \mathrm{Ti}- \\
\mathrm{ISi}, \mathrm{Al}, \mathrm{Y}\end{array}$ & - & 13.5 & 24.6 & $\begin{array}{l}0.54 \mathrm{~A} 1 \\
0.71 \mathrm{Y}\end{array}$ & 250 & 75 & 187 & 9800 \\
\hline Vanstar-7 & BL 28 & 9.7 & - & $\begin{array}{l}3.50 \mathrm{Fe} \\
1.30 \mathrm{Zr}\end{array}$ & 280 & 520 & 640 & - \\
\hline
\end{tabular}


Table 2. Tensile Properties of Vanadium and V-Cr-Ti Alloys ${ }^{*}$

\begin{tabular}{|c|c|c|c|c|c|c|c|c|c|c|c|c|c|}
\hline Material & $\begin{array}{l}\text { ANL } \\
\text { ID }\end{array}$ & $\begin{array}{c}\text { Test Temp., } \\
{ }^{\circ} \mathrm{C}\end{array}$ & $\begin{array}{l}\text { YS, } \\
\mathrm{MPa}\end{array}$ & $\begin{array}{l}\text { UTS, } \\
\text { MPa }\end{array}$ & $\begin{array}{c}\mathrm{E}_{\mathrm{u}}, \\
\%\end{array}$ & $\begin{array}{c}\mathrm{E}_{\mathrm{t}} \\
\%\end{array}$ & Material & $\begin{array}{c}\text { ANL } \\
\text { ID }\end{array}$ & $\begin{array}{c}\text { Test Temp., } \\
{ }^{\circ} \mathrm{C}\end{array}$ & $\begin{array}{l}\mathrm{YS}, \\
\mathrm{MPa}\end{array}$ & $\begin{array}{l}\text { UTS, } \\
\text { MPa }\end{array}$ & $\begin{array}{c}\mathrm{E}_{\mathrm{u}}, \\
\%\end{array}$ & $\begin{array}{r}\mathrm{E}_{\mathrm{t}} \\
\%\end{array}$ \\
\hline$\overline{\mathrm{V}}$ & BL51 & 25 & 259 & 309 & 28 & 49 & V-1Ti & BL 50 & 25 & 268 & 343 & 23 & 34 \\
\hline V & " & 100 & 220 & 290 & 24 & 32 & $V-1 T i$ & " & 120 & 236 & 317 & 23 & 34 \\
\hline V & $"$ & 225 & 175 & 279 & 21 & 28 & $\mathrm{~V}-1 \mathrm{Ti}$ & $"$ & 225 & 188 & 275 & 20 & 28 \\
\hline V & $"$ & 300 & 181 & 348 & 26 & 32 & $\mathrm{~V}-1 \mathrm{Ti}$ & $"$ & 325 & 174 & 396 & 23 & 29 \\
\hline $\mathrm{V}$ & $"$ & 325 & 153 & 335 & 24 & 32 & $\mathrm{~V}-1 \mathrm{Ti}$ & $"$ & 420 & 198 & 402 & 22 & 28 \\
\hline V & $"$ & 350 & 138 & 310 & 24 & 32 & $\mathrm{~V}-1 \mathrm{Ti}$ & " & 520 & 181 & 398 & 28 & 37 \\
\hline V & $"$ & 420 & 167 & 283 & 25 & 36 & $\mathrm{~V}-1 \mathrm{Ti}$ & $"$ & 600 & 174 & 351 & 24 & 32 \\
\hline V & $"$ & 520 & 134 & 187 & 34 & 65 & $\mathrm{~V}-1 \mathrm{Ti}$ & $"$ & 700 & 157 & 317 & 21 & 29 \\
\hline V & $"$ & 600 & 124 & 134 & 28 & 64 & & & & & & & \\
\hline $\mathrm{V}$ & $"$ & 700 & 124 & 124 & 28 & 64 & & & & & & & \\
\hline V-3Ti & BL 62 & 25 & 295 & 409 & 24 & 33 & V-3Ti-0.25Si & BL 27 & 25 & 367 & 465 & 24 & 33 \\
\hline$V-3 T i$ & " & 100 & 210 & 340 & 22 & 27 & V-3Ti-0.25Si & DL & 100 & 300 & 410 & 22 & 27 \\
\hline$V-3 T i$ & $"$ & 225 & 180 & 298 & 22 & 28 & V-3Ti-0.25Si & $"$ & 225 & 235 & 344 & 22 & 28 \\
\hline $\mathrm{V}-3 \mathrm{Ti}$ & $"$ & 325 & 177 & 350 & 20 & 24 & $\mathrm{~V}-3 \mathrm{Ti}-0.25 \mathrm{Si}$ & $"$ & 325 & 227 & 386 & 20 & 24 \\
\hline$V-3 T i$ & $"$ & 420 & 183 & 404 & 20 & 26 & V-3Ti-0.25Si & $"$ & 420 & 242 & 431 & 20 & 26 \\
\hline $\mathrm{V}-3 \mathrm{Ti}$ & $"$ & 520 & 170 & 406 & 19 & 23 & $\mathrm{~V}-3 \mathrm{Ti}-0.25 \mathrm{Si}$ & $"$ & 520 & 228 & 428 & 19 & 23 \\
\hline $\mathrm{V}-3 \mathrm{Ti}$ & $"$ & 600 & 177 & 410 & 21 & 25 & $\mathrm{~V}-3 \mathrm{~T} \mathrm{i}-0.25 \mathrm{Si}$ & $"$ & 600 & 230 & 435 & 21 & 25 \\
\hline $\mathrm{V}-3 \mathrm{Ti}$ & $"$ & 700 & 183 & 405 & 19 & 23 & $\mathrm{~V}-3 \mathrm{Ti}-0.25 \mathrm{Si}$ & $"$ & 700 & 224 & 413 & 19 & 23 \\
\hline V-3Ti-0.5Si & BL 42 & 25 & 473 & 545 & 20 & 26 & $\mathrm{~V}-3 \mathrm{Ti}-1 \mathrm{Si}$ & BL 45 & 25 & 421 & 480 & 25 & 34 \\
\hline V-3Ti-0.5Si & " & 100 & 405 & 519 & 19 & 22 & V-3Ti-1Si & " & 105 & 355 & 430 & 26 & 33 \\
\hline V-3Ti-0.5Si & $"$ & 225 & 317 & 410 & 18 & 23 & V-3Ti-1Si & $"$ & 225 & 286 & 392 & 26 & 32 \\
\hline $\mathrm{V}-3 \mathrm{Ti}-0.5 \mathrm{Si}$ & $"$ & 325 & 300 & 436 & 21 & 27 & V-3Ti-1Si & $"$ & 325 & 259 & 405 & 21 & 26 \\
\hline V-3Ti-0.5Si & $"$ & 420 & 328 & 463 & 16 & 20 & V-3Ti-1Si & $"$ & 420 & 274 & 447 & 24 & 29 \\
\hline V-3Ti-0.5Si & $"$ & 520 & 312 & 466 & 18 & 23 & V-3Ti-1Si & " & 520 & 274 & 447 & 24 & 29 \\
\hline V-3Ti-0.5Si & $"$ & 600 & 308 & 470 & 18 & 21 & V-3Ti-1Si & $"$ & 600 & 265 & 446 & 21 & 26 \\
\hline V-3Ti-0.5Si & $"$ & 700 & 291 & 452 & 17 & 20 & V-3Ti-1Si & $"$ & 700 & 260 & 437 & 17 & 21 \\
\hline V-5Ti & BL 46 & 25 & 336 & 412 & 22 & 35 & V-10Ti & BL 12 & 25 & 435 & 532 & 25 & 33 \\
\hline V-5Ti & " & 108 & 294 & 366 & 16 & 24 & V-10Ti & " & 100 & 374 & 477 & 25 & 32 \\
\hline V.5Ti & $"$ & 160 & 259 & 342 & 20 & 25 & $\mathrm{~V}-10 \mathrm{Ti}$ & $"$ & 225 & 326 & 463 & 23 & 28 \\
\hline V-5Ti & $"$ & 225 & 217 & 317 & 23 & 28 & V-10Ti & $"$ & 325 & 310 & 479 & 21 & 27 \\
\hline $\mathrm{V}-5 \mathrm{Ti}$ & $"$ & 330 & 214 & 342 & 22 & 28 & V-10Ti & $"$ & 420 & 308 & 496 & 21 & 27 \\
\hline V-5Ti & $"$ & 420 & 215 & 334 & 15 & 19 & V-10Ti & $"$ & 520 & 303 & 529 & 21 & 25 \\
\hline V-5Ti & $"$ & 520 & 195 & 350 & 20 & 24 & V-10Ti & $"$ & 600 & 298 & 538 & 23 & 25 \\
\hline V-5Ti & $"$ & 600 & 195 & 388 & 19 & 25 & V-10Ti & $"$ & 700 & 262 & 466 & 19 & 24 \\
\hline V-5Ti & $"$ & 700 & 203 & 376 & 17 & 19 & & & & & & & \\
\hline
\end{tabular}


Table 2. (Continued)

\begin{tabular}{|c|c|c|c|c|c|c|c|c|c|c|c|c|c|}
\hline Material & $\begin{array}{c}\text { ANL } \\
\text { ID }\end{array}$ & $\begin{array}{c}\text { Test Temp., } \\
{ }^{\circ} \mathrm{C}\end{array}$ & $\begin{array}{l}\mathrm{YS}, \\
\mathrm{MPa}\end{array}$ & $\begin{array}{l}\text { UTS, } \\
\mathrm{MPa}\end{array}$ & $\begin{array}{c}\mathrm{E}_{\mathrm{U}} \\
\%\end{array}$ & $\begin{array}{c}\mathrm{E}_{\mathrm{t}}, \\
\%\end{array}$ & Material & $\begin{array}{l}\text { ANL } \\
\text { ID }\end{array}$ & $\begin{array}{c}\text { Test Temp., } \\
{ }^{\circ} \mathrm{C}\end{array}$ & $\begin{array}{l}\mathrm{YS}, \\
\mathrm{MPa}\end{array}$ & $\begin{array}{l}\text { UTS, } \\
\mathrm{MPa}\end{array}$ & $\begin{array}{c}\mathrm{E}_{\mathrm{u}} \\
\%\end{array}$ & $\begin{array}{l}\mathrm{E}_{\mathrm{t}} \\
\% \\
\end{array}$ \\
\hline $\begin{array}{l}\mathrm{V}-18 \mathrm{Ti} \\
\mathrm{V}-18 \mathrm{Ti}\end{array}$ & $\mathrm{BL}_{1} 15$ & $\begin{array}{r}25 \\
100\end{array}$ & $\begin{array}{l}628 \\
525\end{array}$ & $\begin{array}{l}692 \\
640\end{array}$ & $\begin{array}{l}22 \\
22\end{array}$ & $\begin{array}{l}32 \\
30\end{array}$ & $\begin{array}{l}\text { V-5Cr-3Ti } \\
\text { V-5Cr-3Ti }\end{array}$ & $\overline{\text { BL } 54}$ & $\begin{array}{r}25 \\
420\end{array}$ & $\begin{array}{l}337 \\
208\end{array}$ & $\begin{array}{l}430 \\
349\end{array}$ & $\begin{array}{l}18 \\
17\end{array}$ & $\begin{array}{l}25 \\
23\end{array}$ \\
\hline $\mathrm{V}-18 \mathrm{Ti}$ & $"$ & 225 & 437 & 588 & 20 & 25 & V-5Cr-3Ti & " & 600 & 204 & 346 & 14 & 21 \\
\hline $\mathrm{V}-18 \mathrm{Ti}$ & $"$ & 325 & 436 & 636 & 24 & 29 & & & & & & & \\
\hline $\mathrm{V}-18 \mathrm{Ti}$ & $"$ & 420 & 443 & 658 & 24 & 30 & $\mathrm{~V}-4 \mathrm{Cr}-4 \mathrm{Ti}$ & BL 47 & 25 & 387 & 454 & 25 & 34 \\
\hline $\mathrm{V}-18 \mathrm{Ti}$ & $"$ & 520 & 445 & 678 & 29 & 33 & $\mathrm{~V}-4 \mathrm{Cr}-4 \mathrm{Ti}$ & $"$ & 100 & 325 & 420 & 25 & 33 \\
\hline $\mathrm{V}-18 \mathrm{Ti}$ & $"$ & 600 & 417 & 667 & 20 & 28 & $\mathrm{~V}-4 \mathrm{Cr}-4 \mathrm{Ti}$ & $"$ & 225 & 272 & 379 & 26 & 31 \\
\hline $\mathrm{V}-18 \mathrm{Ti}$ & $"$ & 700 & 393 & 496 & 15 & 23 & $\begin{array}{l}\text { V-4Cr-4Ti } \\
\text { V-4Cr-4Ti }\end{array}$ & " & $\begin{array}{l}337 \\
420\end{array}$ & $\begin{array}{l}254 \\
250\end{array}$ & $\begin{array}{l}388 \\
405\end{array}$ & $\begin{array}{l}20 \\
21\end{array}$ & $\begin{array}{l}28 \\
25\end{array}$ \\
\hline $\begin{array}{l}\text { V-5Cr-5Ti } \\
\text { V-5Cr-5Ti }\end{array}$ & ${ }^{B L} 63$ & $\begin{array}{r}25 \\
420\end{array}$ & $\begin{array}{l}386 \\
238\end{array}$ & $\begin{array}{l}465 \\
396\end{array}$ & $\begin{array}{l}22 \\
21\end{array}$ & $\begin{array}{l}34 \\
28\end{array}$ & $\begin{array}{l}\text { V-4Cr-4Ti } \\
\text { V-4Cr-4Ti }\end{array}$ & $"$ & $\begin{array}{l}520 \\
600\end{array}$ & $\begin{array}{l}244 \\
256\end{array}$ & $\begin{array}{l}423 \\
434\end{array}$ & $\begin{array}{l}19 \\
16\end{array}$ & $\begin{array}{l}24 \\
21\end{array}$ \\
\hline $\mathrm{V}-5 \mathrm{Cr}-5 \mathrm{Ti}$ & " & 600 & 225 & 382 & 15 & 20 & $\begin{array}{l}\text { V-4Cr-4Ti } \\
\text { V-4Cr-4Ti }\end{array}$ & " & $\begin{array}{l}650 \\
700\end{array}$ & $\begin{array}{l}264 \\
266\end{array}$ & $\begin{array}{l}453 \\
414\end{array}$ & $\begin{array}{l}19 \\
17\end{array}$ & $\begin{array}{l}23 \\
20\end{array}$ \\
\hline V-4Cr-5Ti- & - & 25 & 510 & 57 & - & 20 & $\mathrm{~V}-8 \mathrm{Cr}-6 \mathrm{Ti}$ & BL 49 & 25 & 440 & 541 & 23 & 33 \\
\hline ISi,Al,Y & & & & & & & $\mathrm{V}-8 \mathrm{Cr}-6 \mathrm{Ti}$ & " & 108 & 393 & 489 & 23 & 30 \\
\hline & $"$ & 200 & 425 & 510 & - & 20 & $\mathrm{~V}-8 \mathrm{Cr}-6 \mathrm{Ti}$ & $"$ & 175 & 318 & 404 & 12 & 13 \\
\hline$"$ & $"$ & 300 & 375 & 500 & - & 21 & $\mathrm{~V}-8 \mathrm{Cr}-6 \mathrm{Ti}$ & $"$ & 225 & 236 & 347 & 17 & 23 \\
\hline$"$ & $"$ & 400 & 350 & 525 & - & 19 & $\mathrm{~V}-8 \mathrm{Cr}-6 \mathrm{Ti}$ & $"$ & 325 & 261 & 429 & 18 & 26 \\
\hline$"$ & $"$ & 500 & 345 & 525 & - & 19 & $\mathrm{~V}-8 \mathrm{Cr}-6 \mathrm{Ti}$ & $"$ & 420 & 287 & 470 & 20 & 25 \\
\hline$"$ & $"$ & 600 & 345 & 550 & - & 19 & $\mathrm{~V}-8 \mathrm{Cr}-6 \mathrm{Ti}$ & $"$ & 600 & 285 & 486 & 19 & 22 \\
\hline$"$ & $"$ & 700 & 300 & 475 & - & 22 & V-8Cr-6Ti & $"$ & 700 & 271 & 487 & 21 & 26 \\
\hline$"$ & $"$ & 800 & 275 & 400 & - & 40 & & & & & & & \\
\hline$"$ & $"$ & 900 & 250 & 285 & - & 60 & & & & & & & \\
\hline$"$ & $"$ & 1000 & 150 & 175 & - & 70 & & & & & & & \\
\hline V-9Cr-5Ti & BL 43 & 25 & 440 & 541 & 23 & 33 & V-11Cr-5Ti & BL 40 & 25 & 491 & 573 & 23 & 31 \\
\hline $\mathrm{V}-9 \mathrm{Cr}-5 \mathrm{Ti}$ & $"$ & 100 & 387 & 482 & 20 & 32 & $\mathrm{~V}-11 \mathrm{Cr}-5 \mathrm{Ti}$ & " & 100 & 402 & 500 & 21 & 27 \\
\hline V-9Cr-5Ti & $"$ & 225 & 334 & 448 & 22 & 29 & $\mathrm{~V}-11 \mathrm{Cr}-5 \mathrm{Ti}$ & $"$ & 225 & 347 & 464 & 21 & 26 \\
\hline $\mathrm{V}-9 \mathrm{Cr}-5 \mathrm{Ti}$ & $"$ & 325 & 312 & 452 & 21 & 30 & $\mathrm{~V}-11 \mathrm{Cr}-5 \mathrm{Ti}$ & $"$ & 325 & 304 & 448 & 17 & 24 \\
\hline V-9Cr-5Ti & $"$ & 420 & 300 & 467 & 20 & 25 & $\mathrm{~V}-11 \mathrm{Cr}-5 \mathrm{Ti}$ & $"$ & 433 & 321 & 501 & 18 & 24 \\
\hline $\mathrm{V}-9 \mathrm{Cr}-5 \mathrm{Ti}$ & $"$ & 520 & 297 & 463 & 18 & 23 & $\mathrm{~V}-11 \mathrm{Cr}-5 \mathrm{Ti}$ & $"$ & 520 & 303 & 488 & 17 & 22 \\
\hline $\mathrm{V}-9 \mathrm{Cr}-5 \mathrm{Ti}$ & $"$ & 600 & 297 & 512 & 21 & 25 & $\mathrm{~V}-11 \mathrm{Cr}-5 \mathrm{Ti}$ & $"$ & 600 & 299 & 519 & 22 & 26 \\
\hline V-9Cr-5Ti & $"$ & 700 & 277 & 488 & 21 & 27 & $\mathrm{~V}-11 \mathrm{Cr}-5 \mathrm{Ti}$ & $"$ & 650 & 310 & 529 & 20 & 25 \\
\hline & & & & & & & $\mathrm{V}-11 \mathrm{Cr}-5 \mathrm{Ti}$ & $"$ & 700 & 299 & 513 & 21 & 26 \\
\hline
\end{tabular}


Table 2. (Continued)

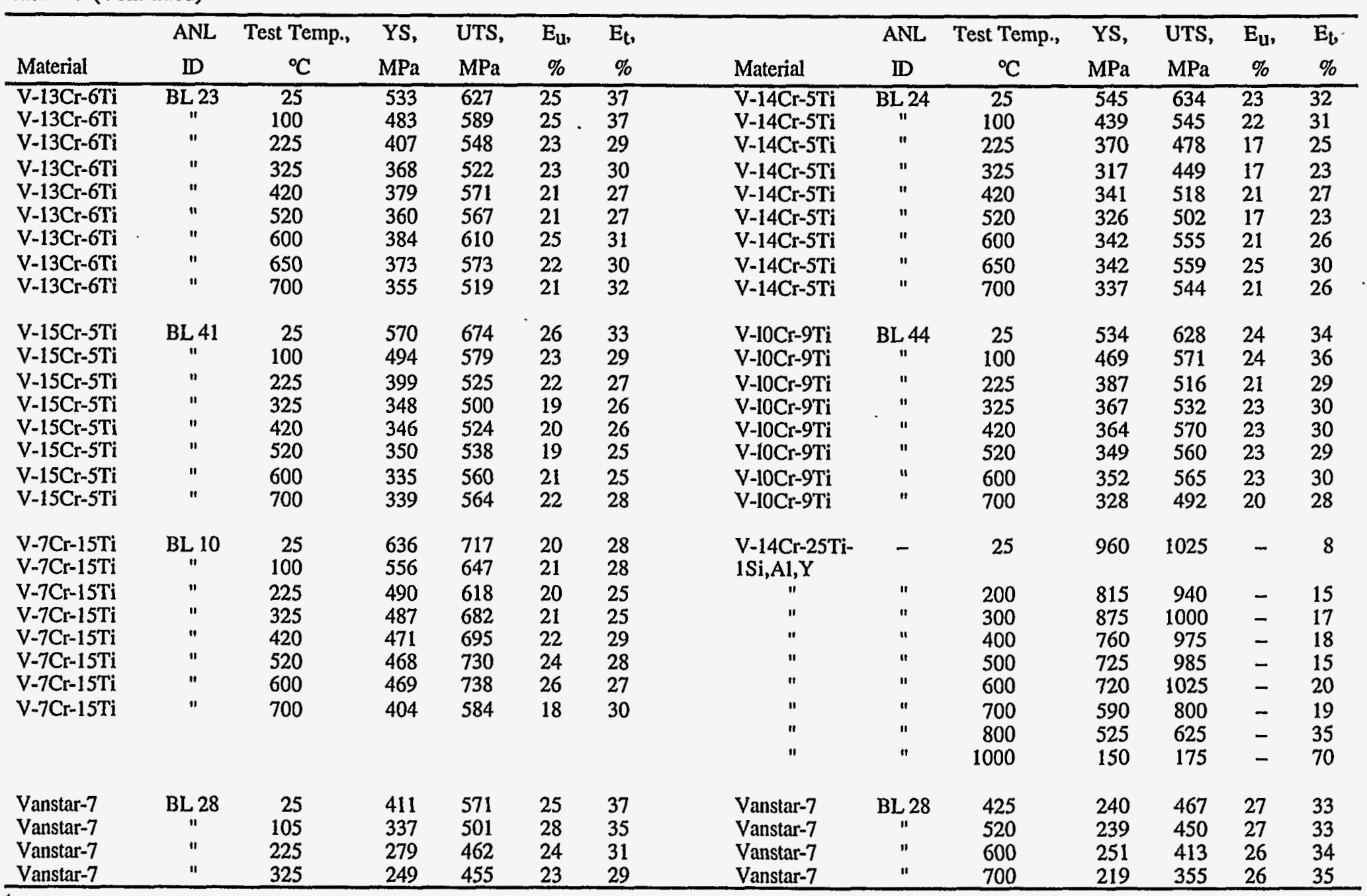

${ }^{*}$ Data for the $\mathrm{V}-4 \mathrm{Cr}-5 \mathrm{Ti}-1 \mathrm{Si}, \mathrm{Al}, \mathrm{Y}$ and $\mathrm{V}-14 \mathrm{Cr}-25 \mathrm{Ti}-1 \mathrm{Si}, \mathrm{Al}, \mathrm{Y}$ alloys were obtained from Ref. 1. 
Dependence of yield strength of V-Ti and V-Cr-(4-6) Ti alloys at $25^{\circ} \mathrm{C}$ on $\mathrm{Cr}+\mathrm{Ti}$ concentration is shown in Fig. 1, which shows that the yield strength of V-Ti and V-Cr-Ti alloys is strongly dependent on Ti and/or $\mathrm{Cr}$ concentration, with Ti a more potent strengthener than $\mathrm{Cr}$. As shown in Figs. 2 and 3, Si can also be a potent strengthener of V-Ti and V-Cr-Ti alloys. Maximum strengthening of these alloys by Si may be 5000 to 10000 ppm Si (Fig. 2).

Additional figures (constructed from the data in Table 2) that show the temperature dependence of yield strength, ultimate tensile strength, uniform elongation, and total elongation of V-Ti and V-Cr-Ti alloys are provided in Refs. 2 and 3.

\section{DISCUSSION OF RESULTS}

Extensive investigations on the effects of neutron irradiation on swelling, tensile properties, impact toughness, and microstructural evolution of $\mathrm{V}-\mathrm{Ti}$ and $\mathrm{V}-\mathrm{Cr}$ - Ti alloys on neutron irradiation have shown that the $\mathrm{V}-4 \mathrm{Cr}$ 4Ti alloy can be expected to have acceptable physical and mechanical properties in the harsh environment of a fusion reactor [4-6]. Nevertheless, it may be desirable to increase the strength of this alloy for additional resistance to thermal- and irradiation-induced creep and fatigue deformation [7-9]. At least three approaches might be used to strengthen the $\mathrm{V}-4 \mathrm{Cr}-4 \mathrm{Ti}$ alloy, i.e., (a) increased $\mathrm{Cr}$ and/or Ti concentration, (b) heat treatment, or (c) increased $\mathrm{Si}$ and/or $\mathrm{Si}, \mathrm{Al}$, and $\mathrm{Y}$ concentration.

\section{Increased $\mathrm{Cr}$ and/or $\mathrm{Ti}$ Concentration}

The strength of V-Ti and V-Cr-Ti alloys is strongly dependent on $\mathrm{Cr}$ and/or Ti concentration in the alloy, as shown in Fig. 1. However, if $\mathrm{Cr}$ or Ti concentration in the alloy is increased to $>6 \%$, the ductile-brittle transition temperature (DBTT) may be $>25^{\circ} \mathrm{C}$ on neutron irradiation [5].

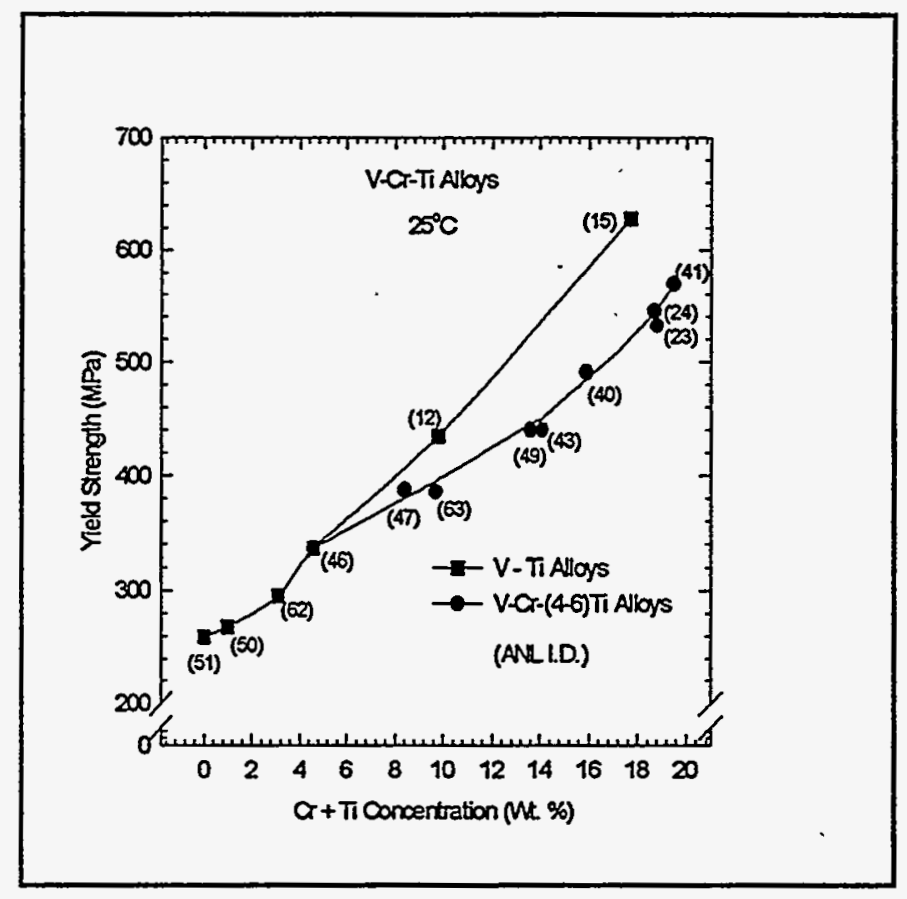

Fig. 1. Dependence of Yield Strength of V-Ti and V-Cr-(4-6)Ti Alloys at $25^{\circ} \mathrm{C}$ on $\mathrm{Cr}+\mathrm{Ti}$ Concentration. 


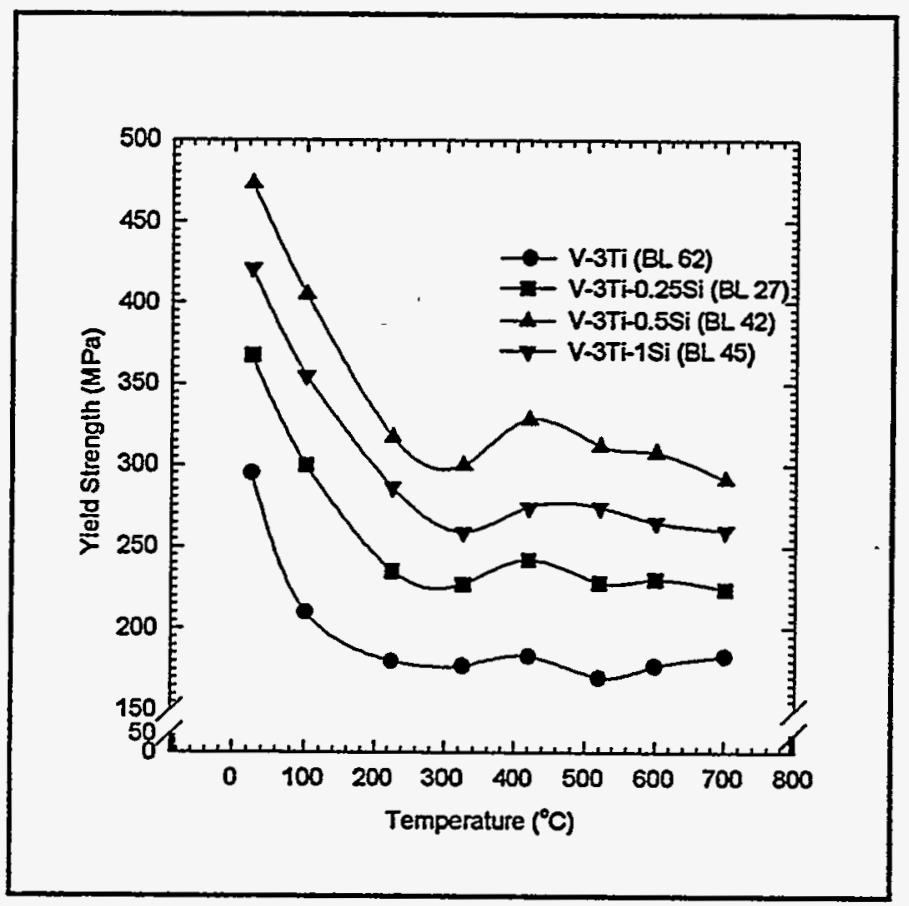

Fig. 2. Dependence of Yield Strength of V-3Ti-Si Alloys on Temperature.

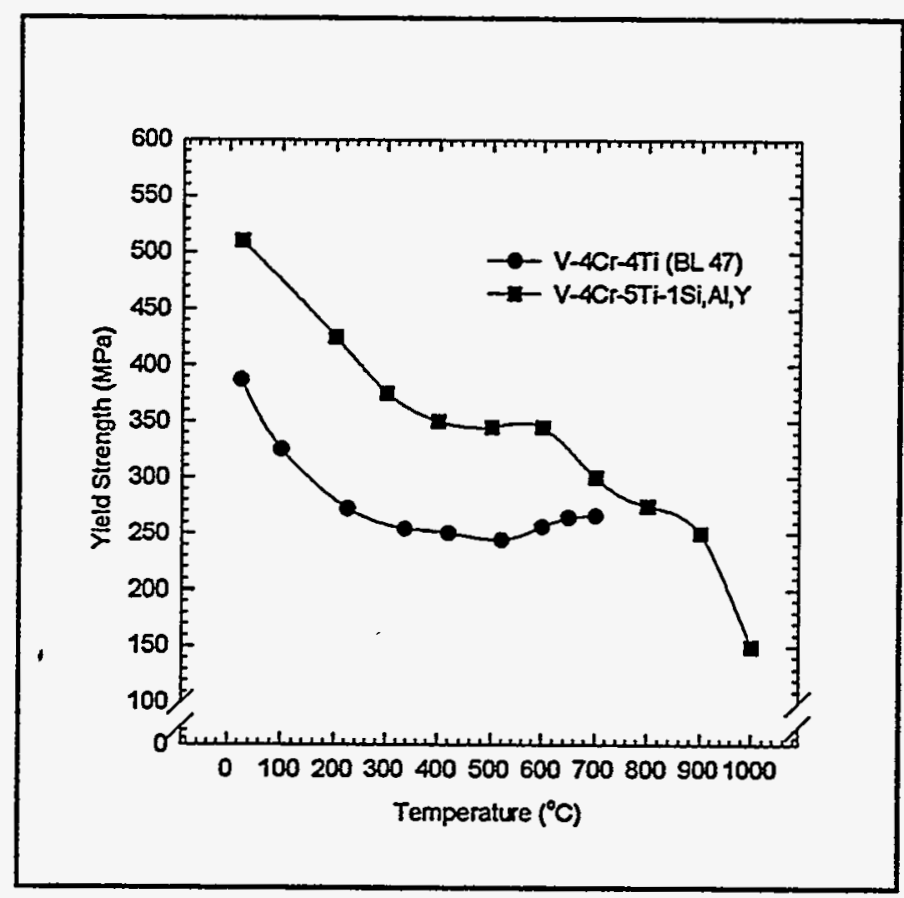

Fig. 3. Dependence of Yield Strength of V-4Cr-4Ti and V-4Cr-5Ti-1Si,Al, Y Alloys on Temperature. 


\section{Heat Treatment}

The strength of V-Cr-Ti alloys is also strongly dependent on heat treatment as suggested by the data in Fig. 3 of Ref. 10. However, experimental data, e.g., Fig. 1 in Ref. 11, suggest that the swelling of V-Cr-Ti alloys may be increased significantly by reducing heat treatment temperature to $<1100-1125^{\circ} \mathrm{C}$.

\section{Increased $\mathrm{Si}$ and/or $\mathrm{Si}, \mathrm{Al}$, and $\mathrm{Y}$ Concentration}

The strength of the V-3Ti alloy and the $\mathrm{V}-4 \mathrm{Cr}-4 \mathrm{Ti}$ alloy is also strongly dependent on $\mathrm{Si}$ concentration in the alloy (Figs. 2 and 3). The addition of $9900 \mathrm{ppm} \mathrm{Si}$ to the V-3Ti alloy did not result in a significant increase in DBTT [5]. Total elongation of the $\mathrm{V}-4 \mathrm{Cr}-5 \mathrm{Ti}-1 \mathrm{Si}, \mathrm{Al}, \mathrm{Y}$ alloy at $25^{\circ} \mathrm{C}$ after irradiation at $420-600^{\circ} \mathrm{C}$ to $24-41$ dpa was $8-15 \%$, and swelling of this alloy after irradiation was low [12]. Therefore, the addition of $\mathrm{Si}$ (and possibly $\mathrm{Al}$ and $\mathrm{Y}$ ) to the $\mathrm{V}-4 \mathrm{Cr}-4 \mathrm{Ti}$ alloy may be the most viable approach for strengthening of this alloy.

\section{CONCLUSIONS}

- The strength of V-Ti and V-Cr-Ti alloys is strongly dependent on $\mathrm{Cr}$, $\mathrm{Ti}$, and $\mathrm{Si}$ concentration.

- The addition of $\mathrm{Si}$ (and possibly $\mathrm{Al}$ and $\mathrm{Y}$ ) to the $\mathrm{V}-4 \mathrm{Cr}-4 \mathrm{Ti}$ alloy may be the most viable approach for strengthening of this alloy.

\section{REFERENCES}

1. M. Satou, K. Abe, and H. Kayano, "High-Temperature Deformation of Modified V-Ti-Cr-Si Alloys," J. Nuclear Materials, 179-181 (1991) 757-761.

2. B. A. Loomis, L. J. Nowicki, and D. L. Smith, "Tensile Properties of Vanadium and Vanadium-Base Alloys," in Fusion Reactor Materials Semiannual Progress Report for Period Ending March 31, 1991, DOE/ER-0313/10, pp. 145-155.

3. B. A. Loomis, R. H. Lee, D. L. Smith, and J. R. Peterson, "Strength, Ductility, and Ductile-Brittle Transition Temperature for MFR Candidate Vanadium Alloys," J. Nuclear Materials, 155-157 (1988) 631-638.

4. H. M. Chung, B. A. Loomis, and D. L. Smith, "Effect of Irradiation Damage and Helium on Swelling and Structure of Vanadium-Base Alloys," J. Nuclear Materials, 212-215 (1994) 804-812.

5. B. A. Loomis, H. M. Chung, L. J. Nowicki, and D. L. Smith, "Effects of Neutron Irradiation and Hydrogen on Ductile-Brittle Transition Temperatures of V-Cr-Ti Alloys," J. Nuclear Materials, 212-215 (1994) 799803.

6. B. A Loomis, L. J. Nowicki, and D. L. Smith, "Effect of Neutron Irradiation on Tensile Properties of V-CrTi Alloys," J. Nuclear Materials, 212-215 (1994) 790-793.

7. B. A. Loomis, L. J. Nowicki, and D. L. Smith, "Creep of V-5Cr-5Ti and V-10Cr-5Ti Alloys at $600^{\circ} \mathrm{C}$," in Fusion Reactor Materials Semiannual Progress Report for Period Ending September 30, 1992, DOE/ER0313/13, pp. 214-216.

8. 'H. M. Chung, B. A. Loomis, and D. L. Smith, "Creep Properties of Vanadium-Base Alloys," J. Nuclear Materials, 212-215 (1994) 772-777.

9. B. G. Gieseke, C. O. Stevens, and M. L. Grossbeck, "Fatigue Behavior of Unirradiated V-5Cr-5Ti," in Compatibility and Irradiation Testing of Vanadium Alloys, Report No. ITER/US/95/IV MAT 10 (1994). 10. B. A. Loomis, L. J. Nowicki, and D. L. Smith, "Hardness Recovery of $85 \%$ Cold-Worked V-Ti and V-CrTi Alloys Upon Annealing at $180^{\circ} \mathrm{C}$ to $1200^{\circ} \mathrm{C}$," in Fusion Reactor Materials Semiannual Progress Report for Period Ending September 30, 1994, DOE/ER-0313/17 (1995).

11. B. A. Loomis, L. J. Nowicki, and D. L. Smith, "Effect of Pre-Irradiation Heat Treatment on Swelling of Neutron-Irradiated Vanadium-Base Alloys, " in Fusion Reactor Materials Semiannual Progress Report for Period Ending March 31, 1995, DOEE/ER-0313/18 (1995).

12. M. Satou, K. Abe, and H. Kayano, "Tensile Properties and Microstructures of Neutron-Irradiated V-Ti-CrSi Type Alloys," J. Nuclear Materials, 212-215 (1994) 794-798. 


\section{EFFECT OF ANNEALING ON IMPACT PROPERTIES OF PRODUCTION-SCALE HEAT OF V-4Cr $-4 T^{*}$ H. M. Chung, L. Nowicki, and D. L. Smith (Argonne National Laboratory)}

\section{OBJECTIVE}

Following reports of excellent properties of a laboratory heat of $\mathrm{V}-4 \mathrm{Cr}-4 \mathrm{Ti}$, the alloy identified as the primary vanadium-based candidate for application in fusion reactor structural components, a large production-scale $(500-\mathrm{kg})$ heat of the alloy was successfully fabricated. The objective of this study is to identify an annealing procedure that produces optimal impact properties in this heat in the unirradiated state.

\section{SUMMARY}

A $500-\mathrm{kg}$ heat of $\mathrm{V}-4 \mathrm{Cr}-4 \mathrm{Ti}$, an alloy identified previously as the primary vanadium-based candidate alloy for application in fusion reactor structural components, has been successfully produced. Impact tests were conducted at -196 to $150^{\circ} \mathrm{C}$ on one-third-size blunt-notch Charpy specimens of the scaleup heat in as-rolled condition and after annealing for $1 \mathrm{~h}$ at 950,1000 , and $1050^{\circ} \mathrm{C}$ in a high-quality vacuum. The annealed material remained ductile at all test temperatures; the ductile-brittle transition temperature was lower than $-200^{\circ} \mathrm{C}$. The upper-shelf energy of the production-scale heat was similar to that of the laboratory-scale $(\approx 30-\mathrm{kg})$ heat of $\mathrm{V}-4 \mathrm{Cr}-4 \mathrm{Ti}$ investigated previously. The effect of annealing temperature between 950 and $1050^{\circ} \mathrm{C}$ was not significant; however, annealing at $1000^{\circ} \mathrm{C}$ for $1 \mathrm{~h}$ not only produced the best impact properties but also ensured a sufficient tolerance to the effect of temperature inhomogeneity that is expected when large components are annealed. The effect of the notch geometry of the Charpy-impact specimens was also investigated. When annealed properly (e.g., at $1000^{\circ} \mathrm{C}$ for $1 \mathrm{~h}$ ), impact properties were not sensitive to notch geometry $\left(45^{\circ}\right.$-notch, root radius $0.25 \mathrm{~mm}$; and $30^{\circ}$-notch, root radius $0.08 \mathrm{~mm}$ ).

\section{INTRODUCTION}

To develop and identify an optimal vanadium-base alloy for application in fusion reactor first wall/blanket structures, extensive investigations were conducted earlier on the swelling behavior, tensile properties, creep strength, impact toughness, and microstructural stability of $\mathrm{V}-\mathrm{Ti}, \mathrm{V}-\mathrm{Cr}-\mathrm{Ti}$, and V-Ti-Si alloys before and after irradiation by fast neutrons at $420^{\circ} \mathrm{C}-600^{\circ} \mathrm{C}$. These investigations revealed that $\mathrm{V}$ $\mathrm{Cr}$ - $\mathrm{Ti}$ alloys that contained $\approx 4 \mathrm{wt} . \% \mathrm{Cr}, \approx 4 \mathrm{wt} . \% \mathrm{Ti}, 500-1000 \mathrm{wt}$. ppm Si, and $<1000 \mathrm{wt}$. ppm $\mathrm{O}+\mathrm{N}+\mathrm{C}$ were most desirable because they exhibit superior physical and mechanical properties. ${ }^{1-5}$ These results were obtained, however, on laboratory-scale $(<30-\mathrm{kg})$ heats, including a small heat (ANL ID BL-47) of $\mathrm{V}-4 \mathrm{Cr}-4 \mathrm{Ti}$ that exhibited excellent resistance to thermal creep, ${ }^{4}$ irradiation-induced embrittlement, 1,2 swelling, ${ }^{3,5}$ and helium embrittlement. ${ }^{6-9}$ In the previous reporting period, a large $(\approx 500-\mathrm{kg})$ productionscale heat of $\mathrm{V}-4 \mathrm{Cr}-4 \mathrm{Ti}$ (Heat ID \#832665) was successfully fabricated in a joint effort between Argonne National Laboratory and Teledyne Wah Chang (Albany, Oregon). The objective of the effort was to demonstrate reliable industrial production of good-quality $\mathrm{V}-4 \mathrm{Cr}-4 \mathrm{Ti} .10 \mathrm{This}$ report describes results of an investigation of the effects of high-temperature $\left(950-1050^{\circ} \mathrm{C}\right)$ annealing on the impact properties of the $500-\mathrm{kg}$ heat. The objective was to identify an annealing procedure that produces optimal impact properties in the unirradiated $\mathrm{V}-4 \mathrm{Cr}-4 \mathrm{Ti}$ alloy class. The Charpy-impact test (at -196 to $150^{\circ} \mathrm{C}$ ) was chosen because it is known to be most sensitive to conditions of thermomechanical treatment of vanadium-base alloys.

\section{EXPERIMENTAL PROCEDURE}

The elemental composition of the 500- $\mathrm{kg}$ heat is given in Table 1. Also in the table is the elemental composition of the laboratory-scale heat of $\mathrm{V}-4 \mathrm{Cr}-4 \mathrm{Ti}$ (ANL ID BL-47) that was shown earlier to exhibit excellent properties. ${ }^{1-9}$

\footnotetext{
* Work supported by U.S. Department of Energy, Office of Fusion Energy Research, under Contract W-31-109-Eng-38.
} 
Table 1. Chemical composition (impurities in wppm) of industrial- $(500 \mathrm{~kg})$ and laboratory-scale heats of $\mathrm{V}-4 \mathrm{Cr}-4 \mathrm{Ti}$

\begin{tabular}{ccccccccccccccccc}
\hline Heat ID & ANL ID & Heat Type & $\mathrm{Cr}$ & $\mathrm{Ti}$ & $\mathrm{Cu}$ & $\mathrm{Si}$ & $\mathrm{O}$ & $\mathrm{N}$ & $\mathrm{C}$ & $\mathrm{S}$ & $\mathrm{P}$ & $\mathrm{Ca}$ & $\mathrm{Cl}$ & $\mathrm{Na}$ & $\mathrm{K}$ & $\mathrm{B}$ \\
\hline- & BL-47 & $\begin{array}{c}\text { laboratory } \\
30 \mathrm{~kg}\end{array}$ & $\begin{array}{c}4.1 \\
\text { wt.\% }\end{array}$ & $\begin{array}{c}4.3 \\
\text { wt.\% }\end{array}$ & 6 & 870 & 350 & 220 & 200 & 20 & $<40$ & 1 & 1 & 0.1 & 0.1 & 15 \\
832665 & BL-71 & $\begin{array}{c}\text { production } \\
500 \mathrm{~kg}\end{array}$ & $\begin{array}{c}3.8 \\
\text { wt.\% }\end{array}$ & $\begin{array}{c}3.9 \\
\text { wt.\% }\end{array}$ & $<50$ & 783 & 310 & 85 & 80 & $<10$ & $<30$ & $<10$ & $<2$ & - & - & $<5$ \\
\hline
\end{tabular}

One-third-size Charpy specimens $(3.33 \times 3.33 \times 25.4 \mathrm{~mm})$ were machined from $3.81-\mathrm{mm}$-thick plates of the material, some of which had been annealed in the production factory (Teledyne Wah Chang, Albany, Oregon) for $2 \mathrm{~h}$ at a nominal temperature of $\approx 1050^{\circ} \mathrm{C}$ and some of which were received in as-rolled $\left(=40-50 \%\right.$ worked at $\left.400^{\circ} \mathrm{C}\right)$ condition. The Charpy specimens were machined so that the plane of crack propagation was perpendicular to the rolling direction (i.e., the $L-S$ direction in Fig. 1). To investigate the effect of notch geometry, two types of $\mathrm{V}$-notch geometry were investigated; one with a $45^{\circ}$ notch angle and $0.25-\mathrm{mm}$ root radius and the other with a $30^{\circ}$ angle and $0.08-\mathrm{mm}$ root radius. Notch depth in both types of specimens was kept constant at $0.61 \mathrm{~mm}$. The impact specimens machined from the factory-annealed plates were tested after a degassing heat treatment at $400^{\circ} \mathrm{C}$ for $1 \mathrm{~h}$ in vacuum, a customary procedure used to expel hydrogen that could be picked up during specimen machining and preparation. To identify the optimal annealing condition, specimens machined from as-rolled (cross-rolled at $400^{\circ} \mathrm{C}$ ) 10 plates were annealed at 950,1000 , and $1050^{\circ} \mathrm{C}$ for $1 \mathrm{~h}$ in a vacuum of $\approx 6 \times 10^{-6} \mathrm{~Pa}$ prior to testing. The cooling rate down to $\approx 400^{\circ} \mathrm{C}$ was $\approx 50^{\circ} \mathrm{C}$ per minute. Details of the drop-weight-type impact test have been described elsewhere. ${ }^{2}$

- V-notch Angle: $45^{\circ}$ and $30^{\circ}$

- Root Radius: 0.25 and $0.08 \mathrm{~mm}$

- Notch Depth: $0.61 \mathrm{~mm}$

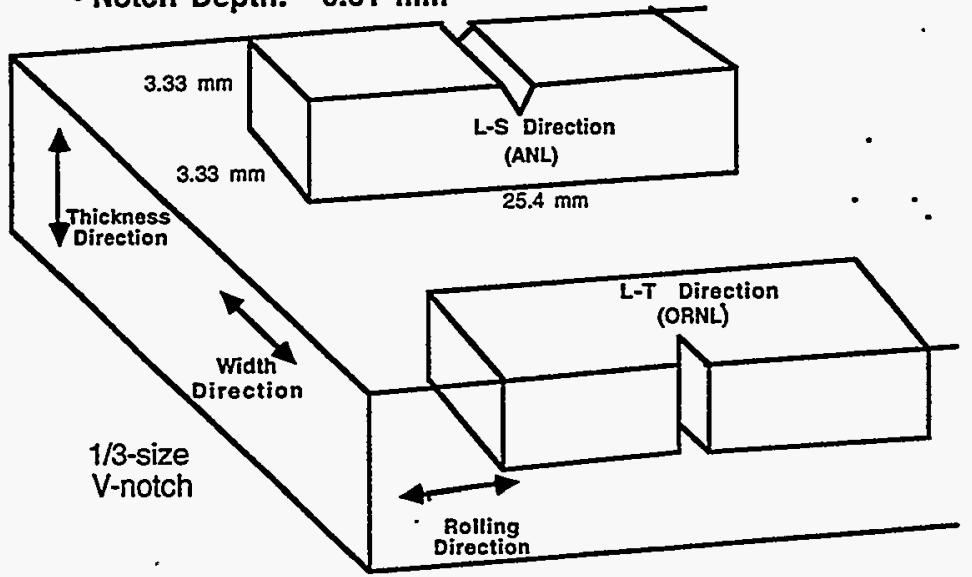

Fig. 1 .

Orientation of Charpy impact specimens with respect to rolling direction of productionscale heat of $\mathrm{V}-4 \mathrm{Cr}-4 \mathrm{Ti}$

\section{RESULTS AND DISCUSSION}

Impact energies, measured on the $45^{\circ}$-notched (root radius $0.25 \mathrm{~mm}$ ) Charpy specimens from the production-scale heat of $\mathrm{V}-4 \mathrm{Cr}-4 \mathrm{Ti}$ in as-rolled condition and after annealing for $1 \mathrm{~h}$ at 950,1000 and $1050^{\circ} \mathrm{C}$, are shown in Fig. 2 as a function of impact test temperature. Also shown in the figure are the impact energies of the heat that was annealed in factory (nominally at $1050^{\circ} \mathrm{C}$ for $2 \mathrm{~h}$ in oil-diffusionpumped vacuum). The geometry of the specimens in the figure was the same as that used in previous 
investigations, including the laboratory-scale $(30-\mathrm{kg})$ heat of $\mathrm{V}-4 \mathrm{Cr}-4 \mathrm{Ti}(\mathrm{BL}-47$, Table 1$){ }^{2}$ From the results in the figure, the optimal annealing temperature appears to be $\approx 1000^{\circ} \mathrm{C}$, the same as that found to produce minimum hardness in $\approx 85 \%$ cold-worked $\mathrm{V}-4 \mathrm{Cr}-4 \mathrm{Ti}$ (i.e., the $30-\mathrm{kg}$ laboratory heat, $\mathrm{BL}-47$, Table 1). 11 Results in Fig. 2 show that the impact properties of the production-scale heat are as good as those of the smaller laboratory heat, which was fabricated by essentially the same procedure. The ductilebrittle-transition temperature (DBTT) of the production-scale heat is no higher than $\approx-200^{\circ} \mathrm{C}$, similar to that of the laboratory-scale heat. To show a direct comparison, Charpy energies of the two heats are plotted in Fig. 3.

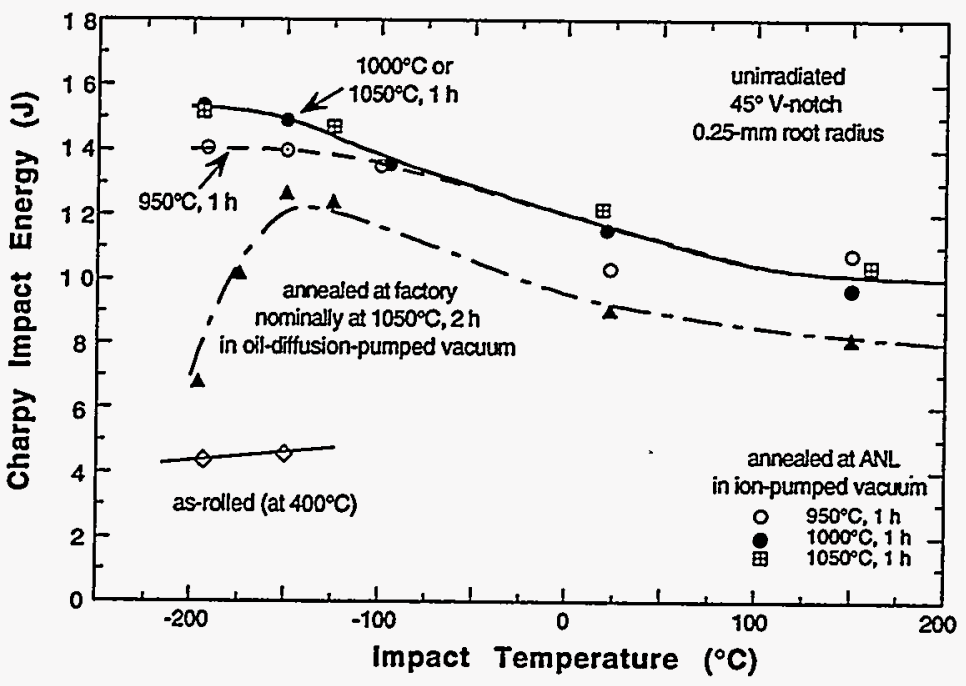

Fig. 2.

Charpy energy as function of impact temperature of production-scale heat of $\mathrm{V}-4 \mathrm{Cr}-4 \mathrm{Ti}$ after annealing for 1 h at 950, 1000, and $1050^{\circ} \mathrm{C}$. Optimal annealing temperature is $\approx 1000^{\circ} \mathrm{C}$

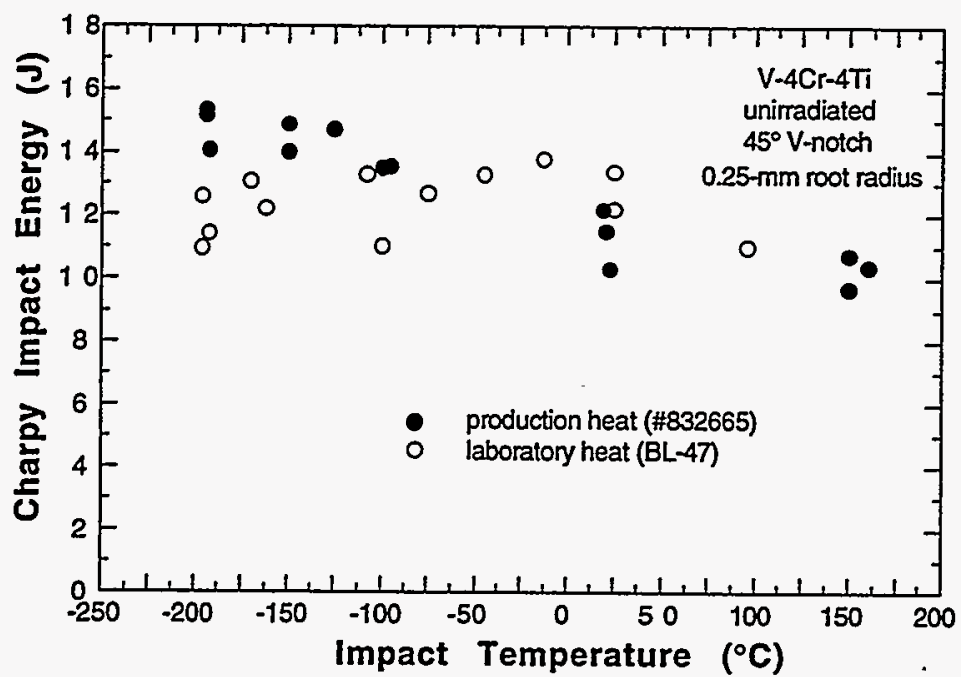

Fig. 3.

Comparison of impact properties of productionand laboratory-scale heats of $\mathrm{V}-4 \mathrm{Cr}-4 \mathrm{Ti}$

Impact properties similar to those in Fig. 2 were also determined for $30^{\circ}$-notched specimens (root radius $0.08 \mathrm{~mm}$ ). The results are shown in Fig. 4 . Slight effects of notch geometry were observed only for specimens (average grain size $\approx 28 \mathrm{~mm}$ ) annealed in the factory at a nominal temperature of $1050^{\circ} \mathrm{C}$ for $2 \mathrm{~h}$. However, the $30^{\circ}$-notched specimens exhibited impact properties as excellent as those of the $45^{\circ}$-notched specimens (DBTT $<-200^{\circ} \mathrm{C}$ ) when annealed at 950,1000 , or $1050^{\circ} \mathrm{C}$ for $1 \mathrm{~h}$ in an ion-pumped vacuum system. When annealed at $1100^{\circ} \mathrm{C}$ for $1 \mathrm{~h}$, there was an indication of a slight increase of DBTT in the heat. 


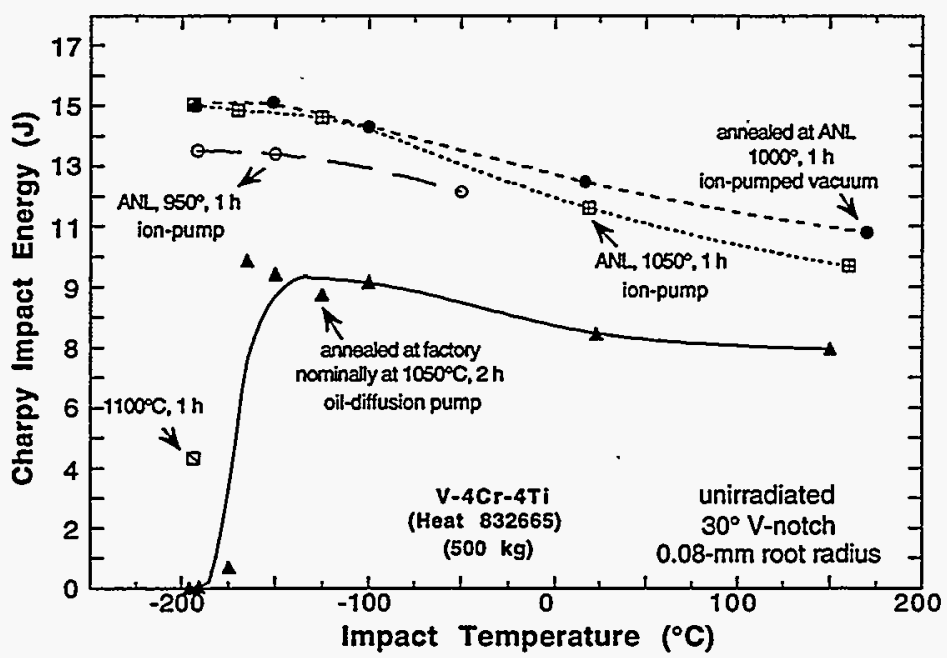

Fig. 4.

Effect of annealing on Charpy impact energy of $30^{\circ}-$ notch specimen as function of test temperature for production-scale heat of $\mathrm{V}-4 \mathrm{Cr}-4 \mathrm{Ti}$

When annealed at 1000 or $1050^{\circ} \mathrm{C}$ for $1 \mathrm{~h}$ in a high-quality vacuum, the production-scale heat exhibited negligible effect of notch geometry on impact properties, as shown in Figs. 5A and 5B, respectively. In Fig. 6, the effect of vacuum quality (i.e., ion-pumped vs. oil-diffusion-pumped) is shown. In the latter vacuum system, Charpy specimens were wrapped with a titanium shroud and annealed in a vacuum of $\approx 1.5 \times 10^{-3} \mathrm{~Pa}$. Apparently, annealing in an ion-pumped vacuum produces higher impact toughness under otherwise identical condition.

Based on the results given in Figs. 2-6, the optimal annealing procedure seems to be to anneal at $1000^{\circ} \mathrm{C}$ for $1 \mathrm{~h}$ in a high-quality vacuum system. These annealing conditions provide a sufficient tolerance (at least $\pm 50^{\circ} \mathrm{C}$ ) to temperature uncertainties and nonuniformities that are expected during annealing of larger and thicker field components. The material annealed at $1000^{\circ} \mathrm{C}$ for $1 \mathrm{~h}$ in the laboratory exhibited partially recrystallized grain structure. ${ }^{10}$

\section{CONCLUSIONS}

(1) Impact tests were conducted on a production-scale $(\approx 500-\mathrm{kg})$ heat of $\mathrm{V}-4 \mathrm{Cr}-4 \mathrm{Ti}$ at -196 to $150^{\circ} \mathrm{C}$. Following annealing at $950-1050^{\circ} \mathrm{C}$ for $1 \mathrm{~h}$ in a high-quality vacuum system, the material remained ductile at $-196^{\circ} \mathrm{C}$ and that the ductile-brittle transition temperature (DBTT) was no higher than $-200^{\circ} \mathrm{C}$. Upper-shelf energies of the production-scale heat were similar to those of a laboratoryscale heat.

(2) The effect of annealing temperature $\left(950-1050^{\circ} \mathrm{C}\right)$ on impact properties of the production-scale heat was not significant, a finding similar to that obtained for a laboratory-scale heat. This is in contrast to the very significant effect of annealing temperature on the impact properties of an incorrectly fabricated heat of $\mathrm{V}-5 \mathrm{Cr}-5 \mathrm{Ti}$ (ANL $\mathrm{D}$ Heat BL-63), which exhibited inferior mechanical properties.

(3) Annealing at $1000^{\circ} \mathrm{C}$ for $1 \mathrm{~h}$ in a high-quality vacuum not only produces optimal impact properties in the production-scale heat but also provides sufficient tolerance to temperature inhomogeneity. Following annealing under these conditions, impact properties of the production-scale heat were not sensitive to notch geometry, and excellent impact toughness was observed at $>-200^{\circ} \mathrm{C}$. 

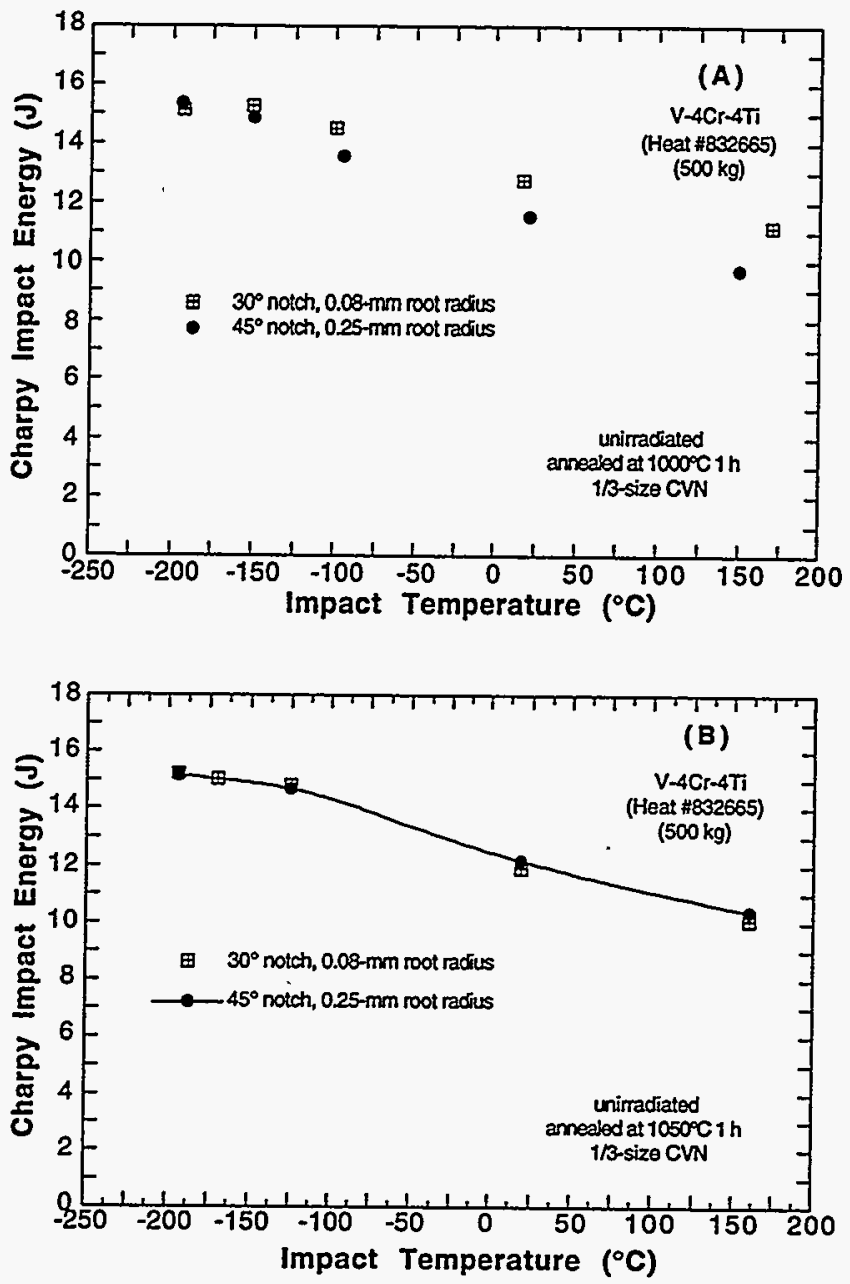

Fig. 5. Effects of notch geometry on impact properties of 500-kg $\mathrm{V}-4 \mathrm{Cr}-4 \mathrm{Ti}$ annealed at $(\mathrm{A}) 1000^{\circ} \mathrm{C}$ and $(B) 1050^{\circ} \mathrm{C}$ for $\mathrm{I} \mathrm{h}$

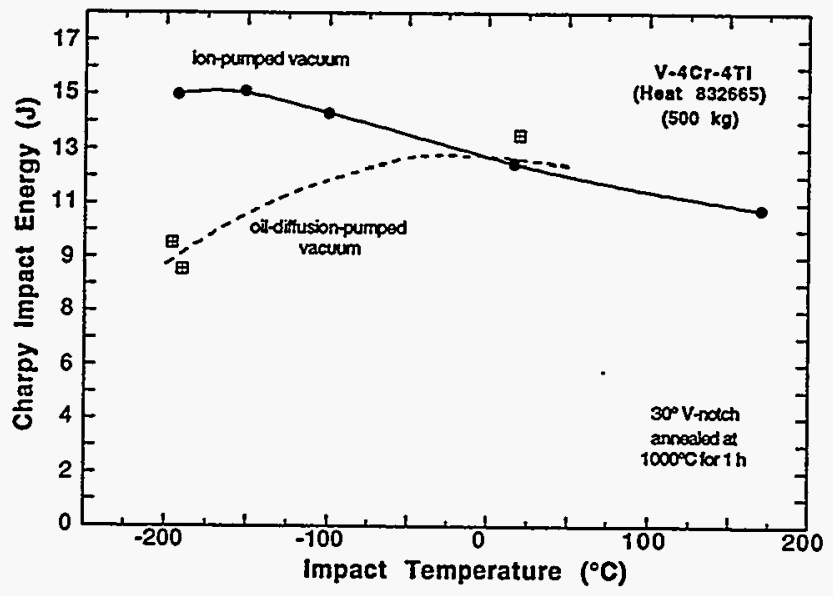

Fig. 6. Effect of vacuum quality of annealing furnace on Charpyimpact energy of production-scale heat of $\mathrm{V}-4 \mathrm{Cr}-4 \mathrm{Ti}$ 


\section{REFERENCES}

1. B. A. Loomis, L. Nowicki, and D. L. Smith, "Effect of Neutron Irradiation on Tensile Properties of V-CI-Ti Alloys," in Fusion Reactor Materials, Semiannual. Prog. Report, DOE/ER-0313/15, Oak Ridge National Laboratory, Oak Ridge, TN (1994), pp. 219-222.

2. B. A. Loomis, H. M. Chung, L. Nowicki, and D. L. Smith, "Effects of Neutron Irradiation and Hydrogen on Ductile-Brittle Transition Temperatures of V-CI-Ti Alloys," ibid., pp. 253-257.

3. H. M. Chung, B. A. Loomis, L. Nowicki, J. Gazda, and D. L. Smith, "Irradiation-Induced Density Change and Microstructural Evolution of Vanadium-Base Alloys," ibid., pp. 223-231.

4. H. M. Chung, B. A. Loomis, and D. L. Smith, "Thermal Creep Behavior of V-5Cr-5Ti and V-10Cr-5Ti Alloys," in Fusion Reactor Materials, Semiannual. Prog. Report, DOE/ER-0313/14, Oak Ridge National Laboratory, Oak Ridge, TN (1993), pp. 309-317.

5. H. M. Chung, B. A. Loomis, and D. L. Smith, "Irradiation-Induced Precipitation in VanadiumBased Alloys Containing Titanium," in Effects of Radiation on Materials, ASTM-STP 1175, A. S. Kumar, D. S. Gelles, R. K. Nanstad, and T. A. Little, Eds., American Society for Testing and Materials, Philadelphia, 1993, pp. 1185-1200.

6. H. M. Chung, B. A. Loomis, and D. L. Smith, "Properties of V-4Cr-4Ti for Application as Fusion Reactor Structural Components," Fusion Eng. Design 29 (1995), pp. 455-464.

7. H. M. Chung, B. A. Loomis, L. Nowicki, and D. L. Smith, "Effect of Dynamically Charged Helium on Tensile Properties of V-4Cr-4Ti," in Fusion Reactor Materials, Semiannual. Prog. Report for Period Ending September 30, 1994, DOE/ER-0313/17, Oak Ridge National Laboratory, Oak Ridge, in press.

8. H. M. Chung, L. J. Nowicki, D. E. Busch, and D. L. Smith, "Ductile-Brittle Transition Behavior of $\mathrm{V}-4 \mathrm{Cr}-4 \mathrm{Ti}$ Irradiated in the Dynamic Helium Charging Experiment," in Fusion Reactor Materials, Semiannual. Prog. Report for Period Ending September 30, 1994, DOE/ER-0313/17, Oak Ridge National Laboratory, Oak Ridge, in press.

9. H. M. Chung, L. Nowicki, J. Gazda, and D. L. Smith, "Void Structure and Density Change of Vanadium-Base Alloys Irradiated in the Dynamic Helium Charging Experiment," in Fusion Reactor Materials, Semiannual. Prog. Report for Period Ending September 30, 1994, DOE/ER-0313/17, Oak Ridge National Laboratory, Oak Ridge, in press.

10. H. M. Chung, H.-C. Tsai, D. L. Smith, R. Peterson, C. Curtis, C . Wojcik, and R. Kinney, "Fabrication of $500-\mathrm{kg}$ Heat of V-4Cr-4Ti," in Fusion Reactor Materials, Semiannual. Prog. Report for Period Ending September 30, 1994, DOE/ER-0313/17, Oak Ridge National Laboratory, Oak Ridge, in press.

11. B. A. Loomis, "Recovery of Hardness of $85 \%$ Cold-Worked V-Ti and V-Cr-Ti Alloys on Annealing at $180^{\circ} \mathrm{C}$ to $1200^{\circ} \mathrm{C}$," in Fusion Reactor Materials, Semiannual. Prog. Report for Period Ending September 30, 1994, DOE/ER-0313/17, Oak Ridge National Laboratory, Oak Ridge, in press. 


\subsection{Copper Alloys} $\checkmark$ 
High Temperature Stability of Dispersion Strengthened

Copper Alloys Irradiated with Fast Neutrons

DJ Edwards ${ }^{(\mathrm{a})}$, FA Garner, ML Hamilton, JD Troxell ${ }^{(\mathfrak{b})}$

(

\section{OBJECTIVE}

The objective of this effort is to further investigate the effects of high temperature neutron irradiation on various GlidCop alloys. The potential for enhancing the performance of the dispersion strengthened copper alloys by additional alloying is also examined.

\section{SUMMARY}

Two dispersion strengthened copper alloys, GlidCop CuAl25 and GlidCop-Nb, were irradiated under three different conditions to study their response to high temperature neutron irradiation. Previous studies demonstrated that GlidCop CuAl25 experienced a decrease in yield and ultimate strength by $50 \mathrm{dpa}$, but no further changes in strength occurred at doses up to $150 \mathrm{dpa}$. The implications of this are that cold worked (CW) CuAl25 alloys will experience most of the changes in mechanical properties at dose levels that are well within the Basic Physics Phase of ITER's operation. Alloying CuA125 with $10 \mathrm{wt} \% \mathrm{Nb}$ produced a DS copper alloy that was completely resistant to any changes in strength during irradiation. These results, when combined with earlier studies, strongly suggest that high temperature neutron irradiation relaxes the dislocation structure within a few dpa (5.8 dpa or less). Alloying with niobium is thought to effectively prevent this relaxation, thereby maintaining the strength of the material.

\section{TECHNICAL PROGRESS}

\section{Introduction}

The first wall and divertor of ITER require a material with a high thermal conductivity, good strength, and excellent swelling resistance when exposed to neutron irradiation. The high heat flux material will act as a heat sink layer between the beryllium plasma-facing armor and the stainless steel, the latter of which will provide the necessary structural support. Current designs place the operating temperature between 423 and $623 \mathrm{~K}$, with temperature excursions due to plasma disruptions producing an upper temperature limit of 723-773 $\mathrm{K}$ for short durations. The operating fluence for the Basic Physics Phase of ITER is currently set at $\sim 3 \mathrm{dpa}$, while for the Engineering Physics Phase the dose level could reach $\sim 30$ dpa.

Dispersion strengthened (DS) copper alloys, commercially known as GlidCop alloys, have been selected over $\mathrm{CuNiBe}$ and $\mathrm{CuCrZr}$ as the main candidate for the heat sink material. Compared to precipitation hardened alloys such as CuNiBe and $\mathrm{CuCrZr}$, DS copper has the advantage of possessing a high electrical and thermal conductivity that is independent of thermomechanical processing, a characteristic not shared by the precipitation hardened alloys.-

(a) Post-doctoral Fellow, Associated Western Universities, Richland, WA 99352

(b) Senior Metallurgist, SCM Metal Products, INC., Triangle Park, NC, 27709-2166 
Many of the experiments conducted in the past have tested irradiated DS copper that has been given a series of cold working and annealing treatments. The final state of the material from which specimens were fabricated was often heavily cold worked in spite of the annealing treatments. This cold work leaves the material in a high energy state due to the stored energy, energy that might promote recovery and recrystallization given the enhanced kinetics that occur during irradiation.

The present study investigates the effect of neutron irradiation on the mechanical properties of two heavily cold worked copper alloys, GlidCop-Nb and CuAl25. The GlidCop-Nb alloy represents an attempt to further enhance the strength of GlidCop alloys by adding niobium particles to form a composite structure. The mechanical properties of the irradiated specimens will be compared to those of as-wrought CuAl25.

\section{Experimental Procedure}

SCM Metal Products supplied two strips of LOX (low oxygen) grade GlidCop CuAl25 alloyed with $9.6 \mathrm{wt} \% \mathrm{Nb}$. The niobium was added to the material by a proprietary process that yields a uniform dispersion of niobium particulates. The alloy also contained $-0.25 \mathrm{wt} \%$ aluminum in the form of $\mathrm{Al}_{2} \mathrm{O}_{3}$ formed by a proprietary internal oxidation process. The GlidCop-Nb alloy contained $200 \mathrm{ppm}$ of boron, which was used to remove any excess oxygen remaining after the internal oxidation process. The GlidCop-Nb strips were $0.254 \mathrm{~mm}$ in thickness, and had been given slightly different cold working treatments prior to the final cold working step. The two strips will be referred to as Heat A and Heat B. The final cold work (CW) level for both sheets was $92 \%$.

SCM Metal Products also supplied CuAl25 in the form of $0.254 \mathrm{~mm}$ thick strips with a final cold work level of $96 \%$. In addition, GlidCop CuAl25 in the as-wrought condition was used for comparison. The as-wrought material was provided by Dr. B.N Singh at Risø National Laboratory in the form of an as-extruded rod product with a diameter of $12.7 \mathrm{~mm}$. Both materials contained $\sim 250 \mathrm{ppm}$ of boron.

Miniature tensile specimens were fabricated from all four of the materials using an electrical discharge machining process (EDM). Specimens from the GlidCop-Nb were fabricated such that the tensile axis (gage length) of the specimens was parallel to the rolling direction. The specimens from the CW CuAl25 were fabricated in two orientations: with the tensile axis parallel to the rolling direction of the sheet and perpendicular to the rolling direction. Specimens of the aswrought $\mathrm{CuAl} 25$ were fabricated parallel to the extrusion axis of the rod. A schematic of the tensile specimen is given in Figure 1.

Specimens of the two heats of GlidCop-Nb and the CW CuAl25 were irradiated in the Fast Flux Test Facility (FFTF) located in Richland, Washington. The specimens were irradiated at three different locations in FFTF, which lead to specimens being irradiated at three different dose rates. The irradiation conditions are provided in Table 1. All specimens, regardless of location, were in reactor a total of 203 effective full power days. At least 3 specimens of each type of material were irradiated at each set of conditions.

The miniature specimens were tested in a specially designed horizontal testing frame used to test both nonradioactive and radioactive specimens. The specimen was held by wedge grips that have a small square grid on one surface of each grip to improve the grip's ability to clamp and hold the specimen. The load on the specimen was monitored during the tightening of the grips to minimize 
any tensile stresses that may be incurred by clamping the specimen. All tensile tests were performed at room temperature using a strain rate of $4 \times 10^{-4} \mathrm{~s}^{-1}$.

Because of the small size and the high residual radioactivity of the irradiated specimens, the strain cannot be directly measured using strain gages. Consequently, the strain is calculated by measuring the crosshead displacement using a linear variable displacement transducer. The displacement is converted to strain by assuming that all of the deformation occurs in the gage section of the tensile specimen. Although the strain values for these miniature specimens may not be directly comparable to that obtained from full size specimens, they can be used to demonstrate major trends in behavior.

The fracture surfaces of individual specimens were examined in a JEOL 840 SEM after testing. The specimens were examined within a few hours of testing in order to minimize oxidation of the exposed fracture surface, which can obscure the surface, especially at high magnifications $(>2000 x)$.

\section{$\underline{\text { Results }}$}

The strength of the four unirradiated GlidCop alloys is provided for comparison in Figure 2, along with the room temperature strength measured after irradiation. Note that the two heats of GlidCop-Nb possess the highest yield and ultimate tensile strength (UTS), nearly double that of the unirradiated as-wrought CuAl25. Although it has a similar cold work level, the $\mathrm{CW}$ CuAl25 has a noticeably lower strength than the GlidCop-Nb alloys.

The difference in mechanical properties of the two GlidCop-Nb heats is evident in the yield strength, which is $\sim 60 \mathrm{MPa}$ lower for Heat B compared to Heat A. The UTS of these two materials, however, are identical for the unirradiated condition. For the CW CuAl25, the effect of changing the rolling direction in relation to the tensile axis is also evident in the yield strength. The specimens with the rolling direction perpendicular to the tensile axis have an average yield strength $\sim 35 \mathrm{MPa}$ lower than CuAl25 specimens with the rolling direction parallel to the tensile axis. The ultimate tensile strengths are essentially identical.

To further demonstrate the differences in tensile behavior between these three types of alloys, the actual tensile curves from representative specimens are given in Figure 3. The as-wrought material clearly possesses the best ductility, with a total elongation roughly double that of the other three alloys. Note that the elongations of the GlidCop-Nb alloys and the $\mathrm{CW} \mathrm{CuAl25}$ are similar despite the differences in strength. Their uniform elongation is around 1.5 to $2 \%$, typical for heavily cold worked GlidCop. Even with a uniform elongation of around $7.5 \%$ for the as-wrought CuAl25, none of the alloys exhibit the ability to strain harden significantly.

It is obvious in Figure 2 that the GlidCop- $\mathrm{Nb}$ alloys exhibit the best resistance to high temperature neutron irradiation. There is very little change in the UTS of the two heats of GlidCop- $\mathrm{Nb}$, although in the yield strength there is a noticeable decrease. The yield strength decrease is by roughly the same amount for the two higher doses but is slightly less for the specimens irradiated at $643 \mathrm{~K}$ to only $5.8 \mathrm{dpa}$.

Representative tensile curves for the irradiated GlidCop-Nb (Heat B) are shown in Figure 4 for comparison with the unirradiated GlidCop- $\mathrm{Nb}$. The most noticeable effect of irradiation is that the irradiated specimens appear to exhibit slightly more strain hardening ability. Although the tensile curves suggest that the total elongation might be increasing with dose, the differences in the 
elongation values of the three curves are not significant.

Of the GlidCop-Nb Heat A specimens irradiated to 34.5 dpa at $706 \mathrm{~K}$, half were found to exhibit an unusual change in the initial plastic region of the tensile curve as illustrated in Figure 5. The reason for the change in the slope of the curve is not apparent. The main effect is to produce a yield strength that is significantly below that of the other Heat A specimens; the UTS was unaffected. The yield strength for these specimens is also shown in Figure 2 /for comparison.

As shown in Figure 2, the $\mathrm{CW}$ CuAl25 specimens experienced the largest change in strength with irradiation. The differences in yield strength between the "parallel" and the "perpendicular" specimens are no longer evident after irradiation. The UTS of both types of specimens dropped roughly $150 \mathrm{MPa}$ after irradiation, and was accompanied by an increase in elongation, as shown by the representative tensile curves of the "parallel" specimens provided in Figure 6. The magnitude of the decrease in the UTS was about the same regardless of the irradiation dose and temperature. The same behavior was observed for the yield strength. Note, however, that the yield strength after irradiation was almost the same as that measured for the unirradiated $\mathrm{CW}$ CuAl25. Unlike the GlidCop- $\mathrm{Nb}$ alloys, the changes in elongation after irradiation are larger, indicating that irradiating to doses higher than $5.8 \mathrm{dpa}$ at higher temperatures produces an increase in both the uniform and total elongation.

One other feature observed in the tensile curves that bears mentioning is that the specimens irradiated to 18.4 and 34.5 dpa exhibited a yield plateau observed in an earlier study by Anderson et al. [1] and Edwards et al. [2]. Figure 7 shows an example of this for the CW CuAl25 irradiated to $18.4 \mathrm{dpa}$. The cause for this phenomenon has yet to be determined. This is due in part to the fact that the deformed specimens are so small, i.e., the small gage width, coupled with the high radioactivity of the specimens, makes it difficult to obtain useful specimens for transmission electron microscopy (TEM).

Fractography on fracture surfaces from both the GlidCop- $\mathrm{Nb}$ and the CuAl25 alloys revealed that the failure mode was microvoid coalescence in both the unirradiated and irradiated specimens. Examples of the fracture surfaces for both alloys are given in Figures 8 and 9. As observed previously by Anderson et al. [1] and Edwards et al. [2], several $\alpha-\mathrm{Al}_{2} \mathrm{O}_{3}$ inclusions were present inside the dimples. After irradiation these particles were no longer visible on the fracture surface, indicative of a possible change in cohesive strength at the interface between the inclusion and the matrix.

\section{Discussion}

DS copper alloys are considered to be extremely stable at high temperatures for short term exposures. However, the influence of displacement rate, temperature, and long term exposure at temperatures near $0.5 \mathrm{~T}_{\mathrm{mp}}$ (melting temperature) has never been fully elucidated with regard to the effect of these variables on the mechanical properties of this class of alloys. The following discussion provides insight into the possible role that these variables may serve in determining the effect of neutron irradiation on the mechanical properties.

\section{CW CuAl25}

As noted earlier, the strength of the CW CuAl25 decreased after irradiation to a level slightly above that of the unirradiated as-wrought CuAl25. This decrease was independent of the displacement rate and temperature, suggesting that the changes in the microstructure responsible for 
the decrease in strength are complete at relatively low dose levels. Evidence to support this can be obtained by comparing the present results with those of the previous microstructural and mechanical property studies of irradiated GlidCop alloys.

It has been shown in previous work by Edwards and coworkers [1-4] that 50\% CW CuAl25 exhibited excellent retention of strength after exposure to neutron irradiation at $\sim 690 \mathrm{~K}$. Although they found that the strength decreased roughly $15 \%$ after irradiation to $48 \mathrm{dpa}$, further irradiation to 104 and $150 \mathrm{dpa}$ did not produce any additional changes in strength. The actual levels of strength achieved in that material were slightly different than that measured for the $\mathrm{CW}$ CuAl25 in this study. This can be attributed entirely to the differences in cold working treatments given to the two materials ( $50 \% \mathrm{CW}$ vs. $96 \% \mathrm{CW}$ ), which would also affect how the materials responded to the neutron flux. Essentially the higher cold work level would result in more recovery and recrystallization because of the stronger driving force arising from the higher stored energy.

Because the lowest dose available in that study was $48 \mathrm{dpa}$, it was not clear whether the saturation in strength changes would be reached at lower doses. However, a previous study by Brager et. al. [5] showed that CuAl25 in the $20 \%$ cold worked condition also experienced a decrease of $~ 15 \%$ in yield strength after irradiation to $16 \mathrm{dpa}$ at $\sim 703 \mathrm{~K}$. The similarity in the change in yield strength suggests that many of the changes in the microstructure have already occurred by $16 \mathrm{dpa}$. Note that the displacement rate for both of the earlier studies was $\sim 1.4 \times 10^{-6} \mathrm{dpa} / \mathrm{sec}$, comparable to that of the current experiment.

Edwards and coworkers found that the GlidCop alloys irradiated at $690 \mathrm{~K}$ experienced varying degrees of recovery and recrystallization dependent upon the volume fraction of $\mathrm{Al}_{2} \mathrm{O}_{3}$. The stability of the microstructure at high doses was found to be directly linked to the presence of the small $\mathrm{Al}_{2} \mathrm{O}_{3}$ particles, typically $7-8 \mathrm{~nm}$ in diameter. As the volume fraction of $\mathrm{Al}_{2} \mathrm{O}_{3}$ increased, the degree of recovery and recrystallization became smaller. For each alloy studied, no further changes in the microstructure were observed after $48 \mathrm{dpa}$, corresponding directly with the observed saturation in changes in the mechanical properties.

There were some early concerns that the particles might be dissolved by ballistic dissolution, thereby compromising the performance of these alloys under irradiation. As the mechanical property measurements and the microstructural studies revealed, these concerns proved unwarranted. The particle morphology changed under irradiation, as discussed elsewhere [6], but in general the size distribution and number density of the oxide particles remained unaltered. The irradiation stability of the $\mathrm{Al}_{2} \mathrm{O}_{3}$ particles in GlidCop and other DS copper alloys has also been investigated by Wanderka et al. [7] and by Zinkle et al. [8,9] in other studies, further establishing the resistance of these particles to complete dissolution. The recrystallization observed in the irradiated alloys occurred in regions where the particle density was relatively low. A high density of particles was far more effective at pinning the dislocations, and in such areas the relaxation of the dislocation structure appeared to be limited to recovery. The density limit at which recrystallization was prevented in localized areas was not established in previous studies, and remains an issue that might bear further investigation.

Since it was established in earlier work that the microstructural alterations that coincide with the changes in strength were completed by $48 \mathrm{dpa}$, and given that the specimens irradiated in this study to $5.8 \mathrm{dpa}$ have basically the same response as the specimens irradiated to 18.4 and $34.5 \mathrm{dpa}$, it seems likely that the microstructure of the three sets of specimens are very similar. If this is confirmed by transmission electron microscopy, it would lead to the conclusion that the relaxation in the dislocation structure occurs independently of the displacement rate and temperature, at least 
within the range investigated in this study $\left(3.3 \times 10^{-7} \mathrm{dpa} / \mathrm{sec}, 643 \mathrm{~K}\right.$, to $\left.2.0 \times 10^{-5} \mathrm{dpa} / \mathrm{sec}, 706 \mathrm{~K}\right)$. If this is true, then the changes in mechanical properties appear to saturate at doses as low as 5.8 dpa.

It is difficult to separate the effects of neutron irradiation at $\sim 673 \mathrm{~K}$ from simple annealing effects that occur during the long term exposure at $\sim 673 \mathrm{~K}$. The specimens irradiated in this study were in reactor at $\sim 673 \mathrm{~K}$ for 203 days, or 4900 hours. Anderson et al. [1] reported that annealing $50 \% \mathrm{CW}$ CuAl25 for 1026 hours at $693 \mathrm{~K}$ produced a decrease in strength very similar to that observed for the same material irradiated to $48 \mathrm{dpa}$ at $\sim 673 \mathrm{~K}$. Similar behavior was observed for $20 \% \mathrm{CW} \mathrm{CuAl} 20$, indicating that some of the changes in mechanical properties may be thermally induced. One way to clarify this issue is to test specimens that were irradiated to comparatively low doses, less than $0.01 \mathrm{dpa}$, at a range of temperatures above and below the irradiation hardening regime $(<473 \mathrm{~K})$. The effects of irradiation at low temperatures and at doses low enough to avoid any significant irradiation hardening may show that the dislocation structure can be relaxed by the extra vacancies and interstitials produced during irradiation [10]. Singh and coworkers have found evidence to support this after irradiating heavily cold worked CuAl25 to doses ranging from 0.01

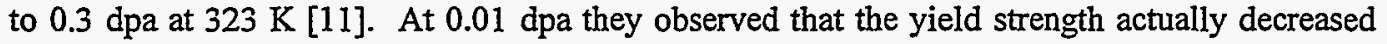
$\sim 10 \%$, demonstrating that irradiating at temperatures near room temperature lowered the strength due to radiation-induced relaxation of the dislocation structure. Beyond 0.01 dpa the strength began to increase dramatically due to the presence of defect clusters, so any further relaxation in the dislocation structure was masked by the irradiation hardening.

\section{GlidCop-Nb Alloys}

While the UTS of these alloys changed very little after irradiation, the yield strength showed a significant drop that may be due either to recovery and recrystallization, or to a change in the dispersion of $\mathrm{Al}_{2} \mathrm{O}_{3}$ particles and niobium particulates. The microstructure of these specimens needs to be examined by TEM to ascertain what changes might be responsible for the drop in yield strength.

The electrical conductivity of this alloy needs to be measured to see if there are any unusual effects related to transmutation. In a previous study by Edwards et. al. [4], a $\mathrm{Cu}-\mathrm{HfO}_{2}$ alloy was found to maintain a minimum level of conductivity after irradiation to $50 \mathrm{dpa}$ and beyond. This type of behavior has not been found in any other copper alloy: rather, the conductivity decreases with increasing neutron exposure due to transmutation. Microstructural analysis revealed that after irradiation the original $\mathrm{HfO}_{2}$ particles were rich in nickel due to transmutant nickel segregating to the $\mathrm{HfO}_{2}$. It has never been established whether the nickel segregation was the result of a Hf-Ni-O phase, or whether the large incoherent interface of the $\mathrm{HfO}_{2}$ particles acted as a sink for nickel. If the interface was the controlling factor in the segregation, then finely dispersed niobium-rich particulates might produce the same effect.

\section{Fracture Surfaces}

The fracture surfaces of all three materials were essentially the same, and indicated that failure occurred as a result of microvoid coalescence. The unirradiated CW CuAl25 had large $\alpha-\mathrm{Al}_{2} \mathrm{O}_{3}$ inclusions present inside some of the dimples on the fracture surface. As noted in a previous study these inclusions were not found on the fracture surfaces of irradiated specimens. Edwards et al. [6] proposed that the reason behind this disappearance was related to the formation of $\eta^{\prime}-\mathrm{Al}_{2} \mathrm{O}_{3}$ at the interface of the inclusions. Faceted platelets of $\eta^{\prime}-\mathrm{Al}_{2} \mathrm{O}_{3}$ were observed at the interface of the $\alpha-$ $\mathrm{Al}_{2} \mathrm{O}_{3}$ inclusions, and were presumed to have formed as the result of enrichment of the matrix near 
the interface due to ballistic dissolution of the inclusion. If deformation voids formed in the unirradiated specimens at the interface of the inclusions, then the presence of $\eta^{\prime}-\mathrm{Al}_{2} \mathrm{O}_{3}$ platelets might affect how easily voids could form at the interface in the irradiated specimens. The ballistic dissolution referred to here does not refer to the dissolution of the $\mathrm{Al}_{2} \mathrm{O}_{3}$ dispersoid responsible for the stable dislocation structure, but only to the large micron-sized $\alpha-\mathrm{Al}_{2} \mathrm{O}_{3}$ inclusions.

\section{Transmutation}

It was shown recently by Edwards et al. [12] that the nickel and zinc produced by transmutation are responsible for the decrease in electrical conductivity observed in the CuAl25 irradiated at $\sim 690 \mathrm{~K}$ to doses between 48 and $150 \mathrm{dpa}$. In previous studies this alloy has never been found to swell due to bubble or void formation, so conductivity changes were attributed exclusively to the nickel and zinc. Density measurements have not been made on the alloys in this study, so it is not known whether any density changes have occurred.

These alloys were all deoxidized using boron, which leaves a residual concentration of $\sim 200 \mathrm{ppm}$ of boron (by weight) in the material. This boron will transmute to form helium and lithium by the ${ }^{10} \mathrm{~B}(\mathrm{n}, \alpha)^{7} \mathrm{Li}$ reaction. Approximately $25 \%$ of the boron in these specimens will be transmuted to helium and lithium. Although the helium to dpa ratio will be different in the three locations used in this experiment, the amount of boron transmutation will be roughly the same regardless of the location. The only swelling data currently available for an irradiated GlidCop alloy containing boron are those of Anderson et al. [1] and Edwards et al. [2-4], which showed that CuAl15 experienced variable swelling during irradiation. The swelling was due to the formation of helium bubbles that formed at or near the oxide particle interfaces. Neither of the other two GlidCop alloys, CuAl2O and CuAl25, contained any boron. The swelling resistance of the CuAl15 might be much less than that of the CuAl25 since it has a lower volume fraction of $\mathrm{Al}_{2} \mathrm{O}_{3}$. Density measurements should be conducted on the specimens irradiated in this study to determine whether the higher volume fraction of $\mathrm{Al}_{2} \mathrm{O}_{3}$ in the $\mathrm{CuAl} 25$ can prevent swelling despite the presence of boron.

\section{Conclusions}

The GlidCop- $\mathrm{Nb}$ alloys exhibit extreme resistance to any degradation in strength. The reason for this is assumed to be related to the presence of a high density of $\mathrm{Nb}$-rich particulates that are very effective at preventing recovery and recrystallization. This assumption must be confirmed by electron microscopy on both the unirradiated and irradiated specimens.

The implications of this study are that the CW CuA125 alloys will experience most of the changes in mechanical properties at dose levels that are well within the Basic Physics Phase of ITER's operation. It is likely that the changes may even occur at dose levels lower than $1 \mathrm{dpa}$, however, additional data must be gathered before this is certain. Whether the same kind of behavior will be observed at lower temperatures remains to be determined.

Transmutation effects bear further investigation since it is not known whether the presence of boron will lead to swelling in the CuAl25.

\section{FUTURE WORK}

TEM will be performed on both the GlidCop- $\mathrm{Nb}$ and $\mathrm{CW}$ CuAl25 to investigate the changes that occurred under irradiation. Density measurements and electrical conductivity measurements will 
also be made to compare with the results obtained in previous experiments.

\section{ACKNOWLEDGEMENTS}

This work was supported by the U.S. Department of Energy Office of Fusion Energy under contract DE-AC06-76RLO 1830. One of the authors (DJ Edwards) would like to thank Dr. B. N. Singh and Risø National Laboratory for supplying the as-wrought CuAl25.

\section{REFERENCES}

1. K. R. Anderson, F. A. Garner, M. L. Hamilton, and J. F. Stubbins, 15th International Symposium on the Effects of Irradiation on Materials, ASTM STP 1125, R. E. Stoller, A. S. Kumar, and D. S. Gelles, Eds., 1992, p. 854.

2. D. J. Edwards, Ph.D Dissertation, University of Missouri-Rolla, (1993).

3. D. J. Edwards, J. W. Newkirk, F. A. Garner, M. L. Hamilton, A. Nadkarni, and P. Samal, 15th International Symposium on the Effects of Irradiation on Materials, ASTM STP 1175, A. S. Kumar, D. S. Gelles, R. K. Nanstad, and E. A. Little, Eds., 1993, p. 1041.

4. D. J. Edwards, K. R. Anderson, F. A. Garner, M. L. Hamilton, J. F. Stubbins, and A. S. Kumar, J. Nucl. Matls., 191-194, (1992), p. 416.

5. H. R. Brager, H. L. Heinisch, and F. A. Garner, J. Nucl. Matls., 133-134, (1985), p. 679.

6. D. J. Edwards, F. A. Garner, J. W. Newkirk, and A. Nadkarni, J. Nucl. Matls., 212-215, (1994), p. 1313.

7. N. Wanderka, Y. Yuan, L. Jiao, R. P. Wahi, and H. Wollenberger, J. Nucl. Matls., 191194, p. 1356.

8. S. J. Zinkle, A. Horsewell, B. N. Singh, and W. F. Sommer, J. Nucl. Matls., 195, (1992), p. 11.

9. S. J. Zinkle, E.V. Nesterova, V. R. Barabash, V. V. Rybin, and A. V. Naberenkov, J. Nucl. Matls., 208, (1994), p. 119.

10. B. N. Singh, Private communication, (1995).

11. B. N. Singh, "Assessment of Physical, Mechanical, and Technological Properties of First Candidate Copper Alloys", ITER Assessment Report, (1994).

12. D. J. Edwards, F. A. Garner, and L. R. Greenwood, J. Nucl. Matls., 212-215, (1994), p. 404. 
TABLE 1 Irradiation Conditions for Cold Worked DS GlidCop Alloys

\begin{tabular}{|c|c|c|c|c|}
\hline \hline Alloy & $\begin{array}{c}\text { Irradiation } \\
\text { Temperature (K) }\end{array}$ & $\begin{array}{c}\text { Fluence } \\
(\mathrm{E}>0.1 \mathrm{MeV})\end{array}$ & $\begin{array}{c}\text { Total } \\
\text { displacement } \\
\text { (dpa) }\end{array}$ & $\begin{array}{c}\text { Displacement } \\
\text { rate (dpa/sec) }\end{array}$ \\
\hline $\begin{array}{c}\text { GlidCop-Nb } \\
\text { CW CuAl25 }\end{array}$ & 643 & $1.14 \times 10^{22}$ & 5.8 & $3.3 \times 10^{-7}$ \\
\hline $\begin{array}{l}\text { GlidCop-Nb } \\
\text { CW CuAl25 }\end{array}$ & 666 & $3.3 \times 10^{22}$ & 18.4 & $1.1 \times 10^{-6}$ \\
\hline $\begin{array}{l}\text { GlidCop-Nb } \\
\text { CW CuAl25 }\end{array}$ & 706 & $6.0 \times 10^{22}$ & 34.5 & $2.0 \times 10^{-6}$ \\
\hline
\end{tabular}

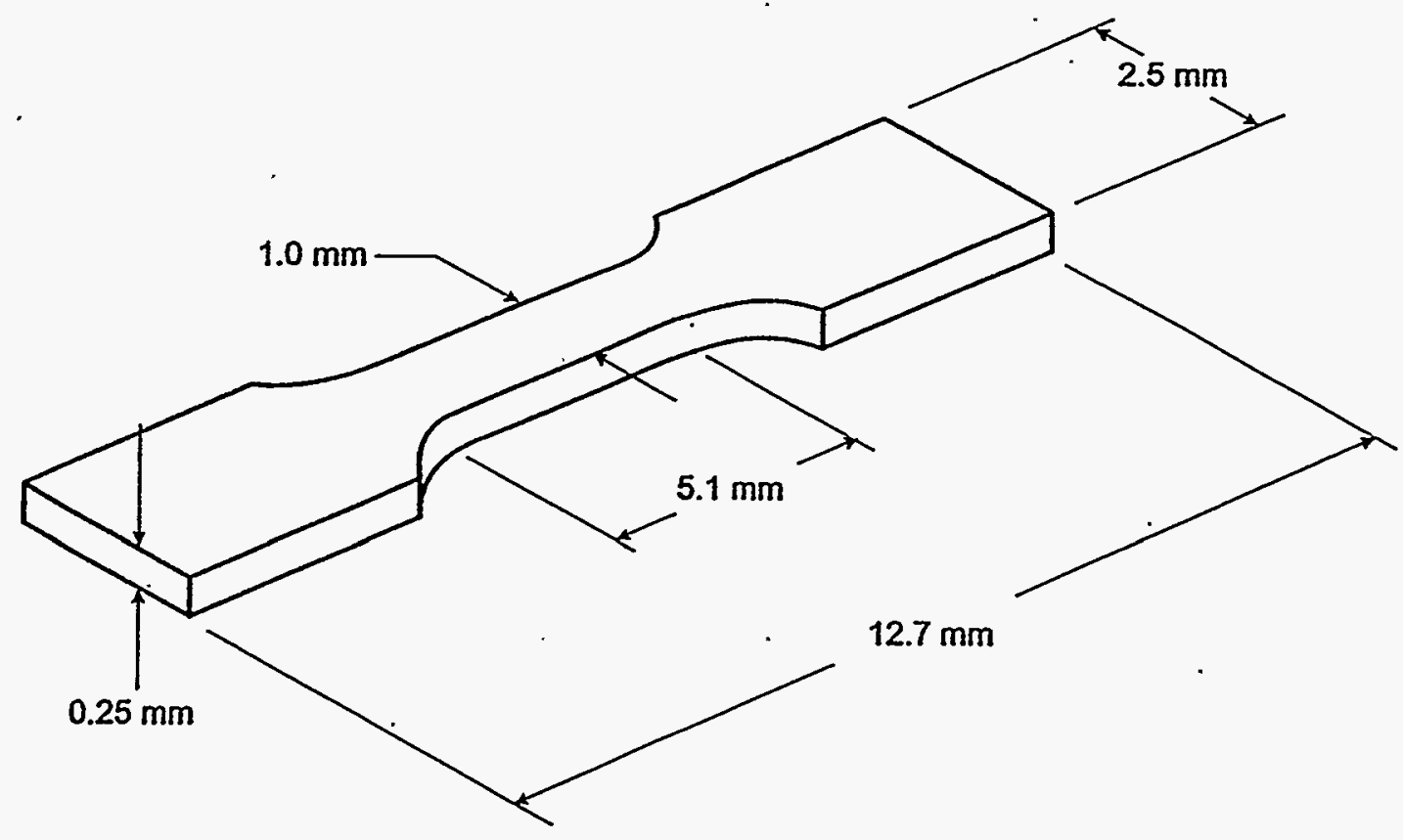

Figure 1. Schematic of the miniaturized tensile specimens. 
Yield Strength of GlidCop Alloys

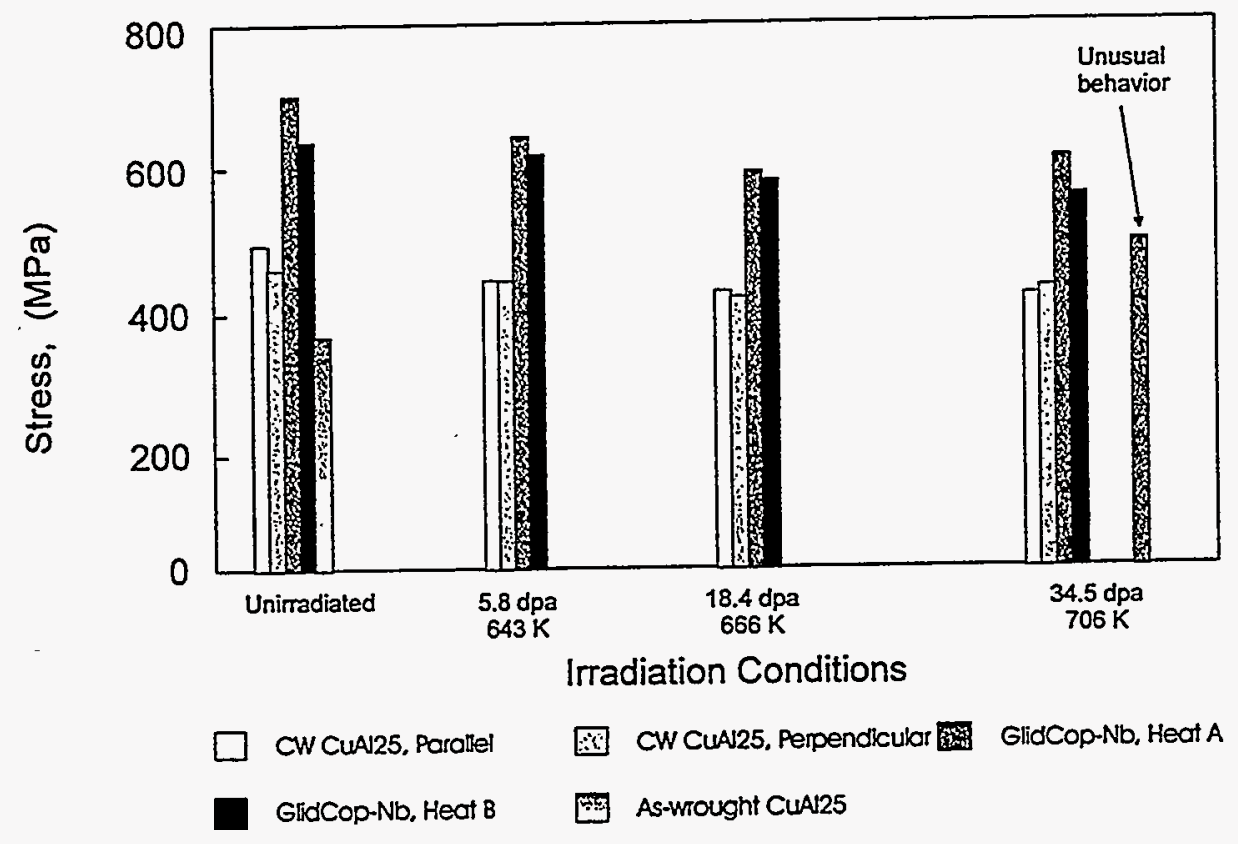

UTS of Irradiated GlidCop Alloys

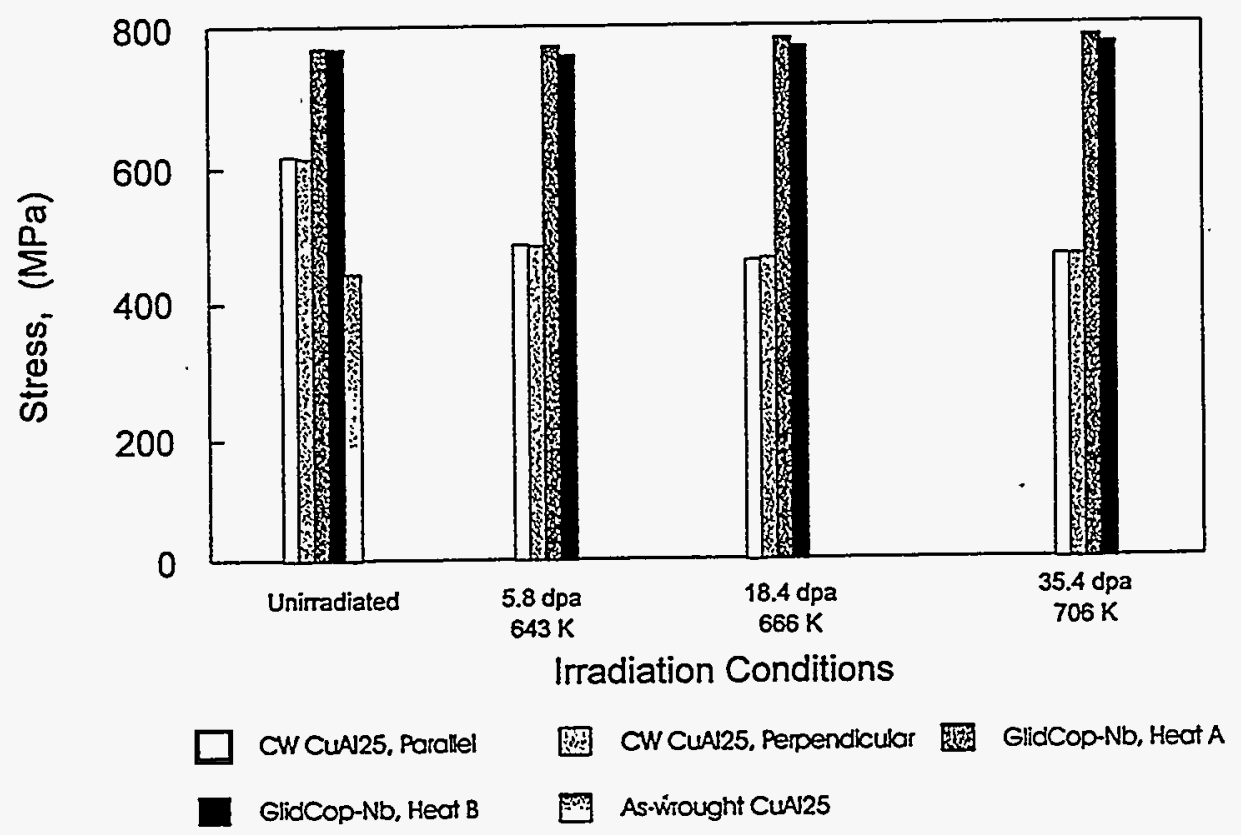

Figure 2. Yield strength (a) and UTS (b) of the unirradiated GlidCop alloys. 
Figure 3. Tensile curves of the unirradiated GlidCop alloys.

Tensile Curves of Unirradiated GlidCop Alloys

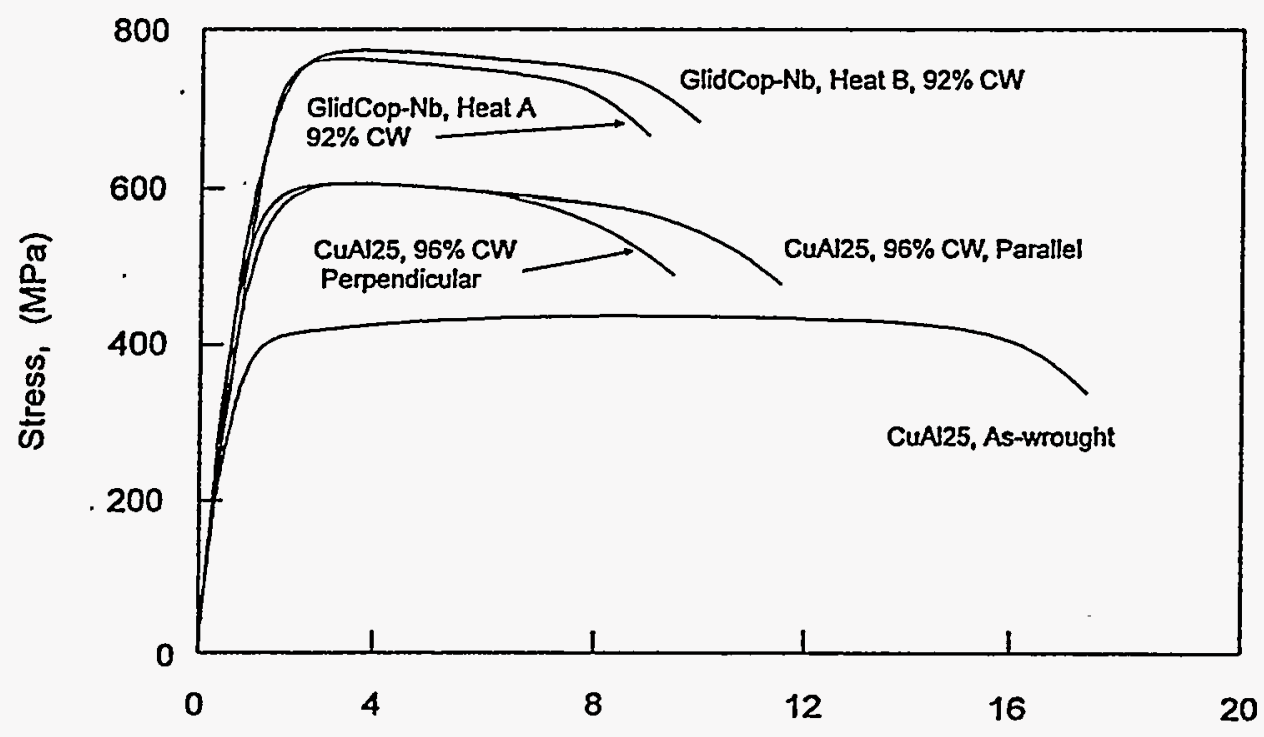

Strain, (\%)

GlidCop-Nb Tensile Curves

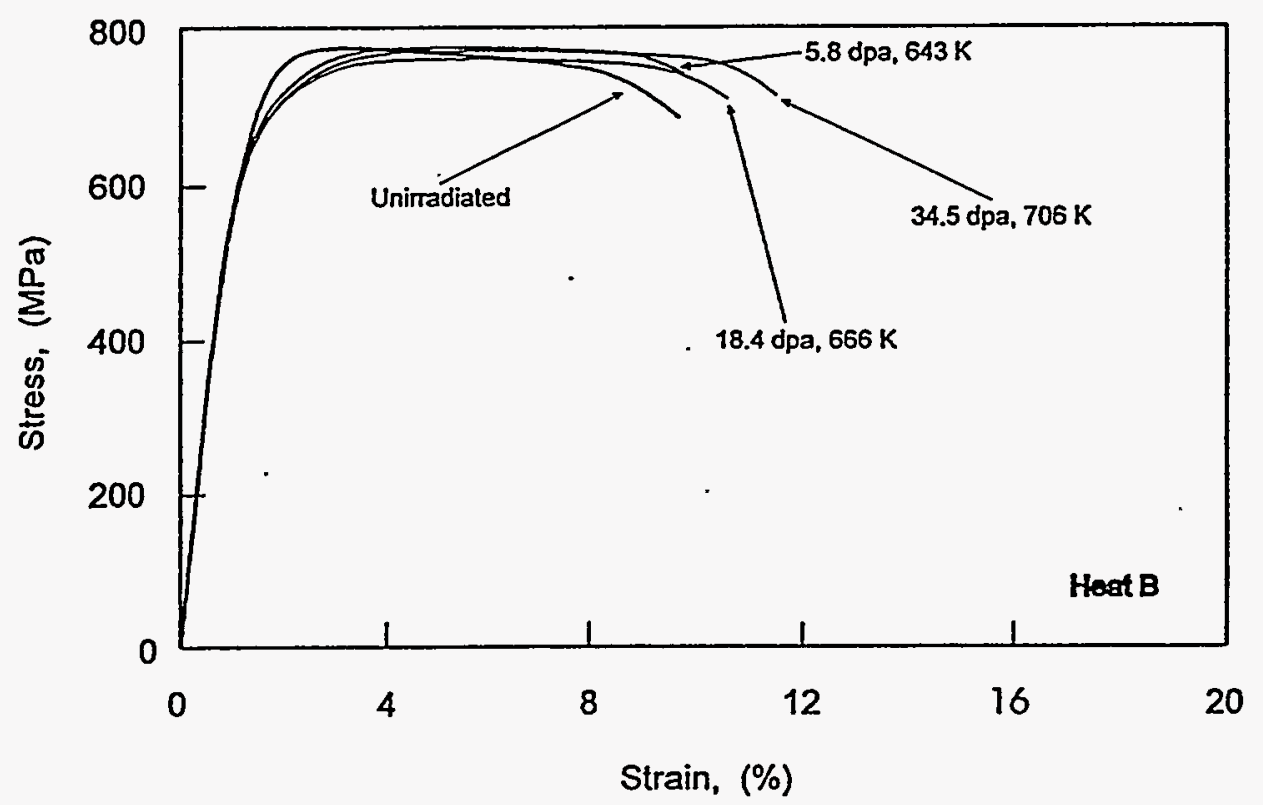

Figure 4. Tensile curves of the unirradiated and irradiated GlidCop- $\mathrm{Nb}$ alloys. 
Figure 5. Unusual tensile behavior observed in the GlidCop-Nb irradiated to $34.5 \mathrm{dpa}$ at $706 \mathrm{~K}$.

\section{Unusual Tensile Behavior}

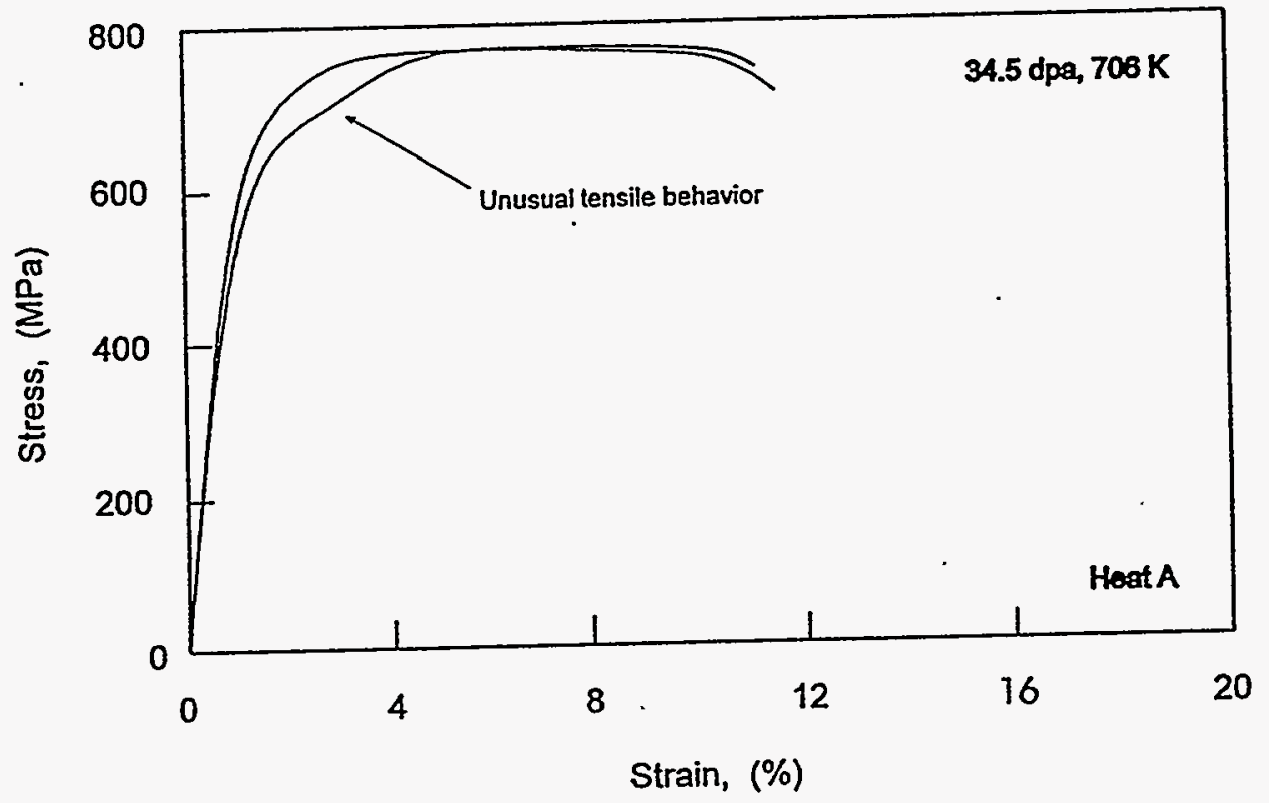

Tensile Curves of CuAl25

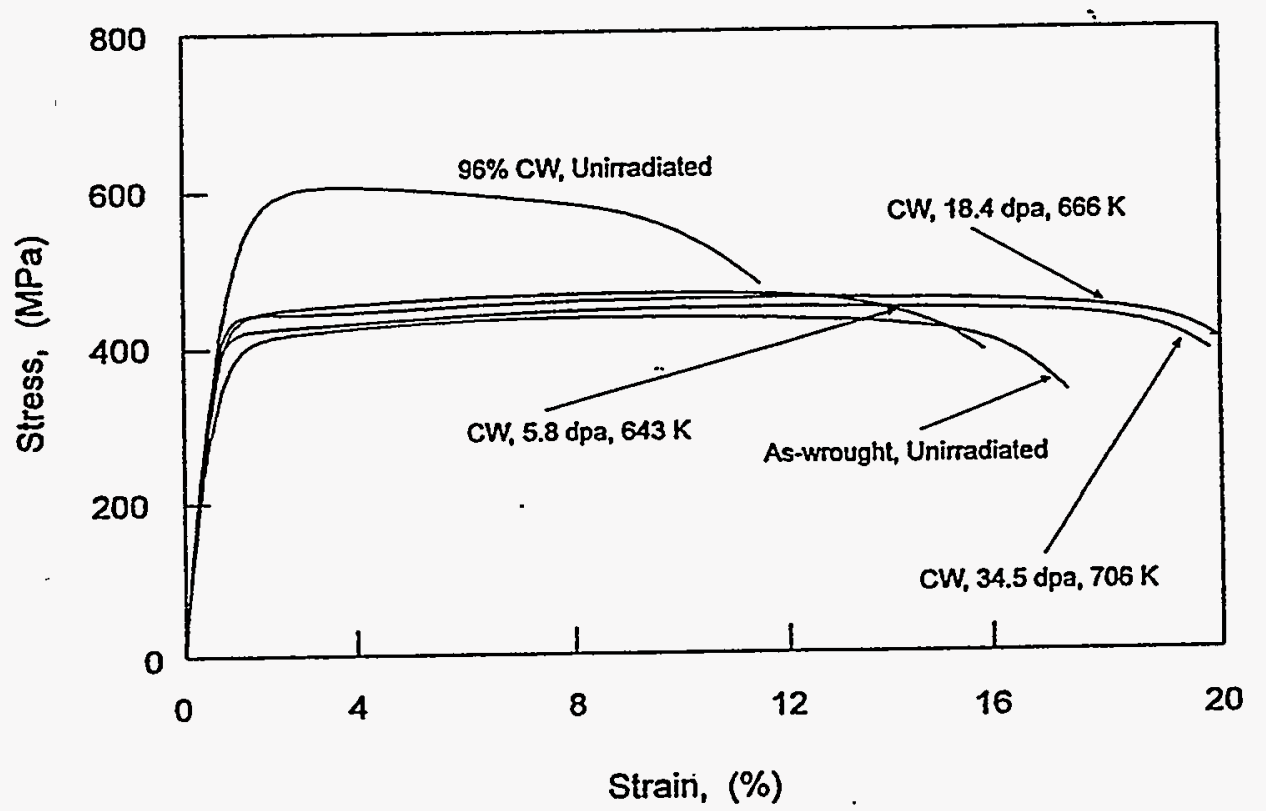

Figure 6. Tensile curves of the unirradiated and irradiated $96 \% \mathrm{CW}$ CuA125. A tensile curve for the unirradiated, as-wrought $\mathrm{CuA} 125$ is provided for comparison. 
Figure 7. Tensile curve demonstrating the yield plateau observed in this study and the work of Anderson et al. [1] and Edwards et al. [4].

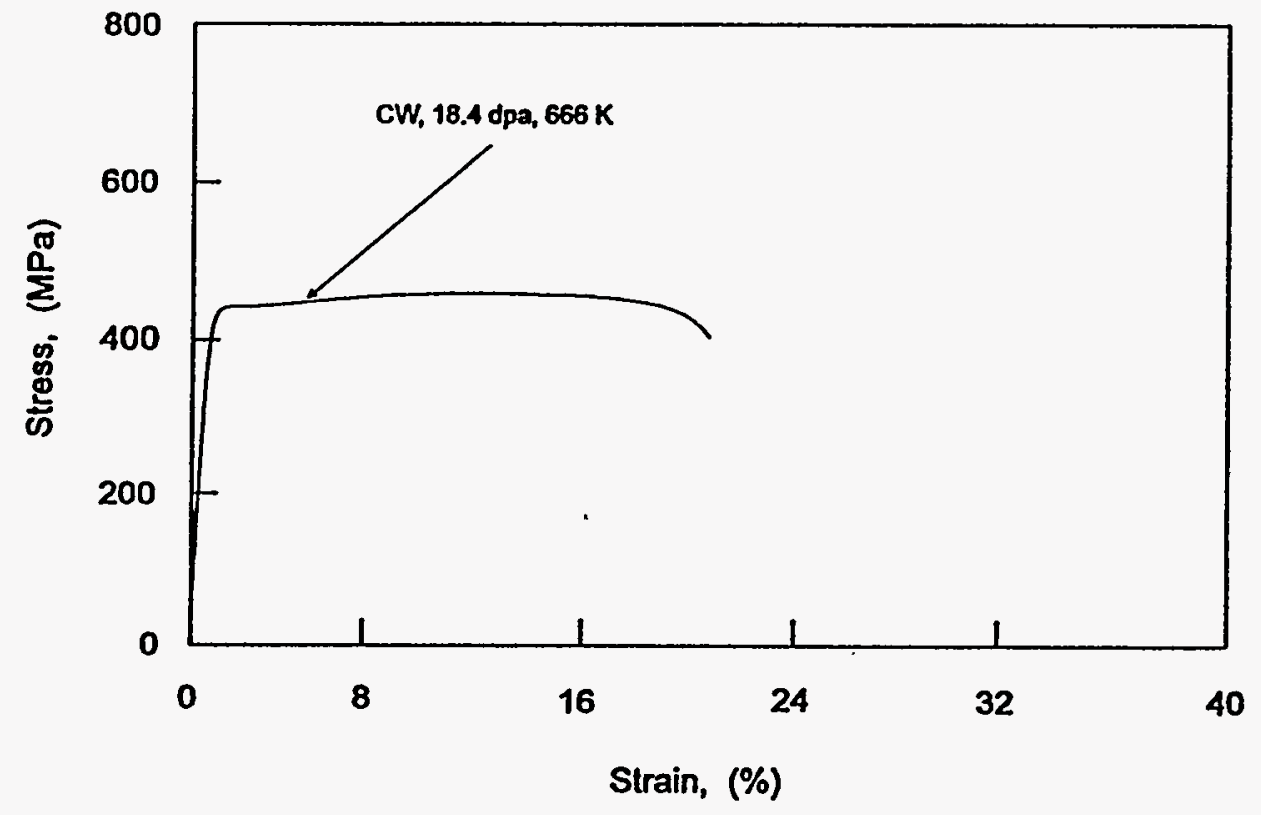


Figure 8a. Fractography of the unirradiated specimen $96 \% \mathrm{CW} \mathrm{CuA125.} \mathrm{Note} \mathrm{the} \mathrm{presence} \mathrm{of} \alpha-$ $\mathrm{Al}_{2} \mathrm{O}_{3}$ inclusions in some of the dimples.
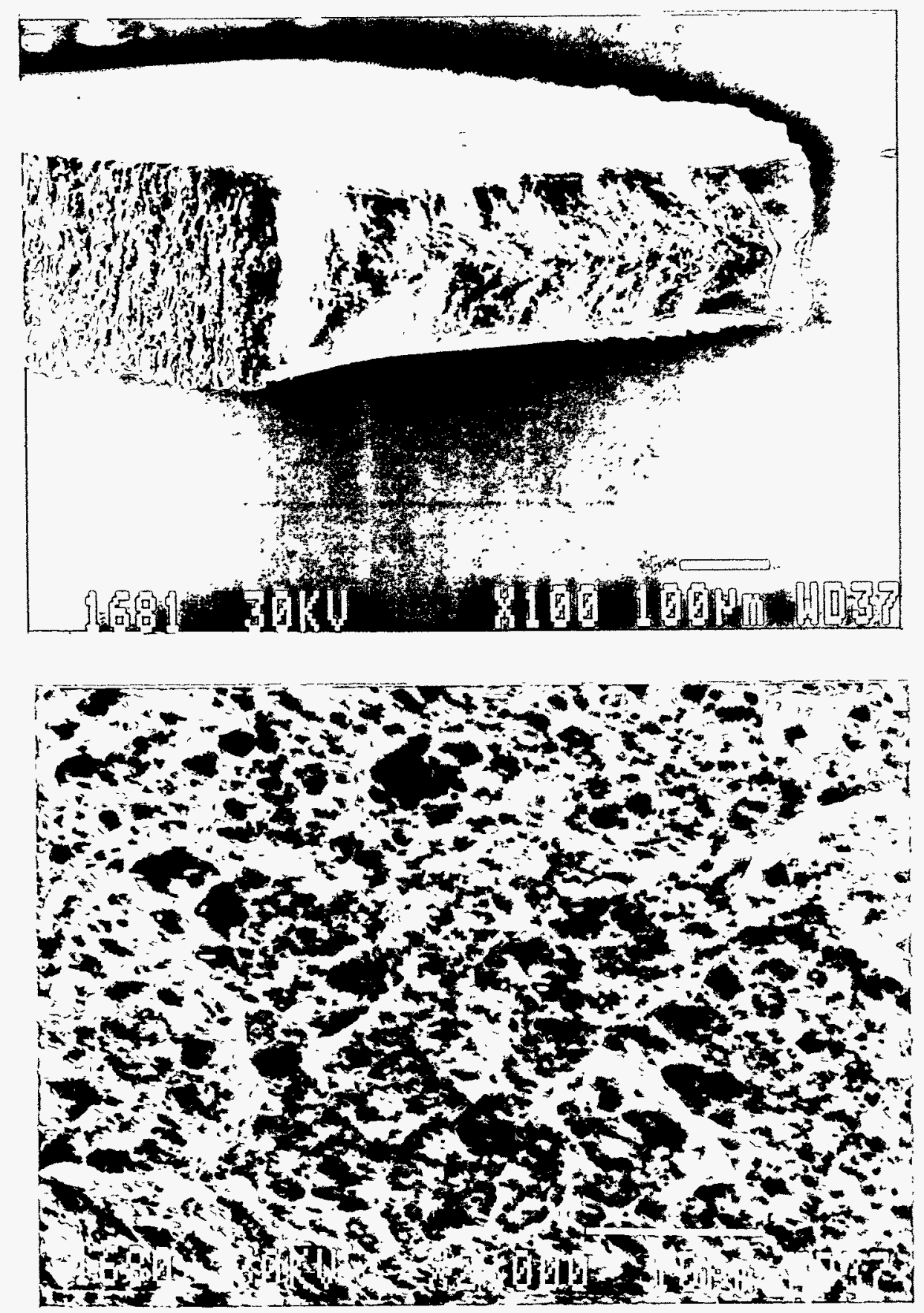
Figure 8b. Fractography of the irradiated specimen $\mathrm{CW}$ CuA125.
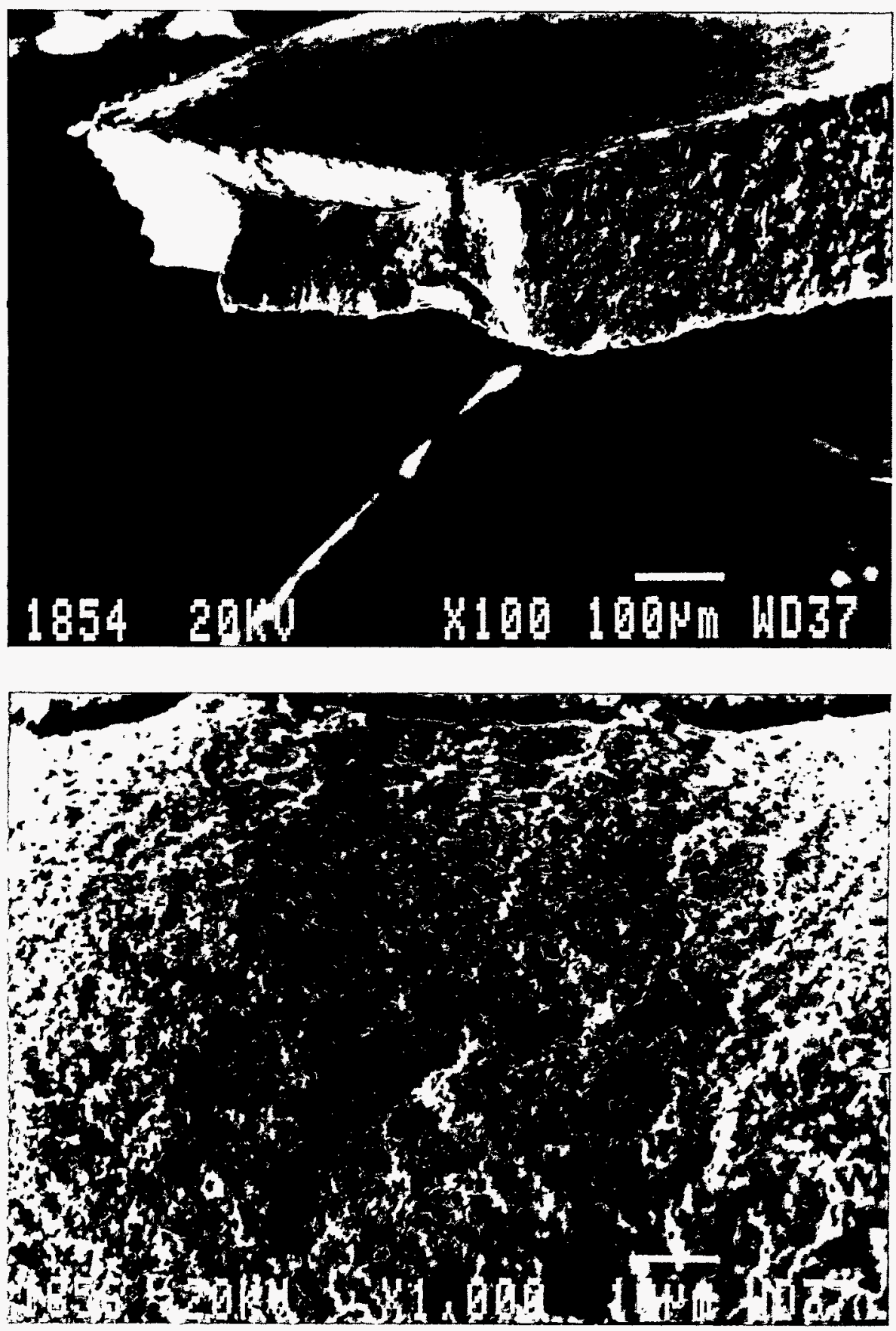

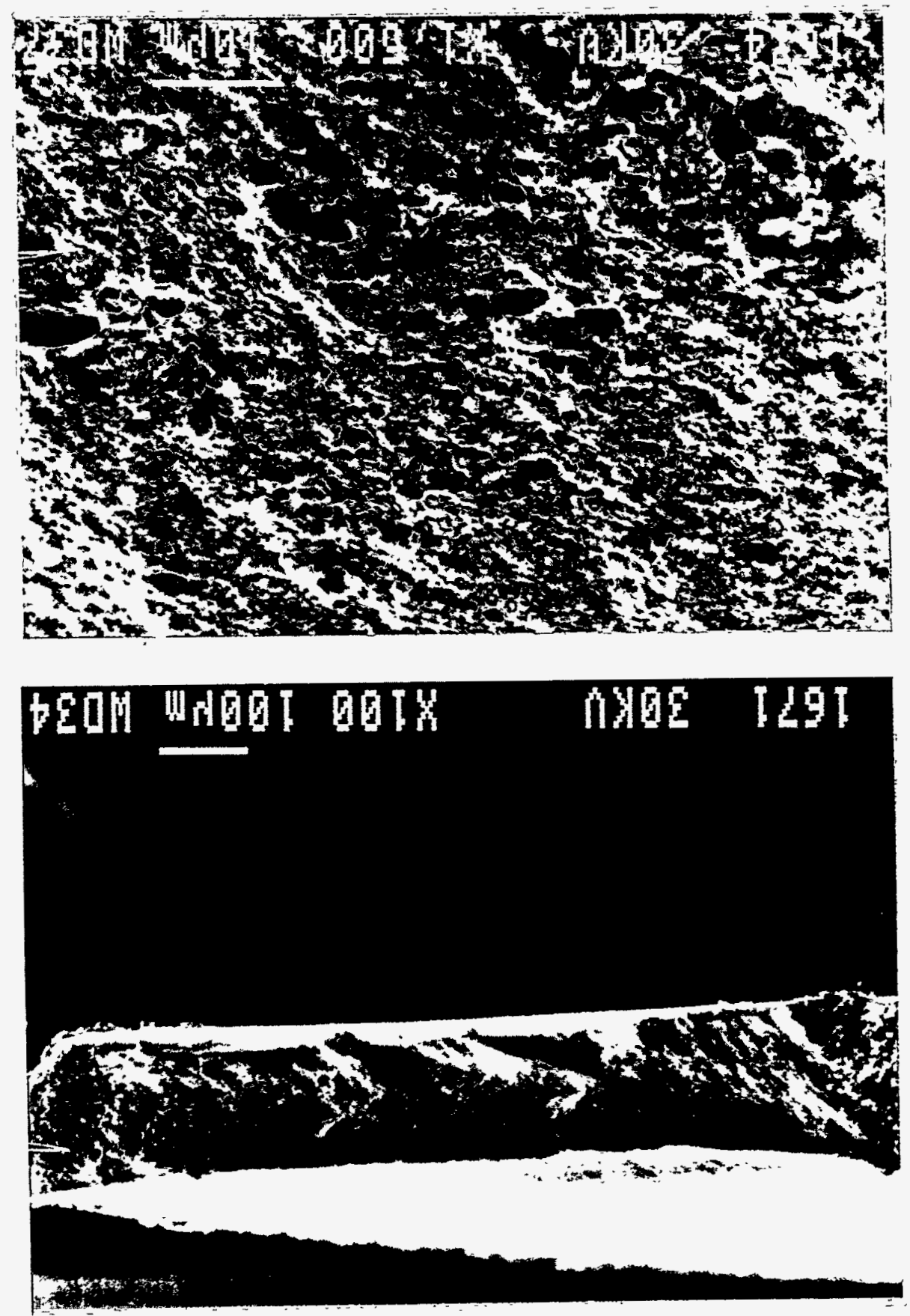

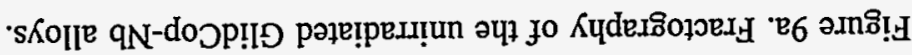


Figure 9b. Fractography of the irradiated GlidCop-Nb alloys.
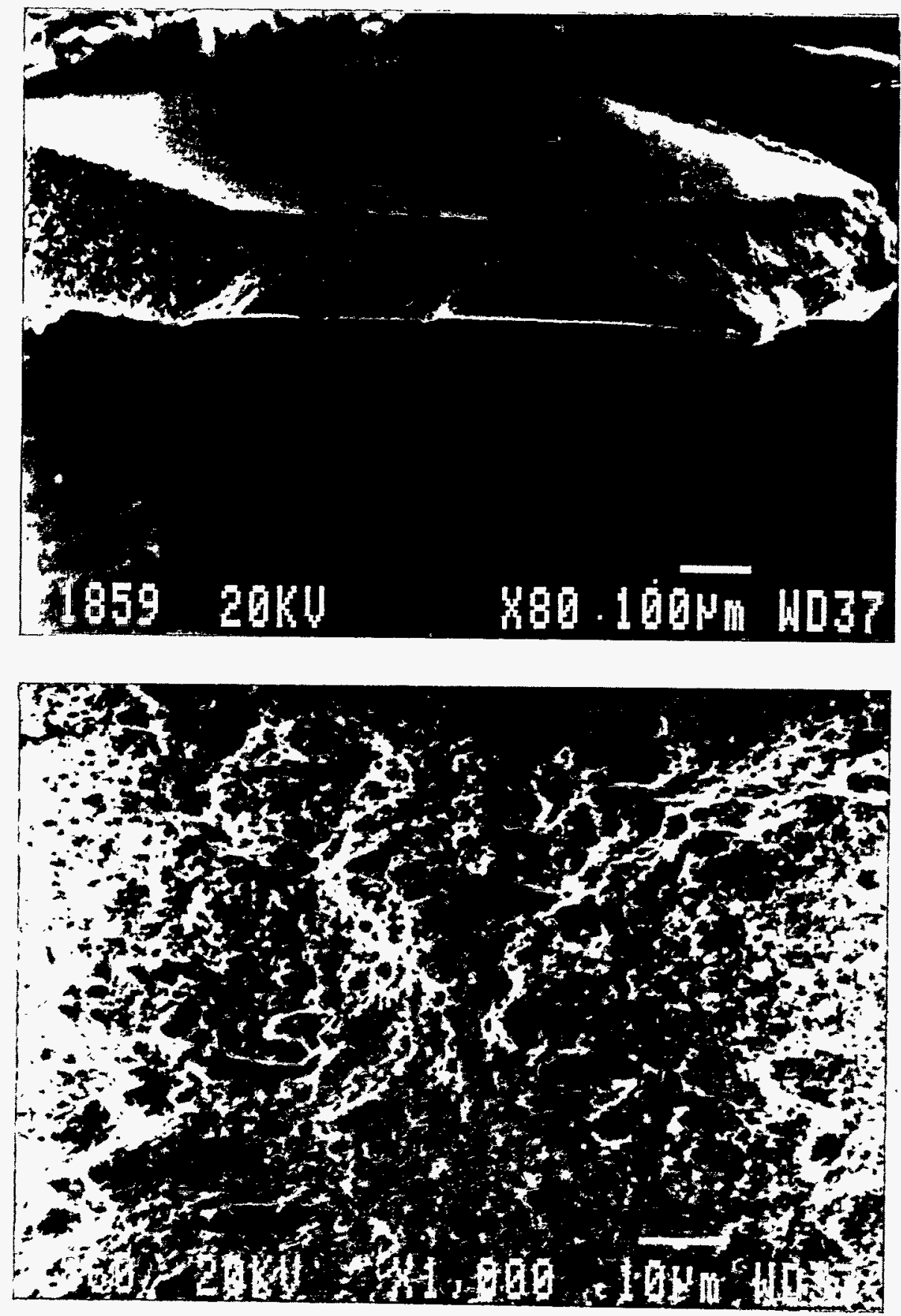


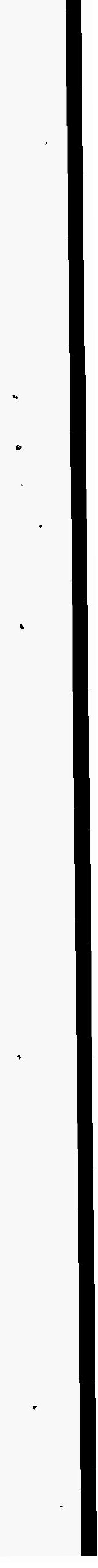




\title{
BRAZED DISPERSION STRENGTHENED COPPER: THE EFFECT OF NEUTRON IRRADIATION AND TRANSMUTATION ON BOND INTEGRITY
}

\author{
D.J. Edwards ${ }^{(2)}$, F.A. Garner, M.L. Hamilton ${ }^{(b)}$, and J.D. Troxell ${ }^{(c)}$
}

\section{OBJECTIVE}

The objective of this study was to investigate the effect of neutron irradiation at high temperatures on the integrity of brazed copper joints. Four different braze alloys were studied to determine their suitability for use in a neutron environment.

\section{SUMMARY}

Four types of brazes were used to join sheets of GlidCop CuAl25. Miniature tensile specimens and TEM disks were fabricated from the joints, and irradiated under various conditions to study their response to high temperature neutron irradiation. Two of the brazes, TiCuAg and TiCuNi, were eliminated from consideration because of the poor quality of the brazed joints. Brazed joints produced using a gold-containing braze were satisfactory for the unirradiated state. However, transmutation of Au to $\mathrm{Hg}$ affected the integrity of some of the joints in the specimens irradiated in a below-core position where the neutron spectrum was much softer. A CuAg braze yielded satisfactory joints in the unirradiated state, and held up very well when the irradiated specimens were tested. However, transmutation of $\mathrm{Ag}$ to $\mathrm{Cd}$ leads to a high residual radioactivity that limits the usefulness of this braze after exposure to neutron irradiation. Further work is necessary to identify brazes that are "transmutation-resistant" and also that minimize the potential for activation by a suitable choice of elemental constituents.

\section{TECHNICAL PROGRESS}

Introduction

The first wall and divertor structure for the ITER device require a material that can withstand both the high heat flux $\left(5 \mathrm{MW} / \mathrm{m}^{2}\right)$ and the irradiation damage resulting from interaction with the fusion plasma. Current designs call for a beryllium or carbon fiber composite (CFC) armor bonded to a copper alloy, which in turn is joined to $316 \mathrm{LN}$ stainless steel. Dispersion strengthened copper (DS Cu) is currently the main candidate alloy, with the precipitation hardened alloys CuNiBe and $\mathrm{CuCrZr}$ being considered as the backup materials.

Past research has centered mainly upon the properties and behavior of the base materials after exposure to neutron irradiation. A new area of research that has only recently been given attention within the fusion materials community is the joining of DS copper to other materials, namely stainless steel and beryllium. A number of methods for joining copper alloys to stainless steel are

\footnotetext{
(a) Associated Western Universities, Richland, WA 99352

(b)Pacific Northwest Laboratory, Richland, WA 99352

(c)SCM Metal Products, Inc., Triangle Park, NC, 27709-2166
} 
being evaluated, including hot isostatic pressing, explosive bonding, and brazing. The bonding of copper alloys to stainless steel or beryllium to form the large, integral structures needed in ITER poses a significant technical challenge, both from the fabrication perspective and from the effect of neutron irradiation on the joints.

Of the three joining methods mentioned above, brazing appears to have several problems that need to be addressed. Most notable is the effect of transmutation on the constituents in the braze [1], as well as excessive diffusion of the braze constituents into the base material during the joining process. The latter is a problem commonly encountered when using brazes with a high silver content [2].

This study is the first effort to gain insight into the effect of neutron irradiation on brazed joints. Brazed DS copper specimens were irradiated at three different conditions in the Fast Flux Test Facility (FFTF) [3], then tested afterwards to ascertain the effect of irradiation damage and transmutation. This report summarizes the results of the mechanical testing and preliminary characterization of the joints.

\section{Experimental Procedure}

Using four different brazing alloys, sheets of LOX grade GlidCop CuAl25 were brazed together to form a lapped joint. The CuAl25 used for this experiment was in the $96 \%$ cold worked condition and nominally $0.254 \mathrm{~mm}$ thick. No post-braze heat treatment was applied. The compositions and brazing conditions are listed in Table 1, along with information concerning the liquidus and solidus temperatures. After brazing, the joined sheets were then shipped to a commercial vendor to have miniature lapped tensile specimens fabricated by a wire electrical discharge machining (EDM) process from the joints. The final dimensions and geometry of the specimens are illustrated in Figure 1. For comparison, tensile specimens were also fabricated by EDM from the original CuAl25 sheet in two orientations: parallel and perpendicular to the rolling direction. Excluding the joint overlap, the size and geometry of the specimens were identical to that of the brazed specimens.

Since the GlidCop alloys typically have a large grain boundary area due to the fine grain size $(\sim 1$ $\mu \mathrm{m}$ wide $\times 5 \mu \mathrm{m}$ long), excessive migration of the silver from the joint into the base metal occurs during brazing. Samal [2] developed a procedure to minimize such diffusion of the silver into the grain boundaries. Essentially the GlidCop surface is plated with a layer of pure copper having a grain size on the order of several microns. The smaller grain boundary area of the interface layer effectively eliminates the migration of the silver. For the $\mathrm{CuAg}$ and $\mathrm{TiCuAg}$ brazes in this experiment, CuAl25 with a $0.015 \mathrm{~mm}$ cladding of pure copper was used in place of plated GlidCop. The copper cladding is a remnant of the extrusion process, and normally would be machined off. In this case the pure copper cladding was left in place after the brazing, so the specimen thickness measurements include the thickness of the cladding. The specimens brazed with $\mathrm{CuAu}$ and TiCuNi were brazed in the declad state. Brazing time was 5 minutes, with the specimens left to cool in the furnace for $\sim 20$ minutes.

Specimens of each type of braze and of the $96 \%$ CW CuAl25 were irradiated in the Fast Flux Test Facility (FFTF) located in Richland, Washington. The specimens were irradiated at three different locations in the FFTF Materials Open Test Assembly, which lead to the specimens being irradiated at three different dose rates due to differences in the neutron spectrum at each location. The 
irradiation conditions are provided in Table 2. All specimens, regardless of location, were in reactor a total of 203 effective full power days. At least three specimens of each type of material were irradiated at each set of conditions. CuAg brazed specimens were not included in the capsules irradiated to $34.5 \mathrm{dpa}$ at $706 \mathrm{~K}$.

The miniature specimens were tested in a specially designed horizontal testing frame used to test both nonradioactive and radioactive specimens. The specimen is held by wedge grips that have a small square grid on one half of each grip to improve the grip's ability to clamp and hold the specimen. The load on the specimen is monitored during the tightening of the grips to minimize any tensile stresses that may be incurred by clamping the specimen. All tensile tests were performed at room temperature using a strain rate of $4 \times 10^{-4} \mathrm{~s}^{-1}$.

Because of the small size and the high residual radioactivity of the irradiated specimens, the latter of which hampers the handling of the specimens, strain cannot be easily measured using strain gages. Consequently, the strain is calculated by measuring the crosshead displacement using a linear variable displacement transducer. The displacement is converted to strain by assuming that all of the deformation occurs in the gage section of the tensile specimen. Although the strain values for these miniature specimens may not be directly comparable to that obtained from full size specimens, they can be used to demonstrate any trends that may occur. However, the strength values are thought to comparable to those measured from full size specimens $[4,5]$.

Maximum shear stress values were calculated at the maximum load using areas measured from optical micrographs of the cross-section of each specimen tested. The joints were not uniform in shape or dimension, so in many cases the lapped area was estimated based on an average of the dimensions that could be measured readily from the optical micrographs. The shear stress values are considered to be rough estimates that might be in error by up to as much as $15 \%$, whereas the experimental error for typical yield and UTS values lies within $\pm 5 \%$. The smaller error in the yield and UTS is due to the more accurate dimensional measurements that can be obtained for the thickness and width of the gage section.

An illustration of the test configuration used for the lapped miniature tensile specimens is provided in Figure 2. Because the two specimen halves were offset, bending stresses were introduced during testing. These were minimized by placing shims in the position indicated in Figure 2. The shims were fabricated by cutting the grip ends off of extra specimens of the base material. It was initially thought that the shims might slip during the testing, but by tightening the grips sufficiently this problem did not occur. Since no adhesive was required to prevent slippage, this simplified the testing procedure and reduced both the radiation exposure to the operator and the potential for contamination.

After testing, fracture surfaces of representative specimens for each braze alloy were examined in a JEOL 840 SEM equipped with an energy dispersive spectrometer. Metallography and SEM were used to examine the polished cross-sections of the unirradiated specimens. The polished crosssections of the joints were imaged using backscattered electrons in the SEM. Backscatter imaging reveals contrast because of atomic number differences, so that those areas containing high concentrations of silver or gold (higher atomic number than copper) appeared brighter than the surrounding areas of pure copper. Conversely, regions with significant levels of titanium or aluminum showed up darker than the surrounding matrix because their atomic numbers were lower than that of pure copper. 


\section{$\underline{\text { Results and Discussion }}$}

Of the four brazing alloys tested, the TiCuAg and TiCuNi did not produce acceptable joints. Figures 3 and 4 illustrate the poor quality of the joints produced using these alloys. Referring to the TiCuAg joints in Figure $3 \mathrm{a}$, massive migration of the silver occurred from the braze into the base material over a distance of several hundred microns. A close look at the surface (Figure 3b) shows that the silver is concentrated primarily at the grain boundaries due to grain boundary diffusion. The dark regions represent porosity at the grain boundaries rather than regions high in titanium or aluminum. Some of the specimens appeared to be warped, possibly as a result of the silver diffusion and the porosity formation in the joint. All of the TiCuAg specimens tested in both the unirradiated and irradiated state failed prematurely. Surprisingly, the specimens failed outside the joint in the region where the silver had reached the limit of its migration. In contrast to the $\mathrm{TiCuAg}$ joints, the $\mathrm{CuAg}$ joints were in general quite good, although there were a few specimens that had small amounts of porosity in the joint. It is not clear why the TiCuAg joints were of such poor quality. Both the $\mathrm{CuAg}$ and the TiCuAg joints were formed using clad CuAl25 from the same stock. The brazing temperature for the $\mathrm{TiCuAg}$ was higher by $\sim 80 \mathrm{~K}$, which is the only known variable in the process and may have been responsible for the problem.

The TiCuNi joint in Figure 4a illustrates that the base metal was melted during the brazing. The resulting microstructure of the joint is rather complex, consisting of intermetallic phases and a Widmanstatten microstructure of beta and alpha titanium. A closeup of a Widmanstatten colony is shown in Figure 4b. The darker regions in the micrograph are regions that contain a high concentration of titanium. The darker the appearance, the more titanium that is present. As with the TiCuAg brazed specimens, the specimens also failed prematurely in both the unirradiated and irradiated specimens. The yield and UTS values for the TiCuNi specimens exhibited a large amount of variability because the melting that occurred in the joint produced uneven cross-sections. The specimens tended to fail in regions near the outer edge of the joint where the specimen was the thinnest.

The remaining two alloys showed the most promise judging by the quality of the joint in the unirradiated specimens. An example of a CuAu braze joint is shown in Figure 5a, again imaged using backscattered electron imaging. The $\mathrm{CuAg}$ joints were identical in overall appearance, although closer examination revealed a eutectic microstructure, which is to be expected considering the eutectic composition of the braze. An example of the eutectic microstructure is shown in Figure $5 b$.

The tensile data for the unirradiated and irradiated specimens of the base CuAl25 (perpendicular and parallel) and the $\mathrm{CuAg}$ and CuAu brazed specimens are listed in Tables 3 through 6 . All of the unirradiated specimens of $\mathrm{CuAu}$ and $\mathrm{CuAg}$ failed in the base metal, not in the joint. The data for $\mathrm{TiCuAg}$ and the TiCuNi were not included since the specimens failed prematurely and produced data with significant scatter. Representative tensile curves for the CuAu brazed specimens and base CuAl25 (parallel orientation) are provided in Figure 6. Several things bear mentioning with respect to these curves and the tabulated data.

All of the brazed specimens, unirradiated and irradiated, exhibited a noticeable change in the slope of what corresponded to the elastic region in the standard CuAl25 specimens. While this could certainly result from a change in the elastic modulus due to the presence of the braze, it was observed after the tensile tests that the joint alignment had changed in all of the brazed specimens, i.e., the joint rotated during the test such that the lap was actually at an angle to the tensile axis. 
This means that the shift in the slope of the elastic region is most likely due to the realignment of the joint. The cause of this realignment is thought to be a combination of the thinness of the specimens and the lack of constraint, but further tests and/or finite element analysis are necessary to be certain. Special care was taken to ensure that the shims were of the same thickness as the base material, and that the specimens was correctly aligned within the grips. However, this could still allow a slight misalignment since the braze filler material would add to the overall thickness of the specimen, and this would not be compensated for by the use of shims.

While it might appear that a change in elastic modulus due to the braze could also have led to such changes as were observed in the initial portion of the tensile curve, the 30 at\% Au expected to transmute to $\mathrm{Hg}$ during irradiation below-core [3] would be expected to cause further changes; since no additional change in the initial portion of the curve was observed following irradiation, the implication is that a change in modulus is probably not responsible for the change in the curve. Void swelling could also lead to additional dimensional changes that might affect not only the alignment of the specimen but also the performance of the braze joint. The change in the slope of the elastic region, for both the unirradiated and the irradiated specimens, leads to the determination of artificially low yield strengths than would otherwise be measured. As such, these data can only be used for comparative purposes to examine trends in material behavior.

The strength of the unirradiated CuAu brazed specimens was much lower than that of the base CuAl25. Note that brazing at $1253 \mathrm{~K}$ for 5 minutes, followed by a 20 minute furnace cool, caused the UTS to drop roughly $150 \mathrm{MPa}$. This suggests that the brazing exposure can lead to a decrease in the strength of the base material. Somewhat surprisingly, it was found that irradiating at temperatures ranging from 643 to $706 \mathrm{~K}$ for $\sim 200$ days did not produce any further changes in strength beyond that already attributed to the brazing cycle. In a separate study on the tensile properties of the irradiated base CuAl25 [6], it was found similarly that the changes in the strength of the alloy were independent of the dose, displacement rate, and temperature. It was also found that the decrease in strength due to neutron irradiation under the same conditions as used in this study was the same as that incurred in the brazed materials due to the thermal exposure during brazing. It is a little unusual that the relatively short thermal exposure during brazing would produce the same effect as neutron irradiation at 643 to $706 \mathrm{~K}$ for $\sim 200$ days. One possible explanation is that the initial $96 \%$ cold worked state of the base CuAl 25 leaves the material very susceptible to recovery and recrystallization during short high temperature exposures and the longer term neutron irradiation at lower temperatures.

As shown in Figure 7, the CuAg brazed specimens behaved essentially the same as their $\mathrm{CuAu}$ brazed counterparts, with one important difference. Both types of specimens exhibited a change in the slope of the initial portion of the curve. However, for reasons unknown, this effect was much more prominent in the irradiated than in the unirradiated $\mathrm{CuAg}$ brazed specimens. Referring to the tensile curves of the irradiated CuAg brazed specimens, the change in slope is even more significant after irradiation. The change in slope was consistent throughout each set of specimens, so it is believed to be real. One possible explanation for this difference between the unirradiated and irradiated $\mathrm{CuAg}$ brazed specimens is that transmutation may have had an effect. For the below-core position in the FFTF/MOTA, Garner and coworkers [3] made calculations that showed that approximately 30 at\% of the $\mathrm{Au}$ and 20 at\% of the $\mathrm{Ag}$ will transmute to $\mathrm{Hg}$ and $\mathrm{Cd}$, respectively. The transmutation rates are higher in the below-core positions because of the softer neutron spectra. For the in-core positions the transmutation levels drop to $\sim 6$ at $\%$ for both $\mathrm{Au}$ and Ag. Although the dpa level in-core is higher, the transmutation level is still considerably lower than below the core. It is not clear whether the presence of a significant amount of $\mathrm{Cd}$ would 
affect the elastic modulus of the $\mathrm{CuAg}$ brazed specimens enough to account for the observed behavior.

In the case of the CuAu brazed specimens irradiated to $5.8 \mathrm{dpa}$ in the capsule located below-core, $30 \%$ transmutation of the Au led to failure in the brazed joint. An example of the fracture surface for an irradiated specimen is provided in Figure 8. The $\mathrm{CuAu}$ specimen failed in the joint by intergranular failure in some areas (Figure 8b), and by what looks like delamination over the rest of the surface. It is thought that $\mathrm{Hg}$ may have segregated to the grain boundaries, but transmission electron microscopy (TEM) will be necessary to confirm this. All of the tested CuAu brazed specimens that were irradiated to $5.8 \mathrm{dpa}$ at $643 \mathrm{~K}$ failed in the joint, whereas the similarly irradiated $\mathrm{CuAg}$ brazed specimens failed in the base material. There were a few other random failures in the joints for both $\mathrm{CuAg}$ and $\mathrm{CuAu}$ brazed specimens, but these are attributed to preexisting defects in the joint rather than transmutation.

The shear strengths calculated for these specimens (Tables 3-6) show that in every case the maximum shear stress was much lower than the uniaxial tensile yield stress, due the size of the overlap. Since the shear stress on the joint was less than the tensile stress applied outside the joint, it is not surprising that the specimens failed outside the joint in those cases where transmutation did not cause the joint to deteriorate. Subsequent experiments will need to investigate specimens with a wide range of overlap distances in the joint to establish what the minimum overlap should be before placing more specimens in reactor.

The higher transmutation rate that will occur in reactors with a softer neutron spectrum than FFTF requires that caution be exercised when irradiating brazed specimens. The level of transmutation will be much larger in mixed spectrum reactors compared to the level expected in a fusion spectrum, which must be taken into account when setting up and analyzing the data from an irradiation experiment.

The residual radioactivity of the specimens is also important in selecting a suitable braze alloy, particularly for those brazes containing significant amounts of Ag. Ag activates strongly [1], much more than the base copper or any of the other elements used in these brazes. Ti is a low activation material, so being able to use a Ti braze would be beneficial from an activation standpoint. However, as this study showed, more effort must be devoted to optimizing the brazing conditions to improve the ductility and performance of the TiCuNi braze. Au is a relatively low activation material but the formation of $\mathrm{Hg}$ limits it usefulness to either very low doses, or to cases where the starting level of $\mathrm{Au}$ in the braze can be reduced. It might be possible to use a $\mathrm{CuAu}$ braze containing $25 \mathrm{wt} \% \mathrm{Au}$ as opposed to $50 \mathrm{wt} \%$, and to use brazed components only for low dose applications within ITER.

\section{Conclusions}

None of the brazes used in this study appear to be particularly well suited for use in a fusion environment. The transmutation of $\mathrm{Au}$ to $\mathrm{Hg}$ has a detrimental affect on the integrity of the joint. Transmutation of $\mathrm{Ag}$ to $\mathrm{Cd}$ may not be as detrimental to the properties of the braze, but the high activation due to $\mathrm{Cd}$ formation is a significant drawback. The TiCuAg braze also contains enough $\mathrm{Ag}$ to limit its usefulness due to activation considerations. The poor quality of the TiCuAg braze joints produced in this study demonstrates the importance of controlling the diffusion of the $\mathrm{Ag}$ into the base material. The TiCuNi braze is well suited from an activation standpoint, and perhaps 
further work to improve the properties of the joint will increase its suitability. The apparent melting of the base material may pose a problem, particularly if the oxide dispersion was altered to the extent that the swelling resistance was lowered.

\section{FUTURE WORK}

The brazed TEM disks, or "sandwiches", included in this experiment will be selectively examined to investigate the possible influence of the transmutation of $\mathrm{Au}$ and $\mathrm{Ag}$, as well as search for evidence of void swelling in the joint. Further tensile tests may be conducted to determine the exact nature of the change in elasticity of the brazed specimens.

\section{REFERENCES}

1. F.A. Garner, L.R. Greenwood, and D.J. Edwards, "Transmutation in Copper-Based Brazing Materials", DOE/ER 0313-16, (1994), p. 47.

2. P. Samal, "Brazing and Diffusion Bonding of GlidCop Dispersion Strengthened Copper", SCM Metal Products, INC. internal report.

3. F.A. Garner and M.L Hamilton, D.J. Edwards, B.N. Singh, J.F. Stubbins, T. Shikama, S.J. Zinkle, P. Samal, "Status of Copper Irradiation Experiments", DOE/ER 0313-10, (1991), p. 186.

4. F.A. Garner, M.L. Hamilton, H.L. Heinisch, and A.S. Kumar, "Application of Miniature Tension Specimens to Studies of Radiation Damage in Metals", ASTM STP 1204, W.R. Corwin, F.M. Haggag, and W.L. Server, Eds., American Society for Testing and Materials, Philadelphia, 1993, pp. 336-355.

5. M.L. Hamilton, M.A. Blotter, and D.J. Edwards, "Evaluation of Miniature Tension Specimen Fabrication techniques and Performance", ASTM STP 1204, W.R. Corwin, F.M. Haggag, and W.L. Server, Eds., American Society for Testing and Materials, Philadelphia, 1993, pp. 368-385.

6. D. J. Edwards, F.A. Garner, M.L. Hamilton, P. Samal, and J.D. Troxell, "High Temperature Stability of Dispersion Strengthened Copper Alloys Irradiated with Fast Neutrons", Fusion Materials Semiannual Progress Report, this publication. 
TABLE 1. Compositions and Brazing Conditions

\begin{tabular}{||l||c|c|c|c||}
\hline & $\mathrm{AgCu}$ & $\mathrm{AuCu}$ & TiCuAg & TiCuNi \\
\hline \hline Composition, wt\% & \multirow{2}{7}{$\begin{array}{l}72 \mathrm{Ag} \\
28 \mathrm{Cu}\end{array}$} & $\begin{array}{l}50 \mathrm{Au} \\
50 \mathrm{Cu}\end{array}$ & $\begin{array}{l}5.2 \mathrm{Ti} \\
26.9 \mathrm{Cu} \\
67.9 \mathrm{Ag}\end{array}$ & $\begin{array}{l}69.6 \mathrm{Ti} \\
15.1 \mathrm{Cu} \\
15.3 \mathrm{Ni}\end{array}$ \\
\hline Brazing temp. & $1069 \mathrm{~K}$ & $1253 \mathrm{~K}$ & $1143 \mathrm{~K}$ & $1253 \mathrm{~K}$ \\
\hline Protective & \multirow{\mathrm{H}_{2}\text{atmosphere}}{\text{atmosphere}}{} & $\mathrm{H}_{2}$ atmosphere & vacuum & vacuum \\
\hline Liquidus & \multirow{2}{*}{$\begin{array}{c}\text { Eutectic } \\
\text { composition }\end{array}$} & $1243 \mathrm{~K}$ & $1123 \mathrm{~K}$ & $1233 \mathrm{~K}$ \\
\cline { 2 - 6 } Solidus & $1228 \mathrm{~K}$ & $1103 \mathrm{~K}$ & $1183 \mathrm{~K}$ \\
\hline
\end{tabular}

TABLE 2. Irradiation Conditions in the FFTF/MOTA Experiment

\begin{tabular}{||c|c|c|c|c||}
\hline Alloy & $\begin{array}{c}\text { Irradiation } \\
\text { Temperature (K) }\end{array}$ & $\begin{array}{c}\text { Fluence } \\
(\mathrm{E}>0.1 \mathrm{MeV})\end{array}$ & $\begin{array}{c}\text { Total } \\
\text { displacement } \\
\text { (dpa) }\end{array}$ & $\begin{array}{c}\text { Displacement } \\
\text { rate (dpa/sec) }\end{array}$ \\
\hline $\begin{array}{c}\text { CuAg, CuAu, } \\
\text { TiCuNi, } \\
\text { TiCuAg } \\
\text { Base CuAl25 }\end{array}$ & 643 & $1.14 \times 10^{22}$ & 5.8 & $3.3 \times 10^{-7}$ \\
\hline $\begin{array}{c}\text { CuAg, CuAu, } \\
\text { TiCuNi, } \\
\text { TiCuAg } \\
\text { Base CuAl25 }\end{array}$ & 666 & $3.3 \times 10^{22}$ & 18.4 & $1.1 \times 10^{-6}$ \\
\hline $\begin{array}{c}\text { CuAu, TiCuNi, } \\
\text { TiCuAg } \\
\text { Base CuAl25 }\end{array}$ & 706 & $6.0 \times 10^{22}$ & 34.5 & $2.0 \times 10^{-6}$ \\
\hline
\end{tabular}


TABLE 3. Mechanical Properties for Unirradiated Base CuAl25 and CuAg and CuAu Brazed Specimens

\begin{tabular}{|c|c|c|c|c|c|c|}
\hline Braze & YS (MPa) & UTS (MPa) & $\begin{array}{c}\text { Shear Strength } \\
(\mathrm{MPa})\end{array}$ & $\begin{array}{l}\text { UE } \\
(\%)\end{array}$ & $\begin{array}{l}\mathrm{TE} \\
(\%)\end{array}$ & $\begin{array}{c}\text { Failed in } \\
\text { joint? }\end{array}$ \\
\hline \multirow{3}{*}{$\mathrm{CuAg}$} & 248 & 457 & 176 & 6.2 & 10.4 & No \\
\hline & 243 & 458 & 197 & 5.4 & 9.8 & No \\
\hline & 225 & 455 & 182 & 5.7 & 10.1 & No \\
\hline \multirow{3}{*}{$\mathrm{CuAu}$} & 237 & 453 & 241 & 5.9 & 12.1 & No \\
\hline & 218 & 448 & 267 & 5.5 & 6.1 & No \\
\hline & 230 & 449 & 306 & 5.5 & 11.3 & No \\
\hline \multirow{3}{*}{$\begin{array}{c}\text { Base CuAl25 } \\
\text { Parallel }\end{array}$} & 498 & 604 & & 1.9 & 8.3 & \\
\hline & 459 & 607 & & 2.3 & 9.9 & \\
\hline & 468 & 602 & & 2.2 & 10.5 & \\
\hline \multirow{3}{*}{$\begin{array}{l}\text { Base CuAl25 } \\
\text { Perpendicular }\end{array}$} & 454 & 603 & $\therefore$ & 2.1 & 10.3 & \\
\hline & 429 & 600 & & 2.4 & 8.5 & \\
\hline & 435 & 600 & & 2.2 & 9.0 & \\
\hline
\end{tabular}

TABLE 4. Mechanical Properties for Base CuAl25 and CuAg and CuAu Brazed Specimens Irradiated to $5.8 \mathrm{dpa}$ at $643 \mathrm{~K}$

\begin{tabular}{|c|c|c|c|c|c|c|}
\hline Braze & YS (MPa) & UTS (MPa) & $\begin{array}{l}\text { Shear Strength } \\
(\mathrm{MPa})\end{array}$ & $\begin{array}{l}\text { UE } \\
(\%)\end{array}$ & $\begin{array}{l}\mathrm{TE} \\
(\%)\end{array}$ & $\begin{array}{l}\text { Failed in } \\
\text { joint? }\end{array}$ \\
\hline \multirow{3}{*}{$\mathrm{CuAg}$} & 227 & 462 & 144 & 7.7 & 12.1 & No \\
\hline & 217 & 460 & 161 & 6.7 & 10.2 & No \\
\hline & 209 & 429 & 175 & 7.6 & 12.1 & No \\
\hline \multirow{3}{*}{$\mathrm{CuAu}$} & 224 & 341 & 96 & 1.0 & 2.3 & Yes \\
\hline & 205 & 303 & 85 & ---י-ים & 2.6 & Yes \\
\hline & 214 & 311 & 76 & 1.0 & 2.2 & Yes \\
\hline \multirow{2}{*}{$\begin{array}{c}\text { Base CuAl25 } \\
\text { Parallel }\end{array}$} & 423 & 477 & & 8.3 & 16.0 & \\
\hline & 420 & 465 & & 7.8 & 14.6 & \\
\hline \multirow{2}{*}{$\begin{array}{l}\text { Base CuAl25 } \\
\text { Perpendicular }\end{array}$} & 425 & 471 & & 8.0 & 16.1 & \\
\hline & 417 & 466 & . & 7.4 & 14.8 & \\
\hline
\end{tabular}


TABLE 5. Mechanical Properties for Base CuAl25 and CuAg and CuAu Brazed Specimens Irradiated to $18.4 \mathrm{dpa}$ at $663 \mathrm{~K}$

\begin{tabular}{|c|c|c|c|c|c|c|}
\hline Braze & YS (MPa) & UTS (MPa) & $\begin{array}{c}\text { Shear Strength } \\
(\mathrm{MPa})\end{array}$ & $\% \mathrm{UE}$ & \%TE & $\begin{array}{c}\text { Failed in } \\
\text { joint? }\end{array}$ \\
\hline \multirow{3}{*}{ CuAg } & 186 & 457 & 119 & 8.4 & 12.7 & No \\
\hline & 193 & 416 & 158 & 3.1 & 3.3 & Yes \\
\hline & 181 & 458 & 161 & 10.3 & 14.7 & No \\
\hline \multirow{3}{*}{$\mathrm{CuAu}$} & 211 & 451 & 113 & 6.8 & 10.2 & No \\
\hline & 230 & 435 & 178 & 6.3 & 8.8 & No \\
\hline & 242 & 443 & 120 & 5.9 & 8.4 & No \\
\hline \multirow{2}{*}{$\begin{array}{c}\text { Base } \mathrm{CuAl} 25 \\
\text { Parallel }\end{array}$} & 389 & 433 & $y_{\because} \quad \therefore$ & 8.3 & 15 & \\
\hline & 419 & 458 & 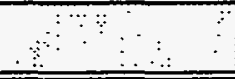 & 7.8 & 19.4 & $\therefore$ \\
\hline \multirow{2}{*}{$\begin{array}{l}\text { Base CuAl25 } \\
\text { Perpendicular }\end{array}$} & 407 & 449 & $\therefore \therefore$ & 8.0 & 18.6 & \\
\hline & 385 & 450 & $\because$ & 7.4 & 18.5 & \\
\hline
\end{tabular}

TABLE 6. Mechanical Properties for Base CuAl25 and $\mathrm{CuAg}$ and $\mathrm{CuAu}$ Brazed Specimens Irradiated to $34.5 \mathrm{dpa}$ at $706 \mathrm{~K}$

\begin{tabular}{|c|c|c|c|c|c|c|}
\hline Braze & YS (MPa) & UTS (MPa) & $\begin{array}{c}\text { Shear Strength } \\
(\mathrm{MPa})\end{array}$ & $\% U E$ & $\% \mathrm{TE}$ & $\begin{array}{c}\text { Failed in } \\
\text { joint? }\end{array}$ \\
\hline \multirow{3}{*}{$\mathrm{CuAg}$} & $\therefore \quad \therefore$ & 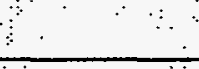 & $\because \because$ & $\therefore \quad$ & & $\therefore$ \\
\hline & $\because$ & $\therefore \quad$. & $\therefore:$ & $\therefore \quad$. & 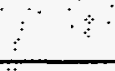 & $\therefore$ \\
\hline & $\because \therefore$ & $\begin{array}{r}\because \quad \ldots \\
\end{array}$ & $\begin{array}{l}\vdots \\
\vdots\end{array}$ & $\because \quad \therefore \quad:$ & : . & $\vdots$ \\
\hline \multirow{3}{*}{$\mathrm{CuAu}$} & 231 & 451 & 115 & ----- & 3.6 & Yes \\
\hline & 207 & 456 & 144 & 7.5 & 13.1 & No \\
\hline & 224 & 446 & 116 & 6.7 & 9.5 & No \\
\hline \multirow{2}{*}{$\begin{array}{c}\text { Base CuAl25 } \\
\text { Parallel }\end{array}$} & 405 & 405 & $\begin{array}{lll}\because & \cdots \\
\end{array}$ & 10.2 & 19.6 & $\because \quad \because \quad \therefore$ \\
\hline & 391 & 447 & $\therefore \quad \therefore$ & 10.6 & 19.1 & $\because$ \\
\hline \multirow{2}{*}{$\begin{array}{l}\text { Base CuAl25 } \\
\text { Perpendicular }\end{array}$} & 409 & 452 & $\because=$ & 9.8 & 18.3 & \\
\hline & $\because \because$ & & $\vdots$ & & & \\
\hline
\end{tabular}


Figure 1. Geometry of miniature lapped tensile specimens.
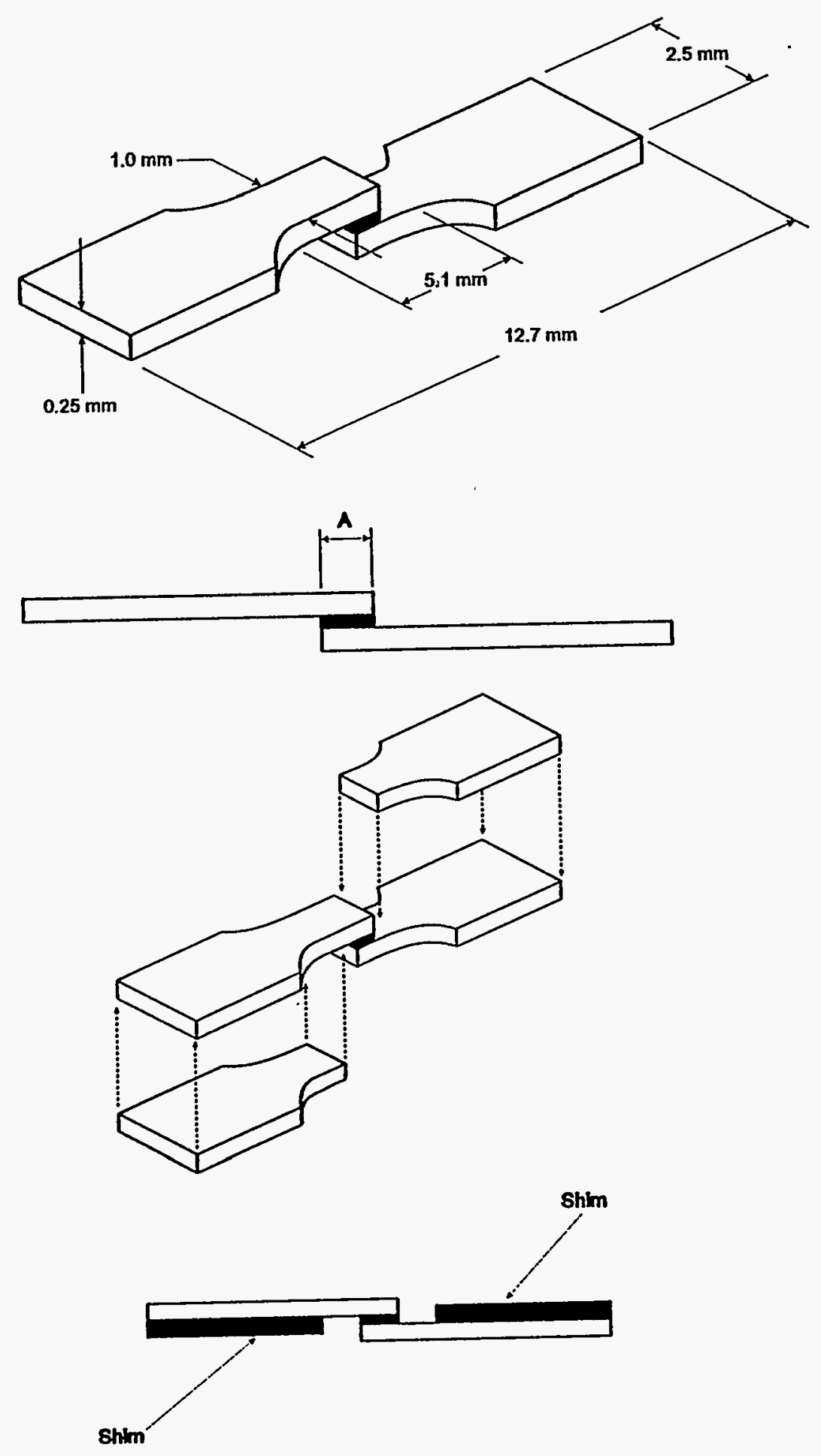

Figure 2. Use of shims during the testing to maintain the uniaxial testing condition. 
Figure 3. Poor quality TiCuAg braze joint due to silver diffusion out of the joint and into the base metal.
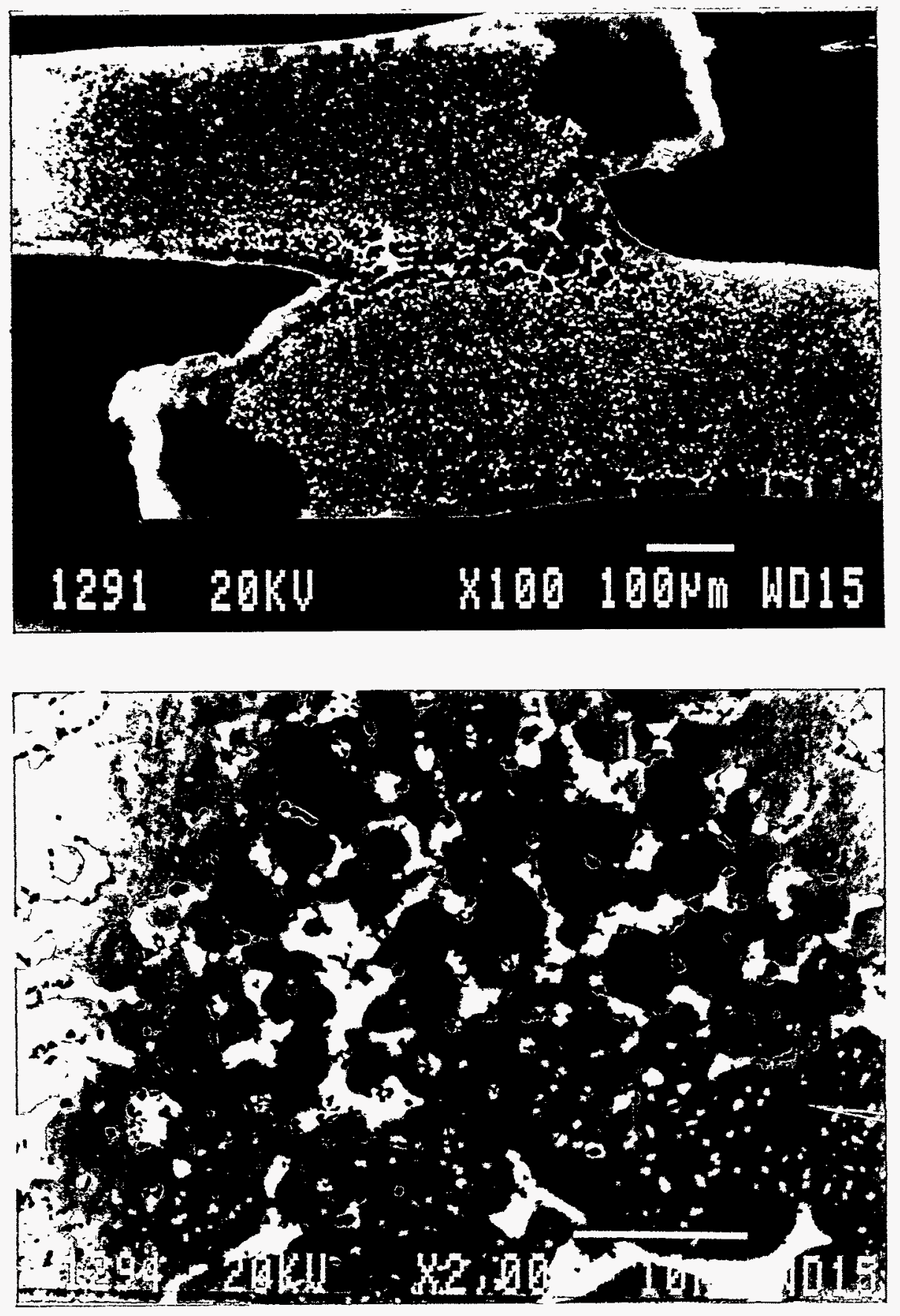
Figure 4. Melted base material and Widmanstatten structure in the TiCuNi brazed joint
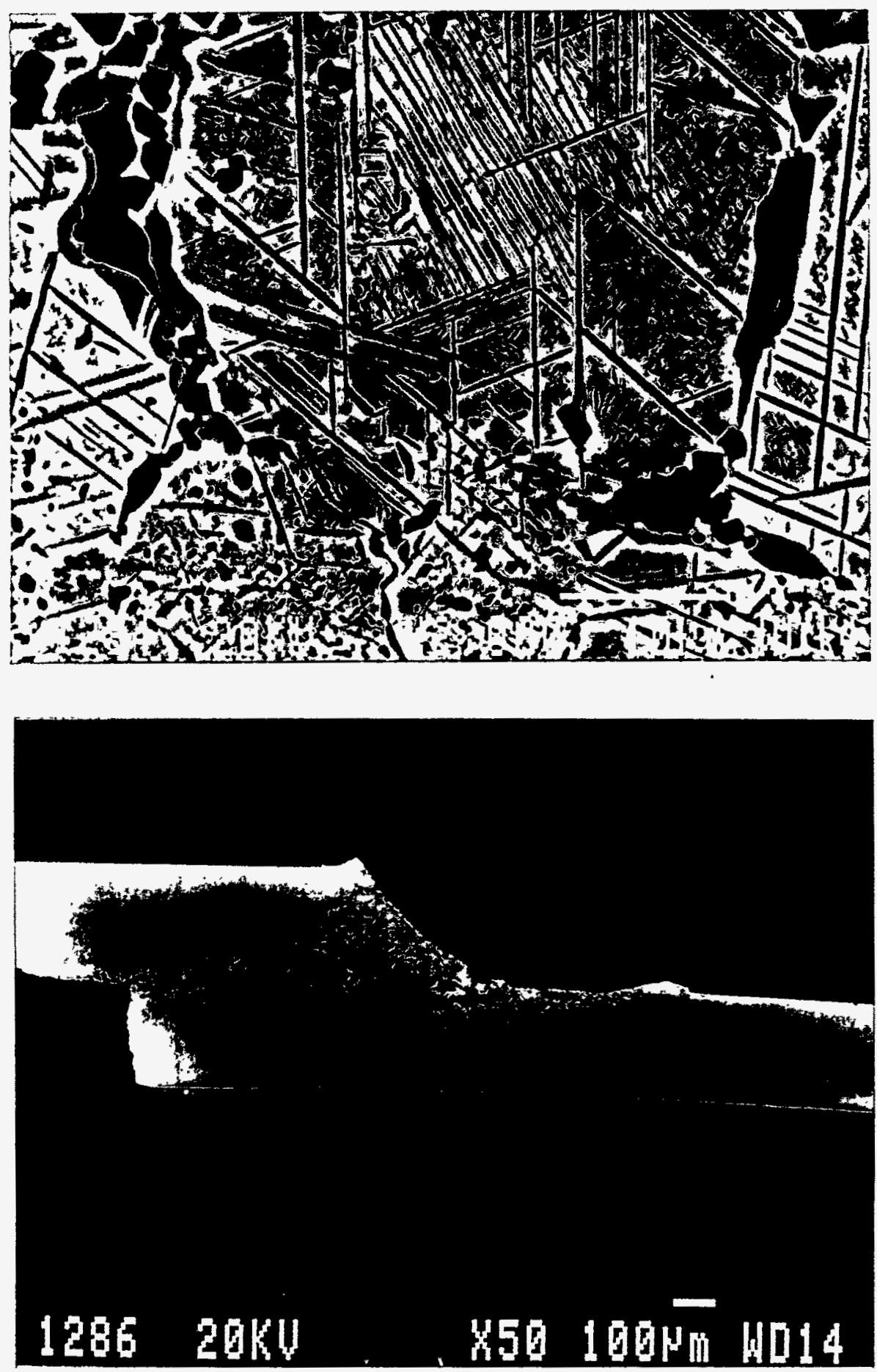
Figure 5. (a) Typical joint in a specimen containing a $\mathrm{CuAu}$ braze.
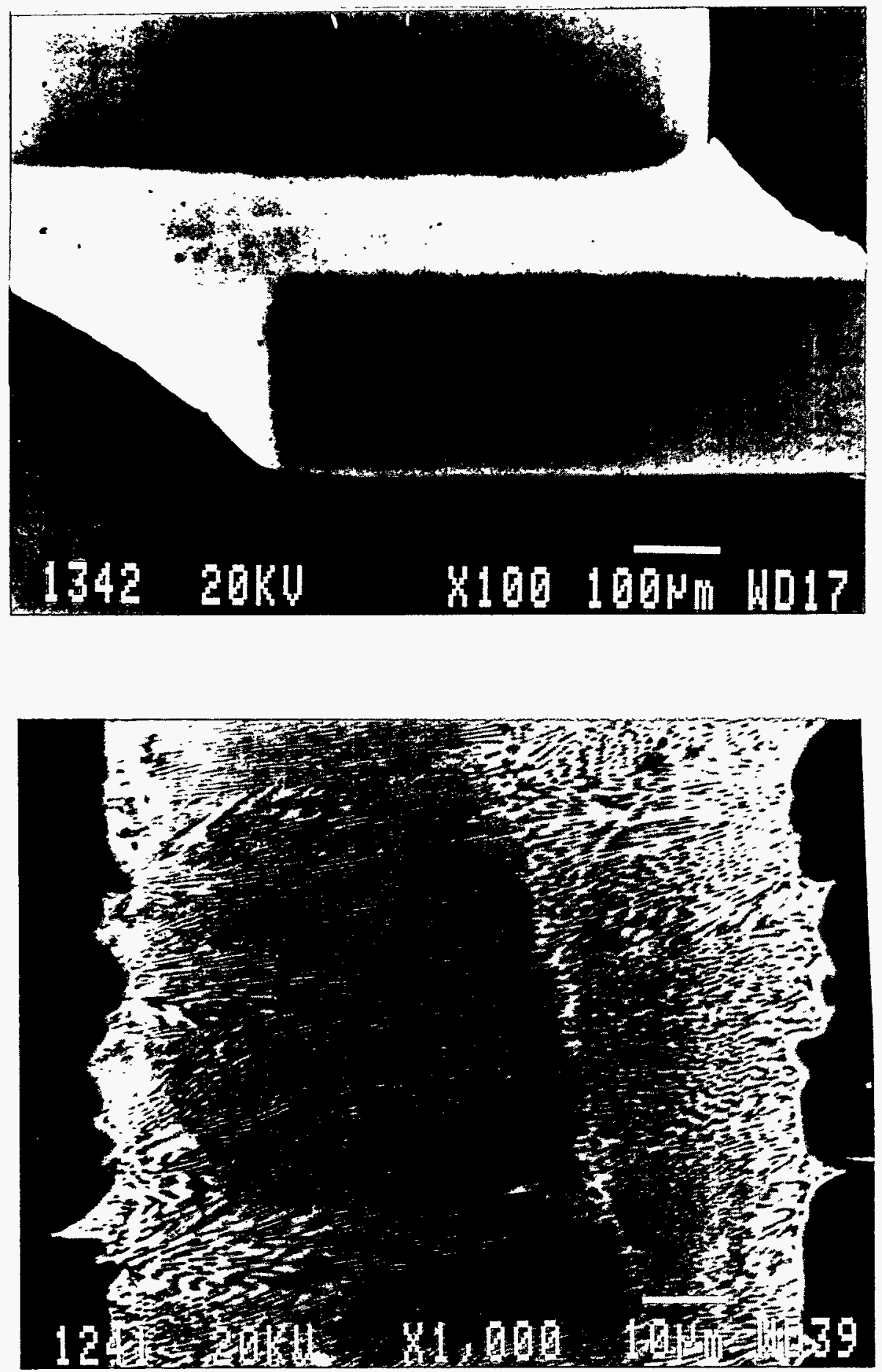

Figure 5. (b) Eutectic microstructure of the $\mathrm{CuAg}$ braze. 
Figure 6. Tensile curves for the CuAu brazed specimens in the unirradiated and irradiated conditions, as well as the unirradiated base CuAl25 used for comparison.

\section{Tensile Curves for CuAu Brazed Specimens}

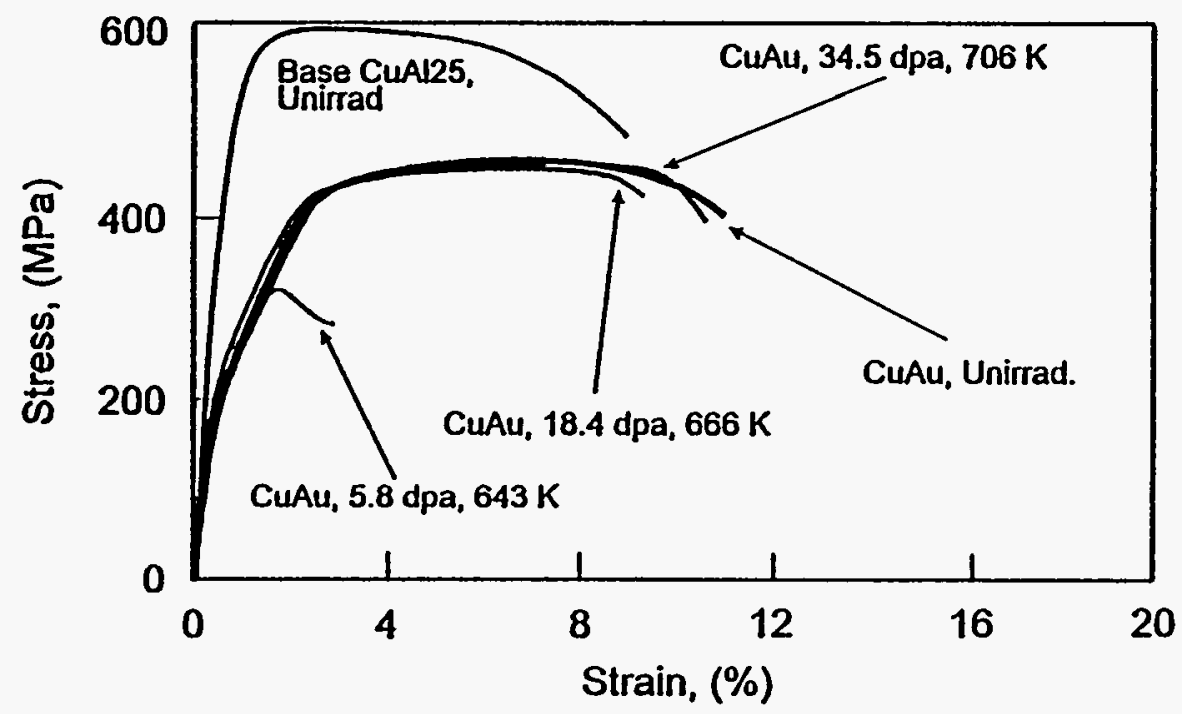

Tensile Curves for CuAg Brazed Specimens

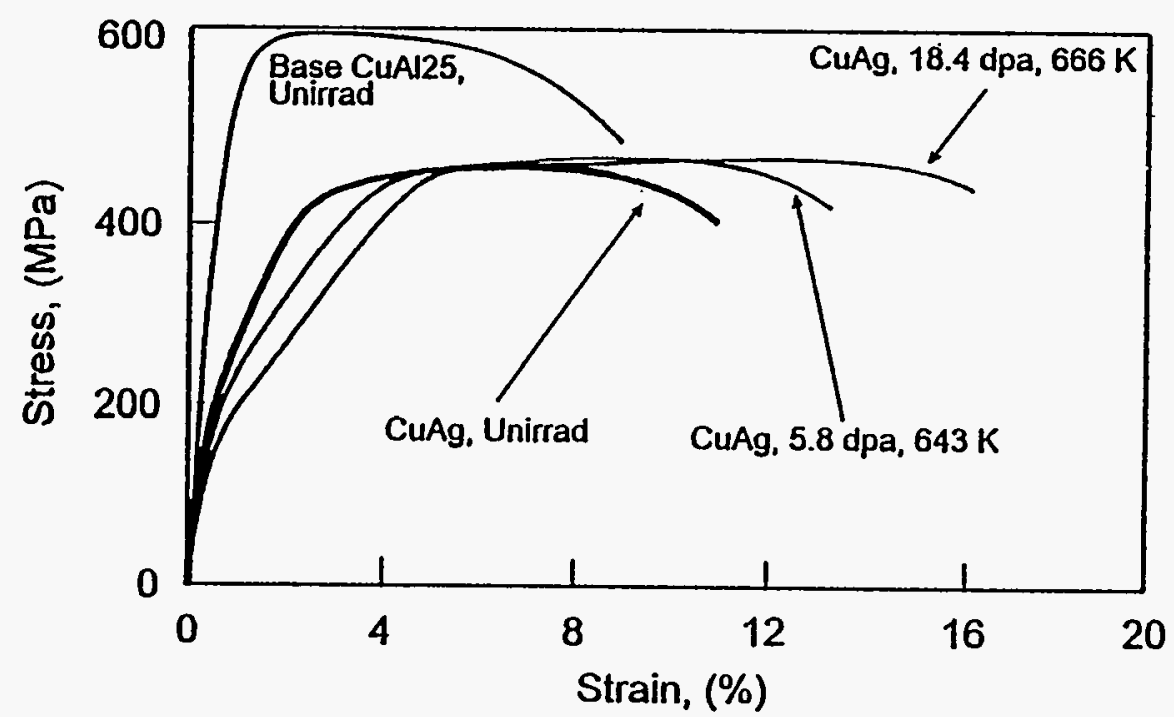

Figure 7. Tensile curves of $\mathrm{CuAg}$ brazed specimens in the unirradiated and irradiated conditions, as well as the unirradiated base CuAl25 used for comparison. 
Figure 8. Fracture surface of the $\mathrm{CuAu}$ brazed specimen that failed in the joint, possibly because mercury segregated to the grain boundaries.
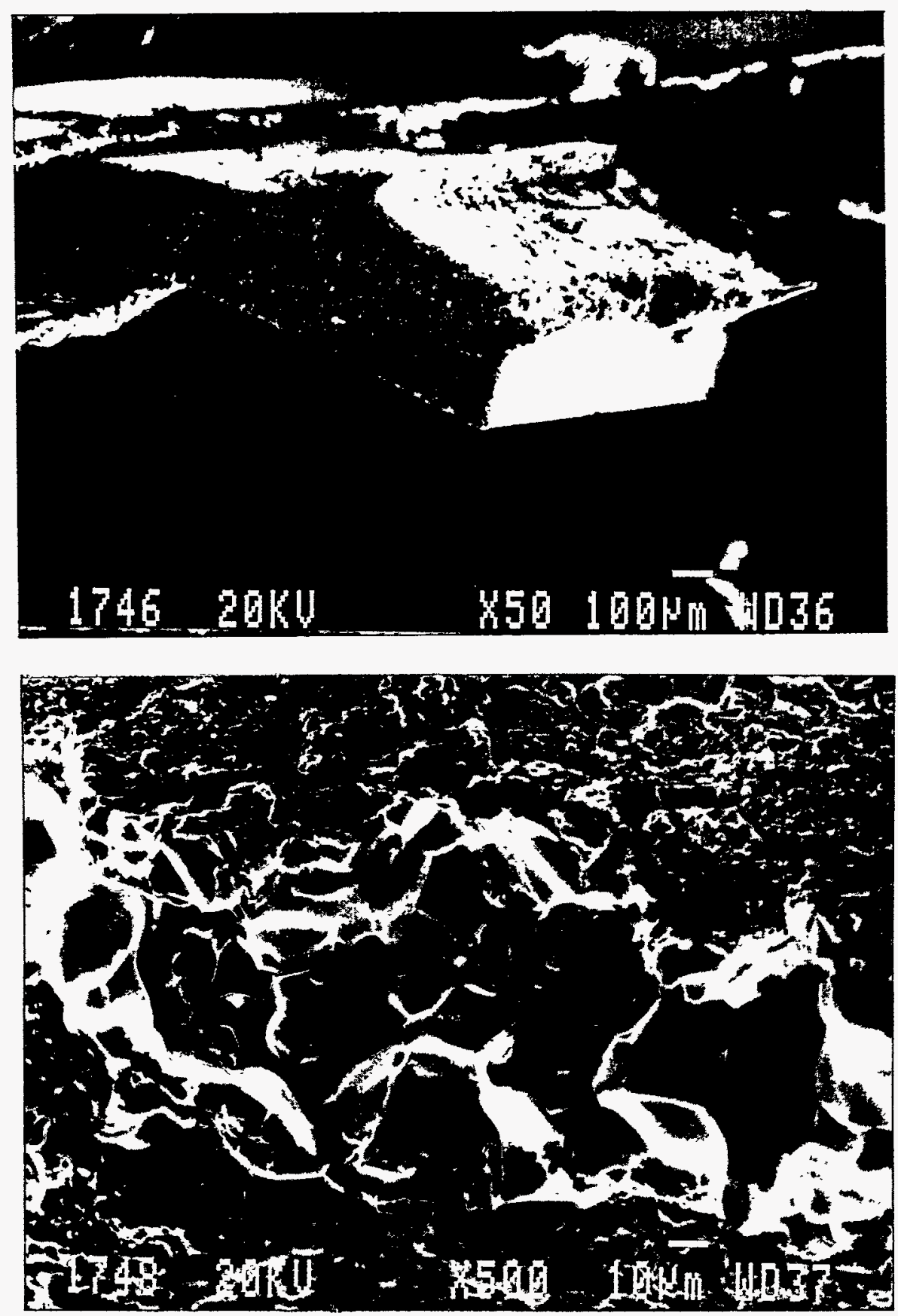
ROOM TEMPERATURE FATIGUE BEHAVIOR

OF CuCrZr OF TWO SIZES

\author{
K. Leedy ${ }^{1}$, J. F. Stubbins', F. A. Garner ${ }^{2}$, D. J. Edwards ${ }^{2}$, and B. N. Singh ${ }^{3}$. \\ 'University of Illinois, Urbana, IL \\ ${ }^{2}$ Pacific Northwest Laboratory, Richland, WA \\ ${ }^{3}$ Risø National Laboratory, Roskilde, Denmark
}

\title{
OBJECTIVE
}

The object of this effort is to supply data on the performance of copper alloys selected for ITER and other fusion applications.

\section{SUMMARY}

The room temperature fatigue behavior of unirradiated $\mathrm{CuCrZr}$ in two specimen sizes has been measured. The fatigue performance was found to be intermediate to those of OFHC copper and CuAl25, which were reported earlier. The size effects correlation is complicated somewhat by the sensitivity of this alloy to details of the heat treatment. Declining interest in this alloy for ITER applications and the shut-down of EBR-II will probably preclude irradiation of this alloy.

\section{PROGRESS AND STATUS}

\section{Introduction}

In an earlier report data on the room temperature fatigue behavior of OFHC copper and CuAl25 were presented for two different specimen sizes. ${ }^{1}$ One size was the ASTM standard size and the other was a smaller size specimen developed to fit in available irradiation capsules. Irradiations of the subsize specimens of OFHC and CuA125 in EBR-II are now complete and the irradiated specimens have been shipped to Denmark for testing.

The ITER project has also considered the use of another alloy, designated $\mathrm{CuCrZr}$, although the commitment to use this alloy recently appears to be waning in favor of CuAl25. In the interim, however, a limited series of fatigue tests on this alloy in the unirradiated condition have been completed. The specimen sizes and test conditions used for $\mathrm{CuCrZr}$ were identical to those employed in earlier tests on OHFC and CuA125. ${ }^{1}$

\section{RESULTS}

Fully reversed cyclic fatigue tests have been performed on $\mathrm{CuCr} Z r$ at room temperature. The tests were performed in strain control on both standard and subsized specimens. The results cover a limited range of fatigue lives, only about an order of magnitude, but provide a good relative indication of how this alloy will perform in fatigue. As shown in Figures 1 and 2, the response falls between CuAl25 and $\mathrm{OFHC} \mathrm{Cu}$ room temperature fatigue performance, as observed in an earlier phase of this program. Limited testing on the $\mathrm{CuCrZr}$ alloy is continuing to complete the characterization of the room temperature fatigue response, particulariy for higher fatigue lives than those tested to date. 
As shown in Figure 3, the subsize specimens show somewhat lower lives at the same strain range than do the standard size specimens. More important is the fact that the elastic response is lower and the plastic response higher for the subsize specimens, indicating that the subsize specimen material is somewhat softer than that of the standard size specimens. This appears to be due to relatively minor differences in alloy heat treatment for the two sizes. The properties of this alloy are known to be very sensitive to heat treatment and production technique. This sensitivity is one of the major reasons that this alloy is being dropped from consideration.

Microstructural analysis of the alloy conducted on both specimens sizes, taken both before and after fatigue testing, indicate that a fine dispersion of precipitates is found uniformly distributed throughout the matrix. The precipitates have not yet been fully identified, but are comprised of $\mathrm{Cu}, \mathrm{Cr}$ and $\mathrm{Zr}$. Grain boundary precipitates are found to be discontinuously distributed along many, but not all grain boundaries. In addition, large precipitates of essentially pure $\mathrm{Cr}$ are found throughout the matrix. The post-fatigue microstructure consists of dislocation subgrains.

Not only has the interest of ITER in this alloy waned, but the shut-down of EBR-II has interrupted plans for the irradiation of subsize $\mathrm{CuCrZr}$ specimens. No further work is planned until better definition of the need is established.

\section{REFERENCES}

1. A. Singhal, J. F. Stubbins, B. N. Singh and F. A. Garner, J. Nucl. Mater. 212-215 (1994) 13071312.

\section{$\mathrm{CuAl} 25, \mathrm{CuCrZr}$, and OFHC Cu Fatigue Behavior Standard Size Specimens, RT, Air}

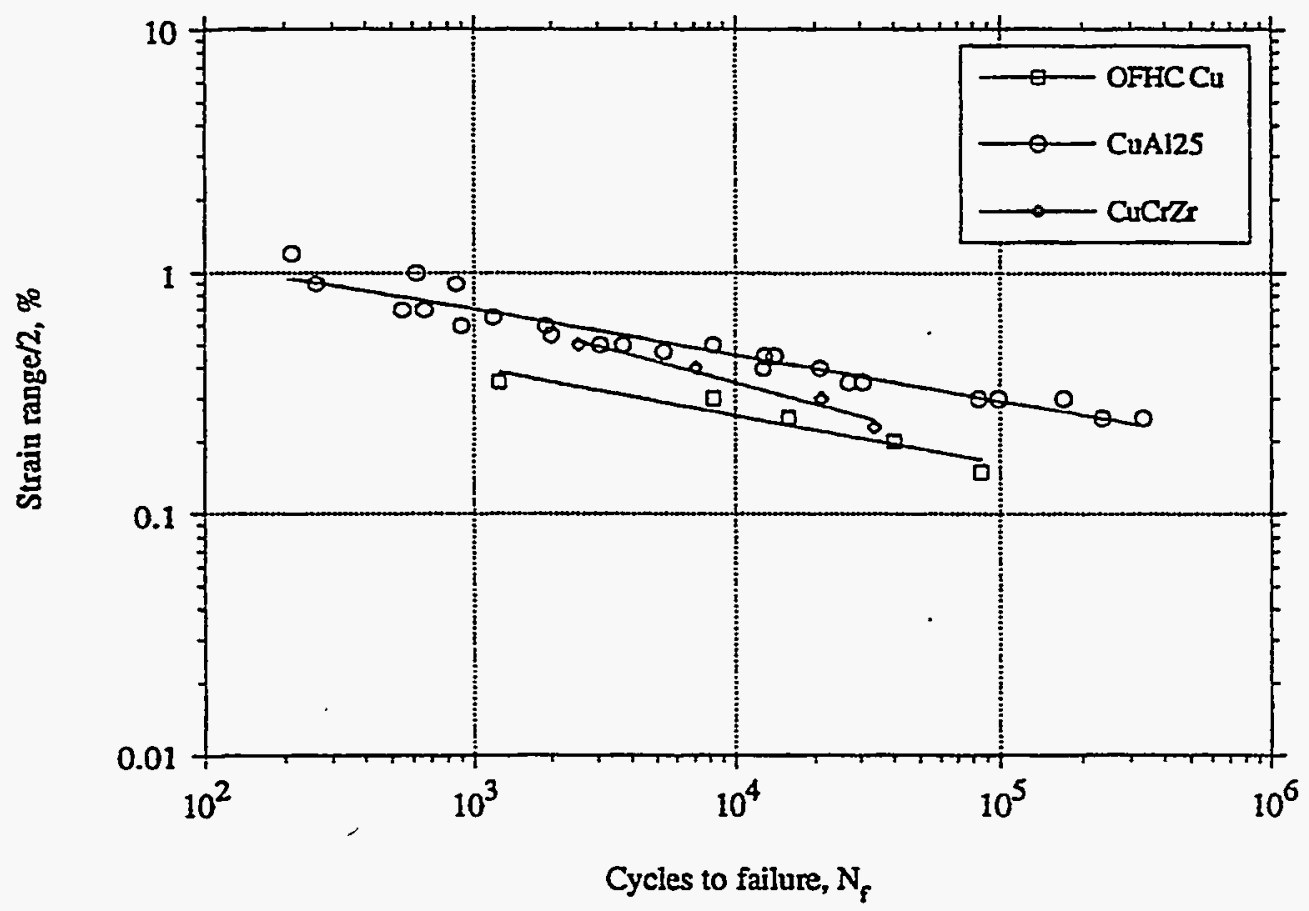

Figure 1. Fatigue response of standard size specimens 
CuCrZr, CuAl25 and OFHC Cu Fatigue Behavior Subsize Specimens, RT, Air

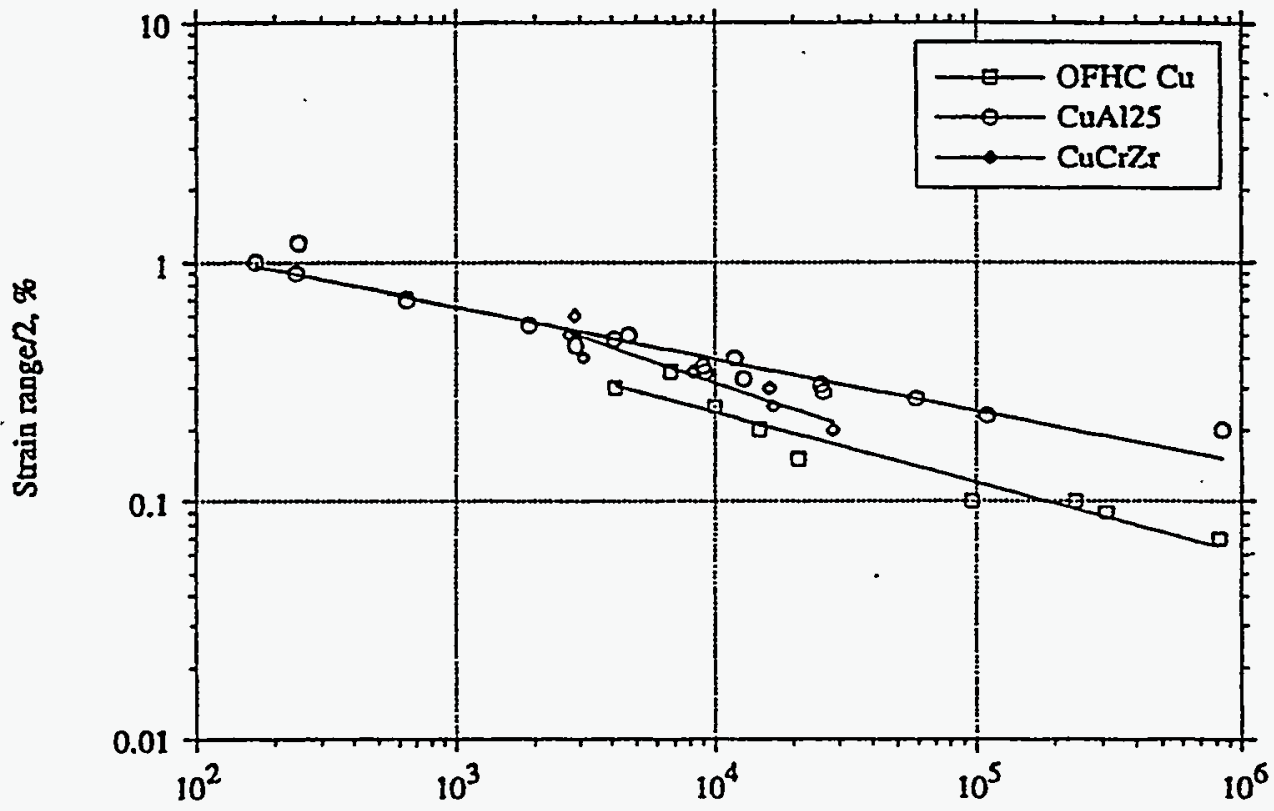

Cycles to failure, $N_{f}$

Figure 2. Fatigue response of subsize specimens

$\mathrm{CuCrZr}$ Fatigue Behavior Standard and Subsize Specimens, RT, Air

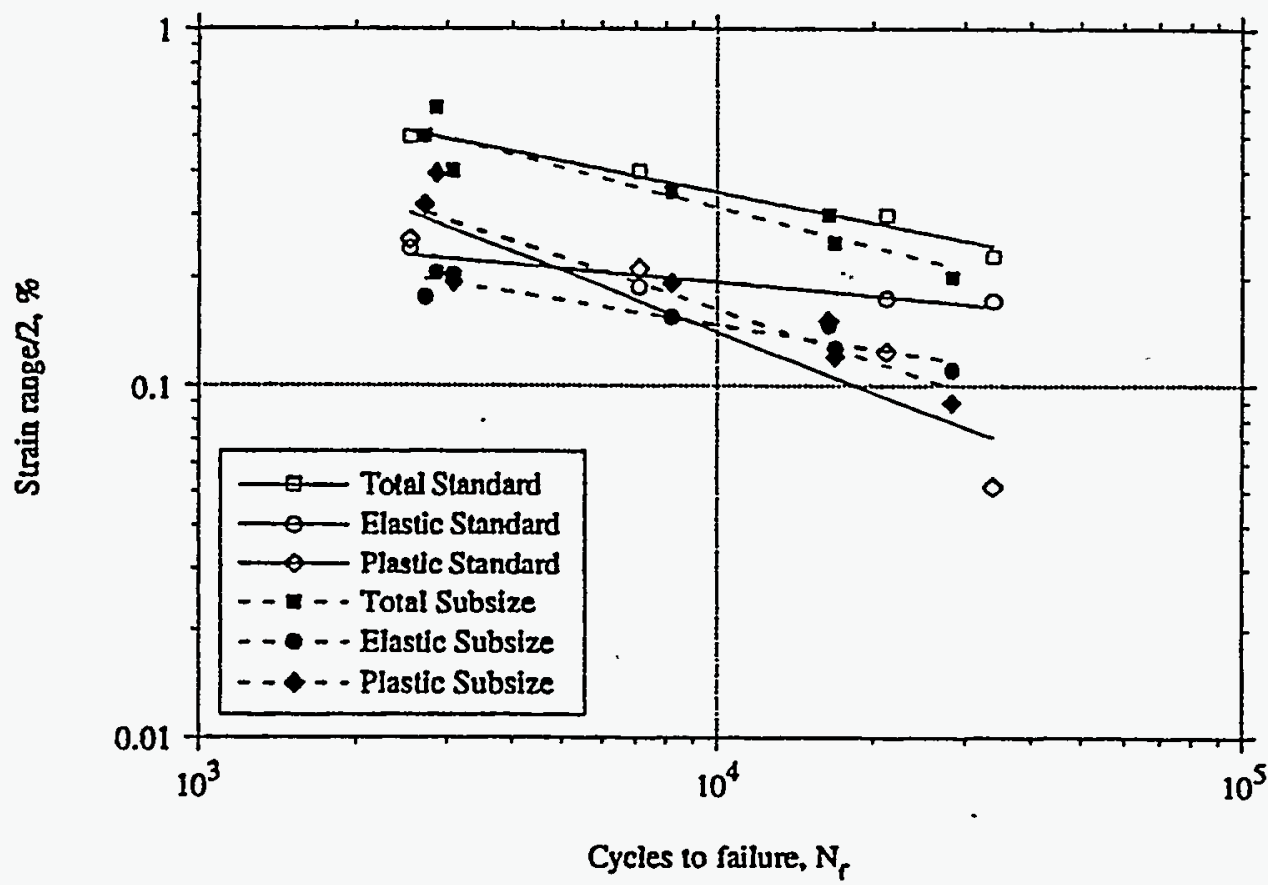

Figure 3. Comparison of the fatigue response of both standard size and subsize $\mathrm{CuCr} \mathrm{Zr}$ specimens 
6.5 Environmental Effects in Structural Materials 
FABRICATION OF ALUMINUM NITRIDE AND ITS STABILITY IN LIQUID ALKALI METALS* K. Natesan and D. L. Rink (Argonne National Laboratory)

\section{OBJECTIVE}

The objectives of this task are to (a) evaluate several fabrication procedures for development of aluminum nitride (AIN) coatings on the candidate first-wall structural material V-5wt.\% Cr-5wt.\% Ti, (b) evaluate the stability of coatings in contact with the structural alloy and liquid $\mathrm{Li}$ at temperatures of $200-400^{\circ} \mathrm{C}$, (c) measure the electrical resistivity of the coated films after exposure to liquid $\mathrm{Li}$, (d) evaluate the effects of coating defects on electrical resistivity, and (e) establish in-situ repair procedures to maintain adequate electrical insulating properties of the coatings.

\section{SUMMARY}

AlN has been selected as a prime candidate to electrically insulate the V-alloy first wall in the self-cooled concept for ITER application. Detailed investigations were conducted on the fabrication, metallurgical microstructure, compatibility in liquid $\mathrm{Li}$, and electrical characteristics of AIN material obtained from several sources. Coating fabrication methods included physical vapor deposition, reaction sputtering, ionbeam-assisted deposition, chemical vapor deposition, and a chemical route. Microstructural characterization of the coated samples was conducted by scanning electron microscopy, energy-dispersive X-ray analysis, and $\mathrm{X}$-ray diffraction. Lithium compatibility studies were conducted in static systems by exposure of AlNcoated specimens to Li for several time periods. Electrical resistance measurements were made at room temperature on the specimens before and after exposure to liquid $\mathrm{Li}$. The results obtained in this study indicate that AlN is a viable coating from the standpoint of chemical compatibility in Li, electrical insulation characteristics, and ease of fabrication, and that the coating should be examined further for fusion reactor application.

\section{BACKGROUND}

Extensive thermodynamic calculations have been performed to evaluate potential electrical-insulator candidates that are chemically compatible in liquid metals for use as a coating on first-wall and blanket structural material (1). The issues of compatibility of the liquid metal and the coating involves the (a) thermodynamic stability of the coating when contacted by the liquid metal; (b) extent of dissolution of the coating in the liquid metal, which is dictated by the solubilities of coating constituents (and structural material constituents, if uncoated material or bimetallic systems are used) in the liquid metal at temperatures and temperature gradients that are present in the system; and (c) degrees of interaction between the coating constituents and the reactants such as $\mathrm{O}, \mathrm{C}, \mathrm{N}$, and $\mathrm{H}$ in the liquid metal, which can result in changes in chemistry of the coating, thereby altering the insulating characteristics. The requirement is that the product of insulator coating electrical resistivity times thickness should exceed a nominal value of $0.01 \Omega \mathrm{m}^{2}$ under operating conditions. This translates to a minimum resistivity value of $10^{4} \Omega$-m for a coating thickness of $1 \mu \mathrm{m}$, or a resistivity of $10^{3} \Omega$-m for a coating thickness of $10 \mu \mathrm{m}$. Based on resistivity values of the materials listed above, a coating layer $<1 \mu \mathrm{m}$ thick of any of these materials would be adequate from the insulating standpoint, provided the resistivity is not reduced during operation, i.e., by irradiation. This report summarizes the ongoing work in the development of AlN coatings; additional details are presented elsewhere $(2,3)$.

\section{EXPERIMENTAL PROGRAM}

Several possible approaches are being examined to develop an AIN coating on the structural material. Some of these are to (a) prealuminize the surface of the material by a (pack) diffusion process and subsequently convert it to nitride in an external gas atmosphere, (b) apply a physical vapor deposition

\footnotetext{
*This work has been supported by the U.S. Department of Energy, Office of Fusion Energy Research, under Contract W-31-109-Eng-38.
} 
process with and without bond coats, (c) use a chemical vapor deposition process at $600-900^{\circ} \mathrm{C}$, (d) apply a low-temperature method that involves sequential reactions, (e) prealuminize the surface of the alloy and convert it to nitride in a high- $\mathrm{N} \mathrm{Li}$ environment, (f) preexpose the material to liquid $\mathrm{Al}$ and convert it to nitride in $\mathrm{Li},(\mathrm{g})$ form, in-situ, a coating in $\mathrm{Li}$ with high thermodynamic activity for $\mathrm{Al}$ and $\mathrm{N}$, and $(\mathrm{h})$ prealuminize a specimen of a structural material and nitride it by using a $\mathrm{N}_{2}$ cover gas during exposure to Li.

Physical vapor deposition (PVD) was one of the methods used to develop AlN coatings on both bare and prealuminized specimens of $\mathrm{V}-5 \mathrm{Cr}-5 \mathrm{Ti}$ alloy. The coatings were produced by Midwest Research Technologies (MRT) of Wisconsin and by BIRL of Illinois. Coatings were also made by reaction sputtering in a $\mathrm{N}$ atmosphere at Argonne National Laboratory (ANL) and by ion-beam-assisted reactive evaporation at Cametoid Advanced Technologies, Inc. (CAT), of Ontario, Canada.

\section{Coatings Deposited by MRT}

Aluminum nitride was sputtered reactively, that is, an aluminum target was sputtered in a partial pressure of high-purity $\mathrm{N}_{2}$, with Ar as the primary sputtering gas. Because the process takes place in a vacuum chamber and uses high-purity reactants, the product should be very pure. The process proceeds at a relatively low temperature and generally does not exceed $\approx 250^{\circ} \mathrm{C}$. Initially, the chamber was pumped down to $2 \times 10^{-6}$ torr before coating was started. Specimens of both bare and prealuminized V-5Cr-5Ti and the Al target were sputter cleaned for $6 \mathrm{~min}$ with high-purity Ar flowing at a rate of $45 \mathrm{~cm} 3 / \mathrm{min}$ and a chamber pressure of 20 mtorr. Subsequently, the sputter deposition of AlN ${ }_{X}$ was done with a $1200-W R F$ power source for $10 \mathrm{~h}$ in an Ar- $\mathrm{N}_{2}$ gas mixture at a chamber pressure of 23 mtorr. The sputtered specimens were cooled in vacuum overnight, and then the second side of the specimens was coated the same way.

\section{Coatings Deposited by BIRL}

Aluminum nitride coatings also were deposited with reaction sputtering by BIRL. Specimens of V-5Cr-5Ti alloy were used as substrate material, and were coated with AlN; some received an intermediate layer of TiN and an outer layer of AlN. An MRC 902M sputtering system was used, with control of the partial-pressure of the reactive gas $\left(\mathrm{N}_{2}\right)$ and arc suppression of the Al sputtering target. The target was powered by a DC supply, which was run at $5 \mathrm{~kW}$. The Ar sputtering gas was maintained at a constant pressure of 8 mtorr during sputtering. The chamber was initially pumped down to $1 \times 10^{-6}$ torr before coating began. The partial pressure of $\mathrm{N}_{2}$ was controlled with an optical gas controller and maintained constant at $1.6 \times 10^{-4}$ torr during coating. The substrate was biased to $150 \mathrm{~V}$ with an Advanced Energy power supply, the coating deposition rate was $1300 \AA / \mathrm{min}$, and the maximum temperature during the coating operation was $<200^{\circ} \mathrm{C}$.

\section{Coatings Made at ANL}

Aluminum nitride coatings were also made at ANL, by reaction sputtering in a low-pressure $\mathrm{N}_{2}$ atmosphere at 350,400 , and $450^{\circ} \mathrm{C}$. The specimens were heated by passing an electrical current through the substrates. The thickness of the coating after $1 \mathrm{~h}$ of deposition was in the range of $0.8-1.4 \mu \mathrm{m}$; after $4 \mathrm{~h}$ of deposition, it was $\approx 5.2 \mu \mathrm{m}$. The coating covered the entire surface of the V-alloy specimen, and the layer was fairly hard. Coatings developed at 350 and $450^{\circ} \mathrm{C}$ tended to crack, but those developed at $400^{\circ} \mathrm{C}$ were fairly adherent, mechanically harder, and scratch resistant.

\section{Coatings made by CAT}

Deposition of single-layer and graded AlN coatings on a V substrate by ion-beam-assisted reactive evaporation was attempted at CAT. In this process, $\mathrm{Al}$ is evaporated and deposited either by resistive heating or by an electron beam source while the growing film is bombarded with accelerated $\mathrm{N}$ ions produced in an ion gun. A basic advantage of this technique is controllability of the flux (arrival rate) and energy of the ion species, independent of the rate of deposition of Al. In contrast, in plasma-based processes, the voltage, current, chamber pressure, and deposition rate are all interdependent. Ten AlN 
coatings were deposited on a pure $\mathrm{V}$ substrate under a range of processing conditions.

Exposure to Lithium

Coupon specimens of V-5Cr-5Ti alloy, Type 316 stainless steel in bare and prealuminized condition, and AIN-deposited samples from several sources (discussed above) were exposed in a liquid-metal system. Weight change was measured to establish corrosion rates for the structural alloys and coatings as a function of temperature, time, and liquid metal chemistry. After exposure, the specimens were examined by a scanning electron microscope (SEM) equipped with an energy-dispersive X-ray (EDX) analyzer and by X-ray diffraction. The coated specimens were examined to evaluate coating integrity after liquid-metal exposure, microstructural changes in coatings, coating/substrate interactions, and electrical insulation characteristics of the coatings.

\section{RESULTS}

\section{Characteristics of Coated Specimens}

MRT-deposited AlN layers were fairly compact and of uniform thickness in the range of 8-12 $\mu \mathrm{m}$. The hexagonal AlN phase with an (002) orientation was dominant. No $V$ nitride was detected because the substrate was at $\angle 200^{\circ} \mathrm{C}$ during the coating process. Even though the coatings were fairly adherent, early exposures of these coated specimens to Li resulted in complete disappearance of the coating layer by either spallation or dissolution. As a result, the coated specimens were given a thermal-hardening treatment at $700-900^{\circ} \mathrm{C}$ prior to exposure to $\mathrm{Li}$. As before, the hexagonal AlN phase with (002) orientation was dominant, but traces of the $\mathrm{V}_{2} \mathrm{~N}$ phase remained because of a reaction between AlN and $\mathrm{V}$ at the coating/substrate interface. X-ray diffraction data for AlN-coated V-alloy specimens, developed at ANL, also indicated that the coatings were hexagonal AIN with an (002) preferred orientation. The coated specimens, analyzed by CAT with the Rutherford backscattering technique, indicated that the N/Al ratio in the coatings ranged from 1.04 to 1.32 .

\section{Exposure to Lithium}

Several AlN-coated V-alloy specimens from different sources were exposed to an $\mathrm{Li}$ environment at $300^{\circ} \mathrm{C}$, after which detailed microstructural analysis of all specimens and X-ray diffraction analysis of selected specimens was performed. Further, electrical resistance of several of the Li-exposed AlN-coated specimens was measured.

Figure 1 shows a cross-sectional SEM photomicrograph and EDX depth profiles for $\mathrm{Al}, \mathrm{N}, \mathrm{V}, \mathrm{Cr}$, and $\mathrm{Ti}$, of an MRT-supplied, AlN-coated V-5Cr-5Ti alloy specimen after a 430 - $\mathrm{h}$ exposure at $300^{\circ} \mathrm{C}$ to an $\mathrm{Li}$ environment in which Ar- $\mathrm{N}_{2}$ gas was bubbled for $24 \mathrm{~h}$. It is evident that the coating was intact and appears dense and fairly adherent to the substrate alloy. The EDX analysis shows that the coating consists predominantly of $\mathrm{Al}$ and $\mathrm{N}$, with almost no contamination from either the impurities in $\mathrm{Li}$ or the substrate constituents. Figure 2 shows a cross-sectional SEM photomicrograph, and EDX depth profiles for Al, N, $\mathrm{V}, \mathrm{Cr}$, and Ti, of an ANL-developed, AlN-coated, prealuminized V-5Cr-5Ti alloy specimen after $430 \mathrm{~h}$ of exposure at $300^{\circ} \mathrm{C}$ to an $\mathrm{Li}$ environment of normal purity. Figure 3 shows data for a similar specimen exposed to an $\mathrm{Li}$ environment in which was $\mathrm{Ar}-\mathrm{N}_{2}$ gas was bubbled for $24 \mathrm{~h}$. The coatings are somewhat thinner in these specimens than in those obtained from MRT, but the integrity of the coating, adhesion to the substrate, and morphology of the coating are very good. Because these specimens were prealuminized, a thin layer of $(\mathrm{Al}, \mathrm{V})$ nitride seems to have formed as an intermediate layer during the coating process, primarily because the specimens were heated to $350-450^{\circ} \mathrm{C}$ during coating in the ANL approach. A comparison of data from specimens exposed to $\mathrm{Li}$ with normal $\mathrm{N}$ content (Fig. 2) and to $\mathrm{Li}$ with $\mathrm{N}_{2}$ bubbling (Fig. 3) shows that the morphology and composition of the two specimens are virtually identical. This indicates that $\mathrm{N}$ concentration in $\mathrm{Li}$ may not have a significant effect on coating performance, especially at $300^{\circ} \mathrm{C}$. The AlN-coated specimens obtained from CAT, were also exposed to Li environments at $300^{\circ} \mathrm{C}$. The coatings on these CAT specimens completely disappeared into the $\mathrm{Li}$ in $120 \mathrm{~h}$ of exposure, as evidenced by the high electrical conductivity of the specimens after exposure. 

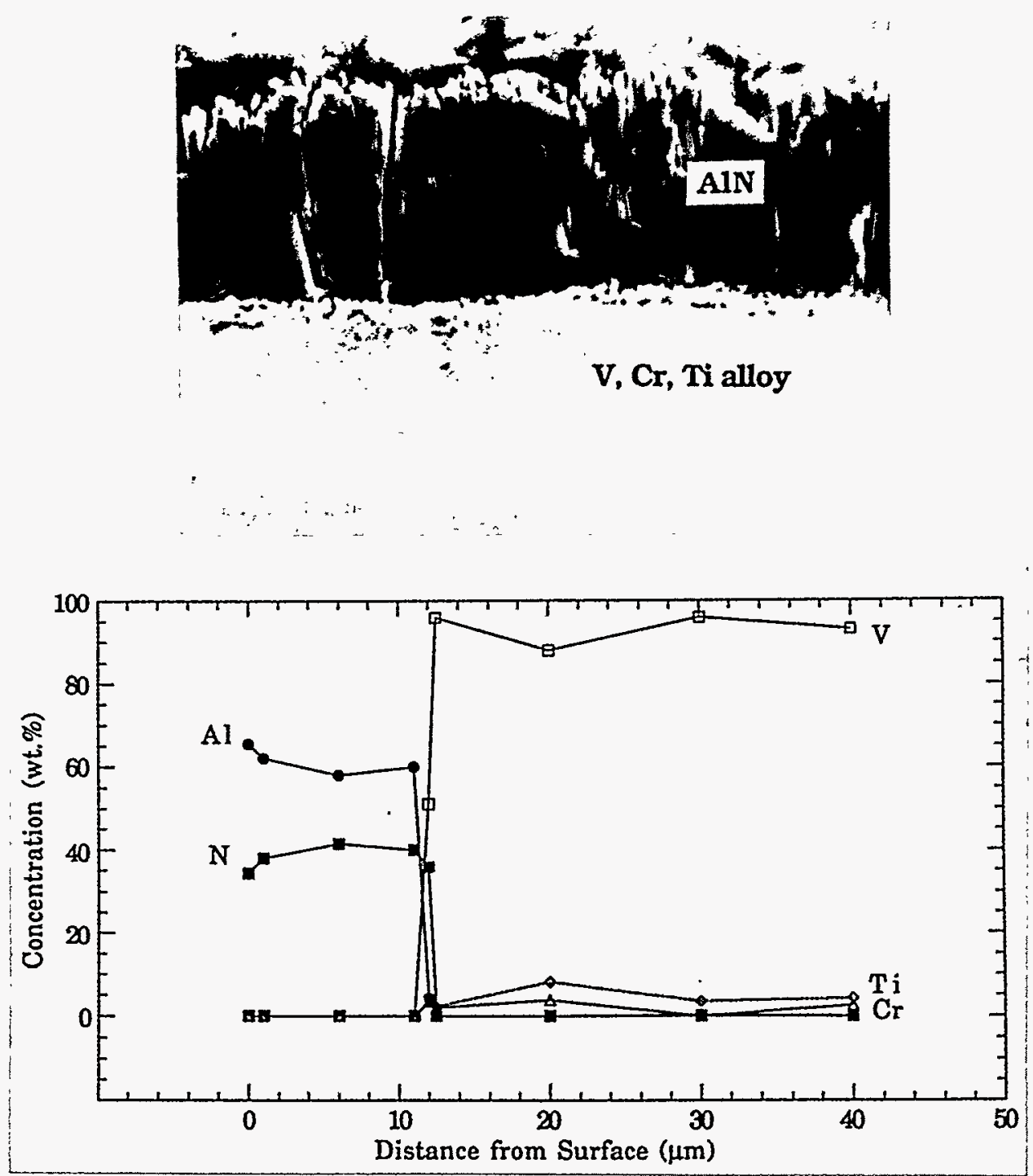

Figure 1. Cross-sectional SEM photomicrograph and EDX depth profiles for $\mathrm{Al}, \mathrm{N}, \mathrm{V}, \mathrm{Cr}$, and Ti for MRT-supplied, AlN-coated V-5Cr-5Ti alloy specimen after $430-\mathrm{h}$ exposure at $300^{\circ} \mathrm{C}$ to $\mathrm{Li}$ environment in which $\mathrm{Ar}-\mathrm{N}_{2}$ gas was bubbled for $24 \mathrm{~h}$ 

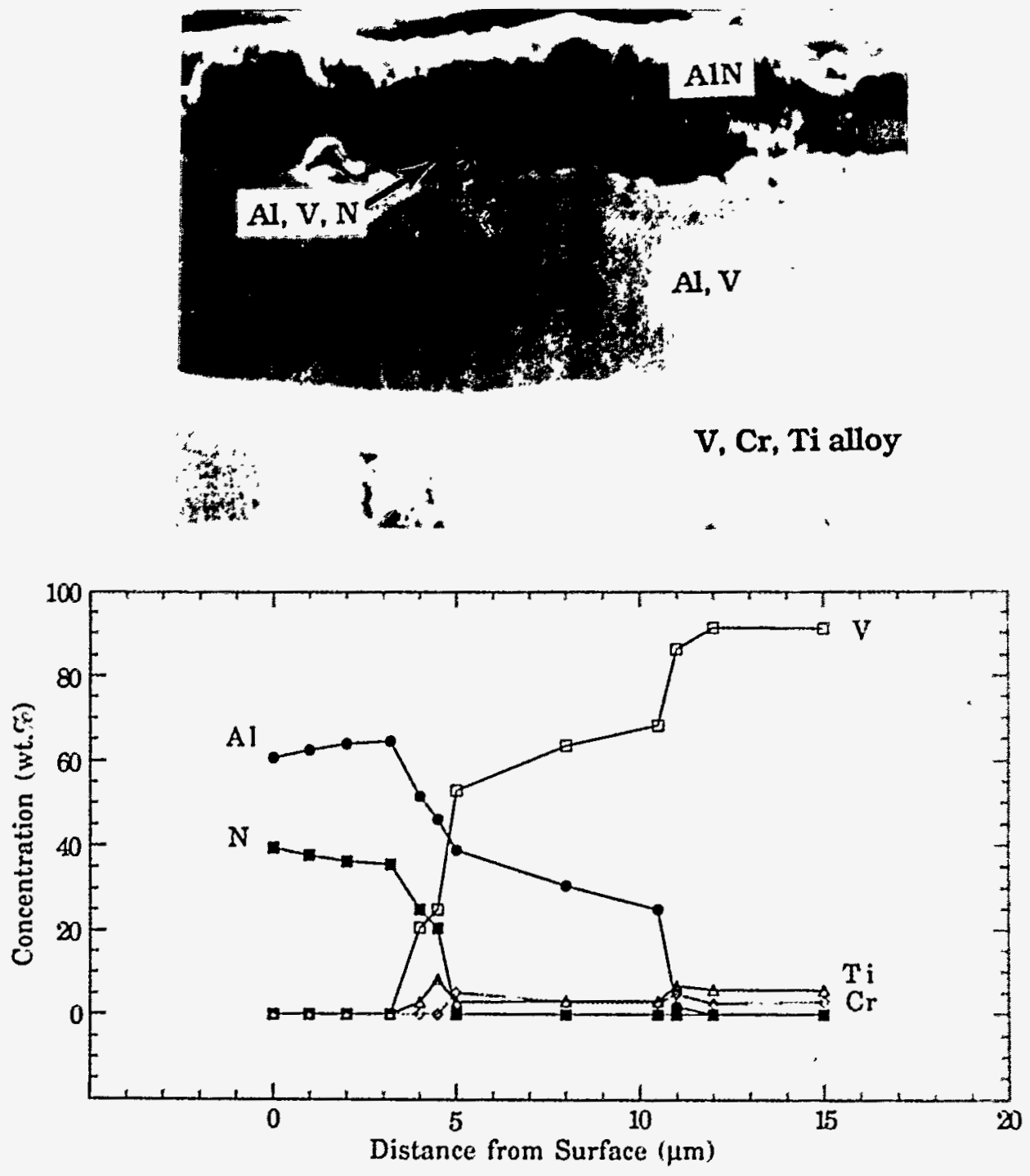

Figure 2. Cross-sectional SEM photomicrograph and EDX depth profiles for $\mathrm{Al}, \mathrm{N}, \mathrm{V}, \mathrm{Cr}$, and Ti for ANL-developed, AlN-coated, prealuminized V-5Cr-5Ti alloy specimen after $430-\mathrm{h}$ exposure at $300^{\circ} \mathrm{C}$ to $\mathrm{Li}$ environment of normal purity 


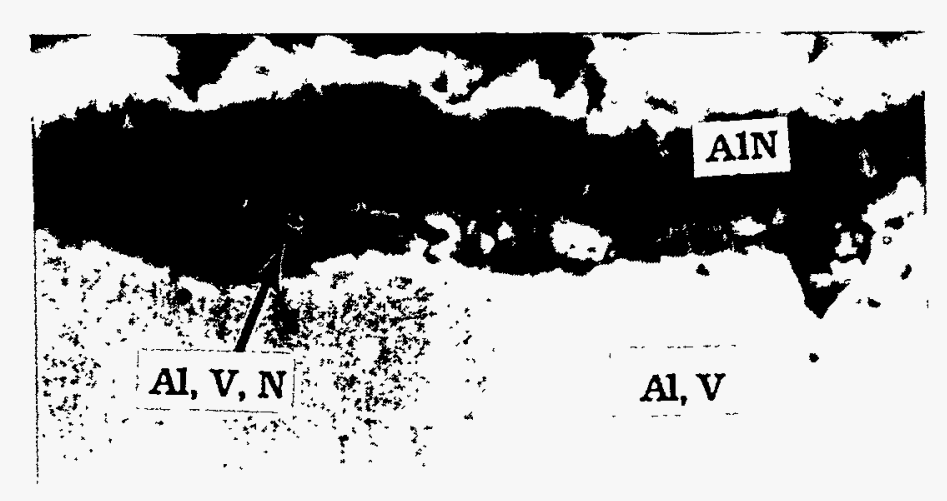

$\mathrm{V}, \mathrm{Cr}, \mathrm{Ti}$ alloy

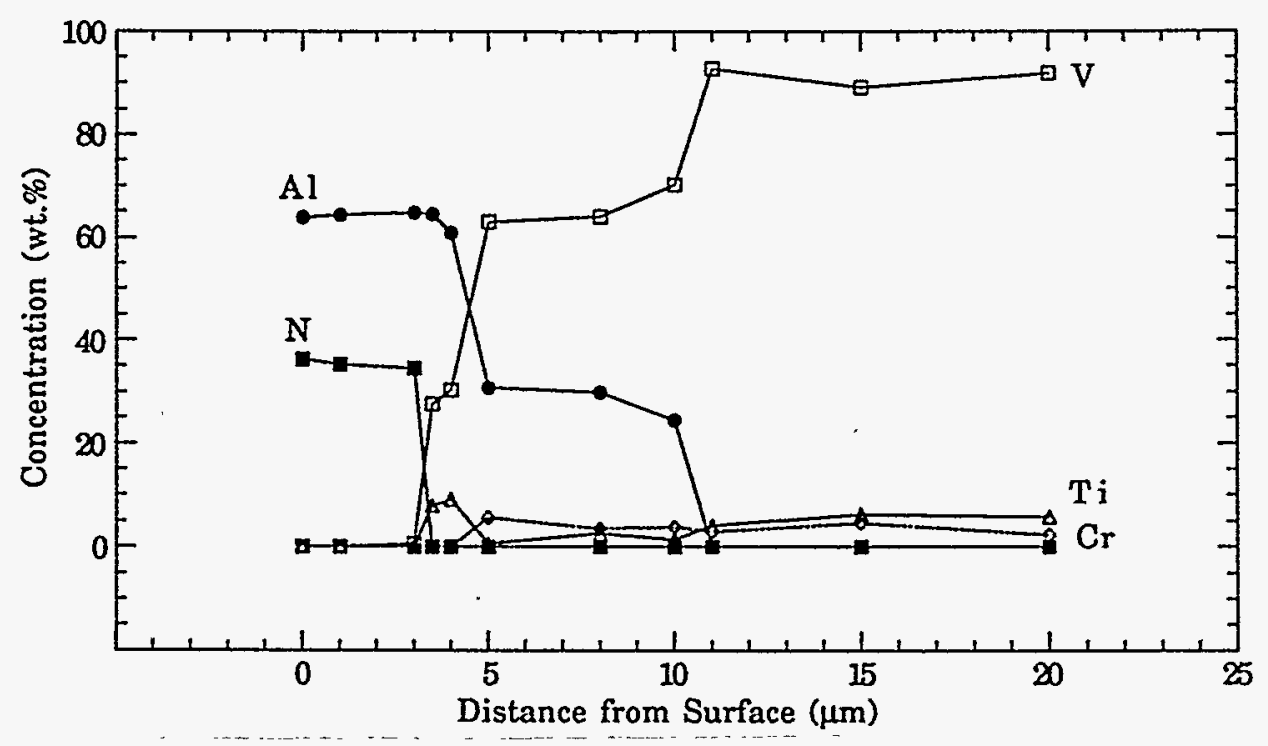

Figure 3. Cross-sectional SEM photomicrograph and EDX depth profiles for $\mathrm{Al}, \mathrm{N}, \mathrm{V}, \mathrm{Cr}$, and Ti for ANL-developed, AlN-coated, prealuminized $\mathrm{V}-5 \mathrm{Cr}-5 \mathrm{Ti}$ alloy specimen after 430 -h exposure at $300^{\circ} \mathrm{C}$ to $\mathrm{Li}$ environment in which $\mathrm{Ar}$ $\mathrm{N}_{2}$ gas was bubbled for $24 \mathrm{~h}$ 


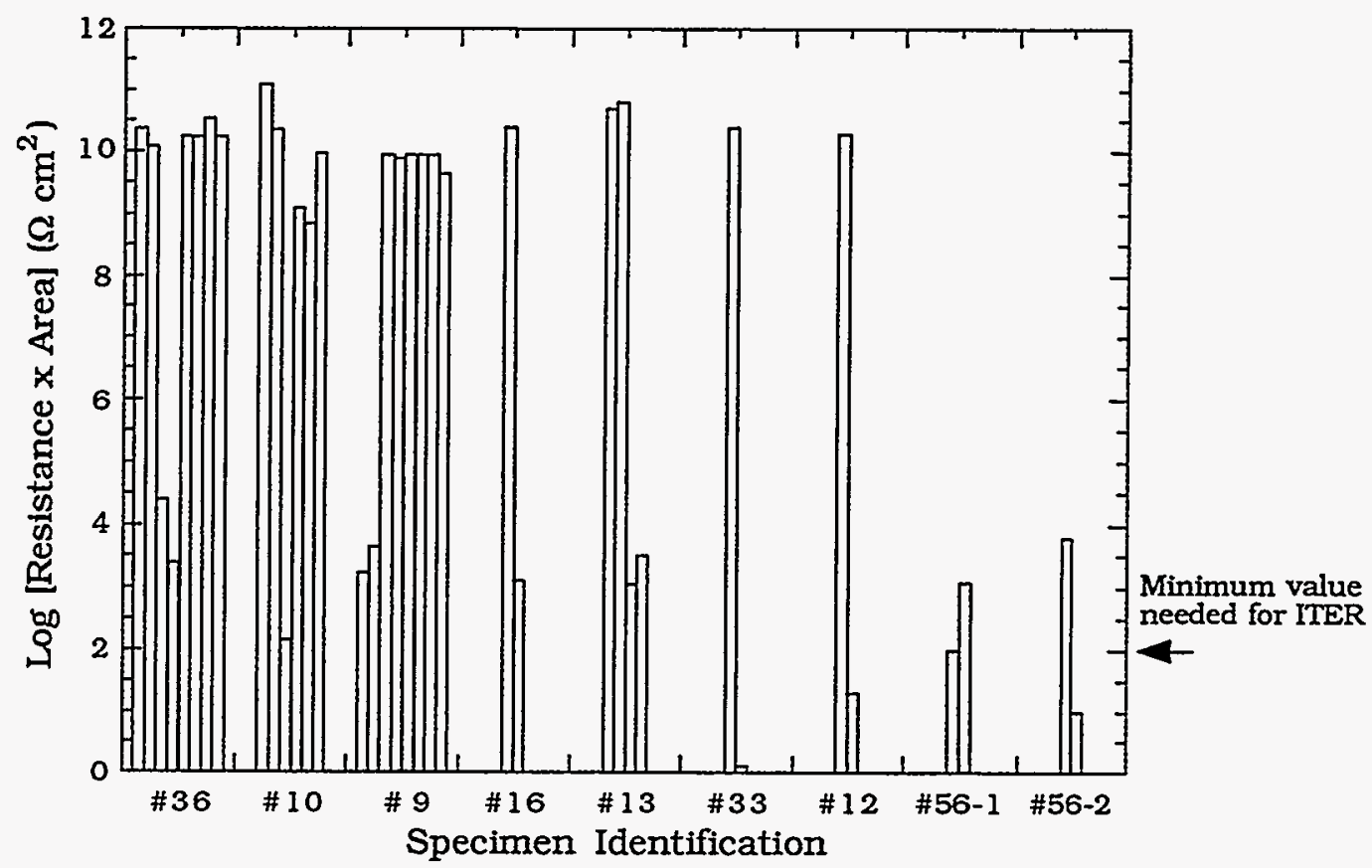

Key to Specimen Treatment

\#36: V-5Cr-5Ti alloy, AlN coated

\#10: Alloy, AlN coated, hardened for $110 \mathrm{~h}$ at $900^{\circ} \mathrm{C}$

\# 9: Alloy, AlN coated, hardened for $110 \mathrm{~h}$ at $900^{\circ} \mathrm{C}$, exposed to $\mathrm{Li}$ for $600 \mathrm{~h}$ at $300^{\circ} \mathrm{C}$

\#16: Alloy, prealuminized, AlN coated, hardened for $110 \mathrm{~h}$ at $900^{\circ} \mathrm{C}$

\#13: Alloy, prealuminized, AlN coated, hardened for $110 \mathrm{~h}$ at $900^{\circ} \mathrm{C}$, exposed to $\mathrm{Li}$ for $600 \mathrm{~h}$ at $300^{\circ} \mathrm{C}$ \#33: Alloy, AlN coated, hardened for $284 \mathrm{~h}$ at $700^{\circ} \mathrm{C}$, exposed to Li for $456 \mathrm{~h}$ at $300^{\circ} \mathrm{C}$

\#12: Alloy, prealuminized, AlN coated, hardened for $284 \mathrm{~h}$ at $700^{\circ} \mathrm{C}$, exposed to Li for $456 \mathrm{~h}$ at $300^{\circ} \mathrm{C}$ \#56-1: Alloy, AlN coated by BIRL, hardened for $110 \mathrm{~h}$ at $900^{\circ} \mathrm{C}$, exposed to Li for $600 \mathrm{~h}$ at $300^{\circ} \mathrm{C}$ \#56-2: Alloy, AlN coated by BIRL, hardened for $284 \mathrm{~h}$ at $700^{\circ} \mathrm{C}$, exposed to Li for $456 \mathrm{~h}$ at $300^{\circ} \mathrm{C}$

Figure 4. Electrical resistance data for several AlN-coated specimens in as-coated and hardened conditions and before and after exposure to $\mathrm{Li}$ 
Even though the corrosion performance of several AlN-coated specimens (especially MRT- and ANLdeveloped coatings) in an Li environment was good, some portions of the coatings seemed to crack and flake after exposure to $\mathrm{Li}$. It was evident that the adhesion of the coatings developed by PVD/reactive sputtering processes is much lower than desired and that some improvement is needed to better bond the coating to the substrate and also to eliminate or minimize the porosity and microdefects in coatings developed by relatively low-temperature PVD processes. As a result, a thermal/chemical hardening treatment was attempted in which AlN-coated specimens were heated to $700-900^{\circ} \mathrm{C}$ in a controlled environment prior to exposure to the $\mathrm{Li}$ environments. Such an approach seemed to harden the coating, as evidenced by substantial improvement in scratch resistance of the coating surface. Several AlN-coated specimens were given a hardening treatment at 900 and $700^{\circ} \mathrm{C}$ and subsequently exposed to $\mathrm{Li}$ at $300^{\circ} \mathrm{C}$. These coatings were also adherent and intact after exposure to $\mathrm{Li}$.

After examination of the coating fabrication methods and the coating integrity in as-coated and hardened conditions and after exposure to Li environments, the next steps were to measure the electrical resistance of these Li-exposed, initially coated specimens and to compare the measured values with the minimum values required for ITER application. For this purpose, several specimens were selected for resistance measurements. Specimens included those that were initially bare and prealuminized condition, covered with coatings form various sources, subjected to various hardening treatments, and exposed to $\mathrm{Li}$ environments for several time periods. The specimens were masked and gold plated (as before) and resistances were measured at room temperature. Figure 4 shows the measured resistance values for several specimens and at different locations within the same specimen. Also shown in the figure is the minimum value for the resistance required for ITER application. The results show that the experimental approaches used in the present program can deliver coatings with adequate electrical resistance for application in $\mathrm{Li}$-cooled fusion reactor blankets. Additional experiments and analysis of the coating procedures and coating/ $\mathrm{L} i$ interactions are in progress to examine the long-term performance of these coatings in flowing Li environments and under irradiation conditions. At present, the coating is being applied by MRT to the internal surface of a 10-12 ft long pipe for proof-of-concept MHD testing to be conducted at ANL.

\section{REFERENCES}

1. K. Natesan and D. L. Rink, "Assessment of Alkali Metal Coolants for the ITER Blanket," Presented at 3rd Intl. Symp. on Fusion Nuclear Technology, Los Angeles, CA, June 27-July 1, 1994, and to be published in symposium proceedings.

2. K. Natesan and D. L. Rink, "Fabrication of Aluminum Nitride and Its Stability in Liquid Alkali Metals," Argonne National Laboratory, Fusion Reactor Materials Semiannual Progress Report for the Period Ending March 31, 1994, Argonne National Laboratory, April 1994.

3. K. Natesan, "Development of Aluminum Nitride Insulator Coatings For Fusion Reactor Applications," Argonne National Laboratory Report, ANL/FPP/TM-278, January 1995. 
ELECTRICAL INSULATOR COATINGS ON V ALLOYS* J.-H. Park, G. Dragel, and W. D. Cho (Argonne National Laboratory)

\section{OBJECTTVE}

Corrosion resistance of structural materials and magnetohydrodynamic (MHD) forces and their influence on thermal hydraulics and corrosion are major concerns in the design of liquid-metal blankets for magnetic fusion reactors. The objective of this study is to develop in situ stable coatings at the liquidmetal/structural-material interface, with emphasis on coatings that can be converted to electrically insulating films to prevent adverse currents that are generated by $\mathrm{MHD}$ forces from passing through structural walls. 1,2

\section{SUMMARY}

Several intermetallic films were applied to $\mathrm{V}$ alloys to provide electrical insulation and corrosion resistance. Grain-growth behavior for the $\mathrm{V}-5 \mathrm{Cr}-5 \mathrm{Ti}$ alloy at $1000^{\circ} \mathrm{C}$ was investigated to determine the stability of the alloy substrate during coating formation by chemical vapor deposition or metallic vapor processes at $800-850^{\circ} \mathrm{C}$. Film layers were examined by optical and scanning electron microscopy and by electronenergy-dispersive and $\mathrm{X}$-ray diffraction analysis; they were also tested for electrical resistivity and corrosion resistance. The results elucidated the nature of the coatings, which provided both electrical insulation and high-temperature corrosion protection.

\section{INTRODUCTION}

Corrosion resistance of structural materials and magnetohydrodynamic (MHD) forces and their influence on thermal hydraulics are major concerns in the design of a liquid-metal cooling system for a firstwall/blanket in a magnetic fusion reactor (MFR). ${ }^{1,2}$ Vanadium and V-base alloys (V-Ti or V-Ti-Cr) are leading candidate materials for structural applications in a fusion reactor. ${ }^{3}$ The objective of this study is to develop stable corrosion-resistant coatings, as well as insulator coatings, at the liquid-metal/structuralmaterial interface. Previous studies focused on in-situ formation of AlN on as-received and prealuminided $\mathrm{V}$ alloys in liquid-Li environments. ${ }^{4,5}$ Subsequent work addressed in-situ formation of $\mathrm{CaO}$ in a liquid- $\mathrm{Li}$ environment because the electrical resistivity of $\mathrm{CaO}$ is 10,000 times greater than that of $\mathrm{AlN}$, and because $\mathrm{CaO}$ has a high thermodynamic stability in liquid $\mathrm{Li}$ among the available insulator candidates (i.e., $\mathrm{CaO}$, $\mathrm{Y}_{2} \mathrm{O}_{3}, \mathrm{BeO}, \mathrm{MgO}, \mathrm{MgAl}_{2} \mathrm{O}_{4}, \mathrm{Y}_{3} \mathrm{Al}_{2} \mathrm{O}_{12}$, etc.). ${ }^{5-7}$ The coatings should be formable on various shapes, such as the inside of tubes or irregular shapes to prevent adverse currents that are generated by MHD forces from passing through the structural walls. The coatings could also improve general corrosion resistance and act as a diffusion barrier for hydrogen isotopes, i.e., deuterium and tritium.

\section{DEVELOPMENT OF INSULATOR COATINGS}

Several experimental steps were employed to develop insulator coatings on V-base alloys, namely, (a) screening of selected electrical insulators in liquid $\mathrm{Li}$ based on thermodynamic stability, electrical resistivity, coefficients of thermal expansion (CTE), and diffusion coefficients of cations and anions within the coating layer; (b) liquid- $\mathrm{Li}$ compatibility tests for candidate electrical insulators; ${ }^{5,6}$ and (c) methods of in-situ fabrication of intermetallic coatings in liquid $\mathrm{Li}$ by conversion of an intermetallic layer to an electrical insulator coating in a controlled environment. Failure (cracking or spallation) and self-healing characteristics of the coating layer are also important in MFR applications.

\footnotetext{
* Work supported by U.S. Department of Energy, Office of Fusion Energy Research, under Contract W-31-109-Eng-38.
} 


\section{Solid-State Interactions: Bonding Of AlN And Metal/Alloy Substrates}

Solid-state interactions between AlN and several metals and alloys (viz., $\mathrm{V}, \mathrm{V}-5 \% \mathrm{Cr}-5 \% \mathrm{Ti}$, $\mathrm{Ti}$, and Type 316 stainless steel) were investigated. Sintered discs of $\mathrm{Y}_{2} \mathrm{O}_{3}$-enriched AIN $(12.7 \times 50 \times 9 \mathrm{~mm})$ were obtained from the Ceramics Section at Argonne National Laboratory. Inductively-coupled-plasma (ICP) spectrochemical analysis of the AlN samples indicated the following composition (in wt.\%); As $<0.05, \mathrm{Ba}$ $=0.005, \mathrm{Be}<0.001, \mathrm{Ca}=0.54, \mathrm{Co}<0.002, \mathrm{Cr}<0.002, \mathrm{Cu}=0.006, \mathrm{Fe}=0.015, \mathrm{Y}=3.77, \mathrm{Y}_{2} \mathrm{O}_{3}=4.79, \mathrm{Mg}$ $=0.004, \mathrm{Mn}<0.001, \mathrm{Ni}=0.002, \mathrm{~Pb}<0.02, \mathrm{Sb}<0.05, \mathrm{Sn}<0.02, \mathrm{Sr}<0.001, \mathrm{Ti}=0.022, \mathrm{~V}<0.002, \mathrm{Zn}$ $<0.002, \mathrm{Zr}<0.002$, and $\mathrm{Te}<0.05$. The discs were cut into pieces measuring $\approx 12.7 \times 12.7 \times 2.7 \mathrm{~mm}$, ground flat on Struers 4000 silicon carbide paper, and then ultrasonically cleaned in isopropyl alcohol. A disc of each metal or alloy was placed between two AlN discs and the entire stack was placed in a furnace. A compressive force was applied to the stack by placing a $120^{\circ}$ three-spring-loaded alumina rod on the top of the stack. A detailed description of the apparatus is provided in Ref. 7. The AlN/alloy stack was annealed in a furnace at $900^{\circ} \mathrm{C}$ for $129 \mathrm{~h}$ in flowing $3 \% \mathrm{H}_{2}-\mathrm{N}_{2}$. After cooling, the specimen stack was examined for indications of strong bonding between AIN and alloy substrates. Interfaces between the alloys and AIN were examined by scanning electron microscopy and energy dispersive spectroscopy to determine diffusion profiles of various elements. Results for the diffusion couples are given below.

V/AIN V diffused into AIN, but a bond was not formed and VN was not detected. The absence of a good bond and no interdiffusion of $\mathrm{N}$ are not conducive to the development of an adherent coating by a hightemperature process. In this case, a low-temperature physical vapor deposition (PVD) technique could be tried, but if the operating temperature increases or the service time is very long, the base metal, V, could be degraded by formation of vacancies at the metal/AIN interface, grain boundaries, and dislocations. Eventually, vacancies could coagulate to form voids within the $\mathrm{V}$ substrate and possibly lead to debonding of the coating.

Ti/AlN Ti did not bond with AlN but a thin layer formed at the Ti/AIN interface. This is indicative of a $\mathrm{Ti}_{\mathrm{X}} \mathrm{N}_{\mathrm{y}}$ phase, and some diffusion of $\mathrm{N}$ into $\mathrm{Ti}$ was evident. Bonding of AlN/Ti $\mathrm{N}_{\mathrm{y}} \mathrm{N}_{\mathrm{y}}$ exhibited sintering-like behavior; however, $\mathrm{Ti}_{\mathrm{X}} \mathrm{N}_{\mathrm{Y}}$ was detached from $\mathrm{Ti}$ in some areas, which indicates outward diffusion of $\mathrm{Ti}$ during the formation of $\mathrm{Ti}_{\mathrm{X}} \mathrm{N}_{\mathrm{y}}$. These processes are shown in Fig. 1.

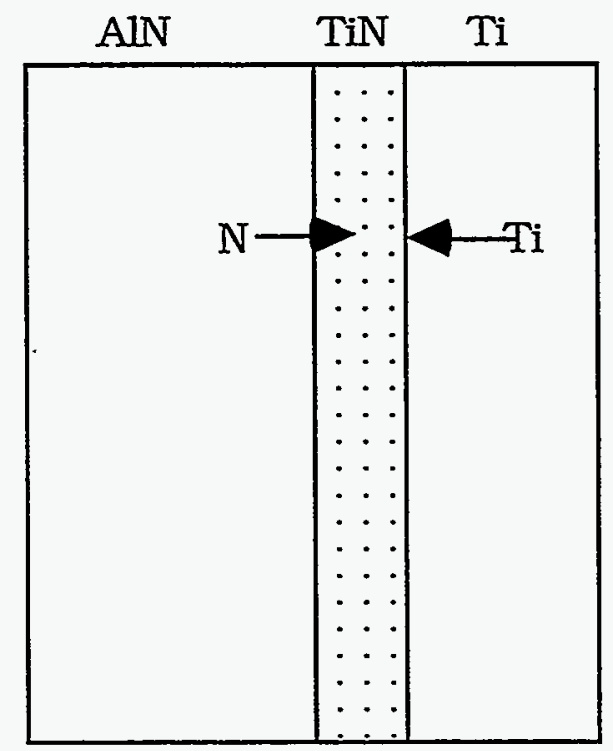

Figure 1 .

Schematic diagram of solid-state reaction steps at Ti/AlN interface:

1) $A l N+T i=T i_{x} N y+A l N_{I-d: \text { initial reaction }}$ ( $x$ and $y \approx I, d<<1$ )

2) AlN/AlN $1-d T i_{x} N_{y} T i \& T_{i} N_{y}$ : layer grows by $N$ diffusion from $A l N$ to $T i$

3) AlN/AlN $1-d / T_{x} N_{y} / T i$ :

$T i$ and $N$ interdiffusion and growth occurs in $T i_{x} N_{y}$ layer; TiN/Ti interface bond weakens due to outward diffusion of $T i$ 
$V-5 C r-5 T i / A l N$ Neither $\mathrm{V}, \mathrm{Ti}$, nor the $\mathrm{V}$ alloy bonded with AlN. Minimal information was obtained because no bonding occurred. Coarsening of grains in $\mathrm{V}-5 \mathrm{Cr}-5 \mathrm{Ti}$ at the alloy/AlN interface was observed, and may have been accelerated by applied pressure.

Type 316 stainless steel/AlN Reaction occurred between a thin oxide scale, $\mathrm{Cr}_{2} \mathrm{O}_{3}$, on Type 316 stainless steel and AlN to form Al-Cr-O. AlN particles were found on the surface of the steel, which suggests that a strong bond could be produced in this couple. Dissolved oxygen in the steel transferred to the surface and reacted with AlN to form Al-O-N at the interface. The predicted products from this diffusion couple are AlN/Al-O-N/Al-Cr-O/SS after long-term exposure. Strong bond formation between the Type 316 stainless steel/AIN interface was observed. This couple is applicable to the development of insulator coatings because the ohmic resistance of $\mathrm{Al}-\mathrm{O}-\mathrm{N}$ phase was higher than expected. In the same vein, we may pursue the interaction of oxygen-charged $\mathrm{V}-5 \mathrm{Cr}-5 \mathrm{Ti}$ alloys with AlN to produce a $\mathrm{V}-5 \mathrm{Cr}-5 \mathrm{Ti}-$ (O)/Al-O-N/AIN couple, which may also reveal enhanced ohmic resistance. Preparation of oxygencharged $\mathrm{V}-5 \mathrm{Cr}-5 \mathrm{Ti}$ was described previously. ${ }^{8}$

\section{Diffusion Approach to In-Situ Formation of Insulator Coatings in Liquid Li}

Ionic diffusion (cation, anion or both) within the coating must be considered during formation of insulator coatings, as should long-term exposure of these coatings in liquid-Li environments.

Outward cation or anion diffusion from alloys or ceramic substrates In this case, a metal ion (cation) or anion leaves the substrate and migrates to the scale/liquid-metal interface, and a vacancy may be produced at a grain boundary, dislocation, or other active defect area within the substrate (Fig. 2). The consequences of predominantly outward-diffusing species at the metal/coating interface are vacancy formation and coalescence (void formation) near the interface, and reduction in the bond strength between coating/substrate. However, if the chemical potential gradient at the coating and substrate is relatively small at elevated temperatures, void formation may not occur. In general, outward cation or anion diffusion from alloys or ceramic substrates should be avoided.

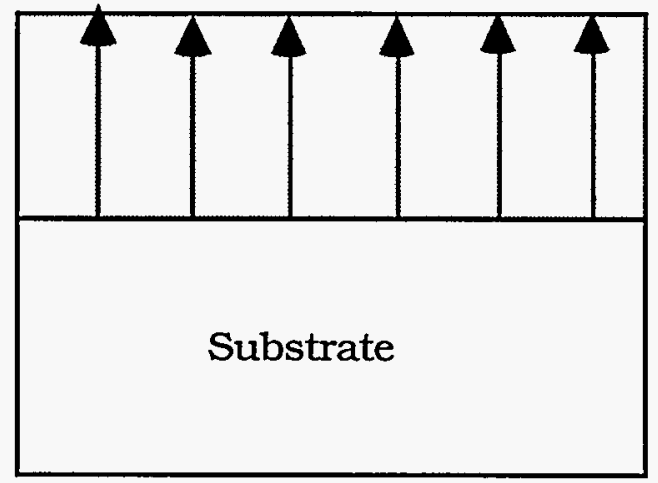

Outward Diffusion

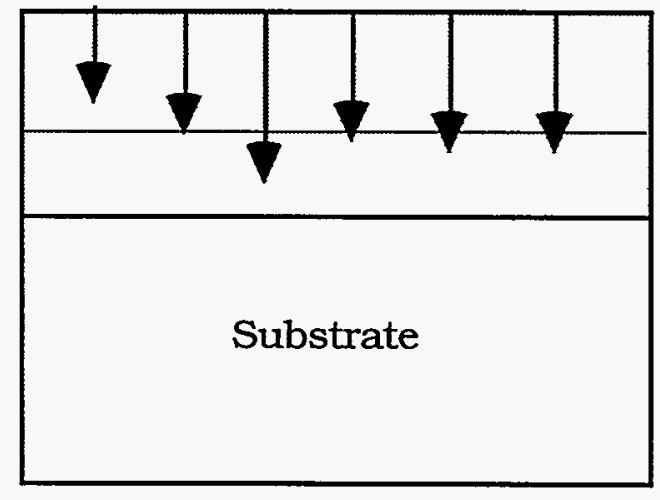

Inward Diffusion

Figure 2. Formation of coating layers by different diffusion profiles

Inward diffusion via insulator layer If anions of $\mathrm{O}, \mathrm{N}$, or $\mathrm{C}$ within the coating layer diffuse inward toward the alloy, insulator-layer growth occurs at the alloy/coating interface. However, diffusion of cations from metal atoms in the liquid environment must also be considered. 


\section{Grain-Growth Behavior of $\mathrm{V}-5 \% \mathrm{Cr}-5 \% \mathrm{Ti}$}

In coatings produced by high-temperature processes, such as chemical vapor deposition (CVD) or thermally grown layers, grain growth and changes in morphology of the alloy influence the coating properties. ${ }^{8}$ Even though the CTE of the substrate and coating layer are similar in magnitude, adherent coatings may not form because of inadequate stabilization of alloy substrate. This is more prevalent in the case of brittle ceramic or intermetallic coatings on metallic substrates because of diffusion-related phenomena in the metal (e.g., grain growth) rather than in the ceramic at high processing temperatures. For high-temperature alloys, viable coatings require alloy stabilization before coating application; ${ }^{9}$ otherwise, the coating layers tend to spall during high-temperature operation because of grain growth or other morphological changes. In the case of Fe-Cr steels, a small amount of $\mathrm{Y}(\approx 0.3 \mathrm{wt} . \%)$ in the alloy inhibits grain growth. 9

The $\mathrm{V}-5 \% \mathrm{Cr}-5 \% \mathrm{Ti}$ specimens were wrapped in Ta foil, sealed in quartz capsules in vacuo to avoid Si or O contamination, and annealed for $0.3-61.3 \mathrm{~h}$ at $1000^{\circ} \mathrm{C}$. Figures 3 and 4 , respectively, show grain morphology and change in grain diameter of $\mathrm{V}-5 \% \mathrm{Cr}-5 \% \mathrm{Ti}$ as a function of time. At $1000^{\circ} \mathrm{C}$, grain growth decreases rapidly after $\approx 2.5 \mathrm{~h}$; the grain size of a specimen annealed for $24 \mathrm{~h}$ is almost the same as the one annealed for $2.5 \mathrm{~h}$. The increase in grain size, $\Delta \mathrm{d}$, was $7 \mu \mathrm{m}$ for an initial average grain size of 7 $\mu \mathrm{m}$. Grain-growth behavior at $1000^{\circ} \mathrm{C}$ in terms of $\log \Delta \mathrm{d}$ versus $\log$ time can be represented by.

$$
\log \Delta d=0.58+\log \mathrm{t}^{0.53}
$$

where the $\approx 0.5$ exponent of time is indicative of a diffusion mechanism. Based on these results, we expect that grain growth will not have a significant effect on high-temperature coatings that are applied by processes such as CVD, pack cementation, or PVD.

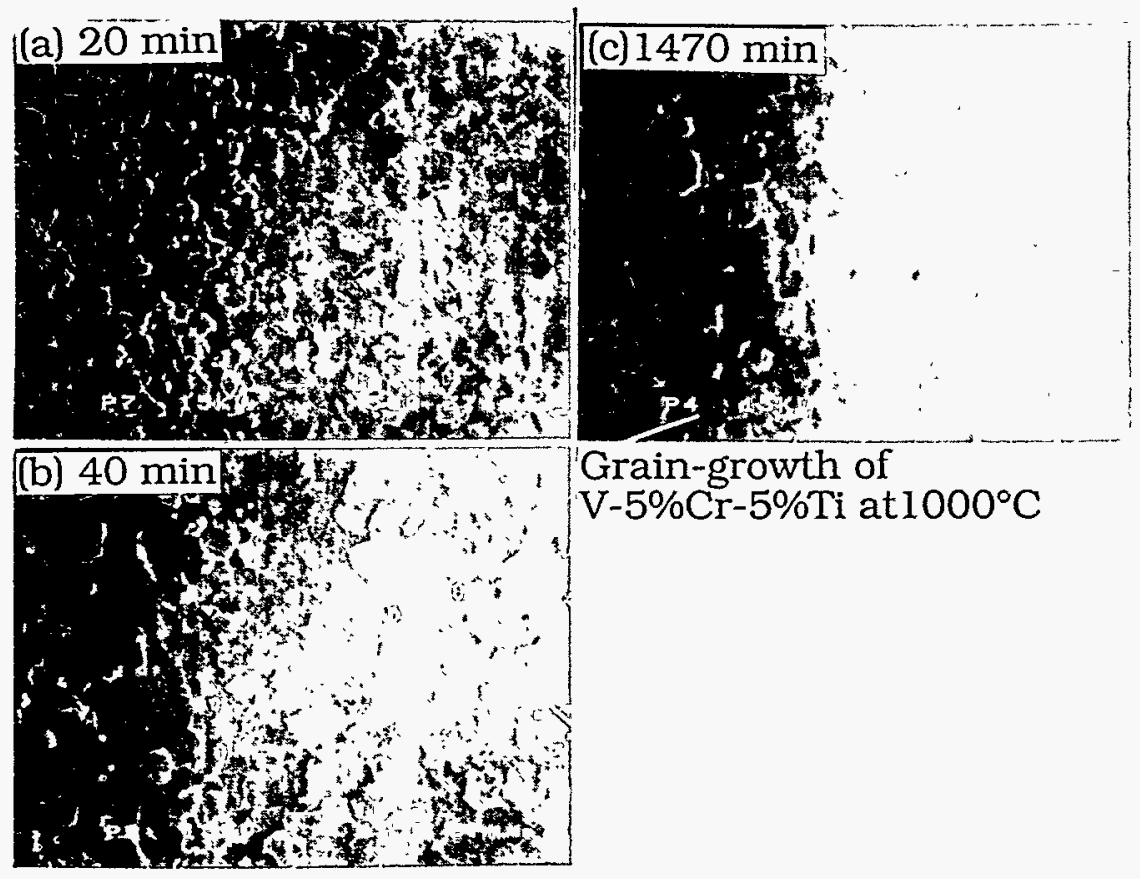

Figure 3. SEM photomicrographs of $\mathrm{V}-5 \% \mathrm{Cr}-5 \% \mathrm{Ti}$ specimens after annealing for 20,40 , and $1470 \mathrm{~min}$. at $1000^{\circ} \mathrm{C}$ in grain-growth experiments 


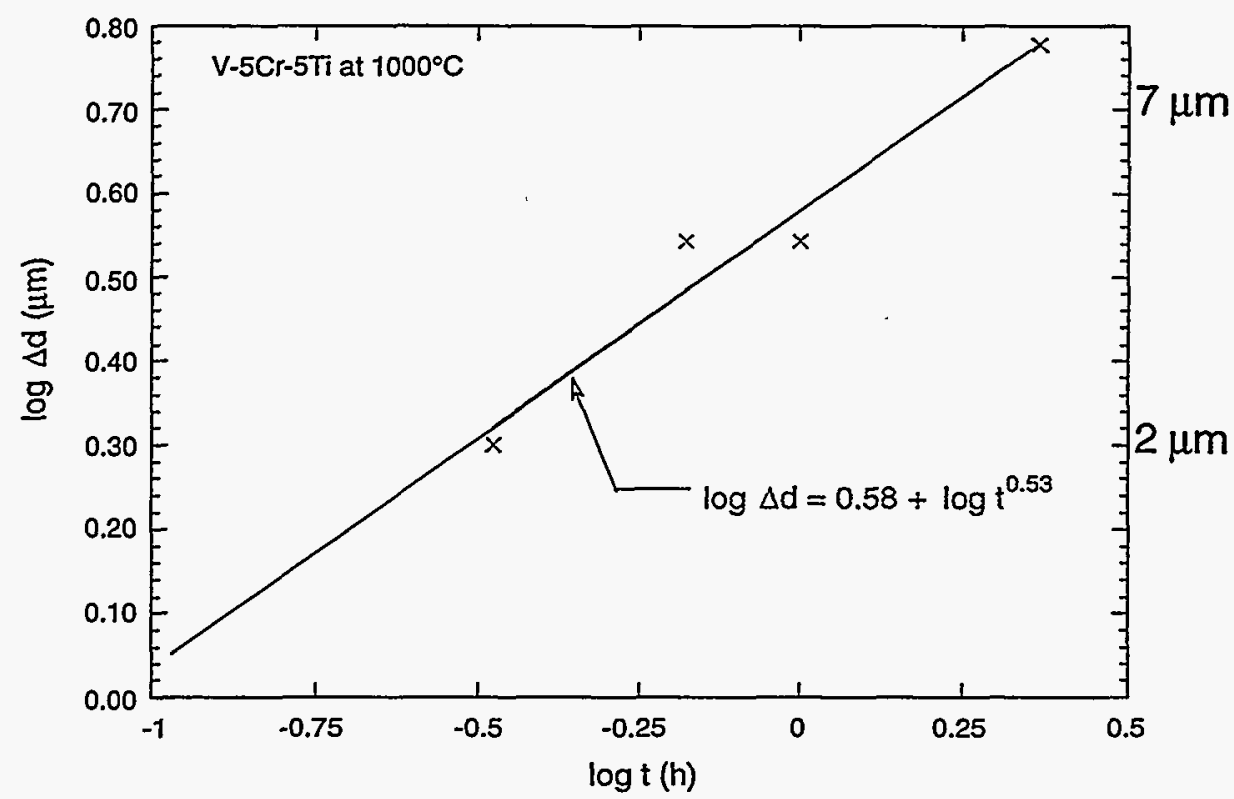

Figure 4. Increase in grain size $(\Delta d, \mu m)$ as a function of time at $1000^{\circ} \mathrm{C}$ for $\mathrm{V}-5 \% \mathrm{Cr}-5 \% \mathrm{Ti}$ specimens from as-received value $7 \mathrm{\mu m}$

\section{Formation of Intermetallic Coatings}

Various intermetallic and insulator layers were developed by different methods, namely, CVD, hightemperature PVD, ion-beam-assisted deposition (IBAD), and exposure of specimens to liquid $\mathrm{Li}$ containing dissolved metallic solutes ( $\mathrm{Al}, \mathrm{Be}, \mathrm{Mg}, \mathrm{Si}, \mathrm{Ca}, \mathrm{Pt}, \mathrm{Y}$, and $\mathrm{Cr}$ ) to form coatings by chemical reaction with constituents in various metals and alloys ( $\mathrm{Ti}, \mathrm{V}-5 \mathrm{Cr}-5 \mathrm{Ti}, \mathrm{V}-\mathrm{Ti}$, Types of 304 and 316 stainless steel, $\mathrm{Fe}-25 \mathrm{Cr}$ with $0.3 \mathrm{Y}$ or $6 \mathrm{Al}$ ). Most of the solutes in $\mathrm{Li}$ were chosen on the basis of thermodynamic stability of their metal oxides or nitrides in $\mathrm{Li}$, as well as on results of compatibility screening tests for ceramic materials in $\mathrm{Li}$.

\section{Chemical Vapor Deposition}

Aluminide and AlN coatings Aluminide coatings that form on structural alloys during exposure to liquid $\mathrm{Li}$ that contained dissolved Al suggest a means for producing stable electrical insulator layers, such as AlN, by subsequent nitration of the intermetallic layer in the liquid-metal environment. ${ }^{7}$ The formation of several aluminides $\left(\mathrm{V}_{\mathrm{X}} \mathrm{Al} \mathrm{y}_{\mathrm{y}}\right)$ that contain $>40-50$ at.\% $\mathrm{Al}$ on $\mathrm{V}$-base alloys can be predicted from the $\mathrm{V}-\mathrm{Al}$ phase diagram. ${ }^{10,11}$ These phase relationships are the basis for the formation of aluminide coatings on $\mathrm{V}$ and its alloys. Aluminide coatings were produced on the alloys by CVD at $800-850^{\circ} \mathrm{C}$ with trimethyl aluminum $\left(\mathrm{CH}_{3}\right)_{3} \mathrm{Al}$ as the source of $\mathrm{Al}$ to be diffused/reacted on the sample surfaces. In this study, atmosphericpressure CVD was used because of its utility for engineering applications. Figure 5 is a schematic diagram of the CVD apparatus. The $\left(\mathrm{CH}_{3}\right)_{3} \mathrm{Al}$ vapor was aspirated by a $3 \% \mathrm{H}_{2}-\mathrm{Ar}$ carrier gas with impurity oxygen and carried to the high-temperature zone via a Ta tube, where the vapor decomposed and reacted with the specimens. The reaction for the formation of aluminides is

$$
\mathrm{V}+3 \mathrm{Al}=\mathrm{Al}_{3} \mathrm{~V}
$$

and the $\Delta G^{\circ}$ range for the reaction is -4 to $-5 \mathrm{kcal} / \mathrm{mole}$ (Fig. 6). This process was followed by mixing $\mathrm{NH}_{3}$ into the gas stream to convert the aluminide to an AlN coating according to the reaction 


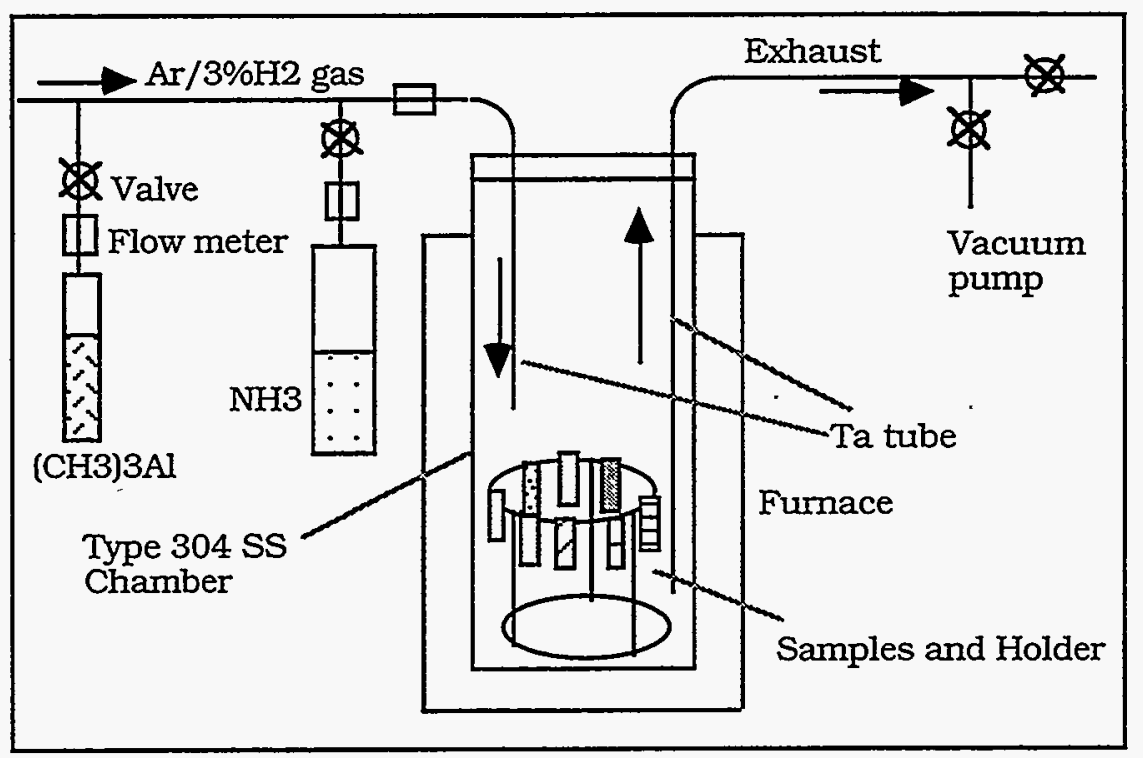

Figure 5. Schematic diagram of CVD apparatus

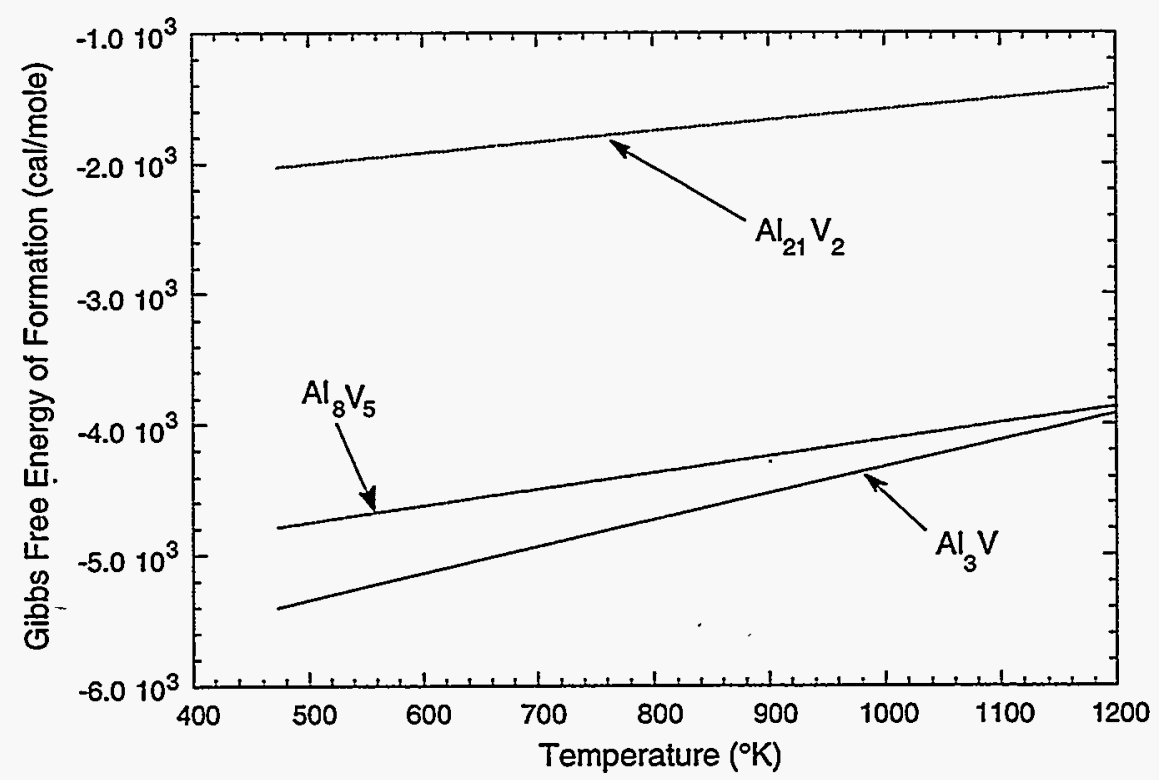

Figure 6. Gibbs free energy of formation for various intermetallic compounds in $A l-V$ system as a function of temperature

$$
\mathrm{Al}_{3} \mathrm{~V}+\underline{\mathrm{N}}=3 \mathrm{AlN}+\mathrm{V}
$$

where $\underline{\mathrm{N}}$ represents nitrogen activity in the gas phase or dissolved in liquid $\mathrm{Li}$. The free energy of formation of AlN is $-45.94 \mathrm{kcal} / \mathrm{mole}$; therefore, the $\Delta \mathrm{G}^{\circ}$ for the reaction in Eq. (3) is $-40.94 \mathrm{kcal} / \mathrm{mole}$ at $700 \mathrm{~K}$. This reaction will occur spontaneously, and the rate-determining step will be ionic diffusion through the nitride layer. Residual $\mathrm{V}$ formed during the reaction will either redistribute within $\mathrm{Al}_{3} \mathrm{~V}$, or AlN will become enriched in $\mathrm{V}$, depending on the direction of $\mathrm{V}$ diffusion and the thermodynamic stability 
of $\mathrm{V}_{2} \mathrm{~N}$ near the $\mathrm{Al}_{3} \mathrm{~V} / \mathrm{AlN}$ interface. Because of the high thermodynamic stability of TiN, formation of this phase on aluminided $\mathrm{V}-5 \% \mathrm{Cr}-5 \% \mathrm{Ti}$ is also a possibility. ${ }^{*}$

Figure 7 (a) is an SEM photomicrograph of an intermetallic V aluminide coating on a V-5Cr-5Ti substrate. The chemical composition of the coating surface, by EDS is as follows:

$\begin{array}{lrr}\text { Al } & \text { 61.34 at.\% } & \text { (45.72 wt.\%) } \\ \text { V } & 33.57 \text { at.\% } & (47.23 \text { wt.\%) } \\ \text { Cr } & 2.72 \text { at.\% } & (3.91 \text { wt.\%) } \\ \text { Ti } & 2.37 \text { at.\% } & (3.13 \text { wt.\%). }\end{array}$

Based on these compositions and the on V-Al binary phase diagram, the composition of the intermetallic phase at the surface lies between $\mathrm{Al}_{3} \mathrm{~V}$ and $\mathrm{Al}_{8} \mathrm{~V}_{5}$. When we consider the free energy of formation of Al-V intermetallic phases (Fig. 6), the $\mathrm{Al}_{3} \mathrm{~V}$ phase should form because of its greater stability, but at high temperatures $\left(850^{\circ} \mathrm{C}, 1123 \mathrm{~K}\right)$ a mixture of $\mathrm{Al}_{3} \mathrm{~V}$ and $\mathrm{Al}_{8} \mathrm{~V}_{5}$ could arise because of the similar magnitudes of the free energies of formation. However, if $\mathrm{Al}$ concentration is too low (e.g., $<40$ at.\%), $\mathrm{V}-\mathrm{Al}$ intermetallic phases will not form at the surface and $\mathrm{Al}$ will only diffuse into the bcc sublattice of $\mathrm{V}$ according to the phase diagram. Based on our previous work, ${ }^{12} \mathrm{Al}_{3} \mathrm{~V}$ was prevalent on various $\mathrm{V}-\mathrm{Cr}-\mathrm{Ti}$ alloys.

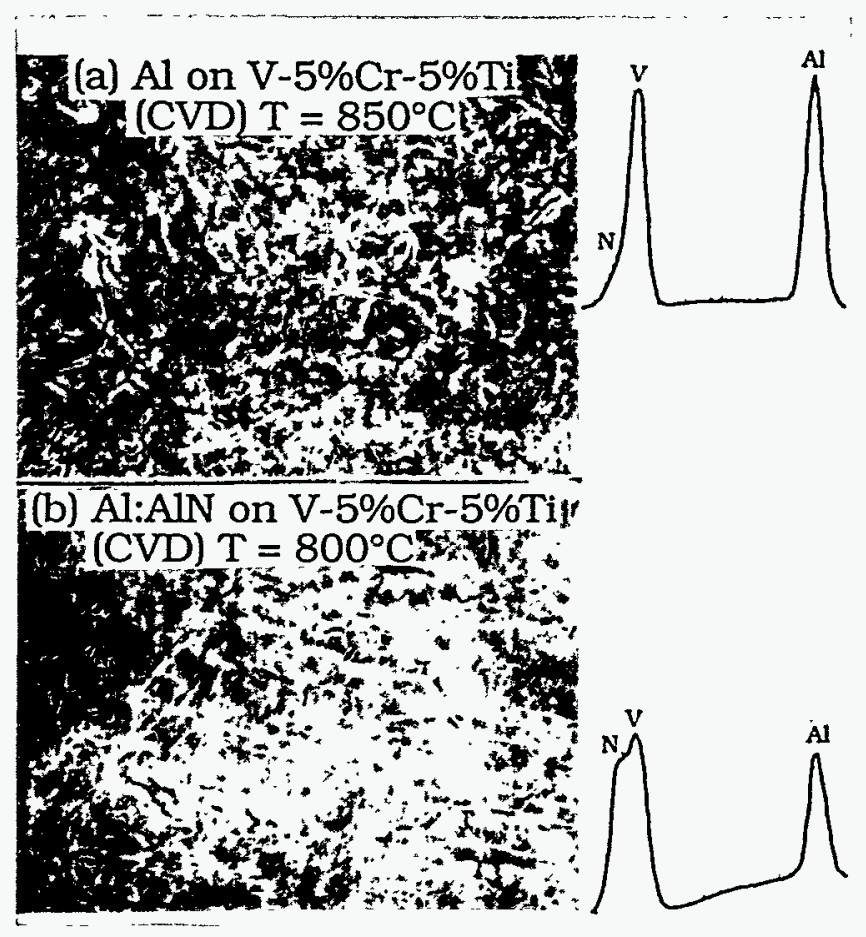

Figure 7. SEM photomicrographs and EDS spectra of (a) aluminide and (b) AVAlN coating deposited by CVD on $\mathrm{V}-5 \mathrm{Cr}-5 \mathrm{Ti}$ specimens at two temperatures

\footnotetext{
* When we exposed prealuminide V-5Cr-5Ti to liquid Li containing 100-200 ppm N, TiN grew outward between the aluminide grains.
} 
Figure 7 (a) also shows the EDS spectra of an aluminide surface on $\mathrm{V}-5 \% \mathrm{Cr}-5 \% \mathrm{Ti}$ at $850^{\circ} \mathrm{C}$, and Fig. 7 (b) shows similar information for an AIN surface formed at $800^{\circ} \mathrm{C}$. The Ta tube that carried the gas into the high-temperature zone was also analyzed. Figure 8 shows the Ta-Al intermetallic and AIN coatings on the inner surface of the tube. CVD, in which $\mathrm{AlCl}_{3} / \mathrm{NH}_{3}$ is the source of $\mathrm{Al}$, may not be applicable to many materials because of $\mathrm{Cl}$-induced corrosion. An SEM photomicrograph of a CVD coating on $\mathrm{V}-5 \% \mathrm{Cr}-$ $5 \% \mathrm{Ti}$ at $850^{\circ} \mathrm{C}$ showed total spallation of deposited $\mathrm{AlN}$ when $\mathrm{AlCl}_{3}$ was used. When $\mathrm{V}$ chloride compounds form during the coating process, they tend to spall and prevent the formation of an adherent AlN layer at the surface.

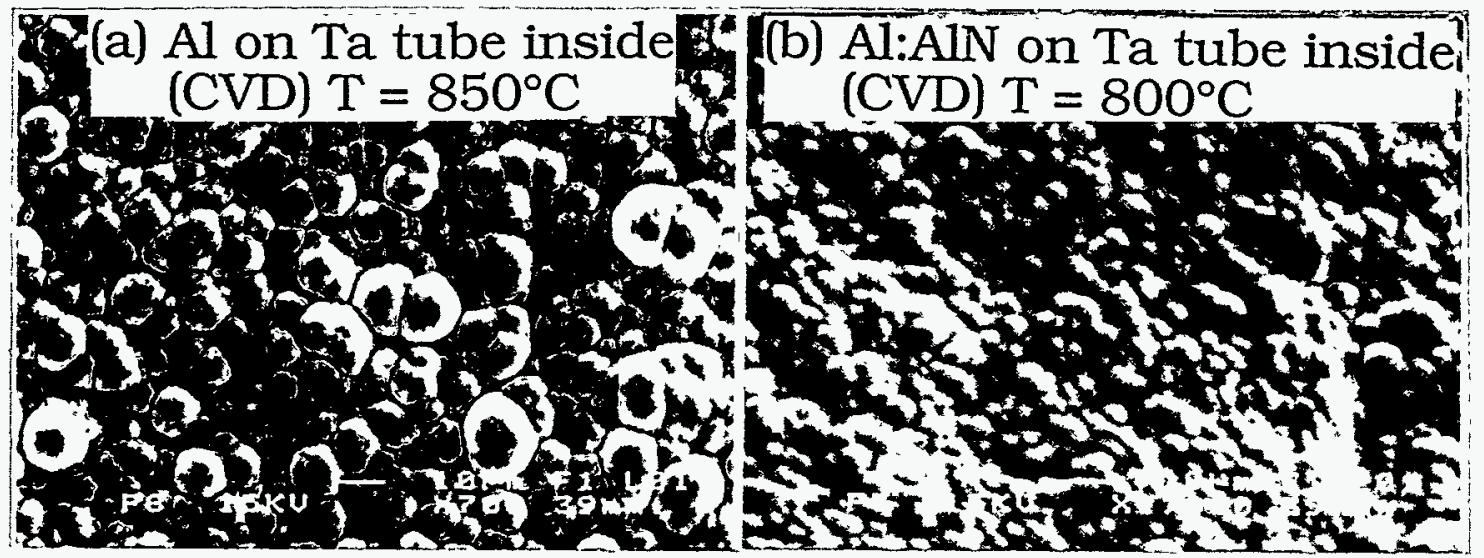

Figure 8. SEM photomicrograph of (a) aluminide, and (b) AUAlN coating on inside surface of Ta tubes

\section{$\mathrm{Al}_{2} \mathrm{O}_{3}$ Coatings on Stainless Steels in Air}

Low rates of elemental diffusion and electron transport in $\mathrm{Al}_{2} \mathrm{O}_{3}$ are desirable properties for hightemperature corrosion-resistant coatings. However, benefits from these properties for high-temperature coating applications are rather limited because crack-free $\mathrm{Al}_{2} \mathrm{O}_{3}$ coatings are extremely difficult to fabricate. In this study, we have had some success in forming $\mathrm{Al}_{2} \mathrm{O}_{3}$ coatings on Types 304 and 316 stainless steel. Coatings were produced by growing an intermetallic aluminide layer ( $\mathrm{FeAl}$ ) on the steels in liquid $\mathrm{Li}$ containing $4-5 \mathrm{wt} . \%$ dissolved $\mathrm{Al}$, followed by oxidation of the aluminide layer in air at $1000^{\circ} \mathrm{C}$. To determine the minimum required $\mathrm{Al}$ content of the steel to form an $\mathrm{Al}_{2} \mathrm{O}_{3}$ coating layer, samples of an aluminided steel tube were sectioned and polished and an Al depth profile was measured by EDS (detection limit of $\approx 1$ at.\%). After oxidation, an $\mathrm{Al}$ spectrum from EDS indicated a continuous $\mathrm{Al}_{2} \mathrm{O}_{3}$ coating layer had formed.

Based on our previous experience, most $\mathrm{Al}_{2} \mathrm{O}_{3}$ coating layers formed on $\mathrm{Fe}-\mathrm{Cr}-\mathrm{Al}$ alloys contained numerous cracks, mainly due to mismatch of the CTEs $\left(\approx 8 \times 10^{-6} / \mathrm{K}\right.$ for $\mathrm{Al}_{2} \mathrm{O}_{3}$ and $\approx 17 \times 10^{-6} / \mathrm{K}$ for stainless steel). We believe that $\mathrm{Li}(130 \mathrm{ppm})$ in the aluminide layer that formed in liquid-Li containing $\mathrm{Al}$ plays a role in accommodating thermal stresses during $\mathrm{Al}_{2} \mathrm{O}_{3}$ growth and cooling because of fast diffusion of $\mathrm{Li}^{+}$ions due to their small size.

\section{High-Temperature Metallic Vapor Deposition of MgO Coating}

$\mathrm{MgO}$ and $\mathrm{CaO} \mathrm{MgO}$ is another potential candidate for an insulator coating in a liquid- $\mathrm{Li}$ blanket of an MFR. An MgO coating could be applied to various components by vapor deposition because metallic $\mathrm{Mg}$ has a high vapor pressure at elevated temperatures. This coating method was investigated with an apparatus similar to that shown in Fig. 5. Mg vapor was generated in a high-temperature Knudsen cell 
located at the bottom of the stainless steel chamber, which provided a homogeneous source of $\mathrm{Mg}$ vapor. $\mathrm{Mg}$ was contained in a tungsten or Type 304 stainless steel boat and covered with a plate that contained an $\approx 1.5-\mathrm{mm}$-diameter pin hole. Sublimation of $\mathrm{Mg}$ in a relatively low vacuum of $10^{-3}-10^{-4}$ torr, in which $\mathrm{O}_{2}$ was present as an impurity, enabled the formation of $\mathrm{MgO}$ clusters by oxidation of $\mathrm{Mg}$ vapor inside the chamber. After coating the $\mathrm{V}-5 \mathrm{Cr}-5 \mathrm{Ti}$ specimens at $800^{\circ} \mathrm{C}$, the system was cooled to room temperature by purging with $\operatorname{Ar}$ (99.999\%). The ohmic resistance of the coatings was measured at room temperature and the coatings were evaluated by SEM/EDS. Figure 9 a shows a typical $\mathrm{MgO}$ coating on $\mathrm{V}-5 \mathrm{Cr}-5 \mathrm{Ti}$; its EDS spectrum is shown in Fig. $9 \mathrm{~b}$. The measured two-point contact resistance at room temperature is $>10^{12} \Omega$. This technique was also applied to the $\mathrm{CaO}$ coating, which showed a trend similar to that observed with $\mathrm{MgO}$. We found that this technique could be extended to other oxides, e.g., $\mathrm{BeO}, \mathrm{MgAl}_{2} \mathrm{O}_{4}$, $\mathrm{Y}_{3} \mathrm{Al}_{2} \mathrm{O}_{12}$, etc.
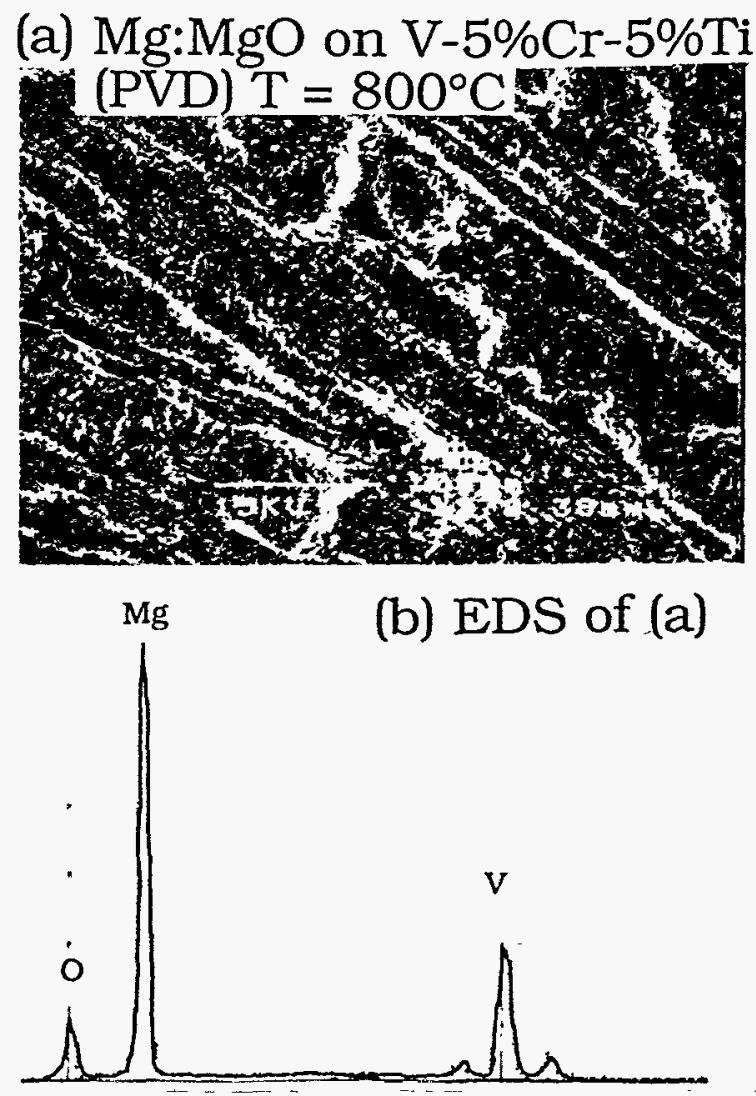

Figure 9. (a) Photomicrograph of $\mathrm{MgO}$ coating on

$V-5 C r-5 T i$; (b) EDS of coating shown in (a)

\section{CONCLUSIONS}

High-temperature couples between AIN and V alloys, Ti, and Types 304 and 316 stainless steel showed different interface bonding behavior. Basically, $\mathrm{V}$ alloy/AlN couples did not bond. In the case of Ti/AlN, TiN formed at the interface, but the bonding strength was too low and separation occurred at the Ti/TiN interface. Strong bonds were obtained between AlN and the stainless steels, but mismatch in the thermal expansion coefficients caused fracture in the relatively thick AlN layer above the alloy/AlN interface. 
Intermetallic films were prepared on V alloys and Types 304 and 316 stainless steel by chemical vapor deposition, high-temperature metallic vapor deposition, and liquid-metal processing in the temperature range of $800-850^{\circ} \mathrm{C}$. The films were examined by optical and scanning electron microscopy and by electron-energy-dispersive and X-ray diffraction analysis. Aluminide films containing $>45 \mathrm{wt} . \% \mathrm{Al}$ and AlN were produced on $V$ alloys by CVD. The aluminide films on Types 304 and 316 stainless steel were converted to $\mathrm{Al}_{2} \mathrm{O}_{3}$ by oxidation in air at high temperature. The results elucidated the nature of the coatings, which provided both electrical insulation and high-temperature corrosion protection.

\section{FUTURE WORK}

Several other ternary oxides systems (e.g., spinel; $\mathrm{MgAl}_{2} \mathrm{O}_{4}$, and/or garnet; $\mathrm{Y}_{3} \mathrm{Al}_{2} \mathrm{O}_{12}$ ) will be fabricated by either a CVD or an in-situ liquid-Li process, and the films will be tested for the liquid-Li compatibility and in-situ electrical resistivity.

\section{REFERENCES}

1. C. C. Baker et al., Tokamak Power System Studies FY 1985, Argonne National Laboratory Report ANL/FPP-85-2 (1985).

2. T. Kammash, Fusion Reactor Physics, Chapter 15, Ann Arbor Science Pub. Inc., Ann Arbor, MI (1975), pp. 405-439.

3. R. F. Mattas, B. A. Loomis, and D. L. Smith, Vanadium Alloys for Fusion Reactor Applications, JOM, 44(8), 26 (1992).

4. J.-H. Park, T. Domenico, G. Dragel, and R. W. Clark, Development of Electrical Insulator Coatings for Fusion Power Applications, Proc. 3rd Intl. Symp. on Fusion Nuclear Technology (ISFNT), June 27-July 1, 1994, Los Angeles, CA.

5. J.-H. Park and G. Dragel, Development of Aluminide Coatings on Vanadium-Base Alloys in Liquid Lithium, Fusion Reactor Materials Semiannual Progress Report for the Period Ending March 31, 1993, DOE/ER-0313/14, pp. 405-410 (1993).

6. R. J. Lauf and J. H. DeVan, Evaluation of Ceramic Insulator for Lithium Electrochemical Reduction Cells, J. Electrochem. Soc., 139, 2087-2091 (1992).

7. J.-H. Park and G. Dragel, Development of Electrical-Insulator Coatings: In-situ Electrical Resistance Measurements on $\mathrm{V}-5 \% \mathrm{Cr}-5 \% \mathrm{Ti}$ in Liquid Lithium, Fusion Reactor Materials Semiannual Progress Report for the Period Ending September 30, 1993, DOE/ER-0313/15 (1993).

8. J.-H. Park, Surface Modification of High-Temperature Alloys, Mater. Technol., 9, 9/10 (1994).

9. J.-H. Park, Surface Modification of High-Temperature Alloys, The Electrochem. Soc. 186th Meeting, The D. Douglass Symp. on High-Temperature Corrosion, Óct. 9-14, 1994, Miami, FL.

10. M. Hansen, Constitution of Binary Alloys, McGraw-Hill, New York (1958).

11. F. A. Shunk, Constitution of Binary Alloys, Second Supplement, McGraw-Hill, New York (1969).

12. J.-H. Park, Intermetallic and Electrical Insulator Coatings on High-Temperature Alloys in Liquid Lithium Environments, Proc. Symp. on High-Temperature Coatings-I, TMS Fall Meeting, Oct. 2-6, 1994, Rosemont, IL. 
FORMATION AND SELF-HEALING BEHAVIOR OF CaO INSULATOR COATINGS ON A VANADIUM-BASE ALLOY IN LIQUID LITHIUM*

J.-H. Park and T. F. Kassner (Argonne National Laboratory)

\section{OBJECTTVE}

Corrosion resistance of structural materials and magnetohydrodynamic (MHD) forces and their influence on thermal hydraulics and corrosion are major concerns in the design of liquid-metal blankets for magnetic fusion reactors. The objective of this study is to develop in situ stable coatings at the liquidmetal/structural-material interface, with emphasis on coatings that can be converted to an electrically insulating film to prevent adverse currents that are generated by MHD forces from passing through the structural walls. ${ }^{1,2}$

\section{SUMMARY}

The electrical resistance of $\mathrm{CaO}$ coatings produced on $\mathrm{V}-5 \% \mathrm{Cr}-5 \% \mathrm{Ti}$ by exposure of the alloy to liquid $\mathrm{Li}$ that contained $0.5-85 \mathrm{wt} . \%$ dissolved $\mathrm{Ca}$ was measured as a function of time at temperatures between 250 and $600^{\circ} \mathrm{C}$. The solute element, $\mathrm{Ca}$ in liquid $\mathrm{Li}$, reacted with the alloy substrate at $400-420^{\circ} \mathrm{C}$ to produce a $\mathrm{CaO}$ coating. Resistance of the coating layer measured in situ in liquid $\mathrm{Li}$ was $\approx 10^{6} \Omega$ at $400^{\circ} \mathrm{C}$. Thermal cycling between 300 and $700^{\circ} \mathrm{C}$ changed the resistance of the coating layer, which followed insulator behavior. Examination of the specimens after cooling to room temperature revealed no spallation, but homogeneous crazing cracks were present in the $\mathrm{CaO}$ coating. In-situ self-healing of the cracks occurred at temperatures $\geq 360^{\circ} \mathrm{C}$. These results suggest that thin coatings can be produced on variously shaped surfaces by controlling the exposure time, temperature, and composition of the liquid metal.

\section{INTRODUCTION}

Electrically insulating and corrosion-resistant coatings are required at the liquid-metal/structural interface in a fusion reactor to minimize magnetohydrodynamic forces and their influence on the thermal hydraulics of liquid-metal cooling systems. ${ }^{1}$ Vanadium and V-base alloys (V-Ti or V-Ti-Cr) are leading candidate materials for structural applications in fusion reactors. ${ }^{2}$ In-situ formation of $\mathrm{CaO}$ on $\mathrm{V}-5 \mathrm{Cr}-5 \mathrm{Ti}$ in liquid $\mathrm{Li}$ was investigated because the electrical resistivity of $\mathrm{CaO}$ is very high and also because $\mathrm{CaO}$ exhibits a higher thermodynamic stability in liquid $\mathrm{Li}$ than do other potential insulator candidates $\mathrm{C}_{2} \mathrm{O}_{3}, \mathrm{BeO}, \mathrm{MgO}$, $\mathrm{MgAl}_{2} \mathrm{O}_{4}, \mathrm{Y}_{3} \mathrm{Al}_{2} \mathrm{O}_{12}$, etc.). ${ }^{3}$ In-situ self-healing behavior of defects (such as cracks in the coating) in liquid-Li environments is also an important consideration. These coatings should be formable on various shapes such as the inside of tubes or irregular configurations. The coatings could also improve general corrosion resistance and act as a diffusion barrier for hydrogen isotopes, i.e., deuterium and tritium.

\section{EXPERIMENTAL PROCEDURE}

Various experimental methods have been explored to fabricate and characterize insulator coatings for use in liquid-Li environments: $\mathrm{O}$ charging of the near-surface region of $\mathrm{V}$-base alloys in $\mathrm{Ar}$ gas and in air, evaluation of liquid-Li compatibility of the $\mathrm{O}$-charged specimens, reaction of the O-enriched V-base alloy with dissolved $\mathrm{Ca}$ in $\mathrm{Li}$ to form a $\mathrm{CaO}$ layer, in-situ electrical resistance measurements of $\mathrm{CaO}$ coatings on $\mathrm{V}-5 \mathrm{Cr}-5 \mathrm{Ti}$ in liquid $\mathrm{Li}$, and characterization of $\mathrm{O}-$ charged specimens and insulator coatings by scanning electron microscopy (SEM), together with optical examination of the coatings for evidence of surface defects such as spallation or cracks. Thermal cycling tests were also conducted to investigate the integrity of coating layers that formed in situ. Fabrication of coatings at relatively low temperatures $\left(320-400^{\circ} \mathrm{C}\right)$ has been emphasized.

\footnotetext{
${ }^{*}$ Work supported by U.S. Department of Energy, Office of Fusion Energy Research, under Contract W-31-109-Eng-38.
} 


\section{RESULTS AND DISCUSSION}

Oxygen charging of the surface of $\mathrm{V}-5 \mathrm{Cr}-5 \mathrm{Ti}$ It is well known that $\mathrm{O}$ can be incorporated into the interstitial sublattice of body-centered-cubic (bcc) $\mathrm{V}$ and its alloys. ${ }^{4}$ Thus, if $\mathrm{O}$ or $\mathrm{N}$ is present in the alloy (as a reactant), these elements may have a higher affinity for solutes, such as $\mathrm{Ca}, \mathrm{Y}$, or $\mathrm{Mg}$ dissolved in $\mathrm{Li}$, than do the alloy elements. In the bcc lattice of $\mathrm{V}-5 \mathrm{Cr}-5 \mathrm{Ti}, \mathrm{O}$ can occupy up to several atomic percent of the interstitial sites within the lattice. Oxygen charging of $\mathrm{V}-5 \mathrm{Cr}-5 \mathrm{Ti}$ was conducted for up to $48 \mathrm{~h}$ at temperatures between 500 and $1030^{\circ} \mathrm{C}$ in flowing high-purity $\mathrm{Ar}$ and $\mathrm{N}_{2}(99.999 \%)$ that contained $\mathrm{O}$ as an impurity. Diffusion coefficients of $\mathrm{O}$ and $\mathrm{N}$ in $\mathrm{V}$ show that diffusion of $\mathrm{O}$ in $\mathrm{V}$ is 10-1800 times faster than that of N. ${ }^{5}$ This property is very important for in-situ formation of $\mathrm{CaO}$. Oxygen charging in an $\mathrm{N}_{2}$ atmosphere lowers the diffusion rate $(\approx 5 \%)$ because of some participation of $N$. Figure 1 shows the weight gain per unit area of the alloy at various temperatures after $17 \mathrm{~h}$ in $\mathrm{N}_{2}$. If we have metallographic information and weight gain, we can control the depth of the $\mathrm{O}$-charged layer by exposure temperature and time in a flowing Ar atmosphere. Oxygen concentration in the near-surface layer was calculated from the weight gain, surface area, and thickness of the hardened region; it ranged from $250 \mathrm{ppm}$ (as-received) to $\approx 2-3 \%$, depending on position within the layer and exposure conditions.

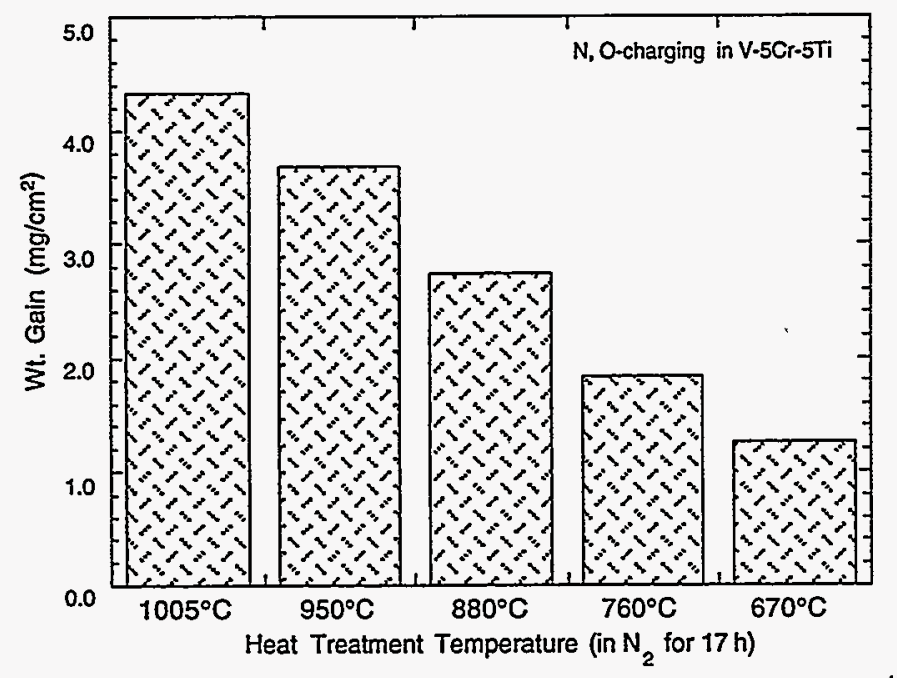

Figure 1.

Weight gain of $\mathrm{V}-5 \mathrm{Cr}-5 \mathrm{Ti}$ specimens after exposure in $99.999 \% \mathrm{~N}_{2}$ for $17 \mathrm{~h}$ at several temperatures

Oxygen charging was also performed in air at $400^{\circ} \mathrm{C}$ to avoid melting of $\mathrm{V}_{2} \mathrm{O}_{5}\left(690^{\circ} \mathrm{C}\right)$ during oxidation. During oxidation in air at $400^{\circ} \mathrm{C}$ for $20 \mathrm{~h}$, a blue amorphous layer $(\approx 1 \mu \mathrm{m}$ thick) formed at the surface. Samples charged with $\mathrm{O}$ in high-purity $\mathrm{Ar}$ or $\mathrm{N}_{2}$ atmospheres showed the same $\mathrm{X}$-ray spectra before and after $\mathrm{O}$ charging. When we measured ohmic resistance (two-point contact) on the surfaces of heat-treated specimens at room temperature, the specimens charged with $\mathrm{O}$ in high-purity $\mathrm{Ar}$ or $\mathrm{N}_{2}$ showed the same ohmic values before and after $\mathrm{O}$ charging. The blue oxide that formed in air at $400^{\circ} \mathrm{C}$ had a resistance of $\approx 5 \Omega$, not very high compared to values for most metal oxides. This oxide is not stable in liquid $\mathrm{Li}$.

Compatibility tests on $\mathrm{O}-$-charged $\mathrm{V}-5 \mathrm{Cr}-5 \mathrm{Ti}$ in liquid $\mathrm{Li}$ Figure 2 shows results of compatibility tests on O-charged samples in flowing liquid $\mathrm{Li}$ at $443^{\circ} \mathrm{C}$ for $298 \mathrm{~h}$. Samples charged with $\mathrm{O}$ at 1030 and $1005^{\circ} \mathrm{C}$ showed the highest weight loss during exposure to liquid Li. Similar results were obtained at $408^{\circ} \mathrm{C}$. In general, specimens that exhibit the greatest weight gain "during $O$ charging undergo the greatest weight loss during exposure to $\mathrm{Li}$. Presumably, this indicates that an oxide phase (e.g., $\mathrm{V}_{2} \mathrm{O}_{3}$ ) that formed during $\mathrm{O}$ charging dissolves in liquid $\mathrm{Li}$. However, weight-loss rates for specimens exposed to $\mathrm{Li}$ at 443 and $408^{\circ} \mathrm{C}$ are virtually the same (i.e., $1.68 \mathrm{mg} / \mathrm{cm}^{2}-\mathrm{h}$ and $0.84 \mathrm{mg} / \mathrm{cm}^{2}-\mathrm{h}$, respectively). By contrast, if weight loss in short-term corrosion tests was controlled primarily by $\mathrm{O}$ diffusion in the alloy, the rates would be expected 
to be relatively independent of the amount of $O$ charged. This would be applicable to any of the thermodynamically stable oxides in the liquid $\mathrm{Li}$, e.g., $\mathrm{BeO}, \mathrm{MgO}, \mathrm{Y}-\mathrm{Al}-\mathrm{O}$ garnet, $\mathrm{Mg}-\mathrm{Al}-\mathrm{O}$ spinel, $\mathrm{Y}_{2} \mathrm{O}_{3}$, and $\mathrm{CaO}$. A similar situation could presumably occur for the formation of nitrides by the reaction of $\mathrm{N}$ in the alloy with metallic elements dissolved in $\mathrm{Li}$. Nevertheless, it is important to determine the optimal condition for $\mathrm{O}$ charging of $\mathrm{V}-5 \mathrm{Cr}-5 \mathrm{Ti}$. O charging in $99.999 \% \mathrm{Ar}$ at $650^{\circ} \mathrm{C}$ was found to be adequate on the basis of the liquid-Li compatibility tests.

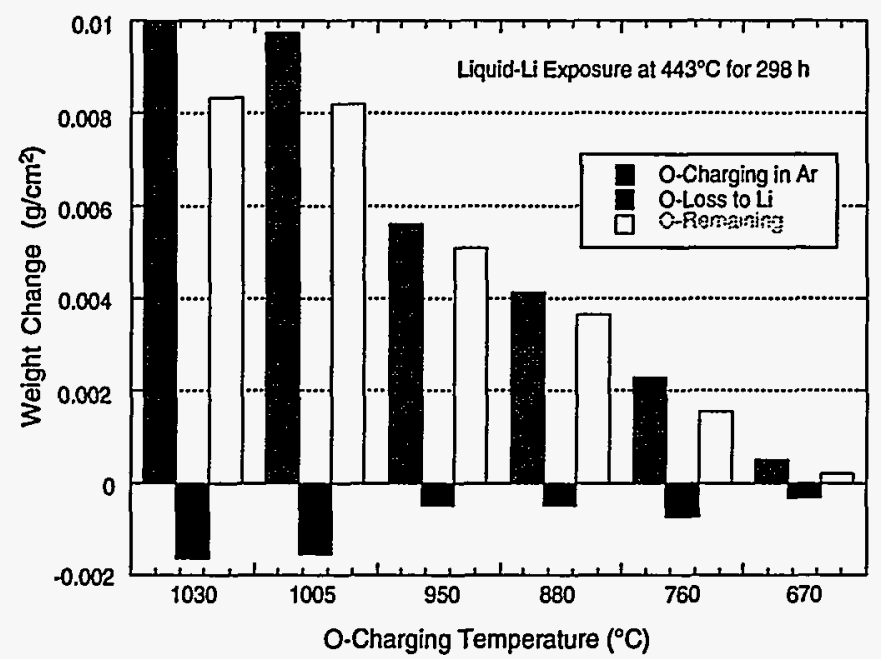

Figure 2.

Weight change of $\mathrm{V}-5 \mathrm{Cr}-5 \mathrm{Ti}$ specimens after $\mathrm{O}$ charging in $\mathrm{Ar}$ for $40 \mathrm{~h}$ at temperatures between 670 and $1030^{\circ} \mathrm{C}$ and after exposure of $\mathrm{O}$-charged specimens to Li at $443^{\circ} \mathrm{C}$ for $298 \mathrm{~h}$

$\mathrm{CaO}$ formation on as-received specimens In-situ formation of $\mathrm{CaO}$ on as-received specimens $(250 \mathrm{ppm}$ O) has been investigated in liquid $\mathrm{Li}$ containing $23 \mathrm{wt} . \% \mathrm{Ca}$ at $700^{\circ} \mathrm{C}$ during a 7-day exposure. We believe the reaction that forms $\mathrm{CaO}$ takes place at the interface between $\mathrm{O}$ at the alloy surface and $\mathrm{Ca}$ in the liquid metal. The coating did not completely cover the $\mathrm{V}-5 \mathrm{Cr}-5 \mathrm{Ti}$ surface, but a high ohmic resistance, typical of $\mathrm{CaO}$ (two-point contact of $>20 \mathrm{M} \Omega$ at room temperature), was obtained.

$\mathrm{CaO}$ formation on $\mathrm{O}$-charged specimens $\mathrm{To}$ improve formation of $\mathrm{CaO}$ on alloy substrates, $\mathrm{O}$-charged specimens were immersed in $\mathrm{Ca}$-bearing $(0.5-85 \mathrm{wt} . \% \mathrm{Ca})$ liquid $\mathrm{Li}$ for various times at various temperatures. This approach was adopted because $O$ in the alloy (as a reactant) may have a higher affinity for a solute such as $\mathrm{Ca}$ dissolved in $\mathrm{Li}$ than for the alloy elements $(\mathrm{V}, \mathrm{Cr}$, and $\mathrm{Ti}$ ). Several experiments were performed to test this hypothesis. Specimens of $\mathrm{V}-5 \mathrm{Cr}-5 \mathrm{Ti}$ were heat treated in flowing $\mathrm{Ar}$ at $650^{\circ} \mathrm{C}$ to charge the surface of the alloy with $O$.

To monitor coating development by electrical resistivity measurements, specimens $(6.35 \times 38 \times 1.0 \mathrm{~mm}$.) were attached to Type $304 \mathrm{SS}$ lead wires $(1.2 \mathrm{~mm}$ diameter) by electron-beam welding. The specimens were charged with $\mathrm{O}$ in an $\mathrm{Ar}$ atmosphere at $650^{\circ} \mathrm{C}$ for $17-20 \mathrm{~h}$ and two specimens were coupled to form one conductivity-measuring unit, as described previously. ${ }^{3}$ The specimens were immersed for $17 \mathrm{~h}$ at $400^{\circ} \mathrm{C}$ in a solution of $\mathrm{Li}$ containing $85 \mathrm{wt} . \% \mathrm{Ca}$, which has a liquidus temperature of $\approx 380^{\circ} \mathrm{C}$ and then elevated above the liquid and exposed to an $\mathrm{Ar}$ atmosphere at $400^{\circ} \mathrm{C}$ to oxidize the $\mathrm{Ca}$, in a manner similar to the $\mathrm{O}$-charging procedure for the $\mathrm{V}$-base alloy. The specimens were again immersed in the liquid $\mathrm{Li}-$ $(0.5 \mathrm{wt} . \%) \mathrm{Ca}$ alloy to measure the electrical resistance of $\mathrm{CaO}$ films at $400^{\circ} \mathrm{C}$. Figure 3 shows the cell resistance $\left(9.5 \times 10^{5} \Omega\right)$ at a current of $100 \mathrm{nA}\left(10^{-7} \mathrm{~A}\right)$ over a $120 \mathrm{~h}$ period at $=400^{\circ} \mathrm{C}$. An initial iR value (where $i=$ current and $R=$ electrical resistance) was obtained at a current of $1 \mathrm{~mA}$, which was too high and caused polarization of the specimen. 


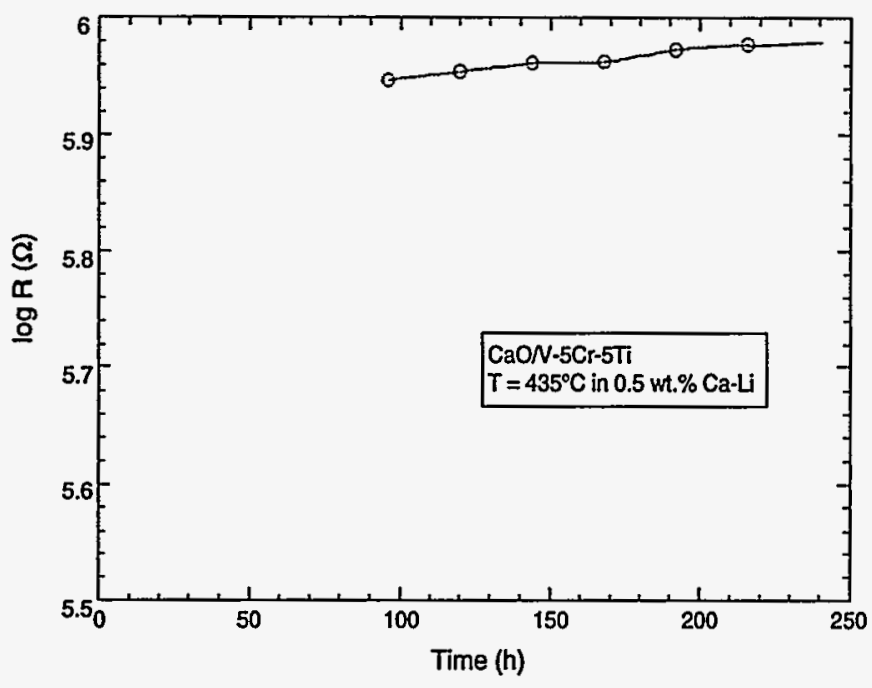

Figure 3.

$\log R(\Omega)$ vs. time of $\mathrm{CaO}$ coating fabricated by exposure of $\mathrm{V}-5 \mathrm{Cr}-5 \mathrm{Ti}$ to $\operatorname{Ar}(99.999 \%)$ at $650^{\circ} \mathrm{C}$ for $17 \mathrm{~h}$ and to 85 wt.\% Ca-Li at $400^{\circ} \mathrm{C}$ for $17 \mathrm{~h}$. Resistance measured in $0.5 w t . \% \mathrm{Ca}-\mathrm{Li}$ at $435^{\circ} \mathrm{C}$

Mechanical integrity and self-healing characteristics Figure 4 shows SEM photomicrographs of the surface of a $\mathrm{CaO}$ coating that contains microcracks. To determine coating thickness, mechanical integrity, and compositional depth profiles in cross section, the specimens were metallographically mounted with an epoxy resin (Fig. 5a). As shown in Fig. 5b, depth profiles of the alloy elements near the interface showed that the composition of $\mathrm{Ti}$ and $\mathrm{Cr}$ remains constant and that only a small amount (1-2\%) of the Ca diffused into the $\mathrm{V}-5 \mathrm{Cr}-5 \mathrm{Ti}\left(1-2 \mu \mathrm{m}\right.$ depth). From our previous investigation at higher temperatures $\left(\approx 700^{\circ} \mathrm{C}\right)$, elemental diffusion was more significant and $\geq 10 \% \mathrm{~V}$ was detected in the $\mathrm{CaO}$ layer. ${ }^{5}$

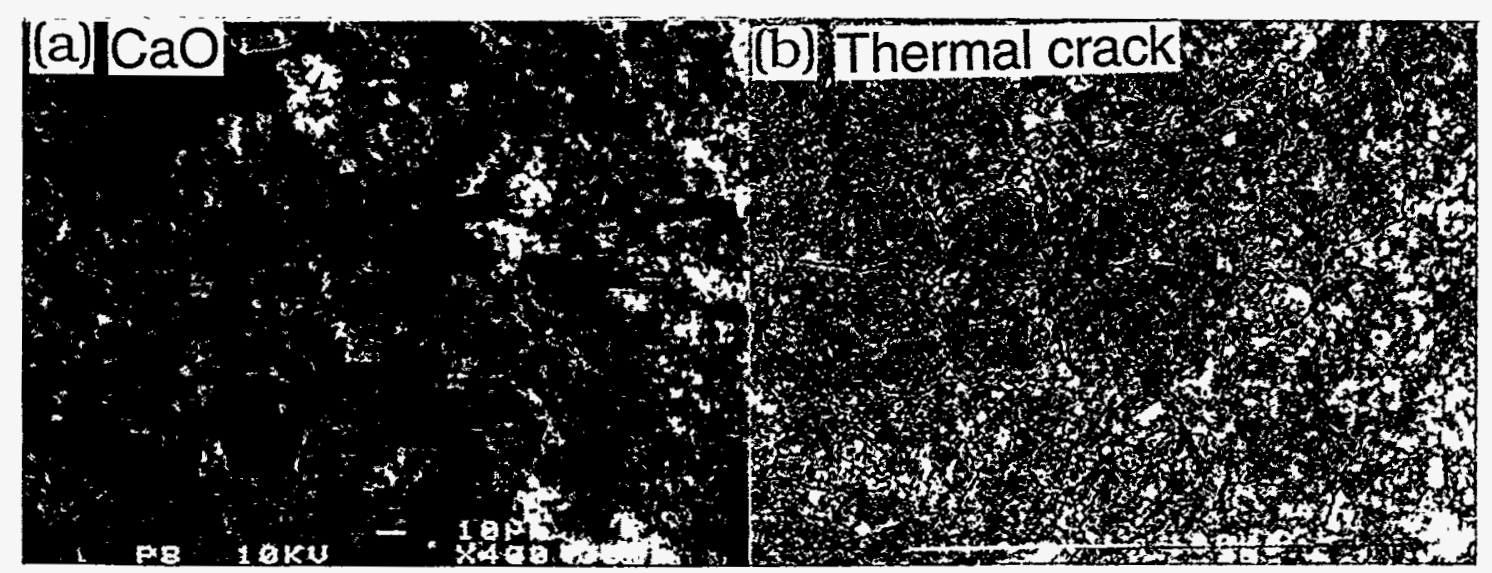

Figure 4. (a) SEM photomicrograph of surface of $\mathrm{CaO}$ coating and

(b) microcracks in coating shown in (a)

The coefficient of thermal expansion of $\mathrm{CaO}$ is higher than that of $\mathrm{V}-5 \mathrm{Cr}-5 \mathrm{Ti}\left(12 \times 10^{-6} \mathrm{vs.} 9.2 \times 10^{-6} / \mathrm{K}\right)$. Therefore, a $\mathrm{CaO}$ layer that forms in situ on a $\mathrm{V}$-alloy will be subjected to a tensile stress during cooling. The photomicrographs of $\mathrm{CaO}$ coatings on $\mathrm{V}-5 \mathrm{Cr}-5 \mathrm{Ti}$ shown in Figs. 4 and 5 reveal that the pattern of microcracks consists of regions with diameters of $\approx 30-40 \mu \mathrm{m}$ and crack widths of $\approx 2000 \AA$ over most of the $\mathrm{CaO}$ surface, which suggests that the cracks originate from a mismatch of the thermal expansion coefficients during cooling, i.e., they are "crazing cracks." Adhesion of the $\mathrm{CaO}$ film to the $\mathrm{V}-5 \mathrm{Cr}-5 \mathrm{Ti}$ substrate appears to be quite good. One way to minimize microcracking would be to decrease the thickness of the $\mathrm{CaO}$ film so that its mechanical strength better matches that of the $\mathrm{V}-5 \mathrm{Cr}-5 \mathrm{Ti}$ substrate. For 


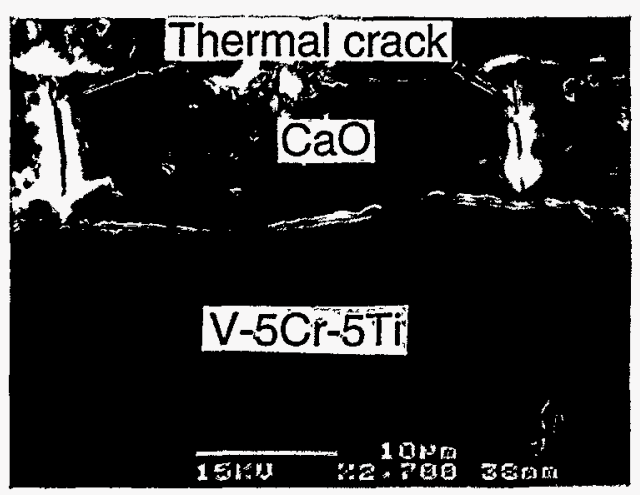

(a)

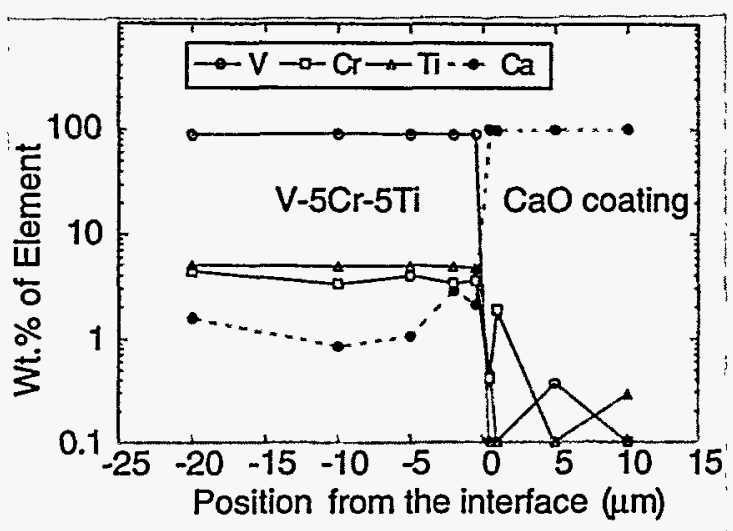

(b)

Figure 5. (a) SEM photomicrograph of cross section and (b) EDS depth profiles of $\mathrm{V}, \mathrm{Cr}, \mathrm{Ti}$, and Ca at CaON-5Cr-5Ti interface of coating formed at $400^{\circ} \mathrm{C}$

example, a $\mathrm{CaO}$ film $\approx 1 \mu \mathrm{m}$ may have a higher fracture strength and also have a resistance $\geq 1 \mathrm{M} \Omega$, which is higher than design requirement for fusion reactors by three to four orders of magnitude.

Liu and Smith ${ }^{6}$ suggest that no coating may be acceptable because calculated stresses are greater than the tensile flexural strengths of most candidate coatings. Therefore, the coatings are subject to cracking in both tension (e.g., $\mathrm{CaO}$ ) and compression. However, their criteria must be viewed in relationship to the conditions under which the coating is formed (viz., temperature and time), as well as the normal operating temperature. For example, when a $\mathrm{CaO}$ film forms at $400^{\circ} \mathrm{C}$, no stress develops when the coating operates at $400^{\circ} \mathrm{C}$. However, because the fabrication and operating temperatures may differ and the coating will undergo thermal fluctuation during operation, acceptable temperature ranges must be defined to account for these situations. The surface cracks developed during cooling from $400^{\circ} \mathrm{C}$ to room temperature. Thermally induced strains are usually calculated by assuming linear thermal expansion, namely

$$
\begin{aligned}
\Delta \varepsilon_{\text {thermal }}= & \left(\alpha_{\mathrm{CaO}}-\alpha_{\mathrm{V}-5 \mathrm{Cr}-5 \mathrm{Ti}}\right) \times\left(\mathrm{T}_{1}-\mathrm{T}_{2}\right) \\
& =\Delta \alpha \times \Delta \mathrm{T} \approx 3 \times 10^{-6} \times 375 \\
& =1.13 \times 10^{-3},
\end{aligned}
$$

where $\alpha_{\mathrm{CaO}}$ and $\alpha_{\mathrm{V}-5 \mathrm{Cr}-5 \mathrm{Ti}}$ are the coefficients of thermal expansion of $\mathrm{CaO}$ and $\mathrm{V}-5 \mathrm{Cr}-5 \mathrm{Ti}$, respectively, and $T_{1}$ and $T_{2}$ are the upper and lower values of the temperature change. Stresses in the $\mathrm{CaO}$ coating can be relieved by either plastic deformation (including creep), crack formation (microcracking), or spallation. Plastic deformation is possible only when the stress is below the critical stress for the formation of any type of material separation (e.g., cracking).

The $\mathrm{CaO}$ layer is subjected to compressive and tensile stress when the temperature is above and below that at which the film formed. When the temperature is cycled slowly, the coating/substrate interface may undergo relaxation so that cracking or spallation does not occur. In any case, because cracking of the $\mathrm{CaO}$ layer during cooling is of the greatest concern, it is important for the coating to exhibit self-healing characteristics in a liquid-metal environment.

Preliminary studies have been conducted to explore the self-healing properties of $\mathrm{CaO}$ coatings under temperature cycling. Self-healing of $\mathrm{CaO}$ was investigated at temperatures between 300 and $740^{\circ} \mathrm{C}$. At $300^{\circ} \mathrm{C}$, self-healing did not occur in a 10 -h period; at temperatures $\geq 360^{\circ} \mathrm{C}$, cracks appeared to heal (e.g., at $450^{\circ} \mathrm{C}$, resistivity was restored to its initial value within several hours, and at $500^{\circ} \mathrm{C}$ in $<1 \mathrm{~h}$ ). When a $\mathrm{CaO}$ coating was subjected to compressive stress by increasing the temperature in a similar manner, no 
appreciable cracking was detected. When temperature was increased to accelerate the healing process, we could not assess whether increases in iR values were caused by closing of cracks or by diffusion-related healing behavior. Nevertheless, when the system temperature was raised, the rapid response resembled healing of the cracks.

Preliminary work was conducted to explore the self-healing process in terms of diffusion, thermal expansion, and contraction processes within the $\mathrm{CaO}$ layer. In this regard, it is more important to consider reactions that take place at the defect area rather than at the surface region, namely, at the $\mathrm{Li}-\mathrm{Ca} / \mathrm{V}-5 \mathrm{Cr}-$ $5 \mathrm{Ti}(\mathrm{O})$ interface. The growth mechanism of the $\mathrm{CaO}$ layer could be as follows; initially a thin $\mathrm{CaO}$ forms at the interface by the reaction $\mathrm{Ca}$ (in $\mathrm{Li}$ ) $+\mathrm{O}$ (in $\mathrm{V}-5 \mathrm{Cr}-5 \mathrm{Ti})=\mathrm{CaO}$, accompanied by inward ambipolar diffusion of the $\mathrm{Ca}^{+2}$ ion and electrons. The spontaneous reaction of $\mathrm{Ca}^{+2}+2 \mathrm{e}^{\prime}+\mathrm{O}=\mathrm{CaO}$ will take place at the $\mathrm{CaO} / \mathrm{V}-5 \mathrm{Cr}-5 \mathrm{Ti}$ interface, including defect areas such as grain boundaries, dislocations, and open voids, microcracks, because the diffusivity of $\mathrm{Ca}^{+2}$ is much higher than that of $\mathrm{O}^{-2}$ in $\mathrm{CaO}$ and because growth of the $\mathrm{CaO}$ layer depends on inward diffusion of $\mathrm{Ca}^{+2}$, presumably by a cation vacancy mechanism. ${ }^{7}$

Figure 6 shows the temperature-and-ohm $\mathrm{x}$ area-versus-time response during thermal cycling of a coated specimen in liquid Li. Resistivity of a coated specimen that was cooled to room temperature and then heated to $432^{\circ} \mathrm{C}$ for $50 \mathrm{~min}$ stabilized at $\approx 600 \Omega \cdot \mathrm{cm}^{2}$, which is indicative of healing of cracks in the coating. During cooling from 430 to $360^{\circ} \mathrm{C}$, the specimen initially exhibited ceramic-type behavior, i.e., the ohmic value increased to $\approx 800 \Omega \cdot \mathrm{cm}^{2}$, but during further cooling to $325^{\circ} \mathrm{C}$, the ohmic value decreased precipitously to $\approx 20 \Omega \cdot \mathrm{cm}^{2}$, which is indicative of further crack development. During heating of the specimen to $\approx 450^{\circ} \mathrm{C}$, the ohmic value increased to $\approx 300 \Omega \cdot \mathrm{cm}^{2}$ and stabilized at that value, which is indicative of self-healing of the defects. However, when the temperature was increased to $490^{\circ} \mathrm{C}$, the ohmic value dropped immediately because thermal expansion of the liquid caused the meniscus at the liquid/specimen interface to rise and the liquid $\mathrm{Li}$ to wet "new" surfaces of O-charged V-5Cr-5Ti. During a 2-h period at $490^{\circ} \mathrm{C}$, the ohmic value increased slowly to the previous value as a $\mathrm{CaO}$ coating formed on this region of the specimen. When the specimen was cooled from 490 to $320^{\circ} \mathrm{C}$, no new cracks developed and the resistivity once again increased, which is indicative of ceramic-type behavior. During the next $\approx 100$-h period at $320^{\circ} \mathrm{C}$, resistivity increased slowly to $\approx 1200 \Omega \cdot \mathrm{cm}^{2}$. This increase could be attributed to further repair of the $\mathrm{CaO}$ layer in less protected regions and/or changes in the defect chemistry of $\mathrm{CaO}$ when $\mathrm{Ca}$ was not present at high concentration in liquid $\mathrm{Li}$. Additional work is required to establish the mechanisms of self-healing of $\mathrm{CaO}$ coatings during thermal cycling.

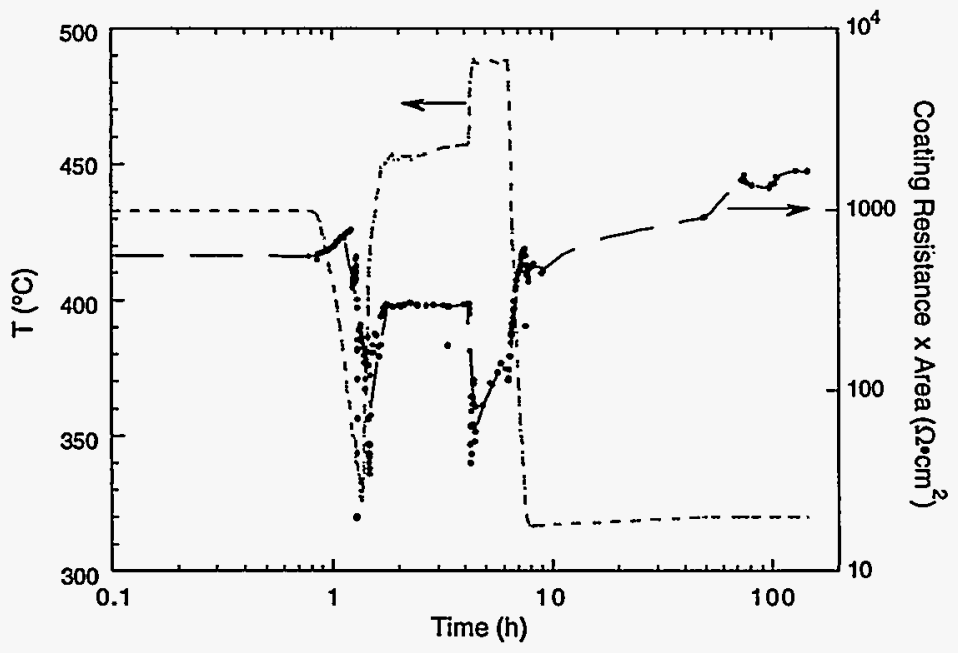

Figure 6.

Temperature and ohmic resistance $x$ area $(R x A)$ vs. time during thermal cycling 


\section{CONCLUSIONS}

A method was developed for in-situ fabrication of an electrically insulating $\mathrm{CaO}$ coating on $\mathrm{V}-5 \mathrm{Cr}-5 \mathrm{Ti}$ in a liquid- $\mathrm{Li}$ environment. The process involves reaction of an $\mathrm{O}$-enriched alloy surface with liquid $\mathrm{Li}$ containing $\mathrm{Ca}$ at $300-400^{\circ} \mathrm{C}$. Thermal cycling tests were conducted on $\mathrm{CaO}$ coatings that form in situ on $\mathrm{V}-5 \mathrm{Cr}-5 \mathrm{Ti}$ in liquid $\mathrm{Li}$ that contains dissolved $\mathrm{Ca}$ at temperatures between 300 and $740^{\circ} \mathrm{C}$. Microcracks develop in the coating layer during cooling from $>400^{\circ} \mathrm{C}$ to ambient temperature because of the higher expansion coefficient of $\mathrm{CaO}$. After heating, the cracks exhibit self-healing within a 10-h period at $360^{\circ} \mathrm{C}$ and in $<1 \mathrm{~h}$ at $500^{\circ} \mathrm{C}$, as evidenced by restoration of the resistivity to its original value. The layer growth and repair mechanism most likely involves the reaction of $\mathrm{Ca}$ (in $\mathrm{Li}$ ) $+\mathrm{O}$ (in $\mathrm{V}-5 \mathrm{Cr}-5 \mathrm{Ti}$ ) to form $\mathrm{CaO}$, accompanied by inward ambipolar diffusion of $\mathrm{Ca}^{+2}$ ion and electrons.

\section{FUTURE WORK}

The performance of $\mathrm{CaO}$ coatings on $\mathrm{V}$-base alloys in flowing liquid $\mathrm{Li}$ will evaluated in-situ by monitoring induced currents in a magnetic field. Hydrogen permeability measurements will be performed on noncoated and $\mathrm{CaO}$ coated $\mathrm{V}$-base alloys.

\section{ACKNOWLEDGMENTS}

B. Tani of Argonne's Analytical Laboratory provided the X-ray diffraction studies. G. Dragel and R. W. Clark assisted in the experiments.

\section{REFERENCES}

[1] C. C. Baker et al., Tokamak Power System Studies FY 1985, Argonne National Laboratory Report, ANL/FPP-85-2 (Dec. 1985).

[2] R. F. Mattas, B. A. Loomis, and D. L. Smith, Vanadium Alloys for Fusion Reactor Applications, JOM, 44(8), 26 (1992).

[3] J.-H. Park, T. Domenico, G. Dragel, and R. W. Clark, Development of Electrical Insulator Coatings for Fusion Power Applications, submitted to 3rd Intl. Symp. on Fusion Nuclear Technology (ISFNT-3), June 27-July 1, 1994, Los Angeles, CA.

[4] A. U. Seybolt and H. T. Sumsion, Vanadium-Oxygen Solid Solutions, Met. Trans. AIME, 292-299 (1953).

[5] J.-H. Park, Intermetallic and Electrical Insulator Coatings on High-Temperature Alloys in Liquid Lithium Environments, Proc. Symp. on High-Temperature Coatings-I, TMS Fall Meeting, Oct. 2-6, 1994, Rosemont, IL.

[6] Y. Y. Liu and D. L. Smith, Ceramic Electrical Insulators for Liquid Metal Blankets, J. Nucl. Mater., 141-143, 38 (1986).

[7] V. Kumar and Y. P. Gupta, Cation Self-diffusion in Single Crystal CaO, J. Phys. Chem. Solid, 30, $677-685$ (1969). 

SELECTION OF A LIQUID CALCIUM-LITHIUM ALLOY FOR FABRICATING CaO INSULATOR COATINGS ON V-5\% Cr-5\%Ti* J.-H. Park and T. F. Kassner (Argonne National Laboratory)

\section{OBJECTIVE}

Electrically insulating $\mathrm{CaO}$ coatings have been produced on $\mathrm{V}-5 \% \mathrm{Cr}-5 \% \mathrm{Ti}$ by exposing the alloy to liquid $\mathrm{Li}$ that contained $0.5-85 \mathrm{wt} . \%$ dissolved $\mathrm{Ca}$ at $400-420^{\circ} \mathrm{C}$, where the solute element ( $\mathrm{Ca}$ in liquid $\mathrm{Li}$ ) reacted with the alloy substrate to produce a $\mathrm{CaO}$ coating. ${ }^{1,2}$ The objective of this study is to determine the optimal $\mathrm{Ca}-\mathrm{Li}$ alloy for formation of the $\mathrm{CaO}$ coating from the liquidus temperature of binary alloys and experience obtained during their preparation.

\section{SUMMARY}

An electrically insulating coating at the liquid-metal/structural-material interface of a magnetic fusion reactor is required to prevent adverse currents generated by the magnetohydrodynamic (MHD) force from passing through the structural walls. 3,4 Thin, homogeneous, electrically insulating $\mathrm{CaO}$ coatings can be produced on variously shaped surfaces of $\mathrm{V}-5 \% \mathrm{Cr}-5 \% \mathrm{Ti}$ by exposing the alloy at controlled times and temperatures to liquid $\mathrm{Li}$ containing $\mathrm{Ca}$. Formation of $\mathrm{Ca}-\mathrm{Li}$ alloys by dissolution of solid $\mathrm{Ca}$ in liquid $\mathrm{Li}$ in an $\mathrm{Ar}$ environment was investigated, and the exothermic heat of solution was found to be low, as indicated by minimal increases in temperature. The recommended composition of a liquid alloy for fabrication of this coating on reactor components is $\mathrm{Li}-82 \mathrm{wt} \% \mathrm{Ca}(44$ at.\% $\mathrm{Ca}$ ), which has a liquidus temperature of $\approx 230^{\circ} \mathrm{C}$. As the solute $\mathrm{Ca}$ in the liquid alloy is consumed during the coating process, the liquidus temperature of the alloy decreases. This coating technique can be applied to various shapes (e.g., inside/outside of tubes, complex geometrical shapes) because the coating is formed by liquid-phase reaction at $=400^{\circ} \mathrm{C}$. Cracks that form in the $\mathrm{CaO}$ coating during thermal cycling exhibit in-situ self-healing behavior at temperatures $\geq 360^{\circ} \mathrm{C}$. $^{2}$

\section{INTRODUCTION}

Corrosion resistance of structural materials, and the $\mathrm{MHD}$ force and its influence on thermal hydraulics, are major concerns in the design of liquid-metal cooling systems for fusion first-wall/blanket applications. ${ }^{3}$ Vanadium and $\mathrm{V}$-base alloys ( $\mathrm{V}-\mathrm{Ti}$ or $\mathrm{V}-\mathrm{Ti}-\mathrm{Cr}$ ) are leading candidate materials for structural applications in fusion reactors. ${ }^{5}$ Our recent work ${ }^{1,2}$ has focused on in-situ formation of $\mathrm{CaO}$ on $\mathrm{V}-5 \mathrm{Cr}-5 \mathrm{Ti}$ in liquid $\mathrm{Li}$ because the electrical resistivity of $\mathrm{CaO}$ is greater than that of other potential insulator candidates (e.g., $\mathrm{AlN})$ and because $\mathrm{CaO}$ exhibits a higher thermodynamic stability than other oxides $\left(\mathrm{Y}_{2} \mathrm{O}_{3}, \mathrm{BeO}, \mathrm{MgO}\right.$, $\mathrm{MgAl}_{2} \mathrm{O}_{4}, \mathrm{Y}_{3} \mathrm{Al}_{2} \mathrm{O}_{12}$, etc.) in liquid $\mathrm{Li}$. $6,7 \mathrm{Thin}$, homogeneous, electrically insulating $\mathrm{CaO}$ coatings were produced on small specimens of $\mathrm{V}-5 \% \mathrm{Cr}-5 \% \mathrm{Ti}$ by controlling the exposure time, temperature, and composition of liquid Li containing dissolved $\mathrm{Ca}^{2}$ The objective of this study is to determine the optimal composition of the liquid $\mathrm{Li}-\mathrm{Ca}$ alloy for use in coating various shapes such as the insides of tubes or irregular shapes in fusion reactor components.

According to the $\mathrm{Ca}-\mathrm{Li}$ binary phase diagram shown in Fig. $1, \mathrm{Ca}$ additions to liquid $\mathrm{Li}$ lower the melting point of $\mathrm{Li}-\mathrm{Ca}$ alloys from $180.6^{\circ} \mathrm{C}$ (for pure $\mathrm{Li}$ ) to $141^{\circ} \mathrm{C}$ for the eutectic mixture that contains 7.7 at.\% $\mathrm{Ca}(\approx 32.5 \mathrm{wt} . \% \mathrm{Ca})$. The liquidus temperature of $\mathrm{Ca}-\mathrm{Li}$ alloys increases slowly from 141 to $230^{\circ} \mathrm{C}$ as the concentration of $\mathrm{Ca}$ increases from $\approx 32.5$ to $82 \mathrm{wt}$. \%. The liquidus temperature then increases rapidly from 230 to $842^{\circ} \mathrm{C}$, which is the melting point of pure Ca. From the standpoint of forming a thin homogeneous $\mathrm{CaO}$ coating on $\mathrm{V}$-base alloys, a high concentration of $\mathrm{Ca}$ in liquid $\mathrm{Li}$ is desirable to provide a large source of $\mathrm{Ca}$ for the coating process, scavenge or "getter" nonmetallic impurities (e.g., $\mathrm{O}, \mathrm{N}$ ) in $\mathrm{Li}$, and minimize incorporation of $\mathrm{Li}$ into the $\mathrm{CaO}$ film. Several $\mathrm{Ca}-\mathrm{Li}$ compositions have been prepared, and

*Work supported by U.S. Department of Energy, Office of Fusion Energy Research, under Contract W-31-109-Eng-38. 
melting/cooling cycles for the alloys have been obtained to verify the $\mathrm{Ca}-\mathrm{Li}$ phase diagram in the range of interest. We also determined whether the initial heating cycle with mixtures of pure components produces an exothermic reaction that could present problems during application of the coating process to large components where a significant quantity of the liquid alloy is required.

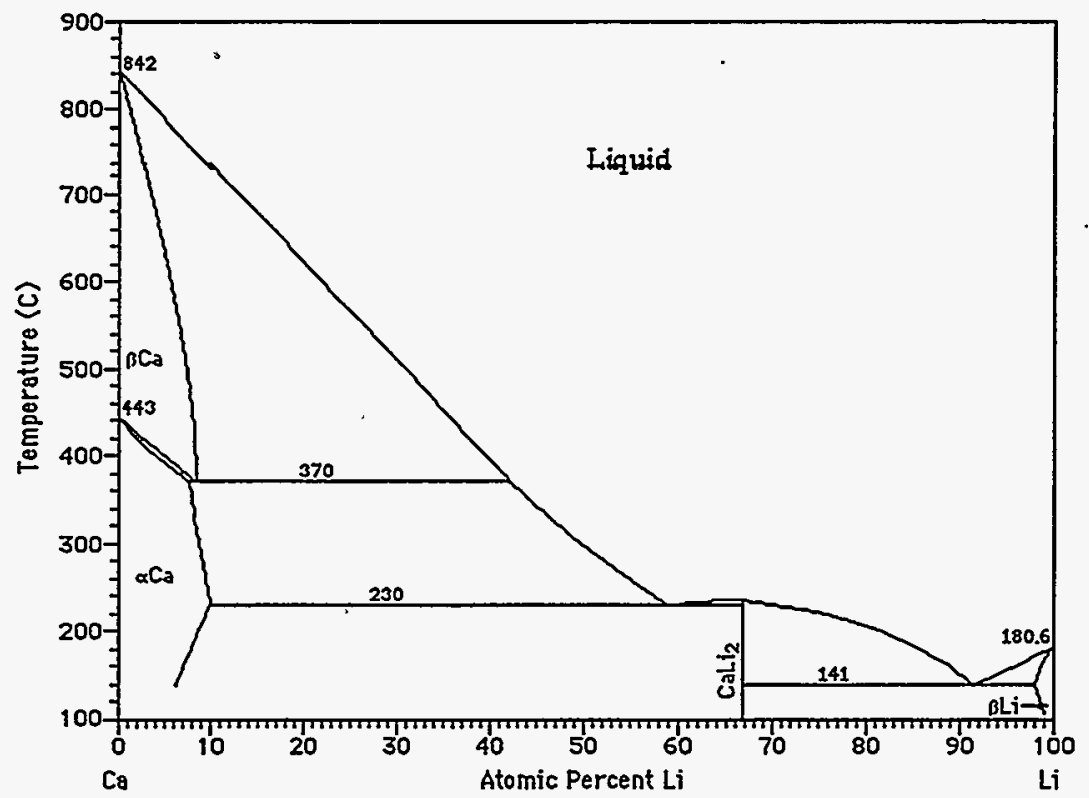

Figure 1. Ca-Li binary phase diagram

\section{EXPERIMENTAL PROCEDURE}

Figure 2 is a schematic drawing of the apparatus used in the heating/cooling experiments. Eight $\mathrm{Ca}-\mathrm{Li}$ samples with 3-82 wt.\% Ca (0.5-44 at.\% Ca) were prepared from small (3-10 mm diameter) pieces of $\mathrm{Ca}$ and $3-\mathrm{mm}$-diameter $\mathrm{Li}$ wire. Isopropyl alcohol was used to rinse mineral oil from the $\mathrm{Li}$ wire. The $\mathrm{Ca}$ and $\mathrm{Li}$ were weighed and then loaded into a 150-mL Type 304 stainless steel (SS) container. Several methods were used to load the constituents $(\approx 60 \mathrm{~mL}$ volume) into the apparatus in an attempt to minimize oxidation of the metals in air. Ar gas was pursed in a plastic bag that held the container, and handling time was minimized. In some cases, the solid metals were place sequentially in the container; in others, $\mathrm{Li}$ was place at the bottom and $\mathrm{Ca}$ at the top of the container. After loading, the container was transferred to the SS chamber shown schematically in Fig. 2. Ar gas was pursed simultaneously with a vacuum pump that purged air from the system. Heating was then started and the temperature was monitored with two thermocouples, which were initially located at the top of the mixture. Once fusion had occurred, one thermocouple was repositioned (lowered) and the temperature of the liquid phase was monitored. Cooling curves were obtained for various alloy compositions by removing the furnace from the SS chamber (Fig. 2) and slowing cooling the container in air. Thermal arrests were determined from cooling curves and the temperatures were compared with published phase diagrams $\mathrm{s}^{8-10}$ for the Ca-Li system.

\section{RESULTS AND DISCUSSION}

Pure $\mathrm{Li}$ to $2.2 \mathrm{at} . \% \mathrm{Ca}$ in $\mathrm{Li}$. Cooling curves for pure $\mathrm{Li}$ and several alloys that contained $0-2.2$ at.\% $\mathrm{Ca}$ were obtained during furnace cooling. Only the liquidus temperature was revealed during cooling of pure $\mathrm{Li}$ and of the alloy with 0.5 at.\% Ca. The liquidus and the eutectic point at $141^{\circ} \mathrm{C}$ were detected in alloys with $1.2,1.6$, and 2.2 at.\% Ca. 


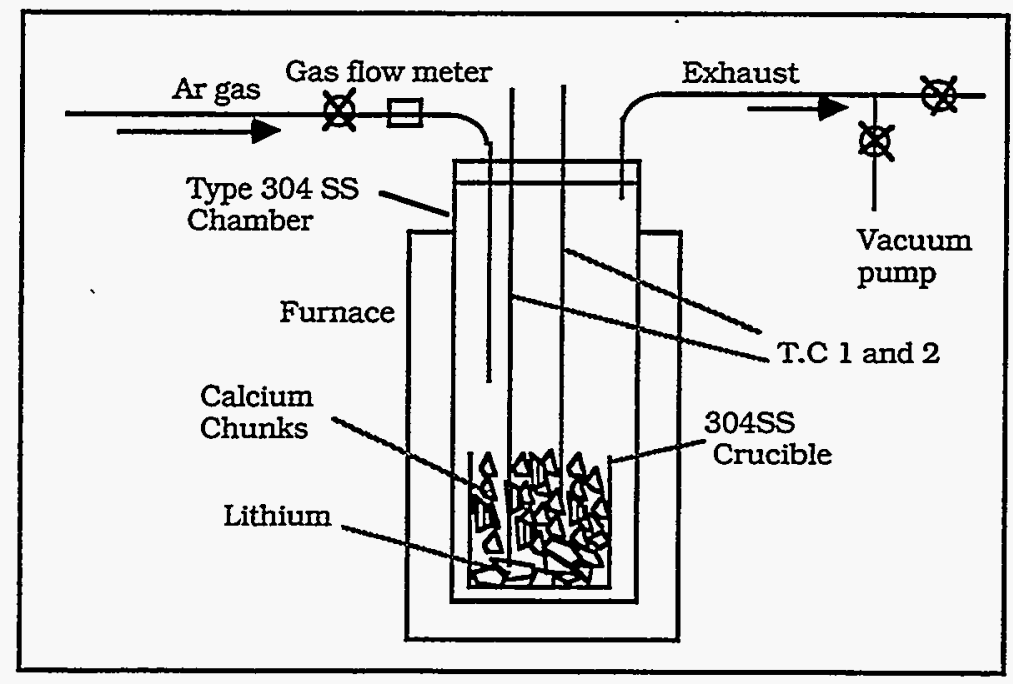

Figure 2. Schematic diagram of apparatus for heating/cooling experiments

4.1-33.3 at.\% Ca in $\mathrm{Li}$. Cooling curves for alloys that contained 4.1, 5.0, 7.7, 10.4, and 28 at.\% Ca were obtained during furnace cooling, and the liquidus and eutectic temperatures were easily detected from breaks in the cooling curves.

33.3-100 at.\% $\mathrm{Ca}$. In this composition range, published $\mathrm{Ca}-\mathrm{Li}$ phase diagrams do not agree with each other. ${ }^{8-10}$ Several heating/cooling cycles were performed on a $\mathrm{Li}-37$ at.\% Ca alloy. No appreciable heat was evolved during the initial heating cycle. Reproducible breaks in the cooling curves occurred at $\approx 230$ and $142^{\circ} \mathrm{C}$, temperatures that are indicative of formation of the $\mathrm{CaLi}_{2}$ intermetallic phase and the eutectic temperature, respectively.

The temperatures and phases associated with thermal arrests during cooling of the various alloys are given in Table 1 and results for the $\mathrm{Li}$-rich portion of the $\mathrm{Ca}-\mathrm{Li}$ phase diagram determined in this study are shown in Fig. 3. The heat of solution of $\mathrm{Ca}$ in liquid $\mathrm{Li}$ is relatively small, as indicated by the thermocouple in the liquid during the initial heating cycle. The low-melting $\mathrm{CaLi}_{2}$ intermetallic phase $\left(\mathrm{mp} \approx 230^{\circ} \mathrm{C}\right.$ ) also exhibits a negligible exothermic heat of formation during initial fusion of $\mathrm{Li}$ ( $\mathrm{mp}$ $\approx 180^{\circ} \mathrm{C}$ ) in the presence of solid $\mathrm{Ca}$, and during heating from the melting temperature to $\approx 230^{\circ} \mathrm{C}$, where this phase is no longer stable.

\section{CONCLUSIONS AND FUTURE STUDIES}

Formation of $\mathrm{Ca}-\mathrm{Li}$ alloys by dissolution of solid $\mathrm{Ca}$ in liquid $\mathrm{Li}$ in an $\mathrm{Ar}$ environment was investigated, and the exothermic heat of solution was found to be low, as indicated by minimal increases in temperature. Based on experience obtained during initial fusion of the alloys and the criterion for a high $\mathrm{Ca}$ concentration in the liquid to facilitate formation of a $\mathrm{CaO}$ coating on $\mathrm{V}$-base alloys, we recommend an alloy that contains $82 \mathrm{wt} . \% \mathrm{Ca}(44$ at.\% $\mathrm{Ca}$ ) for fabrication of this coating on reactor components. The recommended alloy has a liquidus temperature of $\approx 230^{\circ} \mathrm{C}$ and can be produced by charging weighed quantities of the two constituent metals into a stainless steel vessel and heating the mixture to $=400^{\circ} \mathrm{C}$ in an inert-gas environment to form a $\mathrm{CaO}$ coating on $\mathrm{V}$-base alloys that are exposed to the liquid. Alternative methods for in-situ fabrication of a $\mathrm{CaO}$ electrically insulating coating on $\mathrm{V}-5 \mathrm{Cr}-5 \mathrm{Ti}$ in a liquid- $\mathrm{Li}$ environment can be envisioned. For example, liquid $\mathrm{Li}$ could be pumped at a low rate through a vessel containing solid $\mathrm{Ca}$ at $\approx 225^{\circ} \mathrm{C}$ and the $\mathrm{Ca}$-enriched alloy could then flow through a component to be coated at a higher temperature, at which the reaction process occurs at a significant rate. The coating, if it 
deteriorates, can be restored by repeating this technique, or it can be maintained by using a low concentration of $\mathrm{Ca}$ in $\mathrm{Li}$ during normal operation of the system. The latter procedure would promote selfhealing of defects that may form during thermal cycling of the coated structural material.

\begin{tabular}{rrc} 
Table I. & $\begin{array}{l}\text { Alloy composition and } \\
\text { thermal arrest temperatures } \\
\text { on cooling }\end{array}$ \\
\hline \multicolumn{3}{c}{ Thermal Arrest } \\
Ca in Li & $\begin{array}{c}\text { on Cooling } \\
\text { at.\% }\end{array}$ wt.\% & ${ }^{\circ} \mathrm{C}$ \\
\hline 0.0 & 0.0 & 180 \\
0.5 & 3.0 & 170,150 \\
1.2 & 6.5 & 174,158 \\
1.6 & 9.2 & 172,141 \\
2.2 & 11.5 & 169,141 \\
4.1 & 19.9 & 157,141 \\
5.0 & 23.3 & 165,141 \\
7.7 & 32.7 & 141 \\
10.4 & 40.1 & 157,142 \\
28.0 & 69.2 & 210,141 \\
37.0 & 77.2 & 228,142 \\
100.0 & 100.0 & 842 \\
\hline
\end{tabular}

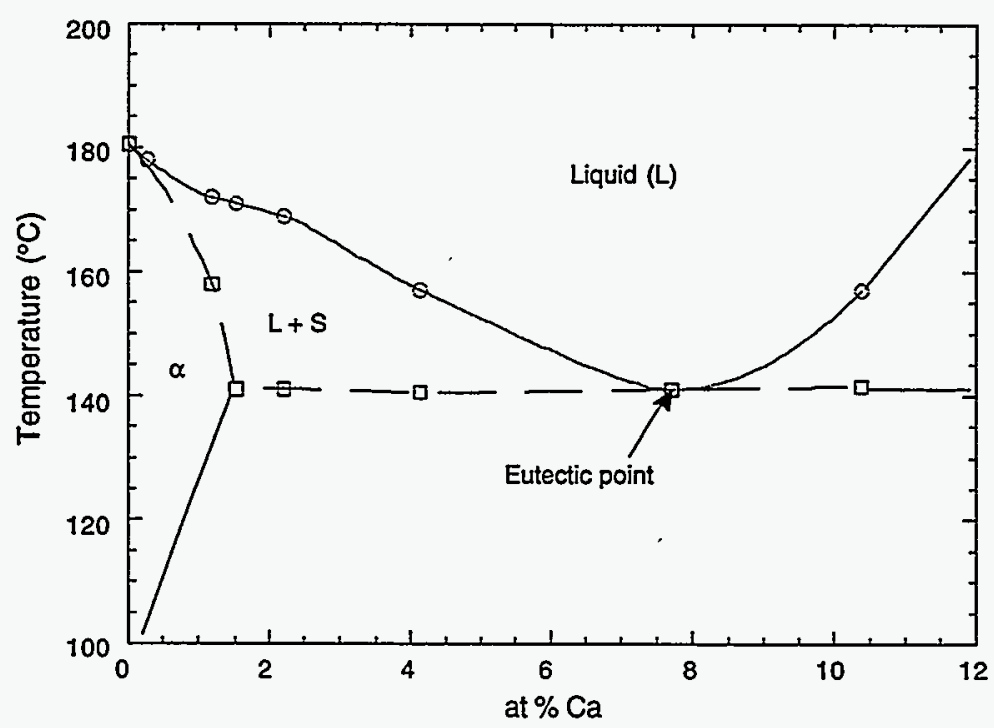

Figure 3. Li-rich region of Ca-Li phase diagram from this study 


\section{ACKNOWLEDGMENTS}

G. Dragel assisted in the liquid-Li experiments.

\section{REFERENCES}

1. J.-H. Park, G. Dragel, and R. W. Clark, Development of Electrical Insulator Coatings: In-situ Electrical Resistance Measurements on CaO Coated V-5\%Cr-5\%Ti in Liquid Lithium, Fusion Reactor Materials Semiannual Progress Report for the Period Ending March 31, 1994, DOE/ER0313/16, pp. 376-381 (Sept. 1994).

2. J.-H. Park and G. Dragel, Fabrication and Performance Testing of $\mathrm{CaO}$ Insulator Coatings on $\mathrm{V}-5 \% \mathrm{Cr}-5 \% \mathrm{Ti}$ in Liquid Lithium, Fusion Reactor Materials Semiannual Progress Report for the Period Ending September 30, 1994, DOE/ER-0313/17, (1995).

3. C. C. Baker et al., Tokamak Power System Studies FY 1985, Argonne National Laboratory Report ANL/FPP-85-2 (Dec. 1985).

4. T. Kammash, Fusion Reactor Physics, Chapter 15, Ann Arbor Science Pub. Inc., Ann Arbor, MI (1975), pp. 405-439.

5. R. F. Mattas, B. A. Loomis, and D. L. Smith, Vanadium Alloys for Fusion Reactor Applications, JOM, 44(8), 26 (1992).

6. J.-H. Park, and G. Dragel, Development of Electrical Insulator Coatings: In-situ Electrical Resistance Measurements on $\mathrm{V}-5 \% \mathrm{Cr}-5 \% \mathrm{Ti}$ in Liquid Lithium, Fusion Reactor Materials Semiannual Progress Report for the Period Ending September 30, 1993, DOE/ER-0313/15, pp. 321-325 (Feb. 1994).

7. J.-H. Park, T. Domenico, G. Dragel, and R. W. Clark, Development of Electrical Insulator Coatings for Fusion Power Applications, paper submitted for 3rd Intl. Symp. on Nuclear Fusion Technology (ISNFT-3), June 27-July 1, 1994, Los Angeles, CA.

8. C. W. Bale and A. D. Pelton, Ca-Li Phase Diagram, Binary Alloy Phase Diagrams, T. B. Massalski, H. Okamoto, P. R. Subramanian, and L. Kacprzak, eds., ASM International, pp. 922-925 (1990).

9. M. Hansen, Constitution of Binary Alloys, McGraw-Hill, New York (1958).

10. F. A. Shunk, Constitution of Binary Alloys, Second Supplement, McGraw-Hill, New York (1969). 


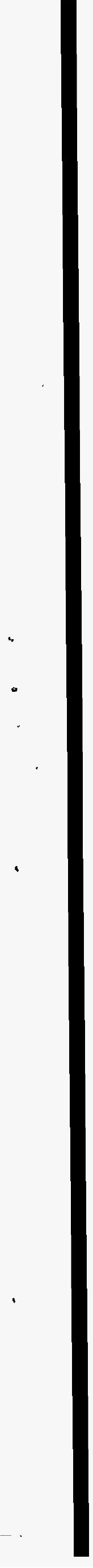


7.0 SOLID BREEDING MATERIALS AND BERYLLIUM 


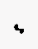

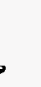

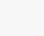


INVESTIGATION OF TRITIUM RELEASE FROM LITHIUM TITANATE

J. P. Kopasz and C. E. Johnson (Argonne National Laboratory)

\section{OBJECTIVE}

The objective of this work is to obtain tritium release information for lithium titanate, a low activation material being considered for tritium breeding in fusion reactors.

\section{SUMMARY}

Tritium release from lithium titanate has been investigated using isothermal anneal experiments. These experiments suggest that the rate-controlling step for tritium desorption is desorption of HTO from a titanium site on the $\mathrm{Li}_{2} \mathrm{TiO}_{3}$ surface. The experiments also indicate that the presence of hydrogen in the purge gas helps the tritium release by increasing the fraction of tritium released at a given temperature.

\section{PROGRESS AND STATUS}

\section{$\underline{\text { Introduction }}$}

Lithium titanate is a low activation ceramic with potential as a tritium breeding material for fusion technology. To date, very little work has been done to characterize tritium release from lithium titanate and develop the requisite properties data base. Initial studies indicate that lithium titanate has excellent tritium release characteristics, comparable to those for lithium oxide or lithium zirconate. To fill in the data base for lithium titanate, we have performed several isothermal anneal tests of tritium release.

\section{Experimental}

Lithium titanate was obtained from AECL Research. The material was formed from an extrusion/tumbled mixture of $\mathrm{Li}_{2} \mathrm{TiO}_{3}$, water, and a binder. The resulting pebbles were sintered at $1673 \mathrm{~K}$ to provide $\mathrm{Li}_{2} \mathrm{TiO}_{3}$. [1] Several of these pebbles were sealed in aluminum capsules and irradiated in the TRIGA reactor at the University of Illinois, Urbana-Champaign, for approximately $1 \mathrm{~h}$. The pebbles were removed from the aluminum capsules under an inert atmosphere and transferred to the annealing apparatus in a specially designed, sealed sample holder. The annealing apparatus has been described previously.[2] The isothermal anneals were performed by preheating the furnace to the desired temperature, while the pebbles were positioned in the cool, sealed sample holder. After the furnace had reached the desired temperature, the pebbles were introduced into the heated zone. Tritium release was monitored on-line using a proportional counter. Integrated values for the amount of tritium released over the duration of an anneal were obtained by oxidizing the tritium over a copper oxide bed and collecting the tritiated water in a set of ethylene glycol traps. The anneals were performed for $24 \mathrm{~h}$ at the initial temperature $\left(300-500^{\circ} \mathrm{C}\right)$ at which point the ethylene glycol traps were replaced. The pebbles were then heated to $900^{\circ} \mathrm{C}$ for an additional $24 \mathrm{~h}$ to remove residual tritium.

\section{$\underline{\text { Results and Discussion }}$}

Tritium anneals were performed with two purge gases, pure $\mathrm{He}$ and $\mathrm{He}+0.1 \% \mathrm{H}_{2}$. The tritium release data were fit to first-order desorption equations to obtain a desorption rate constant. These rate constants are plotted in Figure 1 as a function of inverse temperature. Within the scatter of the data, the rate constant for desorption into pure $\mathrm{He}$ is the same as that for desorption into $\mathrm{He}+0.1 \% \mathrm{H}_{2}$. 
One of the reaction schemes

proposed for tritium desorption is

Scheme I

$$
\begin{gathered}
\mathrm{OH}_{s}^{-}+\mathrm{OT}_{s}^{-} \rightarrow \mathrm{HTO}_{s}+\mathrm{O}_{s} \\
\mathrm{HTO}_{\mathrm{s}} \rightarrow \mathrm{HTO}_{\mathrm{g}}
\end{gathered}
$$

If the rate-controlling step is recombination of surface hydroxyls with OT [step (a)], the rate constant would be dependent on the surface concentration of $\mathrm{OH}$, and this concentration should change with changing hydrogen pressure. However, if the ratecontrolling step is desorption of the surface bound water molecule [ step (b)], the desorption rate constant would be independent of the hydrogen pressure. Our finding that the rate constant for desorption into pure $\mathrm{He}$ is essentially the same as that for desorption into $\mathrm{He}+0.1 \% \mathrm{H}_{2}$ suggests that step (b) is the rate-controlling step for tritium desorption. The activation energy for desorption determined in this work is 37 $\mathrm{kJ} / \mathrm{mol}$. This value is in agreement with the value of $35 \mathrm{~kJ} / \mathrm{mol}$ determined from temperature programmed desorption (TPD)

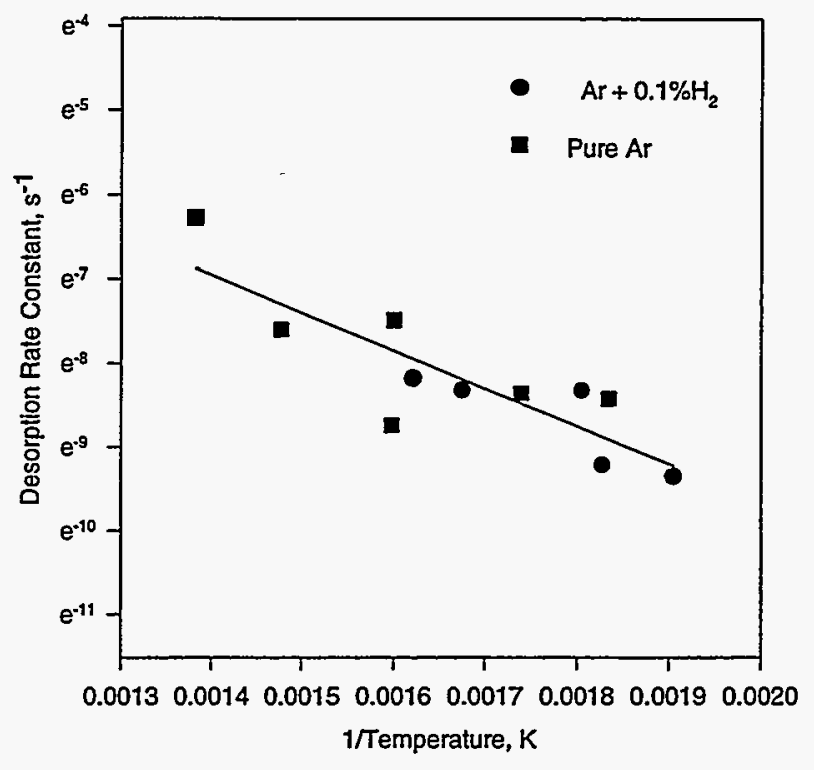
measurements on $\mathrm{Li}_{2} \mathrm{TiO}_{3} \cdot[1,3]$ This activation energy is quite low and suggests that the rate-controlling step does not involve breaking covalent $\mathrm{M}-\mathrm{OH}$ and $\mathrm{O}-\mathrm{H}$ bonds. In comparison, the desorption of tritium from $\mathrm{Li}_{2} \mathrm{O}$, which is believed to follow step (a) as the rate-controlling step, has an activation energy between 102 and $132 \mathrm{~kJ} / \mathrm{mol}$.[4] This step involves breaking $\mathrm{Li}-\mathrm{OH}$ and $\mathrm{LiO}-\mathrm{H}$ bonds.

Some insight into the desorption of tritium from $\mathrm{Li}_{2} \mathrm{TiO}_{3}$ may be gained by studying the adsorption and desorption of water from $\mathrm{TiO}_{2}$. Egashira et al. [5] and Lo et al. [6] report that water is adsorbed and desorbed mainly as an intact molecule from a stoichiometric $\mathrm{TiO}_{2}$ surface; however, dissociative adsorption can occur when $\mathrm{Ti}^{3+}$ defects are present. The TPD experiments of Egashira et al. indicate two types of surface bound water molecules which desorb from the $\mathrm{TiO}_{2}$ surface with desorption activation energies ranging from 36 to $69 \mathrm{~kJ} / \mathrm{mol}$.[5] In contrast, desorption of water from recombination of hydroxyl groups appears to have a desorption activation energy of $104 \mathrm{~kJ} / \mathrm{mol} .[5,6]$ Electron spectroscopy and ultraviolet photoemission spectroscopy have been used to identify the species responsible for these desorption peaks as intact water molecules on the $\mathrm{TiO}_{2}$ surface, or as hydroxyl groups.[6] Assuming that the crystallographic differences between the surfaces of $\mathrm{TiO}_{2}$ and $\mathrm{Li}_{2} \mathrm{TiO}_{3}$ have a minimal impact on the binding of water to a $\mathrm{Ti}^{4+}$ or $\mathrm{O}^{2-}$ ion in the structures, the similarity of the observed tritium desorption activation energy of 37 $\mathrm{kJ} / \mathrm{mol}$ to the activation energy for desorption of water from $\mathrm{TiO}_{2}$ suggests that the rate-controlling step for tritium desorption from $\mathrm{Li}_{2} \mathrm{TiO}_{3}$ in these isothermal anneals is desorption of $\mathrm{HTO}$ from the $\mathrm{Li}_{2} \mathrm{TiO}_{3}$ surface.

During the isothermal anneal experiments, it was found that not all of the tritium was released during the first $24 \mathrm{~h}$ anneal. The fraction of tritium released in the first anneal (total determined by the amount of tritium released during the first anneal plus the amount released during the subsequent anneal at $900^{\circ} \mathrm{C}$ ) is plotted versus anneal temperature in Figure 2. There is a striking difference in the fraction of tritium released into a purge of pure $\mathrm{Ar}$ and one of $\mathrm{Ar}+0.1 \% \mathrm{H}_{2}$. For example, at $300^{\circ} \mathrm{C}, 60 \%$ of the tritium in the sample is released in $24 \mathrm{~h}$ when the purge is Ar+0.1\% H $\mathrm{H}_{2}$ while only about $18 \%$ is released in $24 \mathrm{~h}$ at $302^{\circ} \mathrm{C}$ in pure $\mathrm{Ar}$. 
It is clear that hydrogen addition to the purge gas is beneficial for tritium release from these lithium titanate pebbles. The benefit occurs as a result of increasing the fraction of tritium released at low temperatures. The fraction released is not determined by kinetics, since the calculated fraction of tritium released in $24 \mathrm{~h}$ is consistently greater than $99 \%$ if it is determined from the desorption rate constant obtained from the fits to the desorption data. The observation that the fraction released is less than this percentage suggests that not all of the tritium is available for immediate release. This may be due to more than one chemical form of tritium in the solid (or on the surface), at least one of which is being released very slowly or not at all at the temperatures of the anneals. This hypothesis is supported by TPD experiments which indicate several desorption peaks. ${ }^{1,3}$ However, more work needs to be done to determine whether different chemical forms of tritium actually exist on the surface or in the solid and to identify these species. The role of hydrogen in changing the fraction of

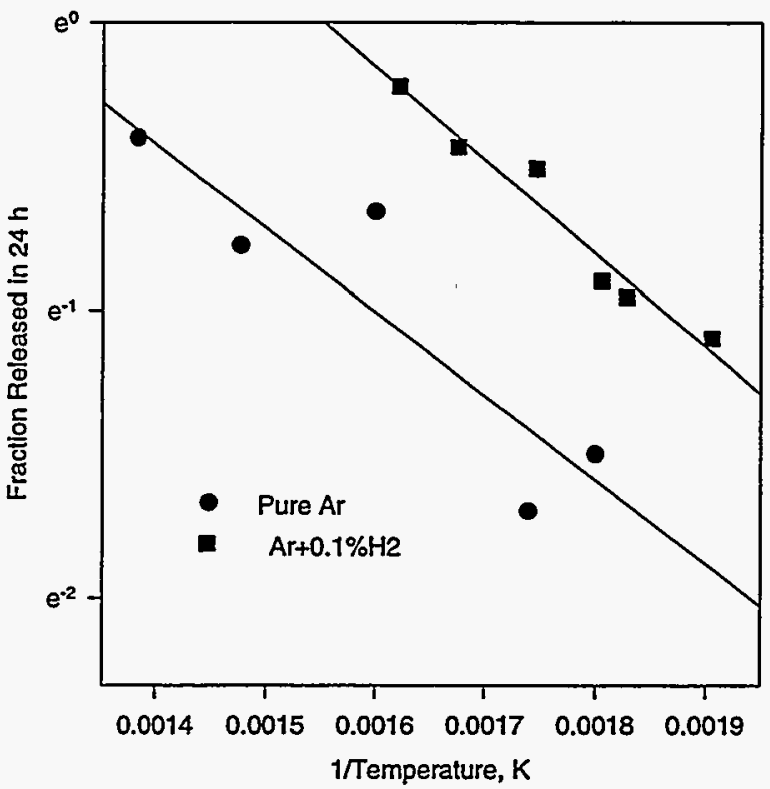

Figure 2. Effect of hydrogen pressure on the fraction of tritium released in $24 \mathrm{~h}$.

tritium released during the low temperature anneals is not understood at this time. It may be influencing electronic defects, reacting with impurities in the solid which control tritium release, or affecting the equilibria between reduced and oxidized tritium species.

\section{FUTURE WORK}

Additional experiments are planned to determine the role of hydrogen in assisting tritium release from ceramic breeder materials. These include diffuse reflectance infrared spectroscopic studies to determine if different hydrogenic species occur on the surface $(\mathrm{TiOH}, \mathrm{LiOH}, \mathrm{LiH}, \mathrm{TiH}$, etc), as well as isothermal anneals in purge gases with varying hydrogen concentrations.

\section{REFERENCES}

1. J. M. Miller, H. B. Hamilton, and J. D. Sullivan, J. Nucl. Mater. 212-215 (1994) 877.

2 J. P. Kopasz, C. A. Seils, and C. E. Johnson, J. Nucl. Mater. 191-194 (1992) 231.

3. J. P. Kopasz, J. M. Miller, and C. E. Johnson, J. Nucl. Mater. 122-215 (1994) 927. 4. J. Quanci, " Tritium Breeding and Release Rate Kinetics from Neutron Irradiated Lithium Oxide," PhD Thesis, Princeton University, Dept. of Chemical Engineering, Jan. 1989.

5. M. Egashira, S. Kawasumi, S. Kagawa, and T. Seiyama, Bulletin of the Chemical Society of Japan, 51 (1978) 3144.

6. W. J. Lo, Y. W. Chung, and G. A. Somorjai, Surface Science 71 (1978) 199. 
-

4 
$A b$ initio CALCULATIONS FOR DISSOCIATIVE HYDROGEN ADSORPTION ON LITHIUM OXIDE SURFACES A. Sutjianto, S.W. Tam, L. Curtiss, and C.E. Johnson (Argonne National Laboratory) and R. Pandey (Michigan Technological University)

\section{OBJECTIVE}

The objective of this work was to investigate dissociative hydrogen adsorption on lithium oxide surfaces. The surfaces were described using the so-called slab model, i.e., a finite number of atomic layers parallel to the exposed face.

\section{SUMMARY}

Dissociative hydrogen chemisorption on the $\mathrm{Li}_{2} \mathrm{O}$ surfaces of the (100), (110), and (111) planes has been investigated with $a b$ initio Hartree-Fock calculations. Calculations for unrelaxed crystal $\mathrm{Li}_{2} \mathrm{O}$ structures indicated that except for the (100) surface, the (110) and (111) surfaces are stable. Results on the heterolytic sites of n-layer (110) slabs (where $n \geq 2$ ) and three-layer (111) slabs suggest that dissociative hydrogen chemisorption is endothermic. For a one-layer (110) slab at $100 \%$ surface coverage, the dissociative hydrogen chemisorption is exothermic, forming $\mathrm{OH}^{-}$and $\mathrm{Li}^{+} \mathrm{H}^{-} \mathrm{Li}^{+}$. This results also indicate that the low coordination environment in surface step structure, such as kinks and ledges, may play an important role in the hydrogen chemisorption process. On the homolytic sites of the (110) and (111) surfaces, there is no hydrogen chemisorption.

\section{PROGRESS AND STATUS}

\section{Introduction}

Lithium ceramics are a leading class of materials being considered as tritium breeders for fusion technology. Hydrogen is known to enhance the release of tritium from irradiated lithium ceramics. This "accelerator" role of hydrogen has been demonstrated in numerous in-pile experiments on tritium release [15]. The enhancement effect is usually accomplished by the addition of hydrogen (typically at a level of around $0.1 \%$ ) to the helium purge gas. Despite this positive benefit, the use of hydrogen is not without problems. Chief among them are problems associated with tritium management via isotopic separation (due to the large hydrogen/tritium ratio) and tritium containment (arising from the presence of reduced form of tritium and the potential permeation loss).

To overcome these problems, one needs to gain an understanding of the mechanism through which hydrogen enhances tritium release. This knowledge would also benefit the search for alternative "accelerator" materials besides hydrogen. Therefore, we have initiated a program to investigate the process of hydrogen adsorption onto lithium oxide surfaces. This program combines an experimental component involving temperature programmed desorption with computer simulations that model the hydrogen adsorption process. This work reports the result of the computer simulation.

\section{Method}

The technique that we have employed is the self-consistent-field Hartree-Fock linear combination of atomic orbital method modified to a crystalline environment. This $a b$ initio method contains no ad hoc adjustable parameters and uses crystal orbital(COs) instead of molecular orbital (MOs). These COs are defined (similar to the quantum molecular approach) as a linear-combination of atomic orbitals but with the periodic environment of the crystal built in. This approach takes the extended nature of the crystalline materials into account. The CRYSTAL code [6] used for such calculationst has adopted this CO approach.

One of the keys to a successful $a b$ initio calculation is obtaining a basis set that represents the electronic structure of the species. In the case of lithium oxide, its bonding characteristic is strongly ionic. 
In free space, the $\mathrm{O}^{2-}$ is an unstable ion; however, in crystalline $\mathrm{Li}_{2} \mathrm{O}$, the anion is actually stabilized by the surrounding cation (in our case, lithium) environment. In this situation the two extra electrons on the oxygen ion would induce a relaxation of the valence electrons. This particular consideration for $\mathrm{O}^{2-}$ is necessary for any oxide that involves this oxygen ion in which the bonding is reasonably ionic. The effect is taken into account in an optimized basis set designed for the oxygen ion in a $\mathrm{Li}_{2} \mathrm{O}$ environment[7]. Recent calculations on bulk crystalline $\mathrm{Li}_{2} \mathrm{O}$ done by Dovesi, et al. [7] have indicated that the optimized basis set is able to give the lattice constant, bulk modulus, and elastic constant in good agreement with experimental values. We have therefore adopted this crystalline basis set [7] for our calculations involving lithium oxide. For the hydrogen, we have used the basis set obtained by Dovesi [8] where the calculated equilibrium Hartree-Fock bond length of $\mathrm{H}_{2}$ of $0.738 \AA$ is in good agreement with its experimental value of $0.742 \AA[9]$

\section{Results and discussion [10]}

The geometrical and electronic structures of the bulk $\mathrm{Li}_{2} \mathrm{O}$, the stability of the $\mathrm{Li}_{2} \mathrm{O}$ surfaces, and dissociative hydrogen chemisorption on the $\mathrm{Li}_{2} \mathrm{O}$ surfaces are discussed in the following sections.

\section{Stability of unrelaxed $\mathrm{Li}_{2} \mathrm{O}$ crystal surfaces}

The surface study was carried out with the slab model. In this model, the semi-infinite $\mathrm{Li}_{2} \mathrm{O}$ crystal was simulated by a finite number of atomic layers parallel to the exposed face, reproducing the crystal geometry. Lithium oxide crystal has three surfaces, namely, (100), (110), and (111). The (100) surface consists of alternating lithium layers and oxygen layers. The distance between the two layers is $1.143 \AA$. Each layer of the (110) surface is neutral and has both lithium and oxygen on the same plane. The layer separation is 1.617 $\AA$. The (111) planes, for the smallest neutral unit have two lithium layers with one oxygen layer. The distance between the lithium layer and the oxygen layer is $0.660 \AA$, and the distance between the two adjacent layers is $1.320 \AA$. The stacking of the layers for these different surfaces is represented in Fig 1 .

Tasker [11] classified the charged layers into three classes, depending on the stacking sequences of the charged planes as one moves into the bulk of the crystal. The stacks of (100) planes are charged and have a dipole moment $(\mu)$ perpendicular to the planes (Fig. 1a). Addition of an extra neutral unit of two planes to the (100) surface creates dipole-dipole interaction, which will affect the energy of ions in the bulk crystal. The potential, therefore, never settles to its normal bulk value, and the surface energy does not converge. Thus, the (100) surface is energetically unstable and, therefore, will not be considered further in this work. Unlike the (100) planes, the (110) layers are built up from a stack of neutral layers (Fig. 1b). Both lithium and oxygen ions are present on each plane in a ratio such that the total charge is zero. The (110) surface is energetically stable since no dipole moment is created by the layer. Addition of (110) planes on the surface will have no electrostatic effect on an ion in the bulk. The (111) planes exhibit two different stackings. For one of these, the surface which terminates with the cation layer [Fig. 1c (i)] has no net dipole moment and is stable. The other, which starts with the anion layer [Fig. 1c (ii)], has a non-zero moment and causes the surface to be unstable. To our knowledge, no experimental study has been done on the ordering and facet properties of $\mathrm{Li}_{2} \mathrm{O}$ surfaces. There has been an experimental study on the properties of (100) and (111) surfaces of $\mathrm{UO}_{2}$ (fluorite crystalline structure) determined by LEED (Low Energy Electron Diffraction) [12]. This study indicates that the (100) surface of uranium dioxide is also not stable.

The calculated surface energy of (111) and (110) surfaces is $0.679 \mathrm{~J} \mathrm{~m}^{-2}$ and $1.443 \mathrm{~J} \mathrm{~m}^{-2}$, respectively. This reflects the fact that the (111) surface is the natural cleavage plane in the anti-fluorite structure. Although the (111) surface is energetically more favorable, in reality, one expects that a faceted $\mathrm{Li}_{2} \mathrm{O}$ crystal would have both (110) and (111) surfaces present on a typical ceramic surface. 
(100)
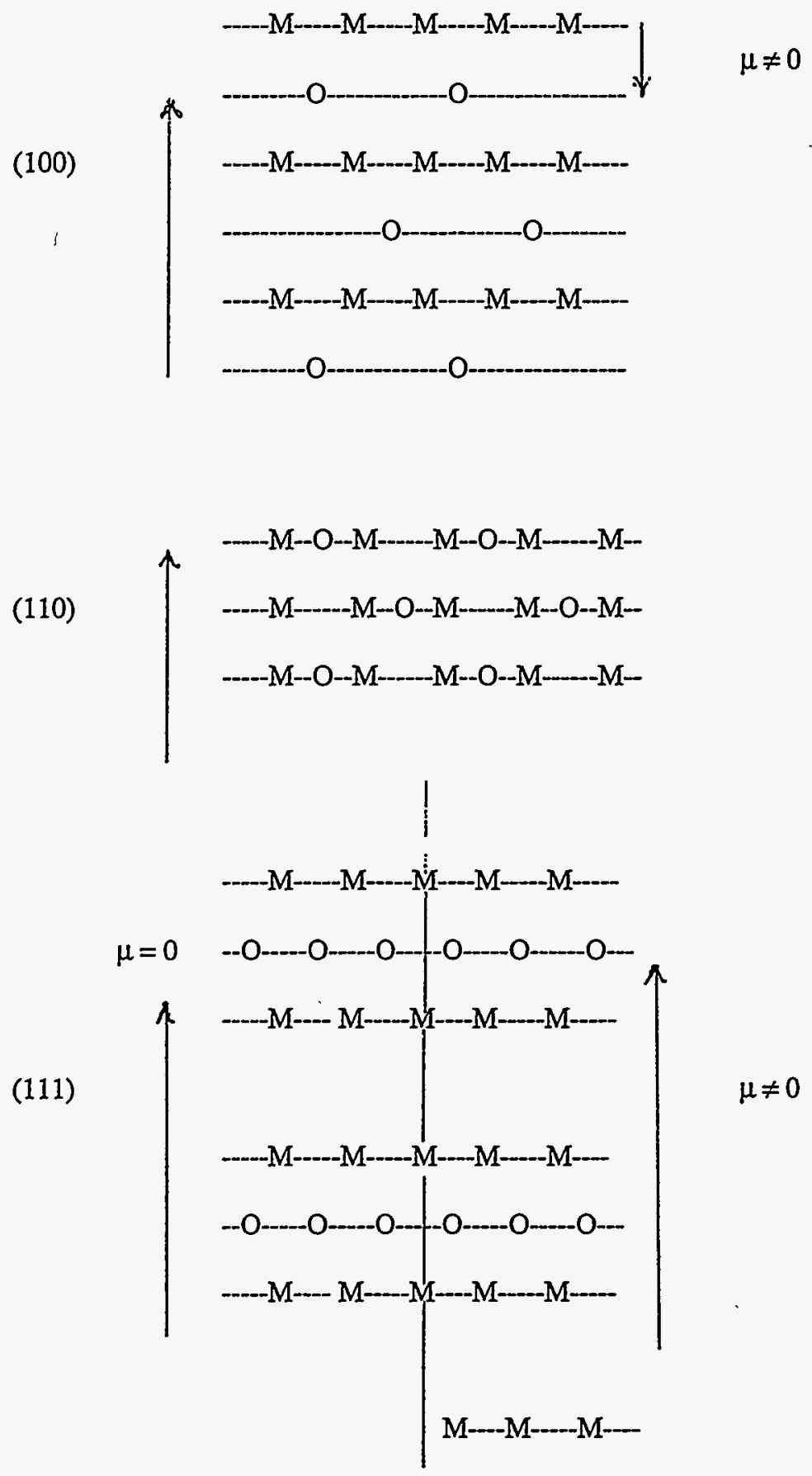

(i)

(ii)

Figure 1. Stacking sequence of (100), (110), and (111) planes. The non-zero dipole moments $(\mu)$ occur on the (100) and (111) planes, with the anion termination. $\mathrm{M}$ denotes the $\mathrm{Li}^{+}$and $\mathrm{O}$ is $\mathrm{O}^{2-}$. 
Dissociative hydrogen chemisorption on the heterolytic site (110) and (111) terraces

Terraces are atomically flat planes on a crystalline surface and may terminate at structures called "steps". Two classes of adsorption sites are considered below: heterolytic sites, in this case Li-O sites, and homolytic sites, such as $\mathrm{Li}-\mathrm{Li}$ and $\mathrm{O}-\mathrm{O}$ sites.

Figs. 2 and 3 show a part of the extended top layer of the (110) terrace and the projection of the three (111) layers. To study $\mathrm{H}-\mathrm{H}$ chemisorption on these terraces, we set up locations, within a unit cell, to place two hydrogen atoms. The unit cell of $(110)$ and (111) surfaces is defined by the basis vectors $\left(\mathbf{a}_{1}, \mathbf{a}_{2}\right)$ and $\left(b_{1}, b_{2}\right)$ as shown in Figs. 2 and 3, respectively. The adsorption locations of the two hydrogen atoms being considered are also shown in these figures. Dissociative hydrogen sites are denoted by $\mathrm{H}(1) \mathrm{H}(2)$, $\mathrm{H}(1) \mathrm{H}(3)$, and $\mathrm{H}(1) \mathrm{H}(4)$, where, for example, $\mathrm{H}(1) \mathrm{H}(2)$ means that, at location 1, one of the hydrogen atoms is on top of oxygen and the other hydrogen is on top of lithium at location 2. Note that the model was set up such that the dissociative hydrogen appears only on top of surfaces; no hydrogen appears below the surfaces.

For each given $\mathrm{H}-\mathrm{H}$ at a particular location, the calculations were done for one, two, and three (110) layers and for three (111) layers. Surface coverage of $100 \%$ and $50 \%$ were also considered for the n-layer slab (where $n=1,2$, and 3 ) for the (110) surface and $100 \%, 50 \%$ and $25 \%$ for the three-layer (111) surface. The $100 \%$ surface coverage means that each unit cell of the slab contains a dissociative hydrogen $(\mathrm{H}-\mathrm{H})$; $50 \%$, and $25 \%$ surface coverage represent an $\mathrm{H}-\mathrm{H}$ within each repeated cell that is two and four times larger than the original unit cell, respectively.

Heat of adsorption, $E_{c h}$, of the hydrogen at each reaction site is calculated by the following equation,

$$
E_{c h}=E^{n}(H-H)-\left[E^{n}+E\left(H_{2}\right)\right] \text {, }
$$

where $E^{\mathrm{n}}(\mathrm{H}-\mathrm{H})$ represents the minimum total energy where dissociative hydrogen is chemisorbed at a given location (with the optimized $h, d, \theta$ and $s$ ) on the surface, $E^{\mathrm{n}}$ denotes the total energies of an n-layer slab, and $\mathrm{E}\left(\mathrm{H}_{2}\right)$ denotes the energy of the free hydrogen molecule. The convention for Eq. (1) is as follows: if $\mathrm{E}_{\mathrm{ch}}$ is negative, then the chemisorption is exothermic; if $\mathrm{E}_{\mathrm{ch}}$ is positive, the chemisorption is endothermic.

\section{Heats of adsorption}

Table 1 lists the calculated heat of adsorption at the given locations (Figs. 2 and 3) for the (110) and (111) terraces. As the number of layer increases from two to three layers, the $\mathrm{H}-\mathrm{H}$ chemisorption energies on (110) surface, particularly at $\mathrm{H}(1) \mathrm{H}(3)$, tend to become less endothermic. The heat of absorption of dissociative hydrogen at the given locations on four- and six-layer (110) slabs has also been studied. The calculated results indicate no further change of the adsorption energy for $n \geq 3$. Thus, all subsequent calculation are for the three-layer slab.

For a one-layer (110) slab as shown in Fig. 2, each anion is surrounded by four cations. This arrangement is of lower coordination when compared with six cations for each anion on a two-layer (110) slab. Consequently, a one-layer (110) slab is more reactive than slabs with more layers. Although a onelayer (110) slab is not a realistic model for a surface, this configuration could be used to understand the role of the lower coordination number of oxygen on surface step structures such as kinks and ledges. On a onelayer (110) slab with $100 \%$ surface coverage of $\mathrm{H}-\mathrm{H}$, the chemisorption state has an energy of $-0.93 \mathrm{eV}$, for which one hydrogen attaches to the oxygen and the other hydrogen is attached between two lithiums (Fig. 2). 
Table 1. The calculated Hartree-Fock LCAO-CO bondlengths $d(\AA)$ of dissociated hydrogen, located on top of the (110) and (111) surfaces (Figs. 2 and 3), and the heat of adsorption, $E_{\mathrm{ch}}(\mathrm{eV})$, for $n=1,2$, and 3 layers as obtained from CRYSTAL.

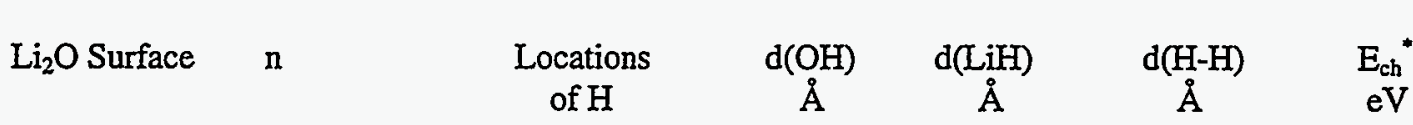

(110)

[Figure 2]

\begin{tabular}{|c|c|c|c|c|c|}
\hline & $\mathrm{H}(1) \mathrm{H}(2)$ & 0.96 & 1.54 & 2.06 & 0.94 \\
\hline & $\mathrm{H}(1) \mathrm{H}(3)$ & 0.96 & 1.59 & 2.08 & -0.93 \\
\hline 1 & $\mathrm{H}(1) \mathrm{H}(4)$ & 0.96 & 2.04 & 2.33 & -0.64 \\
\hline \multirow[t]{3}{*}{2} & $\mathrm{H}(1) \mathrm{H}(2)$ & $\begin{array}{l}0.98 \\
(0.97)\end{array}$ & $\begin{array}{l}1.57 \\
(1.57)\end{array}$ & $\begin{array}{l}2.07 \\
(2.07)\end{array}$ & $\begin{array}{l}1.71 \\
(2.27)\end{array}$ \\
\hline & $\mathrm{H}(1) \mathrm{H}(3)$ & $\begin{array}{l}0.96 \\
(0.96)\end{array}$ & $\begin{array}{l}1.69 \\
(1.73)\end{array}$ & $\begin{array}{l}2.89 \\
(2.90)\end{array}$ & $\begin{array}{l}0.57 \\
(1.02)\end{array}$ \\
\hline & $\mathrm{H}(1) \mathrm{H}(4)$ & $\begin{array}{l}0.96 \\
(0.96)\end{array}$ & $\begin{array}{l}2.20 \\
(2.21)\end{array}$ & $\begin{array}{l}2.60 \\
(2.60)\end{array}$ & $\begin{array}{l}0.86 \\
(1.43)\end{array}$ \\
\hline \multirow[t]{3}{*}{3} & $\mathrm{H}(1) \mathrm{H}(2)$ & $\begin{array}{l}0.97 \\
(0.97)\end{array}$ & $\begin{array}{l}1.57 \\
(1.58)\end{array}$ & $\begin{array}{l}2.07 \\
(2.07)\end{array}$ & $\begin{array}{l}1.54 \\
(1.82)\end{array}$ \\
\hline & $\mathrm{H}(1) \mathrm{H}(3)$ & $\begin{array}{l}0.96 \\
(0.96)\end{array}$ & $\begin{array}{l}1.65 \\
(1.72)\end{array}$ & $\begin{array}{l}2.88 \\
(2.90)\end{array}$ & $\begin{array}{l}0.33 \\
(0.79)\end{array}$ \\
\hline & $\mathrm{H}(1) \mathrm{H}(4)$ & $\begin{array}{l}0.96 \\
(0.96)\end{array}$ & $\begin{array}{l}2.18 \\
(2.21)\end{array}$ & $\begin{array}{l}2.59 \\
(2.61)\end{array}$ & $\begin{array}{l}0.61 \\
(1.05)\end{array}$ \\
\hline
\end{tabular}

(111)

[Figure 3]

3

$\begin{array}{rllll}\mathrm{H}(1) \mathrm{H}(2) & 1.1 & 1.48 & 2.14 & 3.65 \\ & (1.0) & (1.55) & (2.17) & (2.96) \\ & {[1.0]} & {[1.70]} & {[2.31]} & {[2.70]} \\ \mathrm{H}(1) \mathrm{H}(3) & 1.0 & 1.60 & 2.77 & 3.24 \\ & (1.0) & (1.60) & (2.77) & (2.24) \\ & {[1.0]} & {[1.65]} & {[2.80]} & {[1.95]} \\ \mathrm{H}(1) \mathrm{H}(4) & 1.0 & 2.22 & 1.27 & 2.73 \\ & (1.0) & (2.25) & (1.30) & (2.10) \\ & {[1.0]} & {[2.33]} & {[1.41]} & {[1.74]}\end{array}$

The calculated adsorption energies are listed for various surface coverages. For $25 \%, 50 \%$, and $100 \%$ surface coverages are represented by the data in the square bracket, bracket, and without bracket, respectively. 


\section{Electronic structure}

Fig. 4 illustrates the density of states (DOS) for a one-layer slab of (110) surface, and $100 \%$ surface coverage, before and after chemisorption. Before chemisorption (finer lines), the uppermost valence bands are the $O 2 p$ bands indicated by the three peaks (denoting $2 p_{x}, 2 p_{y}$ and $2 p_{z}$ bands). The $O 2 p_{z}$ plays the key role in the interaction with the hydrogen.

The thicker lines in Fig. 4 are the DOS in the presence of dissociative hydrogen at $\mathrm{H}(1) \mathrm{H}(3)$ (see Fig. 2). In the dissociative chemisorption state, the $\mathrm{O} 2 \mathrm{~s}$ band is stabilized downward by a band shift of about $4.5 \mathrm{eV}$. For the $\mathrm{O} 2 \mathrm{p}$ bands, the $2 \mathrm{p}_{\mathrm{x}}$ and $2 \mathrm{p}_{\mathrm{y}}$ bands are also shifted by about $3.58 \mathrm{eV}$. The narrow band between -16.770 and $-16.410 \mathrm{eV}$ represents the formation of $\mathrm{OH}^{-}$as a result of overlapping between the $\mathrm{O}$ $2 \mathrm{p}_{\mathrm{z}}$ and $\mathrm{H}$ 1s orbital. There is no contribution from the $2 \mathrm{px}$ and $2 \mathrm{py}$ orbital in the $\mathrm{O}-\mathrm{H}$ bond. A gap of 1.2 $\mathrm{eV}$ is created between the $2 p_{z}$ and both the $2 p_{x}$ and $2 p_{y}$ bands. The band that lies between -9.470 and -7.960 $\mathrm{eV}$ represents the $\mathrm{H}^{-}$that bonds with the two cations in the form of $\mathrm{Li}^{+} \mathrm{HLi}^{+}$.

The electronic charge densities of the $\mathrm{OH}^{-}$and $\mathrm{Li}^{+} \mathrm{HLi}^{+}$are shown in Figs. 5 and 6. A strong bond appears for $\mathrm{OH}^{-}$with a very localized electronic charge density, while for $\mathrm{Li}^{+} \mathrm{HLi}^{+}$the bonding is more ionic, with a clear-cut charge separation between $\mathrm{Li}^{+}$and $\mathrm{H}$. The $\mathrm{OH}$ and $\mathrm{LiH}$ bond lengths are 0.96 and $1.54 \AA$, respectively, which are closely comparable with the $\mathrm{OH}(0.97 \AA)$ and $\mathrm{LiH}(1.595 \AA)$ bond lengths reported for the gas phase[9]. For lower coverage (50\%) on a one-layer (110) slab, endothermic H-H chemisorption occurs. This means that the exothermic dissociative hydrogen chemisorption at $100 \%$ coverage may be due to the lower coordination of the $\mathrm{Li}-\mathrm{O}$ site or to nearest neighbor adsorbate-adsorbate interactions.

Results from the n-layer (110) slab (where $n=2$ and 3 ) with $100 \%$ surface coverage suggest that its $\mathrm{H}$ $\mathrm{H}$ chemisorption is endothermic. The density of states for the $\mathrm{O} 2 \mathrm{p}$ band of the (110) surface in the one-, two-, and three-layer systems (Fig. 7) indicates that the $\mathrm{O} 2 \mathrm{p}$ band stabilizes as additional layers are introduced. For example, in the case of two- and three-layers, the $\mathrm{O} 2 \mathrm{p}$ band shifts are about 2 and $2.6 \mathrm{eV}$, respectively, relative to the upper-limit $\mathrm{O} 2 \mathrm{p}$ band of a one-layer slab. This means that as more layers are introduced to the surface, the surface becomes more stable, as expected. Lower surface coverage (50\%) also exhibits endothermic chemisorption (Table 1).

For the (111) surface, the $O 2 p$ band lies in the range close to the $O 2 p$ band of a one-layer (110) slab, at -10.638 to $-8.086 \mathrm{eV}$. However, only endothermic hydrogen chemisorption occurs on the (111) surface. One reason is screening of the lithium layers; as a result, it is energetically unfavorable for the $\mathrm{H}^{+}$to move close to the positively charged $\mathrm{Li}^{+}$layer before it can be chemisorbed by the $\mathrm{O}^{2-}$.

\section{Dissociative hydrogen chemisorption on the homolytic site (110) and (111) terraces}

Calculations for the homolytic sites of the terrace, such as, $\mathrm{Li}-\mathrm{Li}$ and $\mathrm{O}-\mathrm{O}$, indicate no $\mathrm{H}-\mathrm{H}$ chemisorption. For H-H chemisorption to occur on the homolytic sites, it has to be in the form of either two $\mathrm{H}^{+}$or two $\mathrm{H}^{-}$ions, where each hydrogen attaches to two oxygens or to two lithiums. For the $\mathrm{O}-\mathrm{O}$ site, each oxygen would have to release its valence electron, or each hydrogen would have to release its electron to the crystal environment, and the released electrons would have to be captured by the cations, forming neutral lithiums. For the Li-Li site, each hydrogen would need to capture an electron from oxygen to form $\mathrm{H}^{-}$while the anion becomes $\mathrm{O}^{-}$. Such phenomena do not occur for the $\mathrm{Li}_{2} \mathrm{O}$ surface under equilibrium conditions since they require transferring electrons into the surrounding crystal environment. This is equivalent to creation of electronic defects, (for example, neutral $\mathrm{Li}$ or $\mathrm{O}^{-}$). The surface band structure that we have obtained indicates that electronic disorder is energetically unfavorable. It is possible that electronic defects may occur under highly non-equilibrium conditions, such as irradiation, which creates electronic structure defects on the crystal surface. However, at equilibrium no homolytic chemisorption occurs. 
Summary

Dissociative hydrogen chemisorption on the (110) and (111) terraces has been studied with the $a b$ initio Hartree-Fock technique. Both the finite cluster and extended crystalline models qualitatively agree that endothermic dissociative hydrogen chemisorption occurs on these terraces. The calculations for the (110) terraces in the n-layer slab model (where $\mathrm{n}=2$ and 3 ), indicate a metastable chemisorption at heterolytic sites and no chemisorption at the homolytic sites. Exothermic chemisorption with $100 \%$ coverage takes place for the case of a one-layer (110) slab around the $\mathrm{Li}-\mathrm{O}$ site. This is caused by the lower coordination of the oxygen and nearest neighbor adsorbate-adsorbate interactions. Although a one-layer (110) slab represents an unphysical surface, this model illustrates that a lower coordination environment, as in surface step structures such as kinks and ledges, may play an important role in the hydrogen chemisorption process. This will be investigated in the next state of our work. Although the oxygen (111) terrace has the same local coordination and similar energy range of $O 2 p$ orbital as it does in the (110) terrace, there is only endothermic hydrogen chemisorption.

\section{FUTURE WORK}

A number of approximations used in this study should be noted. First, correlation effects, which can be important in bond breaking and making, were not included. Second, more polarization functions may need to be introduced, particularly, along the bonding between surface site and hydrogen. Third, local relaxation of the surface was not considered. Future studies will take consideration of these effects, as well as use of other types of basis sets, which may give an improved account of bond energetics.

\section{References}

[1] W. Dienst, D. Schild and H. Werle, Kernforschungszentrum, Karlsruhe, Report KfK-5109, December 1992.

[2] O.D. Slagle, T. Takahashi, F.D. Hobbs, K. Noda, D.L. Baldwin, G.W. Hollenberg, and R.A. Verrall, "Postirradition Examination of BEATRIX-II, Phase I", J. Nucl. Mater. 212-215 (1994) 988-992.

[3] H. Kwast, A. Kout, R.P. Muis, M.P. Stijkel, A.J. Flipot, and J.D. Elen, Fusion Engineering and Design 8 (1989) 359-364.

[4] R.G. Clemmer, P.A. Finn, R.F. Malecha, B. Misra, M.C. Billone, D.L. Bowers, A.K. Fischer, L.R. Greenwood, R.F. Mattas, S.W. Tam, R.B. Poeppel, G.T. Reedy, I.T. Dudley, F.F. Dyer, E.D. Clemmer, J.S. Watson, P.W. Fischer, J.R. Conlin, R.L. Childs, J.L. Scott, R.M. Arons and A.E. Scandora, "The TRIO Experiment" Argonne National Laboratory, Argonne, Report ANL-84-85, September 1984.

[5] H. Kwast, R. Conrad, R. May, S. Casadio, N. Roux, and H. Werle, "The Behaviour of Ceramic Breeder Materials with Respect to Tritium Release and Pellet/Pebble Mechanical Integrity", J. Nucl. Mater. 212-215 (1994) 1010-1014.

[6] R. Dovesi, C. Roetti and V.R. Saunders, CRYSTAL92 program.

[7] R. Dovesi, C. Roetti, C. Freyria-Fava, M. Prencipe, Chem. Phys. 156 (1991) 11.

[8] R. Dovesi, C. Ermondi, E. Ferrero, C. Pisani and C. Roetti, Phys. Rev. B 29 (1984)

[9] Warren J. Hehre et al., Ab Initio Molecular Orbital Theory (Wiley, N.Y., 1986) pp.138 and pp.210.

[10] A. Sutjianto, S.W. Tam, L. Curtiss, and C.E. Johnson, J. Nucl. Mater. 219 (1995) 250-258.

[11] P.W. Tasker, Surf. Sci. 87 (1979) 315.

[12] T.N. Taylor and W.P. Ellis, Surf. Sci. 77 (1978) 321.

[13] A. Lichanot, M. Gelize, C. Larrieu and C. Pisani, J. Phys. Chem. Solids 52 (1991) 1155. 


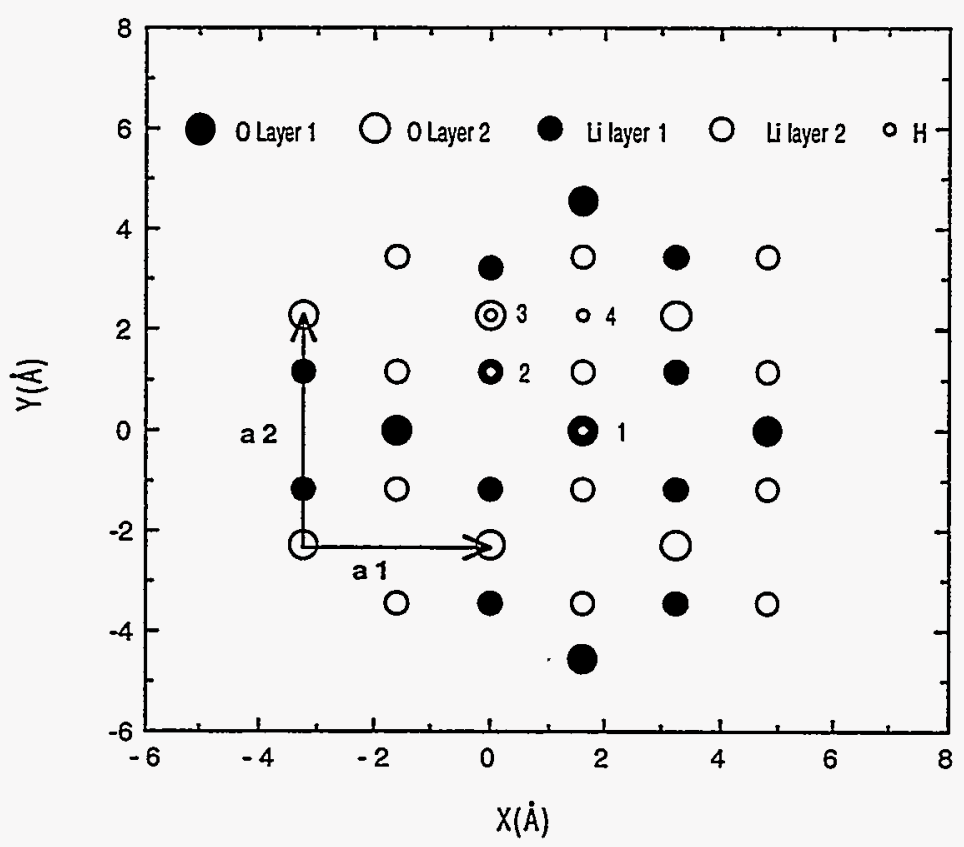

Figure 2. Geometry of the two-layer (110) slab. The unit cell is defined by basis vectors $\mathbf{a}_{1}=(3.23,0.0,0.0) \AA$ and $\mathbf{a}_{2}=(0.0,4.57,0.0) \AA$. The locations of dissociative hydrogen are represented by $1,2,3$, and 4 .

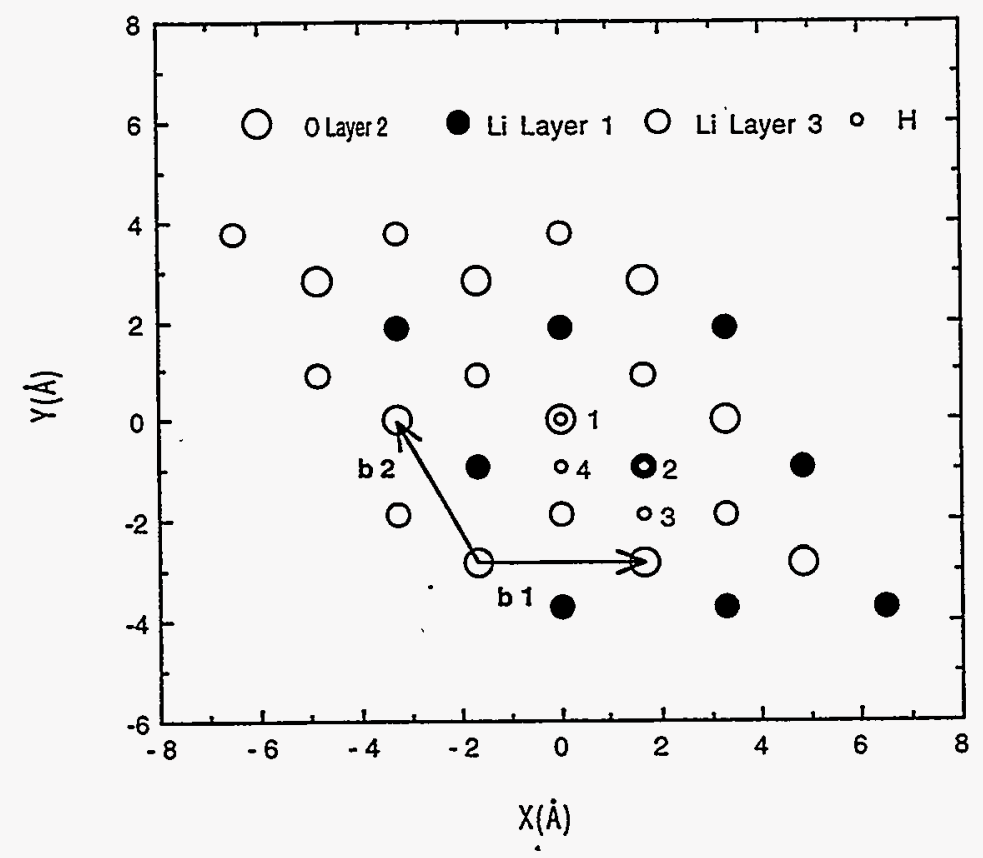

Figure 3. Geometry of the three-layer (111) slab. The unit cell is defined by basis vectors $b_{1}=(3.23,0.0,0.0) \AA$ and $b_{2}=(-1.62,1.87,0.0) \AA$. The locations of and 4. 


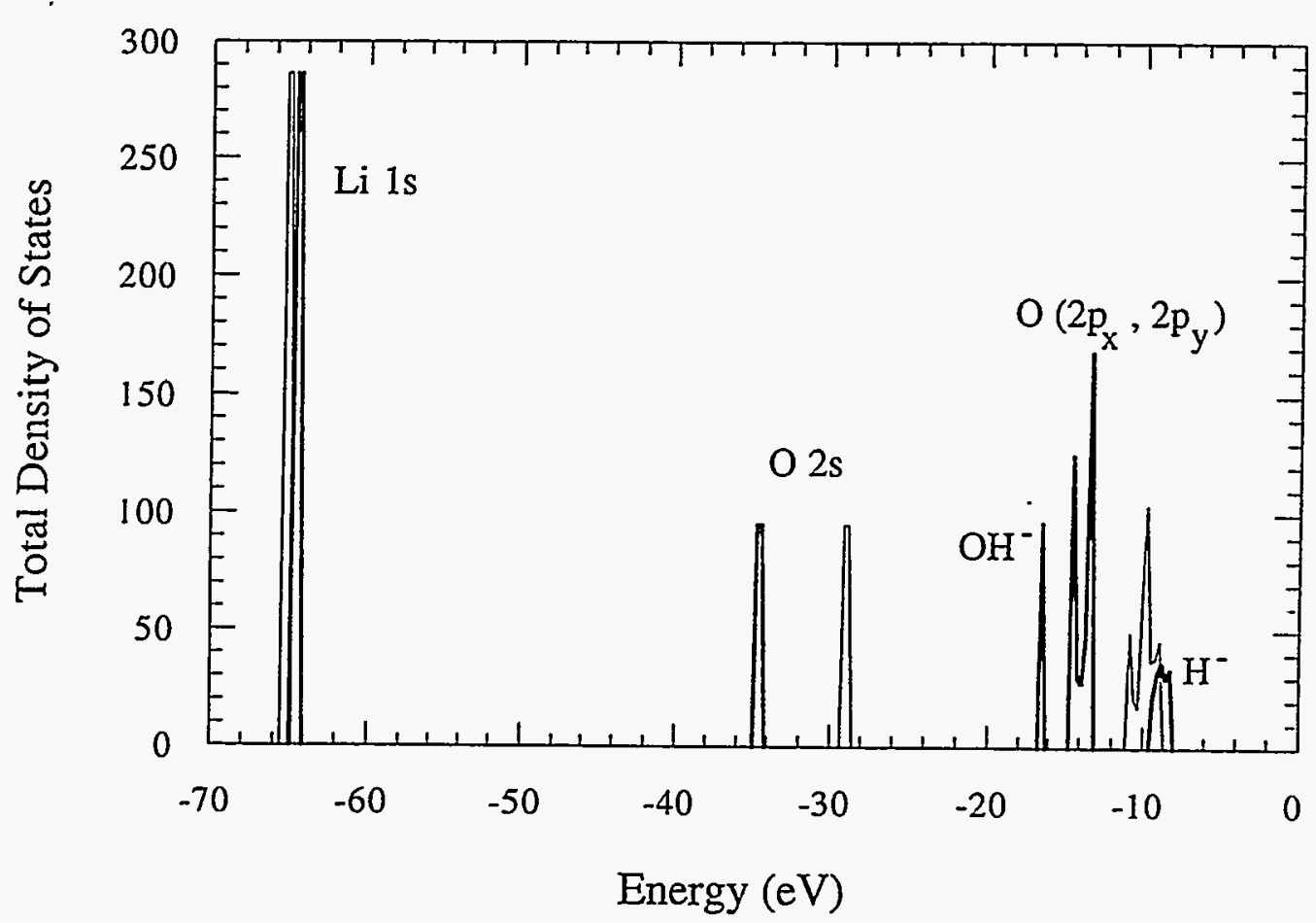

Figure 4. Density of states for a one-layer (110) slab. Before chemisorption is represented by the finer lines. The thicker lines represent the DOS where dissociative hydrogen is chemisorbed.

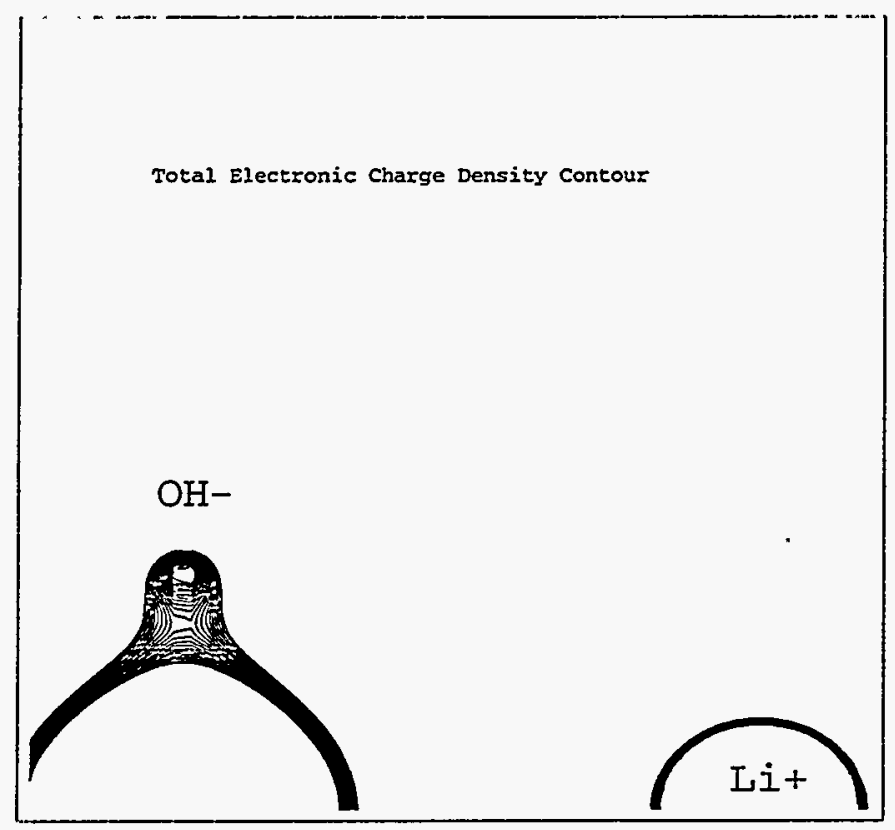

Figure 5. Total electronic charge density map of the $\mathrm{OH}^{-}$bond on a one-layer (110) slab with the contour interval of $0.003 \AA$. 


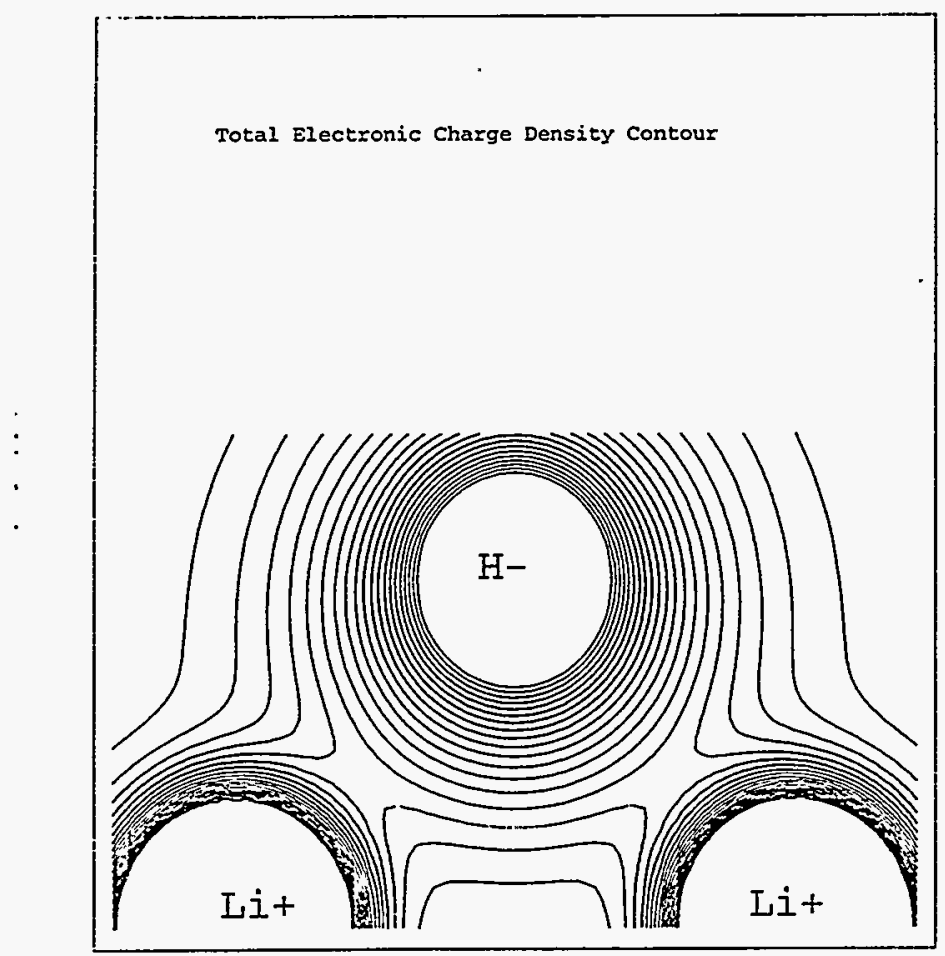

Figure 6. Total electronic charge density map of the ionic bonding of $\mathrm{Li}^{+} \mathrm{HLi}^{+}$on a one-layer (110) slab.

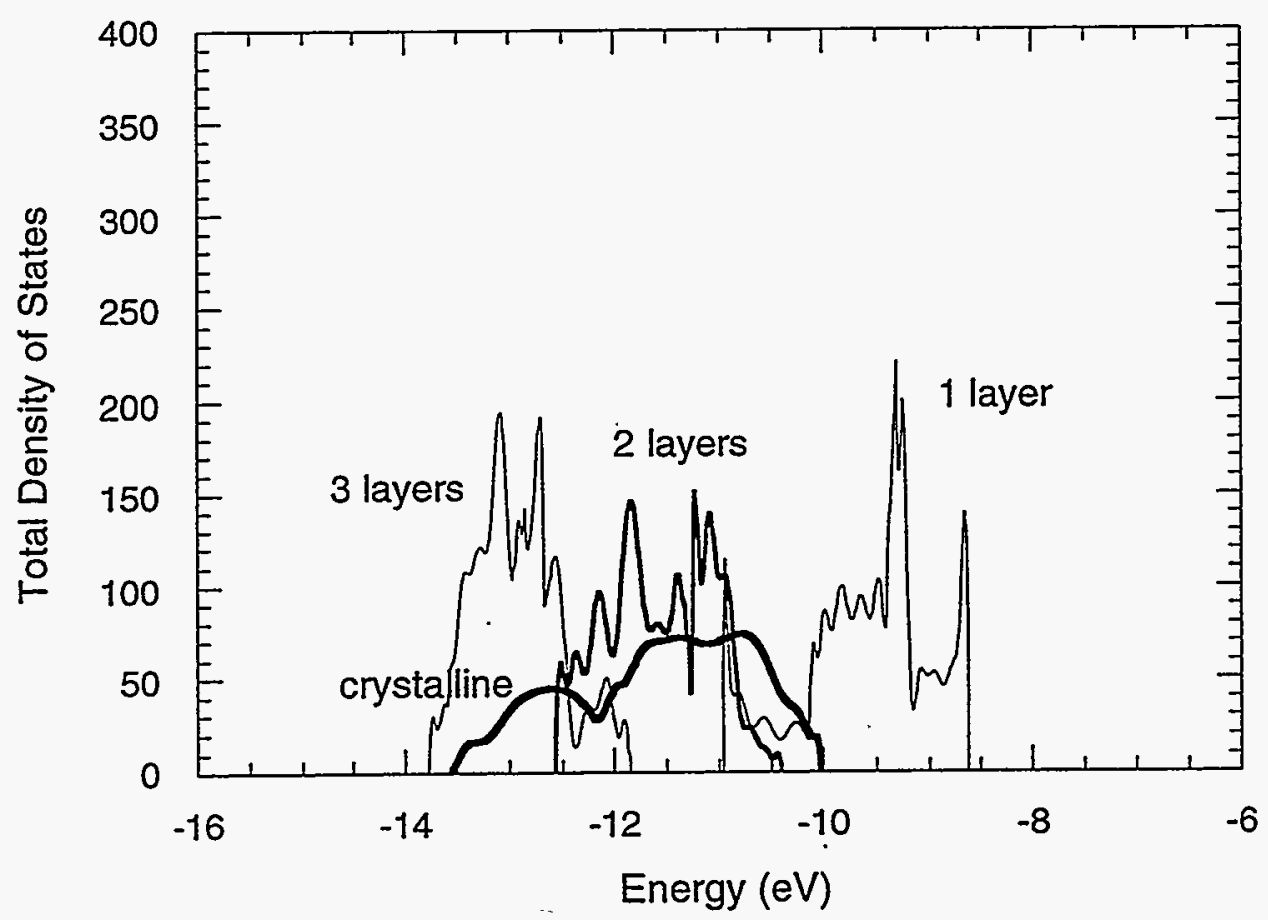

Figure 7. Schematic diagram of the total density of states of $O 2 p$ for the one-, two- and three-layer slab of the (110) surfaces. 


\subsection{CERAMICS}


, 
FATIGUE BEHAVIOR OF NICALON/SiC COMPOSITES - N. Miriyala, P. K. Liaw and C. J. McHargue (University of Tennessee), X. Mao and W. Mao (University of Calgary), L. L. Snead (Oak Ridge National Laboratory) and D. K. Hsu (Iowa State University),

\section{OBJECTIVE}

To develop a fundamental understanding of the fatigue damage phenomenon in Nicalon/SiC composites.

\section{SUMMARY}

A periodic model using a finite element method (FEM) was developed to predict the effect of porosity on the in-plane and through-thickness elastic stiffness constants of Nicalon/SiC composites. The FEM results indicated that the in-plane moduli values will be higher than the through-thickness moduli values. Also, the predicted values were in close agreement with the ultrasonically measured elastic stiffness constants for the composite material under study.

\section{PROGRESS AND STATUS}

\section{Introduction}

Ceramics are endowed with many attractive qualities including low density, high hardness, wear resistance, high melting points and the ability to withstand aggressive environments [12]. As a result, exciting projections have been made about the ability of advanced ceramics to perform structural functions more efficiently than, and in many cases not possible with, the more traditional metallics. Unfortunately, monolithic ceramics are highly sensitive to process and service related flaws, making them inherently brittle. Continuous fiber reinforced ceramics (CFCCs) or whisker reinforced CMCs, however, can provide a significant amount of toughness as well as avoid catastrophic failure [1-3].

Data on the mechanical properties of the CFCCs is rather scarce owing to the experimental difficulties in performing the mechanical tests and often the high material costs. Even more scarce is the theoretical modeling work on mechanical behavior of woven fiber reinforced 
ceramic matrix composites. To our knowledge, only a few attempts have made so far to predict the moduli of woven fabric composites [4-7]. Towards this direction, the FEM study presented in this report augments the recent efforts to predict the mechanical behavior of a woven fiber composite from a knowledge of elastic constants of the constituents that make up the composite.

\section{Theoretical Modeling}

Metallographic examination of the composite revealed that there are two major types of porosity in the Nicalon/SiC composite, viz., porosity at the fiber tow intersection and interlaminar porosity. The extent of interlaminar porosity was found to be greater than the porosity at the fiber tow intersection [4-7]. A finite element model based on periodic microstructure was hence developed to estimate the effect of porosity on the elastic properties of the Nicalon/SiC composites. The representative unit cell shown in Figure 1 was used to model the two major types of porosity and to predict in-plane and through-thickness elastic moduli of the Nicalon/SiC composite.

For stress and strain analysis by the finite element method (FEM), generally the equations of equilibrium are obtained from the principle of minimum total potential energy, and are expressed as

$$
[K]\{U\}=\{P\}
$$

where $[\mathrm{K}],\{\mathrm{U}\}$ and $\{\mathrm{P}\}$ represent total structural stiffness, nodal displacements and applied loads, respectively. After solving for the nodal displacements, the stresses and strains can be evaluated from the following equations.

$$
\begin{gathered}
\{\varepsilon\}=[B]\{U\} \\
\{\sigma\}=[C][B]\{U\}
\end{gathered}
$$

where $\{\varepsilon\},\{\sigma\},\{B\}$ and $[C]$ are strain vector, stress vector, strain-displacement relationship matrix and material property matrix, respectively. 

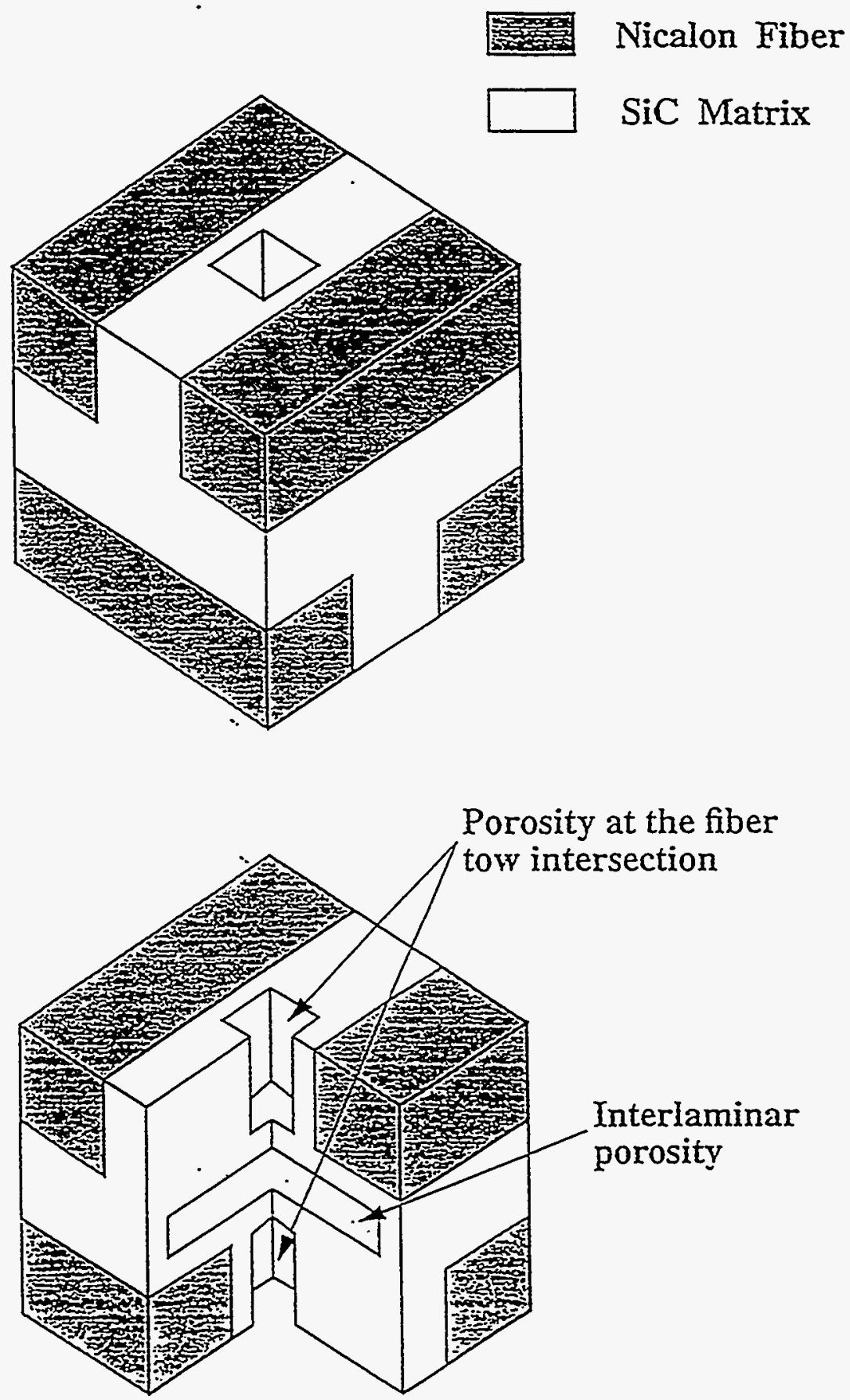

Figure 1. Representative unit cell of Nicalon/SiC composite used in the FEM study 
With $\{\varepsilon\}$ and $\{\sigma\}$, the strain energy of the structure $U$ can be expressed as

$$
U=\frac{1}{2} \int_{V}\{\varepsilon\}^{\top}\{\sigma\} d V
$$

where $\mathrm{V}$ is the volume of the structure.

The method of evaluating the equivalent moduli of the composite is as follows:

1. Calculate the strain energy of a composite material unit by a finite element method

$$
U_{1}=\sum_{i=1}^{n} \int_{V_{i}}\{\varepsilon\}^{\top}\{\sigma\} d V
$$

where $V_{i}$ is the volume of each element and $n$ the number of total elements. The reason for using the finite element method is that it is always possible to mesh the unit in such a way that there is only one type of material in each element.

2. Consider a homogeneous material unit with the same dimensions of the composite material. Apply the same loading and boundary constraint conditions on the homogeneous material unit as on the composite material unit. Then, the strain energy will be

$$
\mathrm{U}_{2}=\frac{1}{2} \int_{V}\{\varepsilon\}^{\top}\{\sigma\} d V=\frac{1}{2} \int_{V}\{\varepsilon\}^{\top}[C]\{\varepsilon\} d V
$$

By choosing specific loading and boundary constraint conditions, we can make only one $\varepsilon_{\mathrm{i}}$ in the $\{\varepsilon\}$ vector remain non-zero. Then,

$$
U_{2}=\frac{1}{2} \int_{V} C_{i i} \varepsilon_{i}^{2} d V
$$

For a homogeneous material, $\mathrm{C}_{\mathrm{ii}}$ is same everywhere. Therefore 


$$
\mathrm{U}_{2}=\frac{\mathrm{C}_{\mathrm{ii}}}{2} \int_{\mathrm{V}} \varepsilon_{\mathrm{i}}^{2} \mathrm{dV}
$$

3. Assume that the equivalent homogeneous unit will contain the same amount of strain energy as its corresponding composite material unit when they are subjected to the same loading and boundary constraint conditions; that is

$$
\mathrm{U}_{1}=\mathrm{U}_{2}
$$

Thus, we finally have

$$
C_{i i}=\frac{U_{1}}{\frac{1}{2} \int_{V} \varepsilon_{i}^{2} d V}
$$

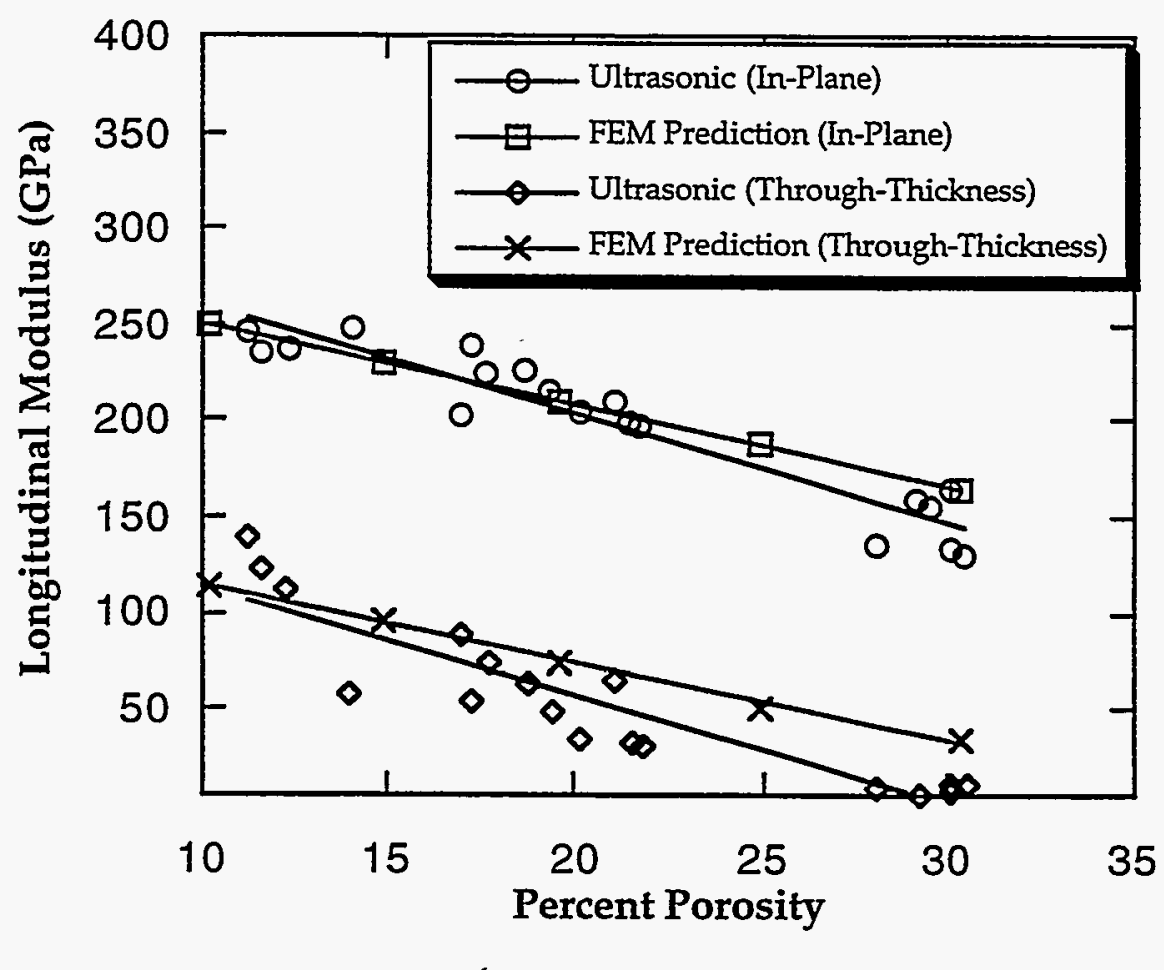

Figure 2. Comparison of ultrasonically measured and FEM predicted longitudinal moduli values in Nicalon/SiC composite 
To calculate the moduli of the composites, the following input data were used [8]; the shear modulus and Poisson's ratio of the Nicalon fiber were $80 \mathrm{GPa}$ and 0.12 , respectively, and those of the matrix were $146 \mathrm{GPa}$ and 0.2 . The predicted in-plane and through thickness

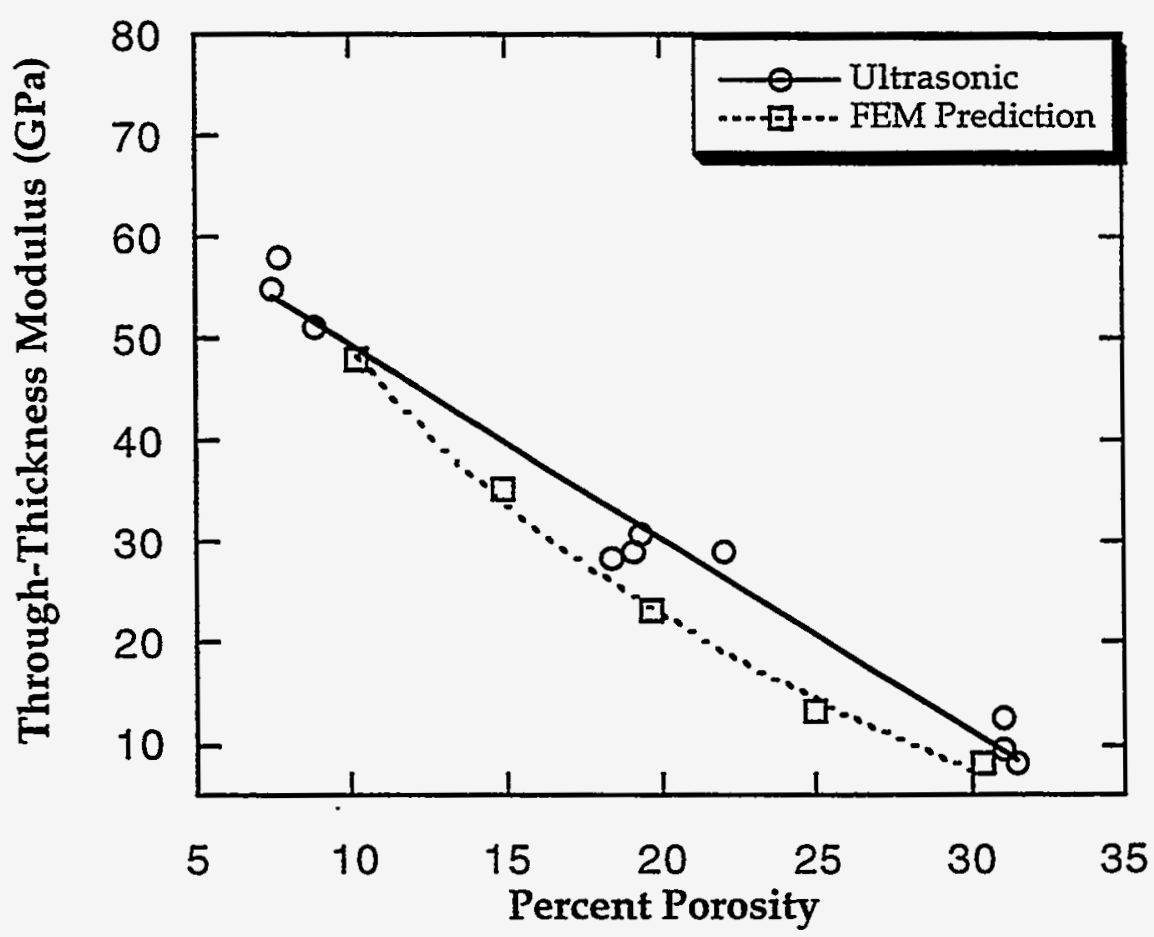

Figure 3. Comparison of ultrasonically measured and FEM predicted shear moduli values in Nicalon/SiC composite

values are plotted in Figures 2 and 3 along with the experimental results. The FEM analysis predicted that (i) the in-plane longitudinal modulus of the composite will be higher than the through-thickness modulus, (ii) the shear modulus will be lower than the longitudinal modulus and (iii) that increased porosity content in the material significantly lowers both longitudinal and shear moduli of the composite. It is evident from Figures 2 and 3 that there is a good agreement between the theoretically predicted values and ultrasonically measured elastic moduli. 


\section{FUTURE WORK}

(i) Flexural fatigue testing of specimens using different R-ratio (minimum stress/maximum stress) values at ambient as well as elevated temperatures.

(ii) Fractography of the specimens to assess the damaging mechanisms that govern the fatigue and fracture behavior of the Nicalon/SiC composites.

(iii) Theoretical modeling of the fatigue damage mechanisms in CFCCs.

\section{ACKNOWLEDGMENTS}

This work is supported by the Department of Energy under contract No. Martin Marietta 11XSL261V to the University of Tennessee. We wish to acknowledge the continued support of Dr. Arthur Rowcliffe and Dr. Everett Bloom of ORNL in our research efforts.

\section{REFERENCES}

[1] K. K. Chawla, "Ceramic Matrix Composites", Chapman \& Hall, London, 1993, pp. 4-10.

[2] T. M. Besmann, B. W. Sheldon, R. A. Lowden and D. P. Stinton, Science, 253, 1991, p. 1104.

[3] J. A. DiCarlo, Adv. Mat. \& Proc., June 1989, p. 41.

[4] P. K. Liaw, D. K. Hsu, N. Yu, N. Miriyala, V. Saini and H. Jeong, Proc. Int. Symp. on High Performance Composites: Commonalty of Phenomena, Rosemont, Illinois, USA, October 2-6, 1994, eds., K. K. Chawla, P. K. Liaw and S. G. Fishman, TMS, Warrendale, 1994, p. 377.

[5] N. J. Fang and T. S. Chou, J. Am. Ceram. Soc., 76, 1993, p. 2539.

[6] P. K. Liaw, N. Yu, D. K. Hsu, N. Miriyala, V. Saini, L. L. Snead, C. J. McHargue and R. A. Lowden, J. Nucl. Mat., 219, 1995, p. 93.

[7] P. K. Liaw, D. K. Hsu, N. Yu, N. Miriyala, V. Saini and H. Jeong, "Investigation of Metal and Ceramic-Matrix Composites Moduli: Experiment and Theory", Acta. Metall. et Mater., in press.

[8] J. L. Bohet, Ph. D Thesis, Bordeaux, France, 1993. 


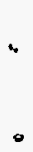

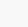


MICROSTRUCTURE OF $\mathrm{Al}_{2} \mathrm{O}_{3}$ IRRADIATED WITH AN APPLIED ELECTRIC FIELD S. J. Zinkle, J.D. Hunn, and R.E. Stoller (Oak Ridge National Laboratory)

\section{OBJECTTVE}

The objective of this study is to examine possible physical causes of permanent radiation-induced electrical degradation in ceramic insulators that are irradiated with an applied electric field.

\section{SUMMARY}

A thin amorphous film of alumina was irradiated with $2-\mathrm{MeV} \mathrm{He}^{+}$ions at $\sim 400^{\circ} \mathrm{C}$ up to a damage level of about 0.01 displacements per atom (dpa). The alumina films were sufficiently thin $(-1.8 \mu \mathrm{m})$ to allow the ion beam to be completely transmitted through the specimen. An electric field of $\sim 280 \mathrm{~V} / \mathrm{mm}$ (dc) was applied continuously during the irradiation. Radiation induced electrical degradation (RIED), i.e. a permanent increase in the conductance of the film, was observed in specimens irradiated at temperatures near 400 to $450^{\circ} \mathrm{C}$ but did not occur in a specimen irradiated above $500^{\circ} \mathrm{C}$. An investigation by transmission electron microscopy found no evidence for colloid formation. The observed increase in the conductance of the alumina film may be due to radiation-induced microcracking.

\section{PROGRESS AND STATUS}

\section{Introduction}

Ceramic insulators are used in magnetic fusion energy components for heating, control and diagnostic measurement of the plasma, and in nuclear thermionic devices under development for space propulsion. The electrical conductivity of the insulator must remain less than $10^{-4} \mathrm{~S} / \mathrm{m}$ during exposure to a radiation field for the proper operation of most of these components [1]. There is a large data base on the electrical conductivity of irradiated ceramics [1,2]. It is generally observed that the prompt radiation induced conductivity (RIC) of insulators such as $\mathrm{Al}_{2} \mathrm{O}_{3}$ is proportional to the ionizing radiation dose rate, with a typical room temperature conductivity of $\sim 10^{-6} \mathrm{~S} / \mathrm{m}$ at a dose rate of $10^{4} \mathrm{~Gy} / \mathrm{s}$. The RIC disappears promptly when the radiation source is turned off (typical prompt lifetime $\sim 10^{-9} \mathrm{~s}$ ).

Several recent studies have reported that ceramic insulators may suffer a dramatic permanent loss in their electrical resistivity if they are irradiated at moderate temperatures while an electric field is applied [110]. This radiation induced electrical degradation (RIED) has been reported to occur in $\mathrm{Al}_{2} \mathrm{O}_{3}$ and other oxide ceramics following irradiation at relatively low displacement damage doses of 0.0001 to 0.1 displacements per atom (dpa) in the presence of an electric field $>50 \mathrm{~V} / \mathrm{mm}$ at temperatures between 300 to $600^{\circ} \mathrm{C}$. The physical mechanisms responsible for this phenomenon have not yet been identified, due in part to a lack of microstructural analysis following electrical degradation. It was originally suggested that colloid formation (small metallic precipitates) may be responsible for RIED [5,6]. This suggestion was based on optical microscope observations.and the similarity between the temperature dependence of RIED and colloid formation in alkali halides. However, colloid formation was not observed in a recent postirradiation transmission electron microscope (TEM) examination of electrically degraded $\mathrm{Al}_{2} \mathrm{O}_{3}$ [9]. A recent spallation neutron irradiation experiment failed to find any evidence for RIED in alumina [11] and furthermore, several recent studies have questioned whether RIED may be an artifact associated with surface contamination by hydrocarbons [11-13]. Recent reviews of this emerging field of study have shown that the electrical degradation reported by different investigators cannot be correlated according to displacement damage or ionizing radiation dose, although it was noted that some of these discrepancies may be due to differences in the materials that were studied $[2,14]$.

One objective of the present study was to verify that RIED occurs in thin films of ceramic insulators during ion irradiation at high vacuum conditions where surface contamination is not significant. Crosssection transmission electron microscopy was used to investigate possible microstructural origins of RIED in an electrically degraded alumina specimen. 


\section{Experimental Procedure}

An alumina film of thickness $1.8 \mu \mathrm{m}$ was if-sputtered from a hot pressed $\mathrm{Al}_{2} \mathrm{O}_{3}$ target onto a polished tantalum substrate using a planar magnetron in an $\mathrm{Ar}$ atmosphere of $2 \times 10^{-3}$ torr [15]. This produced a dense film which was determined to be amorphous from Rutherford backscattering spectroscopy (RBS), electron diffraction and high resolution TEM analysis. The deposited film was determined to be stoichiometric and of uniform thickness by RBS analysis (within the experimental accuracy of $~ 10 \%$ ). Tantalum was chosen as the substrate material due to its close match with alumina's coefficient of thermal expansion. This minimized tendencies for the film to crack or delaminate during thermal cycling. Platinum electrodes of 10 $\mathrm{nm}$ thickness were evaporated in a guard ring configuration on the surface of the alumina film. A center electrode of $3.1 \mathrm{~mm}$ diameter was surrounded by a concentric guard ring electrode with an inner diameter of $5.6 \mathrm{~mm}$.

The target chamber used to measure the in-situ DC electrical conductivity of the alumina thin films is described in detail elsewhere [15]. The target chamber was enclosed within an electrically isolated thin Mo box which provided electrical suppression and also acted as a thermal radiation shield. The sample temperature was measured by a type $\mathrm{K}$ thermocouple that was placed on the guard ring electrode in a region that was exposed to the ion beam, in order to include beam heating effects. The $\mathrm{Ta} / \mathrm{Al}_{2} \mathrm{O}_{3}$ sample was mounted on a massive nickel block that contained resistive heater cartridges for controlling the temperature. Spring contact was made to the center electrode by a $250 \mu \mathrm{m}$ Mo wire. The outer periphery of the sample was covered by a Mo ring ( $9.5 \mathrm{~mm}$ inner diameter), which clamped the sample to the nickel block and provided electrical contact to the Pt guard electrode. The Mo ring shielded most of the guard electrode from the ion beam, but allowed the ion beam to strike the center electrode and part of the guard electrode. The back electrode (the Ta substrate) was in electrical contact with the nickel block. The entire experimental assembly was electrically shielded by a stainless steel vacuum chamber which was held at ground potential.

The conductivity measurements utilized a three electrode guarded configuration [15]. Voltage was applied and current was measured using a Keithley 617 electrometer. The voltage applied during the irradiation was $0.5 \mathrm{~V}$, which corresponds to an electric field of $280 \mathrm{~V} / \mathrm{mm}$. The measured current at $20^{\circ} \mathrm{C}$ for an applied voltage of $0.5 \mathrm{~V}$ in the absence of irradiation was $<10^{-13} \mathrm{~A}$ (corresponding resistivity $>2 \times 10^{13} \Omega-\mathrm{m}$ ), which is near the resolution limit for our measuring system. Typical RIC currents under ion irradiation at $400^{\circ} \mathrm{C}$ were $\sim 10^{-6} \mathrm{~A}$. The current was periodically measured as a function of the applied voltage $(-0.5 \mathrm{~V}$ to $+0.5 \mathrm{~V})$ in order to verify ohmic behavior.

Initital experiments on several specimens not analyzed by TEM showed that RIED occurred during $\mathrm{He}$ ion irradiation at $407^{\circ} \mathrm{C}$ with an applied electric field of $\sim 300 \mathrm{~V} / \mathrm{mm}$, but RIED did not occur in specimens irradiated without an electric field at $407^{\circ} \mathrm{C}$ or in specimens irradiated at $530^{\circ} \mathrm{C}$ [15]. The alumina film for the present study was irradiated at $400^{\circ} \mathrm{C}$ with $2-\mathrm{MeV} \mathrm{He}$ ions at a flux of $450 \mathrm{nA}^{+} \mathrm{cm}^{2}$ in the triple ion beam Van de Graaff accelerator facility at ORNL [16]. This produced a calculated [17] ionizing and displacement damage dose rate of $0.6 \mathrm{MGy} / \mathrm{s}$ and $5 \times 10^{-7} \mathrm{dpa} / \mathrm{s}$, respectively (an average displacement energy of $40 \mathrm{eV}$ was assumed for the dpa calculation). The alumina thickness of $1.8 \mu \mathrm{m}$ allowed the radiation dose rate to be constant within $\pm 10 \%$ between the front and back surface of the ceramic, and ensured that all of the ions were transmitted through the specimen. The pressure was $<10^{-7}$ torr during the irradiation. Following irradiation the specimens were prepared for cross-section TEM examination using standard techniques [18], and were examined in a Philips CM-12 electron microscope (120 keV operating voltage) equipped with an EDAX 9900 energy dispersive X-ray spectrometer (EDS). Separate specimens corresponding to the center electrode, gap, and guard ring (unirradiated) regions were examined.

\section{Results and Discussion}

The specimen was slowly heated to $400^{\circ} \mathrm{C}$ in the target chamber, and the electrical resistance was monitored with an applied electric field of $280 \mathrm{~V} / \mathrm{mm}$ for 30 minutes prior to the start of the irradiation. A slight decrease $(\sim 10 \%)$ in the film resistance was observed during the 30 minute anneal, indicating the presence of some imperfections in the alumina film (Fig. 1). The alumina resistance began to immediately 
MICROSTRUCTURE OF UNIRRADIATED $\mathrm{Al}_{2} \mathrm{O}_{3}$ FILM

EXPOSED TO $400^{\circ} \mathrm{C}$ AND A DC ELECTRIC FIELD OF $260 \mathrm{~V} / \mathrm{mm}$
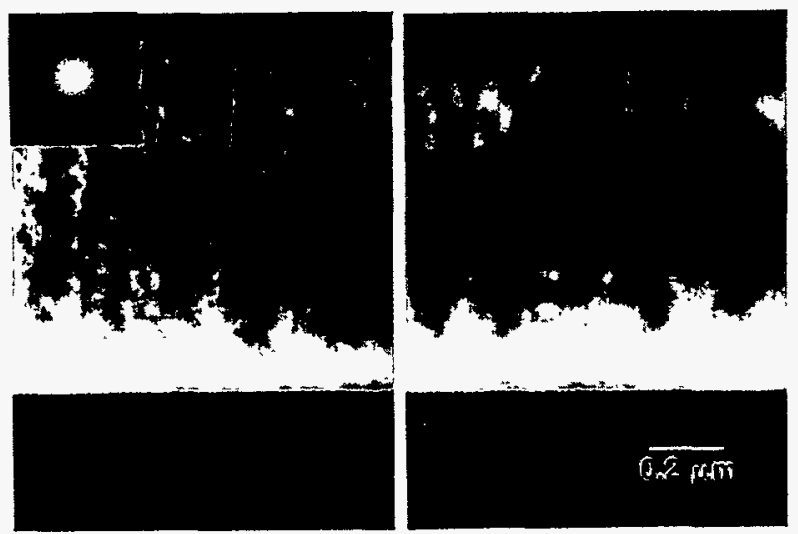

Fig. 1. Decrease in the resistance of the alumina film during annealing and irradiation at $400^{\circ} \mathrm{C}$ with an applied electric field of $280 \mathrm{~V} / \mathrm{mm}$.

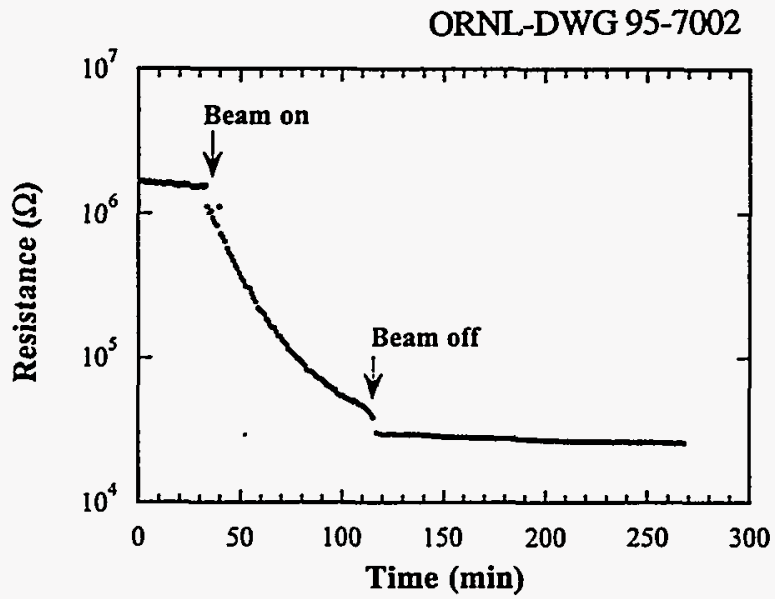

Fig. 2. Microstructure of unirradiated alumina film exposed to $400^{\circ} \mathrm{C}$ and a DC electric field of $280 \mathrm{~V} / \mathrm{mm}$. The left and right photos are underfocussed and overfocussed micrographs, respectively.

decrease at a rapid rate when the specimen was exposed to the $2 \mathrm{MeV}$ He ion beam. The initial RIC in the alumina film at $400^{\circ} \mathrm{C}$ associated with the ionizing dose rate of $0.6 \mathrm{MGy} / \mathrm{s}$ was $\sim 2 \times 10^{-7} \mathrm{~S} / \mathrm{m}(1.2 \mathrm{M} \Omega$ resistance), which was somewhat lower than published [2,15] RIC data obtained for bulk crystalline alumina specimens of $10^{-6}$ to $10^{-5} \mathrm{~S} / \mathrm{m}$. As discussed elsewhere [15], this discrepancy is most likely due to the higher electron trap density in the amorphous film compared to crystalline specimens.

The specimen was irradiated for 85 minutes at $400^{\circ} \mathrm{C}$ with an applied electric field of $280 \mathrm{~V} / \mathrm{mm}$, which produced a cumulative damage level of $0.0025 \mathrm{dpa}$. The measured resistivity of the alumina film decreased dramatically during the irradiation to a value of $1.2 \times 10^{5} \Omega-\mathrm{m}$ after $0.0025 \mathrm{dpa}$. Following the irradiation, the resistance of the film at $400^{\circ} \mathrm{C}$ was monitored for an additional 150 minutes with an applied dc electric field of $280 \mathrm{~V} / \mathrm{mm}$. A slight $(-10 \%)$ decrease in the film resistance was observed during this postirradiation anneal (Fig. 1). The room temperature resistance between the center and guard electrode was 
$>10^{12} \Omega$ following the irradiation, which shows that the measured resistance decrease in the center irradiated area cannot be attributed to surface contamination in the gap region. In addition, the high resistance in the gap region of the alumina film (which was not exposed to an electric field) provides further support for the original observation [3,4] that RIED requires the simultaneous application of an electric field and irradiation. The resistance between the guard and back electrodes decreased following irradiation in a manner similar to that observed for the center electrode. This may be due to the fact that part of the guard ring region was exposed to the ion beam, and hence would be subject to RIED similar to the center electrode region.

Figure 2 shows the typical microstructure of the alumina film in the guard ring region, which was exposed to the electric field and temperature but was not irradiated. The inset electron diffraction micrograph shows the apparent amorphous condition of the film. Small cavities were observed at the interface between the alumina film and the Ta substrate. The most significant microstructural feature in the alumina film was a moderate density of cavities that were elongated in the direction perpendicular to the $\mathrm{Ta}$ interface (i.e., along the electric field direction). A small amount of $\operatorname{Ar}(<1 \%)$ was detected in the alumina film by EDS, which may be associated with trapped argon from the sputter deposition process. The elongated cavities were also observed in the gap and center irradiated regions of the alumina film. Since the resistance of the gap region was relatively high, the elongated cavities and trapped argon apparently do not have a deleterious effect on the alumina film resistivity. Additional tests (including a RIED experiment where the guard ring is completely shielded from the irradiating beam) are needed to confirm this finding.

Figure 3 shows the typical microstructure of the alumina film from the center electrode region, which was exposed to temperature, electric field and irradiation. The microstructure of the center, gap and guard ring regions of the alumina film were generally found to be very similar. There was no evidence of colloid formation in the center irradiated region. Colloids larger than $\sim 5 \mathrm{~nm}$ diameter would have been easily detectable by the TEM observation.

Detailed examination of the center irradiated region of the alumina film revealed several isolated TYPICAL MICROSTRUCTURE OF IRRADIATED $\mathrm{Al}_{2} \mathrm{O}_{3}$ FLM defect structures which were not observed in less EXPOSED TO $400^{\circ}$ CAND A DC ELECTRIC FIELD OF $260 \mathrm{~V} / \mathrm{mm}$ detailed studies of the gap and guard electrode regions. A large cavity $(\sim 0.1 \mu \mathrm{m})$ was observed at the interface between the alumina film and Ta substrate in the center electrode region. However, since the size of this cavity was much less than the film thickness of $1.8 \mu \mathrm{m}$ it does not seem likely that it could be responsible for the observed RIED. A more plausible heterogeneous cause of the RIED in the center irradiated region is microcracking. Figure 4 shows a crack in the irradiated alumina film extending perpendicular to the $\mathrm{Ta}$ interface. Although it cannot be ruled out that the crack formation may have occurred during post-irradiation specimen preparation, this crack is the only significant microstructural difference observed so far between the electrically degraded center region and the insulating gap and guard ring regions of the alumina film.

A simple calculation demonstrates that microcracking could easily account for the large loss in electrical resistance in the center irradiated region of the alumina film. First, it is assumed that the total crack length (either one large crack or a number of small microcracks) completely penetrating the thin alumina film is $\sim 1 \mathrm{~mm}$.

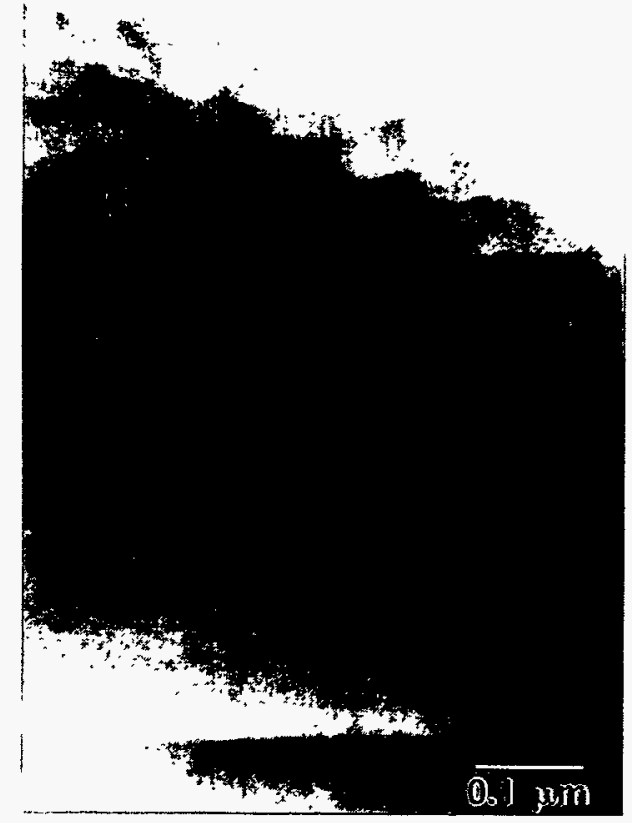

Fig. 3. Typical microstructure of center irradiated region of the alumina film. 


\section{CRACK OBSERVED IN THE IRRADIATED $\mathrm{Al}_{2} \mathrm{O}_{3}$ FILM EXPOSED TO $400^{\circ} \mathrm{C}$ AND A DC ELECTRIC FIELD OF $260 \mathrm{~V} / \mathrm{mm}$}

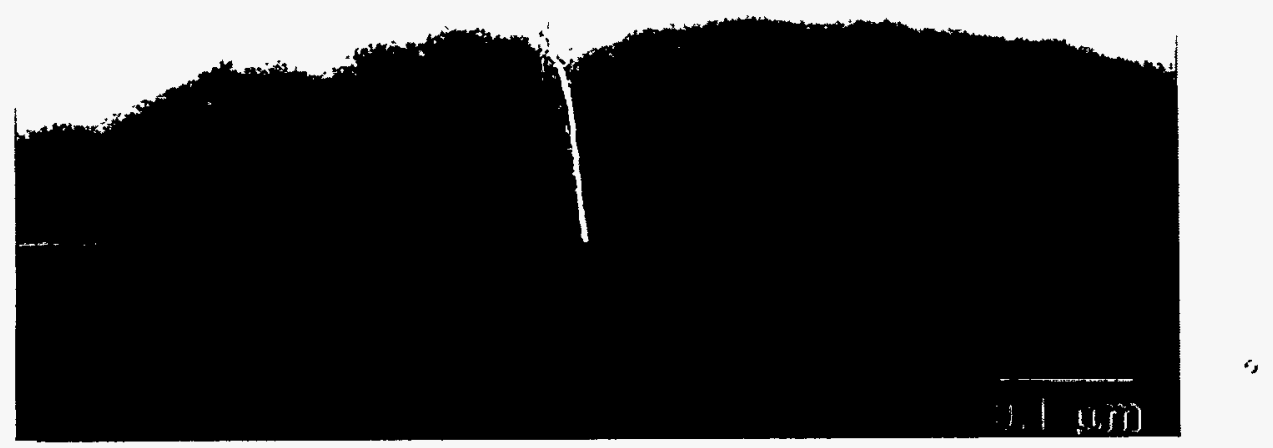

Fig. 4. Crack observed in center irradiated region of the alumina film.

This assumption would be consistent with the TEM observation of only one crack in the center irradiated region of the specimen (a total length of $\sim 0.5 \mathrm{~mm}$ along the irradiated Ta/alumina interface was examined by cross-section TEM). Second, it is assumed that radiation- and electric field-enhanced diffusion at a temperature of $400^{\circ} \mathrm{C}$ would eventually produce a monolayer coverage of $\mathrm{Ta}$ or $\mathrm{Pt}$ (the two electrode materials in this study) along the crack surface. For simplicity, surface scattering effects associated with the monolayer conducting film are ignored and the bulk resistivity of Ta and Pt $\left(-10^{-7} \Omega-\mathrm{m}\right)$ is used for the purposes of this simple calculation (Surface scattering could reduce the conductance of such a thin film by perhaps an order of magnitude). The total resistance associated with this $1 \mathrm{~mm}$ crack containing a monolayer of conducting electrode material would be only $\sim 1 \Omega(0.2 \Omega-\mathrm{m})$, which is more than six orders of magnitude smaller than the initial resistance of the alumina film at $400^{\circ} \mathrm{C}$ and more than four orders of magnitude smaller than the measured resistance of the electrically degraded film (Fig. 1). Therefore, even partial coverage of the $1 \mathrm{~mm}$ crack surface by electrode material or else complete monolayer coverage of a crack only $\sim 1 \mu \mathrm{m}$ long would be sufficient to explain the RIED results in Fig. 1. It is apparent from this simple calculation that a few small cracks can produce a dramatic decrease in the resistance of insulators due to the low resistivity of the electrode material.

A recent study of RIED in a polycrystalline $\mathrm{Al}_{2} \mathrm{O}_{3}$ specimen (produced by anodizing aluminum) found that the electrical degradation was due to radiation enhanced diffusion of the gold electrode material along the grain boundaries [19]. This mechanism for RIED is very similar to the present microcracking proposal. Another recent study suggested that the permanent electrical degradation in a single crystal alumina specimen was associated with an increased dislocation density [9]. However, it is not clear that the observed dislocation density of $\sim 10^{13} / \mathrm{m}^{2}$ in the electrically degraded specimen could account for the RIED without invoking diffusion of the electrode material. The present results are in agreement with another recent TEM study [9] that RIED in alumina is not associated with colloid formation.

Several studies have shown that large inhomogeneous electric fields can be induced in insulators during irradiation due to trapped space charge [20-27]. These studies suggest that the localized field is typically significantly different from the applied electric field and can exceed the dielectric breakdown strength of $>10^{7} \mathrm{~V} / \mathrm{m}$ in many cases $[23,27]$. Localized dielectric breakdown could produce microcracking and could eventually lead to significant permanent degradation of the electrical resistivity, particularly if electrode material diffused along the microcracks. Since the inhomogeneous electric fields in irradiated insulators are sensitive to numerous experimental parameters such as dose rate and chemical impurities, this proposed mechanism could explain why the RIED results obtained by different researchers on different grades of alumina are inconsistent with respect to displacement damage or ionizing radiation dose $[2,14]$. Further microstructural examination of polycrystal and single crystal RIED specimens is needed to confirm if microcracking is generally responsible for the electrical degradation in ceramic insulators. Radiationinduced microcracking would have severe consequences for electrical insulators in most fusion energy or nuclear thermionic applications since the surfaces of the insulator are typically in contact with highly conducting metallic materials. 


\section{Conclusions}

Radiation induced electrical degradation was confirmed to occur in an amorphous alumina film under conditions where surface contamination effects could not have compromised the measurements. Microstructural examination of the electrically degraded alumina film suggests that the RIED is associated with radiation-induced microcracking due to inhomogeneous internal electric fields. Colloid formation was not responsible for the electrical degradation.

\section{Acknowledgements}

The TEM specimens were prepared by J.W. Jones and A.T. Fisher. This research was sponsored by the Office of Fusion Energy and Division of Materials Science, US Department of Energy, under contract DEAC05-84OR21400 with Martin Marietta Energy Systems, Inc. and by appointment to the Oak Ridge National Laboratory Postdoctoral Research Program administered by the Oak Ridge Institute for Science and Education.

\section{REFERENCES}

1. S.J. Zinkle and E.R. Hodgson, J. Nucl. Mater. 191-194 (1992) 58.

2. L.W. Hobbs, F.W. Clinard, Jr., R.C. Ewing and S.J. Zinkle, J. Nucl. Mater. 216 (1994) 291.

3. E.R. Hodgson, Cryst. Latt. Def. Amorph. Mater. 18 (1989) 169.

4. E.R. Hodgson, J. Nucl. Mater. 179-181 (1991) 38.

5. E.R. Hodgson, Rad. Eff. Def. Solids 119-121 (1991) 827.

6. G.P. Pells, J. Nucl. Mater. 184 (1991) 177.

7. T. Shikama, et al., J. Nucl. Mater. 191-194 (1992) 544.

8. E.R. Hodgson, J. Nucl. Mater. 212-215 (1994) 1123.

9. X-F Zong, C-F Shen, S. Liu, Z-C Wu, Y. Chen, Y. Chen, B.D. Evans, R. Gonzalez and C.H. Sellers, Phys. Rev. B 49 (1994) 15514.

10. A. Möslang, E. Daum and R. Lindau, Proc. 18th Symp. of Fusion Technology, Karlsruhe, Germany, August 22-26, 1994, in press.

11. W. Kesternich, F. Scheuermann and S.J. Zinkle, J. Nucl. Mater. 206 (1993) 68.

12. P. Jung, Z. Zhu and H. Klein, J. Nucl. Mater. 206 (1993) 72.

13. B.D. Evans, J. Nucl. Mater. 219 (1995) 202.

14. W. Kesternich, F. Scheuermann and S.J. Zinkle, J. Nucl. Mater. 219 (1995) 190.

15. J.D. Hunn, R.E. Stoller and S.J. Zinkle, J. Nucl. Mater. 219 (1995) 169

16. M.B. Lewis, et al., Nucl. Instr. and Meth. B 43, 243 (1989).

17. J.F. Ziegler, J.P. Biersak and U.L. Littmark, The Stopping and Range of Ions in Solids (Pergamon Press, New York, 1985). Dose rate calculations were performed using TRIM-90.

18. S.J. Zinkle, et al., J. Eln. Microsc. Tech. 19 (1991) 452

19. C. Patuwathavithane, W.Y. Wu and R.H. Zee, 17th ASTM Symposium on Effects of Radiation on Materials, Sun Valley, Idaho, June 1994, J. Nucl. Mater, in press.

20. K.G. McKay, Phys. Rev. 74 (1948) 1606.

21. F.B. Micheletti and F. Kolondra, IEEE Trans. on Nucl. Sci., NS-18, No.6 (1971) 131.

22. B. Gross, in Electrets, Topics in Applied Physics Vol. 33, edited by G.M. Sessler (Springer-Verlag, New York, 1980) p. 217.

23. J.R. Macdonald, D.R. Franceschetti and A.P. Lehnen, J. Chem. Phys. 73 (1980) 5272.

24. V.V. Gromov, Zh. Fiz. Khim. 55 (1981) 1377 [Russ. J. Phys. Chem. 55 (1981) 777].

25. A.G. Rozno and V.V. Gromov, Zh. Fiz. Khim. 55 (1981) 1597 [Russ. J. Phys. Chem. 55 (1981) 901].

26. S.A. Basun, A.A. Kapianskii and S.P. Feofilav, Zh. Eksp. Teor. Fiz 87 (1984) 2047 [Sov. Phys. JETP 60 (1984) 1182].

27. A.R. Frederickson, S. Woolf and F.C. Garth, IEEE Trans. on Nucl. Sci. 40, No. 6 (1993) 1393. 
INVESTIGATION OF RADIATION INDUCED ELECTRICAL DEGRADATION IN ALUMINA UNDER ITER-RELEVANT CONDITIONS - L. L. Snead, D. P. White and S. J. Zinkle (Oak Ridge National Laboratory)

\section{OBJECTIVE}

To investigate whether radiation induced electrical degradation occurs in the IEA reference heat of alumina at irradiation conditions that are appropriate for ceramics in ITER.

\section{SUMMARY}

An in-situ experiment investigating the radiation induced electrical degradation (RIED) effect in polycrystalline alumina is described. A Wesgo AL-995 polycrystalline alumina sample has been irradiated with fission neutrons to 1.4 displacements per atom (dpa) at $340-365^{\circ} \mathrm{C}$ with no evidence of RIED. The implication of these and previous results are discussed in terms of their impact on the International Thermonuclear Experimental Reactor (ITER), with the conclusion that RIED will be of no consequence during the basic performance phase of the machines operation.

\section{PROGRESS AND STATUS}

\section{Introduction}

Ceramic materials are required in several areas of the International Thermonuclear Experimental Reactor (ITER) where design requirements call for highly resistive materials. Unlike previous tokamak machines, the core components of ITER will undergo significant nuclear heating and displacement damage, which raises new questions concerning the stability of these materials under irradiation. Table 1 lists the expected operating temperatures and neutron displacement levels for several ceramic components at the end of the basic performance phase of ITER. Three general areas of application for ceramics listed in Table 1 are 1) microwave heating windows, 2) insulating breaks, and 3) diagnostic probes. For the case of both the electron and ion cyclotron resonance heating (ECRH and ICRH) windows the displacement levels are relatively low (less than $0.1 \mathrm{dpa}$ ) with operating temperatures less than $200^{\circ} \mathrm{C}$. These windows are expected to be monolithic sapphire or polycrystalline alumina and are cooled in order to reduce the amount of heating caused by the transmitted microwave heating beam. Toroidal insulating breaks may be located throughout the blanket and divertor regions of ITER and will typically be operated at less than $200^{\circ} \mathrm{C}$ and receive lifetime displacement levels up to $1 \mathrm{dpa}$. These components are intended to serve as protection against the large toroidal current which could be induced during a plasma disruption. At present, such current breaks are regarded as an option for ITER, mainly due to uncertainty in how the disruption current will develop. It is possible that the use of current breaks in the blanket will not be required. The ceramic components which will receive the highest neutron fluence and operating temperatures are the magnetic probes located at or near the first wall, though the ITER design has not matured to the point where the operating temperature of these coils can be clearly defined.

The leading candidate material for the components listed in Table 1 is alumina, whether in the single crystal or polycrystalline form. In general, neutron irradiation produces only moderate degradation of properties such as thermal conductivity, mechanical strength, and volumetric swelling in alumina. Therefore, relatively straightforward experiments can be made to provide the necessary engineering information for ITER. In contrast with the thermomechanical properties of alumina, the electrical properties of ceramic insulators are known to change significantly under irradiation [1], and have received the greatest amount of attention in recent years.

Alumina, as with any highly insulating material, undergoes a large instantaneous increase in electrical conductivity when subjected to ionizing radiation. This increase is transient, and returns to its original value in the absence of the ionizing field. This radiation induced conductivity (RIC) has been shown to increase the conductivity of alumina by many orders of magnitude at fusion relevant 
Table 1. Summary of anticipated irradiation conditions for ceramic insulators in the ITER device.

\begin{tabular}{lcc}
\hline \multicolumn{1}{c}{ Application } & $\begin{array}{c}\text { Operating } \\
\text { Temperature }\end{array}$ & $\begin{array}{c}\text { Lifetime Displacement Level } \\
\text { (end of basic performance phase) }\end{array}$ \\
\hline ECRH Window & $80 \mathrm{~K}$ & $<0.001 \mathrm{dpa}$ \\
ICRH Window & $<200^{\circ} \mathrm{C}$ & $<0.1 \mathrm{dpa}$ \\
Toroidal Insulating Breaks & $<300^{\circ} \mathrm{C}$ & $\sim 1$ \\
Diagnostic Probe & & 1 to 3 \\
Near First Wall & $>300^{\circ} \mathrm{C}$ & $<1$ \\
Rear of Blanket & $<300^{\circ} \mathrm{C}$ &. \\
\hline
\end{tabular}

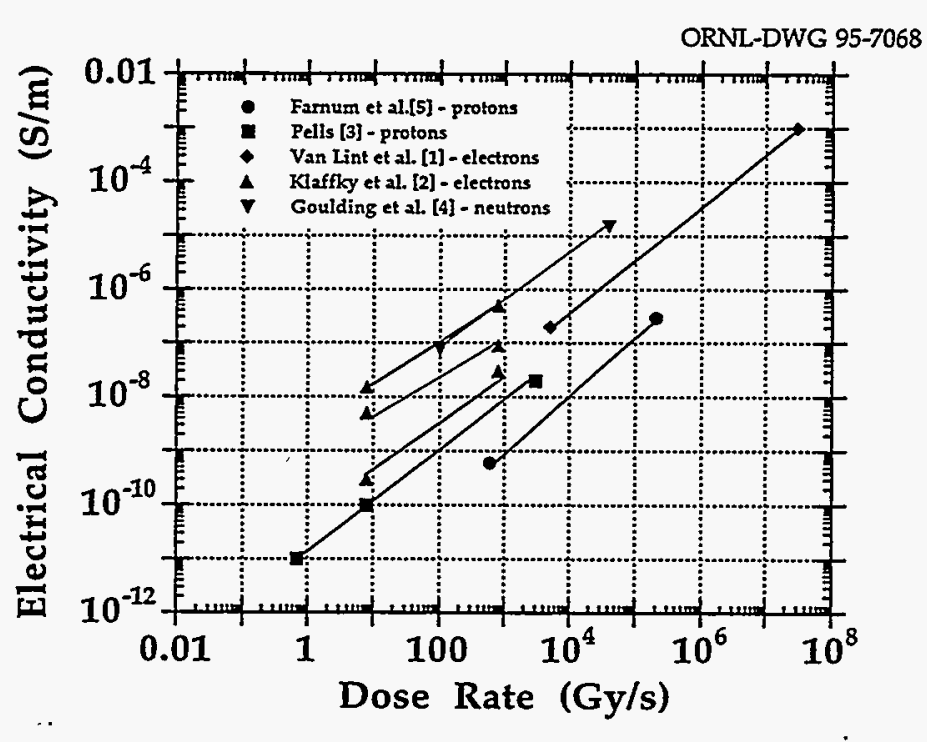

Fig. 1. Radiation induced conductivity measured in alumina during electron $[1,2]$, proton $[3,5]$ and fission neutron [4] irradiation.

ionizing radiation fields. Figure 1 gives a compilation of data from several studies [1-5] of RIC in alumina. As an example, it is seen that the room temperature electrical conductivity of alumina increases by more than six orders of magnitude to a value of approximately $10^{-6}(\mathrm{~W}-\mathrm{m})^{-1}$ at a representative first wall dose rate of $\sim 2000 \mathrm{~Gy} / \mathrm{s}$. While this increase in conductivity is dramatic, it is still two orders of magnitude less than the assumed limit due to joule heating concerns of $\sim 10^{-4} \mathrm{~W}$ $\mathrm{m})^{-1}$ for fusion insulators [6]. It is interesting to note that there can be order of magnitude differences in the RIC not only for the different oxide ceramics but also between different grades of nominally pure polycrystalline alumina. It has also been demonstrated that the doping of single crystal alumina can significantly reduce the level of RIC, because of increased impurity trapping of conduction electrons [2].

In the past few years there have been several papers on a potentially more serious problem relating to the use of insulating ceramics in fusion systems [7-19]. Several research groups have published studies in which electrical conductivity was measured in the presence of ionizing and displacive 
radiation fields while an electric field was applied. The results of some of these studies indicated that in addition to the well-established increase in conductivity due to RIC, a permanent increase in conductivity occurs which greatly exceeds the RIC value after some threshold fluence is reached. As can be seen from Table 2, the observed threshold for RIED ranges from as low as $6 \times 10^{-5} \mathrm{dpa}$ [9] (1.8 MeV electron irradiation) to $0.1 \mathrm{dpa}$ [12] (fission neutrons). This effect has been classified as radiation induced electrical degradation (RIED) and has to this point not exhibited an upper limit in conductivity. The potential effect of this phenomena as it relates to fusion is that critical components of future power reactors, such as microwave windows and diagnostics, would fail in a relatively short time.

While there is not yet a good explanation of the physical mechanism responsible for this effect, it is known that an applied electric field is necessary during irradiation, and there is evidence suggesting that RIED does not occur below $150^{\circ} \mathrm{C}$ or above $650^{\circ} \mathrm{C}[6,10,11,20]$. It has been speculated [9] that radiation induced colloid formation is taking place similar to that seen in alkali-halides [21]. However, RIED has been observed in irradiated alumina specimens that did not contain any colloids [17,22]. A recent analysis [23] has shown that colloid formation is very unlikely to occur in alumina below $500^{\circ} \mathrm{C}$.

Here, we present results of an experiment designed to investigate the RIED effect in Wesgo AL-995 polycrystalline alumina irradiated in a fission neutron spectrum in the High Flux Beam Reactor (HFBR) at Brookhaven National Laboratory. Results from this study are compared with an earlier study by the authors and contrasted with similar studies on RIED where fission neutrons, electrons and charged particles were used. The significance of these new results, and their relation to the current design of ITER, will be presented.

\section{Experimental}

A schematic of the irradiation capsule used to measure the in-situ electrical conductivity of alumina during fission reactor irradiation is shown in Figure 2. The sample was sealed in a helium filled subcapsule in order to minimize the deposition of gaseous impurities (e.g. conductive hydrocarbons) on the sample surface. All components were meticulously cleaned prior to capsule assembly followed by capsule bake-out and repeated evacuation and backfilling of the capsule interior utilizing a turbomolecular vacuum pump and ultra-high purity helium. The Wesgo AL-995 polycrystalline alumina sample of $8.5 \mathrm{~mm}$ in diameter and $0.75 \mathrm{~mm}$ in thickness was vacuum brazed using a TiCuAg braze foil to an alumina platen at $1050^{\circ} \mathrm{C}$ for 15 minutes. This braze material covered the entire bottom surface of the sample and the top of the vanadium pin, thus serving as the rear electrode. This platen was then vacuum brazed to a vanadium heat $\operatorname{sink}\left(880^{\circ} \mathrm{C}, 15\right.$ minutes). A third braze (at a lower temperature) was performed to secure the alumina cap to the heat sink, and was followed by sealing of the electrode lead penetrations in the cap under a high purity helium cover gas. The interior of the subcapsule was filled with ultra-high purity helium to 1 atmosphere at room temperature during the final sealing process. The subcapsule was helium leak checked, and then inserted into an aluminum capsitle $(2.8 \mathrm{~cm}$ outside diameter by $11 \mathrm{~cm}$ long, with a wall thickness of $0.27 \mathrm{~cm}$ ). The electrical leads were fed through a $6 \mathrm{~mm}$ diameter aluminum tube which was connected to a helium gas bottle. The atmosphere inside of the capsule and aluminum tube underwent three cycles of evacuation and back-filling using a turbomolecular pump and ultra-high purity helium prior to insertion of the capsule into the reactor.

Platinum electrodes were sputter deposited on the alumina specimen in a guard ring configuration with a $4 \mathrm{~mm}$ central electrode diameter and a $1.0 \mathrm{~mm}$ gap between the central electrode and guard ring. A dc potential of $100 \mathrm{~V}$ was continuously applied during the irradiation to the brazed sample back with a Hewlett-Packard 6634A power supply, which corresponds to an applied electric field of $133 \mathrm{~V} / \mathrm{mm}$. Sample current was periodically measured from the (low-side) central electrode with a Keithley model 237 electrometer with the aid of a Keithley model 7001 high density switch system and a model 7153 high voltage matrix switching card [25]. The thermocouple potentials were measured with a Keithley 199 digital multimeter using a Keithley model 7014 themocouple multiplexer. The data acquisition and control program was written using National Instruments' LabVIEW II software. Bulk current 
Table 2 . Compilation of significant RIED-related studies.

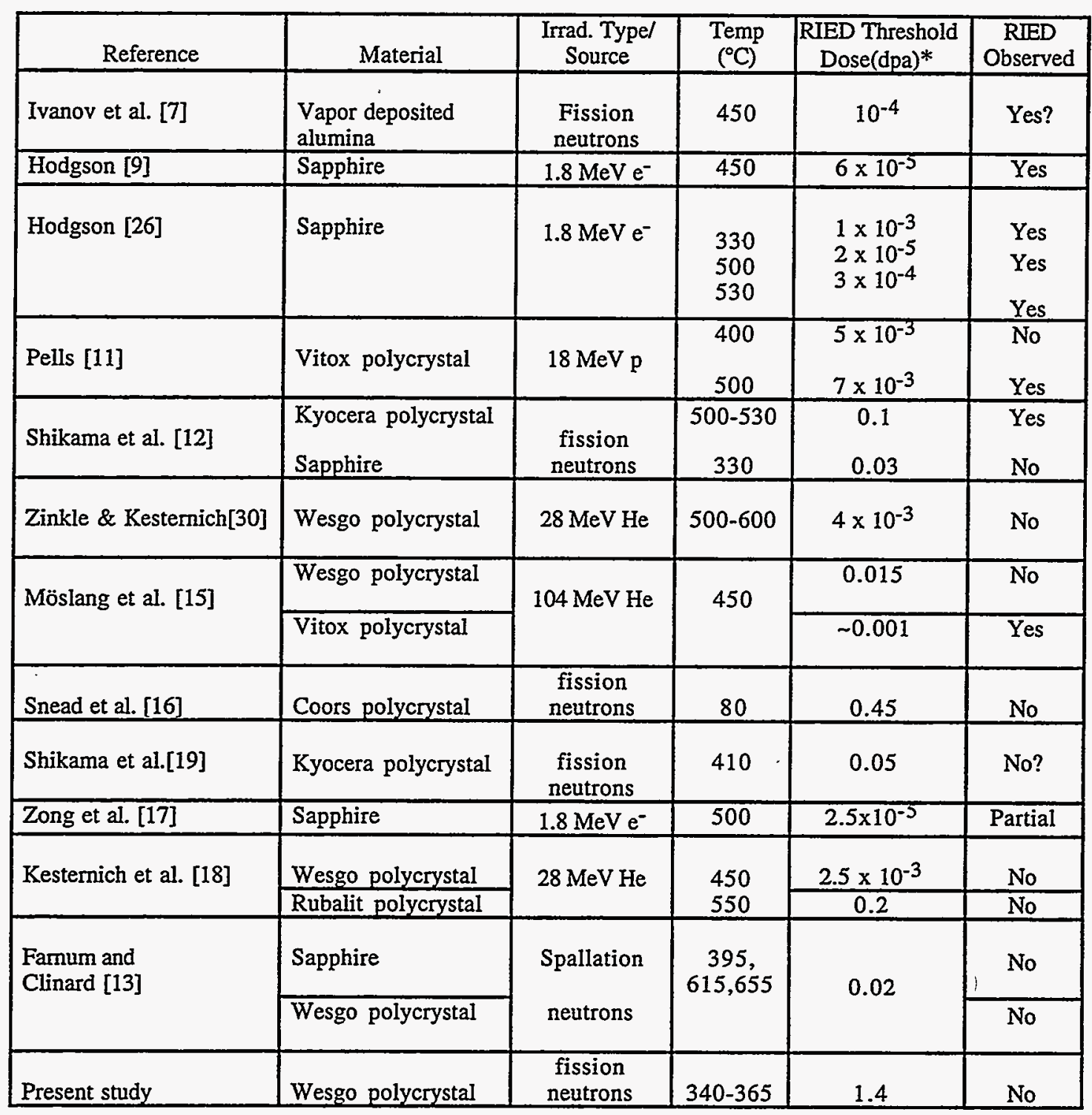

* for cases where RIED was not observed, this column give the maximum dose investigated

measurements were typically recorded every 15 minutes during the $\sim 40$ day irradiation. A settling time of 4 seconds after switching from the power supply to the electrometer was found by trial and error to eliminate signal noise associated with the capacitance of the data leads. The ohmic nature of the sample was periodically checked by ramping the applied voltage from 0 to $100 \mathrm{~V}$. Mineral insulated coaxial and triaxial cables were designed by ORNL and fabricated by the DeltaM Corporation [24]. High purity $\mathrm{MgO}$ powder insulation was used with OFHC copper for the center and guard leads. The outer sheath of the 13 meter cables was Type 304 stainless steel. The coaxial cable was $1.57 \mathrm{~mm}$ in diameter and supplied the high side voltage, while a triaxial cable $(1.07 \mathrm{~mm}$ outer diameter) carried the low-side signal. The center conductor and inner shield of the triaxial cable had lead resistances of 1.5 and $6 \mathrm{ohms}$, respectively. A more complete description of the measurement technique has been reported elsewhere [16,25]. 


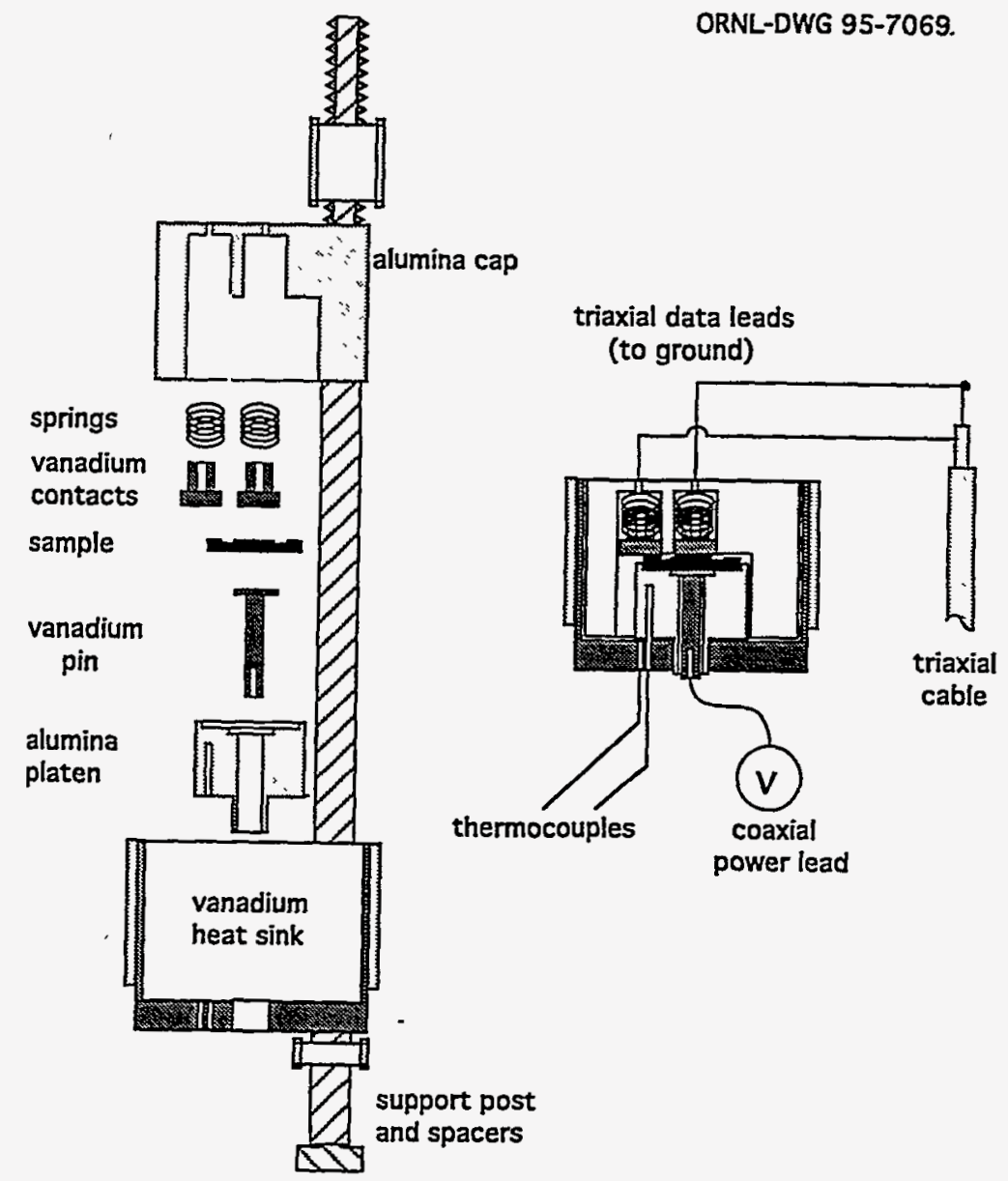

Fig. 2. Schematic of the RIED capsule.

The irradiation capsule was designed to perform a guarded electrical conductivity measurement. However a problem arose during the final brazing step causing the braze material from the rear electrode to contact the guard electrode. This shorted the guard electrode and thereby allowed surface currents to contribute to the measured specimen current. The guard ring lead was disconnected at the electronics equipment during the irradiation to avoid large leakage currents from the high side electrode along the triaxial conductor inner sheath. Due to the shorted guard ring, the measurements reported here constitute an upper limit to the bulk conductivity of the sample, the measured current being a combination of surface leakage currents and the material "bulk current" due to RIC and RIED. It should be noted that the electric field under the center electrode would be reasonably uniform ( 133 $\mathrm{V} / \mathrm{mm}$ ) even though the guard ring was at potential, due to the $1 \mathrm{~mm}$ gap between the center electrode and guard ring.

The irradiation was performed in the V-16 thimble mid-core position of the High Flux Beam Reactor (HFBR) at Brookhaven National Laboratory. The fast neutron flux ( $\mathrm{E}>0.1 \mathrm{MeV}$ ) in this position is 4 $\times 10^{18} \mathrm{n} / \mathrm{m}^{2}$-s and the sample was irradiated to a total fast neutron fluence of $1.4 \times 10^{25} \mathrm{n} / \mathrm{m}^{2}$ (about 1 $1 / 2$ cycles). This is approximately equivalent to $1.4 \mathrm{dpa}$ in alumina assuming a sublattice-averaged displacement energy of $40 \mathrm{eV}$. The gamma heating rate for this thimble is about $6 \mathrm{~W} / \mathrm{g}(6000 \mathrm{~Gy} / \mathrm{s})$. The sample temperature was generated by gamma heating using a $0.18 \mathrm{~mm}$ helium gas gap between the aluminum capsule wall and the vanadium subcapsule wall, and was continuously measured in-situ 
with a chromel-alumel type- $K$ thermocouple located $1 \mathrm{~mm}$ from the sample. A second thermocouple was located in the base of the vanadium heat sink (cf. Fig. 2). The temperature difference between the two thermocouples was $-30^{\circ} \mathrm{C}$ when the reactor was at full power, due to the temperature drop over the lower $9 \mathrm{~mm}$ of the alumina pedestal. The actual specimen temperature is calculated to be $\sim 3{ }^{\circ} \mathrm{C}$ above the measured thermocouple temperature in the alumina pedestal. The measured temperature in the alumina pedestal varied between 360 and $365^{\circ} \mathrm{C}$ during the first 100 hours of irradiation, and then the reactor was shut down for fuel reloading. When the reactor was restarted, the measured temperature slowly decreased from $345^{\circ} \mathrm{C}$ at the start of the new cycle to $330^{\circ} \mathrm{C}$ at the end of the irradiation.

\section{Results and Discussion}

The capsule was inserted into the HFBR core while the reactor was at full power ( $30 \mathrm{MW}$ ). The application of the electric field and the initial sample measurements occurred within approximately one hour of entry. An example of an current-voltage curve taken during full-power reactor operation (at $\sim 0.75 \mathrm{dpa}$ ) is shown in Fig. 3 and demonstrates the nearly ohmic behavior of the system. This ohmic behavior was observed throughout the experiment.

The raw data for the low-side center electrode current is given in Figure 4 and represents $~ 4300$ data points taken during the experimental run. At the beginning of the irradiation, the signal was somewhat erratic at approximately $10^{-7}$ amps and slowly increased to $\sim 10^{-6}$ amps. The initial level of current $\left(10^{-7} \mathrm{amps}\right)$ would be consistent, though on the lower end of the scatter band, with the expected level of RIC as seen in Figure 1. The gradual increase from this initial value may have been due to contamination of the sample surface. The dramatic drop in current at approximately 100 hours into the irradiation corresponds to the start of the ten day reactor shutdown for refueling. Following the subsequent startup, the signal was relatively steady at approximately $8 \times 10^{-6}$ amps, which corresponds to a conductivity of $\sim 3.0 \times 10^{-6} \mathrm{~S} / \mathrm{m}$ assuming that the effective center electrode area extends halfway between the Pt-deposited center and guard ring electrodes. Data for the sample conductivity were generated from the slope of a best linear fit to the current-voltage plots and are given as a function of displacement level in Figure 5. This figure also includes results from several previous RIED studies on alumina performed at temperatures where the RIED effect is expected to be most pronounced $\left(450-500^{\circ} \mathrm{C}\right)$. It is seen that the present results for the Wesgo AL-995 material do not show a dramatic increase in conductivity associated with the onset of RIED as seen in some previous studies.

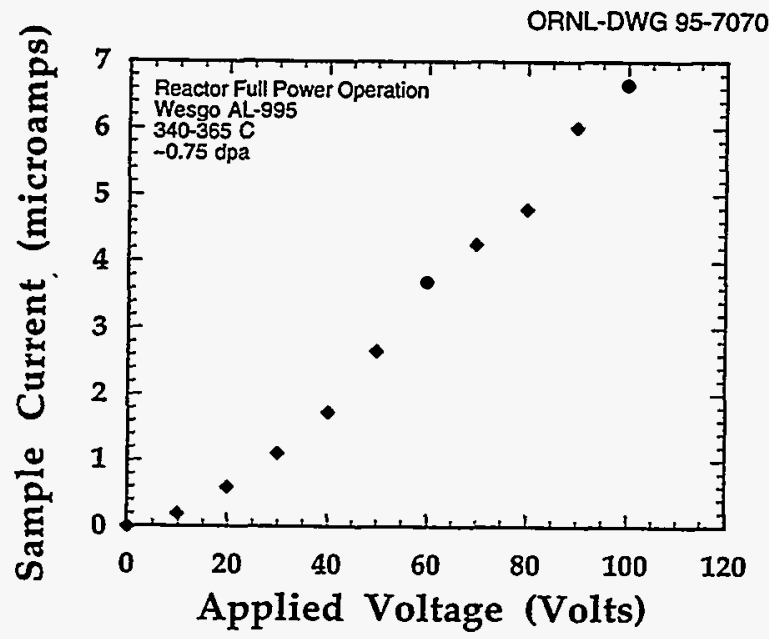

Fig. 3. Characteristic current vs. voltage curve measured during full-power irradiation. 


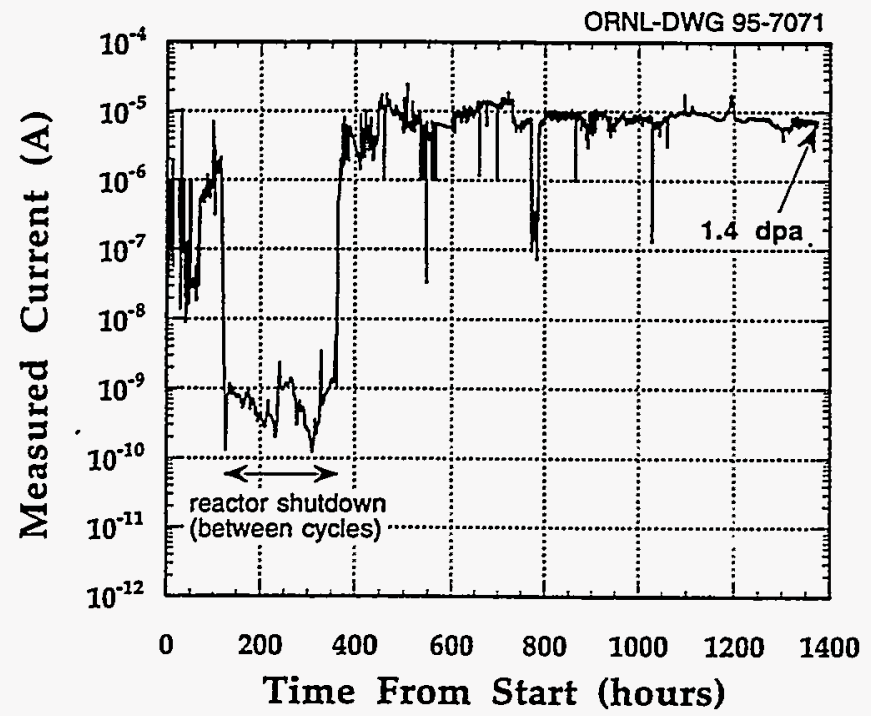

Fig. 4. Raw data of the low-side sample current during the HFBR irradiation.

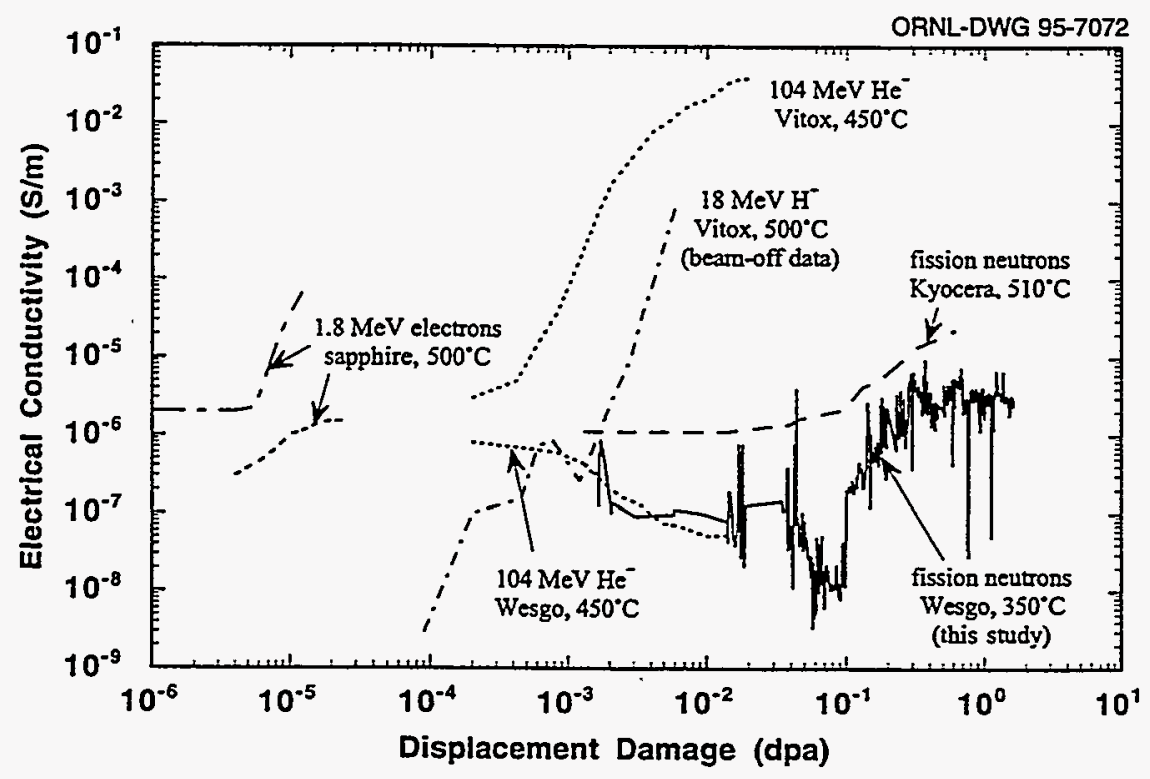

Fig. 5. Comparison of the present results at $350^{\circ} \mathrm{C}$ with previous RIED studies performed with electron $[9,17]$, light ion $[11,15]$ and fission neutron [12] irradiation sources near the peak degradation temperature of $\sim 500^{\circ} \mathrm{C}$. 
The present results demonstrate that RIED is not present to any significant level in Wesgo AL-995 polycrystalline alumina irradiated near $350^{\circ} \mathrm{C}$ up to a dose of $1.4 \mathrm{dpa}$. Due to the nature of the lowside measurement made in this experiment, and to the fact that the sample remained ohmic throughout the measurement period, there is complete confidence regarding the integrity of the measurement. In particular, the ohmic response on the low (ground) side of the sample as the voltage was periodically ramped demonstrated that the voltage was applied to the sample and there was contact to the sample electrodes. While it is possible that some fraction of the measured signal was due to surface contamination, had the RIED-like behavior occurred as seen in previous studies, it should have produced a specimen current orders of magnitude larger than the observed value (cf. Fig. 5 and refs. 10$12,15,17)$. It is also worth noting that the measured conductivity was quite close to that expected from simple radiation induced conductivity $\left(\sim 10^{-6} \mathrm{~S} / \mathrm{m}\right)$. It is certainly possible that some effect has taken place which has altered the base, permanent bulk conductivity of the sample, although this conductivity level would necessarily be less than the RIC (plus surface contamination) level measured here of $\sim 10^{-6} \mathrm{~S} / \mathrm{m}$. This possibility will be examined by performing post-irradiation testing of the sample.

The results of this work are another data point in what is proving to be a difficult phenomena to study. Following the initial work by Ivanov [7], which showed a large in-reactor conductivity increase followed by a decrease to nearly the initial RIC value, several researchers have studied this effect, albeit under quite different experimental conditions. The results of these studies are quite variable. Table 2 gives a synopsis of the significant work to date on the RIED effect starting with the first published research by Ivanov [7], Hodgson [8] and Pells [11]. Both Hodgson and Pells have observed significant levels of RIED at temperatures between 300 and $600^{\circ} \mathrm{C}$. Following these initial results, and the realization of their potential impact on fusion reactor design, there have been numerous studies in this area. Researchers have utilized an array of irradiation sources and types of alumina, with some observing the RIED effect and some not. Work by Kesternich and coworkers [18] has been instrumental in showing that RIED does not always occur in alumina; for example, RIED was not detected in a Rubalit grade of alumina irradiated up to $0.2 \mathrm{dpa}$ at $\sim 550^{\circ} \mathrm{C}$ [18] nor in Wesgo-AL995 alumina irradiated at $\sim 500^{\circ} \mathrm{C}$ to $0.004 \mathrm{dpa}$ [30] or $450^{\circ} \mathrm{C}$ to $0.0025 \mathrm{dpa}$ [18]. In one particularly interesting recent study by Möslang and coworkers [15], RIED was observed to occur in Vitox alumina, but not in Wesgo AL-995, at identical irradiation conditions [15]. It is worth noting that, in published studies to date, RIED has never been observed in Wesgo AL-995 alumina $[13,15,18,30]$.

As seen in Figure 5, there is apparently a critical dose at which the RIED conductivity appears above the RIC conductivity level, raising the question of a required threshold dose. Several studies have shown that a lower and upper temperature limit also exists $[9,14,20]$ with a peak temperature for observing RIED of $\sim 450^{\circ} \mathrm{C}$ and an apparent minimum temperature of $\sim 150^{\circ} \mathrm{C}$. Most recently, Hodgson has suggested [26] that there is an effect of displacement rate which can shift the displacement threshold towards higher values for higher dose rates. Hodgson also showed that the form of material, i.e. polycrystalline alumina as compared to sapphire, may affect the onset of RIED. Furthermore, it can be speculated based on the work of Möslang et al. [15] that the grade of polycrystalline alumina chosen will affect the results.

It has been suggested by some researchers $[18,23,27]$ that, due to the intrinsically difficult nature of making these measurements, the RIED effect may actually be due to experimental error rather than a bulk material effect. In particular, it has been shown [18,27] that an apparent RIED effect could be produced as a result of surface contamination during the in-beam experiments. Other plausible explanations include sample cracking which could lead to conduction through the sample simply due to crack-surface conduction or from diffusion of electrode material [22] along internal cracks. Such cracking could either be a radiation induced phenomena or simply be in response to stress which develops during the pre-irradiation processing (e.g. brazing). Other design related issues such as degradation of mineral insulated cables (in the case of in-reactor irradiations) are also potential experimental problems. Evidently, the real significance of RIED on ceramic component performance remains unclear at this point. Because of the large number of variables elucidated above, a fully comprehensive experimental investigation of the RIED phenomenon will be lengthy, complex and expensive. However, the data reported here, along with our previously reported data [16] $\left(80^{\circ} \mathrm{C}\right.$ fission 
neutron irradiation) allow us to definitively address whether RIED will be a design issue for fusion reactor ceramic components of near-term fusion reactors, ITER in particular.

Referring to Table 1, it is seen that, with the possible exception of diagnostic coils located near the first wall, the expected operating temperatures for all ITER ceramic components are $300^{\circ} \mathrm{C}$ or below. The displacement levels which are expected at the end of the basic performance phase of ITER will vary due to component location in the machine and will be highest for the diagnostic probes located near the first wall ( 1 to $3 \mathrm{dpa}$ ), and generally less than 1 dpa for other probes and the toroidal insulating breaks. Due to the extreme sensitivity of alumina windows to radiation induced changes in both the thermal conductivity and the dielectric loss, these components will be positioned to limit their dose to $<0.1 \mathrm{dpa}$ for ICRH, and $<0.001 \mathrm{dpa}$ for ECRH windows [28]. The allowable dose limits to these components may be reduced even further as more information becomes available on the effect of low temperature neutron irradiation on the loss tangent.

It is very plausible that the threshold for the observance of RIED is not simply dictated by the irradiation temperature, material and total dose. Other variables such as irradiation spectrum, applied field and dose rate could affect the incubation dose for RIED, or whether the degradation occurs at all. Assuming that RIED is a bulk material effect, however, arguments can be made that RIED is of no concern for ITER, given the appropriate choice of material. This is based on the absence of RIED in polycrystalline Wesgo AL-995 alumina irradiated in this study $\left(-350^{\circ} \mathrm{C}\right.$ to $\left.1.4 \mathrm{dpa}\right)$ and a previous lower temperature neutron irradiation on a Coors $\mathrm{AD}-998$ polycrystalline alumina $\left(80^{\circ} \mathrm{C}\right.$ to $\left.0.45 \mathrm{dpa}\right)$ [16]. It should be noted that the displacement dose of this previous study has been corrected from our originally published value of $0.11 \mathrm{dpa}$ due to a recent clarification on the E>0.11 to E>1 MeV neutron flux ratio of the HFBR.

From the conditions of these experiments it can be argued that all the possible variables influencing a shift in the incubation dose for RIED have been satisfactorily addressed. Specifically, the neutron spectrum in these experiments was a water moderated fission neutron spectrum which, while somewhat lower in average energy than the blanket spectrum of a fusion reactor, is not fundamentally different in its spectrum-integrated damage characteristics. The temperatures of the two studies under consideration are directly relevant, or slightly higher than the expected operating temperatures in ITER. Assuming there is a temperature threshold for RIED (for the Wesgo AL-995 irradiated with neutrons) it would be expected to be higher than the $\sim 350^{\circ} \mathrm{C}$ temperature of this study, therefore above the operating temperature for ITER. In both the present work and the lower temperature irradiation [16] , the applied field was $133 \mathrm{~V} / \mathrm{mm}$, which is higher than the field which would be experienced by ceramic insulators in ITER and is therefore conservative.

Finally, a comparison of the dose and dose rate of this experiment and the proposed ITER parameters needs to be addressed. As can be seen from Table 1, the dose of $1.4 \mathrm{dpa}$ from this experiment is above the proposed range any ITER ceramic component would undergo during the basic performance phase, with the possible exception of the near-wall diagnostic probes. However, the fast neutron dose rate for the HFBR $\left(\sim 4 \times 10^{18} \mathrm{n} / \mathrm{m}^{2}-\mathrm{s}, \mathrm{E}>0.1 \mathrm{MeV}\right)$ can be significantly different from these encountered by ITER ceramic components. The fast neutron flux at the first wall of ITER will be comparable with this $\left(-1.5 \times 10^{18} \mathrm{n} / \mathrm{m}^{2}-\mathrm{s}\right)$ [29], but the displacement rate decreases rapidly with distance from the first wall. For example, the dose rate has been calculated to be a factor $\sim 1000$ less at the vacuum vessel of the ITER machine [29].

The effect which this difference in dose rate will have on RIED is unknown, again due to the lack of knowledge of the physical mechanism responsible for this phenomenon. However, if aluminum colloid formation [9] is assumed to be the triggering mechanism, it would be reasonable to expect the main effect of a change in dose rate would be to induce a shift in the temperature dependence of RIED. Temperature shifts due to changes in irradiation dose rate have been commonly applied to studies of colloid formation in alkali-halides [21] and the formation of voids in metals [31]. While experimental verification of the dose rate effect has not been sufficiently demonstrated for the formation of sodium colloids [21], the effect of displacement rate on the temperature dependence of voids in metals under 
irradiation has been experimentally verified. In its simplest form the effective temperature shift can be calculated from chemical rate theory to be :

$$
T_{2}-T_{1}=\frac{\frac{k T_{2}^{2}}{E_{m}^{A l}} \ln \left(\frac{D_{2}}{D_{1}}\right)}{1-\frac{\mathrm{kT}_{2}}{E_{m}^{A l}} \ln \left(\frac{\mathrm{D}_{2}}{\mathrm{D}_{1}}\right)}
$$

where $D_{1}$ and $T_{1}$ are the assumed dose rate and temperature for ITER, $D_{2}$ and $T_{2}$ are the dose rate and temperature of the present work, $\mathrm{k}$ is Boltzmann's constant and $E_{m}^{A l}$ is the migration energy for aluminum vacancies, assumed here to be $3.9 \mathrm{eV}$ [32]

As mentioned earlier, the flux expected in ITER near the first wall is very close to the HFBR flux of this study and therefore is directly relevant, i.e. no temperature shift is required to correct for dose rate effects. However, if one assumes a thousand-fold reduction in fast neutron flux over the HFBR flux, which is expected near the ITER vacuum vessel [29], equation (1) yields a temperature shift of $64^{\circ} \mathrm{C}$. Thus the present (high dose rate) results at $\sim 350^{\circ} \mathrm{C}$ are equivalent to that expected at the ITER vacuum vessel (low dose rate) irradiated to the same dose at $-290^{\circ} \mathrm{C}$. The consequences of this temperature shift would be to move the "effective" temperature of the present work into a more ITER-relevant range (Table 1). The preceding calculation ignores ionization enhanced diffusion effects, which may cause a reduction in the vacancy migration energy in insulators. However, even if the migration energy were reduced by a factor of two, the corresponding temperature shift would be only 139 degrees and the present study would still be ITER-relevant.

It should be noted that a slightly different analysis of the effect of dose rate on the displacement threshold for ITER has been developed by Hodgson [26] based on the formation of aluminum colloids. In his analysis, Hodgson has developed curves which predict the threshold displacement dose required to produce RIED (in this case for neutron irradiated polycrystalline alumina) as a function of dose rate and temperature. Following his analysis, however, the onset of RIED at $350^{\circ} \mathrm{C}$ should have occurred at $\sim 0.05 \mathrm{dpa}$ for the HFBR dose rate of $\sim 4 \times 10^{-7} \mathrm{dpa} / \mathrm{s}$, significantly less than the $1.4 \mathrm{dpa}$ of the present study. Furthermore, even if RIED would have occurred at (just greater than) 1.4 dpa for the HFBR Wesgo AL995 material, and Hodgson's analysis was applied to predict when RIED would occur at appropriate blanket dose rates, Hodgson's theory predicts that RIED would not occur in the basic performance phase of ITER. For example, extrapolation of a 1.4 dpa HFBR incubation dose to the mid-blanket ITER dose rate of $3 \times 10^{-9} \mathrm{dpa} / \mathrm{s}$ predicts RIED would occur at $0.18 \mathrm{dpa}$ compared to the expected dose of $0.045 \mathrm{dpa}$ at the end of the basic performance phase.

In any event, the $-350^{\circ} \mathrm{C}$ HFBR results indicate that the Wesgo AL-995 alumina should not suffer significant RIED in ITER components during the basic performance phase. It then appears that if RIED did exist as a bulk effect in some grades of alumina, RIED could be avoided in ITER by the appropriate selection of alumina grade. The obvious choice of material at this point would be to select a material such as Wesgo AL-995 which has been shown in this and previous studies $[13,15,18,30]$ not to be susceptible to RIED, as opposed to Vitox alumina which has demonstrated RIED in studies by Pells [11] and Möslang [15].

A second consideration for ceramic insulators in ITER is surface contamination $[13,18,27]$, which is a very real possibility for certain tokamak components such as current breaks and microwave windows. For the case of microwave windows this contamination problem would have no significant effect on the loss tangent and therefore is not a great concern other than any possible optical problems 
associated with the contaminating layer. For current breaks, however, an increase in conductivity, whether it be bulk RIED in the insulator or simply surface contamination, would increase the magnitude of the disruption currents and would therefore need to be kept below some minimum value. For the case of the diagnostic probes in which the alumina is used as an insulator in a coaxial cable, there would obviously be no problem associated with surface contamination.

The final piece of the RIED puzzle which needs to be addressed for ITER is a problem which has been categorized as both a bulk phenomenon and an artifact. The possibility of irradiation induced cracking [22] appears to be a plausible explanation for RIED and will require some investigation. However, this would be a very design dependent phenomenon and would require proof testing once the engineering design of ITER has matured to the point where temperatures and stresses on its ceramic components can be defined.

\section{CONCLUSIONS}

The results of the study reported here indicate that Wesgo AL-995 polycrystalline alumina does not exhibit catastrophic radiation induced electrical degradation (RIED) during irradiation up to a neutron dose level of $1.4 \mathrm{dpa}$ in the temperature range of $340-365^{\circ} \mathrm{C}$. Given these results, in combination with the results of several other published studies, RIED appears not to pose a problem for ceramic insulator components in the basic performance phase of ITER, with the possible exception of diagnostic mineral insulated cables due to the very high dose, high temperature conditions these cables must withstand.

However, considering the puzzling, diverse behavior observed in different RIED studies, it is also clear that the phenomenon of RIED is poorly understood and that many questions remain as to its cause and extent. A continuing study of RIED is necessary in order to fully understand this effect.

\section{Acknowledgments}

The authors would like to thank W. S. Eatherly, Jr. for his excellent technical assistance and Joe O'Conor, Joel Errante and Guy Hartsough for their assistance with accessing the HFBR facility. The Wesgo AL-995 material used in this study was provided to the U. S. Fusion Ceramics Program as a reference material by GTE Wesgo, Belmont, California. This research was sponsored by the Office of Fusion Energy U. S., Dept. of Energy under contract DE-AC05-84OR21400 with Martin Marietta Energy Systems, Inc.

\section{REFERENCES}

[1] V.A.J. van Lint, J. W. Harrity and T. M. Flanagan, IEEE Trans. on Nucl. Sci., NS-15, No. 6 (1968) 194 .

[2] R.W. Klaffky et. al., Phys. Rev., B21 (1980) 3610 .

[3] G.P. Pells, Rad. Effects, 97 (1986) 199.

[4] R.H. Goulding, S.J. Zinkle, D.A. Rasmussen and R.E. Stoller, in Fusion Reactor Materials Semiannual Progress Report DOE/ER-0313/15 (1994) 434.

[5] E.H. Farnum, et. al., J. Nucl. Mater., 191-194 (1992) 548, and private communication.

[6] S. J. Zinkle and E.R. Hodgson, J. Nucl. Mater. 191-194 (1992) 58.

[7] V.M. Ivanov, et al, Inorganic Mater. 17 (1981) 1203.

[8] E.R. Hodgson, Cryst. Latt. Def. Amorph. Mat. 18 (1989) 169.

[9] E.R. Hodgson, J. Nucl. Mater. 179-181 (1991) 383.

[10] E.R. Hodgson, J. Nucl. Mater. 191-194 (1992) 552.

[11] G.P. Pells, J. Nucl. Mater. 184 (1991) 177.

[12] T.Shikama, et al., J. Nucl. Mater. 191-194 (1992) 575. 
[13] E.H. Farnum and F.W. Clinard, in Fusion Materials Semiannual Progress Report DOE/ER-0313/16 (1994) 512.

[14] E.R. Hodgson, Rad. Eff. Def. Solids 119-121 (1991) 827.

[15] A. Möslang, E. Daum and R. Lindau, Proceedings of the 18th Symp. on Fusion Tech. Karlsruhe, Aug. 22-26, 1994.

[16] L.L. Snead, D.P. White and S.J. Zinkle, J. Nucl. Mater. 212-215 (1994) 1107.

[17] X-F Zong, et al., Phys. Rev. B , 49 (1994) 15514.

[18] W. Kesternich, F. Scheuermann, and S.J. Zinkle, J. Nucl. Mater. , 219 (1995) 190.

[19] T. Shikama, et al., J. Nucl. Mater. 212-215 (1994) 1133.

[20] A. Morono and E.R. Hodgson, J. Nucl. Mater. 212-215 (1994) 1119.

[21] W. Soppe and E. Kotomin. Nucl. Instrum. Meth. Phys. Res. B 91 (1994) 87.

[22] S.J. Zinkle, J.D. Hunn and R.E. Stoller, in Proc. Symp. on Microstructure of Irradiated Materials, I.M. Robertson et al., eds. MRS Symp. Proc. Vol. 373 (Mater. Res. Society, Pittsburgh, 1994) p. 299.

[23] B.D. Evans, J. Nucl. Mater. 219 (1995) 202.

[24] J. Stamp, DeltaM Corp., 525 Warehouse Rd. Oak Ridge, TN 37830 USA.

[25] D.P. White, in Fusion Materials Semiannual Progress Report, DOE/ER-0313/17 (1994) 346.

[26] E.R. Hodgson, J. Nucl. Mater. 212-215 (1994) 1123.

[27] P. Jung, Z. Zhu and H. Klein, J. Nucl. Mater. 206 (1993) 72.

[28] R. Heidinger, J. Nucl. Mater. 212-215 (1994) 1101.

[29] E.T. Cheng and L.L. Snead, unpublished calculations, TSIR-40 Report (1995).

[30] S.J. Zinkle and W. Kesternich, in Fusion Reactor Materials Semiannual Progress Report, DOE/ER-0313/14 (1993), p 437.

[31] L.K. Mansur, J. Nucl. Mater. 206 (1993) 306-323.

[32] P.W.M. Jacobs and E.A. Kotomin, Phil. Mag. A 68 (1993) 695. 
X-RAY-INDUCED LUMINESCENCE FROM HYDROXYL-DOPED SILICA FBBERS -- D. W. Cooke, E. H. Farnum, F. W. Clinard, Jr., B. L. Bennett (Los Alamos National Laboratory) and A. M. Portis (UCBerkeley)

\section{OBJECTTVES}

The objectives of this work are to 1$)$ measure the luminescence emitted from low- $(\sim 1 \mathrm{ppm})$ and high- $(\sim 600-800 \mathrm{ppm}) \mathrm{OH}-$ doped silica fibers subjected to continuous $\mathrm{x}$ irradiation as a function of temperature and time, 2) analyze the emission in terms of Gaussian lineshapes, 3) compare the time and temperature dependence of each peak, and 4) utilize the results to gain a better understanding of the origin of the radiation-induced luminescence. Our goal is to understand the $\mathrm{x}$-ray-induced luminescence in pristine silica fibers so that we may proceed to an investigation of luminescence in neutron-irradiated fibers.

\section{SUMMARY}

Fiber optics is expected to play a very important role in ITER diagnostics. Minutes of the 2nd Meeting of the ITER Physics Expert Group on Diagnostics outlined several plasma parameters that must be measured to ensure machine protection and plasma control. Many of these parameters (total radiated power, plasma line-averaged density, plasma rotation, impurity species monitor, etc.) are expected to require optical techniques for assessment. And regardless of the specific tool applied, it is evident that fiber optics form the basis for many of the diagnostic measurements. It is envisioned that fibers, in some cases, may be very close to the plasma with limited possibility for neutron and gamma shielding. Therefore it is imperative to fully understand the behavior of candidate fibers under extreme conditions, viz., exposure to mixed radiation fields at elevated temperatures.

The present consensus is that silica fibers comprised of low-OH silica cores and F-doped cladding are the best candidates for use in optical diagnostic systems in a high-fluence radiation environment. There are, however, two main concerns regarding their use: 1) radiation-induced attenuation, and 2) radiationinduced visible luminescence. Both properties affect the transmission and subsequent evaluation of diagnostic signals and, consequently, must be either sufficiently ameliorated or properly characterized to be useful. Accordingly, we have examined the visible luminescence of silica fibers subjected to continuous $x$ irradiation as a function of temperature and time. Two types of fibers were investigated: 1) low $\mathrm{OH}$ fiber (containing $\sim 1 \mathrm{ppm} \mathrm{OH}$, as stated by the manufacturer, and labeled anhydroguide), and 2) high $\mathrm{OH}$ fiber (containing $\sim 600-800 \mathrm{ppm} \mathrm{OH}$, as stated by the manufacturer, and labeled superguide). These fibers were obtained from Fiberguide Industries, Inc., and were used in the as-received state [1].

In the temperature interval $7-300 \mathrm{~K}$, anhydroguide exhibits two well-defined luminescence peaks at about 520 and $670 \mathrm{~nm}$ with the exact position being dependent upon temperature. Superguide is characterized by one broad peak near $590 \mathrm{~nm}$ with evidence of a second very weak peak near $620 \mathrm{~nm}$. Generally we find that luminescence peak intensities decay with increasing temperature, the exception being the $670-\mathrm{nm}$ peak of anhydroguide. The time dependence of each luminescence peak was measured at various fixed temperatures, and was found to exhibit exponential-type decay. Rate equations were written to explain the time dependent intensities in terms of exciton and luminescence center creation and annihilation.

Although we do not yet have an electronic model to adequately describe the observations, the results clearly show that $\mathrm{x}$-ray-induced luminescence from low-OH silica fibers is very weak at room temperature. This observation has been made only for fibers subjected to ionizing radiation (in the absence of neutroninduced knock ons), but it suggests that recent observations of intense visible emission from neutronirradiated fibers may be attributable to Cherenkov radiation, which at elevated temperatures $\left(\sim 250^{\circ} \mathrm{C}\right.$, for 
example) is expected to be much more intense than luminescence. This implies that present concern over neutron-induced luminescence in silica fibers may be less important than Cherenkov radiation.

\section{PROGRESS AND STATUS}

\section{Introduction}

The anticipated use of fiber optics for ITER diagnostics requires an assessment of their optical characteristics during and after exposure at various temperatures to mixed neutron and $\gamma$ radiation fields. Recent observations of intense visible emission emanating from silica fibers during neutron exposure have raised questions about the origin of this light and its possible interference with diagnostic signals. To gain a better understanding of the nature of this emission and its impact on transmission of diagnostic signals, we have embarked upon a systematic investigation of radiation-induced luminescence in silica fibers.

\section{Experimental Procedure}

Silica fibers containing $<1 \mathrm{ppm}$ of $\mathrm{OH}$ (hereafter referred to as fiber " $A$ ") and $\sim 600-800 \mathrm{ppm} \mathrm{OH}$ (hereafter referred to as fiber " $S$ ") were obtained from Fiberguide Industries, Inc. [1] and tested in the asreceived condition. They each consisted of a pure fused-silica core with fluorine-doped ( $\sim 4$ mole \%) cladding and either nylon (fiber $A$ ) or aluminum (fiber $S$ ) jackets. Core/cladding/jacket diameters were $200 / 220 / 280 \mu \mathrm{m}$. Luminescence measurements were done by placing the fibers on an aluminum sample block in a continuous-flow cryostat, evacuating the chamber, exposing them to continuous $\mathrm{x}$ irradiation (25 $\mathrm{keV}$ effective energy; $\sim 13 \mathrm{~Gy} / \mathrm{s}$ exposure rate) as a function of either temperature $(\sim 7-300 \mathrm{~K})$ or time, and collecting the emission with a CCD-based optical multichannel analyzer. In some cases the emission was directed to a cooled photomultiplier tube for detection. In this latter arrangement we collected total light emitted by the fiber without regard for wavelength information. Typically, data were taken in the interval $300-800 \mathrm{~nm}$, corrected for the non-linear response of the spectrophotometer, plotted in energy units and fitted with Gaussian lineshapes.

\section{$\underline{\text { Results }}$}

\section{Anhydroguide}

Figure 1 shows the $x$-ray-induced luminescence from fiber $A$ taken at $7.3 \mathrm{~K}$. The spectra consist of two well-defined Gaussian bands (dashed lines) centered at 521 and $671 \mathrm{~nm}$ (these maxima shift to lower wavelength by about $20 \mathrm{~nm}$ as temperature increases to $150 \mathrm{~K}$ ). The fitted composite of the two bands is shown by the thin solid line where intensities are plotted as optical multichannel analyzer (OMA) counts. Temperature dependences of the peak intensities are shown in Fig. 2. Although we have not yet attempted to write rate equations describing the temperature dependence of luminescence peaks in silica fibers, we did find that a simple exponential adequately described the 521-nm peak decay. The $671-\mathrm{nm}$ peak exhibits an initial increase with increasing temperature followed by a decrease. No attempt was made to fit the latter peak intensity to a functional form. Data of Fig. 2 were taken from the fittted Gaussian curves and the statistical errors are smaller than the plot symbols. The total time required to obtain a full spectrum at each temperature was 15 seconds (total OMA integration time), which is also the $\mathrm{x}$-ray exposure time. That is, the specimens were exposed to $x$ radiation only during the 15 -second measurment interval. Data in Fig's. 1 and 2 were taken by cooling the sample to $7.3 \mathrm{~K}$ and recording spectra during warming. Hysteresis of the data were examined by also observing spectra upon cooling; only minimal effects were found. Tme dependence of the peak intensities was investigated by maintaining the sample temperature at $7.3 \mathrm{~K}$ and observing the change in intensity as the sample was subjected to continuous $\mathrm{x}$-ray exposure. Results of this experiment are shown in Fig. 3. 


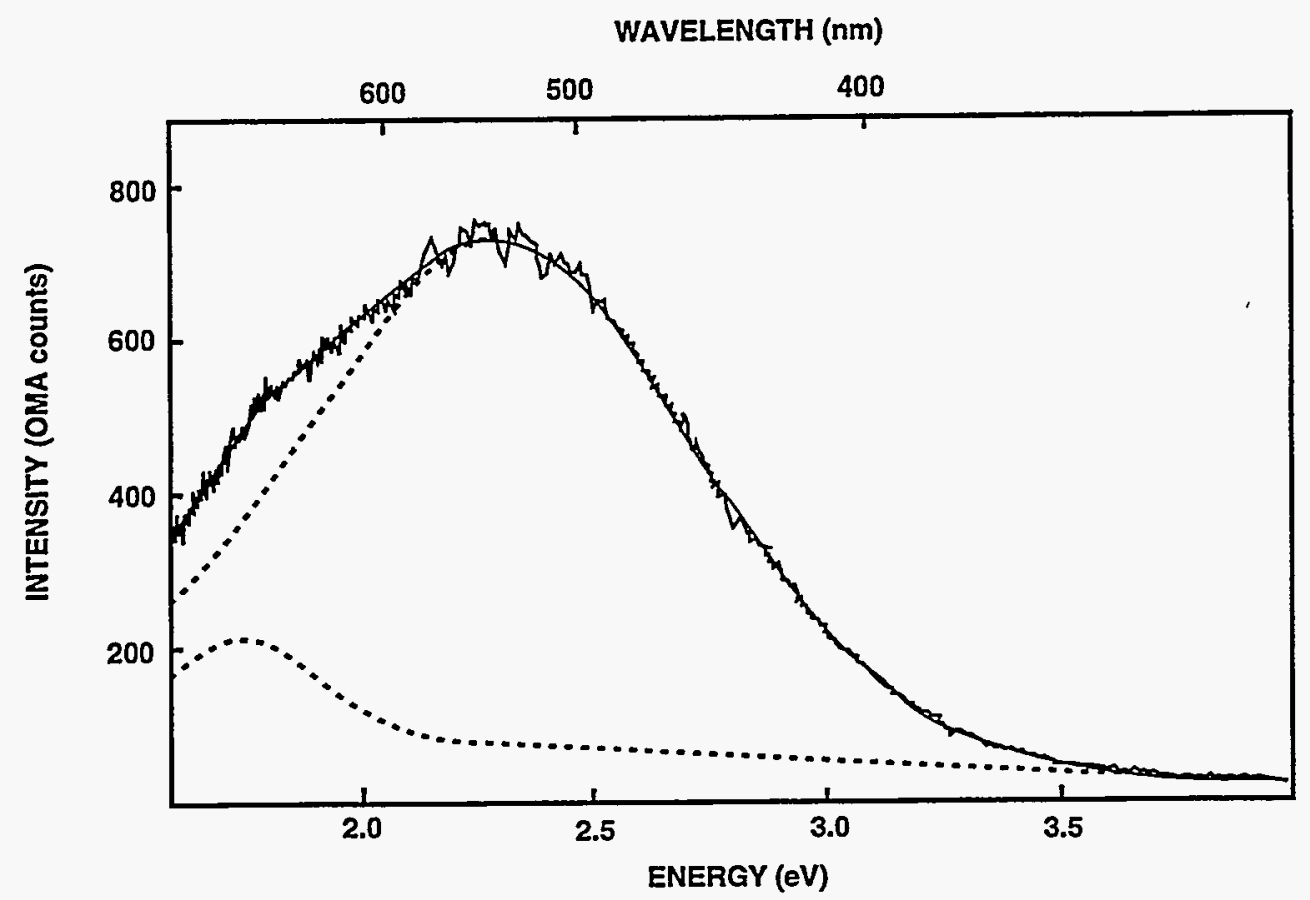

Fig. 1. X-ray-induced luminescence from silica fiber $A$ taken at $7.3 \mathrm{~K}$. Dashed lines are the doconvolved Gaussian peaks (521 and $671 \mathrm{~nm}$ ) and the solid line is the composite fit.

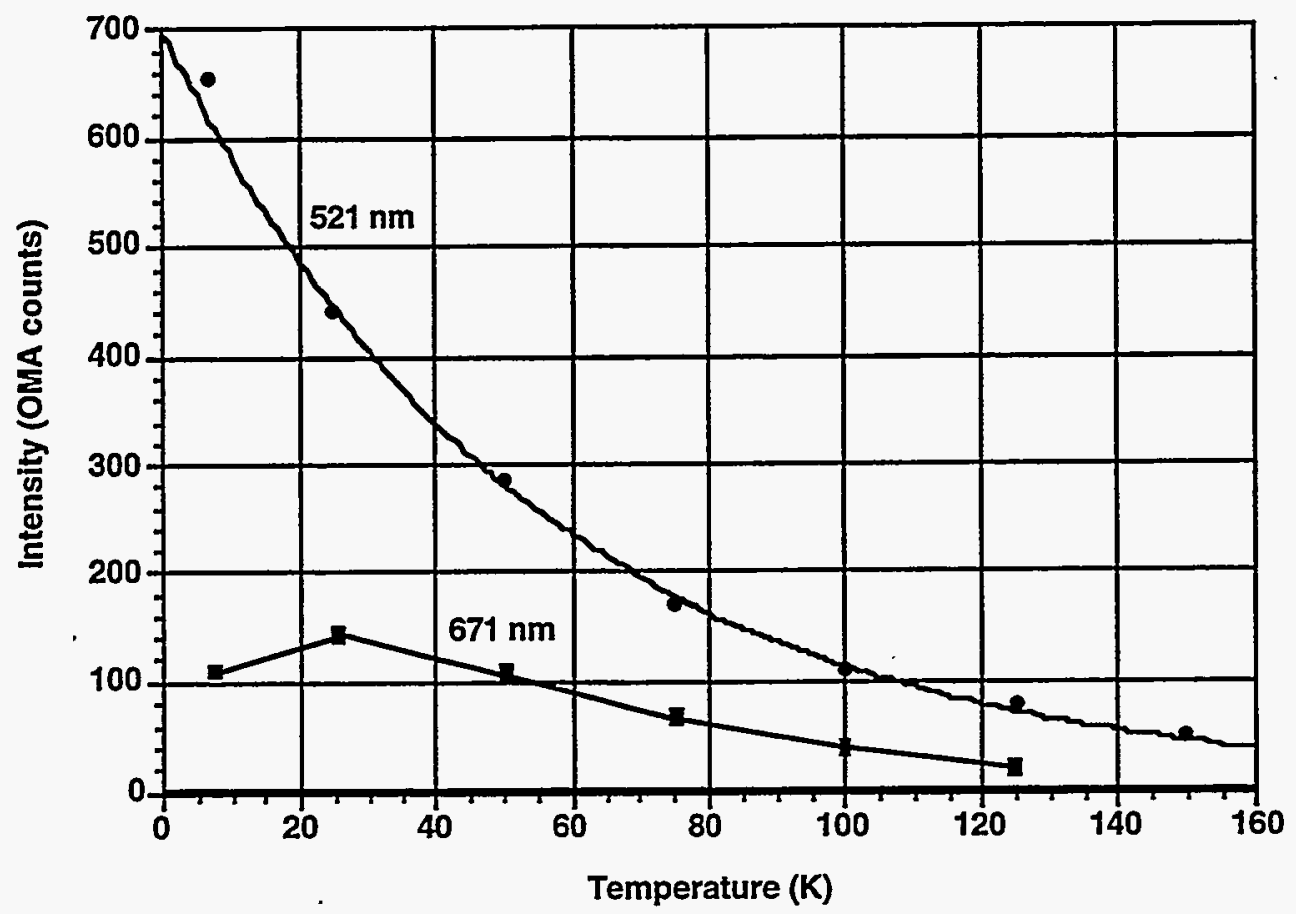

Fig. 2. Temperature dependence of luminescence peaks in silica fiber $A$. Solid line of upper curve is an exponential fit whereas the lower solid line is only a guide to the eye. 


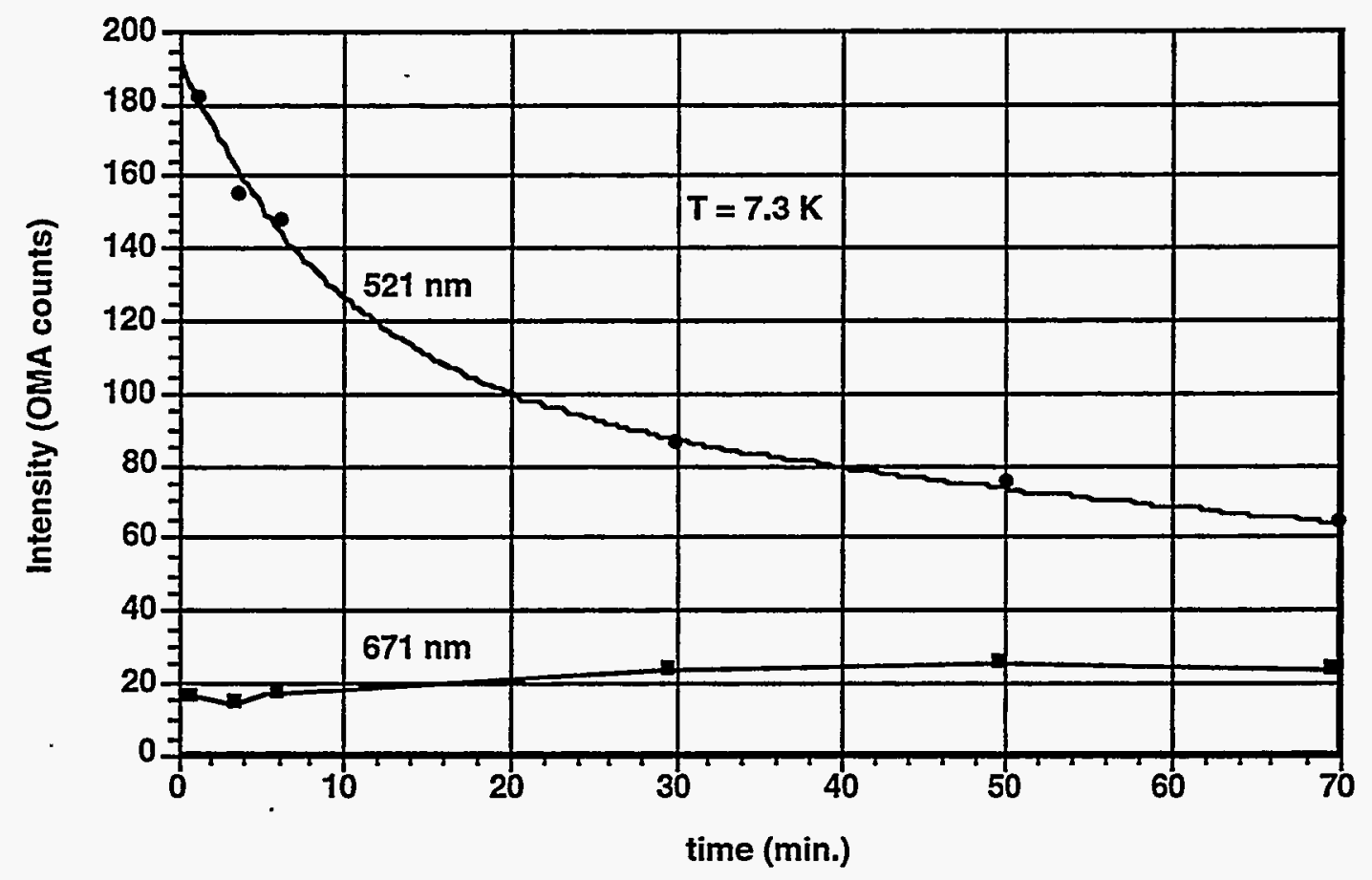

Fig. 3. Time dependence of luminescence peaks in silica fiber $A$. Solid line of upper curve is a fit to Eq. (7) of text and the lower curve is a guide to the eye.

Superguide

$\mathrm{X}$-ray-induced luminescence from fiber $S$ taken at $\mathrm{T}=8 \mathrm{~K}$ is shown in Fig. 4. The spectrum was taken under similar conditions as those previously described for fiber $A$. Unlike fiber $A$, however, the spectrum does not exhibit two well-defined peaks. Instead there exists one main peak with maximum at $596 \mathrm{~nm}$ and a hint of a second very weak peak near $660 \mathrm{~nm}$. This latter peak was sufficiently weak at all temperatures that we did not attempt to separately fit it with an individual Gaussian lineshape. A reasonably good fit to all of the spectra for fiber $S$ was obtained by invoking a single Gaussian lineshape, which is shown as the thin solid line of Fig. 4.

Temperature dependence of the luminescence intensity for fiber $S$ is shown in Fig. 5. It is clear that a simple exponential (shown as the solid curve) cannot properly describe the relaxation. We postpone efforts to model the temperature dependence of the luminescence intensity at the present time and focus only on the time dependent data shown in Fig's. 3 and 6 . Subsequent work will address the temperature dependence of the luminescence.

To gain an understanding of the time dependence of the $\mathrm{x}$-ray-induced luminescence of pristine silica, we plotted the total light output as a function of irradiation time at a fixed temperature. For this particular experiment we directed the luminescence onto a cooled photomultiplier tube (PMT) and plotted intensity vs. time in seconds. Notice that the ordinate is measured in units of PMT current instead of OMA counts as in Fig. 3. Surprisingly, we found that in the interval $8 \leq \mathrm{T} \leq 60 \mathrm{~K}$, the overall luminescence intensity decays with a rate constant that is independent of temperature (the model will be described in the discussion section). For $\mathrm{T} \geq 80 \mathrm{~K}$ the rate constant changes such that for $\mathrm{T} \geq 125 \mathrm{~K}$ there is no measurable decay in the intensity as a function of time. 


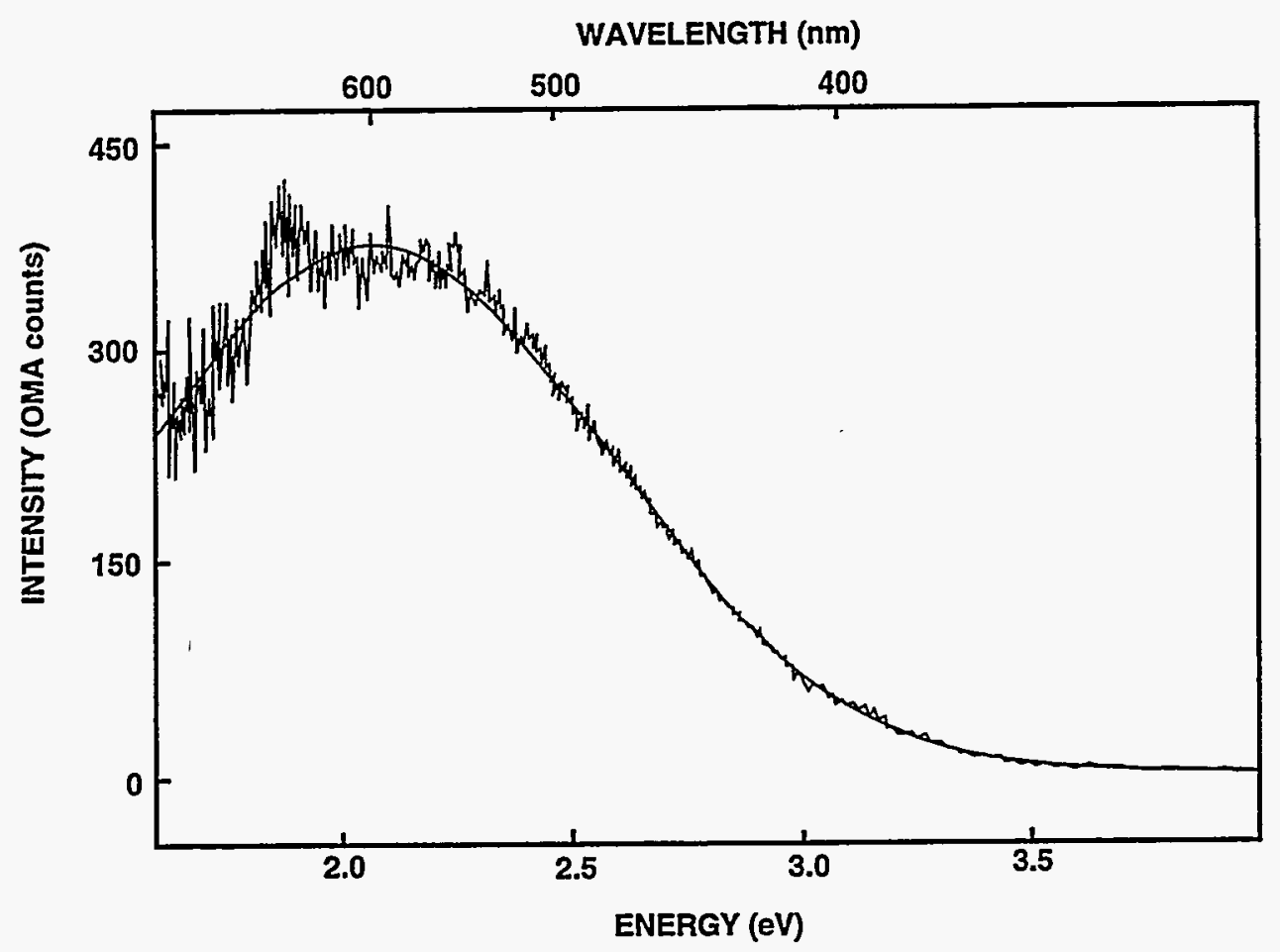

Fig. 4. X-ray-induced luminescence from fiber $S$ taken at $\mathrm{T}=8 \mathrm{~K}$. The solid line is a Gaussian fit to the data.

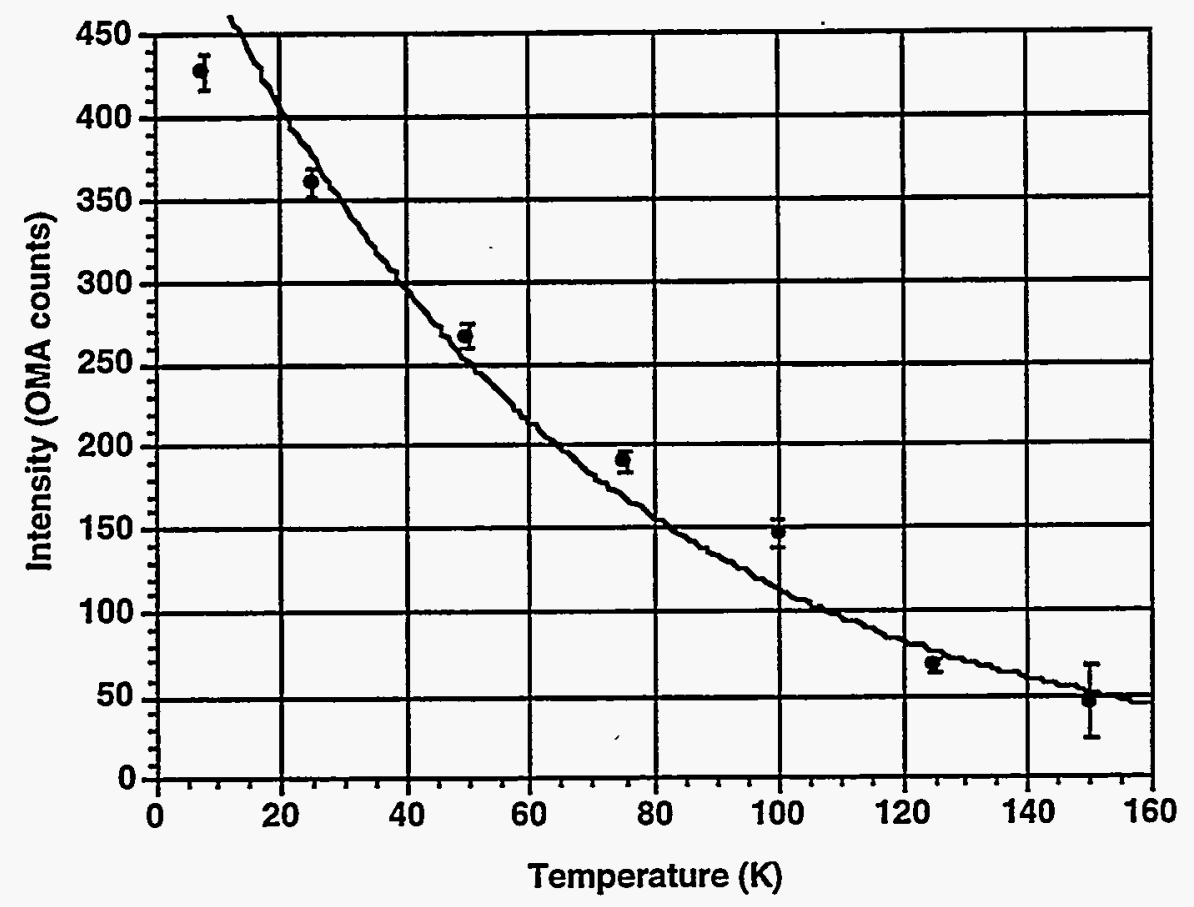

Fig. 5. Temperature dependence of luminescence from fiber $S$. The solid line is a simple exponential similar to the one shown in Fig. 2 and is included only for comparative purposes. 


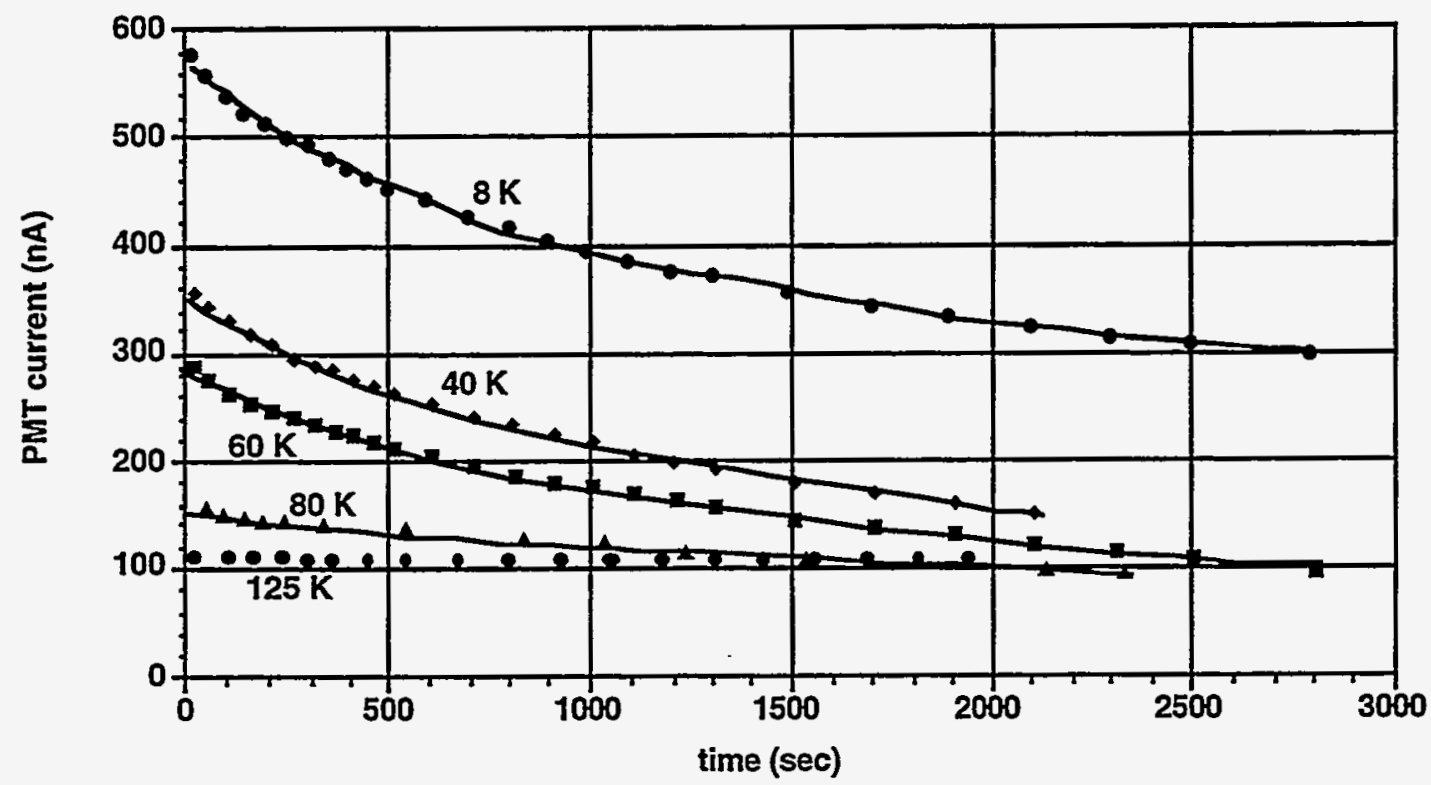

Fig. 6. Time dependence of the x-ray-induced luminescence intensity of fiber $S$ taken at several fixed temperatures. The solid lines are fits to Eq. (7) of text.

\section{Discussion}

We now develop rate equations to describe the time dependence of the luminescence intensity at fixed temperatures in silica fibers. In subsequent work we will address the temperature dependence. Primarily we are presently attempting to model the behavior exhibited in Fig's 3 and 6.

We assume that $x$ radiation produces energetic electrons, which produce both lattice defects and excitons. Radiation-produced excitons are either self-trapped, likely decaying nonradiatively, or are trapped at a defect with the possibility of radiative recombination. Self-trapping is certainly expected to involve phonons and thus should be temperature dependent; increasing the temperature should increase the probability of their decay. For the present work, however, we concentrate on the time dependence.

Under $\mathrm{x}$-ray excitation the rate of increase in exciton concentration $n$ is described by the equation:

$$
\frac{d n}{d t}=\alpha-\beta n-\sum_{i} D_{i} n N_{i}
$$

The parameter $\alpha=A I$, with $I$ the intensity of the $\mathrm{x}$-ray radiation, gives the exciton production rate and $\beta=$ $B I+C$ gives the decay rate. The parameter $D_{i}$ gives the capture rate (velocity times cross-section) by $N_{i}$ recombination centers.

Now we allow for the possibility that recombination centers may be created under irradiation. These centers may be destroyed either by the action of the radiation or through thermal processes. Some of the generation of these centers will be first-order, increasing at a rate proportional to $I$ and some second-order, increasing at a rate proportional to $n^{2}$. We simplify the discussion by assuming that the generation is firstorder and thus proportional to $I$ : 


$$
\frac{d N_{i}}{d t}=\alpha_{i}-\beta_{i}\left(N_{i}-N_{i}^{0}\right)
$$

Here $\alpha_{i}=A_{i} I$ is the rate of generation of recombination centers and $\beta_{i}=B_{i} I+C_{i}$ is the decay rate, where $B_{i} I$ represents power-induced decay and $C_{i}$ represents thermal decay. $N_{i}^{0}$ is a fixed concentration of recombination centers. At constant radiation intensity the concentration of recombination centers increases as:

$$
N_{i}=N_{i}^{0}+\left(\alpha_{i} / \beta_{i}\right)\left(1-e^{-\beta_{i} t}\right)
$$

We further assume that the exciton relaxation rate $\beta+\sum_{i} D_{i} N_{i}$ is much greater than the relaxation rates $\beta_{i}$ of the recombination centers. This assumption allows us to take for the instantaneous exciton concentration the steady state value corresponding to the current concentrations of the recombination centers:

$$
n=\frac{A I}{B I+C+\sum_{i} D_{i} N_{i}}
$$

where the $N_{i}$ are given by Eq. (3).

Much of the exciton recombination is nonradiative while some recombination may be radiative and identified as luminescence. We separate the recombination rate into two terms:

$$
D_{i}=D_{i}^{n}+D_{i}^{r}
$$

where $D_{i}^{n}$ is the nonradiative fraction and $D_{i}^{r}$ is the radiative fraction. The luminescence intensity of the $j^{\prime}$ th center is from Eqs. (1), (4) and (5):

$$
L_{j}=D_{j}^{r} n N_{j}=\frac{D_{j}^{r} N_{j}}{B I+C+\sum_{i} D_{i} N_{i}} A I
$$

The decrease in $L_{j}$ with increasing temperature is a consequence of the increase in $C$ and possibly the $D_{i}$ with temperature. The decrease in $L_{j}$ with time is a consequence of the increase in the $N_{i}$ with time. Where a particular $L_{j}$ is found to increase with time, this increase may be a consequence of a growth in the corresponding $N_{j}$ with time.

Substituting Eq. (3) into Eq. (6) gives for the decay in the luminescence of the $j^{\prime}$ th center:

$$
L_{j}=D_{j}^{r} n N_{j}=\frac{D_{j}^{r}\left[N_{j}^{0}+\left(\alpha_{j} / \beta_{j}\right)\left(1-e^{-\beta_{j} t}\right)\right]}{B I+C+\sum_{i} D_{i}\left[N_{i}^{0}+\left(\alpha_{i} / \beta_{i}\right)\left(1-e^{-\beta_{i} t}\right)\right]} A I
$$

The asymptotic value of $L_{j}$ from Eq. (7) is: 


$$
L_{j}=D_{j}^{r} n N_{j}=\frac{D_{j}^{r}\left(N_{j}^{0}+\alpha_{j} / \beta_{j}\right)}{B I+C+\sum_{i} D_{i}\left(N_{i}^{0}+\alpha_{i} / \beta_{i}\right)} A I
$$

As the temperature is increased, the asymptotic value can be expected to decrease as a result of an increase in $C$ but may compensated somewhat by increases in the $\beta_{i}$. in the denominator. At sufficiently high power, the luminescence is expected to saturate at the value:

$$
L_{j}=D_{i}^{r} n N_{r j} \approx D_{j}^{r}\left(N_{j}^{0}+\frac{A_{j}}{B_{j}}\right) \frac{A}{B}
$$

The model calculations were compared to experimental results by fitting the data of Fig's 3 and 6 (under simplifying assumptions) to Eq. (7). Excellent fits were obtained as shown by the solid lines in Fig's 3 and 6, thereby supporting our conclusion that the decrease in luminescence intensity is attributable to an increase in recombination center concentration. Moreover, it was found that the recombination center rate constants for data taken at 8,40 and $60 \mathrm{~K}$ were essentially equivalent; $\left\langle\beta_{i}\right\rangle=4.94 \times 10^{-4} \mathrm{~s}^{-1}$. Therefore the rate of increase in recombination center concentration is independent of temperature in this interval. The value of the rate constant changes for $T \geq 80 \mathrm{~K}$ and we speculate that this thermal dependence is likely due to increased mobility of an as yet unknown species, possibly $\mathrm{H}$ or $\mathrm{O}$. Identification of these defects must await our planned optical absorption and electron spin resonance studies. However, it is well established that non-bridging oxygen hole, $E^{\prime}$, and peroxy radical centers are the main defects induced in silica by $x$ radiation, and the conversion of $E^{\prime}$ centers to peroxy radicals is controlled by the diffusion of molecular oxygen [2]. Radiolytically-produced atomic hydrogen is also known to exist below about $130 \mathrm{~K}$ in OH-containing silica and may play a role in the luminescence process [2]. Further work is required to identify the luminescence centers and their interconversions.

Our current results clearly demonstrate that $\mathrm{x}$-ray-induced luminescence in pristine silica fibers of both low and high $\mathrm{OH}$ content decays with temperature and time, and is very weak at room temperature. Similar studies are now underway to examine the behavior of neutron-irradiated fibers. It is important to establish the role and relative intensities of radiation-induced luminescence and Cherenkov emission in fibers subjected to neutron exposure. If the Cherenkov emission dominates at temperatures of interest in ITER applications as suggested by other data [3], attention should be focused on ways to mitigate this problem rather than luminescence. Of course there still remains the problem of radiation-induced absorption in silica, which is certainly due to the production and/or interconversion of defects. The usefulness of silica fibers for ITER diagnostics may depend upon how well we understand the production, destruction and interconversion of these defects. Because precursors are believed to play a role in radiation hardening of silica [4] and because interconversion of defects depends upon radiation dose, temperature and time [5], it is necessary to study both pristine and neutron-irradiated silica at low temperatures where initial defects still exist. As our present data demonstrate, below about $80 \mathrm{~K}$ there is a temperature independent rate of decay of luminescence intensity that we speculate to be associated with the mobility of either $\mathrm{H}$ or O. Our aim is to understand the defects, model the kinetics, and predict ways to ameliorate the luminescence (and absorption) in silica fibers.

\section{FUTURE PLANS}

We are presently investigating luminescence of silica fibers which have been irradiated to high neutron fluences $\left(10^{23} \mathrm{n}-\mathrm{m}^{2}\right)$ at the Los Alamos Spallation Radiation Effects Facility. Luminescence data similar to that reported in the present work will be taken on these specimens and compared to the prisitine fibers. Optical absorption measurements on both sets of fibers will be conducted to ascertain expected correlations between absorption and luminescence centers. These data should aid identification of the radiation-induced defects. 


\section{REFERENCES}

[1] Fiberguide Industries, Inc., 1 Bay Street, Stirling, NJ 07980.

[2] D. L. Griscom, J. Ceram. Soc. Jpn. 99,923 (1991).

[3] S. F. Paul, J. L. Goldstein, R. D. Durst and J. R. Fonck, Rev. Sci. Instrum. 66, 1252 (1995).

[4] D. L. Griscom, J. Appl. Phys. To be published.

[5] L. Zhang, V. A. Mashkov and R. G. Leisure, Phys. Rev. Lett. 74, 1605 (1995). 
4 
OXYGEN EFFECTS ON SIC/SIC COMPOSITES FOR FUSION STRUCTURAL APPLICATIONS G. D. Springer, C. F. Windisch, Jr., C. H. Henager, Jr., and R. H. Jones, Pacific Northwest Laboratory.

\section{OBJECTIVE}

The purpose of this study was to quantitatively assess the stability of $\mathrm{SiC} / \mathrm{SiC}$ composites in hightemperature, low-oxygen ( $<2500 \mathrm{ppm}$ ) environments by thermal gravimetric analysis (TGA) in regards to their potential use as structural materials in fusion reactors.

\section{SUMMARY}

Linear-parabolic kinetics governed the oxidation reaction with 100 to $1500 \mathrm{ppm}$ oxygen at $1100^{\circ} \mathrm{C}$. This behavior concurs with the previous research of Windisch et al..$^{(1)}$ which observed a deviation from linearity beginning below $2500 \mathrm{ppm}$. By focusing on the linear region, a simple model estimated the linear rate dependency on oxygen partial pressure to be on the order of 0.911 . Future tests will be performed with 100 and $1000 \mathrm{ppm}$ in the temperature range of 800 to $1000^{\circ} \mathrm{C}$ in order to refine the understanding of temperature and partial pressure effects. The relationship between interfacial oxidation and experimental parameters, such as temperature, pressure, and interfacial thickness, will be described in an upcoming comprehensive model.

\section{$\underline{\text { Introduction }}$}

Ceramic matrix composites (CMCs) are being considered for advanced first-wall and blanket structural applications in fusion reactors. This consideration is based on a host of favorable properties, including low density, low neutron activation, low coefficient of thermal expansion, good thermal conductivity, and good corrosion resistance. An area of concern, however, is the interfacial depletion in oxygen environments leading to a decline in mechanical properties by increased fiber/matrix debonding.

This study will focus on the exposure of $\mathrm{SiC} / \mathrm{SiC}$ composites with $\mathrm{C}$ interfaces to oxygen concentrations between 100 and $1500 \mathrm{ppm}$. The composite can be expected to evolve gas by the following reactions ${ }^{(2,3)}$ :

Fiber and Matrix:

$$
\begin{array}{cc}
\mathrm{SiC}(\mathrm{s})+3 / 2 \mathrm{O}_{2}(\mathrm{~g})= & \mathrm{SiO}_{2}(\mathrm{~s})+\mathrm{CO}(\mathrm{g}) \quad \text { High } \mathrm{P}_{\mathrm{O} 2}[1] \\
\mathrm{SiC}(\mathrm{s})+\mathrm{O}_{2}(\mathrm{~g})= & \mathrm{SiO}(\mathrm{g})+\mathrm{CO}(\mathrm{g}) \quad \text { Low } \mathrm{P}_{\mathrm{O} 2}[2] \\
& \text { Interface: } \\
\mathrm{C}(\mathrm{s})+\mathrm{O}_{2}(\mathrm{~g})=\mathrm{CO}_{2}(\mathrm{~g})[3] \\
\mathrm{C}(\mathrm{s})+1 / 2 \mathrm{O}_{2}(\mathrm{~g})=\mathrm{CO}(\mathrm{g})[4]
\end{array}
$$

Below $1200^{\circ} \mathrm{C}$ there should be no reaction with the fiber or matrix. If silica did form between the fiber and matrix by reaction 1 , the pore could seal under the proper conditions and effectively stop the reaction by cutting off gaseous diffusion. This sealing effect has been observed to be dependent on several factors, primarily interface thickness, test duration, and oxygen concentration ${ }^{(4,5)}$. The $\mathrm{SiC} / \mathrm{SiC}$ samples used in this study had a relatively large interface thickness of 1.0 micron and it is unlikely that the pore could be completely sealed even if reaction 1 did take place.

The purpose of this study was to measure the loss of C-interface due to reaction 3 and/or reaction 4 under low-oxygen concentrations and high temperatures, typical of the environment in a gas cooled fusion blanket. 


\section{Experimental}

The samples used in this study were acquired from Refractory Composites, Inc. of Whittier, California. Fabrication was accomplished by the chemical vapor infiltration (CVI) of Beta-SiC matrix into 8-ply Nicalon fiber cloth, pre-coated with C-interface. This formed a $0^{\circ} / 90^{\circ}$ weave pattern with fiber diameters of 15 microns and interface thicknesses of 1 micron. Final sample shape was rectangular with average dimensions of $0.3 \times 0.3 \times 0.4 \mathrm{~cm}$. In order to better isolate the reaction fronts, three faces were uncoated, while three sides were completely coated with $\mathrm{SiC}$ in order to prevent any reaction.

A TA Instruments SDT 2960 TGA/DTA was used for all experiments. This unit provided high sensitivity and good accuracy. Experimental conditions were programmed into the computer, specially designed for the SDT 2960 , with capabilities of data acquisition, storage, and real-time monitoring. Next, TGA preparation was necessary that included sample taring, reference material placement, and furnace closure. Purging, the final step before testing, achieved good gas mixing by maintaining a flow rate of $100 \mathrm{~mL} / \mathrm{min}$ for about an hour. Actual testing was done at $100 \mathrm{~mL} / \mathrm{min}$, with real-time temperature and weight measurements being continually observed.

\section{PROGRESS AND STATUS}

\section{TGA Data}

Figure 1 displays the raw data from TGA testing at $1100^{\circ} \mathrm{C}$ with $0,100,500,1000$, and $1500 \mathrm{ppm}$ oxygen. The sample weight losses, taken directly from the TGA, were divided by the total exposed surface area to produce the normalized units of $\mathrm{mg} / \mathrm{cm}^{2}$. This normalization assumes that interfacial oxidation along one fiber axis does not affect interfacial removal down the perpendicular fiber axis.

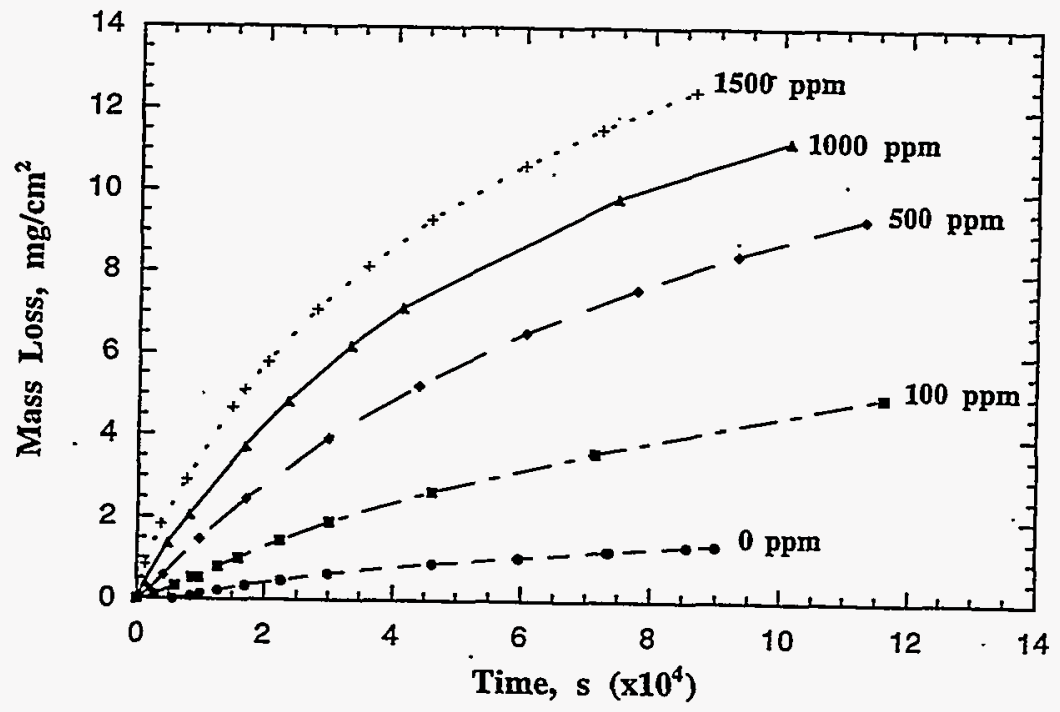

Figure 1: TGA Data for C-Interface SiC/SiC Composites in $\mathrm{O}_{2}$ (balance $\mathrm{Ar}$ ) at $1100^{\circ} \mathrm{C}$ 
Clearly, all of the curves deviate from linear behavior and exhibit parabolic characteristics. Although there are no distinct transition points, the curves likely shift from linear to parabolic regions over a wide range of time. This transition typically indicates that the oxidation has changed from reaction control to diffusion control and is expected to depend on carbon type, system pressure, partial pressure, and temperature ${ }^{(6)}$.

The baseline curve, tested in ultrahigh-purity argon, revealed a slight amount of weight loss. This loss is best explained by either the imperfect sealing of the SDT 2960, possibly from the backflow of outside air through the exhaust nozzle, or the evolution of a volatile species, such as SiO, from the Nicalon fibers. Adsorbed oxygen may have been trapped in the sample, but its contribution to oxidation would have appeared early on as a quick burst of weight loss, which was not the case. Data were corrected for the background weight loss by simply subtracting the baseline curve from the other curves at equivalent times.

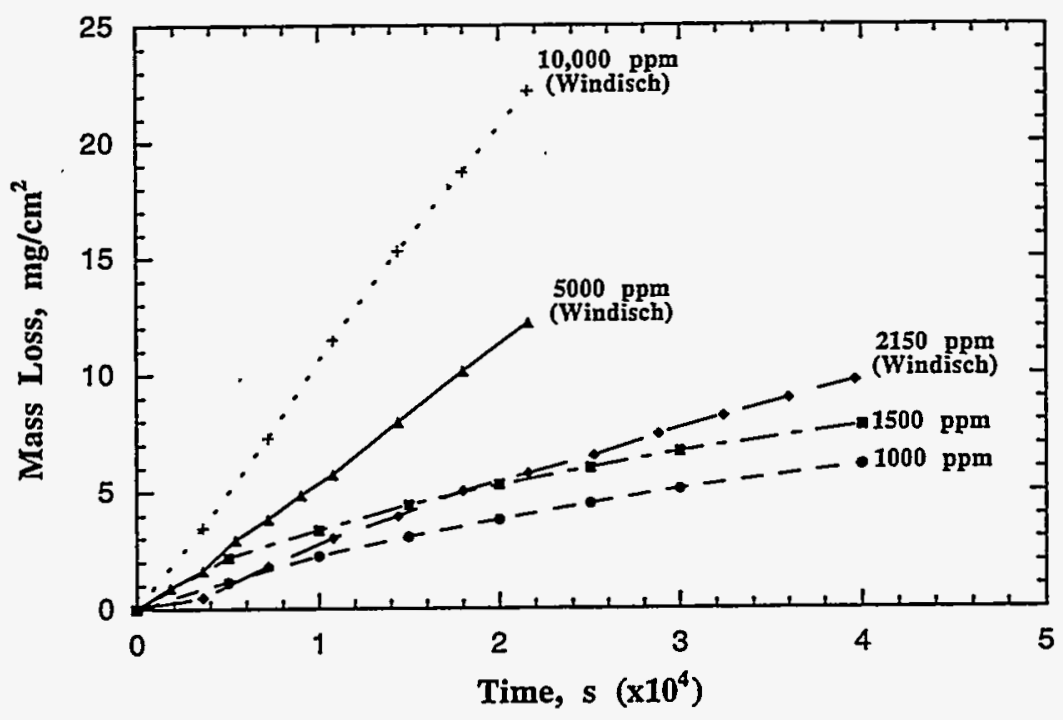

Figure 2: TGA Comparison Data for C-Interface SiC/SiC Composites in $\mathrm{O}_{2}$ at $1100^{\circ} \mathrm{C}$

Figure 2 offers a comparison with the results of Windisch et al. It can be seen that the 5000 and 10,000 ppm curves are linear, while the $2150 \mathrm{ppm}$ curve departs from linear behavior around 15,000 seconds. Overlapping the lower two curves from Windisch are the upper two curves from the present study, which exhibit parabolic behavior much sooner than the $2150 \mathrm{ppm}$ curve. Surprisingly, the 1000 and $1500 \mathrm{ppm}$ runs initially exceed the $2150 \mathrm{ppm}$ experiment in normalized weight loss. Future work will attempt to explain this result.

\section{Modeling and Fitting}

A comparison of results other than normalized weight loss was also desired. Equation 4, which focuses on the linear region, was chosen for modeling and comparative purposes.

$$
\mathrm{k}_{1}=\mathrm{k}_{1}^{\prime} \times \mathrm{p}\left(\mathrm{O}_{2}\right)^{\mathrm{n}}[5]
$$


By this equation, the oxygen-dependent linear rate constant, $\mathrm{k}_{\mathrm{l}}$, is related to the partial pressure of oxygen, $\mathrm{p}\left(\mathrm{O}_{2}\right)$, where $\mathrm{k}_{1}^{\prime}$ is the oxygen-independent linear rate constant, in units of $\mathrm{cm} / \mathrm{s} / \mathrm{atm}$, and $\mathrm{n}$ is the order of the reaction with respect to oxygen.

Cawley et al. have proposed the linear-parabolic model for the oxidation of carbon.

$$
x^{2} / k_{p}+x / k_{1}=t[6]
$$

At some oxidation time, $t$, and recession distance, $x$, the reaction shifts from being dominated by the linear term, $x / k_{1}$, to being governed by the parabolic term, $x^{2} / k_{p}$. As mentioned earlier, this shift most likely corresponds to a transition from reaction control to diffusion control.

In order to obtain $k_{1}$ and the order of the oxygen dependency, $n$, the following steps were applied to the normalized weight loss per unit time data:

1) The baseline curve from the $0 \mathrm{ppm}$ run was subtracted from the other curves.

2) Time was plotted versus normalized weight loss and the curves were fit to a parabolic function.

3) From these parabolic fits, the linear coefficients for the first-order terms were reciprocated, divided by the density of carbon, and divided by the fraction of surface area that is interface.

These manipulations yield the oxygen-independent linear rate constant, $k_{1}$. For valid comparisons with other sources, the $\log$ of $\mathrm{k}_{1}{ }^{\prime}$ was plotted against the $\log$ of $\mathrm{p}\left(\mathrm{O}_{2}\right)$. Figure 3 depicts this plot along with a simple linear fit. According to equation 7 , the logarithm of both sides of equation 5 , this linear fit provides $\mathrm{k}_{\mathrm{l}}$, at $1 \mathrm{~atm}$ partial pressure, by its intercept and $\mathrm{n}$ by its slope.

$$
\log k_{1}=\log k_{1}^{\prime}+n \log p\left(O_{2}\right)[7]
$$

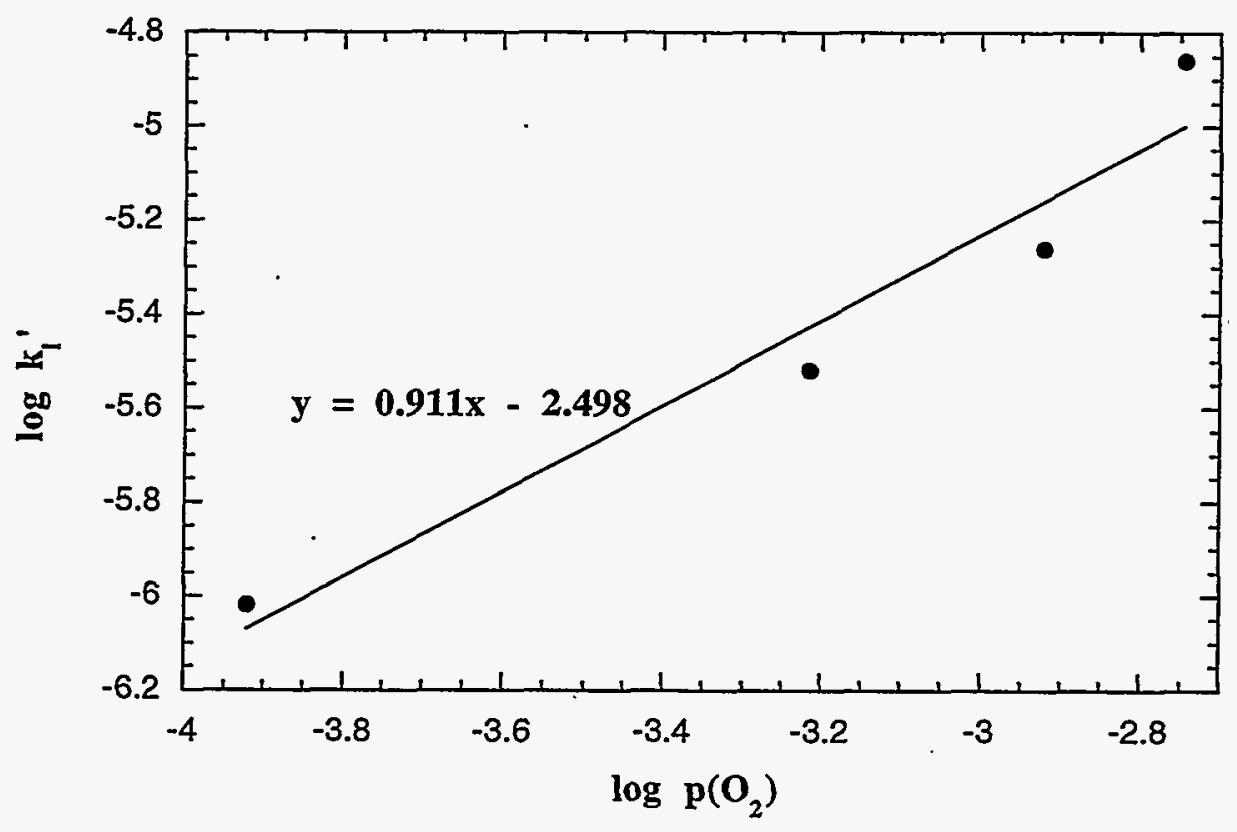

Figure 3: Log of Linear Rate Constant vs. $\log$ of Partial Pressure of $\mathrm{O}_{2}$ 
The parabolic coefficients from step 2 can also be translated into oxygen-independent parabolic rate constants. Step 3 is the same except the coefficients are divided by the square of the density of carbon. Figure 4 shows the $\log$ of $\mathrm{k}_{\mathrm{p}}$ ' versus the $\log$ of $\mathrm{p}\left(\mathrm{O}_{2}\right)$ along with a linear fit. Similar to the linear region, this fit produces $k_{p}$, at $1 \mathrm{~atm}$ partial pressure, by its intercept.

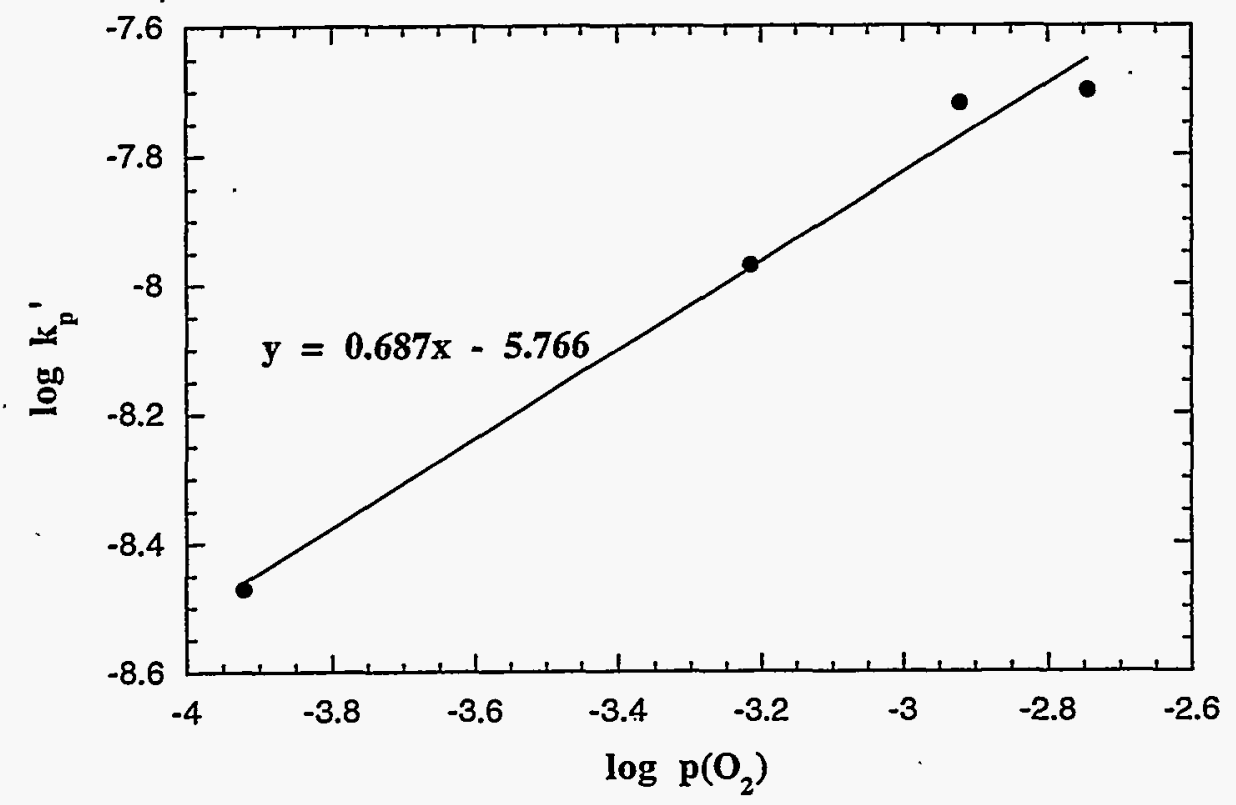

\section{Literature Comparison}

Figure 4: Log of Parabolic Rate Constant vs. Log of Partial Pressure of $\mathrm{O}_{2}$

A comparison with the work of Windisch and Cawley is given by Table 1. As can be seen, the $\mathrm{n}$ terms compare closely while the values of $k_{1}$ and $k_{p}$ differ to a greater degree.

All of the $\mathrm{n}$ terms given are reasonably close to one, indicating that the partial pressure of oxygen has a nearly linear effect on oxidation. The geometric $\mathrm{n}$ term reported by Windisch was done by optical examination of interfacial recession distances. Currently, a similar examination is being done with the samples from this study.

\begin{tabular}{|l|c|c|c|c|}
\hline Source & Temp $\left({ }^{\circ} \mathrm{C}\right)$ & $\mathrm{n}$ & $\mathrm{k}_{\mathrm{f}}(\mathrm{cm} / \mathrm{s})$ & $\mathrm{k}_{\mathrm{p}}\left(\mathrm{cm}^{2} / \mathrm{s}\right)$ \\
\hline \hline Springer & 1100 & 0.911 & $3.2 \mathrm{E}-3$ & $1.7 \mathrm{E}-6$ \\
\hline Windisch & 1100 & $0.9(\mathrm{geom})$ & $6.4 \mathrm{E}-4$ & - \\
\hline & 1100 & $0.8(\mathrm{TGA})$ & $4.0 \mathrm{E}-4$ & - \\
\hline Cawley & 1000 & - & $1.7 \mathrm{E}-4$ & $6.4 \mathrm{E}-4$ \\
\hline & 1200 & - & $3.2 \mathrm{E}-4$ & $6.8 \mathrm{E}-4$ \\
\hline
\end{tabular}

Table 1: Literature Comparison of the Partial Pressure Exponent Term, Linear Rate Constant, and Parabolic Rate Constant 
Reasons for the discrepancy in $k_{p}$ and $k_{1}$ values are uncertain at this point. Differences in sample geometry and carbon type may help explain the variation with Cawley, while differences in $p\left(\mathrm{O}_{2}\right)$ range and the number of exposed faces may account for the lower results of Windisch. Also worth considering is the unknown nature of the oxidants, $\mathrm{CO}$ and $\mathrm{CO}_{2}$, which may change at lower partial pressures.

\section{CONCLUSIONS}

In the oxygen range of 100 to $1500 \mathrm{ppm}$, linear-parabolic kinetics governed the oxidation of carbon interface at $1100^{\circ} \mathrm{C}$. Further experimentation at lower temperatures should refine the understanding of the interfacial oxidation. An upcoming comprehensive model will incorporate the results of this work with several other sources to predict interfacial loss given various experimental parameters, such as temperature, partial pressure, system pressure, and interfacial thickness.

\section{FUTURE WORK}

Testing will be done with 100 and $1000 \mathrm{ppm}$ oxygen in the temperature range of 800 to $1000^{\circ} \mathrm{C}$. Recession distances will be measured along two fiber axes through microscopic analysis. All of this work is aimed at the development of a comprehensive model including temperature dependence.

\section{REFERENCES}

1. C. F. Windisch, Jr., G. D. Springer, E. P. Simonen, C. H. Henager, Jr., and R. H. Jones, "TGA Study of the Oxidation of the C Interface in Nicalon-Fiber-Reinforced SiC-Matrix CMC Material," to be submitted to J. Am. Ceram. Soc. (1995).

2. R. H. Jones, "Environmental Effects on SiC/SiC Composites for Fusion Structural Applications," Pacific Northwest Laboratory, DOE/ER-0313/10, Fusion Reactor Materials Semiannual Report for Period Ending March 31, 1991, p. 216.

3. T. J. Clark, R. E. Woodley, and D. R. De Halas, "Gas-Graphite Systems," Nuclear Graphite. Academic Press (1962), p. 412.

4. L. Filipuzzi, G. Camus, and R. Naslain, "Oxidation Mechanisms and Kinetics of 1D-SiC/C/SiC Composite Materials: I, An Experimental Approach," J. Am. Ceram. Soc., Vol. 77, No. 2, Feb. (1994), p. 459-66.

5. L. Filipuzzi and R. Naslain, "Oxidation Mechanisms and Kinetics of $1 \mathrm{D}-\mathrm{SiC} / \mathrm{C} / \mathrm{SiC}$ Composite Materials: II, Modeling," J. Am. Ceram. Soc., Vol. 77, No. 2, Feb. (1994), p. 467-79.

6. J. D. Cawley, A. J. Eckel, and T. A. Parthasarathy, "Oxidation of Carbon in Fiber-Reinforced Ceramic Matrix Composites," Ceram. Eng. and Sci. Proc., Vol. 15, No. 5, Sept. (1994), p. 967. 
HYDROGEN EFFECTS ON SIC/SIC COMPOSITES FOR FUSION STRUCTURAL APPLICATIONS

- G. D. Springer and R. H. Jones, Pacific Northwest Laboratory

\section{OBJECTIVE}

The purpose of this study is to quantitatively assess the stability of $\mathrm{SiC} / \mathrm{SiC}$ composites in hightemperature, low-hydrogen environments by the measurement of weight loss, in relation to their potential use as structural materials in fusion reactors.

\section{SUMMARY}

Two exploratory experiments at $1100^{\circ} \mathrm{C}$ and $1200^{\circ} \mathrm{C}$ in an argon $+1 \%$ hydrogen environment have demonstrated a relatively slow reaction rate. This slow reaction rate concurs with literature ${ }^{1}$ yet a better understanding of kinetics is still needed. Further experimentation will test the reproducibility of these early results and better determine the influence of experimental conditions by varying temperature and the partial pressure of hydrogen.

\section{Introduction}

Silicon carbide composites are a leading type of ceramic matrix composite (CMC) being evaluated for use as a structural material in fusion reactors ${ }^{2}$. In this evaluation, positive factors include high strength at elevated temperatures, low density, high stiffness, and low neutron activation, with some negative factors being material cost and fabrication complexity. The mechanical properties of $\mathrm{SiC} / \mathrm{SiC}$, such as strength and toughness, have been shown adequate for the design requirements. What needs to be further established for $\mathrm{SiC} / \mathrm{SiC}$ composites is the predicted performance under the conditions of irradiation and exposure to fusion relevant environments.

This study will focus only on the exposure of $\mathrm{SiC} / \mathrm{SiC}$ composites with $\mathrm{C}$-interfaces to low concentrations of hydrogen in order to simulate a gas cooled, solid-breeding blanket. The interfacial carbon should react with hydrogen to produce methane gas, with negligible traces of other hydrocarbons ${ }^{(3)}$. The matrix and fibers should be stable under the experimental conditions and should not skew the weight loss measurement by other reactions. Therefore, the primary reaction to consider is:

$$
\mathrm{C}(\mathrm{s})+2 \mathrm{H}_{2}(\mathrm{~g})=\mathrm{CH}_{4}(\mathrm{~g})
$$

The purpose of this study was to assess the loss of $\mathrm{C}$-interface due to this reaction under various temperatures and hydrogen partial pressures.

\section{Experimental}

The samples used in this study were acquired from Refractory Composites, Inc. of Whittier, California. Fabrication was done by the chemical vapor infiltration (CVI) of Beta-SiC matrix into 8-ply Nicalon fiber cloth, pre-coated with C-interface. This formed a $0^{\circ} / 90^{\circ}$ weave pattern with fiber diameters of 15 microns and interface thicknesses of 1 micron. Final sample shape was rectangular with average dimensions of $0.4 \times 0.4 \times 0.5 \mathrm{~cm}$. In order to better isolate the reaction fronts, only two faces were uncoated, while four sides were completely coated with $\mathrm{SiC}$ in order to prevent any reaction.

A Netzsch STA409 thermogravimetric analyzer (TGA) was used for these measurements. Both exploratory tests were executed on this unit according to the following procedure: 
1) The composite sample was weighed and placed in the left furnace crucible such that neither of the uncoated sides faced downward. (Alumina powder rested in the right furnace crucible as an inert reference material used to stabilize the TC rod.)

2) The furnace was sealed.

3) Gas flow was adjusted to 3.2 standard cubic feet per hour (SCFH) and the system was purged for about 2 hours.

4) Cooling water flow was brought to a steady level.

5) The balance was released and the scale adjusted to the proper zero level.

6) Initiation of the profile controller program brought the furnace to peak temperature in half an hour by ramping.

7) Peak temperature was maintained for the experiment duration and was followed by a 2-hour cooldown period to ambient levels.

8) The flow of gas and cooling water was stopped.

9) The furnace was opened.

10) The composite sample was removed and re-weighed.

\section{PROGRESS AND STATUS}

The results of the two exploratory tests are shown in Figure 1. Three items are important to bear in mind when examining these results. First, they are merely single points, not curves. The Netzsch stripchart was originally designed to record dynamic weight measurements, but has been found unreliable at lower gas concentrations. Weight losses depicted in Figure 1 were obtained simply by total sample weight change, with weights recorded on a balance separate from the Netzsch unit before and after testing. Second, these weight losses have been normalized with respect to exposed surface area. This normalization assumes that interfacial removal along one fiber axis does not affect interfacial reduction down the perpendicular fiber axis. Finally, since little weight loss was detected on the first test the same sample was used for the second test.

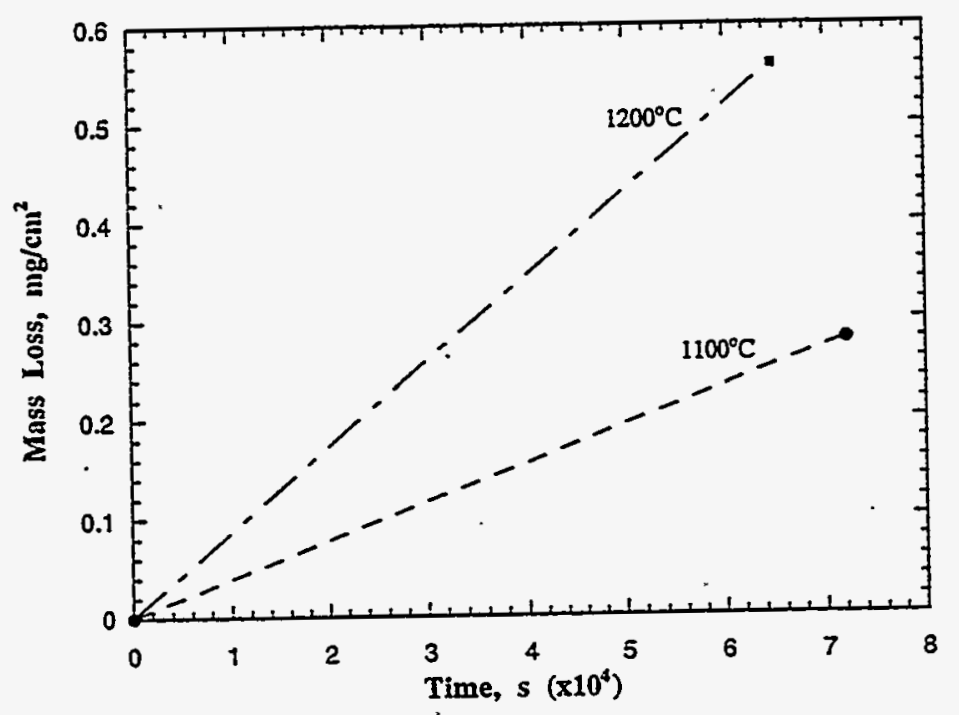

Figure 1: Weight Loss Data for C-Interface SiC/SiC Composites in $1 \% \mathrm{H}_{2}$ (balance $\mathrm{He}$ ) 
The weight losses observed in hydrogen were about an order of magnitude less than those observed in oxygen at equivalent times and even lower partial pressures ${ }^{(4)}$. Table 1 shows data by Walker et al. for gas-carbon reactions at $800^{\circ} \mathrm{C}$ and $0.1 \mathrm{~atm}$. Similar to the results reported in this study, Walker observed that the carbon-oxygen reaction proceeded much faster than that of carbon-hydrogen.

A noticeable temperature dependency was observed for the carbon-hydrogen reaction. At similar times, weight losses at $1200^{\circ} \mathrm{C}$ were about twice as much as those at $1100^{\circ} \mathrm{C}$. Worth noting in the $1200^{\circ} \mathrm{C}$ run was the formation of small white deposits in crevices on the uncoated faces of the sample. If these deposits were substantial enough to affect measured weight loss, they would have increased the sample weight slightly and downplayed the actual effect of temperature on interfacial removal.

Additional tests are being planned with similar conditions, to test the reproducibility of these early results, and at lower hydrogen concentrations, to better simulate the hydrogen concentration expected in a gas cooled blanket.

\begin{tabular}{|c|c|}
\hline Reaction & Relative Rate \\
\hline $\mathrm{C}-\mathrm{O}_{2}$ & $1 \mathrm{ES}$ \\
\hline $\mathrm{C}-\mathrm{H}_{2} \mathrm{O}$ & 3 \\
\hline $\mathrm{C}-\mathrm{CO}_{2}$ & 1 \\
\hline $\mathrm{C}-\mathrm{H}_{2}$ & $3 \mathrm{E}-3$ \\
\hline
\end{tabular}

Table 1: Approximate Relative Rates of the Gas-Carbon Reactions at $800^{\circ} \mathrm{C}$ and 0.1 Atm Pressure. (Walker et al, Advances in Catalysis)

\section{CONCLUSIONS}

Exploratory test results have indicated a relatively slow rate of interfacial carbon removal in hydrogen environments for $\mathrm{SiC} / \mathrm{SiC}$ composites. These results concur with literature, but much more experimentation is necessary to refine the understanding of temperature and hydrogen partial pressure influences.

\section{FUTURE WORK}

The reproducibility of preliminary data will be assessed by more studies with $1 \%$ hydrogen at high temperatures, between $1100^{\circ} \mathrm{C}$ and $1200^{\circ} \mathrm{C}$. $\cdot$ Realistic fusion conditions will be better simulated by additional testing in $1000 \mathrm{ppm}$ hydrogen at various temperatures. 


\section{REFERENCES}

1. P. L. Walker, Jr., F. Rusinko, Jr., and L. G. Austin, "Gas Reactions of Carbon," chapter in Advances in Catalysis, Vol. 11, editors D. D. Eley, P. W. Selwood, and P. B. Weisz, Academic Press (1959), p. 162-4.

2. R. H. Jones, "Environmental Effects on SiC/SiC Composites for Fusion Structural Applications," Pacific Northwest Laboratory, DOE/ER-0313/10, Fusion Reactor Materials Semiannual Progress Report for Period Ending March 31, 1991, p. 215.

3. T. J. Clark, R. E. Woodley, and D. R. De Halas, "Gas-Graphite Systems," Nuclear Graphite. Academic Press (1962), p. 421.

4. G. D. Springer, C. F. Windisch, Jr., C. H. Henager, Jr., and R. H. Jones, "Oxygen Effects on SiC/SiC Composites for Fusion Structural Applications," Pacific Northwest Laboratory, DOE/ER-0313/18, Fusion Reactor Materials Semiannual Progress Report for Period Ending March 31, 1995. 


\title{
DIMENSIONAL STABILITY OF SIC-TYPE FIBERS NEUTRON IRRADIATED TO HIGH DOSES
}

\author{
GE Youngblood, DJ Senor and GW Hollenberg \\ Pacific Northwest Laboratory"
}

\section{OBJECTIVE}

The objective of this study is to examine the dimensional stability after neutron irradiation of a selection of $\mathrm{SiC}$ fiber types.

\section{SUMMARY}

Silicon carbide based fibers with a range of stoichiometries and microstructures (Nicalon CG, Nicalon HVR, HPZ, Tyranno, and Dow/NASA Xstalline) were selected for evaluation of their dimensional stability after neutron irradiation to high doses. For comparison, carbon fibers with a range of graphitization also were evaluated.

The fibers were irradiated in the MOTA 2B cycle of the FFTF reactor. Two sets of the selected C and $\mathrm{SiC}$ fiber types were exposed at $430^{\circ} \mathrm{C}$ to a fluence of $5.5 \times 10^{21} \mathrm{n} / \mathrm{cm}^{2}$ or $2.5 \times 10^{22} \mathrm{n} / \mathrm{cm}^{2}(\mathrm{E} \geq 0.1 \mathrm{MeV})$, equivalent to relatively high doses of 5.3 and $25 \mathrm{dpa}-\mathrm{SiC}$. Dimensional stability was determined by measuring the length and density changes of the fibers after the irradiations.

For the SiC-based fibers above $5 \mathrm{dpa}-\mathrm{SiC}$, little dose dependence was observed except for the Tyranno fiber. The HPZ, Tyranno and Nicalon HVR fibers, whose pre-irradiated densities were quite low, exhibited substantially more axial shrinkage than the Nicalon $C G$ fiber. Even though the shrinkage of the Nicalon CG fiber was moderate (about $2 \%$ at $430^{\circ} \mathrm{C}$ ), fiber shrinkage and debonding from the matrix previously had been observed to result in decreased strengths in Nicalon fiber $\mathrm{SiC} / \mathrm{SiC}$ composites irradiated to the same fluence and at similar and at higher temperatures. The developmental fiber, Dow/NASA Xstalline, actually exhibited slight swelling rather than shrinkage. The composition of the Dow/NASA fiber was near stoichiometric SiC, the density was $90 \%$ of theoretical for $\mathrm{SiC}$, and the microstructure was reported to be more crystalline than for the other SiC-based fibers.

For the $\mathrm{C}$ fibers, the amount of axial shrinkage was much greater than observed for the irradiated SiCbased fibers and generally was greater the lower the degree of initial graphitization. Also, in contrast to the irradiated $\mathrm{SiC}$ behavior, the radiation damage did not appear to saturate, but continuously increased with increasing dose. The axial shrinkage exceeded about $20 \%$ for the most graphitic $C$ fiber and exceeded $60 \%$ for the less graphitic fiber at the higher dose. Independent of the initial degree of graphitization, the densities of all the $C$ fibers increased and appeared to saturate at a common value by the $3 \mathrm{dpa}-\mathrm{C}$ dose. With increasing dose above $3 \mathrm{dpa}-\mathrm{C}$, the densities decreased and returned almost to their unirradiated values by $15 \mathrm{dpa}-\mathrm{C}$. The density change data indicated that $\mathrm{C}$ fibers will continuously shrink in the axial direction (i.e., the preferred alignment of the graphitic a-axis in $\mathrm{C}$ fibers) under irradiation. However, in the diametral direction, graphitic c-axis growth will be accommodated by porosity and/or amorphicity initially, but with continued irradiation diametral swelling will commence once the accommodation is over.

* Pacific Northwest Laboratory is operated for the U.S. Department of Energy by Battelle Memorial Institute under contract DE-AC06-76RLO-1830. 
Silicon carbide based fibers that are close to stoichiometric and crystalline appear to have the radiation damage tolerance necessary to make $\mathrm{SiC} / \mathrm{SiC}$ composites suitable for further testing and development for fusion power system applications. Due to the fundamental nature of radiation damage in graphite, dimensional instability (extreme axial shrinkage and diametral swelling) of $\mathrm{C}$ fiber irradiated to high doses will prevent their use in $\mathrm{C} / \mathrm{C}$ composites for long-term operations in a fusion power system.

\section{PROGRESS AND STATUS}

\section{Introduction}

Silicon carbide ( $\mathrm{SiC} / \mathrm{SiC})$ and carbon $(\mathrm{C} / \mathrm{C})$ continuous fiber reinforced composites have been considered for fusion power system applications because they exhibit favorable physical and mechanical properties $[1,2]$ as well as low residual neutron activation [3,4]. Furthermore, because of their design flexibility, such composites offer the possibility to be tailored for specific applications. For instance, the conceptual design of the ARIES I reactor, a first generation fusion electrical power plant, is based on the use of $\mathrm{SiC} / \mathrm{SiC}$ composite for the diverter and first wall [5]. This design takes advantage of the high operating temperature capability $\left(800\right.$ to $\left.1000^{\circ} \mathrm{C}\right)$, moderate structural toughness, and a low interaction with the contained plasma. One conceptual design of the International Thermonuclear Experimental Reactor (ITER) proposes the use of $\mathrm{C} / \mathrm{C}$ composite tiles to protect the first wall against melting and fatigue [6]. Currently, the JT-60 tokamak test reactor in Japan uses these C/C composite tiles to line the first wall to provide protection against the tremendous heat generated during pulsed plasma tests [7].

However, eventual longer term operation of a fusion test power system will require a material with an improved radiation damage tolerance. Previous tests at Pacific Northwest Laboratory of $\mathrm{C} / \mathrm{C}$ composite coupons exhibited unacceptable performance after irradiations simulating fusion power system operating temperatures and neutron fluences. Extreme dimensional changes, warping and delamination occurred in the tested composites. Later tests of irradiated $\mathrm{SiC} / \mathrm{SiC}$ composite exhibited much improved performance; however test coupons still indicated an unacceptable degree of degradation [8]. By far, the most important cause of degradation of $\mathrm{C} / \mathrm{C}$ or $\mathrm{SiC} / \mathrm{SiC}$ composites during irradiation was the dimensional instability of the fibers [8,9]. Until an irradiation tolerant fiber is developed and used in making composites, optimizing other composite design or fabrication parameters such as the type and thickness of interfacial fiber coatings, matrix processing conditions, and fiber weave architectures cannot be conducted.

The purpose of this study was to examine the dimensional stability after neutron irradiation of a selection of $\mathrm{C}$ and $\mathrm{SiC}$ fiber types. For this study, one developmental and four commercially available SiC-based fiber types were selected to cover a range of $\mathrm{SiC}$ stoichiometries and microstructures. Pitch-based $\mathrm{C}$ fibers were selected to cover a range of graphitization. Based on these results, desired fiber properties or promising fiber types may be recommended for inclusion in further testing for the composite development program for fusion power system applications.

\section{Experimental Description}

The fibers were irradiated in the MOTA 2B cycle of the FFTF reactor, a sodium-cooled reactor possessing a fast neutron spectrum with more than $60 \%$ of the flux greater than $0.1 \mathrm{MeV}$. Duplicate sets of representative fiber bundles, either

$2.54 \pm 0.01$ or $3.05 \pm 0.01 \mathrm{~cm}$ long and containing 500-1000 individual fibers, were cut from as-received fiber yarns and loaded into individual Poco graphite holders. Each set of graphite holders was loaded into one of two stainless steel weeper capsules which were out-gassed and heated overnight to $450^{\circ} \mathrm{C}$, backfilled with helium to approximately atmospheric pressure and welded closed. The two sets of encapsulated fiber samples were irradiated at $430^{\circ} \mathrm{C}$, but at different core locations. One set was exposed to a fluence 
of $5.5 \times 10^{21} \mathrm{n} / \mathrm{cm} 2$, the other to $2.5 \times 10^{22} \mathrm{n} / \mathrm{cm} 2(E \geq 0.1 \mathrm{MeV})$. Since the high energy neutrons cause most of the irradiation damage in $\mathrm{SiC}$ and carbon, irradiation dose is reported in units of displacements per atom (dpa-SiC or dpa-C, respectively).

After irradiation, the graphite holders were opened in a glove box and the fiber bundles were removed and photographed. The irradiated fiber lengths were measured directly from photographs of each bundle using a traversing microscope. The accuracy of the fiber length measurements was dominated by the alignment of the fiber bundle ends. After making length measurements, the bundles were cut in half. One of the half-bundles was mounted in resin for optical microscopy of the fiber cross-sections; the other half was used for density measurements. Average fiber diameters and associated variances were determined by digital image analysis of the fiber cross-sections.

The fiber densities were determined before and after irradiation using a liquid density gradient column technique with appropriate mixtures of carbon tetrachloride $\left(\mathrm{CCl}_{4}\right)$, bromoform $\left(\mathrm{CHBr}_{3}\right)$ and methylene iodide $\left(\mathrm{CH}_{2} \mathrm{I}_{2}\right)$. A single column covered a $0.4 \mathrm{~g} / \mathrm{cm}^{3}$ density range over a $100 \mathrm{~cm}$ length; therefore a number of columns with different liquid ratios were necessary to cover the fiber density range 2.0 to 3.1 $\mathrm{g} / \mathrm{cm}^{3}$. Even though the fiber bundles sometimes separated and spread over $\approx 1 \mathrm{~cm}$ along the column, the precision of the density measurements was estimated to be $\leq 0.002 \mathrm{~g} / \mathrm{cm}^{3}$.

\section{$\underline{\text { Results and Discussion }}$}

Tables 1 and 2 list the unirradiated properties for the tested SiC-based and C fibers, respectively. The compositions, room temperature tensile strengths and moduli were taken from the literature $[10,11]$. The Dow Xstalline fiber is a developmental SiC product, whereas the other SiC-based fibers are commercially available. The HPZ and Nicalon HVR fiber microstructures are rather amorphous; the Nicalon CG and Tyranno microstructures contain a considerable amount of $\approx 2 \mathrm{~nm} \beta$-SiC crystallites in a Si-O-C or Si-O-C-Ti matrix with excess $\mathrm{C}$; and the Dow Xstalline microstructure is primarily 100 $\mathrm{nm} \beta-\mathrm{SiC}$ grains. The degree of graphitization of the $\mathrm{C}$ fibers depends on their final heat treatment temperature (HTT); as the HTT increases, the degree of graphitization and the tensile modulus increase [12]. The tensile modulus values ranged from 179 to $894 \mathrm{GPa}$ for these $\mathrm{C}$ fibers.

Table 1. Unirradiated properties of tested SiC-based fibers.

\begin{tabular}{|c|c|c|c|c|c|c|}
\hline Name & Source & $\begin{array}{c}\text { Composition } \\
(\mathbf{w} / \mathrm{h})\end{array}$ & $\begin{array}{c}\text { RT Tensile } \\
\text { Strength } \\
\text { (GPa) }\end{array}$ & $\begin{array}{c}\text { RT Tensile } \\
\text { Modulus } \\
\text { (GPa) }\end{array}$ & $\begin{array}{l}\text { Density } \\
\text { (g/cc) }\end{array}$ & $\begin{array}{c}\text { Diameter } \\
\text { (ym) }\end{array}$ \\
\hline Nicalon_CG & Ninpon Carbor & Si-31C-120 & 26 & 190 & 2582 & $137+14$ \\
\hline Nicalon HVR & Nippon Carhor & Si-31C-120 & 2.9 & 190 & 2.308 & $154+23$ \\
\hline Tyranno & The & Si-28C-170-3T & 2.5 & 190 & 2.350 & $60+05$ \\
\hline HPZ & Dow Corning & Si-28N-10C-4 & 23 & 180 & 2242 & $59 \times 13.2$ \\
\hline Dow Xstallind & Dow/NASA & $S i-(30-35) C$ & & 420 & 2.872 & $71+02$ \\
\hline
\end{tabular}

NOTES: $\quad$ 1. Values from references $[9,10]$ indicated by normal type.

2. Values measured in this study indicated by italic type.

3. HPZ fiber has a non-circular cross-section. 
Table 2. Unirradiated properties of tested C Fibers.

\begin{tabular}{|c|c|c|c|c|c|}
\hline Name & Source & $\begin{array}{c}\text { RT Tensile } \\
\text { Strength } \\
(\mathbf{G P a})\end{array}$ & $\begin{array}{c}\text { RT Tensile } \\
\text { Modulus } \\
(\mathbf{G P a})\end{array}$ & $\begin{array}{c}\text { Density } \\
(\mathbf{g} / \mathrm{cc})\end{array}$ & $\begin{array}{c}\text { Diameter } \\
(\mathbf{\mu m})\end{array}$ \\
\hline E35 & DuPont & 2.8 & 241 & 2030 & $93+0.9$ \\
\hline E55 & DuPont & 3.2 & 378 & 2.083 & $82+08$ \\
\hline E75 & DuPont & 3.1 & 516 & 2.100 & $93+07$ \\
\hline E105 & DuPont & 3.3 & 724 & 2.119 & $96+06$ \\
\hline E120 & DuPont & 3.4 & 827 & 2.127 & $89+08$ \\
\hline E130 & DuPont & 39 & 894 & 2.132 & $22+08$ \\
\hline K139 & Mitsubishi & & 738 & 2132 & $91+05$ \\
\hline K321 & Mitsubishi & & 179 & 2.030 & $96+04$ \\
\hline
\end{tabular}

NOTES: $\quad 1$. Values from the manufacturer indicated by normal type.

2. Values measured in this study indicated by italic type.

Figures $1 \mathrm{a}$ and $1 \mathrm{~b}$ present post-irradiation photographs of a low modulus $\mathrm{C}$ fiber (E35) and a Nicalon CG fiber bundle, respectively. The pre-irradiated bundle lengths were each $3.05 \mathrm{~cm}(1.20 \mathrm{in})$. As for the E35 fiber in Fig. 1a, axial shrinkage of all the irradiated $C$ fibers was visually apparent. Shrinkage (or swelling) of the irradiated SiC fibers could only be discerned by length measurements with a traversing microscope.
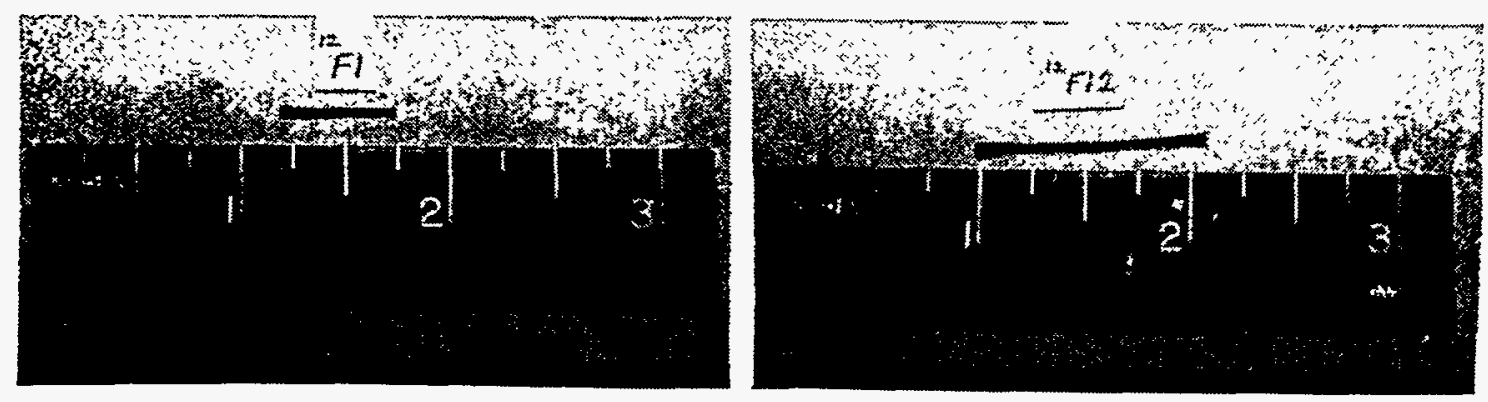

Figures $1 \mathrm{a}$ and $\mathrm{lb}$. Representative post irradiation photographs of E35 C (left) and Nicalon CG SiC (right) fiber bundles. Each fiber bundle, originally cut to lengths of 1.20 inches, had been irradiated to the same fluence $\left(2.5 \times 10^{22} \mathrm{n} / \mathrm{cm}^{2}, \mathrm{E} \geq 0.1 \mathrm{MeV}\right)$ at $430^{\circ} \mathrm{C}$. 
Figures $2 \mathrm{a}$ and $2 \mathrm{~b}$ present typical cross-sectional views of $\mathrm{SiC}$ and $\mathrm{C}$ fiber bundles after they were mounted and polished. From digital image analysis of such views, the average diameters and associated standard deviations listed in Tables 1 and 2 for each fiber type were determined. Unfortunately, the large cross-sectional area variation within each fiber type precluded the possibility of making diametral dimensional change measurements for the irradiated fibers.
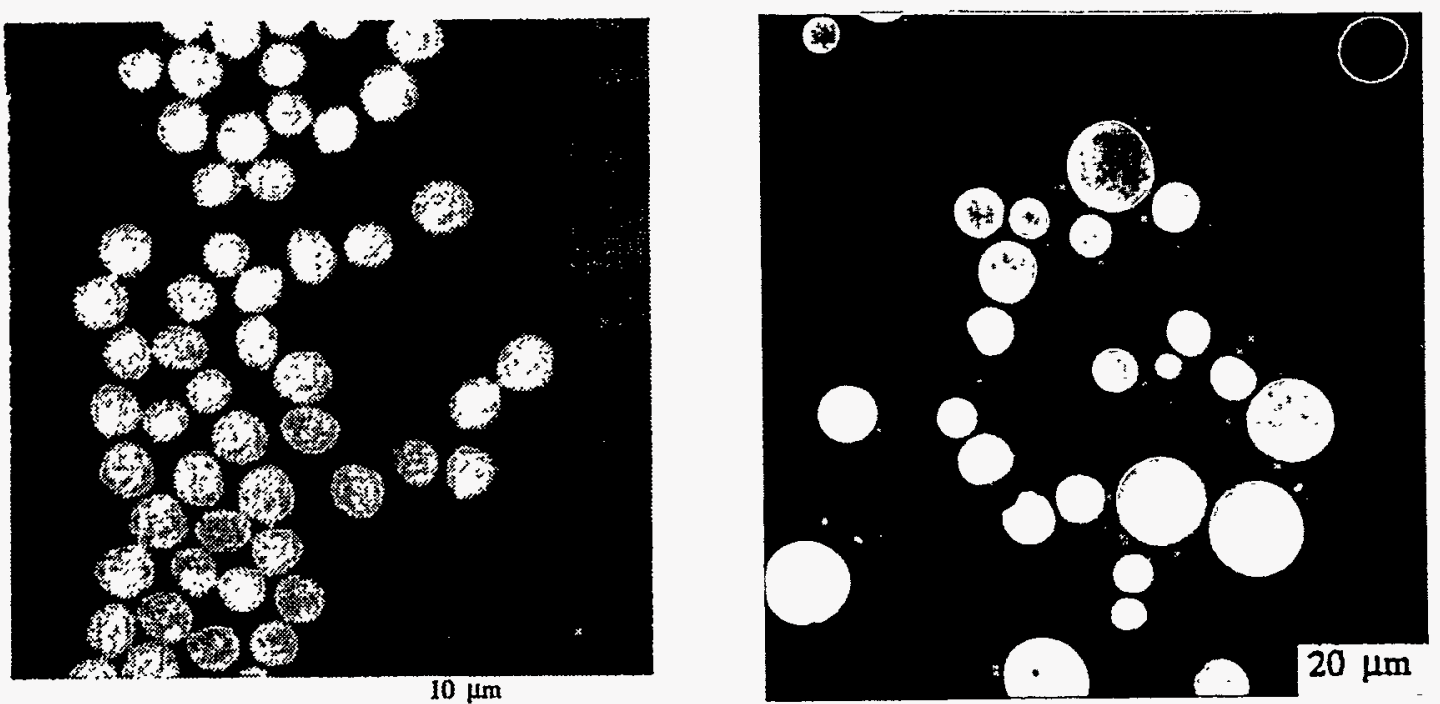

Figures $2 \mathrm{a}$ and $2 \mathrm{~b}$. Cross-sectional views of the resin mounted and polished E35 C (left) and Nicalon CG SiC (right) fiber bundles.

Table 3 presents a comparison of length changes for the irradiated SiC-based fibers determined by two methods.

Table 3. Comparison of two methods for determining length changes of SiC-based fibers due to neutron irradiation.

\begin{tabular}{|c|c|c|c|c|}
\hline \multirow[b]{2}{*}{ Name } & \multicolumn{2}{|c|}{$5.3 \mathrm{dpa}-\mathrm{SiC}$} & \multicolumn{2}{|c|}{26 dpa-SiC } \\
\hline & $\begin{array}{c}\text { Direct } \\
(\mathscr{q})\end{array}$ & $\begin{array}{c}\text { Density Change } \\
(\%)\end{array}$ & $\begin{array}{c}\text { Direct } \\
(\%)\end{array}$ & $\begin{array}{c}\text { Density Change } \\
\text { (\%) }\end{array}$ \\
\hline Nicalon CG & $-24+08$ & $-19+02$ & $-35+07$ & $-18+02$ \\
\hline Nicalon CG (a) & & & $-4.4+0.7$ & $-49+03$ \\
\hline Nicalon HVR & $-52+08$ & $-56+02$ & $-58+08$ & $-5.5+02$ \\
\hline Tyranno & $-09+06$ & $-3.1+0.4$ & $-16+20$ & $-60+0.4$ \\
\hline HPZ & $-73+09$ & & $-8.3+0.7$ & $-8.0+0.2$ \\
\hline Dow Xstallind & $1.5+1.5$ & & $20+20$ & $0.5+0.2$ \\
\hline
\end{tabular}

NOTES: $\quad$ a. Irradiation temperature was $430^{\circ} \mathrm{C}$ except for (a) where it was $850^{\circ} \mathrm{C}$. 
In the direct method, the fractional length change was determined from the difference between the unirradiated and irradiated fiber bundle lengths as measured by using the traversing microscope. The density change method relates the measured density change before and after irradiation to the expected length change. If the fiber mass is unchanged during irradiation, the fractional change in density, $\Delta \rho / \rho$, for a circular fiber of diameter $D$ and length $L$ is given by:

$$
\Delta \rho / \rho \approx-(\Delta L / L)-2(\Delta \mathrm{D} / \mathrm{D})
$$

Then if the volumetric fiber shrinkage (or swelling) is isotropic:

$$
\Delta \mathrm{L} / \mathrm{L} \approx-1 / 3(\Delta \rho / \rho)
$$

One would expect isotropic shrinkage (swelling) in the SiC-based fibers due to the cubic structure of the B-SiC crystallites which comprise much of the fiber micro-structure. Except for the Tyranno fiber, which contains a high concentration of $\mathrm{O}$ and some $\mathrm{Ti}$ as well as excess $\mathrm{C}$, general agreement between the length changes determined by the direct and density change methods justifies using Eq. (2) for estimating the $\mathrm{SiC}$-based fiber length change. By comparison of the estimated variations listed in Table 3, it also is apparent that the density change method is more precise than the direct method for estimating the length changes if the change is isotropic.

Figure 3 presents the fractional length change, determined by the density change method where possible, as a function of dose for the $\mathrm{SiC}$-based fibers. Above $5 \mathrm{dpa}-\mathrm{SiC}$, little dose dependence is observed except for the Tyranno fiber. However, this may be an artifact due to using the density change method for determining the Tyranno fiber length change. From Table 3, it is apparent that the assumption of isotropic shrinkage may not be valid for the Tyranno fiber. At $430^{\circ} \mathrm{C}$, the $\mathrm{HPZ}$ and the Nicalon HVR fibers, whose pre-irradiated densities were quite low, exhibited substantially more axial shrinkage than the Nicalon CG fiber. Even though the shrinkage of the Nicalon CG fiber was moderate (about $2 \%$ at $430{ }^{\circ} \mathrm{C}$ and $4.9 \%$ at $850^{\circ} \mathrm{C}$ ), such shrinkage has been observed to cause complete debonding from the matrix resulting in decreased strengths in continuous fiber reinforced $\mathrm{SiC} / \mathrm{SiC}$ composites irradiated under similar conditions [8]. The developmental fiber, Dow/NASA Xstalline, actually exhibited slight swelling rather than shrinkage. The composition of the Dow/NASA fiber was near stoichiometric $\mathrm{SiC}$, the unirradiated density was $90 \%$ of theoretical for $\mathrm{SiC}$, and the microstructure was reported to be more crystalline than for the other SiC-based fibers [11]. The swelling observed for the irradiated Dow/NASA fiber is reasonably consistent with trends previously observed for irradiated crystalline $\mathrm{SiC}[8,12]$. 


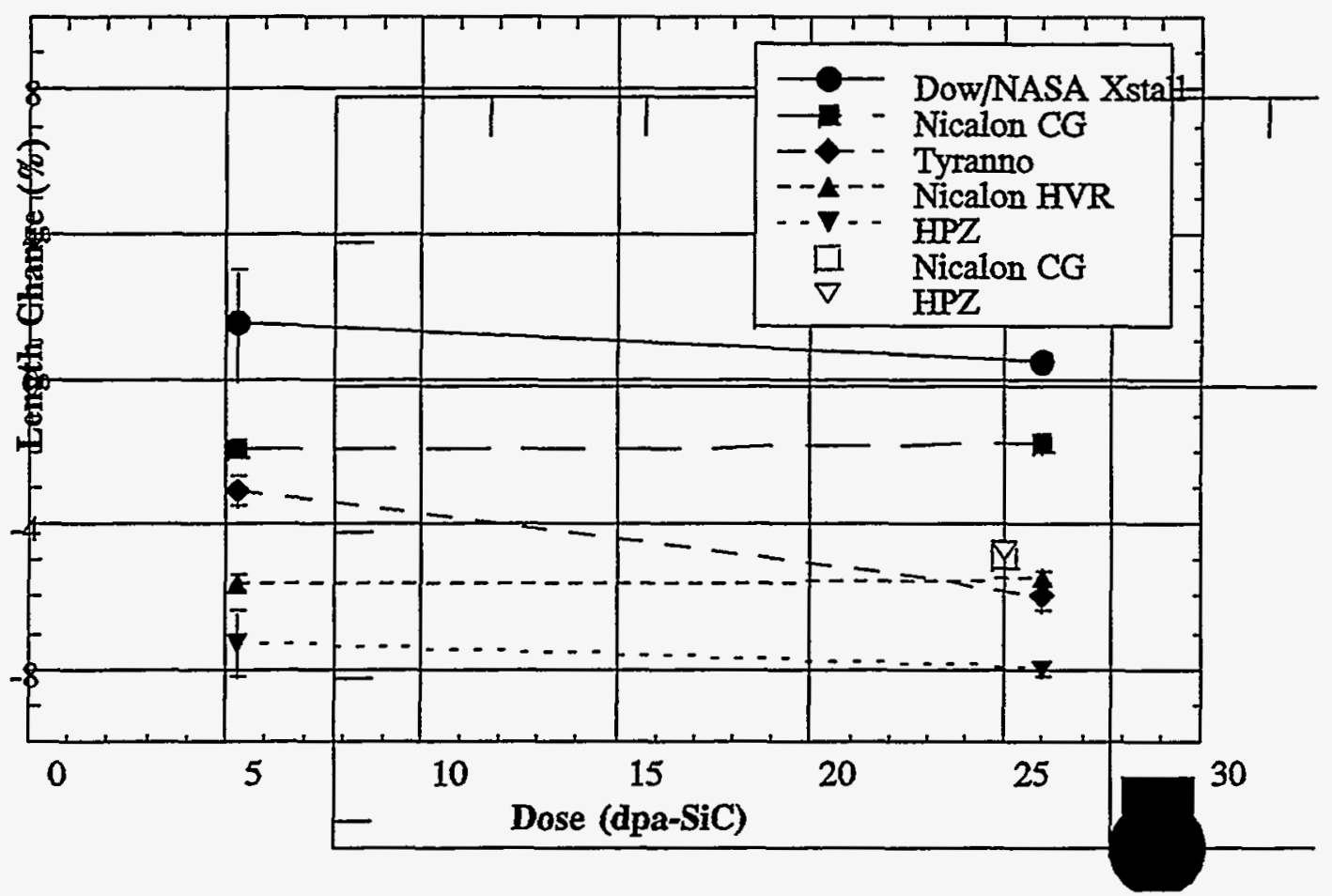

Figure 3. Shrinkage (Swelling) of SiC-based fibers after irradiation to 5.3 and $26 \mathrm{dpa}-\mathrm{SiC}$ at $430^{\circ} \mathrm{C}$. Single data points (open symbols) for Nicalon CG and HPZ fibers were irradiated at $850^{\circ} \mathrm{C}$ to 25 dpa-SiC.

Figure 4 presents the axial shrinkage for the $C$ fibers with a range of graphitization for two relatively high irradiation doses, 3 and 15 dpa-C. Irradiation effects in $C$ fibers have been examined by others [13], but only to doses less than 1 dpa-C. For these high dose irradiations, the amount of axial shrinkage for the $\mathrm{C}$ fibers was greater at low degrees of initial graphitization (as represented by initial values of tensile modulus) and generally was much greater than observed for the irradiated SiC-based fibers. Also, in contrast to the irradiated $\mathrm{SiC}$ fiber behavior, the radiation damage did not appear to saturate, but continuously increased with increasing dose. The axial shrinkage exceeded $20 \%$ for the most graphitic $\mathrm{C}$ fiber and exceeded $60 \%$ for the less graphitic fiber at the higher dose. It is the fundamental nature of radiation damage in graphite that leads to severe fiber dimensional instability at higher neutron doses, and thus to the unacceptable performance observed in irradiated continuous fiber reinforced $\mathrm{C} / \mathrm{C}$ composites mentioned earlier. 


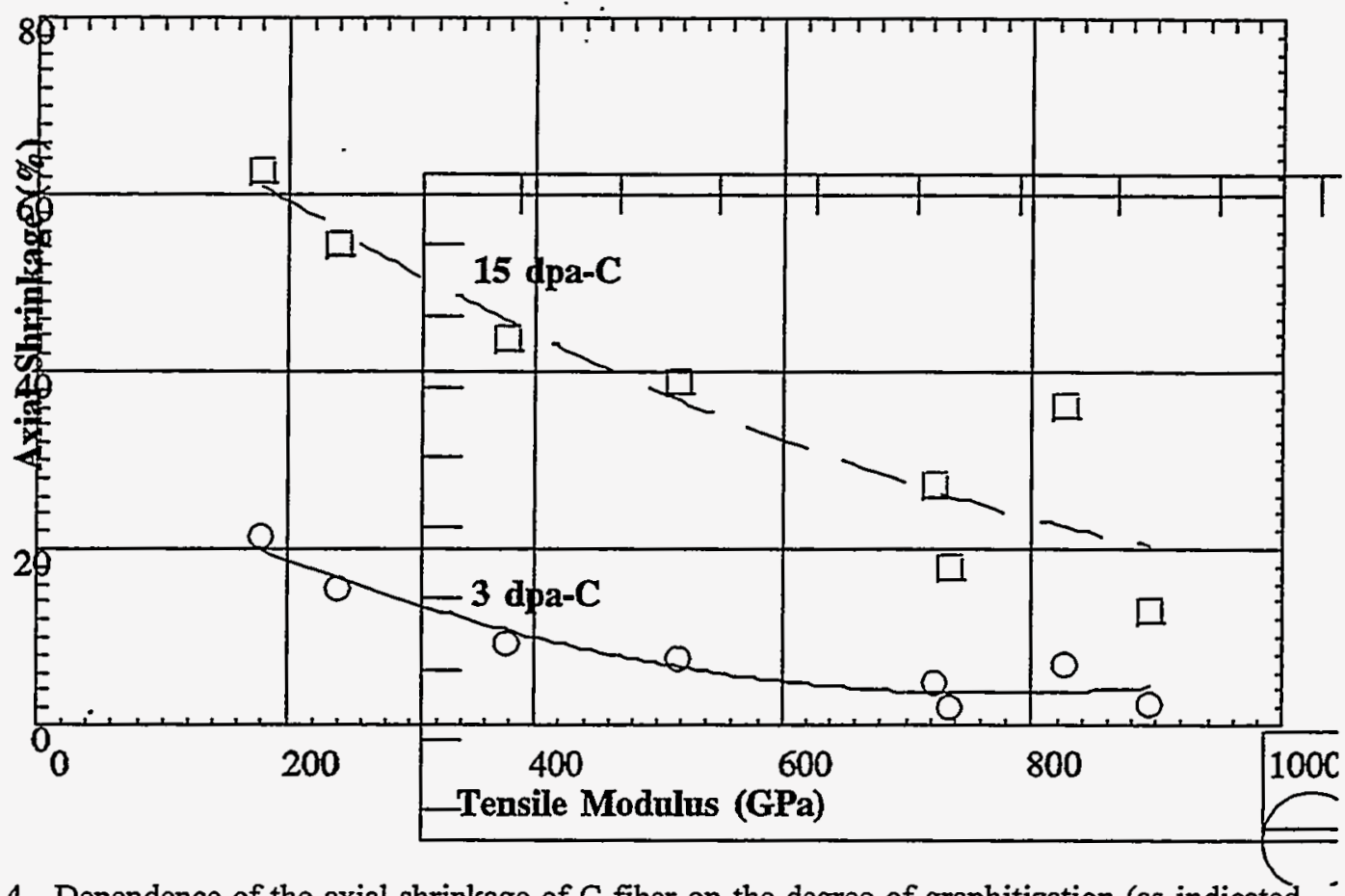

Figure 4. Dependence of the axial shrinkage of $\mathrm{C}$ fiber on the degree of graphitization (as indicated by the initial tensile moduius) for fibers irradiated at $430^{\circ} \mathrm{C}$ to relatively high doses, 3 and 15 dpa-C. The curves are for guidance only.

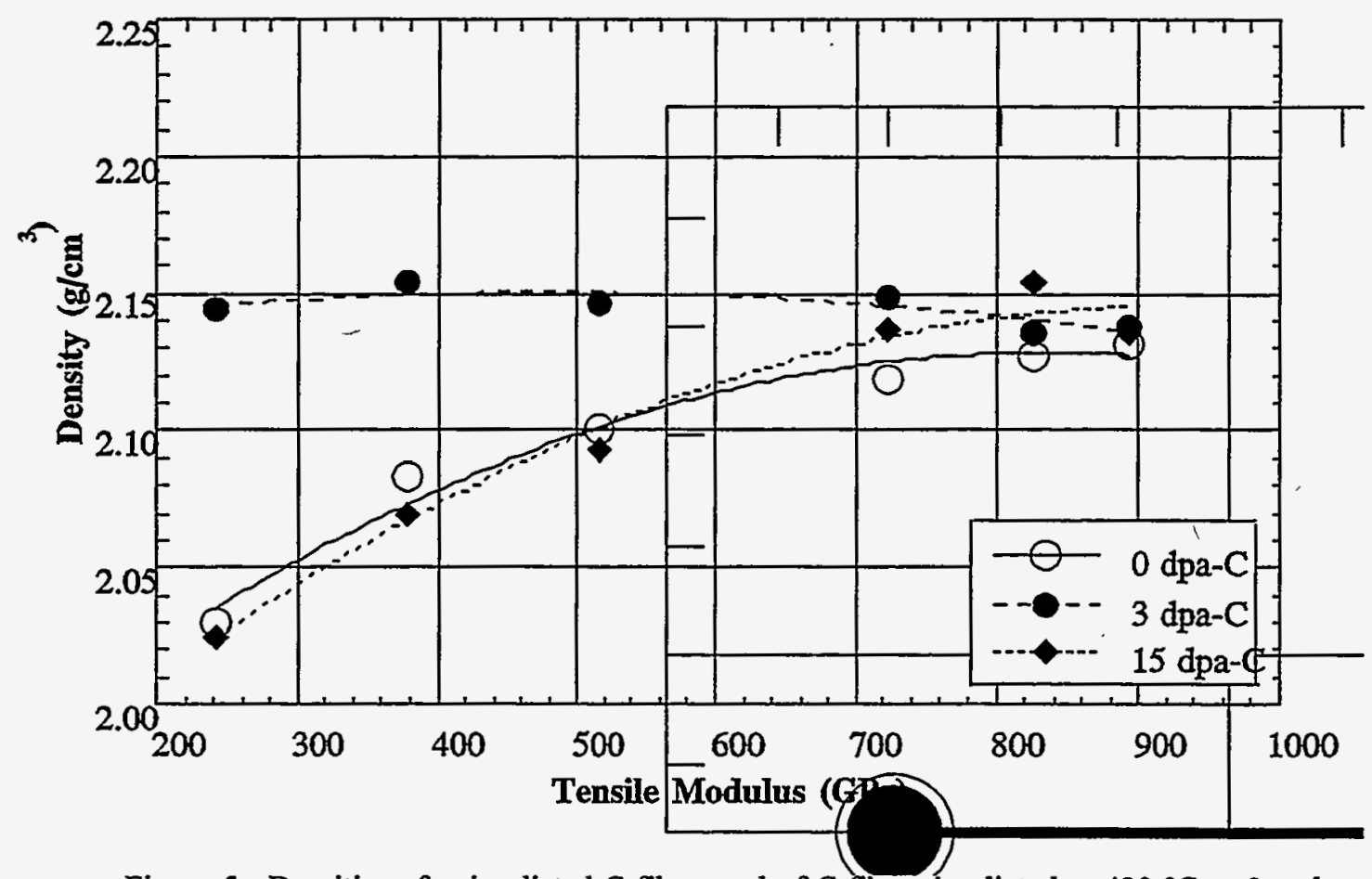

Figure 5. Densities of unirradiated $\mathrm{C}$ fibers and of $\mathrm{C}$ fibers irradiated at $430^{\circ} \mathrm{C}$ to 3 and 15dpa-C as a function of their initial tensile modulus. The curves are for guidance only. 
Figure 5 (shown on the preceding page) presents the densities of the unirradiated $\mathrm{C}$ fibers as a function of their degree of initial graphitization (again as represented by the tensile modulus) together with the densities of the same fibers irradiated at $430^{\circ} \mathrm{C}$ to 3 and $15 \mathrm{dpa}-\mathrm{C}$. As expected, the density of unirradiated $\mathrm{C}$ fiber increases continuously as the degree of graphitization increases. However, independent of the initial degree of graphitization, the densities of all the $C$ fibers appeared to saturate at about $2.15 \mathrm{~g} / \mathrm{cm}^{3}$ by the $3 \mathrm{dpa}-\mathrm{C}$ dose. With increasing dose above $3 \mathrm{dpa}-\mathrm{C}$, the densities appeared to decrease and returned almost to their unirradiated values by 15 dpa-C for each of the $C$ fiber types. This observation coincides with the character of the dimensional changes of irradiated $C$ fiber and the extreme amount of anisotropy in the hexagonal graphitic structure. X-ray analysis has indicated a preferential alignment of the hexagonal graphitic basal planes parallel to the fiber axis [14]. The data indicate that $C$ fibers will continuously shrink in the axial direction (graphitic a-axis) under irradiation. Initially, diametral (graphitic c-axis) swelling will be accommodated by porosity and/or amorphicity until the saturation density of about $2.15 \mathrm{~g} / \mathrm{cm}^{3}$ has been reached. Continued irradiation damage will lead to additional $c$-axis growth and expected diametral swelling of the $C$ fibers. This effect appears to be much more severe for the $C$ fibers with a lower degree of initial graphitization.

\section{CONCLUSIONS}

- Due to the fundamental nature of radiation damage in graphite, dimensional instability (extreme axial shrinkage and diametral swelling) of $\mathrm{C}$ fiber irradiated to high doses will prevent their use in $\mathrm{C} / \mathrm{C}$ composites for long-term operations in a fusion power system.

- Silicon carbide based fibers that are close to stoichiometric and crystalline appear to have the radiation damage tolerance necessary to make $\mathrm{SiC} / \mathrm{SiC}$ composites suitable for further testing for fusion power system applications.

\section{FUTURE WORK}

Emphasis will be focused on examining the irradiation effects on additional alternate commercial and developmental SiC-based fibers. Irradiation exposures also will include a broader range of conditions. For instance, in the COBRA series of irradiations recently completed in the EBR II reactor, nine SiCbased fiber types were irradiated to a very high dose $(\approx 80 \mathrm{dpa}-\mathrm{SiC})$ at $800^{\circ} \mathrm{C}$. Post-irradiation analysis of these fibers will be carried out during the next reporting period. The primary goal will be to identify other more radiation tolerant fibers, then use the best fibers to ultimately fabricate a high performance $\mathrm{SiC}_{f} / \mathrm{SiC}$ composite suitable for advanced fusion power system applications.

\section{REFERENCES}

1. G. R. Hopkins and J. Chin, "SiC Matrix/SiC Fiber Composites: A High-Heat Flux, Low Activation, Structural Material," J. of Nucl. Mat. 141-143, 148-151 (1986).

2. R. H. Jones, C. H. Henager, Jr. and G. W. Hollenberg, "Composite Materials for Fusion Applications," J. of Nucl Mat. 191-194, 75-83 (1992).

3. L. L. Snead, "Neutron Activation Analysis of Monolithic Ceramics and Ceramic Composites," DOE/ER-0313/11, p. 46-55.

4. L. L. Snead, "Development of Silicon Carbide Composites for Fusion," Fusion Technology 24, 65-82 (1993). 
5. R. H. Jones and G. E. Lucas (eds.), Proceedings Office of Fusion Energy/DOE Workshop on Ceramic Composites for Structural Applications in Fusion Reactors, Santa Barbara, CA, PNL-SA17843, CONF-9005225 (1990).

6. R. W. Conn, V. A. Chuyanov, N. Inoue and D. R. Sweetman, "The International Thermonuclear Experimental Reactor," Scientific American, 103-110, April (1992).7.S. Sato, A. Kurumada, K. Kawamata, T. Takizawa and K. Teruyama, "Neutron Irradiation Effects on Thermal Shock resistance and fracture Toughness of Graphites as Plasma-facing first Wall Components for fusion Reactor Devices," Carbon 27(4), 507-516 (1989).

8. G. W. Hollenberg, C. H. Henager,Jr., G. E. Youngblood, D. J. Trimble, S. A. Simonson, G. A. Newsome, and E. Lewis, "The Effect of Irradiation on the Stability and Properties of Monolithic Silicon Carbide and $\mathrm{SiC}_{\mathrm{f}} / \mathrm{SiC}$ Composites up to $25 \mathrm{dpa}$," accepted for publication in the J. of Nucl. Mat. (1994).

9. G. E. Youngblood, C. H. Henager, Jr., D. J. Senor and G. W. Hollenberg," Effects of Neutron Irradiation on Dimensional Stability and on Mechanical Properties of SiC/SiC Composites," In Fusion Materials, Semiannual Progress Report for Period ending September 31, 1994, U.S. Department of Energy, In Press.

10. K. K. Chawla, Chapter 3 in Ceramic Matrix Composites. Chapman and Hall, London (1993).

11. G. N. Morscher and J. A. DiCarlo, "Creep and Stress Relaxation Properties in Relation to Microstructures for SiC Fibers," Proceedings 6th Annual HITEMP Review, Oct. 25-27, 1993. NASA CP 19117.

12. J. E. Palentine, "The Calibration of Fast Reactor Irradiated Silicon Carbide Temperature Monitors Using a Length Measurement Technique," J. Nucl. Mater. 48, 47-57 (1973).

13. B. F. Jones and I. D. Peggs, "The Effect of Fast Neutron Irradiation on the Structure and Mechanical Properties of a High Modulus Graphite Fiber,"

J. Nucl. Mater. 40, 141-150 (1971).

14. D. W. McKee, "Carbon and Graphite Science," In the Annual Review of Materials Science 3, 195-231 (1973). 
Distribution

1-15. Argonne National Laboratory, 9700 South Cass Avenue, Argonne, II 60439
M. C. Billone
A. B. Hull
L. A. Niemark
O. K. Chopra
C. E. Johnson
J. H. Park
H. M. Chung
F. Kassner
D. L. Smith
D. R. Diercks .
J. P. Kopasz
S. W. Tam
J. Gazda
R. F. Mattas
H. C. Tsai

16-17. Argonne National Laboratory, EBR-II Division, P.O. Box 2528, Idaho Falls, ID 83403-2528
H. P. Planchon
D. L. Porter

18. Auburn University, Department of Mechanical Engineering, 201 Ross Hall, Auburn, AL 36849

B. A. Chin

19-32. Battelle-Pacific Northwest Laboratory, P.O. Box 999, Richland, WA 99352
J. L. Ethridge
M. L. Hamilton
R. H. Jones
F. A. Garner (5)
H. L. Heinisch
W. W. Laity
D. S. Gelles
G. W. Hollenberg
O. D. Slagle
L. R. Greenwood

33. Carnegie Institute of Technology, Carnegie-Mellon University, Schenley Park, Pittsburgh, PA 15213

W. M. Garrison, Jr.

34. Commissariat à l'Energie Atomique, Direction des Technologies Advancées, M2R1/DECM Cen-Saclay, Gif Sur Yvette, Cedex, France

F. Tavassoli

35-38. General Atomics, P.O. Box 85608, San Diego, CA 92138
T. A. Lechtenberg
K. R. Schultz
D. I. Roberts
C. Wong

39. General Dynamics Corp., 5001 Kearny Villa Rd., San Diego, CA 92138

T. L. Cookson

40. Georgia Institute of Technology, Fusion Research Center, 0225, Atlanta, GA 30332 W. M. Stacey

41. Grand Canyon University, Department of Natural Science, 3300 W. Camelback Rd., Phoenix, AZ 85017

W. A. Coghlan

42-44. Idaho National Engineering Laboratory, Fusion Safety Program, P.O. Box 1625, Idaho Falls, ID 83415-3523
G. Longhurst
D. Petti
K. McCarthy

45-46. Lawrence Livermore National Laboratory, P.O. Box 808, Livermore, CA 94550
E.C.N. Dalder
J. Perkins

47-55. Los Alamos National Laboratory, P.O. Box 1663, Los Alamos, NM 87545
J. L. Anderson
E. H. Farnum
R. E. Siemon
F. W. Clinard
H. M. Frost
W. F. Sommer
D. W. Cooke
J. C. Kennedy
K. E. Sickafus 
56. Manlabs, Inc., 231 Erie Street, Cambridge, MA 02139

D. Tognarelli

57-59. Massachusetts Institute of Technology, Department of Metallurgy and Materials Science,

Cambridge, MA 02139
L. W. Hobbs
K. C. Russell
N. J. Grant

60-61. Massachusette Institute of Technology, Plasma Fusion Center Headquarters,

Cambridge, MA 02139
H. D. Becker
D. B. Montgomery

62-63. McDonnell-Douglas Aerospace, Mail Code 306 4204, P.O. Box 516, St Louis, MO 63166
J. W. Davis
G. W. Wille

64. M. J. Schiff \& Associates, 1291 N. Indian Hill Blvd., Claremont, CA 91711-3897 G.E.C. Bell

65-67. National Institute of Standards and Technology, Boulder, CO 80302
F. R. Fickett
R. P. Reed
H. I. McHenry

68-69. Naval Research Laboratory, Code 6506, Washington, DC 20375
D. L. Gibson
J. A. Sprague

70-112. Oak Ridge National Laboratory, P.O. Box 2008, Oak Ridge, TN 37831
Central Research Library
Document Reference Section
Laboratory Records Department (2)
Laboratory Records-RC
Patent Section
D. J. Alexander
J. Bentley
E. E. Bloom
T. D. Burchell
G. M. Goodwin
R. H. Goulding

M. L. Grossbeck

A. N. Gubbi

J. F. King

E. A. Kenik

R. L. Klueh

E. H. Lee

L. K. Mansur

P. J. Maziasz

M. C. Osborne

J. E. Pawel

T. C. Reuther
T. K. Roche

A. F. Rowcliffe (10)

M. J. Saltmarsh

J. Sheffield

L. L. Snead

R.E. Stoller

K. R. Thoms

P. F. Tortorelli

R. L. Wallace

D. P. White

S. J. Zinkle

113. Oregon Graduate Institute, Dept. of Materials Science \& Engineering, 19600 N.W. Von Neumann Drive, Beaverton, OR 97006 J. M. McCarthy

114-116. Princeton University, Princeton Plasma Physics Laboratory, P.O. Box 451, Princeton, NJ 08540
R. C. Davidson
D. M. Meade
Long-Poe Ku

117-118. Rensselaer Polytechnic Institute, Troy, NY 12181

D. Steiner

David Duquette

119. Rockwell International Corporation, NA02, Rocketdyne Division, 6633 Canoga Avenue, Canoga Park, CA 91304

D. W. Kneff 
120-122. Sandia National Laboratories, Fusion Technology Dept., Dept. No 6531, P.O. Box 5800, Albuquerque, NM 87185-5800
M. J. Davis
M. Ulrickson
R. D. Watson

123-125. Sandia National Laboratories, Livermore Division 8316, Livermore, CA 94550

W. Bauer

W. G. Wolfer

K. Wilson

126. San Diego State University, Mechanical Engineering Dept., San Diego, CA 92182-0191

L. D. Thompson

127. TSI Research, 225 Stevens Ave., \#110, Solana Beach, CA 92075

E. T. Cheng

128-129. University of California at San Diego, U.S. ITER Project Office, 9500 Gilman Drive, Bldg. 302, La Jolla, CA 92093-0035

C. C. Baker

T. R. James

130-131. University of California, Dept. of Mechanical, Aerospace, and Nuclear Engineering, Santa Barbara, CA 93106
G. E. Lucas
G. R. Odette

132-134. University of California, Dept. of Chemical, Nuclear, and Thermal Engineering,

Los Angeles, CA 90024
M. A. Abdou
S. Sharafat

N. M. Ghoniem

135. University of Michigan, Dept. of Nuclear Engineering, Ann Arbor, MI 48109

T. Kammash

136. University of Missouri, Department of.Nuclear Engineering, Rolla, MO 65401
A. Kumar

137-138. University of Wisconsin, Nuclear Engineering Dept., 1500 Johnson Drive, Madison, WI 53706
J. B. Blanchard
G. L. Kulcinski

139-142. Westinghouse Hanford Company, P.O. Box 1970, Richland, WA 99352
R. E. Bauer
F. M. Mann
A. M. Ermi
R. J. Puigh

143-145. Hokkaido University, Faculty of Engineering, Kita 13, Nishi 8, Kita-ku, Sapporo 060, Japan Heischichiro Takahashi Akira Okada Somei Ohnuki

146-147. Japan Atomic Energy Research Institute, Tokai Research Establishment, Tokai-mura, Naka-gun, Ibaraki-ken 319-11, Japan
Akimichi Hishinuma
K. Noda

148. Kyushu University, Dept. of Nuclear Engineering, Faculty of Engineering, Kyushu University 36, Hakozaki, Fukuoka 812, Japan

C. Kinoshita

149-150. Muroran Institute of Technology, Dept. of Metallurgical Engineering, 27-1 Mizumoto-cho, Mororan 050, Japan

Toshihei Misawa Akihiko Kimura 
151. Nagoya University, Dept. of Nuclear Engineering, Furo-Cho, Chikusa-ku, Nagoya 464-01, Japan Michio Kiritani

152-155. National Institute for Fusion Science, Furo-cho, Chikusa-ku, Nagoya 464-01, Japan Osamu Motojima Takeo Muroga

\section{Chusei Namba}

Nobuaki Noda

156-158. National Research Institute for Metals, Tsukuba Branch, Sengen, Tsukuba-shi, Ibaraki-ken, 305, Japan
Fujio Abe
Josei Nagakawa
Haruki Shiraishi

159. Osaka University, Dept. of Nuclear Engineering, 2-1 Yamadaoka, Suita, Osaka 565, Japan Tetuo Tanabe

160. PNC Oarai, 4002 Narita, Oarai, Ibaraki 311-13, Japan Itaru Shibasaki

161. Science University of Tokyo, Dept. of Materials Science \& Technology, 2641 Yamazaki

Noda City, Chiba Prefecture 278, Japan Naohira Igata

162. Teikyo University, Otsuka, Hachioji, Tokyo 192-03, Japan Akira Miyahara

163. Tohoku University, Institute for Materials Research, Katahira 2-2-1, Sendai 980, Japan Hideki Matsui

164-165. Tohoku University, Institute for Materials Research, Oarai Branch, Oarai, Ibaraki 311-13, Japan Hideo Kayono Tatsuo Shikama

166. Tohoku University, Dept. of Nuclear Engineering, Tohoku University, Aoba, Aramaki, Sendai 980 , Japan

Katsunori Abe

167. Tohoku University, Dept. of Machine Intelligence and Systems Engineering, Aramaki, Aoba-ku, Sendai 980, Japan

Tatsuo Kondo

168. Tokai University, Dept. of Nuclear Engineering, 1117 Kitakaname, Hiratsuka-shi, Kanagawaken 259-12, Japan

Shiori Ishino

169. University of Tokyo, Dept. of Nuclear Engineering, 3-1, Hongo 7-Chome, Bunkyo-Ku, Tokyo 113, Japan Naoto Sekimura

170-171. University of Tokyo, Dept. of Materials Science, 3-1, Hongo 7-Chome, Bunkyo-ku, Tokyo 113, Japan Akira Kohyama Yutaka Kohno

172. Commission of European Communities, Directorate-General for Research Science and Education, Fusion Programme RUE De La Loi 200, B-1049 Brussels, Belgium J. Darvas 
173-174. Chalk River Nuclear Laboratories, Atomic Energy of Canada, Ltd., Chalk River, Ontario KOJ 1J0, Canada
I. J. Hastings
D. P. Jackson

175. Southwestern Institute of Physics, P.O. Box 432, Chenedu 610041, Sichuan, P.R. China J. P. Qian

176. Institute of Atomic Energy, Academia Sinica, P.O. Box 275-51, Beijing, P.R. China J. Yu

177. Riso National Laboratory, Materials Dept., P.O. Box 49, DK-4000, Roskilde, Denmark B. N. Singh

178. Centre d'Etudes Nucleaires, Saclay, DLPC/SMCM, Commissariat a l'Energie Atomique, 91191 Gif-Sur-Yvette, Cedex, France

N. Roux

179. Commission for European Communities, Joint Research Centre, I.A.M. Ispra Establishment 21020 Ispra (Varese), Italy

P. Fenici

180. EURATOM/CIEMAT Fusion Association, Avenida Complutense 22, 28040, Madrid, Spain E. R. Hodgson

181. Paul Scherrer Institute, CH-5232 Villigen, Wuerenlingen PSI, Switzerland M. Victoria

182. Harwell Laboratory, B393, Radiation Damage Dept., Oxfordshire, OX11 ORA, United Kingdom C. A. English

183. Metallurgical and Nuclear Consultant, 9A Cumnor Rise Road, Cumnor Hill, Oxford OX2 9HD, United Kingdom

D. R. Harries

184. Hahn-Mietner-Institut fur Kernforschung Berlin, Postfach 390128, Glienicker Str. 100, D-14109, Germany

H. Wollenberger

185. Institut fur Festkorperforschung Forschungszentrum Jülich, Postfach 1913, D-52425 Jülich, Germany

H. Ullmaier

186-189. ITER Garching Joint Work Site, Max-Planck-Institute für Plasmaphysik, Boltzmannstrasse 2,

D-85748 Garching bei München, Germany
B. Barabash
G. Kalinin
Y. Gohar
R. Parker

190-191. ITER Naka Joint Work Site, 801-1 Mukouyama, Naka-machi, Naka-gun, Ibaraki-Ken, 311-01, Japan

M. Huguet (2)

192-195. ITER San Diego Joint Work Site, 11025 N. Torrey Pines Road, La Jolla, CA 92037
V. Chuyanov
F. Puhn
S. J. Piet
P. Smith 
196-197. Kernforschungszentrum Karlsruhe, Postfach 3640, 75 Karlsruhe 1, Germany
M. Dalle-Donne (INR)
K. Ehrlich (IMF-II)

198. Max-Planck-Institut für Plasmaphysik, Boltzmannstrasse 2, D-85748 Garching bei München, Germany

Patrick Lorenzetto

199. A. A. Baikov Institute of Metallurgy, USSR Academy of Sciences, Leninsky Prospect 49, Moscow, Russia

L. I. Ivanov

200. CRISM "Prometey," Naberezhnava r. Monastyrick 1, 193167, St. Petersburg, Russia V.V. Rybin

201. D. V. Efremov Institute of Electro-Physical Apparatus, 189631, St. Petersburg, Russia S. A. Fabritsiev

202. Kharkov Institute of Physics \& Technology, Radiation Damage and Materials Dept., Akademicheskaya 1, 310108 Kharkov, Ukraine

I. M. Neckludov

203-205. V. I. Lenin Research Institute of Atomic Reactors, 433510 Dimitrovgrad-10, Ulyanovsk Region, Russia
V. Kazakov
A. S. Pokrovsky
V. K. Shamardin

206. Korean Atomic Energy Research Institute, P.O. Box 105, Yusung, Taejon, 305-600, Korea Jun Hwa Hong

207. Department of Energy, DOE Oak Ridge Field Office, P.O. Box 2008,

Oak Ridge, TN 37831-6269

Assistant Manager for Energy Research and Development

208. Department of Energy, DOE Oak Ridge Field Office, P.O. Box 2008,

Oak Ridge, TN 37831-6269

S. D. Frey

209. Department of Energy, Office of Basic Energy Sciences, Washington, D.C. 20585

R. J. Gottschall

210-217. Department of Energy, Office of Fusion Energy, Washington, D.C. 20585
S. E. Berk
W.F. Dove
M. M. Cohen
R. McKnight
R. E. Price
N. A. Davies
W. Marton
F. W. Wiffen

218. Department of Energy, Richland Operations Office, Federal Bldg., MS-A590,

Richland, WA 99352

D. Segna

219-220. Department of Energy, Office of Scientific and Technical Information, Office of Information Services, P.O. Box 62, Oak Ridge, TN $378 \dot{3} 1$

For distribution by microfiche as shown in DOE/OSTI-4500-R75, Distribution Categories UC-423 (Magnetic Fusion Reactor Materials) and UC-424 (Magnetic Fusion Energy Systems) 


\title{
THREE-YEAR MOVEMENT PATTERNS OF ADULT DESERT TORTOISES
}

\section{AT YUCCA MOUNTAIN}

\author{
Eric A. Holt and Kurt R. Rautenstrauch \\ EG\&G Energy Measurements, Inc., P.O. Box 1912, Las Vegas, Nevada 89125
}

Abstract. We studied the home-range size and site fidelity of adult (>180-mm MCL) desert tortoises (Gopherus agassizii) at Yucca Mountain, Nevada, during 1992-1994. Of 67 adult tortoises monitored at Yucca Mountain during this period, we evaluated the movements of 22 female and 16 male radiomarked tortoises that were located $>50$ times during each of the 1992, 1993, and 1994 activity seasons. By including only tortoises that were located many times in all three years, we may have biased our sample toward the resident tortoises that were easiest to locate. We used two methods to measure annual and three-year home range size: $100 \%$ minimum convex polygon (MCP) (Mohr 1947) and 95\% cluster (Kenward 1987). MCP represents the maximum area a tortoise used, whereas $95 \%$ cluster represents the area a tortoise used most often. To evaluate whether tortoises used the same areas in consecutive years, we measured the shift in arithmetic-mean center of activity (Hayne 1949) and the overlap (i.e., the percent of one year's home range included in the previous year's home range) in consecutive annual home ranges (MCP only). In addition, we measured the percentage of each tortoise's three-year home range used annually (MCP only). Analysis of variance was used to test for differences $(P<0.05)$ among years and sexes for all criteria.

Males had larger $(P<0.01)$ annual MCP home ranges $(\bar{x}=53$ ha, $\mathrm{SD}=51)$ than females $(\bar{x}=18$ ha, $\mathrm{SD}=12)$. The average three-year MCP home range also differed $(P<0.01)$ between 
males $(\bar{x}=93$ ha, $S D=27)$ and females $(\bar{x}=27$ ha, $S D=17)$. MCP home ranges did not differ $(P=0.22)$ among years $(\bar{x}=33$ ha, $\mathrm{SD}=39)$.

Males also had larger $(P<0.01)$ annual cluster home ranges $(\bar{x}=17$ ha, $\mathrm{SD}=25)$ than females $(\bar{x}=4, \mathrm{SD}=6)$. The average three-year cluster home ranges also differed between $(P<$ $0.01)$ males $(\bar{x}=25, \mathrm{SD}=31)$ and females $(\bar{x}=7, \mathrm{SD}=4)$. Cluster home ranges during 1994 $(\bar{x}=5$ ha, $\mathrm{SD}=7)$ were smaller $(P<0.01)$ than $1992(\bar{x}=10$ ha, $\mathrm{SD}=18)$ or $1993(\bar{x}=14$ ha, $\mathrm{SD}=24)$

Males had larger $(P<0.01)$ shifts in arithmetic-mean center of activity between consecutive years $(\bar{x}=151 \mathrm{~m}, \mathrm{SD}=130, n=32)$ than females $(\bar{x}=83 \mathrm{~m}, \mathrm{SD}=85, n=44)$. There was no difference $(P=0.56)$ in shift $(\bar{x}=112 \mathrm{~m}, \mathrm{SD}=111)$ between consecutive year groups.

The average overlap in consecutive annual MCP home ranges was $78 \%(\mathrm{SD}=19$, range $=7-100 \%, n=76$ ). Only one annual home range had $<30 \%$ of its area in common with the previous year's home range, while 41 annual home ranges had $>80 \%$ of their area in common with the previous year's home range. Overlap of 1993 on $1992(\bar{x}=72 \%, \mathrm{SD}=21)$ was smaller $(P<0.01)$ than 1994 on $1993(\bar{x}=83 \%, \mathrm{SD}=14)$, indicating that in 1994 , as compared to 1993 , tortoises used fewer areas that they did not use the previous year. There was no difference $(P=$ 0.78 ) in percent overlap between sexes across the year groups.

Tortoises used an average of $65 \%$ of their MCP three-year home range annually (SD = 20 , range $=17-100 \%)$. The percentage of the three-year home range used in $1994(\bar{x}=54 \%, S D$ $=18)$ was smaller $(P<0.01)$ than in $1992\left(\bar{x}^{-}=69 \%, \mathrm{SD}=19\right)$ or $1993(\bar{x}=70 \%, \mathrm{SD}=18)$. This measure did not differ $(P=0.49)$ between sexes. 
We conclude that males have larger home ranges than females and that tortoise movements vary annually, possibly in response to differences in rainfall. Adult tortoises at Yucca Mountain moved less during 1994, which was drier than the previous two years. Although average MCP home range size did not differ among years, tortoises had smaller cluster home ranges in 1994, indicating that they spent most of their time in smaller areas. Tortoises also used smaller portions of their three-year home range in 1994 than they did in the previous two years. In addition, tortoise used fewer areas different from the previous year in 1994 than in 1993. We also conclude that most adult tortoiseSat Yucca Mountain show strong site fidelity. One reason for this conclusion is that shifts in arithmetic-mean center of activity between consecutive years were small compared to home range sizes. In addition, overlap in consecutive annual home ranges and percentage of the three-year home range used annually were relatively large. It should be noted, however, that a few tortoises we monitored at Yucca Mountain, but did not include in this analysis because we were unable to locate them often enough, moved great distances and had little site fidelity.

\section{LITERATURE CITED}

Hayne, D.W. 1949. Calculation of size of home range. Journal of Mammalogy 30:1-18.

Kenward, R. E. 1987. Wildlife Radio Tagging. Academic Press, London. 222 pp.

Mohr, C.O. 1947. Table of equivalent populations of North American small mammals. American Midland Naturalist 37:233-249.

\footnotetext{
"Work supported by the U.S. Department of Energy Yucca Mountain Site Characterization Project, Contract No. DE AC08 93NV11265."
} 


\section{Three Year Movement Patterns of Adult Tortoises at Yucca Mountain 1995 Tortoise Council, Las Vegas \\ Presentation Outline by Eric A. Holt (EG\&G)}

\section{Introduction}

- I'd like to first mention that this work was funded by the U.S. Department of Energy, Yucca Mountain Site Characterization Project.

\section{Slide 1}

The concept of a home range is based on the belief that animals do not wander around randomly; instead, they use specific areas and return to those areas that provide resources that they require, such as food, shelter, and mates.

The size of a home range provides some idea of how much space an individual uses during a given time period. The few studies that have been done on movements of desert tortoises, have found that over a one to two year period, males use about 20-45 ha and females use about 10-20 ha. Today I will report the home range sizes of adult tortoises at Yucca Mountain during the last three years.

There is another aspect of space use that is seldom reported, and that is site fidelity. What I am referring to as site fidelity is the use of the same areas in different years. Today I will also address this issue of site fidelity.

\section{Slide 2}

At Yucca Mountain, we began monitoring radiomarked tortoises in 1989, and have been locating about 100 tortoises per year since 1992.

We locate our radiomarked tortoises twice weekly during the activity season, and when located we record information on behavior and location.

\section{Slide 3}

Locations are recorded as UTM coordinates and for the data used in this presentation, about $54 \%$ of the UTM coordinates were obtained using dGPS, which is accurate to within 5 meters.

The remaining locations were obtained using regular GPS or map and compass, which have assumed accuracies of 30 meters. 
Slide 4

To study 3-year movement patterns, we chose from our sample of radiomarked tortoises all individuals $>180 \mathrm{~mm}$ Mid-Carapace Length that were located at least 50 times during the 1992,93 , and 94 activity seasons.

The resulting sample consisted of 22 female and 16 male radiomarked tortoises.

\section{QUESTIONS}

\section{Slide 5 .}

When deciding how to evaluate the three-year movement patterns of adult tortoises at Yucca Mountain, we came up with three questions:

First, what is the size of the area tortoises use each year, or, what is their annual home range?

Second, what is the size of the area tortoises used during a 3-year period?

And lastly, did individual tortoises use the same area each year? In other words, did they show site fidelity.

I'm going to break the next part of my talk into 2 parts. First I will describe our methods and results for our first 2 questions, which deal with annual and 3-year home range size. After that I will discuss the methods and results for our question of site fidelity.

\section{METHODS/RESULTS}

\section{Slide 6}

We used two different methods to estimate home range size:

the $100 \%$ minimum convex polygon method, because we feel it represents the maximum area a tortoise used,

and the $95 \%$ Cluster method, because we feel it represents the area a tortoise used the most.

The software package "Ranges" was used to estimate these home ranges. 


\section{Slide 7}

This slide shows an example of a convex polygon. As you can see this method draws a single polygon around the outer locations and measures the area of the polygon.

Based on this method, an adult male identified as 209 , had a convex polygon home range of $33 \mathrm{ha}$, in 1992.

\section{Slide 8}

This histogram shows the average annual and 3-year convex polygon sizes for males and females.

Based on analysis of variance males had significantly larger annual convex polygon home ranges than females.

The average annual eonvex polygon size for males was 53 ha. 53 ha is about the size of a circle with a diameter of 800 meters.

Females, on the other hand, had an average size of only $18 \mathrm{ha}: 18 \mathrm{ha}$ is about the size of a circle with a diameter of 500 meters.

Máles also had statistically larger 3-year convex polygon home ranges. Males averaged $93 \mathrm{ha}$, which is about one square kilometer, and females averaged $27 \mathrm{ha}$.

There was no statistical difference in convex polygon size between the three years.

However, in 1994, convex polygon size did decrease for both males and females.with males showing a 33\% decrease and females a $12-19 \%$ decrease.

\section{Slide 9}

In comparison to the convex polygon method, the Clustering method draws multiple polygons around groups of locations clumped together.

As you can see by this slide, the area between clusters are not included in the measurement of home range, and thus cluster home ranges are smaller than convex polygon home ranges.

Referring back to tortoise 209, its 1992 cluster home range was only 5 ha, as compared to its convex polygon home range for the same year of 33 ha.

Slide 10

This histogram shows the average annual and 3-year cluster sizes for males and females.

Based on analysis of variance, there was again a statistical difference in annual 
homerange size between sexes, with males averaging 17 ha and females averaging 4 ha. On average, annual cluster size was $1 / 4$ th the size of convex polygons.

Males also had significantly larger 3-year cluster home ranges. Males averaged 25 ha and females averaged 7 ha.

There was a statistical difference in annual cluster home range size between the three . years, with 1994 being smaller

We have now answered our questions about home range size, so I will now move on to discuss the question of site fidelity.

\section{Slide 11}

To determine site fidelity, we calculated three things:

shift in arithmetic mean-center of activity between consecutive years, convex polygon overlap between consecutive years, and the $\%$ of the 3-year convex polygon used each year.

\section{Slide 12}

Shift in mean-center of activity is defined as the distance between the arithmetic mean locations for two consecutive years.

The arithmetic mean location is calculated by taking the average of the northing and easting coordinates.

This slide shows a map of tortoise 209s 1992 and 1993 active season locations. I have also included the convex polygons for the same years.

The large spheres represent the arithmetic mean location for each year.

Based on this, you can see that 209s center of activity shifted 100 meters to the south east from 1992 to 1993, this is a fairly small distance when compared to annual home range size.

Slide 13

These histograms show the distribution of shift in center of activity.

Since there was no statistical difference between years, I combined the data among years and only present the data by sex. 
As with home range size, males had statistically larger shifts in center of activity than females.

The average shift for females was $83 \mathrm{~m}$ while the average shift for males was $151 \mathrm{~m}$.

If you remember that the average annual convex polygon home range for males is equivalent to a circle with a diameter of 800 meters, you realize that a shift in center of activity of 151 meters, is relatively small.

Slide 14

The second parameter we measured to evaluate site fidelity was convex polygon overlap between consecutive years.

$\%$ overlap between consecutive years is defined as the percent of a given years home range that was used, or is in common with, the previous years home range.

This slide shows the convex polygon home ranges for tortoise 209 during 1992 and 1993. As you can see, approximately $61 \%$ of his 1993 home range is in common with his 1992 home range.

Thus, in 1993 this tortoise mostly used areas that it also used in 1992.

\section{Slide 15}

These histograms show the convex polygon overlap distribution for 1993 on 1992, and 1994 on 1993.

Since there was no statistical difference between sexes, I combined the data by sex and only present the results by the two-year combinations.

The average amount of 1993 home ranges used in 1992 was $72 \%$, with 11 tortoises only using areas in 1993 that they also used in 1992.

The average amount of 1994 home ranges used in 1993 was $83 \%$, with 16 tortoises only using areas in 1994 that they used in 1993.

Based on analysis of variance, we found that 1994 overlapped on 1993 more than 1993 did on 1992.

This indicates, that in 1994, tortoises used fewer areas different from what they used in 1993, as compared to areas shared between 1993 and 1992. In other words, in 1994 they restricted their movements to mostly areas they used the previous year, but in 1993 they used many areas not used in the previous year. 


\section{Slide 16}

And finally, the third parameter measured to evaluate site fidelity was the percent of a tortoises 3-year convex polygon used during a given year.

This measurement is easily seen on this slide.

The large polygon represents the 3-year home range of an adult female, called 798, and the smaller polygon represents her 1994 home range.

Thus, in 1994 this tortoise used $20 \%$ of her three year home range.

\section{Slide 17}

These histograms show the distribution of the $\%$ of 3 -year home range used each year.

Since there was no statistical difference between sexes, I again combined the data by sex and am presenting the results by years only.

As you can see, the distribution and means for 1992 and 1993 are very similar.

Then, in 1994, the distribution shifted left and the mean dropped to $54 \%$.

Based on analysis of variance, in 1994, tortoises did use less of their three year convex polygon home ranges.

Based on the results of our analysis of annual overlap we conclude that this decrease in \% of 3-year home range used in 1994 was because tortoises restricted their movements to a smaller part of the area they used previously, not because they used new areas.

\section{CONCLUSIONS}

\section{Slide 18}

In conclusion, we determined that males have larger annual convex polygon home ranges than females.

Males averaged 53 ha and females average 18 ha.

Males also had larger annual cluster home ranges than females.

Males averaged 17 ha and females averaged 4 ha. 


\section{Slide 19}

We also concluded that males have larger 3-year convex polygon home ranges than females.

Males averaged 93 ha and females average 27 ha.

Males also had larger 3-year cluster home ranges than females.

Males averaged 25 ha and females averaged 7 ha.

\section{Slide 20}

Third, because we found a year differences in cluster home range size, annual overlap, and percent of 3-year home range used each year, we concluded that tortoise movement is dependent upon a year factor.

Our best guess is that precipitation, temperature, and their influence on plant productivity are probably the main factors influencing tortoise movements.

In 1994, the driest of the three years and one of the hottest summers on record, tortoises spent most of their time in small areas.

In addition, in 1994 they used fewer areas different from the previous year and they used smaller portions of their 3-year home range.

\section{Slide 21}

Our final conclusion is that adult tortoises at Yucca Mountain show strong site fidelity, at least over our three year sampling period.

We conclude this because shifts in mean center of activity are small when compared to home range size. Males had an average shift of about 150 meters and females had an average shift of about 80 meters.

In addition, convex polygon overlap between consecutive years is large with annual averages ranging from 72 to $83 \%$.

And finally, the \% of the three-year home range used each year is also large, averaging $70 \%$ in 1992 and 1993 and 54\% in 1994. 
THREE YEAR MOVEMENT PATTERNS OF ADULT TORTOISES

\section{AT YUCCA MOUNTAIN}

(TORTOISE SLIDE)

DOE 
INTRODUCTION

\section{QUESTIONS}

- What is the Size of the Area Tortoises use Each Year and During a 3-year Period?

- Do Tortoises Use the Same Area Every Year? 


\section{METHODS}

\section{SAMPLE}

\section{7 \\ - 21 Females and 18 Males $>180 \mathrm{MCL}$}

- 1992,1993 , and 1994

- >50 Active-Season Locations 

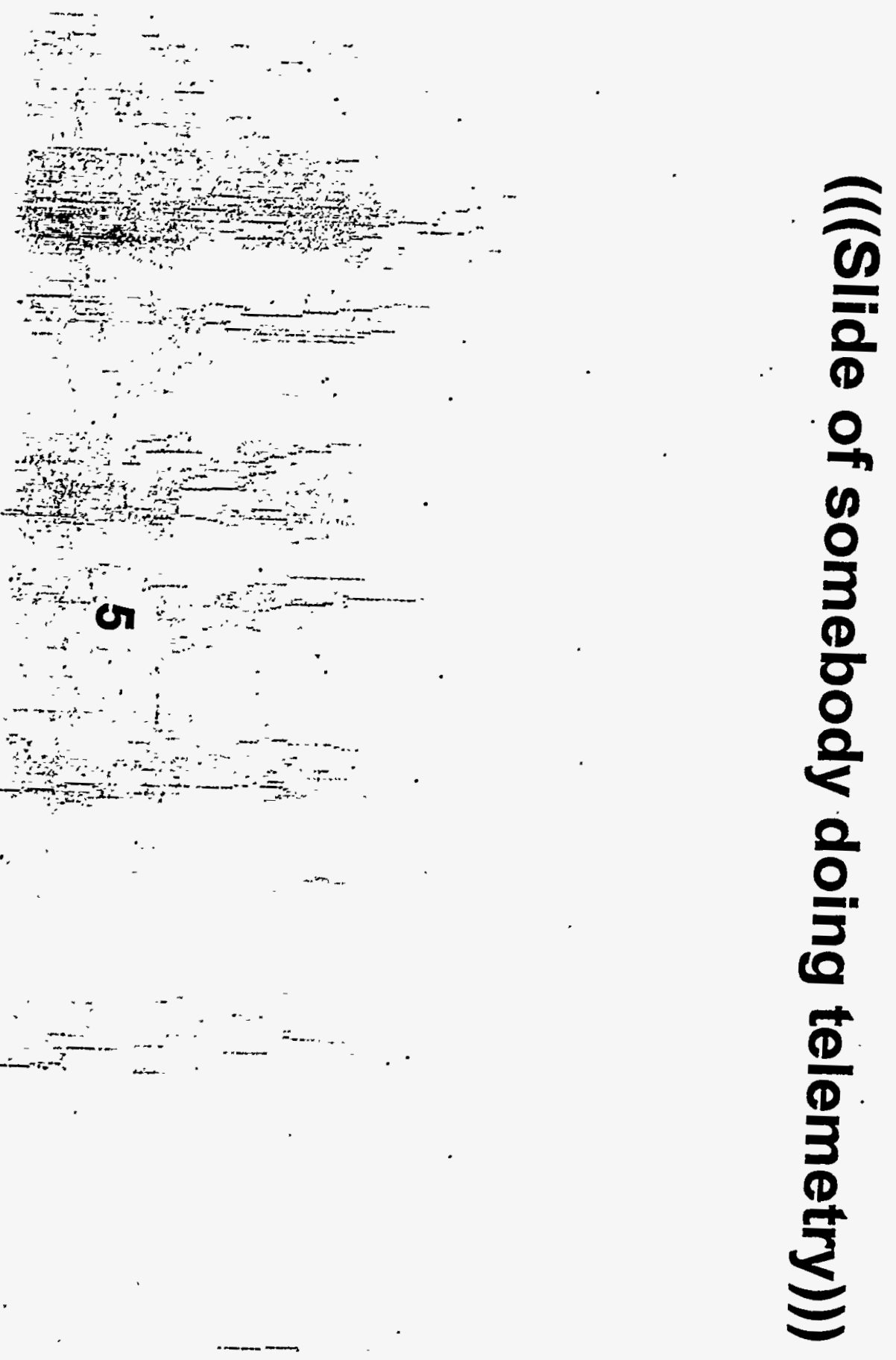
(((Slide of a field GPS unit with antenna on a stick next to a well flagged obviouse burrow))) 


\section{METHODS}

What is the Size of the Area Tortoises Use?

- $100 \%$ Minimum Convex Polygon (MCP) Home Range Size

- $95 \%$ Cluster Home Range Size 


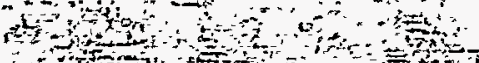

of

$$
\begin{aligned}
& \text { - }
\end{aligned}
$$

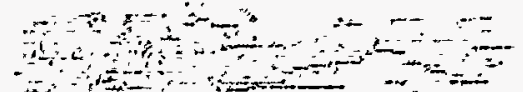

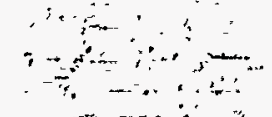$$
\text { 西 }
$$$$
\therefore \quad \cdots, \cdots+\cdots
$$$$
\ldots
$$$$
\bullet \bullet
$$$$
\because
$$

$\infty$

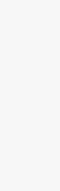




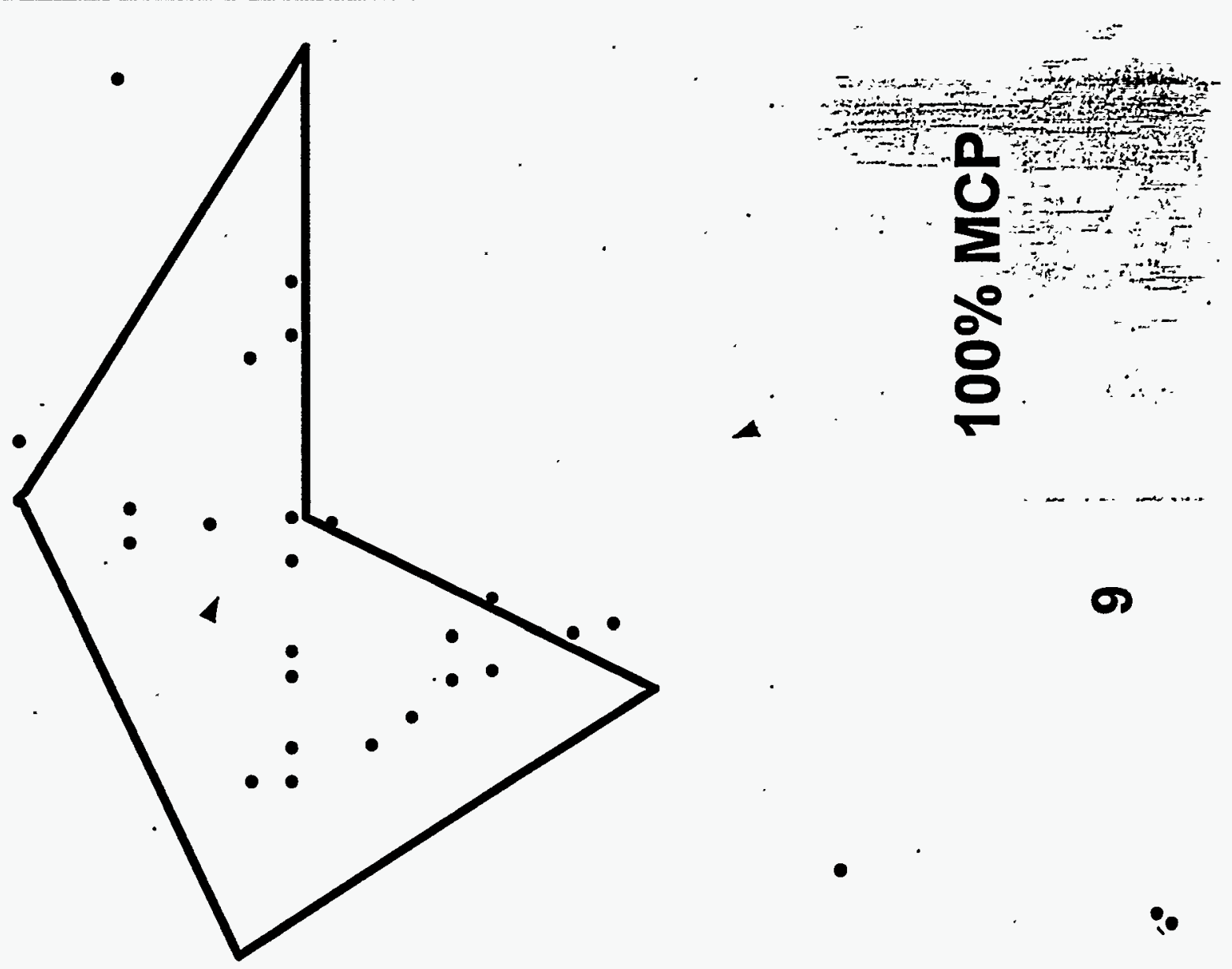

11
11
0
0
0
0
0
0

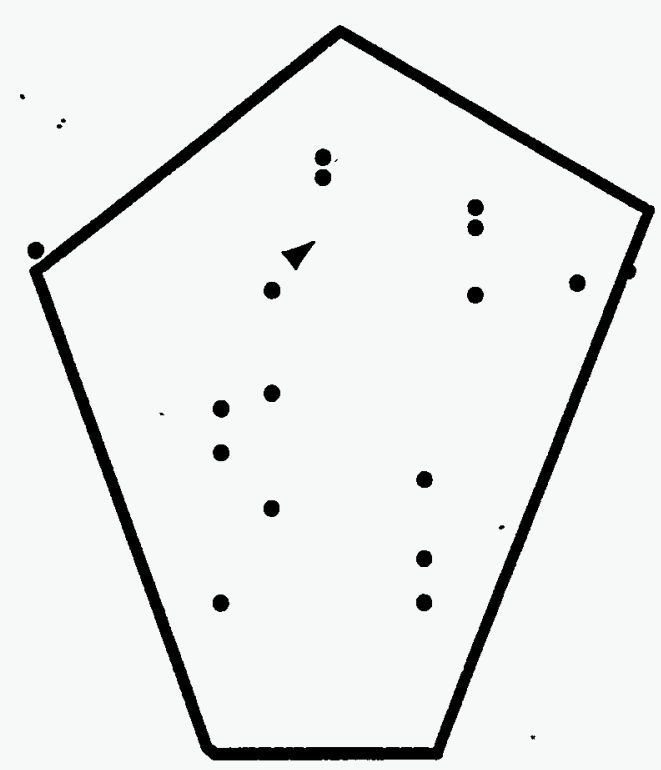

$\bullet$

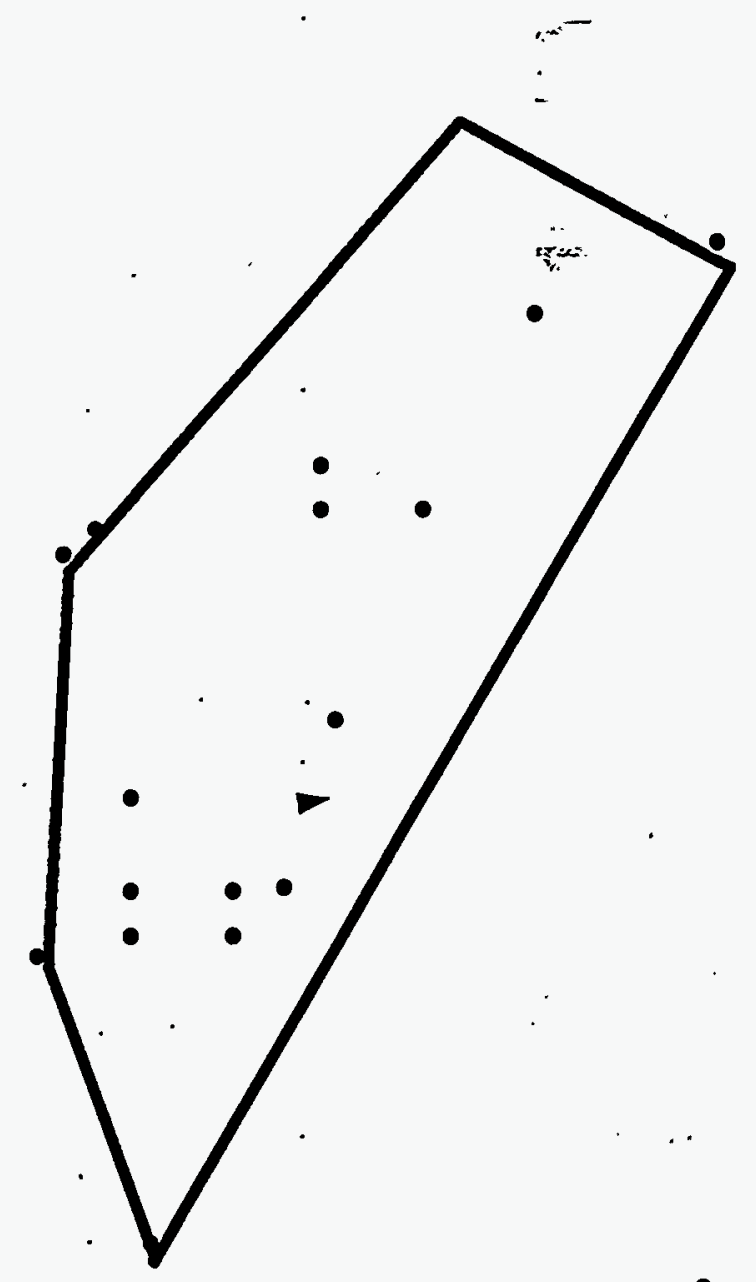

I 


\section{METHODS}

\section{DO TORTOISES USE THE SAME AREA EVERY YEAR?}

- Shift in Arithmetic-Mean Center of Activity

- MCP Overlap Between Consecutive Years

\section{\% of 3-Year MCP Used Each Year}



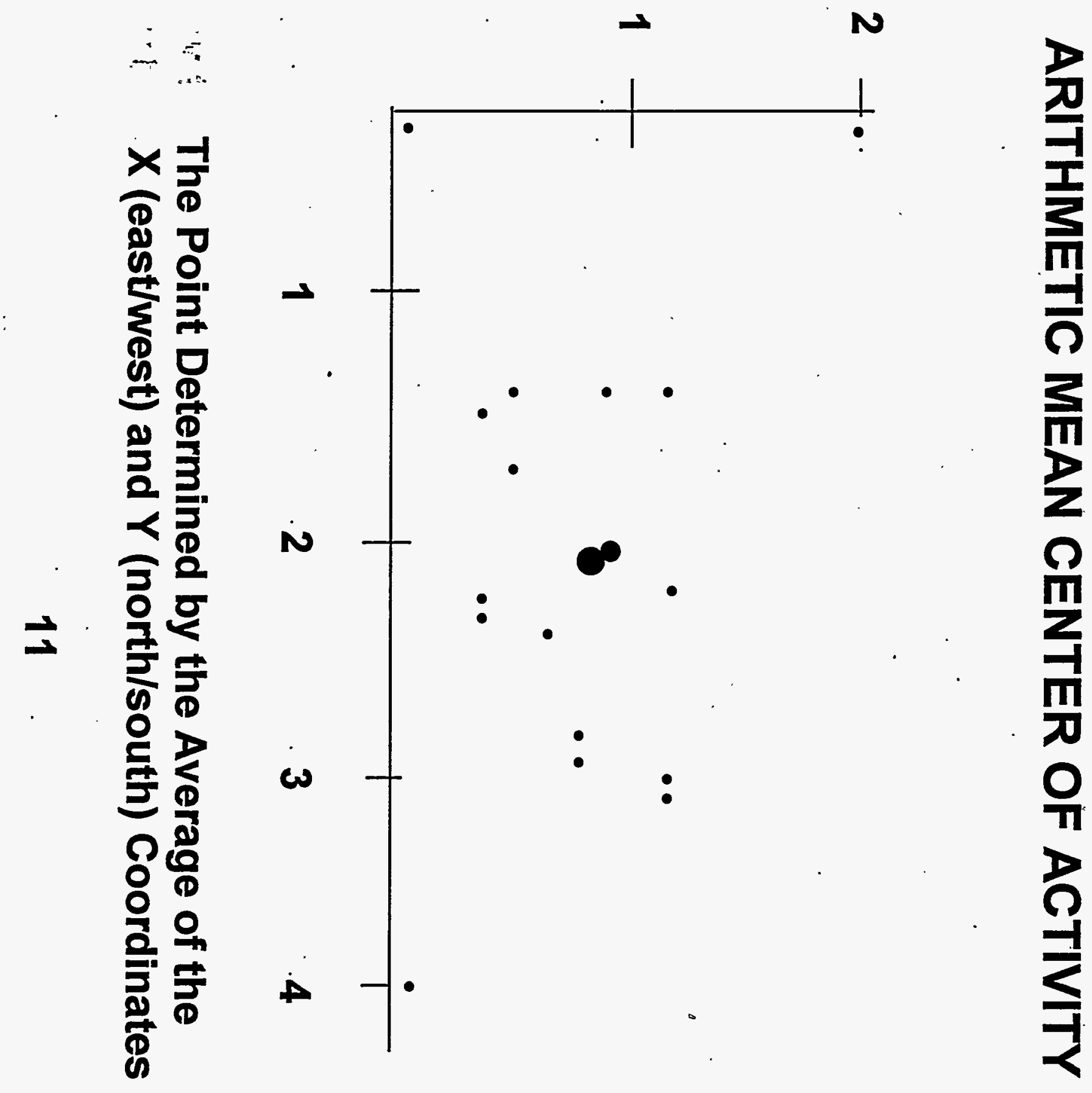

$\Omega$

m

Z

恧

유

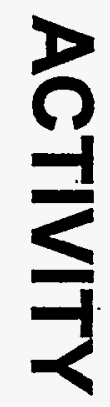

용 


\section{MCP Home Range Overlap Among Consecutive Years}

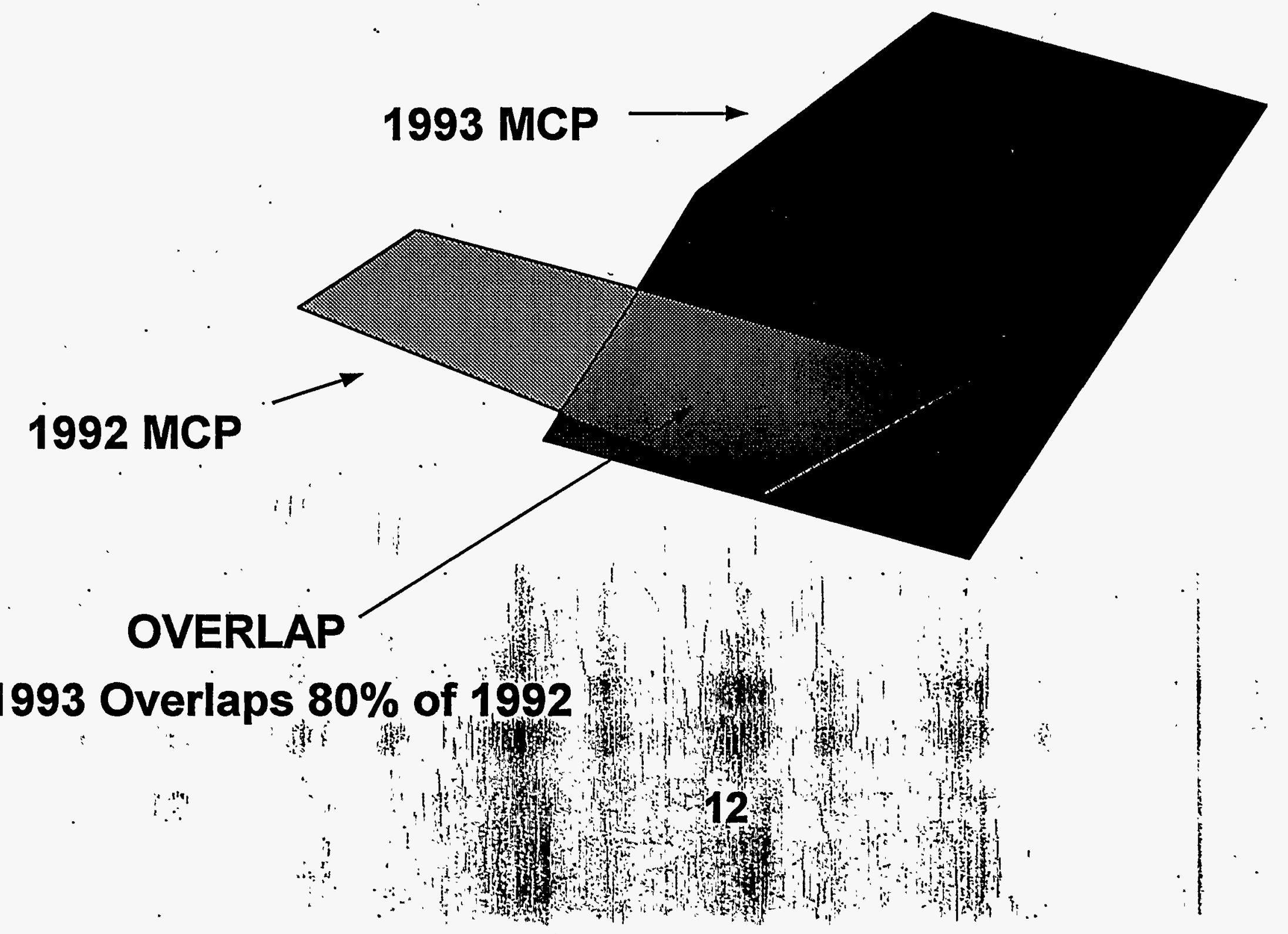




\section{$\%$ of Three-Year Home Range Used Each Year}

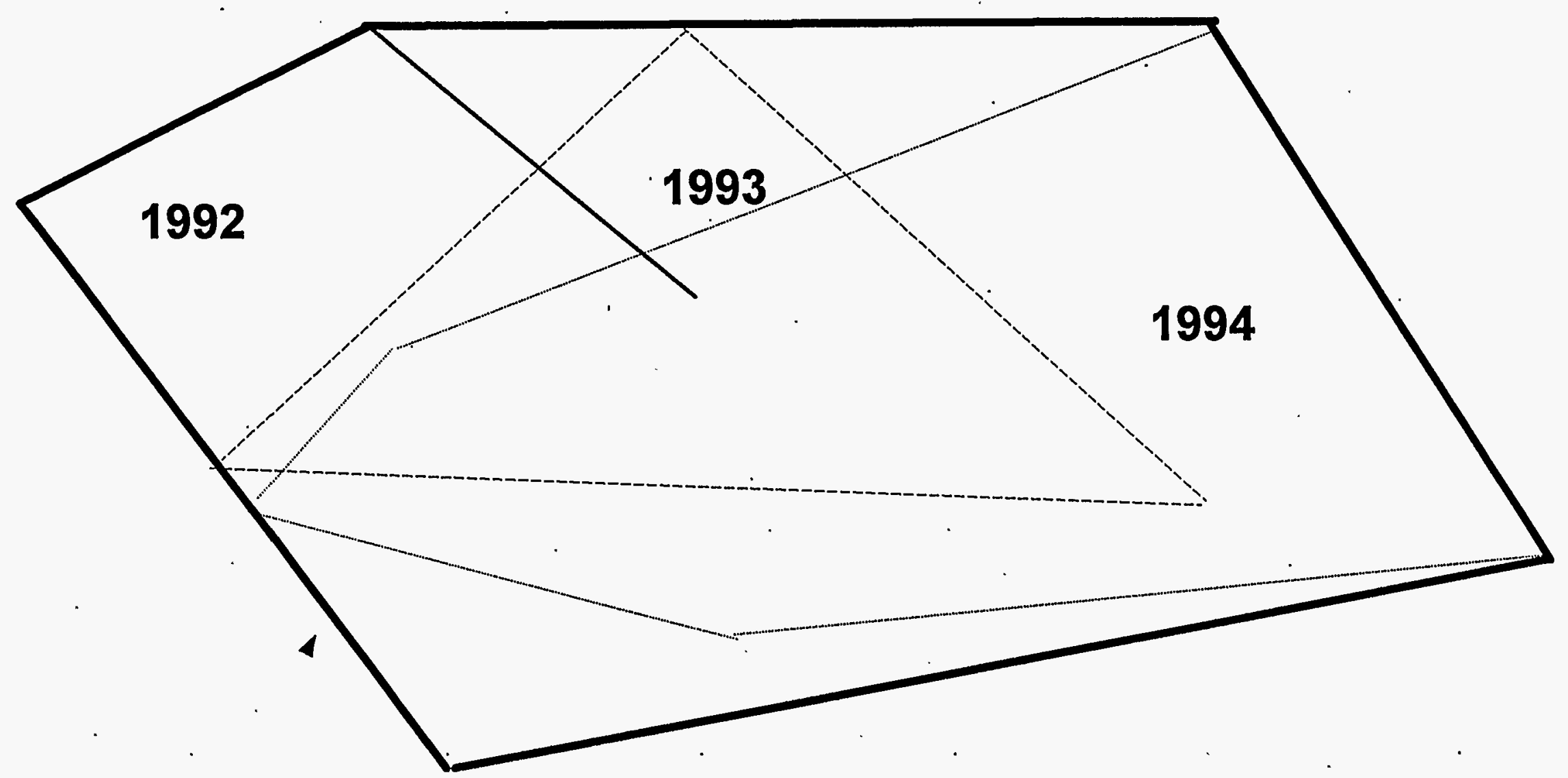

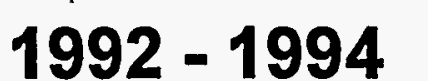

1992 - 1994

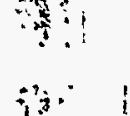

$\because$

$\%$

i
1992 Overlaps $30 \%$ of $1992-94$ 1993 Overlaps $30 \%$ of $1992-94$ 1994 Overlaps $60 \%$ of $1992-94$ 


\section{RESULTS}

\section{HOME RANGE SIZE}

- No Difference Among Years ( $\mathrm{P}=$ ??)

- Males Have Larger Home Ranges $(\mathrm{P}=$ ??)

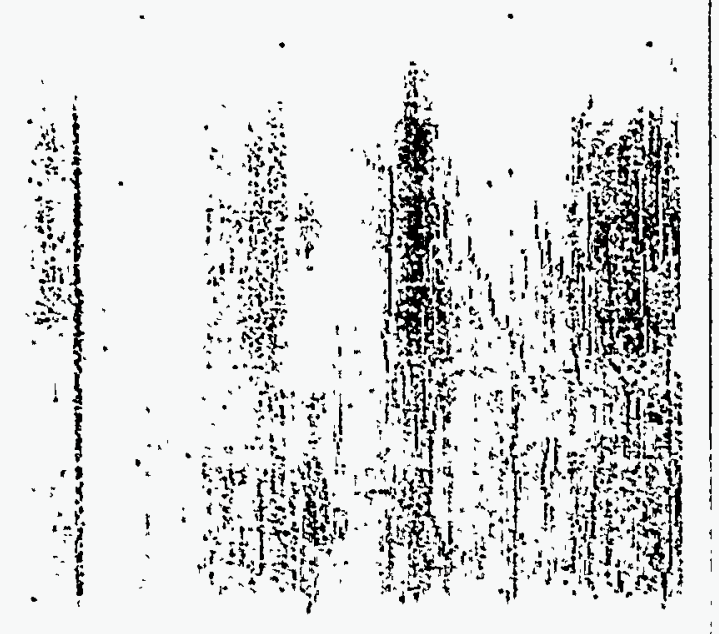




\section{RESULTS}

\section{AVERAGE 100\% MCP HOME RANGE SIZE (HA)}

\begin{tabular}{|c|c|c|c|c|}
\hline YEAR & MALE & RANGE & FEMALE & RANGE \\
\hline 1992 & 58 & $13-295$ & 18 & 3-54 \\
\hline 1993 & 53 & $8-149$ & 21 & $2-77$ \\
\hline 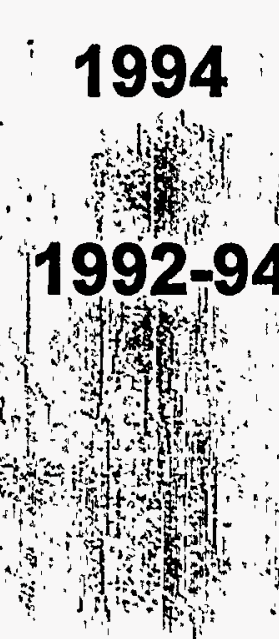 & $\begin{array}{l}? \\
? \\
? \\
?\end{array}$ & $\begin{array}{c} \\
\vdots \\
\vdots \\
\vdots \\
\vdots \\
\vdots \\
\vdots \\
\vdots\end{array}$ & $\begin{array}{l}? \\
?\end{array}$ & \\
\hline
\end{tabular}




\section{RESULTS}

\section{AVERAGE 95\% CLUSTER HOME RANGE SIZE (HA)}

\begin{tabular}{rrrrr} 
YEAR & MALE & RANGE & FEMALE & RANGE \\
\hline 1992 & 18 & $1-89$ & 4 & $1-10$ \\
1993 & 18 & $2-77$ & 5 & $<1-20$ \\
1994 & $?$ & & $?$ & \\
$1992-94$ & $?$ & & $?$ &
\end{tabular}




\section{SHIFT IN CENTER OF ACTIVITY}
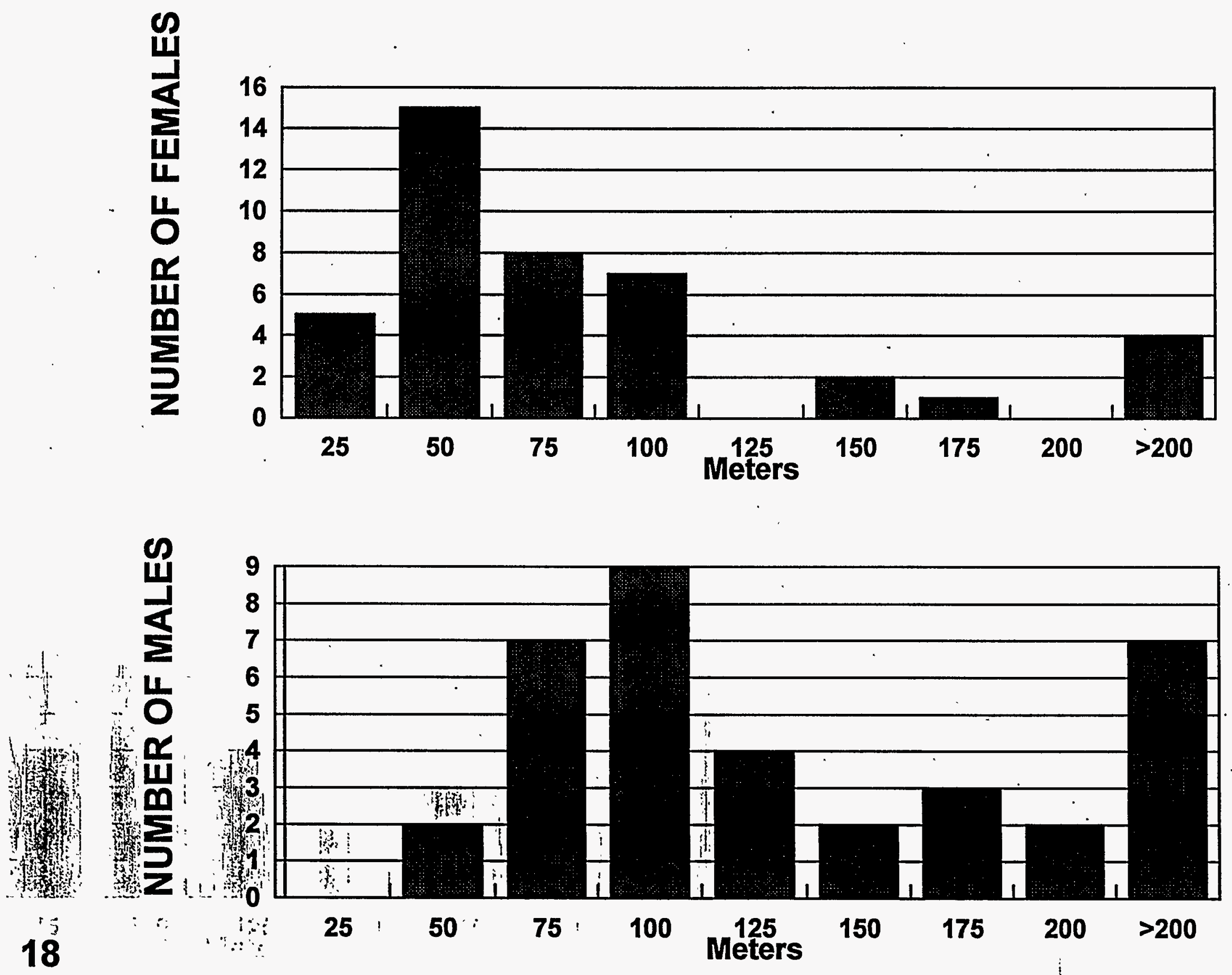


\section{RESULTS}

\section{MCP HOME RANGE OVERLAP AMONG CONSECUTIVE YEARS}

\section{No Difference $(P=$ ??) Between Sexes}

1993 on 1992 Was Higher $(\mathrm{P}=$ ??) Than 1994 on 1993
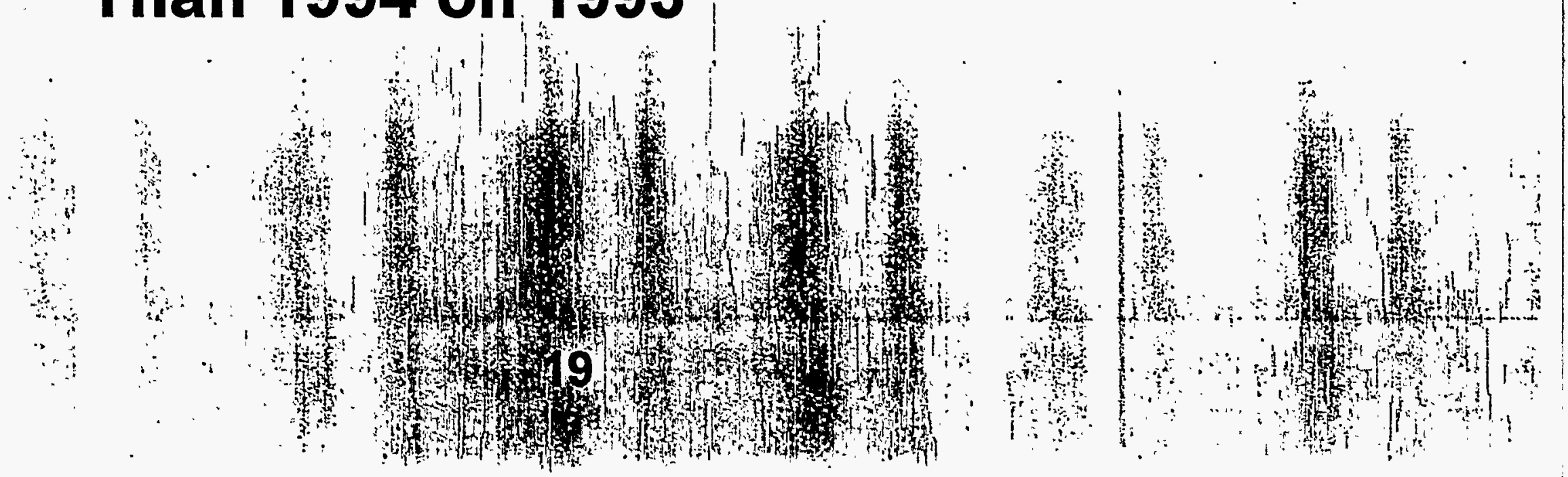


\section{MCP OVERLAP DISTRIBUTION}
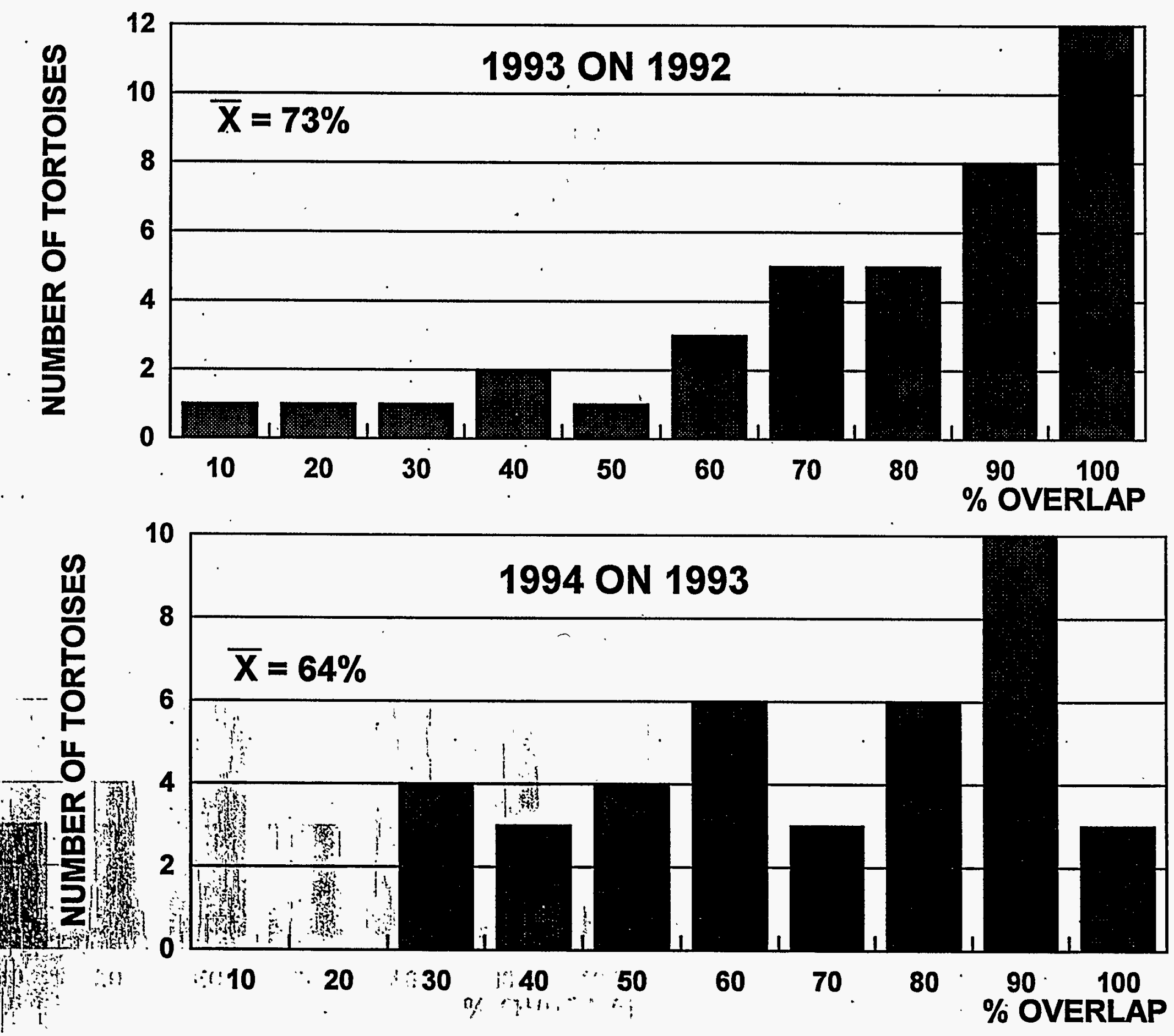


\section{RESULTS}

\section{\% OF 3-YEAR HOME RANGE USED EACH YEAR}

No Difference ( $P=$ ??) Between Sexes

1994 was Smaller $(P=$ ? $)$ than 1992 or 1993

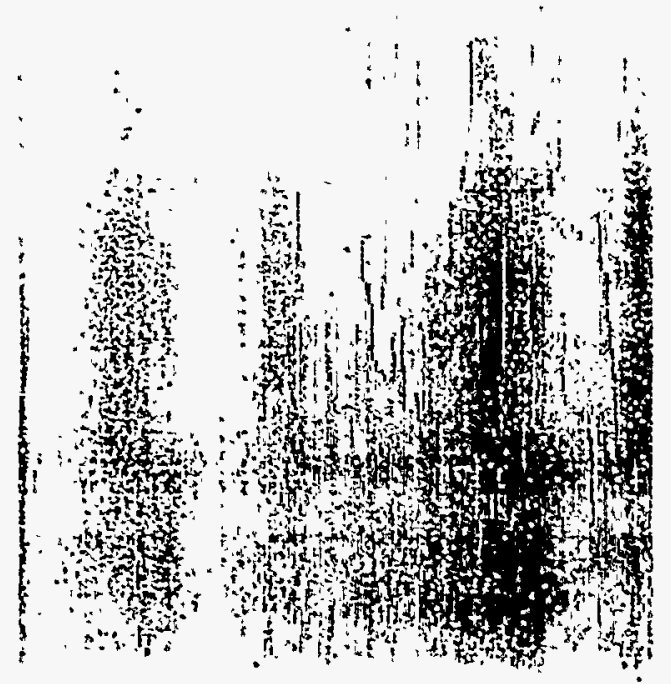




\section{ANNUAL 100\% MCP OVERLAP ON 3-YEAR 100\% MCP}

1992

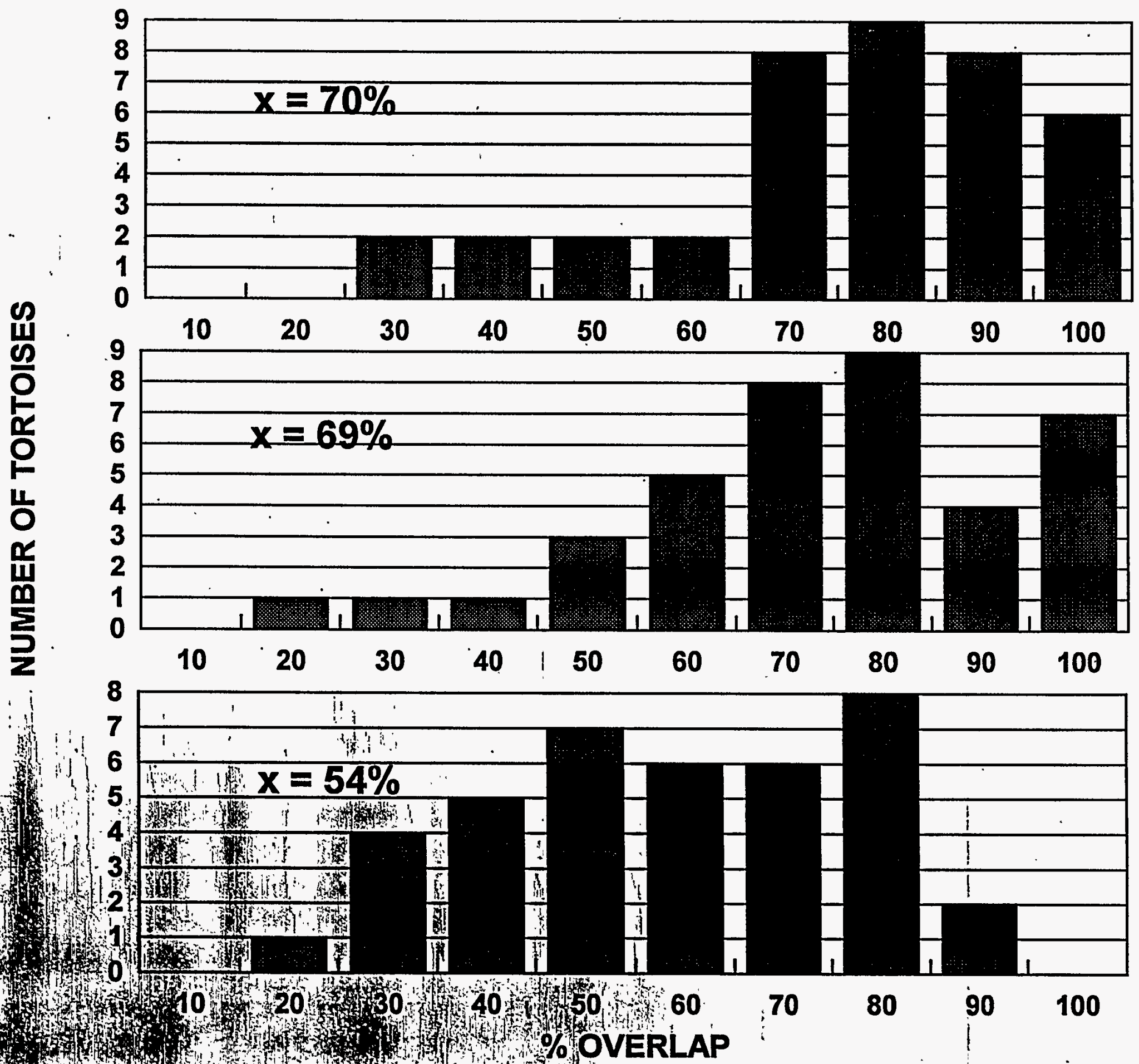




\section{CONCLUSIONS}

- Most Adult Tortoises at Yucca Mountain Show Strong Site Fidelity

- Shift in Center of Activity is Small

- Overlap in Consecutive Annual Home Ranges is Large

- Percentage of 3-year Home Range Used Each Year is Large

- Some Tortoises Exhibit Long-Distance Movements 